NOAA Technical Report NMFS Circular 434

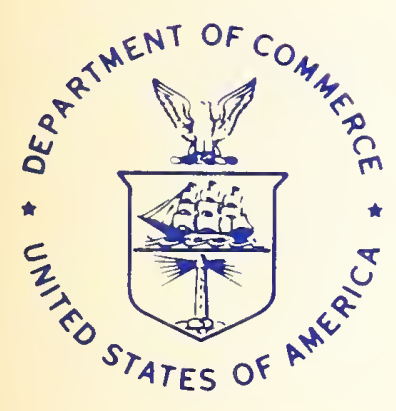

Osteology, Phylogeny, and Higher Classification of the Fishes of the Order Plectognathi (Tetraodontiformes)

James C. Tyler

OCTOBER 1980 


\section{NOAA TECHNICAL REPORTS}

\section{National Marine Fisheries Service, Circulars}

The major responsibilities of the National Marine Fisheries Service (NMFs) are to monitor and assess the ahundance and gergraphic distrihution of fishery resources, to understand and predict fluctuations in the quantity and distribution of these resources. and to establish levels for optimum use of the resources. N.MFS is also charged with the development and implementatun of policies for managing national fishing grounds, development and enforcement of domestic fisheries regulations. surveillance of foreign fishing off l'nited states coastal water. and the development and entorcement of international fishery agreements and policies. NMFS also assists the fishing industry through marketing service and economic analysis programs, and mortgage insurance and vessel construction subsidies. It collects. analyzes. and publishes statistics un various phases of the industry:

The NOAA Technical Report XMFs Circular series continues a series that has been in existence since 1941. The ('ircular are technical puhlication of general interest intended to aid conservation and management. Publications that review in considerable detail and at a high technical level certain broad areas of research appear in this series. Technical papers originating in economics studies and tron managenent inventigations appear in the Circular series.

NOAA Technical Report NMFS Circulars are available free in limited numbers to governmental agencies, both Federal and silate. They are also availahle in exchange for other scientific and technical puhlications in the marıne sciences. Individual copies may he (ibiained lunlen. otherwise noted) from D822, User Services Branch, Environmental Science Information Center. NOAA, Rockville. MD 20852. Recent Circulars are:

396. Whales, dolphins, and porpoises of the western North Atlantic. A guide to their identification. By Stephen Leatherwood, David K. Caldwell, and Howard E. Winn. August 1976, iv + 176 p., 168 figs., 1 table. 14 app. figs. For sale by the Superintendent of Documents, U.S. Government Printing Office, Washington, DC 20402; Stock No. 003-020$00119-0$.

397. Marine flora and fauna of the northeastern United States. Cnidaria: Scyphozoa. By Ronald J. Larson. August 1976. iii +18 p. 28 figs. For sale by the superintendent of Documents, U.S. Govern ment Printing Office, Washington, DC 20402; Stock No. 003-01700387

398. Marine flora and fauna of the northeastern United States. Higher fungi: Ascomycetes, Deuteromycetes, and Basidiomycetes. By A. R. Cavaliere. March 1977, iii +49 p., 24 figs. For sale by the Super intendent of Documents, U.S. Government Printing Office, Washington, DC 20402; Stock No. 003-020-00126-2.

399. Marine flora and fauna of the northeastern United States. Copepoda: Harpacticoida. By Bruce C. Coull. March 1977, iii +48 p. 100 figs. For sale by the Superintendent of Documents, U.S. Government Printing Office, Washington, DC 20402; Stock No. 003-020-00125 -

400. Fishery publication index, 1965-74. By Mary Ellen Engett and Lee C. Thorson. March 1977, iii + 220 p. For sale by the Superintendent of Documents, U.S. Government Printing Office, Washington, DC 20402; Stock No. 003-020-00127-1.

401. Fisheries and fishery resources of New York Bight. By J. L McHugh. March $1977, v+50$ p., 43 figs., 49 tables. For sale by the Superintendent of Documents, U.S. Government Printing Office, Washington, DC 20402; Stock No. 003-020-00129-7.

402. Guide to the identification of scorpionfish larvae (Family Scorpaenidae) in the eastern Pacific with comparative notes on species of Sebastes and Helicolenus from other oceans. By H. Geoffrey Moser, Elbert H. Ahlstrom, and Elaine M. Sandknop. April 1977, v + 71 p., 40 figs., 38 tables. For sale by the Superintendent of Documents, U.S. Government Printing Office, Washington, DC 20402; Stock No. 003-02000128-9

403. Marine flora and fauna of the northeastern United States. Sipun cula. By Edward B. Cutler. July 1977 , iii +7 p., 6 figs. For sale by the Superintendent of Documents, U.S. Government Printing Office, Washington, DC 20402; Stock No. 003-012-00404-0

404. Revision of the sea basses of the genus Diplectrum (Pisces: Serranidae). By Stephen A. Bortone. September 1977, v +49 p., 15 figs., 9 tables.

405. Marine flora and fauna of the northeastern United States. Echinodermata: Holothuroidea. By David L. Pawson. September 1977, iii + 15 p., 3 figs. For sale by the Superintendent of Documents, U.S. Gov ernment Printing Office, Washington, DC 20402: Stock No. 003-017$0040-4$

406. Marine flora and fauna of the northeastern Lnited States. Copepoda: Lernaeopodidae and Sphyriidae. By Ju-Shey Ho. December 1977, iii +14 p., 16 tigs. For sale by the Superintendent of Documents, U.S. Government Printing Office, Washington, DC 20402; Stock No. 003-017-00412-1.

407. Distribution of decapod Crustacea off northeastern Lnited States based on specimens at the Northeast Fisheries Center, Woods Hole, Massachusetts. By Austin B. Williams and Roland L. Wigley. December 1977 , iii +44 p., 2 tigs., 1 table, 57 charts.

408. Collection of tuna baitfish papers. (20 papers.) By Richard S Shomura (editor). December 1977 , iii $+167 \mathrm{p}$

409. Marine flora and fauna of the northeastern United States Copepoda: Cyclopoids parasitic on fishes. By Ju-Shey Ho. February 1978 , iii +12 p., 17 figs

410. The 1976 Ceratium tripos bloom in the New York Bight: Causes and consequences. By Thomas C. Malone. May 1978, iv - 14 p., 17 fïgs., 1 table.

411. Systematics and biology of the tilefishes (Perciformes: Branchiostegidae and Malacanthidae), with descriptions of two new species. By James K. Dooley. April 1978, v + 78 p.. 44 figs., 26 tables.

412. Synopsis of biological data on the red porgy, Pagrus pagrus (Linnaeus). By Charles S. Manooch III and William IV. Hassler. May 1978, iii +19 p., 12 figs., 7 tables. For sale by the Superintendent of Documents, U.S. Government Printing Office, Washington, DC 20402; Stock No. 003-017-00418-0.

413. Marine flora and fauna of the northeastern United States. Crustacea: Branchiura. By Roger F. Cressey. May 1978, iii +10 p., 15 figs. For sale by the Superintendent of Documents, U.S. Government Printing Office, Washington, DC 20402; Stock No. 003-017-00419-8.

414. Synopsis of biological data for the winter flounder, Pseudopleuronectes americanus (Walbaum). By Grace Klein-MacPhee. November 1978, iii +43 p., 21 figs., 28 tables.

415. A basis for classifying western Atlantic Sciaenidae (Teleostei: Perciformes). By Labbish Ning Chao. September $1978, v+64$ p., 41 figs., 1 table.

416. Ocean variability: Effects on U.S. marine fishery resources 1975. (20 papers.) By Julien R. Goulet, Jr. and Elizabeth D. Haynes, Editors. December 1978 , iii +350 p.

417. Guide to the identification of genera of the fish Order Ophidiiformes with a tentative classification of the order. By Daniel M. Cohen and Jørgen G. Nielsen. December 1978, vii + 72 p., 103 figs., 2 tables. 
NOAA Technical Report NMFS Circular 434

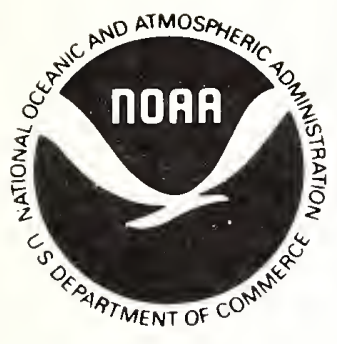
Osteology, Phylogeny, and
Higher Classification of
the Fishes of the
Order Plectognathi
(Tetraodontiformes)

James C. Tyler

OCTOBER 1980

U.S. DEPARTMENT OF COMMERCE

Philip M. Klutznick, Secretary

National Oceanic and Atmospheric Administration

Richard A. Frank, Administrator

National Marine Fisheries Service

Terry L. Leitzell, Assistant Administrator for Fisheries 
The National Marine Fisheries Service (NMFS) does not approve, recommend or endorse any proprietary product or proprietary material mentioned in this publication. No reference shall be made to NMFS, or to this publication furnished by NMFS, in any advertising or sales promotion which would indicate or imply that NMFS approves, recommends or endorses any proprietary product or proprietary material mentioned herein, or which has as its purpose an intent to cause directly or indirectly the advertised product to be used or purchased because of this NMFS publication. 


\section{CONTENTS}

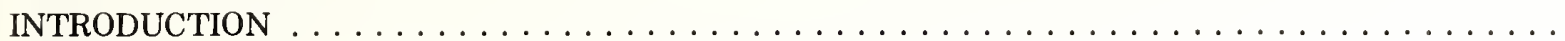

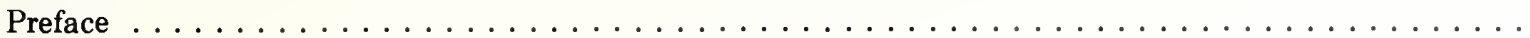

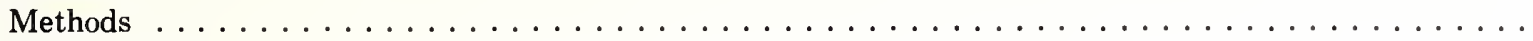

PROLOGUE

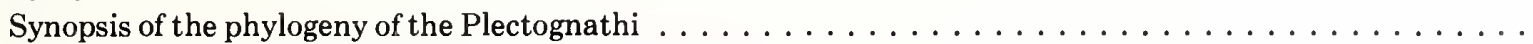

Synopsis of the higher classification of the Plectognathi $\ldots \ldots \ldots \ldots \ldots \ldots \ldots \ldots \ldots$

Historical review of the classification of the Plectognathi $\ldots \ldots \ldots \ldots \ldots \ldots \ldots \ldots \ldots$

Historical review of the nonclassificatory anatomical work on the Plectognathi $\ldots \ldots \ldots \ldots \ldots$

Relationship of the Plectognathi to the Perciformes $\ldots \ldots \ldots \ldots \ldots \ldots \ldots \ldots \ldots \ldots \ldots$

SYSTEMATIC SECTION . . . . . . . . . . . . . . . . . . . . . . . .

Definition and synopsis of the osteology of the Order Plectognathi (Tetraodontiformes) . . . . . . . . . .

Suborder Balistoidei (Sclerodermi)

Comparative diagnosis (contrast with that of the Tetraodontoidei)

Infraorder Triacanthoideo $[$ and Superfamily Triacanthoidea $] \ldots \ldots \ldots \ldots \ldots \ldots \ldots \ldots \ldots$

Comparative diagnosis (contrast with that of the Balistoideo) . . . . . . . . . . .

Family Triacanthodidae . . . . . . . . . . . . . . . . . . . . .

Comparative diagnosis (contrast with that of the Triacanthidae) $\ldots \ldots \ldots \ldots \ldots \ldots$

Detailed description of Parahollardia lineata . . . . . . . . . . . . . . . .

Comparative diagnoses of subfamilies (Spinacanthinae, Eoplectinae, Hollardiinae, Triacan-

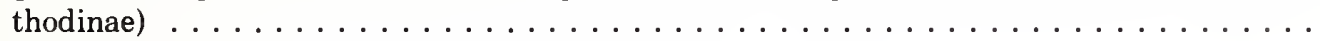

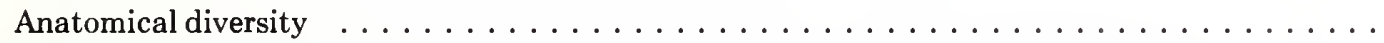

Generic relationships . . . . . . . . . . . . . . . . . . . . .

Subfamilial relationships, and relationships to the Triacanthidae and Gymnodontes . . . . . .

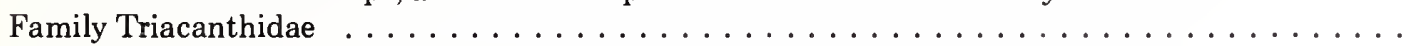

Comparative diagnosis (contrast with that of the Triacanthodidae) $\ldots \ldots \ldots \ldots \ldots$

Detailed description of Pseudotriacanthus strigilifer . . . . . . . . . . . . . . . . .

Comparative diagnoses of subfamilies (Protacanthodinae, Cryptobalistinae, Triacan-

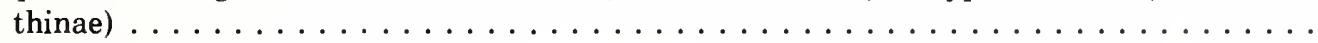

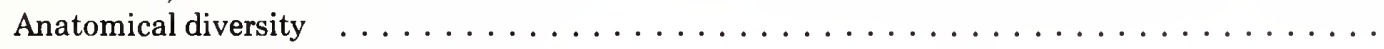

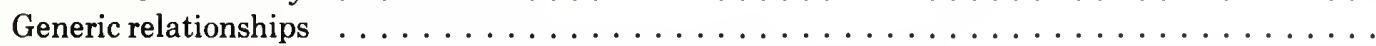

Infraorder Balistoideo . . . . . . . . . . . . . . . . . . . . . . .

Comparative diagnosis (contrast with that of the Triacanthoideo) $\ldots \ldots \ldots \ldots \ldots \ldots$

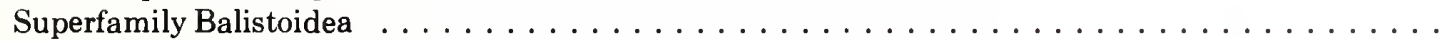

Comparative diagnosis (contrast with that of the Ostracioidea) $\ldots \ldots \ldots \ldots \ldots \ldots \ldots$

Family Balistidae . . . . . . . . . . . . . . . . . . . . . .

Comparative diagnosis (contrast with that of the Monacanthidae) $\ldots \ldots \ldots \ldots \ldots$

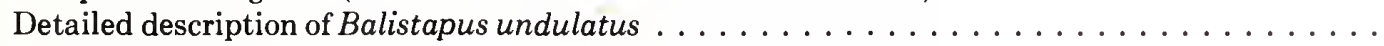

Anatomical diversity

Generic relationships . . . . . . . . . . . . . . . . . . . . .

Relationship to the Monacanthidae . . . . . . . . . . . . . . . . .

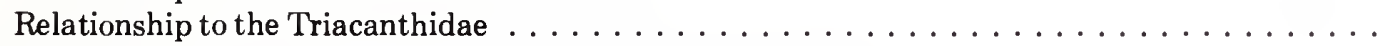

Family Monacanthidae . . . . . . . . . . . . . . . . . . . . .

Comparative diagnosis (contrast with that of the Balistidae) $\ldots \ldots \ldots \ldots \ldots \ldots$

Detailed description of Monacanthus ciliatus

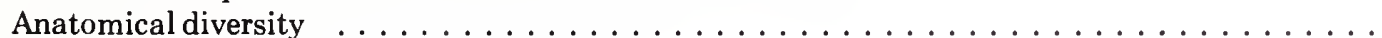

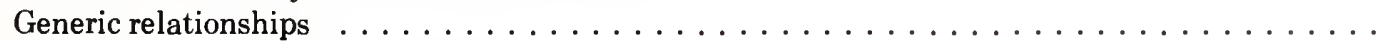

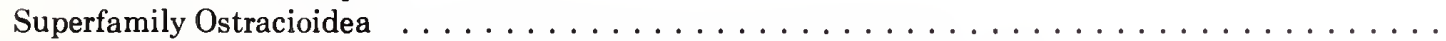

Comparative diagnosis (contrast with that of the Balistoidea) $\ldots \ldots \ldots \ldots \ldots \ldots$

Family Aracanidae . . . . . . . . . . . . . . . . . . . . . . . . .

Comparative diagnosis (contrast with that of the Ostraciidae) $\ldots \ldots \ldots \ldots \ldots \ldots$

Detailed description of Kentrocapros aculeatus

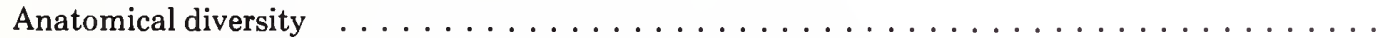

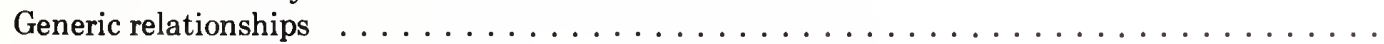

Relationship to the Ostraciidae . . . . . . . . . . . . . . . . .

Relationship to the Balistidae . . . . . . . . . . . . . . . . . . .

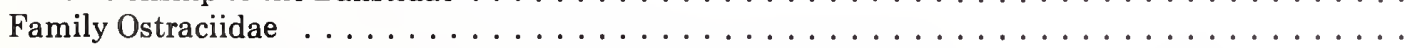

Comparative diagnosis (contrast with that of the Aracanidae) $\ldots \ldots \ldots \ldots \ldots \ldots$

Detailed description of Acanthostracion quadricornis 


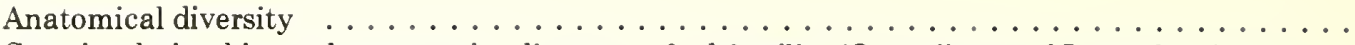

Generic relationships and comparative diagnoses of subfamilies (Ostraciinae and Lactophrysinae) . . .

Suborder Tetraodontoidei (Gymnodontes)

Comparative diagnosis (contrast with that of the Balistoidei) . . . . . . . . . . . . .

Infraorder Triodontoideo [and Superfamily Triodontoidea, Family Triodontidae] . . . . . . . . . .

Comparative diagnosis (contrast with that of the Tetraodontoideo) $\ldots \ldots \ldots \ldots \ldots \ldots$

Detailed description of Triodon macropterus . . . . . . . . . . . . . . . .

Anatomical diversity

Relationships to the Balistoidei and to the other Tetraodontoidei . . . . . . . . . . .

Infraorder Tetraodontoideo . . . . . . . . . . . . . . . . . . . . . .

Comparative diagnosis (contrast with that of the Triodontoideo) $\ldots \ldots \ldots \ldots \ldots \ldots \ldots$

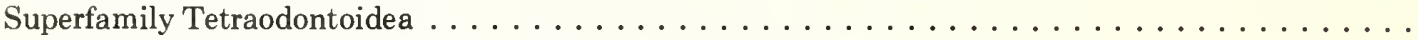

Comparative diagnosis (contrast with that of the Moloidea) $\ldots \ldots \ldots \ldots \ldots \ldots$

Family Tetraodontidae . . . . . . . . . . . . . . . . . . . .

Comparative diagnosis (contrast with that of the Diodontidae) $\ldots \ldots \ldots \ldots \ldots \ldots$

Comparativediagnoses of subfamilies (Tetraodontinae and Canthigasterinae) . . . . . . . .

Detailed description of Lagocephalus laevigatus . . . . . . . . . . . . . . . . .

Detailed description of Canthigaster rostrata . . . . . . . . . . . . . . . .

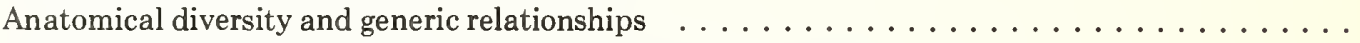

Summary of generic relationships and intrafamilial classification $\ldots \ldots \ldots \ldots \ldots$

Relationships to the Diodontidae and to the other Tetraodontoidei . . . . . . . . . .

Family Diodontidae . . . . . . . . . . . . . . . . . . . . . .

Comparative diagnosis (contrast with that of the Tetraodontidae) $\ldots \ldots \ldots \ldots \ldots \ldots$

Detailed description of Diodon holocanthus . . . . . . . . . . . . . . . . .

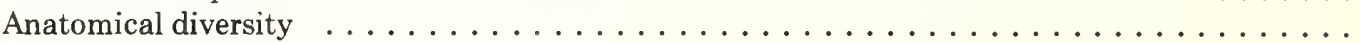

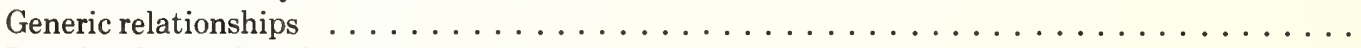

Relationship to the other Tetraodontoidei $\ldots \ldots \ldots \ldots \ldots \ldots \ldots \ldots \ldots \ldots$

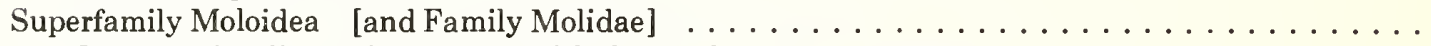

Comparative diagnosis (contrast with that of the Tetraodontoidea) $\ldots \ldots \ldots \ldots \ldots$

Detailed description of Mola mola . . . . . . . . . . . . . . . . . . . . .

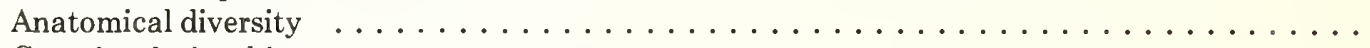

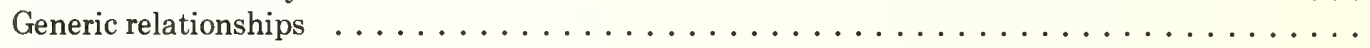

Material examined

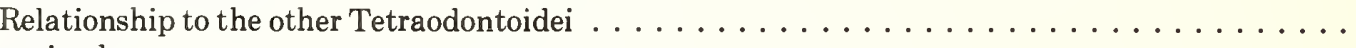

Recent species

Fossil species . . . . . . . . . . . . . . . . . . . . . . .

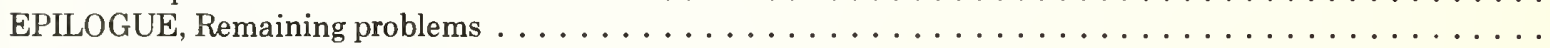

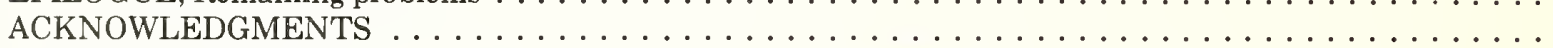

LITERATURE CITED

INDEX OF DISCUSSION OF GENERA

\section{Figures}

1. Flowing-line illustrated version of hypothesized familial and subfamilial groupings of the Plectognathi

2. Angular-line version of hypothesized familial and subfamilial groupings of the Plectognathi . . . . . . .

3. Flowing-line illustrated version of hypothesized familial, subfamilial, and generic relationships of the Superfamily Triacanthoidea, the basal Plectognathi . . . . . . . . . . . . . . . .

4. Range of diversity in body form in the Recent Triacanthodidae: Parahollardia lineata and Halimo-

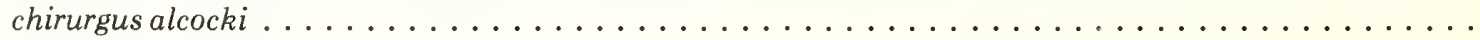

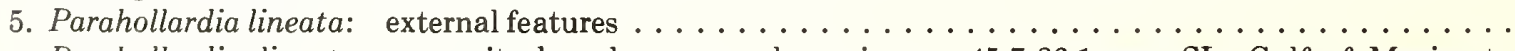
Parahollardia lineata, composite based on several specimens, 45.7-86.1 mm SL, Gulf of Mexico to South Carolina:

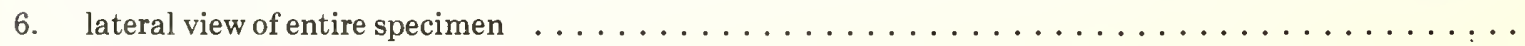

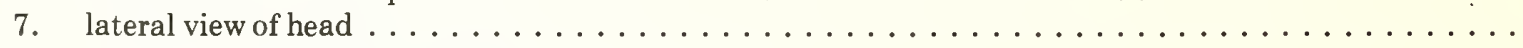

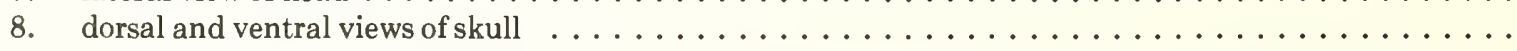

9. posterior view of orbit; posterior view of skull; posterior and lateral views of first abdominal vertebra .

10. dorsal view of branchial arches; lateral view of hyoid arch and urohyal

11. lateral view of pectoral girdle 
13. Parahollardia lineata, $62.2 \mathrm{~mm} \mathrm{SL}$, Florida: dorsal, lateral, and ventral views of pelvis and pelvic fin

14. Parahollardia lineata, $82.0 \mathrm{~mm} \mathrm{SL}$, Florida: lateral and anterior views of first two dorsal spines . . . . .

15. Protobalistum imperiale, lateral view of holotype, $522 \mathrm{~mm} \mathrm{SL}$, Eocene of Monte Bolca, Italy . . . . .

16. Spinacanthus cuneiformis, lateral view of holotype, $104 \mathrm{~mm} \mathrm{SL}$, Eocene of Monte Bolca, Italy . . . . . . .

17. Eoplectus bloti, lateral view of holotype, $65.2 \mathrm{~mm} \mathrm{SL}$, Eocene of Monte Bolca, Italy . . . . . . . . . . . . .

18. Zignoichthys oblongus, lateral view of holotype, ca. $161 \mathrm{~mm} \mathrm{SL}$, Eocene of Monte Bolca, Italy . . . . . . . Lateral views of entire specimens of other representative triacanthodid genera of the Subfamily Triacanthodinae:

19. Triacanthodes anomalus, $71.5 \mathrm{~mm}$ SL, Japan, example of a relatively generalized member . . . . . . .

20. Tydemania navigatoris, $64.4 \mathrm{~mm} \mathrm{SL}$, Bay of Bengal, example of a moderately specialized member . . . .

21. Macrorhamphosodes uradoi, $69.9 \mathrm{~mm}$ SL, Japan, example of a highly specialized member . . . . . . . .

22. Hollardia hollardi: lateral views of moderate-sized specimen, $62.7 \mathrm{~mm}$ SL, and extremely large specimen, $174 \mathrm{~mm} \mathrm{SL}$, both from Caribbean . . . . . . . . . . . . . . . . . . . . . .

23. Parahollardia schmidti, lateral view of head, $62.0 \mathrm{~mm} \mathrm{SL}$, Nicaragua . . . . . . . . . . . . . .

24. Triacanthodes anomalus, lateral view of head, $71.5 \mathrm{~mm}$ SL, Japan . . . . . . . . . . . . . .

25. Paratriacanthodes retrospinis, lateral view of head, $85.3 \mathrm{~mm}$ SL, Mozambique . . . . . . . . . . .

26. Johnsonina eriomma, lateral view of head, $67.0 \mathrm{~mm} \mathrm{SL}$, Puerto Rico . . . . . . . . . . . . . . .

27. Atrophacanthus japonicus, lateral view of head, $43.1 \mathrm{~mm} \mathrm{SL}$, Celebes . . . . . . . . . . . . . .

28. Tydemania navigatoris, lateral view of head, $64.4 \mathrm{~mm} \mathrm{SL}$, Bay of Bengal . . . . . . . . . . . .

29. Macrorhamphosodes uradoi, lateral view of head, $69.9 \mathrm{~mm} \mathrm{SL}$, Japan . . . . . . . . . . . . . . . . .

30. Halimochirurgus centriscoides, lateral view of head, $99.2 \mathrm{~mm} \mathrm{SL}$, Bay of Bengal . . . . . . . . . . .

31. Typical body form in the Recent Triacanthidae: Pseudotriacanthus strigilifer . . . . . . . . . . . . .

Pseudotriacanthus strigilifer:

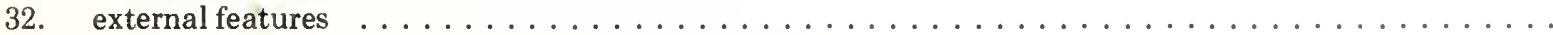

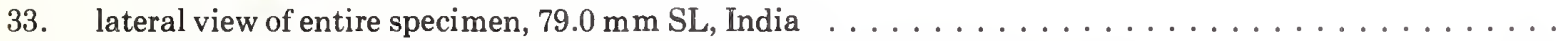

34. lateral view of head, $79.0 \mathrm{~mm} \mathrm{SL}$, India . . . . . . . . . . . . . . . . . . . .

35. dorsal, ventral, and posterior views of skull, $79.0 \mathrm{~mm}$ SL, India . . . . . . . . . . . . .

36. posterior view of orbit, $130 \mathrm{~mm}$ SL, Thailand . . . . . . . . . . . . . . . . . .

37. Tripodichthys angustifrons: dorsal view of branchial arches; lateral view of hyoid arch and urohyal; $137 \mathrm{~mm}$ SL, Australia . . . . . . . . . . . . . . . . . . . . . . .

38. Triacanthus biaculeatus: lateral and anterior views of first two dorsal spines, $113 \mathrm{~mm} \mathrm{SL}$, Borneo . . . .

39. A, Parahollardia lineata, $45.7 \mathrm{~mm} \mathrm{SL}$, Florida, and B, Triacanthus biaculeatus, $113 \mathrm{~mm} \mathrm{SL}$, Borneo; lateral views of pelvis and pelvic fin; anterior views of the base of the pelvic spine . . . . . . .

40. Trixiphichthys weberi: lateral view of entire specimen, $101 \mathrm{~mm} \mathrm{SL}$, Bay of Bengal . . . . . . . . . .

41. Trixiphichthys weberi: lateral view of head, $101 \mathrm{~mm} \mathrm{SL,} \mathrm{Bay} \mathrm{of} \mathrm{Bengal} \mathrm{.} \mathrm{.} \mathrm{.} \mathrm{.} \mathrm{.} \mathrm{.} \mathrm{.} \mathrm{.} \mathrm{.} \mathrm{.} \mathrm{.} \mathrm{.}$

42. Protacanthodes ombonii: lateral views of holotype, $112 \mathrm{~mm} \mathrm{SL}$, Eocene of Monte Bolca, Italy . . . . . .

43. Protacanthodes ombonii: lateral view of abdominal region, holotype, $112 \mathrm{~mm} \mathrm{SL}$, Eocene of Monte Bolca, Italy . . . . . . . . . . . . . . . . . . . . . . . . .

44. Acanthopleurus serratus: lateral view of entire specimen, syntype, ca. $91 \mathrm{~mm} \mathrm{SL}$, Oligocene of Canton Glarus, Switzerland . . . . . . . . . . . . . . . . . . . . . . . . . . .

45. Acanthopleurus serratus: lateral views of entire specimens, $153 \mathrm{~mm} \mathrm{SL}$ and $127 \mathrm{~mm} \mathrm{SL}$, and $A$. collettei, ca. $120 \mathrm{~mm}$ SL and $96.2 \mathrm{~mm} \mathrm{SL}$, paratypes, Oligocene of Canton Glarus, Switzerland . . . . . . .

46. Charts showing two proportional measurements as percent of standard length that differentiate Acan-

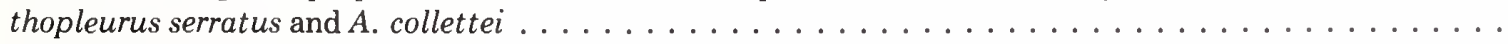

47. Marosichthys huismani: lateral view of anterior part of body of holotype, ca. $36 \mathrm{~mm}$ head length, Miocene of the Celebes

48. Cryptobalistes brevis: lateral view of holotype, ca. $88 \mathrm{~mm} \mathrm{SL}$, Oligocene of Canton Glarus, Switzer-

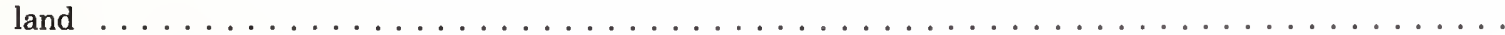

49. Range of diversity in body form in the Recent Balistidae: Balistapus undulatus and Odonus niger . . . .

50. Balistapus undulatus: external features . . . . . . . . . . . . . . . . . . .

Balistapus undulatus, composite based on several specimens, ca. 120-124 mm SL., western Pacific:

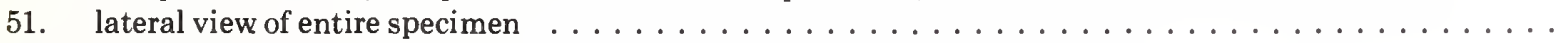

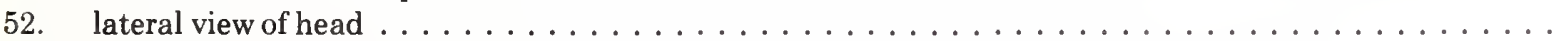

53. dorsal and ventral views of skull $\ldots \ldots \ldots \ldots \ldots \ldots \ldots \ldots \ldots \ldots \ldots \ldots$

54. posterior views of skull and orbit; posterior and lateral views of first abdominal vertebra . . . . . . . .

55. dorsal view of branchial arches; lateral view of hyoid arch and urohyal $\ldots \ldots \ldots \ldots \ldots \ldots$

56. lateral view of pectoral girdle . . . . . . . . . . . . . . . . . . . .

57. medial view of upper jaw; lateral view of pelvis and encasing scales at end of pelvis; posterior view of

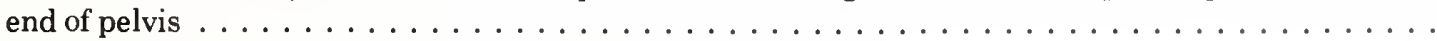

58. lateral view of spiny dorsal fin and $i t s$ pterygial supports $\ldots \ldots \ldots$ 
59. dorsal view of pterygial supports of spiny dorsal fin; posterior view of first dorsal spine and anterior

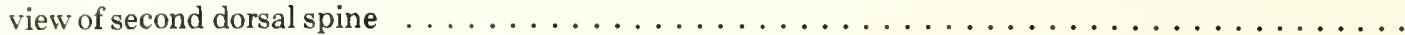

60. lateral view of caudal fin supporting structures $\ldots \ldots \ldots \ldots \ldots \ldots \ldots \ldots \ldots \ldots \ldots$

External features of other representative balistid genera:

61. Abalistes stellaris . . . . . . . . . . . . . . . . . . . . . . . . . . .

62. Canthidermis maculatus . . . . . . . . . . . . . . . . . . . . . . .

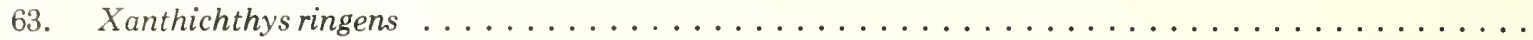

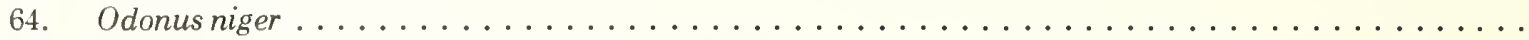

65. Fossil balistids: A, Balistomorphus ovalis, lateral view of holotype, $121 \mathrm{~mm} \mathrm{SL}$; B, B. ovalis, lateral view of entire specimen, $119 \mathrm{~mm} \mathrm{SL}$; C, B. spinosus, lateral view of holotype, ca. $90 \mathrm{~mm} \mathrm{SL}$;,$B$. orbiculatus, lateral view of holotype, $65.6 \mathrm{~mm} \mathrm{SL}-$ specimens A through D from Oligocene of Canton Glarus, Switzerland; E, Oligobalistes robustus, lateral view of syntype, ca. $60 \mathrm{~mm} \mathrm{SL}$, Maikop deposits of the Oligocene of the Caucasus . . . . . . . . . . . . . . . . . . . . . . .

66. Hypothesized phylogenetic relationships of the genera of Balistidae $\ldots \ldots \ldots \ldots \ldots \ldots$

67. Dentition of representative balistids: A, Balistes polylepis, $56.1 \mathrm{~mm}$ SL, Galapagos; B, Xanthichthys lineopunctatus, $181 \mathrm{~mm}$ SL, Hawaii; C, Odonus niger, $173 \mathrm{~mm}$ SL, New Guinea; D, Melichthys niger, $147 \mathrm{~mm}$ SL, locality unknown . . . . . . . . . . . . . . . . . . . . . . . .

68. Scales just above tip of pectoral fin of Balistoides viridescens, $114 \mathrm{~mm} \mathrm{SL}$, Indonesia $\ldots \ldots \ldots \ldots$

69. Balistes polylepis, lateral view of entire specimen, $56.1 \mathrm{~mm} \mathrm{SL}$, Galapagos . . . . . . . . . . . . .

70. Sufflamen frenatus, lateral view of entire specimen, $74.3 \mathrm{~mm} \mathrm{SL}$, Somalia . . . . . . . . . . . .

71. Rhinecanthus rectangulus, lateral view of entire specimen, $37.4 \mathrm{~mm}$ SL, Phoenix Islands . . . . . . .

72. Canthidermis maculatus, lateral view of entire specimen, $80.1 \mathrm{~mm} \mathrm{SL}$, Alabama . . . . . . . . . . .

73. Xanthichthys lineopunctatus, lateral view of entire specimen, $181 \mathrm{~mm} \mathrm{SL}$, Hawaii . . . . . . . . . .

74. Lateral views of relatively normal balistid skulls: Balistes capriscus, ca. $360 \mathrm{~mm} \mathrm{SL}$, Gulf of Mexico; $B$. polylepis, ca. $390 \mathrm{~mm} \mathrm{SL}$, Mexico . . . . . . . . . . . . . . . . . . . . . . .

75. Lateral view of most specialized balistid skull and suspensorium, Odonus niger, $173 \mathrm{~mm}$ SL, New Guinea

76. Balistes polylepis: ventral and dorsal views of skull, ca. $390 \mathrm{~mm} \mathrm{SL}$, Mexico . . . . . . . . . . .

77. Balistes capriscus: ventral view of skull, ca. $360 \mathrm{~mm} \mathrm{SL}$, Gulf of Mexico . . . . . . . . . . . . . .

78. Range of diversity in body form in the Monacanthidae: A, Monacanthus ciliatus; B, Amanses scopas; C, Brachaluteres trossulus; D, Psilocephalus barbatus . . . . . . . . . . . . . . . .

Monacanthus ciliatus:

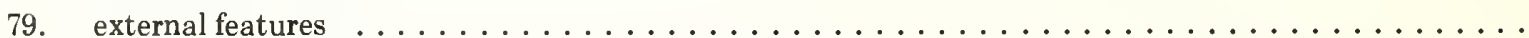

80. lateral view of entire specimen, $81.3 \mathrm{~mm} \mathrm{SL}$, Florida $\ldots \ldots \ldots \ldots \ldots \ldots \ldots \ldots \ldots$

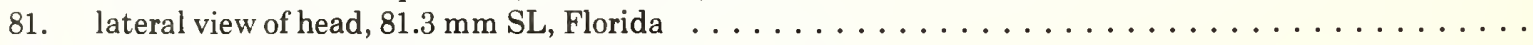

82. dorsal and ventral views of skull, $51.3 \mathrm{~mm} \mathrm{SL}$, Colombia $\ldots \ldots \ldots \ldots \ldots \ldots \ldots \ldots$

83. posterior views of skull and orbit, $81.3 \mathrm{~mm} \mathrm{SL}$, Florida . . . . . . . . . . . . . . .

84. dorsal view of branchial arches; lateral view of hyoid arch and urohyal; $75.7 \mathrm{~mm} \mathrm{SL}$, Florida . . . . . .

85. lateral view of pelvis and encasing scales at end of pelvis; detail of the end of pelvis; $81.3 \mathrm{~mm} \mathrm{SL}$,

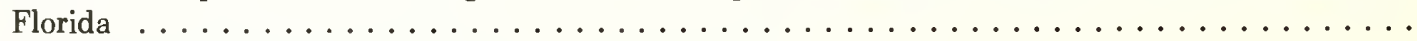

External features of other representative monacanthid genera:

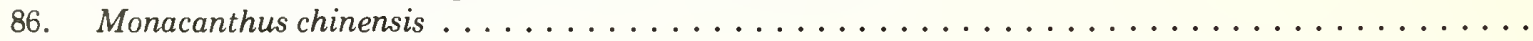

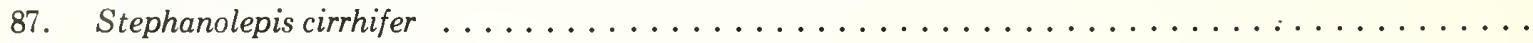

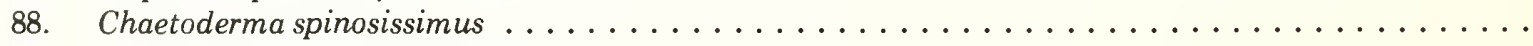

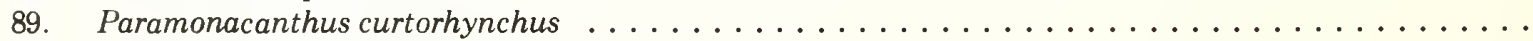

90. Pervagor melanocephalus . . . . . . . . . . . . . . . . . .

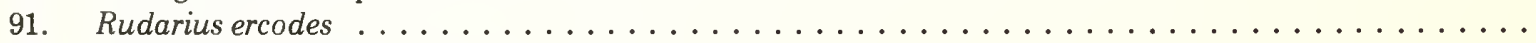

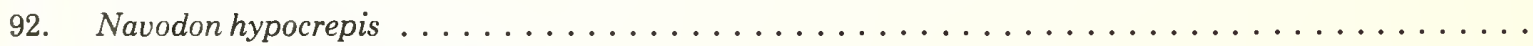

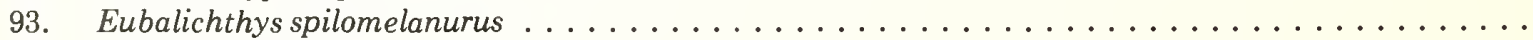

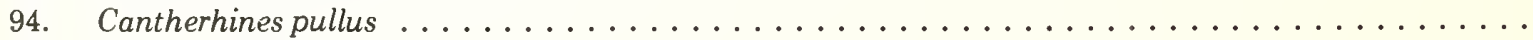

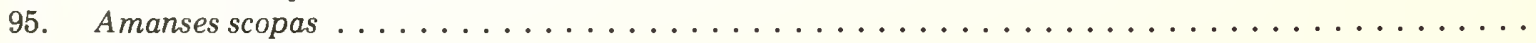

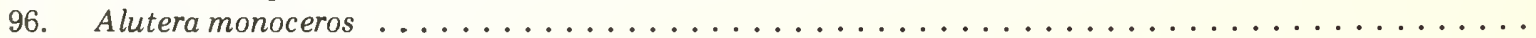

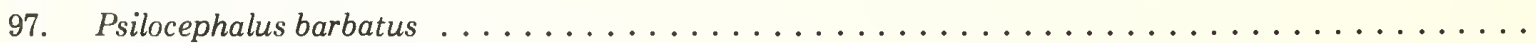

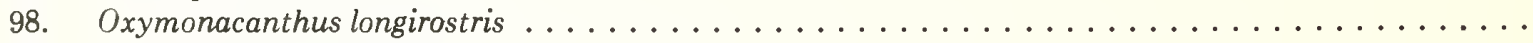

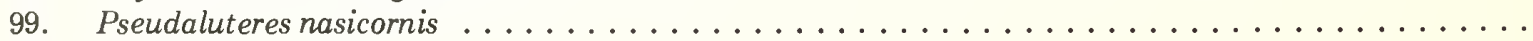

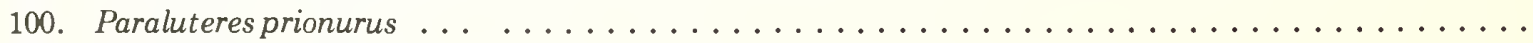

101. Brachaluteres trossulus . . . . . . . . . . . . . . . . . . . . . . .

102. Stephanolepis hispidus, lateral view of entire specimen, $50.4 \mathrm{~mm}$ SL, Florida . . . . . . . . . .

103. Paramonacanthus cryptodon, lateral view of entire specimen, $68.5 \mathrm{~mm}$ SL, Thailand . . . . . . .

104. Chaetoderma spinosissimus, lateral view of entire specimen, $33.0 \mathrm{~mm} \mathrm{SL}$, Malaya . . . . . . . . . . 


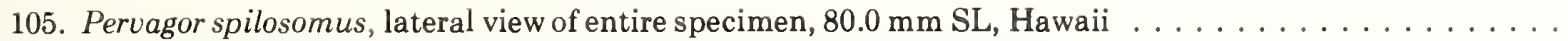

106. Rudarius minutus, lateral view of entire specimen, $17.9 \mathrm{~mm} \mathrm{SL}$, Borneo . . . . . . . . . . . . . . . . . .

107. Amanses scopas, lateral view of entire specimen, $167 \mathrm{~mm} \mathrm{SL}$, Japan . . . . . . . . . . . . . . . . . .

108. A canthaluteres spilomelanurus, lateral view of entire specimen, $63.7 \mathrm{~mm} \mathrm{SL}$, Australia . . . . . . . . .

109. A lutera heudelotii, lateral view of entire specimen, $107 \mathrm{~mm} \mathrm{SL}$, Florida . . . . . . . . . . . . . . . . .

110. Psilocephalus barbatus, lateral view of entire specimen, $137 \mathrm{~mm} \mathrm{SL}$, Singapore . . . . . . . . . . . . .

111. Brachaluteres trossulus, lateral view of entire specimen, $55.5 \mathrm{~mm} \mathrm{SL}$, Australia . . . . . . . . . . . . . .

112. Paraluteres prionurus, lateral view of entire specimen, $46.4 \mathrm{~mm} \mathrm{SL}$, Seychelles . . . . . . . . . . . . . .

113. Oxymonacanthus longirostris, lateral view of entire specimen, $34.2 \mathrm{~mm}$ SL, Seychelles . . . . . . . . . .

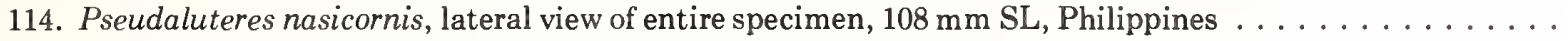

115. Stephanolepis hispidus, lateral view of head, $50.4 \mathrm{~mm} \mathrm{SL}$, Florida . . . . . . . . . . . . . . . . .

116. Paramonacanthus cryptodon, lateral view of head, $68.5 \mathrm{~mm} \mathrm{SL}$, Thailand . . . . . . . . . . . . .

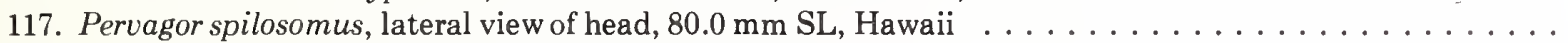

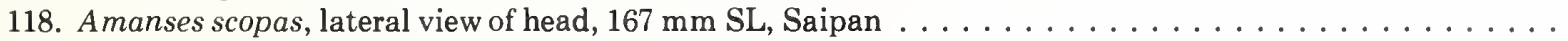

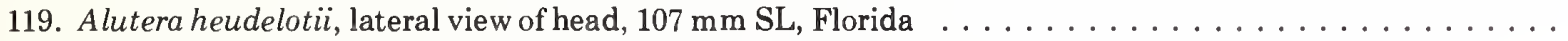

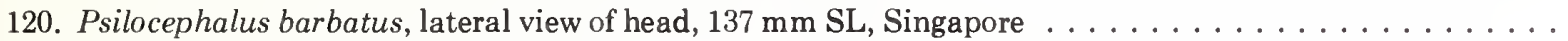

121 Brachaluteres trossulus, lateral view of head, $55.5 \mathrm{~mm} \mathrm{SL}$, Australia . . . . . . . . . . . . . . .

122. Oxymonacanthus longirostris, lateral view of head, $26.5 \mathrm{~mm} \mathrm{SL}$, Seychelles . . . . . . . . . . . .

123. Pseudaluteres nasicornis, lateral view of head, $108 \mathrm{~mm} \mathrm{SL}$, Philippines . . . . . . . . . . . . . . .

124. Dorsal views of skulls of: A, Pseudaluteres nasicornis, $108 \mathrm{~mm} \mathrm{SL}$, Philippines, highly specialized; B, Paraluteres prionurus, $46.4 \mathrm{~mm}$ SL, Seychelles, moderately specialized; C, Chaetoderma spinosissimus,

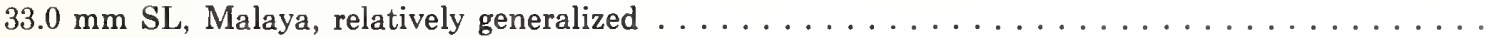

125. A, Paraluteres prionrus, ventral view of skull, $46.4 \mathrm{~mm} \mathrm{SL}$, Seychelles; B, Pervagor spilosomus, ventral view of skull, ca. $65 \mathrm{~mm} \mathrm{SL}$, Hawaii; C, Psilocephalus barbatus, dorsal and ventral views of skull, 137

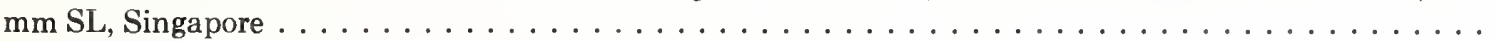

126. Dorsal view of branchial arches and lateral view of hyoid arch and urohyal of: Alutera heudelotii, 114 mm SL, Florida, and Psilocephalus barbatus, $139 \mathrm{~mm}$ SL, Singapore . . . . . . . . . . . . . . .

127. Medial views of upper and lower jaws of: A, Alutera heudelotii, $114 \mathrm{~mm} \mathrm{SL,} \mathrm{Florida;} \mathrm{B,} \mathrm{Monacanthus}$ ciliatus, $51.3 \mathrm{~mm}$ SL, Colombia; C, Psilocephalus barbatus, $137 \mathrm{~mm} \mathrm{SL}$, Singapore; D, Amanses scopas, $167 \mathrm{~mm}$ SL, Saipan; E, Acanthaluteres spilomelanurus, $63.7 \mathrm{~mm} \mathrm{SL,} \mathrm{Australia} \mathrm{.} \mathrm{.} \mathrm{.} \mathrm{.} \mathrm{.} \mathrm{.} \mathrm{.} \mathrm{.} \mathrm{.} \mathrm{.} \mathrm{.} \mathrm{.} \mathrm{.} \mathrm{.} \mathrm{.}$

128. Hypothesized phylogenetic relationships of the genera of Monacanthidae . . . . . . . . . . . . . . .

129. Typical body form in the Recent Aracanidae: A racana aurita . . . . . . . . . . . . . . . . . . Range of diversity in body form and external features of representative aracanid genera:

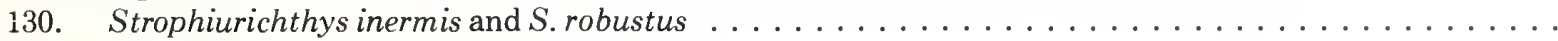

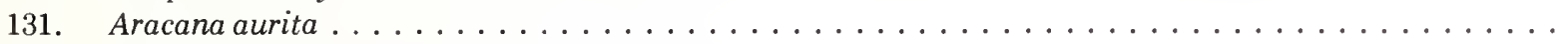

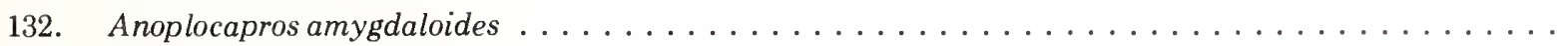

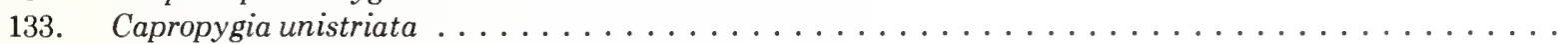

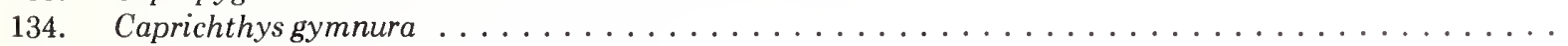

Kentrocapros aculeatus:

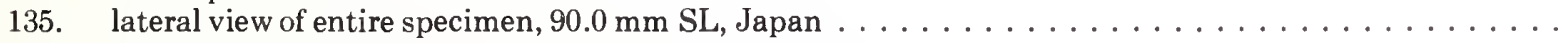

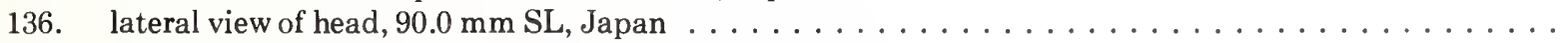

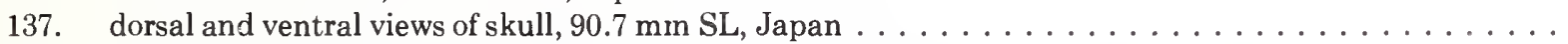

138. posterior views of skull and orbit, $90.7 \mathrm{~mm} \mathrm{SL}$, Japan . . . . . . . . . . . . . . . . . . . .

139. dorsal view of branchial arches, lateral view of hyoid arch and urohyal, $90.7 \mathrm{~mm}$ SL, Japan . . . . . . .

140. Strophiurichthys robustus, lateral view of entire specimen, $150 \mathrm{~mm} \mathrm{SL}$, Australia . . . . . . . . . . . . . . . . . . . . . . . . . . . . . . .

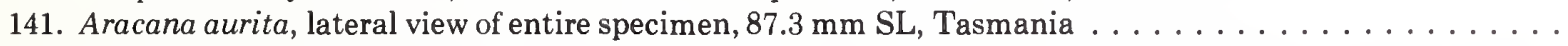

142. Aracana ornata, lateral view of entire specimen, $70.5 \mathrm{~mm} \mathrm{SL}$, Australia . . . . . . . . . . . . . . .

143. Lateral views of heads of typical aracanids: Strophiurichthys robustus, $150 \mathrm{~mm}$ SL, Australia, and

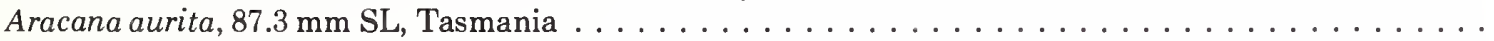

144. Ventral views of the two types of configuration of the ventral surface of the vertically expanded anterior portion of the parasphenoid: A, Caprichthys gymnura, $74.1 \mathrm{~mm} \mathrm{SL}$, Australia; B, Aracana aurita, 87.3

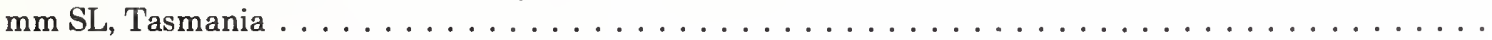

145. Proaracana dubia: lateral view of entire specimen; composite based on three specimens, including the

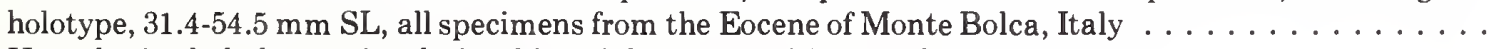

146. Hypothesized phylogenetic relationships of the genera of Aracanidae . . . . . . . . . . . . . . . .

147. Typical body form in the Recent Ostraciidae: Ostracion lentiginosum . . . . . . . . . . . . . . . .

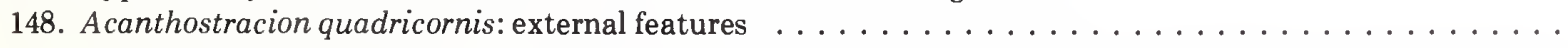
Acanthostracion quadricornis, composite based on several specimens, $58.2-350 \mathrm{~mm} \mathrm{SL}$, Gulf of Mexico and Caribbean:

149. lateral view of entire specimen 
151. dorsal and ventral views of skull $\ldots \ldots$

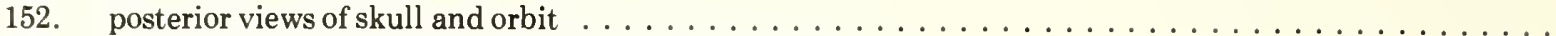

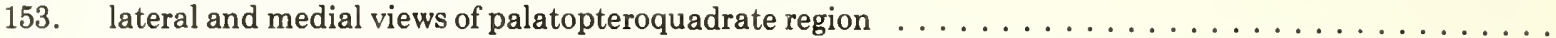

154. Acanthostracion quadricornis, $77.7 \mathrm{~mm} \mathrm{SL}$, Florida: lateral view of occipital region of skull and the fused first five abdominal vertebrae; posterior view of fused first five abdominal vertebrae . . . . . . . . . . . .

Acanthostracion quadricornis, composite based on several specimens, 58.2-350 mm SL, Gulf of Mexico and Caribbean:

155. medial and lateral views of pectoral girdle $\ldots \ldots \ldots \ldots \ldots \ldots \ldots$

156. ventral views of vertebral column from the fused first five abdominal vertebrae to the fourth caudal vertebra and of the basal pterygiophores of the anal fin $\ldots \ldots \ldots \ldots$

157. dorsal view of branchial arches; lateral view of hyoid arch; lateral and dorsal views of urohyal ......

158. lateral view of caudal fin supporting structures . . . . . . . . . . . . . . . . . .

External features of other representative ostraciid genera:

159. A, Rhinesomus bicaudalis, B and C, R. triqueter . . . . . . . . . . . . . . . . .

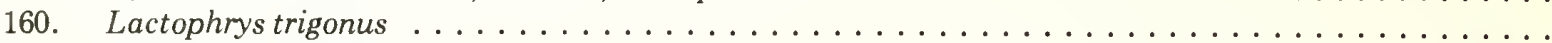

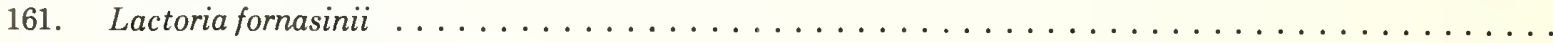

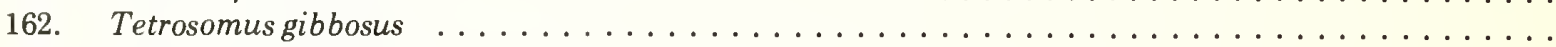

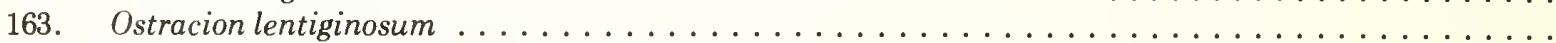

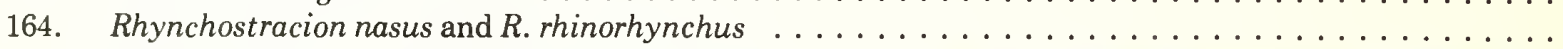

Number of teeth in upper and lower jaws in relation to standard length and the relatively negligible increase in number of teeth with increasing standard length at sizes greater than about $40 \mathrm{~mm}$ SL:

165. Lactophrys trigonus, Rhinesomus triqueter, $R$. bicaudalis . . . . . . . . . . . . . . . . . . .

166. Ostracion tuberculatus, O. lentiginosum, Acanthostracion quadricornis, A. polygonius . . . . . . . . .

167. Rhinesomus triqueter, lateral view of entire specimen, $134 \mathrm{~mm} \mathrm{SL}$, Colombia . . . . . . . . . . . . .

168. Lactoria cornuta, lateral view of entire specimen, $104 \mathrm{~mm} \mathrm{SL,} \mathrm{Philippines} \mathrm{.} \mathrm{.} \mathrm{.} \mathrm{.} \mathrm{.} \mathrm{.} \mathrm{.} \mathrm{.} \mathrm{.} \mathrm{.} \mathrm{.} \mathrm{.} \mathrm{.} \mathrm{.} \mathrm{.} \mathrm{.}$

169. Tetrosomus concatenatus, lateral view of entire specimen, $43.4 \mathrm{~mm} \mathrm{SL}$, Thailand . . . . . . . . . . . .

170. Ostracion tuberculatus, lateral view of entire specimen, $54.5 \mathrm{~mm} \mathrm{SL}$, Aldabra Atoll . . . . . . . . . . .

171. Rhinesomus triqueter, lateral view of head, $134 \mathrm{~mm} \mathrm{SL}$, Colombia . . . . . . . . . . . . . . . . .

172. Ostracion tuberculatus, lateral view of head, $54.5 \mathrm{~mm} \mathrm{SL}$, Aldabra Atoll . . . . . . . . . . . . . . .

173. Tetrosomus concatenatus, lateral view of head, $43.4 \mathrm{~mm} \mathrm{SL,} \mathrm{Thailand} \mathrm{.} \mathrm{.} \mathrm{.} \mathrm{.} \mathrm{.} \mathrm{.} \mathrm{.} \mathrm{.} \mathrm{.} \mathrm{.} \mathrm{.} \mathrm{.} \mathrm{.} \mathrm{.}$

174. Lactoria cornuta, ventral view of skull, $88.2 \mathrm{~mm} \mathrm{SL}$, Philippines . . . . . . . . . . . . . . . . .

175. Lactoria fornasinii, posterior view of orbit, $65.2 \mathrm{~mm} \mathrm{SL}$, Hawaii . . . . . . . . . . . . . . . . . . . . .

176. Rhynchostracion rhinorhynchus: ventral and dorsal views of skull, $88.2 \mathrm{~mm} \mathrm{SL}$, Java . . . . . . . .

177. Lactoria cornuta, dorsal view of branchial arches; lateral view of hyoid arch and urohyal; $88.2 \mathrm{~mm} \mathrm{SL}$, Philippines

178. Hypothesized phylogenetic relationships of the genera of Ostraciidae

179. Eolactoria sorbinii: lateral view of holotype, $15.5 \mathrm{~mm}$ SL, Eocene of Monte Bolca, Italy . . . . . .

180. Body form in the only known Recent species of Triodontidae: Triodon macropterus ........... Triodon macropterus:

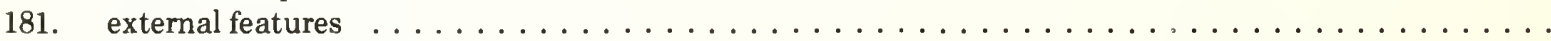

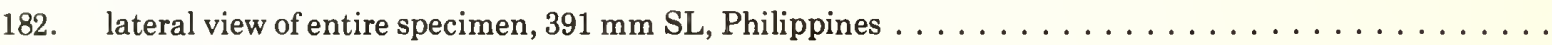

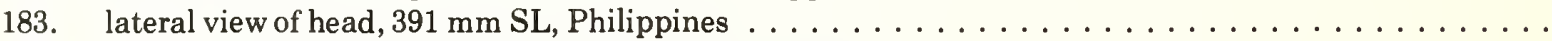

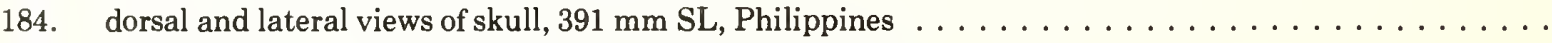

185. posterior views of skull and orbit, $391 \mathrm{~mm} \mathrm{SL}$, Philippines . . . . . . . . . . . . . . . . . . .

186. dorsal view of branchial arches; lateral view of hyoid arch; dorsal and lateral views of urohyal; $391 \mathrm{~mm}$

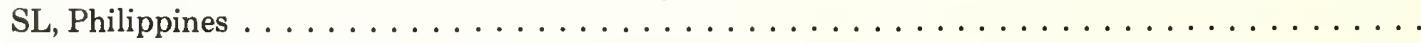

187. lateral view of pectoral girdle, $391 \mathrm{~mm} \mathrm{SL}$, Philippines . . . . . . . . . . . . . . . . . .

188. lateral view of scapula and first actinost in representatives of all superfamilies . . . . . . . . . . . .

189. lateral views of alternate pleural ribs and their epipleurals; dorsal view of lower jaw; $391 \mathrm{~mm}$ SL, Phil-

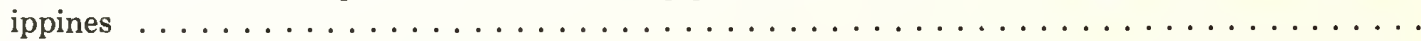

190. lateral and dorsal views of rudimentary spiny dorsal fin and its basal pterygiophores, $463 \mathrm{~mm}$ SL, Japan

191. ventral, dorsal, and lateral views of pelvis, $391 \mathrm{~mm}$ SL, Philippines . . . . . . . . . . . . . . . .

192. lateral view of caudal fin supporting structures, $391 \mathrm{~mm} \mathrm{SL}$, Philippines . . . . . . . . . . . . . . . .

193. Range of diversity in body form in the Recent Tetraodontidae: A, Lagocephalus spadiceus, B, Xenopterus naritus; C, Amblyrhynchotes piosae; and D, Canthigaster rostrata . . . . . . . . . . . . . .

194. Lagocephalus laevigatus, with $L$. lunaris and $L$. scleratus for comparison: external features . . . . . . . 
Lagocephalus laevigatus, composite based on several specimens, 61.4-166 mm SL, Gulf of Mexico:

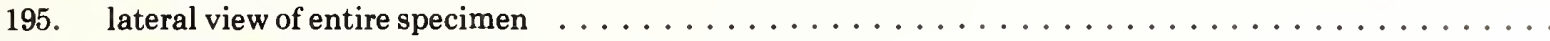

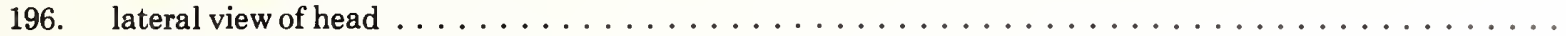

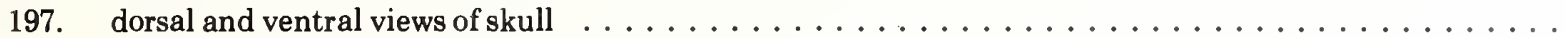

198. posterior view of skull; lateral and posterior views of first abdominal vertebra; posterior view of

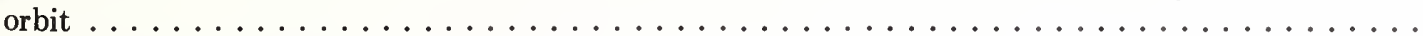

199. dorsal view of branchial arches and lateral and medial views of hyoid arch $\ldots \ldots \ldots \ldots \ldots \ldots$

200. lateral view of pectoral girdle . . . . . . . . . . . . . . . . . . .

201. lateral view of caudal fin supporting structures . . . . . . . . . . . . . . .

202. Canthigaster rostrata, with C. valentini and two renditions of C. amboinensis: external features ......

Canthigaster rostrata, composite based on several specimens, 55.2-96.5 mm SL, Texas:

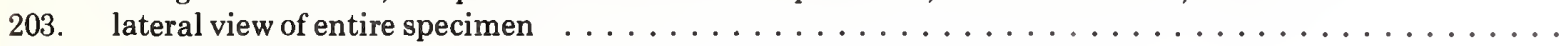

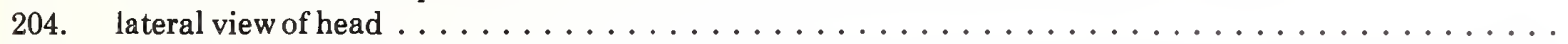

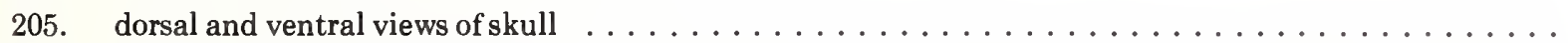

206. posterior view of skull; lateral and posterior views of first abdominal vertebra; posterior view of or-

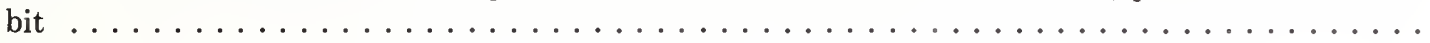

207. dorsal view of branchial arches; lateral and medial views of hyoid arch $\ldots \ldots \ldots \ldots \ldots \ldots$

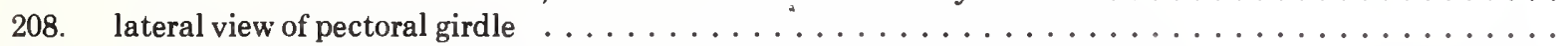

209. lateral view of caudal fin supporting structures . . . . . . . . . . . . . . . .

210. External features of other representative tetraodontid genera: A, Sphoeroides nephelus; B, S. testudineus; C, S. dorsalis; D, S. lobatus; E, S. pachygaster . . . . . . . . . . . . . . . . . . .

211. Nasal organs and olfactory lamellae of representative species of Sphoeroides and Lagocephalus: A, Sphoeroides trichocephalus; B, S. spengleri; C, S. maculatus; D, Lagocephalus spadiceus; E, L. lagocephalus; F, L. inermis .

External features of other representative tetraodontid genera:

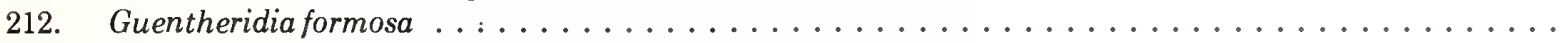

213. Colomesus psittacus . . . . . . . . . . . . . . . . . . . . . . . .

214. A, Amblyrhynchotes piosae; B, A. honckenii; C, A. richei . . . . . . . . . . . . . . . . .

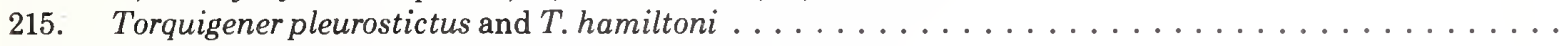

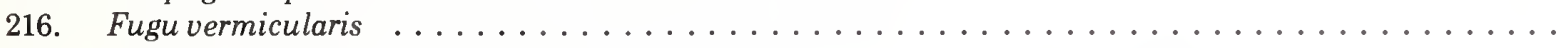

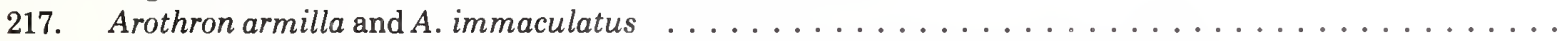

218. A, Tetraodon miurus; B, T. lineatus; C, T. kretamensis; and D, T. schoutedeni .............

219. Ephippion guttifer of decreasing sizes $(325,232$, and $101 \mathrm{~mm} \mathrm{SL}) \ldots \ldots \ldots \ldots \ldots$

220. Photographic detail of interdigitated scale plates from lower side of body of Ephippion guttifer, 325 $\mathrm{mm} \mathrm{SL}$

External features of other representative tetraodontid genera:

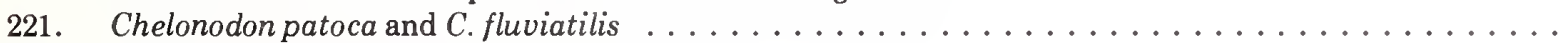

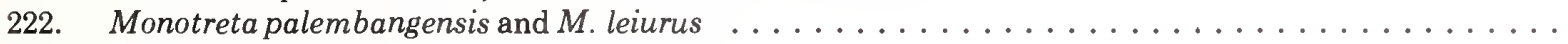

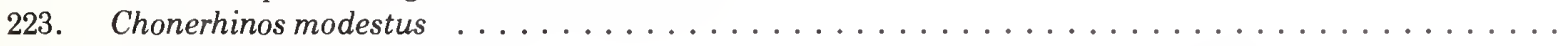

224. Xenopterus naritus . . . . . . . . . . . . . . . . . . . . . . . .

225. Carinotetraodon lorteti . . . . . . . . . . . . . . . . . . . . . . .

226. Sphoeroides maculatus, lateral view of entire specimen, $97.5 \mathrm{~mm} \mathrm{SL}$, Virginia . . . . . . . . . . .

227. Sphoeroides pachygaster, lateral view of entire specimen, $80.6 \mathrm{~mm} \mathrm{SL}$, Nigeria . . . . . . . . . .

228. Guentheridia formosa, lateral view of entire specimen, $175 \mathrm{~mm} \mathrm{SL}$, Panama (Pacific) . . . . . . . . . .

229. Colomesus psittacus, lateral view of entire specimen, $178 \mathrm{~mm} \mathrm{SL}$, Surinam . . . . . . . . . . . .

230. Amblyrhynchotes honckenii, lateral view of entire specimen, $70.7 \mathrm{~mm} \mathrm{SL}$, India . . . . . . . . . .

231. Amblyrhynchotes richei, lateral view of entire specimen, $59.4 \mathrm{~mm}$ SL, New Zealand . . . . . . . . .

232. Amblyrhynchotes piosae, lateral view of entire specimen, $33.8 \mathrm{~mm} \mathrm{SL}$, Australia . . . . . . . . . . .

233. Fugu chrysops, lateral view of entire specimen, $98.6 \mathrm{~mm} \mathrm{SL}$, Japan . . . . . . . . . . . . . .

234. Fugu oblongus, lateral view of entire specimen, $46.2 \mathrm{~mm}$ SL, India . . . . . . . . . . . . . .

235. Arothron stellatus, lateral view of entire specimen, $292 \mathrm{~mm} \mathrm{SL}$, India . . . . . . . . . . . . . .

236. Arothron armilla, lateral view of entire specimen, $61.3 \mathrm{~mm} \mathrm{SL}$, Australia . . . . . . . . . . . . . .

237. Tetraodon $\mathrm{mbu}$, lateral view of entire specimen, $47.7 \mathrm{~mm} \mathrm{SL}$, Congo . . . . . . . . . . . . . . . . .

238. Ephippion guttifer, lateral view of entire specimen, $108 \mathrm{~mm}$ SL, Guinea . . . . . . . . . . . . .

239. Chelonodon fluviatilis, lateral view of entire specimen, $84.7 \mathrm{~mm} \mathrm{SL}$, Thailand . . . . . . . . .

240. Monotreta leiurus, lateral view of entire specimen, $61.5 \mathrm{~mm} \mathrm{SL}$, Thailand . . . . . . . . . . . .

241. Chonerhinos modestus, lateral view of entire specimen, $31.0 \mathrm{~mm}$ SL, Borneo . . . . . . . . . . .

242. Xenopterus naritus, lateral view of entire specimen, $143 \mathrm{~mm} \mathrm{SL}$, Bay of Bengal . . . . . . . . . . .

243. Carinotetraodon lorteti, lateral view of entire specimen, $35.9 \mathrm{~mm} \mathrm{SL}$, locality unknown . . . . . . . . .

244. Canthigaster amboinensis, lateral view of entire specimen, $80.3 \mathrm{~mm} \mathrm{SL}$, Hawaii . . . . . . . . . 
245. Sphoeroides maculatus, lateral view of head, $97.5 \mathrm{~mm} \mathrm{SL}$, Virginia . . . . . . . . . . . . . . . .

246. Colomesus psittacus, lateral view of head, $178 \mathrm{~mm}$ SL, Surinam . . . . . . . . . . . . . .

247. Amblyrhynchotes richei, lateral view of head, $59.4 \mathrm{~mm} \mathrm{SL,} \mathrm{New} \mathrm{Zealand} \mathrm{.} \mathrm{.} \mathrm{.} \mathrm{.} \mathrm{.} \mathrm{.} \mathrm{.} \mathrm{.} \mathrm{.} \mathrm{.} \mathrm{.} \mathrm{.} \mathrm{.} \mathrm{.}$

248. Fugu chrysops, lateral view of head, $98.6 \mathrm{~mm} \mathrm{SL}$, Japan . . . . . . . . . . . . . . . . .

249. Fugu oblongus, lateral view of head, $46.2 \mathrm{~mm} \mathrm{SL}$, India $\ldots \ldots \ldots \ldots \ldots \ldots$

250. Arothron stellatus, lateral view of head, $292 \mathrm{~mm}$ SL, India . . . . . . . . . . . . . . . . . . .

251. Tetraodon mbu, lateral view of head, $47.7 \mathrm{~mm} \mathrm{SL}$, Congo . . . . . . . . . . . . . . . . .

252. Chelonodon fluviatilis, lateral view of head, $84.7 \mathrm{~mm} \mathrm{SL}$, Thailand . . . . . . . . . . . .

253. Monotreta leiurus, lateral view of head, $61.5 \mathrm{~mm} \mathrm{SL}$, Thailand . . . . . . . . . . . . . . . .

254. Chonerhinos modestus, lateral view of head, $31.0 \mathrm{~mm}$ SL, Borneo . . . . . . . . . . . . .

255. Xenopterus naritus, lateral view of head, $143 \mathrm{~mm}$ SL, Bay of Bengal . . . . . . . . . . . . . .

256. Carinotetraodon lorteti, lateral view of head, $35.9 \mathrm{~mm} \mathrm{SL}$, locality unknown . . . . . . . . . . . . Dorsal views of skulls:

257. Sphoeroides maculatus, $12.4-201 \mathrm{~mm} \mathrm{SL}$, New Jersey and Virginia . . . . . . . . . . . . . . .

258. A, Sphoeroides dorsalis, $155 \mathrm{~mm}$ SL, Florida; B, S. nephelus, $128 \mathrm{~mm}$ SL, Bahamas; C, S. lobatus, $67.5 \mathrm{~mm} \mathrm{SL}$, Panama (Pacific) . . . . . . . . . . . . . . . . . . . . . . . .

259. A, Sphoeroides angusticeps, $172 \mathrm{~mm} \mathrm{SL}$, Galapagos; B, S. spengleri, $92.8 \mathrm{~mm}$ SL, Nicaragua; C, $S$. maculatus, $179 \mathrm{~mm}$ SL, Virginia

260. A, Sphoeroides greeleyi, $60.8 \mathrm{~mm} \mathrm{SL}$, locality unknown; B, S. trichocephalus, $57.1 \mathrm{~mm}$ SL, Panama (Pacific); C, S. pachygaster, $117 \mathrm{~mm}$ SL, Mozambique . . . . . . . . . . . . . . . . . .

261. Sphoeroides testudineus, $68.5 \mathrm{~mm}$ SL, Venezuela, and S. annulatus, $174 \mathrm{~mm}$ SL, locality unknown ... 262. Guentheridia formosa, $175 \mathrm{~mm}$ SL, Panama (Pacific), and Colomesus psittacus, $179 \mathrm{~mm}$ SL, Suri-

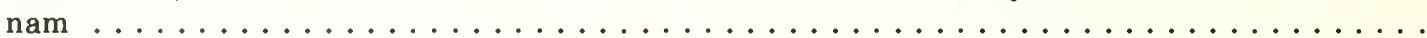

263. A, Lagocephalus inermis, $52.2 \mathrm{~mm} \mathrm{SL}$, Bay of Bengal; B, L. scleratus, $80.9 \mathrm{~mm}$ SL, Philippines; C, L. lunaris, $62.3 \mathrm{~mm} \mathrm{SL}$, Bay of Bengal . . . . . . . . . . . . . . . . . . .

264. Lagocephalus spadiceus, $98.2 \mathrm{~mm}$ SL, Mozambique, and L. lagocephalus, $214 \mathrm{~mm}$ SL, Malpelo Islands

265. Amblyrhynchotes honckenii, $97.4 \mathrm{~mm} \mathrm{SL}$, Mozambique, and A. richei, $59.4 \mathrm{~mm} \mathrm{SL}$, New Zealand ...

266. Torquigener pleurogramma, $113 \mathrm{~mm} \mathrm{SL}$, Australia, and Amblyrhynchotes piosae, $33.8 \mathrm{~mm}$ SL, Aus-

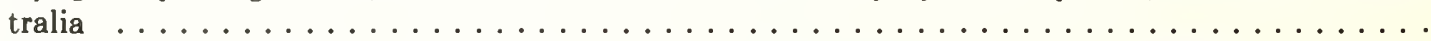

267. Torquigener pleurostictus, $87.1 \mathrm{~mm} \mathrm{SL}$, Australia, and Fugu chrysops, $98.6 \mathrm{~mm}$ SL, Japan . . . . . .

268. Fugu oblongus, $46.2 \mathrm{~mm} \mathrm{SL}$, India, and $F$. rubripes, $151 \mathrm{~mm}$ SL, Japan . . . . . . . . . . . . . . . . . .

269. Arothron stellatus, ca. $420 \mathrm{~mm} \mathrm{SL}$, Seychelles, and A. armilla, $61.3 \mathrm{~mm} \mathrm{SL}$, Australia . . . . . . . . .

270. Tetraodon lineatus, $222 \mathrm{~mm}$ SL, French Equatorial Africa, and T. mbu, $47.7 \mathrm{~mm}$ SL, Congo . . . . . . .

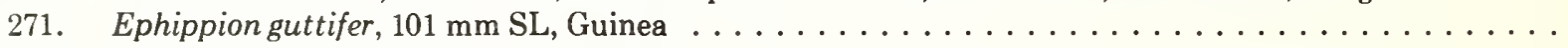

272. Chelonodon patoca, $70.6 \mathrm{~mm}$ SL, New Guinea, and C. fluviatilis, $84.7 \mathrm{~mm}$ SL, Thailand . . . . . . .

273. Monotreta gularis, $46.8 \mathrm{~mm} \mathrm{SL}$, Burma, and M. leiurus, $61.5 \mathrm{~mm}$ SL, Thailand . . . . . . . . .

274. Chonerhinos modestus, $54.5 \mathrm{~mm}$ SL, Borneo, and Xenopterus naritus, $143 \mathrm{~mm}$ SL, Bay of Bengal ...

275. Carinotetraodon lorteti, $33.1 \mathrm{~mm}$ SL, locality unknown . . . . . . . . . . . . . . . . . .

276. Ventral views of skulls of: Sphoeroides maculatus, $179 \mathrm{~mm} \mathrm{SL}$, Virginia, and Arothron stellatus, ca. $420 \mathrm{~mm} \mathrm{SL}$, Seychelles . . . . . . . . . . . . . . . . . . . . . . . . . . . . .

277. Dorsal views of branchial arches and lateral views of hyoid arches of: Xenopterus naritus, $108 \mathrm{~mm} \mathrm{SL}$, Bay of Bengal, and Arothon nigropunctatus, $56.8 \mathrm{~mm} \mathrm{SL}$, Solomon Islands . . . . . . . . . . . .

278. Hypothesized phylogenetic relationships of the genera of Tetraodontidae . . . . . . . . . . . .

279. Range of diversity in body form in the Diodontidae: Diodon holocanthus and Chilomycterus schoepfi . .

280. Diodon holocanthus, with Chilomycterus schoepfi for comparison: external features . . . . . . . . . . Diodon holocanthus, composite based on several specimens, 12.3-124 mm SL, Gulf of Mexico and Caribbean:

281. lateral view of entire specimen

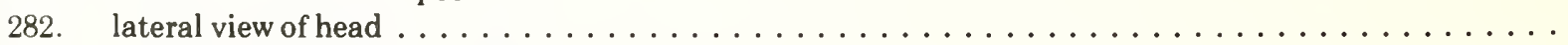

283. dorsal and ventral views of skull $\ldots \ldots \ldots \ldots \ldots \ldots \ldots \ldots \ldots \ldots \ldots \ldots \ldots \ldots \ldots \ldots$

284. posterior view of skull; lateral and posterior views of first abdominal vertebra; posterior view of orbit;

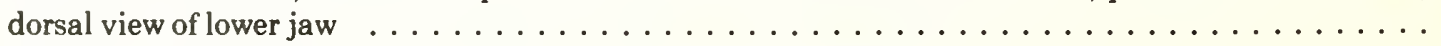

285. dorsal view of branchial arches; lateral and medial views of hyoid arch . . . . . . . . . . . . .

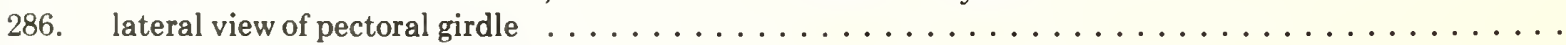

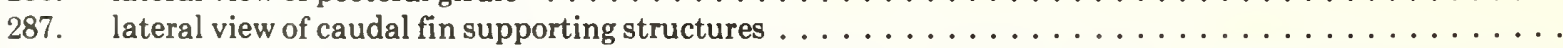

288. Lateral view of entire specimen of another representative diodontid genus: Chilomycterus schoepfi,

$60.1 \mathrm{~mm} \mathrm{SL}$ Louisiana . . . . . . . . . . . . . . . . . . . . . . . . . . . .

Dorsal views of skulls:

289. Chilomycterus schoepfi, $60.1 \mathrm{~mm} \mathrm{SL}$, Louisiana, and C. affinis, $310 \mathrm{~mm} \mathrm{SL,} \mathrm{Galapagos} \mathrm{.} \mathrm{.} \mathrm{.} \mathrm{.} \mathrm{.} \mathrm{.} \mathrm{.} \mathrm{.}$ 
290. Diodon jaculiferus, $53.4 \mathrm{~mm} \mathrm{SL}$, Australia, and Chilomycterus orbicularis, $72.9 \mathrm{~mm}$ SL, Somalia ...

291. Dicotylichthys punctulatus, $226 \mathrm{~mm} \mathrm{SL}$, Australia . . . . . . . . . . . . . . . . . .

292. Chilomycterus schoepfi: dorsal view of branchial arches and lateral view of hyoid arch, $168 \mathrm{~mm}$ SL, Florida . . . . . . . . . . . . . . . . . . . . . . . . . .

293. Nasal apparatuses of representative diodontids: A, Chilomycterus mauretanicus; $B, C$. orbicularis; C, C. schoepfi; D, C. antennatus; E, C. reticulatus; F, C. atinga; G, Diodon hystrix; H, D. holocanthus; I, $D$. jaculiferus; J, Dicotylichthys punctulatus; K, D. nicthemerus

294. Ventral views of upper jaws to show trituration tooth plates: A, Chilomycterus orbicularis, $77.0 \mathrm{~mm}$ SL, Somalia, and $158 \mathrm{~mm} \mathrm{SL}$, Philippines; B, C. schoepfi, $62.5 \mathrm{~mm} \mathrm{SL}$, Texas, and $168 \mathrm{~mm} \mathrm{SL}$, Florida ... .

295. Chilomycterus schoepfi: lateral view of upper jaw; cross section through middle of one of the individual flattened disklike trituration teeth; outline of about one-half of a trituration tooth; $168 \mathrm{~mm}$ SL, Florida

Cross sections of upper and lower jaws just to one side of the midline:

296. Diodon hystrix, $88.3 \mathrm{~mm} \mathrm{SL}, 228 \mathrm{~mm} \mathrm{SL}, 505 \mathrm{~mm} \mathrm{SL} \mathrm{\ldots ...} \mathrm{.} \mathrm{.} \mathrm{.} \mathrm{.} \mathrm{.} \mathrm{.} \mathrm{.} \mathrm{.} \mathrm{.} \mathrm{.} \mathrm{.} \mathrm{.} \mathrm{.} \mathrm{.} \mathrm{.}$

297. Diodon holocanthus, $63.4 \mathrm{~mm} \mathrm{SL}, 122 \mathrm{~mm} \mathrm{SL}, 183 \mathrm{~mm} \mathrm{SL}, 375 \mathrm{~mm} \mathrm{SL} \ldots \ldots$. . . . . . . . . . .

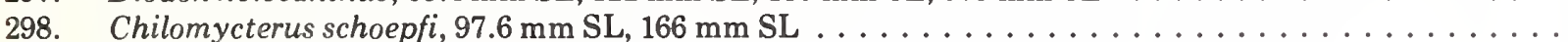

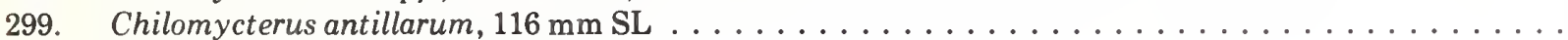

300. Chilomycterus atinga, $173 \mathrm{~mm}$ SL . . . . . . . . . . . . . . . . . . .

301. Chilomycterus mauretanicus, $92.2 \mathrm{~mm} \mathrm{SL} \mathrm{\ldots .......................}$

302. Chart showing the increased number of trituration plates in the upper jaw in Diodon holocanthus, $D$. hystrix, Chilomycterus schoepfi, C. mauretanicus, C. atinga, C. antillarum, and C. reticulatus . . . . .

303. Hypothesized phylogenetic relationships of the genera of Diodontidae . . . . . . . . . . . .

304. Range of diversity in body form in the Molidae: Mola mola and Ranzania laevis . . . . . . . . . . . .

305. Mola mola: external features . . . . . . . . . . . . . . . . . . . . . . . . . . .

Mola mola, composite based on two specimens, 306 and $310 \mathrm{~mm} \mathrm{SL}$, California:

306. lateral view of entire specimen . . . . . . . . . . . . . . . . . . .

307. lateral view of head . . . . . . . . . . . . . . . . . . . . . . . . .

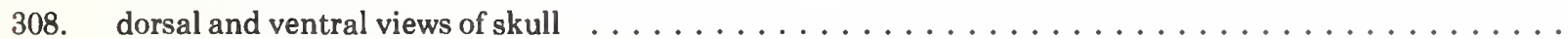

309. posterior view of skull; lateral and posterior views of first abdominal vertebra; posterior view of orbit;

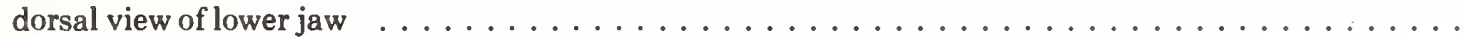

310. dorsal view of branchial arches; lateral view of hyoid arch $\ldots \ldots \ldots \ldots \ldots \ldots \ldots \ldots$

311. lateral view of pectoral girdle . . . . . . . . . . . . . . . . . . . . .

312. lateral view of pseudocaudal fin supporting structures $\ldots \ldots \ldots \ldots \ldots \ldots \ldots \ldots$

External features of other representative molid genera:

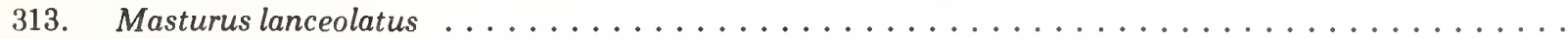

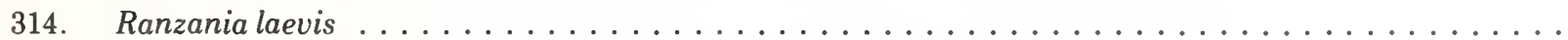

315. Masturus lanceolatus, lateral view of entire specimen, $127 \mathrm{~mm} \mathrm{SL}$, Florida . . . . . . . . . . . . . .

316. Ranzania laevis, lateral view of entire specimen, $65.1 \mathrm{~mm} \mathrm{SL}$, Hawaii . . . . . . . . . . . . . . . .

317. Masturus lanceolatus, ventral and dorsal views of skull, $127 \mathrm{~mm} \mathrm{SL}$, Florida . . . . . . . . . . . . . .

318. Ranzania laevis, ventral and dorsal views of skull, $65.1 \mathrm{~mm} \mathrm{SL}$, Hawaii . . . . . . . . . . . . . .

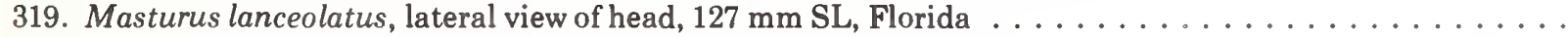

320. Ranzania laevis, lateral view of head, $65.1 \mathrm{~mm} \mathrm{SL,} \mathrm{Hawaii} \mathrm{.} \mathrm{.} \mathrm{.} \mathrm{.} \mathrm{.} \mathrm{.} \mathrm{.} \mathrm{.} \mathrm{.} \mathrm{.} \mathrm{.} \mathrm{.} \mathrm{.} \mathrm{.} \mathrm{.} \mathrm{.}$

321. Dorsal views of branchial arches and lateral views of hyoid arches: Ranzania laevis, $66.9 \mathrm{~mm}$ SL, Hawaii, and Masturus lanceolatus, $127 \mathrm{~mm} \mathrm{SL}$, Florida

322. Masturus lanceolatus: dorsal view of lower jaw, $127 \mathrm{~mm} \mathrm{SL}$ Florida

323. Ranzania laevis: dorsal view of lower jaw and ventral view of upper jaw, $493 \mathrm{~mm}$ SL, Hawaii; dorsal view of lower jaw, $65.1 \mathrm{~mm} \mathrm{SL}$, Hawaii

324. Ranzania laevis: diagrammatic representation of the relationships between the basal pterygiophores of the dorsal, anal, and pseudocaudal fins and the neural and haemal spines of the supporting vertebrae; $65.1 \mathrm{~mm}$ SL, Hawaii

325. Ranzania laevis: scales from upper middle region of body; $493 \mathrm{~mm} \mathrm{SL}$, Hawaii

326. Hypothesized phylogenetic relationships of the genera of Molidae

\section{Tables}

1. Characteristics of the hyoid and branchial arches in families of Tetraodontiformes . . . . . . . . .

2. Total number of vertebrae and vertebral formulas of Recent plectognath fishes examined as radiographed and as cleared and stained specimens

3. Numbers of teeth in the upper and lower jows of ostracioids $\ldots \ldots \ldots \ldots$ 



\title{
Osteology, Phylogeny, and Higher Classification of the Fishes of the Order Plectognathi (Tetraodontiformes) ${ }^{1}$
}

\author{
JAMES C. TYLER ${ }^{2}$
}

\begin{abstract}
The osteology of over 160 species of fossil and Recent plectognath or tetraodontiform fishes is described and illustrated in relation to the supposed phylogeny and proposed higher classification (subfamilial to ordinal levels) of this group of approximately 320 Recent species of primarily tropical and temperate forms of the Atlantic, Pacific, and Indian oceans. The history of the classification and of the previous work on the osteology of the order is reviewed, while one new species ( $\dagger$ Acanthopleurus collettei, Oligocene of Canton Glarus, Switzerland) and one new genus (†Eotetraodon, Eocene of Monte Bolca, Italy) are described. Comparative inclusive and exclusive definitions are given for all higher categories based on both external and internal anatomical features. The Order Plectognathi (Tetraodontiformes) is divided into two suborders, the Sclerodermi or Balistoidei and the Gymnodontes or Tetraodontoidei, with a variety of other infraordinal and superfamilial categories, and 10 families, with subfamilial groupings in 4 of the latter.
\end{abstract}

\section{INTRODUCTION}

\section{Preface}

The Plectognathi are widely, but not unanimously, recognized as one of the major orders or phyletic lines of teleostean fishes derived of perciform ancestors. The primary reason that there is any doubt concerning the naturalness of the Plectognathi, regardless at what taxonomic level it is recognized, is that it is a highly diversified group for which adequate definitions have not yet been given either for it as a whole or for most of its subdivisions. Until there appears and is accepted a consistent and systematic general osteological survey and comparison of the basic types of organization found among the fossil and Recent species of plectognaths, both generalized and highly modified, it will be impossible to state without reasonable refutation that they are all closely related, and more similar to one another than to any other group of fishes.

The aims of the present monograph are: first, to anatomically define, especially with osteologically based characters, the higher categories in the classification of the plectognaths proposed here, these categories being from the subfamilial to ordinal levels; and second, to in-

\footnotetext{
${ }^{2}$ Contribution No. 77-25M from the Southeast Fisheries Center Miami Laboratory, Miami, Fla.

${ }^{2}$ Southeast Fisheries Center Miami Laboratory, National Marine Fisheries Service, NOAA, Miami, FL 33149, and Research Associate, Department of Ichthyology, American Museum of Natural History, New York, NY 10024; present address: Office of Marine Mammals and Endangered Species, National Marine Fisheries Service, NOAA, 3300 Whitehaven Street, N.W., Washington, DC 20235.
}

terpret the phylogenetic relationships between these divisions and most genera of the fossil and Recent Plectognathi, dating back to the upper portion of the lower Eocene, approximately 60 million years ago.

This is done by pointing out, as much by illustrations as by written descriptions, the many common osteological features of numerous representatives of each of the families of plectognaths, including both relatively generalized and specialized species when available. The totality of these characteristics of the fossil and Recent species demonstrates beyond question the distinctiveness and phylogenetic naturalness of the plectognath fishes, while at the same time providing the bases for the detailed comparative diagnoses given here for the taxonomic subdivisions of the Plectognathi.

As classified here, the Order Plectognathi (or Tetraodontiformes), comprising today about 320 species of mostly shallow-water, circumtropical, and subtropical marine forms, is divided into two suborders (Sclerodermi or Balistoidei and Gymnodontes or Tetraodontoidei), a variety of categories from infraorders to superfamilies, and into 10 families, in 4 of which subfamilies are recognized. The Plectognathi are much more diversified than the great majority of fish groups of a comparable number of species. Relative to its comparatively few species, mostly marine, the Plectognathi are as highly diversified as that prime example of diversity among fishes, the speciose freshwater characids of South America and Africa.

Just as interesting as the plectognath's diversity itself, 
is an analysis of the evolutionary mechanism leading to it. This presents a strikingly clear case of intraordinal evolution primarily through the processes of reduction, simplification, and loss of elements, especially of the bony parts. Reductive tendencies in the evolution of vertebrates, including many groups of fishes, are not uncommon (Myers 1958), and the reductions that have taken place in plectognaths are of especial interest only because of the extreme exaggeration of the tendency in this order. The reductive trend in the evolution of plectognaths obviously is not absolute, and certain morphological units in circumscribed groups show an opposite tendency, e.g., the stomach and complex musculature of tetraodontoids, the pectoral girdle of ostracoids, the scales in nearly all groups except a few tetraodontids, etc.

The main point, however, is that the generalized members of the order, the triacanthoids, possess only slightly less than the percoid complement of bones, but many bones have become reduced or simplified, fused with others, or entirely lost in what appear to be clear evolutionary lines derived from these basal plectognaths. This is especially evident in the: branchial apparatus; caudal, dorsal, and anal fin supporting structures; dorsal fin spines; pelvic fin and girdle; jaws and teeth; and myodome.

The plectognaths are also of biological interest because of their supposed position at one of the major end lines of modern teleost radiation and because of their great diversification in structure, size, behavior, way of life, and habitat (Tyler 1965c). They range from $22 \mathrm{~mm}$ and $30 \mathrm{~g}$ to $2 \mathrm{~m}$ and $1,000 \mathrm{~kg}$ in adult length and weight, from relatively normal shapes to strangely specialized forms with long tubular snouts or aborted caudal regions, from scaleless to heavily armored, from nearly toothless to equipped with massive crushing beaks, from drably colored to gaudy, from palatable to poisonous flesh, etc., and with comparable contrariety in behavior, habits, and habitats. They include the spikefishes, triplespines, triggerfishes, filefishes, boxfishes, trunkfishes, pursefishes, pufferfishes, porcupinefishes, and giant ocean sunfishes.

The plectognaths are of some commercial interest directly, for the dried skins or encasements of the weirder forms are sold as curios, while a few species are sold for human consumption, such as tetraodontids, called sea squabs on the east coast of the United States and fugu in Japan, but of greater worth indirectly - the young of many plectognath species are important forage for such popular large oceanic fishes as dolphins, tunas, and billfishes.

The Plectognathi are thought to have been derived from a percoid ancestry related to the same line which gave rise to the acanthuroids (the surgeonfishes and their allies) in the late Cretaceous, but the evidence of this hypothesized relationship is not yet conclusive (Tyler 1968, 1970c). The osteology of the fossil and Recent acanthuroids is not well known, but with the osteology of the plectognaths being made better known here, it will be easier to search among the acanthuroids for a group which shows a preplectognath type of organization and which may be related to the speculated ancestral stock common to the two groups.

Because the plectognaths are often of exotic form and occur in European waters, even though their center of diversification is the Indo-Pacific, a few species were described by early naturalists from Aristotle and Pliny to Linnaeus. But some species still remain to be described, many others are inadequately known, and much con. fusion remains about the systematics of the group, even at the familial level.

\section{Methods}

The majority of the specimens of the Recent species studied for this monograph were prepared by potassium hydroxide clearing, alizarin staining, and glycerin preservation, prior to the advent of techniques using trypsin. A few specimens were prepared by maceration as dry or alcohol wet whole skeletons, or parts thereof, while limited dissections were made on alcohol-preserved whole materials. For fossil species, only superficial surface preparation with chipping and weak acid washes was employed.

A list of the species examined, along with the numbers of specimens and their sizes, general localities, and catalogue (or other identifying) numbers of their repositories, appears toward the end of this work.

Length of specimens is always standard length (SL), unless otherwise noted, taken from the anteriormost middle point of the upper jaw (often from the tip of the exposed upper teeth) to the middle of the line of flexure at the caudal fin base, and measured and recorded with a needlepoint dial caliper to the nearest 10th of a millimeter $(\mathrm{mm})$, but with lengths given here of over $100 \mathrm{~mm}$ rounded off to the nearest $\mathrm{mm}(0.5$ and above to the next highest integer).

The survey of the osteology of the order was hindered by the poor showing of internal features in several fossil forms, by the relative unavailability of specimens for clearing and staining of about one-fifth of the described species currently considered valid, by a lack of time and purpose to describe and illustrate each available species (especially in genera with large numbers of osteologically similar forms), and by the demands of space conservation and publication costs. It is felt, however, that the species selected for osteological inclusion (167 studied, and 115 illustrated, for one skeletal region or another, of the approximately 320 Recent species, and nearly all of the fossil forms) adequately cover the anatomical diversity of the group, and almost always cover the entire range of external and osteological differences of the more highly modified as well as more normal representatives of each family. I find it difficult to believe that there is a missing link or living relic among those Recent and fossil plectognaths not examined for this work which 
would materially change the concepts of the phylogeny and classification presented here.

For each of the 10 families treated here, one relatively generalized species is described in detail and extensively illustrated, with other species as appropriate described and illustrated less fully, except in the Tetraodontidae, with two species representative of the two subfamilies that have often been considered as separate families being given the fuller descriptive and illustrative treatment to aid in comparisons of their osteological distinctiveness. Line drawings show the most diagnostically important or anatomically interesting external features of representatives of each group.

Lateral view illustrations of the entire skeleton are usually supplemented by other views of various parts of the skeleton showing features of particular phylogenetic or morphological interest.

Statements concerning the numbers of such serial elements as basal pterygiophores, epipleurals, neural and haemal spines, epurals, and hypurals are based mostly on cleared and stained specimens and not on radiographs, because all of the members of such series of these elements usually are not clearly defined in radiographs due to the often thickened nature of the scales. Vertebral counts are based on both cleared and stained specimens and radiographs, except for those of diodontids in which radiographs of the vertebral column are usually undeciferable because of the massive roots of the skin spines.

The lateral view illustrations of entire skeletons and of most of the skeletal parts were prepared by photographing the skeleton or its parts submerged in a glycerin solution. The $35 \mathrm{~mm}$ negatives were projected and outline drawings showing as much detail as possible made, of about 40 to $50 \mathrm{~cm}$ length in the case of entire skeletons. Details were filled in by examination through a dissecting microscope of the photographed skeleton or part. The completed pencil drawings were transferred by ink tracing on paper, with contours and depth approximately shown by varying intensities of stippling. While the pencil drawings and ink tracings are all by the author, the stippling is by a combination of the author and his illustrators listed in the Acknowledgments. Photographed entire specimens and/or one or more additional specimens of the same species were partially disarticulated in order to prepare, if necessary, drawings of selected parts or views of regions of diagnostic or morphological interest, as well as generally to examine the skeleton and its parts in greater detail. A few of the simpler supplemental illustrations were made with the aid of proportional dividers rather than photography. Some of the drawings are composite, based on several specimens, and are so indicated.

Fin rays usually are shown only partially and diagrammatically as an outline of the positions of the bases of the rays, with, for the caudal fin, the unbranched rays indicated by solid bases and the branched rays by open bases. Only the pelvic fin rays and uppermost pectoral fin ray routinely were fully drawn. Epipleurals, especially if slender, usually are shown in solid black rather than stipple. The finer details of the surface sculpturing of the bones usually is not shown, for, even though it is beautiful, it is exceedingly time consuming to accurately portray and normally is of little value to an understanding of the relationships of the species in question.

The otoliths of the species treated here are not illustrated, for they only rarely were intact and uncorroded enough in the cleared and stained study material to be useful.

The osteological descriptions of the species treated in greatest detail were written from microscopic reexamination of the skeletons or parts thereof, and corrections were made in the drawings whenever necessary. Corrections were frequent, for nothing brings to light the errors in illustrations more quickly than having to verbally describe the shapes of bones and, particularly, their articulations.

The osteological terminology used here is conservative, and hopefully that most readily understandable by the majority of ichthyologists. For the most part, it is that of Starks (1901), although such terms as pterosphenoid, ectopterygoid, first pharyngobranchial, cleithrum, and scapula are substituted, respectively, for Starks alisphenoid, pterygoid, suspensory pharyngeal, clavicle, and hypocoracoid. Certain names, such as prefrontal rather than lateral ethmoid or dermethmoid, are used in order to be deliberately topological and to avoid implications of the dermal versus endochondral origin of the bone.

Subsequent to the beginning of this monograph, and of the pervasive decisions on the names of bones to be employed in the text and illustrations, several researchers have provided more precise and homologously correct terminologies for certain skeletal regions than used here. It has not been possible for reasons of practicality to make the numerous desirable changes, especially in labeling of the illustrations, that would be necessitated by incorporating these changing terminologies into the present work. Examples of the more modern and accurate names for certain skeletal regions, such as the branchial arches and lower jaw, are found in the exemplary publications of Weitzman (e.g., 1967 et seq.) and Nelson (e.g., 1969 et seq.).

In describing the types of articulations between bones, purely descriptive phrases often are used, for the technical terminology is not standardized and it is sometimes more precise than my observations. Whenever an amount of cartilage observable under the dissecting microscope (ca. 30X) is seen to intervene between the articular faces of two bones, these bones are said to articulate through cartilage. When bones have relatively smooth articular faces held to one another without the intervention of cartilage, they are said to articulate by fibrous tissue. A large number of bones are said to articulate with one another by interdigitation, and this simply means that the closely apposed surfaces of two bones have their articulation strengthened by delicate to coarse emarginations of one bone fitting into similar indentations of the other bone. At its fullest development, this interdigitation can be distinguished from fusion only 
by attempting to disarticulate the bones after long maceration. When a bone is said to be cartilage filled along a particular edge, this refers to the presence of cartilaginous material extending into the otherwise ossified substance of the bone so that an upper and a lower layer of bone, separated by cartilage, are distinguishable at the edge of the bone. Such a condition, of course, is only possible in endochondral bones. As a general rule, the amount of interdigitation between bones increases with increasing specimen size, while at the same time the amount of cartilage at the edges of endochondral bones decreases.

The suffix oideo is adopted for the names of infraordinal categories.

Throughout the text, vernacular versions of the classically based and more formal superfamilial, familial, and subfamilial names, ending respectively in oidea, idae, and inae, are employed, with the last two vowels dropped for adjectival usage and with these replaced by an "s" for nominative usage, so that superfamilies end in -oid or -oids (triacanthoid, balistoid, ostracioid, triodontoid, tetraodontoid, moloid), families in -id or -ids (triacanthodid, triacanthid, balistid, monacanthid, aracanid, ostraciid, triodontid, tetraodontid, diodontid, molid), and subfamilies in -in or -ins (spinacanthin, eoplectin, hollardiin, triacanthodin, protacanthodin, cryptobalistin, triacanthin, ostraciin, lactophrysin, tetraodontin, canthigasterin). The names of two of the familial categories, the Triacanthodidae and Triacanthidae, unfortunately are rather similar, and the distinction between such terms as triacanthoid, triacanthodid, and triacanthid is a necessary mental excercise.

\section{PROLOGUE}

\section{Synopsis of the Phylogeny of the Plectognathi}

The anatomical data on the fossil and Recent Plectog. nathi presented in this monograph indicate that the family Triacanthodidae contains the most generalized fossil and Recent species of the order, and that these basal plectognaths gave rise on the one hand to the line leading to the triacanthids, their nearest relatives, and through them to the balistoids and ostracioids, while, on the other hand, and with even greater modification away from the ancestral level of organization, the triacanthodids gave rise to the triodontids, and through them to the tetraodontoids and molids. The triacanthodids and their anatomically and phylogenetically closest derivative groups, the triacanthids, balistoids, and ostracioids, are here considered to represent the suborder Scleroder$\mathrm{mi}$ or Balistoidei, while the other major line of plectognath radiation, that has diverged even further from the ancestral triacanthodid type, comprising the triodontids, tetraodontoids and molids, is here considered to represent the suborder Gymnodontes or Tetraodontoidei.

Two fossil forms of the basal triacanthoids from the Eocene are thought to be especially pertinent to the phylogeny of the plectognaths, for Protacanthodes forms a strong link between the triacanthodids and the triacanthids and thus to the other derived scleroderms (balistoids and ostracioids), while Eoplectus is nearly a perfect intermediary between the triacanthodids and the triodontids, the most generalized of the gymnodonts, and thus to the derived tetraodontoids and molids.

More particularly, of the four subfamilies of Triacanthodidae recognized here, it is obvious that the Triacanthidae are derived from the Hollardiinae rather than from the Triacanthodinae or the fossil Spinacanthinae and Eoplectinae because of similarities in the shapes and positions of the bones in the rear of the skull and of the shape of the pelvis and because there is every reason to believe that the Spinacanthinae were evolutionary dead ends without issue surviving today and that the Eoplectinae were ancestral to the triodontids and the other gymnodonts.

The evolution of the Triacanthidae from the Triacanthodidae was probably mediated through a form like Protacanthodes, the Eocene representative of the most generalized subfamily of triacanthids. Of the other two subfamilies of triacanthids, the triacanthins include all of the Recent species and obviously evolved from such Oligocene forms as Acanthopleurus, while the aberrant cryptobalistins of the Oligocene were, like the spinacanthin triacanthodids, failed evolutionary experiments that did not give rise to forms living today. The balistoids and ostracioids are reasoned to share a common ancestral line to the triacanthids in the Eocene, and it is unquestioned that the balistids gave rise to the monacanthids and that the aracanids are ancestral to the ostraciids. Two subfamilial lines of evolution are evident in the ostraciids.

The recent discovery of the eoplectin triacanthodids, with a well-developed spiny dorsal fin, the best developed pelvic fin among plectognaths, and a generaliy triacanthodid appearance, but with a fully developed gymnodontlike crushing beak, tends to confirm that the triacanthodids gave rise to a line of triodontidlike forms which in turn were ancestral to the two main radiations of the gymnodonts, the molids on the one hand and the tetraodontids and diodontids on the other hand. The tetraodontids show two subfamilial phyletic lines, the tetraodontins for the vast majority of diversified forms, related through Carinotetraodon to the canthigasterins.

In summary, it seems clear, especially in the light of our present knowledge of Protacanthodes and Eoplectus, as discussed by Tyler (1973b), that the basic diversification of the plectognaths was a relatively rapid event of the lower Eocene. In the upper portion of the lower Eocene of Monte Bolca, Italy, alone, there are represen- 


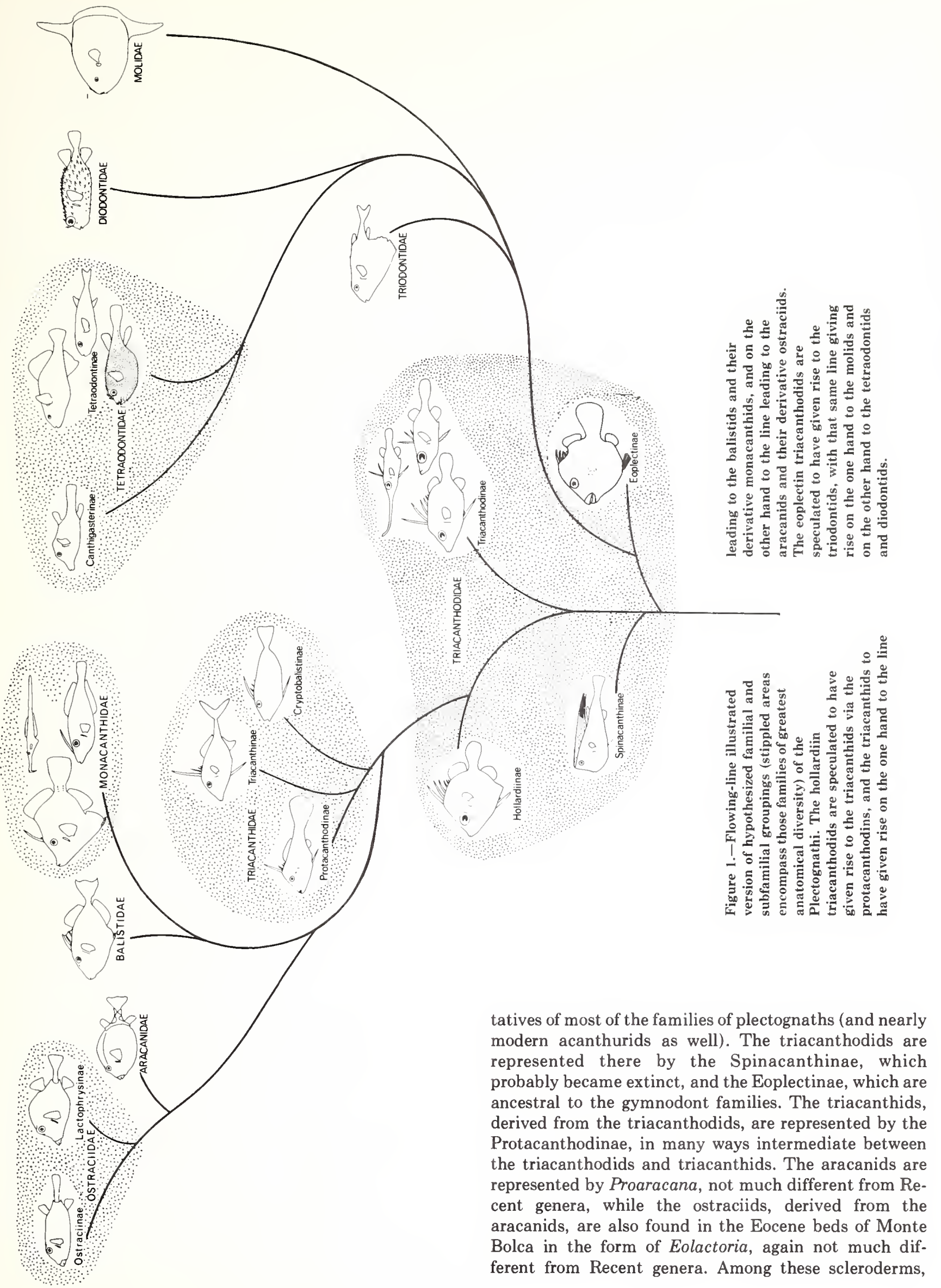



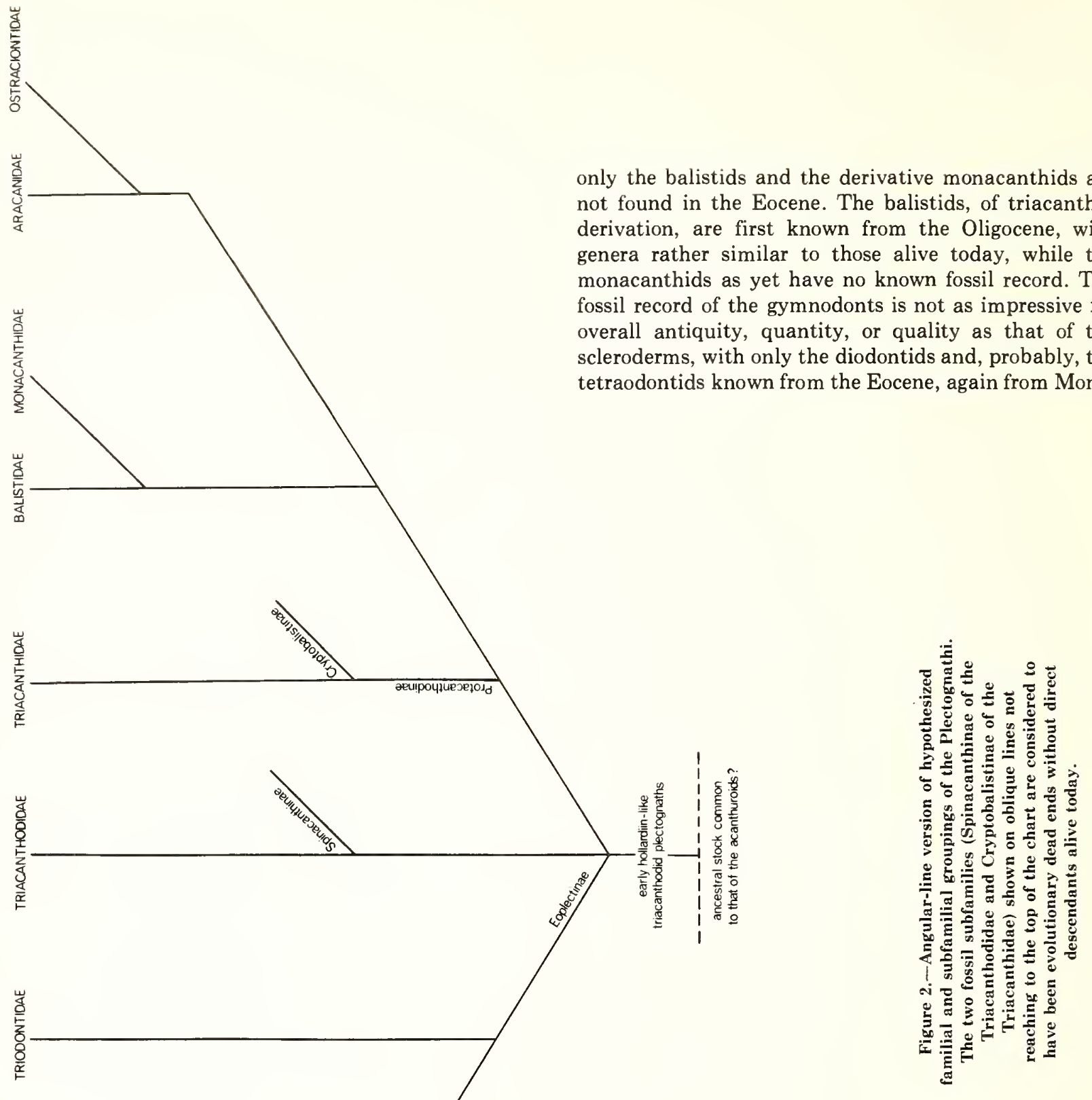

Bolca. Triodontids have been described from the Eocene of Africa and Europe (not including Monte Bolca), but only on the basis of jaws alone, with the dentaries fused into a single piece and the premaxillaries separate. The teeth in these jaws are small rounded units such as are found in Triodon and diodontids, but this is scarcely sufficient evidence of a fish of truly Triodon-like general configuration in the Eocene. Molids are first known from the Miocene. 


\section{Synopsis of the Higher Classification of the Plectognathi}

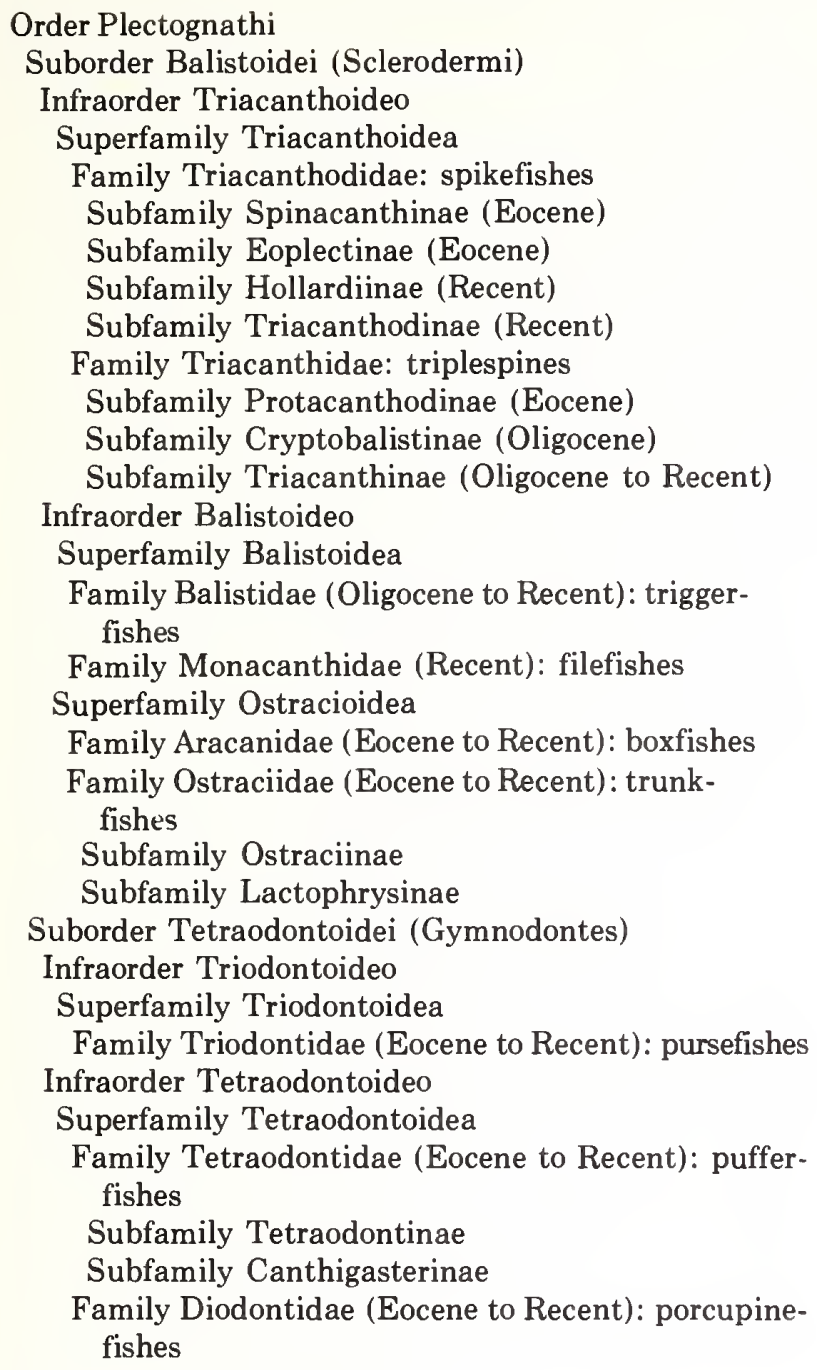

\author{
Superfamily Moloidea \\ Family Molidae (Miocene to Recent): giant ocean \\ sunfishes.
}

Alternative arrangements of subordinal and lower groupings are obviously possible and perhaps equally appealing to some. One of these would be to recognize the triacanthodids as subordinally distinct from both of the two major lineages to which they gave rise, a suborder Sclerodermi (Balistoidei), in this case comprising the triacanthids, balistoids, and ostracioids but minus the triacanthodids, and a suborder Gymnodontes (Tetraodontoidei), with the triodontids, tetraodontoids, and molids. Another would be to recognize both the triacanthodids and triacanthids as subordinally distinct from both the remainder of the suborder Sclerodermi (in this case only the balistoids and ostracioids) and the suborder Gymnodontes (as above). Or, as Winterbottom (1974) has so ably suggested, a recognition of a suborder for the triacanthodids and triacanthids as distinct from a suborder for all of the other plectognaths, with the latter divided into two superfamilies, one for the balistoids and ostracioids (the remnants of the Sclerodermi) and one for the gymnodonts (as above) along with the Eocene Eoplectus and its relatives.

It is felt here that the entire constellation of overall similarities and differences in both generalized and specialized features between the various species and higher categories support the reasonableness of continuing to divide the Plectognathi into two suborders: the Sclerodermi for the basal triacanthodids and their closely related triacanthids as well as the balistoids and ostracioids derived from the latter, and the Gymnodontes for the more modified tetraodontoids and molids linked together through the triodontids to the Eocene eoplectin triacanthodids.

\section{Historical Review of the Classification of the Plectognathi}

Since representatives of most of the major subgroups of plectognaths occur in the Mediterranean and off the Atlantic coast of Europe, they were familiar to the early Greeks and Romans. A rather long article could be devoted to just the pre-Linnaean occidental knowledge of the plectognaths, for almost every naturalist who dealt with fishes, from Aristotle to Marcgrave, made prominent mention of various balistoids, ostracioids, tetraodontoids, and molids (the similar oriental, primarily Chinese, history of the plectognaths cannot be dealt with here). Passing over those nearly 2,000 years that intervened between Aristotle and the person who is most often considered the founder of modern ichthyology, Peter Artedi, only one example of the type of classificatory scheme that preceded Artedi's work need be cited.
In his "Historia Piscium," Willughby (1686:22-25) divided "fishes" (including elasmobranchs and cetaceans) into 11 major categories, one of which was the Pinnis ventalibus carentes, containing the plectognaths, syngnathids, and swordfishes.

Within any one of the 11 categories were described a variable number of species, most of them based on the literature of such previous naturalists as Clusius, Rondelet, Gesner, Marcgrave, Belon, Salviani, and Aldrovandi, but with a few supposedly new species also described. The types of fishes that occurred (Willughby 1686:143-164) in the "de Piscibus corpore contractiore vel saltem non admodum lubrico, qui pinnis ventralibus carent," or "Pinnis ventralibus carentes," were for the most part plectognaths. This section consisted of 14 chapters, each of which described either a single species 
or a group of supposedly related species. For example, Chapter I (p. 143-148) was devoted to "De Orbe Pisce" and described 11 species in which the first word of the binomial or polynomial was, in all but two cases, Orbis. The two exceptions had the species name beginning with Orbibus or Histrici and are diodontids. One might expect that all of the Orbis species would be tetraodontids or diodontids and in fact they are, with a single exception: the Orbis Ranae rictu (p. 145, fig. 2 of pl. 19, after Clusius) is Cyclopterus lumpus. Another species, Orbis oblongus Testudinis capite (p. 147-148, fig. 3 of pl. 19, after Clusius) is probably a tetraodontoid, but the figure shows a creature whose front end reminds one of a fetal seal but whose hind end is fishlike. Chapters II (p. 148) and III (p. 148-149) described, respectively, Ostracion Nili and Ostracion prior, both of which are ostraciids, as is Pisces triangularis of Chapter IV (p. 149-150). Chapter V (p. 150-151) described Monoceros pisces, which is probably a monacanthid, while Chapter VI (p. 151-152) was devoted to the Mola of Salviani or Orthagoriscus of Rondelet. Chapter VII (p. 152-156) described the balistid Capriscus pesce Balestra, but an appendix to this chapter described three species of Orbes: a tetraodontid, a diodontid, and an ostraciid. The remaining seven chapters described nonplectognaths, these being, to use only the "generic" term, Stromateus (a butterfish), Hippocampus (a seahorse), Acus (a pipefish), Acui (a syngnathid), Scolopax (Macrorhamphosus), and Xiphias (a swordfish). The latter seven types have little, if anything, in common with the plectognaths, making for an odd mixture of forms within the "Pinnis ventralibus carentes," but it is more realistic to dwell on the fact that by the 17 th century the plectognaths were already placed together in the same subgroup of fishes.

In an appendix, written by Lister, to Willughby's (1686) "Historia Piscium," an illustration of a shallowwater triacanthid was given, based on the Hoornvisch of the Dutch East Indies first described by Nieuhof (1682) in his work on the fishes of Batavia. An account of this species of triacanthid was not to reappear until Bleeker (1852b) formally described this first-mentioned triacanthid as Triacanthus Nieuhofii, while in the interim the first triacanthid to be binomially described was Balistes Biaculeatus Bloch 1786. By contrast, the deepwater triacanthodids were not described until Schlegel (1850).

With the advent of Artedi, the classification of fishes in general as well as that of the plectognaths was placed on a much more refined basis, for the groupings of supposedly related forms were far superior to any that had previously appeared. In his "Genera Piscium," Artedi (1738) recognized five basic divisions within his Pisces. One of these, the Plagiuri, had the caudal fin horizontal and is the Cetacea, while the other four divisions (Malacopterygii, Acanthopterygii, Branchiostegi, and Chondropterygii) had the caudal fin perpendicular and are true fishes. The Branchiostegi contained the following genera: Ealistes, Ostracion, Cyclopterus, and Lophius.

The generic categories of Artedi are usually recog- nized today at the familial or ordinal levels. The name Branchiostegi (branchio, gills, and stegein, to be covered) implies that Balistes, Ostracion, Cyclopterus, and Lophius should have the superficial similarity of the gills being relatively well hidden from external view by the constricted aperture of the branchial cavity. We now know, of course, that the last two genera mentioned above are neither closely related to one another nor to Balistes and Ostracion. Ostracion contained 22 species which represent not only the ostraciids but also the tetraodontids, diodontids, and molids. It should be noted that the Ostracion category was composed of species of extreme diversity in external appearance, which are nevertheless closely related to one another. Moreover, the group was not as heterogeneous as it might superficially seem to be, for within it the species were described successively in a manner which shows that Artedi had an insight into the relative closeness of relationship of the various forms. Thus, the first 10 species are ostraciids, and the next 3 species are tetraodontids. All of the next seven species (nos. 14 to 20) are diodontids, with the exception of species no. 17, which is the Orbis Ranae rictu of Willughby and of Clusius, a cyclopterid. The next to the last species (no. 21) is probably a tetraodontid, but since it was based on the poorly figured Orbis oblongus Testudinis capite of Willughby and of Clusius, one could scarcely have expected Artedi to have placed it with his other tetraodontids. The last species (no. 22) is the commonest (as an adult, at least) of the molids, Mola mola. The Balistes group contains five balistoids and a macrorhamphosid (the only nonplectognath included). In short, Artedi did justice to those plectognaths which he had actually seen or which were reasonably described in the literature, and the several errors were only the result of occasionally being forced to rely solely on poor descriptions by earlier naturalists.

The plectognaths appeared in a somewhat different assemblage in Klein's (1742) "Historiae Piscium Naturalis." Like previous workers since the time of Aristotle, Klein included in his Pisces both cetaceans and fishes, separating them from one another on the basis of possession of lungs or gills. Whereas Artedi's first dichotomous division of the true fishes was on the basis of bone as opposed to cartilage in the skeleton, Klein's was on whether the gills were hidden or easily observed. Thus, the Branchiis Apertis contained a large array of relatively normal fishes, such as Silurus, Acipenser, Xiphias, Mastacembelus, Solea, Tetragonopterus, etc. By contrast, the Branchiis Occultis contained a less plausible association of 15 genera, including elasmobranchs and cyclostomes.

The plectognaths were all included in Crayracion (Klein 1742:17) and Capriscus (p. 23), which, along with Batrachus and Conger, supposedly had the following combination of characters: paired fins present; branchial cavity with a single aperture; gills placed laterally and hidden from view. Klein's Batrachus is the same as Artedi's Lophius, while Artedi's Cyclopterus appeared as a part of Klein's Crayracion. The addition of a number of eels, as Conger, to a place of proximity with 
the plectognaths and Lophius and the placement of all of these with the elasmobranchs and cyclostomes were major differences in the treatment of the plectognaths by Artedi and Klein. Klein's Crayracion and Capriscus are more or less synonymous with, respectively, Artedi's Ostracion and Balistes. Both of Artedi's groups contained only plectognaths (except for Macrorhamphosus), but the same cannot be said of Klein's. The latter described 32 species of Crayracion, of which most are ostraciids, tetraodontids, diodontids, or molids, but species 7 (p. 19) and 11 (p. 19) are Cyclopterus and species 32 (p. 23) is a syngnathid. On the other hand, all 11 species of Klein's Capriscus are balistoids.

In his "Museum Ichthyologicum," Gronovius (1754) followed precisely the classification adopted by Artedi, with Pisces containing the Plagiuri, Malacopterygii, Acanthopterygii, Branchiostegi, and Chondropterygii. The Branchiostegi again contained four types: Balistes, Ostracion, Cyclopterus, and Lophius. Gronovius made no innovations in the Balistes category; on the contrary, one of his species of Balistes appears to be Marcgrave's antenneriid frogfish from Brazil. However, Gronovius did go a step beyond Artedi in his handling of the Ostracion group. Gronovius divided his Ostracion into three subgroups on the basis of body shape, thus: Corpore quadrangulo, with three ostraciids; Corpore triangulato, with three more ostraciids; and Corpore cathetoplateo, vel rotundo, with two tetraodontids and a molid. Although Gronovius' (1763) subsequent "Zoophylacium" is postLinnaean chronologically, it is pre-Linnaean in its terminology. His Pisces were now divided into Plagiuri, Chondropterygii, Branchiostegi, and Branchiales, the latter group being roughly equivalent to his previously used Malacopterygii and Acanthopterygii. Within these groups the species were segregated according to fin structure. Thus, his Branchiostegi were arranged as follows:

Pinnis Ventralibus nullis: Muraena, Gymnotus, Syngnathus, Ostracion.

Pinnis Ventralibus spuriis: Balistes, Cyclopterus, Cyclogaster.

Pinnis Ventralibus veris praesentibus: Gonorynchus, Cobitis, Uranoscopus, Lophius.

New groups were added to the Artedian Branchiostegi, and, beyond that, Gronovius (1763) added a further subdivision to the Ostracion category. The Balistes category remained a simple descriptive list of a number of balistoids and a macrorhamphosid. The four Ostracion subgroups that Gronovius recognized were: Corpore quadrangulo, with four ostraciids; Corpore triangulato, with three more ostraciids; Sphaerico, vel oblongorotundo corpore, with two diodontids and one tetraodontid; Corpore cathetoplateo, with two tetraodontids and two molids. When comparison is made between the classification of the nonbalistoid plectognaths of Gronovius and that of Linnaeus, it is obvious that Gronovius simply incorporated into his Ostracion subgroups a few of Linnaeus' ideas without an excess of precision.
With the 10th edition of Linnaeus' (1758) "Systema Naturae," a basic division of the plectognaths into four genera (Balistes, Ostracion, Tetraodon, Diodon) was presented for the first time. Five groups of Pisces were recognized by Linnaeus: Apodes, Jugulares, Thoracici, Abdominales, and Branchiostegi. The latter contained the following genera: Mormyrus, Balistes, Ostracion, Tetraodon, Diodon, Centriscus, Syngnathus, and Pegasus.

But to the above Pisces must be added the fishes which Linnaeus placed in the Amphibia Nantes, containing Petromyzon, Raja, Squalus, Chimaera, Lophius, and Acipenser.

Such a classification shows an eclectic approach to the systems of previous workers. The Branchiostegi of Artedi is a much smaller group than that of Linnaeus, and the only species that are common to the Branchiostegi of both are the plectognaths. Thus, Cyclopterus and Lophius appeared in Artedi's Branchiostegi, but Linnaeus placed Cyclopterus in the Thoracici and Lophius in the Amphibia Nantes. Mormyrus, Centriscus, Syngnathus, and Pegasus of the Linnaean Branchiostegi are found among the Acanthopterygii and Malacopterygii of Artedi. In short, as far as the plectognaths are concerned, Linnaeus (1758) had followed Artedi's views, only adding generic names to the four plectognath subgroups that Artedi had at least implicitly recognized. The Linnaean Balistes contained seven balistoids and a macrorhamphosid; Ostracion, nine ostraciids; Tetraodon (spelled Tetrodon on p. 243 in the list of genera of Branchiostegi but Tetraodon on p. 332 where defined), five tetraodontids and one molid; Diodon, seven diodontids. Linnaeus thus recognized 29 plectognath species, only two more than Artedi had recognized 20 years previously. Many of Klein's 43 species of Crayracion and Capriscus were synonymized by Linnaeus, or disregarded as unrecognizable.

In the 12th edition of Linnaeus' (1766) "Systema Naturae" a major change took place in the classification of the plectognaths-Branchiostegi was eliminated. All of the genera of the former Branchiostegi were placed in the Amphibia Nantes, except for Mormyrus, which was placed in the Abdominales. The Amphibia Nantes then consisted of an odd assortment of types: Petromyzon, Raja, Squalus, Chimaera, Lophius, Balistes, Ostracion, Tetrodon, Diodon, Cyclopterus, Centriscus, Syngnathus, Acipenser, and Pegasus. The motive behind the placement of the plectognaths in the Amphibia Nantes was the erroneous report sent to Linnaeus by Dr. Garden, a physician in Charleston, S.C., who informed Linnaeus that Diodon possessed a lung. A combination of three anatomical peculiarities in Diodon probably led to the confusion, for Diodon not only has a distensible diverticulum of the oesophagus that can be filled with either air or water (at the time of Linnaeus it was thought to undergo inflation only by the intake of air), but the swim bladder is bilobed anteriorly and the welldeveloped kidneys are placed far forward. Linnaeus wrote (1766:348) that "Garden in America habitanti, petere, vellet dissecare Diodontis respirationis organa \& 
inquirere numne Pulmones haberent." It is possible that Garden mistook either the swim bladder, kidneys, or distensible diverticulum of the oesophagus for lungs. Broussonet $(1780: 680)$ believed that it was the distensible diverticulum that had been misinterpreted, but Cuvier (1817:146) thought that it was the kidney, and the particular source of Garden's error is impossible to identify. Severe as was the elimination of the Branchiostegi, the only significant change in the assemblage of species of plectognaths described was the synonymizing of several of his previously numerous species of Diodon, so that only two species of that genus were recognized.

Among the 29 Linnaean species were representatives of the balistids, monacanthids, both subfamilies of ostraciids, the tetraodontin tetraodontids, diodontids, and molids. As discussed in the preceding section on Willughby, the triacanthids were known before 1758 , even though Linnaeus did not recognized them, and they were not binomially described until Bloch (1786), while triacanthodids were not described until Schlegel (1850). As discussed in the succeeding section on Cuvier, the aracanids and triodontids were not formally described until well after Linnaeus, respectively by Shaw (1798) and Cuvier (1829), but see Tyler (1967) for a history of the impressionistic pre-Linnaean illustrations of Triodon. Several names for canthigasterin tetraodontids were inadvertently listed by Linnaeus as synonyms for several species of tetraodontin tetraodontids (e.g., see Shipp 1974 for Lagocephalus), but the first binomial description of a canthigasterin was in a now mostly forgotten publication by Paterson (1786), as Tetrodon electricus, and the currently used specific name of one of the more common Indo-Pacific species of Canthigaster may have to be changed.

Gmelin's 13th edition (1788) of the "Systema Naturae" reestablished the Branchiostegi in the Pisces and entirely eliminated the Amphibia Nantes, while at the same time the "Systema Naturae" introduced the Chrondropterygii. Fishes were thus all included in six categroies of Pisces: the Apodes, Jugulares, Thoracici, Abdominales, Branchiostegi, and Chondropterygii.

This general classification was a distinct improvement over any of those in previous editions of the "Systema Naturae" and was largely the synthesis of Gmelin himself. Within the Branchiostegi the genera appeared in the following order: Mormyrus, Ostracion with 10 species of ostraciids, Tetrodon with 12 species of tetraodontids and 2 species of molids, Diodon with 6 species of diodontids and 1 species of molid, Syngnathus, Pegasus, Centriscus, Balistes with 18 species of balistoids, Macrorhamphosus, Cyclopterus, and Lophius. Thus, the treatment of the individual genera of plectognaths was inferior to that of previous editions, for molids were placed in both Tetrodon and Diodon, while Balistes was spatially separated from the other plectognaths by the intervening Syngnathus, Pegasus, and Centriscus. Even if this separation of Balistes was deliberate, its significance, if any, is unknown.

The classification adopted by Goüan (1770:94) in his "Historia Piscium" divided the Pisces into three main groups, the Acanthopterygii, Malacopterygii, and Branchiostegi, each with the same four subdivisions: the Apodes, Jugulares, Thoracici, and Abdominales.

Such subdivisions of the three major categories have a deductive simplicity that is truly alluring, but, unfortunately, fishes are not constructed to fit into such logical pigeonholes. The Acanthopterygii and Malacopterygii contained the expected genera, and the Branchiostegi sorted out to:

Apodes:

Jugulares:

Thoracici:

Syngnathus, Balistes (with a footnote saying that certain Balistes have ventral fins and thus must be placed in the Abdominales), Ostracion, Tetraodon, Diodon.

Abdominales: Centriscus, Pegasus (and, according to the footnote, a few Balistes, which are not specifically named, but may imply Macrorhamphosus).

Only genera were described, but the species of Balistes or of other plectognaths that would have to have been placed in the Branchiostegi Abdominales are the triacanthoids, which had not yet been described binomially. The above treatment of the Branchiostegi is basically that of Gmelin's 13th edition of the "Systema Naturae," except that Mormyrus was placed by Goüan in the Malacopterygii Abdominales.

In Bonnaterre's (1788) "Tableau Encyclopédique," the plectognaths reverted to the cartilaginous fishes, for five classes were recognized: the Cartilagineux, Apodes, Jugulares, Thoracici, and Abdominales. These five groups are those of the 12th edition of Linnaeus' (1766) "Systema Naturae," the only difference being the substitution of the term Cartilagneux for Amphibia Nantes. The Cartilagineux contained exactly the same genera as the Amphibia Nantes, differing only in that Petromyzon was called Lampetra. The value of Bonnaterre's work to the study of plectognaths rests on the fact that of the 41 species described, the great majority were figured with some accuracy, and outline cross sections of the body were given for many.

If fishes were ever to fit into a deductively logical scheme of classification, they were given a chance to do so in Lacepède's $(1798,1800,1802 a, b, 1803)$ categories, as outlined in his "Histoire Naturelle," even more so than in Goüan's work. The "Classe des Poissons" was divided into the Sous-classe Poissons Cartilagineux and the Sous-classe Poissons Osseux. Each of these subclasses was split into the same four divisions, and each of these divisions was split into the same four orders. Thus, there was a dichotomy followed by two successive sets of quadrichotomies, to give a total of 32 orders in eight sets of Apodes, Jugulaires, Thoracins, and Abdominaux (following Goüan). The balistoids were in the third order (Thoracins) of the second division of the 
Poissons Cartilagineux, while the other plectognaths were in the first order (Apodes) of the fourth division, well separated from the balistoids.

When one considers the "Poissons Cartilagineux" as a whole, the plectognaths were associated with much the same genera as they were in Gmelin's 13th edition (1788) of the "Systema Naturae." Again, just as in Gmelin, Balistes was separated from the other plectognaths, although in a more definite manner. One innovation was Lacepède's handling of the plectognath genera. His contemporaries had accepted four genera (Balistes, Ostracion, Tetrodon, and Diodon) but Lacepède admitted six (Balistes, Ostracion, Tetrodon, Les Ovoides, Diodon, and Les Sphéroides). It happened that his two new genera were based on artifacts or misinformation and thus lost their value, except for nomenclatural purposes. Les Ovoides (Lacepède 1798:520) was based on a damaged specimen described by Commerson which lacked dorsal, caudal, and anal fins. Lacepède had never seen the single specimen used by Commerson but thought that it probably represented a new genus, and so named it. Les Sphéroides (Lacepède 1800:22) was likewise said to lack dorsal, anal, and caudal fins. It was based on an unpublished figure by Plumier of the anterior view of the body of what we know now as Sphoeroides spengleri. Lacepède did somewhat better with his other genera, for each of these was divided into unnamed subgenera.

Balistes (Lacepède 1798:332) contained four subgenera; the first for those forms with more than one spine in both the pelvic and first dorsal fins; the second for those with more than one spine in the pelvic fin but only one spine in the first dorsal fin; the third for those with only one spine in the pelvic fin but more than one spine in the first dorsal fin; the last for those with but a single spine in both the pelvic fin and first dorsal fin.

The first subgenus should only contain triacanthoids, which by common definition are those plectognaths with well-developed pelvic spines. Lacepede mistook the enlarged scales that occur in the midventral line of the abdominal region of many balistoids between the end of the pelvis and the anus for pelvic fin spines. These scales strengthen the "abdominal fan" of those balistoids whose pelvis is especially movable around its anterior articulation with the pectoral girdle. The distal ends of the enlarged scales are tapered into narrow shafts which often project out through the skin on either side of the midventral line (see Monod 1959a), and it is not surprising that they should have been considered to be some kind of pelvic fin spines. Lacepède also observed the thickened scales that encase the posterior end of the pelvis and mostly obscure from view the modified fin-ray element of most balistoids, and understandably thought them also to be a pelvic fin spine, as had others before him and afterward (e.g., Garman 1891). For these reasons Lacepède's first subgenus contained not only the single binomially described triacanthid then known but also three balistids. His second subgenus contained a single monacanthid, whose modified scales in the abdominal fan were again mistaken for pelvic fin spines. The third subgenus was by far the largest of his sub- genera, containing numerous balistids and a few monacanthids. The fourth subgenus contained two monacanthids.

Intervening between the descriptions of Balistes and the next group of plectognaths (Ostracion) were the descriptions of Chimaera, Polyodon, and Acipenser. Ostracion (Lacepède 1798:441) was divided into four subgenera on the basis of the four logical combination possibilities of the presence, or absence, of cuirass spines in the ocular region and of the presence, or absence, of cuirass spines in the caudal region. These categories are superficial and have not withstood the test of time. Tetrodon (Lacepède 1798:474) had three subgenera, of which the first two were described as not having the body particularly compressed and consisted of tetraodontids, while the third subgenus was said to have a compressed body and contained a single molid. Diodon (Lacepède 1800:1) had no subgenera and contained four diodontids as well as two molids, one of which was the same species that also occurred in the third subgenus of Tetrodon.

Lacepède's only subgeneric groups of lasting value were those of Balistes, which have since, at least in part, been elevated to familial rank. His contribution to the plectognaths was primarily the recognition of the fact that the Linnaean genera could, and should, be subdivided. His subgenera tended to be arbitrarily drawn and factual errors pervaded his descriptions, but he began the trend of subdivision of the Linnaean categories of plectognaths.

Like that of Lacepède, the classification adopted by Bloch and Schneider (1801) in their "Systema Ichthyologiae" was deductively logical and equally artificial. Eleven classes of fishes were recognized on the basis of the number of fins, i.e., Hendecapterygii (11 fins) to Monopterygii (1 fin). Each class was divided, on the basis of pelvic fin position, into such orders as Apodes, Jugulares, Thoracici, Abdominales, and Achiri (= without hands, but with reference to pelvic rather than pectoral fins, and thus would seem to be equivalent to Apodes). The plectognath genera fell within the following classes and orders (Bloch and Schneider 1801:LIII-LVIII):

Classis VI: Hexapterygii [i.e., two dorsals, an anal, a caudal and two pectorals]

Ordo Apodes: Balistes, Rynchobdella [a mastacembelid]

Ordo Pinna Anali Carentes: Trachypterus, Gymnetrus [ = Regalecuś $]$

Classis VII: Pentapterygii [i.e., a dorsal, anal, caudal, and two pectorals]

Ordo Apodes: Ophidium, Pomatias, Gnathobolus, Muraena, Stromateus, Ammodytes, Sternoptyx, Anarrhichas, Channa, Sternarchus, Ostracion, Tetrodon, Orthagoriscus, Diodon, Syngnathus.

This was the manner of listing in the index, but in the text the Pentapterygii were placed in two orders (Bloch and Schneider 1801:484-516), Apodes for the genera from 
Ophidium to Anarrhichas, Achiri for the genera Channa to Syngnathus. Thus, Balistes, along with the mastacembelids, was one of the Apodes Hexapterygii, while the other plectognaths, along with Channa and the syngnathids, were Achiri Pentapterygii. Such a system could scarcely be more artificial, but several new species were described and the use of Orthagoriscus for molids set a generic usage to be followed for the next hundred years.

One of the widest separations of the balistoids from the other plectognaths was that made by Rafinesque (1810) in his "Indice d'Ittiologia Siciliana." He recognized two subclasses of fishes, the Pomniodi (branchial apparatus with both an operculum and branchiostegal membrane) and the Atelini (branchial apparatus incomplete). The Sotto-Classe Pomniodi contained four divisions based on pelvic fin position: Guigulari, Toracici, Abdominali, and Apodi. Each of these four "Divisione" was subdivided into a variable number of "Sezione," which in turn contained the orders. Tetrodon, Diodon, and Orthagoriscus were placed in the Ordine Gli Odontini (Rafinesque 1810:40; all but the pelvic fins present; jaws in the form of a bony beak), while Ostracion was placed in the Ordine Ostracidi (p. 39; body covered by a cuirass; all but pelvic fins present; jaws with teeth not formed as a bony peak). Both of these orders were in the Sezione Branchiosomi (body short; spherical or elliptical) of the Divisione Apodi of the Pomniodi. Balistes, however, was elevated as the Ordine Balistini of the Divisione Gli Omnanchidi (branchial apparatus with a branchiostegal membrane but without an operculum) of the Atelini. Rafinesque's treatment of the plectognaths is best remembered as a nomenclatural curiosity.

The name of Cuvier looms large, of course, in the study of plectognaths, and not only because it was he who established them as a natural group at the ordinal level. In his "Leçons d'Anatomie Comparée," Cuvier (1805) followed a classification (folding sheet at end of volume 1) that borrowed heavily from previous systems. Fishes were divided into those with "a squelette cartilagineux" and those with "a squelette osseux," with the bony fishes subdivided into Apodes, Jugulares, Thoraciques, and Abdominaux. The cartilaginous fishes were subdivided into two groups of Chondroptérygiens and six groups of Branchiostèges, of which two were the "bouche au bout du museau; des dents" for Balistes and Ostracion, and the "os des mâchoires tenant lieu de dents" for Tetrodon, Ovoides, Mola, and Diodon.

The plectognaths were thus associated with much the same genera as in the 12th edition of Linnaeus' (1766) "Systema Naturae." An important improvement was made, however, by the fact that Balistes and Ostracion were placed together as a subgroup distinct from the other plectognaths. This was the first time that such a distinction had been made so clearly. Cuvier further contributed to the study of plectognaths in this work, for throughout all five volumes numerous anatomical notes were given for this group.

Cuvier (1817) put this anatomical information to good use in his "Le Règne Animal," in which the Order Plec- tognathi was established, as one of the six orders of Poissons Osseux (in contrast to Chondroptérygiens), as follows:

\section{Ordre Plectognathes. \\ La première famille, ou les Gymnodontes. \\ La deuxième famille, ou les Sclerodermes.}

Cuvier placed the Plectognathi as the first order of Poissons Osseux, just after the Chondroptérygiens, because (1817:144) "il se rapproche un peu par l'imperfection des mâchoires, et par le durcissement tardif du squelette; cependant ce squelette est fibreux, et en général toute sa structure est celle des poissons ordinaries." He continued with the diagnosis of the order, of which "Le principal caractère distinctif tient à ce que l'os maxillaire est soudé ou attaché fixement sur le côté de l'intermaxillaire qui forme seul la mâchoire, et à ce que l'arcade palatine s'engrène par suture avec le crâne, et n'a par conséquent aucune mobilité." He added that the operculum and branchiostegal rays were hidden under the thick skin and that the branchial aperture was restricted. He further stated that there were only vestiges of ribs, no pelvic fins, a large intestine without caeca and usually a large swim bladder. The Gymnodontes (p. 145) were defined as those Plectognathi which "A, au lieu de dents apparentes, les mâchoires garnies d'une substance d'ivoire, divisée intérieurement en lames," while the operculum was small and there were five branchiostegal rays. Three genera were described: Diodon, Tetrodon, and Orthagoriscus. The Sclerodermes (p. 149-150) were defined as being distinguished by "le museau conique ou pyramidal prolongé depuis les yeux, terminé par une petite bouche armée de dents distinctes en petit nombre à chaque mâchoire. Leur peau est généralement âpre ou revêtue d'écailles dures; leur vessie natatoire ovale, grande et robuste." Five generic groups were recognized, three of them for the first time: Balistes, Les Monacanthes, Les Aluteres, Les Triacanthes, and Ostracion.

This, then, was the basic anatomical classification of the Plectognathi upon which all subsequent work on the group rests. It is perhaps unfortunate that the order was not more carefully diagnosed, for subsequent workers found it easy to erode the structure that Cuvier had erected. For instance, the principal character used by Cuvier, the suturing (or at least immovable attachment) of the maxillary to the premaxillary is true for all plectognaths, except for the triacanthoids. But since Cuvier had examined Triacanthus biaculeatus he might have been expected to have noticed that his principal diagnostic character of the Plectognathi did not apply to one of the genera. The definition of the order can also be criticized because some nonplectognaths also have the two bones of the upper jaw intimately connected. These criticisms, of course, are valid, but by far the more important point is that it was Cuvier who clearly saw in the early 19 th century the naturalness of the plectognaths as a group, elevated them to ordinal rank, and defined the 
basic subgroups within the two families. His families are now of subordinal rank, and his genera have become the bases for most of the families now recognized.

In only one group did Cuvier miss an important major distinction, i.e., the ostracioids can be divided easily into ostraciids and aracanids, but Cuvier could not have been very familiar with the aracanids, for these mostly Japanese and Australian deepwater forms were rarely collected at that time and known primarily from a single species (aurita, Shaw 1798 illustration and 1804 description). Of the 10 families of plectognaths presently recognized, only the triacanthodids and triodontids were unmentioned by Cuvier, and they were not to be discovered for another decade or more. Cuvier's description of Reinwardt's specimen of the unique Triodon bursarius (= macropterus) appeared in the second edition of Cuvier's "Le Règne Animal" (1829:370) as the fourth genus of the family Gymnodontes, while the first triacanthodid was described by Schlegel (1850). In summary, most of the basic groupings of plectognaths were made known by Cuvier, with the notable exception of the two subdivisions of the ostracioids. At about the same time that his (1817) first edition of "Le Règne Animal" appeared, Cuvier (1818) published a short paper on Diodon, describing some new species, but, more importantly, correcting a number of anatomically erroneous statements about diodontids made by such workers as Broussonet, Plumier, and Bloch.

The appearance of the classifications of Latreille (1825) and Risso (1826) shortly after Cuvier's (1817) "Le Règne Animal" set the precedent for the thereafter nearly unanimous ordinal recognition of the Plectognathi. Risso followed Cuvier rather closely, and as far as the plectognaths are concerned, added nothing to their classification. In his (1825) "Familles Naturelles," Latreille used Cuvier's definition of the Ordre Plectognathes, but placed them in a different relationship with other orders (with the sturgeons and lophobranchs).

At about this time Geoffroy Saint-Hilaire (1827) published his "Poissons du Nil." His description (p. 176-214, pls. 1-2) of Tetrodon physa (= lineatus Linnaeus), the common pufferfish of the Nile, was the finest description of a plectognath that had appeared up to that time, describing the general anatomy, habits, distribution, and nomenclature of the fish and gently setting aside the errors made by Bloch and by Lacepède on the inflation mechanism, showing the sac to be a diverticulum of the oesophagus and describing its general structure and musculature.

The year 1833 saw the beginning of the publication of Agassiz's "Recherches sur les Poissons Fossiles" [vols. 1 (1844a) and $2(1833,1842,1844 b)]$, which was to make a major (or at least temporarily so) change in the classification of nearly all groups of fishes. Based on the configuration and composition of the scales, Agassiz hoped to establish a more natural grouping of orders than had previously been available. Agassiz's system as a whole did not stand the test of time, and his association of the plectognaths with the ganoids was a major error. His Ordre des Ganoides (1844a:169) contained six groups: Acipenserides, Siluroides, Lophobranches, Gymnodontes, Sclerodermes, and Sauroides.

To Agassiz the plectognaths were ganoides for various reasons. The scales of Ostracion were described (Agassiz 1844a:75) as consisting of a horny substance deposited in strata and covered with a thick layer of dentine characterized by ramifying calcareous tubes like those of the teeth. The major references to plectognaths, however, were contained in a section (1844b:248-267) entitled "De la famille des Gymnodontes" where brief osteological descriptions of a Tetraodon and a Diodon were given, along with a comparison of the structure of the teeth and spines of these two gymnodonts. Agassiz found the gymnodont spines to be similar to the scales of scleroderms, in that both possessed a dentine layer with calcareous tubes, while the teeth of gymnodonts were said to be similar to the teeth of sharks. Agassiz (1857) also published a brief note on the structure of Mola.

Agassiz (1833:1-2) listed the six families of his Ordre Ganoides as: Famille Lepidoides (with Acanthodes, Palaeoniscus, Osteolepis, Lepidotus, etc.); Famille Sauroides (with Leptolepis, Sauropsis, etc.); Famille Pycnodontes (with Placodus, Pycnodus, Microdon, etc.); Famille Sclerodermes; Famille Gymnodontes; and Famille Lophobranches (with Syngnathus, etc.). It is strange to see the plectognaths associated in the same order with such forms as the placoderm Acanthodes, the crossopterygian Osteolepis, and the isospondyl Lep. tolepis. Even stranger, however, was the assemblage included in the Sclerodermes (1844b:248-267). Not only were Balistes, Ostracion, the Balistes-like fossil Acanthoderma, and the Triacanthus-like fossil Acanthopleurus placed there, but also included in the Sclerodermes were such obviously nonplectognath fossils as Blochius (which Woodward, 1901:591, referred to the Blenniiformes), Dercetis (which Woodward, p. 171, referred to the Isospondyli), and Rhinellus (which Woodward, p. 265, referred to the Isospondyli). Agassiz recognized in later years that his classification was highly artificial (see Agassiz 1860).

With the appearance of Müller's (1844) "Ueber den Bau und die Grenzen der Ganoiden," the Ganoides of Agassiz were modified to a considerable extent. Müller purged the Ganoides of the plectognaths, lophobranchs, and most of the other living species placed there by Agassiz. Müller pointed out that the true ganoids had, among other characteristics, more than two valves in the conus arteriosus, while the teleosts had only two. Among the supposed ganoids of Agassiz that Müller had examined for this characteristic were Balistes, Ostracion, and Tetraodon. The classification at which Müller arrived (1844:85-88) recognized six subclasses of Pisces, with the Subclass Teleostei containing the Order Plectognathi and its three families: Balistini, Ostraciones, and Gym. nodontes.

Müller pointed out (1844:6) that whereas the true ganoids are physostomes with abdominal pelvics, the Plectognathi are physoclists and that when obvious pelvic fins are present, as in the triacanthoids, they are not abdominal. He also disagreed (p. 7) with Agassiz's con- 
tention that the scales of plectognaths have much in common with those of ganoids. Just as Müller had purged the Ganoides, so he also rid (p. 26) the Scleroderms of Agassiz's Blochius, Dercetis, and Rhinellus. Elsewhere (p. 78-79) Müller gave systematic notes on the tetraodontoids, based on the structure of the nasal aperture and tube. The character of the nasal organ was thereafter to play an important (and exaggerated) role in the classification of the tetraodontoids. Müller made a clear statement (p. 84) of the fact that the maxillary and premaxillary are not fused or firmly attached to one another in all of the plectognaths, as Cuvier had said that they were, for he noted that in the triacanthoids these two bones have a more normal relationship to one another.

Müller's contribution to the classification of fishes was so outstanding that the outline given above in relation to the plectognaths cannot do it justice, for his was the finest classification of fishes to appear up until that time, and in the magnitude of the changes it wrought in ichthyology it was at least equal to the work of Artedi and Cuvier.

With Agassiz saying one thing about the highly modified scales and teeth of plectognaths and with Müller saying something else, a controversy broke out in the literature which has not yet been fully resolved (see references under subsequent discussion of Owen).

Some of Müller's classificatory conclusions came in for immediate criticism. Vogt (1845) took exception to Müller's recognition of the Orders Pharyngognathi and Plectognathi. Vogt thought these orders to have been founded on insufficient criteria, i.e., the fusion of the lower pharyngeals in the Pharyngognathi and the fusion of the upper jaw bones in the Plectognathi.

Müller's classification is discussed here slightly out of chronological order so that it can be more easily compared with that of Agassiz. Intervening between these two monumental works were the classifications of Swainson, Nardo, and Bonaparte.

In his (1832) "Saggio d'una Distribuzione Metodica" Bonaparte adopted a classification that was basically that of Cuvier's (1817) "Le Règne Animal," but with significant changes in the rank of the groups recognized. Bonaparte introduced here for the first time, in a consistent manner, the "idae" ending for familial and the "ini" for subfamilial names for his Classe Pisces. Bonaparte recognized two monotypic orders in his Sezione 3, or Plectognathi: the Gymnodontes (for the family Tetraodontidae) and the Sclerodermi (for the family Balistidae).

The Tetraodontidae contained the usual four genera: Diodon, Tetraodon, Orthagoriscus, and Triodon. The Balistidae contained three genera: Ostracion, Triacanthus, and Balistes (with the latter divided into four subgenera: Balistes, Balistapus, Monacanthus, and Aluterus).

In his (1841a) magnum opus, the "Iconografia della Fauna Italica," Bonaparte treated the plectognaths as one of the three sezione (along with the Micrognathi and Teleostomi) of the Sottoclasse Pomatobranchii (in contrast to the Elasmobranchii, Lophobranchii, and Marsipobranchii) as follows:
Sezione Plectognathi

Ordine Sclerodermi

Famiglia Balistidi [sic]

[Subfamily] Balistini

[Subfamily] Ostraciontini

Ordine Gymnodontes

Famiglia Tetraodontidae

[Subfamily] Tetraodontini

[Subfamily] Diodontini

Famiglia Orthagoriscidae

[Subfamily] Orthagoriscini

[Subfamily] Molini.

In the same year, Bonaparte (1841b) published his "A New Systematic Arrangement of Vertebrae Animals," and the classification adopted was that outlined above, with only minor changes. In the plectognaths, for example, the one difference was that in the family Orthagoriscidae only one subfamily was recognized, the Orthagoriscini, which was thus equal to his previous two subfamilies, Orthagoriscini and Molini.

The classification used by Swainson $(1838,1839)$ in his "Natural History of Fishes, Amphibians, and Reptiles" was, like the rest of his work, a careless hodge-podge. The pseudometaphysical "systems" by which Oken (1816) compared orders of fishes with various classes of invertebrates and vertebrates obviously made an impression on Swainson, for the latter carried on where the former had left off. To Swainson the plectognaths were equated with such groups as amphibians and turtles, whereas Oken had equated them with mammals. Swainson (1838:189) included all of the plectognaths (or Cheloniform Order) in a family Balistidae, in which were recognized five subfamilies: Balistinae, Ostracinae, Cephalinae, Diodoninae, and Tetraodinae, each of which included the expected forms.

Nardo (1842) presented a brief outline of his classification of the Sclerodermi, in which he closely followed Bonaparte (1832), but attributed all of the familial names to himself.

The first person after Cuvier to extensively analyze the classification of the plectognaths as a whole was Dareste. His first paper (1849) dealt with the osteology of Triodon macropterus, the monotypic representative of its family. Dareste saw that Triodon had many features in common with the gymnodonts, but that it also possessed certain characteristics of the scleroderms. One might expect that this would strengthen the union of these two groups in an Order Plectognathi. Such was not the interpretation of Dareste, however, for he concurred with Vogt's (1845:67) belief that the Order Plectognathi was ill-defined, unnatural, and not long for this world. Although Dareste made this point in his work on Triodon, he did not substantiate it with a discussion until 1850, in his "Recherches sur la Classification de l'Ordre des Plectognathes." In the latter work Dareste took apart Cuvier's definition of the Order Plectognathi sentence by sentence. To review very briefly Dareste's critique, he stated 
that: Mola is the only plectognath with a skeleton less ossified than that of the majority of fishes (but Cuvier had stated only that the ossification was "tardif," while otherwise like that of other fishes); the premaxillaries and maxillaries are fixed firmly to one another in a number of fishes other than plectognaths; the palatine is movable in certain scleroderms (Cuvier implied that it was sutured to the cranium in all plectognaths); the operculum and branchiostegal rays are hidden beneath the skin in a number of fishes other than plectognaths; Triodon possesses ribs; some scleroderms possess pelvic fins (Cuvier said that they are always absent in plectognaths); Mola does not have a swim bladder (Cuvier said that it is well developed in all plectognaths).

Dareste (1850) went too far when he criticized Cuvier for not knowing that Triodon possessed ribs. In the first edition of the "Le Règne Animal," Cuvier (1817) stated that the plectognaths had only very small vestiges of ribs. Triodon was not to be discovered until after the first edition of the "Le Règne Animal," and while its original description appeared in the second edition (1829), it was still not known that Triodon possessed well-developed ribs until Dareste published his 1849 paper. Cuvier could scarcely have been expected to have known the osteology of an as yet undiscovered fish, or to have personally investigated the ribs of every species of fish, plectognath or otherwise, described in the "Le Règne Animal."

The only features that Dareste (1850) believed the plectognaths to have in common were a reduced operculum, a rodlike interoperculum, and a low number of vertebrae. To Dareste these characteristics were not important enough to merit the recognition of the plectognaths as an order, or even as a natural group.

One must admit that Cuvier's definition was imprecise, but Dareste temporarily neglected (see Dareste 1872c:1019) the fact that ordinal definitions are best founded on a combination of characters possessed by the group in question and not by other fishes. Even accepting Cuvier's far-from-perfect diagnosis, it is doubtful that any fishes other than plectognaths would fit into it. Unfortunately, a significant number of plectognaths also would be excluded from it, but this could be cured by a little rewording.

Dareste proceeded to split the plectognaths into (1872c:117) "cinq petites familles bien distinctes les unes des autres" which were numbered as follows:

\section{Première Famille - Diodon and Tetraodon \\ Deuxième Famille - Triodon \\ Troisième Famille - Orthagoriscus \\ Quatrième Famille - Balistes (which included "les petits generes Balistes, Alutere, Cinquième Famille - Ostracion. Monacanthe et Triacanthe")}

His definitions of these families were anatomically, and especially osteologically, founded, and included not only a good summation of the contemporary knowledge of the plectognaths but also some original observations.

In his later publications Dareste $(1872 a, b, c)$ con- fined himself to the placement of the scleroderms "among the Acanthopterygians, in the vicinity of the Acanthuri and other fishes belonging to the small family of the Teuthyes" (1872b:68). However, he despaired of showing the relationships of the gymnodonts, for he said (1872c:1088): "Ce type est assez difficile à définir, par suit de la diversité des formes sous lesquelles il se présente, et qui en font une famille par chaine, plutôt qu'une famille en groupe" and (1872c:1089): "Le Triodon diffère notablement des autres Gymnodontes, et forme par conséquent un type à part, quoique voisin."

Dareste (1872b:69-70) pointed out the many characteristics held in common by the "Acanthuri and Balistidae, especially the true Balistes, which are more nearly allied to the Acanthuri than the Triacanthi, Monacanthi and Aluterae." The particular features he noted in Balistes and acanthurids were: firm and immovable union of the premaxillary and maxillary; general shape of skull; supraoccipital with a long forward extension and an elevated crest; ethmoid elongate; parasphenoid as a vertical plate anterior to the orbit; vomer small and toothless; palatine small, toothless, and movable; interoperculum at least partially rodlike and hidden beneath the preoperculum; pelvis elongate, its two halves more or less fused together; few vertebrae. In comparison to these similarities, Dareste said (1872b:70) that "The differences between the skeletons of the Acanthuri and Balistes are but few and of slight importance," these differences being: the presence of suborbitals in acanthurids and their absence in balistids; the spiny dorsal and soft dorsal fins of acanthurids being continuous, but separated in balistids; the branchial aperture of acanthurids being larger than in balistids, due to the shape of the preoperculum; the acanthurids possessing true ribs, but not balistids.

Great credit is due to Dareste for having so definitely pointed out these similarities. They are for the most part correct, although just as Dareste had torn apart Cuvier's definition so also could a person familiar with both acanthurids and balistids find many osteological details at variance with the above information. But the only reasonable and useful criticism that can be made of Dareste's scheme is that the comparison was made between acanthurids and balistids rather than between acanthurids and triacanthoids. The triacanthoids are obviously the most generalized of the plectognaths and the balistids show every indication of having arisen from triacanthoid ancestors, perhaps not long after the triacanthoids had themselves arisen from an ancestral stock which also gave rise to the acanthurids. Dareste's arguments are still convincing, but they would have been even more so had the comparison been between the acanthurids and triacanthoids.

At the same time that Dareste was attempting to dismantle the Order Plectognathi, another Frenchman took a diametrically opposed view. Hollard stands second to no one in the study of the plectognaths. While Dareste's primary contribution was to relate scleroderms to acanthurids, Hollard's was to describe the anatomy and relationships of the families within the Plectognathi. 
Hollard's (1853, 1854a, b, 1855) first contribution was the "Monographie de la Famille des Balistides," which described the differences and similarities of $B a$ listes, Monacanthus, and Triacanthus, the three genera he recognized. Whereas Alutera had previously been recognized as a distinct genus by many workers, Hollard relegated it to subgeneric rank, with the genus Monacanthus containing two subgenera, Monacanthus and Aluteres. He believed these two types to be essentially the same, except that the posterior end of the pelvis protruded and was covered by modified scales (his "pointe pelvienne") in Monacanthus, while the pelvis remained covered by skin in Aluteres. One might notice that in the excellent review of the group by Berry and Vogele (1961) this concept still stands. Not only did Hollard described the general anatomy, including osteology, viscera, integument, muscles, etc., but he also gave systematic descriptions of all of the then known species of balistoids and triacanthoids and described many new species.

Several years later, Hollard's (1857a) "Monographie de la Famille des Ostraciontides" treated trunkfishes in the same fine style as he had done with the other scleroderms. Hollard pointed out that, in the progression from Triacanthus to Balistes to Monacanthus and Aluteres, the pelvic fin and spiny dorsal fin elements decrease in number and that in Ostracion there is no trace of either. Thus, to Hollard (1857a:125) the acanthopterygians and malacopterygians "ne s'en séparent pas d'une manière absolue, et que le caractère tiré de la présence des rayons épineux n'a qu'une valeur relative et conditionelle, bien inferieure à celle que lui attribuaient Artédi et G. Cuvier." Regarding the actual classification of the trunkfishes, it must be remembered that at this time a great number of new species of plectognaths were being made known by Bleeker and a host of others, and that Kaup (1855) had just reviewed the ostracioids. Kaup synonymized many of Bleeker's species and defined a number of new generic groups, as follows: Cibotion Kaup, Laetophrys (sic) Swainson, Ostracion Linnaeus, Acerana (sic) Gray (with four subgenera-Acerana Gray, Capropygia Kaup, Kentrocapros Kaup, Anoplocapros Kaup), Centaurus Kaup (for the larval Mola described by Richardson [1845:52] as Ostracion boops). Hollard did not wish to recognize as many generic and subgeneric categories as Kaup had given. Whereas Kaup had placed great importance on the number and placement of cuirass spines, Hollard thought them to be of a superficial or secondary nature and of no real value to an understanding of the phylogeny of the trunkfishes. Thus, Hollard recognized only two genera, Ostracion and Aracana. Since Hollard had never seen a specimen of Ostracion boops, he was correctly skeptical of it and mentioned it only in passing-quite in contrast to Kaup's establishing a new genus for it.

The next in Hollard's (1857b) series of papers was the "Etude sur les Gymnodontes," of the same high quality as the preceding works. The osteological illustrations that Hollard presented here were to be used by all subsequent workers on plectognaths, and they were even reproduced by Gill (1892a). Hollard had at his disposition the unpublished manuscript left upon the death of Bibron, who had been reviewing the pufferfishes and had established in his manuscript numerous new genera, some of which were in name only, for the diagnoses had not yet been written. This manuscript was published almost in its original condition, with only a few notes added by Duméril (1855), its editor. Bibron had completed the diodontids, but was still working on the tetraodontids at the time of his death. Suffice it to say that, on the whole, Bibron's generic groupings were highly artificial and are unacceptable in a modern phylogenetic classification. Hollard, for example, synonymized seven of Bibron's genera (Dilobomycter, Aphanacanthus, Amblyrhynchotus, Stenometopus, Geneion, Epipedorhynchus, Promecocephalus) into one genus, to which, unfortunately, he gave yet another new name, Apsicephalus.

The last, summarizing, article in Hollard's (1860) series was the "Memoire sur le Squelette des Poissons Plectognathes," in which he condensed all his anatomical observations and arrived at the following classification (p. 46; genera were not listed, but are here inserted below as he recognized them in his previous three articles):

Plectognathes ou Echinoides
Sclérodermes
Balistides
Triacanthiens
Triacanthus
Balistines
Balistes
Monacanthiens
Monacanthus
subgenus Monacanthus
subgenus Aluteres
Ostracionides
Aracaniens
Aracana
Ostraciens
Ostracion
Gymnodontes
Loganiosomes ou
Triodoniens
Triodon
Sphérosomes (Orbes épin.)
Tetrodoniens
Rhynchotus
Xenopterus
Batrachops
Apsicephalus
Brachycephalus
Monotreta
Diodoniens
Diodon
Ellipsomes ou
Orthagorisciens
Orthagoriscus.


The above classification was rarely accepted in its entirety by subsequent researchers on the plectognaths, and it was not a radical departure from previous arrangements of the order. By present-day standards, Hollard's osteological observations were often incorrect, with two inaccuracies being of particular prominence. The bone now called the parasphenoid was thought by Hollard to be composed of two entities, a large anterior piece or "sphenoide antérieur" and a small posterior piece or "sphenoide postérieur." What is presently termed the frontal was recognized as such by Hollard, except that he believed a small portion at its posteromedial end to be separated from it, and called this small piece the "parietal." But Hollard had to rely, for the most part, on dried skeletons, and if he occasionally saw a few too many bones in the cranium, it is readily understandable. With the present techniques of clearing and staining, the sutural regions between bones are much easier to define, and surface sculpturing of individual bones is less likely to be confusing. Hollard's contribution, then, was that he systematically made known for the first time the general morphological structure of all of the primary types of plectognath fishes.

Coming after Dareste's (1850) critique of Cuvier's ordinal recognition of the Plectognathi but before the general plectognath classification of Hollard (1860) was the "Ichthyologie Analytique" by Andre Duméril (1856), father of the August Duméril who had edited Bibron's manuscript. In probable deference to Dareste, the elder Duméril did not recognize an Order Plectognathi, but, on the other hand, his families Sclerodermes and "Gymnognathes" followed one another in his subclass Chondrostichthes, as outlined in the large folding sheet between pages 92 and 93 :

Famille Lophobranches (syngnathids)

Famille Podoptères (Cyclopterus, Lophius, antennariids, ogcocephalids, etc.)

Famille Sclérodermes (scleroderms)

Famille Gymnognathes (gymnodonts)

Famille Hypostomates (climaerids, Polyodon, Acipenser, Pegasus).

Whereas the two plectognath groups were listed one after the other in the folding sheet, in the text they were described discontinuously. Duméril did not seem to have any confidence in the validity of the Plectognathi. In the section on "Les Chondrostés Gymnognathes," Duméril (1855:159-160) simply and conservatively listed the four genera he recognized: Diodon, Triodon, Tetraodon, and "Cèphale" (= Mola). "Les Chondrostès Sclèrodermes" (p. 173-182) were treated in only a slightly more detailed manner. Two groups were recognized, the Ostracides and the Balistides. There were four genera of trunkfishes (Ostracion, Aracana, Cibotion, and Doryophrys) and the standard four genera (Monacanthe, Alutère, Triacanthe, and Baliste) in his Balistides. One will notice that the term "Gymnognathes" (of Bleeker) replaced Cuvier's "Gymnodontes." But the term Gymnodontes was not simply stricken from the record, for
Duméril used it as the name of one of the families of his Ordre Hémisopodes. This "Famille Gymnodontes" included such items as Gerres, sparids, Upeneus, mullids, etc.

In Duméril's (1806) much earlier "Zoologie Analytique," the fish classification of Lacepède was followed with only the addition of a large number of familial and ordinal names.

Perhaps the fish classification that appears in the various editions of the Encyclopaedia Britannica can be taken as an example of the standard or average condition of our knowledge of that subject. Richardson's (1856) article on "Ichthyology" (8th edition) recognized the Order Plectognathi (p. 312-314) within the teleosts. For the arrangement of the families of plectognaths Richardson followed Kaup (1855). Kaup, however, had not finished his major groupings of plectognaths in that paper, and Richardson filled in the missing categories with what he thought to be Kaup's logic, as follows:

Family Balistidae

Sub-Family Balistini: Pyrodon, Melichthys, Xanthichthys, Canthidermis, Balistes, Balistapus.

Sub-Family Monacanthini: Monacanthus, Aluterius, Triacanthus.

Family Ostraciontidae

Cibotion, Doryophrys, Ostracion, Aracana (with four subgenera: Aracana, Capropygia, Kentrocapros, Anoplocapros), Centaurus.

Family Diodontidae

Sub-Family Diodontini: Diodon, Dicotylichthys, Cyclichthys, Cyanichthys, Chilomycterus.

Sub-Family Tetraodontini: Tetraodon (with four subgenera, after Müller: Physogaster, Chelonodon, Cheilichthys, Arothron).

Sub-Family Orthagoriscini: Orthagoriscus.

There are two obvious errors in the above scheme, one of omission and the other of commission. The unique Triodon is not even mentioned, and all of the triacanthids (Triacanthus) were placed in the Monacanthini. The explanation is that when Kaup treated the Balistidae he included all the balistid species he described under the Sub-Family Balistini, but did not mention any other subfamily since he was not describing any triacanthoids or monacanthids. Richardson assumed that if in the Balistidae there was a Sub-Family Balistini, then there should be a counterbalancing subfamily, so he set up the Sub-Family Monacanthini to include all the other nonostracioid scleroderms. This treatment of the Plectognathi was later adopted by Fitzinger (1873), but after that it fortunately disappeared from use.

After the turn of the 18th century there was an almost unanimous, with the few exceptions to be discussed later, belief that the plectognaths of Cuvier were indeed a natural group, although there would continue to be much discussion about the rank at which they were to be recognized. Attention was then turned to better descriptions, diagnoses, and arrangements of the species within the 
order. This task would have been long delayed had it not been for Bleeker, that great describer of the Indo-Australian ichthyofauna. As with so many other orders of fishes, a knowledge of the Indo-Pacific representatives of the plectognaths is indispensable to an understanding of their evolution. Here is to be found a far greater number and diversity of species of plectognaths than in all other areas of the world combined. If the Indo-Pacific was not the cradle of the evolution and distribution of the plectognaths, then at least it is their present center of greatest speciation and morphological diversity.

It is impossible to give here a full review of Bleeker's contributions to the study of plectognaths, or to mention more than a few of the numerous papers in which he described new species of that order. Of particular descriptive, but not classificatory, interest is Bleeker's (1852a) "Bijdrage tot de Kennis der Blookakige (Gym-" nognathen)" in which numerous new species were described and his (1852b) "Bijdrage tot de Kennis der Balistini en Ostraciones." Of most importance to this discussion, however, is Bleeker's complete classification of the plectognaths, which appeared in two places: in volume 5 (1865) of his monumental "Atlas Ichthyologique" and in his 1866 "Systema Balistidorum, Ostracionidorum, Gymnodontidorumque Revisum." The classification was the same in both works, and that which is here condensed is that of the "Systema" only because the definitions of the categories were more complete there and all of the ordinal names were latinized, which they were not in the "Atlas." Bleeker never used the term Order Plectognathi, since he gave each of his three major groups of plectognaths ordinal rank, but he obviously thought of them as a natural assemblage, as examination of the titles of his articles will show. His classification was as follows:

\author{
Ordo Balistidi \\ Familia I. Triacanthoidei \\ Subfamilia I. Triacanthiformes \\ Triacanthus, $\dagger$ Acanthopleurus \\ Subfamilia II. Paratriacanthiformes \\ Triacanthodes, Hollardia \\ Familia II. Balisteoidei \\ Subfamilia I. Balistidiformes \\ Leiurus, Erythrodon, Melichthys, Balistes (with \\ five subgenera: Parabalistes, Pseudobalistes, $B a$ - \\ listapus, Balistes, Canthidermis) \\ Subfamilia II. Monacanthiformes \\ Phalanx 1. Monacanthini \\ Monacanthus, Chaetodermis, Paramonacan- \\ thus, Amanses, Pseudomonacanthus, Liomona- \\ canthus, Oxymonacanthus \\ Phalanx 2. Aluterini \\ Brachaluteres, Acanthaluteres, Ceratacanthus, \\ Paraluteres, Pseudaluteres, Aluteres \\ Phalanx 3. Psilocephalini \\ Psilocephalus
}

Ordo Ostracionidi

Familia Ostracionoidei

Ostracion (with four subgenera: Ostracion, Laetophrys, Tetrosomus, Acanthostracion), Aracana (with four subgenera: Aracana, Capropygia, Kentrocapros, Anoplocapros), Centaurus

Ordo Gymnodontidi

Familia I. Orthagoriscoidei Orthagoriscus

Familia II. Tetraodontoidei

Subfamilia I. Diodontiformes

Phalanx 1. Trirhizacanthini Chilomycterus, Diodon

Phalanx 2. Dirhizacanthini Atopomycterus, Paradiodon, Trichodiodon

Subfamilia II. Tetraodontiformes

Phalanx 1. Tetraodontini

Tetraodon, Crayracion, Leiodon, Chonerhinus, Ephippion

Phalanx 2. Canthogasterini Canthogaster

Familia III. Triodontoidei

Triodon.

The precise separation of the triacanthids from the triacanthodids and of the tetraodontins from the canthigasterins appeared here for the first time. Although his groupings of the balistoids owed much to the work of Hollard, they were well defined and concisely executed. If one bears in mind that what Bleeker called Diodon we now refer to as Chilomycterus, then one sees that he also realized the natural division of the diodontids into those with erectile two-rooted spines (Phalanx Dirhizacanthini) and those with permantly fixed three-rooted spines (Phalanx Trirhizacanthini). In short, Bleeker made good use of what had come before him and added much new information based on both observation and synthesis in his own right. His is a reasonable classification even today, and at the time of its appearance it was superb.

Owen (1840 \& 1845) in his "Odontography" gave what are now the classic descriptions of the teeth of plectognaths. The fish classifications he used in his various publications were not his own, but they are cited here to show the variable handling of the plectognaths that one finds up until the turn of the 19th century. In his "Odontography," which appeared several years after Agassiz's (1833) "Poissons Fossiles," Owen placed the plectognaths in two groups (scleroderms and gymnodonts) within the ganoid fishes, and an Order Plectognathi was not recognized. But in his "Lectures on Comparative Anatomy," which appeared after Müller's (1844) "Ueber den Bau," Owen (1846) recognized the Order Plectognathi, with three families: Balistinae, Ostraciones, and Gymnodontes. The same plectognath groups were recognized by Owen in his (1853) "Descriptive Catalogue of the Osteological Series," but a new term for a 
higher plectognath category appeared in his (1866) "On the Anatomy of Vertebrates." In the latter work, the Order Plectognathi was composed of two suborders: Sclerodermi, with the family Balistini; and Apleuri, with the families Ostraciontidae and Gymnodontidae.

This is not the place to discuss the histological structure and composition of the plectognath teeth and scales, nor to attempt to summarize the highly conflicting information available. But since some recent workers are not aware of all the older literature dealing with this subject, it is useful to list the more important references to the histology of the scales and teeth of plectognaths: Born 1827 (teeth of gymnodonts). Owen 1839 (teeth of Tetraodon and Diodon); 1840 \& 1845 (teeth of Balistes, Tetraodon, and Diodon). Williamson 1851 (scales of Balistes and Ostracion). Hollard 1857a (scales of Ostracion). Cleland 1862 (bony tubercles in skin of Mola). Turner 1862 (bony tubercles in skin of Mola). Hertwig 1881 (scales of numerous plectognaths, mostly gross morphology, but some histology). Hilgendorf 1886 (mostly gross morphology of teeth of Tetraodon and Diodon); 1893 (teeth of Mola, Tetraodon, and Diodon). Wortman 1886 (teeth of Balistes and Diodon). Green 1901 (subdermal tissue of Mola). Green and Tower 1902 (albuminoids in scales of Mola and Sphoeroides). Ghigi 1905a, 1905b (teeth of Balistes); 1921 (teeth of Ostracion and Tetraodon). Rosen 1913 (scales of numerous plectognaths); 1916b (scales of plectognaths in comparison with those of other fishes). Kaschkaroff 1914a (scales of numerous plectognaths). Rauther 1919, 1927a (scales of Balistes); $1927 \mathrm{~b}$ (teeth of numerous plectognaths). Tretjakoff 1924a, b, 1926a, b (scales of numerous plectognaths); 1925 (pectoral fin rays of Tetraodon compared with body scales); 1926c (teeth of numerous plectognaths). Pflugfelder 1930 (teeth of Tetraodon and Diodon in particular, but also of Ostracion and Balistes). Grieb 1935 (pharyngeal teeth of Sphoeroides). Arsuffi 1939 (teeth of Tetraodon). Bartolini 1941 (general discussion of plectognath teeth). Isokawa 1955 (teeth of Monacanthus and Cantherhines). Soule 1969a, b, 1970 (tooth attachment in balistids). More recently Roberto Andreucci and his colleagues in Brazil have begun a systematic reexamination of the histology of plectognath teeth (so far confined to gymnodonts): Andreucci $1966 \mathrm{a}, \mathrm{b}$, 1967a, b, 1968a, b, 1969, 1970; Andreucci and Britski 1968a, b, 1969a, b, 1970, 1971; Britski and Andreucci 1971; Andreucci and Blumen 1971.

A landmark in the study of almost all groups of fishes was the publication of Günther's "Catalogue of the Fishes in the British Museum." Here was a consistent, standarized description of nearly every order, family, genus, and species of known fishes. The Plectognathi appeared in volume 8 , published in 1870 . In the subclass Teleostei, six orders were recognized: Acanthopterygii, Acanthopterygii Pharyngognathi, Anacanthini, Physostomi, Lophobranchii, and Plectognathi. The plectognaths were divided as follows:
Order Plectognathi

Family Sclerodermi

First Group: Triacanthina

Triacanthodes, Hollardia, Triacanthus

Second Group: Balistina

Balistes (with six subgenera: Liurus, Balistes, Canthidermis, Parabalistes, Melanichthys, Erythrodon), Monacanthus (with two subgenera: Monacanthus and Aluteres), Anacanthus

Third Group: Ostraciontina

Ostracion (with two subgenera: Ostracion and Aracana)

Family Gymnodontes

First Group: Triodontina

Triodon

Second Group: Tetrodontina

Xenopterus, Tetrodon (with 10 subgenera: Tetrodon, Hemiconiatus, Gastrophysus, Cheilichthys, Liosaccus, Crayracion, Chelonodon, Monotretus, Arothron, Anosmius), Diodon, Chilomycterus, Dicotylichthys, Atopomycterus, Trichodiodon, Trichocyclus

Third Group: Molina Orthagoriscus (with two subgenera: Orthagoriscus and Ranzania).

The classification of the Plectognathi followed by Günther (1880) in his "An Introduction to the Study of Fishes" was essentially the same as that given above.

There was nothing special about Günther's (1870) treatment of the Plectognathi, and it could be held to be distinctly inferior to that given 4 years earlier by Bleeker (1866). Günther's most notable failure was his handling of the admittedly difficult "Tetrodontina." The tetraodontids are a far larger and more diversified group than the diodontids, yet Günther recognized only two genera of the former (albeit with 10 subgenera, but these were based primarily on the form of the nostril, an unreliable character when used alone rather than in conjunction with a number of other anatomical systems) but six genera of the latter (defined by the form of the nasal tentacle and the movability of the spines).

In his (1871a) "Observations on the Systematic Relations of the Fishes," Cope, while giving credit to Müller as (p. 580) "the father of modern ichthyology," nevertheless thought that within the teleosts the Plectognathi and Lophobranchii were not of equal rank with the Physostomi and Physoclisti. Thus, within the Subclass Actinopteri (= Müller's Teleostei and Ganoidei), Cope recognized three tribes: the Chondrostei (= Müller's Order Chondrostei of the Subclass Ganoidei), Physostomi, and Physoclisti. The Physoclisti contained 10 orders, including the Plectognathi. Cope stated (1871a:582) that phylogenetic lines radiate out from the Percomorphi and that "one leads from the Chaetodontidae, through the Acroneuridae [= Acanthuridae], to the Plectognathi, by the similarity in the arrangement of 
the posttemporal and forms of the pharyngeal apparatus." In the same year Cope (1871b) again expressed the idea that the Plectognathi and Lophobranchii were natural groups, but that Müller had given them too high a rank in comparison with the other teleosts. Cope's opinion is almost unanimously accepted today.

Winther (1877), in part three of his "Fiskenes Ansigt: en Comparativ-Anatomisk Undersфgelse," briefly described the general anatomy, especially of the head region, of such representative plectognaths as Triacanthus, Balistes, Monacanthus, Ostracion, Tetraodon, Diodon, and Mola. He was the last person with a knowledge of the plectognath fishes as a whole who did not believe that they were a natural group. Like others before him, Winther criticized Cuvier's character of the intimate fixation of the upper jaw bones to one another as being neither unique to, nor characteristic of, all of the plectognaths. He believed the plectognaths to represent three families: Triacanthini, Sclerodermi (including balistoids and ostracioids), and Gymnodontes. He was unsure of the relationship of the triacanthoids to his Sclerodermi, but he concurred with Dareste that the balistoids were related to the acanthurids. For some unaccountable reason, Winther thought that the Gymnodontes were related to the Discoboli (Cyclopterus).

A good summary of the then prevailing feeling about plectognaths by knowledgeable ichthyologists is found in Gill's (1882) "Arrangement of the Families of Fishes ...," published shortly after Bleeker's "Atlas," Günther's "Catalogue," and Cope's "Systematic Relationships." While Gill's arrangement was drawn up to serve as the fish filling system to be used at the Smithsonian Institution, it was more than a mere list of families, for Gill gave numerous comments on the phylogeny of the higher categories. After reviewing the characteristics of the plectognaths, Gill expressed the contemporary view that (1872:XLI) "the nuany common characters justify their association together, and the characters that are peculiar to them sanction their isolation as a group," while "Their differences sink into comparative insignificance." Gill agreed that the scleroderms "have been deemed more related to ordinary Acanthopterygian types than to the other admitted Plectognaths. And it is quite true that they (and especially the Triacanthids) are much more similar to the ordinary fishes than are the typical Plectognaths. This, however, is quite explicable by the supposition that they are the most generalized, and represent the immediate line of descent...." It was thus agreed that the work of Dareste and others related the scleroderms to the acanthurids and that the gymnodonts were obviously highly specialized offshoots of the scleroderms. This was then, as it is now, the more or less accepted view. In the actual arrangement used by Gill, the Plectognathi were divided into three major subgroups, as had been done by Müller and Bleeker, instead of into two major subgroups, as had Cuvier, Hollard, and Günther. The families that Gill recognized in each of the three subgroups were those as recognized by Bleeker.
Several years later Gill (1885) published his "Synopsis of the Plectognath Fishes." This was a skillful diagnosis, based almost entirely on the literature, of the characteristics of the various plectognath subgroups, and of the nomenclatural labyrinth that surrounds the order. Gill relied heavily for the osteological information in his diagnoses on the various publications of Hollard, whose papers he thought had been unwisely neglected. Gill's classification of the plectognaths was much more elaborate than that of his "Arrangement of the Families of Fishes," and although it has much in common with Bleeker's system, it is sufficiently different to merit citation:

\author{
Order Plectognathi \\ Suborder Sclerodermi \\ Family Triacanthidae \\ Subfamily Triacanthodinae \\ Subfamily Triacanthinae \\ Family Balistidae \\ Subfamily Balistinae \\ Subfamily Monacanthinae \\ Subfamily Psilocephalinae \\ Suborder Ostracodermi \\ Family Ostraciontidae \\ Suborder Gymnodontes \\ Superfamily Triodontoidea \\ Family Triodontidae \\ Superfamily Tetrodontoidea \\ Family Tetrodontidae \\ Subfamily Tetrodontinae \\ Subfamily Colomesinae \\ Family Psilonotidae \\ Family Chonerhinidae \\ Superfamily Diodontoidea \\ Family Diodontidae \\ Superfamily Moloidea \\ Family Molidae \\ Family Molacanthidae.
}

The above scheme differs only slightly from Bleeker's handling of the scleroderms, the difference being that the elongate monacanthid Psilocephalus was elevated by Gill to familial rank. In regard to the gymnodonts, Gill recognized a great many more higher categories than had Bleeker, but few of Gill's extra divisions have continued to be recognized. To Gill's credit, however, was the fact that all of the subgroups were diagnosed, and his systematic handling of the maze of names that have been applied to the various plectognath groups was a boon to all subsequent researchers.

A number of years later Gill (1892a) published his "Notes on the Tetraodontoidea," in which he expanded on his nomenclatural treatment of the tetraodontids, without any basic change in the classification he had previously used. In a series of notes, Gill (1888a, b, $1889,1892 \mathrm{~b}, 1897)$ dealt effectively with a number of other nomenclatural problems which need not be discussed here. In the same vein, Eigenmann's (1885) only 
paper on plectognaths might be noted, since he worked out the 36 specific names that had been applied to the six species of diodontids that occur off the American coasts, while that of Goode (1880) did the same for ostraciids.

No mention has yet been made of works on fossil plectognaths, other than Agassiz's species descriptions, for the simple reason that until part IV of Woodward's "Catalogue of Fossil Fishes" (1901) appeared, there was no systematic account of them. The order Plectognathi was not recognized by Woodward; rather, the plectognaths occurred in the families Balistidae and Gymnodontidae, which, along with the Chaetodontidae and Acronuridae ( $=$ acanthurids), composed the Division Chaetodontiformes of the Suborder Acanthopterygii. Admittedly the higher categories adopted by Woodward for the purpose of his pioneering catalogue were somewhat artificial, but it is significant that the one person who had reviewed the fossil plectognaths felt that they were so closely related to the acanthurids and chaetodontids that all of these groups should be placed in the same higher category.

The plectognaths were the first of the long series of orders that Regan (1903a) revised; his "On the Classification of the Fishes of the Suborder Plectognathi" was in sharp contrast to Gill's plectognath work. Whereas Gill concentrated on examining the literature, and particularly Hollard's figures, Regan made direct use of the skeletal material of the British Museum and nearly completely shunned nomenclatural matters, Gill having already straightened out most of the latter. Not only were the research styles much different but the classifications arrived at were equally dissimilar.

Regan recognized the Plectognathi as one of the. suborders of the Acanthopterygii in close relationship with the acanthurids. He (1903a:285) felt that the "feature of most importance in diagnosing the suborder Plectognathi is the absence of ribs, although in some well-ossifed epipleurals are present which have been mistaken for ribs," but he pointed out that, like everyone else since Dareste and Hollard, he had not had the opportunity to examine Triodon and only supposed that it also lacked ribs. On the other hand, Regan believed that "the coalescence of the teeth in the jaws is a feature of little importance, and has, as probably as not, originated independently..." in the gymnodonts and scleroderms. One could not do justice to Regan's classification without quoting in full his brief but excellent osteologically grounded diagnoses for the various subdivisions, but space forbids and in outline his system was as follows:

Suborder Plectognathi

Division Sclerodermi

Family Triacanthidae: Triacanthus, Triacanthodes, Halimochirurgus

Family Triodontidae: Triodon

Family Balistidae: Balistes, Monacanthus, Paraluteres, Pseudaluteres, Pseudomonacanthus, Alutera, Psilocephalus

Family Ostraciontidae: Aracana, Ostracion, Lactophrys

\section{Division Gymnodontes}

Family Tetrodontidae: Tetrodon, Ephippion, Tropidichthys, Chonerhinus, Xenopterus

Family Diodontidae: Diodon, Lyosphaera

Family Molidae: Mola, Ranzania.

The most obvious feature of Regan's classification is that it was much more conservative than that of such predecessors as Bleeker and Gill, but the differences were more basic than a simple and inevitable "lumper-splitter" disagreement. The unique Triodon had always been placed in the Gymnodontes because of the fusion of its teeth, following the lead of Cuvier (1829) in the second edition of the "Le Règne Animal." Regan (1903a:285), however, thought that "the structure of the pectoral arch and vertebral column, as well as the presence of a pelvis and well-ossifed epipleurals" related it to the triacanthoids and balistids, and thus Triodon for the first time appeared in the Sclerodermi. Contrary to Müller and Bleeker, who recognized three subdivisions of the Plectognathi, Regan followed Hollard and Günther in recognizing only the original two Cuvierian subdivisions, for the "Ostraciontidae do not seem to me to differ sufficiently from the Sclerodermi to rank as another division-Ostracodermi" (Regan 1903a:285). Whereas Gill recognized three families of tetraodontids, Regan preferred a single family. Regan pointed out that Gill based his diagnoses of the tetraodontid families on the figures given by Hollard of the top of the skull of various puffers, but that "the figures of Hollard have met with too ready an acceptance, that author having mistaken ridges on and fissures in the frontal bones for sutures" ( $p$. 293). Regan's objection to Hollard's figures and Gill's use of them was entirely correct. In short, Regan gave excellent diagnoses for the limited number of plectognath subgroups that he recognized, and corrected numerous osteological errors that had prevailed up to that time. Unfortunately, as was typical of most of Regan's revisions, only a few figures were given to accompany the great amount of osteological information that was discussed in the text. It is impossible, for example, to tell what Regan meant by the presence of an "ossified praeorbital" in the Balistidae. But these are relatively minor criticisms of the work that became the standard treatment of the major plectognath subgroups.

Regan's only other effort devoted solely to the plectog. naths was a brief, but useful at its time, revision of the genus Triacanthus (1903b). In the only complete fish classification that Regan ever presented, his "Fishes" (1929) in the 14th edition of the Encyclopaedia Britannica, the plectognaths were discussed and diagnosed as in his 1903 revision of the order. But now the Plectognathi were an order of the Neopterygii rather than a suborder of the Acanthopterygii. Thus, in the years that intervened between his revision of the plectognaths and his general fish classification, the plectognaths would seem to have grown in stature in Regan's view.

After Regan's (1903a) plectognath classification, the diagnoses that were there given were used to a greater or 
lesser extent by all subsequent ichthyologists. For example, Boulenger's "A Synopsis of Suborders and Families of Teleostean Fishes" (1904a) and "Fishes, Systematic Account of Teleostei" (1904b) followed Regan without deviation, and Boulenger's (1907) only other interest in plectognaths was his lateral view illustration of the skeleton of the Nile puffer, Tetraodon fahaka (= lineatus Linn.).

On the other hand, Jordan (1905) accepted Regan's work more critically, for while sparingly using Regan's diagnoses, Jordan had his own ideas about the plectognath subdivisions. For one thing, Jordan continued to recognize three suborders of the Plectognathi, with the Ostracodermi being one of them, rather than being relegated, in Regan's fashion, to familial rank within the Sclerodermi. Like Regan, Jordan (1905, 2:411) wished to stress the close association of the plectognaths and acanthurids, and did so by recognizing a "Series Plectognathi" which is "derived directly from the Acanthuridae, from which they differ by progressive steps of degeneration." But since the plectognaths "differ from one another more widely than the highest or most generalized forms differ from the Acanthuridae, we do not regard it as a distinct order. The forms included in it differ from the Acanthuridae much as the swordfishes differ from ordinary mackerel" (Jordan 1905, 2:411). It is a matter of opinion whether the magnitude of difference, external and internal, between such plectognaths as Mola and Triacanthus is of a higher degree than that between the swordfish and mackerel, but in any case Jordan was restating Dareste's acanthurid-plectognath relationship. In Jordan's somewhat vague terminology, the Chaetodontidae, Zanclidae, Acanthuridae, and related forms comprised the Squamipinnes, which gave rise to the Series Plectognathi. But in 1898 Jordan and Evermann, in their "The Fishes of North and Middle America" (part 2) made the same point, the Plectognathi being called either an "Order" (p. XVII) or a "Group" (p. 1696); and in 1923, Jordan, in his "A Classification of Fishes," recognized an Order Plectognathi with the following conservative subgroupings:

\author{
Order Plectognathi \\ Suborder Sclerodermi \\ $\dagger$ Family Spinacanthidae [for all fossil triacanthoids] \\ Family Triacanthidae \\ Family Balistidae \\ Family Monacanthidae \\ Family Psilocephalidae \\ Suborder Ostracodermi \\ Family Ostraciidae \\ Suborder Gymnodontes \\ Family Triodontidae \\ Family Tetraodontidae \\ Family Canthigasteridae \\ Family Diodontidae \\ Family Molidae.
}

Of more importance than the above classification were
Jordan's collaborative reviews of various families of plectognaths, making known many new species and redescribing poorly known ones: Jordan and Edwards (1887); Jordan and Snyder (1901); Jordan and Fowler (1903). Before continuing on to other researchers, it should be noted that Jordan's belief in the close relationship of the plectognaths and acanthurids was reinforced by the osteological observations of his colleague Starks (1907:217) on the Siganidae and Acanthuridae.

An example of the combined effect that Woodward's (1901) "Catalogue" and Jordan's numerous publications had on the subsequent handling of the plectognaths can be seen in Goodrich's (1909) "Cyclostomes and Fishes." Woodward had used the Division Chaetodontiformes for plectognaths, acanthurids, and chaetodontids, while Jordan had stressed again and again the close relationship of his "Series Plectognathi" with his Squamipinnes. These messages were taken to heart by Goodrich, for, even though he made free use of Regan's osteological diagnostic information, he adopted a modification of Woodward's and Jordan's views about the placement of the Plectognathi. The eclectic result was as follows:

Subtribe Chaetodontiformes
(of the Tribe Perciformes)
Division A, Squammipennes
Chaetodontidae
Drepanidae
Division B, Plectognathi
Subdivision A
Teuthididae
Siganidae
Acanthuridae
Subdivision B
Branch 1, Sclerodermi
Series 1
Triacanthidae
Balistidae
Monacanthidae
Series 2
Ostraciontidae
Branch 2, Triodontes
Triodontidae
Branch 3, Gymnodontes
A Tetrodontidae
Diodontidae
B Molidae.

Although the above "Plectognathi" was the logical extension of Jordan's championing of Dareste's ideas, it is nevertheless the first time that the term Plectognathi had included within its folds the acanthuridlike fishes. More important, however, was the fact that the plectognaths proper (Subdivision B) were divided into three major groups, one of which had never been recognized previously at that level. The Triodontidae had formerly 
been placed in either the Sclerodermi or Gymnodontes, and thus had always had a subordinate position until Goodrich gave it equal ranking with the two Cuvierian divisions. However, Goodrich's (1909:439) remarks on why Triodon had been so elevated were only that this is "a family intermediate between the first and third subgroups, whose exact position it is difficult to determine." Thus, the new third category was only a matter of convenience. In his (1930) "Studies of the Structure and Development of Vertebrates," Goodrich followed exactly the same classification.

The handling of the acanthurid-plectognath line in Gregory's (1933) "Fish Skulls" was modified from that of Goodrich. Gregory recognized a Balistoidei as one of the 23 subdivisions of the Acanthopterygii. The Balistoidei contained five large assemblages: acanthurids, zanclids, siganids, teuthids, and plectognaths (Gregory hesitated to give any of them a precise rank). His Balistoidei was therefore equal to the expanded "Plectognathi" (or Division B of the Subtribe Chaetodontiformes) of Goodrich. Goodrich's "Squammipennes" (Division A of the Subtribe Chaetodontiformes) became the Chaetodontoidei of Gregory, a group equal in rank with the Balistoidei. Gregory felt that the chaetodontids, acanthurids, and plectognaths formed a natural series, but he split apart Goodrich's Chaetodontiformes because it was his opinion (1933:281) "that the cleft between the typical chaetodonts and acanthurids is much greater than that between the latter and the plectognath stem as represented by the balistids." Just as with Dareste, one wonders why the comparison was not made between acanthurids and triacanthoids, which are the most generalized of the plectognaths, rather than between acanthurids and balistids, which are obviously of triacanthoid derivation. Gregory even illustrated the skull of a triacanthid (1933:282, fig. 160), but no mention at all was made of it in the text. Highly useful as Gregory's plectognath figures (1933:figs. 160-172) are for obtaining a general idea of cranial construction, they lack detail.

The tentative classification as seen in Gregory's (1933) "Fish Skulls" was a great change from that Gregory (1907) used in his much earlier "Orders of Teleostomous Fishes." In the earlier work Gregory recognized the Plectognathi as one of the 10 orders of the Superorder Acanthopteroidei. The Plectognathi were subdivided in the same way as Regan had done, with the exception that the monacanthids were recognized as two separate families (with the Alutera-like species as a distinct family) rather than being placed in the Balistidae. One other paper should be mentioned in connection with Gregory. Gregory and Raven (1934) discussed the anatomy and relationships of Mola and supported previous workers' placement of the molids in close association with the diodontids.

During the period 1912 to 1916 a number of papers of great importance to the study of plectognaths were published by Rosen in Sweden and Kaschkaroff in Russia. Rosen produced five successive articles in his "Studies on the Plectognaths" which dealt, respectively, with the anatomy of the blood-vascular system (1912), the airsac and intestine (1913a), the integument (1913b), the body muscles (1913c), and the skeleton (1916a). In the introduction to the series, Rosen (1912:1) explained his purpose to be the study of a number of anatomical systems, since "to base the building up of a phylogenetical tree solely on one anatomical system is a great error which far too many anatomists commit." $\mathrm{He}$ then promised to "end this series of studies on the Plectognaths with a section in which all the phylogenetical results attained independently from the study of each organ will be discussed together" (1912a:2). Unfortunately, such a last summary article on phylogeny never appeared, the last of the series being the 1916 paper on the skeleton, in which almost no phylogenetic conclusions were drawn. One can go to his earlier papers for his tentative views on the phylogeny of plectognaths, but he certainly would not have drawn his final conclusions until after the osteological paper had appeared. The tentativeness of the conclusions that will be quoted from his earlier work should be stressed, for the series is a good anatomical survey of the plectognaths, but his phylogenetic remarks based on the blood-vascular, intestinal, and integumentary systems do not seem to me to be substantiated by the osteology of the order. Rosen's ideas were most clearly expressed in his paper on the air-sac and intestine (1913a:19) in which he stated that, "The Molids and the Ostraciontids, which possess no such sac, must have developed independently of the other families. The inquiry given above on the air-sac has clearly shown that we have every reason to believe that the families Triacanthidae, Balistidae (including the genus Monacanthus), Diodontidae, and Tetrodontidae form a continuous series of development. This is an evident proof against the present classification of the Plectognaths into two subgroups, Sclerodermi and Gymnodontes, as proposed by Regan." Rosen's work on the integument confirmed his opinions and he (1913c:25-26) added that "The Molids and Ostraciontids are primitive Plectognaths, both groups separately specialized." The fourth paper in the series, like the fifth, contained no phylogenetic remarks.

Regardless of how the above statements would have been modified in a summarizing article, Rosen's series was highly useful as a pioneering survey of the soft, as well as the osteological, anatomy of the.plectognaths. His first four papers are presently the only publications that even attempt to treat as a whole all of the main nonosteological systems of the plectognaths, although Winterbottom's (1974) superb myological analysis is a major step in that direction. Rosen added much new information and reviewed the then existing knowledge. Without going into details, a few of the leading structural peculiarities summarized by Rosen in his first paper of the series should be mentioned as examples of the type of information with which he dealt. He was particularly impressed by the fact, known since the time of Cuvier, that Mola has a larger, and supposedly rather primitive, number of valves in its conus arteriosus and atrioventricular region than do the other plectognaths, 
which are normal in this respect. This fact, along with his observations of the primitive condition of the "circulus cephalicus" vessels in Lactophrys and Balistes (the only scleroderms in which he was able to examine the vascular system) and of its highly specialized condition in the gymnodonts, led Rosen (1912:19) to comment on "the occurrence of a great number of both primitive and highly specialized characters not only within the group but also in the same form." Thus, he felt that "Judging from the number of primitive characters that we have found in some Plectognaths we have all reason to believe, that this fish group has branched off rather early from the Teleostean main stock" (1912:20).

On matters of osteology, and considering that he had examined only four species of Plectognathi, Rosen's observations were generally quite accurate. He was able to substantially improve our knowledge of the plectognaths and to correct one of Regan's major errors. Regan had said in his diagnoses of the Sclerodermi and Gymnodontes that the former had all of the neural arches forming single spines, while in the latter the anterior vertebrae had bifid neural spines. Rosen correctly pointed out that in balistoids the first vertebra has a bifid neural spine and no bony roof over the neural canal. One would probably disagree, however, with Rosen's assessment of Regan, whose contribution Rosen (1916a:1) said "does not seem to me to have increased our knowledge either of the skeleton or of the phylogeny of the group." Rosen's description of the developmental and adult cranial osteology of Sphoeroides was well done, for he described it with more precision than had been given to a plectognath up until that time. But like Regan before him, Rosen included very few figures of the structures he discussed so well. However, since Rosen described these was not until 3 years after he had finished his manuscript that he had seen Rosen's first three articles. Kaschkaroff (1914a:365) simply said that he found them "sehr interessante." Whereas only a small, but highly significant, part of Rosen's output was devoted to osteology, the majority of Kaschkaroff's work concerned the osteology of the plectognaths and the histology of their bones, and only minor excursions were taken into soft anatomy. In this respect Kaschkaroff's treatment of the order was similar to that of Hollard. Whereas Hollard produced the first work that could be called a monograph on the osteology of the plectognaths, Kaschkaroff produced what until now is the last such work.

Kaschkaroff began his study at one of the end points of plectognath radiation, for he (1914a:265) admitted that "Meines Erachtens ist Orthagoriscus mola die interessanteste Form genannter Gruppe." That view has many advocates, as attested to by the practically infinite number of distributional and natural history notes that have been devoted to that species. Kaschkaroff proceeded to describe, with many more illustrations than had Rosen, the general osteology of members of all the major groups of plectognaths, with the exception of Triodon, of which he had no specimens. While on the whole Kaschkaroff's work is highly valuable, it contains a number of serious observational errors that will be mentioned in the osteological section of this monograph. Regardless of osteological errors, Kaschkaroff had intelligently examined a large number of plectognaths and the conclusions at which he arrived are important to note. These conclusions were best summarized in the diagram he presented (1914a:359), while cautioning the reader that this was only a chart of anatomical similarity and not necessarily a phylogenetic tree.

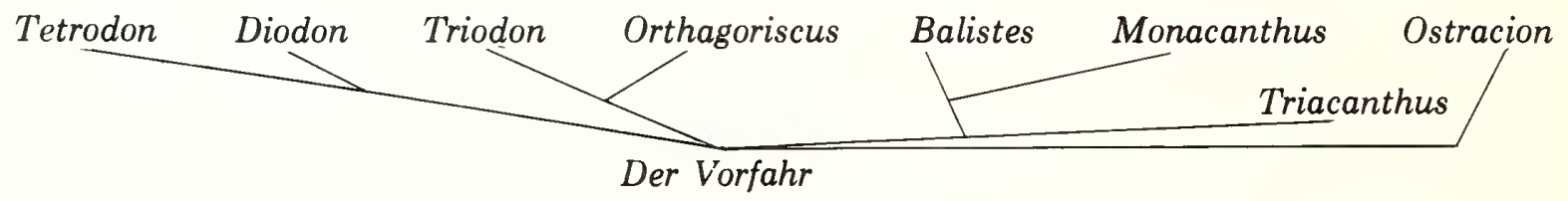

structures in some detail, it is not overly difficult to reconstruct what he saw. The same cannot be said of Regan's telegraphic summaries of his osteological observations.

In the middle of the 4-year period during which Rosen's series was published, there appeared Kaschkaroff's (1914a) "Vergleichendes Studium der Organisation von Plectognathi." This was evidently to be the first of a series of anatomical monographs concerned with "Materialen zur Vergleichenden Morphologie der Fische," but, just as with Rosen, something in those troubled times was to cut short the series. Kaschkaroff was not aware of Rosen's work until after completing his own studies, for he said at the close of his paper that it
The only outstanding peculiarity of the above was the close association of Orthagoriscus (= Mola) with Triodon, but there was no explanation in the text as to the reasoning that lead to this association. Kaschkaroff went on to say, however, that Hollard's classification was acceptable, and the latter was presented by Kaschkaroff (1914a:360) with the statement that "die alte Klassifikation von Hollard erscheint mir vollkommen begrundet."

Kaschkaroff discussed what "Der Vorfahr" of the Plectognathi should be, listing the characteristics of this hypothetical ancestor. The list (1914a:359) added up, in essence, to a triacanthoid with a large amount of cartilage in its skeleton. He did not believe that the plectognaths arose from an acanthurid stock, for the latter did 
not possess a large amount of cartilage in the skeleton, a characteristic he considered to be of great importance. Rather, he felt that the plectognaths might possibly best be placed in association with the Lophobranchii and Lophius. If one wishes to place such an emphasis on the amount of cartilage present in the skeleton of some plectognaths, then one could just as well relate the order to Cyclopterus as well as to Lophius, and return to the Artedian Branchiostegi.

In his "Studien über die Flossenmuskulatur der Teleostier," Grenholm (1923:245) supported Rosen's view that "Die alte Zweiteilung der Plectognathen in Gymnodontes und Sclerodermi ist nach meiner Ansicht ... schwer aufrecht zu erhalten," while at the same time admitting that the Plectognathi were a distinct group related through the Acanthuridae to the other acanthopterygians. It is of interest that Grenholm's research on the fin muscles and Rosen's on the soft anatomy lead to the same conclusion, a conclusion not supported by the great majority of osteologically based works, nor by Winterbottom's (1974) general myology of the plectognaths.

Whenever one wishes to identify most plectognath genera, there is only one place to which one usually turns, and that is to the long series of revisionary papers by Fraser-Brunner (1935a, b, 1940a, b, c, 1941a, b, c, 1943, 1950, 1951). For species identification the story is somewhat different. Fraser-Brunner simply listed under the keyed-out genus the species which he found to be recognizable. Only for the molids and several genera of monacanthids were keys to the species provided. However, since Fraser-Brunner typically drew his generic lines rather finely, there are usually only a few species within any one genus and the practical matter of species identification is not as difficult as it might first appear. The exemplary service that Fraser-Brunner performed will be appreciated by anyone who attempts to identify plectognaths, especially those from the Indo-Pacific.

Throughout the series Fraser-Brunner promised eventually to publish a comprehensive monograph on the order, but, since that has not yet appeared, there is presented below his tentative classification as brought together from his various publications. No genera will be listed by name, for with Fraser-Brunner the number usually accepted was greatly increased:

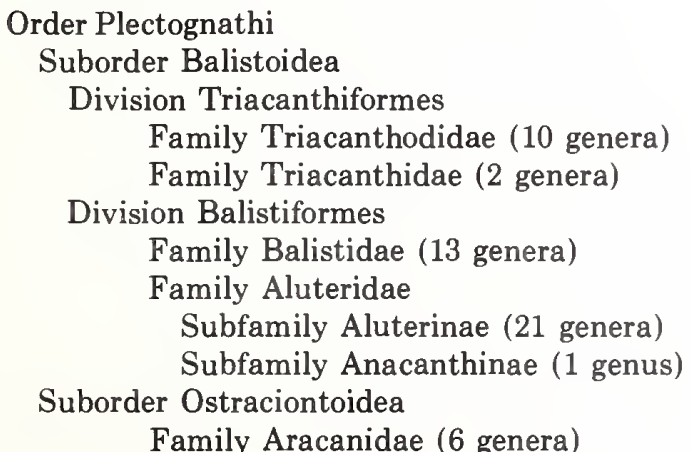

\author{
Family Ostraciontidae \\ Subfamily Ostraciontinae (3 genera) \\ Subfamily Lactophrysinae (3 genera) \\ Suborder Tetraodontoidea \\ Division Moliformes \\ Family Molidae \\ Subfamily Ranzaniinae (1 genus) \\ Subfamily Molinae (2 genera) \\ Division Tetraodontiformes \\ Subdivision Tetraodontines \\ Family Canthigasteridae (1 genus) \\ Family Lagocephalidae \\ Subfamily Lagocephalinae.(1 genus) \\ Subfamily Sphaeroidinae (3 genera) \\ Family Colomesidae (1 genus) \\ Family Tetraodontidae \\ Subfamily Tetraodontinae ( 2 genera) \\ Subfamily Arothroninae (1 genus) \\ Family Chonerhinidae (2 genera) \\ Subdivision Diodontines \\ Family Diodontidae (3 genera).
}

The above is obviously not complete, for Fraser-Brunner has not yet assigned a place to Triodon, although he (1943:4) did say that the "Tetraodontoidea are almost certainly derived from the Triacanthiformes, a somewhat fragile connection between the two being provided by the existing Triodon."

Fraser-Brunner's classification is basically similar to that of Bleeker's, with, of course, the refinements made possible by Fraser-Brunner's own skill and by the results of the researchers who intervened between these two. It is nevertheless a compliment to Bleeker that FraserBrunner should, nearly a hundred years later, arrive at essentially the same classificatory scheme-although Fraser-Brunner's diagnoses are, naturally, incomparably better. Fraser-Brunner relied heavily on Regan's osteological observations and pointed out (1943:1), e.g., that Regan's diagnosis of the Gymnodontes "here regarded as the Suborder Tetraodontoidea, cannot be surpassed, and its salient features are given below, practically unaltered." This is not to imply that Fraser-Brunner relied only on previous diagnoses of the subgroups, for he contributed many original and significant observations on the osteology of various families, notably in the tetraodontids, triacanthodids, and ostracioids. His strong point was his combination of his own and previously published osteological observations with his knowledge of the relative importance of external characteristics in arriving at his familial categories. This is particularly evident in his diagnoses of the tetraodontid subgroups, in which csteology (albeit only the top of the cranium in most cases) is uniquely combined with the structure of the nostril and lateral line, two systems notoriously misleading in this group when used by themselves.

In one of his more recent papers, Fraser-Brunner (1950) speculated about the basic phylogeny within the Plectognathi. There is little doubt today about the 
naturalness of the triacanthoid-balistid-monacanthid line, but from what stock the tetraodontoids and ostracioids arose is an open question. After examination of the larvae of a triacanthodid, Fraser-Brunner suggested that both the tetraodontoid and ostracioid lines may have been derived neotenously from the triacanthodids.

Whereas Müller and Bleeker had started the trend toward the recognition of three major subgroups of plectognaths, rather than the original two of Cuvier, Berg's (1940) "Classification of Fishes" went one step further and recognized four. Berg came to the following classification on the basis of his analysis of the works of Regan, Rosen, Kaschkaroff, Gregory, and Fraser-Brunner:

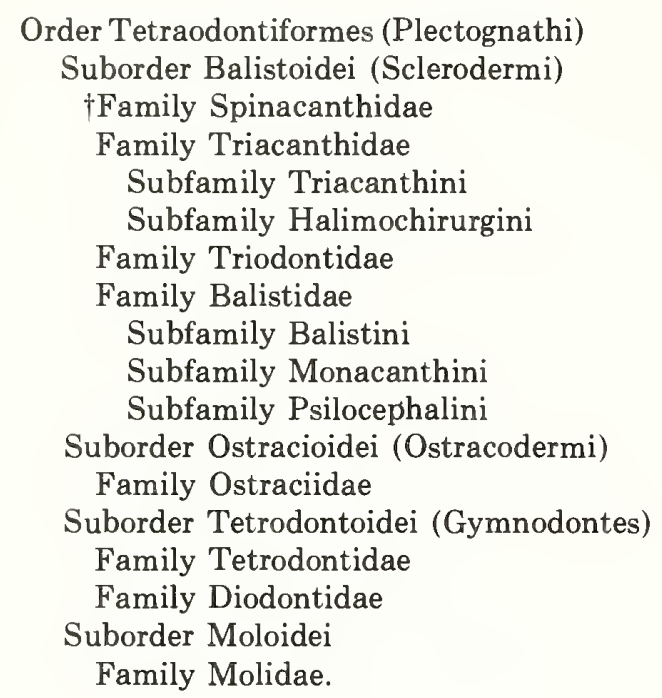

Other than the fact that the molids were given subordinal rank, this was a very conservative classification, based entirely on works already mentioned.

Breder and Clark's (1947) "A Contribution to the Visceral Anatomy, Development and Relationships of the Plectognathi" is a useful, and interesting, comparison of the anatomy of the acanthurid-plectognath line. It is indicative of the then current state of our knowledge of plectognath anatomy (Breder and Clark 1947:312-313, table 2) that these two authors, on the basis of the literature and their own research, were unable to state whether the palatine was movable in either Triodon or the trunkfishes. One also sees in table 2 that even greater gaps exist in our knowledge of the characteristics associated with reproduction. It has been mentioned several times in this historical review that the rarity of museum specimens of Triodon had hampered the phylogenetic investigations of all workers after the time of Dareste and Hollard. Breder and Clark were able to make a partial dissection of one of the Stanford University specimens of Triodon obtained by Herre in the Philippines in 1931. Their report on the intestine was the first addition that had been made in 100 years to our knowledge of Triodon. This same specimen has been utilized for the present monograph.
The classification adopted by Breder and Clark was modified from that of Fraser-Brunner:

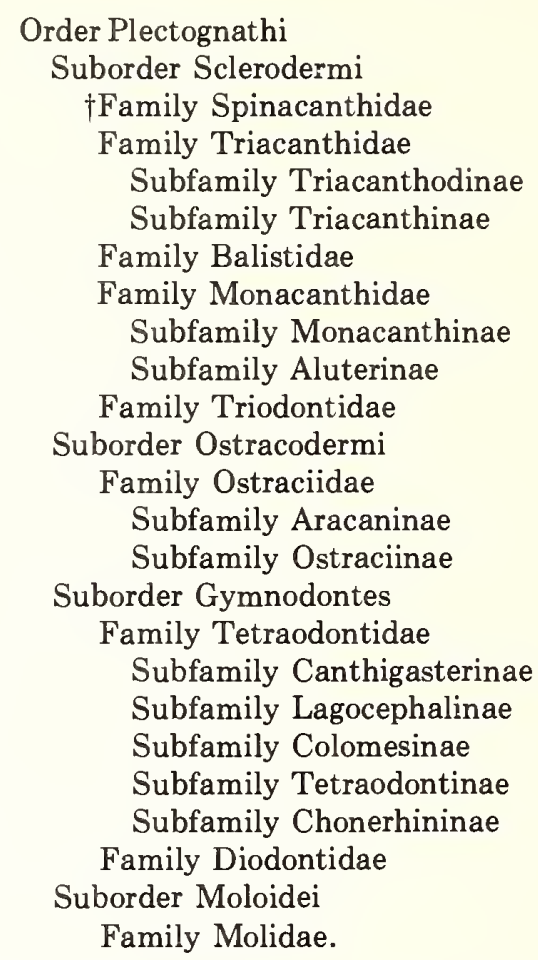

On the basis of their research, Breder and Clark (1947) felt that the trunkfishes deserved subordinal rank rather than inclusion in the Sclerodermi: "In view of the marked differences in the ontogeny from that of Monacanthus and its resemblance to that of Spheroides, we cannot feel justified in holding these fishes within the Sclerodermi almost solely on the basis of cranial characters" (p. 311). Their justification for following Berg's handling of the molids was that "Although these fishes represent an offshore modification of the gymnodontid type, they are so much further modified as, in our judgement, to warrant such a separation. The fact they have lost their tail and its associated musculature .... indicates a fundamental change in the whole plan of organization" (p. 311). Breder and Clark's views were summarized in a phylogenetic tree (p. 315 , fig. 8) that is one of the most sensible and understandable that has been presented for the plectognaths, and the reader is referred to it.

The extensive work by Y. Le Danois (1954, 1955, 1956, 1959, 1961a, b) on the osteology, myology and other soft anatomy, taxonomy, and phylogeny of the plectognath fishes, including monographs on the tetraodontoids and ostracioids, has not had a favorable reception. The osteology and systematics were criticized by Tyler (1963b) and the myology by Winterbottom (1974). To more fully comment on the controversial aspects of Le Danois' work would require hundreds of pages, and it must suffice to summarize Le Danois' conclusions: the triacanthoids and balistoids are of acanthurid origin; the other plectognaths (Orbiculati) are not even of percoid 
derivation, being related to the isospondylous fishes; and Canthigaster is related to the ostracioids rather than the tetraodontids. Le Danois' classification of the "Orbiculati" is as follows:

Sous-ordre Orbiculati

Division Orbispiniformes ou Tetraodontoidea

Familles: Xenopteridae, Colomesidae, Diodontidae, Tetraodontidae, Lagocephalidae.

Division Ostracioniformes ou Ostraciontoides

Familles: Canthigasteridae, Aracanidae, Ostracionidae.

Division Moliformes ou Moloidea

Families: Ranzanidae, Molidae.

Division Triodontiformes ou Triodontoidea

Famille: Triodontidae.

To what order the "Orbiculati" belong is not stated. Le Danois' work can be dismissed, except nomenclaturally.

Although not directly concerned with the general phylogeny and higher classification of the plectognath fishes, several outstanding recent works on the systematics of limited groups of plectognaths have made certain species complexes far better known than in the past, and represent the basic building blocks upon which such revisions as this monograph are based. de Beaufort (1962) systematically treated all of the more common species of the Indo-Pacific plectognaths (104 species) for the first time since Bleeker, immensely aiding the often difficult task of specifically identifying the plectognaths of that region. Berry and Vogele (1961) carefully analyzed the systematics of the Atlantic species of monacanthids, and Berry and Baldwin (1966) did the same for the Pacific balistids. Shipp (1970, 1972a, b, 1974) and Shipp and Yerger (1969a, b) have brought order to the numerous Atlantic species of Sphoeroides, discussing external morphological features, delimiting distributional patterns, and describing new species. With such exemplary work as that of Berry and Shipp and colleagues, the American balistoids and tetraodontoids have become the best known of their respective families. In Asia the exceptionally speciose and mainly freshwater pufferfishes of the genus Tetraodon received their first systematic review by Dekkers (1975), who placed them in five species groups and unraveled most of the systematic snarls that previously surrounded them. Similarly, the marine species (primarily of Arothron and Canthigaster) of tetraodontids from Taiwan were redescribed by Shen and $\operatorname{Lim}$ (1974a) and Shen et al. (1975) in that general area for the first time since the series of articles by Abe (1942, 1944, 1949a, b, c, 1950-51, 1952, 1954, 1960), while Shen and Lim also reviewed the ostracioids (1973) and balistids (1974b) of Taiwan. Allen and Randall (1977) provided an excellent and superbly photographed review of the Indo-Pacific pufferfishes of the subfamily Canthigasterinae, recognizing 22 species, of which 7 were described as new, in this group of notoriously difficult tetraodontids, while Leis (1978) has performed a similarly fine service for the five species of Diodon he recognizes worldwide. The fossil and Recent triacanthoids were redefined and revised by Tyler (1968), which monograph was reviewed by Myers (1970).

The provisional reclassification of fishes by Greenwood et al. (1966), which is wisely accepted as the contemporary standard, does not attempt to include new information on the plectognaths. While I agree with their basic subgroupings of the Recent Plectognathi, I consider their families as superfamilies, a matter of opinion that I hope is supported by the numerous differences given here between the 6 superfamilies and their included 10 families as recognized in this monograph.

In Gosline's (1971) combination of functional morphology and fish classification, the plectognaths are recognized in 7 superfamilies with 12 families (the Aluteridae recognized as distinct from the Monacanthidae, and the Canthigasteridae from the Tetraodontidae) in the usual two suborders, while Gosline (1968:16) had previously related the acanthuroids and plectognaths.

The tentative classification of the plectognaths proposed by Tyler (1974), with 7 superfamilies and 11 families, is modified here by the combination of the Canthigasteridae with the Tetraodontidae and of the Diodontoidea with the Tetraodontoidea.

It is pleasant to be able to conclude this historical review of the higher classification of the plectognaths with praise for the latest significant publication, that by Winterbottom (1974) on "The Familial Phylogeny of the Tetraodontiformes (Acanthopterygii: Pisces) as Evidenced by Their Comparative Myology." This is a beautifully illustrated and thoroughly analyzed survey of the muscles of numerous representative plectognaths and of its implications to the phylogeny and classification of the order. It is unquestionably the finest comparative myological study of any major group of fishes. A phylogenetic interpretation is given for the condition of every main muscle ( 75 in toto) in representatives of every plectognath family and of various reinterpretations of these data. It is a forcefully reasoned analysis based on an exceptional amount of myological data.

A hallmark of Winterbottom's work is a rigorous application of the principal that only synapomorphies (shared specialized characters) can be used to link together related groups, while symplesiomorphies (shared generalized or primitive characters) are not valid as phylogenetic indicators. The excellence of Winterbottom's contribution can best be seen by perusal of his brilliant monograph, and only the highlights of his phylogenetic conclusions and an outline of his proposed major reclassification can be given here.

Winterbottom (1974:ii) states in his abstract that ". . . using only those characters of a shared specialized (synapomorph) nature ... suggests that the Triacanthodidae and Triacanthidae are sister groups, and separated off first from the ancestral stock. The remaining families are divided into two lines. On the one hand, the Balistidae form the sister group of the Monacanthidae, and together form the sister group of the Aracanidae and Ostraciidae. In the other linage, the Triodontidae 
separated off first, followed by the Molidae. The Diodontidae form the sister group of the Tetraodontidae plus Canthigasteridae." The classification based on this phylogeny divides the plectognaths into two suborders in a rather different way than ever proposed before, revised as follows (Winterbottom 1974:99):

\author{
Order Tetraodontiformes \\ Suborder Triacanthoidei \\ Family Triacanthodidae \\ Subfamily Triacanthodinae \\ $\dagger$ Subfamily Cryptobalistinae \\ Subfamily Hollardiinae \\ Family Triacanthidae \\ Subfamily Triacanthinae \\ $\uparrow$ Subfamily Protacanthinae \\ Suborder Tetraodontoidei \\ Superfamily Balistoidea \\ $\dagger$ Family Spinacanthidae \\ Family Balistidae \\ Subfamily Balistinae \\ Subfamily Monacanthinae \\ Family Ostraciidae \\ Subfamily Aracaninae \\ Subfamily Ostraciinae \\ Superfamily Tetraodontoidea \\ $\dagger$ Family Eoplectidae \\ $\dagger$ Family Zignoichthyidae \\ Family Triodontidae \\ Family Tetraodontidae \\ Subfamily Tetraodontinae \\ Subfamily Canthigasterinae \\ Family Diodontidae \\ Family Molidae.
}

The phylogenetic conclusions reached by Winterbottom on the basis of the myology of the plectognaths and those presented here on the basis of their osteology are in general agreement, although the hypotheses of this monograph emphasize the role on the one hand of a hollardiinlike Eocene stock of triacanthodids as ancestral to triacanthids through a protacanthodinlike line, with the basal triacanthids giving rise to the balistoids and ostracioids, and on the other hand of an eoplectinlike Eocene stock of triacanthodids as ancestral to the triodontids and hence to the tetraodontoids and molids. Even though the phylogenies based on Winterbottom's myological analysis and that of the osteology given here are not far apart, and differ mainly in details of the relationships of fossil forms for which there is no myological evidence, the classifications adopted are widely divergent.

While finding Winterbottom's philosophy of classification highly worthwhile, eminently logical and entirely defensible, the preference followed here is to weigh and balance the value of both the generalized and specialized features of the fossil and Recent species, rather than to rely on the specialized alone, and the classification suggested here reflects that bias.

Winterbottom and I plan to prepare a joint paper after the publication of this monograph discussing the merits of alternatives to our respective modes of phylogenetic interpretation and classification of various plectognath linages and subgroups. Until then, the reader is left to his own inclination.

\section{Historical Review of the Nonclassificatory Anatomical Work on the Plectognathi, with notes on certain anatomical systems of special historical interest.}

Comments are given in the preceding section on the contributions of such anatomically oriented workers as Cuvier, Dareste, Hollard, Winther, Regan, Kaschkaroff, Rosen, Gregory, Fraser-Brunner, and Le Danois, all of whom were using an osteological framework for their classifications of the plectognath fishes. A number of other workers have described the general osteology of one or several species of Plectognathi from a more or less purely anatomical point of view, without concerning themselves with questions of phylogeny and classification. Specific details of these works are mentioned in the subsequent analysis, but some of these shorter contributions are of sufficient importance to merit brief general comment.
Wellenbergh (1840) was the first person to treat an individual plectognath species in a manner similar to that of Geoffroy Saint-Hilaire's (1827) anatomy of the Nile puffer. Wellenbergh's description of the bones of the skull of Mola leaves much to be desired by contemporary standards, but the branchial and hyoid arches were described rather accurately. After Wellenbergh's work there came a veritable flood of literature on the anatomy of molids. Goodsir (1841) described with some detail the histology of the shagreenlike skin and the gelatinous subdermal tissue of Mola, as well as its general myology. His work is of importance here because of his description of the abortive nature of the posterior end of the molid vertebral column. Cleland (1862) like- 
wise gave a general account of the soft anatomy of Mola, with an emphasis on the structure of the caudal region, its bony supports, cartilaginous pterygials, and unusual fin rays. Two of Cleland's most often quoted statements were that Mola possessed no otoliths and had only two semicircular canals. Cleland was not aware that Cuvier (1805, 2:456-457) had described the otoliths of Mola as being gelatinous and mucoid, rather than calcareous, and that he had even figured (pl. 18, fig. 1) the three semicircular canals. Cleland's error has been corrected a number of times: vide, Harting (1865), Thompson (1888), and Meek (1904).

Harting's (1865) general anatomy of Mola contained very few references to osteology, but he did give a brief description of the long, sharp-pointed teeth on the upper pharyngeals. Walgren's (1867) work on Mola was mostly confined to external characteristics, but brief notes were given on the skeleton, and the jaws, with their trituration plates, were well described and figured. The first worker to publish on the general anatomy of the distinctive molids of the genus Ranzania was Trois (18831884), whose osteological interest, however, was mainly confined to the comparison of the histology of the bones of Ranzania with that of Masturus and Mola. He pointed out, for example, that Ranzania has a much more completely ossified skeleton than that of the other molids. Trois' histologically oriented work was soon followed by Beauregard's (1893) descriptive osteology of Ranzania. Beauregard gave us our basic knowledge of the general osteology of Ranzania, and the information that he presented was not supplemented.until Raven (1939b) published his brief article on its anatomy. One of the more accurate of the early general osteologies of Mola was that of Steenstrup and Lütken (1898); the various figures (unnumbered; occurring on p. 91-94) of the skull and branchial apparatus are, with the exception of the orbital region, notably accurate, and the lateral view of the entire skeleton ( $\mathrm{pl} .2$ ) is only questionable in the region of the pseudocaudal fin. Two other papers should be mentioned here in relation to molid anatomy, that of Gregory and Raven (1934) on Mola and that of Raven (1939a) on Masturus. Both of these papers were primarily concerned with the myology, but information was also given on the osteology of the supporting structures of the pseudocaudal fin.

Of a much more ambitious nature than any of the above-mentioned papers on molid anatomy was Brühl's (1856) "Osteologisches aus dem Pariser Pflanzengarten," in which there appeared (p. 58-70) brief osteological descriptions of Balistes, Ostracion, Alutera, Tetraodon, and Diodon. Brühl confined himself almost entirely to the cranium, and the few figures which he gave of various regions of the plectognath skeleton show very little detail, but if one takes the time to translate the archaic terminology of the bones, one finds that Brühl's osteological observations were substantially correct. It is hard to explain, however, how he mistook part of the sphenotic in Diodon for a parietal; possibly it was because Wellenbergh had found a "parietal" in Mola, and thus one might expect to also find one in Diodon, if one believed very strongly in the close relationship of those two types. In his "Zootomie," Brühl (1880) presented excellent illustrations (pl. 24, with two unnumbered pages of explanation; also see Brühl 1891) of Balistes, and the only serious error in his various figures of the skeleton is the presence of an extra suture between the parasphenoid and basioccipital.

A work very similar to Brühl's (1856) "Osteologisches" in its conception, but broader in its scope of coverage, was Klein's (1884, 1885, 1886) "Bildung des Schadels der Knochenfische." In this general work on the teleost skull, Klein discussed the cranial osteology of representatives of most of the major plectognath subgroups. His descriptions were, on the whole, accurate, and since his illustrations were so well executed, it is unfortunate that there were so few of them. Klein corrected a great many of Hollard's osteological errors, and stressed (1886:230234) the presence of a myodome in the nonostracioid scleroderms and its absence in the gymnodonts. In an earlier paper Klein (1872) had described the cranial osteology of four species of Balistes, and while his descriptions were relatively accurate, his illustrations were so reduced in size for publication that little detail can be seen. Klein (1881) published one other paper on plectognath osteology, devoted primarily to the description of the spiny dorsal fin locking mechanism in triacanthoids and balistoids.

Rosenthal (1839) produced rather accurate lateral views of the entire skeletons and other detailed views of Balistes, Ostracion, Tetraodon, and Diodon.

Several other papers of special importance to the osteology of particular species should be mentioned here.

The osteology of the skull of Balistes and Mola was described and reasonably well illustrated by Supino (1905), as was the branchial apparatus of each spécies, the latter being an important anatomical system which had all too often been neglected by previous workers. Much of the information that Supino published in his 1905 paper appeared again in his more general work (1907) on "II Crano dei Pesci."

Awati and Bal (1933) initiated a series of papers on the anatomy of Indian puffers with a description of the skeleton of Tetraodon ( = Fugu) oblongus, but their osteological descriptions suffer from numerous serious defects, as will be detailed later. The second paper in this series (Awati and Bal 1934) dealt with the blood vascular system, and the third paper (Bal 1937) with the nervous system. A far more detailed and accurate survey of the functional anatomy of the head of that species was given by Sarkar (1960) in a published doctoral dissertation.

A work of importance to the generic classification of the tetraodontids is Kuronuma's (1943) survey of the configuration of the top of the cranium of 14 species of Japanese puffers. Besides giving a photograph of the top of the cranium of each of these species, diagrammatic illustrations were presented of lateral views of the skulls of species representative of the three genera to which the species belong. Kuronuma's osteology is correct and he has made available much information of diagnostic value 
for the genera and species studied. Klausewitz (1964) accurately described and illustrated the skull of an Arothron, and Rishi (1969) that of a Chelonodon.

The otic region of the skull of plectognaths has been the subject of much misinterpretation in the literature. One source of the error has evidently been the feeling that the plectognaths, like most other fishes, should possess a pair of parietals. But the plectognaths have lost all trace of the parietals and what have been called the parietals in plectognaths are portions of the epiotics, sphenotics, or frontals. Wellenbergh (1840) referred to a portion of the epiotic in Mola as a parietal. Brühl (1856) described the parietals as being absent in all plectognaths except Diodon and Mola, calling the posterior part of the sphenotic in Diodon a parietal and accepting Wellenbergh's statement that a parietal existed in Mola. In Hollard's (1853, 1854a, b, 1855, 1857a, b, 1860) various publications the posterior portion of the frontal is called the parietal, although a definite suture between the bones is not usually shown in his figures. Goeldi (1884) pointed out that many of the sutures shown by Hollard were artifacts and criticized Hollard for the excessive number of bones that had been described as separate elements. What Siebenrock (1901) described as a parietal in Balistes, even though he could not find one in Triacanthus, or Monacanthus, is probably a part of the epiotic. Supino (1905) thought that in Balistes the parietals were fused to the frontals, but in Mola he described the medial half of the pterotic as being a parietal. Kaschkaroff (1914a) described a parietal as being present only in Balistes, his parietal evidently being part of the epiotic. Kaschkaroff believed that the frontal of Mola might represent the product of the fusion of the frontal with the parietal. Rosen (1916a:13) said that the parietals were absent in plectognaths, and expressed the prevailing view that "they have perhaps fused with the frontals." The above statements are exclusive of those instances in which there is a purely nomenclatural difference, e.g., Regan's (1903a) use of the term "parietal" as being synonymous with "epiotic." Since Rosen's time, no knowledgeable worker has described a parietal in a plectognath fish, and if that bone has fused with the frontal it has done so indistinguishably. Not even a trace of a separate ossification which could conceivably be referred to as a parietal has been seen in any of the developmental stages of various plectognaths examined for this work. Under these circumstances it would seem best to assume that the parietal simply fails to develop in plectognaths.

The other major source of error in the interpretation of the otic region has been the description of the upper and lower surfaces of the epiotic as two separate and distinct bones, because of a certain anatomical peculiarity of the development of the endochondral bones, particularly in the otic region. The otic bones begin to develop in the normal manner as small ossifications in the appropriate region of the chondrocranium. From this center of ossification in a plate of cartilage, the gradual peripheral movement of the ossification does not proceed evenly. Rather, the ossification spreads through the upper sur- face and through the lower surface of the cartilage, so that toward its edges the bone is composed of an upper and a lower layer separated by cartilage. The two layers are continuous with one another only at their original center of ossification. As the specimen becomes larger, there is a slow and gradual ossification that fills in the otherwise cartilaginous area between the two peripheral layers of the bone. It is only in extremely large specimens that all of the cartilage between the double-layered peripheral parts of the bone is replaced by ossified tissue. Thus, in the descriptions given here of the otic and other regions, there is reference to these endochondral bones having the edges filled with cartilage, simply because in all but the largest specimens of any particular species the replacement of the cartilage between the upper and lower layers in the peripheral region of the bone is incomplete. This double-layered condition is particularly evident in the epiotic and sphenotic, and is progressively less evident in the pterotic, prootic, exoccipital, supraoccipital, and the other endochondral bones of the skull. In adult specimens the cartilage-filled edges of these endochondral bones are usually not evident on external examination, and they can be seen only when the bones are disarticulated.

The reason that this condition is not particularly apparent is that the edges of the upper layers of two adjacent bones, e.g., epiotic and sphenotic, may interdigitate with one another, hiding the fact that just below this interdigitated surface there is a thin layer of cartilage separating the upper and lower layers of the bones. It is usually true, except in large adults, that when the upper layers of two bones articulate by interdigitation, the lower layers of these bones are separated from each other by a small amount of cartilage, this cartilage extending for a short distance into the substance of each of the bones. It must be emphasized that even though a bone such as the epiotic has an upper and a lower layer separated by cartilage peripherally, these two layers converge toward one another centrally to be connected by a core of bone representing the original center of ossification. This central core of bone is delicate enough in some cases to be easily broken when skeletal material is prepared by drying, because of the contorted shrinkage of the cartilage that lies between the double-layered peripheral regions of the bone. If the drying of the skeleton does not break the central core, then the process of disarticulation of the skull often will.

It is thus not surprising to find that Klein $(1872,1881$, $1884,1885,1886)$ stated that in plectognaths there is an epiotic which is covered over by a parietal. Klein's "parietal" was simply the upper layer of the epiotic, which had become separated from its lower layer during the drying and disarticulation of the skull by breaking of the central ossified core which normally makes the two layers continuous. Awati and Bal (1933) have done essentially the same thing in their study of Fugu oblongus, for they refer to the ventral surface of the epiotic as the "epiotic," but to its dorsal surface as the "parietal." Furthermore, they refer to the ventral surface of the sphenotic as the "sphenotic," but to its dorsal surface as 
the "squamosal." Like Klein, they were using dried skeletal material.

Rosen (1916a) had some insight into this problem of the "double-layered" condition, which is especially prominent in the otic region of tetraodontids. In his brief description of Sphoeroides testudineus he contradicted Klein's statement that the epiotics are covered by the parietals, for Rosen stated (1916a:19) that "I have not been able to find distinguishable such elements either in adult specimens or in young ones (18 mm. in length)." But, quite unaccountably, Rosen went on a few lines later to say, without any elaboration, that there were "Parietals present." Unfortunately, there were no figures of plectognath skulls in that paper, and one can only guess that Rosen was referring to a portion of the posterior end of the frontal in Sphoeroides as the parietal. Rosen's most interesting statements, however, were about the sphenotic and pterotic in Sphoeroides, for he described them as follows: "Sphenoticum. Sections of specimens $18 \mathrm{~mm}$ in length show that this bone originated as two elements: a dermosphenoticum and an autosphenoticum in the same mode as, e.g., squamosum. Squamosum is formed by the fusion of a dermosquamosum and an autosquamosum." No other comments were made about this condition of the otic region, nor were any figures presented of it. Rosen was obviously aware of the double-layered condition in the otic region, but why he did not notice it in the epiotic is a mystery. Rosen was probably incorrect in assuming that the upper layers of the sphenotic and pterotic were of dermal origin, for in the many young tetraodontids examined for the present work, this upper layer is obviously ossified in the upper region of the cartilage of the chondrocranium. This is not to say, however, that there is not any dermal ossification eventually incorporated into the external surface of the upper endochondral layer of the otic bones, but only that the great bulk of these bones is endochondral in origin. In Parahollardia and other triacanthodids, for example, most of the substance of the part of the pterotic that overlies the sphenotic and epiotic appears to be of dermal origin, but this is only a very small, and irregular, portion of the pterotic.

A number of workers have erroneously referred to certain portions of the pterotic as the "opisthotic." Awati and Bal (1937) did so in Fugu oblongus, and Garnaud (1956) did likewise in Balistes. Kaschkaroff (1914a:351) seems to be the one who began the mistake, for he said that an opisthotic was present in scleroderms but not in gymnodonts. Kaschkaroff"s "opisthotic" is only a region of the pterotic.

A well-developed myodome has long been known to be present in triacanthoids and balistoids, and more recently in triodontids (Tyler 1962a), but it was thought to be absent in all other plectognaths. Klein $(1884,1885,1886)$ was the first person to point out the diagnostic value of this structure (see part 1:150-152 and part $3: 230-234$ ) in plectognaths, but Regan (1903a) rather unaccountably stated that the Sclerodermi have the "basis cranii more or less distinctly double" (p. 280) and that the Gymnodontes have the "basis cranii simple" (p. 291), which implies that the ostracioids have a myodome. Kaschkaroff (1914a:351) described the longitudinal concavity on the ventral surface of the basioccipital in Triacanthus, Balistes, and Monacanthus, but he did not mention that this channel leads into the myodome. Holmgren and Stensiö (1936:488) contended that the myodome of plectognaths and a few other fishes corresponds to the dorsal part of the myodome of Salmo, because it encloses only the $M$. recti externi. Be that as it may, the important fact that Triodon possesses a welldeveloped myodome was overlooked by Dareste (1849) and Hollard (1857b), and it is significant to know that at least a rudiment of the dorsal roofing of the myodome is present in some tetraodontids (Tyler 1963b).

Frost (1930:621) gave cursory descriptions of the otoliths of a few plectognaths and said that they "are curiously aberrant in form, showing little affinity with those of the other orders."

In the orbital region there has been much controversy in the literature concerning the bones with which the frontal articulates posteriorly. The difficulty stems from Hollard's (1857b) inaccurate figures of the top of various gymnodont skulls. Gill's $(1885,1892 a)$ reproduction and use of these figures could only lead to erroneous diagnoses, with the tetraodontids being said to have the frontals in contact with the supraoccipital, except for Canthigaster and Chonerhinus, which were supposed to have these bones separated from one another by the intervention of the sphenotics. This erroneous difference between the tetraodontins and canthigasterins was used by Jordan and his associates (Jordan and Edwards 1887; Jordan and Evermann 1898; Jordan and Snyder 1901) and thus it gained popularity. However, Regan (1903a) showed that the differences were purely in Hollard's figures and presented figures of his own which showed the correct relationships of the bones of the top of the skull in a tetraodontin and a canthigasterin. FraserBrunner (1943) used the fact that the sphenotic separates the frontal and epiotic in diodontids as one of the diagnostic characteristics of that group. Sexual dimorphism in the size of the frontals has been pointed out by Ebina (1932) in filefishes, and supposedly by Le Danois (1954) in diodontids. In relation to this discussion of the frontal, it is worthwhile to mention that none of the dermal bones of the head develop in conjunction with the sensory canal system, a fact first stated by Rosen (1916a:20). The dermal bones show no trace of canals, bridges, or troughs that could in any way be associated with the cephalic sensory canal system, which is confined entirely to the skin in plectognaths. Le Danois' (1956) statements to the contrary are unproven.

A basisphenoid is present only in two groups of plectognaths-Triodon and molids. Neither Dareste (1849) nor Hollard (1857b) observed the basisphenoid in Triodon, but that of molids has been described often, although under a variety of names. A few workers have described the anterior region of the prootic in various scleroderms as a “basisphenoid" (Klein 1884; Supino 1905; Rosen 1916a), but, strangely, there has been agreement (as early as Stannius 1854:61) that gymnodonts, except for molids, 
do not possess a basisphenoid. It is indeed food for thought that a basisphenoid occurs only in Triodon, which by all odds is the most primitive of the Recent gymnodonts, and in molids, which are one of the end lines of gymnodont radiation. Starks (1905:755), in discussing the myodome of fishes, noted that "the dichost (=basisphenoid of Huxley) is always absent when the myodome is. I know of no case where it is at all ossifed when the myodome is absent." Molids are thus an exception to the rule. The basisphenoid of Triodon is relatively normal in appearance, but that of molids is expanded anterodorsally until it makes contact with the pterosphenoids (in Mola and Masturus) or frontals (in Ranzania).

In the ethmoid region the size and shape of the ethmoid have been prominently used in the classification of the tetraodontids by Fraser-Brunner (1943). While the ethmoid of tetraodontids is sometimes rather small, by far the most reduced state of the bone is found in diodontids, where there is a thin plate of bone that represents the only remains of the ossifications of the entire ethmoid region of the skull in a position analogous to that of both the vomer and the ethmoid. For that reason, this bone is called here the ethmoid-vomer, supposing that it represents the fused rudiments of both elements. Starks (1926:286) recognized the dual anatomical position of this bone in Diodon, but preferred to call it the ethmoid. It should be mentioned briefly that in Hollard's various publications the medial portion of the plectognath ethmoid was called the "ethmoid," while its lateral portions were referred to as the "nasals." Hollard did not, however, show any sutures between these two regions, so his terminology was undoubtedly based on theoretical considerations. Awati and Bal (1933) divided the ethmoid of their tetraodontid in the Hollardian manner, but referred to the medial portion of the ethmoid as the "lateral ethmoid" and to the lateral portions of the ethmoid as the "nasals." Swinnerton (1902) found the ethmoid and palatine regions of balistids and acanthurids to be similar.

The vomer of tetraodontids and ostracioids is sometimes so closely interdigitated, or even fused, with the ethmoid and parasphenoid that even a relatively knowledgeable worker such as Kaschkaroff (1914a:350) mistakenly said that the vomer was absent in those groups.

In the mandibular region the presence of a symplectic has sometimes been overlooked. Cope (1871:591) stated that in the Physoclisti "the symplectic is present, except in Ostracion, where it is not ossified," but Regan (1903a:290) corrected Cope's error. In view of Regan's statements, it is surprising to find that Kaschkaroff (1914a:352) extended Cope's misstatement to include Triacanthus as well as Ostracion, both of which Kaschkaroff said lacked a symplectic. Raven (1939b:4) said that the symplectic was absent in Ranzania, but figures 316 and 320 given here show it to be long and prominent.

In the palato-pterygoid region the size, shape, and articulations of the palatine have been used as important diagnostic features for a number of plectognath subgroups, sometimes erroneously. A summary of the condition of the palatine in plectognaths, with brief comments on the literature, follows. In triacanthoids the palatine is basically a flattened rectangular or squarish bone with a small posterodorsal lobe about midway along its upper edge for firm anchoring through fibrous tissue with a region of the ethmoid-prefrontal-vomer, while ventrally the palatine is firmly anchored by fibrous tissue with the ectopterygoid, except in the long-snouted species in which it forms a portion of the tubelike snout; an anterior process of the palatine movably articulates with the recessed dorsolateral surface of the maxillary so that the latter can rotate around this articulation and allow for a slight protraction of the upper jaw, except in the long-snouted species in which the protractibility of the upper jaw is not so directly associated with a maxillary-palatine articulation. In balistids what is the squarish ventral portion of the palatine in most triacanthoids becomes shaftlike and the whole palatine T-shaped, with the ventral shaft firmly anchored by fibrous tissue with the ectopterygoid, the posterodorsal end similarly held to the ethmoid and vomer, and the anterodorsal end movably articulated with a slight concavity on the lateral surface of the maxillary, around which point of articulation the upper jaw rotates, without being protracted. In monacanthids the palatine is rodlike, but sometimes with a bulge on its ventral surface representing the long foot of the $T$ as found in balistids, connected ventrally by a long ligament to the anterior edge of the ectopterygoid, while posteriorly the rod is anchored by fibrous tissue to the ethmoid and anteriorly is movably articulated with a slight concavity on the lateral surface of the premaxillary and maxillary.

The differences in the shape of the palatine in the triacanthoids, balistids, and monacanthids have long been known, but with Regan's (1903a) use of these features as diagnostic characteristics an error crept into the literature. Regan said that the triacanthoids had the palatine immovably articulated with the other bones of the skull, but that the balistoids had it either movably articulated with the ectopterygoid (balistids) or entirely free from it (monacanthids), and Fraser-Brunner (1941b) has said much the same thing. The differences in the shape of the bone are real enough, but the palatine immovably articulates with the ectopterygoid and with the ethmoid-vomerine region in all of these groups. It is the firm anchoring of the palatine to these two regions which provides the upper jaw with the immovable prop around which it can rotate. The ventral edge of the palatine and the dorsal edge of the ectopterygoid in triacanthoids and balistids are often not in close contact with one another, but the sheet of tough fibrous tissue that binds the palatine to the ectopterygoid and to the ethmoidvomerine area makes the palatine immovable for all practical purposes.

In ostracioids the palatine is a relatively small and elongate block of bone, representing an enlarged foot of the T-shaped balistid palatine, which is usually extensively interdigitated with the dorsal end of the ectopterygoid and mesopterygoid. The rounded dorsomedial edge of the palatine is firmly held by fibrous 
tissue primarily to the vomer, usually to a slight concavity on the surface of the latter. The palatine is so small and closely apposed to the ectopterygoid that most authors have been noticeably vague about its articulation or even about is presence, although Hollard (1860: fig. 6 of pl. 3) presented an accurate figure of it.

The palatine in the gymnodonts is a much larger bone than it is in the scleroderms. The ventral edge of the palatine in gymnodonts always immovely articulates, usually by interdigitation, with the ectopterygoid. Posteroventrally the palatine articulates with the mesopterygoid, and in some cases with the metapterygoid as well. The anterodorsal edge of the palatine supports the upper jaw, primarily through a flexible fibrous tissue articulation with the concave facet on the maxillary. There is some variability, however, in the immovable articulation of the palatine with the ethmoid region of the skull. In Triodon the medial surface of the palatine articulates with the ethmoid, vomer, parasphenoid, and prefrontal. Rather unexpectedly, the shape and articulation of the palatine in molids is strikingly similar to that in Triodon. The characteristic feature of the palatine in tetraodontids is that its posterodorsal region possesses an anteriorly directed cleft which fits closely around some type of flange on the lateral surface of the vomer. With the almost total reduction of the ethmoid region in diodontids, the palatine becomes extensively interdigitated with the frontals and makes only a secondary and functionally unimportant contact medially with the ethmoid-vomer.

Gregory (1933:287) presented highly diagrammatic figures of the palato-pterygoid region of the skull in Triacanthus, Balistes, Alutera, and Psilocephalus to illustrate the progressive elongation of the snout in that series. Fraser-Brunner (1941a:423) showed, with more detailed illustrations, the changes that take place in the palato-pterygoid region when the same type of elongation of the snout takes place in the triacanthodid genera Johnsonina, Tydemania, and Macrorhamphosodes, while Tyler (1968) did so for all the genera of that family. The figures and descriptions given by Thilo (1920) of the jaws and palato-pterygoid region of Triacanthus, Balistes, and Tetraodon are too crude to be of any value, but those of Winther (1877) are much more useful. Others have presented accurate descriptions and figures of the palato-pterygoid region in particular species, e.g., Steenstrup and Lütken (1898) for Mola, and Supino $(1905,1907)$ for Mola and Balistes.

In the opercular region the length and posterior articulation of the interoperculum have been used as diagnostic familial characters. A summary of the interoperculum in plectognaths with brief comments on the literature follows. The interoperculum is best developed in the triacanthoids, in which it is relatively broad and rounded posteriorly and only gradually tapers to a point anteriorly. Posteriorly the interoperculum articulates closely with the suboperculum. In balistoids the interoperculum is a short rod which never extends posteriorly past the level of the epihyal. The posterior end of the interoperculum in balistoids has its main articulation with the epihyal, while more posteriorly it connects by a long band of fibrous tissue with the operculum, or with the region of articulation between the operculum and the suboperculum. In ostracioids the interoperculum is even slightly shorter than it is in most balistoids, and similarly it has its main posterior articulation with the epihyal. In contrast to the balistoids, however, the long band of fibrous tissue running posteriorly from the ostracioid interoperculum attaches exclusively to the suboperculum, rather than to the operculum or to both the operculum and suboperculum. Among the gymnodonts the interoperculum is relatively long and well developed in all groups, except in the molids. In the latter group the interoperculum is reduced to a thin but sometimes long splint of bone entirely embedded in the long ligament which runs between the angular and suboperculum. In tetraodontids and diodontids the rodlike interoperculum always has a ventral flange in about the middle of its length which articulates by fibrous tissue with the epihyal. The bifurcate posterior end of the interoperculum in Triodon is unique among the plectognaths, with it being hypothesized that the ventral process of the bifurcate portion corresponds to the ventral flange of the interoperculum in tetraodontids and diodontids. The interoperculum articulates posteriorly with the anteriorly directed process of the suboperculum in Triodon, diodontids, and molids, but in tetraodontids it articulates with the operculum.

While many early workers described the unusual shape of the interoperculum in this order, and Dareste (1850) said that it was one of the few characters that the plectognath fishes had in common, it was not until Regan (1903a) that the structure of the interoperculum was used diagnostically for various plectognath subgroups. Regan incorrectly said that in the Sclerodermi the interoperculum was attached to the suboperculum, while in the Gymnodontes it was attached to the suboperculum in all groups except the tetraodontids. Fraser-Brunner (1943) similarly used this supposed difference in the posterior articulation of the interoperculum as a diagnostic character.

In his various publications on the respiratory apparatus of plectognaths and related forms, Willem (1941, $1942,1944,1945,1947,1949)$ pointed out the correlation between the presence of a distensible diverticulum of the oesophagus and the size of the suboperculum (i.e., the suboperculum is relatively well developed in the tetraodontids and diodontids) and discussed the role of the interoperculum in coordinating the opening of the lower jaw with the expansion of the opercular apparatus at the beginning of the inspiration phase of the respiratory cycle.

The structure of the jaws of plectognaths has played such an important role in the diagnoses of various families since the founding of the order that it must be summarized here. Cuvier's (1817) term Plectognathi (from the Greek: plektos, plaited or twisted together; gnathos, jaw) refers to the intimate and inflexible union of the premaxillary and maxillary in all families except the triacanthoids. 
In all plectognaths except the triacanthoids, the upper jaw is nonprotractile and the premaxillary immovably articulates, usually by extensive interdigitation, with the maxillary. In triacanthoids the premaxillary and maxillary movably articulate with one another and the upper jaw is slightly protractile. The premaxillary of triacanthoids is more or less L-shaped, with the long arm of the $\mathrm{L}$ forming the posteriorly directed ascending process which slides over the dorsal surface of the ethmoid in the process of protracting and retracting the upper jaw. In balistoids and ostracioids the posteriorly directed process of the premaxillary is essentially absent, and the posteromedial end of the premaxillary articulates with the anterior edges of the ethmoid and vomer, particularly with the former. Along its anterior edge the premaxillary of the scleroderms bears a variable, but usually small, number of discrete teeth. The premaxillary of gymnodonts is modified, in conjunction with the teeth, into a crushing plate which is often and aptly referred to as a parrotlike beak. The posteromedial end of the premaxillary articulates with the ethmoid, and to a lesser extent with the vomer, in Triodon, but in most tetraodontids this articulation is primarily with the vomer. In Triodon and in the tetraodontids the medial edges of the two premaxillaries are closely apposed and articulate with one another by fibrous tissue. Emarginations from the medial surfaces of each of the premaxillaries in tetraodontids alternate with one another and strengthen the articulation between the two elements. In diodontids and molids the two premaxillaries are indistinguishably fused together into a large U-shaped bone.

Hollard (1857b:308) did not believe that fusion of the premaxillaries, or dentaries, was a character of much systematic importance, possibly because it was known that the premaxillaries and dentaries of extremely large specimens of tetraodontids occasionally fuse together in the same way as do those of diodontids. More interesting, however, is Reuven's (1894:130) observation of a phenomenon in Mola of just the opposite nature to that occasionally observed in tetraodontoids. In his description of a young Mola, Reuven said that he "found that the maxilla superior is splitted up in the middle, the inferior is not cleft," and a figure was presented (pl. 5) to show this "tetraodont" condition of the upper jaw. Hollard's view that too much importance has been attributed to the fusion of the premaxillaries, or dentaries, as a major indicator of phylogenetic affinity seems well taken. It might be mentioned here that the premaxillary and maxillary are often said to be fused or coalesced, when in actuality they, at least in the great majority of instances, only extensively interdigitate with one another. Only very rarely is an extremely large specimen of a tetraodontid or diodontid found in which the premaxillary and maxillary are for all practical purposes fused. One of the more extreme statements about the fusion of the various jaw bones in plectognaths is that of Wagner (1845:190) who said that the upper jaw bone "coalesces with the vomerine, palatal and nasal bones to form a single bone, which unites, however, with that of the other side by suture, as in Orthagoriscus." Such a condition would certainly be the death of any plectognath and whether Wagner had ever actually examined a molid is problematical, although he had (1841) once presented a figure of the skeleton of a balistid.

Only in the triacanthoids is the maxillary movably articulated and not closely apposed to the premaxillary, for in all other plectognaths the maxillary firmly articulates, usually by extensive interdigitation, with the premaxillary. In triacanthoids the lateral surface of the rounded dorsal end of the maxillary movably articulates with the anterior process of the palatine. In balistids the palatine articulates with a slight concavity on the surface of the maxillary and premaxillary, but in monacanthids the maxillary scarcely makes contact with the palatine or is even entirely excluded from articulation with it. With reduction of the palatine in ostracioids the maxillary articulates with only the anterior edges of the vomer and ethmoid. In gymnodonts the maxillary always articulates over a broad, and usually slightly concave, area with the anterodorsal end of the palatine, and it is this articulation which is the major source of support for the upper jaw in gymnodonts. In triacanthoids the support of the upper jaw is shared about equally between the articulation of the maxillary with the palatine and the articulation of the premaxillary with the ethmoid and vomer, but in balistoids the palatine-maxillary articulation becomes progressively less important and in ostracioids it is completely absent. The posterior edge of the maxillary of most balistoids and ostracioids bears an indentation which is characteristic of these two groups, but not of the other plectognaths. The lateral surface of the maxillary is relatively flat in all plectognaths except the diodontids, in which this surface is upraised into a stout flange for muscle attachment. The lower end of the maxillary forms the lower part of the anterior edge of the upper jaw in all plectognaths. Among Shufeldt's (1917) nearly totally erroneous observations on the osteology of Diodon, there occurs the statement that an "admaxillary" is present on the dorsal edge of each maxillary, but since no description or illustration was given of this structure, that author's statement is best forgotten, as is his other work (1926) on plectognaths.

In scleroderms the teeth are usually few in number but they are always individually recognizable units. In the gymnodonts, however, the teeth are so highly modified that they are scarcely recognizable as such. The number and shape of the teeth in the jaws are discussed in the diagnoses of the familial groupings recognized here and are summarized below.

The number and shape of the teeth vary most in the triacanthodids, and Günther (1870), Myers (1934), Fraser-Brunner (1941a), and Tyler (1968) have all made prominent use of dental formulae in their revisions of the family. The teeth of Recent triacanthodids are usually conical and usually occur in a single series. This outer series contains the majority of teeth, which usually vary in number from about 10 to 50 , but with reduced num. bers (sometimes absent) in the long-snouted genera. When teeth in an inner series are present, in the more 
generalized genera, they vary from 1 to about 10 in number. The teeth of the upper and lower jaws are basically similar, but there are usually a few more teeth in the lower jaw than in the upper. In a few moderately to highly specialized genera the teeth are truncate rather than conical, while the fossil genera sometimes have enlarged teeth.

In triacanthids there is an outer series of about 8 to 10 heavy incisors in each jaw, internal to which are several more or less molariform teeth, usually 4 ( 2 in one genus) in the upper jaw and 2 in the lower. The structure and number of the teeth in balistids are strikingly similar to those found in triacanthids, for in balistids the heavy incisors invariably (with rare individual exceptions) occur in an outer series of eight teeth and an inner series of six teeth in the upper jaw, while in the lower jaw there is only a single series (corresponding to the outer series of the upper jaw) of eight teeth. The number of teeth becomes further reduced in monacanthids to six in an outer series in the upper jaw and six (sometimes only four) in the outer series of the lower jaw, with an inner series of four teeth in the upper jaw and no inner series teeth in the lower jaw.

The dental formulae of the various balistoids have been common features of the diagnoses of that group ever since the time of Bleeker (1866:8-10), who was the first to give prominent attention to these differences. The development of balistoid teeth from deep sockets in continuity with the pulp cavity was accurately described for the first time by Owen (1840 \& 1845:82-85). Goodrich (1909:438, fig. 448) gave a figure of the replacement teeth developing in Balistes, and Isokawa (1955) presented a description of the general development and histology of the teeth in monacanthids. The teeth of ostracioids are elongate and rodlike, with between 6 and 17 teeth in a single series in each jaw.

The teeth of gymnodonts are so highly modified that they have attracted a great deal of attention in the literature. There is, however, a phyletically important distinction to be made about the teeth of the various gymnodont subgroups which usually is not clearly stated. In Triodon and diodontids the teeth always take the form of relatively small and discrete units which become densely packed with one another and incorporated with the bony matrix of the premaxillary and dentary. In tetraodontids the teeth are relatively more discrete long rods which lie parallel to the biting edge of the jaws. There are no discrete teeth present in the jaws of molids, nor can any individual tooth primordia be found in the pulp cavity. The intimate incorporation of the teeth with the bony matrix of the premaxillary and dentary has reached its zenith in the molids, and one can only speculate that the highly irregular surface of the floor of the pulp cavity, with its numerous individual "tooth" or bone forming cavities, indicates that the molid condition has evolved from the Triodon and diodontid type rather than from the tetraodontid type.

The structure, and even the mere presence or absence, of a trituration plate is also of diagnostic interest. In Triodon a trituration plate composed of right and left halves is present in the upper jaw, while the trituration plate of the lower jaw is undivided. In both jaws about five individual teeth can be seen at the posterior edge of the trituration plate to each side of the midline. In diodontids and molids there is a trituration plate in each jaw, but the number of dental units that go into its make up differs. In diodontids there is a single dental unit along the posterior edge of each half of the trituration plate in each jaw, except for one species with several dental units. In molids there is a single dental unit along the posterior edge (and sometimes anteriorly) of each half of the trituration plate in the upper jaw, but in the lower jaw several such teeth are present.

Steenstrup and Lütken (1898) described the differences between the trituration plates in two genera (Mola and Ranzania) of molids, as did Hilgendorf (1893). Wahlgren (1867) gave one of the earliest and best descriptions of the trituration plate in Mola, and his figure of that structure was reproduced by Steenstrup and Lütken. Trituration plates are never developed in canthigasterins, but, contrary to Fraser-Brunner (1943), they are sometimes present in tetraodontins. In the upper jaw of many tetraodontids there is a single longitudinal series of a small number of teeth, to each side of the midline. In the lower jaw, however, these trituration teeth are of less frequent occurrence. They have been reported in the lower jaws of several tetraodontids by Kaschkaroff (1914a:317-318), in the lower jaw of the tetraodontid Colomesus by Pinto (1959), and in many other tetraodontids described here. There are a number of papers describing the general structure of the teeth in plectognaths to which the reader should be referred before passing on to other topics. Cuvier (1805, vol. 3) gave descriptions of the gross morphology of the teeth in plectognaths, but it was not until Owen (1840 \& 1845) that their detailed structure was made known. Owen took exception to the view advocated by Cuvier (1805, 3:125) and by Born (1827) that the dental lamellae in gymnodonts develop by the "apposition or the transudation of layers of calcareous matter from the pulp's surface" (Owen 1840:77). On the contrary, Owen showed that these lamellae developed by "intus-susception or the deposition of calcareous tubes in the pulp's substance." Owen pointed out that whereas the teeth of the biting part of the jaws in diodontids and tetraodontoids were different, there was a marked similarity between the dental lamellae of the trituration plate of diodontids and the elongate dental lamellae of the biting portion of the jaws in tetraodontids. A more modern treatment of the general anatorny of the teeth in gymnodonts is that presented by Pflugfelder (1930), Andreucci (1966a, b, 1967a, b, 1968a, b, 1969, 1970), Andreucci and Britski (1968a, b, 1969a, b, 1970, 1971), and Andreucci and Blumen (1971). The rodlike structure of the dental units of tetraodontids and the platelike trituration lamellae have been described by a number of workers other than those mentioned above, notably by Goodrich (1909), Ghigi (1921), and Tretjakoff (1926c). Jenyns (1842:150) was probably the first to call attention to the discrete dental units that are visible on the external surface of the 
crushing beak of diodontids in his description of a species of Diodon: "the true teeth appear on the surface of the jaws like minute scales, as in several species of the genus Scarus."

It will be recalled that Regan (1903a) placed the genus Triodon in the Sclerodermi, and, as a consequence of this, it was necessary for him to state (p. 285) that "the coalescense of the teeth in the jaws is a feature of little importance, and has, as probably as not, originated independently in ... [the Sclerodermi] ... and in the Gymnodontes." That view is not followed here, as the placement of Triodon in the Gymnodontes indicates.

For a discussion of the surface structure of plectognath teeth in relation to sound production by stridulation the reader is referred to Burkenroad (1931:22-24), Fish et al. (1952:189-190), Fish (1954:62-77), Moulton (1958:359-362), and Vincent (1963).

The two dentaries are indistinguishably fused with one another in Triodon, diodontids, and molids. The fibrous tissue articulation of the two dentaries in tetraodontids is strengthened by emarginations from the medial edges of the two bones, just as is the case with the premaxillaries.

In triacanthodids and molids the articular and dentary are firmly held to one another mainly by fibrous tissue, but in other plectognaths there is normally an extensive interdigitation between the surfaces of these two bones. It is not true, however, that the dentary and articular are fused into a single piece, as was maintained by Gill (1872:XL; 1885:412) for plectognaths in general, and as Smith (1935:359) gave as a characteristic of the balistoids. Regan (1903a:286) correctly stated that the dentary and articular are not fused in the gymnodonts, but, rather unaccountably, he agreed with Gill that these two bones are fused in the scleroderms. In the descriptions of the representative plectognaths given here no attempt is made to differentiate between a dermal and an endochondral portion of the articular, for this requires histological study of the developing bone for consistant accuracy. Only two papers in the literature treat this subject in plectognaths. Rosen (1916a:19) simply said, without any elaboration, that in Sphoeroides the "articulare develops as an autarticulare and a dermarticulare." Haines (1937:14-21) gave a detailed description of the growth and fate of Meckel's cartilage and the surrounding ossifications in Tetraodon, and concluded that the endochondral portion of the articular was either greatly reduced or absent. The sesamoid articular is present in all plectognaths, except some tetraodontids and molids. It has been described in a number of different plectognath genera by Starks (1916:32-33), who said that in Sphoeroides annulatus "the sesamoid articular more evidently originates within the tendon than in any other examples I have encountered."

With the exception of Ranzania, which has lost the sixth branchiostegal ray, all gymnodonts have six such rays, and statements in the literature giving a lesser number probably reflect the loss of a ray during dissection, while Hubbs (1919:69) pointed out that "in Tetraodon the uppermost ray basally is an unossified liga- ment," which is true also of some other tetraodontids where the sixth ray tends to be an especially slender shaft. McAllister (1968) accurately surveyed the number of branchiostegal rays and the structure of the hyoid arch in a wide selection of plectognaths, far more so than ever previously attempted, and found them to be related to the acanthopterygian type.

Wellenbergh (1840) gave an accurate description and figure of the six branchiostegal rays in Mola, but Kaschkaroff (1914a:282) and Van Dobben (1935) stated that there are only five branchiostegal rays present in Mola. Roon and Pelkwijk (1939) and Roon (1942) have again called attention to the fact that there are six branchiostegal rays in Mola. Thilo (1899a, 1914) first pointed out that species such as Stephanolepis setifer and Brachaluteres trossulus possess only five branchiostegal rays. In contrast to Ranzania, however, it is not the sixth branchiostegal that is lost; rather, it is the second branchiostegal. The branchiostegal counts given by Willen $(1941,1942,1944,1945,1947,1949)$ are not reliable. He said that there were six branchiostegals in Triacanthus, Monacanthus, Ostracion and Mola, but that there were seven in Balistes and five in Tetraodon and Diodon. The supposed "seventh ray" of balistids was neither figured nor well described, and it is only possible to guess that Willem may have mistaken the rodlike interoperculum for a seventh branchiostegal.

The branchial region is one of the most neglected anatomical systems of fishes, for cleared and stained specimens and especially delicate dissections are required, although Nelson (1969 et seq.) has made great strides in rectifying this situation. In plectognaths the extensive variation in branchial structure reported here (Table 1) forms an important part of the diagnoses of the higher categories recognized and of the phylogenetic interpretations offered, and yet the only previous survey of the plectognath branchial apparatus is the cursory one by Kaschkaroff (1914a). There are, however, a few papers containing descriptions of the branchial or hyoid arches of particular genera, such as Awati and Bal (1933) for Tetraodon, Borcea (1907) for Balistes, Steenstrup and Lütken (1898) for Mola, Supino (1905) for Balistes and Mola, and Wellenbergh (1840) for Mola.

The condition of the plectognath branchial apparatus, with comments on the literature, is summarized below. A basihyal is always present but the dorsal hypohyal is absent in many tetraodontids and a few diodontids. The hypohyals are enlarged in ostracioids, and it was probably the size of the dorsal hypohyal that lead Hörshelmann (1866:23) to say that Ostracion possessed a tongue while the other plectognaths did not.

The ceratohyal and epihyal are always present, while the interhyal is absent in diodontids and most tetraodontids. The urohyal is well developed only in triacanthoids and balistoids, although it is present in a muchreduced state in ostracioids and in Triodon. The branchiostegal rays usually are present in the $2+4$ arrangement typical of percoid fishes (Hubbs 1919), although the second and sixth branchiostegal rays are absent in a few species of monacanthids and aracanids, and 
the sixth absent in one of the molids. There are a number of diagnostically important differences given here in the manner by which the branchiostegal rays are articulated to the ceratohyal and in the form of the modified first branchiostegal ray of many gymnodonts.

Thilo (1899b, 1914) drew attention to the obvious correlation between the presence of an inflation mechanism in many gymnodonts and the enlargement of the first branchiostegal ray, and described the pumping action of that platelike element. Thilo (1914) contended that when the distensible diverticulum of the oesophagus is not well developed (as in Fugu rubripes and Lagocephalus scleratus, according to Thilo) the first branchiostegal ray is as small as it is in most balistoids. Thilo is guilty of exaggeration, for the first branchiostegal ray in those two species is much larger than it is in any balistoid, even though it is somewhat reduced in size from that seen in more typical gymnodonts.

There are always three basibranchials (except in the monacanthid Psilocephalus with two), three pairs of hypobranchials, five pairs of ceratobranchials, and four pairs of epibranchials (except in Psilocephalus with three), but the number of pharyngobranchials is variable and of much diagnostic interest. There are always at least two pharyngobranchials, those of the second and third arches, except that in diodontids they are of the first and second arches. The pharyngobranchial of the first arch is absent in monacanthids, molids, and some ostraciids, while that of the fourth arch is absent in balistids, monacanthids, ostraciids, tetraodontids, and diodontids and that of the third arch absent only in diodontids. The dentition of the pharyngobranchials is also of great diagnostic use, for teeth are present on the pharyngobranchial of the first arch in diodontids and some tetraodontids, on that of the second arch in all but a few aracanids, on that of the third arch in all but some ostraciids and diodontids, and on that of the fourth in triacanthodids, triacanthids, aracanids, triodontids, and molids. The fifth ceratobranchial is toothed in triacanthodids, triacanthids, balistids, triodontids, and, with minute teeth, in a few diodontids.

In Canthigaster the first three ceratobranchials are more compressed and deeper than in other tetraodontids, while in molids the ceratobranchials are so deep that in Mola they have been called (Barnard 1935:657) "knife-like bones." These support the enormous gills of molids, which were well illustrated as long ago as Alessandrini (1839). The first pharyngobranchial in triacanthoids, balistoids, and triodontids is usually a toothless, often rodlike, suspensory element.

Grieb (1935) has said that teeth are present on the lower pharyngeals of "Spheroides sp.," but that has not been found to be the case in any tetraodontids examined here. The reader is referred to Al-Hussaini (1947) for an interesting discussion of the correlation between diet, length of intestine, and development of pharyngeal teeth in a number of plectognaths. Iwai (1964) has carefully surveyed the taste buds on the gill rakers and gill arches of Fugu and Rudarius.

In the pectoral girdle the position of the supracleith- rum varies from more or less vertical in scleroderms to being obliquely placed in relation to the skull in triodontids and tetraodontids, while in diodontids and molids it is almost horizontal to the skull. Regan (1903a) used the position of the supracleithrum as one of the distinguishing features between the Sclerodermi and Gymnodontes.

It was probably Gill $(1872,1885)$ who made best known that there is some rudiment of a posttemporal present between the supracleithrum and pterotic in at least some plectognaths, and much the same was said by Regan (1903a:285), Rosen (1916a:21), and Berg (1940:495). Even though relatively small and closely sutured and interdigitated to the skull, careful examination reveals its presence in all scleroderms except one monacanthid, and its absence in all gymnodonts.

Siebenrock's (1901) descriptions of the pectoral girdle in a number of plectognaths are so erroneous that they are useless, and Regan (1903a:291) called attention to the incorrectness of Seibenrock's contention that the supracleithrum of Mola was really a posttemporal. Sorensen's (1883) mainly myological description of the pectoral region of Tetraodon is highly detailed.

Both the dorsal and the ventral postcleithra are present in most plectognaths as distinct elements, but in monacanthids, diodontids, and molids the two elements tend to indistinguishably fuse. Fraser-Brunner (1941c:307) used size of the postcleithra as one characteristic to distinguish aracanids from ostraciids. The suture between the dorsal and ventral postcleithra is difficult to trace in many ostracioids, and it is possible that the two elements occasionally fuse together. The anteriorly directed process, which lies just lateral to the actinosts, of the fused postcleithra of molids is a diagnostic feature of that group. Kuronuma (1943) has used the shape of the ventral postcleithrum in tetraodontids as a systematic character and Parr (1927) gave an interesting discussion of the function of the postcleithra in gymnodonts, while Winterbottom (1971) has thoroughly surveyed the matter. Thilo (1899b) was surely in error in saying that the postcleithra could be moved through an arc of $90^{\circ}$. The role played by the postcleithra and cleithra in sound production has been discussed by Möbius (1889), Cunningham (1910:117), and Fish (1954:69). For a general survey of the endochondral bones of the plectognath pectoral girdle the reader is referred to Starks' (1930:206-210) excellent work on that subject. Sound production by pectoral fin drumming is reviewed by Salmon et al. (1968), and by this and other methods by Schneider (1961).

The scapula completely encloses the scapular foramen in most scleroderms and in Triodon, but in tetraodontids and diodontids the foramen is incomplete, being enclosed by both the scapula and the cleithrum. In molids the scapular foramen is essentially absent or highly incomplete, being represented only by a small hole in the sheet of fibrous tissue holding the bottom half of the scapula to the cleithrum. In scleroderms and in Triodon the dorsal edge of the scapula always bears an emargination to which is attached the first pectoral fin ray, but in the other plectognaths no such emargination is present. Four 
actinosts are present in all plectognaths, except in molids, which have three.

The close connection of the scapula with the first actinost is such that Regan (1903a:291) drew attention to the fact that "On a superficial examination there appears to be no scapula, and the pectoral fin to be supported by a series of four enlarged pterygials. In fact, the united upper pterygial and scapula together resemble one of the enlarged pterygials." Even after this statement, others (e.g., Kaschkaroff 1914a:355; Awati and Bal 1933:91) continued to misidentify the actinosts and scapula. On the other hand, Regan's (1903a) statement that the scleroderms have the "pterygials (pectoral basalia) not enlarged, movably attached by ligament to the scapula and coracoid, three to the former and one to the latter" (p. 286) while the gymnodonts have the "lower three pterygials enlarged and immovable united to the coraco-scapula" (p. 291) is only partially true (see above). In molids what was the first actinost of other plectognaths is either lost or fused with the scapula, so that only three actinosts are present. Somewhat understandably, a number of workers have mistaken the scapula of Mola for an actinost and have concluded that Mola possessed four actinosts and no scapula. However, Gregory and Raven (1934:148) described Mola as having four actinosts (i.e., three actinosts and a scapula), as well as a "vestigial scapula" represented by a "bone which is crowded between the expanded first pterygial and the posterior recurved border of the cleithrum." It is impossible to state what it was that Gregory and Raven saw, for their description is brief and there is no illustration of the vestigial scapula.

The structure of the pelvis and pelvic fin in plectognaths has been the cause of much confusion in the literature, for the relatively normal pelvic apparatus of triacanthoids is replaced by a highly modified and specialized structure in balistoids that has been often misinterpreted. Tyler (1962b) has surveyed in detail the reduction and eventual loss of the pelvic apparatus in plectognaths, and these features are used prominently in the diagnoses given here, while Winterbottom (1970) surveyed the muscles of the triacanthoid pelvic fin. The locking mechanism of the triacanthoid pelvic spines (continuous series of positions of erection in triacanthodids and two positions in triacanthids) is also treated by Tyler (1962b). Hollard (1853:107) and Thilo (1896a, 1896b:327, 1898, 1899a, 1900) incorrectly described only a single position of erection in Triacanthus, but the twoposition mechanism has been correctly described by Sorensen (1884:69, 1897) and Monod (1959c).

The true nature of the rudimentary pelvic fin element in balistids was first made known by Monod (1959a), in excellent style for Balistes forcipatus.

As detailed in the accounts of each family given here, the number of vertebrae in plectognaths varies from 16 to 30 (Table 2) but is usually less than 24 and normally in the range of 17 to 21 , while the structure of the vertebral column is highly modified in some groups, especially the ostracioids (Tyler 1963a) and molids. In aracanids the first two, and in ostraciids the first four or five, ab- dominal vertebrae are at least partially fused to the skull, and the whole vertebral column is relatively inflexible except in the caudal peduncular region extending outside of the carapace. Another unusual feature of the ostraciid vertebral column, first pointed out by Fraser-Brunner (1941c:307), is that the course of the haemal canal is displaced to one side or the other from the midline, while Tyler (1963a) called attention to the uniquely divergent positions away from the midline of the anal fin basal pterygiophores. Abe (1942) presented an extensive study of the variation in the form and number of elements of the tetraodontid vertebral column. Ford (1937) compared the balistid and zeoid vertebral columns.

The fact that true or pleural ribs are found in the monacanthid Pseudaluteres and in the gymnodont Triodon negates Regan's (1903a:285) statement that “the feature of most importance in diagnosing the suborder Plectognathi is the absence of ribs."

The sequence of vertebrae to which the epipleural bones are attached is a character of systematic importance, as first shown by Fraser-Brunner (1941b:176) in his differentiation of the triacanthodids from the triacanthids and of the balistids from the monacanthids. The epipleurals in some monacanthids tend to become swollen (hyperostotic) and closely applied to the transverse processes of the vertebrae, and it is not surprising that they have been misinterpreted (e.g., Smith 1935). The development of the epipleurals has been studied in several monacanthids by Göeppert (1895) and Goette (1879).

The structure and reduction in number of elements in the caudal fin supports is documented by Tyler (1970b), while comments are given by Pope (1945), Okada (1950), Randall (1964), and Tyler (1970d) on abnormalities of vertebral structures. The work of Abe (1949b) should be consulted for a detailed survey of hypural fusion in tetraodontids. The description given by Whitehouse (1910) was one of the earlier accurate accounts of a balistid caudal skeleton. Monod (1968) accurately surveyed and illustrated the ural structures of a wide variety of plectognaths, and agreed with Dareste (1850) and Le Danois (1955) that the triacanthoids and balistoids are not closely related to the ostracioids and gymnodonts (the Orbiculates).

Gosline (1961:269) pointed out that "there seems to have been a general trend toward fusion of parts in the caudal skeleton of teleostean fishes that has occurred repeatedly and independently in various lineages." The Plectognathi are certainly a perfect example of this, since there are several uroneurals, one epural, and six hypurals in the primitive triacanthodids, but the number of elements becomes reduced in the triacanthid-balistidmonacanthid series and becomes even more reduced in the ostracioids. The same reduction takes place independently in the gymnodonts. Gosline said that the caudal skeletons of Zanclus, Acanthurus, and the plectognath fishes form a series, but Monod (1959b:728) has said that the caudal skeleton of Acanthurus and Balistes are "toutefois profondément différente" and thus the 
acanthurids and balistids "ne sauraient être tenues pour très éloignées." What Monod did not realize was that if the caudal skeleton of a triacanthodid is compared with that of an acanthurid, one finds the two to be rather similar.

Just as the number of epurals, uroneurals, and hypurals becomes reduced in the more specialized plectognaths, so also the number of caudal fin rays becomes reduced. In triacanthoids and balistoids there are 12 caudal fin rays; the uppermost ray and the lowermost ray unbranched, the others branched (except Psilocephalus). In aracanids there are 11 rays, but in ostraciids the number is further reduced to 10. As with the other scleroderms, the uppermost ray and the lowermost ray are unbranched, but the others are branched. Triodon has 12 principal caudal fin rays, but in addition to these it also possesses a series of procurrent rays. Triodon is thus the only Recent plectognath with more than 12 fin rays in the caudal fin, but its number of principal caudal fin rays is still the same as in triacanthoids and balistoids. In tetraodontids there are usually 11 caudal fin rays; the uppermost ray and the lowermost two rays unbranched, the others branched. As a part of his long and useful series of papers $(1942,1944,1949 a, 1950-51,1952,1954,1960)$, Abe extensively and accurately surveyed the variability of the caudal fin rays $(1949 \mathrm{~b})$ in tetraodontids, showing the $\mathrm{i}, 8$, ii arrangement to be the normal condition for all of the numerous species he studied. In diodontids the number of caudal fin rays is either 9 or 10 , with the uppermost ray and the lowermost ray unbranched, and the other rays branched.

The complicated subject of the pseudocaudal fin of molids can only be summarized here. A number of early workers (Wellenbergh 1840; Goodsir 1841; Cleland 1862; Wahlgren 1867; Putnam 1871) gave brief descriptions of the highly modified structures of the caudal fin of molids, but it was not until Ryder's (1886) work that the origin of this fin was adequately discussed. Ryder described some of the developmental stages of the molid caudal fin and came to the conclusion that that structure was a gephyrocercal tail; the true caudal fin having been lost and replaced by posteriorly migrated dorsal and anal fin rays. Ryder said that molids and carapids were the only two groups with gephyrocercal tails. Ryder's opinion did not meet with unanimous acceptance, and Kaschkaroff (1914a), Grenholm (1923), and Gregory and Raven (1934) continued to describe it as a true caudal fin, while Whitehouse (1910) and Regan (1910) both agreed that the structure was a gephyrocercal tail. With typical thoroughness, Gudger (1935; 1936; 1937a, b, 1939) and Gudger and MacDonald (1935) reviewed the literature on the subject and also personally examined a few developmental stages of molids. Gudger came to the conclusion that both Mola and Masturus have a gephyrocercal tail, and Raven (1939a) agreed with that analysis. Raven (1939b) described the tail of Ranzania as also being gephyrocercal. FraserBrunner (1951) was in basic agreement with Gudger and Raven on this subject, but Fraser-Brunner stated that the few fin rays that are found in the "nipple" part of the tail of Masturus are the remnants of the true caudal fin rays, whereas the rest of the caudal structure is gephyrocercal. In short, there is general agreement that the entire caudal structure in Mola and in Ranzania is gephyrocercal, and that in Masturus at least the great majority of the caudal structure is gephyrocercal. It is also agreed that the bony supporting elements of the pseudocaudal fin in molids are posteromedially migrated dorsal and anal fin basal pterygiophores. Owen's (1846:64) description of these pterygiophores as "rudimental vertebrae ... blended together at right angles to the rest of the column" does not seem plausible. The variability in the number of fin rays said to be present in Mola (summarized by Beauregard 1893) attests to the fact that it is difficult to delimit the pseudocaudal fin from the dorsal and anal fins, as well as to the fact that a great many of the descriptions of Mola in the literature are actually based on Masturus (summarized by Gudger 1937a). To complicate matters even more, Fraser-Brunner (1951) attempted to distinguish two species of Mola, partially on the basis of the number of fin rays borne on modified basal pterygiophores. Barnard (1935) has pointed out the diagnostic value of the degree of branching of the fin rays of the pseudocaudal fin in molids.

The dorsal and anal fins, and especially the dorsal fin spines, being highly visible and variable between groups of plectognaths, have been featured prominently in nearly all diagnoses, including here, as summarized below.

In triacanthodids there are six dorsal fin spines supported by five basal pterygiophores, with the first two spines always prominent and visible externally, the third to fifth either normally developed or rudiments buried beneath the skin or barely protruding to the surface, and the sixth spine either a short protruding element or a rudiment buried beneath the skin or barely protruding to the surface. There are 12 to 18 dorsal fin rays and 11 to 16 anal fin rays in Recent species.

In triacanthids there are nearly always six dorsal fin spines, except that the fifth and sixth spines are sometimes absent in one Recent species and perhaps in several fossil forms, supported by four, rarely only three, basal pterygiophores, with the first four spines always visible externally, the fifth spine usually very short but nearly always protruding at least a short distance through the skin, and the sixth spine nearly always present as a buried rudiment. There are 19 to 26 dorsal fin rays and 13 to 22 anal fin rays.

In balistids there are three dorsal fin spines, the second more than one-half the length of the first, supported by two basal pterygiophores and a supraneural strut. In monacanthids there are usually two dorsal fin spines, but sometimes only one, the second spine, when present, not more than one-third the length of the first, with both spines supported by a single basal pterygiophore, without a supraneural strut. In balistoids there are 23 to 52 dorsal fin rays and 20 to 66 anal fin rays. The locking mechanism of the spines of triacanthoids is described by Tyler (1968), and that of balistoids by the references given in the description of Balistapus undulatus.

In ostracioids there is no spiny dorsal fin, and the dor- 
sal and anal fins are both short-based, with 9 to 13 rays each.

Among the gymnodonts only Triodon has even a trace of a spiny dorsal fin, as a minute structure composed usually of two spines, occasionally only one but with possible rudiments of a third spine, borne on two basal pterygiophores, present in most specimens of one of the populations (Indonesia to Japan) of the single species, with the second basal pterygiophore succeeded by two supraneural elements.

It is possible that the supraneural elements in gymnodonts are rudiments of the basal pterygiophores of the now absent spiny dorsal fin. The structure and position of the single supraneural element in tetraodontids give no indication of its possible derivation from a spiny dorsal fin pterygiophore, but the structure and number of the supraneurals in Triodon are reminiscent of the spiny dorsal fin pterygiophores of triacanthids. An at least analogous situation is present in ostracioids, for the aracanids have a very long supraneural element which extends throughout almost the entire distance between the supraoccipital and soft dorsal fin, but in ostraciids this supraneural is short and confined to a position just in front of the soft dorsal fin.

One should refer to Bridge (1896) and Rosen (1916a) for descriptions of the cartilaginous distal pterygiophores in the dorsal and anal fins of several plectognaths. Hora's $(1924,1925)$ descriptions of Kanduka as a genus of tetraodontid without a dorsal fin and with the anal fin at least rudimentary, if not absent, are to be looked upon skeptically. His two small (14 and $54 \mathrm{~mm}$ SL) specimens were highly inflated, and the fins were undoubtedly hidden beneath the skin. The fact that Hora's radiographs did not show these fins probably only means that the pictures were overexposed and that the specimens were still weakly ossified.

Much has been said in the literature about the general structure of the bones of plectognaths. Some of the early workers obviously thought the plectognaths to be similar to the "cartilaginous" fishes, probably because of the relatively late ossification of the bones that is seen in some plectognaths and because of misinterpretation of the spongy nature of the ossifications in Mola and of the large amount of cartilage that is present even in the adult Mola. The consensus, however, seems to be that while many plectognaths simply have a relatively late ossification of the endochondral bones of the skull, the composition of the ossification is normal. This is more or less what Cuvier (1817:144) said in his definition of the Order Plectognathi. The principal references to the histology of the bones of plectognaths are the following: Quekett (1850-1855, bones of a number of plectognaths), Leydig (1857, bones of Mola), Kölliker (1859, bones of numerous plectognaths; 1860 , bones of Mola), Harting (1865, bones of Mola), Goette (1879, epipleurals of Monacanthus), Trois (1883-1884, bones of Ranzania and Mola), Goeldi (1884, general bone structure in Balistes), Göeppert (1895, development of epipleurals of Monacanthus), Stephan (1900, bones of Mola, Tetraodon, and Balistes), Supino (1904, bones of Mola), Nowikoff (1910, bones of Mola), Kaschkaroff (1914a and 1925, bones of numerous plectognaths; $1914 \mathrm{~b}$ and 1916, bones of Mola), Studnička (1916, bones of Mola), Rauther (1927b, epipleurals and vertebrae of Monacanthus), Haines (1937, Meckel's cartilage in Tetraodon).

The literature on the muscles of plectognaths has been thoroughly reviewed by Winterbottom (1974) and duplication of that laudable effort is avoided here.

The smatterings of information available on other systems (such as the blood-vascular, digestive, renal, neural, chromosomal, cellular, physiological, developmental, etc.) are too incomplete for plectognaths to be of immediate value to the present studies, and this literature will not be routinely reviewed here. It will be analyzed in a forthcoming synopsis of the biological data on plectog. naths, and specific papers will only be cited here if they have direct bearing on other matters discussed.

\section{Relationship of the Plectognathi to the Perciformes}

As indicated in the historical review of the classification of the Plectognathi, it is commonly thought that the plectognaths are a derivative of the perciform fishes, and perhaps most closely related to the acanthurid surgeonfishes. The features of the osteology of the Recent acanthurids most pertinent to an interpretation of their classification and interrelationships have been reviewed by Tyler (1970c), aiming especially at ascertaining what is generalized versus specialized in that family. The complementary analysis of the fossil forms of acanthurids is not yet completed, and the necessary comparisons between them and the fossil plectognaths studied here, especially those of both groups from the Eocene, must await a subsequent publication under preparation by J. Blot (Mus. Nat. Hist. Nat., Paris) and the author.

However, as indicated by Tyler (1968), it is obvious that the skeletal structure of acanthurids is not far removed from that of triacanthoids, the basal plectognaths, differing mainly in the presence of a number of bones absent in triacanthoids and in a greater number of certain meristic elements. In general appearance the acanthurid skeleton is closer to that of triacanthids among the plectognaths rather than to that of the more generalized triacanthodids. This might suggest that if the triacanthoids and thus the other plectognaths share a common Upper Cretaceous ancestral stock (as suggested by Patterson 1964:400) with the acanthurids, that the Recent acanthurids are not as generalized a group as the triacanthodids are relative to the triacanthids.

Acanthurids differ most significantly from plectognaths by having: two or three anal fin spines (none in plectognaths); a relatively better developed pelvic fin varying from I, 5 to $I, 3$, with the rays cross-striated and branched (one spine followed by, at the most, two much 
smaller unbranched rays without cross-striations in Recent triacanthodids, but with the Eocene Eoplectus having a spine and four long branched and presumedly cross-striated rays); 16 principal caudal fin rays (12 in triacanthodids, the maximum for the order); the presence of a folding spine or fixed plates on the caudal peduncle (folding spine lacking in all plectognaths but with fixed plates in some scleroderms); a complete series of suborbital bones (none in plectognaths); nasal or other bones lateral to the ethmoid and anterior to the prefrontal (none in plectognaths); parietals (none in plectognaths); true or pleural ribs (lacking in all plectognaths except in one monacanthid and in the primitive gymnodont Triodon); a basisphenoid (lacking in all plectognaths except Triodon and molids); a relatively normal percoid type pelvis without a long extension posterior to the level of the pelvic fin origin (a long extension of the pelvis present only in triacanthoids posterior to the level of the pelvic fin origin, this portion being at least half, and usually more, of the total length of the pelvis); very short premaxillary pedicels and a nonprotractile upper jaw (premaxillary pedicels well developed and upper jaw protractile only in triacanthoids); and a dorsal fin consisting of an anterior portion of 4 to 9 (rarely 3 or 10) spines not decreasing much, if at all, in length pos- teriorly in the series (except in the young of some species) and followed without spatial interruption or indentation of the membrane by about 20 to 33 rays (as many as six dorsal spines present only in triacanthoids, decreasing greatly in length posteriorly in the series, except in the Eocene Spinacanthus, and followed either without spatial interruption or with only a slight spatial interruption, but always with an indentation of the membrane to the base of the fin, by 12 to 26 rays in Recent species of triacanthoids and as few as about eight in Spinacanthus; no more than three dorsal spines in other plectognaths).

A number of other features of acanthurids (e.g., the ridged surfaces, deep indentations, and hooks found on the distal articular areas of the first basal pterygiophores of the spiny dorsal and anal fins and the laterally expanded distal ends of many of the others; the usually highly modified dentition; less restricted gill opening; longer and more anteriorly placed ethmoid; two or three more vertebrae; fewer and less well-developed branchiostegal rays anteriorly in the series, etc.) distinguish them from triacanthoids and other plectognaths, but these will be dealt with in detail along with their similarities to triacanthoids in a subsequent work comparing the fossil acanthurids and triacanthoids.

\section{SYSTEMATIC SECTION}

\section{Definition and Synopsis of the Osteology of the Order Plectognathi (Tetraodontiformes)}

Until such time as most other orders of fishes have been extensively studied anatomically, and especially osteologically, it is impossible to give a comparative inclusive diagnosis of the Plectognathi that would clearly and succinctly distinguish them at once from all other orders of Acanthopterygii, and especially from all subgroups of the Order Perciformes, of which order the plectognaths are most likely a specialized derivative. The perciform suborder Acanthuroidei has often been thought to be the closest extraordinal relative of the plectognaths, the implication being that the acanthurids and plectognaths share a common ancestral line in the Cretaceous, with Patterson (1964:400) having suggested that this was the Pharmacichthyidae. Tyler (1968:42-43) briefly pointed out that the Recent acanthurids differ from the most generalized plectognaths, the triacanthodids, mainly in the retention of a number of bones not now found in triacanthodids and in a greater number of certain meristic elements. I subsequently studied the osteology of numerous additional Recent species (the major features summarized in Tyler $1970 \mathrm{a}, \mathrm{c}$ ) and of a large majority of the specimens of fossil acanthurids available (unpubl. data), mainly from the Eocene of Monte Bolca, Italy. These subsequent studies of acanthurids tend to support the view that acanthurids are probably relatively generalized (except in dentition, caudal peduncle armature, and dorsal and anal spine locking mechanisms) representatives of the same ancestral line which gave rise to the plectognaths, with at least the majority of plectognaths becoming far more specialized than the acanthurids in most respects.

These matters will be discussed in a subsequent paper on the anatomy of fossil and Recent acanthurids by J. Blot and the author, and then on their differences from and similarities to the plectognaths.

For the moment, the Order Plectognathi is defined below by listings of the bones that are either constantly present throughout the order or are of variable occurrence.

Certain bones apparently are always present in plectognaths, although in many cases these bones are highly variable in size and shape from one family or genus to the next. Those elements which are constantly present are: basioccipital; exoccipital; supraoccipital; pterotic; sphenotic; epiotic; prootic; frontal; parasphenoid; ethmoid; vomer (with the possible exception of diodontids); hyomandibular; quadrate; metapterygoid; symplectic; palatine; ectopterygoid; operculum; suboperculum; preoperculum; premaxillary; maxillary; dentary; articular; angular; ventral hypohyal; ceratohyal; epihyal; four branchiostegal rays (at least one in the anterior group and three in the posterior group); two basibranchials (of the second and third arches); three hypobranchials (of the first to third arches); five ceratobranchials (support- 
ing at least three gills, of the first to third arches); three epibranchials (of the second to fourth arches); two pharyngobranchials (at least of the second and third arches; except in diodontids, of at least the first and second arches); supracleithrum; cleithrum; postcleithrum as at least a single piece; coracoid; scapula; three actinosts (second to fourth sequentially from anterodorsal to posteroventral); between 9 and 25 pectoral fin rays (fin placed in about middle of side of body); between 7 and 52 dorsal fin rays and a similar or only slightly lesser number of basal pterygiophores; between 7 and 66 anal fin rays and a similar or only slightly lesser number of basal pterygiophores; between 16 and 30 vertebrae (usually less than 24); gill rakers on the anterior and posterior edges of the first to third arches.

Those elements which are present in some plectognaths, but not in others, are: basisphenoid (consistently present only in triodontids and molids, but rarely present in at least one species of triacanthodid); sesamoid articular (absent only in several species of tetraodontids and molids); basihyal (present only in triacanthodids); dorsal hypohyal (absent only in a few diodontids and many tetraodontids); interhyal (absent only in diodontids and most tetraodontids); second and sixth branchiostegal rays (one or both absent only in a few species of monacanthids and aracanids; the sixth absent in one species of molid), urohyal (absent in all Tetraodontoidei except triodontids); first and fourth pharyngobranchials (pharyngobranchial of first arch absent in monacanthids, molids, and some ostraciids; that of the fourth arch absent in balistids, monacanthids, ostraciids, tetraodontids, and diodontids) and third pharyngobranchial (absent only in a few diodontids); teeth on the pharyngobranchials (that of the first arch with teeth in diodontids and some tetraodontids; that of the second with teeth in all but a few aracanids; that of the third with teeth in all but some ostraciids and diodontids; that of the fourth with teeth in triacanthodids, triacanthids, aracanids, triodontids, and molids); teeth on fifth ceratobranchial (toothed in triacanthodids, triacanthids, balistids, and triodontids and with minute teeth in a few diodontids); basibranchial and epibranchial of the first arch (absent only in one species of monacanthid); first actinost (absent only in molids); pterosphenoid (absent only in one species of tetraodontid); prefrontal (absent only in two species of tetraodontids and several species of diodontids); posttemporal (absent in one species of monacanthid and in all Tetraodontoidei); mesopterygoid (absent in most species of triacanthids and in one species of tetraodontid); interoperculum (absent only in one species of molid); pelvis (absent in aracanids, ostraciids, tetraodontids, diodontids, molids); well-developed pelvic fin spine (present only in triacanthodids, with the possible exception of several Eocene species, and triacanthids; thoracic in position, placed under pectoral fin base); well-developed pelvic fin rays (present only in one Eocene species of triacanthodid, with four rays); poorly developed pelvic fin rays immediately following the spine (one or two present in many species of triacanthodids; one even less well-developed ray present in some species of triacanthids); a rudimentary but complex composite pelvic fin element at the posterior end of the pelvis mostly hidden from view by enlarged encasing scales (present only in balistids and many monacanthids); pleural ribs (present only in triodontids, one species of monacanthid, and probably in one of the Eocene species of both the triacanthodids and the tetraodontids); epipleurals (present in all triacanthodids, with the possible exception of one of the Eocene species, and in all triacanthids, balistids, monacanthids, and triodontids); a separate epural (absent in aracanids, ostraciids, and molids and in at least most diodontids); uroneurals (present as one or two pairs in triacanthodids, triacanthids, and triodontids, and, rarely, in at least one species of balistid); a separate parhypural (autogenous in triacanthodids, balistids, monacanthids, triodontids, and tetraodontids); one or more separate hypurals (usually five, sometimes only three or four, separate hypurals in triacanthodids, four in triodontids, one in triacanthids, balistids, and tetraodontids, and one in at least most monacanthids); a separate haemal spine of the penultimate vertebra (autogenous in triacanthodids, balistids, monacanthids, aracanids, triodontids, tetraodontids, and a few species of ostraciids); a separate haemal spine of the antipenultimate vertebra (autogenous only in triodontids); procurrent caudal fin rays (present in triodontids and in at least one species of Eocene triacanthodid); principal caudal fin rays (apparently absent in at least two of the three species of molids, but perhaps represented in the other species by the rays in the central nipple of the pseudocaudal fin otherwise formed of posteriorly migrated dorsal and anal fin rays; 12 principal rays in triacanthodids, triacanthids, balistids, monacanthids, and triodontids, 11 in aracanids (10 in one species) and tetraodontids, 10 in ostraciids, and 9 or 10 in diodontids; in all cases the uppermost ray and the lowermost ray being unbranched and the intervening rays branched, except in tetraodontids in which the uppermost ray and the two lowermost rays are unbranched, and in one species of monacanthid in which several rays both above and below are unbranched); dorsal fin spines and their basal pterygiophores (six spines, the last four of which may be rudimentary and mostly buried beneath the skin, the spines borne on five basal pterygiophores in triacanthodids; usually six spines, rarely only four or five, the sixth spine nearly always a buried rudiment, the spines borne on four, rarely three or five, basal pterygiophores in triacanthids; three spines borne on two basal pterygiophores in balistids; two spines, rarely only one, borne on one basal pterygiophore in monacanthids; two, possibly three, rudimentary spines borne on two basal pterygiophores in triodontids; no spines in aracanids, ostraciids, tetraodontids, diodontids, and molids); supraneural elements (one, as a strut supporting the second basal pterygiophore, in balistids; one in aracanids and ostraciids; one in several molids and in most tetraodontids; absent in all monacanthids and diodontids); ossified Baudelot's ligament (present only in aracanids and ostraciids); trituration teeth or teeth internal to the ma- 
jor outer series (present in both the upper and lower jaws of a few triacanthodids and in all triacanthids, diodontids, and molids; present only in the upper jaw of balistids and monacanthids; present in the upper jaw of many tetraodontids and, to a lesser extent, in the lower jaw; absent in all aracanids and ostraciids); gill rakers along anterior edge of first gill slit (present only in molids); gill rakers along anterior edge of fourth arch (absent only in a few diodontids); gill rakers along posterior edge of fourth arch (absent in tetraodontids and diodontids); gill rakers along anterior edge of fifth arch (present in monacanthids, aracanids, ostraciids, and molids); scales (present on at least a part of the body in all species except a few tetraodontids).

The few major features in the soft anatomy of plectognaths treated here are about as variable between or within various families as the bony parts just discussed. Of most importance here, neglecting for the moment the musculature that has been so superbly studied by Winterbottom (1974), is the presence of four gills and a gill slit between the fourth and fifth arches in all groups except tetraodontids and diodontids, which have lost the gill of the fourth arch and the slit between it and the fifth. A pseudobranch is present in all species, but the degree of development and number of lamellae are highly variable, the number of lamellae ranging from only 4 or 5 to about 70 , with balistids and a few tetraodontids tending to have the pseudobranch the least well developed. The olfactory epithelium is in the form of a rosette in triacanthodids, triacanthids, and triodontids, but it is variously modified in all other families as folds (often extensive but never as a rosette), ridges, pits and plications, or relatively smooth. There are two nostrils in all families, except in tetraodontids and diodontids in which there are either one or two nostrils. There is basically a single lateral line on the body in all families, except in tetraodontids in which there are one, two, or three lateral lines on the body. A well-developed air bladder is present in all families, except that it is absent in molids, at least as adults. An inflatable diverticulum of the gut is well developed only in tetraodontids and diodontids, while an expansible dewlap of skin between the end of the rotatable pelvis and the anus is moderately developed in most balistids, well developed in many monacanthids, and greatly developed in triodontids. Whether a slighly inflatable diverticulum of the gut is present in a few monacanthids (especially Brachaluteres) is still debateable (see Thilo 1899b, 1914; Rosen 1912; Breder and Clark 1947; Clark and Gohar 1953; Arbocco 1957), but, if so, it is far less well developed than in tetraodontids and diodontids and has undoubtedly been independently evolved. Molids may be unique among plectognaths by having a single ovary (according to Cleland 1862 and Wahlgren 1867 for Mola, and Pellegrin 1912 for Ranzania). With the possible exception of molids, all plectognaths have hard otoliths of normal size, but these are usually so corroded or otherwise dissolved in the formaldehyde-preserved, cleared, and stained study material that they cannot be adequately described or figured, and are not further dis- cussed here. Cleland (1862) said that otoliths were absent in Mola, while Cuvier (1805) and Thompson (1888; repeated by Kaschkaroff 1914a) found that the otoliths in Mola were represented by small calcareous granules grouped together. It is not known whether this is also the case in Masturus and Ranzania, but there is no evidence of otoliths in the present study specimens.

The large number of bones not mentioned above in either of the two lists (constant versus variable occurrence) that are often found in perciform fishes are absent in plectognaths and will help form a large segment of the defining characteristics of the Order Plectognathi when the other orders and suborders of acanthopterygian fishes are better known anatomically. Some of these structures typical of perciforms that have been lost by plectognaths are: anal fin spines; suborbital bones; parietals; at least one and usually several of the otherwise five pelvic fin rays, and in all but the Eocene triacanthodid Eoplectus of the branched and crossstriated structure of the fin rays that are retained; nasals; tabulars; scale bones; intermuscular bones other than 5 to 11 epipleurals; intercalars or "opisthotics"; supramaxillae; any sheath or surface concavity for the upper jaw; canals in the skull bones for the lateral line system; vomerine and palatine teeth, and of any other teeth except those of the dentary, premaxillary, pharyngobranchials, and fifth ceratobranchials; reduced ornamentation of the skull bones and lack of spiny processes; simplification of the posttemporal to a relatively flat rod sutured along all of its medial surface to the skull (mostly to the pterotic); development of a small and only slightly, if at all, protractile mouth, although often with massive jaws, and the relatively great restriction of the gill opening (never ending ventrally very far below the pectoral fin base); the complete covering by scaly to scaleless skin of the branchiostegal region, and the usual development of relatively spinulose or heavy scales probably derived from ctenoid scales.

The two suborders of plectognaths (Balistoidei and Tetraodontoidei) are difficult to comparatively diagnose, primarily for two reasons. One reason is that both groups contain an anatomically highly diverse assemblage of families. For example, the diagnosis of the Balistoidei must encompass such widely anatomically differentiated families as the Triacanthodidae and Ostraciidae, and that of the Tetraodontoidei has to include such similarly diverse families as the Triodontidae and Molidae or Diodontidae. Moreover, the diagnoses must also take into account the great diversity found within certain families, such as the differences between a generalized monacanthid such as Stephanolepis and a highly specialized one like Psilocephalus, or the differences between a generalized tetraodontid such as Sphoeroides and a highly specialized one like Xenopterus. However, the most important reason that the two suborders of plectognaths are difficult to comparatively diagnose is that we are fortunate in having alive today a very generalized or primitive Recent member of the Tetraodontoidei, Triodon, and that we also have available the specialized Eocene fossil subfamily of triacanthodid Balistoidei, the 
Eoplectinae, that was ancestral to Triodon and the other Tetraodontoidei. From the very fact of their close ancestor-derivative relationship, many of the characteristics of the eoplectins and triodontids bridge what are otherwise the morphological gaps between the known fossil and $\mathrm{Re}$ cent Balistoidei and Tetraodontoidei.

\section{SUBORDER BALISTOIDEI (SCLERODERMI)}

Comparative diagnosis (contrast with that of the Tetraodontoidei).- Teeth relatively large (small in one highly specialized genus of triacanthodids) and discrete separate units protruding out from sockets in the jaws, except in the Eocene eoplectin triacanthodids in which the teeth are small, nonprotruding, and fully incorporated into the matrix of the jaw bones just as in many of the Tetraodontoidei, to which they are ancestral; dentaries and premaxillaries never fused to their opposite members, except in at least some eoplectins; the medial articulation of the premaxillaries to one another not strengthened by alternating emarginations and indentations; posttemporal present, except in one highly specialized species of monacanthid; urohyal present; pelvis present, except in the ostracioids, the most specialized superfamily; pelvic fin present, at least as a rudiment at the posterior end of the pelvis, except completely absent in many of the more specialized monacanthids and in all ostracioids; palatine relatively small and not firmly sutured to both the ethmoid-vomerine region and the pterygoid arch, except probably so sutured in the eoplectins; myodome with a complete dorsal roof present, except small to absent in ostracioids; prootic shelf under the orbit present, except in triacanthoids, the most generalized superfamily, and in several highly specialized monacanthids; supracleithrum placed vertically or only slightly obliquely to the axis of the skull; scapular foramen complete, except in two highly specialized species of monacanthids; scapula with a knob or crest for articulation with the uppermost pectoral fin ray; at least some of the distal pterygiophores of the soft dorsal and anal fins ossified, except in ostracioids; spiny dorsal fin varying from six well-developed spines to a single slender spine, or, in ostracioids, absent altogether, but when present having its origin above or close behind the skull; first branchiostegal ray relatively unmodified, without an inturned dorsomedial edge.

\section{Infraorder Triacanthoideo}

Comparative diagnosis (contrast with that of the Balistoideo), which is also that of its only contained Superfamily, the Triacanthoidea.-Premaxillary with a well-developed pedicel or ascending process, the pedicel usually a sturdy rodlike shaft (but variously modified in the two long-snouted genera of triacanthodids) sliding along the dorsal surface of the ethmoid and, sometimes, vomer as well; premaxillary movably articulated with the maxillary, allowing for a slight protraction of the upper jaw; maxillary deeply indented dorsally for articulation with the anterior end of the palatine, except in the long-snouted triacanthodids; palatine usually with a squarish or oblong major portion (as seen laterally) from which arises an anterior prong for articulation with the maxillary, although much modified in the long-snouted triacanthodids, but never as a $\mathrm{T}$ shaped bone or a simple rod, or as a bony column sutured to the palato-pterygoid arch; ethmoid with a more or less evenly convex upper surface, without a laterally expanded dorsal or dorsolateral region and always narrower dorsally than ventrally; no prootic shelf developed under the orbit in front of and above the major articulation of the posterior region of the parasphenoid with the prootics; dorsal end of the hyomandibular articulated with the prootic, pterotic, and sphenotic; interoperculum long and, at least posteriorly, relatively deep and flattened, never as a stout rod throughout its length, and extending posteriorly well behind the level of the epihyal and interhyal to approach closely and connect by a short ligament to the anterior edge of the suboperculum; dorsal fin spines usually six, rarely only five, supported by five or four, and rarely only three, basal pterygiophores; the first dorsal spine not lockable in an erected position through the agency of the second spine, but with an independent locking mechanism between the base of the first spine and its basal pterygiophore; first basal pterygiophore of spiny dorsal fin with a high dorsomedial flange articulating through an anteroposterior canal in the basal region of the first dorsal spine; pelvic fin consisting of at least a large erectile and lockable spine, sometimes followed by one to four rays of greatly varying degrees of development, at about the middle of the length of the pelvis, except in several Eocene triacanthodids in which the spine may have been reduced in size and possibly absent; pelvis either shaftlike or basinlike posterior to the pelvic spines and never with a dorsal lobe posteriorly, but always with a laterally expanded portion anterior to the spines; pelvis not particularly rotatable in life around its anterior articulation with the cleithra and no expansible dewlap of skin present between the posterior end of the pelvis and the anus; one or two sets of uroneurals usually present; vertebrae nearly always $8+12=20(9+11=20$ in one Eocene species); three pharyngobranchials with prominent large protruding teeth; posteromedial edges of epiotics slightly to decidedly inturned to form, in association with the exoccipitals and neural spine of the first vertebra, a pocket in which the shaftlike base of the first basal pterygiophore of the spiny dorsal fin is held, with the probable exception of the Oligocene triacanthid Cryptobalistes; mesopterygoid in neither direct nor indirect contact with the quadrate and ectopterygoid, except sometimes very slightly so with the quadrate by the agency of the symplectic making contact with both the quadrate and mesopterygoid. 


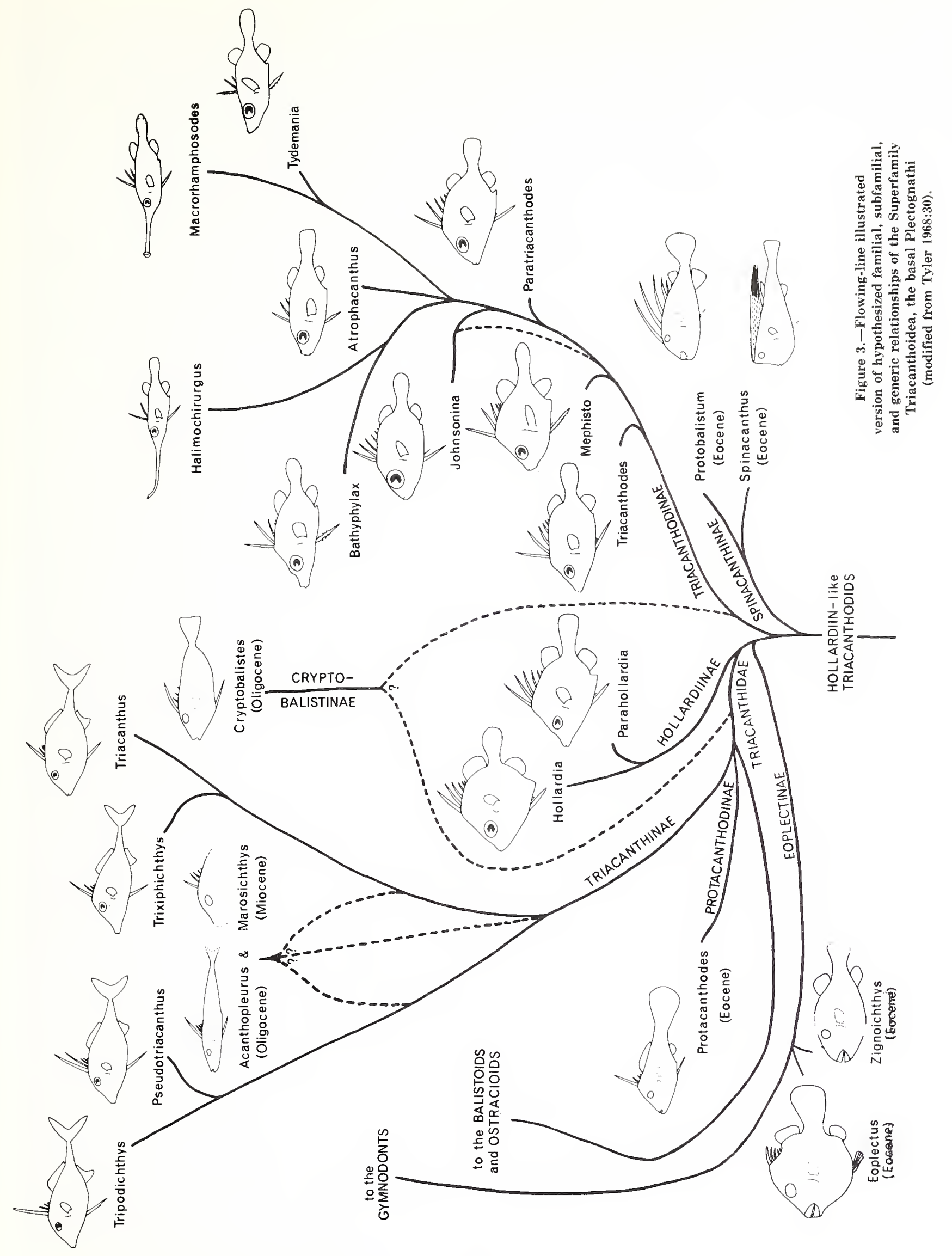


Family Triacanthodidae

Comparative diagnosis (contrast with that of the Triacanthidae) (modified from Tyler 1968:58-62). - A not especially strongly sutured skull and a variety of body forms none of which are built for particularly active, strong swimming; many areas of cartilage visible on the external surface of the skull between the limited areas of suturing between the bones in the otic and occipital regions; teeth in the jaws various, conical or truncate, in a single series or with a numerous outer series followed by a few teeth in an inner series, or absent altogether (in adults of one of the long-snouted genera, Macrorhamphosodes) in the upper jaw, or of numerous rounded dental units incorporated into the matrix of the premaxillary and dentary in beaklike jaws in the Eocene Eoplectus, but never as heavy incisor teeth (except perhaps somewhat so in the Eocene Protobalistum); a normal ethmoid-frontal complex for support of jaws without massive dentition (except in the Eocene Eoplectus, with a modified ethmoid-vomer-palatine complex to support the massive beaklike jaws); the prefrontal without a long anterior extension sutured to the ethmoid and vomer, and the vomer without posterolateral extensions toward the prefrontal; premaxillary pedicels when retracted reaching most of the way along the dorsal surface of the ethmoid, almost to the tip of the frontals, except in both of the long-snouted genera (Halimochirurgus and Macrorhamphosodes), in which the premaxillary is far removed from both the ethmoid and frontal, and in the Eocene Eoplectus, which has only very short premaxillary pedicels and a nonprotractile jaw; supraoccipital either domelike with a convex posterior surface, or mostly flattened with a small dome or laterally compressed crest; epiotics meeting one another in the midline on the dorsal surface of the skull and separated from the frontals by the sphenotics in one group (those with a flattened supraoccipital) but separated from one another on the dorsal surface of the skull in the other group by the supraoccipital and meeting medially only on the posterior surface of the skull, and articulating anterolaterally with the frontals (for illustrations see Tyler 1968:fig. $4 \mathrm{a}-\mathrm{d})$; pterosphenoids not meeting in the midline of the posterior wall of the orbit; neural processes of the first vertebra not meeting in the midline above the neural canal, forming in conjunction with the exoccipitals an only partially enclosed bony region (without a bony bottom) in which the shaftlike end of the first basal pterygiophore of the spiny dorsal fin is immovably held; parasphenoid in region of orbit relatively straight or with a ventral arch and with a poorly developed ventral flange below the orbit, the flange not deeper than the depth of the shaftlike portion of the bone, except in the Eocene Eoplectus, with a much deeper flange; hyomandibular without a prominent groove and crest along its lateral surface; pterotic without a ventral process overlying the hyomandibular; supracleithrum usually placed obliquely to the horizontal axis of the skull, only the approximate lower half of its length overlying the cleithrum; mesopterygoid always present as a separate element, sometimes sutured along its ventral edge with the metapterygoid; olfactory cavity between the ethmoid and prefrontal not well defined by bony outlines; basihyal present; lower two branchiostegal rays more or less like the others, not enlarged; operculum more or less triangular; air bladder usually thin walled, somewhat rounded, extending posteriorly to no more than the level of about two-thirds the length of the abdominal cavity; pelvis either a sturdy shaft more or less triangular or broadly heart-shaped in cross section (the apex or rounded surface ventrally) just behind the level of the pelvic spine or a flat basin with upturned edges; the two halves of the pelvis only lightly sutured to one another; the side of the pelvis at the level of the flange of the pelvic spine either smooth and allowing for only a single position of erection of the spine or with numerous small grooves allowing for numerous, continuous positions of erection of the spine, but never with a single relatively large oblique crest allowing for only two positions of erection; the ventrolateral surface of the pelvis at the base of the spine with a complete foramen through which the two sides of the base of the spine meet medially; the haemal arch and spine of the penultimate vertebra usually autogenous (occasionally extensively sutured to the centrum), the other haemal arches and spines fused to their centra; the epural, parhypural, and five hypurals usually separate elements articulated by connective tissue to each other and to the centrum, but occasionally a few of the middle hypurals may be partially to fully fused to one another; usually two pairs of uroneurals present; slender epipleurals present from the first or second abdominal vertebra to the seventh or eighth abdominal vertebra, and, sometimes, on the first or second, rarely third, caudal vertebra, except in the Eocene Eoplectus, in which epipleurals, if present, probably did not occur on at least the more posterior abdominal vertebrae; fifth basal pterygiophore of spiny dorsal fin present, normally developed; first basal pterygiophore of spiny dorsal fin with anterior and posterior medial flanges well developed, many times the width of the relatively slender shaftlike portion of the bone, except in the Eocene Eoplectus in which the flanges are only moderately developed and in Halimochirurgus in which they are poorly developed (in the Eocene Protobalistum and Spinacanthus the more anteriorly placed spiny dorsal fin probably was supported high on the rear of the skull by basal pterygiophores with short shafts and poorly developed anterior and posterior medial flanges); first basal pterygiophore of spiny dorsal fin with a medial flange dorsally completely enclosing a foramen through which the two sides of the first dorsal spine meet medially; second to fifth basal pterygiophores of spiny dorsal fin well developed, their shafts reaching ventrally to or between the distal regions of the neural spines of the fourth to eighth abdominal vertebrae; at least the first two basal pterygiophores of spiny dorsal fin sutured together distally; spiny dorsal fin base (including rudiments) much longer than soft dorsal fin base, except in the Eocene Eoplectus, with these two bases of equal length; neural spines of all eight abdominal vertebrae 


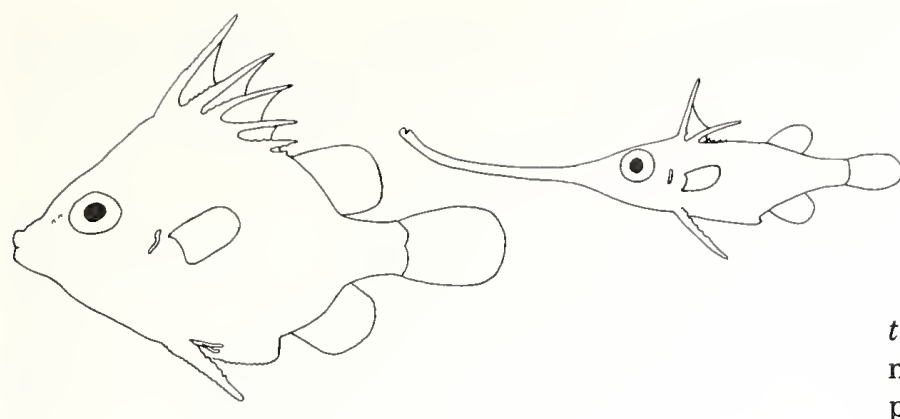

placed anterior to first basal pterygiophore of soft dorsal fin (the Eocene Eoplectus with nine abdominal vertebrae, all but the last with their neural spines anterior to the first soft dorsal fin basal pterygiophore); first anal fin basal pterygiophore either with or without a medial flange anterior to its lateral flanges, the pterygiophore either $\mathrm{T}$ - or +-shaped in cross section; well-developed lateral flanges for muscle attachment present only on the first anal fin basal pterygiophore, those present, if any, on the other pterygiophores very poorly developed; no lateral flange present horizontally along the last centrum or on the hypurals; soft dorsal fin basal pterygiophores 11 to 16 , anal fin basal pterygiophores 11 to 13 , these pterygiophores not sutured to one another distally (probably fewer basal pterygiophores in both fins in the Eocene Spinacanthus); distal pterygiophores of soft dorsal and anal fins always ossified in adults, usually as two separate halves; sixth dorsal spine either a short (probably longer in the Eocene Spinacanthus) protruding element or a rudiment buried beneath the skin or barely protruding to the surface; third to fifth spines either normally developed or rudiments buried beneath the skin or barely protruding to the surface; first and second spines always prominent and visible externally; dorsal fin rays 12 to 18; anal fin rays 11 to 16 (fewer rays in both fins in the Eocene Spinacanthus); pelvic fin with a large (smaller in the Eocene Protobalistum and Spinacanthus) spine followed in the Eocene Eoplectus by four well-developed branched rays but in all Recent species by no more than one or two small unbranched rays, both of which, but especially the second, become in some species buried rudiments in adults; adults of some species with one or two protruding pelvic rays; dorsal and pelvic spines with deep lengthwise grooves, obscured by the overlying scale plates except at the naked distal end (one-half to one-tenth or less of the length); uppermost pectoral fin ray short but not reduced to a nubbin, the two halves of the ray of about equal length and the basal region of the medial half not immensely larger than that of the lateral half; the slightly overlapping basal plates of the scales of the body bearing a vertical row of upright spinules arising from individual bases, large specimens of some species acquiring supplemental spinules in front of and behind the principal row (the Eocene Eoplectus with a single upright spinule per scale plate and the body not completely covered with scales, some of the plates being isolated and nonoverlapping, and the Eocene Protobalis-
Figure 4.- Range of diversity in body form in the Recent Triacanthodidae: Parahollardia lineata (left) and Halimochirurgus alcocki (right).

tum with huge more or less hexagonal plates bearing numerous rounded tubercules, as in ostracioids); peritoneum light tan to jet black, except in Hollardia meadi in which it is pale or silvery; coloration basically reddish, often with darker red, blue, yellow, or green markings; lateral line inconspicuous; scaly skin not forming a definite low sheath along the bases of the soft dorsal and anal fins; olfactory lamellae 9 to 20, relatively plump; anterior nostril with a tube, lowest in front, highest in back; posterior nostril more or less flush with the surface, or with a slightly upraised rim anteriorly; gill rakers laterally on first arch relatively long, as long as or longer than the width of the fleshy arch; two to seven, rarely only one, rakers laterally on the upper limb of the first arch above the angle; caudal peduncle relatively short, 10 to $19 \%$ SL ( $24 \%$ SL in the Eocene Eoplectus) not distinctly tapered and without a narrow transversely indented region above and below just in front of the caudal fin base; least depth of the caudal peduncle 5 to $12 \% \mathrm{SL}(21 \% \mathrm{SL}$ in the Eocene Eoplectus); caudal peduncle deeper than wide; caudal fin rounded to almost truncate.

\section{Detailed description of Parahollardia lineata.}

Material examined.-Seven cleared and stained specimens, 45.7-86.1 $\mathrm{mm}$. The large amounts of cartilage visible on the surface of the skull, particularly in the otic and occipital regions, is the norm for the family, in contrast to the closely related and derivative Triacanthidae. Even as large specimens, all species of Triacanthodidae retain cartilaginous regions between some of the cranial bones, although the amount slightly decreases with increasing specimen size. The largest specimen of a Recent triacanthodid presently recorded (Tyler 1968:64) is a 174 $\mathrm{mm}$ female Hollardia hollardi (ANSP 97654) which has subsequently been cleared and stained. As can be seen in Figure 22, areas of cartilage are still present on the surface of the skull in the occipital and otic regions, although the various bones are more extensively interdigitated to one another than in the $62.7 \mathrm{~mm}$ specimen illustrated by Tyler (1968:fig. 198) and relatively less cartilage is present.

\section{SKULL.}

\section{Occipital Region.}

Basioccipital. -A short column, dorsolaterally expanded; cartilage filled along its anterior and anterodorsal edges; articulates through cartilage posterolaterally 


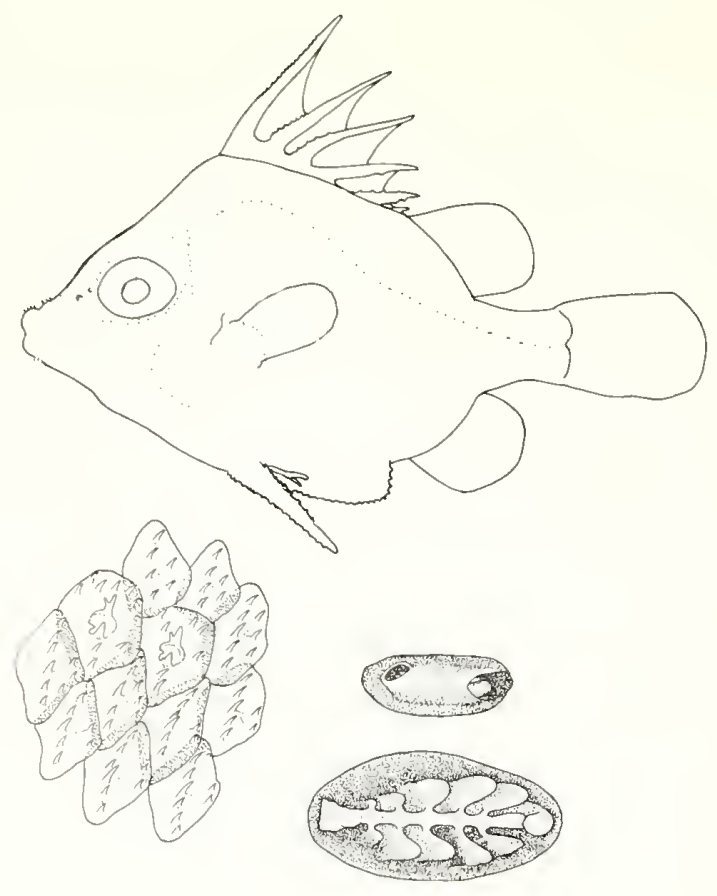

Figure 5.-Parahollardia lineata: with dots representing the course of the inconspicuous lateral line; lower left, scales from upper middle region of body, including two lateral line canal bearing scales; lower right, nasal region as seen externally (above) and the olfactory lamellae as seen with the top of the nasal sac removed.

with the exoccipitals, anterolaterally with the prootics, and, with slight interdigitation, anteroventrally with the overlying posterior end of the parasphenoid. The rim of the round concave posterior end of the basioccipital articulates by fibrous tissue with the rim of the concave anterior face of the centrum of the first vertebra. A deeply concave medial channel is present on the anterior half of the ventral surface of the basioccipital, but the channel is mostly hidden from view by the overlying parasphenoid. Posteriorly this channel is open to the exterior at the base of the posterior bifurcation of the parasphenoid, while anteriorly it opens into the myodome where the anterior end of the basioccipital forms the posterodorsal and posterolateral walls of the myodome.

Exoccipital. - Cartilage filled at its dorsal, lateral, and ventral edges; articulates through cartilage dorsally with the epiotic, anteroventrally with the prootic, ventromedially with the basioccipital; articulates laterally through cartilage and slight interdigitation with the overlying pterotic. Medially the exoccipital forms the lateral and ventral walls of the foramen magnum, the foramen being closed dorsally by the cartilage between the dorsomedial edges of the two exoccipitals. Posteromedially the exoccipitals are firmly attached by fibrous tissue and slight interdigitation to the anterior surface of the elongate, laterally expanded, bifid neural spine of the first vertebra. The exoccipital condyle is a short posterior prolongation of the posterior edge of the bone just above its articulation with the basioccipital, forming a plate which overlies the lower anterolateral surface of the neural arch of the first vertebra just above the region of the centrum.

Supraoccipital. - Dome-shaped, its stout rounded anterodorsal edge forming the apex of the cranium and its posterior surface convex; cartilage filled along all of its ventral edges; articulates posteroventrally through cartilage with the epiotics and anteroventrally through cartilage and slight interdigitation with the overlying frontals.

\section{Otic Region.}

Pterotic. - Cartilage filled along all of its edges of articulation with the other cranial bones; articulates posterodorsally through cartilage and extensive interdigitation with the epiotic, posteroventrally through cartilage and slight interdigitation with the exoccipital, anterodorsally through cartilage with the sphenotic, and anteroventrally through cartilage with the prootic. Along the middle of the anterior half of its ventral surface the pterotic articulates with the hyomandibular through fibrous tissue, the articulation being somewhat flexible. Posterolaterally the pterotic is broadly overlain by the posttemporal to which it is firmly interdigitated.

Sphenotic. - Cartilage filled along all of its edges of articulation with the other cranial bones; articulates through cartilage posterodorsally with the epiotic, posteroventrally with the slightly overlying pterotic, ventromedially with the prootic and dorsomedially with the pterosphenoid. Dorsally the sphenotic is broadly overlain by and slightly interdigitated with the frontal. On its ventral surface the medial edge of the sphenotic articulates by fibrous tissue with the hyomandibular.

Epiotic. - Cartilage filled along all of its edges of articulation with the other cranial bones; articulates through cartilage dorsally with the supraoccipital, anterodorsally with the occasionally slightly overlying frontal, anteriorly with the sphenotic, and posteroventrally with the exoccipital. Ventrolaterally the epiotic articulates anteriorly through cartilage with the pterotic, but more posteriorly the pterotic broadly overlies and interdigitates with the epiotic. Along the lower portion of its posteromedial edge the epiotic bends anteriorly so that a shallow, vertical depression or groove is formed where the two epiotics articulate through cartilage with one another medially. The ventral end of the stout shaft of the first basal pterygiophore of the spiny dorsal fin fits into this depressed area and is held tightly to it by fibrous tissue. This depression in the back of the skull is continued ventrally by a similar inturning of the upper third of the medial edges of the exoccipitals.

Prootic. - Cartilage filled along all of its edges of articulation with the other cranial bones, except anteriorly; articulates through cartilage anterodorsally with 
the pterosphenoid, anterolaterally with the sphenotic, posterolaterally with the pterotic, posteriorly with the exoccipital, and posteromedially with the basioccipital. Anteromedially the prootic articulates for most of its length through cartilage with the parasphenoid, but at its extreme anteromedial end the articulation of the prootic with the short dorsal wing of the parasphenoid is by slight interdigitation. It is at this place of interdigitation between the prootic and parasphenoid that the first pharyngobranchial makes a firm ligamentous connection with the cranium. Along its ventral surface the anterior half of the lateral edge of the prootic helps support the dorsal head of the hyomandibular. The lateral walls of the myodome are formed by the ventromedial surfaces of the prootics, while the dorsal walls of the myodome are formed by medially directed horizontal shelves, which are attached to one another medially by fibrous tissue, from the ventromedial surfaces of the two prootics. The prootics also form most of the anterior wall of the myodome.

\section{Orbital Region.}

Frontal. - Wide posteriorly but tapering to a point anteriorly; articulates posterodorsally and posteroventrally by overlying and slightly interdigitating with, respectively, the supraoccipital and sphenotic. Occasionally the most posterior portion of the frontal slightly overlies the anterodorsal portion of the epiotic. Posteromedially on its ventral surface the frontal somewhat overlies and articulates by fibrous tissue with the pterosphenoid. Anteriorly the frontal overlies the ethmoid cartilage and articulates by fibrous tissue with the ethmoid and prefrontal. Ventrally the medial edges of the frontals are widely separated by a large cartilaginous mass which is continuous anteriorly with the ethmoid cartilage.

Prefrontal. - In the form of a basally expanded column; cartilage filled along its dorsomedial and ventromedial edges; articulates through cartilage along all of its medial surface with the ethmoid and ethmoid cartilage; articulates by fibrous tissue dorsally with the frontal and anteroventrally with the posterior end of the palatine. The prefrontal articulates ventrally with the dorsal surfaces of the vomer and parasphenoid, by way of the fact that the ethmoid cartilage is firmly attached to the dorsal surfaces of the posterior region of the vomer and the anterior region of the parasphenoid.

Parasphenoid. - An elongate shaft with a slight keel along its ventral surface in the region of the orbit. A deep, anteriorly directed cleft is present in the wide posterior portion of the parasphenoid, giving rise to the forked region which broadly overlies and interdigitates with the basioccipital and at the same time covers over the medial groove on the ventral surface of the basioccipital leading into the rear of the myodome. About two-thirds the way back, the parasphenoid possesses paired dorsolateral wings which interdigitate with the anteroventral edges of the prootics and thus form the lower part of the anterior edge of the myodome. Behind this restricted area of interdigitation with the anteroventral edge of the prootic, the lateral edges of the parasphenoid articulate through cartilage with the medial edges of the prootics and thus form the floor of the myodome. Anteriorly the parasphenoid broadly overlies and interdigitates with the dorsal surface of the posterior shaftlike portion of the vomer, and, to a much lesser extent, with the ventral surface of the latter. The anterior end of the parasphenoid thus essentially possesses a deep concavity into which the shaft of the vomer fits. Anterodorsally the parasphenoid is tightly held to the ethmoid cartilage, and hence to the ethmoid and prefrontals.

Pterosphenoid.-Cartilage filled along all of its edges, except medially; articulates through cartilage ventrally with the prootic and ventrolaterally with the sphenotic. Dorsolaterally the pterosphenoid is held by fibrous tissue to the overlying frontal.

Ethmoid Region.

Ethmoid. - The ethmoid remains largely cartilaginous, the ossification being restricted to the surface regions. It articulates through cartilage dorsally with the slightly overlying frontals, posterolaterally with the prefrontals, and ventrally with the vomer and parasphenoid.

Vomer. - Large and rounded anteriorly, but tapering to a stout shaft posteriorly which interdigitates with the concavity at the anterior end of the parasphenoid. Dorsally the vomer is attached by fibrous tissue to the base of the ethmoid cartilage and thus secondarily with the bases of the ethmoid and prefrontals. At the lateral edges of its rounded anterior portion the vomer articulates by tough fibrous tissue with the medial surfaces of the palatines.

\section{Mandibular Region.}

Hyomandibular. - Somewhat expanded dorsally, tapering to a stout shaft anteroventrally; cartilage filled at its dorsal and anteroventral edges; articulates by fibrous tissue at its dorsal head with the pterotic posteriorly, the sphenotic anterolaterally, and the prootic anteromedially. Along the lower three-fourths of its posterior edge it articulates by fibrous tissue with the preoperculum. Just above the dorsal end of the preoperculum, the hyomandibular articulates by fibrous tissue at a small groove on its posterior edge with the knob at the dorsal end of the operculum. Anteriorly the hyomandibular ends at the cartilaginous plate that lies between it and the symplectic and metapterygoid.

Quadrate. - Wide posteriorly, tapering to a knob anteriorly for articulation through fibrous tissue with the articular in the lower jaw; cartilage filled along its posterior edge; with a long posteriorly directed process from 
its posteroventral region; articulates by fibrous tissue dorsally with the ectopterygoid, ventrally with the preoperculum, and anteriorly with the articular. Posteriorly the quadrate articulates through cartilage with the metapterygoid and symplectic.

Metapterygoid. - Broad anteriorly, narrowing posteriorly; cartilage filled along its anterior and ventral edges; articulates through cartilage anteriorly with the quadrate, ventrally with the symplectic, and posteriorly with the cartilaginous area in front of the anterior end of the hyomandibular. Dorsally the metapterygoid articulates by fibrous tissue with the mesopterygoid.

Symplectic. -Long and rod-shaped; cartilage filled at its anterior and posterior ends; articulates through cartilage anteriorly with the quadrate, dorsally with the metapterygoid, posteriorly with the cartilaginous area in front of the anterior end of the hyomandibular. Ventrally the symplectic articulates by fibrous tissue with the preoperculum.

\section{Palato-Pterygoid Region.}

Palatine.-Cartilage filled at its anterior and posterior ends; articulates by fibrous tissue anteriorly with the dorsolateral surface of the maxillary, medially with the lateral surface of the expanded portion of the vomer, posteriorly with the mesopterygoid. A posterodorsal projection from its dorsal edge articulates by fibrous tissue with the base of the ventrolateral surface of the prefrontal, and also connects to a band of fibrous tissue that runs over and above the premaxillary pedicels to join with the posterodorsal wing of the palatine on the other side. The palatine is firmly held in place by these fibrous tissue articulations even though it is not sutured to any of the surrounding bones.

Ectopterygoid. - Somewhat triangular in shape; articulates closely by fibrous tissue along its ventral edge with the quadrate, while along its posterodorsal edge it articulates through a sheet of fibrous tissue with the palatine and mesopterygoid.

Mesopterygoid. - Relatively well developed, only slightly smaller than the metapterygoid; articulates by fibrous tissue anterodorsally with the palatine, anteroventrally with the ectopterygoid, and ventrally with the metapterygoid.

\section{Opercular Region.}

Operculum.-Thin and broad ventrally, narrowing to a stout shaft dorsally; articulates by fibrous tissue dorsally with a groove on the upper posterior edge of the hyomandibular. Ventrally the operculum slightly overlies and is held by fibrous tissue to the suboperculum.

Suboperculum. - Rounded anteriorly, tapering to a point posteriorly; with a small dorsal projection located in about the middle of its dorsal edge; articulates by fibrous tissue dorsally with the operculum, and anteriorly with the interoperculum.

Interoperculum. - Very elongate; wide and rounded posteriorly but tapering to a point anteriorly; articulates by fibrous tissue posteriorly with the suboperculum, while anteriorly it makes a ligamentous attachment to the angular in the lower jaw. In the posterior half of its length the dorsal edge of the interoperculum connects by a band of fibrous tissue to the epihyal in the region where the epihyal articulates with the interhyal.

Preoperculum. - Slightly expanded posteroventrally; the dorsal edge along the anterior half of the bone slightly expanded laterally for articulation with the quadrate; articulates by fibrous tissue along the posterior region of its dorsal edge with the hyomandibular, along the middle region of its dorsal edge with the cartilaginous plate between the symplectic, metapterygoid, hyomandibular, and quadrate, along the anterior region of its dorsal edge with the quadrate.

\section{Upper Jaw.}

Premaxillary. - L-shaped, with the long posterior arm (pedicel) movably articulated by fibrous tissue along the dorsal surface of the vomer and ethmoid, allowing for protraction of the upper jaw. When fully retracted the pedicel reaches most of the way along the dorsal surface of the ethmoid, almost to the tip of the frontals. The shorter ventral arm of the premaxillary forms the anterior edge of the upper jaw, except for a short distance ventrally where the maxillary forms the border. The premaxillary articulates by fibrous tissue along the middle of the lateral surface of its posterior arm with the medial surface of the upper expanded portion of the maxillary, while along the medial surface of its posterior arm the premaxillary articulates with its opposite member. The ventral arm of the premaxillary articulates by fibrous tissue along its posterior edge with the anterior edge of the maxillary. Six to seven bluntly conical teeth, decreasing in size laterally, are borne in deep sockets along the anterior edge of the premaxillary. Behind and internal to this outer row of teeth there is usually a single conical tooth, about half the size of the largest tooth in the outer series, but several such inner teeth may be present on each premaxillary. The teeth are replaced by new ones developing in new sockets just above and external to the sockets of the outer row of teeth. After a new tooth erupts through the surface of the premaxillary, it gradually migrates slightly forward and downward into the area of the socket of the older tooth which it is replacing.

Maxillary. - Rounded dorsally, constricted in the middle, and only slightly expanded ventrally; articulates by fibrous tissue dorsally along the lateral surface of its rounded portion with the anterior end of the palatine, while along the medial surface of its rounded 
portion it attaches to the lateral and ventral surfaces of the premaxillary. Ventrally the medial surface of the maxillary articulates by tough fibrous tissue with the lateral surface of the posterodorsal part of the dentary, while along its anteroventral edge the maxillary articulates similarly with the premaxillary.

\section{Lower Jaw.}

Dentary. - The posterior end concave to accommodate the anterior end of the articular, which it broadly overlies laterally but only slightly overlies medially; articulates by fibrous tissue anteromedially with its opposite member, posteroventrally with the angular, and posteromedially with the articular. Along the posterodorsal region of its lateral surface the dentary articulates by tough fibrous tissue with the medial surface of the ventral portion of the maxillary. Seven to eight bluntly conical teeth, decreasing in size laterally, are borne in deep sockets along the anterior edge of the dentary. Behind and internal to this outer row of teeth there is usually a single conical tooth, about half the size of the largest tooth in the outer series, but several such inner teeth may be present on each dentary. The teeth of the outer series are replaced by new ones developing in new sockets just below and external to the sockets of the outer row of teeth, in the same manner as described for the premaxillary.

Articular.-More or less triangular in shape; cartilage filled at its anterior edge, where it is continuous with the remains of Meckel's cartilage; articulates by fibrous tissue dorsally, ventrally, and laterally with the broadly overlying dentary, posteroventrally with the angular, and posteriorly at the groove on its posterior edge with the knob at the anterior end of the quadrate. The sesamoid articular is a small ossification held by fibrous tissue to the region of juncture of Meckel's cartilage and the anteromedial surface of the articular.

Angular. - Small; articulates by tough fibrous tissue with the dentary and articular. Posteriorly the angular connects by ligament to the anterior end of the interoperculum.

\section{BRANCHIAL APPARATUS.}

Hyoid Arch, Branchiostegal Rays, and Urohyal.

Basihyal. - Elongate; slightly expanded laterally at posterior end; cartilage filled at posterior end; articulates by fibrous tissue posteriorly with the first basibranchial and laterally with the dorsal hypohyals.

Hypohyals. - Both hypohyal elements well developed; dorsal hypohyal cartilage filled at its ventral and posterior edges, the ventral hypohyal cartilage filled at its dorsal and posterior edges. The dorsal and ventral hypohyals articulate through cartilage with one another and with the ceratohyal, while they articulate by fibrous tissue anteromedially with their opposite members, and in the case of the dorsal hypohyal with the region of articulation between the basihyal and first basibranchial. The ventral edge of the ventral hypohyal articulates by fibrous tissue with the urohyal.

Ceratohyal. - Large, somewhat expanded posteriorly; cartilage filled at its anterior and posterior edges; articulates through cartilage anteriorly with both of the hypohyals and posteriorly with the epihyal. The six branchiostegal rays articulate by fibrous tissue with the ceratohyal; the first two rays to about the middle of the ventral edge and the last four rays to the lateral surface of its posteroventral region.

Epihyal. - Large; cartilage filled at its anterior and ventral edges; articulates through cartilage anteriorly with the ceratohyal and posterodorsally by fibrous tissue with the interhyal.

Interhyal. - Short, columnar; cartilage filled at its dorsal and ventral edges; articulates by fibrous tissue ventrally with the epihyal and dorsally with the cartilaginous plate between the symplectic and hyomandibular.

Branchiostegal rays. - Six in number, increasing in length posteriorly in the series; the first ray somewhat flattened or laterally compressed, the succeeding rays less compressed so that the sixth ray is rodlike; articulate by fibrous tissue with the ceratohyal as described above.

Urohyal. - Thick at its dorsal and anterior edges, otherwise very thin; articulates by fibrous tissue with the ventromedial surfaces of the ventral hypohyals.

Branchial Arches.-All the elements are cartilage filled at their edges of articulation with the other elements of the series, and the articulations are usually through cartilage and fibrous tissue. The branchial arches are composed of three basibranchials, three pairs of hypobranchials, five pairs of ceratobranchials, four pairs of epibranchials, and four pairs of pharyngobranchials. Four gills are present, with a slit between the fourth arch and the lower pharyngeal.

First Arch. -Basi-, hypo-, cerato-, epi-, and pharyngobranchial elements present. First basibranchial short, laterally compressed in the middle of its length; displaced forward so that it articulates posteriorly mainly with the second basibranchial and only secondarily posterolaterally with the first hypobranchials, while anteriorly it articulates with the basihyal. First hypobranchial the largest of the hypobranchial elements, which decrease in size posteriorly in the series; articulates mainly with the anterior half of the lateral surface of the second basibranchial, and to a lesser extent along its extreme anteroventral edge with the first basi- 
branchial. First ceratobranchial the shortest of the ceratobranchial elements, which, except for the fifth, increase slightly in size posteriorly in the series; possesses a ventrally directed flange along most of its ventral surface, this flange on the succeeding ceratobranchials becoming progressively less developed until it is nonexistent on the fifth. First epibranchial with the dorsal one-third of its length bifurcate into two projections; the anterior projection articulating with the base of the first pharyngobranchial, and the posterior projection articulating with the second pharyngobranchial. First pharyngobranchial (suspensory pharyngeal) a narrow rod articulating ventrally with the anterior projection of the first epibranchial and dorsally by fibrous tissue with the area of articulation of the dorsolateral wing of the parasphenoid with the anteroventral edge of the prootic.

Second arch. -Basi-, hypo-, cerato-, epi-, and pharyngobranchial elements present. Second basibranchial the largest of the three basibranchial elements; articulates anteriorly with the first basibranchial, anterolaterally with the first hypobranchials, posteriorly with the third basibranchial, and posterolaterally with the second hypobranchials. Second hypobranchial very wide ventrally; articulates ventrally with the posterior end of the second basibranchial and anterior end of the third basibranchial, articulates dorsally with the second ceratobranchial, which in turn articulates dorsally with the somewhat laterally expanded second epibranchial. The second pharyngobranchial is the first of the tooth bearing pharyngobranchials, having seven or eight teeth, set in sockets, in a single row on its ventral surface. The teeth are of the same type as those of the jaws, although slightly smaller and with sharper points. They are replaced by new teeth developing in new sockets just anterior to the sockets of the old teeth, in the same manner as in the replacement of the teeth in the jaws.

Third arch.-Basi-, hypo-, cerato-, epi-, and pharyngobranchial elements present. Third basibranchial articulates anteriorly with the second basibranchial, anterolaterally with the second hypobranchials, posterolaterally with the third hypobranchials, and posteriorly with the fourth ceratobranchials. Third hypobranchial with an anteroventral process which articulates by fibrous tissue with the posterodorsal edge of the urohyal; at its posterodorsal end it articulates medially with the posterior end of the third basibranchial and laterally with the ventral end of the third ceratobranchial. Third ceratobranchial articulated dorsally with the third epibranchial, which in turn articulates with the third pharyngobranchial, the largest of the three tooth-bearing pharyngobranchial elements. It possesses six to seven teeth in a row along its anterior edge and about three more teeth irregularly placed behind the anterior row. The teeth are similar to those described for the second pharyngobranchial. The third pharyngobranchial closely articulates by fibrous tissue with the other two toothed pharyngobranchials (second and fourth).
Fourth arch.-Cerato-, epi-, and pharyngobranchial elements. With the disappearance of the fourth basi- branchial and fourth hypobranchial, the fourth ceratobranchial articulates ventrally with the posterior end of the third basibranchial. Fourth epibranchial an elongate rod which articulates ventrally with the fourth ceratobranchial and dorsally with the small fourth pharyngobranchial. The latter is the smallest of the toothed pharyngobranchial elements, and closely articulates by fibrous tissue with the third pharyngobranchial. It bears five or six teeth in an anterior row and three or four more teeth, irregularly placed, behind this anterior row.

Fifth arch. - Ceratobranchial (lower pharyngeal) element only. Fifth ceratobranchial wide anteroventrally but tapering to a short stout column dorsally. Teeth more or less placed in three rows, with those of the posterior row the largest; 7 to 10 teeth in the anterior row, 7 to 9 teeth in the middle row, and 7 to 11 teeth in the posterior row. The teeth are of the same type as those of the pharyngobranchials. Ventrally the fifth ceratobranchial articulates with the base of the fourth ceratobranchial.

\section{PAIRED FIN GIRDLES.}

\section{Pectoral Fin.}

Posttemporal. - A straight shaft of bone without evidence of a forked condition, broadly overlying and strongly interdigitated to the pterotic in the lower twothirds of its length and to the epiotic above. The rounded ventral head of the posttemporal articulates by fibrous tissue with the concave dorsal end of the supracleithrum.

Supracleithrum. - Located slightly obliquely anterodorsally to posteroventrally in relation to the axis of the body; articulates by fibrous tissue dorsally with the ventral head of the posttemporal, and ventrally with the cleithrum, which it broadly overlies.

Cleithrum. - Laterally expanded along the ventral two-thirds of its length; articulates by fibrous tissue dorsolaterally with the overlying supracleithrum, while dorsomedially it overlies the dorsal postcleithrum. Along the middle of its posterior surface the cleithrum articulates by fibrous tissue with the scapula and the rounded anterodorsal portion of the coracoid. Ventromedially the cleithrum articulates by tough fibrous tissue with its opposite member, while just above this region the anterior end of the pelvis is firmly held between the cleithra.

Postcleithra. - The postcleithra form a long posteroventrally directed strut from the dorsomedial region of the cleithrum along the abdominal wall musculature to the region just above the middle of the posterior half of the pelvis. The dorsal postcleithrum is expanded into a thin plate dorsally and articulates by 
fibrous tissue anterolaterally with the somewhat overlying cleithrum and posteroventrally with the ventral postcleithrum. The ventral postcleithrum is a slightly compressed shaft which articulates by fibrous tissue anterodorsally with the dorsal postcleithrum in the region behind the pectoral fin rays.

Coracoid. - Rounded dorsally, tapering ventrally to a narrow shaft; produced posterodorsally into a prong below the lowermost actinosts; cartilage filled along the dorsal and anterior edges of its rounded dorsal region and at the end of its ventral shaft; articulates by fibrous tissue anterodorsally and anteroventrally with the posterior surface of the cleithrum, dorsally through cartilage with the scapula and through fibrous tissue with the bases of the last two actinosts.

Scapula.-Completely encloses the scapular foramen; cartilage filled at its anterior and ventral edges; articulates anteriorly by fibrous tissue with the cleithrum and ventrally through cartilage with the coracoid. Posteriorly the scapula articulates by fibrous tissue with the following elements, in order from dorsal to ventral; the first pectoral fin ray, the small first actinost, the second actinost, and the dorsal part of the base of the third actinost. The first fin ray is supported on a stubby projection, and the first actinost on a flattened surface just posteroventral to the articulation of the first fin ray.

Actinosts. - Four elements; all cartilage filled at both ends; the first two actinosts articulating with the scapula, the third actinost articulating with the dorsal edge of the region of articulation between the scapula and coracoid, the fourth actinost articulating with the coracoid; distally the actinosts support all of the pectoral fin rays, except for the first. The actinosts increase in size from the first to the fourth.

Fin rays. - Thirteen fin rays in most specimens; the first ray normal, of two equal halves, but only onefifth to one-fourth the length of the second ray and articulating directly with the scapula rather than with the actinosts, as do the other fin rays; the first two rays and the last or lowermost ray unbranched, the intervening rays branched. First ray without cross-striations; all other rays with cross-striations.

\section{Pelvic fin.}

Pelvis.-Formed of two distinct lateral halves tightly bound together medially by fibrous tissue; tapers to a sharp point posteriorly, but terminates bluntly anteriorly where it is tightly held by fibrous tissue between the medial edges of the cleithra; expanded ventrolaterally in the area anterior to the articulation of the pelvic spines so that a large basin for muscle attachment is formed on the ventral surface of the pelvis.

Pelvic spine. - Large and strong; articulates broadly by fibrous tissue at its concave medial edge with the lateral edge of the pelvis, as well as ventrally with the pelvis by an anteroventral flange from the base of the spine, and dorsally with the pelvis by a smaller dorsomedial flange (the anterior direction of the ventral flange and the medial direction of the dorsal flange are for the unerected spine). The spine can be envisioned to lock in an erect position by a combination of three movements. The whole spine is rotated approximately $70^{\circ}$ forward and outward around its base of articulation with the pelvis. By this movement the ventral flange, that was originally directed anteriorly, is now directed medially, and the dorsal flange, that was originally directed medially, is now pointed posteriorly and is no longer in contact with the dorsal surface of the pelvis, but rather is lying just lateral to the edge of the pelvis. The spine is then slightly rotated so that the dorsal flange very slightly overlies the ventrolateral edge of the pelvis. When the spine is then rotated slightly backward and inward, the dorsal flange hits flatly against the ventrolateral surface of the pelvis and any further backward and inward movement of the spine is stopped. The spine is unlocked by the simple rotation of the spine slightly forward and outward, and then slightly backward and upward, until the dorsal flange is out of contact with the ventrolateral surface of the pelvis and is lying just lateral to it. The spine can then be drawn back to its unerected position, with the dorsal flange sliding over the dorsal surface of the pelvis to its original medially directed position.

Fin rays. - Two rays present, only the first of which can be seen externally. The first ray short, about onethird the length of the spine, unbranched and without cross-striations, the two halves of the ray distinct from one another throughout their lengths and held together by fibrous tissue. Basally the two halves of the first ray are widely divergent, the base of the medial half of the ray articulating broadly across the ventral surface of the pelvis, while the base of the lateral half of the ray articulates along the lateral surface of the pelvis. The second fin ray is small and easily overlooked, for it lies flat against the ventral surface of the pelvis and is completely covered by the thick spinulose skin of the body. Like the first ray, the second ray is composed of two distinct halves that are held together by fibrous tissue. The medial half of the second ray is wider than the lateral half and both halves are unbranched and without crossstriations. No pterygial elements are present. See Tyler (1962b) for additional details on the pelvis and pelvic fin, and Winterbottom (1970) for their muscular evolution.

VERTEBRAL COLUMN. - All vertebrae with biconcave centra, except the last, which ends posterodorsally in the urostyle.

\section{Abdominal Vertebrae.}

First vertebra. - Neural spine enlarged, laterally expanded dorsally, bifid to the centrum and hence without a bony roof over the neural canal; articulates over all of the anterior surface of its neural spine by 
fibrous tissue with the epiotics and by slight interdigitation with the exoccipitals. Over the anterior half of the neural arch area just above its centrum, the first vertebra articulates by fibrous tissue with the overlying posteriorly directed exoccipital condyles. The rim of the concave anterior end of the centrum articulates with the rim of the concave posterior end of the basioccipital. Posteriorly the first vertebra articulates with the second vertebra by apposition of the rims of their centra and by the short, but wide, neural postzygapophysis of the first vertebra slightly overlying the neural prezygapophyseal area of the second vertebra. No haemal zygapophyses are present.

Other abdominal vertebrae. - In 17 specimens the abdominal vertebrae numbered eight. Except for the first vertebra, all of the abdominal vertebrae, as well as the caudal vertebrae, have a bony roof over the neural canal and a single, undivided, neural spine. The basal regions of the neural spines and dorsal regions of the neural arches become progressively more anteroposteriorly expanded from the second to the eighth abdominal vertebra. This expansion involves both the neural pre- and postzygapophyses, which become broadened into large articular surfaces, with the prezygapophyses of the seventh and eighth (sometimes sixth to eighth) abdominal vertebrae slightly overlying the postzygapophyseal area of the vertebrae anterior to them. No haemal pre- or postzygapophyses are present. Each neural arch has a neural foramen along the middle of its lateral surface. The first three abdominal vertebrae have no transverse or haemal processes, but the fourth and fifth vertebrae have transverse processes from the anterolateral edges of their centra, the process of the fifth being somewhat longer and more ventrally curved than that of the fourth. The sixth vertebra has a slightly longer transverse process, which differs from that of the fourth and fifth vertebrae in that the two processes of the sixth vertebra possess medial projections that meet and are continuous in the midline beneath the centrum, enclosing the haemal canal and thus representing a haemal arch without a haemal spine. The seventh vertebra has the haemal arch more strongly developed and possesses ventrally directed processes from each side of the haemal arch representing a bifid haemal spine. The haemal apparatus of the eighth vertebra is like that of the seventh, except larger. Six epipleurals or intermuscular bones are present in the myocommata between the epaxial and hypaxial musculature, and borne on the second to seventh abdominal vertebrae. The first and second epipleurals articulate with the neural arches of, respectively, the second and third abdominal vertebrae. The third epipleural articulates with the dorsal surface of the short transverse process of the fourth abdominal vertebra; the fourth epipleural with the dorsal surface of the transverse process of the fifth abdominal vertebra. The fifth and sixth epipleurals articulate with the ventrolateral surfaces of the haemal arches of, respectively, the sixth and seventh abdominal vertebrae.
Caudal Vertebrae.-In 17 specimens the caudal vertebrae numbered 12 . As is true with the last two or three abdominal vertebrae, the first four to six caudal vertebrae have the neural spine area around and above the neural zygapophyses expanded into large articular surfaces so that the neural prezygapophyses of the first four or five caudal vertebrae overlie the neural postzygapophyseal area of the vertebrae anterior to them. With the exception of the last two vertebrae, each neural arch has a completely enclosed neural foramen. All of the abdominal vertebrae have a bony roof over the neural arch and a single, undivided, neural spine. The haemal arches and spines are well-developed and normal, except for those of the first caudal vertebra, which has the haemal spine single and undivided for the upper onethird of its length, but bifid for the ventral two-thirds of its length. The bifid portion of this spine overlies the upper anterior surface of the first basal pterygiophore of the anal fin. The haemal arch of the penultimate vertebra is not fused to its centrum, but, rather, is tightly held to it by fibrous tissue. The haemal arch of the last vertebra is described below.

Caudal Skeleton. - The caudal skeleton consists of the last vertebral centrum, one epural, two pairs of uroneurals, five hypurals, and the parhypural, with the whole complex receiving support from the prolonged neural and haemal spines of the penultimate vertebra. The last vertebral centrum is prolonged posterodorsally into a urostyle and supports along its posterior edge the five hypurals and the parhypural. From the dorsolateral surface on each side, the centrum bears anterodorsal projections which do not meet in the midline dorsally. These projections represent the lateral walls of the neural arch of the last vertebra and its neural prezygapophyses, since they form the lateral borders of the neural canal and at their dorsal ends articulate by fibrous tissue with the neural postzygapophyses of the penultimate vertebra. The epural is a long rod articulating by fibrous tissue along its posterior edge with the uroneurals and at its anteroventral edge with the area between the dorsal ends of the two anterodorsal projections of the last vertebral centrum. The epural thus forms the dorsal roof of the neural canal of the last vertebra and it is, evidently, the very little modified neural spine of the last vertebra. The uroneurals in this and the other species of triacanthodids are highly variable in shape, size, number and condition of pairing, as described in detail by Tyler (1970b; see fig. 1 for illustrations of the uroneurals in six specimens of $P$. lineata). There is usually clear evidence of two pairs of uroneurals, with the first pair usually smaller and more variable than the second, more posterior, pair. In the caudal skeleton of $P$. lineata illustrated here, the first pair of uroneurals is represented by a single small rounded plate above the anterior end of the second uroneural, it being obvious that either one half of the first uroneural has failed to develop or that the two halves have fused into one piece. One other study specimen also has a single first uroneural ossification, but three others have a 
pair of pieces and another has three small pieces, as discussed by Tyler (1970b:5). The second pair of uroneurals is represented by two long separate pieces in three of the specimens, while in the other three specimens the two halves are fully fused anteriorly.

The hypurals decrease in length from the first (lowermost) to the fifth. Fifth hypural directed posterodorsally from just behind and slightly below the uppermost point of the urostyle; more or less rod-shaped; supports, along with the uppermost edge of the fourth hypural, the uppermost caudal fin ray. Fourth hypural the deepest of the hypural elements; articulates anteriorly with the posterior edge of the urostyle and posteriorly supports the uppermost five caudal fin rays, although it shares the support of the uppermost and lowermost of these five rays with, respectively, the fifth hypural and third hypural. Third hypural broad posteriorly but becoming narrow anteriorly where it articulates with the posterior edge of the urostyle; posteriorly it supports the upper of the middle two caudal fin rays and partially supports the lowermost of the upper five caudal fin rays. Second hypural similar to third hypural, but slightly larger; articulates anteriorly with the posterior edge of the urostyle, while posteriorly it supports the lower of the middle two caudal fin rays. First hypural articulated anteriorly with the posterior edge of the urostyle, while posteriorly it supports three fin rays. The parhypural the largest of the hypural series and enclosing the end of the haemal canal with its deeply concave anterior end; the lateral edges of its concave anterior end articulate by fibrous tissue with the posterolateral surfaces of the centrum. A slight indentation on the anterodorsal edge of the parhypural marks the end of the haemal canal. The parhypural is thus the not greatly modified haemal arch and spine of the last vertebra.

Caudal fin rays. - Twelve in number; the uppermost ray and the lowermost ray unbranched, the others becoming increasingly branched toward the two middle fin rays, which are branched in triple dichotomies. The fin rays articulate at their bifid bases by fibrous tissue with the hypurals, as described above.

\section{DORSAL AND ANAL FINS.}

\section{Dorsal Fin.}

Spines and pterygiophores. - Six spines borne on five basal pterygiophores, without the intervention of distal pterygial elements. The first spine long, the others decreasing in length posteriorly in the series. First spine with its generally concave base somewhat expanded ventrolaterally. The ventrolateral flanges of the first spine are in close contact with one another medially, although they are not fused together. Just above the basal area of close apposition of the flanges, a hole is present anteroposteriorly through the middle of the spine. The generally concave basal surface of the spine fits over the generally convex upper surface of the first pterygiophore, while at the same time a high medial flange from the upper surface of the pterygiophore fits into the hole through the base of the first spine. The medial flange of the pterygiophore possesses a large hole through which the two medial surfaces of the base of the first spine come into close fibrous tissue contact. The first spine is thus impossible to disarticulate from its pterygiophore without cutting the fibrous tissue or breaking either the base of the spine or the medial flange of its pterygiophore. The first spine can be held in an erect position by a very simple mechanism. The ventral articular surface of the first spine and the dorsal articular surface of the first pterygiophore, on either side of its medial flange, are rough and irregular. When the spine is erected at a right angle to the dorsal surface of the pterygiophore and then pulled slightly downward, a firm contact is established between the two roughened articular surfaces and the spine is effectively locked in position. The spine is unlocked by relaxation of the strong, vertically directed pressure of the spine against the pterygiophore, so that the articular surface of the spine can slide forward over the articular surface of the pterygiophore without undue frictional resistance. The second spine articulates at its concave ventral end with the generally convex surface of the first pterygiophore directly behind the articular area of the first spine, but the second spine has no function in the locking mechanism of the first spine. There is a small medial flange of the pterygiophore that fits loosely into the slight concavity in the middle of the base of the second spine. The third to the sixth spines articulate to their individual basal pterygial elements and have, from the third to sixth, progressively less concave articular surfaces fitting against the progressively less convex articular surfaces of their pterygiophores, so that the articulation of the sixth spine to its pterygiophore is at the relatively flat surfaces of both elements.

The first basal pterygiophore has a strong anteroventrally directed columnar process which fits into a groove formed by the inturned posteromedial surfaces of the ventral half of the epiotics and the dorsal one-third of the exoccipitals, as well as by the medial surfaces of the bifid neural spine of the first vertebra, which overlies these regions of the epiotics and exoccipitals. The columnar portion of the first pterygiophore is held in this groove by tough fibrous tissue. The second to fifth pterygiophores bear, respectively, the third to sixth dorsal fin spines. The ventral regions of the second to fifth pterygiophores articulate, respectively, between the neural spines of the third and fourth vertebrae, the fifth and sixth veriebrae, the sixth and seventh vertebrae, and the seventh and eighth vertebrae. The pterygial elements are cartilage filled at their extreme ventral edges.

Fin rays and pterygiophores. - Sixteen fin rays usually present; the first two rays and the last ray unbranched, the others branched in single or double dichotomies. Each fin ray has a small pair of distal pterygiophores as two distinct halves between the bifurcate base of the ray, except for the last one or two rays, in which these elements, if present, are unossified. Basally 
the fin rays are supported by about 14 basal pterygiophores, which decrease in size posteriorly in the series. The more anterior of the pterygiophores have weakly developed lateral flanges along their lengths, but these lateral projections for muscle attachment become reduced posteriorly in the series and are entirely absent from the more posterior pterygiophores. The basal pterygiophores articulate by fibrous tissue ventrally with the neural spines of the vertebrae. The first and second basal pterygiophores of the soft dorsal fin are usually located between the neural spines of the eighth abdominal and first caudal vertebrae while the last basal pterygiophore is located between those of the sixth and seventh caudal vertebrae. The basal pterygial elements are cartilage filled at their dorsal and ventral ends.

\section{Anal Fin.}

Fin rays and pterygiophores. - Fourteen fin rays usually present; the first ray and the last ray unbranched, the others branched in single or double dichotomies. Each fin ray has a small pair of distal pterygiophores as two distinct halves between the bifurcate base of the ray, except for the last one or two rays, in which these elements, if present, are unossified. Basally the fin rays are supported by about 13 basal pterygiophores, which decrease in size posteriorly in the series. They possess weakly developed lateral flanges for muscle attachment along their lengths, as in the case of the dorsal fin basal pterygiophores, and they are cartilage filled at their dorsal and ventral ends. The first basal pterygiophore is by far the largest of the series and has welldeveloped lateral flanges for muscle attachment along each side of its anterior surface. It articulates by fibrous tissue to the posterior surface of the bifid portion of the haemal spine of the first caudal vertebra and to the anterior surface of the haemal spine of the second caudal vertebra. The $2 \mathrm{~d}$ to 13 th basal pterygiophores articulate by fibrous tissue to the haemal spines of the $2 \mathrm{~d}$ to 7 th caudal vertebrae.

Comparative diagnoses of subfamilies (Spinacanthinae, Eoplectinae, Hollardiinae, Triacanthodinae). -As discussed in greater detail by Tyler (1968, 1973b), there are four subfamilies of triacanthodids, two fossil, and two Recent, whose most pertinent diagnostic features are summarized below. See Sorbini (1968) and Blot (1969) for the upper portion of the lower Eocene age of the Monte Bolca, Italy, fish beds.

The Eocene Spinacanthinae differ from both the Eocene Eoplectinae and the Recent species (Hollardiinae and Triacanthodinae) in having: enormously elongate dorsal fin spines ( 50 to $90 \%$ SL) in an exceptionally longbased fin (slightly over $50 \% \mathrm{SL}$ ), with the soft dorsal and anal fins exceptionally short-based (about 11 to $12 \% \mathrm{SL}$ ); the spiny dorsal fin origin over the level of the middle or front of the eye; the eye small ( 5 to $7 \% \mathrm{SL}$ ) and placed high in the head; a probably only poorly developed pelvic fin, if it is present at all. Two species: Protobalistum imperiale (Massalongo 1857) and Spinacanthus cuneiformis (Blainville 1818).

The Eocene Eoplectinae differ from both the Spinacanthinae and the Recent species in having: gymnodontlike jaws and upper jaw suspension, with numerous small rounded dental units incorporated in the matrix of the premaxillary and dentary, with the premaxillary and maxillary immovably articulated, and the jaws probably nonprotrusible; a well-developed pelvic fin of one spine and four long branched rays; the ventral shaft of the second basal pterygiophore of the spiny dorsal fin directed anteroventrally and articulated either to the base of the skull or between the neural spines of the first and second vertebrae; $9+11$ vertebrae in a highly arched column; decidedly more soft dorsal and anal fin rays than basal pterygiophores. Two species: Eoplectus bloti Tyler (1973b) and Zignoichthys oblongus (Zigno 1874a).

The Recent species are divided into two subfamilies mainly on the basis of the shape of the posterior portion of the skull, the placement of the epiotics and the shape of the pelvis, none of which features are known for the fossil species. Comparative diagnoses of the two Recent subfamilies follows:

Hollardiinae. The dorsal surface of the supraoccipital entirely domelike, without a broad flat expanse, the posterior surface of the dome convex; epiotics not meeting medially on the dorsal surface of the skull, separated there by the supraoccipital and meeting medially only on the posterior surface of the skull, and articulating anteriorly with the frontals; pelvis a sturdy shaft more or less triangular or broadly heart-shaped in cross section; first anal fin basal pterygiophore tending to be +-shaped in cross section, with an anteromedial process; teeth conical. Four western Atlantic species and one from Hawaii, in two genera (Hollardia and Parahollardia).

Triacanthodinae. The dorsal surface of the supraoccipital with a broad flat expanse, anteromedially on which is an upraised area varying in shape from a small dome to a laterally compressed thin crest; epiotics meeting medially on the dorsal surface of the skull as well as on the posterior surface, and separated anteriorly from the frontals by the sphenotics; pelvis a flat basin with upturned edges; first anal fin basal pterygiophore $\mathrm{T}$-shaped in cross section, without an anteromedial process; teeth conical or wider than thick and more or less truncate distally. Of the 14 species in 9 genera, 13 species belong to 8 genera (Triacanthodes, Mephisto, Paratriacanthodes, Atrophacanthus, Bathyphylax, Tydemania, Macrorhamphosodes, Halimochirurgus) in the Indo-western Pacific, and 1 species belongs to a monotypic genus (Johnsonina) in the western Atlantic.

Anatomical diversity.-The anatomical diversity of the two Recent subfamilies has been treated in detail by 


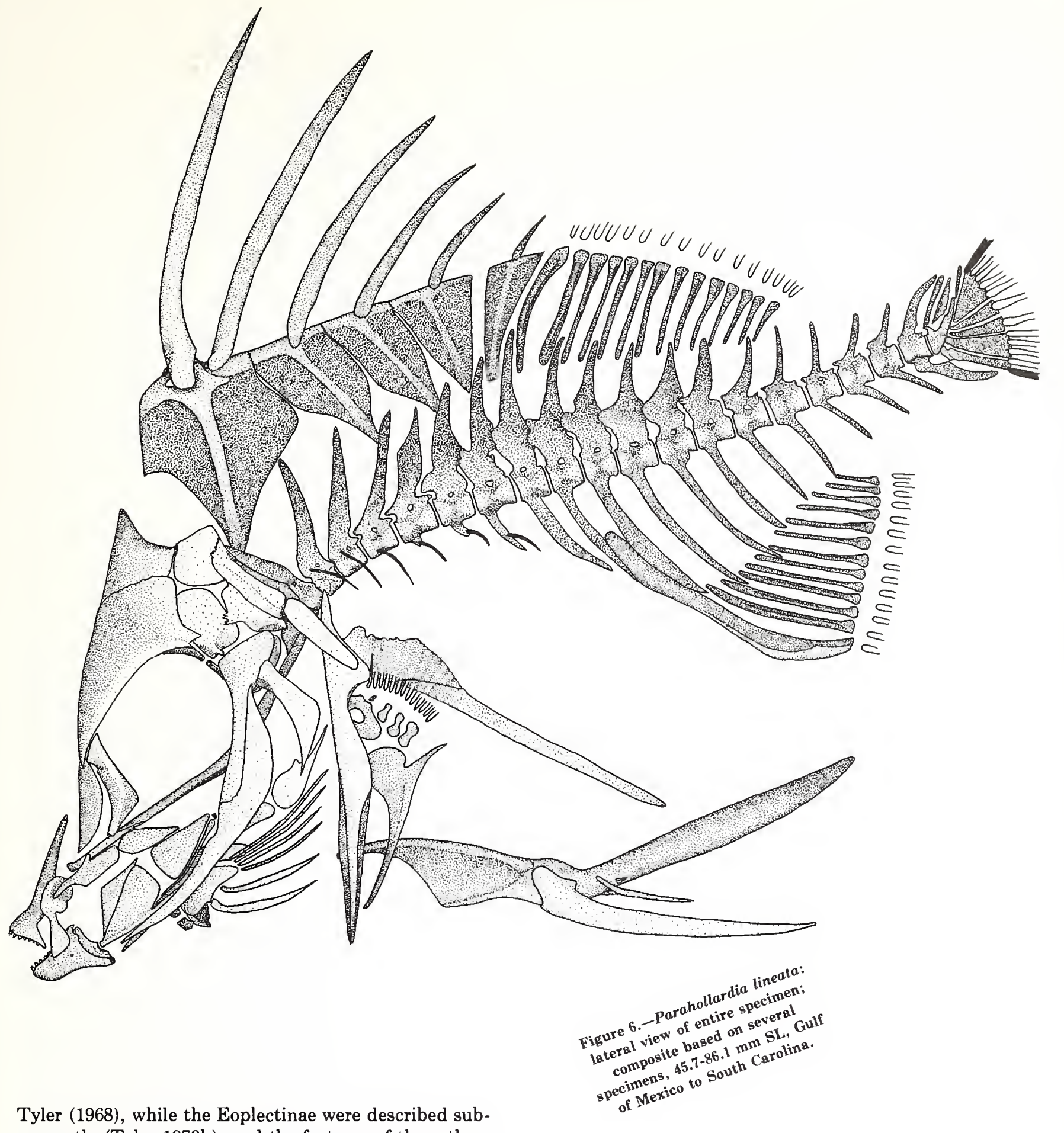
sequently (Tyler 1973b), and the features of these three subfamilies need be only briefly summarized here. The Spinacanthinae were discussed by Tyler (1968) on the basis of the literature alone, but the holotypes and only known specimens of the two species of this subfamily have been examined for the present work and are redescribed below.

Protobalistum imperiale (Massalongo 1857:775), in counterpart, MCSNV T9 (head left)-10, $522 \mathrm{~mm} \mathrm{SL}$, and $655 \mathrm{~mm}$ TL (total length), is gigantic by comparison to the other members of the superfamily Triacanthoidea,

the largest triacanthodid otherwise known being a 174 mm SL specimen of Hollardia hollardi and the largest triacanthid a $272 \mathrm{~mm}$ SL specimen of Triacanthus biaculeatus (Tyler 1968:64; 1970f:5). The spiny dorsal fin is enormous, with five well-developed strong spines decreasing in length posteriorly in the series, with the possibility that a much smaller sixth spine is present just behind the base of the fifth spine but hidden there by a slightly misplaced scale plate. All of the spines are covered with the same kind of granulations as those of 
Figure 7.-Parahollardia lineata: lateral view of head; composite based on several specimens, 45.7-86.1 mm SL, Gulf of Mexico to South Carolina.
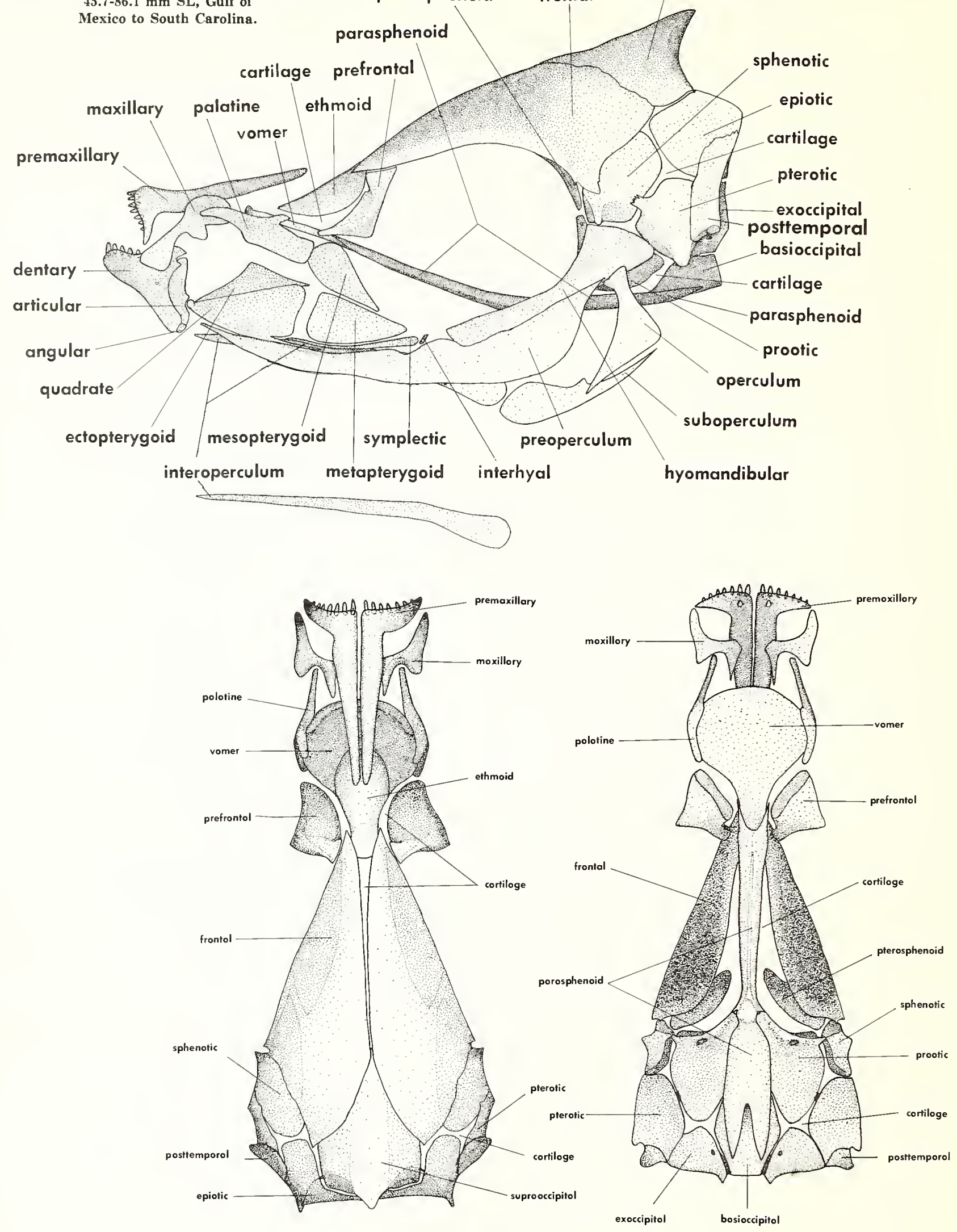


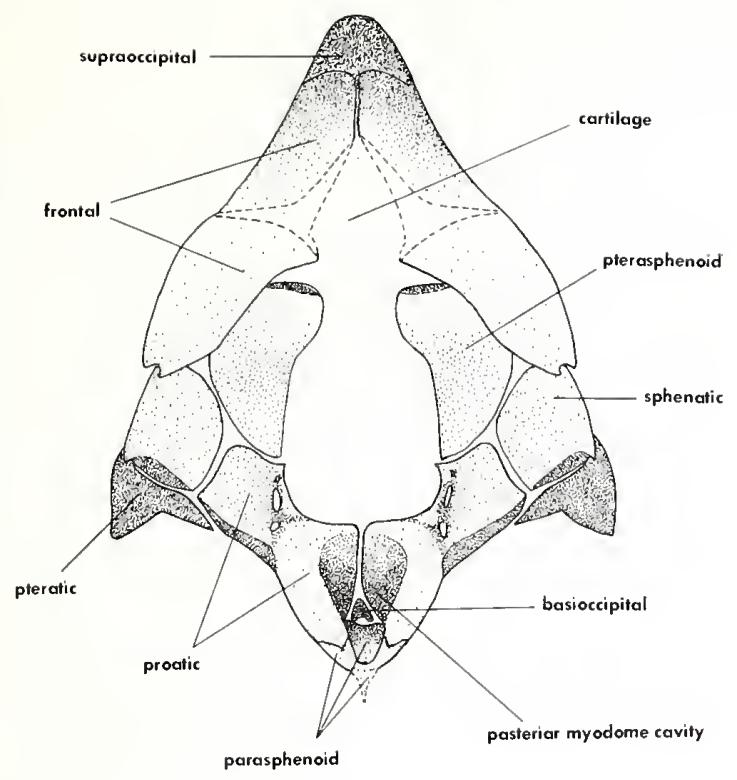

the scale plates of the body. The first dorsal spine, including the groove representing at least part of the missing distal end of the spine, is at least $279 \mathrm{~mm}(53.6 \% \mathrm{SL})$, the second at least $273 \mathrm{~mm}(52.4 \% \mathrm{SL})$, the third at least $210 \mathrm{~mm}(40.3 \% \mathrm{SL})$, the fourth at least $139 \mathrm{~mm}(26.6 \%$ $\mathrm{SL})$, and fifth, which seems complete even distally, $90.3 \mathrm{~mm}(17.3 \% \mathrm{SL})$. There are about nine dorsal fin rays, of which the fourth is the longest, $79.5 \mathrm{~mm}$ $(15.2 \% \mathrm{SL})$. The anal fin is directly below the soft dorsal fin and likewise has about nine rays, of which the third is the longest, $91.3 \mathrm{~mm}(17.5 \% \mathrm{SL})$. The spiny dorsal fin base is about $276 \mathrm{~mm}$ ( $53 \% \mathrm{SL}$ ) long, while the bases of the soft dorsal and anal fins are both about $57 \mathrm{~mm}(11 \%$ SL) long. All but the first ray in the soft dorsal and anal fins are extensively branched.

The broadly rounded caudal fin is $133 \mathrm{~mm}$ ( $25.6 \% \mathrm{SL}$ ) and has 12 rays, of which the uppermost ray and the lowermost ray are unbranched and the intervening 10 rays extensively branched. The length of the caudal peduncle (from end of anal fin base to middle of caudal fin base) is $126 \mathrm{~mm}(24.1 \% \mathrm{SL})$ and its least depth 55.0 $\mathrm{mm}(10.5 \% \mathrm{SL})$. The greatest body depth is about 210 $\mathrm{mm}(40 \% \mathrm{SL})$. The eye is placed high in the head just below the base of the first dorsal spine and has an approximate diameter of $39 \mathrm{~mm}(7 \% \mathrm{SL})$.

There are remains of pectoral fin rays, but the number cannot be counted. It is impossible to state whether a pelvic fin was present or not. In redescribing the species,

Figure 8.-Parahollardia lineata: dorsal (left) and ventral (right) views of skull; composite based on several specimens, $45.7-86.1 \mathrm{~mm} \mathrm{SL}$, Gulf of Mexico to South Carolina.
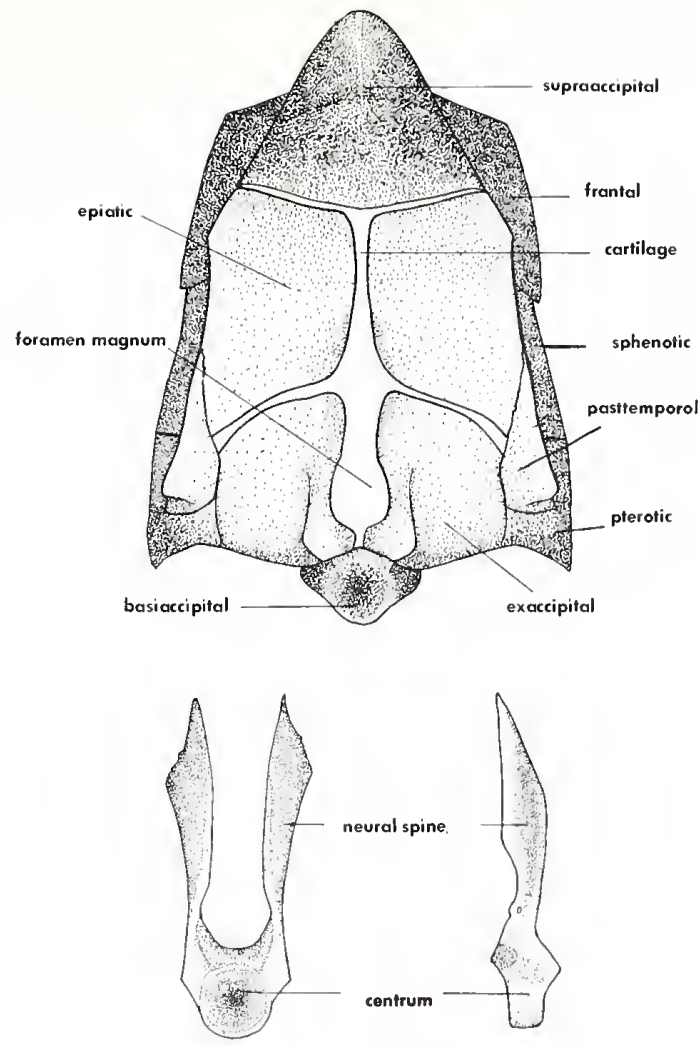

Figure 9.-Parahollardia lineata: posterior view of orbit (left) (cross section of skull; dashed lines represent cut surfaces of frontals and parasphenoid); posterior view (right) of skull; below, posterior and lateral views of first abdominal vertebra; composite based on several specimens, 45.7-86.1 $\mathrm{mm} \mathrm{SL}$, Gulf of Mexico to South Carolina.

Zigno (1887a:4) said that there was a pelvic spine of 30 $\mathrm{mm}$ length, bent backward along the side of the body. Along the lower edge of the body at the level between the bases of the second and fourth dorsal fin spines, there is a ridge of bone with the same type of surface granulation as found on the scale plates, described below. This ridge is about $173 \mathrm{~mm}$ long ( $33 \% \mathrm{SL}$ ) but is discontinuous, with some segments showing surface granulations and others the bone beneath the granulations. Zigno may have had one of these granular segments in mind for the pelvic spine. If this ridge does represent a pelvic spine, then it was almost as well developed as the more anterior dorsal fin spines. However, it is at least equally likely that this ridge is simply the ventrolateral curved edge of the carapace of scale plates that fully covers this region of the body, as described below. In short, it is not known at present whether Protobalistum had pelvic spines.

The teeth are well-preserved. They are large and relatively massive, some with straight or rounded distal edges as in incisors but others with a distinct cusp or distal constricted region. The teeth with more rounded distal edges may represent those toward the middle of the jaws that have been worn down through use. There are about four or five teeth in each half of the upper and 

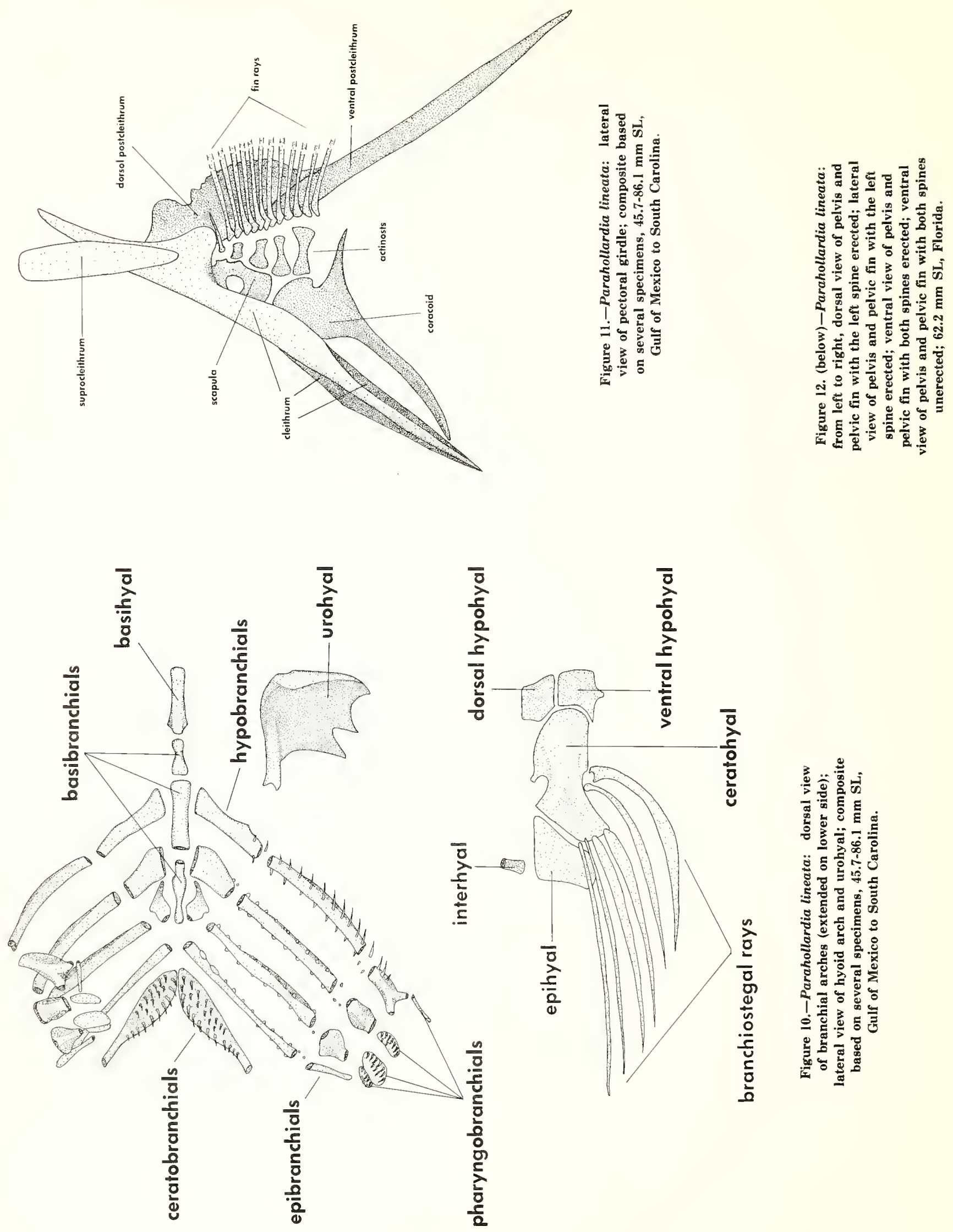

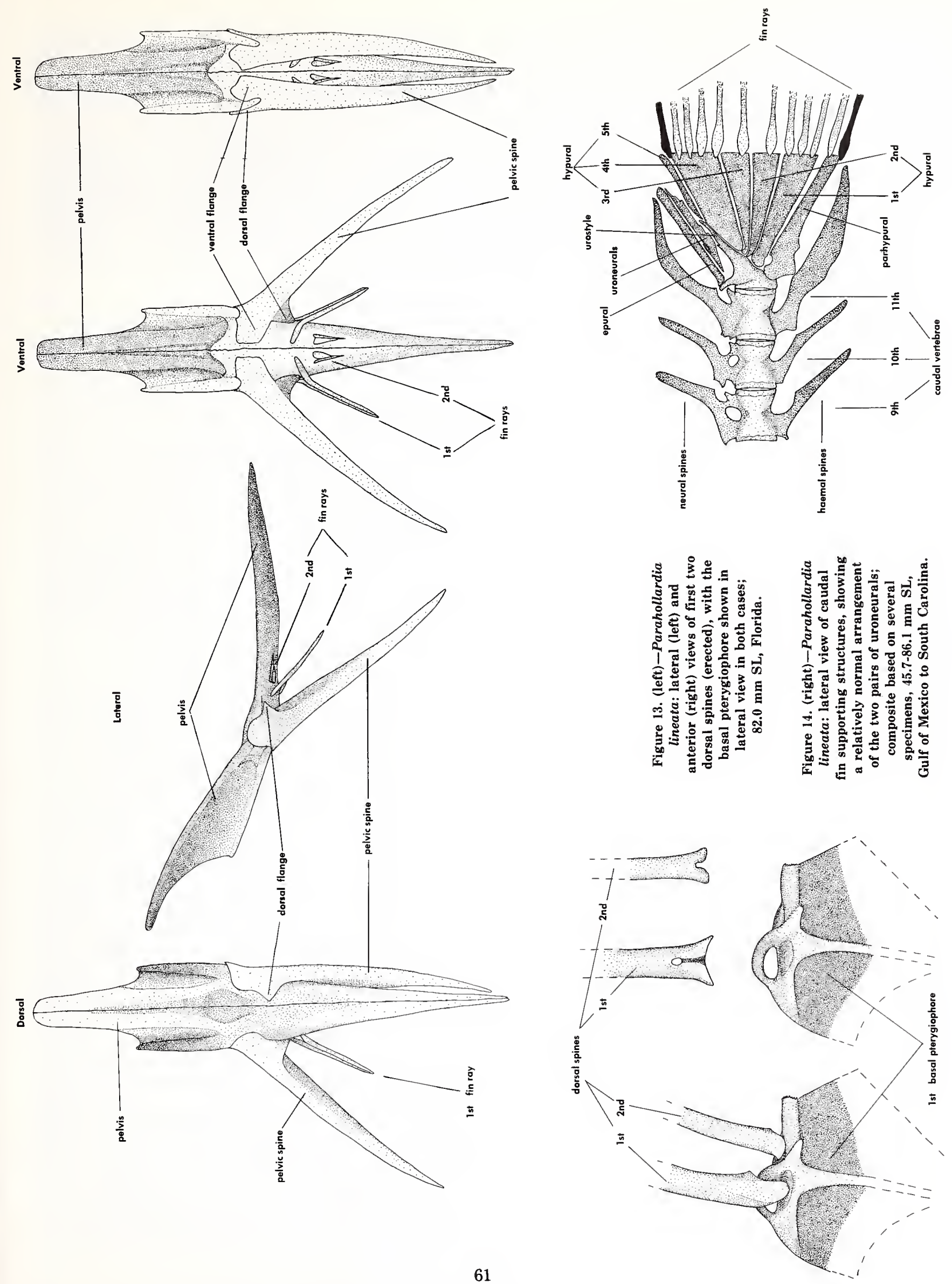

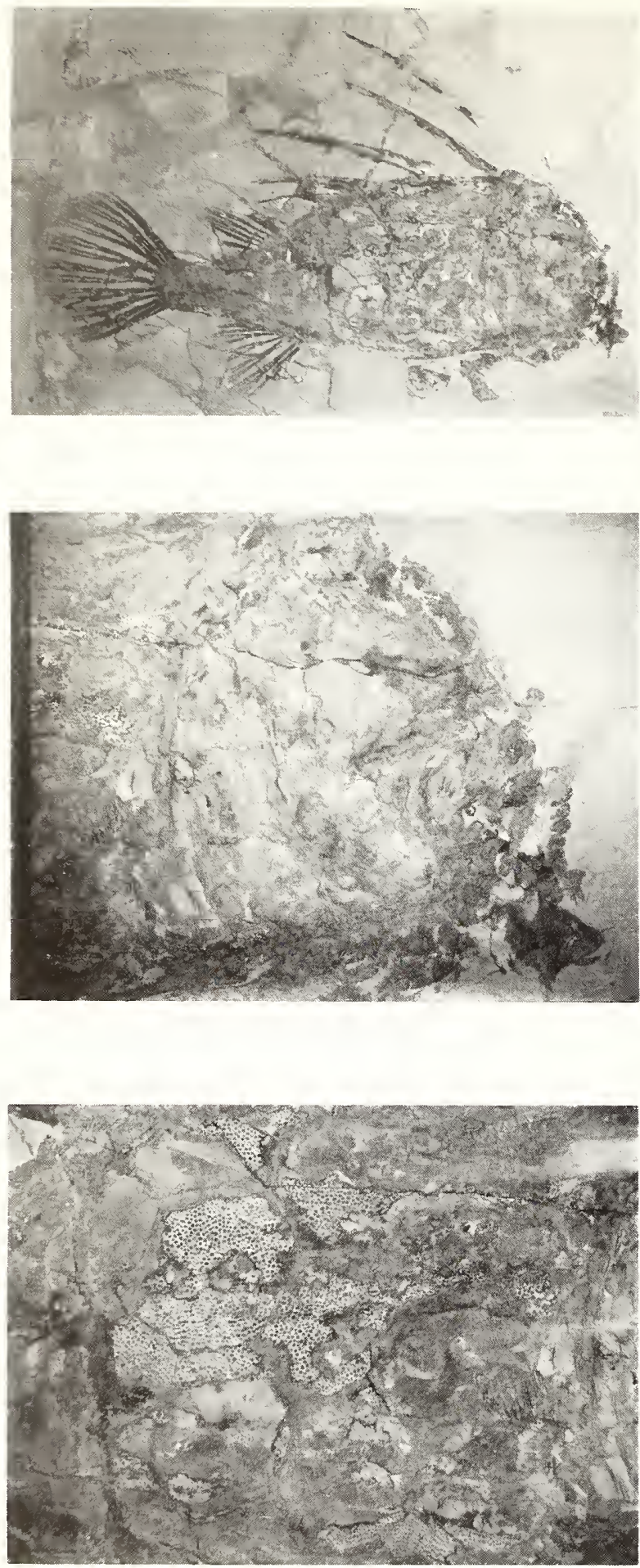

Figure 15.-Protobalistum imperiale: top, lateral views of the two counterparts; middle left, lateral view of head, showing pharyngeal and jaw teeth; lower right, lateral view of caudal region; bottom, lateral view of middle of body (head to right), showing remains of scale plates, pectoral fin rays, coracoid, and pharyngeal teeth; holotype, $522 \mathrm{~mm} \mathrm{SL}$, Eocene of Monte Bolca, Italy.
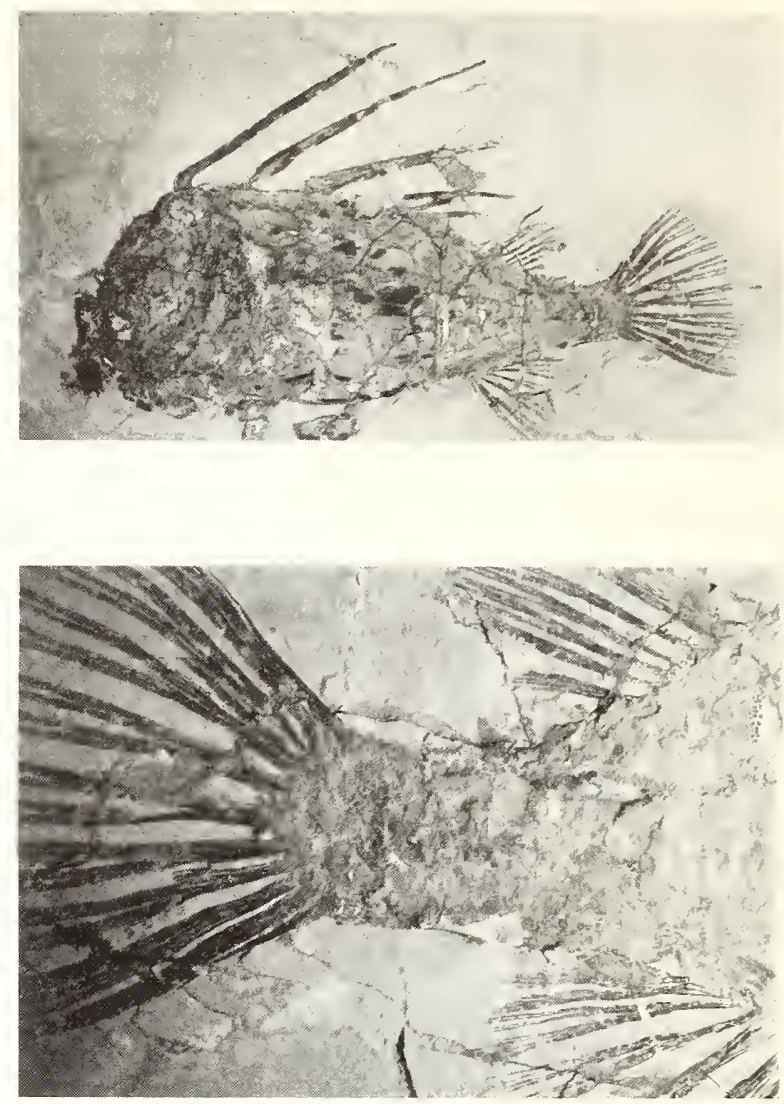

lower jaws, but it cannot be determined if they occurred in a single series or in a major outer series internal to which were a few other teeth. Pharyngeal teeth are present in the appropriate area at the intersection of the levels of the horizontal through the middle of the mouth and the vertical to the base of the second dorsal fin spine. They are small and more elongate versions of the cusped teeth of the mouth.

The anterior half of the body exclusive of the head (i.e., in the region below the bases of the second to fifth dorsal spines) is completely (taking into account missing pieces) covered by relatively huge, thick bony plates with numerous rounded bumps or granulations on their surface. Many of these plates are distinctly hexagonal, and all of them articulate to one another along all of their edges of apposition by intermeshed delicate denticulations, all of this being remarkably similar to the scale plates in ostracioids. Measurements of a few of the more complete scale plates are as follows: a plate below the bases of the fourth and fifth dorsal spines is $56.9 \mathrm{~mm}$ (10.9\% SL) deep and $64.3 \mathrm{~mm}(12.3 \% \mathrm{SL})$ wide; a plate just below the former is $51.6 \mathrm{~mm}(9.9 \% \mathrm{SL})$ deep and 52.3 $\mathrm{mm}(10.0 \% \mathrm{SL})$ wide; one of the few scale plates on the head, approximately midway between the eye and mouth, is about $31 \mathrm{~mm}(5.9 \% \mathrm{SL})$ deep and $27 \mathrm{~mm}(5.2 \%$ SL) wide. While a continuous ostracioidlike carapace apparently is present only on the anterior half of the body exclusive of the head, there are numerous, usually much 
smaller, isolated scale plates with the same kind of surface granulations on the head, especially dorsally and ventrally, and on the body posterior to the carapace in the region between the soft dorsal and anal fins and on the caudal peduncle. The scale plates, and apparently thick skin, on the caudal peduncle completely obscure the vertebral column.

The possible phylogenetic implications of the presence of ostracioidlike scales in the triacanthodid Protobalistum is discussed in the section on subfamilial relationships.

Spinacanthus cuneiformis (Blainville 1818:359), a sirgle plate, MNHN (LP) 10918, $104 \mathrm{~mm} \mathrm{SL}$, presently is a very incomplete and poorly preserved specimen which appears to have lost some of its surface and bony structure since it was studied by Volta (1796), Blainville (1818), and Agassiz (1839 illustration, 1844c description). Much less can be seen in the specimen today than in the illustrations of it by Volta and Agassiz. The spiny dorsal fin is even more enormous than in Protobalistum, with the first spine, even with a slight amount of the distal tip missing and not measurable, being $95.7 \mathrm{~mm}(92.0 \%$ $\mathrm{SL})$. The second to fourth dorsal spines are missing too much of their distal ends to be measureable, but apparently they were almost as long as the first spine. The fifth spine is about $35 \mathrm{~mm}$ ( $34 \% \mathrm{SL})$ long, and a smaller sixth spine, if present, cannot be detected. There are large retrorse thornlike barbs along the anterior edge of at least the basal third of the first dorsal spine. There appear to have been about 10 fin rays in both the apposed soft dorsal and anal fins. The slightly rounded caudal fin is poorly preserved, but it had about 12 rays (Agassiz thought 7 or 8 branched rays plus an unbranched ray above and below). The pectoral fin has about 12 or 13 rays (Agassiz thought 12). Agassiz estimated the number of vertebrae to be no more than 20 , and I would guess at about 20 judging on the basis of the size of those that show and of the space available for those that do not show. The length of the caudal peduncle is $26.0 \mathrm{~mm}(24.9 \% \mathrm{SL})$ and its depth at least $7.0 \mathrm{~mm}$ (6.7\% SL). The greatest body depth is $39.0 \mathrm{~mm}(37.4 \%$ SL). The eye is placed high in the head just below the base of the first dorsal spine and has a diameter of 7.2 $\mathrm{mm}(6.9 \% \mathrm{SL})$.

The branchiostegal rays from both sides are evident, and in the more clearly seen set there appear to be six rays. The prefrontal is one of the few bones that are relatively well preserved, and it has an appropriately moderate size. Agassiz thought that a pelvic spine was present and displaced in the region of the branchiostegals. At least at present I find no structure in the branchiostegal region that could possibly be interpreted as a pelvic spine. However, just posterior to the branchiostegals and below the pectoral fin is a vague indication of a long rodlike strut of bone oriented vertically. It is possible that this is the structure seen by Agassiz, and it might possibly be a thin, weakly developed barbless pelvic spine. It would appear to me more likely to be a part of the pectoral girdle, perhaps the thickened posterior edge of the coracoid. As with Protobalistum, it is not known with surety whether Spinacanthus had a pelvic fin.

The teeth in the lower jaw are well-preserved. There appear to have been about seven of them in the left dentary. A few of these teeth are especially fully exposed and can be seen clearly in three dimensions. One of these is $2.0 \mathrm{~mm}(1.9 \% \mathrm{SL})$ long from its flat circular base to its distal tip. The tooth tapers only very slightly from basally to distally throughout most of its length, but in the

Figure 16.-Spinacanthus cuneiformis: lateral view of holotype, $104 \mathrm{~mm} \mathrm{SL}$, Eocene of Monte Bolca, Italy.

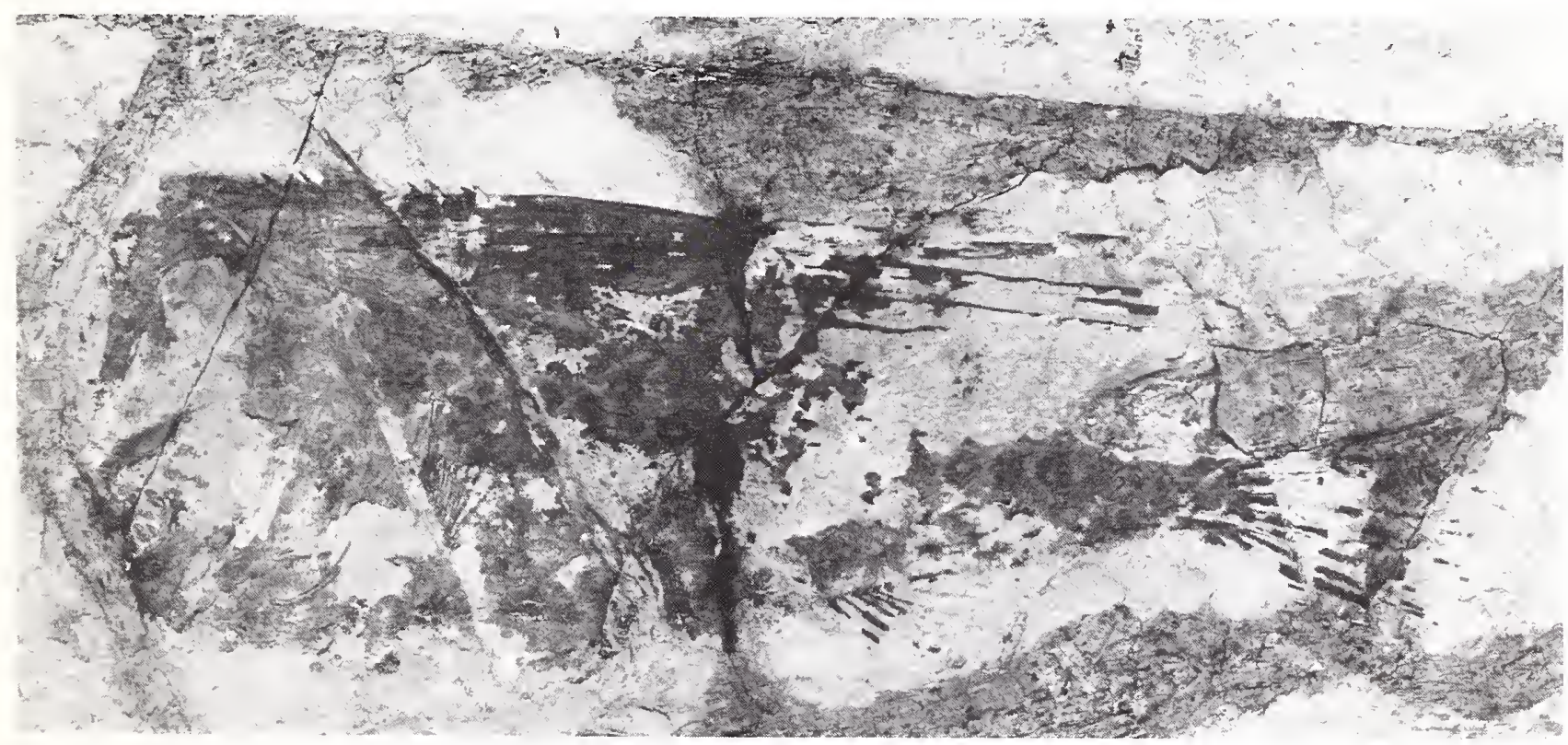


distal one-fifth of the length the tooth is strongly constricted into a blunt nipple. In the distal halves of their lengths the teeth bear about 10 annularlike rings, which I doubt are artifacts. In the upper jaw, grooves represent where teeth once were present, and perhaps of their sockets. More than 20 pharyngeal teeth are present in the region in front of the pectoral fin base, these being similar to those of the jaws but much smaller, the largest being about $0.5 \mathrm{~mm}(0.5 \% \mathrm{SL})$ long.

The body bears numerous, mostly isolated, scale plates of moderate size. Each plate has a strong relatively high central spine peripheral to which are much smaller and lower rounded bumps or granulations similar to those of Protobalistum. The more or less isolated plates, which probably covered only about one-fourth of the surface of the body, seem to become more numerous ventrally, where they may have been placed in more or less regular horizontal rows, with some contact between individual plates. The plates are largest and most regularly arranged along the ventral edge of the body from the region of the branchiostegals posteriorly to the anal fin base, the largest plates being in the abdominal area. The largest plates have a diameter of about $5.0 \mathrm{~mm}$ $(4.8 \% \mathrm{SL})$. Very few scale plates are evident on the head, the only one clearly seen being on the profile of the snout about midway between the mouth and eye. The scale covering of Spinacanthus is comparable to that found on Protobalistum anterior and posterior to its carapace of articulated hexagonal plates.

The anatomical features of the Eoplectinae, recently described by Tyler (1973b), are summarized briefly below.

The Eoplectinae are represented by two species known only from their holotypes, only one of which (Eoplectus) is well preserved.

In most of its features Eoplectus bloti Tyler (1973b) is a generalized plectognath at the triacanthodid level of organization. It has at least five and probably six dorsal fin spines, a rounded caudal fin of 12 rays (i, 10, i), a generalized caudal skeleton, a short caudal peduncle, and the most generalized condition of the pelvic fin known among the plectognaths, this being a spine and four well-developed branched rays. The overall configuration of the body is also triacanthodid. However, Eoplectus has the jaws and dentition modified into a crushing beak, with numerous small rounded dental units incorporated into the matrix of the premaxillary and dentary. This condition otherwise is found among

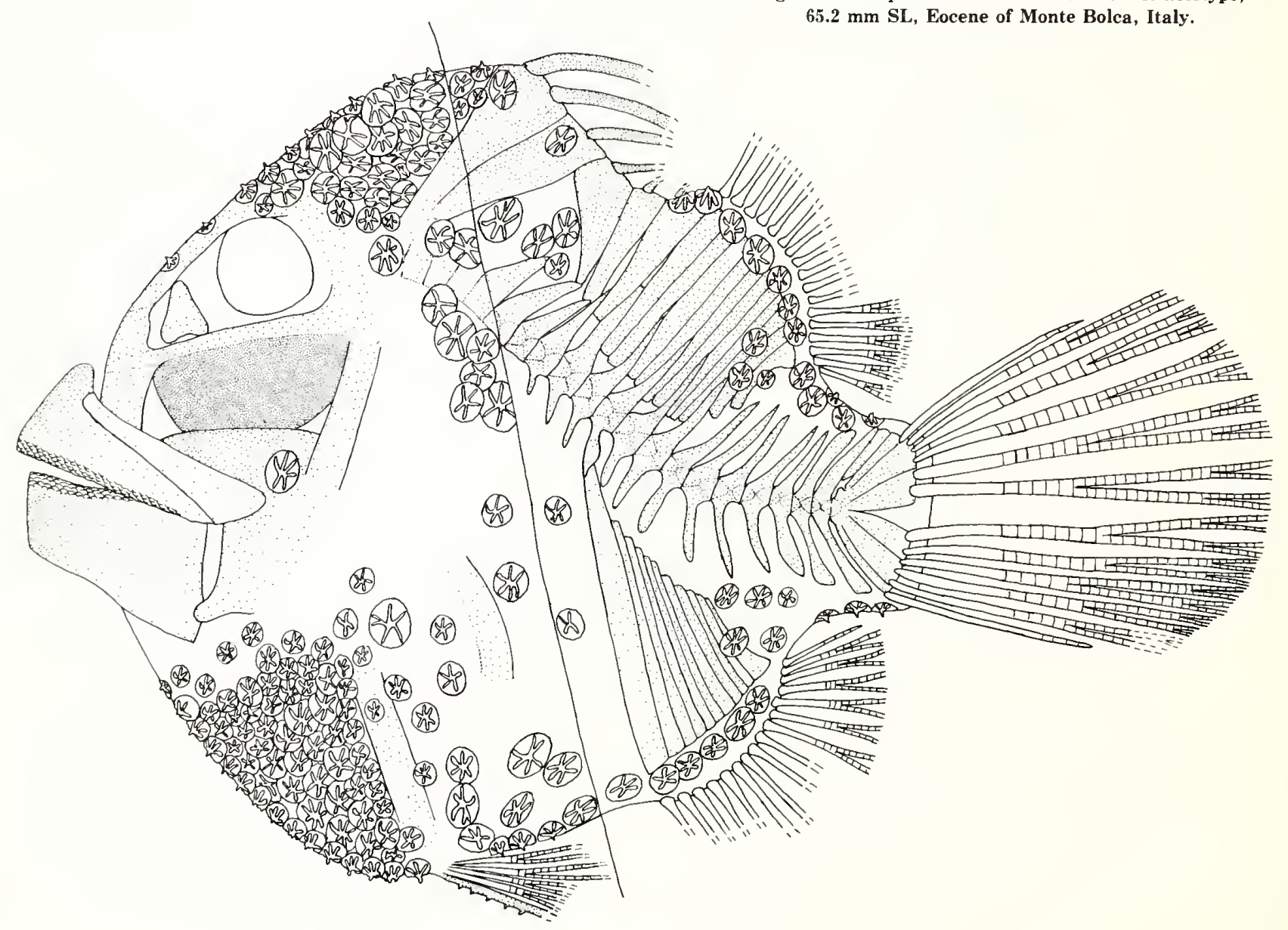

Figure 17.-Eoplectus bloti: lateral view of holotype, $65.2 \mathrm{~mm} \mathrm{SL}$, Eocene of Monte Bolca, Italy. 
the plectognaths only in the suborder Gymnodontes (Tetraodontoidei), and it is closely similar to that of Triodon, the monotypic representative of the Triodontidae and the most generalized member of its suborder.

Eoplectus is similar to Recent triacanthodids and differs from Triodon in the following ways: 1) Recent triacanthodids have the most fully developed pelvic fin among plectognaths, in more generalized forms consisting of a spine and two unbranched rays, while in Eoplectus this fin is even better developed as a spine and four branched rays, the better development in Eoplectus being less reduced than in triacanthodids from the ancestral perciform condition of one spine and five branched rays; 2 ) the rounded i, 10 , i caudal fin, without procurrent fin rays; 3 ) the short caudal peduncle; 4) six dorsal fin spines borne on five well-developed basal pterygiophores; 5) first basal pterygiophore of the spiny dorsal fin articulated low on the base of the skull and bearing the first two spines; 6) third to fifth basal pterygiophores of the spiny dorsal fin with their shafts directed ventrally or posteroventrally in relation to the vertebral axis and articulated with the neural spines of the fifth to eighth vertebrae; 7) 20 vertebrae; 8 ) probably no ribs; 9) small prefrontal not extensively sutured to the frontal, parasphenoid and ethmoid; 10) moderately large eye located about midway between the snout and spiny dorsal fin origin; 11) relatively large numbers of dorsal and anal fin rays.

Eoplectus is similar to Triodon and differs from the other triacanthodids in the following ways: 1) the small individual rounded dental units intimately associated with the matrix of the premaxillaries and dentaries to form a crushing beak; 2) premaxillary probably immovably held by suturing to the maxillary, the ascending process of the premaxillary poorly developed and the upper jaw probably nonprotrusible, rotating around a ball and socket joint between the palatine and the maxillary; 3) the palatine probably immovably sutured to the ethmoid-vomerine region; 4) vertebrae in a $9+11$ arrangement.

Eoplectus is similar to both the other triacanthodids and to Triodon in the following ways: 1) the pelvis with a long anterodorsal shaft probably held between the anteromedial edges of the cleithra; 2) a generalized caudal skeleton with the parhypural, numerous hypurals, and single epural probably not fused to one another or to the last centrum.

Eoplectus differs from both the other triacanthodids and Triodon in the following ways: 1) probably no uroneurals, or only very small ones at the most; 2 ) the great depth of the caudal peduncle; 3 ) the placement of the well-developed shaft of the second basal pterygiophore of the spiny dorsal fin, directed strongly anteroventrally and articulating either with the base of the skull or between the neural spines of the first and second vertebrae; 4 ) the spiny dorsal fin base equal in length to the soft dorsal fin base rather than either much greater or much less than it; 5) soft dorsal and anal fin rays far more numerous than the basal pterygiophores supporting them; 6) the extremely well developed ventral flange of

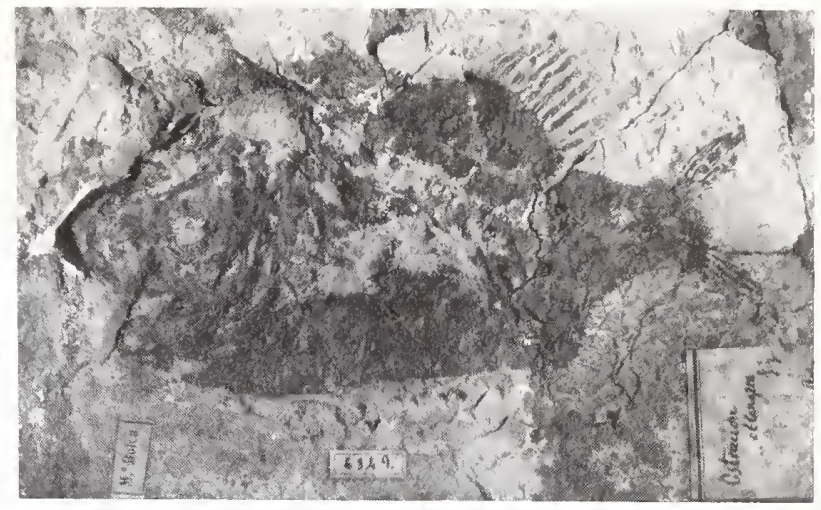

Figure 18.-Zignoichthys oblongus: lateral view of holotype, ca. $161 \mathrm{~mm}$ SL, Eocene of Monte Bolca, Italy.

the parasphenoid versus weakly to moderately developed; 7) the highly arched vertebral column; 8) the body with an incomplete covering of scales, many of which are isolated and nonoverlapping.

The other species of Eoplectinae is the extremely poorly known Zignoichthys oblongus (Zigno 1874a, b) from the same strata of the Eocene of Monte Bolca, Italy, in which Eoplectus occurs. Of its few known features, redescribed by Tyler (1973b) and briefly summarized here, the most important is the huge jaw bone composed of two equal sides fully fused together in the midline with no evidence of any kind of separation or suture between the right and left halves. The biting edge of the beaklike jaw is not exposed, but the teeth can be expected to be small dental units incorporated into the matrix of the bone much as in Eoplectus, Triodon, and some of the other gymnodonts. The body is covered with numerous small scales with numerous upright spinules, and the caudal fin has about 12 principal rays in addition to at least two or three procurrent rays both above and below. Among plectognaths, procurrent rays are otherwise known only in Triodon. It is not known with surety whether dorsal fin spines were present, for most of the appropriate region of the body is missing, but it is probably best to assume that a spiny dorsal fin of unknown size was present. The region where one would expect to find a pelvic fin if one were present is relatively well preserved, and no pelvic fin is apparent, and it can probably be assumed that the pelvic spine, if present at all, was of reduced size.

Too few critical features are known of Zignoichthys to allow a precise placement of it among the plectognaths, and it has very tentatively been associated (Tyler 1973b) with Eoplectus and the Eoplectinae of the Triacanthodidae for the following reasons. It has a generalized condition of the caudal fin and caudal peduncle, and of the soft dorsal and anal fins and scales consistant with the triacanthodids, and, if a spiny dorsal fin was present, it would probably have been longer based than the soft dorsal fin, judging from the space available for it, while the jaw that is exposed is similar to that of Eoplectus. 
The Eoplectinae differ from the other fossil subfamily of triacanthodids, the Spinacanthinae, mainly by having a larger eye located about midway between the snout and spiny dorsal fin origin, the lesser development of the spiny dorsal fin and its shorter base and more posterior position, better developed and longer based soft dorsal and anal fins, and the massive beaklike jaws.

The anatomical diversity of the two Recent subfamilies of triacanthodids is summarized below from Tyler (1968). Of greatest phylogenetic significance is the arrangement and form of the bones of the posterodorsal region of the skull and in the shape of the pelvis, which features divide the Recent species into different subfamilies.

In the Hollardinae, which form a compact group of five species in two genera, the supraoccipital is domelike and separates the epiotics on the dorsal surface of the skull, while the epiotics directly contact the frontals and the pelvis is a sturdy shaft with a more or less triangular shape in cross-section. In the Triacanthodinae, whose 14 species in 9 genera range from relatively normal species through intermediates to weirdly specialized forms with extremely long tubular snouts, the supraoccipital basically is a broad flat bone with a variously developed crest and does not separate the epiotics on the dorsal surface of the skull, while the epiotics are separated from the frontals by the sphenotics and the pelvis is a broad flat basin with upturned edges.

The two genera of Hollardiinae differ mainly in that Parahollardia retains a small number of teeth internal to the major outer series while the inner teeth on the premaxillary and dentary are lost in Hollardia.

Similarly, in the Triacanthodinae, one genus (Triacanthodes) retains inner series teeth which are lost in the other eight genera. In the Triacanthodinae the teeth are usually conical, as they are also in the Hollardiinae, but in a few genera the teeth are large, thin, and wide, much compressed from front to back, and either truncate (Tydemania) or truncate to rounded or pointed (Macrorhamphosodes) distally. In Johnsonina the conical teeth are smaller and far more numerous than in the other genera of triacanthodins, while in Halimochirurgus the teeth are small and conical but of low to moderate ( 3 to 15 ) number in both jaws. In one species, Macrorhamphosodes platycheilus, the few upper jaw teeth are lost in adults.

The snout in most triacanthodins is of short to moderate length and normal shape, but in one of the two species of Bathyphylax, the snout, although of only moderate length, is decidedly concave in front of the eyes, giving it a tubular appearance, while in Macrorhamphosodes and Halimochirurgus the snout is enormously ( 26 to $49 \% \mathrm{SL}$; least so in young) elongate and tubular. The mouth is more or less terminal in Triacanthodes, Mephisto, and Paratriacanthodes, as it is in the Hollardiinae, but it is slightly supraterminal in Johnsonina and Atrophacanthus, slightly to decidedly supraterminal in Bathyphylax, and decidedly supraterminal in Tydemania, Macrorhamphosodes, and Halimochirurgus.
The bones of the long tubular snouts of Macrorhamphosodes and Halimochirurgus are strangely rearranged from the condition of other members of the family. In both species of Halimochirurgus and in $M$. uradoi the upper three-fourths of the tube is composed, from anteriorly to posteriorly, more or less successively by the ectopterygoids, palatines, and vomer, which are thin, curved, and elongate plates. In $M$. platycheilus, however, the vomer extends further forward than in the others to form the roof of the anterior region of the snout to the exclusion of the ectopterygoids and palatines. The ventrolateral region of the tube in all four species is formed by the elongate quadrate and the long slender anterior prolongation of the preoperculum. The premaxillary pedicels of $M$. uradoi are prolonged posteriorly as thin filaments but in none of the four long-snouted species do the pedicels extend posteriorly to the region of the ethmoid, as they do in other triacanthodids. The bones of the snout of Halimochirurgus more completely roof over the tube than in Macrorhamphosodes, and the tube is narrower and more elongate in Halimochirurgus than in Macrorhamphosodes.

In Halimochirurgus the lips are of normal triacanthodid size and shape, while in Macrorhamphosodes the lips form a wide disklike structure around the mouth. The size of the lips in Tydemania is more or less intermediate between that of Macrorhamphosodes and other triacanthodids. In Macrorhamphosodes the mouth becomes twisted to the left or right, usually progressively so with increasing specimen size, while in Halimochirurgus it is symmetrically placed at all sizes.

The spiny dorsal fin is relatively well developed, with all six spines protruding through the surface and of gradually decreasing length posteriorly in the series in Triacanthodes, Mephisto, Paratriacanthodes, and Johnsonina, as in the Hollardiinae, while in Bathyphylax the fourth spine is much shorter than the third but protrudes through the surface and is clearly seen, with the fifth and sixth spines only slightly shorter than the fourth and protruding only slightly less. In Atrophacanthus, Tydemania, Macrorhamphosodes, and Halimochirurgus the last three dorsal spines are rudimentary and usually only barely, if at all, protrude through the surface, while in Halimochirurgus the third spine also tends to be rudimentary.

Triacanthodes, Johnsonina, and Paratriacanthodes herrei usually have two pelvic fin rays, although in large specimens the second may tend to become a buried rudiment and be resorbed, while in $P$. retrospinis, Mephisto, Atrophacanthus, Bathyphylax, Tydemania, Macrorhamphosodes, and Halimochirurgus there is only a single pelvic fin ray.

The size of the gill opening varies from relatively huge for a plectognath fish in Mephisto, in which the slit extends down well below the level of the lower edge of the pectoral fin base, to simply large, as in Triacanthodes, Halimochirurgus centriscoides, and Macrorham. phosodes platycheilus, in which the slit extends down to or around the level of the lower edge of the pectoral fin base, to moderate or short, as in all the other species, in 


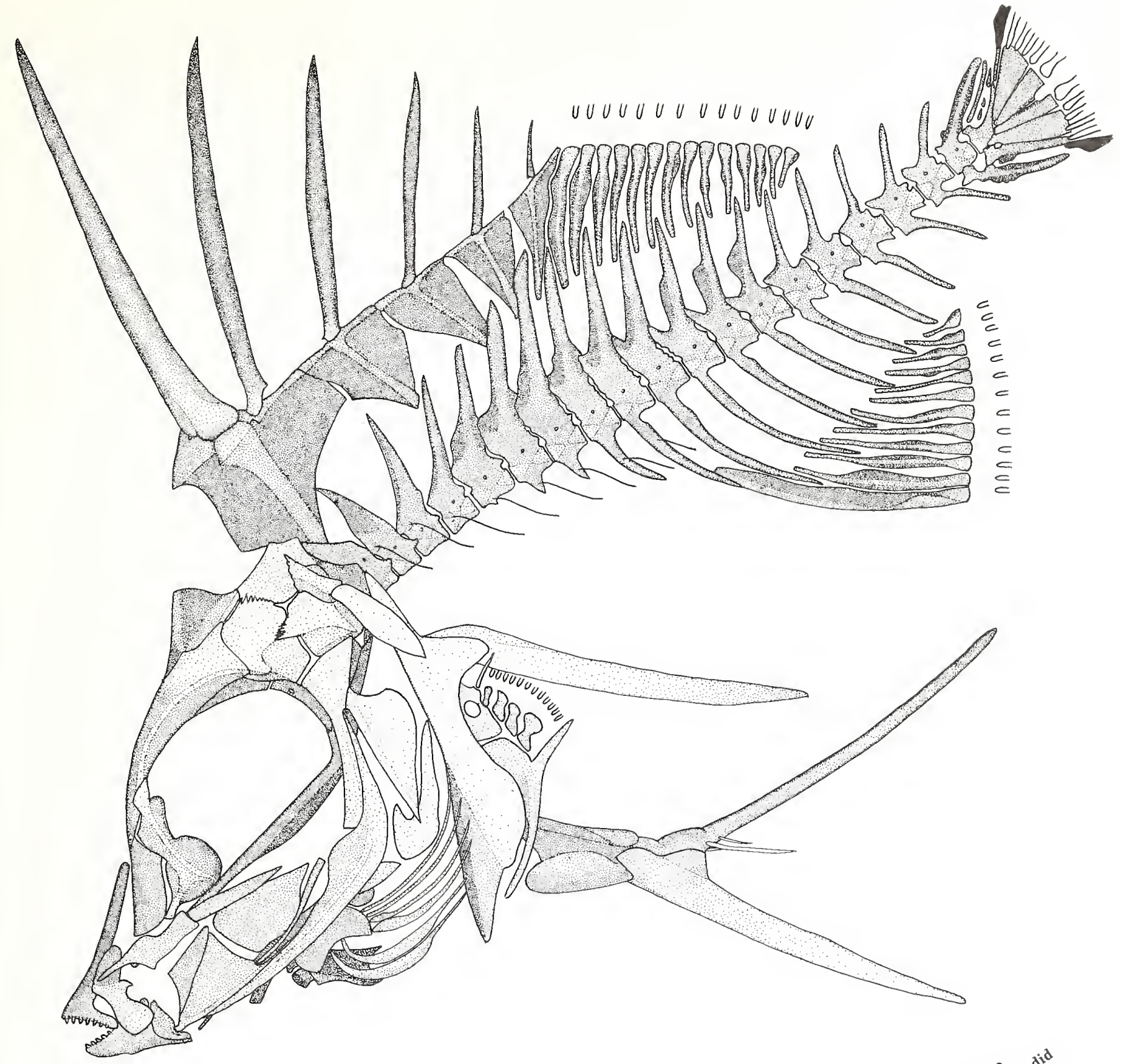

and 0

which it extends to somewhere between the level of about one-third to three-fourths down the pectoral fin base, the slit being especially short in Halimochirurgus alcocki and Macrorhamphosodes uradoi.

The length of the pseudobranch, more or less correlated with its number of lamellae, varies from especially long, as in Triacanthodes, in which it extends below the level of the lower edge of the pectoral fin base, to short, as in Mephisto, Bathyphylax, and Macrorhamphosodes, in which it extends to the level of the upper edge of the pectoral fin base, with the other genera variously intermediate.

The greatest depth of the body in adults of Triacanthodes, Mephisto, Paratriacanthodes, Johnsonina, and 


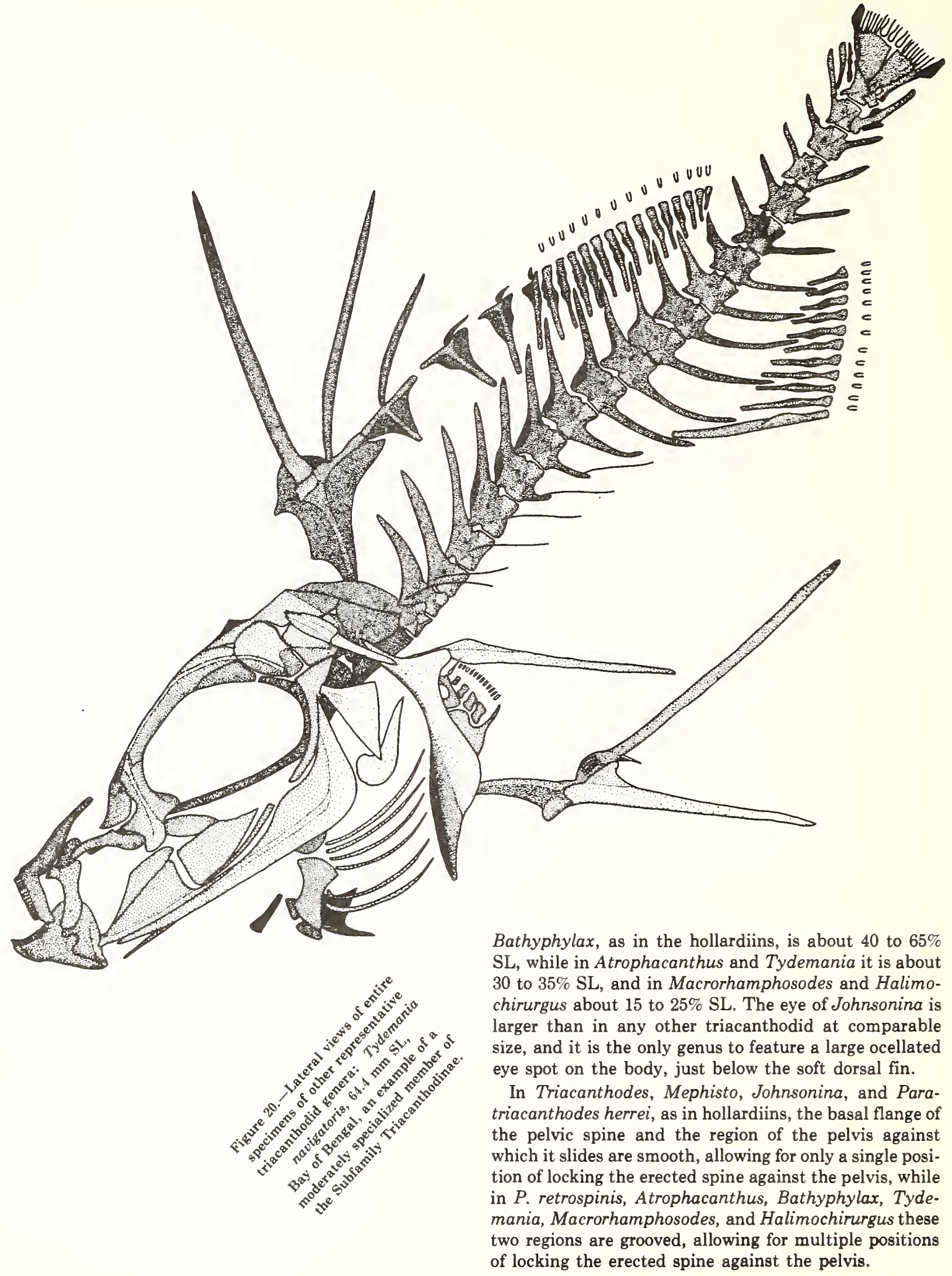




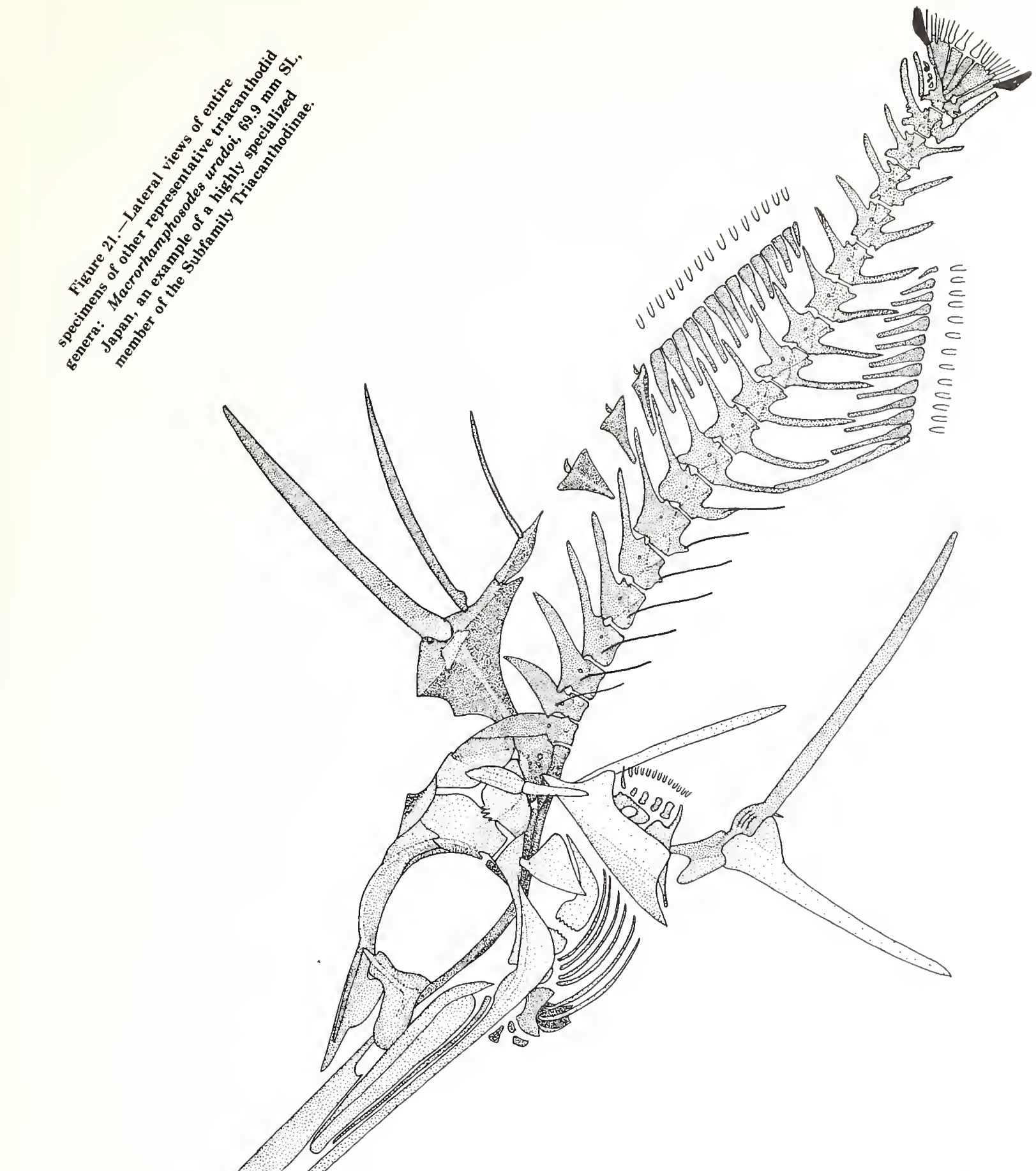

The crest on the otherwise flattened supraoccipital of triacanthodins is best developed in Triacanthodes and Johnsonina, being high and relatively wide at the anterior edge, while in all the other genera the crest is low and thin. Other features of the anatomical diversity of the triacanthodids are discussed by Tyler (1968), and for the muscles by Winterbottom (1974).

Generic relationships._Parahollardia and Hollardia are obviously very closely related, with the former slightly the more generalized of the two, based on the evidence of its retention of a series of teeth internal to the major 


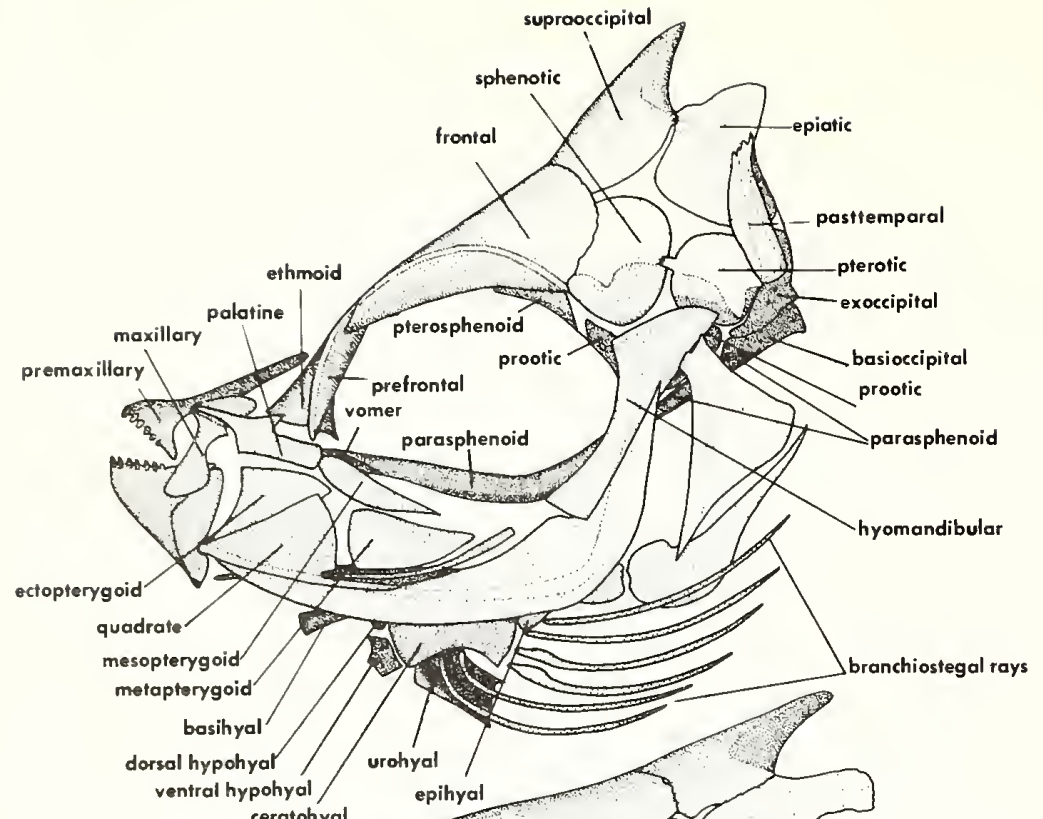

Figure 22.-Hollardia hollardi: lateral view of heads of moderate-sized specimen, $62.7 \mathrm{~mm} \mathrm{SL}$, (above) and extremely large specimen, $174 \mathrm{~mm} \mathrm{SL}$.

(the largest Recent triacanthodid fish recorded), Caribbean, showing the change in configuration, increased suturing in the occipital-otic region and decreased amount of cartilage visible externally in large specimens.

canthodes-like level of organization. An Atrophacanthus-like form, with the last three dorsal spines rudimentary, the second pelvic ray absent, and the mouth slightly but distinctly supraterminal, is probably not ancestral to any other living triacanthodid, for the tendencies it shows are for the snout to slightly decrease in length and the conical teeth to increase in number while becoming smaller and more sharply pointed. These tendencies are not compatible to ancestry of any of the other moderately or highly specialized genera.

However, a Tydemania-like form is ancestral to Macrorhamphosodes, while a Bathyphylax-like one is ancestral to Halimochirurgus. Thus, the two longsnouted genera which are superficially closely related in actuality have independently evolved long snouts and are not as closely related to one another as to other genera.

Tydemania and Macrorhamphosodes are the only two genera of triacanthodids in which the teeth are wide and thin and variously pointed to rounded to truncate distally. Tydemania has a snout of moderate length, a distinctly supraterminal mouth of moderate width with wide fleshy lips, the truncate teeth well developed in both jaws but slightly fewer in the upper than in the lower jaw, the last three dorsal spines rudimentary, and the second pelvic ray absent. These are all characteristics that one would expect to find in an ancestor of Macrorhamphosodes, in which the elongate snout bears a distinctly supraterminal mouth in a wide fleshy disk, the teeth are more or less truncate and well developed in the lower jaw but few in number or absent in the upper jaw, the last three dorsal spines are rudimentary, and the second pelvic fin ray is absent.

In Halimochirurgus the distinctly supraterminal mouth has thin lips and feeble teeth in reduced number in both jaws at the end of an extremely long tubular 
Figure 23.-Parahollardia schmidti: lateral view of head;

$62.0 \mathrm{~mm}$ SL, Nicaragua.

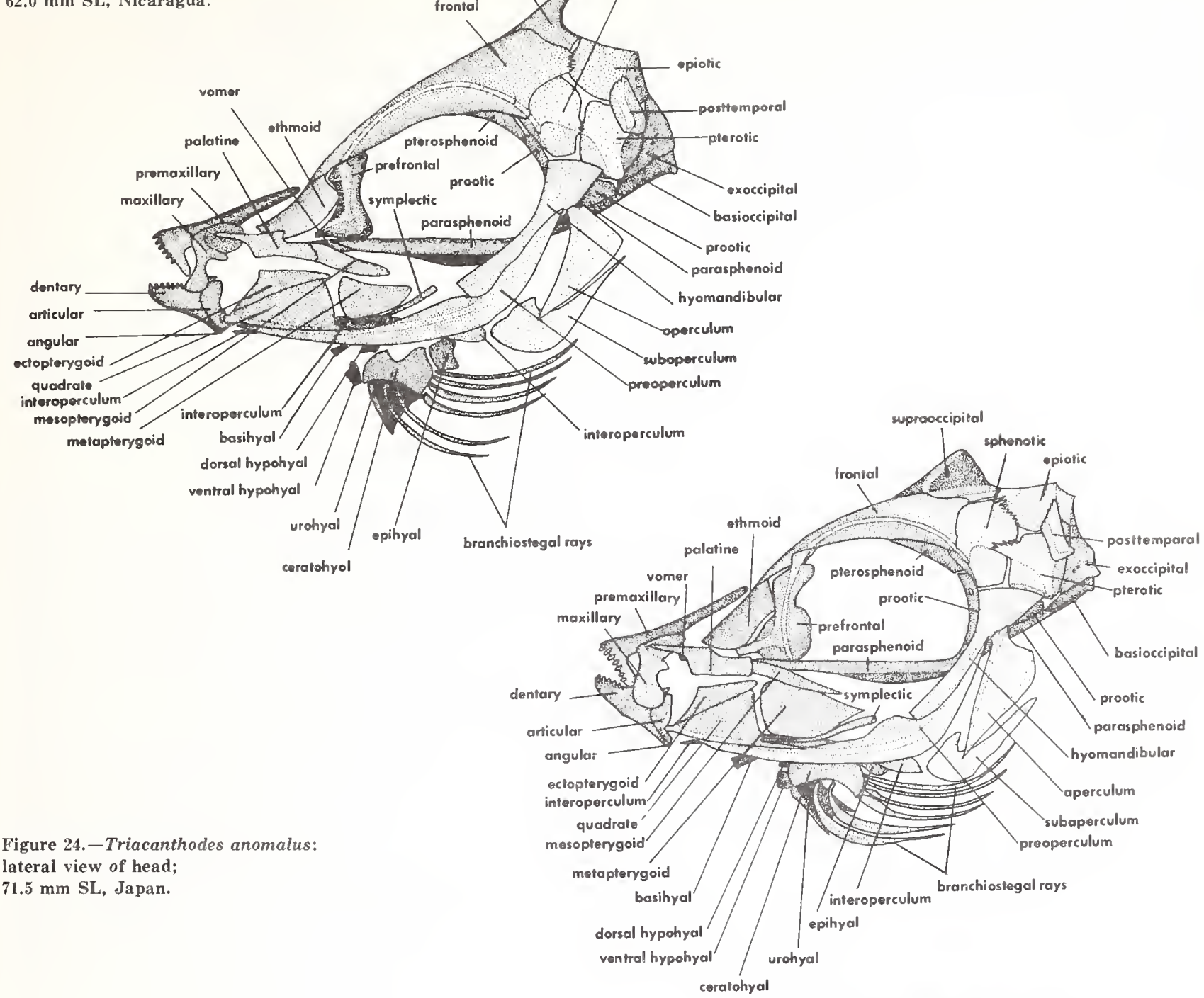

Figure 24.-Triacanthodes anomalus:

lateral view of head:

$71.5 \mathrm{~mm}$ SL, Japan.

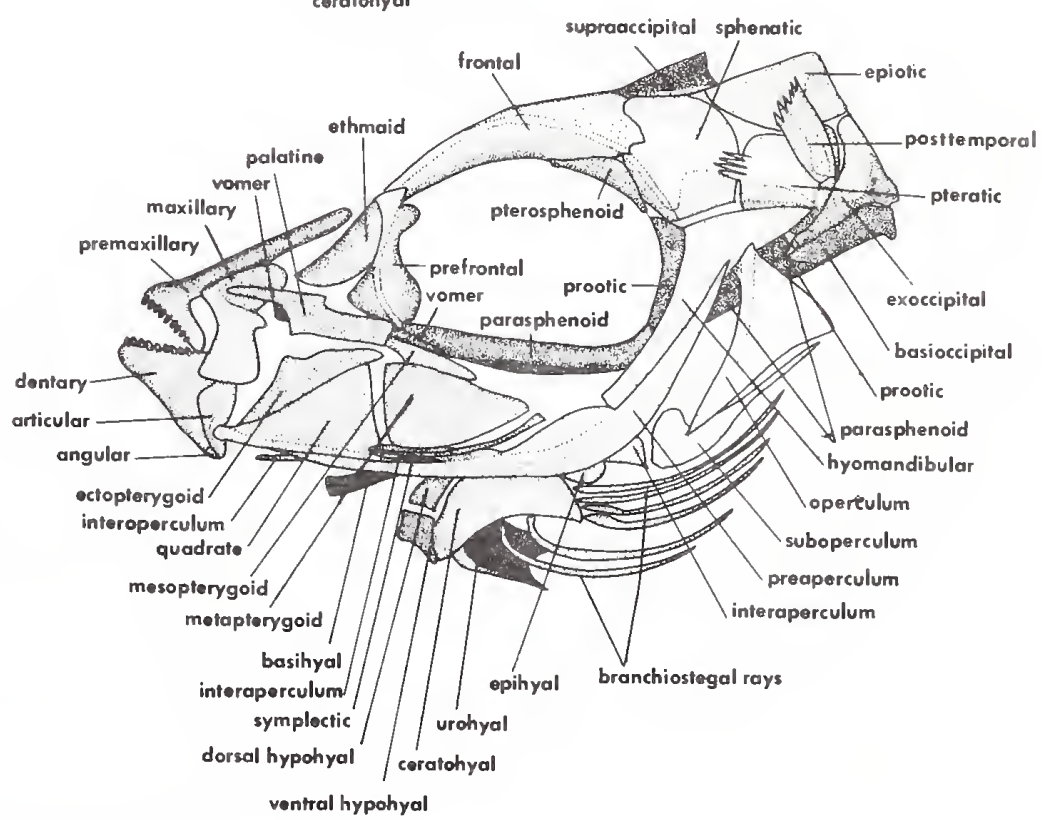

Figure 25.-Paratriacanthodes

retrospinis: lateral view of head;

$85.3 \mathrm{~mm}$ SL, Mozambique.

ventral hypohyal 
Figure 26.-Johnsonina eriomma: lateral view of head: $67.0 \mathrm{~mm} \mathrm{SL}$.

Puerto Rico.

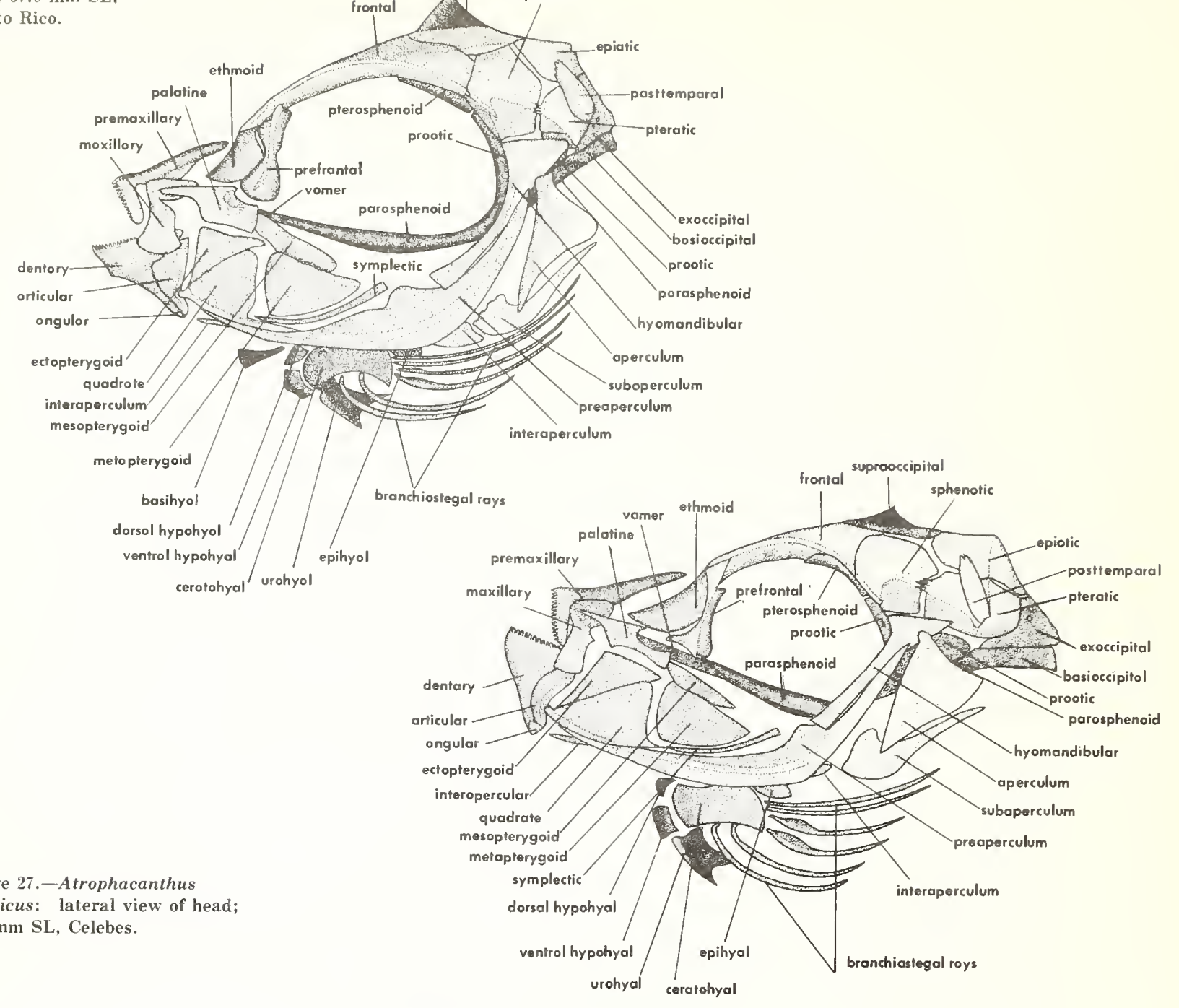
japonicus: lateral view of head; $43.1 \mathrm{~mm}$ SL, Celebes.
Figure 28.-Tydemania navigatoris: lateral view of head; $64.4 \mathrm{~mm} \mathrm{SL}$, Bay of Bengal.

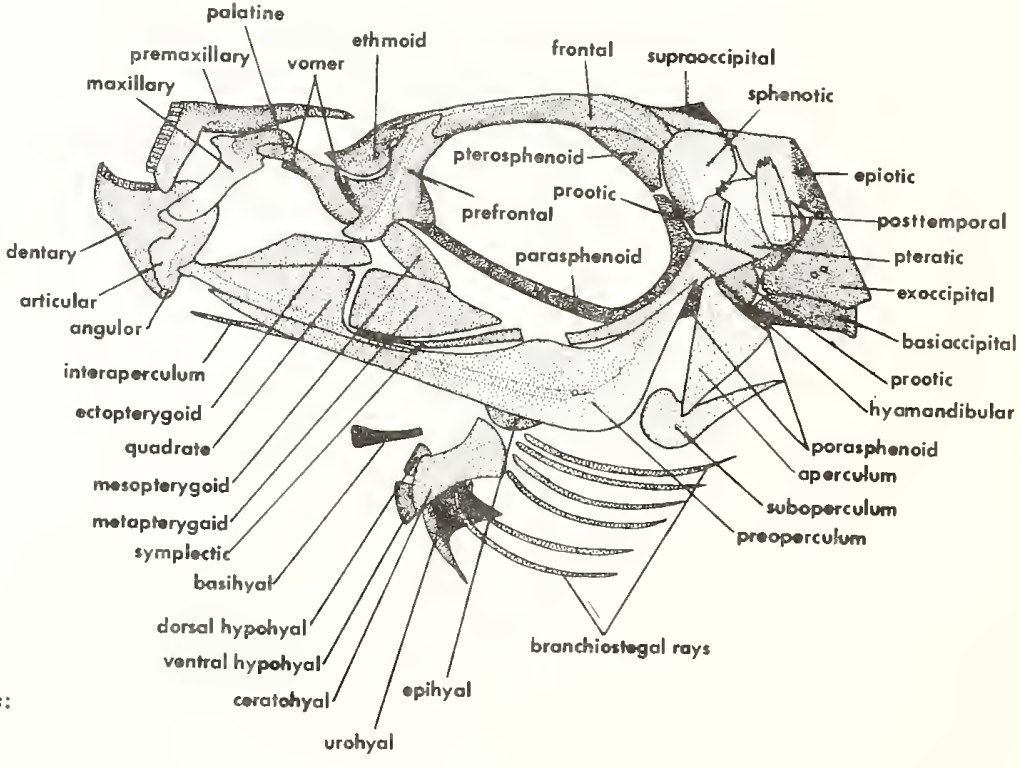




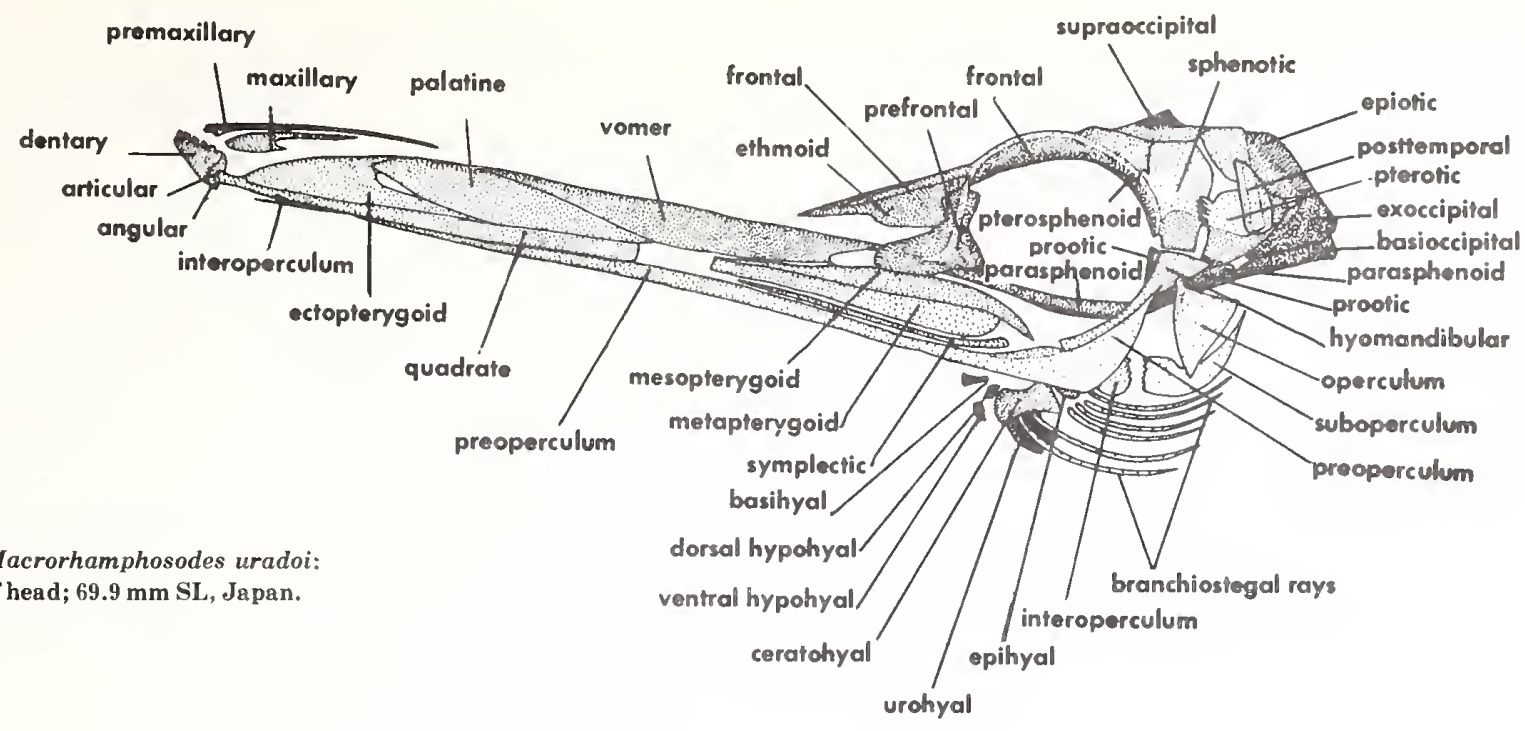

Figure 29.-Macrorhamphosodes uradoi: lateral view of head; $69.9 \mathrm{~mm} \mathrm{SL}$, Japan.

snout, the last three dorsal spines rudimentary and the second pelvic fin ray absent, all of which features are foreshadowed in Bathyphylax, in which the snout is of moderate width, the mouth slightly to distinctly supraterminal, the lips thin, the teeth conical and slightly reduced in number in both jaws, the last two or three dorsal spines rudimentary, and the second pelvic fin ray absent.

Subfamilial relationships, and relationships to the Triacanthidae and Gymnodontes.-Since the shape of the posterodorsal region of the skull and of the portion of the pelvis posterior to the pelvic spines, the primary distinguishing features of the two Recent subfamilies, is not known in the two fossil subfamilies, a pertinent question about the basal genus in each of the two Recent subfamilies is which comes closest in basic structure to the ancestral stock which gave rise to them: was it a stock with a domelike supraoccipital separating the epiotics on the dorsal surface of the skull and with a shaftlike pelvis, or a stock with a flattened supraoccipital bearing a medial crest and allowing the epiotics to meet on the dorsal surface of the skull and with a basinlike pelvis, or perhaps a stock with intermediate conditions? In the absence of a solution from the fossil triacanthodids there is but one clue as to which condition is more likely to have been that of the early triacanthodids, and that is the condition of the supraoccipital and epiotics in the acanthurids, which are often considered to have evolved in the Eocene from the same Cretaceous stock (perhaps the Pharmacichthyidae, according to Patterson 1964) as that which gave rise in the Eocene to the triacanthodids and other plectognaths.

The supraoccipital of acanthurids is basically domelike and without a flattened basal portion, while the epiotics are separated from each other medially on the

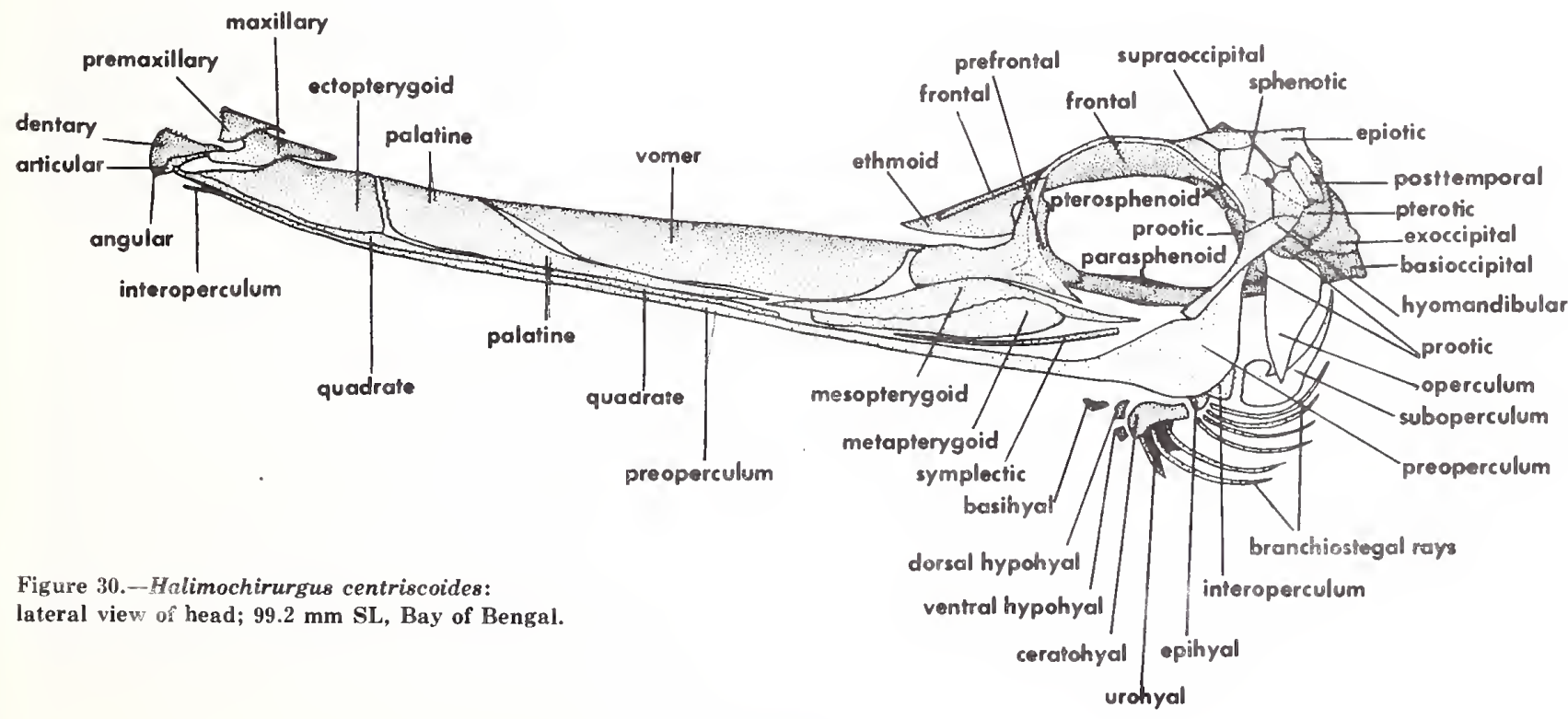


dorsal surface of the skull, basically the same condition as found in the hollardiins and in contrast to that of the triacanthodins. The acanthurid epiotic is separated for a short distance from the frontal by a parietal, a bone lost in all plectognaths, but the epiotic in acanthurids approaches the frontal closely enough to be more similar to the condition in hollardiins than to that in triacanthodins. The indication from the acanthurids is that the domelike supraoccipital excluding the epiotics from the midline of the dorsal surface of the skull in hollardiins is the more generalized of the two and ancestral to the flattened condition of the supraoccipital found in triacanthodins.

The phylogenetic implications of the shaftlike pelvis of hollardiins versus the basinlike pelvis of triacanthodins are unknown, for these differentially shaped portions of the pelvis are long extensions behind the level of the pelvic fins, and most fishes, including acanthurids, have no such structure with which that of triacanthodids can be compared.

While the triacanthodins are more speciose and anatomically diversified than the other Recent subfamily, from which they were derived, they apparently are not ancestral to any other group of plectognaths, for it is the hollardiins that are ancestral to the triacanthids, and that same line probably is ancestral to the balistoids and ostracioids as well, while the gymnodonts are derived from the eoplectins, as discussed below. The hollardiin ancestry of the triacanthids is attested to by the similarity in the domelike shape of the supraoccipital, which excludes the epiotics from meeting on the dorsal surface of the skull, and in the shaftlike nature of the pelvis posterior to the pelvic spines found in this subfamily of triacanthodids and in the derived triacanthids.

Since the nature of the supraoccipital and pelvis is not known in the fossil Eoplectinae and Spinacanthinae, it is impossible to say whether one was more closely related to the hollardiin or triacanthodin line of triacanthodid radiation than the other. However, it is clear that the eoplectins were ancestral to the gymnodonts and that the spinacanthins were perhaps an unsuccessful experiment of the early triacanthodids that gave rise to at least one species with some superficial similarities to ostracioids but which became extinct without derivatives alive today.

The phylogenetic significance of the Eoplectinae is discussed in detail by Tyler (1973b) and need be only briefly summarized here. It is assumed to be extremely unlikely that the highly specialized condition of small and numerous dental units intimately incorporated into the matrix of the premaxillaries and dentaries, forming a parrotlike crushing beak, has arisen independently in two or more lines of plectognath radiation. It is more parsimonius to assume that this highly specialized condition arose in only one basic line of plectognaths, that leading to the gymnodonts, whose most generalized family is the Triodontidae, and that all plectognaths with this condition are phylogenetically related. Eoplectus basically is triacanthodid and generalized (general body shape, welldeveloped pelvic and spiny dorsal fins, rounded i, 10, i caudal fin) in most of its structure, but has a distinctly triodontid and highly specialized dentition and jaw structure. It represents almost precisely the kind of Eocene ancestral line that has been speculated (Tyler 1962a:793) between the triacanthodids and triodontids, and thus between the basal scleroderms and the derivative gymnodonts.

The conversion of an Eoplectus-like form into a Triodon-like one involves mostly reductive tendencies, which are well-known to be of great importance in the evolutionary diversification of the plectognaths, as follows: 1) complete loss of pelvic fin but retention of pelvis; 2) reduction of spiny dorsal fin and its basal pterygiophores into a posteriorly migrated rudimentary structure; 3) reduction in number of soft dorsal and anal fin rays; 4) great increase in length and decrease in depth of caudal peduncle concomitant with conversion of rounded into forked caudal fin; 5) decrease in height of neural and haemal spines of caudal peduncular vertebrae and development of anterolateral flanges on neural spines, associated again with elongation and slenderization of peduncle for more powerful swimming with forked caudal fin; 6) increased covering of scales with more elaborate surface spinulation and development of expansible dewlap of skin between finless pelvis and anal region; 7) increase in size of prefrontal and of its sutural connections to surrounding snout bones for stronger buttressing of crushing beak; 8 ) probable similar increase in size of palatine for same reason; 9) decrease in depth of ventral flange of parasphenoid; 10) straightening of vertebral column associated with elongation of body.

Triodon has only two anatomical features known to be more generalized than in Eoplectus: the presence of procurrent caudal fin rays and of well-developed ribs and epipleurals. It is unlikely that these are de novo acquisitions of Triodon, and the ancestry of Triodon should have these structures. In fact, the Eocene Zignoichthys, apparently closely related to Eoplectus, does have procurrent caudal fin rays, indicating that these were simply lost by Eoplectus after it gave rise to the line leading to Triodon. It is possible that small ribs and epipleurals were present on the obscured anterior abdominal vertebrae of Eoplectus, but it still must be assumed that well-developed ribs and epipleurals were lost by Eoplectus only after it gave rise to the Triodonlike line. Thus, $E$. bloti must be considered a slightly specialized member of the Eoplectinae line which gave rise to the Triodon line, and not the immediate direct ancestor of Triodon.

The number of dorsal and anal fin rays in Eoplectus is in the high part of the range for triacanthodids, but the number of basal pterygiophore supports is in the low part of the range, and even lower for the dorsal pterygiophores. The fact that there are many more rays than pterygiophores, especially in the posterior regions of these fins, may indicate a prelude to an eventual reduction in the number of rays from posteriorly to anteriorly in the series leading to the Triodon condition. This reduction in number of rays would also tend to lengthen the caudal peduncle, which would probably continue to 
lengthen by posterior elongation as less reliance was placed on the soft dorsal and anal fins for locomotion and greater emphasis was placed on the caudal fin as it gradually became forked and more heavily muscled in the tapering peduncular region. Perhaps as it became a more sustained rapid swimmer there was less advantage to having a large defensive spiny dorsal fin, which eventually was reduced to a rudimentary structure, such as in Triodon, in which it is sometimes absent altogether.

The spiny dorsal fin of Eoplectus has one important characteristic which may shed light on the phylogeny of the other scleroderms, and that is the placement of the second basal pterygiophore, perhaps seemingly trivial. The long shaft of this pterygiophore is oriented distinctly anteroventrally and articulates either between the neural spines of the first and second vertebrae or between the neural spine of the first vertebra and the base of the skull just behind the shaft of the first pterygiophore. This is a decidedly nontriacanthodid arrangement, in which the shaft of the second pterygiophore is otherwise always directed ventrally or posteroventrally and articulates with the neural spine of the fourth vertebra. In direct contrast to the triacanthodids, the short shaft of the second pterygiophore of triacanthids is directed slightly to distinctly anteroventrally toward the region between the neural spines of the first and second vertebrae. This is similar to the situation in Eoplectus, except that the shaft as well as the rest of the pterygiophore is of much reduced size, as could be expected by the much smaller size of the spine it bears in triacanthids relative to Eoplectus. A forward shift in the orientation of the shaft of the second pterygiophore (and of those posterior to it) occurred somewhere in the line of evolution between the ancestral triacanthodids and the derived triacanthids, and Eoplectus shows such a shift of the second pterygiophore (but not of those posterior to it).

It is entirely possible that a pre-Eoplectus-like fish, before the jaws and dentition had become Triodon-like, was on the line of hollardiin triacanthodids that gave rise to the triacanthids, undoubtedly through a line of evolution including the Eocene Protacanthodes, the most generalized or triacanthodidlike of all the triacanthids. Protacanthodes has a reduced spiny dorsal fin whose base is much shorter than that of the long-based soft dorsal fin, an apparently shaftlike pelvis with a welldeveloped spine and other features typical of triacanthids, while retaining from its triacanthodid ancestry a deep and only slightly tapered caudal peduncle and a large well-rounded caudal fin.

A pre-Eoplectus-like fish with: 1) a hollardiin domed posterodorsal region of the skull; 2) shaftlike pelvis; 3) generalized triacanthodid jaws with well-developed ascending premaxillary processes and discrete conical teeth in sockets; 4) approximately one to one ratio of dorsal and anal fin rays to their basal pterygiophores; 5) uroneurals; 6) full-scale covering; 7) only moderately developed parasphenoid ventral flange; 8) $8+12$ arrangement of vertebrae; etc., could be on a line ancestral to the beak-jawed Eoplectus and hence to Triodon and the other gymnodonts on the one hand, and on the other hand to the line ancestral to the Recent hollardiins, from which latter line early arose the Eocene Protacanthodes and its decendent Recent triacanthids.

This hypothetical generalized triacanthodid ancestral line of pre-Eoplectus-like configuration could well have diverged into two distinct radiations: one retained distinct well-developed individual teeth protruding from sockets in the jaws, as well as relatively well-developed spiny dorsal and pelvic fins, and the $8+12$ vertebral arrangement; the other specialized the jaws and dentition into a crushing beak, while eventually losing the spiny dorsal and pelvic fins and converting to a $9+11$ vertebral arrangement.

The evolution of Protacanthodes from a conically toothed pre-Eoplectus-like line would involve: 1) an increase in the number of soft dorsal fin rays and of their basal pterygiophores; 2) an elongation of the soft dorsal fin base concomitant with a reduction in the size of the second and subsequent dorsal spines and of their basal pterygiophores; 3) a shortening of the spiny dorsal fin base; 4) a slight elongation of the caudal peduncle; 5) a reduction in the number of pelvic fin rays and of their size. All of this is well within the range of possibility. Somewhere along the line between the pre-Eoplectuslike form, Protacanthodes, and the Recent triacanthids, the enlargement of the prefrontal and its anterior extension alongside the ethmoid and vomer, and other such typical triacanthid specializations, could have taken place, while the caudal peduncle structure and caudal fin shape would not have changed until between the Protacanthodes and Recent triacanthid stage.

The configuration of the first three basal pterygiophores of the spiny dorsal fin in Eoplectus is also of interest to the phylogeny of the balistids, for it in some ways represents what one might expect a balistid ancestral group to have, at least in this one respect. That is, there is a large open space between the second (anteroventrally directed shaft) and third (posteroventrally directed shaft) pterygiophores. The third pterygiophore already seems to be acting partially as a strut supporting the posterodorsal end of the second pterygiophore and has the ventral end of its shaft in contact with the neural spine of the fifth vertebra, as in balistids. If the first two pterygiophores in Eoplectus had greatly reduced ventral shafts so that the first pterygiophore articulated high on the rear of the skull and the second pterygiophore to the posterior end of the first, with the latter concurrently becoming anteriorly elongate to reach the rear of the skull, then a prototype of the balistid structure is achieved. The spine of the third pterygiophore would become lost and the sole function of this pterygiophore would be to brace the developing specialized carina accommodating the complex locking mechanism of the first two spines, with the third spine, borne on the small second pterygiophore forming the rear end of the carina, becoming reduced in size. At the same time that these transformations would be taking place, the fourth and fifth pterygiophores and their spines would also become reduced in size and eventually entirely lost. Such is a reasonable scenario for the de- 
velopment of the balistid spiny dorsal fin apparatus.

The above hypothesis in no way implies that Eoplectus is directly ancestral to the balistids, for the balistids clearly are derived from triacanthids. However, fishes like the Recent triacanthids are too specialized to be considered as the ancestral group to the balistids, and it is simply suggested that balistids could have evolved from an early line of Protacanthodes-like triacanthids in the Eocene still having an Eoplectus-like arrangement of the first three basal pterygiophores of the spiny dorsal fin.

The Spinacanthinae appear to me to represent an extinct lineage of triacanthodids not ancestral to any of the Recent groups of plectognaths, although with our present negligible knowledge of the internal anatomy of the two species of this subfamily, almost any phylogenetic statement about them is mostly speculation. If the Spinacanthinae were evolutionary dead ends, this sub"family of triacanthodids joins the Cryptobalistinae subfamily of triacanthids as the only two groups of fossil plectognaths not clearly on evolutionary lines leading to Recent groups of plectognaths. The reasons for considering the Cryptobalistinae as an evolutionary dead end are discussed at length by Tyler (1968:243-249) and for the Spinacanthinae below.

The Spinacanthinae seem to have been an unsuccessful experiment in specialization from a more normal basal triacanthodid configuration. These specializations include: 1) the enormous elongation of the dorsal fin spines and increased length of the fin base; 2) the reduction in number of fin rays in the soft dorsal and anal fins and the shortening of the fin bases; 3 ) the extremely high placement of the small eye in the head; 4) the forward migration of the spiny dorsal fin origin to above the eye; 5 ) the probably reduced size of the pelvic fin spine, if present at all; 6) the steep profile of the snout; 7 ) the immense size of the body of one of the species; 8) the development of enormous more or less hexagonal scale plates forming a complete carapace over the anterior part of the body behind the head in one of the species.

The trend for the elaboration of the dorsal fin spines and lengthening of its base concomitant with a reduction in the number of soft dorsal and anal fin rays and a shortening of their bases is not compatible with a possible ancestry of the triacanthids or balistids, both of which have reduced the spiny dorsal fin and elaborated the soft dorsal and anal fins. The position of the eye and the origin of the spiny dorsal fin in spinacanthins are, respectively, higher and further forward than in any triacanthids or balistids, and the snout is much steeper than in those two families. Additionally, there is good evidence that the hollardiin triacanthodids gave rise to the triacanthids through a Protacanthodes-like line, and that the balistids were derived from the early triacanthids before they became as specialized as the Recent species.

All of this would seem to me to exclude the spinacanthins from further consideration as possible ancestors of the triacanthids and balistids, and, even neglecting the role of the eoplectins as the ancestors of the gymnodonts, there is nothing compelling in the com- position of spinacanthins to think of them as possibly related to the gymnodonts, other than that the pelvic fin may have been reduced in size or absent and that the soft dorsal and anal fins are reduced in size.

This leaves but one group of plectognaths to be considered as hypothetically derivable from spinacanthins: the ostracioids. Ostracioids, like spinacanthins, have short-based soft dorsal and anal fins and have completely lost the pelvis and pelvic fin, while in spinacanthins the pelvic fin may have been of reduced size or $a b$ sent, and the condition of the pelvis is unknown. The scales in one of the two genera of spinacanthins, Protobalistum, are large thick hexagonal plates which form a continuous cuirass around the anterior half of the body behind the head, the plates interdigitating along their edges of contact and having surface granulations. In ostracioids the plates of the carapace are remarkably similar to those of Protobalistum, although they cover the head as well as most of the body. It is easy to envision a transition from the mostly isolated and approximately circular scale plates of Spinacanthus, with surface granulations and a higher central spine, to the hexagonal carapace plates in the partial body cuirass of Protobalistum, with surface granulations and interdigitated edges, to the fuller carapace covering of ostracioids.

While the teeth of Protobalistum are too large and heavy to be conveniently ancestral to those of ostracioids, the smaller more conical teeth of Spinacanthus could easily be ancestral to those of ostracioids. The profile of the snout of some ostracioids is as equally steep as in spinacanthins, and the eye of ostracioids, although somewhat larger than in the two species of spinacanthins, is located high in the head. However, it is difficult to compare eye position between two groups in which one has a spiny dorsal fin and the other does not.

Weighing against any phylogenetic significance to these similarities between spinacanthins and ostracioids are three factors: 1) the presence of an enormously welldeveloped spiny dorsal fin in spinacanthins, which one would expect to be at least no larger than in other triacanthodids if not of greatly reduced size in a line leading to the ostracioids; 2) enlarged scale plates, whether or not with granulations and hexagonal pattern, are not unique to Protobalistum and ostracioids among the plectognaths, but are found in some tetraodontids and molids as well, and the scales of balistids can easily be envisioned as ancestral to those of ostracioids; 3) the osteological evidence from Recent species indicates that the ostracioids are derived from the same ancestral line as that which gave rise to the balistids, while it is discussed above why the spinacanthins are unlikely to be ancestral to the triacanthids and balistids.

The low number of fin rays and short base of the soft dorsal fin in spinacanthins is probably correlated with the trend for the enormous enlargement of the spiny dorsal fin, while for hydrodynamic reasons the apposed anal fin would similarly become reduced in size to match its equivalent above it. Thus, the short-based soft dorsal and anal fins in spinacanthins could have no phy- 
logenetic relationship to the short-based soft dorsal and anal fins of ostracioids. Nevertheless, considering the reductive tendencies in the spiny dorsal fin in the plectognaths, it is not inconceivable that a group like the spinacanthins at one time early in their history greatly enlarged the spiny dorsal fin, an experiment which eventually proved a failure and gave way to the more usual trend of reduction, leading to a spinacanthin line with the spiny dorsal fin reduced in size and eventually lost, leaving a hypothetical form much more suitable for consideration as an ancestral line to the ostracioids than are the two presently known species.

The scales in the tetraodontid Ephippion guttifer are relatively normal prickles in the young, with two or three radiations from the basal plate supporting the projecting spine. By about $100 \mathrm{~mm} \mathrm{SL}$, however, only the prickles on the belly retain the normal shape, those of the body having the basal plate enlarged and elongate, and the projecting spine reduced in size. By $200 \mathrm{~mm}$ SL the basal plates of the scales between the levels of somewhat behind the pectoral fin base and the soft dorsal and anal fin origins are further enlarged into irregularly rounded plates, with irregularly granular surfaces, closely held together by numerous interdigitations along their edges of contact. The scale plates anterior and posterior to the girdle of sutured plates are progressively more distantly spaced from one another and elongate rather than rounded. The scales of the belly, below the carapace girdle, remain as normal prickles. At larger sizes, as illustrated for a $325 \mathrm{~mm}$ specimen, the scales of the girdle become progressively larger and thicker and the girdle itself extended further anteriorly and posteriorly. The surface sculpturing of the plates becomes more regularly granular and the firmness of the interdigitation between the plates along all their edges of contact stronger and less flexible, the largest and heaviest plates mostly in the ventral region of the girdle. The plates have relatively irregular outlines, but many range from triangular to hexagonal.

This girdle of interdigitated thickened scale plates in Ephippion adults is fully as strong and solid as that of ostracioids, and only slightly more flexible, mainly because it does not completely enclose the body, the belly always retaining normal prickles, and the girdle not extending onto the head. In four specimens, the size of the largest scale plates increased as follows: $3.6 \% \mathrm{SL}$ at $101 \mathrm{~mm} ; 4.3 \% \mathrm{SL}$ at $232 \mathrm{~mm} ; 7.1 \% \mathrm{SL}$ at $325 \mathrm{~mm} ; 9.2 \%$ $\mathrm{SL}$ at $391 \mathrm{~mm}$. In ostracioids the largest scale plates range from about 6 to $13 \% \mathrm{SL}$ relatively independent of specimen size beyond juvenile stages.

Among the molids the individual scale plates are relatively small. In Mola and Masturus the basal plates are more or less rounded and flexibly articulated with one another by delicate denticulations. In Ranzania, however, the basal plates become thicker with increasing specimen size and the extent of the interdigitation also increases so that adults have nearly the entire body covered by an only slightly flexible carapace of small (in two specimens, $0.8 \% \mathrm{SL}$ at $65.1 \mathrm{~mm}$ and $1.2 \%$ $\mathrm{SL}$ at $493 \mathrm{~mm}$ ) minutely denticulated and irregularly geometrically arranged basal plates with only low and inconspicuous surface sculpturing, ranging from 3 to 12 sided, but with some distinctly hexagonal. This carapace of scale plates never attains the thickness of that of ostracioids or Ephippion.

In balistids the thick scale plates are usually rhomboidal with slightly overlapping edges (plates not overlapping in Canthidermis) and usually with low surface sculpturing of wide variety, while some plates (especially on the caudal peduncle) may bear higher spiny processes. Although usually rhomboidal, the anterior and posterior apices sometimes are flattened, the plate then having a decidedly hexagonal shape. Scale plates such as found in balistids could easily be ancestral to those of ostracioids, by an increase in thickness and surface area, more usual hexagonal shape, and conversion from slightly overlapping edges to apposed interdigitated edges.

The strongest reason, however, for not considering the spinacanthins as ancestral to the ostracioids is that the osteological evidence from Recent species indicates that the balistids and ostracioids evolved from a common triacanthid ancestral stock, as discussed fully under the relationships of the ostracioids, but basically because balistids and ostracioids have a well-developed prootic shelf, the hyomandibular supported by the prootic and pterotic but not by the sphenotic, an expanded parasphenoid, and similarities in the shape or size of the interoperculum, operculum, suboperculum, premaxillary, and maxillary.

Thus, for the present at least and until more is known of the internal anatomy of the spinacanthins, it seems to me reasonable to tentatively consider the spinacanthins an extinct line of early triacanthodid experimentation not ancestral to any of the other known subgroups of plectognaths.

In summary, there is good evidence that the Hollardiinae are ancestral to the Triacanthidae and the Eoplectinae to the Tetraodontoidei, while probable that the Triacanthodinae are derived from the hollardiins and possible that the Spinacanthinae were an evolutionary dead end.

In fact, the Eoplectinae are so obviously ancestral to the Gymnodontes that the eoplectins could be considered as the most basal family of that suborder, even more generalized than the Triodontidae, rather than as a subfamily of the Triacanthodidae with highly specialized jaws. Similarly, the Protacanthodinae are so obviously ancestral to the Recent Triacanthidae and intermediate between them and the Triacanthodidae that the protacanthodins could be considered a specialized subfamily of the Triacanthodidae rather than as the most generalized subfamily of the Triacanthidae. It is on the basis of my own personal assessment of the overall similarities and differences between most triacanthodids, Eoplectus, Zignoichthys, and triodontids and between triacanthodids, Protacanthodes, and most triacanthids that I subjectively feel that Eoplectus and Zignoichthys are best placed in the Triacanthodidae and Protacanthodes in the Triacanthidae. 


\section{Family Triacanthidae}

Comparative diagnosis (contrast with that of the Triacanthodidae) (modified from Tyler 1968:234236). - A compact, strongly sutured skull and a muscular body built for active swimming near the bottom; very little cartilage visible on the external surface of the skull between the regions of apposition of the bones in the otic and occipital regions, the bones usually strongly sutured to one another along all edges of proximity; an outer series of about 8 to 10 heavy incisor teeth in each jaw, internal to which are several more or less molariform teeth, usually four (two in Trixiphichthys weberi) in

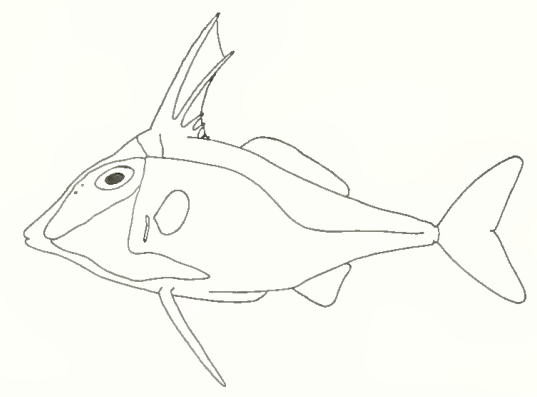

Figure 31.-Typical body form in the Recent Triacanthidae: Pseudotriacanthus strigilifer.

the upper jaw and two in the lower; a large sturdy ethmoid-frontal complex for the support of the massive dentition; the prefrontal with a long anterior extension, sutured medially to the ethmoid and anteriorly to the posterolateral extensions of the vomer; premaxillary pedicels when fully retracted reaching only to the anterior basal region of the ethmoid, well-separated from the frontals (probably least so in the Eocene Protacanthodes); supraoccipital domelike, its posterior surface concave; epiotics separated on the dorsal surface of the skull by the supraoccipital and meeting medially only on the posterior surface of the skull and articulating anterolaterally with the frontals; pterosphenoids meeting and suturing in the midline of the posterior wall of the orbit; neural processes of the first vertebra meeting and suturing in the midline above the neural canal, forming with the exoccipitals a completely enclosed bony well (with a bony bottom) in which the shaftlike end of the first basal pterygiophore of the spiny dorsal fin is immovably held (a different arrangement present in the Oligocene Cryptobalistes); parasphenoid in region of orbit with a dorsal arch and a well-developed ventral flange below the orbit, the flange about 2 or 3 times as deep as the upper shaftlike portion of the bone (except in the Eocene Protacanthodes, the shaft relatively straight and the flange not much deeper than the shaft); hyomandibular with a well-developed groove and crest along its lateral surface more or less transversely; pterotic with a ventral process overlying and firmly articulating with the upper posterior portion of the hyomandibular; supracleithrum placed vertically to the horizontal axis of the skull, nearly its entire length overlying the cleithrum; mesopterygoid absent (at least in adults) in all but one species (Trixiphichthys weberi), and when present small and difficult to distinguish from the metapterygoid, to which it is mostly fused; olfactory cavity between the ethmoid and prefrontal well defined, with distinct bony boundaries; basihyal absent; lower two branchiostegal rays enlarged (except in the Eocene Protacanthodes), much wider than the upper branchiostegal rays; operculum elongate, usually widest in the middle, not triangular; air bladder thick walled, somewhat elongate, large and extending posteriorly almost the entire length of the abdominal cavity; pelvis a sturdy shaft; the two halves of the pelvis variously fused or extensively interdigitated, like a railroad rail in cross section just behind the level of the pelvic spine (except in the Oligocene Cryptobalistes, which has a basinlike pelvis); a single oblique crest on the side of the pelvis at the level of the flange of the pelvic spine, allowing for two, and only two, positions of locking the erected spine (probably a different arrangement in the Oligocene Cryptobalistes); the ventrolateral surface of the pelvis at the base of the spine without a complete foramen and the two sides of the base of the spine not meeting medially; all haemal arches and spines of adults fully fused to their centra; only the epural and uppermost hypural as separate elements articulated by fibrous tissue to each other and to the centrum, the other hypurals and the parhypural fully fused to one another and to the centrum (probably some separation of the middle hypurals in the Eocene Protacanthodes); a single pair of uroneurals present; thick epipleurals present from the third or fourth abdominal vertebra to the first or second, sometimes the third and rarely the fourth, caudal vertebra; fifth basal pterygiophore of the spiny dorsal fin usually absent, rarely present as a tiny buried bony splint beneath the usually rudimentary sixth dorsai spine; first basal pterygiophore of the spiny dorsal fin a stout shaft (except very short in the Oligocene Cryptobalistes) with poorly developed anterior and posterior medial flanges, the flanges never wider than the shaft; first basal pterygiophore of spiny dorsal fin with a medial flange dorsally not completely enclosing a foramen; second to fourth basal pterygiophores of spiny dorsal fin reduced in size, their shafts not reaching ventrally to between the tips of the neural spines (but associated with those of the first to third vertebrae, except in the Eocene Protacanthodes, in which the shafts reach to the distal ends of the neural spines of the second to fourth vertebrae) and the fourth pterygiophore occasionally missing; none of the basal pterygiophores of the spiny dorsal fin sutured to one another distally; spiny dorsal fin base (including rudiments) much shorter than soft dorsal fin base (except the Eocene Protacanthodes, with spiny dorsal base slightly longer than soft dorsal base); only four or five (six in the Eocene Protacanthodes and perhaps in the Oligocene Cryptobalistes) abdominal vertebrae anterior to the first basal pterygiophore of the soft dorsal fin; first anal fin basal pterygiophore with a sturdy medial flange anterior to its lateral flanges, the 
pterygiophore + -shaped in cross section; well developed lateral flanges for muscle attachment present along most of the length of most of the basal pterygiophores of the soft dorsal and anal fins; a sturdy lateral flange present horizontally along the middle of the posterior half of the last centrum and the anterior region of the hypural plate; soft dorsal fin basal pterygiophores 20-26, anal fin basal pterygiophores $14-19$, most of these pterygiophores sutured to one another distally; distal pterygiophores of soft dorsal and anal fins often unossified, the ossification, when present, always as a single piece and not as a pair of elements to either side of the midline; sixth dorsal spine nearly always present as a rudiment, in all but very young specimens usually as a splint of bone buried beneath the skin, but sometimes protruding to the surface even in adults; the fifth spine usually very short, but nearly always protruding at least a short distance through the skin; the first four spines always visible externally, but the fifth and sixth spines sometimes absent in one Recent species and perhaps in several fossil forms; dorsal fin rays 19-26; anal fin rays 13-22; pelvic fin with a large spine followed in some species by a single ray which becomes a buried rudiment in adults; adults never with a protruding pelvic ray; dorsal and pelvic spines with numerous shallow lengthwise grooves (except in the Miocene Marosichthys, in which the grooves seem to be deep), mostly obscured by the overlying scale plates except at the naked distal end (one-tenth or less of the length); uppermost pectoral fin ray nubbinlike, the two halves of the ray about equally short or the lateral half shorter, the basal region of the medial half always immensely larger than that of the lateral half; the slightly overlapping basal plates of the scales of the body bearing either an emarginate cruciform ridge or an anterior to posterior series of vertical emarginate ridges (except in the Eocene Protacanthodes, with numerous upright spinules, and in the Oligocene Cryptobalistes, without elaborate ornamentation); peritoneum pale, often with silvery overtones; coloration basically silvery-gray, with yellowish or greenish overtones; lateral line relatively conspicuous (least so in Trixiphichthys weberi); scaly skin forming a definite low sheath along the bases of the soft dorsal and anal fins; olfactory lamellae 23-54, relatively thin; anterior nostril with an upraised rim posteriorly, essentially flush with the surface anteriorly, the rim not tubelike; posterior nostril with an upraised rim anteriorly; gill rakers laterally on first arch relatively short, shorter than the width of the fleshy arch; usually only one, rarely two, rakers laterally on the upper limb of the first arch above the angle; caudal peduncle relatively long, 16 to $31 \%$ SL, distinctly tapering to a narrow transversely indented region above and below just in front of the caudal fin base (except in the Eocene Protacanthodes, which has a relatively deep and only slightly tapered peduncle); least depth of the caudal peduncle, between the precaudal grooves, 2 to $5 \%$ SL (except in the Eocene Protacanthodes, the depth 15\% SL, and in the Oligocene Acanthopleurus collettei, the depth 5 to $8 \% \mathrm{SL}$, versus 4 to $5 \% \mathrm{SL}$ in the Oligocene $A$. serratus and 2 to $4 \%$ SL in Recent species); the caudal peduncle wider than deep at this point (except in $A$. collettei, the width probably about equal to the depth, and in the Eocene Protacanthodes, the width unknown but obviously less than the depth); caudal fin deeply forked (except in the fossil genera Protacanthodes, with a rounded caudal, and Cryptobalistes, with an almost truncate caudal).

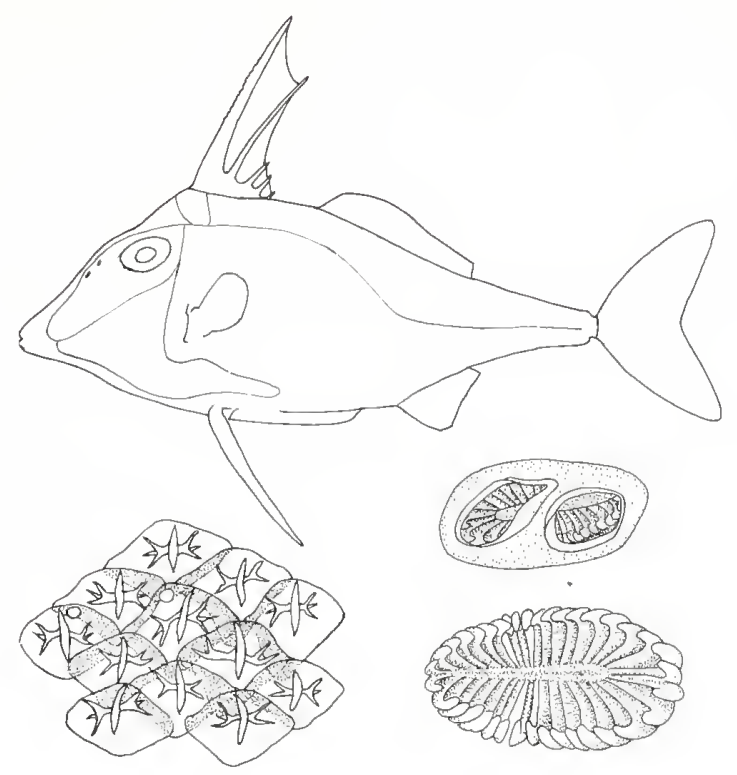

Figure 32.-Pseudotriacanthus strigilifer: showing the course of the lateral line; lower left, scales from upper middle region of body, including two lateral line canal bearing scales; lower right, nasal region as seen externally (above) and the olfactory lamellae as seen with the top of the nasal sac removed.

\section{Detailed description of Pseudotriacanthus strigilifer.}

Material examined.-Five cleared and stained specimens, $79.0-145 \mathrm{~mm}$.

\section{SKULL.}

\section{Occipital Region.}

Basioccipital. -A short column, dorsolaterally expanded; cartilage filled along its anterior and anterodorsal edges; articulates by extensive interdigitation posterolaterally with the exoccipitals, anterolaterally with the prootics and anteroventrally with the overlying posterior end of the parasphenoid. The rim of the round concave posterior end of the basioccipital articulates by fibrous tissue with the rim of the concave anterior face of the centrum of the first vertebra. A deeply concave medial channel is present on the anterior three-fourths of the ventral surface of the basioccipital. The anterior end of this channel is mostly hidden from view by the overlying parasphenoid. Posteriorly this channel is open to the 
exterior at the base of the posterior bifurcation of the parasphenoid, while anteriorly it opens into the myodome where the anterior end of the basioccipital forms the posterodorsal and posterolateral walls of the myodome.

Exoccipital. - Cartilage filled at its dorsal, lateral, and ventral edges; articulates by interdigitation dorsally with the epiotic, anteroventrally with the prootic, ventromedially with the basioccipital and laterally with the pterotic, while dorsomedially it interdigitates with its opposite member above the foramen magnum. The foramen is entirely surrounded by the exoccipitals, except ventromedially where it is bounded by the upper surface of the basioccipital. Posteromedially the exoccipitals interdigitate with the neural spine of the first vertebra. An exoccipital condyle is present only in the form of a slightly posteriorly elongate region of the posteroventral end of the exoccipital, the short condyle overlying the anterolateral surface of the lower neural arch region of the vertebra just above the region of the centrum. The neural processes from either side of the first vertebra meet and interdigitate in the midline above the neural canal, forming, in conjunction with the exoccipitals to which they are also sutured, a completely enclosed bony well in which the shaftlike end of the first basal pterygiophore of the spiny dorsal fin is immovably held by fibrous tissue. The bony bottom of this well is formed mainly by the exoccipitals where they meet medially to roof over the foramen magnum.

Supraoccipital. - Dome-shaped; its stout rounded anterodorsal edge forming the apex of the cranium and its posterior surface concave; cartilage filled along most of its ventral edges; articulates through interdigitation posteroventrally with the epiotics and anteroventrally with the frontals, the frontals overlying the anterolateral edges of the supraoccipital.

\section{Otic Region.}

Pterotic. - Cartilage filled along most of its edges of articulation with the other cranial bones; articulates through extensive interdigitation posterodorsally with the epiotic, posteromedially and ventromedially with the exoccipital, anteromedially with the prootic, and anterolaterally and anterodorsally with the sphenotic. The anteroventral end of the pterotic is the main support for the hyomandibular, its extreme anteroventral edge abutting against the rear half of the dorsal end of the hyomandibular while a sturdy ventral flange from its ventrolateral edge broadly overlies the posterodorsal region of the lateral surface of the hyomandibular. While the articulation between the pterotic and hyomandibular is through fibrous tissue, it is very firm and relatively immovable, especially so because of the presence of the ventral flange of the pterotic broadly overlying the hyomandibular. Much of the posterolateral surface of the pterotic is overlaid by the posttemporal, to which it is firmly interdigitated.
Sphenotic. - Cartilage filled along all of its edges of articulation with the other cranial bones; articulates by extensive interdigitation anteromedially with the prootic, pterosphenoid, and frontal in the posterior wall of the orbit, respectively from below to above. Laterally on the skull the sphenotic articulates by interdigitation dorsally with the frontal and epiotic and posteriorly with the pterotic. Posterodorsally the sphenotic interdigitates for a short distance with the anterodorsal edge of the posttemporal. Anterolaterally the sphenotic helps form the concave groove that supports the dorsal edge of the hyomandibular. The sphenotic forms the anterolateral part of the groove, the anteromedial part being formed by the prootic and the posterior half by the pterotic. The articulation of all these bones with the hyomandibular is through fibrous tissue.

Epiotic. - Cartilage filled along all of its edges of articulation with the other cranial bones; articulates through extensive interdigitation posterodorsally with the supraoccipital and anterodorsally with the frontals. Medially the edges of the two epiotics interdigitate with one another, while posteroventrally they interdigitate with the exoccipital and pterotic. Anteroventrally the epiotic interdigitates with the posterodorsal region of the sphenotic, while the extreme posterolateral edge of the epiotic is broadly overlain by the upper end of the posttemporal, with which it interdigitates. Ventromedially on the posterior surface the epiotic helps form a very short portion of the upper anterior region of the bony well supporting the shaft of the first basal pterygiophore of the spiny dorsal fin, while the main support for this shaft is the portion of the well formed by the exoccipitals and neural spine of the first vertebra.

Prootic. - Cartilage filled along all of its edges of articulation with the other cranial bones, except anteriorly; articulates by extensive interdigitation anterodorsally with the pterosphenoid, anterolaterally with the sphenotic, posterolaterally with the pterotic, posteriorly with the exoccipital, and posteromedially with the basioccipital. The prootic interdigitates along all of its length medially with the parasphenoid, while laterally the prootic helps support the dorsal head of the hyomandibular. The lateral walls of the myodome are formed by the ventromedial surfaces of the prootics, while the dorsal walls of the myodome are formed by the medially directed horizontal shelves, which are attached to one another through extensive interdigitation, from the ventromedial surfaces of the two prootics. The prootics also form the upper two-thirds to three-fourths of the anterior wall of the myodome.

\section{Orbital Region.}

Frontal. - Wider posteriorly than anteriorly where it tapers to a blunt point above the posterior end of the ethmoid and medial to the prefrontals; articulates by extensive interdigitation posteromedially with the supraoccipital, whose anterior edge it broadly overlies, pos- 
teriorly with the epiotic, posterolaterally with the sphenotic, anteriorly with the ethmoid, and anterolaterally with the prefrontal. Posteromedially on its ventral surface in the rear of the orbit the frontal interdigitates medially with the pterosphenoid and ventrally with the sphenotic. Medially the two frontals are in close apposition with one another and articulate either through fibrous tissue or interdigitation, but at one or more places along their lengths there is usually a small amount of cartilage visible between the two halves. The frontal interdigitates anteriorly with the ethmoid and anterolaterally with the prefrontal, both of which bones it overlies.

Prefrontal. -Cartilage filled along most of its broad medial surface except for the long anterior strut that lies alongside the ethmoid. Posteromedially the edges of the two prefrontals interdigitate with one another but anteromedially the prefrontals articulate through cartilage with the ethmoid, except for the long anterior strut which lies alongside and interdigitates with the lateral surface of the anterior half of the ethmoid, the shaft at its extreme anterior end also interdigitating with the posterolateral wing of the vomer. Posteroventrally the prefrontal articulates through cartilage with the dorsal surface of the parasphenoid below.

Parasphenoid. - An elongate shaft with a welldeveloped keel along its ventral surface in the region of the orbit. A deep, anteriorly directed cleft is present in the posterior portion of the parasphenoid, giving rise to the forked region which broadly overlies and interdigitates with the basioccipital and at the same time covers over the medial groove on the basioccipital leading to the rear of the myodome. About two-thirds of the way back the parasphenoid possesses paired dorsolateral wings which interdigitate with the anteroventral edges of the prootics and thus form the lower part of the anterior edge of the myodome, while more posteriorly the parasphenoid forms the floor of the myodome. Posterior to its articulation with the prootics, the parasphenoid overlies and interdigitates with the basioccipital. Just below its region of articulation with the anteroventral ends of the prootics, the lateral surface of the parasphenoid is slightly expanded into a knob, anterior to which the keeled portion of the bone is slightly concave. It is to this concavity that the upper elements of the branchial arches are held by fibrous tissue, especially the epibranchials and pharyngobranchials. The first pharyngobranchial or suspensory element articulates through fibrous tissue to the lateral surface of the parasphenoid in this region. In the region of the orbit the parasphenoid is slightly arched dorsally and the keel is 2 to 3 times the depth of the more rounded shaftlike portion above it. At its extreme anterior end the ventral surface of the parasphenoid is somewhat concave to receive and interdigitate with the posterior shaftlike portion of the vomer, while dorsally at its anterior end the parasphenoid articulates through cartilage with the prefrontals and ethmoid.
Pterosphenoid. - Cartilage filled along its lateral edges; articulates by interdigitation dorsally with the frontals, posteriorly with the sphenotic, and ventrally with the prootic. Along the middle of its medial edge the pterosphenoid possesses a medial extension which meets with that of its opposite member to interdigitate in the midline.

\section{Ethmoid Region.}

Ethmoid.-The ethmoid remains largely cartilaginous, the ossification being mostly restricted to the surface regions. However, the ossification is more extensive than in triacanthodids. The bone is widest along the middle of its lateral surface where it interdigitates with the long forward extensions of the prefrontals. Posterodorsally the ethmoid interdigitates with the overlying anterior end of the frontal. Posterolaterally it articulates through cartilage and some interdigitation with the prefrontals, and ventrally through cartilage with the dorsal surface of the parasphenoid and shaftlike portion of the vomer. Anteromedially the ethmoid has a prolongation which interdigitates with the posteromedial region of the dorsal surface of the vomer. The surface of the medial region of the anterior one-fourth of the ethmoid is somewhat thickened, this being the region over which the premaxillary pedicel slides in the opening and closing of the mouth.

Vomer. - The vomer is expanded laterally at its anterior end, while its flattened shaftlike posterior extension fits into and interdigitates with a concave area on the ventral surface of the parasphenoid. Posterolaterally the vomer has a pair of extensions which extensively interdigitate with the anterior ends of the extensions from the prefrontals alongside the anterior end of the ethmoid. The dorsal surface of the vomer helps support the premaxillary pedicel, while laterally the expanded anterior region of the vomer articulates by tough fibrous tissue with the medial surface of the middle region of the palatine. Posteromedially the vomer interdigitates with the anterior end of the parasphenoid, while the dorsal surface of the posterior shaft of the vomer abuts against the ethmoid cartilage above it.

\section{Mandibular Region.}

Hyomandibular. - A stout rectangular shaft whose dorsal end firmly articulates by fibrous tissue with the groove on the lateral surface of the underside of the skull formed anterolaterally by the sphenotic, anteromedially by the prootic, and posteriorly by the pterotic, the latter bone also having a ventral flange which broadly overlies the posterodorsal region of the lateral surface of the hyomandibular. A well-developed crest for muscle attachment is present about midway along the lateral surface of the hyomandibular. Posteriorly the hyomandibular articulates by fibrous tissue along most of its length to the anterior edge of the upper region of the preoperculum, just above the end of which latter bone 
the hyomandibular articulates by fibrous tissue with the anterodorsal head of the operculum. Anteriorly the hyomandibular ends in the cartilaginous plate between it and the metapterygoid.

Quadrate. -Wide posteriorly, tapering anteriorly to a head for articulation through fibrous tissue with the articular of the lower jaw; cartilage filled along posterior edge; with a long posteriorly directed process from its posteroventral region which articulates by interdigitation and fibrous tissue with the anteroventral edge of the symplectic in large specimens, whereas in smaller specimens intimate contact between the symplectic and posterior extension of the quadrate is not made and the articulation is purely by fibrous tissue. Along the posterior edge the quadrate articulates through cartilage with the anterior edge of the metapterygoid, at this region being cartilage filled. Ventrally the quadrate articulates through fibrous tissue with the dorsal surface of the anterior end of the preoperculum.

Metapterygoid. - A more or less flat plate; cartilage filled along its anterior, ventral, and posterior edges; articulates through cartilage anteriorly with the quadrate, while along its ventral edge it extensively interdigitates with the symplectic in large specimens but only articulates to it through fibrous tissue in smaller specimens. Posteriorly the metapterygoid articulates through cartilage with the hyomandibular.

Symplectic. - Long and rod-shaped; cartilage filled at its posterior end; articulates dorsally by interdigitation (in large specimens, see above) with the metapterygoid and anteriorly variously through interdigitation and fibrous tissue with the posteroventral end of the quadrate. Posteriorly the symplectic is in contact with the cartilaginous plate between the metapterygoid and hyomandibular. The upper end of the epihyal is attached by fibrous tissue to this cartilaginous plate immediately behind the posterior end of the symplectic. Ventrally the symplectic articulates by fibrous tissue with the dorsal surface of the preoperculum.

\section{Palato-Pterygoid Region.}

Palatine. - Cartilage filled at its extreme posterior end; articulates by fibrous tissue anteriorly with the dorsolateral surface of the maxillary, medially with the lateral surface of the expanded portion of the vomer, posteroventrally by fibrous tissue to the posterior end of the ectopterygoid, and directly posteriorly through cartilage and fibrous tissue to the anterodorsal region of the metapterygoid. The posterodorsal wing of the palatine connects to a broad band of fibrous tissue that runs over and above the premaxillary pedicels to join with the posterodorsal wing of the palatine on the other side. Although not sutured to any of the surrounding bones the palatine is in effect firmly held in place by its extensive fibrous tissue articulations.
Ectopterygoid. - Somewhat in the shape of an elongate rectangle; articulates along all of its ventral edges by interdigitation with the quadrate. Dorsally it articulates by fibrous tissue with the posteroventral region of the palatine and posteriorly through cartilage to the anterodorsal region of the metapterygoid.

Mesopterygoid.-Absent in this and all other species of triacanthids with the exception of Trixiphichthys weberi, in which it is a small plate of bone closely interdigitated to the posterior third of the dorsal edge of the far larger metapterygoid.

\section{Opercular Region.}

Operculum.-A thin sheet of bone broadest in the middle and tapering to a point ventrally; with a short dorsally prolonged flange above its anterodorsal head which articulates by fibrous tissue with a groove on the posterior edge of the hyomandibular just above the dorsal tip of the preoperculum. Ventrally the operculum sligntly overlies and articulates by fibrous tissue with the suboperculum.

Suboperculum. - Rounded anteriorly, tapering to a dorsally directed point posteriorly; articulates by fibrous tissue dorsally with the operculum and anteriorly with the interoperculum.

Interoperculum. - Very elongate and flat; rounded posteriorly but tapering to a point anteriorly; articulates by fibrous tissue posteriorly with the suboperculum and anteriorly ligamentously with the angular in the lower jaw. In the posterior half of its length the dorsal edge of the interoperculum connects by a band of fibrous tissue to the epihyal in the region where the epihyal articulates with the interhyal.

Preoperculum. - Slightly expanded posteroventrally in the region below the hyomandibular; the dorsal edge along the anterior half of the bone slightly thickened for articulation by fibrous tissue with the quadrate; articulates dorsally in about the middle of its length variously by fibrous tissue and through cartilage with the symplectic, metapterygoid, and anterior end of the hyomandibular, whereas the main articulation to the hyomandibular is by fibrous tissue along the posterodorsal edge of the preoperculum.

\section{Upper Jaw.}

Premaxillary. - L-shaped, with the long dorsal arm (pedicel) much longer than the ventral arm and movably articulated by fibrous tissue along the dorsal surfaces of the vomer and the extreme anterior end of the ethmoid, allowing for a slight protraction of the upper jaw. When fully retracted, the pedicel reaches to the anterior basal region of the ethmoid. The shorter ventral arm of the premaxillary forms the upper two-thirds of the anterior edge of the upper jaw, the rest of the border being formed by 
the maxillary. The premaxillary articulates by fibrous tissue along the middle of the lateral surface of the posterior arm with the medial surface of the upper portion of the maxillary, while along the medial surface of its posterior arm the premaxillary articulates through fibrous tissue with its opposite member. The ventral arm of the premaxillary articulates through fibrous tissue along its posteroventral edge with the anterior edge of the maxillary. There are usually five incisorlike teeth, decreasing in size laterally, borne in shallow sockets along the anterior edge of the premaxillary. Behind and internal to this outer row of teeth there are usually two additional teeth, the more medial of the two being the largest, of a size and shape similar to that of the large most medial tooth in the outer row, and the lateral inner tooth similar to the small outermost tooth in the outer row. The teeth are replaced by new ones developing in new sockets which have pores to the exterior just above and external to the sockets of the outer row of teeth. After a new tooth erupts through the surface of the premaxillary, it gradually migrates slightly forward and downward to the area of the socket of the older tooth which it is replacing.

Maxillary. -A more or less heavy rectangular bone, rounded ventrally and less so dorsally, and slightly constricted above the middle region; articulates by fibrous tissue dorsally along the lateral surface of its rounded portion with the anterior end of the palatine, while along the medial surface of its rounded portion it attaches to the lateral and ventral surfaces of the posterior arm of the premaxillary. Ventrally the medial surface of the maxillary articulates by tough fibrous tissue with the lateral surface of the posterodorsal part of the dentary, while along the middle of its anterior edge the maxillary articulates by similar tissue with the ventral arm of the premaxillary.

\section{Lower Jaw.}

Dentary.-The posterior end concave on the medial surface to accommodate the anterior end of the articular, which it broadly overlies laterally but only slightly overlies medially and to which it articulates by fibrous tissue; articulates anteromedially by fibrous tissue to its opposite member in the midline and posterolaterally by interdigitation with the small angular. Along the posterodorsal region of its lateral surface the dentary articulates by tough fibrous tissue with the medial surface of the ventral portion of the maxillary. There are usually five incisorlike teeth borne in shallow sockets along the anterior edge of the dentary and usually a single tooth behind and internal to the outer series, the single inner tooth being of a size comparable to that of the two larger more medially placed teeth in the outer series. The lower jaw teeth have the same form as the upper jaw teeth and are replaced by teeth developing in the same manner as described for the premaxillary.

Articular. - More or less triangular in shape; cartilage filled at its anterior end, where it is continuous with the remains of Meckel's cartilage; articulates by fibrous tissue dorsally, ventrally, and laterally with the broadly overlying dentary, posteroventrally by interdigitation with the angular, and posteriorly at the groove on its posterior edge with the knob at the anterior end of the quadrate. 'The sesamoid articular is a small ossification held by fibrous tissue to the region of juncture of Meckel's cartilage and the anteromedial surface of the articular.

Angular. - A small block of bone; articulates by interdigitation dorsally with the articular and anteriorly with the dentary. Posteriorly the angular connects by ligament to the anterior end of the interoperculum.

\section{BRANCHIAL APPARATUS.}

\section{Hyoid Arch, Branchiostegal Rays, and Urohyal.}

Hypohyals. - Both hypohyal elements well developed; dorsal hypohyal cartilage filled along its ventral and posterior edges, the ventral hypohyal cartilage filled at its dorsal and posterior edges. The dorsal and ventral hypohyals articulate through cartilage with one another and with the ceratohyal, while they articulate by fibrous tissue anteromedially with their opposite members, and in the case of the dorsal hypohyal with the anterior third of the first basibranchial, which is held between the posterior halves of the medial edges of the apposed dorsal hypohyals. The ventral edge of the ventral hypohyal articulates by fibrous tissue with the urohyal. In large specimens there is sometimes a slight amount of interdigitation between the dorsal and ventral hypohyals.

Ceratohyal.-A large plate expanded posteriorly; cartilage filled at its anterior and posterior edges; articulates through cartilage anteriorly with both of the hypohyals and posteriorly with the epihyal, the articulation with the epihyal sometimes strengthened by interdigitation in large specimens. The six branchiostegal rays articulate by fibrous tissue with the ceratohyal; the first two rays along the ventral edge of the posterior half of the ceratohyal and the last four rays to the posterodorsal edge of the ceratohyal and, in the case of the uppermost one or two rays, to the lower lateral surface of the epihyal.

Epihyal. - Large; cartilage filled at its anterior and ventral edges; articulates anteriorly through cartilage with the ceratohyal, this articulation sometimes being strengthened by interdigitation, while posterodorsally it articulates by fibrous tissue with the interhyal.

Interhyal.--Short, columnar; cartilage filled at its dorsal and ventral edges; articulates by fibrous tissue ventrally with the epihyal and dorsally with the cartilaginous plate between the symplectic and hyomandibular immediately behind the posterior end of the symplectic. 
Branchiostegal rays. - Six in number; increasing only slightly in length posteriorly in the series. The branchiostegal rays are mostly flat plates of decreasing width posteriorly in the series and articulate anteriorly by fibrous tissue variously to the posterior end of the ceratohyal and the lower lateral surface of the epihyal, as described above. The decreasing width of the rays posteriorly in the series makes the last few rays somewhat rodlike rather than flat plates.

Urohyal. - Laterally expanded and thickened along its anterior edge and, to a lesser extent, for a short distance anterodorsally. Otherwise a flat, thin plate articulating by fibrous tissue anterodorsally primarily with the undersurfaces of the ventral hypohyals.

Branchial Arches. - All of the elements are cartilage. filled at their edges of articulation with the other elements of the series, and the articulations are usually through cartilage and fibrous tissue. The branchial arches are composed of three basibranchials, three pairs of hypobranchials, five pairs of ceratobranchials, four pairs of epibranchials, and four pairs of pharyngobranchials. Four gills are present, with a slit between the fourth arch and the lower pharyngeal.

First arch.-Basi-, hypo-, cerato-, epi-, and pharyngobranchial elements present. First basibranchial the shortest of the three basibranchial elements, laterally compressed in the anterior half of its length, where it is held by fibrous tissue between the medial edges of the dorsal hypohyal, while posteriorly it articulates mainly. with the anterior end of the second basibranchial and only secondarily posterolaterally with the first hypobranchials. First hypobranchial about the same size as the second hypobranchial but more rectangular in form; articulates ventrally with an indented region along the lateral surface of the anterior half of the second basibranchial. First ceratobranchial slightly the longest of the ceratobranchial elements, which decrease slightly in size or length posteriorly in the series; a more or less columnar shaft of bone without a prominent ventral keel. First epibranchial a more or less rectangular block of bone except distally where it slightly bifurcates into two short projections; the anterior projection articulating with the base of the first pharyngobranchial, or suspensory element, and the posterior projection articulating with the second pharyngobranchial. First pharyngobranchial (suspensory pharyngeal) a short sturdy rod of bone articulating ventrally with the anterior projection of the first epibranchial and dorsally by fibrous tissue to the lateral surface of the ventral keel of the parasphenoid in the region just below the articulation of the anteroventral edge of the prootic with the parasphenoid.

Second arch.-Basi-, hypo-, cerato-, epi-, and pharyngobranchial elements present. Second basibranchial slightly the longest of the three basibranchial elements, with concave lateral surfaces in the anterior half of its length for articulation with the ventral ends of the first hypobranchials; articulates anteriorly with the first basibranchial, posteriorly with the third basibranchial and posterolaterally with the second hypobranchials. Second hypobranchial expanded ventromedially where it articulates with the posterior end of the second basibranchial and the anterior end of the third basibranchial; articulates dorsally with the second ceratobranchial, which in turn articulates dorsally with the laterally expanded basal portion of the second epibranchial. The second pharyngobranchial is the first of the tooth bearing pharyngobranchials, having six or seven teeth, set in deep sockets, in a single row along its ventral edge. The teeth are laterally compressed and taper to blunt points distally and are much smaller than those in the jaws. They are replaced by teeth which develop in new sockets just anterior to the sockets of the old teeth, much in the same manner as in the replacement of the teeth in the jaws.

Third arch.-Basi-, hypo-, cerato-, epi-, and pharyngobranchial elements present. Third basibranchial articulates anteriorly with the posterior end of the second basibranchial, anterolaterally with the second hypobranchials, posterolaterally with the third hypobranchials, and posteriorly, more distantly, with the fourth ceratobranchials. Third hypobranchial with an anteroventral process which articulates by fibrous tissue with the posterodorsal edge of the urohyal; at its posterodorsal end it articulates medially with the posterior end of the second basibranchial, anterolaterally with the end of the third ceratobranchial. Third ceratobranchial articulates dorsally with the third epibranchial, which is about equal in size to the second pharyngobranchial. Third pharyngobranchial bears six to seven teeth in a single row along its ventral edge, similar to those on the second pharyngobranchial. The three tooth bearing pharyngobranchial elements (second to fourth) are more or less closely held to one another by fibrous tissue.

Fourth arch.-Cerato-, epi-, and pharyngobranchial elements present. In the absence of a fourth basibranchial and fourth hypobranchial, the fourth ceratobranchial articulates ventrally with the posterior ends of the third basibranchial and hypobranchials. Fourth epibranchial a more or less rodlike element, slightly expanded ventrally; articulates ventrally with the fourth ceratobranchial and dorsally with the small fourth pharyngobranchial. The fourth pharyngobranchial is the smallest of the three tooth bearing elements, and bears four or five teeth in a single row along its ventral edge, these teeth being smaller than those on the second and third pharyngobranchials but of similar shape.

Fifth arch. -Ceratobranchial (lower pharyngeal) element only. Fifth ceratobranchial wider in the middle than anteriorly where it is generally rounded or posteriorly where it tapers to a short shaft, bearing teeth more or less placed in three rows, with those of the posterior row the largest. All of the teeth tend to be more 
bluntly rounded than are the teeth of the upper pharyngeals. There are up to 15 teeth in the anterior series and only slightly fewer on the average in the larger posterior row, with 5 to 8 teeth in the middle row. Ventrally the fifth ceratobranchial articulates with the base of the fourth ceratobranchial.

\section{PAIRED FIN GIRDLES.}

\section{Pectoral Fin.}

Posttemporal. - A straight shaft of bone without evidence of a forked condition, broadly overlying and strongly interdigitated to the pterotic in the lower half of its length and to the epiotic above, and, to a much lesser extent, with the posterodorsal part of the sphenotic. The rounded ventral head of the posttemporal articulates by fibrous tissue with the concave dorsal end of the supracleithrum.

Supracleithrum. - Located more or less vertically in relation to the axis of the body; articulates by fibrous tissue dorsally with the ventral head of the posttemporal and ventrally with the cleithrum, which it broadly overlies for its entire length.

Cleithrum. - Laterally expanded along the ventral two-thirds of its length; articulates by fibrous tissue dorsolaterally with the overlying supracleithrum, while dorsomedially it overlies the dorsal one-sixth or one-fifth of the postcleithrum. Along the middle of its posterior surface the cleithrum articulates by fibrous tissue with the scapula and the anterodorsal region of the coracoid, which it slightly overlies and mildly interdigitates with in larger specimens. Ventromedially the cleithrum articulates by tough fibrous tissue with its opposite member, while just behind the top of this region the anterior end of the pelvis is firmly attached to the rear edge of the cleithra.

Postcleithrum. - The postcleithrum forms a long posteroventrally directed, sturdy, more or less flattened shaft from the dorsomedial region of the cleithrum along the abdominal wall musculature to the region over the posterior third to one-half of the posterior half of the pelvis. The postcleithrum is a single piece without evidence, even in small specimens, of being divided into an upper and lower portion. The middle region of the postcleithrum is strengthened on the inner surface by a thick shaft.

Coracoid. - Rounded dorsally, tapering ventrally to a narrow shaft; produced posterodorsally into a prong below the lowermost actinost; cartilage filled along its dorsal edge and at the extreme anteroventral end; articulates anterodorsally by fibrous tissue and slight interdigitation with the posterior edge of the cleithrum, which slightly overlies it; articulates dorsally through cartilage with the scapula and by fibrous tissue with the base of the lowermost actinost.
Scapula.-Completely encloses the scapular foramen; concave and cartilage filled at its anterior and ventral edges; articulates anteriorly by fibrous tissue with the cleithrum which overlies its extreme anterior region, while ventrally it articulates through cartilage with the coracoid. Posteriorly the scapula articulates by fibrous tissue with the following elements, in order from dorsal to ventral; the first pectoral fin ray borne on a long knoblike projection and just behind it the small first or uppermost actinost followed by the second and third actinosts which articulate along the lower third of the posterior edge of the scapula.

Actinosts. - Four elements; cartilage filled at the dorsal end and, to a lesser extent, at the ventral end; the three uppermost actinosts articulating with the scapula, the lower actinost being supported by the posterodorsal edge of the coracoid; distally the actinosts support all of the pectoral fin rays except for the first. The actinosts increase in size from the first to the fourth.

Fin rays. - Usually 13 or 14 fin rays; the first ray very short, only about one-tenth the length of the second ray, the medial half much larger than the lateral half and articulated directly with the scapula rather than with the actinosts as are the other fin rays; the first two rays and the last or lowermost ray unbranched, the intervening rays branched. The small first ray without cross-striations; all other rays with cross-striations.

\section{Pelvic Fin.}

Pelvis.-A sturdy shaft, the two halves either variously fused or extensively interdigitated together so that the impression is that of a solid bone like a railroad rail in cross section behind the level of the pelvic spine. A single oblique crest on the side of the pelvis at the level of the flange of the pelvic spine allowing for two and only two positions of locking the erected spine. The shaft of the pelvis tapering to a point posteriorly. Anterior to the level of the pelvic spine, the anteroventral end of the pelvis bifurcates into a concave region for muscle attachment, extending up along the anterior base of the anterodorsal shaft of the pelvis. The anterodorsal shaft of the pelvis articulates by strong fibrous tissue just above the region of close medial articulation of the two cleithra.

Pelvic spine. - Large and strong; the medial end articulating to the pelvis in much the same manner as previously described for the triacanthodid Parahollardia lineata. However, in the Triacanthodidae the side of the pelvis at the level of the flange of the pelvic spine is either smooth and thus allowing for a single position of erection of the spine or it has numerous small grooves allowing for numerous, continuous positions of erection of the spine, rather than as in the Triacanthidae, exemplified by Pseudotriacanthus strigilifer, in which there is a single relatively large oblique crest allowing for only two positions of erection. The rotation of the spine is 
the same as described for Parahollardia lineata, the difference being only that when the erected spine is returned to its unerected position it can have its flange, after the latter is out of contact with the ventrolateral edge of the pelvis, stopped by the oblique groove on the lateral surface of the pelvis, permitting the second or partial position of erection of the spine.

Fin rays. - No pelvic fin rays have been found in any of the cleared and stained specimens or in other specimens examined closely in the pelvic axil but not cleared and stained. However, this is perhaps partially attributable to the relatively large size of the specimens examined, as explained in Tyler (1968:290), for a single rudimentary fin ray is present in the young of some species of triacanthids, the ray being resorbed in adults.

VERTEBRAL COLUMN. - All vertebrae with biconcave centra, except the last, which ends posterodorsally in the urostyle.

\section{Abdominal Vertebrae.}

First vertebra. - Neural spine thick, the left and right halves meeting above the neural canal to come into close apposition and interdigitation posteromedially; from this point of meeting the neural spine spreads anterolaterally to form the posterior half of the walls of the bony well surrounding the ventral end of the stout shaft of the first basal pterygiophore of the spiny dorsal fin, the well also forming a bony roof over the neura] canal in this region. The anterolateral edge of the neural arch and lower region of the neural spine articulate by extensive interdigitation with the exoccipital and, in some cases, with the extreme posteroventral edge of the epiotic as well, but the articulation is mainly to the exoccipital. Over the anterior third of the neural arch region just above the centrum, the first vertebra extensively interdigitates with the short and irregularly shaped exoccipital condyles that overlie this region. The rim of the concave anterior end of the centrum of the first vertebra articulates with the rim of the concave posterior end of the basioccipital. Posteriorly the first vertebra articulates with the second vertebra by apposition of the rims of their centra and by the short and bluntly rounded neural postzygapophysis of the first vertebra slightly overlying the neural prezygapophyseal area of the second vertebra. No haemal zygapophyses are present.

Other abdominal vertebrae. - In 21 specimens the abdominal vertebrae numbered eight. All of the abdominal vertebrae, as well as the caudal vertebrae, have a bony roof over the neural canal and a single undivided neural spine. The neural spine of the second abdominal vertebra is of about the same size as that of the first, while the neural spines of the third and subsequent vertebrae are longer than those of the first two abdominal vertebrae and of approximately the same size. The last abdominal vertebra has its neural prezy. gapophysis overlying the neural postzygapophyseal area of the preceding vertebra. No haemal pre- or postzygapophyses are present. Each neural arch has a neural foramen along the middle of its lateral surface. The first three abdominal vertebrae have no transverse or haemal processes, but the fourth to last abdominal vertebrae variously have transverse processes or haemal arches and spines which bear the intermuscular bones. These transverse processes become more ventrally directed until they eventually form complete haemal arches. The processes of the fourth to sixth vertebrae are incomplete, whereas those of the seventh and eighth vertebrae form complete haemal arches with very short spines. Eight epipleurals or intermuscular bones are present in the myocommata between the epaxial and hypaxial musculature, five borne on the fourth to eighth abdominal vertebrae, followed in series by three others on the first three caudal vertebrae. The epipleurals articulate basally by fibrous tissue with the lateral surfaces of the transverse processes of the fourth to sixth abdominal vertebrae and of the haemal arches and spines of the seventh abdominal to third caudal vertebrae.

Caudal Vertebrae. - In 21 specimens the caudal vertebrae numbered 12 . The haemal spine of the first caudal vertebra articulates by fibrous tissue with the anterior surface of the dorsal one-fifth of the first anal fin basal pterygiophore. The neural spine of the first caudal vertebra is similar to that of the preceding vertebra, but the other caudal vertebrae have progressively slightly less long neural spines. The haemal spines similarly decrease slightly in size from the second caudal vertebra to the penultimate vertebra, which has its neural and haemal spines of slightly increased length. The neural prezygapophyses of the more anterior of the caudal vertebrae overlie the neural postzygapophyseal area of the preceding vertebrae. The haemal spines of the caudal vertebrae support the anal fin basal pterygiophores by fibrous tissue but do not make close contact with them. The same is true of the neural spines of the abdominal and caudal vertebrae that support the basal pterygiophores of the soft dorsal fin. With the exception of the last vertebra, each neural arch has a completely enclosed neural foramen along the middle of the neural arch region, and all have a bony roof over the neural and haemal canals. All of the haemal arches and spines are fused to their centra.

Caudal Skeleton. - The parhypural and all but the uppermost hypural are indistinguishably fused to the last vertebral centrum. There is a free epural and a uroneural represented by a single solid piece, the two halves of the uroneural apparently having fused together. The low neural arch of the vertebral centrum bifurcates anteriorly but comes together in the midline over the neural canal posteriorly. It is to this anterior bifurcate region that the ventral end of the epural articulates by fibrous tissue. The single free hypural is rodlike and articulates along the oblique upper anterior edge of the fused hypural plate, the anterior end of the free hypural being just behind the posterior end of the short neural arch of 
the last vertebral centrum. The uroneural is located between the epural and free hypural and has a tube through its length enclosing the neural canal. The tube also extends through the distal region of the epural to exit near to the tip of the neural spine of the penultimate vertebra. A large foramen just below the middle of the fused hypural plate represents the region of fusion of the parhypural with the hypurals above it, but otherwise the hypurals (except for the uppermost free element) and the parhypural are indistinguishably fused with the last vertebral centrum. As explained by Tyler (1970b:10) the single uroneural probably represents the second pair of uroneurals of triacanthodids, in which the first of the two pairs usually is much smaller and more variable in occurrence than is the second pair. A prominent horizontal crest is present on the fused centrumparhypural-hypural plate for muscle attachment.

Caudal fin rays. - Twelve in number; the uppermost ray and the lowermost ray unbranched, the others becoming increasingly branched toward the two middle rays, which are branched in triple to quadruple dichotomies. The upper unbranched ray has its bifurcate base articulated with the distal end of the free hypural and the extreme dorsal end of the fused hypural plate. The uppermost two or three branched rays have their bifurcate bases overlapping the fused hypural plate, whereas the middle four to five rays to not overlap the plate. Similarly, the lower unbranched ray slightly overlaps the fused parhypural-hypural plate, and the branched rays above increasingly less so.

\section{DORSAL AND ANAL FINS.}

\section{Dorsal Fin.}

Spines and pterygiophores. - Six spines of greatly decreasing length posteriorly in the series and only four basal pterygiophores, without the intervention of ossified distal pterygial elements. The first two spines are borne on the first basal pterygiophore, whereas the third, fourth, and fifth spines are borne on their own individual basal pterygiophores. There is no basal pterygiophore supporting the minute rudimentary sixth spine which is buried beneath the skin. The concave medial region of the base of the first spine rotates over a low medial flange at the dorsal surface of the first basal pterygiophore. However, this medial flange more posteriorly becomes a tall, somewhat anteriorly directed prong which fits into a transverse hole through the base of the spine. It is around this dorsal flange of the pterygiophore that the first spine rotates. The spine can be erected and locked in any of a continuous series of positions by the close apposition of the base of the first spine with the dorsal articular surface of the first pterygiophore on either side of its medial flange, both surfaces being somewhat rough and irregular. This mechanism is basically the same as that described for the triacanthodid Parahollardia lineata, although the medial flange of the basal pterygiophore in the case of triacanthids is much less elaborately developed than it is in triacanthodids (see Tyler 1968:fig. 7 for a comparative illustration of the structure in the two families of triacanthoids). The second spine articulates basally with the dorsal surface of the first basal pterygiophore just behind the posterior edge of the anterodorsal flange around which the first spine rotates, at a slight concavity on the surface of the pterygiophore in this region. This slight concavity has a very small medial flange fitting into the concave base of the second spine. The third to the fifth spines articulate at their generally rounded basal ends with simple shallow concavities in the dorsal surfaces of their individual pterygiophores. The sixth spine is rudimentary and has no basal pterygiophore supporting it.

The first basal pterygiophore is a very stout shaft of bone with only narrow anteromedial and posteromedial flanges for muscle attachment. Basally the stout shaft is firmly held in place by fibrous tissue within the deep bony well formed posteriorly by the neural spine of the first abdominal vertebra and anteriorly by the exoccipitals. This is a relatively immovable articulation. The second to fourth basal pterygiophores are much smaller than is the stout first pterygiophore and each bears its own individual dorsal spine of decreasing length in the series. The four basal pterygiophores articulate to one another by fibrous tissue or, in some cases, by a very slight interdigitation of their apposed surfaces. The second to fourth pterygial elements are cartilage filled at their extreme ventral ends, at the end of the vertical shaft along their lateral surfaces. The second and third pterygiophores also often remain cartilaginous at the extreme posterodorsal tip.

Fin rays and pterygiophores.-Usually 21 or 22 fin rays are present; the first 1 or 2 rays unbranched, the others branched in single to double dichotomies. No ossified distal pterygiophores are present between the bifurcate bases of the rays in the specimens of $P$. strigilifer studied, but in some other species of triacanthids ossified distal pterygiophores are present, at least in large adult specimens (see Tyler 1968:268). When ossified distal pterygiophores are present they are a single piece in the midline rather than a pair of pieces as found in triacanthodids. Basally the fin rays are supported by a number of basal pterygiophores similar in number to that of the fin rays. The pterygiophores extensively interdigitate with one another in their upper regions just below the apposed concavities in their anterior and posterior edges which give rise to the round holes between the distal heads of the pterygiophores that are present at least anteriorly in the series. Lateral flanges for muscle attachment are very well developed along the lengths of the pterygiophores. These flanges are widest toward the distal end of the pterygiophore where they form prominent hooklike processes. The first basal pterygiophore of the soft dorsal fin usually is located between the neural spines of the fourth and fifth abdominal vertebrae, while the last few basal pterygiophores lie between the neural spines of the fifth and sixth 
caudal vertebrae. The pterygial elements are cartilage filled at their dorsal and ventral ends.

\section{Anal Fin.}

Fin rays and pterygiophores. - Usually 15 or 16 fin rays are present; the first ray and sometimes the second ray unbranched, the others branched in single to double dichotomies. No ossified distal pterygiophores are present between the bifurcate bases of the rays. Basally the fin rays are supported by a number of basal pterygiophores equal to or sometimes one less than the number of rays. The pterygiophores articulate to one another by extensive interdigitation in a manner similar to that described for the basal pterygiophores of the soft dorsal fin and possess holes distally between the apposed anterior and posterior edges of the pterygiophores, at least anteriorly in the series. Well-developed lateral flanges with hooklike processes are present just as with the basal pterygiophores of the soft dorsal fin. The first basal pterygiophore of the anal fin is by far the largest of the series, the others decreasing in length posteriorly in the series. There is a prominent crest anterodistally on the first basal pterygiophore of the anal fin in addition to the lateral flange similar to that which is present on the other basal pterygiophores. The first basal pterygiophore is held immovably by fibrous tissue against the posterior edge of the haemal spine of the ninth vertebra, making the latter by definition the first caudal vertebra. The last several basal pterygiophores of the anal fin articulate by fibrous tissue between the neural spines of the fifth and sixth caudal vertebrae, just as the last few basal pterygiophores of the soft dorsal fin are held between the neural spines of the same two vertebrae.

Comparative diagnoses of subfamilies (Protacanthodinae, Cryptobalistinae, Triacanthinae).-There are three subfamilies of triacanthids: two exclusively fossil (one from the Eocene and one from the Oligocene) and one with both fossil (Oligocene and Miocene) and Recent species. These three subfamilies are comparatively diagnosed as follows, modified and expanded from Tyler (1968), especially on the basis of the reexamination of the holotype of the Eocene Protacanthodes.

The Eocene Protacanthodinae have: the pelvis shaftlike posterior to the region of the pelvic spines and probably not bifurcate anterior to the spines and of unknown cross-sectional shape; the spiny dorsal fin base slightly longer than the soft dorsal fin base; six abdominal vertebrae anterior to the first basal pterygiophore of the soft dorsal fin; second to fourth basal pterygiophores of the spiny dorsal fin with welldeveloped ventral shafts oriented more or less vertically in relation to the vertebral axis and with their proximal ends in contact with the distal ends of the neural spines of the second to fourth abdominal vertebrae; ventrally directed portion of the first basal pterygiophore of the spiny dorsal fin long and well developed, articulated with the middle to basal region of the posterior surface of the skull; most neural spines relatively oblique; skeletal appearance similar to that of the Recent triacanthids and not to that of balistids; caudal peduncle only slightly tapering toward the tail, deeper than wide at the place of least depth; caudal fin extremely long (53\% SL) and rounded; scales with numerous upright spinules. A single species, Protacanthodes ombonii (Zigno 1887a).

The Oligocene Cryptobalistinae have: the pelvis basinlike from the region of the pelvic spines posteriorly, but bifurcate anterior to the spines; pelvis in cross section behind the pelvic spines flat, with upturned edges forming a concave dorsal surface, wider than deep; spiny dorsal fin base much shorter than the soft dorsal fin base; probably six abdominal vertebrae anterior to the first basal pterygiophore of the soft dorsal fin; second to third (fourth, if present, unknown) basal pterygiophores of the spiny dorsal fin essentially without ventral shafts, these pterygiophores far removed from the distal ends of the neural spines of the abdominal vertebrae; ventrally directed portion of the first basal pterygiophore of the spiny dorsal fin very short, articulated with the upper region of the posterior surface of the skull; most neural spines relatively vertical; skeletal appearance generally similar to that of the balistids rather than to that of Recent triacanthids; caudal peduncle probably tapered to a constricted region in front of the caudal fin, and probably about as wide as deep; caudal fin of moderate length ( $31 \% \mathrm{SL}$ ), basically truncate, with a slight medial concavity; scales apparently without elaborate ornamentation. A single species, Cryptobalistes brevis (Rath 1859).

The Oligocene to Recent Triacanthinae have: the pelvis shaftlike from the region of the pelvic spines posteriorly and not bifurcate anterior to the spines; pelvis in cross section behind the pelvic spines like a railroad rail, deeper than wide or at least about as deep as wide, the lateral edges not upturned; spiny dorsal fin base much shorter than the soft dorsal fin base; four or five abdominal vertebrae anterior to the first basal pterygiophore of the soft dorsal fin; second to fifth basal pterygiophores of the spiny dorsal fin with moderately developed ventral shafts, usually directed anteroventrally toward the region between the neural spines of the first to third abdominal vertebrae but not in direct contact with them, usually well separated from them; ventrally directed shaft of the first basal pterygiophore of the spiny dorsal fin long and well developed, articulated with the middle to basal region of the posterior surface of the skull; most neural spines relatively oblique; skeletal appearance similar to that of the Recent triacanthids and not to that of balistids; caudal peduncle tapered to a narrow trans. versely indented region above and below in front of the caudal fin, wider than deep at this point; caudal fin of short to moderate length ( 15 to $30 \% \mathrm{SL}$ ), deeply forked; scales with low emarginate ridges. Seven Recent species in four genera (Triacanthus, Trixiphichthys, Pseudotriacanthus, Tripodichthys) in the Indo-western Pacific, two fossil species in a single Oligocene genus (Acanthopleurus), and one species from the Miocene (Marosichthys). 


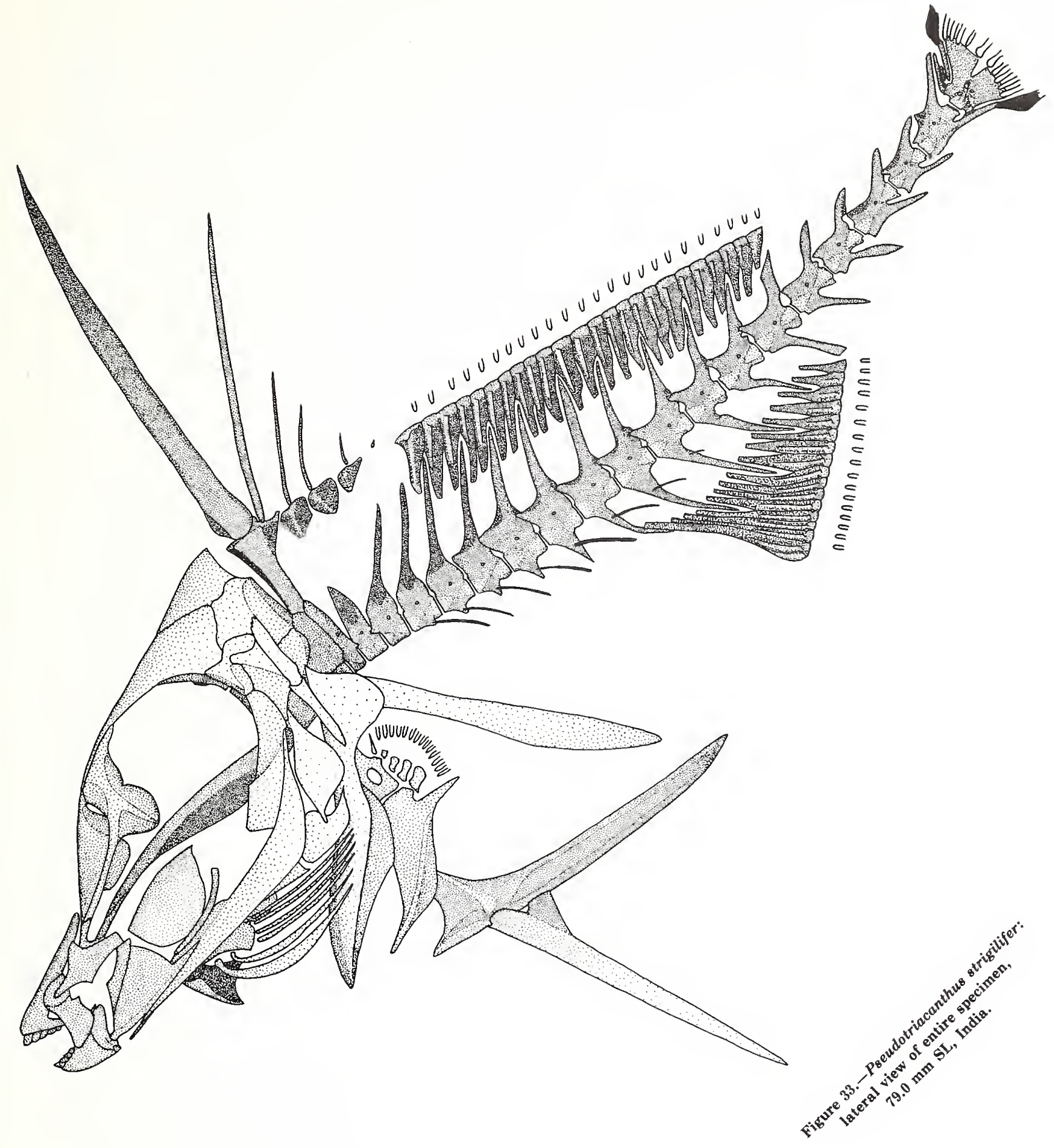



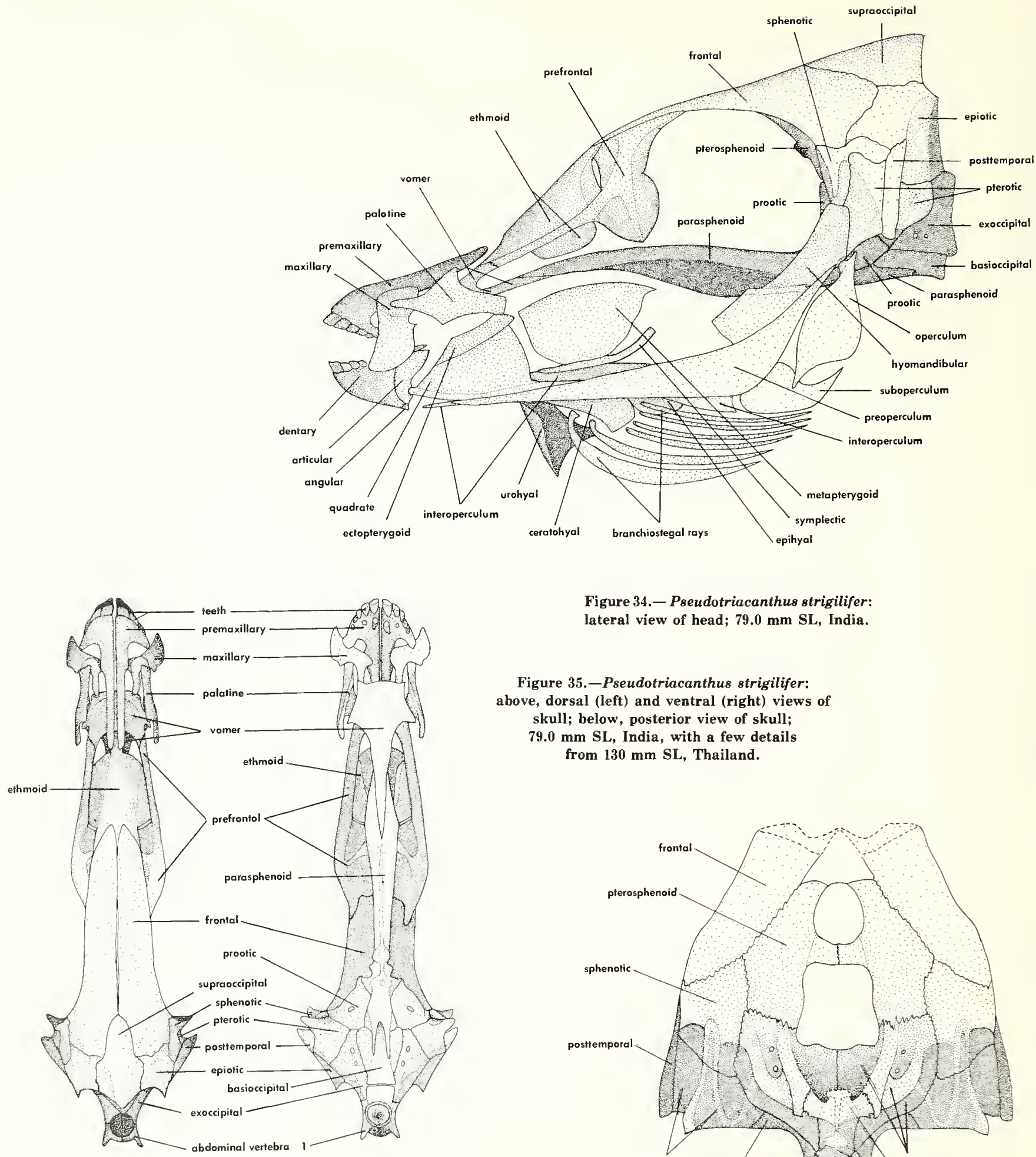

Figure 34.-Pseudotriacanthus strigilifer: lateral view of head; $79.0 \mathrm{~mm}$ SL, India.

Figure 35.-Pseudotriacanthus strigilifer: above, dorsal (left) and ventral (right) views of skull; below, posterior view of skull;

$79.0 \mathrm{~mm}$ SL, India, with a few details from $130 \mathrm{~mm} \mathrm{SL}$, Thailand.

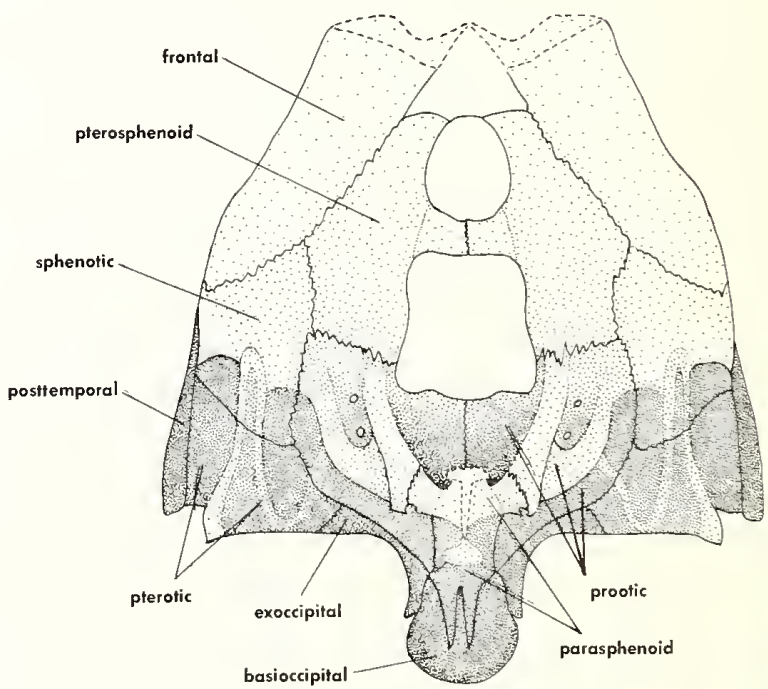

Figure 36.-Pseudotriacanthus strigilifer: posterior view of orbit (cross section of skull; dashed lines represent cut surfaces of frontals and parasphenoid); $130 \mathrm{~mm}$ SL, Thailand. 

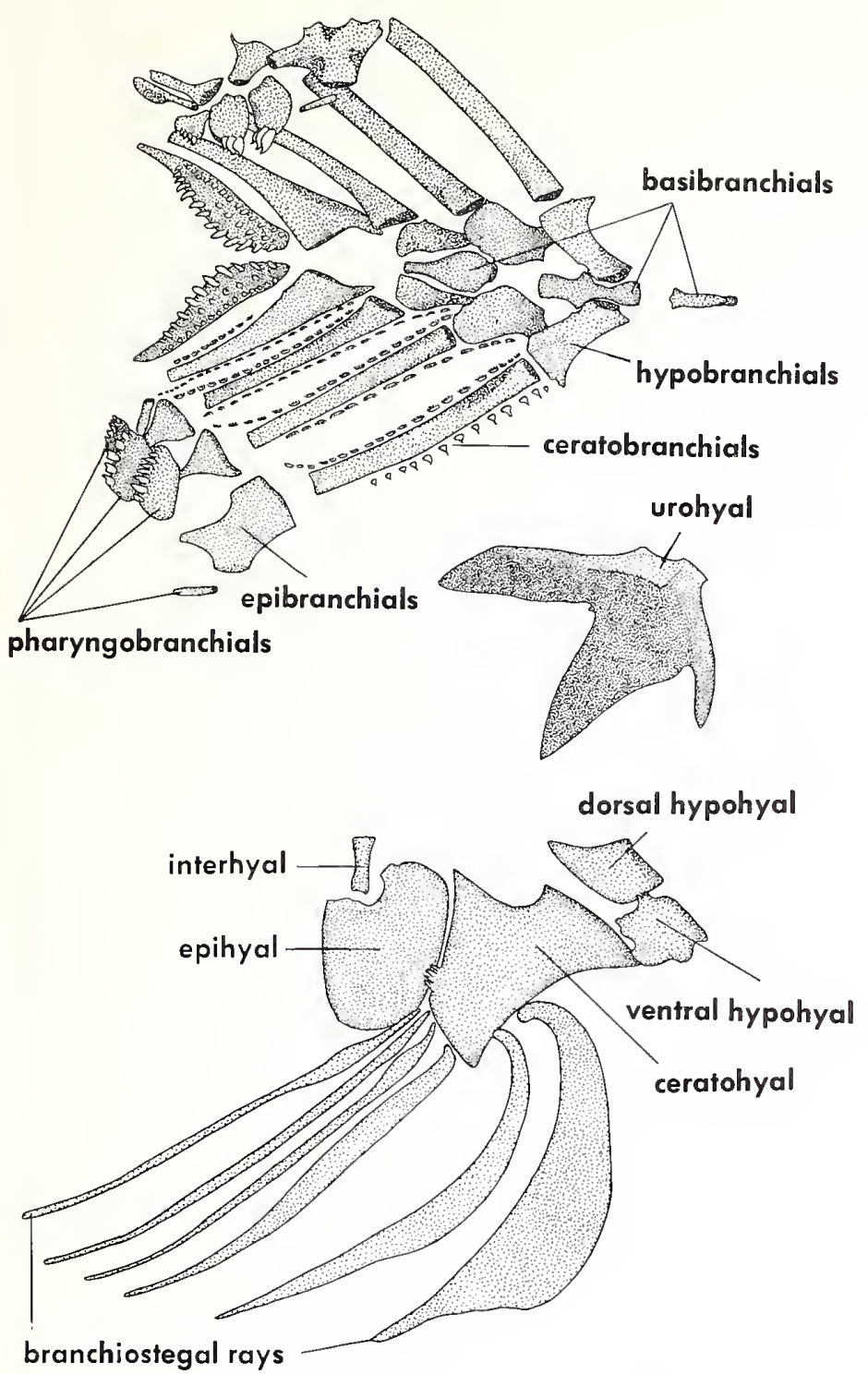

branchiostegal rays

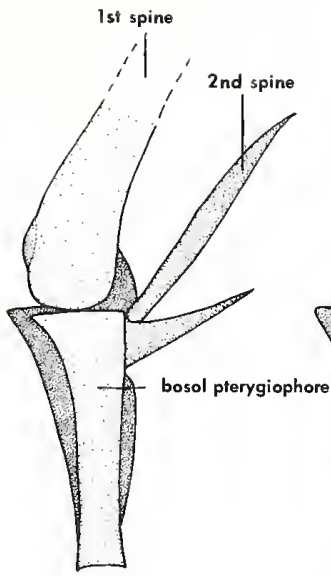

onterior view of base of

1 st and 2nd

1.dorsol spines
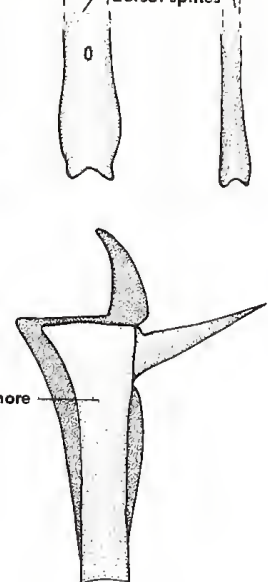

Figure 38.-Triacanthus biaculeatus: lateral (left) and anterior (right) views of first two dorsal spines (erected), with basal pterygiophore shown in lateral view in both cases, $113 \mathrm{~mm} \mathrm{SL}$, Borneo.
Figure 37.-Tripodichthys angustifrons: dorsal view of branchial arches (extended on lower side); lateral view of hyoid arch and urohyal; $137 \mathrm{~mm}$ SL, Australia.
Figure 39.-A, Parahollardia lineata, $45.7 \mathrm{~mm} \mathrm{SL}$,

Florida, and B, Triacanthus biaculeatus,

$113 \mathrm{~mm}$ SL, Borneo: lateral views of pelvis and pelvic fin in place (above) and of pelvis with pelvic fin removed (middle); anterior views of the base of the pelvic spine (below), to show the structural differences in the locking mechanism of the Triacanthodidae (indefinite number of positions of erection) and

Triacanthidae (two positions of erection).
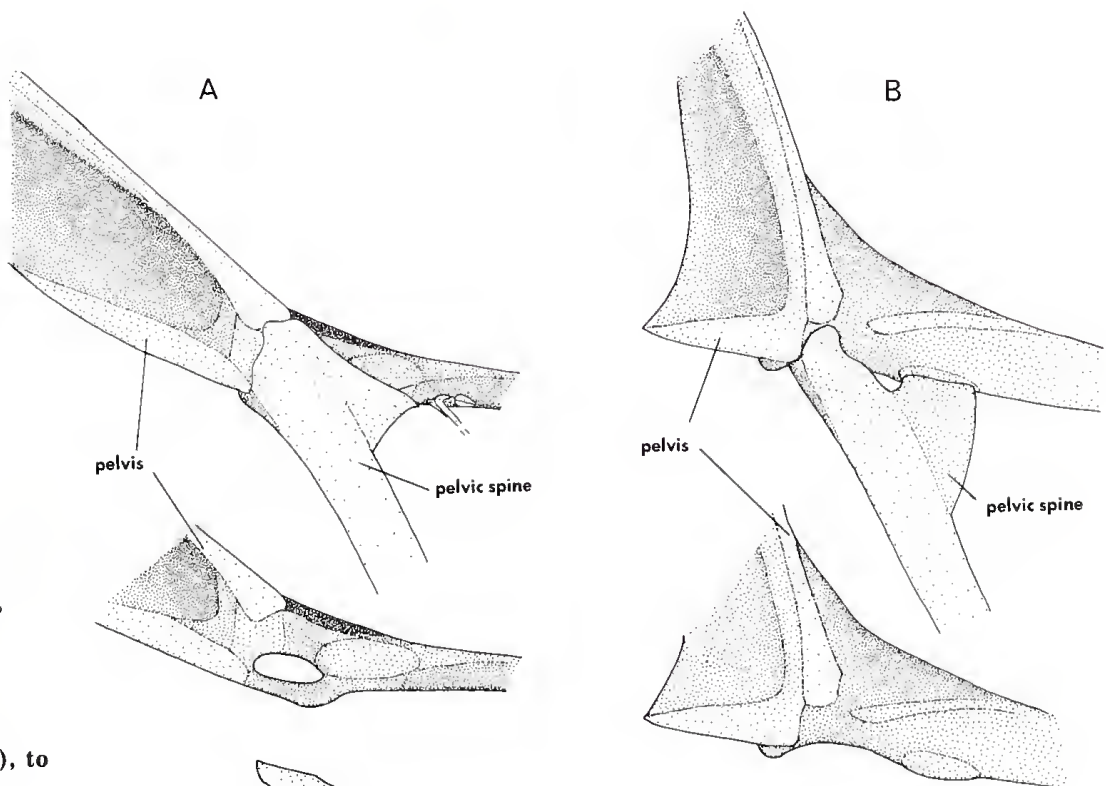

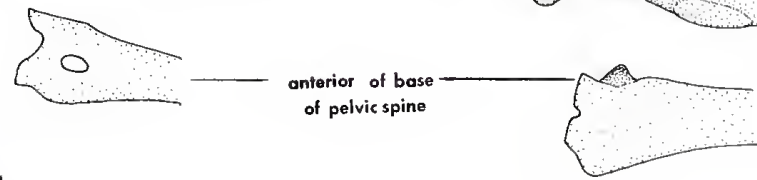




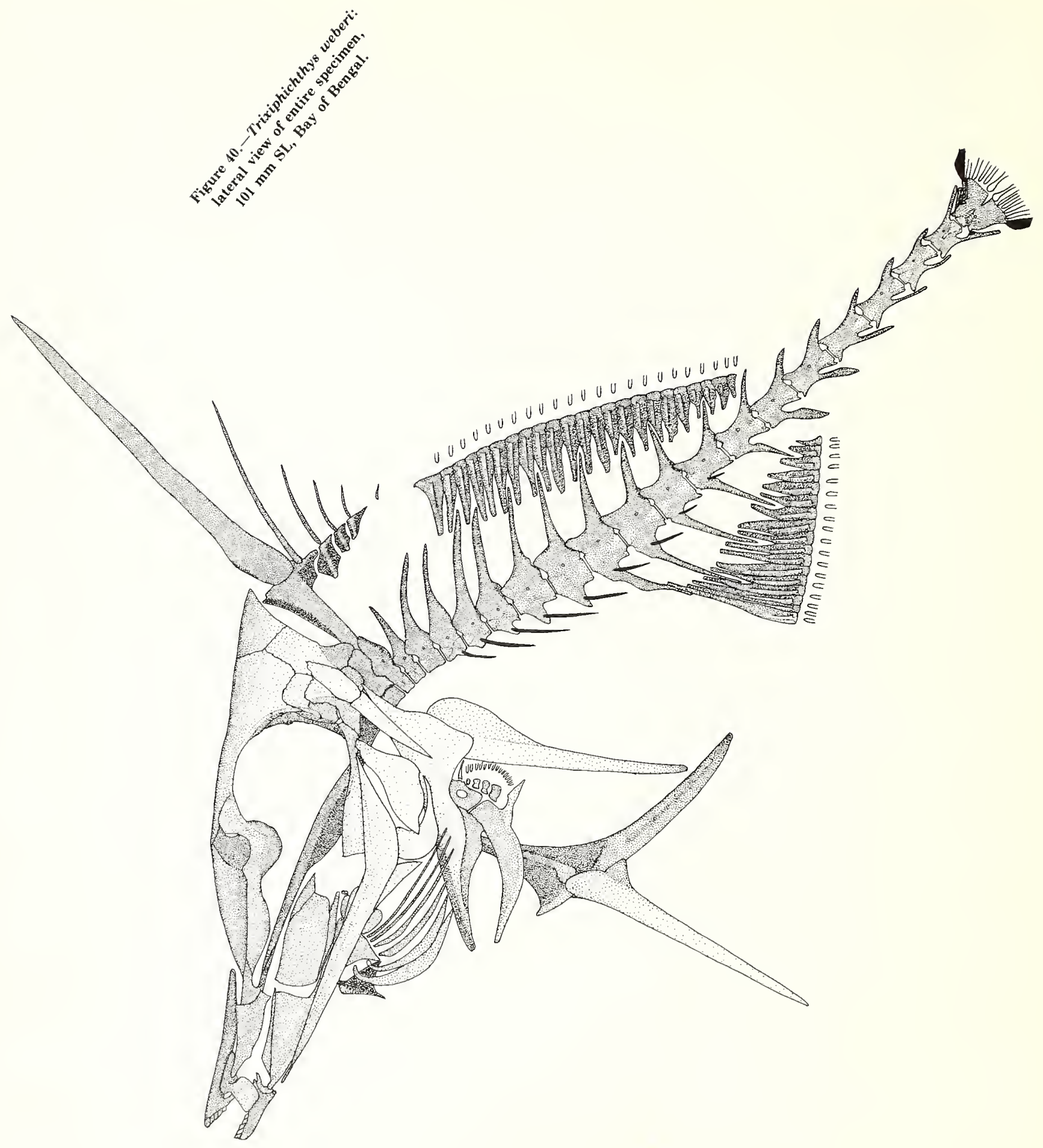

Anatomical diversity.-The anatomical diversity of this family has been treated in detail by Tyler (1968) and the major features need be only briefly summarized here.

The Recent species form a very slightly diversified group of four rather finely split genera that in the near past were all accommodated in one genus. The heavy incisorlike teeth of Triacanthus, Pseudotriacanthus, and Tripodichthys occur in an outer series of 10 in both jaws, the upper jaw with an inner series of four molariform teeth and the lower jaw with two. In Trixiphichthys, however, the teeth are smaller and the number of inner series teeth in the upper jaw is reduced to two, while the snout is longer and the mouth is narrower than in the other three genera. A mesopterygoid is absent except in Trixiphichthys, in which it is small. The caudal peduncle is much shorter and the lateral line slightly less con- 
Figure 41.-Trixiphichthys weberi: lateral view of head, $101 \mathrm{~mm}$ SL, Bay of Bengal.

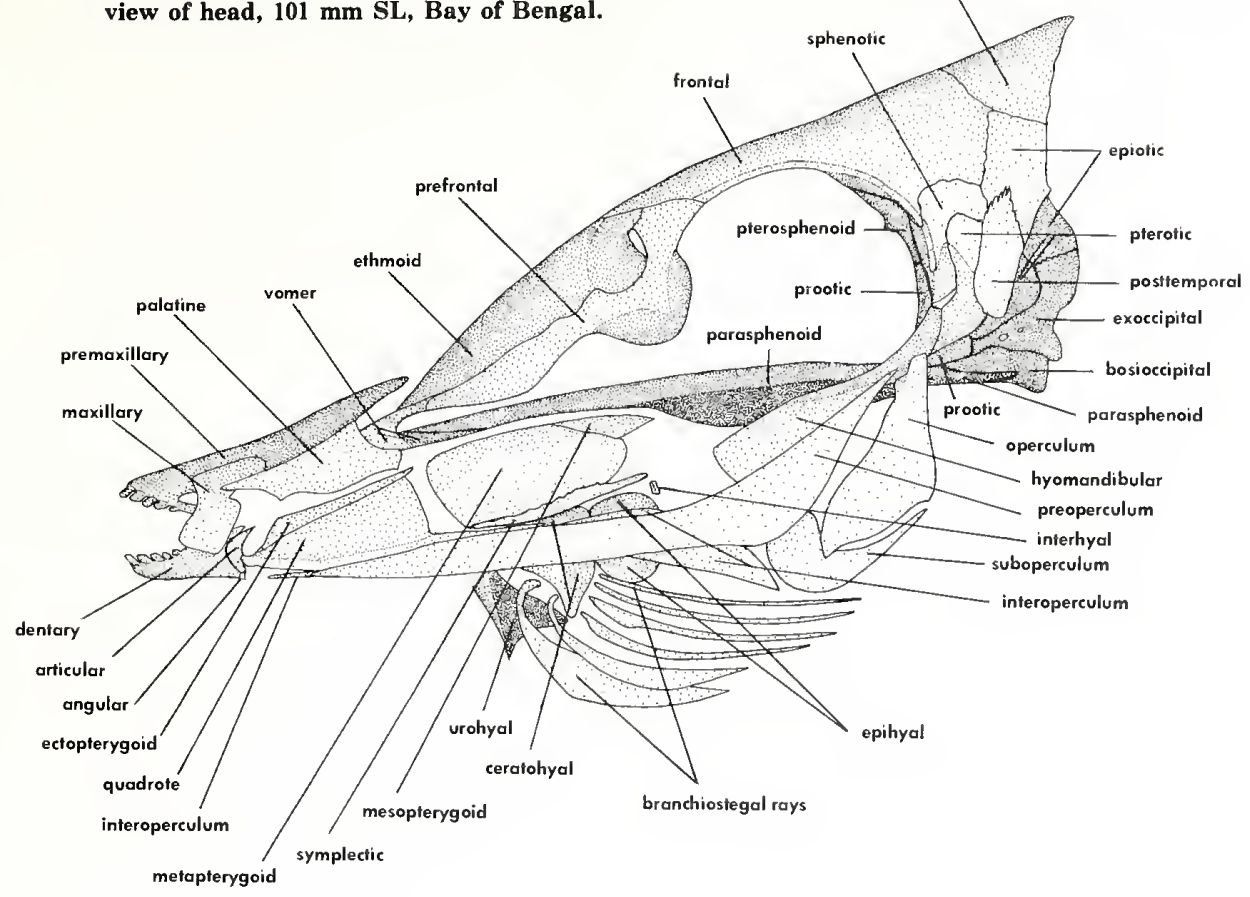

spicuous in Trixiphichthys than in the other three genera. The second dorsal fin spine is best developed in Pseudotriacanthus (greater than half the length of the first spine), next best developed in Trixiphichthys (about half the length of the first spine) and relatively short in the other two genera (about one-third or less the length of the first spine). The scales in Pseudotriacanthus have an anterior to posterior series of high thin distally emarginate vertical ridges, while in the other three genera the scales have a low, distally emarginate cruciform ridge. The shaft of the pelvis posterior to the pelvic spines tapers to a sharp point posteriorly in Pseudotriacanthus and Tripodichthys, but does not taper to a sharp point in Triacanthus and Trixiphichthys. The length of the anal fin base is shorter (usually about 2 times in the soft dorsal fin base) in Pseudotriacanthus than in the other three genera (usually about 1.4 to 1.7 times in the soft dorsal fin base). The lateral edge of the sagitta is relatively straight or somewhat convex in Triacanthus, but has a distinct indentation or cavity in the other three genera. The base of the pseudobranch has a forward pointed apex about onethird down its length in Trixiphichthys but is an even curve without an apex in the other three genera, which usually have a shorter base to the pseudobranch and fewer lamellae. There are fewer dorsal, anal, and pectoral fin rays in Pseudotriacanthus than in the other three genera. The sixth, and last, dorsal fin spine is more often completely lost in Triacanthus biaculeatus than in the other six species. Externally visible rudiments of the pelvic fin ray buried in the skin are retained longer in Tripodichthys oxycephalus than in the other six species.

The fossil triacanthids include at least one genus highly similar to the Recent species, another genus highly dissimilar to the Recent species, and one genus obviously intermediate in many respects between the triacanthodids and triacanthids. These were treated by Tyler (1968) mainly on the basis of the literature, but some of the specimens have subsequently been reexamined, and notes are given here on their anatomy.

The Eocene Protacanthodes ombonii, the only representative of the Protacanthodinae, is known from a single specimen which has recently been reexamined. The holotypic specimen, in counterpart, IGUP 10.901 (head to left) - 902, from the upper portion of the lower Eocene of Monte Bolca, Italy, is $112 \mathrm{~mm}$ SL, an excellent impression with well-preserved scales that obscure many osteological features.

Proportional measurements (percent of standard length in parentheses) for $P$. ombonii are: greatest depth $45.7 \mathrm{~mm}$ ( $40.7 \% \mathrm{SL})$; snout to base of first dorsal spine $44.2 \mathrm{~mm}$ ( $39.3 \% \mathrm{SL})$; eye $11.4 \mathrm{~mm}$ (10.1\% SL); spiny dorsal fin base $25.8 \mathrm{~mm}(23.0 \% \mathrm{SL})$; soft dorsal fin base $23.5 \mathrm{~mm}$ (20.9\% SL); anal fin base $12.4 \mathrm{~mm}$ (11.0\% SL); caudal peduncle length $26.2 \mathrm{~mm}$ (23.3\% SL); least caudal peduncle depth $16.4 \mathrm{~mm}$ (14.6\% SL); caudal fin length $50.6 \mathrm{~mm}(45.0 \% \mathrm{SL})$; length of pelvis posterior to the base of the pelvic spine $17.9 \mathrm{~mm}(15.9 \% \mathrm{SL})$; length of pelvic spine $27.9 \mathrm{~mm}$ ( $24.8 \% \mathrm{SL})$; soft dorsal fin height $10.5 \mathrm{~mm}$ (9.3\% SL); anal fin height $10.0 \mathrm{~mm}$ (8.9\% SL); and the approximate lengths of the dorsal fin spines are as follows: first $36.5 \mathrm{~mm}(2.5 \% \mathrm{SL})$, second $10.5 \mathrm{~mm}$ (9.3\% SL), third $6.0 \mathrm{~mm}(5.3 \% \mathrm{SL})$, fourth $5.0 \mathrm{~mm}(4.4 \%$ $\mathrm{SL})$, fifth $1.9 \mathrm{~mm}(1.7 \% \mathrm{SL})$, sixth $1.4 \mathrm{~mm}(1.2 \% \mathrm{SL})$.

The six dorsal spines, which decrease greatly in length posteriorly in the series, are followed by 19 fin rays, the distal ends of those that show being branched. The distance between the last spine and the first ray $(5.1 \mathrm{~mm}$, 

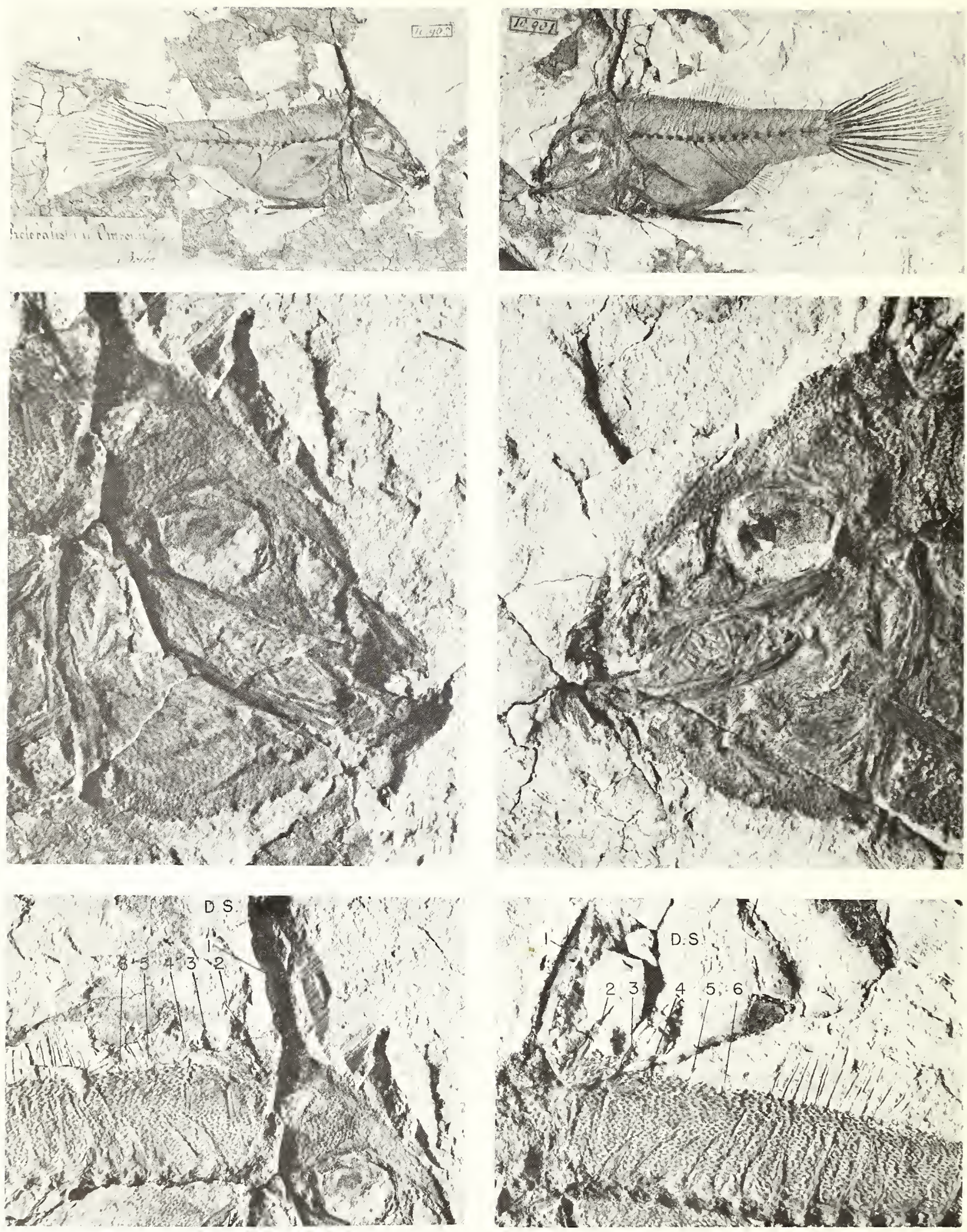

Figure 42.-Protacanthodes ombonii: above, lateral views of the two counterparts; middle, lateral views of the heads of the two counterparts; below, lateral views of the dorsal parts of the head and anterior body of the two counterparts, to show the six dorsal spines; holotype, $112 \mathrm{~mm}$

SL, Eocene of Monte Bolca, Italy. 
$4.5 \% \mathrm{SL}$ ) is slightly greater than that between the last few spines $(4.1 \mathrm{~mm}, 3.6 \% \mathrm{SL})$. The anal fin has 14 rays, the distal ends of those that show being branched. The elongate rounded caudal fin has 12 rays, the uppermost ray and the lowermost ray unbranched and the intervening 10 rays branched. The pectoral fin rays cannot be counted, nor are any pelvic fin rays evident, although a small ray or two could well be present but obscured by the pelvic spine. The branchiostegal rays are $2+4=6$, and the first two rays are not much wider than the others. There are clearly 12 caudal vertebrae and probably 8 abdominal vertebrae. The supracleithrum is placed vertically in relation to the axis of the skull. The parasphenoid is relatively straight in the region of the orbit, and the ventral flange seems to have been only moderately developed, probably only slightly deeper than the depth of the shaftlike portion of the bone above it.

The prefrontal is very large and sturdy, and has at least a moderate anteroventral extension alongside the lower region of the ethmoid, although it is not clear whether this extension took the form of a long process which also sutured anteriorly with the posterolateral wing of the vomer, as in Recent triacanthids. The upper half of the prefrontal apparently was well separated from the upper half of the ethmoid by a block of cartilage larger than in the Recent species. The ethmoid appears to have been large and sturdy, with a steeply oblique anterior face that then tapered posterodorsally to suture with the frontal and prefrontal, much as illustrated by Tyler (1968:361, fig. 206) for Triacanthus biaculeatus, but with the frontal extending a little further forward.

The upper jaw apparently is unnaturally displaced posteriorly, for the tip of the upper jaw is well behind that of the lower jaw, a functionally unlikely arrangement in this family. As presently placed, the posterior end of the premaxillary pedicel abuts against the top of the oblique anterior face of the ethmoid just anterior to the anterior end of the frontal. In life, however, the pedicel undoubtedly never was retracted this far posterodorsally and probably slid along the anterior basal region of the ethmoid when the mouth was protracted, as in the Recent species. The moderate-sized eye is located just above the middle of the distance between the snout and the spiny dorsal origin. The pelvis posterior to the pelvic spines appears to be a stout shaft of bone. The anterior and lateral surfaces of the first dorsal spine and the anterior, dorsal, and ventral surfaces of the pelvic spine are covered with low spiny processes, probably asperities on the scales covering these spines.

The caudal fin supporting structures are not well preserved, but grooves indicate that there was probably a good separation between what in generalized triacanthoids are the second and third hypurals. The condition of the parhypural, epurals, and uroneural elements, if present and separate, is unclear. The first basal pterygiophore of the spiny dorsal fin (supporting the first two spines) has a strong ventral shaft directed ventrally to between the middle to basal region of the skull and what is probably the neural spine of the first vertebra closely applied to the skull. The second basal pterygio-

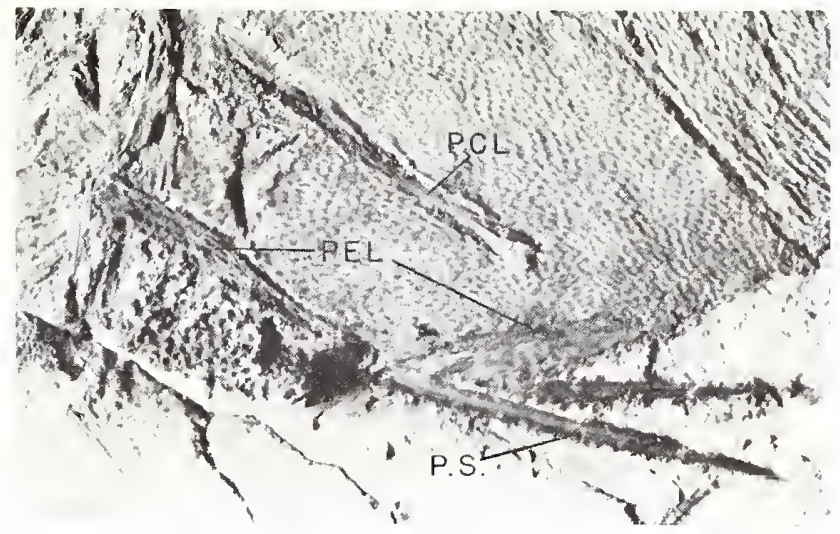

Figure 43.-Protacanthodes ombonit: lateral view of abdominal region (head to left) to show the pelvis and pelvic spine (one from each side), holotype, $112 \mathrm{~mm} \mathrm{SL}$, Eocene of Monte Bolca, Italy.

phore (supporting the third spine) has its shaft angled slightly anteroventrally and in contact with the distal end of the neural spine of the second vertebra. The third and fourth basal pterygiophores have their shafts directed ventrally, about vertical to the vertebral column, and in contact, respectively, with the distal ends of the neural spines of the third and fourth vertebrae. If a fifth basal pterygiophore supporting the slender, minute sixth spine was present, it apparently was very small, for it does not show in either plate. The first basal pterygiophore of the soft dorsal fin is placed between the neural spines of the sixth and seventh abdominal vertebrae, and there appears to have been an approximately one to one ratio between the number of dorsal and anal fin rays and their basal pterygiophore supports.

The teeth are relatively large incisors, about five in each half of each jaw judging from the size of the somewhat scattered elements. It is not possible to tell whether an inner series of teeth was present in addition to the major outer series. The largest teeth, anteromedially in each jaw, have stout bases toward the sockets but taper into blunt nipplelike caps distally, while the teeth more laterally in each jaw have lesser cusps and, in some cases, almost rounded distal edges.

Protacanthodes differs from the other triacanthids mainly by having: 1) a deep and only slightly tapered caudal peduncle; 2) an extremely elongate rounded caudal fin; 3) the spiny dorsal fin base slightly longer than the soft dorsal fin base; 4) better developed spiny dorsal fin basal pterygiophores whose ventral shafts are slightly differently arranged; 5) the upper shaftlike portion of the parasphenoid in the region of the orbit relatively straight and its ventral flange only slightly deeper than the depth of the shaftlike portion; 6) the lower two branchiostegal rays not enlarged; 7) possibly less fusion of the hypurals; 8) one more abdominal vertebra anterior to the first basal pterygiophore of the soft dorsal fin; 9) and in having scales with a row of upright spinules. All of these features of difference between Protacanthodes and Recent triacanthids relate Protacanthodes to the 


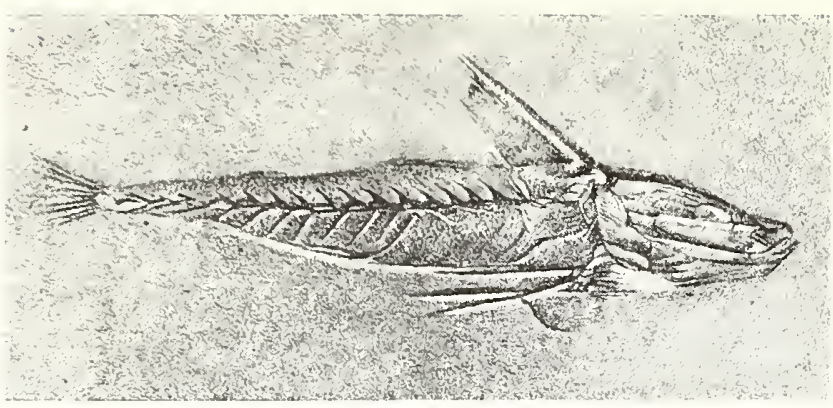

Figure 44.-Acanthopleurus serratus: lateral view of entire specimen, syntype, ca $95 \mathrm{~mm} \mathrm{SL}$, Oligocene of Canton Glarus, Switzerland (Agassiz 1842:pl. 75).

triacanthodids and establish it as an intermediate between the two families, as discussed more fully in the preceding section on the relationships of the Triacanthodidae.

The fossil species of Triacanthinae are represented mainly by several dozen specimens of the Oligocene Acanthopleurus. These specimens are little more than impressions, although in some cases rather complete, left in the black schist of Canton Glarus, Switzerland, and 18 of them have recently been reexamined for this work. The general appearance of all the specimens is decidedly like that of Recent triacanthids. The specimens of Acanthopleurus examined fall naturally into two groups: 1) moderately elongate, like most of the Recent species; and 2) decidedly elongate, much more so than any of the Recent species. The moderately elongate specimens differ from all the Recent species by having a slightly deeper (5-8\% SL vs. $2-4 \%$ SL) caudal peduncle, i.e., less constricted just in front of the caudal fin base. Only one specific name is available in Acanthopleurus, this being serratus Agassiz (1842 illustration, 1844b description), based on decidedly elongate specimens.

The deeper bodied Acanthopleurus is described here as collettei in honor of Bruce B. Collette, National Marine Fisheries Service, National Systematics Laboratory, who is a valued colleague, diving companion, editor of this monograph, and a responsible agent for having it published. It is diagnosed on the basis of the depth of its body and caudal peduncle, as specified above and in the measurements given below and in Figure 46. The seven type specimens of collettei are designated in the list of fossil specimens examined for this work.

Proportional measurements as percent of standard length for $A$. collette $i$ are as follows, with the number of specimens on which data were recorded for the character preceding in parenthesis the range, which is followed by the average value in parenthesis when appropriate: greatest depth (7) 24.0-31.4 (27.7)\% SL; least caudal peduncle depth (6) 5.5-8.3 (6.7)\% SL; length of pelvic spine (6) $20.0-30.8(25.5) \% \mathrm{SL}$; length of first dorsal spine (6) 20.3-35.2 (27.1)\% SL; length of second dorsal spine (6) 6.1-10.3 (8.2)\% SL; length of third dorsal spine (5) 2.6-3.9 (3.7)\% SL; length of fourth dorsal spine

Figure 45.-Acanthopleurus serratus (above), lateral views of entire specimens, left, $153 \mathrm{~mm} \mathrm{SL}$, and, right, $127 \mathrm{~mm} \mathrm{SL}$, to contrast with the deeper bodied A. collettei (below), left, ca. $120 \mathrm{~mm} \mathrm{SL}$, paratype, and right, $96.2 \mathrm{~mm}$ SL, paratype; all specimens from the Oligocene of Canton Glarus, Switzerland.
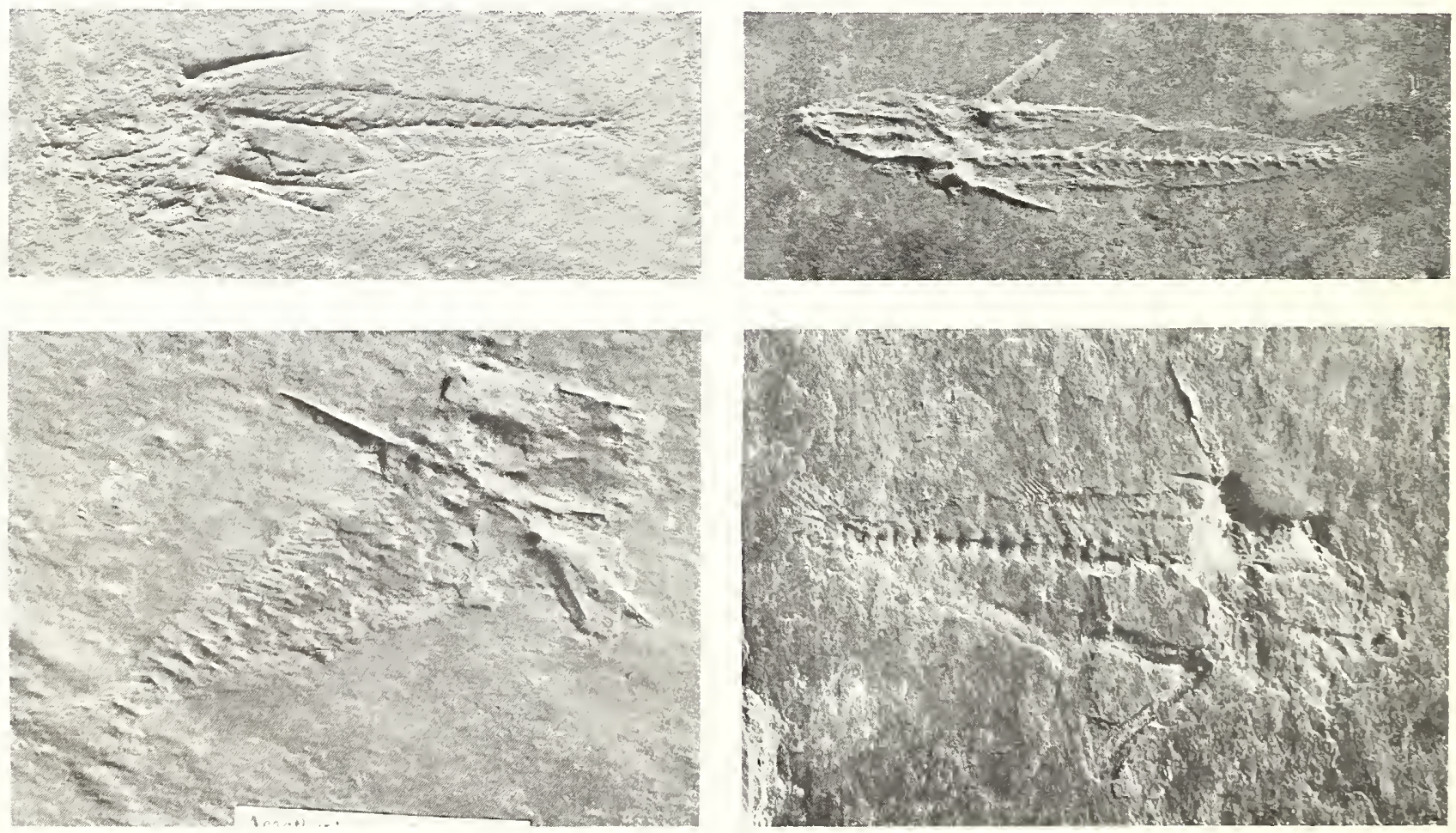


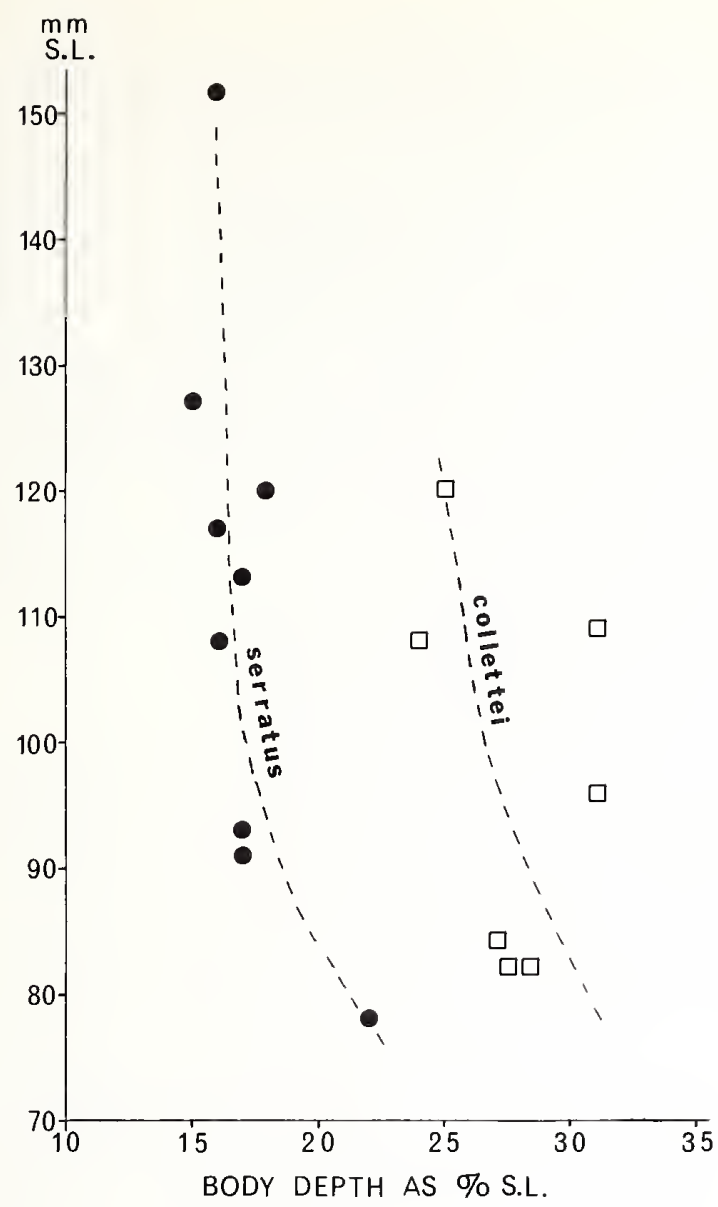

Figure 46.-Charts show two proportional measurements as percent of standard length that differentiate Acanthopleurus serratus and $A$. collettei.

(2) $1.5-3.9 \% \mathrm{SL}$; distance between tip of snout and spiny dorsal fin origin (1) $24.1 \% \mathrm{SL}$; length of pelvis posterior to region of axil of pelvic spine (3) 14.7-15.6 (15.1)\% SL.

Comparable proportions of $A$. serratus are as follows: greatest depth (9) 16.0-21.8 (17.3)\% SL; least caudal peduncle depth (5) $3.8-4.7(4.4) \% \mathrm{SL}$; length of pelvic spine (7) 19.7-28.2 (22.9) \% SL; length of first dorsal spine (9) 19.7-29.5 (23.7) $)^{\circ} \mathrm{SL}$; length of second dorsal spine (1) $8.6 \% \mathrm{SL}$ (third and subsequent dorsal fin spines not measurable in any of the specimens examined); distance between tip of snout and spiny dorsal fin origin (1) $31.1 \% \mathrm{SL}$; length of pelvis posterior to region of axil of pelvic spine (2) 17.6-17.8

In reviewing the Oligocene fishes of the black schist of Canton Glarus, Wettstein (1886) believed that the differences in depth of the specimens of Acanthopleurus were due to distortion. However, many of the specimens of both $A$. serratus and $A$. collettei seem to be in excellent proportion, and the impressions of the scales and of their orientation and spacing do not seem to me to be distorted, as one would expect them to be if the slender specimens were simply artificially stretched out versions

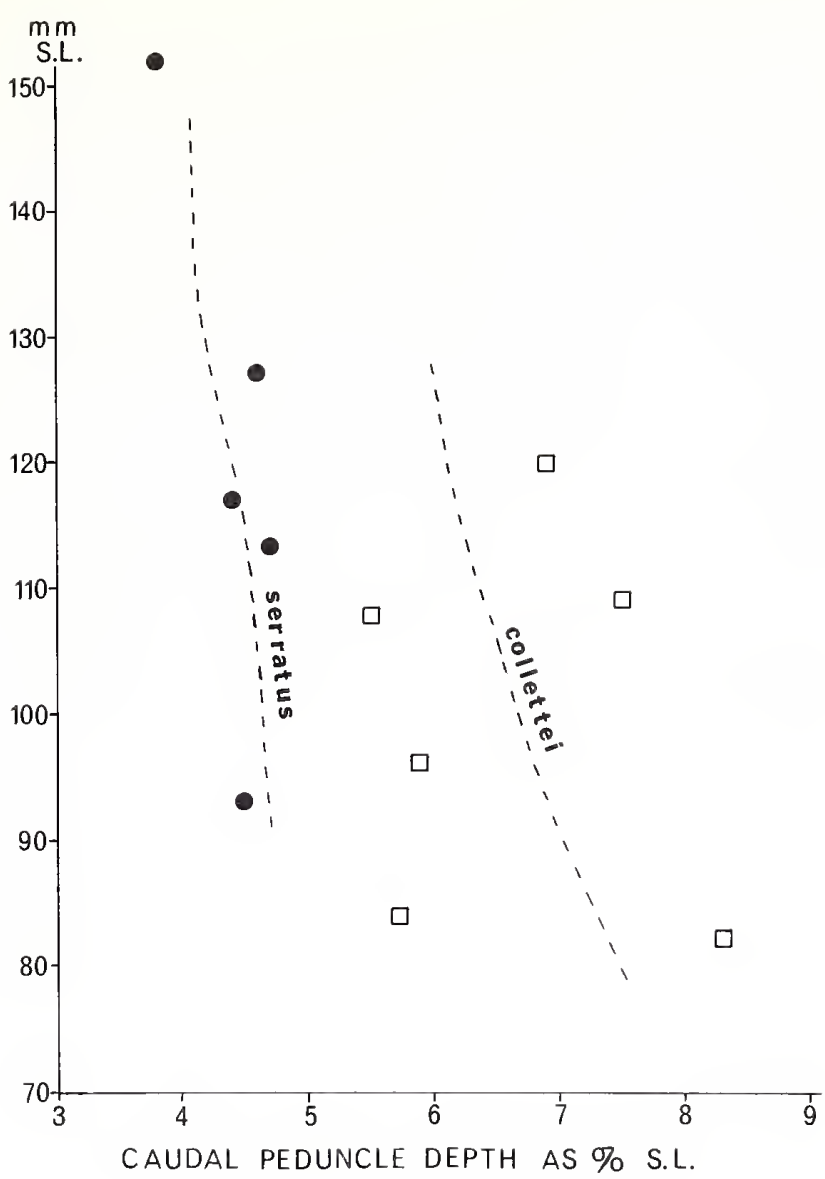

of the deep-bodied specimens. Moreover, in the few specimens of both species in which the sculpturing of the scales can be at least partially deciphered, it appears that $A$. collettei had a series of vertical emarginate ridges, approximately like those of the Recent Pseudotriacanthus, while $A$. serratus had more of a cruciform emarginate ridge, approximately like that of the other three Recent genera of triacanthids. It seems clear that at least two species of Acanthopleurus were present in the Oligocene seas of Europe.

Both species of Acanthopleurus have the first dorsal and pelvic spines as well developed as in Recent species, and with a similarly roughened surface. As in most of the Recent species, the second dorsal spine is less than half (about one-third) the length of the first spine, with the third and fourth spines progressively smaller. None of the impressions of Acanthopleurus show a fifth or sixth spine, but such could easily have been present but not indicated in the impressions at such small size. Epipleurals appear to have been as well developed on the abdominal and more anterior of the caudal vertebrae as they are in the Recent species. The dentition is not clear in any of the specimens of Acanthopleurus, but some specimens clearly show the presence of 12 caudal rays in a deeply forked fin. There appear to have been 12 caudal vertebrae in the few specimens that show this region relatively well, while the abdominal vertebrae cannot be 
counted in any of them, although they presumedly numbered eight as in the Eocene Protacanthodes, the Oligocene Cryptobalistes, and the Recent species of the family.

On the basis of the configuration of Acanthopleurus, the Triacanthinae have changed very little from at least the Oligocene.

The other fossil species of Triacanthinae is the very poorly known Marosichthys huismani (de Beaufort 1926), based on a single very incomplete specimen from the Miocene of the Celebes comprising the head and upper anterior part of the body. The dorsal fin spines are better developed than in Acanthopleurus, and the body deeper, but Marosichthys can be considered to be at the same level of organization as Acanthopleurus, as discussed by Tyler (1968:241-242).

The Oligocene Cryptobalistes brevis (Rath 1859), the only representative of the Cryptobalistinae, is known from a single specimen (perhaps two, see Winterbottom 1974:96) from the same black schist of Canton Glarus, Switzerland, in which the apparently thoroughly modern Acanthopleurus is found. The specimen of Cryptobalistes was not reexamined for this work, for the holotype cannot be located, and the following very briefly summarizes the long phylogenetic discussion of the species presented by Tyler (1968:243-249).

Cryptobalistes is an enigma. In general appearance it is rather balistoid, although it has (probably) 20 rather than 18 vertebrae, 12 of which are caudal, at least four dorsal spines and no locking mechanism of the first by the second, no supraneural strut bracing the last spiny dorsal fin basal pterygiophore, a large pair of pelvic spines, and a relatively wide, dorsally concave, basinlike pelvis.

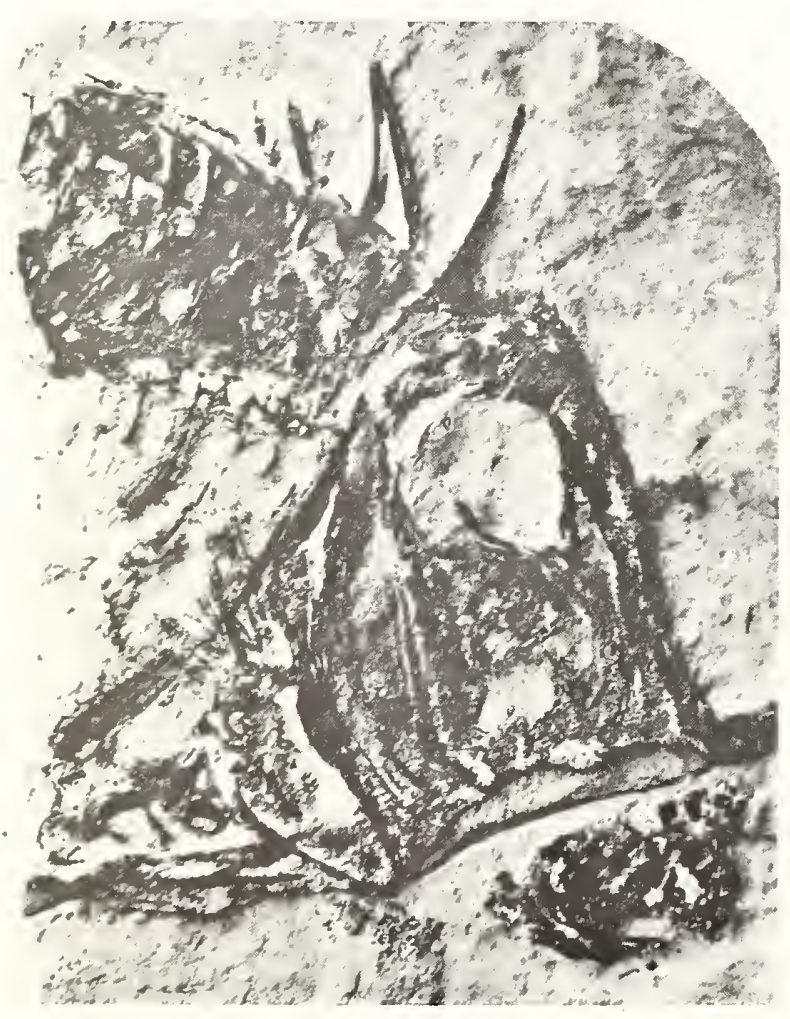

Although Cryptobalistes is in most ways an excellent anatomical intermediate between the triacanthids and balistids, the shape of its pelvis negates the other evidence, and the balistoid appearance of Cryptobalistes is presumed to be due to parallelism. Cryptobalistes represents an extinct lineage, for in the same Oligocene strata in which it is found there are also thoroughly modern balistids (Balistomorphus) not much different from genera alive today, and these Oligocene balistids already posses a stout shaftlike pelvis with a dorsal lobe, three dorsal fin spines with a locking mechanism, a carina with a supraneural supporting strut, and no pelvic spines. While Cryptobalistes represents an evolutionary dead end, it greatly increases the known anatomical diversity of the Triacanthidae and proves that the triacanthids were capable to giving rise to balistidlike forms.

Generic relationships.-As discussed by Tyler (1968:250), the four Recent genera fall naturally into two groups on the basis of the structure of the posterior shaft of the pelvis, Triacanthus and Trixiphichthys having a relatively untapered pelvis and Pseudotriacanthus and Tripodichthys a distinctly tapering pelvis ending in a point. On the meager evidence of the better development of the second dorsal spine and shorter anal fin base in Pseudotriacanthus, conditions closer to those of the ancestral triacanthodids, Pseudotriacanthus can be considered slightly more generalized than Tripodichthys. On the basis mainly of the specialized reduced dentition and of the elongate and narrow snout, Trixiphichthys is less generalized than Triacanthus. The relationship between the two more generalized genera in the two basic subdivisions of the Recent species is not clear, but both are certainly closely related to the Oligocene Acanthopleurus, with the Miocene Marosichthys of unknown relationship to Acanthopleurus. The Oligocene Cryptobalistes is of uncertain relationship with the other triacanthids, while the Eocene Protacanthodes is clearly on the line directly intermediate between the ancestral triacanthodids and the derived triacanthids, as discussed in the preceding section on the relationships of the Triacanthodidae.

The relationship of the Triacanthidae to the Balistidae is discussed under the latter, with the conclusion being that Protacanthodes is not far removed from the line of early triacanthids that gave rise to the balistids and aracanids, and thus, respectively, to the monacanthids and ostraciids as well.

In spite of its name, Protriacanthus gortanii d'Erasmo (1946:116), from the upper Cretaceous, is not a plectognath (see Patterson 1964:429-432).

Figure 47.-Marosichthys huismani: lateral view of anterior part of body of holotype, ca. $36 \mathrm{~mm}$ head length, Miocene of the Celebes (de Beaufort 1926; fig. 5 of pl. 5). 


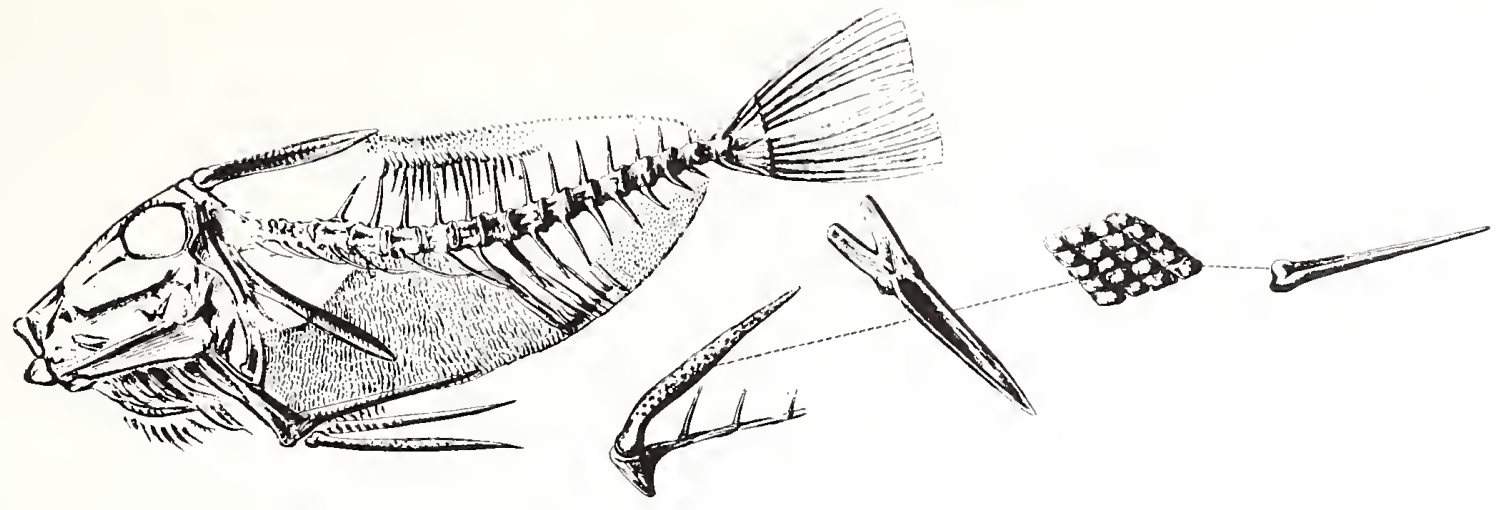

Figure 48.-Cryptobalistes brevis: lateral view of holotype, with insets from left to right showing the spiny dorsal fin, the pelvis in dorsal view, scale plates, and the pelvic spine, ca. $88 \mathrm{~mm} \mathrm{SL}$, Oligocene of Canton Glarus, Switzerland (Rath 1859:fig. 4 of pl. 5).

\section{Infraorder Balistoideo}

Comparative diagnosis (contrast with that of the Triacanthoideo).-Premaxillary without a pedicel or ascending process, the blunt posterodorsal end of the premaxillary rotating around the anterior ends of the ethmoid and vomer; premaxillary immovably articulated with the maxillary, often by suture, and the upper jaw not even slightly protractile; maxillary only slightly if at all indented dorsally for articulation with the anterior end of the palatine; palatine varying from $\mathrm{T}$ shaped (as seen laterally) to a simple rod and not sutured to other bones, or as a bony column sutured to the palatopterygoid arch; ethmoid with a laterally expanded dorsal or dorsolateral region, at least anteriorly, and never narrower dorsally than ventrally, forming a strong buttress for the rotation of the upper jaw; a prootic shelf of varying size developed under the orbit in front of and above the major articulation of the posterior region of the parasphenoid with the prootics, except secondarily lost in two closely related genera of highly specialized monacanthids; dorsal end of the hyomandibular articulated only with the prootic and pterotic, not in direct contact with the sphenotic; interoperculum a short rod extending posteriorly no further than the level of the epihyal and interhyal, connecting to the suboperculum or operculum around the anterior edge of the region of overlap of these two bones only by way of a long unossified ligament; dorsal fin spines three, two, one, or absent altogether, if present supported by one or two basal pterygiophores; the first dorsal spine capable of being locked in an erected position through the agency of the second spine, if present, but without an independent locking mechanism between the base of the first spine and its basal pterygiophore; first basal pterygiophore of spiny dorsal fin without a high dorsomedial flange and no anteropos- terior canal present in the basal region of the first dorsal spine; pelvic fin present or absent, when present never as a prominent erectile and lockable spine at about the middle of the pelvis, but as a rudiment at the extreme posterior end of the pelvis consisting of delicate, poorly ossified, partially fused together flexible filaments or bony nubbins mostly, or entirely, hidden from external view by modified scales; pelvis present or absent, when present laterally compressed and shaftlike throughout its length, and with or without a dorsal lobe posteriorly; pelvis usually slightly to greatly rotatable around its anterior articulation with the cleithra and a slightly to greatly expansible dewlap of skin usually present between the posterior end of the pelvis and the anus; uroneurals rarely present; vertebrae $(6-10)+(8-23)=18$ 30 , but rarely, if ever, $8+12$ or $9+11$; no more than two pharyngobranchials with prominent large protruding teeth; posteromedial edges of epiotics not inturned and neither they nor the exoccipitals and neural spine of the first vertebra associated with the articulation of the first basal pterygiophore of the spiny dorsal fin, when present; articulation of the mesopterygoid varying from direct contact with both the quadrate and ectopterygoid to indirect contact with both of them through the agency of, respectively, the symplectic and mesopterygoid.

\section{SUPERFAMILY BALISTOIDEA}

Comparative diagnosis (contrast with that of the Ostracioidea).- - Head and entire body (except in the relatively naked monacanthid Paraluteres prionurus and in the snout region of several balistids) covered with a more or less continuous field of scales whose edges are either slightly separated from one another (the balistid Canthidermis and several monacanthids) or slightly overlapping, but never with apposed interdigitated edges, the basal plates thick and usually rhomboidal in balistids but thin and variously rounded to rectilinear in monacanthids; body outline in cross section a simple gently rounded and laterally compressed oblong; a spiny dorsal fin of one to three spines; soft dorsal and anal fins 
long-based, with 23 to 52 dorsal rays and 20 to 66 anal rays, and usually a slightly lesser number of basal pterygiophores; caudal fin with 12 rays; pelvis always present but a modified rudimentary pelvic fin either present (balistids and some monacanthids) or absent at the posterior end of the pelvis; teeth relatively large and compressed, more or less notched and incisorlike, six to eight in an outer series and four to six in an inner series in the upper jaw and four to eight in a single series in the lower jaw; lateral line associated with grooves or spiny processes of the scale plates (with the possible exception of the monacanthid Pseudaluteres nasicornis); branchiostegals usually $2+4$, but sometimes $1+4$ or $1+3$, with none of the rays in the posterior division as broad and laterally compressed as those in the anterior division; distal end of last branchiostegal ray usually not closely held to inner surface of suboperculum; elements of the hyoid arch less compacted together anteroposteriorly and most elements more elongate or less deep bodied; urohyal relatively large and more or less L-shaped, with a ventral flange of varying degrees of development; fifth ceratobranchial either toothed or toothless; pharyngobranchials consisting of two elements bearing large protruding teeth, with an anterior toothless suspensory element present or absent; epibranchials usually four, but three in the monacanthid Psilocephalus; gill rakers present or absent along anterior edge of fifth ceratobranchial (posterior edge of last gill slit); caudal fin supporting structures only moderately consolidated, always having at least the epural and parhypural autogenous and usually having an autogenous uppermost hypural as well; haemal spine of penultimate vertebra autogenous; neural and haemal arches of the last vertebra incomplete, the neural and haemal canals at least partially open respectively above and below; uroneurals rarely present; vertebrae normally $7+11=18$ (balistids) or (6$8)+(12-23)=19-30$ (monacanthids), but never nine or more abdominal vertebrae; the first vertebra of normal size and firmly sutured but not fused to the rear of the skull; five (balistids) or four to eight (monacanthids) abdominal vertebrae with neural spines anterior to the first basal pterygiophore of the soft dorsal fin; four to six caudal vertebrae posterior to the last basal pterygiophores of both the soft dorsal and anal fins; at least three and usually four soft dorsal fin basal pterygiophores placed between at least some of the successive neural spines; most neural spines positioned only slightly obliquely in relation to the axis of the vertebral column; haemal spines above the anal fin basal pterygiophores with relatively long stout shafts similar to those of the neural spines and penetrating into the proximal region of the series of anal fin basal pterygiophores; soft dorsal fin basal pterygiophores 22 to 51 ; anal fin basal pterygiophores 20 to 64 ; prominent thin lateral flanges present along at least a part of the length of the soft dorsal and anal fin basal pterygiophores; distal pterygiophores present as ossified single or paired pieces in both the soft dorsal and anal fins, except often absent or unossified under the more posterior rays in both fins; all anal fin basal pterygiophores in the midline of the body; one or two basal pterygiophores supporting the anteriorly placed spiny dorsal fin of one to three spines, but no supraneural element present anteriorly from the dorsal end of the first basal pterygiophore of the sott dorsal fin; epipleurals always present on some of the abdominal vertebrae and sometimes on some of the more anterior caudal vertebrae, while ribs are rarely present; uppermost pectoral fin ray never of two relatively well-developed halves of about equal length, either a single piece without a foramen or a larger medial half and a much smaller lateral nubbin; actinosts flexibly articulated with the scapula and coracoid, not sutured to them or to one another; coracoid and cleithrum not especially enlarged; coracoid not expanded ventrally, much less wide there than dorsally, without prominent flanges; coracoid always with a well-developed posterior prong just below the lowermost actinost; scapular foramen usually complete, incomplete only in a few monacanthids; cleithrum without an anterior flange from its lower anteromedial edge; postcleithrum usually as a single piece, rarely with two halves, in the form of a long sturdy rod directed strongly obliquely toward the end of the pelvis; at least the proximal end of the supracleithrum not in contact with the cleithrum, and usually slightly less firmly held to the cleithrum and posttemporal; Baudelot's ligament not ossified; posttemporal usually relatively small; palatine varying from $T$-shaped to a simple rod of bone representing the top of the $T$ and not sutured to any of the bones with which it articulates, the foot of the $\mathrm{T}$ connected by ligament to the anterodorsal edge of the ectopterygoid and the top of the T primarily connected to the maxillary and ethmoid; vomer not especially enlarged, having a moderately laterally expanded anterior end and a long posterior tapering shaft fitting into a deep concavity in the parasphenoid; ventral edge of the ventral flange of the parasphenoid not at all laterally expanded; ventral flange of parasphenoid with a deep indentation at about the level of the prefrontal; parasphenoid without a dorsal flange in the medial septum of the orbit, the parasphenoid and pterosphenoids not being in contact there and there being no anteroventral extensions of the pterosphenoids into the medial septum; the medial edges of the pterosphenoids in contact in the posterior wall of the orbit, usually in light contact dorsally and broader sutural contact ventrally; myodome large; apposed surfaces of parasphenoid and basioccipital excavated to form a canal leading anteriorly into the myodome cavity; epiotics broadly in contact and sutured to one another medially on the posterior surface of the skull, not separated there by the more anteriorly placed supraoccipital; supraoccipital never with a posterior crest, but with or without an anterior crest on the surface of the main body of the bone; prootic shelf usually relatively smaller, never with a prominent ventral or ventrolateral flange from its lateral edge; the major foramen in the prootic shelf relatively small and rounded, and completely enclosed by the prootic alone; anterior edge of upper part of preoperculum articulated only along the rear edge of the hyomandibular; hyomandibular a more or less flattened shaft, not greatly expanded. 


\section{Family Balistidae}

Comparative diagnosis (contrast with that of the Monacanthidae). - Teeth very sturdy, more or less incisorlike, developed more for crushing than nibbling, four outer and three inner on each premaxillary and four in a single series on each dentary; pharyngobranchials consisting of a toothless suspensory element and two uniserially toothed elements; fifth ceratobranchial toothed but without gill rakers along its anterior edge (posterior edge of last gill slit); three dorsal spines, the second more than one-half the length of the first and ending ventrally in large sturdy ventrally directed processes from either side; dorsal fin spines supported by two basal pterygiophores and a supraneural strut; dorsal spines and their basal pterygiophores placed behind the posterodorsal apex of the skull, the anterior edge of the first basal pterygiophore abutting against the rear of the posterodorsal surface of the skull; first basal pterygiophore with a large lateral foramen to accommodate the ventral prong of the second dorsal spine; supraoccipital large and stur$\mathrm{dy}$, with a variously high (usually) to low (Rhinecanthus) but sturdy vertical crest medially throughout its length, the crest expanded laterally at its posterior end to help support the anterior end of the first basal pterygiophore; posterior region of the epiotic expanded dorsally, the medial edges of the two epiotics well-separated dorsally, bounding the posterolateral region of the deep foramen in the skull between the epiotics and the supraoccipital in which the short anteroventral shaft of the first basal pterygiophore is held; palatine T-shaped, the long foot of the $\mathrm{T}$ directed ventrally or posteroventrally to connect by a short ligament with the anterior edge of the ectopterygoid; exoccipital meeting its opposite member in the midline above the foramen magnum between the medial edges of the bifid neural spine of the first vertebra; prefrontal relatively large and heavy, firmly articulated, often by interdigitation, with the frontal, ethmoid, and parasphenoid; parasphenoid only slightly expanded laterally just behind the orbit, the medial edge of the pterotic on the ventral surface of the skull only narrowly separated from its opposite member there by the basioccipital and parasphenoid; parasphenoid much expanded dorsally in front of the orbit, broadly overlying the ethmoid and contacting the prefrontal; the laterally expanded dorsal region of the ethmoid wide and thick,

Figure 49.-Range of diversity in body form in the Recent Balistidae: Balistapus undulatus, left; Odonus niger, right. about as wide as or wider than the depth of the ventral platelike portion; ventral platelike flange of the ethmoid thick and sturdy, relatively shallow, not much if at all deeper posteriorly than anteriorly, and broadly overlain by the parasphenoid; posttemporal held in a deep groove on the lateral surface of the pterotic; medial edge of dentary either denticulate or smooth; prootic shelf well developed, extending forward at least to the level of the middle of the orbit; posterior edge of supracleithrum with a posteriorly directed process or hump; postcleithrum with a dorsal spur from its upper dorsal edge supporting the ventral region of the tympanum regardless of whether enlarged scales are present there or not; postcleithrum either a single piece or divided into dorsal and ventral segments; branchiostegal rays always $2+4$; pelvis always with a dorsal lobe posteriorly on its dorsal surface; encasing scales at the posterior end of the pelvis in four segments, always flexible (least and only slightly so in Canthidermis); a relatively well-developed rudimentary pelvic fin element always present, running the length of the last two segments and protruding to the exterior through a foramen in the fourth segment (except in Melichthys and Xanthichthys, in which the element is reduced in size and does not protrude, and in Canthidermis, in which the ray is an even smaller nubbin of bone not protruding to the exterior); vertebrae $18(7+$ 11); vertebrae anterior to the first basal pterygiophore of the soft dorsal fin always five, those posterior to the last basal pterygiophores of both the soft dorsal and anal fins always four; neural and haemal arches of the last centrum relatively well developed although incomplete; the last centrum with a vertical crest for muscle attachment; uroneurals rarely present; an upper free hypural always present; lateral flanges on the soft dorsal and anal fin basal pterygiophores not ending distally in prominent hooklike lateral expansions; the basal pterygiophores extending proximally relatively closely to the neural and haemal arches throughout the length of the series; the great majority of the dorsal, anal, and pectoral fin rays branched, only the first few rays, and sometimes the last, being unbranched; scales large, with thick basal plates and relative coarse spinulation, the basal plates broadly overlapping (except in Canthidermis) and more or less regularly arranged; scales above the pectoral fin base usually enlarged and more or less separated, forming a flexible covering to the tympanum (scales unmodified in Canthidermis and only slightly modified but unenlarged in Xanthichthys); species relatively large, adults usually reaching well over $200 \mathrm{~mm}$.

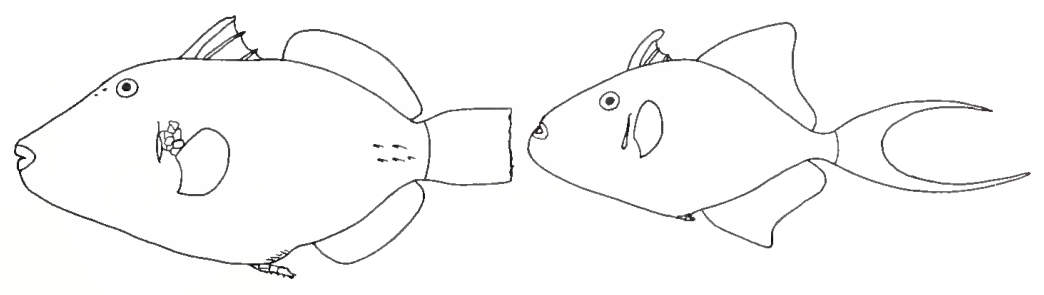


Figure 50.-Balistapus undulatus: upper left, scale plates of the tympanum region just behind the gill slit and above the pectoral fin base; upper middle, scales from upper middle region of body, including lateral line canal bearing scales; upper right, ventral view of encasing scales at end of pelvis (anterior to left), with arrow indicating major region of flexibility (two terminal branches of modified fin-ray element protrude posteriorly);

lower left, nasal region as seen externally (above) and the olfactory lamellae as seen with the top of the nasal sac removed.

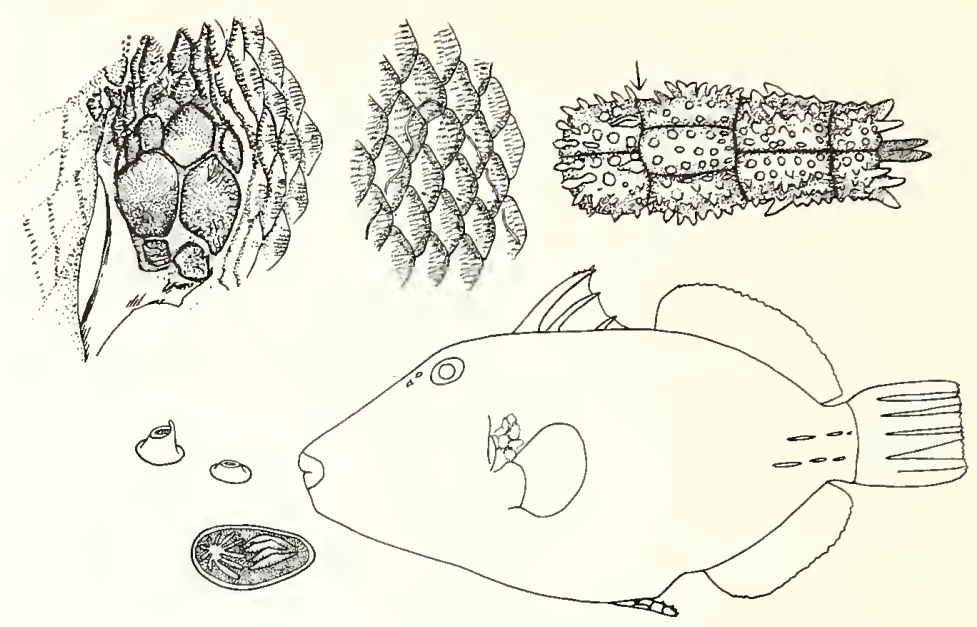

Detailed description of Balistapus undulatus.

Material examined.-Two cleared and stained specimens, $122-124 \mathrm{~mm}$, and three wet partially disarticulated skeletons of approximately the same size as the two previous specimens, prepared by maceration.

\section{SKULL.}

\section{Occipital Region.}

Basioccipital. - A short column, expanded anterodorsally; cartilage filled at its anterior and dorsal edges; articulates by interdigitation dorsaliy with the exoccipitals, anterolaterally with the prootics, and anteromedially with the overlying posterior end of the parasphenoid. The rim of the round concave posterior end of the basioccipital articulates by fibrous tissue with the concave anterior face of the centrum of the first vertebra. The ventromedial surface of the basioccipital is deeply concave throughout its length. This concave channel is mostly hidden from view by the overlying parasphenoid, but the channel opens to the exterior posteriorly at the base of the posterior bifurcation of the parasphenoid. Anteriorly the channel opens into the myodome where the anterior end of the basioccipital forms the posterolateral and posterodorsal walls of the myodome.

Exoccipital.-Cartilage filled at its ventral edge; articulates by interdigitation dorsally with the epiotic, laterally with the pterotic and ventromedially with the basioccipital. Posteriorly the exoccipitals form the lateral and ventral walls of the foramen magnum, while dorsally the foramen is closed by the thin piece of cartilage between the dorsomedial edges of the two exoccipitals. The posterior surface of the exoccipitals firmly articulates by fibrous tissue and slight interdigitation with the anterior surface of the bifid neural spine of the first vertebra. The posteromedial portion of the exoccipital, which forms the lateral wall of the myodome and the firmest place of attachment of the neural spine of the first vertebra, is stout and thickened, probably representing the much modified region of the exoccipital condyle.

Supraoccipital. - Wide posteriorly, tapering to a point anteriorly; expanded dorsomedially throughout its length into a low crest; cartilage filled at its edges of articulation with the other cranial bones; articulates by interdigitation anterolaterally with the slightly overlying frontals and posterolaterally with the epiotics. The posterodorsal end of the supraoccipital is expanded into a thickened articular face with a medial concavity to support the anteroventral shaft of the first basal pterygiophore of the spiny dorsal fin. This medial concavity is partially bordered by the epiotics. The anteroventral shaft of the pterygial element is held by tough fibrous tissue to both the supraoccipital and the epiotics.

\section{Otic Region.}

Pterotic. - Cartilage filled along all of its edges of articulation with the other cranial bones; articulates by interdigitation dorsomedially with the epiotic, anterolaterally with the sphenotic, anteroventrally with the prootic, and anteromedially on its ventral surface with the basioccipital. More or less transversely along its ventral surface, the pterotic is produced into a sturdy flange whose depth is greatly increased in about the middle of its length. The anterior surface of this stout and elongate portion of the ventral flange of the pterotic articulates by fibrous tissue with the posterodorsal edge of the hyomandibular. Just anterior to its ventral flange, the pterotic bears a slight depression which continues anteriorly over the prootic and into which the dorsal head of the hyomandibular is held by fibrous tissue. In about the middle of its lateral surface, the pterotic bears a deep vertical groove into which the posttemporal fits and is held immovably by extensive interdigitation. 
Sphenotic. - Cartilage filled along all of its edges of articulation with the other cranial bones; articulates by interdigitation anterodorsally with the frontal and pterosphenoid, posterodorsally with the epiotic, posteroventrally with the pterotic and posttemporal, and anteroventrally with the prootic.

Epiotic. - Cartilage filled along all of its edges of articulation with the other cranial bones; articulates by interdigitation dorsally with the supraoccipital, dorsolaterally with the frontal, laterally with the sphenotic, ventrolaterally with the pterotic and a short section of the posttemporal, posteroventrally with the exoccipital, and medially with its opposite member. The posterodorsal edge of the epiotic is deeply concave where it interdigitates with the supraoccipital, forming, with the latter bone, the concavity in the skull in which is held by fibrous tissue the anteroventral shaft of the first basal pterygiophore of the spiny dorsal fin.

Prootic. - Cartilage filled along all of its edges of articulation with the other cranial bones, except anteromedially; articulates by interdigitation medially with the lateral surface of the parasphenoid, anteromedially with the ascending fork of the parasphenoid, anterodorsally with the pterosphenoid, anterolaterally with the sphenotic, and posteriorly with the pterotic. A concavity is present in the middle of the ventral surface of the prootic in which is held by fibrous tissue the anterior half of the dorsal head of the hyomandibular. The medial edges of the prootics form the lateral walls of the myodome, while medially directed shelves from the medial edges of the prootics interdigitate with one another in the midline to form the dorsal roof of the myodome. The anterior edge of the myodome is formed by the prootics, except ventrally where it is formed by the parasphenoid. The anterior end of the prootic is prolonged anteriorly as a subocular shelf which serves for muscle attachment.

\section{Orbital Region.}

Frontal. - Widest posteriorly, tapering to a point anteriorly; its lateral edge above the orbit slightly upraised and thickened; articulates by interdigitation posteromedially with the supraoccipital, which it slightly overlies, posterolaterally with the sphenotic and posteriorly with the epiotic. Posteriorly in the rear of the orbit it interdigitates with the pterosphenoid. The frontal interdigitates anteriorly with the ethmoid and anterolaterally with the prefrontal. On its ventral surface, the medial edges of the frontals are narrowly separated by the cartilaginous mass which is continuous anteriorly with the remains of the ethmoid cartilage.

Prefrontal. -Large and elongate; cartilage filled along its medial edge; articulates by interdigitation dorsomedially with the frontal, ventrally with the parasphenoid, and anteriorly with the ethmoid. Along most of its medial edge, the prefrontal is continuous with the remains of the ethmoid cartilage.

Parasphenoid. - Elongate, running almost the entire length of the skull; ventrally expanded into a thin keel along the anterior half of its length. The bifurcate posterior end of the parasphenoid broadly overlies and interdigitates with the basioccipital, roofing over the longitudinal concavity in the ventral surface of the basioccipital. Under the posterior region of the orbit, the parasphenoid possesses a pair of short, slightly forked, dorsolateral projections which interdigitate with the prootics and form the anterior edge of the ventral region of the myodome. Posterior to these dorsal wings, the parasphenoid interdigitates with the ventromedial edges of the prootics and, more posteriorly, with the ventral surface of the basioccipital. Just anterior to the orbit, the parasphenoid interdigitates with the base of the prefrontals. Anterior to the level of its articulation with the prefrontals, the dorsal edge of the parasphenoid becomes concave and fits around the ventral edge of the ethmoid keel. At its anterior end the parasphenoid possesses a short, narrow concavity into which fits and interdigitates the posterior shaftlike portion of the vomer.

Pterosphenoid. - Cartilage filled along all of its edges of articulation with the other cranial bones; articulates by slight interdigitation dorsally with the frontal, laterally with the sphenotic, and ventrally with the prootic. Medially the pterosphenoid articulates broadly through cartilage and interdigitation with its opposite member.

\section{Ethmoid Region.}

Ethmoid. -Wide and elongate; slightly expanded laterally and ventrally at its anterior end; produced ventrally into a keel which is relatively low along most of its length, but which increases in depth at its anterior end above the shaftlike portion of the vomer; cartilage filled at its posteroventral edge where it is continuous with the remains of the ethmoid cartilage. The ventral edge of the ventral flange of the ethmoid articulates by fibrous tissue with the concave dorsal edge of the platelike portion of the parasphenoid. At its posterior end the ethmoid articulates by interdigitation laterally with the prefrontal and dorsally with the frontal. The ethmoid articulates by fibrous tissue anteroventrally with the anterior edge of the vomer, while directly anteriorly the ethmoid supports the posterodorsal edge of the upper jaw.

Vomer. - Short; laterally expanded anteriorly but tapering to a shaft posteriorly; articulates posteriorly by slight interdigitation of its posterior shaftlike portion with the concavity at the anterior end of the parasphenoid; articulates by fibrous tissue dorsally with the anteroventral surface of the ethmoid and anterolaterally with the medial surfaces of the palatines and the posterodorsal edges of the upper jaw. 


\section{Mandibular Region.}

Hyomandibular. - Somewhat expanded dorsally, but tapering to a stout shaft ventrally; cartilage filled at its posterodorsal and anteroventral edges; articulates by fibrous tissue dorsally with the longitudinal groove on the ventral surfaces of the prootic and pterotic, while posterodorsally the hyomandibular abuts against and is firmly held by fibrous tissue along the medial surface of the elongate portion of the ventral flange of the pterotic. Along the lower three-fourths of its posterior edge the hyomandibular articulates by fibrous tissue with the preoperculum. Just posterior to the dorsal end of the preoperculum, the ventral edge of the hyomandibular is thickened and bears a concavity with which the dorsal end of the operculum articulates by fibrous tissue. The anterior end of the hyomandibular articulates variously through cartilage and fibrous tissue with the metapterygoid, symplectic, interhyal, and preoperculum.

Quadrate. -Widest posteriorly, tapering to a knob anteriorly for articulation with the articular in the lower jaw; cartilage filled at its posterior edge; deeply cleft along its lower posterior edge to accommodate the anterior end of the symplectic; articulates by slight interdigitation dorsally with the ectopterygoid, while it articulates by fibrous tissue posteriorly with the metapterygoid and symplectic, both of which somewhat overlie the quadrate. Ventrally the quadrate articulates by fibrous tissue with the preoperculum.

Meta pterygoid. - Large; a more or less rounded flat plate; cartilage filled at its anterior edge; articulates by fibrous tissue anteriorly with the quadrate, posteriorly with the interhyal and hyomandibular; articulates by slight interdigitation dorsally with the mesopterygoid, anterodorsally with the ectopterygoid, and ventrally with the symplectic.

Symplectic. - Large; cartilage filled at its anterior and posterior edges; dorsally expanded in the middle of its length; articulates by fibrous tissue anterodorsally and anteroventrally with the quadrate; articulates by slight interdigitation posterodorsally with the metapterygoid, while along its posteroventral edge the symplectic is attached to the fibrous tissue sheet that is present between the preoperculum, hyomandibular, and metapterygoid.

\section{Palato-Pterygoid Region.}

Palatine. - T-shaped; articulates by fibrous tissue ventrally with the ectopterygoid, anterodorsally with the premaxillary and maxillary, and posterodorsally with the laterally expanded anterior ends of the ethmoid and vomer.

Ectopterygoid. -Elongate; articulates by slight interdigitation anteroventrally with the quadrate, which it somewhat overlies, posteroventrally with the metapterygoid, and posterodorsally with the mesopterygoid. Along the middle of its anterior edge it articulates by tough fibrous tissue with the base of the palatine.

Mesopterygoid. - Small; articulates by interdigitation anteriorly with the ectopterygoid and ventrally with the metapterygoid.

\section{Opercular Region.}

Operculum. - Thin and flat, except dorsally where it thickens into a rounded articular facet; articulates by fibrous tissue with the slightly upraised area on the ventral surface of the posterodorsal region of the hyomandibular, while ventrally it overlies and articulates by fibrous tissue with the suboperculum.

Suboperculum. - Very thin and flat, slightly wider anteriorly than posteriorly; held to the overlying operculum by fibrous tissue.

Interoperculum. - A straight rod, slightly wider posteriorly than anteriorly; extends from the region of the interhyal to about the anterior end of the preoperculum; articulates by a tough ligament anteriorly with the angular in the lower jaw, while at its posterior end two ligaments are present. One of these ligaments is short and connects with the dorsal surface of the epihyal, while the other one is long and runs posteriorly to connect with the anterior edge of the operculum just above the point where the operculum begins to overlie the suboperculum.

Preoperculum. - Not greatly expanded in its middle region; its dorsal surface only slightly flattened for articulation with the quadrate; articulates by fibrous tissue along the posterior portion of its dorsal edge with the hyomandibular, along the middle portion of its dorsal edge with the symplectic, metapterygoid, and interhyal, and along the anterior portion of its dorsal edge with the quadrate.

\section{Upper Jaw.}

Premaxillary. - A slightly curved plate, wider dorsally than ventrally; its posterodorsal edge slightly concave to articulate by fibrous tissue with the anterior ends of the ethmoid and vomer. It also articulates by fibrous tissue laterally with the medial surface of the palatine. The anterior edge of the premaxillary forms the border of the upper jaw, except for a short distance ventrally where the maxillary does so. The premaxillary is in close apposition with the maxillary and articulates immovably with it by fibrous tissue and slight interdigitation. The flat dorsomedial edges of the two premaxillaries are held closely to one another by fibrous tissue. Each premaxillary bears seven teeth, four in an outer row and three in an inner row. Both of these rows are in close contact with 
one another. The teeth are borne in very shallow depressions on the surface of the premaxillary in their fully formed condition. They develop, however, from large deep sockets which open to the surface just anterior to the base of the old tooth which they will replace. As the tooth erupts to the surface to replace an old tooth, the socket from which it arose seems to become overgrown or filled in with bone and to disappear so that the tooth rests flatly against the surface of the premaxillary. Most of the interior of the premaxillary is given over to the dental pulp cavity, this cavity communicating with the exterior through a foramen in the posterodorsal surface of the bone as well as through numerous smaller holes on the inner and outer surfaces of the bone.

Maxillary. - Widest ventrally, becoming narrower dorsally; articulates firmly with the premaxillary by fibrous tissue and slight interdigitation. The medial surface of the ventral region of the maxillary articulates by fibrous tissue with the lateral surface of the upper portion of the dentary. The posterodorsal surface of the maxillary articulates by fibrous tissue with the lateral expansions of the ethmoid and vomer and with the medial surface of the palatine.

\section{Lower Jaw.}

Dentary. - Wide posteriorly; its posterior edge concave to accommodate the anterior portion of the articular, with which it articulates by interdigitation. Posteroventrally the dentary articulates by interdigitation with the angular. From the lateral surface of its posterodorsal region the dentary articulates by fibrous tissue with the medial surface of the maxillary. Ventromedially the flat surface of the dentary articulates by fibrous tissue with its opposite member. Each dentary bears four teeth in a single row, corresponding to the outer row of teeth in the premaxillary. The teeth are borne flush against the surface and are replaced by new teeth developing in deep sockets, just as described for the teeth of the upper jaw. Most of the interior of the dentary is filled with the dental pulp, the cavity opening to the exterior at the concave posterior edge of the dentary, as well as at pores on the inner and outer surface of the bone.

Articular. - Wide along its posterior edge, with a concave facet for articulation by fibrous tissue with the anterior knob of the quadrate; articulates by interdigitation with the concave posteromedial surface of the dentary. Along its ventral edge the articular interdigitates with the angular. The sesamoid articular is a small but thick nodule of bone closely held by fibrous tissue to the medial surface of the articular just in front of the concave articular facet of that bone.

Angular.-Small, squarish; articulates by interdigitation dorsally with the articular and anteriorly with the dentary. Posteriorly the angular connects by ligament with the interoperculum.

\section{BRANCHIAL APPARATUS.}

Hyoid Arch, Branchiostegal Rays, and Urohyal.

Hypohyals. - Both hypohyal elements well developed, the ventral element considerably larger than the dorsal element; the dorsal element cartilage filled at its dorsal and posterior edges; the two elements articulate with one another through the cartilage that lies between them; the dorsal and ventral elements articulate by fibrous tissue at their anteromedial edges with their opposite members. The dorsal hypohyal articulates by fibrous tissue at its dorsal edge with the lateral surface of the first basibranchial. The ventral hypohyal articulates through cartilage at its posterior edge with the ceratohyal, and by fibrous tissue from its ventromedial surface with the urohyal.

Ceratohyal. - A short shaft, wider posteriorly than anteriorly; cartilage filled at its anterior and posterior edges; articulates through cartilage anteriorly with the ventral hypohyal; articulates posteriorly through cartilage and interdigitation with the epihyal. The first two branchiostegal rays articulate with slight depressions on the ventral edge of the ceratohyal. The ventralmost one or two rays of the remaining four rays have their fibrous tissue articulation principally with the ceratohyal.

Epihyal. - Large; cartilage filled at its ventral edge; articulates through cartilage and interdigitation ventrally with the ceratohyal, while dorsally it articulates by fibrous tissue with the interhyal and interoperculum.

Interhyal. - A short, thick rod; cartilage filled at both ends; articulates by fibrous tissue ventrally with the epihyal and dorsally with the symplectic.

Branchiostegal rays. - Six in number; increasing slightly in length posteriorly in the series; first ray considerably flatter and wider than the others. The first two rays articulate by fibrous tissue with shallow grooves on the ventral edge of the posterior half of the ceratohyal. The other four rays articulate by fibrous tissue with the ceratohyal and epihyal. The more ventral of these four rays have their connective tissue fibers attached principally to the ceratohyal, while the more dorsal rays have them attached principally to the epihyal.

Urohyal. - Thick along its dorsal and anterior edges, otherwise a thin plate; articulates by fibrous tissue anteroventrally with the medial surface of the ventral hypohyal, while posteriorly it articulates with the ventral surface of the first two basibranchial elements.

Branchial Arches. - All the elements are cartilage filled at their edges of articulation with the other elements of the series, and the articulations are usually 
through cartilage and fibrous tissue. The branchial arches are composed of three basibranchials, three pairs of hypobranchials, five pairs of ceratobranchials, four pairs of epibranchials, and three pairs of pharyngobranchials. Four gills are present, with a slit between the fourth arch and the lower pharyngeal.

First arch.-Basi-, hypo-, cerato-, epi-, and pharyngobranchial elements present. First basibranchial short, wider posteriorly than anteriorly; displaced forward so that it articulates posteriorly with the second basibranchial and posterolaterally with the first hypobranchials. First hypobranchial very wide, more so posterodorsally than ventrally; the largest of the hypobranchial elements, which decrease in size posteriorly in the series; articulates ventrally with the region of articulation between the first and second basibranchials and dorsally with the first ceratobranchial. First ceratobranchial a sturdy rod; the longest of the ceratobranchial elements, which decrease in length posteriorly in the series; no ventrally directed flange present on the ceratobranchials, although from the second to the last ceratobranchial the ventral ends of the elements become increasingly enlarged; articulates dorsally with the first epibranchial. First epibranchial with its ventral end rounded and its dorsal end forming two divergent stubby projections; its rounded ventral end articulates with the first ceratobranchial, while the anterior projection of its dorsal end articulates with the first pharyngobranchial, and the posterior projection of its dorsal end with the dorsal end of the second epibranchial and the ventral end of the second pharyngobranchial. First pharyngobranchial (suspensory pharyngeal) short, slightly wider ventrally than dorsally; articulates ventrally with the first epibranchial and dorsally by fibrous tissue with the ventral edge of the keel of the parasphenoid at the level of the middle of the orbit.

Second arch.-Basi-, hypo-, cerato-, epi-, and pharyngobranchial elements present. Second basibranchial longer than the first basibranchial and about the same length as the third basibranchial, but wider than either of the other two; articulates anteriorly with the first basibranchial, anterolaterally with the first hypobranchials, posteriorly with the third basibranchial and posterolaterally with the second hypobranchials. Second hypobranchial squarish, with a short posterior extension; articulates ventrally with the area of articulation between the second and third basibranchial and dorsally with the second ceratobranchial. Second ceratobranchial a long rod with a slightly expanded ventral end; articulates dorsally with the second epibranchial. Second epibranchial a short rod; articulates dorsally with the second pharyngobranchial and the posterodorsal arm of the first epibranchial. Second pharyngobranchial with an elongate tooth bearing portion and a short arm for articulation with the second epibranchial and the posterodorsal arm of the first epi- branchial; about 12 to 15 teeth present in a single row, the teeth like those of the outer series of the jaws, but much smaller and with sharper points. The teeth decrease in size posterolaterally in the series and are replaced by new teeth developing in sockets below the bases of the old teeth.

Third arch.-Basi-, hypo-, cerato-, epi-, and pharyngobranchial elements present. Third basibranchial narrow anteriorly and posteriorly, but expanded in the middle; articulates anteriorly with the second basibranchial, anterolaterally with the second hypobranchials, posterolaterally with the third hypobranchials, and posteriorly with the fourth ceratobranchials. Third hypobranchial rounded posteriorly but with a tapering anteroventral process that articulates by fibrous tissue anteriorly with the ventral surface of the more anterior basibranchials; articulates posterolaterally with the third ceratobranchial and posteromedially with the posterior end of the third basibranchial. Third ceratobranchial with a much expanded ventral end; articulates ventrally with its opposite member and with the third hypobranchial, and dorsally with the third epibranchial. Third epibranchial a short rod with a slightly expanded base and a short projection posteriorly from the basal part of its posterior edge; articulates dorsally with the third pharyngobranchial; the projection from the basal portion of its posterior edge articulates by fibrous tissue with a similar projection from the anterior edge of the fourth epibranchial. Third pharyngobranchial like the second pharyngobranchial, except slightly smaller and with its ventral arm shorter and wider; teeth in about the same number and arrangement as described for the second pharyngobranchial; articulates with the dorsal ends of the third and fourth epibranchials. The two toothed pharyngobranchial elements are held to one another by fibrous tissue.

Fourth arch. - Cerato- and epibranchial elements only. Fourth ceratobranchial much expanded ventrally; articulates ventrally with the ventral end of its opposite member and with that of the third ceratobranchial. Fourth epibranchial rodlike; longer than the second and third epibranchials; articulates ventrally with the fourth ceratobranchial and dorsally with the base of the third pharyngobranchial, and, from a short projection on its lower anterior edge, with the third epibranchial.

Fifth arch. - Ceratobranchial (lower pharyngeal) element only. Fifth ceratobranchial the shortest of the ceratobranchial elements; wider ventrally than dorsally, with a short anterior projection from its anteroventral edge; articulates ventrally with the base of the fourth ceratobranchial; bearing two rows of teeth, the posterior row much larger than the anterior row; teeth in both rows similar to those of the pharyngobranchials, and becoming smaller dorsally; about 25 teeth in the anterior row and 15 in the posterior row. 


\section{PAIRED FIN GIRDLES.}

\section{Pectoral Fin.}

Posttemporal. - A slender wedge of bone ventrally where it is held in a deep concavity on the lateral surface of the pterotic, but slightly expanded posterodorsally where it contacts the sphenotic and, to a lesser extent, the epiotic. It is firmly and immovably held to all three of these bones, and especially to the pterotic, by a combination of fibrous tissue and interdigitation. Ventrally the posttemporal articulates by fibrous tissue with the supracleithrum.

Supracleithrum. - More or less vertical in position in relation to the axis of the body; articulates immovably by fibrous tissue dorsally with the rounded ventral head of the posttemporal and ventrally with the cleithrum, which it broadly overlies.

Cleithrum. - Laterally expanded at its anterior edge, particularly in the middle one-third of its length; articulates by fibrous tissue dorsally with the overlying supracleithrum and with the dorsal postcleithrum, which it overlies. Along its posterior edge the cleithrum broadly overlies and articulates by fibrous tissue with the anterior edges of the scapula and coracoid. Ventromedially the cleithrum articulates by fibrous tissue with its opposite member, and just above this region the anterior end of the shaftlike pelvis is held between the cleithra.

Postcleithra. - The postcleithra form a long posteroventrally directed strut from the dorsomedial surface of the cleithrum along the abdominal wall musculature to the area just above the dorsal lobe of the pelvis. The dorsal postcleithrum is wide anteriorly where it articulates by fibrous tissue with the overlying cleithrum; with a short dorsal projection from about the middle of its length supporting the posteroventral edge of the enlarged scales of the tympanum; tapering to a point posteriorly where it broadly overlies and articulates by fibrous tissue with the anterodorsal region of the ventral postcleithrum. The ventral postcleithrum a simple shaft, tapering to a point posteriorly.

Coracoid. - Wide dorsally, tapering to a blunt point ventrally; with a short spinelike process under the lowermost actinost from its posteroventral edge; the upper one-third of its posterior edge with an inturned flange directed anteromedially, forming a broad basin for muscle attachment; cartilage filled at its dorsal edge and for a short distance at its anteroventral edge; articulates by fibrous tissue anteriorly with the cleithrum, which broadly overlies the dorsal one-half of its anterior edge; articulates anterodorsally through cartilage and interdigitation with the scapula; articulates dorsally by fibrous tissue with the bases of the ventralmost two actinosts.
Scapula.-Completely encloses the scapular foramen; cartilage filled at its anterior and ventral edges; articulates anteriorly and anteroventrally by fibrous tissue with the overlying cleithrum; articulates posteroventrally through cartilage and interdigitation with the coracoid. Along its posterodorsal edge the scapula articulates by fibrous tissue with the following elements, in order from anterodorsal to posteroventral: the first pectoral fin ray, the small first actinost, the second actinost, and the anterior half of the base of the third actinost. The articulations with the first pectoral fin ray and the first actinost occur at upraised areas on the dorsal edge of the scapula, the stubby projection supporting the first pectoral fin ray being slightly larger than that supporting the first actinost.

Actinosts. - Four elements; all cartilage filled at both ends; first actinost small, the others increasing slightly in size posteroventrally in the series; first two actinosts articulated to the scapula as described in the preceding section; third actinost articulated with the dorsal edge of the articular area between the scapula and coracoid and the fourth actinost with the coracoid; all the articulations are by fibrous tissue. Distally the actinosts support by fibrous tissue all of the fin rays, except for the first, which is supported by the scapula.

Fin rays. - Fourteen fin rays in most specimens, with the first ray about one-fifth the length of the second ray and articulated directly with the scapula, rather than with the actinosts, as are the other rays. First ray with its medial half enlarged and thickened at its basal region of articulation with the scapula; its lateral half reduced to a thin, short splint closely held to the medial half, or even fused to it. First two rays and the last ray unbranched, the others branched. First ray without cross-striations, all the other rays cross-striated.

\section{Pelvic Fin.}

Pelvis. -A stout shaft; not divided into separated right and left halves; anterior half of its lateral surface with a concavity for muscle attachment; a large dorsal lobe present from its posterodorsal region which serves as a place of tough fibrous tissue attachment for the overlying skin of the distensible abdominal area or ventral flap (dewlap). A series of enlarged scales encircles the posterior end of the pelvis and obscures from view the rudimentary fin-ray (or spinous) element present in the midline just behind the end of the pelvis. The lateral surface of the posterior end of the pelvis bears several ridges for articulation with these scales. The scales occur in four segments, the anteriormost of which is immovably held to the end of the pelvis, while the other three segments are movable in a dorsoventral plane against the scales of the first segment and the end of the pelvis. The fin-ray element is deeply bifurcate anteriorly into divergent dorsal and ventral halves, as described in detail by Tyler (1962:228-229, figs. 30-37). The anterior one-third of the 
dorsal surface of the element has a groove in the midline which superficially separates the element into right and left halves, but the ventral surface shows no such groove. Posteriorly the element becomes divided into four slender rods, the tips of which project posteriorly a short distance beyond the end of the encasing scales, through a hole in the posterodorsal surface of the last scale segment. A large plug of cartilage intermediates between the bifurcate anterior end of the fin-ray element and the posterior end of the pelvis. The fin-ray element is movable in a dorsoventral plane around the posterior end of the pelvis, for ligaments are attached to the dorsal and ventral halves of the anterior end of the element, and the ligaments connect anteriorly to strong muscles. The ventral ligament runs along a concavity on the ventral surface of the pelvis to its muscle, while the dorsal ligament runs anteriorly through a longitudinal tunnel in the basal region of the dorsal lobe of the pelvis to make contact with its muscle, which is housed in a concavity along the dorsal surface of the pelvis anterior to the dorsal lobe. The pelvis itself is movable in a dorsoventral plane around its fibrous tissue attachment between the ventromedial edges of the cleithra.

VERTEBRAL COLUMN. - All vertebrae with biconcave centra, except the last, which posteriorly ends in a plate representing the fused centrum, hypurals, and parhypural.

\section{Abdominal Vertebrae.}

First vertebra. - Neural spine enlarged, somewhat laterally expanded, bifid to the centrum and thus not forming a bony roof over the neural canal; articulates by fibrous tissue and slight interdigitation along all of the anterior face of its neural spine with the exoccipitals. The rim of the concave anterior face of its centrum articulates by fibrous tissue with the rim of the concave posterior end of the basioccipital, while the rim of its posterior face articulates similarly with the rim of the anterior face of the second vertebra. From about the middle of its posterolateral surface, the centrum possesses a posteroventrally directed process which makes fibrous tissue contact over the anterior half of the lower surface of the centrum of the second vertebra. The neural prezygapophysis of the second vertebra makes close fibrous tissue contact with the dorsolateral surface of the first vertebral centrum.

Other abdominal vertebrae. - In five specimens the abdominal vertebrae numbered seven. Except for the first vertebra, all the abdominal vertebrae, as well as all of the caudal vertebrae except the last, possess bony roofs over the neural canal and have single, undivided neural spines. The neural spine of the third vertebra is the largest of those of the abdominal vertebrae, for it is much expanded dorsally. The basal regions of the neural spines and the dorsal regions of the neural arches become increasingly anteroposteriorly enlarged, from the second to the last abdominal vertebra, into broad articular sur- faces. These enlarged neural spines may have their anterior and posterior edges interdigitated with the preceding and succeeding neural spines in large specimens, but normally they articulate with one another only by fibrous tissue. Each neural arch has a neural foramen in its lateral surface. Short haemal postzygapophyses are present which slightly overlie the ventrolateral surface of the succeeding vertebral centra, but there are no haemal prezygapophyses. The second to the seventh abdominal vertebrae possess processes from their centra which bear all but one of the seven epipleural ribs. These processes become increasingly longer and stouter posteriorly in the series. The second vertebra bears a short lateral projection from its centrum just below the anterior region of the neural arch, and this projection articulates by fibrous tissue with the first epipleural. The third to fifth vertebrae bear their transverse processes progressively lower on their centra, so that the fifth vertebra has its transverse process taking its origin from the anteroventral edge of the centrum, while the process itself is directed posteroventrally. The third to the fifth vertebrae bear, respectively, the second to fourth epipleurals from the dorsal surfaces of their transverse processes. The processes of the sixth and seventh vertebrae differ from those anterior to them in that from the medial surface of the process on each side of the centrum there is a medially directed projection which meets and is continuous with that of its opposite member, completely enclosing the haemal canal. The haemal arch of the sixth vertebra does not have a haemal spine, but that of the seventh vertebra does. The haemal spine of the seventh vertebra, however, is not a single medial piece. Rather, it is bifid and forms a short posteroventrally directed process on either side of the midline. The sixth and seventh vertebrae bear, respectively, the fifth and sixth epipleurals from the lateral surfaces of their haemal arches. The neural spine of the fifth vertebra articulates by fibrous tissue dorsally with the supraneural strut that supports the posterior end of the spiny dorsal fin pterygial elements, while posterodorsally it articulates with the first basal pterygial element of the soft dorsal fin. The neural spines of the sixth and seventh vertebrae articulate by fibrous tissue between, respectively, the first and second and the second and third basal pterygial elements of the soft dorsal fin.

Caudal Vertebrae. - The caudal vertebrae numbered 11 in five specimens. As with the more posterior of the abdominal vertebrae, the first two caudal vertebrae have their neural spines enlarged. From the third to the last vertebra, however, the degree of enlargement progressively decreases so that the more posterior caudal vertebrae have relatively normal neural spines. All of the caudal vertebrae, except the last, possess complete neural and haemal arches. There are no haemal prezygapophyses, and small haemal postzygapophyses are only developed on a few of those vertebrae supporting the anal fin. The first caudal vertebra has a thick haemal spine that articulates firmly by fibrous tissue with the upper anterior surface of the enlarged first anal fin basal 
pterygiophore. From the lateral surface of the haemal spine of the first caudal vertebra, just below the level of the haemal arch, the seventh or last epipleural articulates by fibrous tissue. The second caudal vertebra has the largest haemal spine of any of the vertebrae, and posterior to this vertebra the length of the haemal spines progressively decreases until the 10th caudal vertebra is reached. The 10th caudal vertebra has its haemal spine longer than those just anterior to it, and in contrast to all the others, its haemal spine is autogenous. The lengths of the neural spines decrease from the first to the 10th caudal vertebra. The 10 th caudal vertebra has its neural spine longer than those just anterior to it. The haemal and neural spines of the last caudal vertebra are described below.

Caudal Skeleton. - The caudal complex consists of an epural, a free upper hypural, a free parhypural, and a large plate composed of the centrum fused to most of the hypural elements. The epural is a narrow shaft dorsally but an expanded plate ventrally, where it articulates by fibrous tissue with the neural arch of the centrum, sometimes more closely than that in the illustrated specimen. The free upper hypural is wider dorsally than ventrally and is held by fibrous tissue between the edges of the epural and the posterior half of the dorsal edge of the fused hypural plate. The parhypural is a flattened rod similarly held between the edges of the posteroventral half of the autogenous haemal spine of the penultimate vertebra and the ventral lobe of the fused hypural plate. The large hypural plate is the centrum fused to what in more generalized plectognaths are the first to fourth hypurals, the deep indentation on the posterior edge of the plate representing what would be the division between the second and third hypurals. The centrum region is thickened into a broad vertical crest for muscle attachment. The two halves of the neural arch of the last centrum diverge anteriorly, but more posteriorly they sometimes approach each other more or less closely in the midline, although they do not interdigitate or fuse. The neural canal is thus relatively open above, never being more than very partially roofed over. Similarly, the two halves of the haemal arch closely approach one another ventromedially, but do not interdigitate or fuse and leave the haemal canal only partially roofed over. The haemal canal courses through the haemal arch to exit at the deep notch in the anteroventral end of the fused hypural plate. The parhypural thus represents only the haemal spine of the last vertebra, and not both the spine and arch.

As discussed and illustrated by Tyler (1970b:14, fig. 22) three of the five study specimens show no evidence of uroneurals, nor do any of the other species of balistids examined, but two of the specimens of Balistapus undulatus do. In one of these specimens there is a pair of small nubbins of bone resting on the dorsal surface of the upper free hypural and directly behind the posterior edge of the epural, these apparently being the two halves of a rudimentary uroneural. In the other specimen, the "uroneural" elements are much further forward, being a pair of ossifications just above and behind the posterodorsal region of the neural arch of the last centrum. Whether these elements are homologous to the uroneurals of the other specimen is questionable, for they could also be unconsolidated neural arch material, as sometimes found in triacanthodids, which have relatively well-developed uroneurals.

Caudal fin rays. - Twelve in number; the uppermost ray and the lowermost ray unbranched, the others becoming increasingly branched toward the middle fin rays, which are branched in triple dichotomies. The bifid bases of the fin rays articulate by fibrous tissue with the caudal skeleton as follows: the uppermost two rays to the upper free hypural; the lowermost ray to the parhypural and the remaining eight rays to the lobes of the fused hypural plate, four to the dorsal lobe and four to the ventral, with the lowermost branched ray receiving partial support from the parhypural as well.

\section{DORSAL AND ANAL FINS.}

\section{Dorsal Fin.}

Spines and pterygiophores. - Three spines borne on two basal pterygiophores. First spine long and stout; second spine slightly shorter and narrower; third spine about one-fourth the length of the first spine. The first two spines are borne on the enlarged first pterygiophore and the third spine on the much smaller second pterygiophore. The mechanism by which the bifid bases of the first two dorsal spines rotate over the medial upraised portion of the dorsal surface of their pterygiophore and lock themselves in an erected position, with the posteroventral edge of the first spine resting against the anteroventral edge of the second spine, has been described so often in the past that a detailed redescription of it here seems superfluous. For such descriptions see Hollard (1853:102), Brühl (1856:59; 1880; 1891:pl. 24), Mayer (1864:fig. 4 of pl. 7), Bliss (1872:10), Thilo (1879:12; 1896b:291; 1902), Klein (1881:350), Sdrensen (1884:50; 1897), Mohr (1928), Jacobs (1935:156-157), Clothier (1939), Smith (1949a:406), and Monod (1950, 1960). The papers of Sdrensen, Clothier, and Monod are particularly recommended. Anteriorly the first pterygiophore has a short, bluntly rounded, ventral process which is firmly held by fibrous tissue in the concavity in the midline of the posterodorsal region of the skull formed dorsally by the supraoccipital and laterally and ventrally by the epiotics. Posteriorly the first pterygiophore is broadly overlain by the anterior region of the second pterygiophore, with which it interdigitates. On the ventral edge of the second pterygiophore, there is a shallow indentation where fibrous tissue articulation is established with the thick shaftlike supraneural element. The supraneural slants posteroventrally from its articulation with the second pterygiophore to make fibrous tissue contact with the dorsal edge of the neural spine of the fifth abdominal vertebra and with the lower anterior edge of the first basal pterygiophore of the soft dorsal fin. 
Fin rays and pterygiophores. - Twenty-six fin rays are present in most of the study specimens; the first ray unbranched, the others branched in single or double dichotomies. Each fin ray has a small, unpaired, distal pterygiophore between the bifurcate base of the ray. Basally the fin rays are supported by 27 basal pterygiophores. Each basal pterygiophore has a well-developed lateral flange throughout its length, except at the very proximal and distal ends of the element, for muscle attachment. The lateral flanges decrease slightly in height posteriorly in the series. The first basal pterygiophore is somewhat shorter, but stouter, than those just posterior to it, and articulates by fibrous tissue ventrally between the neural spines of the fifth and sixth abdominal vertebrae, while anteroventrally it supports the base of the supraneural. Posterodorsally the first basal pterygiophore interdigitates with the second basal pterygiophore, and all of the subsequent basal pterygiophores extensively interdigitate to one another along their edges of contact, the more posterior elements only slightly less extensively so than more anteriorly. The last few basal pterygiophores articulate between the neural spines of the seventh and eighth caudal vertebrae. The degree of interdigitation between the pterygiophores, and their closeness of apposition with the neural spines, increases with increased size of the individual, so that in very large specimens a massive, almost solid plate is present between the vertebrae and the soft dorsal fin. The basal pterygial elements are cartilage filled at their dorsal and ventral edges. In all but one of the five study specimens the number and arrangement of the basal pterygial elements is as described above, but slight variation in the number of elements is to be expected.

\section{Anal Fin.}

Fin rays and pterygiophores. - Twenty-three fin rays are present in most of the study specimens; first ray unbranched, the others branched in single or double dichotomies. Each fin ray with a small, unpaired, distal pterygiophore between its bifurcate base. Basally the rays are supported by 22 basal pterygiophores, like those of the dorsal fin. The first basal pterygiophore is by far the largest of the series and has its anterior edge expanded laterally. It articulates by fibrous tissue dorsally between the haemal spines of the first and second caudal vertebrae, while posteroventrally it interdigitates with the second basal pterygiophore, and all of the subsequent basal pterygiophores are extensively interdigitated to one another, as in the soft dorsal fin, with the interdigitation and closeness of apposition to the haemal spines increasing with increasing specimen size. The last few basal pterygiophores articulate between the haemal spines of the seventh and eighth caudal vertebrae.

Anatomical diversity.-The balistids are one of the least anatomically and otherwise diversified families of plectognaths, of a degree of diversity comparable to that of the Triacanthidae, Aracanidae, and Diodontidae. Internaily the balistids differ remarkably little from one another in fundamental plan. The vertebral column $(7+$ 11 ), basal pterygiophore support system of the soft dorsal and anal fins, and the caudal fin supporting structures are basically the same in all species. The skulls differ mainly in the degree of development and massiveness of the supraoccipital and epiotic supports of the basal pterygiophores of the spiny dorsal fin (least developed in Rhinecanthus), perhaps correlated at least in part with the size of the third spine, and of the degree of anterior displacement of the suspensorium (most displaced in Xanthichthys and, especially, Odonus), correlated with the degree of upturning of the mouth.

The genera of balistids are, in fact, distinguishable mainly by external features such as: the degree of development of a cusp or enlargement on the medial end of the biting edge of the teeth (least developed in Melichthys, in which at least the more medial of the cusped teeth of young specimens become truncate true incisors with increasing size; best developed in Xanthichthys and, especially, Odonus, in both of which the most medial tooth of the premaxillary is smaller than that just lateral to it, whereas it is the medial tooth that is the largest in all other balistids; the enlarged cusp of the second most medial tooth in Odonus projecting far beyond the others and resting on the lower lip as a fang when the jaws are closed); the presence or absence of a deep groove in front of the eye and below the nostrils of unknown functional significance (absent in Balistapus and Rhinecanthus, and only weakly present in Pseudobalistes); the presence or absence of enlarged, rounded, or otherwise modified nonoverlapping and flexible scales covering the tympanum (not enlarged in Canthidermis and Xanthichthys); scales and spinulation patterns on the head and body; degree of development of the third dorsal spine (least developed in Melichthys, Rhinecanthus, and Xanthichthys; becoming minute in large specimens of Canthidermis and Balistoides conspicillum), these diagnostic features supplemented by the shape of the caudal peduncle and caudal fin. These and other features in the anatomical diversity of the Recent species are discussed further in the section on generic relationships.

The balistids have changed little since the Oligocene. In the black schist of Canton Glarus, Switzerland, there are three species of balistids placed in the genus Balistomorphus that are, from what little is known of them from their impressions, thoroughly modern in appearance. The holotypes and a few additional specimens of these three species have recently been reexamined and data on them is given below.

Balistomorphus ovalis (Agassiz 1842 illustration, 1844b description) is the most slender bodied of the three species in the genus. The holotype, IGUN uncatalogued (but XXXVII scratched on the back of the plate), a single impression (head left) is $121 \mathrm{~mm}$ SL. The depth of the body between the soft dorsal and anal fin origins is $45.3 \mathrm{~mm}$ ( $37.3 \% \mathrm{SL})$. The least depth of the caudal peduncle is $12.8 \mathrm{~mm}(10.5 \% \mathrm{SL})$. The length of the first dorsal spine is $25.7 \mathrm{~mm}(21.2 \% \mathrm{SL})$. The second dorsal spine cannot be measured, but the third spine is $4.5 \mathrm{~mm}$ (3.7\% SL). There are 11 caudal vertebrae, as in Recent 


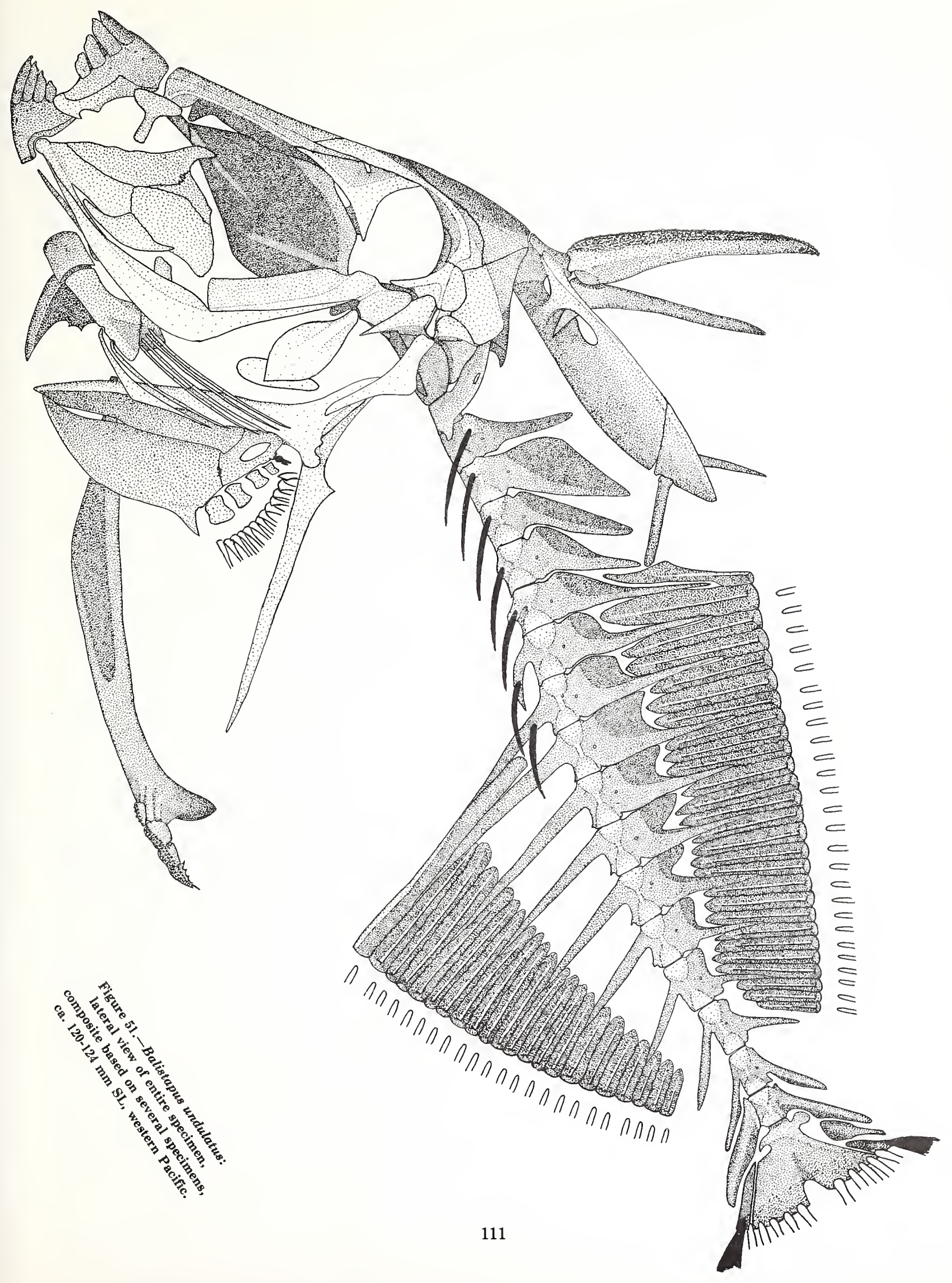




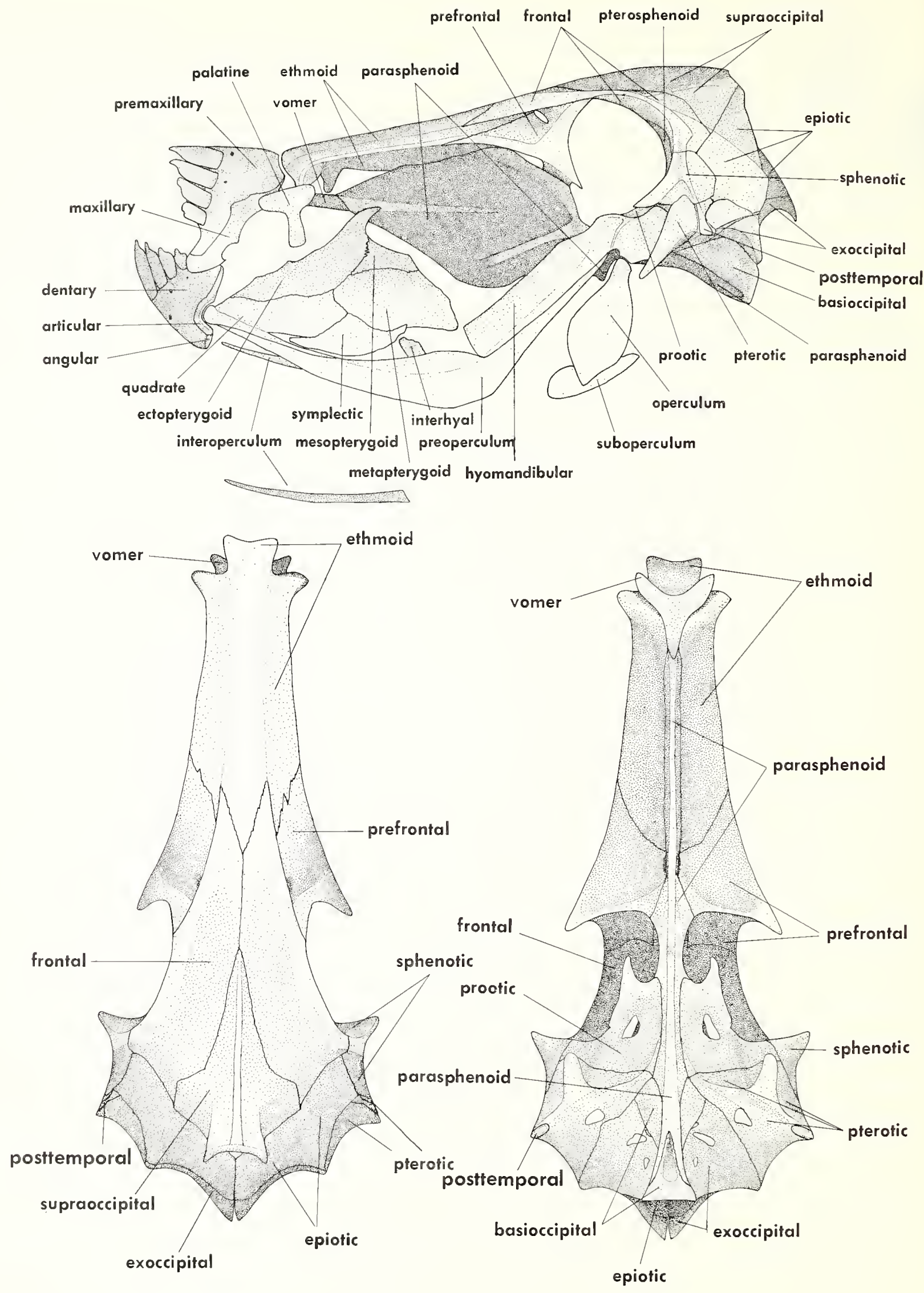


Figure 52. (opp. page, upper)-Balistapus undulatus: lateral view of head, composite based on several specimens, ca. 120-124 mm SL, western Pacific.

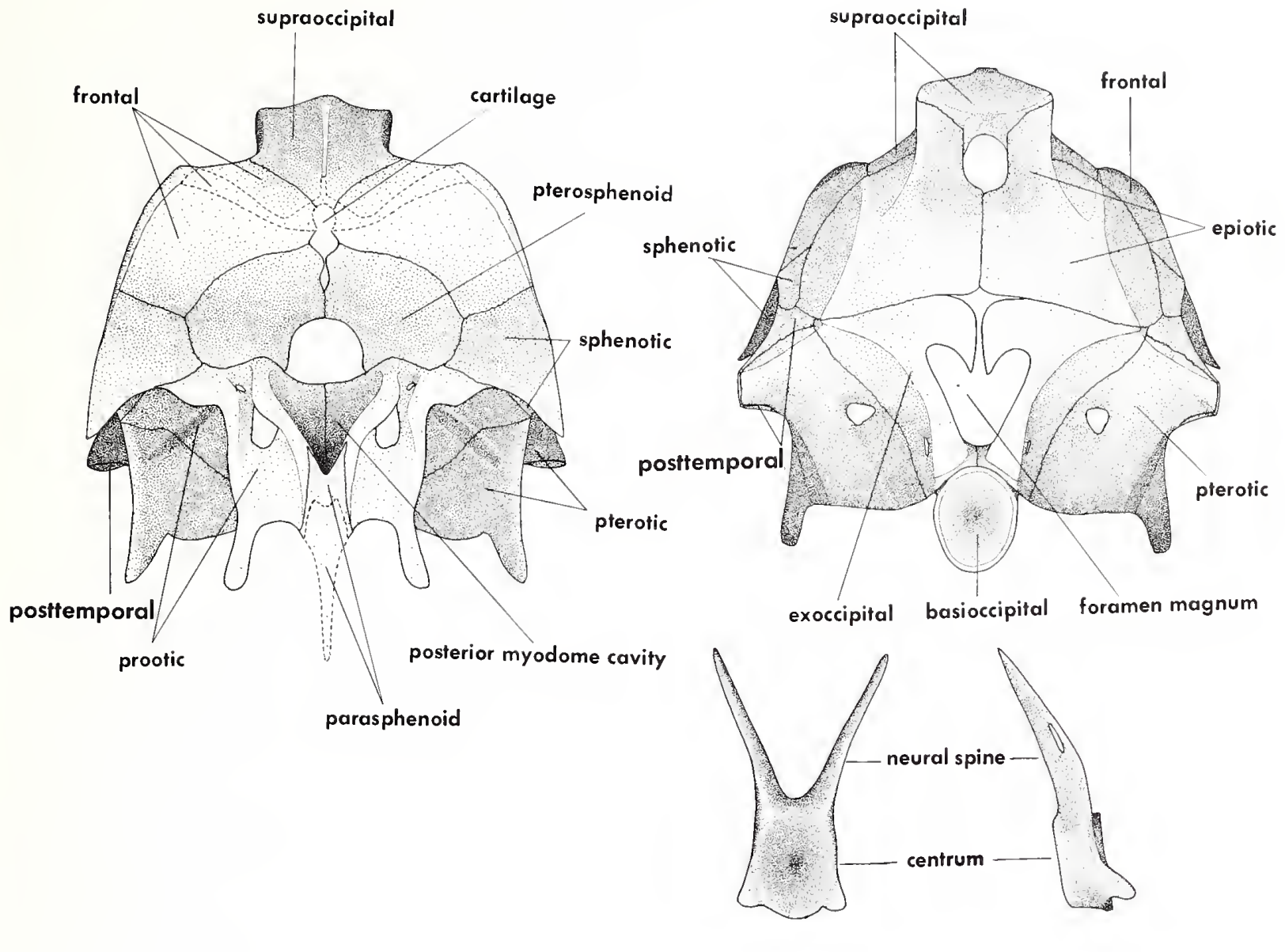

Figure 54.-Balistapus undulatus: posterior view of orbit (left) (cross section of skull; dashed lines represent cut surfaces of frontals, supraoccipital, and parasphenoid) and posterior view of skull (right); below, posterior and lateral views of first

abdominal vertebra; composite based on several specimens, ca. 120-124 mm SL, western Pacific.

Figure 53. (opp. page, lower)-Balistapus undulatus: dorsal (left) and ventral (right) views of skull, composite based on several specimens, ca. 120-124 mm SL, western Pacific. 

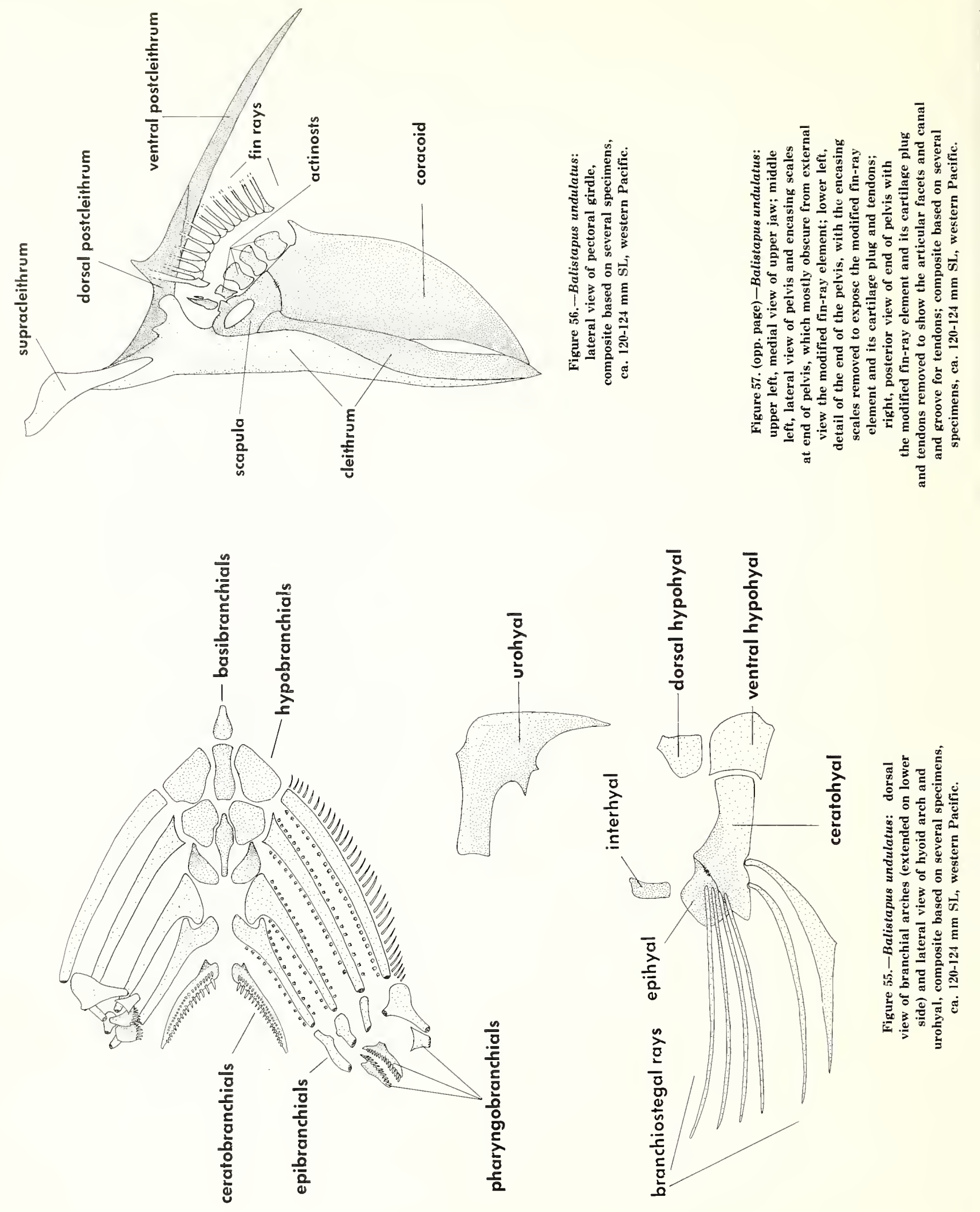


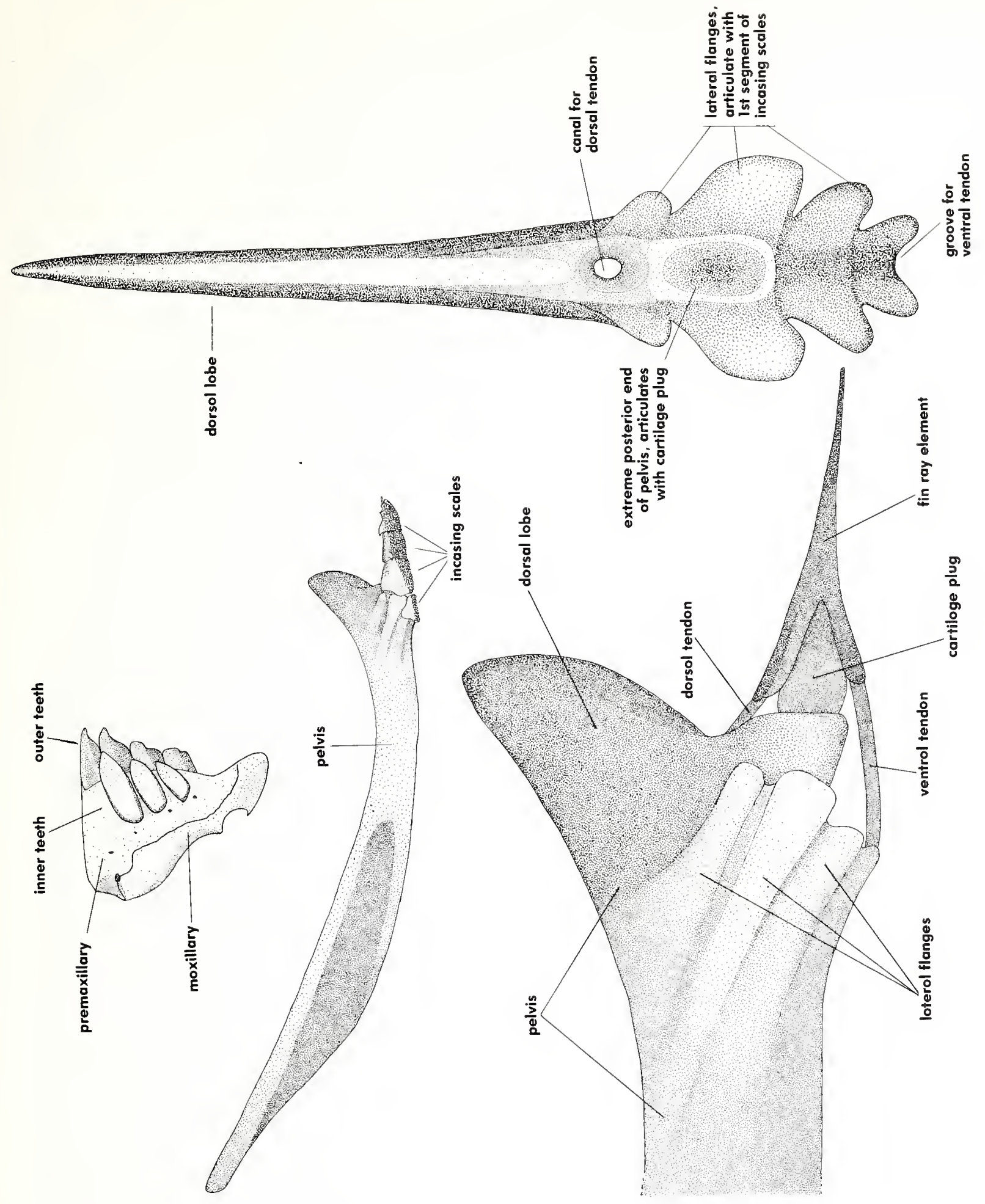




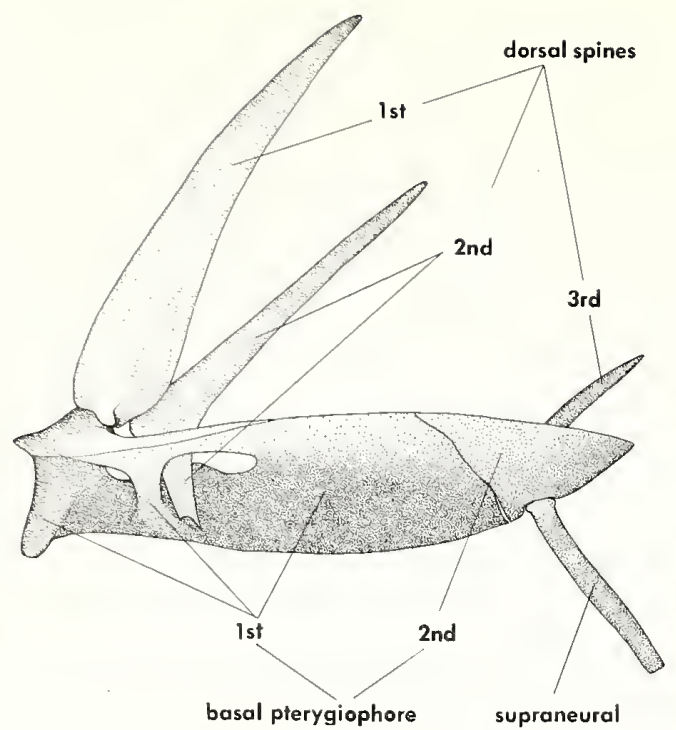

Figure 58.-Balistapus undulatus:

lateral view of spiny dorsal

fin and its pterygial supports,

composite based on several specimens,

ca. 120-124 mm SL, western Pacific.
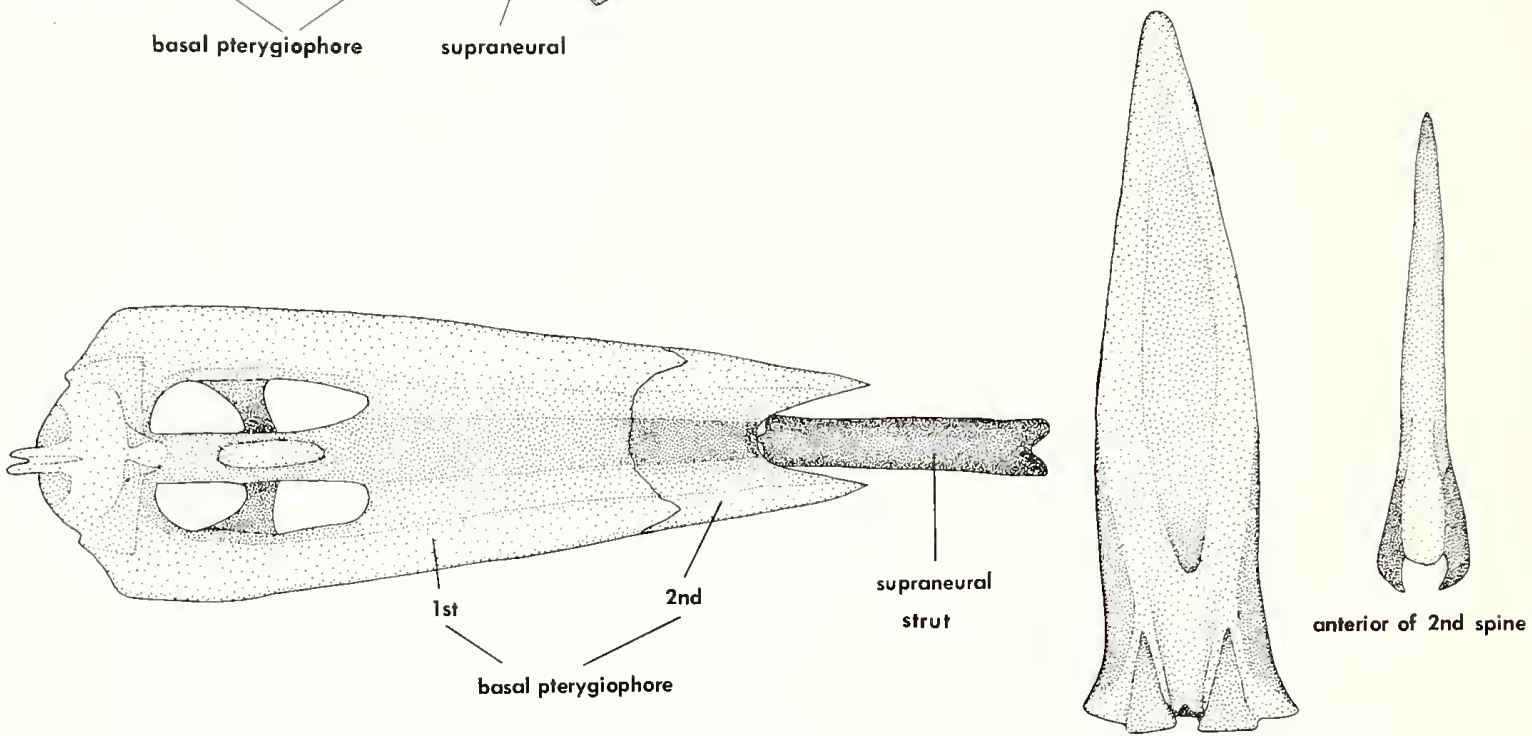

posterior of lst spine

Figure 59.-Balistapus undulatus: left, dorsal view of pterygial supports of spiny dorsal fin, with the spines

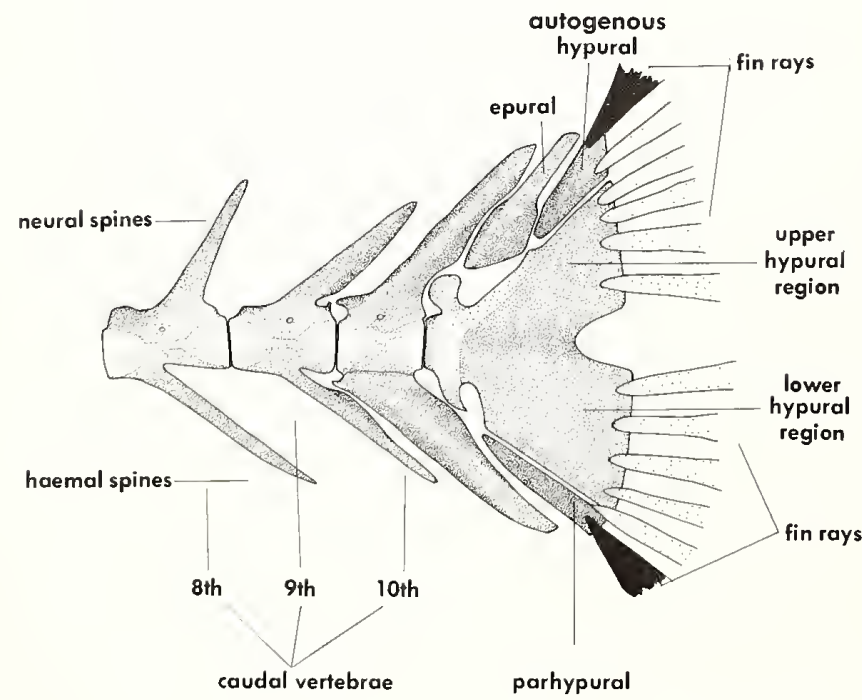
removed; right, posterior view of first dorsal spine and anterior view of second dorsal spine to show their articular facets; composite based on several specimens, ca. $120-124 \mathrm{~mm} \mathrm{SL}$ western Pacific.

Figure 60.-Balistapus undulatus: lateral view of caudal fin supporting structures, composite based on several specimens, ca. 120-124 mm SL, western Pacific. 


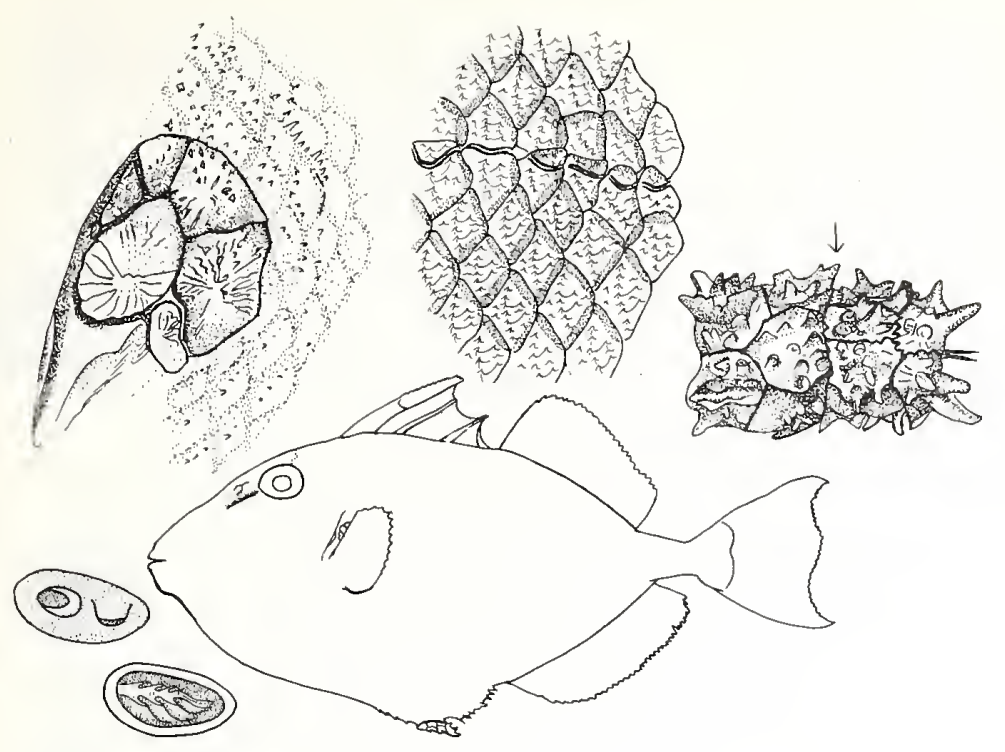

Figure 61.-External features of other representative balistid genera: Abalistes stellaris-upper left, scale plates of the tympanum region just behind the gill slit and above

the pectoral fin base; upper middle, scales

from upper middle region of body, including lateral line canal bearing scales; upper right, ventral view of encasing scales at end of pelvis (anterior to left), with arrow indicating major region of flexibility (two terminal branches of modified

fin-ray element protrude posteriorly); lower left, nasal region as seen externally

(above) and the olfactory lamellae as seen with the top of the nasal sac removed.

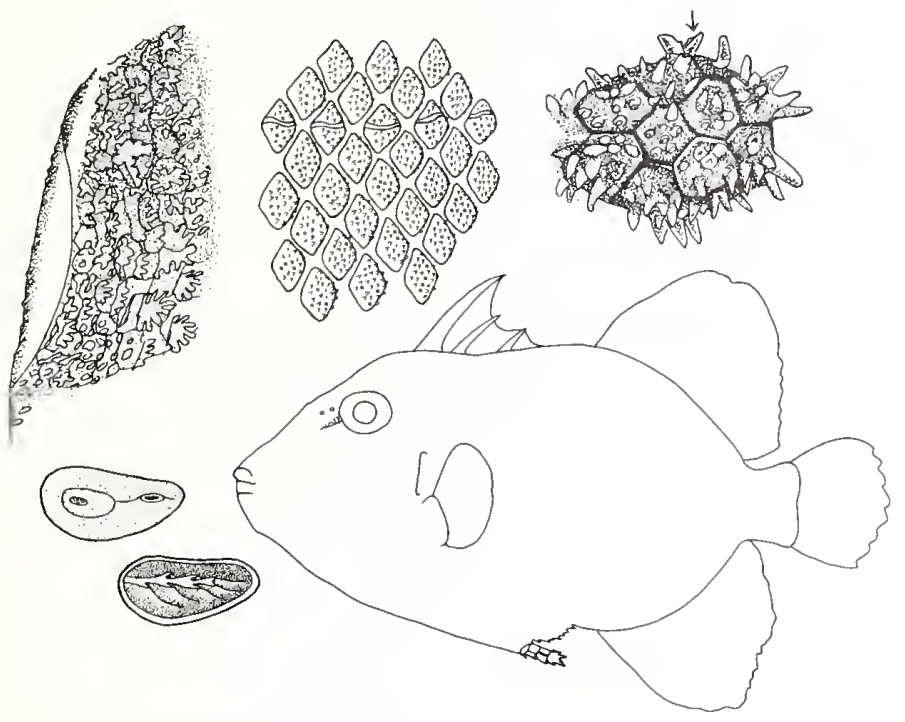

Figure 62.-External features of other representative balistid genera: Canthidermis maculatus-upper left, scales of the relatively unmodified tympanum region just behind the gill slit and above the pectoral fin base; upper middle, scales from upper middle region of body, including lateral line canal bearing scales; upper right, ventral view of encasing scales at end of pelvis (anterior to left), with arrow indicating major region of flexibility (modified fin-ray element not protruding); lower left, nasal region as seen externally (above) and the olfactory lamellae as seen with the top of the nasal sac removed.

Figure 63.-External features of other representative balistid genera: Xanthichthys ringensupper left, scales of tympanum region just behind the gill slit and above the pectoral fin base; upper middle, scales from upper middle region of body, including lateral line canal bearing scales; upper right, ventral view of encasing scales at end of pelvis (anterior to left), with arrow indicating major region of flexibility (three terminal branches of modified fin-ray element protrude posteriorly); lower left,

nasal region as seen externally (above) and the olfactory

lamellae as seen with the top of the nasal sac removed.
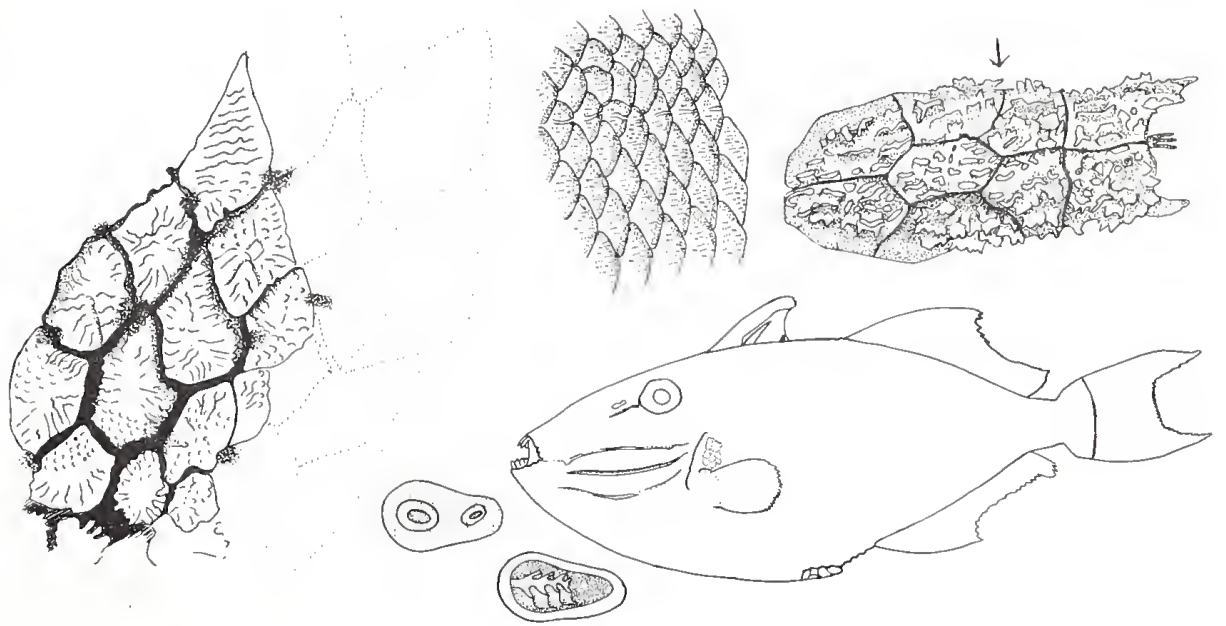
Figure 64.-External features of other representative balistid genera: Odonus nigerupper left, scale plates of the tympanum region just behind the gill slit and above the pectoral fin base; upper middle.

scales from upper middle region of body, including lateral line canal bearing scales; upper right, ventral view of encasing scales at end of pelvis (anterior to left), with arrow indicating major region of flexibility (two terminal branches of modified fin-ray element protrude posteriorly); lower left, nasal region as seen externally (above) and the olfactory lamellae as seen with the top of the nasal sac removed.

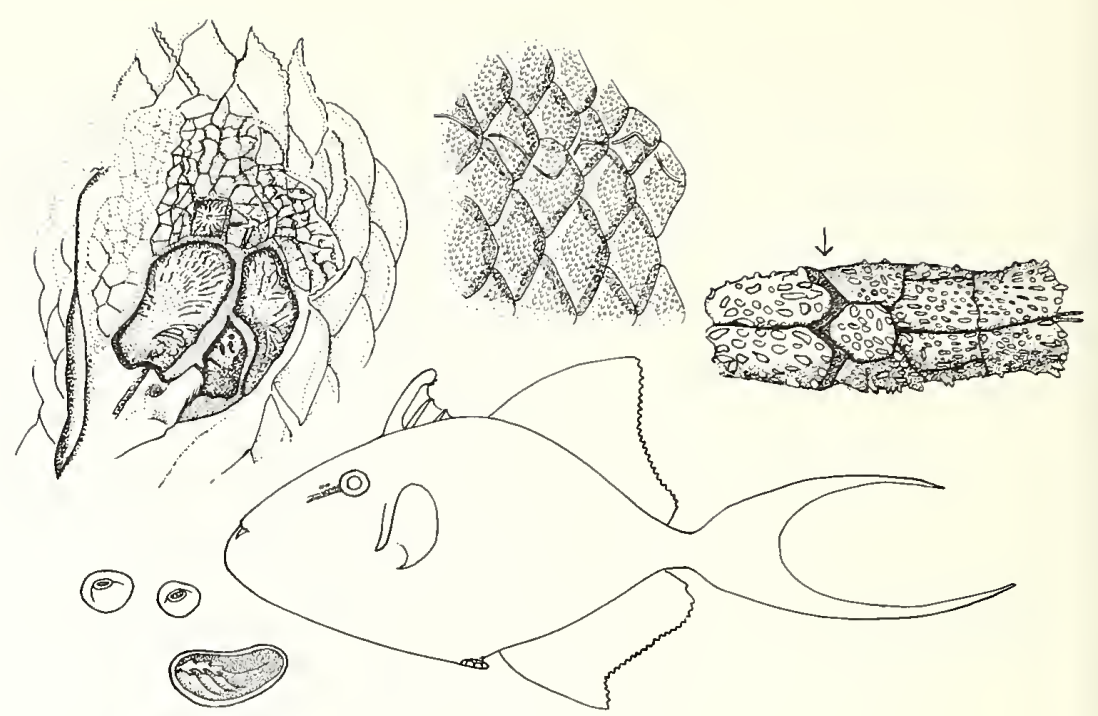

species, and room for about seven abdominal vertebrae, also as in Recent species, although only the last four abdominal vertebrae can be seen relatively clearly. There appear to be about 12 caudal fin rays in a slightly rounded fin. There is a well-developed supraneural strut supporting the rear end of the carina. The basal pterygiophores that are best shown, anteriorly in the soft dorsal fin, have well-developed lateral flanges. The form and number of the teeth do not show. The stout pelvis has a small but distinct dorsal lobe posteriorly. The scales, best seen posteriorly on the body, bear one or more low longitudinal ridges along the basal plate, those in the region of the caudal peduncle being larger and longer than elsewhere and oriented in longitudinal rows, just as in many Recent species.

An additional specimen from the black schist of Canton Glarus, NSKG 178b, $119 \mathrm{~mm} \mathrm{SL}$, can be assigned to Balistomorphus ovalis, mainly on the basis of its slender body, the depth between the soft dorsal and anal fin origins being about $36 \mathrm{~mm}$ ( $30 \% \mathrm{SL})$. It is a poor impression that at one time was in counterpart, but the head to the right plate (presumably numbered 178a) cannot be found. The caudal peduncle depth is $12.4 \mathrm{~mm}(10.4 \%$ $\mathrm{SL})$. The first dorsal spine is $22.8 \mathrm{~mm}(19.2 \% \mathrm{SL})$, the second $9.5 \mathrm{~mm}(8.0 \% \mathrm{SL})$, and the third $5.1 \mathrm{~mm}(4.3 \%$ $\mathrm{SL}$ ), all of which measurements are compatible with that of the holotype of $B$. ovalis from the same strata, as are the well-developed supraneural strut supporting the carina and the approximately 11 caudal vertebrae. Little else of interest can be seen.

Balistomorphus spinosus (Agassiz 1842 illustration, 1844b description) is a moderately deep bodied species. The holotype, and only relatively complete specimen available, BMNH P. 3973, a single impression (head right) is $92.0 \mathrm{~mm} \mathrm{SL}$. The depth of the body between the soft dorsal and anal fin origins is $46.0 \mathrm{~mm}$ ( $50 \% \mathrm{SL})$. The least depth of the caudal peduncle is $12.2 \mathrm{~mm}(13.3 \%$ $\mathrm{SL})$. The length of the first dorsal spine, which bears low asperities laterally, is $21.0 \mathrm{~mm}$ ( $22.8 \% \mathrm{SL})$. The second dorsal spine cannot be measured, but the third spine is
$5.0 \mathrm{~mm}(5.4 \% \mathrm{SL})$. The vertebral column can be interpreted either as $7+11$, as in Recent species, or as $8+10$. The caudal fin appears to have 12 rays. There is a welldeveloped supraneural strut supporting the rear end of the carina. The basal pterygiophores have welldeveloped lateral flanges. The form and number of the teeth do not show. There is a slight indication that the stout pelvis had a low dorsal lobe posteriorly. The scales are not as well indicated as in $B$. ovalis, but low granulations of some sort were present on the basal plates. The anal fin base seems to have been substantially shorter than the soft dorsal fin base, more so than in $B$. ovalis.

An additional specimen from the black schist of Canton Glarus, NSKG 189a and b, which is too poor an impression in counterpart to accurately measure, can probably be assigned to $B$. spinosus on the basis of its moderately deep body, as can another not listed in the material examined (BMNH P. 1819) from the same strata whose bones are too disorganized to measure. These additional specimens add little to our knowledge of the species, except that the first dorsal spine in one of them bears even better developed asperities laterally, and apparently anteriorly, than does the holotype of $B$. spinosus.

Balistomorphus orbiculatus (Heer 1865, see also 1876) is an extremely deep bodied species. The holotype, and only known specimen, NSKG 2688 , a single impression (head left), is $65.6 \mathrm{~mm} \mathrm{SL}$. Heer's illustration of the specimen shows the head facing right, so either the illustration was reversed or, less likely, the specimen was originally in counterpart and only the head to left half remains in the Glarus collection. Woodward (1901:568) believed the great depth of the specimen to be due to distortion, but, as with the other specimens of Balistomorphus (and of the Oligocene triacanthid Acanthopleurus, which see) from the black schist of Canton Glarus, the neural and haemal spines of the vertebrae have a normal relationship with the basal pterygiophores of the soft dorsal and anal fins and the patterns of the scales are normal, neither of which would be the case if $B$. orbiculatus 

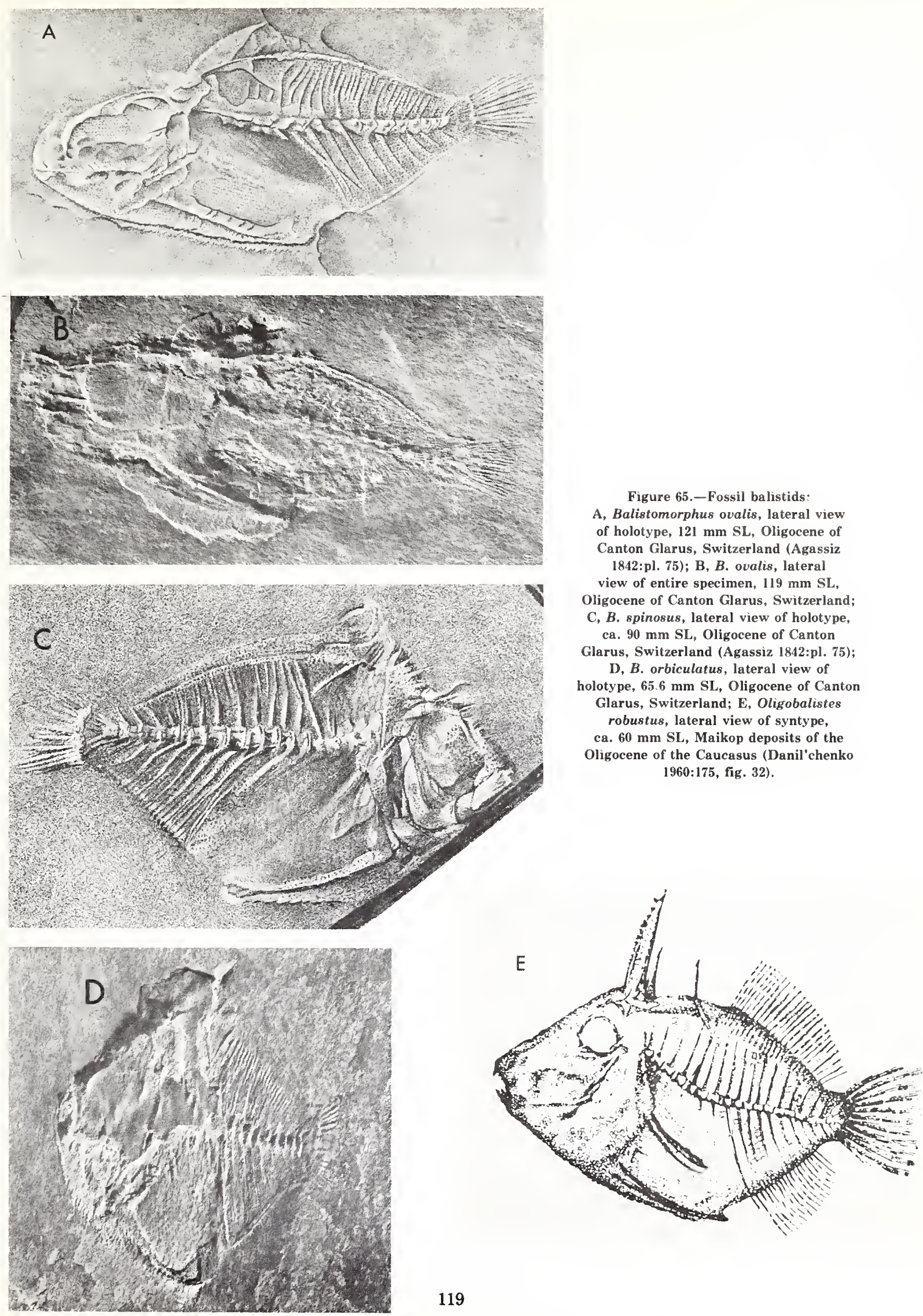

A, Balistomorphus ovalis, lateral view of holotype, $121 \mathrm{~mm} \mathrm{SL}$, Oligocene of Canton Glarus, Switzerland (Agassiz

1842:pl. 75); B, B, ovalis, lateral

view of entire specimen, $119 \mathrm{~mm} \mathrm{SL}$,

Oligocene of Canton Glarus, Switzerland;

C, B. spinosus, lateral view of holotype,

ca. $90 \mathrm{~mm} \mathrm{SL}$, Oligocene of Canton

Glarus, Switzerland (Agassiz 1842:pl. 75);

D, $B$. orbiculatus, lateral view of

holotype, $65.6 \mathrm{~mm} \mathrm{SL}$, Oligocene of Canton

Glarus, Switzerland; E, Oligobalistes

robustus, lateral view of syntype,

ca. $60 \mathrm{~mm}$ SL, Maikop deposits of the

Oligocene of the Caucasus (Danil'chenko 1960:175, fig. 32). 
were unnaturally drawn out vertically. The depth of the body between the soft dorsal and anal fin origins is 63.6 $\mathrm{mm}(97.0 \% \mathrm{SL})$. The least depth of the caudal peduncle is $20.1 \mathrm{~mm}(30.6 \% \mathrm{SL})$, this being substantially deeper than in the other two species of the genus. The length of the first dorsal spine is $24.6 \mathrm{~mm}(37.5 \% \mathrm{SL})$. The second dorsal spine cannot be measured, but the third spine is $3.9 \mathrm{~mm}(5.9 \% \mathrm{SL})$. The number of dorsal and anal fin rays appears to have been similar, and between about 20 and 25 . The vertebral column cannot be seen in the abdominal region, but the caudal series can be interpreted as either 11, as in Recent species, or 12. The caudal fin appears to have 12 rays. There is a well-developed, especially obliquely placed, supraneural strut supporting the rear end of the carina. The basal pterygiophores have exceptionally well-developed lateral flanges. The form and number of the teeth are poorly indicated as large in: cisors, with at least three probably located in an outer series in the upper jaw. The stout pelvis has a low but distinct dorsal lobe posteriorly, and there is some indication that the scales between the posterior end of the pelvis and the anus were enlarged and elongate to support a small fan or dewlap in this region, as in most $\mathrm{Re}$ cent species. The scale pattern is relatively well preserved, and the basal plates appear to bear two or three more or less vertically oriented low emarginate ridges, substantially different from the condition of spinulation in the other two species of the genus.

In addition to the three species of Balistomorphus, one other species of balistid is known from the Oligocene seas of Europe. Oligobalistes robustus Danil'chenko (1960), known from three specimens of 27 to $60 \mathrm{~mm}$ SL from the Maikop deposits of the Caucasus, is the best preserved fossil balistid. It has not been reexamined for this work, and the following is based on the description by Danil'chenko. Oligobalistes differs from Balistomorphus by having no surface sculpturing on the scale plates, and by the better development of the second and third dorsal spines (respectively 15 and $10 \% \mathrm{SL}$ in Oligobalistes versus 8 and 4 to $6 \%$ SL in Balistomorphus), although the first dorsal spine of Oligobalistes is slightly less well developed ( $30 \% \mathrm{SL})$ than in one of the species of Balistomorphus (B. orbiculatus, $37.5 \% \mathrm{SL}$ ). Danil'chenko believed Oligobalistes to differ from all of the Recent genera by the large size of the first dorsal spine and the presence of longitudinal rows of spinules along its anterior edge. The first dorsal spine is slightly longer, but not stouter, than in the adults of any Recent genera, some of which (e.g., Rhinecanthus) have longitudinal rows of spinules along the anterior and lateral edges of the scales that are as well developed as in Oligobalistes. If the scales of Oligobalistes are completely smooth then it also differs in this respect from the Recent genera, all of which have at least low emarginations or spinules.

The teeth in Oligobalistes were described as numbering four to six in each jaw, but presumedly any number above the four in an outer series (as found in all Recent species) represent misplaced teeth from another outer series or from any of the inner series. The vertebral column was described as $7+10$, but the illustratic clearly shows 11 caudal vertebrae, and a $7+11$ colum as in all Recent species.

Danil'chenko thought Oligobalistes most close related to the Recent Balistes, but because of the a sence of a preocular groove, Oligobalistes is probab more closely related to Balistapus and Rhinecanthus, discussed under Generic Relationships.

Generic relationships.-The generic relationshi within the Balistidae are not especially clear on the ba of the present work. Features that a priori seem gener ized on the basis of the evolution of balistids from tr canthids are a terminal mouth, well-developed third d sal spine and overlapping scale plates.

The relatively straight-edged or gently curved hea crushing incisors of triacanthids contrast to the slight fewer in number, but at least superficially larger, notc ed teeth basic to balistids. While slightly larger in st face area, balistid teeth are thinner edged and less hea than in triacanthids, except in very large individuals most species of balistids, in which the teeth become ju as massive if not more so than in triacanthids, while st retaining at least some degree of notching. The presen of unnotched edges on the more medial teeth in adv Melichthys is not an indication of a generalized co dition, for Berry and Baldwin (1966:449) have shown th the teeth are normally cusped in juveniles and or gradually do the more medial teeth become worn down a relatively straight edge in adults, definite remnants the notching always being present on the more late teeth.

However, the dentition of Xanthichthys and Odon can surely be considered a specialization, with the largement of the second most medial tooth in $t$ premaxillary and, in Odonus, of its cusp, into a fang. $T$ second most medial tooth in the dentary is also oft slightly larger in Xanthichthys and Odonus than would be in other balistids. In contrast to all oth balistids, which have white teeth, the teeth of Xanthic thys have a dark tinge, at least as adults (Berry a Baldwin 1966:456), and those of Odonus are a deep re Also in contrast to other balistids, the teeth in Xanthic thys and Odonus, as well as in Canthidermis, the on truly oceanic balistid, do not become exceedingly me sive and thickened in large adults, the dietary chang between juveniles and large adults in these three gene apparently not being at all as extensive as in oth balistids.

The specialized condition of the anterior displac ment of the suspensorium and lower jaw is found mc prominently in Xanthichthys and, especially, Odon the mouth being distinctly supraterminal. The mouth Melichthys is slightly supraterminal, but in oth balistid genera it is essentially terminal.

Probably not much importance should be placed the size of the third dorsal spine as an indicator specialization and relationship. The third spine is not $i$ volved in the locking mechanism of the first two spine and it has neither a complex basal articulati 


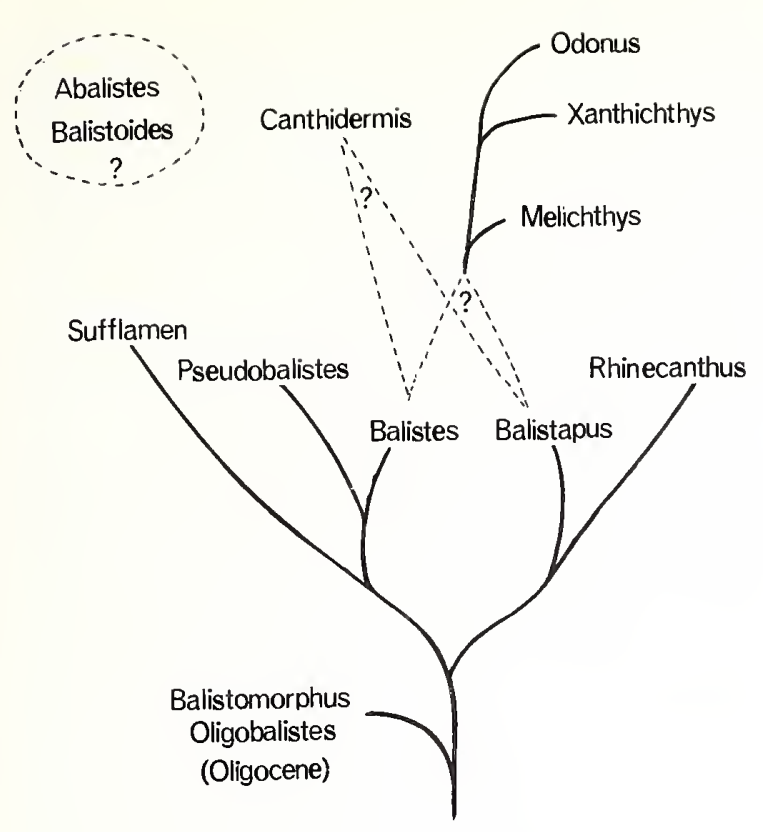

Figure 66.-Hypothesized phylogenetic relationships of the genera of Balistidae.

mechanism with its basal pterygiophore nor a complex extensive musculature. The third spine functionally seems rather insignificant, and great variation in such a structure can be expected, the variation from genus to genus or within a genus being of little value to determining relationships. Thus, the minute third dorsal spine found in Rhinecanthus, Melichthys, and Xanthichthys probably does not indicate close relationship between these three otherwise relatively dissimilar genera, nor does it necessarily indicate that they are specialized in the face of almost any other evidence to the contrary. The third dorsal spine is well developed in the Oligocene genera Balistomorphus and, especially, Oligobalistes.

The significance of the presence of a preocular groove and of specialized flexibly articulated nonoverlapping scales over the tympanal region above the pectoral fin base is difficult to interpret. Neither structure is present in triacanthids. They occur only in balistids and not in the derived monacanthids. The fossil record of the balistids, first known from the Oligocene, consists of less than a dozen specimens, many of them rather imperfect. The specimens assigned to the three species of Balistomorphus from the Oligocene of Switzerland, including the holotypes of each, have recently been reexamined, and there is no indication of a preocular groove or of specialized tympanal scales, but these regions are not well shown on any of the specimens. However, in describing the well-preserved Oligobalistes robustus from the Oligocene of Russia, Danil'chenko (1960:173-174) specifically says that a preocular groove is absent, while his statement that there is a "small body plate with radial sculpture'situated directly behind gill slit, level
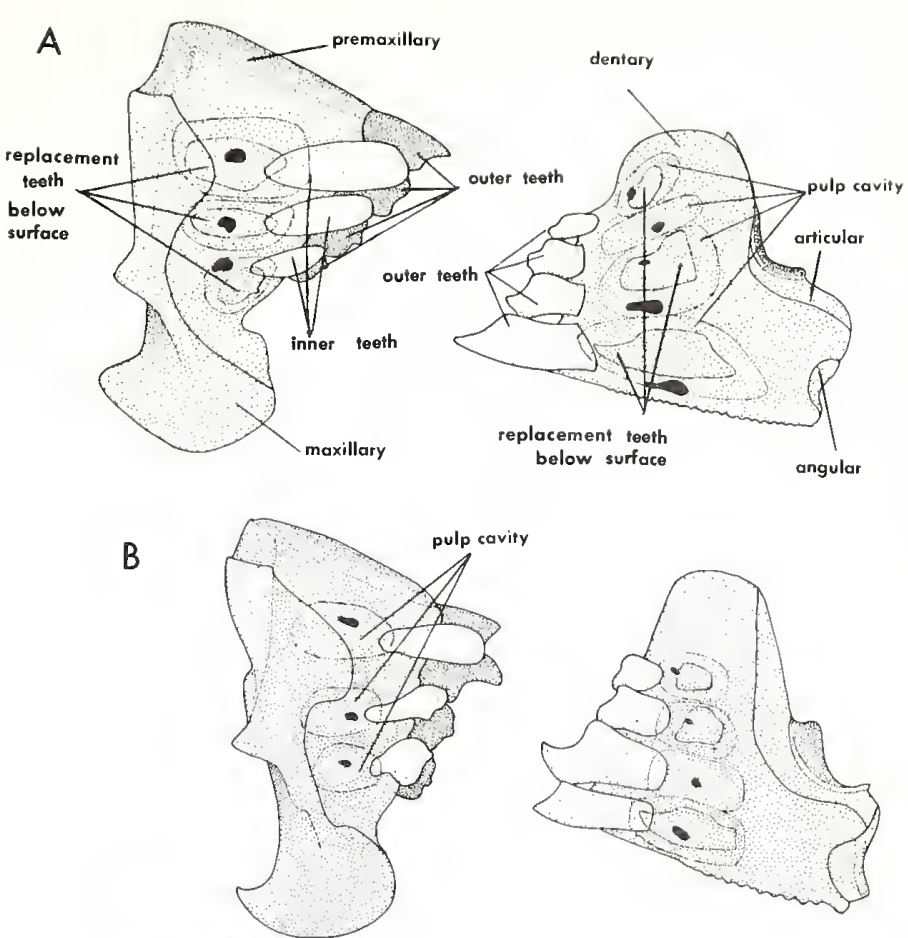

C
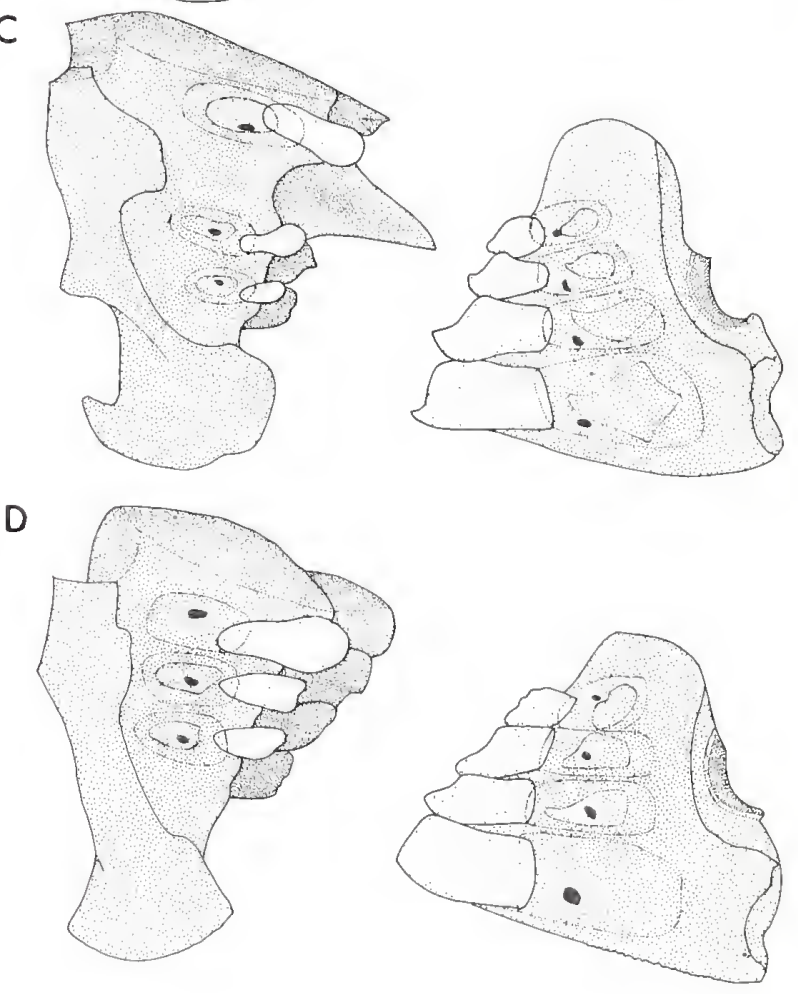

Figure 67.-Dentition of representative balistids: A, Balistes polylepis, $56.1 \mathrm{~mm}$ SL, Galapagos; B, Xanthichthys lineopunctatus, $181 \mathrm{~mm}$ SL, Hawaii; C, Odonus niger, $173 \mathrm{~mm}$ SL, New Guinea;

D, Melichthys niger, $147 \mathrm{~mm} \mathrm{SL}$, locality unknown. 
with dorsal end of latter" would seem to describe a modified tympanal scale.

The two Recent genera which lack large tympanal scales, Canthidermis and Xanthichthys, are otherwise very different in structure and surely are not closely related. It is simply impossible to say precisely at present whether the generalized condition of balistids is the presence of enlarged plates which have subsequently been lost by a few genera, or whether the basal balistids lacked specialized tympanal scales which were subsequently developed by most genera. I think the former view to be the more likely, and that the development of specialized tympanal scales aiding in and refining sound production was one of the major features of the basal balistids which led to their differentiation from the triacanthids, concomitant with the reduction of the spiny dorsal fin and development of a complex locking mechanism of the first two spines, the reduction of the pelvic fin and modification of the pelvis into a stout rotatable shaft, and increased sturdiness of the skull to support the nonprotrusible jaws with a change in dentition.

In this view, Canthidermis lacks specialized tympanal scales simply because all of its scales have become relatively small and nonoverlapping, perhaps associated with the more flexible body covering necessary for lateral flexion of the caudal peduncle in a strong swimming and truly oceanic species. Xanthichthys, on the other hand, seems closely related to Odonus, which has large specialized tympanal scales, and I have no explanation for the lack of them in Xanthichthys, except that in Xanthichthys the scales in the tympanal region are smaller than those surrounding them, but they are not overlapping and are just about as flexible as those of the tympanal region of other balistids. It would seem that
Xanthichthys has not truly lost the specialized tympanal scales, but simply reduced their size. It would be of interest to know if the sound productions associated with the drumming of the pectoral fin against the side of the body (and thereby against the anterolateral end of the swim bladder) differ in Canthidermis and Xanthichthys from other balistids.

If the supposed absence of a preocular groove in the fossil species of balistids, of which relatively complete specimens are known only from the Oligocene, is correct, then that structure is a more recent acquisition by all genera except Balistapus and Rhinecanthus. The latter two genera are very closely related, differing only by Rhinecanthus having a lower supraoccipital crest, a much smaller third dorsal spine and a more constricted caudal peduncle with fewer rows of spine bearing scales. In fact, Balistapus could serve as a model for a generalized balistid. The mouth is terminal, the third dorsal spine well developed, the large specialized tympanal scales well developed, the encasing scales at the end of the pelvis with great flexibility (although with a slightly reduced number of scales in one of the segments) and wellcusped teeth at all sizes and the teeth of decreasing size laterally in both jaws. It is possible, but hardly proven here, that Balistapus is a relative generalized balistid and that its lack of a preocular groove may also represent the generalized condition.

One final character must be considered, that of the degree of development and massiveness of the supraoccipital and epiotic supports of the basal pterygiophores of the spiny dorsal fin. Is a high sturdy supraoccipital crest, such as found in most balistids, the generalized condition? In the early development of balistids from triacanthids, it is reasonable to expect that the process of conversion of the domelike uncrested supraoccipital of

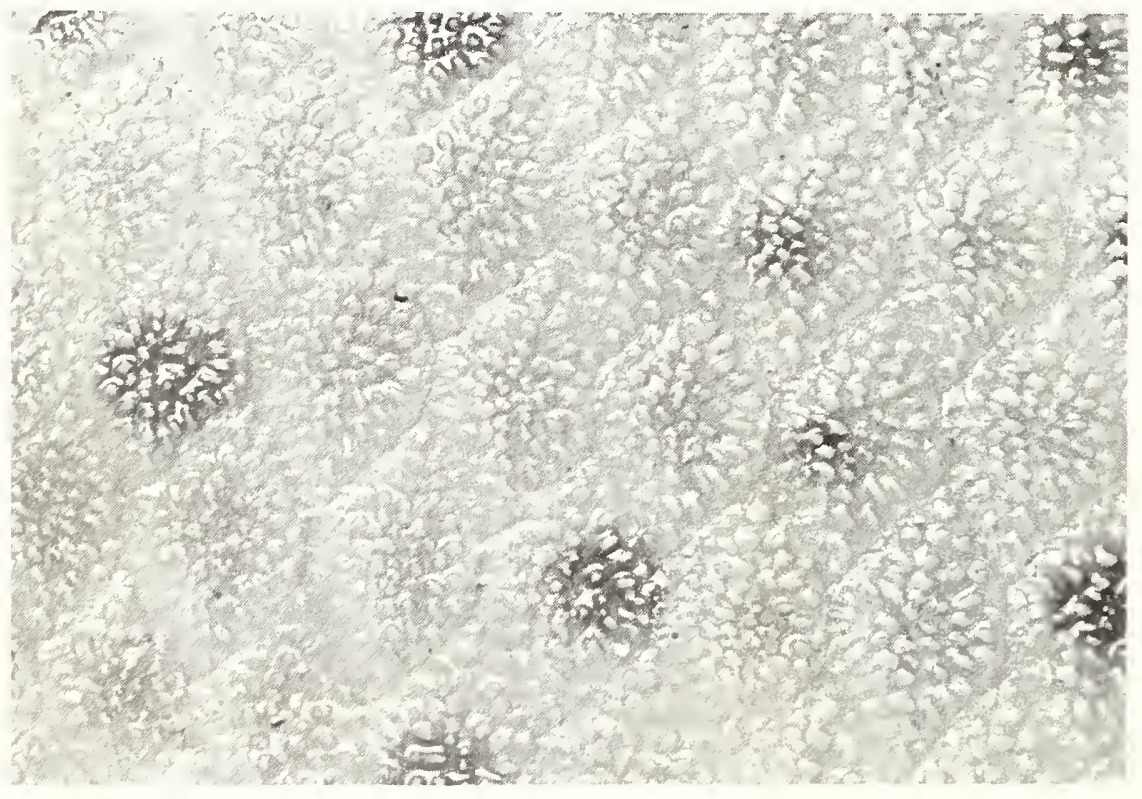

Figure 68.-Scales just above tip of pectoral fin of Balistoides viridescens, $114 \mathrm{~mm} \mathrm{SL}$, Indonesia, to show the hexagonal shape often obtained by the scale plates in adults as the anterior and posterior edges of the rhomboid plate become flattened. 
triacanthids into the flatter and crested supraoccipital of balistids passed through a low crest stage such as is found today in Rhinecanthus before achieving the higher and sturdier buttressing crest found in most other Recent balistids. However, the low crest of Rhinecanthus could well be a secondary reduction of the crest from a high crested ancestral stock and simply be associated with the low nape of Rhinecanthus.

In short, the generic relationships within the Balistidae are not clear on the basis of the osteological data presented here, nor are many of them clear on the basis of external features. However, Xanthichthys and, especially, Odonus, are two of the most specialized genera and are probably closely related, the former ancestral to the latter. Canthidermis is also specialized, in a much different way, for an oceanic existence, the scales all being reduced in size and nonoverlapping and the body thus more flexible. Canthidermis is also specialized in having the full ossification of the skeleton much delayed, as well as in having the most rudimentary pelvic apparatus among the balistids. Instead of the firm ossification and sturdiness of the skeleton of all other balistids, the bones of specimens of Canthidermis under about $100 \mathrm{~mm}$ remain poorly ossifed and slightly spongy, although not to the extent found in the molids Mola and Masturus, but less ossifed than in the molid Ranzania. Only in fully adult specimens of Canthidermis is the skeleton fully ossified. The pelvic fin ray of Canthidermis is discussed below.

Balistapus and Rhinecanthus are also obviously closely related, as explained above, the latter probably being a specialized offshoot of the former. Likewise, Balistes (including Nematobalistes and Verrunculus, properly synonymized with Balistes by Berry and Baldwin 1966:435) and Pseudobalistes seem closely related, the latter a derivitive of the former with reduced cheek scales and preocular groove. Sufflamen may be related to Balistes, and Melichthys to Xanthichthys, but Abalistes and Balistoides are not clearly (to me) related closely to any of the groups of genera discussed above. I suppose that the basic question is whether the Balistes-like genera are more generalized than the Balistapus-like genera. I suspect the latter are the more generalized, but have no firm evidence of it.

Fraser-Brunner (1935a:660-661) thought Canthidermis to be the most primitive genus, "since there is no evidence that it is derived from any of the forms having ossified plates behind the gill opening." With this I do not agree, Canthidermis simply having lost the overlapping body scales found in all other genera, but from what stock Canthidermis is derived I cannot say, although I would suspect a Balistes-like origin.

Fraser-Brunner thought Abalistes to be a slightly modified derivative of Balistes on a line leading to Balistoides, Sufflamen, and Balistapus, with Rhinecanthus a derivative of the latter. He also thought Balistoides to be ancestral to Pseudobalistes on the one hand and to Melichthys and hence Xanthichthys on the other, with Odonus a derivative of Melichthys. I can add nothing to these unproven speculations.
Relationship to the Monacanthidae.-Balistids are clearly derived from triacanthids, with the major changes involving the sturdier, stronger skull structure associated with the nonprotrusible jaws with less massive crushing teeth, and heavier scales with less body flexibility but more delicacy of swimming movements associated with the sacrifice of speed for defensive features, including the development of the complex locking mechanism of the first two spines and a rotatable pelvis. Balistids are likewise clearly ancestral to monacanthids, the major changes involving a reduction in massiveness of the skull associated with the thinner, more sharply edged teeth serving a more nibbling function with finer food and thinner, less regularly overlapping scales associated with a sacrifice in defensive features such as the reduction of the spiny dorsal fin and less swimming strength for a more secretive and often cryptic existence, blending into the environment rather than standing out conspicuously from it. The more secretive monacanthids also tend to be much smaller in size than balistids, which are among the largest of plectognaths (exclusive of molids), except that the four species of Alutera all reach sizes in excess of $200 \mathrm{~mm}$; one, A. monoceros, reaching over $500 \mathrm{~mm}$ SL (Berry and Vogele 1961).

The more important osteological differences between the balistids and monacanthids, as pointed out in the comparative diagnosis of each, are mostly concerned with the reduction in size and forward displacement of the spiny dorsal fin and its basal pterygiophores and the features associated with the more delicate teeth and jaws and their supporting structures.

The heavy crested supraoccipital of balistids supporting the front end of the first basal pterygiophore of the spiny dorsal fin becomes, at least posteriorly, a delicate flattened plate in monacanthids upon which the ventral surface of the basal pterygiophore rests, at least in part. However, a few genera of monacanthids retain a vestige of the large vertical crest of balistids as a smaller crest on an anterior prolongation of the bone above the orbit, the crest supporting the ventral edge of the vertical platelike anterior region of the basal pterygiophore. The deep hole in the balistid skull surrounded by the supraoccipital and epiotics in which is held the short anteroventral shaft of the first basal pterygiophore is lost in monacanthids, and the epiotics in the latter no longer have the dorsal extension that in balistids helps buttress the apex of the skull for the support of the anterior end of the first basal pterygiophore.

The second basal pterygiophore of balistids supporting the third spine is lost by monacanthids along with the third spine and the supraneural strut that in balistids supports the posterior end of the carina against the vertebral column. The second dorsal spine of balistids becomes much reduced in size in monacanthids, but the locking mechanism, involving only the basal regions of the two spines, remains the same. The massive first dorsal spine of balistids becomes more slender in monacanthids, and usually more highly ornamented with spinules and barbs. However, the first 


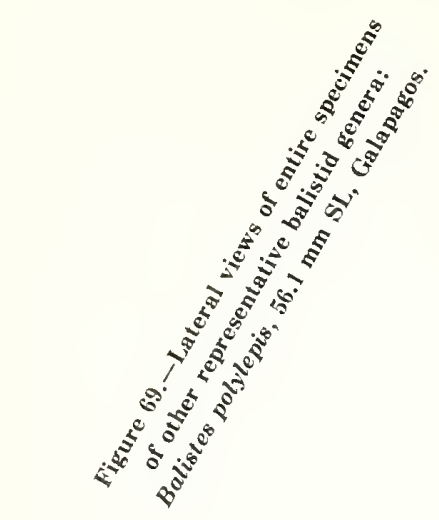




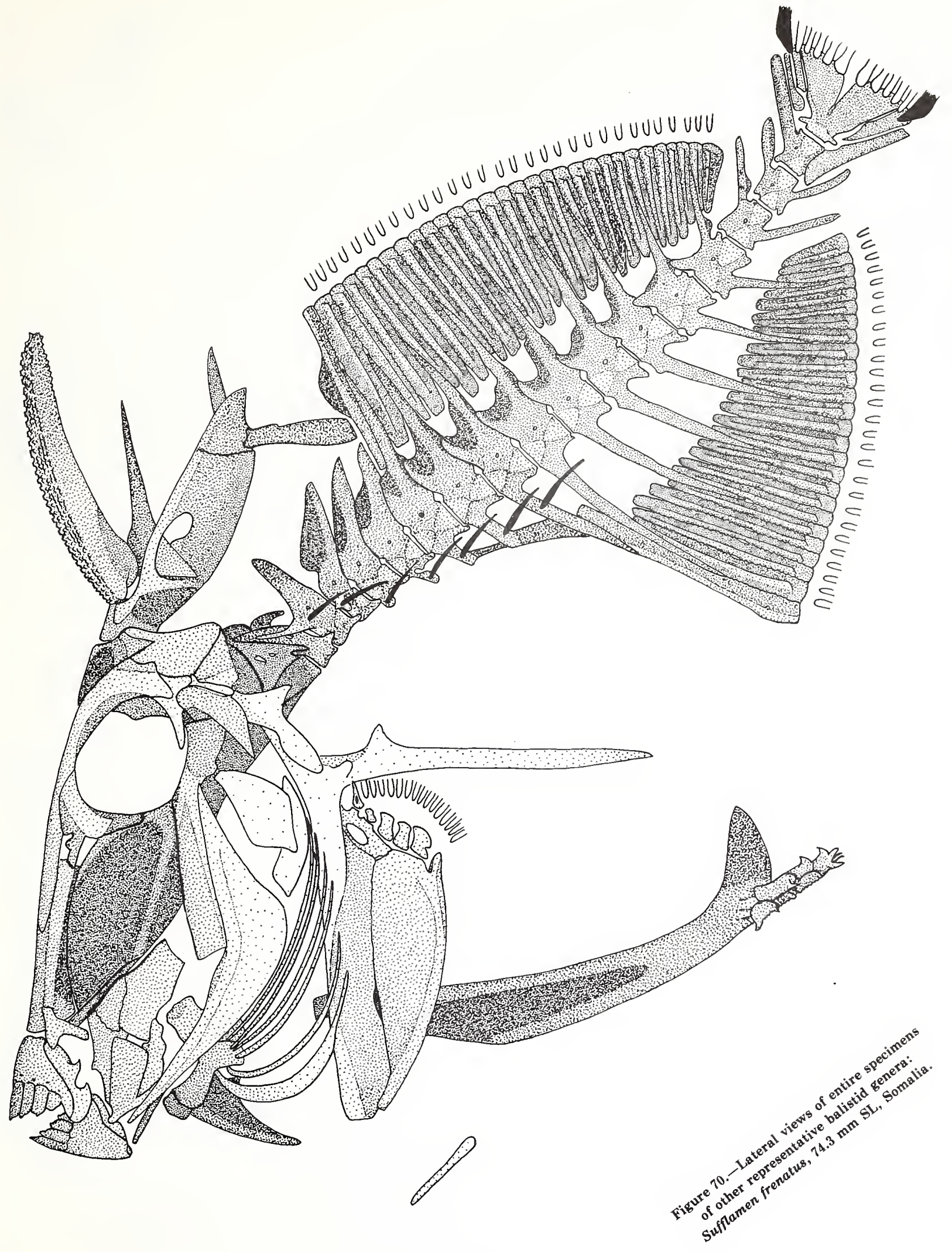




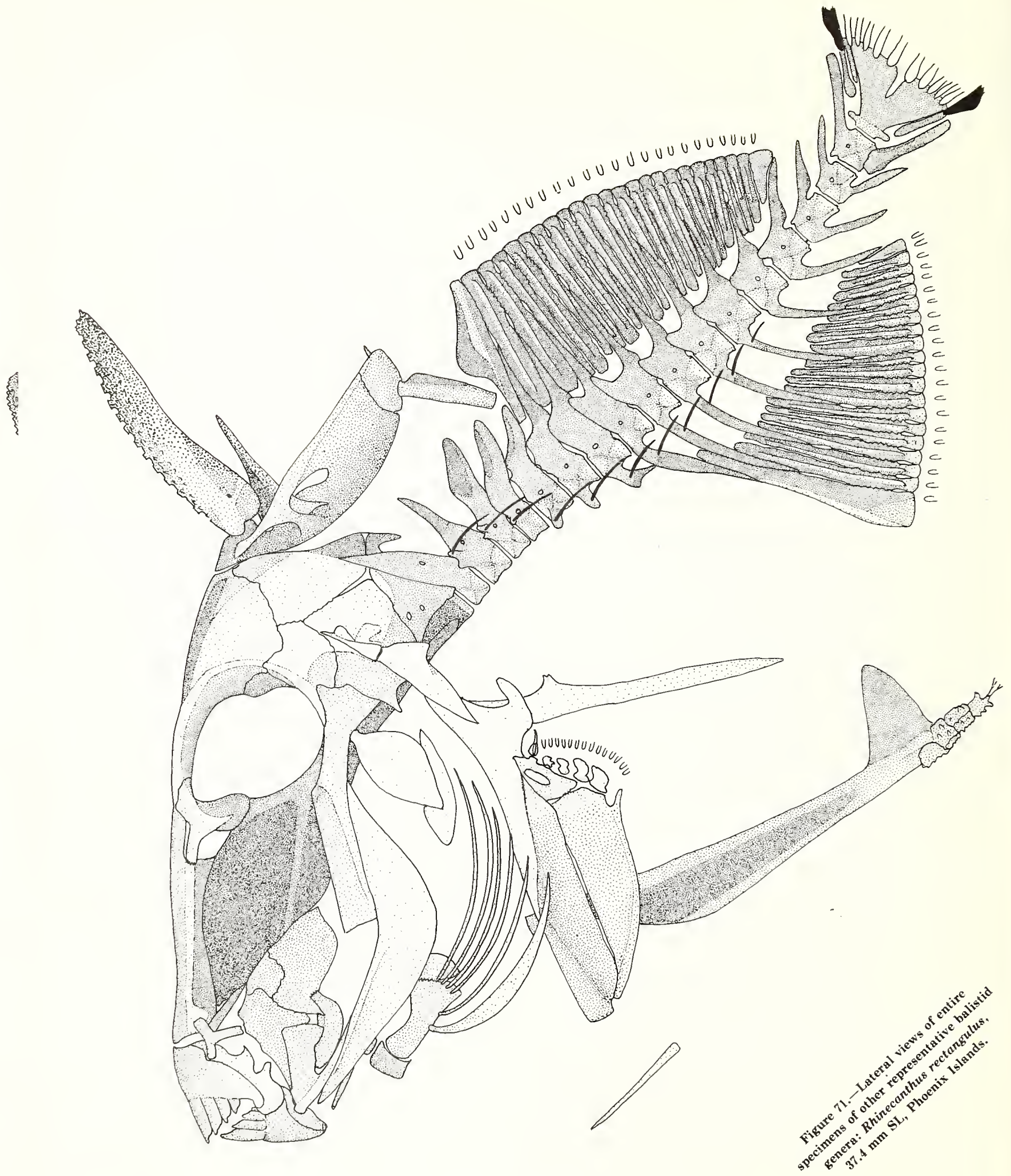




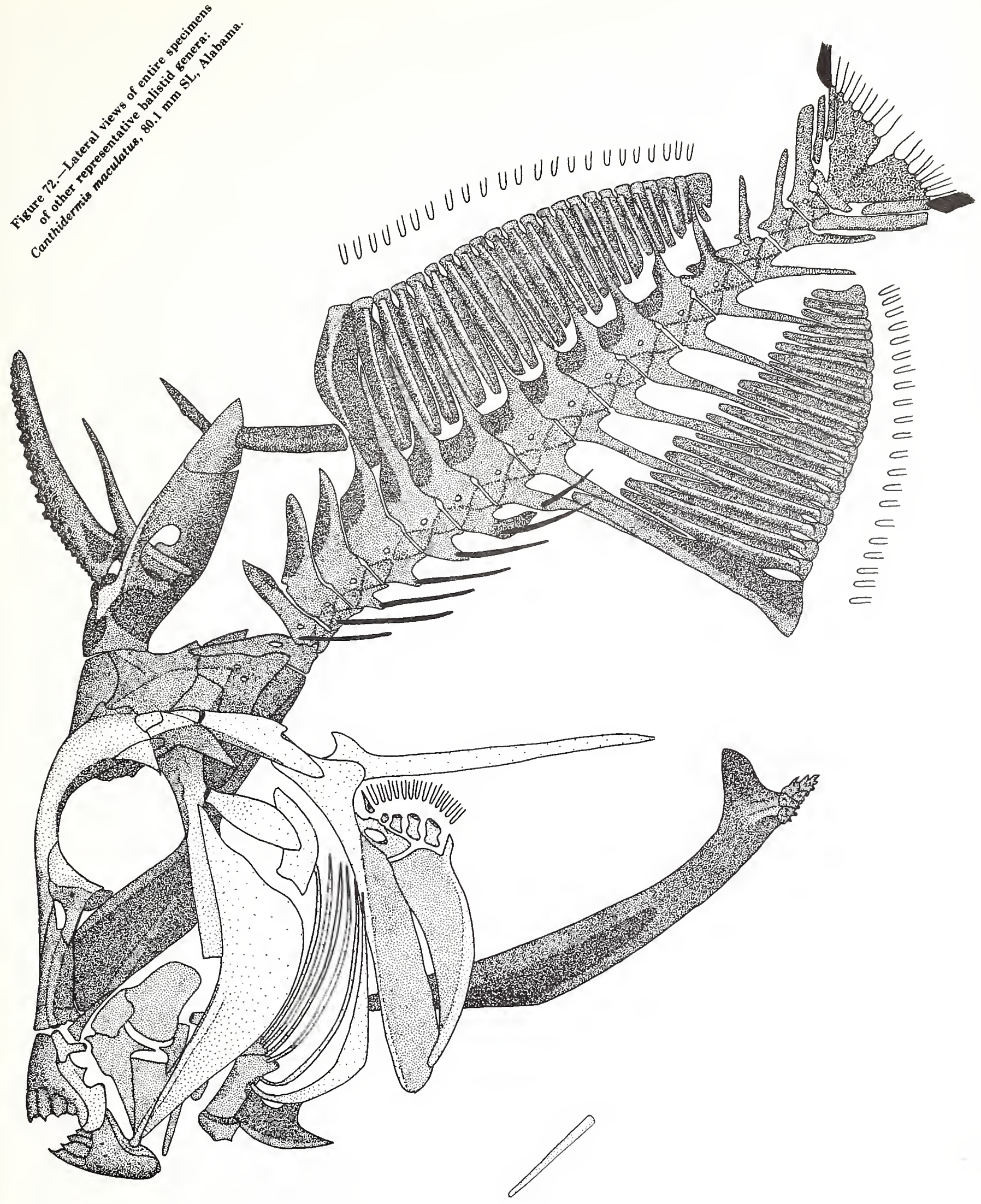




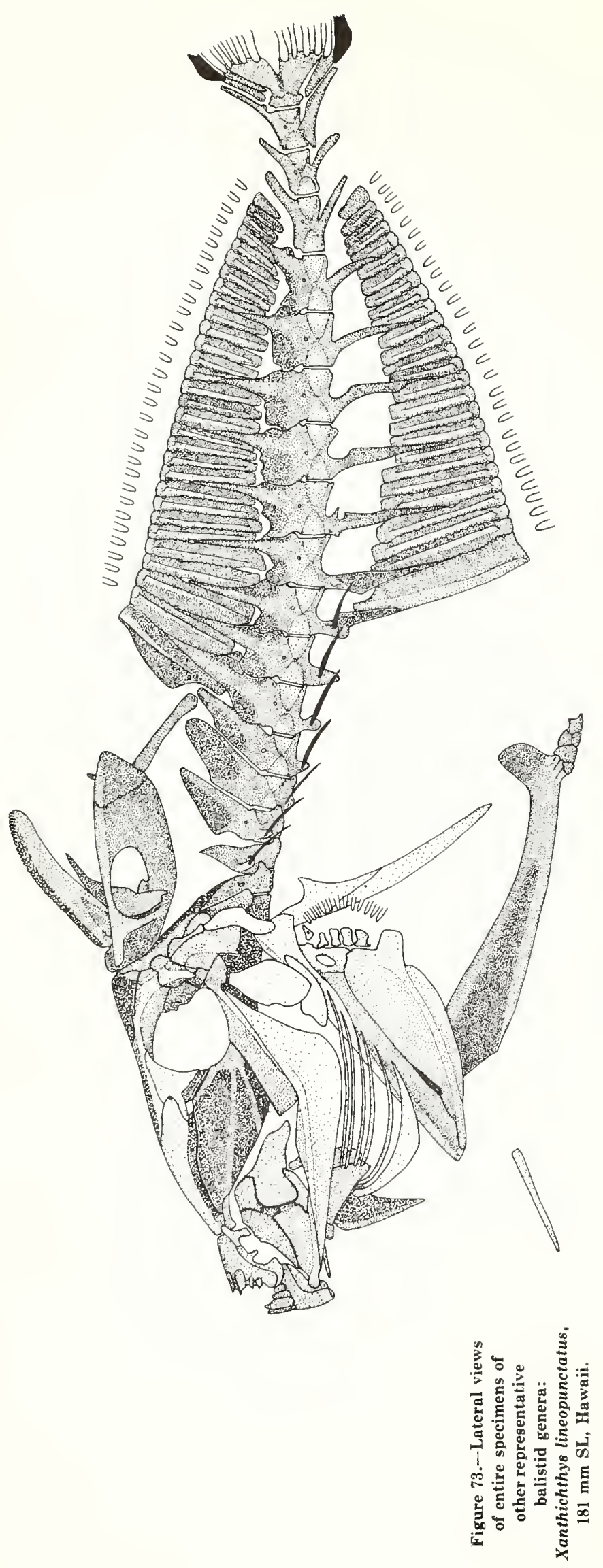

dorsal spine in some balistids (especially Rhinecanthus) has its anterior face well ornamented with relatively large barbs, while some monacanthids have the first dorsal spine absolutely smooth. The first dorsal spine of balistids serves, among other defensive functions, to wedge the fishes into holes and cavities that they seek out in danger and in rest. I suspect that the first dorsal spine in most monacanthids is used less in this manner and more as a rapid vibrator in communication during agonistic and breeding behavior. In some monacanthids the spine can be vibrated back and forth with such speed that it blurs before the eyes.

The typical crushing dentition of balistids has been converted in monacanthids to more of a nibbling form, while the massive supporting structures of the balistid jaws give way in monacanthids to a much more delicate suspensorium, the palatine being reduced in size and less intimately connected with the ectopterygoid, and the ethmoid and parasphenoid far less massive. The pharyngeal apparatus of balistids is changed in monacanthids by the loss of the suspensory pharyngobranchial, the loss of teeth on the fifth ceratobranchial, and the usual loss of the second branchiostegal ray.

A balistidlike pelvis is found in the more generalized monacanthids, although it usually is not quite so massive as in balistids. However, the main difference between the pelvic apparatus in balistids and generalized monacanthids is in the reduction in the size of the rudimentary fin ray (or spinous element) at the end of the pelvis and of the number of series of specialized scales surrounding it. In all balistids there are four series of encasing scales, and in all but Canthidermis these series have a dorsoventral flexibility. In the great majority of balistids the rodlike ossification extending posteriorly from the end of the pelvis, representing a compound formed from a right and left rudimentary and highly modified fin ray or spine (see Tyler 1962b) of the otherwise absent pelvic fin, exits through a foramen in the fourth and last segment of encasing scales to protrude to the exterior. The compound rod usually is branched distally, although it has lost its segmentation. This is the condition found in the various species examined of Balistes, Balistoides, Abalistes, Hemibalistes, Balistapus, Rhinecanthus, Sufflamen, and Odonus. Of the two species of Xanthichthys examined, the ray is like that in most other balistids in $X$. ringens, but in $X$. lineopunctatus the ray is shorter, and, while branched distally, it does not protrude to the exterior and there is no foramen in the last series of encasing scales in the single large $(181 \mathrm{~mm})$ specimen examined. Since the ray itself is similar in $X$. ringens and $X$. lineopunctatus other than the shorter distal portion in the latter, it is possible that small specimens of $X$. lineopunctatus have the ray protruding through a foramen which eventually closes over while the distal portion of the ray is resorbed. However, I have no small specimens of the relatively rarely collected $X$. lineopunctatus to examine for this. In both of the two species of Melichthys examined the finray element is a large cone-shaped ossification representing only the anterior end of the element as found in most 

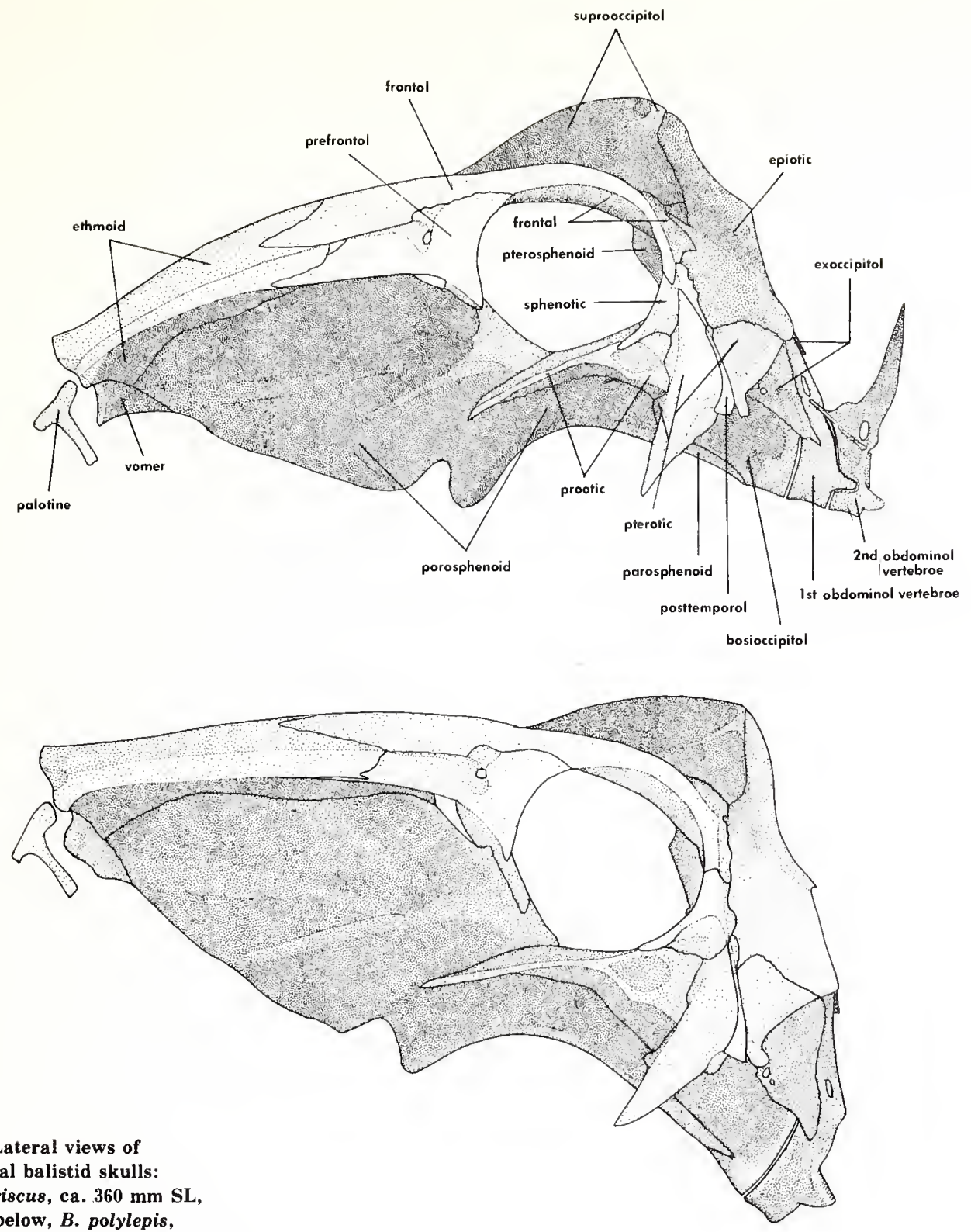

Figure 74.-Lateral views of relatively normal balistid skulls: above, Balistes capriscus, ca. $360 \mathrm{~mm} \mathrm{SL}$

Gulf of Mexico; below, B. polylepis, ca. $390 \mathrm{~mm}$ SL, Mexico.

other balistids. It does not project to the exterior and there is no foramen in the last series of scales. In Melichthys the encasing scales are flexible in young specimens but tend to become less flexible in large adults (Berry and Baldwin 1966). In Canthidermis, in which the encasing scales are only slightly flexible even in young specimens and more or less immovable in large adults, the fin-ray element is even more reduced than in Melichthys, being only a small conelike ossification at the end of the pelvis which is far too short to protrude to the exterior even if a nonexistant foramen in the last series of encasing scales were present.

In the more generalized monacanthids there are three series of encasing scales, and there is always at least one region of great dorsoventral flexibility between them. One of the encasing scale series of balistids has been lost, but the flexibility retained, as is a dorsal lobe of the pelvis to strengthen the support of the modified enlarged scales of the distensible skin between the end of the pelvis and the anus. In these generalized monacanthids the fin-ray element is much more rudimentary than in balistids, and, in contrast to the single rodlike piece of balistids (except a stubby cone in Melichthys and Canthidermis), the element in monacanthids is always further reduced in size and divided into a dorsal and ventral half widely separated by the plug of cartilage on which they rest at the end of the pelvis. These two splints represent only the anterodorsal and anteroventral ends of the element as found in balistids. As discussed under the anatomical diversity of the Monacanthidae, about half of the species of that family examined have the above described generalized condition of the pelvic apparatus, a 


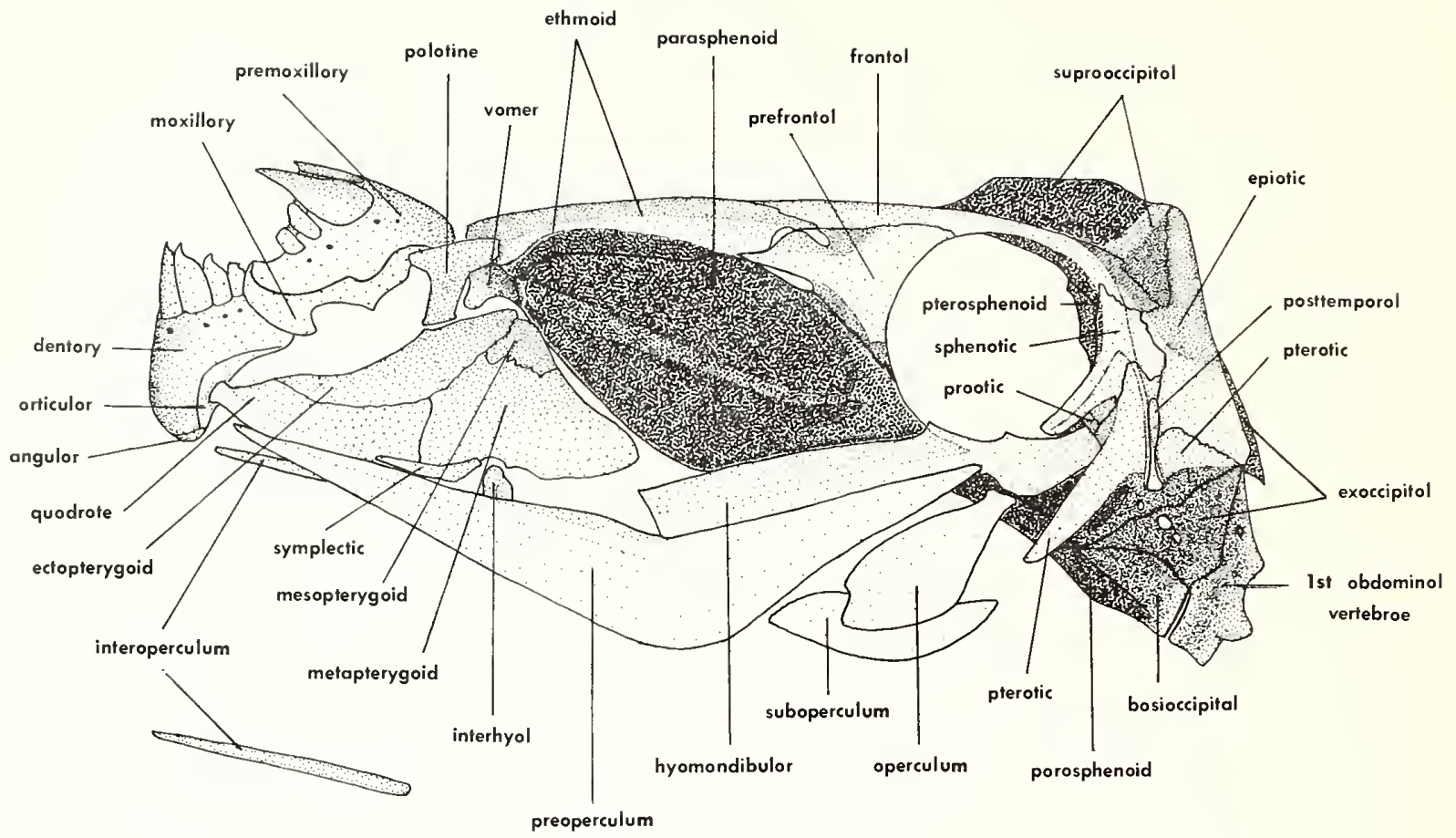

reduced but functionally similar version of that of balistids, but the other monacanthids have further reduced the apparatus variously to the point of the total absence of a fin-ray element, encasing scales and dorsal pelvic lobe. It is clear, however, that it was a balistid group with a flexible series of encasing scales that gave rise to the monacanthids, the most generalized of which also have a flexible series of scales.

Probably associated with a greater body flexibility in monacanthids, the constant $7+11=18$ vertebral formula of balistids is changed in monacanthids by an increase of at least one vertebra in the caudal series, and often more. In balistids the basal pterygiophores of the soft dorsal and anal fins bear a flange for muscle attachment along their lengths. This is true also of monacanthids, but in the latter family the crest is further elaborated, particularly distally, where it is especially expanded laterally into a more or less hooklike process partially separating the inclinator, erector, and depressor muscles of each fin ray from those of the preceding and succeeding rays. The distal pterygiophores are much less different between the two groups. Those of most balistids, like their triacanthid ancestral group, have the right and left halves fused into a single piece, although far posteriorly in the soft dorsal and anal fins the right and left halves may remain separate. The distal pterygiophores of balistids may also be expected to be in separate halves in very young specimens. Of the

Figure 75.-Lateral view of most specialized balistid skull and suspensorium: Odonus niger, $173 \mathrm{~mm}$ SL, New Guinea.

balistids examined, only Balistes polylepis, B. capriscus, B. veluta, and Sufflamen verres have most of the distal pterygiophores as separate halves, but the specimens of these are all relatively small, and the distal pterygiophores can be expected to be fused into a single piece in adult specimens of these species. Only in Canthidermis maculatus do the distal pterygiophores remain as separate halves even in large specimens. In an $80.1 \mathrm{~mm}$ specimen nearly all the distal pterygiophores have separate halves, while in a large $217 \mathrm{~mm}$ adult those in approximately the anterior one-third of the soft dorsal and anal fins have the two halves fused into a single piece while more posteriorly they remain separate. The retention of mostly separate halves in the distal pterygiophores of Canthidermis is probably related in some way both to its oceanic existence and late develop. ment of full ossification.

In the derived monacanthids, nearly all of the distal pterygiophores are single pieces even in small specimens, and always so in large specimens. 


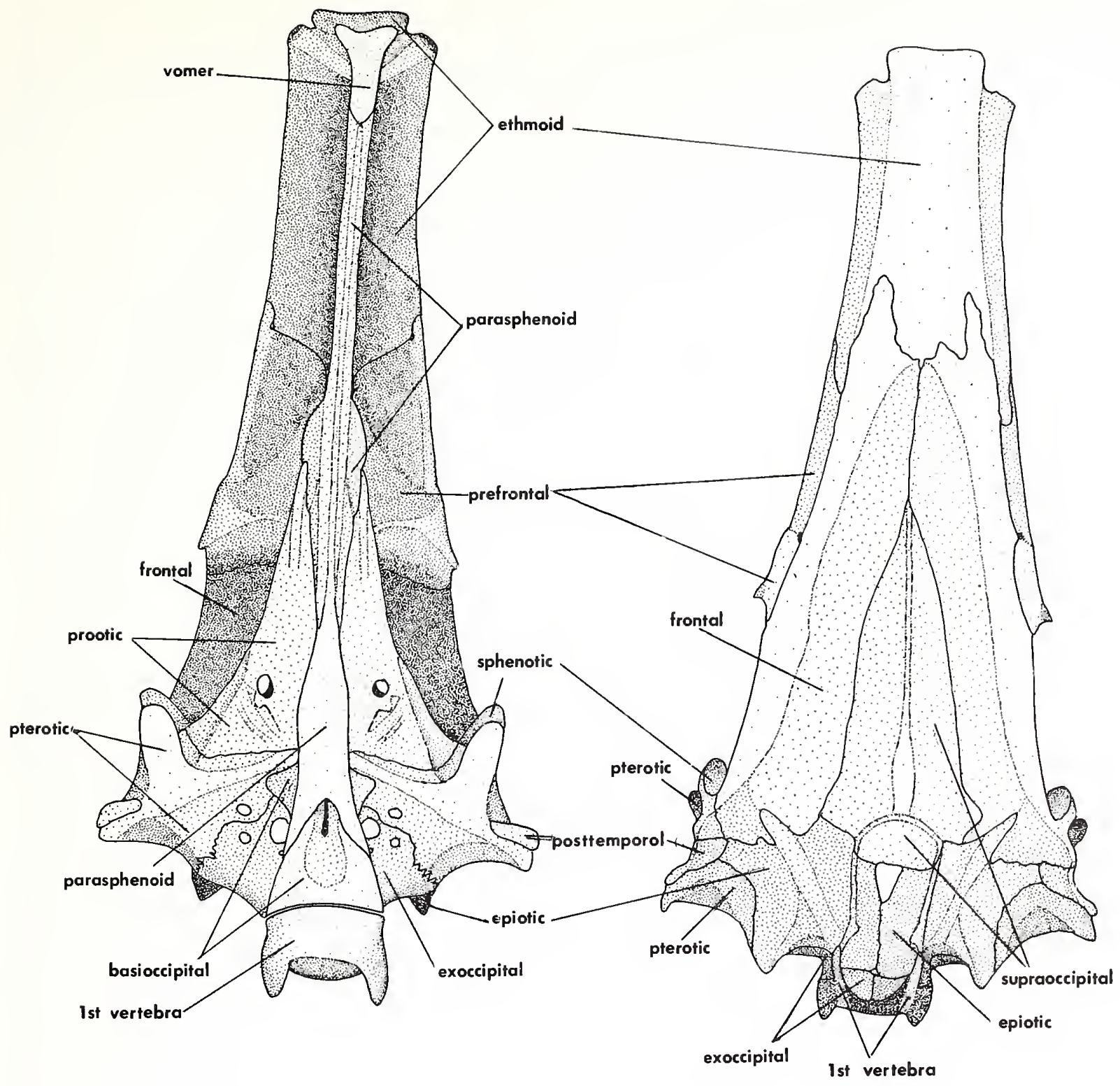

Figure 76.-Balistes polylepis: ventral (left) and dorsal (right) views of skull, ca. $390 \mathrm{~mm}$ SL, Mexico.

Relationship to the Triacanthidae.-The presence in balistids of such features as a well-developed spiny dorsal fin, a well-developed pelvis with a pelvic fin (even though highly modified), discrete teeth in the jaws, a caudal fin with 12 rays, supported by a complex with a free epural and parhypural, and a free palatine obviously relates the balistids to the triacanthoids, while a number of characteristics shared by balistids and triacanthids but not by triacanthodids indicates that the triacanthids are the most closely related ancestral group of the balistids.
The main features of similarity between balistids and triacanthids, followed by the dissimilar condition in triacanthodids, as mostly summarized from Tyler (1968), are: 1) large heavy incisorlike teeth in an outer series and more molariform teeth in the inner series versus relatively smaller, conical to wide and thin in an outer series and, when present, of the same type in an inner series; 2) hyomandibular with a well-developed crest across its outer surface versus no such crest; 3 ) pterotic with a large ventral flange over the posterodorsal end of the hyomandibular versus no such flange; 4) operculum 
expanded in the middle about equally anteriorly and posteriorly versus triangular in shape; 5 ) basihyal absent versus present; 6) pterosphenoids suturing to one another in the midline of the posterior wall of the orbit versus not in contact there; 7) spiny dorsal fin base much shorter than soft dorsal fin base (except Protacanthodes, the bases about equal) versus much longer (except Eoplectus, the bases about equal); 8) epipleurals relatively thick versus thin; 9 ) basal pterygiophores of soft dorsal and anal fins with lateral flanges along their lengths and sutured to one another distally versus without flanges and not sutured; 10) a single free hypural (probably more in Protacanthodes) versus three or more free hypurals; 11) uppermost pectoral fin ray very short, the lateral half smaller than the medial, versus moderately short, the two halves of about the same size. It is extremely unlikely that this great array of similarities between balistids and triacanthids in con-

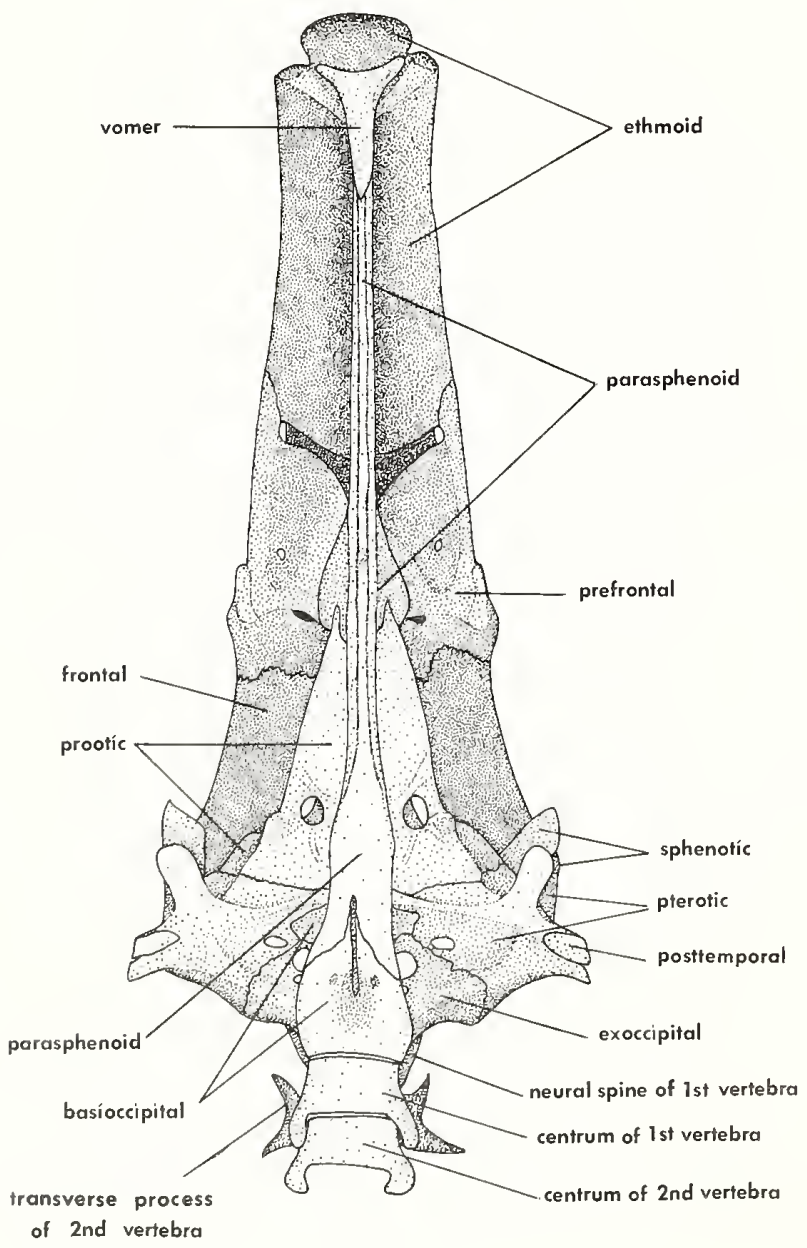

Figure 77.-Balistes capriscus: ventral view of skull, ca. $360 \mathrm{~mm} \mathrm{SL}$, Gulf of Mexico. tradistinction to triacanthodids has been arrived at independently.

There are only three important ways in which balistids are more similar to triacanthodids than to triacanthids: 1) the parhypural is free; 2) the haemal spine of the penultimate vertebra is autogenous; 3) and the caudal peduncle is relatively shorter in balistids and triacanthodids than in triacanthids, except Protacanthodes. These specializations of the Recent triacanthids are associated with their more rapid sustained swimming in comparison to balistids and triacanthodids, and it must be assumed that balistids evolved from triacanthids at a level of organization less specialized than that of the Recent species, probably at about the level of Protacanthodes.

Although balistids (and, by implication, the monacanthids and ostracioids, which see) are clearly derived from triacanthids, the number of ways in which balistids differ from triacanthids is impressive. Most of these differences are associated with the development in balistids of: 1) a locking mechanism of the first dorsal spine through the agency of the second spine; 2) an even heavier skull structure for greater buttressing of nonprotractile jaws adapted to an even heavier crushing or biting function of the teeth than found in triacanthids; 3 ) a rudimentary but complex pelvic fin-ray element; 4) heavier scales and less flexible body for less powerful sustained swimming but with greater delicacy of movement.

The principal differences between balistids and triacanthids, summarized and modified from Tyler (1968), are as follows: There are usually six, and rarely only five, dorsal fin spines and usually four, rarely three or five, basal pterygiophores supporting them in triacanthids, while in balistids there are only three spines supported by two basal pterygiophores, although the supraneural element of balistids is homologous to the third basal pterygiophore of triacanthids, as discussed subsequently.

In triacanthids there is an autogenous mechanism of locking the first dorsal spine in an erected position involving the apposition of its roughened ventral end against the similarly roughened dorsal surface of the first basal pterygiophore below it, the first spine having an anteroposterior canal through its base which rotates around a high dorsal pronglike flange on the basal pterygiophore, the locking mechanism not directly involving the second spine. In balistids the locking of the first spine is not autogenous, depending on a roughened area on the slightly convex anteroventral surface of the second spine fitting into a roughened medial concavity on the posteroventral surface of the first spine, while the first spine has no anteroposterior canal through it and the basal pterygiophore no pronglike flange.

In triacanthids the first basal pterygiophore is of simple structure, being a stout vertical shaft articulated between the lower rear of the skull and the neural spine of the first vertebra, except in the Oligocene Cryptobalistes in which it has only a short ventral shaft and articulates high on the rear of the skull and apparently out 
of contact with the first vertebra. In balistids the first basal pterygiophore is a highly complex, horizontally elongate structure articulated high on the rear of the skull by a short ventral shaft. The pterygiophore features a concave dorsal surface in the region of the first two spines that opens laterally through the wall of the pterygiophore to admit the muscles controlling the locking mechanism, there being nothing similar to this in triacanthids.

In triacanthids the second basal pterygiophore, bearing the third spine, is relatively small, has a relatively flat dorsal surface, and is not sutured to the first basal pterygiophore, while in balistids it is relatively large, deeply concave dorsally, and is firmly sutured to the first. The third basal pterygiophore of triacanthids, bearing the fourth spine, is probably the pterygiophore modified in balistids into the supraneural strut bracing the rear end of the carina (formed by the first two pterygiophores) against the tip of the neural spine of the fifth vertebra and the anteroventral edge of the first basal pterygiophore of the soft dorsal fin.

The articulation of the carina high on the rear of the skull in balistids has drastically changed the configuration of the skull in this region, but it still bears evidence of the triacanthid ancestry of the balistids. In both the triacanthids and balistids the posterior surface of the supraoccipital is concave, and while the supraoccipital of balistids is so modified that it is no longer a simple dome, it does exclude the epiotics from meeting one another on the dorsal surface of the skull, and the epiotics contact the frontals, just as in triacanthids and their ancestral hollardiin triacanthodids, and not as in the triacanthodin triacanthodids. The face that one Oligocene triacanthid (Cryptobalistes) has the otherwise triacanthidlike spiny dorsal fin articulated high on the rear of the skull by a short ventral shaft, even though the more numerous basal pterygiophores are small and do not form a carina, and there is neither a supraneural strut nor a locking mechanism between the first two spines, shows the potentiality and preadaptation of the triacanthids to give rise to the balistid-type spiny dorsal fin and pterygiophores.

In triacanthids the premaxillary pedicels are well developed and help allow the protusibility of the upper jaw, while the premaxillary and maxillary are movably articulated to one another through fibrous tissue. In balistids there are no premaxillary pedicels, the upper jaw is not protrusible and the premaxillary and maxillary are immovably held to one another, often by suturing. The palatine in triacanthids is a flat squarish bone with an anterior prong articulating with the deeply recessed dorsolateral surface of the maxillary, while in balistids the palatine is $\mathrm{T}$-shaped, the anterior end of the cross bar articulated with a slight concavity on the dorsolateral surface of the maxillary. In triacanthids there are usually five teeth in an outer series in each half of each jaw, internal to which are one or two teeth in each half of the upper jaw and one in each half of the lower jaw. In balistids there are always four teeth in an outer series in each half of each jaw, and three inner series teeth in each half of the upper jaw but none in the lower jaw. Thus, balistids have slightly reduced the number of teeth as found in triacanthids, and also modified their form. In triacanthids the edges of the teeth are straighter than in the typically notched teeth of balistids, and while the size of the teeth in balistids is usually larger than that of triacanthids, they are thinner and less massive, except in most large adult balistids in which the teeth become just as massive as in triacanthids. The teeth in the balistids Canthidermis, and, to a lesser extent, Odonus and Xanthichthys, do not tend to become so massive in large adults.

In triacanthids the pelvis is shaftlike only posterior to the level of the pelvic spines in about the middle of its length and cannot be rotated around its anterior articulation with the cleithra. In balistids the pelvis is shaftlike throughout its length and can be rotated in a vertical plane around its anterior articulation with the cleithra, while the pelvic fin is represented by a rudimentary but complex structure representing the fused fins from each side at the posterior end of the pelvis, surrounded by enlarged encasing scales. Whether this complex fusion product of the pelvic fins represents the spines or rays of triacanthids is problematical. One suspects that because the fin rays in triacanthids are relatively rudimentary and often lost while the spines are always well developed, that, in the process of reduction of the pelvic fin from that of triacanthids to that of balistids, the rays would be irrevocably lost early in the process, leaving the spine alone to become further reduced in size and eventually fused with its opposite member at the rear of the pelvis. As the spine became of relatively minute size and less fully ossifed, it may have secondarily become branched distally, as in many balistids, this branching of the unstriated element perhaps not at all homologous to that of rays.

It is possible that the reduced spine migrated posteriorly along the shaftlike posterior portion of the pelvis eventually to arrive at its extreme posterior end while at the same time the anterior half of the pelvis became shaftlike and rotatable. This seems more likely to me than to account for the position of the balistid pelvic fin as a result of the loss of the shaftlike posterior half of the triacanthid pelvis at the same time that the spine was reduced and the anterior half of the pelvis was becoming shaftlike and rotatable and also greatly elongate so that the stationary spine was moved posteriorly to the anal region by the growth of the anterior half of the pelvis rather than by migration.

The shaftlike form of at least the posterior half of the pelvis in balistids, triacanthids, and hollardiin triacanthodids is additional evidence of the phylogenetic validity of their relationship.

The vertebrae of triacanthids are $8+12$, while those of balistids are $7+11$. In triacanthids there are three toothed pharyngobranchials following the toothless suspensory element, but only two toothed elements in balistids. In triacanthids the hyomandibular is supported dorsally by the prootic, pterotic, and sphenotic, but in balistids only by the prootic and pterotic. In triacanthids there is 
no prootic shelf such as is present in balistids. In triacanthids the interoperculum extends posteriorly to the suboperculum, but in balistids it is shorter and more rodlike, not extending posteriorly beyond the epihyal. In triacanthids the parasphenoid is a relatively narrow shaft in front of the orbit, but it is greatly expanded there into a thick plate in balistids. In triacanthids the vomer is larger and less concave anteriorly than in balistids, which lack the posterolateral wings that in triacanthids suture to the long forward extensions of the prefrontal (with the possible exception of Protacanthodes). In triacanthids the posttemporal is larger and more superficially held to the skull than in balistids.

The above outline of the similarities and differences between triacanthids and balistids clearly indicates that while balistids are highly differentiated from triacanthids, the latter are the closest ancestral group of the balistids, and that the level of organization of the Recent triacanthids (and their close Oligocene relatives) is too specialized in a few ways for their consideration as being ancestral to balistids. Moreover, the same line of triacanthids that gave rise to the balistids also gave rise to the aracanids, and the few features of both balistids and aracanids that are more generalized than in Recent triacanthids must have been present in the early triacanthids leading to the balistids and aracanids. These few generalized features required of the early triacanthids are: 1) a free parhypural; 2) haemal spine of penultimate vertebra autogenous; 3) caudal peduncle relatively deep and not yet elongate and highly tapered and the caudal fin not deeply forked; 4) soft dorsal fin base probably not yet highly elongate; 5) the uppermost pectoral fin ray only moderately reduced in size and the two halves still of about equal length; 6 ) the teeth not yet enlarged to massive incisors but somewhat intermediate between conical and incisorlike; 7) the prefrontal not yet with a long forward extension alongside the ethmoid sutured anteriorly with posterolateral wings of the vomer; 8) the second and third basal pterygiophores of the spiny dorsal fin not yet greatly reduced in size.

Among the fossil triacanthids, the Oligocene Acanthopleurus and Marosichthys are so like the Recent triacanthids that they are unlikely to be closely related to the line of early triacanthids giving rise to the balistids and aracanids, while the Oligocene Cryptobalistes has certain balistid features in its configuration which shows the possibility of triacanthids being able to give rise to certain balistidlike features, even though Cryptobalistes seems to have been an evolutionary dead end unrelated to the line of triacanthids which were ancestral to the balistids. The Eocene Protacanthodes, which is intermediate between the triacanthodids and triacanthids, is the only known example of the early triacanthids, and of those features of its anatomy that are exposed it is generalized enough to encompass some of the critical generalized features required of the triacanthid line leading to the balistids and aracanids as listed above.

In Protacanthodes the condition of the uppermost pectoral fin ray, the parhypural and the haemal spine of the penultimate vertebra are not known, but the caudal peduncle is relatively deep and of only moderate length and the caudal fin is rounded. These are conditions to be expected in the balistid-aracanid ancestral line, except that the caudal peduncle of Protacanthodes is probably already somewhat too long for that line. The more medial of the teeth in the jaws are large incisors with constricted distal ends, and thus somewhat notched, while more laterally the edges were relatively straighter. While the teeth in Protacanthodes may have been slightly smaller than in Recent species (except Trixiphichthys), they are probably already slightly too enlarged and incisorlike to be conveniently ancestral to those of the balistid-aracanid line, even assuming that early balistids had less massive teeth than at present and that those of early aracanids were larger and less conical than at present. The prefrontal in Protacanthodes is large and has at least a moderate anteroventral extension alongside the ethmoid, although there is no evidence that it formed a long process articulating anteriorly with the vomer, and it is better separated anterodorsally from the ethmoid than in Recent triacanthids. Thus, the prefrontal of Protacanthodes is not known to have been much more specialized than in the balistid-aracanid line, although it may have been slightly more specialized. The soft dorsal fin base in Protacanthodes is not yet greatly elongate, and the second and third basal pterygiophores of the spiny dorsal fin are still moderately large, even though the spiny dorsal fin base is much shorter than in the ancestral triacanthodids. The second basal pterygiophore articulates ventrally with the tip of the neural spine of the second vertebra and the third basal pterygiophore to that of the third, so that the articulations of both of these pterygiophores has already shifted forward relative to the condition in triacanthodids. In the line ancestral to balistids and aracanids the third basal pterygiophore would be expected to retain an articulation with a more posteriorly located neural spine, as in triacanthodids, and especially as in Eoplectus, as discussed in detail there. Thus, the second and third basal pterygiophores of Protacanthodes are already slightly too specialized to be conveniently ancestral to the condition postulated to be necessary in the balistid-aracanid line.

While Protacanthodes is by far the most generalized of the triacanthids, a number of its characteristics (caudal peduncle length, tooth size and shape, placement of third basal pterygiophore of spiny dorsal fin) are already slightly too specialized for it to have given rise to the balistids and aracanids. The divergence of the balistidaracanid line must have taken place among the early triacanthids at a slightly more generalized (that is, more triacanthodidlike) level of organization than as seen in certain anatomical regions of Protacanthodes. In this light the line of early triacanthids derived of a hollardiinlike triacanthodid ancestry diverged into one line leading with little change to Protacanthodes and to another line which after far greater change gave rise to the balistids and aracanids, the latter diverging the furthest from the common triacanthid ancestral stock, and the Protacanthodes line continuing on to give rise to the Triacanthinae and probably Cryptobalistinae as well. 
Comparative diagnosis (contrast with that of the Balistidae).-The more or less incisorlike teeth relatively more delicate, developed for nibbling, three outer and two inner on each premaxillary, and three, occasionally only two, in a single series on each dentary; pharyngobranchials consisting only of two uniserially toothed elements; fifth ceratobranchial toothless but with a series of gillrakers along its anterior edge (posterior edge of last gill slit); usually two dorsal spines, sometimes only one, the second spine, when present, not more than about one-third the length of the first, and usually much smaller, ending ventrally in delicate ventrolaterally directed prongs from either side; dorsal fin spines supported by a single basal pterygiophore, without a supraneural strut; dorsal spines and at least most of the length of the basal pterygiophore placed over the top of the skull; no lateral foramen in the basal pterygiophore to accommodate the venterolateral prongs of the second dorsal spine; at least the posterior region and usually all of the supraoccipital a flat or slightly rounded thin plate without a vertical crest and broadly overlain (only slightly in Psilocephalus) by the first basal pterygiophore above it, while in some genera an anterior prolongation of the supraoccipital above the orbit bears a vertical crest for articulation with the ventral edge of the vertical platelike portion of the anterior region of the first basal pterygiophore; posterior region of the epiotic not expanded dorsally, the medial edges of the two epiotics in contact throughout their lengths, there being no large foramen in the skull between the epiotics and the supraoccipital; palatine more or less rodlike, never distinctly $\mathrm{T}$-shaped, but sometimes with a bulge or short process on its ventral edge representing a rudiment of the long foot of the $\mathrm{T}$ as found in balistids, usually connected by a long ligament with the anterior edge of the ectoptergiod; exoccipital not meeting its opposite member in the midline above the foramen magnum, only slightly if at all protruding medially beyond the medial edge of the bifid neural spine of the first vertebra; prefrontal relatively small and delicate, articulated by fibrous tissue mainly with the frontal and sometimes, to a much lesser extent, with the ethmoid, but never directly contacting the parasphenoid; parasphenoid moderately to much expanded laterally just behind the orbit (except in the elongate Psilocephalus), the medial edge of the pterotic on the ventral surface of the skull broadly separated from its opposite member there by the basioccipital and parasphenoid; parasphenoid not expanded or only very slightly expanded dorsally in front of the orbit, only slightly if at all overlying the ethmoid and not contacting the prefrontal; the laterally expanded dorsal region of the ethmoid relatively narrow and thin, much less wide than the depth of the ventral platelike portion; ventral platelike flange of the ethmoid thin and delicate, relatively deep, much deeper posteriorly than anteriorly, and only slightly if at all overlain by the parasphenoid; posttemporal (absent in Psilocephalus) held more superficially and in a much less deep groove on the lateral surface of the pterotic; medial edge of dentary always denticulate; prootic shelf less well developed (and sometimes absent), not extending forward to the level of the middle of the orbit, except in Psilocephalus in which it reaches the front of the orbit; posterior edge of supracleithrum relatively straight and not posteriorly expanded; postcleithrum without a dorsal spur on its dorsal edge and no specialized tympanal region present; postcleithrum always a single piece; branchiostegal rays $2+4,1+4$, or $1+3$; pelvis with or without a dorsal lobe posteriorly on its dorsal surface; encasing scales at the posterior end of the pelvis in three or fewer segments, or of indeterminate number or absent, when present either flexible or fixed; a rudimentary pelvic fin element either present or absent; vertebrae 19 (usually $7+12$, sometimes $6+13$ ) or more ( 7 or $8+13$ to 23 ), up to 30 ; vertebrae
Figure 78. - Range of diversity in body form in the Monacanthidae:

A, Monacanthus ciliatus; B, Amanses scopas;

C, Brachaluteres trossulus;

D, Psilocephalus barbatus.

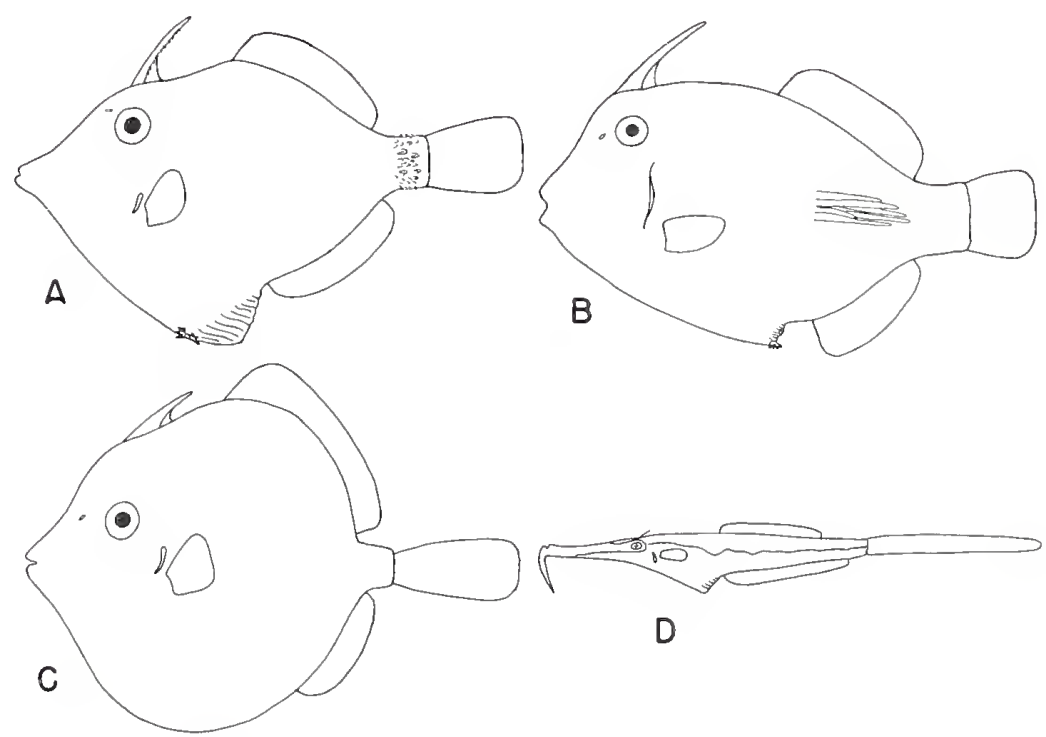


anterior to the first basal pterygiophore of the soft dorsal fin four to eight, those posterior to the last basal pterygiophores of both the soft dorsal and anal fins four to six; neural and haemal arches of the last centrum poorly developed and nearly always incomplete (complete in Brachaluteres trossulus); the last centrum with a horizontal crest for muscle attachment (reduced to a prong in $B$. trossulus); uroneurals never present; an upper free hypural occasionally absent; lateral flanges on the soft dorsal and anal fin basal pterygiophores ending distally in prominent hooklike lateral expansions, except in Chaetoderma spinosissimus and Rudarius minutus; the basal pterygiophores extending proximally relatively closely to the neural and haemal arches usually only anteriorly in the length of the series; all of the dorsal, anal, and pectoral fin rays unbranched; scales small, with thin basal plates and usually fine spinulation, the basal plates either overlapping or well separated but usually not regularly arranged; scales above the pectoral fin base unmodified; most species relatively small, adults usually being $200 \mathrm{~mm}$ or smaller, except for some species of a few genera (e.g., Cantherhines, Navodon) that have larger adults and, especially, Alutera, at least one species (monoceros) of which reaches over $500 \mathrm{~mm}$ (Berry and Vogele 1961:66).

\section{Detailed description of Monacanthus ciliatus.}

Material examined.-Twelve cleared and stained specimens, $38.3-119 \mathrm{~mm}$.

\section{SKULL.}

\section{Occipital Region.}

Basioccipital. - A short column, expanded anterodorsally; cartilage filled at its anterior and anterodorsal edges; articulates by interdigitation dorsally with the exoccipitals, anteroventrally with the prootics, and anteromedially with the overlying posterior end of the parasphenoid. The rim of the round concave posterior end of the basioccipital articulates by fibrous tissue with the concave anterior face of the centrum of the first vertebra. The ventromedial surface of the basioccipital is deeply concave throughout its length. This concave channel is mostly hidden from view by the overlying parasphenoid, but the channel opens to the exterior posteriorly at the base of the posterior bifurcation of the parasphenoid. Anteriorly the channel opens into the myodome where the anterior end of the basioccipital forms the posterolateral and posterodorsal walls of the myodome.

Exoccipital. - Cartilage filled along most of its ventral, anterior, and dorsal edges; articulates through cartilage and slight interdigitation dorsally with the epiotic, laterally through cartilage and interdigitation with the pterotic, and ventromedially mainly through interdigitation with the basioccipital. Posteriorly the exoccipitals form the lateral and ventral walls of the foramen magnum, while dorsally the foramen is closed by the epiotics. The posterior surface of the exoccipitals is firmly attached by fibrous tissue and interdigitation with the anterior surface of the bifid neural spine of the first vertebra. A short posterior process from the posteromedial portion of the exoccipital overlies the upper anterior region of the centrum of the first vertebra, this posterior extention representing the modified exoccipital condyle.

Supraoccipital. - Widest posteriorly, where its relatively flat dorsal surface is mostly obscured from external view by the large basal pterygiophore of the spiny dorsal fin, but with a long forward extension above the orbit with a vertical crest intervening between the frontals and the anterior third of the basal pterygiophore; cartilage filled along all of the edges of its posterior flattened surface; articulates dorsally by interdigitation with the basal pterygiophore of the spiny dorsal fin, posteriorly through cartilage and interdigitation with the epiotics, laterally and anteriorly, and ventrally on its an. terior prolongation, through interdigitation with the frontals, while the extreme anterior end of the anterior extension reaches to the posterior end of the ethmoid in large specimens.
Figure 79.-Monacanthus ciliatus: upper left, nasal region as seen externally (far left) and the olfactory

lamella as seen with the top of the nasal sac removed; middle left, scales from upper middle region of body, including two lateral line canal bearing scales; lower left, ventral view of encasing scales at end of pelvis (anterior to left).

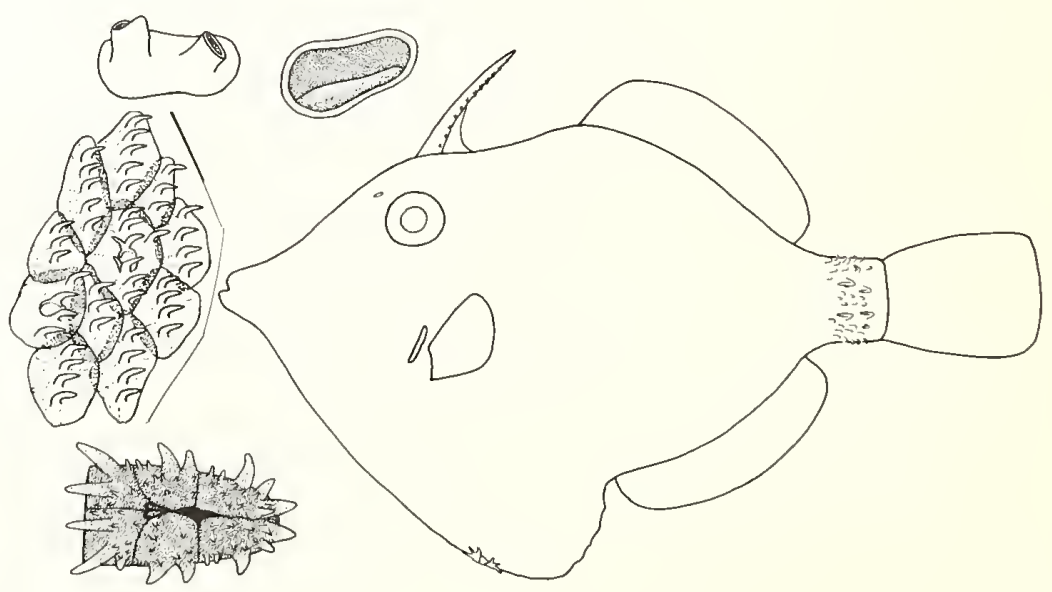




\section{Otic Region.}

Pterotic. - Cartilage filled along all of its edges of articulation with the other cranial bones; articulates through cartilage and interdigitation dorsally with the epiotic, posteriorly with the exoccipital, ventromedially on the ventral surface of the skull with the basioccipital and parasphenoid, anterolaterally with the sphenotic, laterally through extensive interdigitation with the posttemporal which overlies a portion of its lateral surface, and anteromedially in the region of the orbit by interdigitation with the prootic. The anteroventral region of the pterotic is prolonged ventrally as a shaftlike projection overlying and extending ventral to the posterodorsal end of the hyomandibular, to which it articulates by fibrous tissue. Just anteromedial to its ventral shaft the pterotic bears a deep depression which continues over the prootic and to which depression the dorsal head of the hyomandibular is held by fibrous tissue.

Sphenotic. - Cartilage filled along all of its edges of articulation with the other cranial bones except for its anteroventral prong; articulates in the orbit through cartilage and interdigitation anteromedially with the pterosphenoid, prootic, and pterotic; articulates anterolaterally by extensive interdigitation with the frontal, posterodorsally through cartilage and slight interdigitation with the epiotic, and posteroventrally with the pterotic.

Epiotic. - Cartilage filled along all of its edges of articulation with the other cranial bones; articulates dorsomedially by extensive interdigitation with the overlying basal pterygiophore of the spiny dorsal fin. Below this articulation with the basal pterygiophore the dorsomedial edge of the epiotic articulates through cartilage and interdigitation with its opposite member in the midline. Anteriorly the epiotic articulates through cartilage and interdigitation dorsally with a short portion of the posterior edge of the supraoccipital and through extensive interdigitation along most of its anterior edge with the frontal, while anteroventrally it articulates through cartilage and interdigitation with the posterodorsal edge of the sphenotic. Ventrally the epiotic articulates through cartilage and interdigitation with the pterotic and exoccipital, while the posterolateral surface of the lower half of the epiotic is broadly overlain and articulates by interdigitation with the bifid neural spine of the first abdominal vertebra.

Prootic. - Cartilage filled along all of its edges of articulation with the other cranial bones, except anteromedially; articulates by interdigitation medially with the lateral surface of the parasphenoid, anteromedially with the ascending fork of the parasphenoid, through cartilage and interdigitation anterodorsally with the pterosphenoid, anterolaterally with the sphenotic, and posteriorly with the pterotic. A deep concavity on the ventral surface of the prootic articulates by fibrous tissue with the anterior half of the dorsal head of the hyomandibular. The medial edges of the prootics form the lateral walls of the myodome, while medially directed shelves from the medial edges of the prootics meet in the midline and articulate through cartilage and fibrous tissue with one another to form the dorsal roof of the myodome. The anterior edge of the myodome is formed by the prootics, except ventrally, where it is formed by the parasphenoid. The anterior end of the prootic is prolonged anteriorly as a subocular shelf which serves for muscle attachment.

\section{Orbital Region.}

Frontal. - Widest posteriorly, tapering to a point anteriorly; its lateral edge above the orbit only slightly upraised and thickened; articulates by interdigitation posteromedially with the flattened posterior portion of the supraoccipital, which it slightly overlies, posteriorly with the epiotic, and posteroventrally with the sphenotic. Posteriorly in the rear of the orbit it articulates by fibrous tissue with the pterosphenoid and by interdigitation with the sphenotic. Medially above the orbit the frontal slightly overlies and articulates by fibrous tissue and slight interdigitation with the ventrolateral edge of the anterior extension of the supraoccipital, just posterior to which the frontal is broadly overlain and articulates by extensive interdigitation with the laterally expanded middle region of the basal pterygiophore of the spiny dorsal fin. The frontal interdigitates anteriorly with the ethmoid, whose posterodorsal surface it broadly overlies, while laterally at the front of the orbit the frontal articulates by interdigitation with the dorsolateral surface of the prefrontal. On its ventral surface, the medial edges of the frontals are separated by the cartilaginous mass which is continuous anteriorly with the remains of the ethmoid cartilage.

Prefrontal. -Expanded dorsolaterally; cartilage filled along its medial edge below the frontal; articulates by interdigitation dorsomedially with the frontal, while ventromedially it is continuous with the ethmoid cartilage lying between it and its opposite member and the posterior end of the ethmoid.

Parasphenoid. - Elongate, expanded laterally only posteriorly in the region below the rear of the orbit; ventrally expanded into a thin keel in the region below and just anterior to the orbit. The bifurcate posterior end of the parasphenoid broadly overlies the ventral surface of the basioccipital in the region of the deep concave groove in the latter, roofing over in this region the channel leading into the myodome. Articulates posteriorly by interdigitation with the basioccipital, pterotics, and prootics. Under the posterior region of the orbit the parasphenoid possesses a pair of short, slightly forked, dorsolateral projections which interdigitate with the prootics and form the anterior edge of the ventral region of the myodome. Anterior to the orbit the dorsal surface of the 
parasphenoid is concave and receives the rounded ventral edge of the platelike portion of the ethmoid, to which it articulates by fibrous tissue. The anterior end of the parasphenoid is deeply concave to receive the posterior shaftlike portion of the vomer, to which it is held by fibrous tissue.

Pterosphenoid.-Cartilage filled along all of its lateral edges of articulation with the other cranial bones; articulates through cartilage and fibrous tissue with the frontal, which broadly overlies it, and through cartilage and interdigitation with the sphenotic and prootic. Medially the pterosphenoid possesses a projection toward the midline which interdigitates with a similar projection from its opposite member, the pterosphenoids here meeting in the midline. The pterosphenoids also are in contact through cartilage at their extreme dorsomedial ends.

Ethmoid Region.

Ethmoid. -Elongate and deep; expanded laterally along its dorsal region but a deep flattened plate ventrally, the rounded edge of the ventral plate fitting into a concavity along the dorsal surface of the anterior end of the parasphenoid and held there by fibrous tissue. More anteriorly the ventral edge of the ethmoid articulates by fibrous tissue and light interdigitation with the dorsal surface of the anterior half of the vomer. Posterolaterally the dorsal surface of the ethmoid is overlain and interdigitated to the extreme anterior ends of the frontals. Posteriorly the ethmoid articulates through its cartilage filled posterior edge with the anteroventral cartilaginous ends of the prefrontals. The anterior end of the ethmoid is somewhat more laterally expanded than is the dorsal edge behind it, especially ventrally where a flange protrudes anteroventrally and articulates through fibrous tissue with the posterior end of the palatine. The extreme anterior end of the ethmoid remains somewhat cartilaginous centrally, and it is against this cartilaginous face that the rear edge of the premaxillary abuts in rotation.

Vomer. - An elongate shaft except anteriorly where it is laterally expanded; articulates posteriorly at its shaftlike portion by fibrous tissue to the concavity at the anterior end of the parasphenoid; articulates by fibrous tissue and slight interdigitation dorsally with the anteroventral end of the ethmoid, while anteriorly it helps support the posterior end of the upper jaw.

\section{Mandibular Region.}

Hyomandibular. - A flat shaft for most of its length, somewhat expanded dorsally; cartilage filled anteroventrally; the posterior edge thickened for articulation by fibrous tissue with the preoperculum and, just above the dorsal end of the latter, with the anterodorsal head of the operculum; articulates by fibrous tissue dorsally with the groove on the ventral surfaces of the prootic and pterotic, while posterodorsally the hyomandibular abuts against and is firmly held by fibrous tissue along the medial surface of the elongate portion of the ventral flange of the pterotic. The articulation with the head of the operculum is at a slight bulge of the hyomandibular whose concave face is cartilage filled and abuts against the similarly cartilage filled head of the operculum. The anteroventral end of the hyomandibular articulates variously through cartilage and fibrous tissue with the posterior end of the metapterygoid, symplectic, interhyal, and preoperculum.

Quadrate. - Widest posteriorly, tapering to a knob anteriorly for articulation with the articular in the lower jaw; cartilage filled at its posterior edge; deeply cleft along its posterior edge to accommodate the anterior end of the symplectic; articulates dorsally by extensive interdigitation with the ectopterygoid, while posteriorly it articulates through cartilage with the mesopterygoid and metapterygoid; articulates by fibrous tissue and interdigitation with the symplectic. Ventrally the quadrate articulates by fibrous tissue with the preoperculum.

Metapterygoid. - A large flat plate curving medially along its dorsal edge; cartilage filled at its anterior and posterior edges; articulates anteriorly through cartilage with the quadrate while anterodorsally it is overlain and interdigitated with the mesopterygoid and anteroventrally extensively interdigitated with the symplectic. Along the middle of its ventral edge it articulates through fibrous tissue with the dorsal end of the interhyal. Posteroventrally the metapterygoid articulates through fibrous tissue and cartilage with the preoperculum and anteroventral edge of the hyomandibular.

Symplectic. - A flattened shaft; relatively large; cartilage filled at its posterior and, to a lesser extent, anterior edges; articulates by extensive interdigitation posterodorsally with the metapterygoid and anteriorly with the indented region of the quadrate; ventrally articulates by fibrous tissue and, in some cases, by slight interdigitation with the dorsal edge of the preoperculum. The posterior cartilaginous end of the symplectic is in contact with the region of articulation between the interhyal and metapterygoid.

\section{Palato-Pterygoid Region.}

Palatine. - A more or less simple short rod with a slight bulge along its ventral edge for articulation by fibrous tissue with the extreme anterodorsal edge of the ectopterygoid; articulates anteriorly by fibrous tissue with the dorsal head of the maxillary and posteriorly with the lateral flanges of the ethmoid and, to a lesser extent, with the anterolateral expansion of the vomer.

Ectopterygoid. -Elongate; more or less triangular, the apex of the triangle being anterior in the middle of its length where the ectopterygoid articulates through 
fibrous tissue with the middle of the ventral edge of the palatine; articulates by extensive interdigitation ventrally with the quadrate and posteriorly with the mesopterygoid.

Mesopterygoid. -A small plate extensively interdigitated anteriorly with the ectopterygoid and, to a slight extent, with the quadrate in some specimens, and posteriorly with the metapterygoid; its anteroventral edge in contact with the cartilaginous region between the quadrate and the mesopterygoid.

\section{Opercular Region.}

Operculum.-More or less thin and flat, except dorsally where it thickens into a rounded shaft with an articular facet for articulation by fibrous tissue with the posterior edge of the dorsal region of the hyomandibular, while ventrally it overlies and articulates by fibrous tissue with the suboperculum.

Suboperculum. - Very thin, flat, and oblong; held to the overlying operculum by fibrous tissue.

Interoperculum. - A straight rod, tapering slightly to a point anteriorly; extends from the region of the interhyal to just beyond the anterior end of the preoperculum; articulates by a tough ligament anteriorly with the angular in the lower jaw, while at its posterior end two ligaments are present. One is short and connects with the dorsal surface of the epihyal just below the articulation of the latter with the interhyal, while the other one is long and runs posteriorly to connect to the anterior edge of the operculum just above the point where the operculum begins to overlie the suboperculum.

Preoperculum. - Expanded in its middle region; its dorsal surface only slightly flattened for articulation with the quadrate; articulates along the posterior portion of its dorsal edge by fibrous tissue with the hyomandibular, along the middle portion of its dorsal edge through cartilage and fibrous tissue with the symplectic, metapterygoid, and interhyal, and along the anterior portion of its dorsal edge by fibrous tissue with the quadrate.

\section{Upper Jaw.}

Premaxillary. -A medially curved plate, wider dorsally than ventrally; its posterodorsal edge slightly concave to articulate by fibrous tissue with the anterior ends of the ethmoid and vomer. It also articulates by fibrous tissue laterally with the medial surface of the palatine, although the main articulation of the latter is with the maxillary. The anterior edge of the premaxillary forms the entire anterior border of the upper jaw and only shares the border with the maxillary ventrally. The premaxillary is in close apposition with the maxillary and articulates immovably with it by fibrous tissue and slight interdigitation. The flat dorsomedial edges of the two premaxillaries are held closely to one another by fibrous tissue. Each premaxillary bears five teeth, three in an outer row and two in an inner row. Both of these rows are in close contact with one another. The teeth are borne in very shallow depressions on the surface of the premaxillary in their fully formed condition. They develop, however, from large deep sockets which open to the surface just at the base of the old tooth which they will replace. As a tooth erupts to the surface to replace an old tooth, the socket from which it arose apparently is overgrown or filled in with bone and disappears and the tooth rests only in a shallow depression on the surface of the premaxillary. Most of the interior of the premaxillary is given over to the dental pulp cavities, these cavities communicating with the exterior through numerous holes on the inner and outer surfaces of the bone.

Maxillary. - Widest ventrally, becoming narrow in the middle, and expanded again dorsally where it articulates with the anterior head of the palatine; articulates firmly with the premaxillary by fibrous tissue and slight interdigitation. The medial surfaces of the ventral regions of the maxillary and, to a lesser extent, of the premaxillary articulate with the lateral surface of the up. per portion of the dentary, by fibrous tissue. The posterodorsal surface of the maxillary articulates by fibrous tissue with the lateral expansions of the ethmoid and vomer and with the medial surface of the palatine.

\section{Lower Jaw.}

Dentary.-Wide posteriorly; its posterior edge concave to accommodate the anterior portion of the articular, with which it articulates by interdigitation. Posteroventrally the dentary articulates by fibrous tissue and slight interdigitation with the angular. From the lateral surface of its posterodorsal region the dentary articulates by fibrous tissue with the medial surfaces of the maxillary and, to a lesser extent, of the premaxillary. Ventromedially the dentary has broad denticulations with which it articulates through fibrous tissue with its opposite member. Each dentary bears three teeth in a single row, corresponding to the outer row in the premaxillary. The teeth are borne in shallow sorkets on the surface of the dentary and are replaced by new teeth developing in deep sockets just as described for the teeth of the upper jaw. Most of the interior of the dentary is filled with the pulp cavity of the developing teeth, the cavity opening to the exterior at the concave posterior edge of the dentary as well as at pores on the inner and outer surface of the bone.

Articular.-Wide along its posterior edge, with a concave facet for articulation by fibrous tissue with the anterior knob of the quadrate; articulates by interdigitation with the concave posteromedial surface of the dentary. At its extreme posteroventral edge the articular interdigitates slightly with the angular. The sesamoid articular is a small nubbin of bone closely held by fibrous 
tissue to the medial surface of the articular just in front of and above the concave articular facet of that bone.

Angular. - A small wedge of bone articulated by interdigitation dorsally with the articular and anteriorly with the dentary. Posteriorly the angular connects by ligament with the interoperculum.

\section{BRANCHIAL APPARATUS.}

\section{Hyoid Arch, Branchiostegal Rays, and Urohyal.}

Hypohyals. - Both hypohyal elements well developed, and of about equal size; the dorsal element cartilage filled at its ventral and posterior edges, the ventral element cartilage filled at its dorsal edge; the two elements articulate with one another through the cartilage that lies between them; the dorsal and ventral elements articulate by fibrous tissue at their anteromedial edges with their opposite members. The dorsal hypohyal articulates posteromedially by fibrous tissue with the lateral surface of the first basibranchial. The posterior edge of the ventral hypohyal and a short portion of the posteroventral edge of the dorsal hypohyal articulate through cartilage and fibrous tissue with the ceratohyal, while the medial surface of the ventral hypohyal is held by fibrous tissue to the anterodorsal region of the urohyal.

Ceratohyal. - A flat shaft, wider posteriorly than anteriorly; cartilage filled at its lower posterior edge; articulates through cartilage anteriorly with the ventral hypohyal and, to a lesser extent, with the dorsal hypohyal; articulates posteriorly through cartilage and interdigitation with the epihyal. If six branchiostegal rays are present, the first two rays articulate in about the middle or just behind the middle of the ventral edge of the ceratohyal. However, only five branchiostegal rays are usually present and only one articulates to the ventral edge of the ceratohyal. Of the four branchiostegal rays always present in the posterior group, the lower two or even three have their fibrous tissue articulation primarily with the lateral surface of the posterior end of the ceratohyal in the region immediately below the interdigitation with the epihyal.

Epihyal. - Large, about the same size as each of the hypohyals; cartilage filled at its ventral edge; articulates through cartilage and interdigitation anteriorly with the ceratohyal, while dorsally it articulates by fibrous tissue with the interhyal and interoperculum.

Interhyal. - A short, thick rod; cartilage filled at both ends; articulates by fibrous tissue ventrally with the epihyal and dorsally with the extreme posterior end of the symplectic and the ventral edge of the metapterygoid just behind the symplectic.

Branchiostegal rays. - Usually five in number. Of the 12 specimens examined, 11 have five branchiostegals on each side, one articulated to the middle of the ventral surface of the ceratohyal and four articulated to the lateral surfaces of the posterior and ventral ends of, respectively, the ceratohyal and epihyal. However, one specimen has five branchiostegals on one side and six on the other. The side with the five branchiostegals has a typical arrangement of one ray articulated to the ventral surface of the ceratohyal and four articulated to the lateral surface of the ceratohyal and epihyal. On the one side with six branchiostegals, two are articulated to the ventral surface of the ceratohyal and the other four more posteriorly. In the illustration of the branchial apparatus of $M$. ciliatus, the additional branchiostegal ray occasionally present is indicated by dashed lines, this being the branchiostegal ray immediately behind the large first branchiostegal articulated to the ventral surface of the ceratohyal. The branchiostegal rays are all articulated by fibrous tissue to the ceratohyal or epihyal. The first branchiostegal is much wider than are the succeeding rays, the more posterior of which are so narrow that they are, in essence, slender rods.

Urohyal. - Thick along its anterior and anterodorsal edges, otherwise a relatively thin plate; articulates by fibrous tissue anterodorsally between the medial edges of the ventral hypohyal, while posteriorly it articulates with the ventral surfaces of the posterior end of the first basibranchial and the anterior end of the second basibranchial.

Branchial Arches.-All the elements are cartilage filled at their edges of articulation with the other elements of the series, and the articulations are usually through cartilage and fibrous tissue. The branchial arches are composed of three basibranchials, three pairs of hypobranchials, five pairs of ceratobranchials, four pairs of epibranchials, and two pairs of pharyngobranchials. Four gills are present, with a slit between the fourth arch and the lower pharyngeal.

First arch.-Basi-, hypo-, cerato-, and epibranchial elements present. First basibranchial short, wider posteriorly than anteriorly; articulates posteriorly with the second basibranchial and posterolaterally with the first hypobranchial. First hypobranchial of increasing width posterodorsally; the largest of the hypobranchial elements, which decrease in size posteriorly in the series; articulates ventrally with the region of articulation between the first and second basibranchials and dorsally with the first ceratobranchial. First ceratobranchial a stout rod; the longest of the ceratobranchial elements, which decrease in length posteriorly in the series; no ventrally directed flange present on the ceratobranchials, except for the fourth, which is somewhat compressed and has a small ventral flange basally; articulates ventrally with the first hypobranchial and dorsally with the first epibranchial. First epibranchial a flattened plate, rounded ventrally where it articulates with the cerato- 
hyal but then diverging into two prongs; the anterior prong articulates by fibrous tissue with the ventral keel of the parasphenoid just anterior to the middle of the orbit, while the posterior prong articulates with the anteriormost pharyngobranchial (that of the second arch) and the dorsal end of the second epibranchial. The pharyngobranchial element of the first arch is absent.

Second arch.-Basi-, hypo-, cerato-, epi-, and pharyngobranchial elements present. Second basibranchial the longest of the three elements of the series and slightly wider posteriorly than anteriorly; articulates anteriorly with the first basibranchial, anterolaterally with the first hypobranchials, posteriorly with the third basibranchial, and posterolaterally with the second hypobranchials. Second hypobranchial wider posterodorsally than anteroventrally; articulates ventrally with the area of articulation between the second and third basibranchials and dorsally with the second ceratobranchial. Second ceratobranchial a long rod with a slightly expanded ventral end; articulates dorsally with the second epibranchial. Second epibranchial a short rod; articulates dorsally with the second pharyngobranchial and, to a lesser extent, with the posterodorsal arm of the first epibranchial. Second pharyngobranchial (the first of the two remaining elements of the series) an oblong block bearing on its ventral surface a row of about five slender sharply pointed teeth and articulating ventrally with the dorsal end of the second epibranchial and the posterodorsal projection of the first epibranchial. New teeth develop in sockets just behind and below the bases of the old teeth.

Third arch.-Basi-, hypo-, cerato-, epi-, and pharyngobranchial elements present. Third basibranchial a short column, widest in the middle; articulates anteriorly with the second basibranchial, anterolaterally with the second hypobranchials, posterolaterally with the third hypobranchials, and posteriorly with the fourth ceratobranchials. Third hypobranchial rounded posteriorly but with a short tapering anteroventral process that articulates by fibrous tissue anteriorly with the ventral surface of the more anterior basibranchials and the posterior arm of the urohyal; articulates posterolaterally with the third ceratobranchial and posteromedially with the posterior end of the third basibranchial. Third ceratobranchial expanded ventrally but shaftlike more distally; articulates ventrally with its opposite member and with the third hypobranchial, and dorsally with the third epibranchial. Third epibranchial rodlike distally and expanded in the middle region; articulates dorsally with the third pharyngobranchial; the expanded middle region is directed anteriorly and articulates with the basal region of the second epibranchial. Third pharyngobranchial like the second pharyngobranchial except smaller and usually with only three teeth, the teeth slightly smaller than those of the other pharyngobranchial; articulates ventrally with the distal ends of the third and fourth epibranchials. The two pharyngobranchial elements are held to one another by fibrous tissue.

Fourth arch. - Cerato- and epibranchial elements only. Fourth ceratobranchial more compressed than the other ceratobranchials and with a narrow ventral flange; articulates ventrally with the ventral end of its opposite member and that of the third ceratobranchial. Fourth epibranchial rodlike, only slightly larger in the middle than at either end; articulates ventrally with the fourth ceratobranchial and dorsally with the third pharyngobranchial.

Fifth arch. - Ceratobranchial (lower pharyngeal) element only. Fifth ceratobranchial the shortest of the ceratobranchial elements; narrowest dorsally, widest in the middle, and with an expanded base articulating with the base of the fourth ceratobranchial; toothless.

\section{PAIRED FIN GIRDLES.}

\section{Pectoral Fin.}

Posttemporal. - A short relatively straight shaft broadly overlying the lateral surface of the pterotic and, to a lesser extent, the sphenotic and extensively interdigitated to both, and therefore immovably held to the skull; articulates ventrally through fibrous tissue with the dorsal head of the supracleithrum.

Supracleithrum. - A straight shaft of bone oriented more or less vertically to the axis of the body; most of its medial surface broadly overlying and held by fibrous tissue to the lateral surface of the upper end of the cleithrum, while dorsally it articulates immovably through fibrous tissue with the head of the posttemporal.

Cleithrum.-Laterally expanded at its anterior edge in the middle of its length; articulates by fibrous tissue dorsally with the overlying supracleithrum and with the upper end of the postcleithrum, which it broadly overlies. Along its posterior edge the cleithrum overlies the anterior region of the scapula and coracoid and articulates with both through fibrous tissue and slight interdigitation. Along the ventral two-thirds of its length the medial edges of the two cleithra are firmly held to one another by fibrous tissue, while ventromedially they also articulate through strong fibrous tissue with the anterior end of the shaftlike portion of the pelvis which is closely held between the two cleithra.

Postcleithrum. - The postcleithrum is a long flattened strong strut not divided into dorsal and ventral parts. The dorsal end of the postcleithrum articulates by fibrous tissue with the dorsomedial surface of the cleithrum. The postcleithrum is angled obliquely down from its upper point of attachment toward the region of the abdominal wall in front of the dorsal lobe of the pelvis. 
Coracoid. - Widest dorsally, tapering to a shaft ventrally; with a slender spinelike process under the lowermost actinost from its posteroventral edge; the upper one-third of its posterior edge with an inturned flange medially; cartilage filled at its dorsal end and at the tip of its ventral shaft; articulates by fibrous tissue and interdigitation anteriorly with the cleithrum, which overlies the upper anterior edge of the coracoid; articulates anterodorsally through cartilage with the scapula; posterodorsally the edge of the coracoid supports the lowermost and largest actinost and sometimes, to a lesser extent, the lower edge of the base of the third actinost.

Scapula.-Completely encloses the scapular foramen; cartilage filled at its anterior and ventral edges; articulates anteriorly by fibrous tissue and slight interdigitation with the cleithrum, while ventrally it articulates through cartilage with the coracoid. Along its posterodorsal edge the scapula articulates by fibrous tissue with the following elements, in order from anterior to posterior or above to below: the first and uppermost pectoral fin ray attached to a projection from the surface of the scapula, immediately below which the scapula supports on a small flange the small uppermost actinost, with the second and third actinosts articulating along the relatively unmodified posterior edge of the scapula, although the posterodorsal edge of the coracoid helps to support the lower basal region of the third actinost.

Actinosts. - Four elements; all cartilage filled at both ends; the first actinost small, the others increasing slightly in size from above to below in the series; articulated to the scapula and coracoid as described in the preceding section. Distally the actinosts support by fibrous tissue all of the fin rays except the first, which is supported by the scapula.

Fin rays. - Twelve fin rays in most specimens, with the first ray about one-tenth the length of the second ray and articulated directly with the scapula, rather than with the actinosts, as are the other rays. First ray with its medial half enlarged and thickened at its basal region of articulation with the scapula; its lateral half reduced to a thin short splint closely held to the medial half. All of the pectoral fin rays unbranched; the first ray without crossstriations, all the other rays cross-striated.

\section{Pelvic Fin.}

Pelvis. - A stout shaft; not divided into separate right and left halves; anterior three-fourths of its lateral surface with a concavity for muscle attachment; a large relatively slender dorsal lobe present from its posterodorsal region which serves as a place of tough fibrous tissue attachment for the overlying skin of the highly distensible abdominal area or ventral flap (dewlap). A series of enlarged scales encircle the posterior end of the pelvis and obscure from view the rudimentary fin-ray element present in the midline just behind the end of the pelvis. The lateral surface of the posterior end of the pelvis bears several ridges for articulation with these scales. The scales occur in three segments, with only the distal segment movably articulated, the major region of flexibility in the series being between the second and third series. The fin-ray element is reduced to a single nubbin of bone above and below the plug of cartilage that extends posteriorly from the end of the pelvis, as described in detail by Tyler (1962b:229-232, figs. 38-45). These bony nubbins, representing the remains of a fin-ray (or spinous) element, are closely held by fibrous tissue to the cartilaginous plug. Running anteriorly from each of the nubbins is a tendon. The tendon from the dorsal nubbin courses through a hole in the dorsal flange of the pelvis to attach to a muscle housed in the concave region on the dorsal surface of the pelvis, while the tendon from the ventral nubbin runs along a similar concavity on the ventral surface of the pelvis. The fin-ray nubbin and the attached plug of cartilage at the end of the pelvis are movable in a dorsoventral plane around the posterior end of the pelvis by the contractions of the muscles on the dorsal and ventral surface of the pelvis to which they are connected by ligament. The pelvis itself is movable in a dorsoventral plane around its fibrous tissue attachment between the ventromedial edges of the cleithra.

VERTEBRAL COLUMN. -All vertebrae with biconcave centra, except the last, which posteriorly ends in a plate representing the fused centrum, hypurals, and parhypural.

\section{Abdominal Vertebrae.}

First vertebra. - Neural spine shorter than those of the succeeding vertebrae but sturdy; laterally expanded, bifid to the centrum and thus not forming a bony roof over the neural canal; articulates by extensive interdigitation along most of its anterior face with the exoccipitals and epiotics. The rim of the concave anterior face of its centrum articulates by fibrous tissue with the rim of the concave posterior end of the basioccipital, while the rim of its posterior face articulates similarly with the rim of the anterior face of the second vertebra. Anteriorly between the region of the centrum and the neural arch, the first vertebra is slightly overlain by the short exoccipital condyle. From the lower region of its posterolateral surface the centrum possesses a short posteroventrally directed process which makes fibrous tissue contact over the anterior fifth of the lower surface of the centrum of the second vertebra, although this is mostly obscured from lateral view by the lateral flange of the second vertebra.

Other abdominal vertebrae. - In 12 specimens the abdominal vertebrae numbered six. Except for the first vertebra, all the abdominal vertebrae, as well as all of the 
caudal vertebrae except the last, possess bony roofs over the neural canal and have single, undivided neural spines. The neural spines of the abdominal vertebrae are all of about the same length but they are of increasing width posteriorly in the series. Their edges of apposition articulate with one another through fibrous tissue and, in some cases, slight interdigitation. Each neural arch has a neural foramen in its lateral surface. Haemal prezygapophyses are weakly developed on a few vertebrae, but mostly they are absent or insignificant. Except for the first, all of the abdominal vertebrae have transverse processes which bear epipleural ribs. These processes become increasingly laterally expanded and stouter posteriorly in the series. The transverse process of the second vertebra arises in about the middle of the anterior region of the centrum, but the transverse processes of the subsequent vertebrae originate low on the centrum. The epipleurals articulate by fibrous tissue to the dorsolateral surfaces of the transverse processes. The transverse processes of the fifth and sixth abdominal vertebrae have posteromedial flanges from each side which make contact with the haemal regions of the succeeding vertebrae, roofing over the haemal canal under the fifth and sixth vertebrae, while more anteriorly the haemal canal is open. The first basal pterygiophore of the soft dorsal fin articulates between the neural spines of the fourth and fifth vertebrae, the articulation being by fibrous tissue. The second basal pterygiophore of the soft dorsal fin articulates similarly between the neural spines of the fifth and sixth abdominal vertebrae.

Caudal Vertebrae. - The caudal vertebrae number 11 in 12 specimens. The neural spines of the caudal vertebrae become less expanded anterodorsally and increasingly shorter posteriorly in the series, except for the last few vertebrae, behind the soft dorsal and anal fin bases, which have the neural and haemal spines expanded. All of the caudal vertebrae, except for the last, possess complete neural and haemal arches and spines. Haemal pre- and postzygapophyses are essentially absent, but neural pre- and postzygapophyses are distinctly developed in both the caudal and abdominal series. The sturdy haemal spine of the first caudal vertebra is somewhat concave ventrally along its posterior surface and slightly bifurcate at its extreme distal end. It is against the posterior surface of this haemal spine that the first basal pterygiophore of the anal fin is firmly held by fibrous tissue. The haemal spines of the second and third caudal vertebrae are progressively slightly longer than that of the first, but more posteriorly the length of the spines decreases until those of the 10th to 12th vertebrae, which are of increased length. The length of the neural spine similarly decreases posteriorly in the series and then increases behind the soft dorsal fin base. The haemal spine of the penultimate vertebra is autogenous. The haemal and neural spines of the last caudal vertebra are described below.

Caudal Skeleton. - The caudal complex usually consists of an epural, a free parhypural, and a large plate composed of the centrum fused to the hypural elements. The free epural and parhypural are of about equal size. The neural arch of the last centrum is incomplete, the neural canal not being roofed over. Similarly the haemal canal is not roofed over and its presence is simply indicated by an indentation in the anteroventral edge of the hypural plate just below the centrum and above the dorsal end of the parhypural. The fused hypural plate bears a horizontal keel for muscle attachment on the rear portion of the centrum area and anterior region of the fused hypurals. There is also a deep indentation on the middle of the posterior edge of the fused plate, this indentation representing what would be the division between the second and third hypurals in a more generalized plectognath having five free hypurals. The above is the condition found in 10 of the 12 study specimens. However, as described and illustrated by Tyler (1970b:16, fig. 31), 2 of the 12 specimens have an upper free hypural, representing the fifth hypural of generalized plectognaths. The presence of an upper free hypural is the norm for the family, all species examined having one with the exception of, usually, $M$. ciliatus, and the several specimens of Rudarius ercodes and $R$. minutus cleared and stained or radiographed, and the single specimen of Amanses scopas cleared and stained.

Caudal fin rays. - Twelve in number; the uppermost ray and the lowermost ray unbranched, the others becoming increasingly branched toward the middle fin rays, which are branched in triple dichotomies. The bifid bases of the fin rays articulate by fibrous tissue with the caudal skeleton as follows: the upper six rays to the upper half of the fused hypural plate and the lower six rays to the lower half of the plate.

\section{DORSAL AND ANAL FINS.}

\section{Dorsal Fin}

Spines and pterygiophores. - Two spines borne on a large and elongate basal pterygiophore. First spine long and moderately stout; second spine much smaller, consisting of a basal rounded region, a slender tapering distal end and, from the ventrolateral edge of the basal expanded region, a laterally projecting flange for muscle attachment. The concave ventromedial region of the first spine rotates over a low medial flange on the pterygiophore, while posteromedially the first spine has a ventrally directed flange which rotates into a deep concavity on the basal pterygiophore just behind the medial flange. The thick posterior region of this posteromedial flange of the first spine is roughened and makes contact with the similarly roughened anterior edge of the basally expanded portion of the second spine to form the locking mechanism. The concave ventral surface of the second spine rotates over a low medial flange on the pterygio- 
phore just posterior to that supporting the first spine. The second spine also has a very short and blunt posteromedial expansion which is accommodated in a low concavity on the pterygiophore just behind the medial flange over which the base of the spine rotates. The locking mechanism of the two spines is basically similar to that in the Balistidae and continuous positions of erection from partial to full are possible.

The ventral surface of the basal pterygiophore is strongly interdigitated with the top of the skull, especially with the frontals, and extends forward to the level of the prefrontals. In addition to the frontals, the basal pterygiophore is interdigitated with the supraoccipital and epiotics. The pterygiophore is especially sturdy and laterally expanded in the region below the first dorsal spine.

Fin rays and pterygiophores. - There are usually between 30 and 36 fin rays; all of the rays unbranched, but with cross-striations. In the illustrated specimen the 31 fin rays are borne on an equal number of basal pterygiophores. Each fin ray has a small, unpaired, distal pterygiophore between the bifurcate base of the ray. Each basal pterygiophore, except for the last several, has a well-developed lateral ridge along its length, except at the very proximal and distal ends of the element, for muscle attachment. The lateral ridges decrease slightly in height posteriorly in the series. Distally the ridge is especially laterally expanded and curved slightly ventrally to form a hooklike process. The first basal pterygiophore is slightly the largest in the series, the other pterygiophores decreasing slightly in length posteriorly in the series. The first basal pterygiophore articulates by fibrous tissue between the neural spines of the fourth and fifth abdominal vertebrae, while the last few basal pterygiophores are between those of the 9 th and 10th caudal vertebrae. Posterodorsally the first basal pterygiophore interdigitates with the second basal pterygiophore, and all of the subsequent basal pterygiophores are extensively interdigitated to one another along their edges of contact, except for the last few basal pterygiophores which are held to one another mainly by fibrous tissue instead of extensive interdigitation. Just below their distal ends the successive pterygiophores are not in close contact and a foramen is formed between their apposed edges. The degree of interdigitation between the pterygiophores decreases slightly in the series posteriorly, as does their degree of contact with the neural spines supporting them. The basal pterygial elements are cartilage filled at their dorsal and ventral edges.

\section{Anal Fin.}

Fin rays and pterygiophores.-There are usually between 30 and 35 fin rays supported by an equal number of basal pterygiophores or by only one or two less than the number of rays; all of the rays unbranched but with cross-striations. In the illustrated specimen the 31 fin rays are supported by 29 basal pterygiophores. Each fin ray has a small, unpaired, distal pterygiophore between its bifurcate base. The basal pterygiophores of the anal fin are similar to those of the soft dorsal fin and bear the same kind of lateral flanges for muscle attachment along most of their lengths. The first two basal pterygiophores of the anal fin articulate by fibrous tissue between the haemal spines of the first and second caudal vertebrae, while they articulate by extensive interdigitation with one another, as do the other pterygiophores in the series. This interdigitation decreases posteriorly in the series to the extent that the last few pterygiophores articulate to one another mainly by fibrous tissue. The pterygiophores decrease slightly in length posteriorly in the series, as does the height of their lateral flanges. There are usually three to four anal fin basal pterygiophores articulated between successive haemal spines, whereas in the dorsal fin there are usually only two or three basal pterygiophores between successive neural spines, this because the number of basal pterygiophores in the dorsal and anal fins is similar, whereas the dorsal fin is longer based and extends over more vertebrae than does the anal fin.

Anatomical diversity. - The monacanthids are one of the more diversified families of plectognaths, comparable in many ways to the degree of diversity found in the Recent triacanthodids, although without as much diversity in dentition and with no indication of two major phyletic lines within the family such as is evident in the Recent triacanthodids. Fossil species of monacanthids are not yet known, although the ancestral balistids have been found as early as the Oligocene. The monacanthids, with about 90 species, are one of the most speciose families of plectognaths, only the tetraodontids having more species, perhaps a few over 100. Even though two subfamilies of tetraodontids (tetraodontins and canthigasterins) are easily recognizable and none such are in the monacanthids, the latter still are probably more anatomically diversified than the former. That is, there is no sharp break in the structural continuity of monacanthids, while there is in tetraodontids between Canthigaster and the tetraodontins, only partially bridged by Carinotetraodon.

Most monacanthids have an only slightly elongate body form, similar to that of balistids, although they tend to be thinner bodied (more laterally compressed) than balistids. However, monacanthids range from those of nearly perfectly rounded outline (Brachaluteres, Chaetoderma), in which the greatest body depth, including the normal pelvic region expansion, approaches the standard length, to the extremely elongate Psilocephalus, whose depth is contained many times in the standard length.

Although always over the top of the head, the placement of the first dorsal spine is variable, ranging from over the rear edge of the eye (many genera) to well forward of the eye (Pseudaluteres only), while in most genera it originates somewhere over the rear half of the eye. Two dorsal spines are present in all genera except 


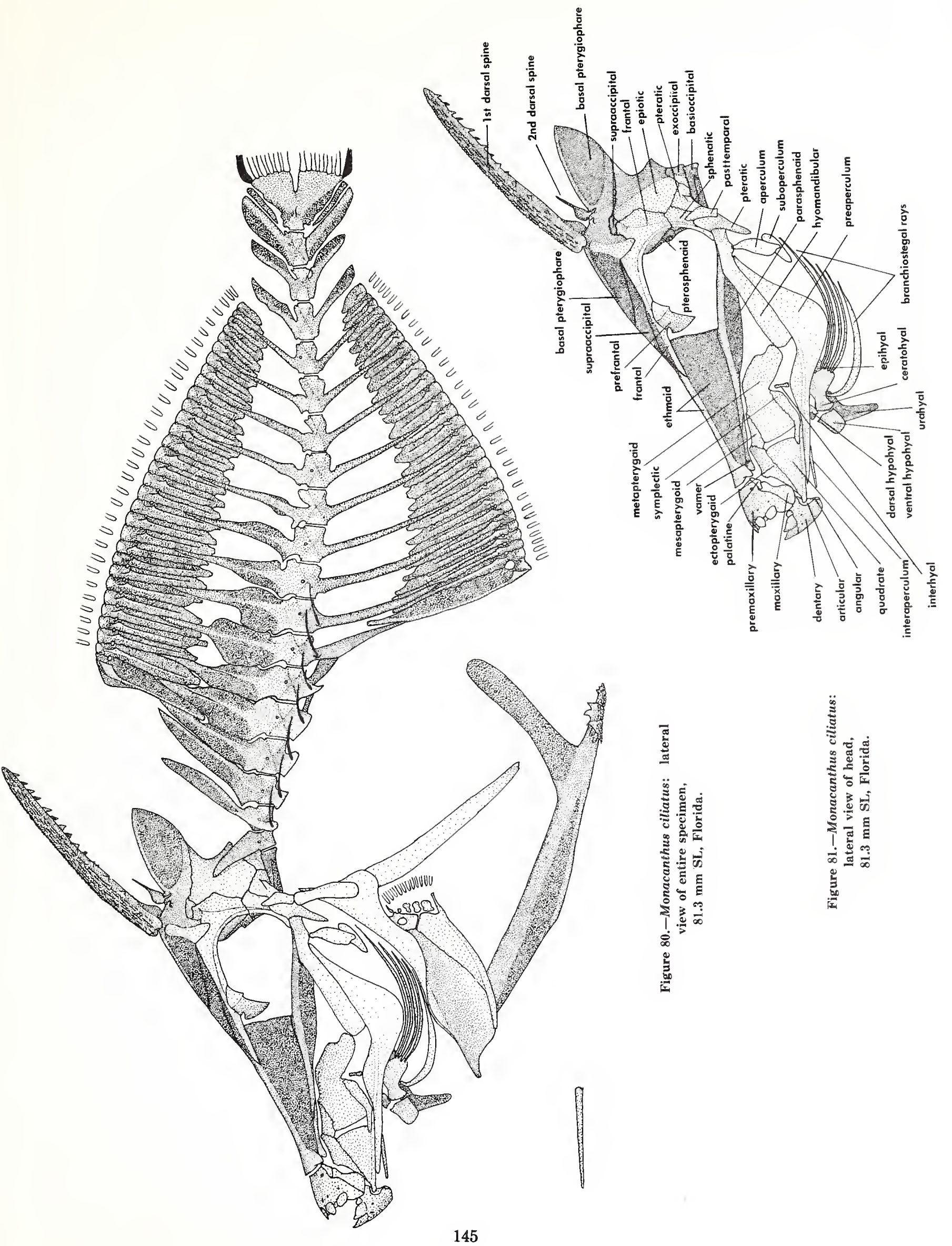



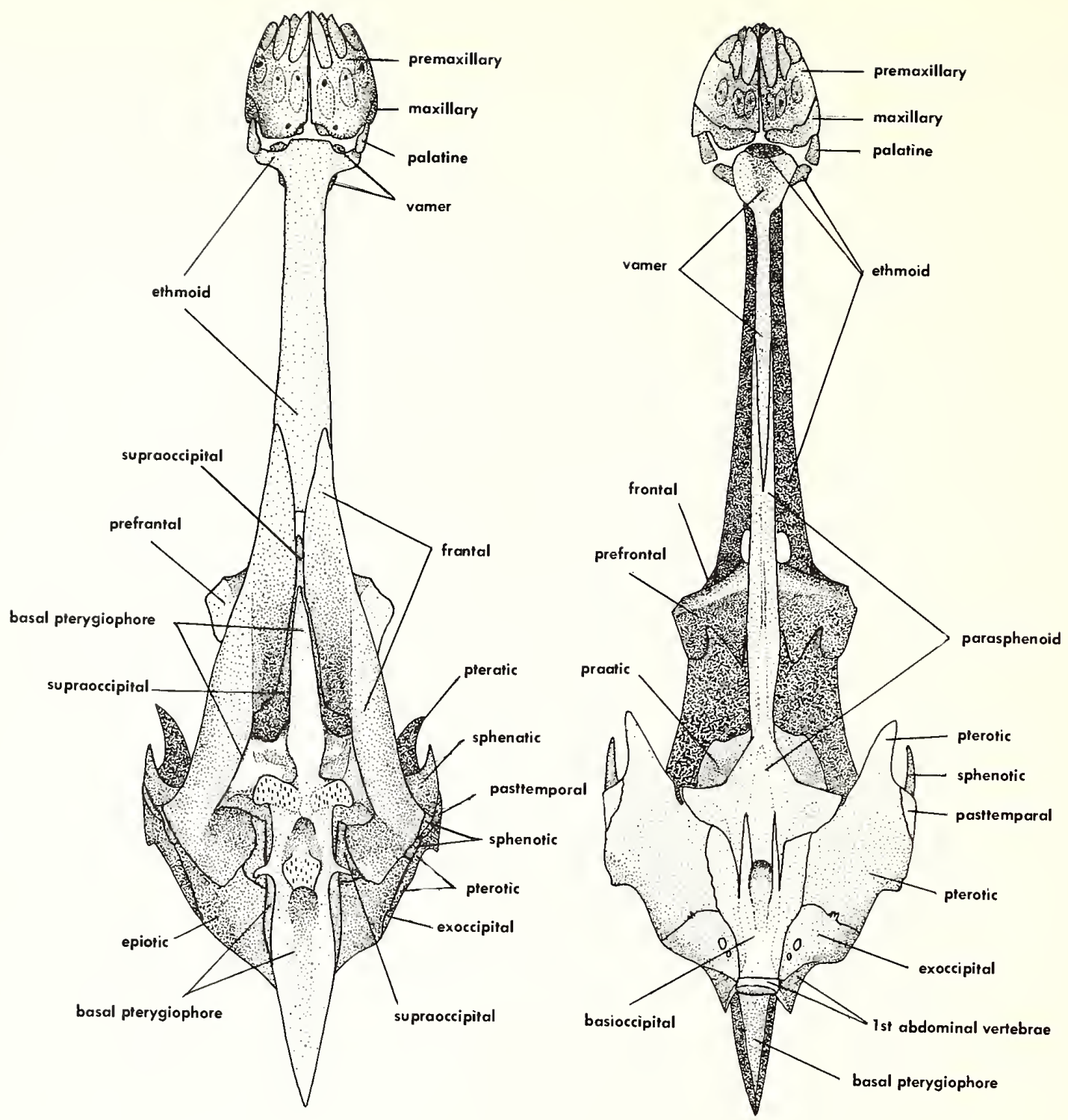

Figure 82.-Monacanthus ciliatus: dorsal (left)

and ventral (right) views of skull, $51.3 \mathrm{~mm} \mathrm{SL}$, Colombia.

Brachaluteres and Psilocephalus, in which only the first spine remains. The single spine of Brachaluteres is rela. tively well developed, but that of Psilocephalus is very short and weak, as is its pterygiophore. In most genera the first dorsal spine is ornamented with downward and backward projecting spiny processes, especially along the two posterolateral edges, while the anterior surface is usually ornamented with smaller and less regularly arranged barbs, these oriented either upward, downward, or straight forward. However, a few genera have the barbs on the anterior face of the spine as well developed, or almost so, as on the posterolateral edges: Laputa, Chaetoderma, Arotrolepis, and Acanthaluteres. Others have a relatively low and plain ornamentation over most of the surface of the spine which is not greatly rougher than that of the skin: Amanses, Cantherhines, and Alutera. In a few genera (Brachaluteres and Pseudaluteres) there are low barbs mainly on the anterior face, these continued onto the posterior face only distally. In two genera, Paraluteres and Psilocephalus, there are no barbs at all. In Paraluteres the barbs have obviously been lost in conjunction with the role of this filefish as a mimic of the pufferfish Canthigaster valentini, the spine being covered by smooth scaleless skin and probably not fully erectile in life. The smoothness of the spine of Psilocephalus is undoubtedly related to the reduction of the spine in that genus.

The second dorsal spine is always much smaller than the first and is absent in Brachaluteres and Psilocephalus. The second spine always has a sturdy rounded basal 

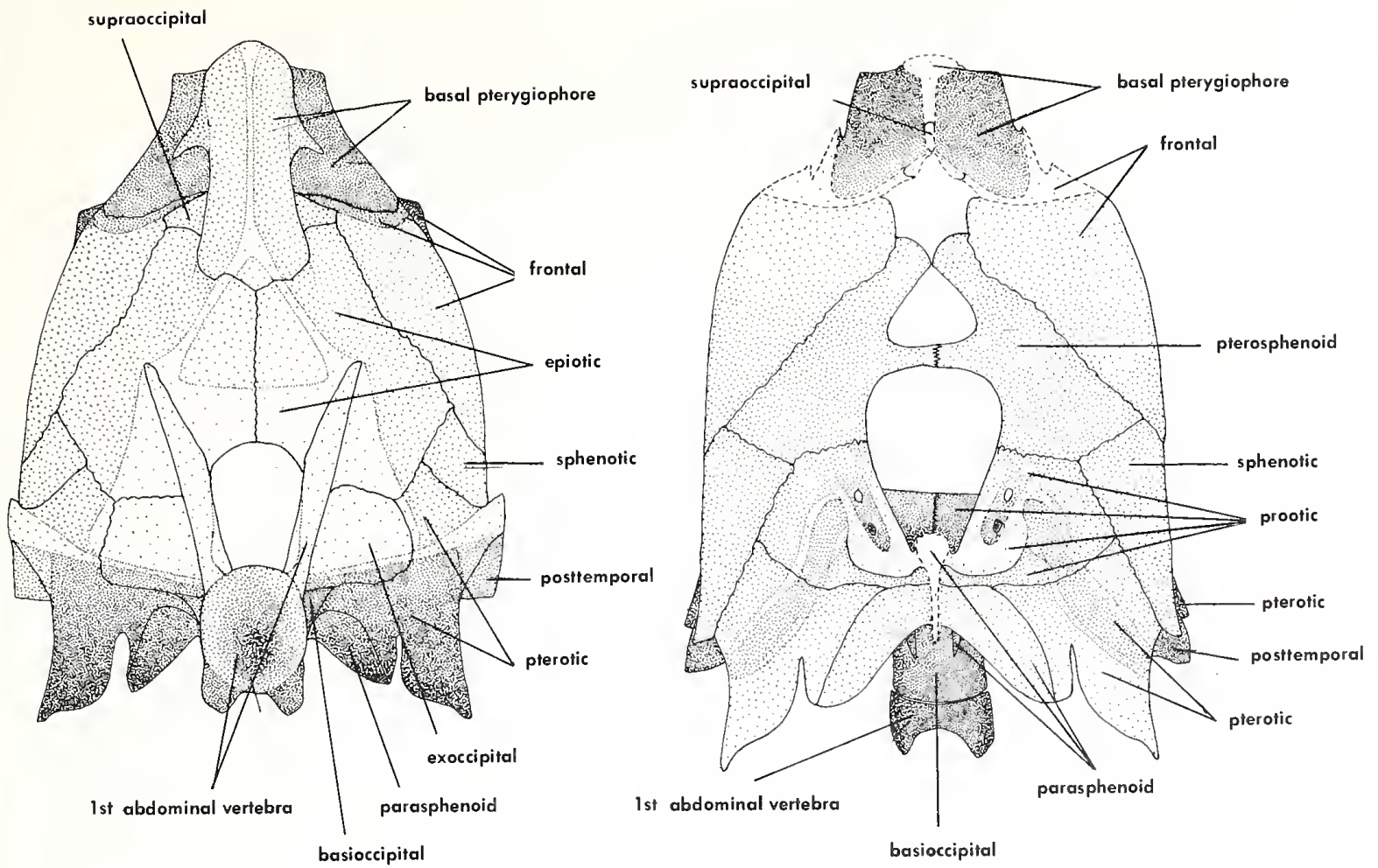

Figure 83.-Monacanthus ciliatus: posterior views of skull (left) and

of orbit (right) (cross section of skull; dashed lines represent cut surfaces of frontals, supraoccipital, basal pterygiophore of spiny dorsal fin and parasphenoid), $81.3 \mathrm{~mm}$ SL, Florida.

region for locking contact with the posterior edge of the posteromedial flange of the first spine and has a pair of ventrolateral processes for muscle attachment, but the length of the thin narrow distal shaft of the second spine is variable. The distal shaft is usually so short that it is difficult to see as it lies buried in the narrow band of skin between the posterior edge of the first spine and the dorsomedial edge of the body just behind it, and even when relatively long, it never conspicuously protrudes through the skin.

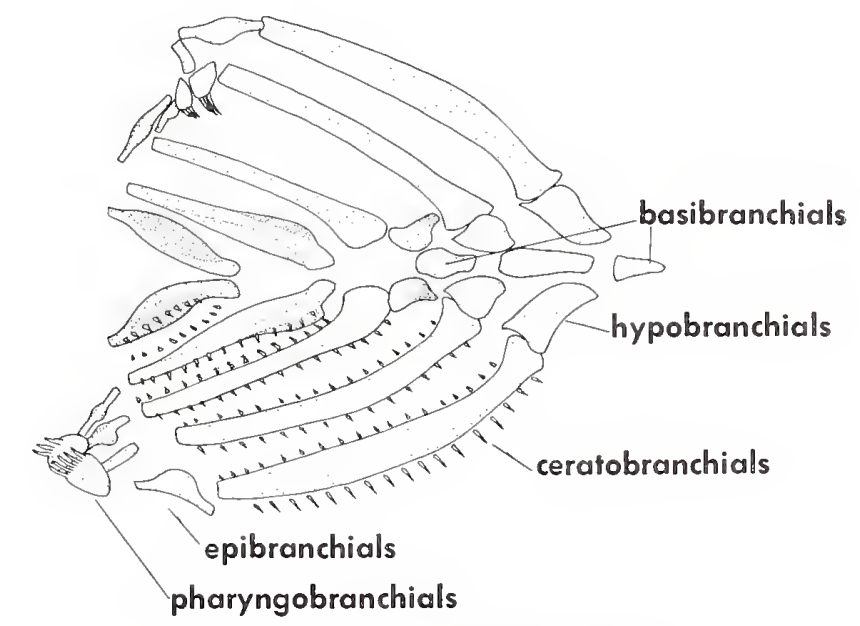

Figure 84.-Monacanthus ciliatus: dorsal view of branchial arches (extended on lower side); lateral view of hyoid arch and urohyal; $75.7 \mathrm{~mm}$ SL, Florida.

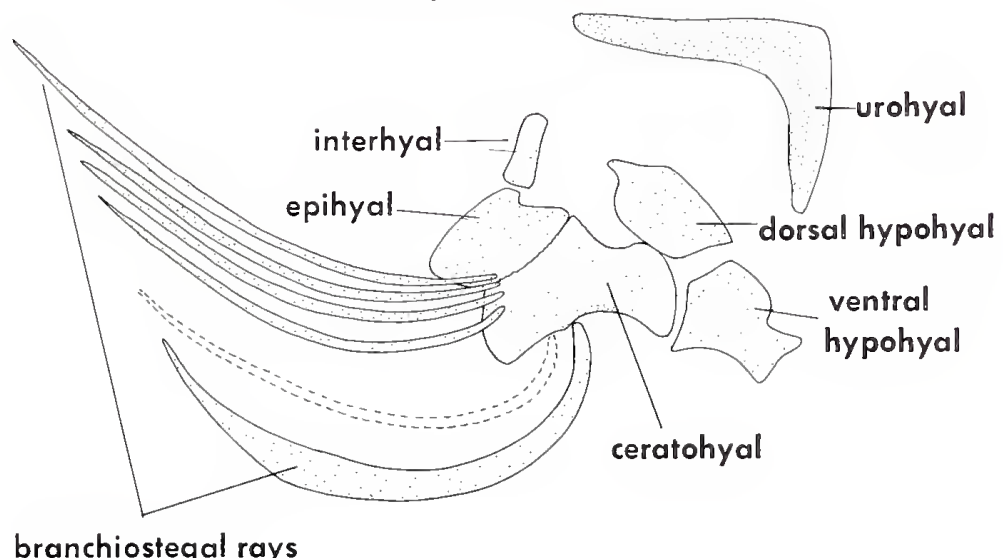

branchiostegal rays 


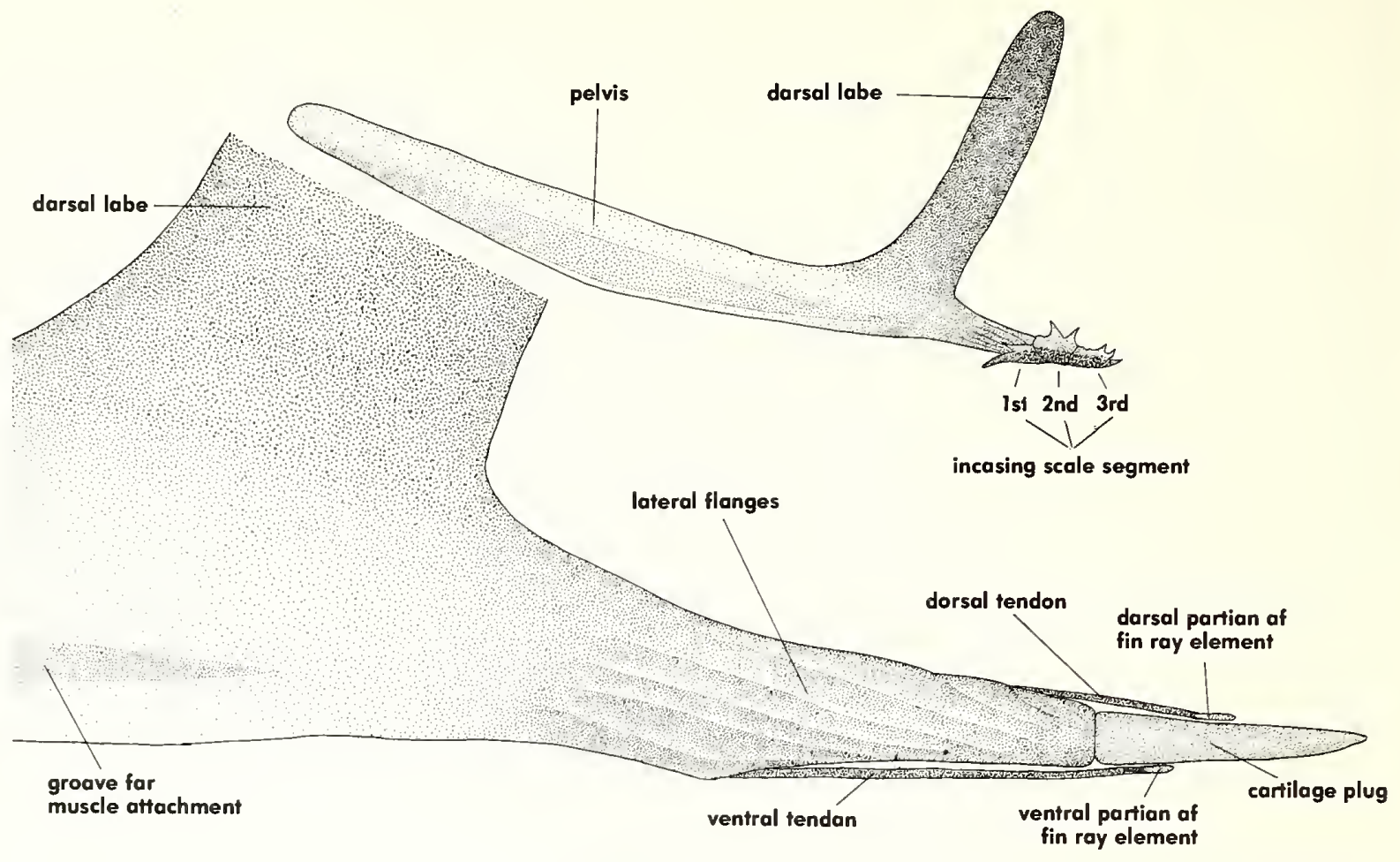

Figure 85.-Monacanthus ciliatus: above, lateral view of pelvis and encasing scales at end of pelvis which completely obscure from external view the rudimentary fin-ray element; below,

detail of the end of the pelvis, with the encasing scales removed to expose the rudimentary rin-ray element and its cartilage plug and tendons: $81.3 \mathrm{~mm} \mathrm{SL}$, Florida.

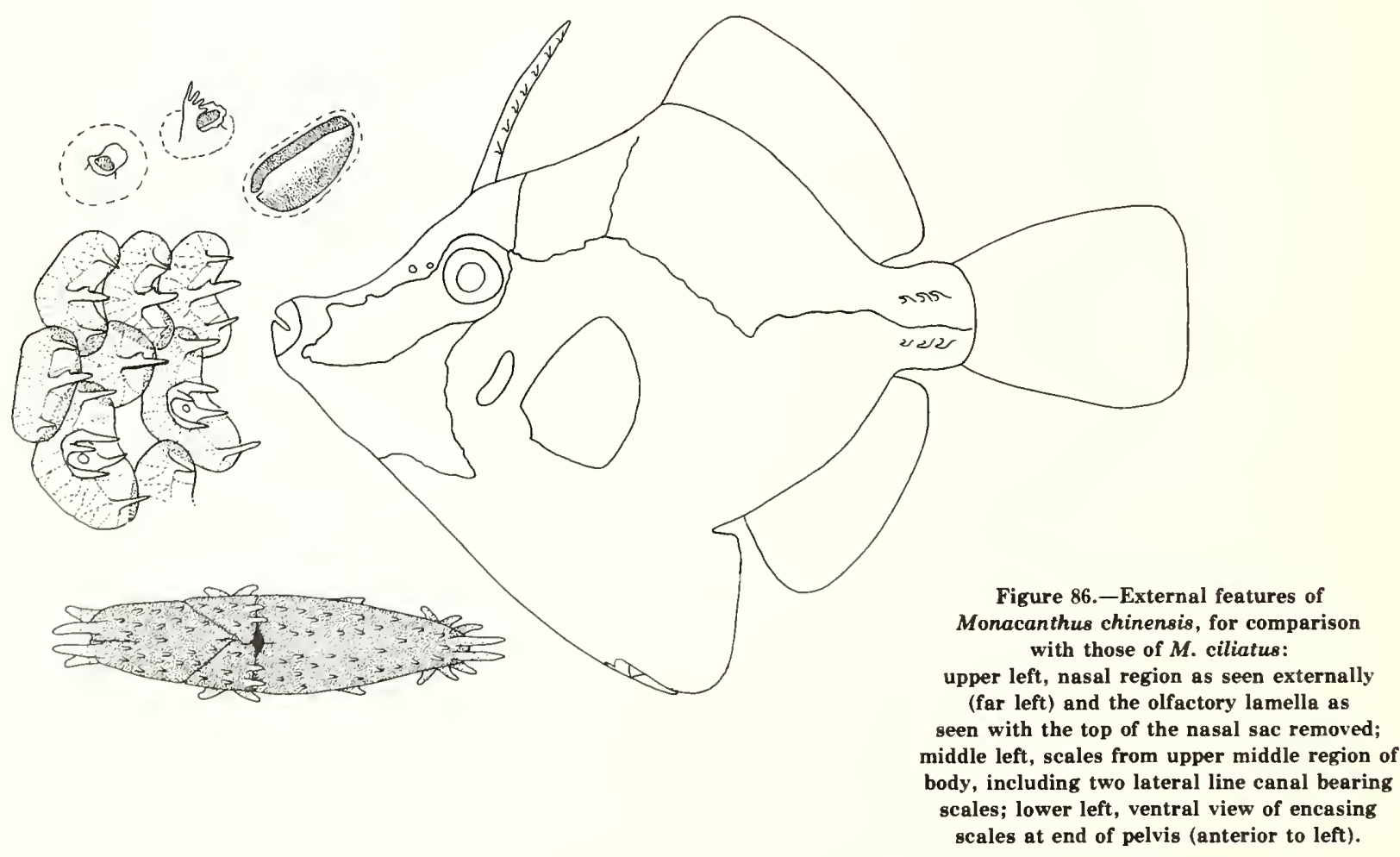


Figure 87.-External features of other representative monacanthid genera: Stephanolepis cirrhiferupper left, nasal region as seen externally (far left) and the olfactory lamella as seen with the top of the nasal sac removed; middle left, scales from upper middle region of body, including two lateral line canal bearing scales; lower left, ventral view of encasing scales at end of pelvis (anterior to left).

Figure 88.-External features of other representative monacanthid genera: Chaetoderma spinosissimusupper left, scales from upper middle region of body, including two

lateral line canal bearing scales; middle left, nasal region as seen externally (olfactory lamella, if present, indistinct in specimen examined); lower left, ventral view of encasing scales at end of pelvis (anterior to left).
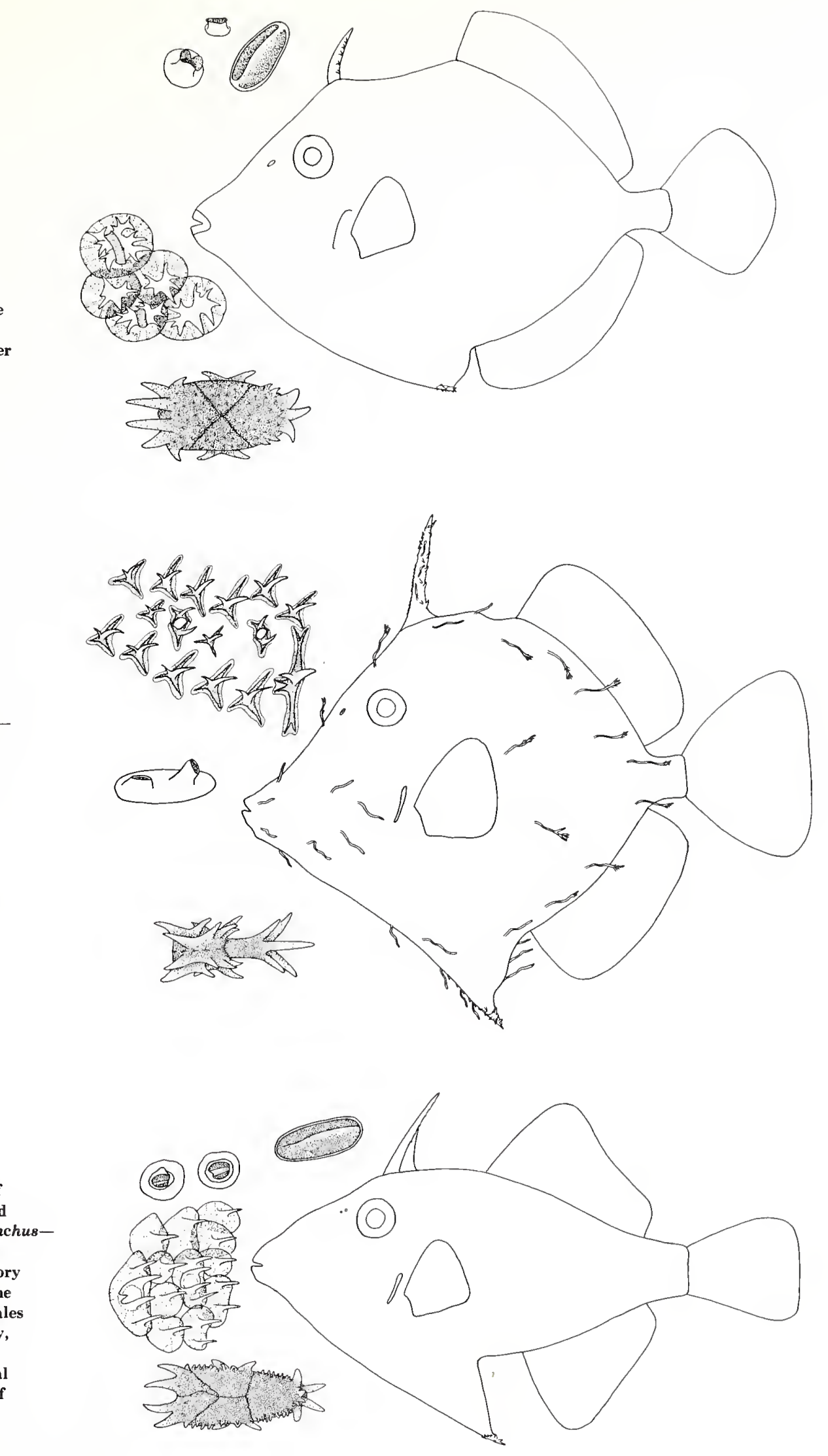

Figure 89.-External features of other representative monacanthid genera: Paramonacanthus curtorhynchusupper left, nasal region as seen cxternally (far left) and the olfactory lamella as seen with the top of the nasal sac removed; middle left, scales from upper middle region of body, including two lateral line canal bearing scales; lower left, ventral view of encasing scales at end of pelvis (anterior to left). 
Figure 90.-External features of other representative monacanthid genera: Pervagor melanocephalusupper left, nasal region as seen externally (far left) and the olfactory lamella as seen with the top of the nasal sac removed; middle left, scales from upper middle region of body, including three lateral line canal bearing scales; lower left, ventral view of encasing scales at end of pelvis (anterior to left).

Figure 91.-External features of other representative monacanthid genera: Rudarius ercodes - upper left, nasal region as seen externally (olfactory lamella, if present, indistinct in specimen examined); middle left, scales from upper middle region of body, including two lateral line canal bearing scales; lower left, ventral view of encasing scales at end of pelvis (anterior to left).
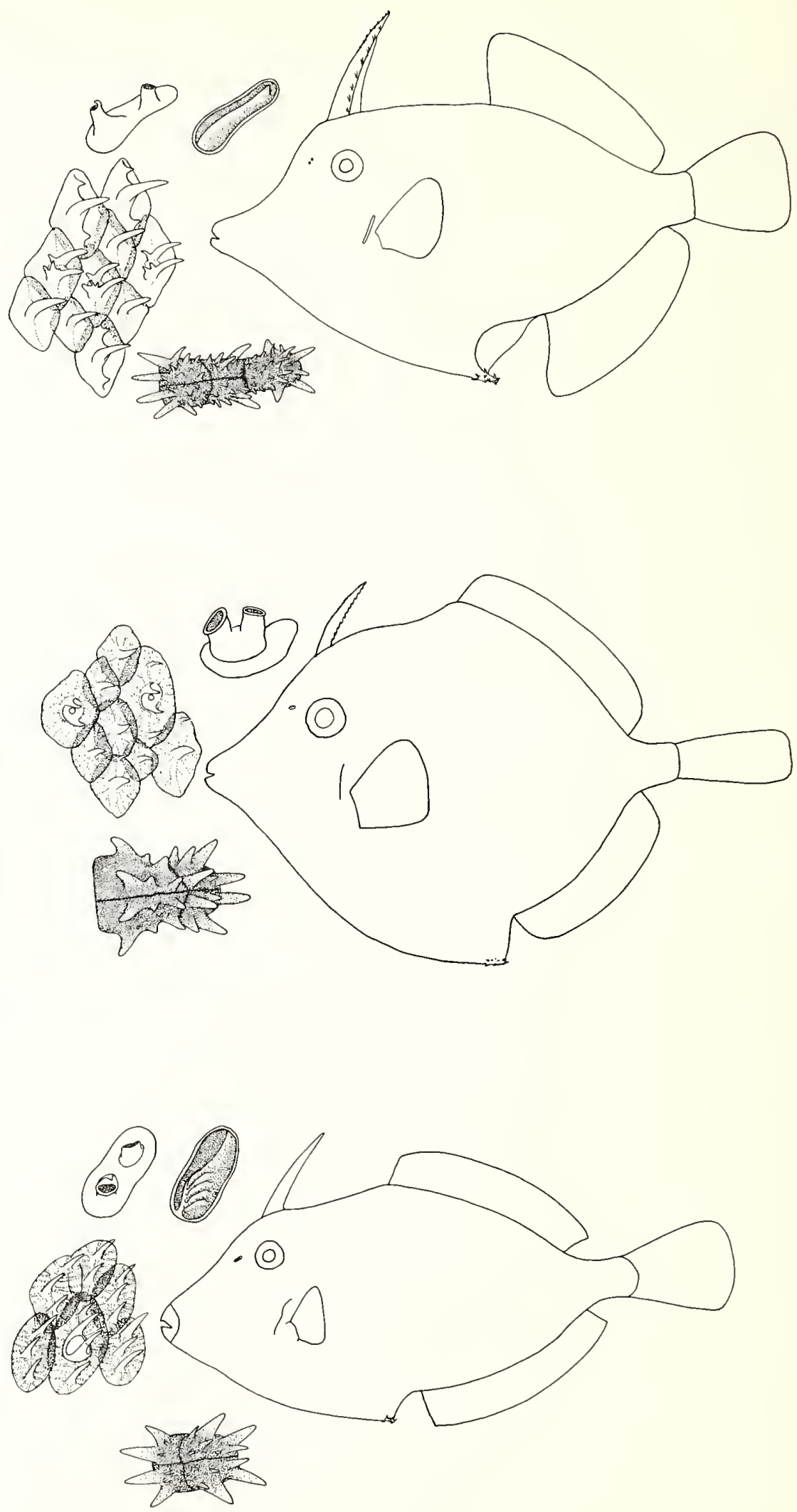

Figure 92.-External features of other representative monacanthid genera: Navodon hypocrepis - upper left, nasal region as seen externally (far left) and the olfactory lamellae as seen with the top of the nasal sac removed; middle left, scales from upper middle region of body, including a lateral line canal bearing scale; lower left, ventral view of encasing scales at end of pelvis (anterior to left). 
Figure 93.-External features of other representative monacanthid genera:

Eubalichthys spilomelanurus - upper left, nasal region as seen externally

(far left) and the olfactory lamella as seen with the top of the nasal sac removed;

lower left, scales from upper middle

region of body, including a lateral line canal bcaring scale; no encasing scales at end of pelvis (or below it).

Figure 94.-External features of other representative monacanthid genera:

Cantherhines pullus-upper left, nasal region as seen externally (far left) and the olfactory lamella as seen with the top of the nasal sac removed; middle left, scales from upper middle region of body, including two lateral line canal bearing scales; lower left, ventral view of encasing scales at end of pelvis (anterior to left).

Figure 95. - External features of other representative monacanthid genera: Amanses scopas-upper left, nasal region as seen externally (far left) and the olfactory lamellae as seen with the top of the nasal sac removed; middle left, scales from upper middle region of body, none of which have apparent lateral line canals or pores; lower left, ventral view of encasing scaies at end of pelvis (anterior to left).

Figure 96.-External features of other representative monacanthid genera: Alutera monoceros-upper left, nasal region as seen externally (far left) and the olfactory lamella as seen with the top of the nasal sac removed; lower left, scales from upper middle region of body, including a lateral line canal bearing scale; no encasing scales at end of pelvis (or below it).
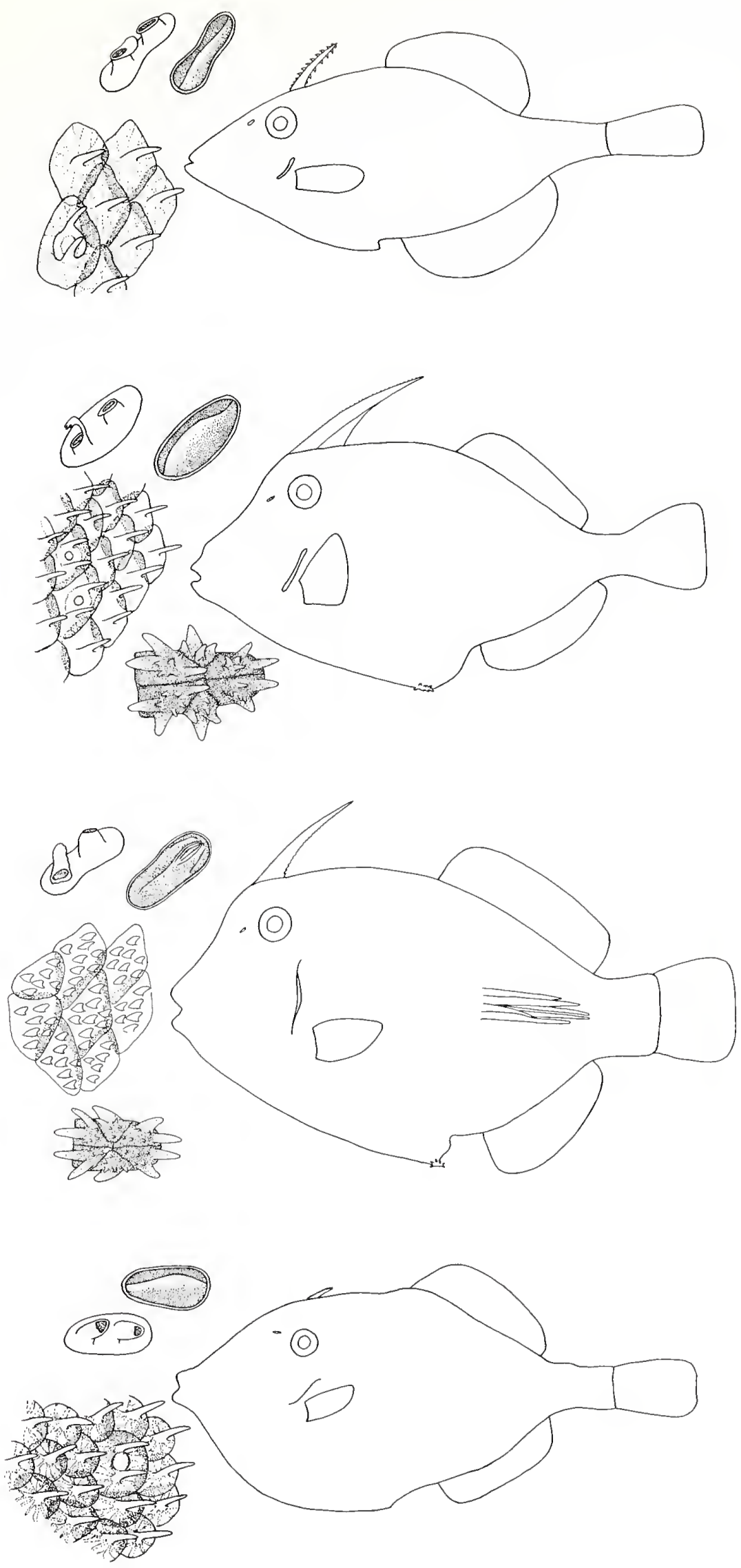
Figure 97.-External features of other representative monacanthid genera: Psilocephalus barbatus-upper left,

nasal region as seen externally

(olfactory lamella, if present,

indistinct in specimen examined); lower left, scales from upper middle region of

body, including a series of numerous

lateral line canal bearing scales; no

encasing scales at end of pelvis (or below it).

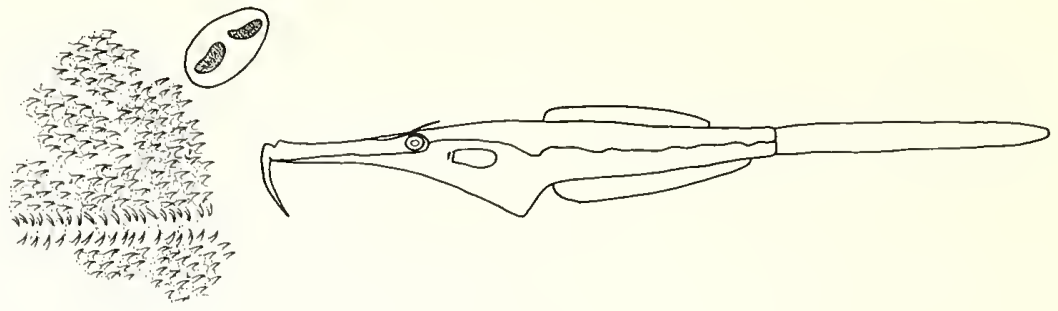

Figure 98. - External features of other representative monacanthid genera: Oxymonacanthus longirostris-upper left, scales of upper middle region of body, including three lateral line canal bearing scales; middle left, nasal region as seen externally (olfactory lamella, if present, indistinct in specimen examined); ventral view of encasing scales at end of pelvis (anterior to left).

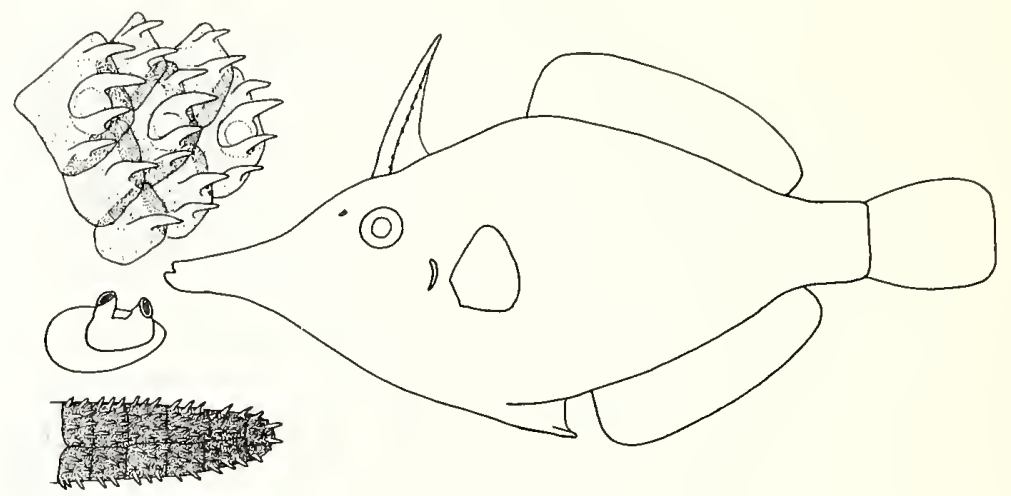

Figure 99.-External features of other representative monacanthid genera: Pseudaluteres nasicornis-upper left, nasal region as seen externally (olfactory lamella, if present, indistinct in specimen examined); lower left, scales of upper middle region of body (specialized lateral line canal or pore-bearing scales absent); no encasing scales at end of pelvis (or below it).

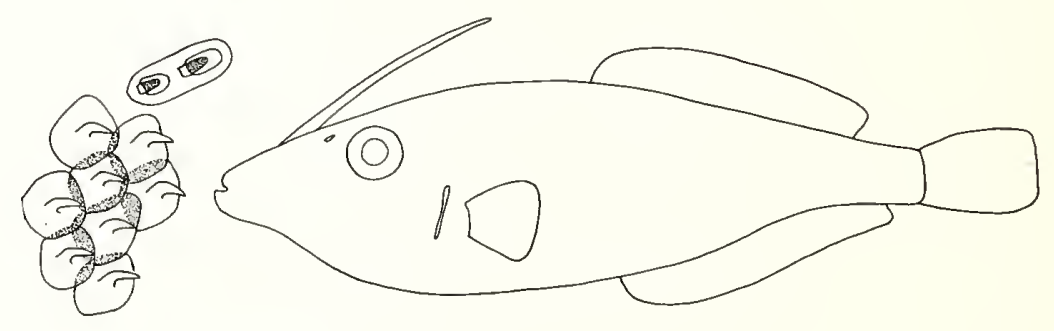

Figure 100.-External features of other representative monacanthid genera:

Paraluteres prionurus-upper left, nasal

region as seen externally (olfactory

lamella, if present, indistinct in specimen examined); lower left, scales from upper middle region of body, including a lateral line canal bearing scale; no encasing scales at end of pelvis (or below it).

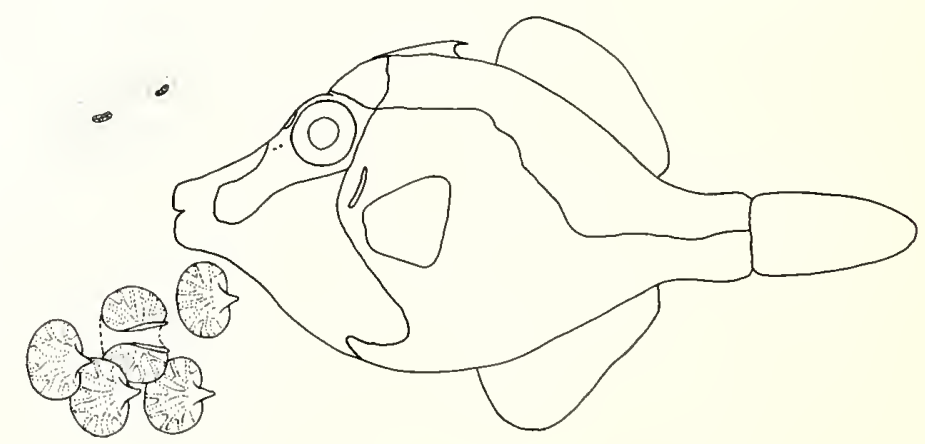


Figure 101.-External features of other representative monacanthid genera: Brachaluteres trossulus-upper left, nasal region as seen externally (olfactory lamella, if present, indistinct in specimen examined); lower left, scales from upper middle region of body, including a lateral line canal bearing scale; no encasing scales at end of pelvis (or below it).

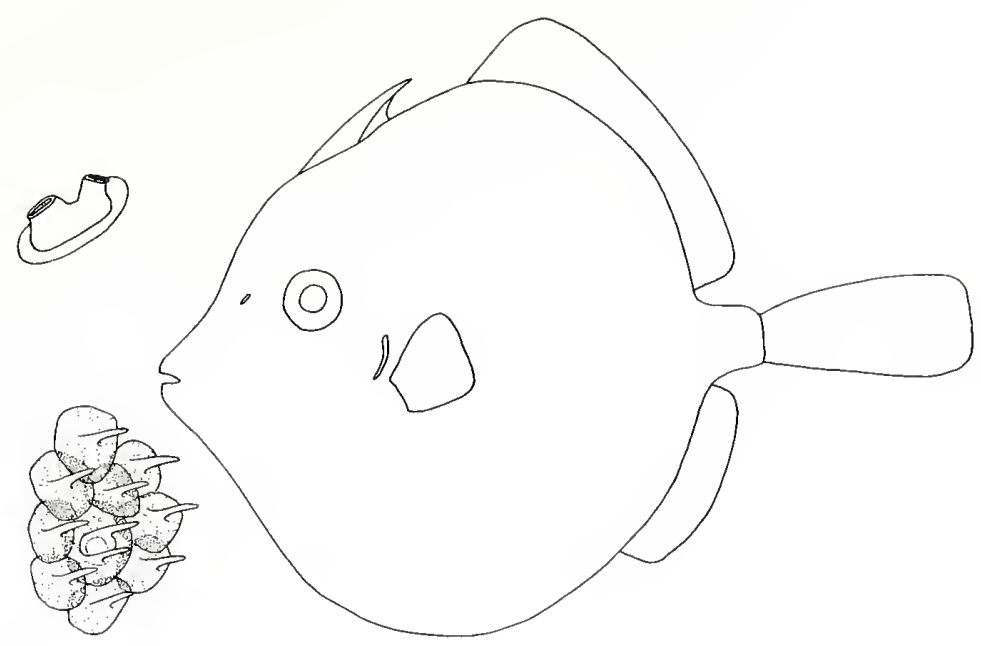

The size and shape of the basal pterygiophore supporting the spiny dorsal fin are highly diverse among the monacanthids. It is expectedly least developed in Psilocephalus, in which only a single, short, thin rudimentary spine is present. The basal pterygiophore of Psilocephalus is a thin triangular bone (as seen in lateral view) whose dorsal edge is only slightly expanded laterally and whose ventral edge is held by fibrous tissue only anteriorly to the dorsal surface of the supraoccipital. The dorsal surface of the pterygiophore at the place of articulation of the spine is only slightly expanded laterally and upraised to support the equally only slightly laterally expanded base of the spine, the whole mechanism being far less complex than in other monacanthids.

In all other monacanthids the basal pterygiophore is relatively much larger and sturdier than in Psilocephalus. Most typically, as illustrated for Monacanthus ciliatus, it is a large bone whose flattened or gently curved ventral surface is closely applied by fibrous tissue and sometimes interdigitation to the dorsal surface of the skull from the level of the front or middle of the eye posteriorly, obscuring much of the supraoccipital from view. It is laterally expanded in about the middle of its length into two thick buttresses supporting the articular facets of the base of the first spine, while posteriorly an upraised medial buttress supports the second spine, posterior to which the basal pterygiophore becomes a thick vertical plate with a laterally expanded, slightly concave, dorsal edge. Anterior to the large lateral expansion supporting the first spine, the pterygiophore rapidly narrows into a thinner vertical plate whose dorsal edge is slightly expanded laterally and either flattened or convex. The region of the pterygiophore posterior to the second spine is supported mainly by the epiotics, while the middle region is supported by the supraoccipital, and, especially in the case of the buttresses for the first spine, by the frontals. Anterior to the first spine, the laterally compressed portion of the pterygiophore is supported by the frontals alone in most genera, but by the supraoccipital as well in those three genera (Monacanthus, Stephanolepis, Paramonacanthus) in which that bone extends far forward above the orbit as a low vertical crest (the possible phylogenetic significance of which is discussed under the section on generic relationships).

The above applies well to most of the genera in which the first dorsal spine is above or behind the middle of the eye, with the basal pterygiophore extending from behind the skull to about the level of the front of the eye. In Paraluteres, with the dorsal spine distinctly in front of the eye, the basal pterygiophore is enormously elongate, reaching nearly the entire length of the skull, although it retains the same basic makeup as in more normal monacanthids. The basal pterygiophore in Paraluteres articulates posteriorly with the supraoccipital, which it broadly overlies, and along the ventral edge of its laterally compressed plate with the epiotics, while the middle twothirds of its length is firmly held to the frontals and its anterior end to the ethmoid. Many of the specializations of Paraluteres are associated with its mimetic relationship with a Canthigaster pufferfish (Tyler 1966).

The basal pterygiophore in the especially deep-bodied Chaetoderma is very high and domelike, while in the species of Alutera it is slightly smaller than in most other monacanthids, having only a short anterior vertical crest in front of the level of the first spine, and the pterygiophore is not as broadly held ventrally to the supraoccipital and epiotics.

In two genera the basal pterygiophore is of more or less normal size in lateral surface area, but much thinner than in other monacanthids (Psilocephalus excepted). In the deep-bodied Brachaluteres the pterygiophore supporting the single but well-developed dorsal spine is especially high, but it is much thinner and less heavy than normal, the buttresses for the spine being only slightly expanded laterally and most of the surface of the pterygiophore being a thin compressed plate. In Paraluteres, in which the two skin covered dorsal spines are probably not fully erectible in life, the pterygiophore is of reduced sturdiness and of relatively short length, although the buttressing for the spines is more or less normal.

In comparison to the spiny dorsal fin, there is even 
greater diversity in the pelvic apparatus of monacanthids. The number of segments of scales in the encasing series ranges from three to two to one to none, and a rudimentary fin ray represented by a pair of bony splints above and below a plug of cartilage at the end of the pelvis is variously present or absent. The encasing scales are either flexible or fixed, the dorsal lobe to the pelvis varies from greatly to only slightly developed or absent altogether, and the pelvis itself ranges from relatively massive and extending to the region of the anus to slender and reduced in length.

In what can be considered the most generalized condition of the pelvic apparatus in monacanthids (i.e., the least reduced from that of balistids), the pelvis is welldeveloped and has at least a moderate dorsal lobe, the encasing scales are flexible and in three series, and a finray element is present as two bony splints. This generalized condition is found in Monacanthus, Paramonacanthus, Stephanolepis, Pervagor, and Laputa. Tendons attach to the splints and run forward to muscles on the dorsal and ventral surface of the pelvis, the dorsal tendon passing through a horizontal tube in the basal region of the dorsal lobe, as described by Tyler (1962b) for Monacanthus ciliatus. The splints representing the fin-ray element are of moderate size, about like that illustrated by Tyler (1962b) for $M$. ciliatus, in all of the species examined of the above genera, except that they are longer in $M$. mylii and $M$. chinensis and shorter in Paramonacanthus barnardi. In one other genus a fin-ray element and flexible encasing scales are present, this being the monotypic Chaetoderma, in which there are only two series of encasing scales and the fin-ray splints are minute. The only genus not examined which has a flexible encasing scale series, Arotrolepis, can be expected to have fin-ray splints.

In all of the genera examined in which the encasing scales are fixed or absent, the fin-ray splints are absent, although in a few species tendons still attach to the small cartilaginous plug at the end of the pelvis, as described by Tyler (1962b) for Cantherhines sandwichiensis. Tyler (1962b) attributed three series of encasing scales to that species. Examination of additional specimens of $C$. sandwichiensis and of other species of Cantherhines makes it unclear to me now whether the scales are in two or three series; perhaps it should be counted as two and a half series, the half series being a pair of scales scarcely if at all meeting in the midline ventrally between the larger anterior and posterior pair. Whether these represent two or three series of scales is problematical, but, in any case, when the encasing scale series is inflexible, the length of the series is shorter than in those genera in which there are clearly three series and in which flexibility is present.

Of the genera examined with an inflexible series, there are two and a half or clearly only two series of encasing scales in Amanses, Cantherhines, Navodon, and Acanthaluteres, and there is no fin-ray element. This is probably also the case in the other genera with fixed encasing scales: Scobinichthys, Pseudomonacanthus, and Meuschenia; and, questionably, in Eubalichtys, as discussed below. In Rudarius there are two series of encasing scales and no fin-ray element in $R$. ercodes, but only a single series and no ray in $R$. minutus, the reduction of the series into a single, although highly spinous, series in the latter perhaps being associated with the extremely small adult size of that species. In Oxymonacanthus there is no fin-ray element and no precisely delineated series of encasing scales; rather, the scales bordering the ventral surface of the posterior end of the pelvis simply gradually become larger and more spinous distally so that the encasing scales are of indeterminate number.

The genus Alutera provides an example of the process of loss of the encasing scales. No fin-ray element is present, but Berry and Vogele (1961) have shown that in small specimens of three of the four species ( $A$. heudelotii, $A$. scripta, and $A$. monoceros) there is a single enlarged spinous scale present on the midline below the ventral edge of the pelvis, this being the last remnant of the encasing scales. This scale becomes unornamented and then lost in large adults. In $A$. schoepfi there is no rudimentary encasing scale at any size (Berry and Vogele 1961).

In Acanthaluteres, the specimens of the single species here examined (spilomelanurus, if I have it properly identified, and I am not sure) lack encasing scales, whereas Fraser-Brunner (1941b:178) gives as a key character for the genus "Pelvic shield present at all stages (sometimes minute or inconspicuous)." It is possible that there are allometric changes in the encasing scales, just as in Alutera. This may also be true of Eubalichthys, of which Fraser-Brunner (1941b:180) says: "Pelvic shield minute, inconspicuous."

There are no encasing scales or fin-ray elements in Psilocephalus, Brachaluteres, Paraluteres, and Pseudaluteres, and, according to Fraser-Brunner (1941b:181), in Blandowskius.

The structure of the pelvis itself is highly diversified in monacanthids. In those species with flexible encasing scales, the pelvis is always, relatively well developed and has a dorsal lobe of at least moderate height. The dorsal lobe is largest in the genus Monacanthus, the species of which are noted for the especially large size of the fan of distensible skin with enlarged scales that can be flared out between the anus and pelvis when the latter is rotated downward and forward. However, the presence of a dorsal lobe is not absolutely correlated with the expansion of the abdominal dewlap, for one genus (see below) without a lobe has the ability to flare a remarkably large fan.

In general, however, most of the genera (Pseudaluteres, Paraluteres, Brachaluteres, Alutera) without a dorsal lobe also do not flare fans, the exception being Psilocephalus, which not only has no dorsal lobe but also the most slender and weakly developed pelvis in the family, and yet can flare as large a fan as in Monacanthus. The presence of a dorsal lobe is probably more strictly correlated with the presence of enlarged scales along the posterior edge of the fan, these scales being supported by the lobe. The scales along the posterior 


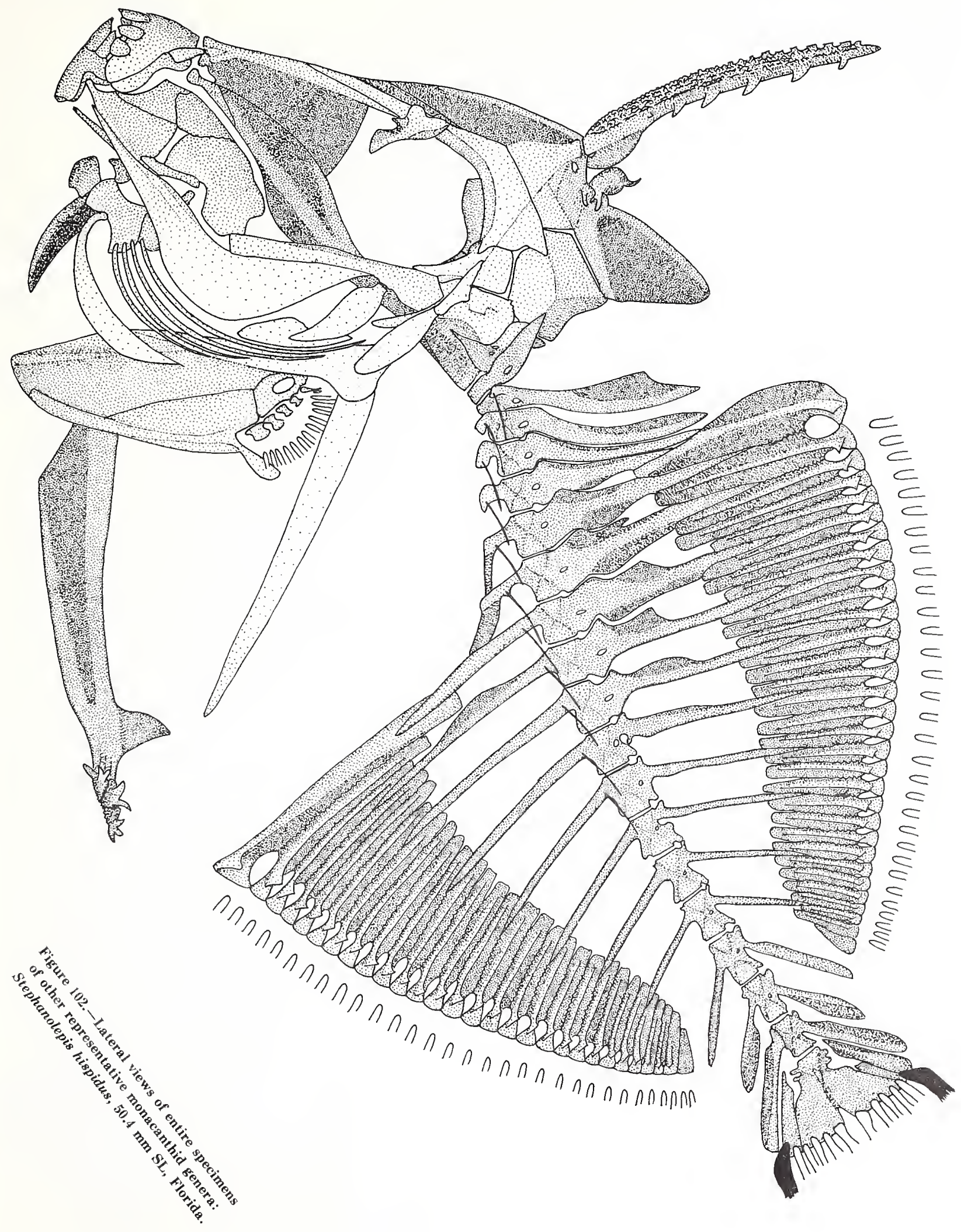




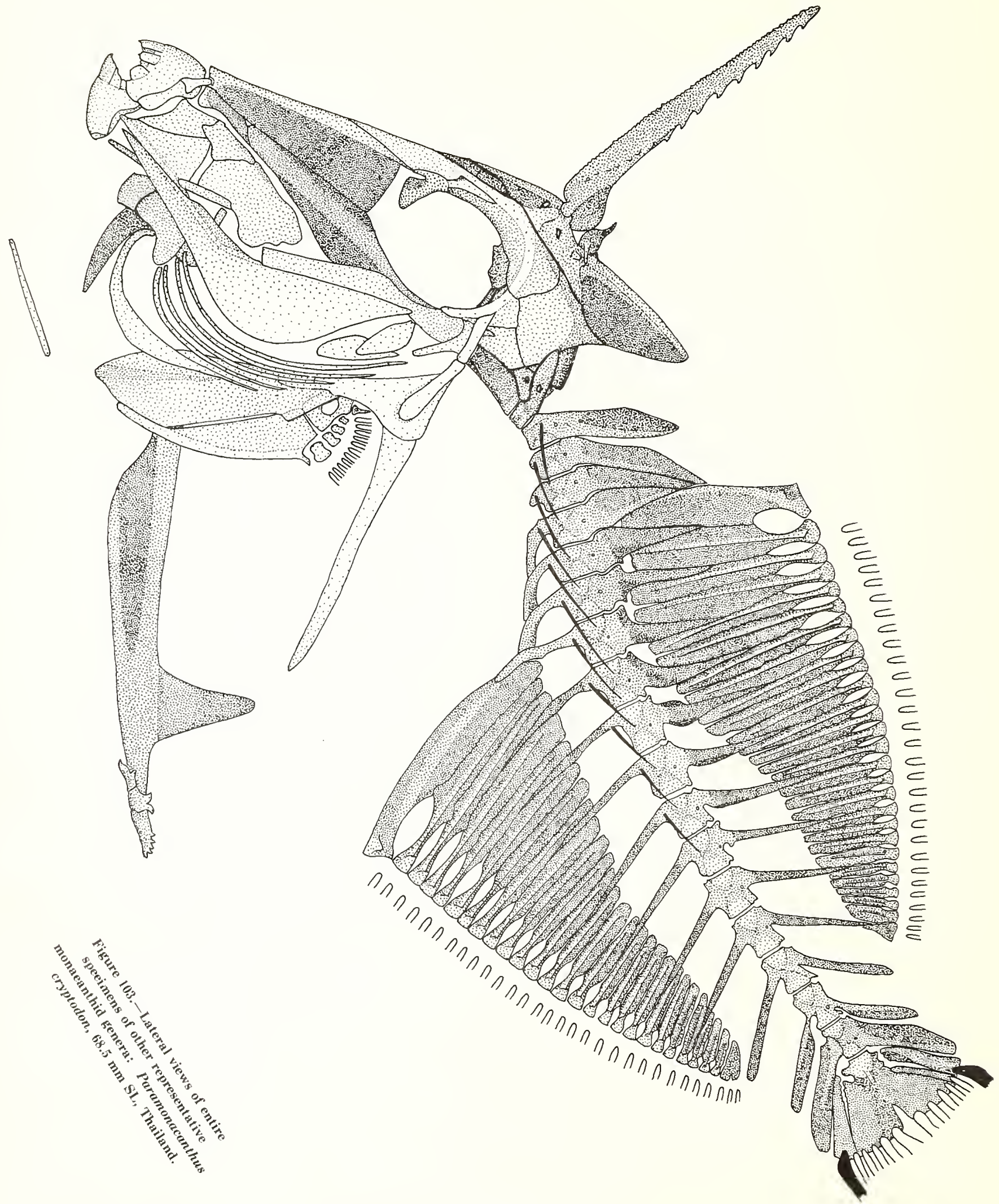




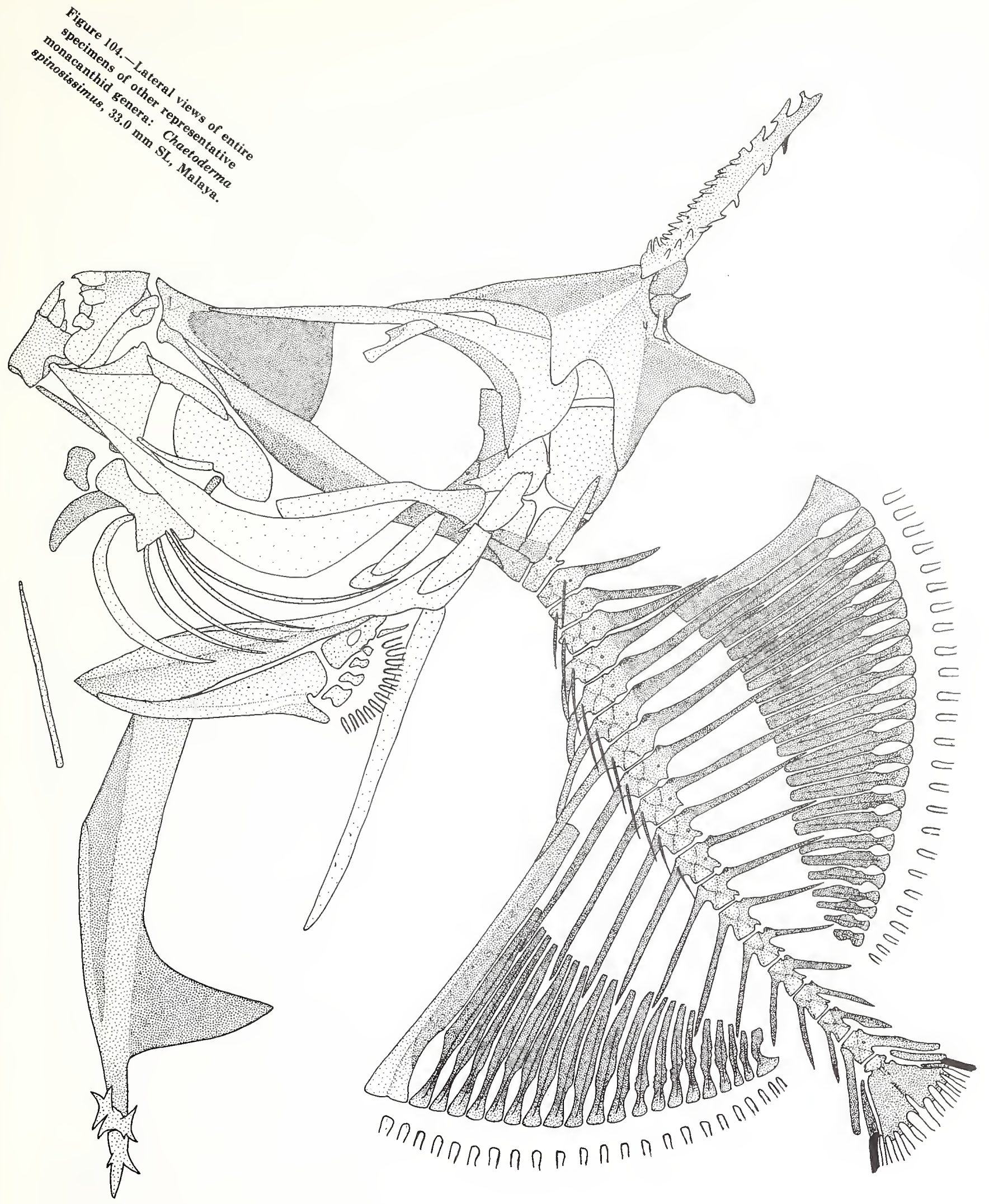




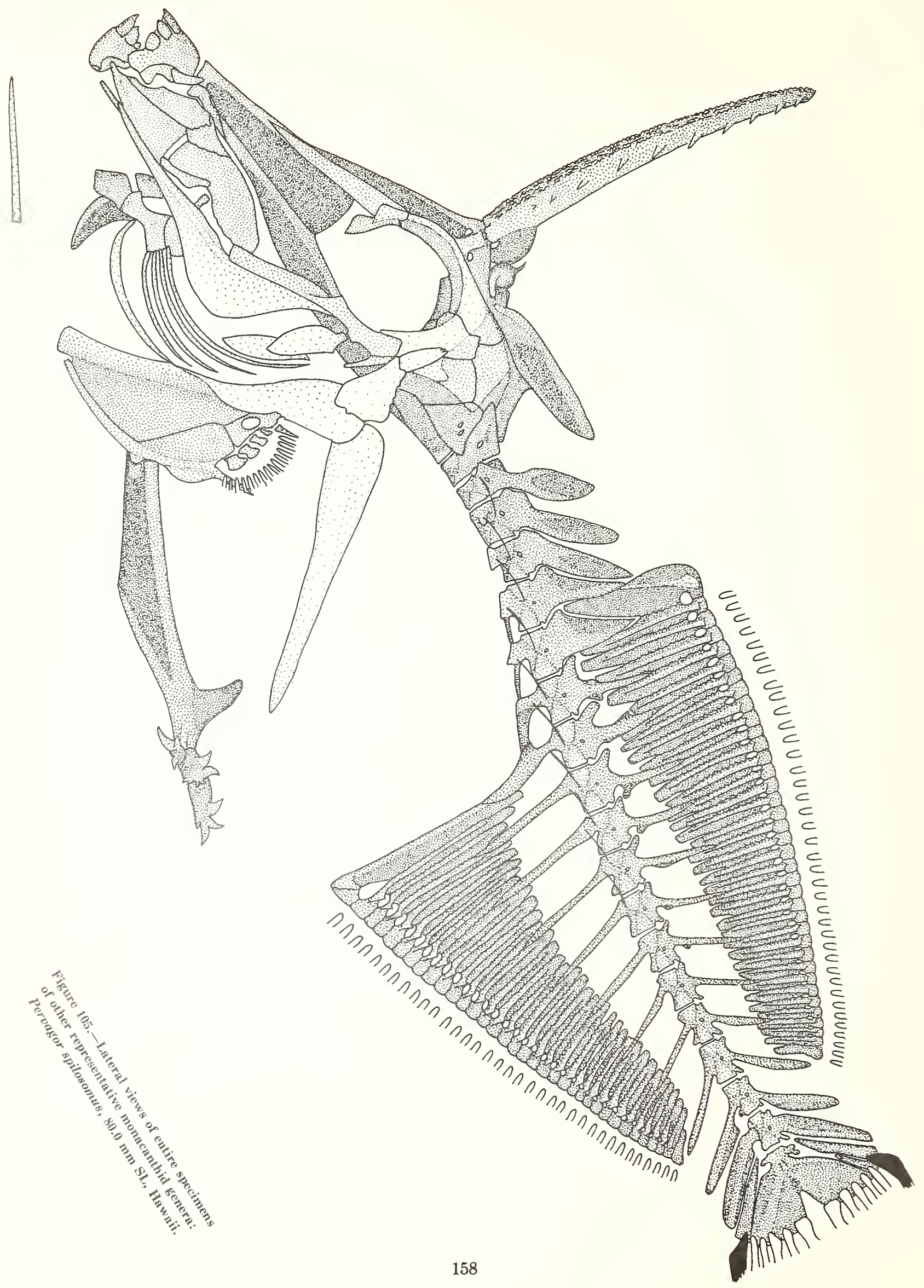




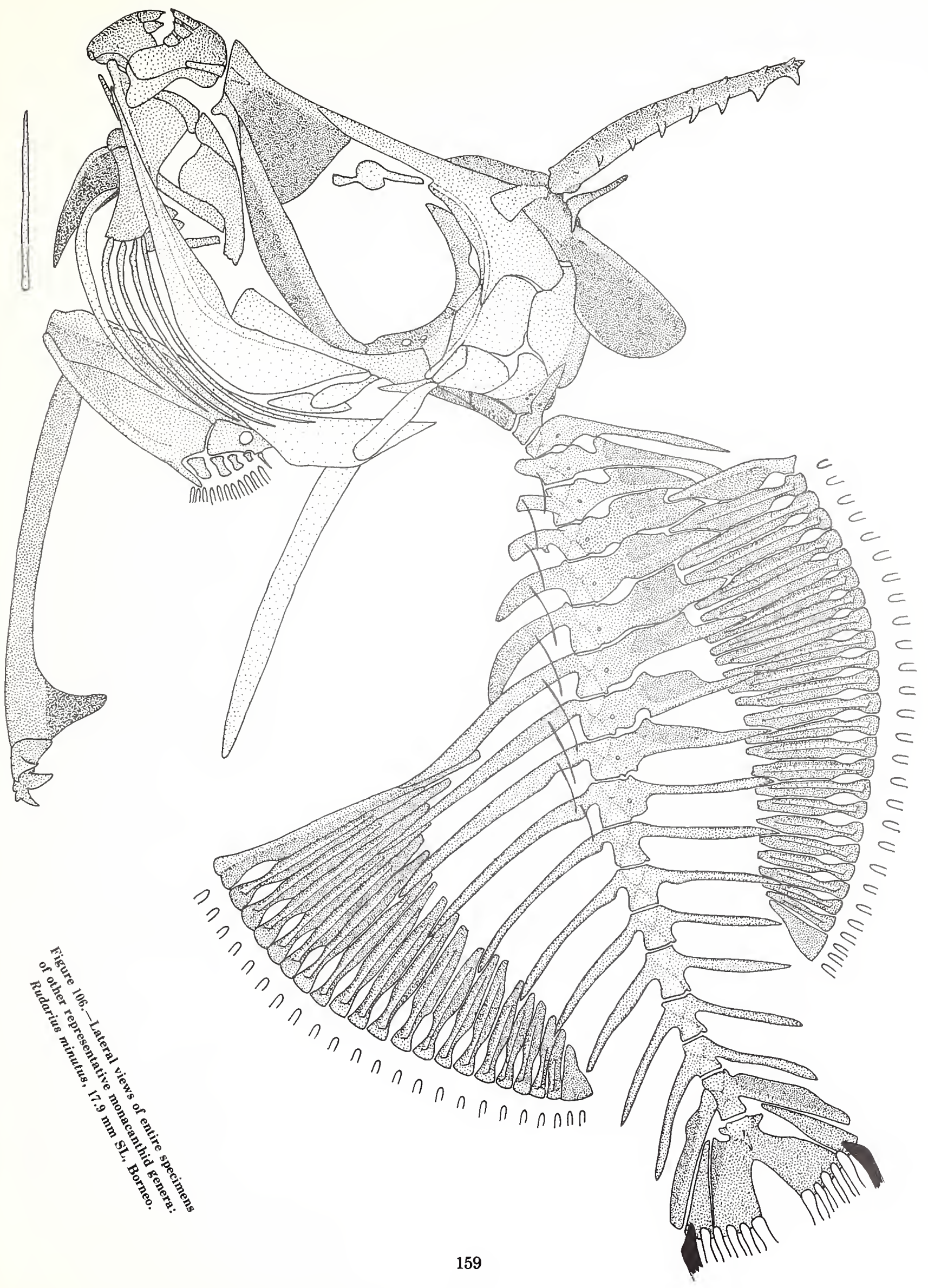




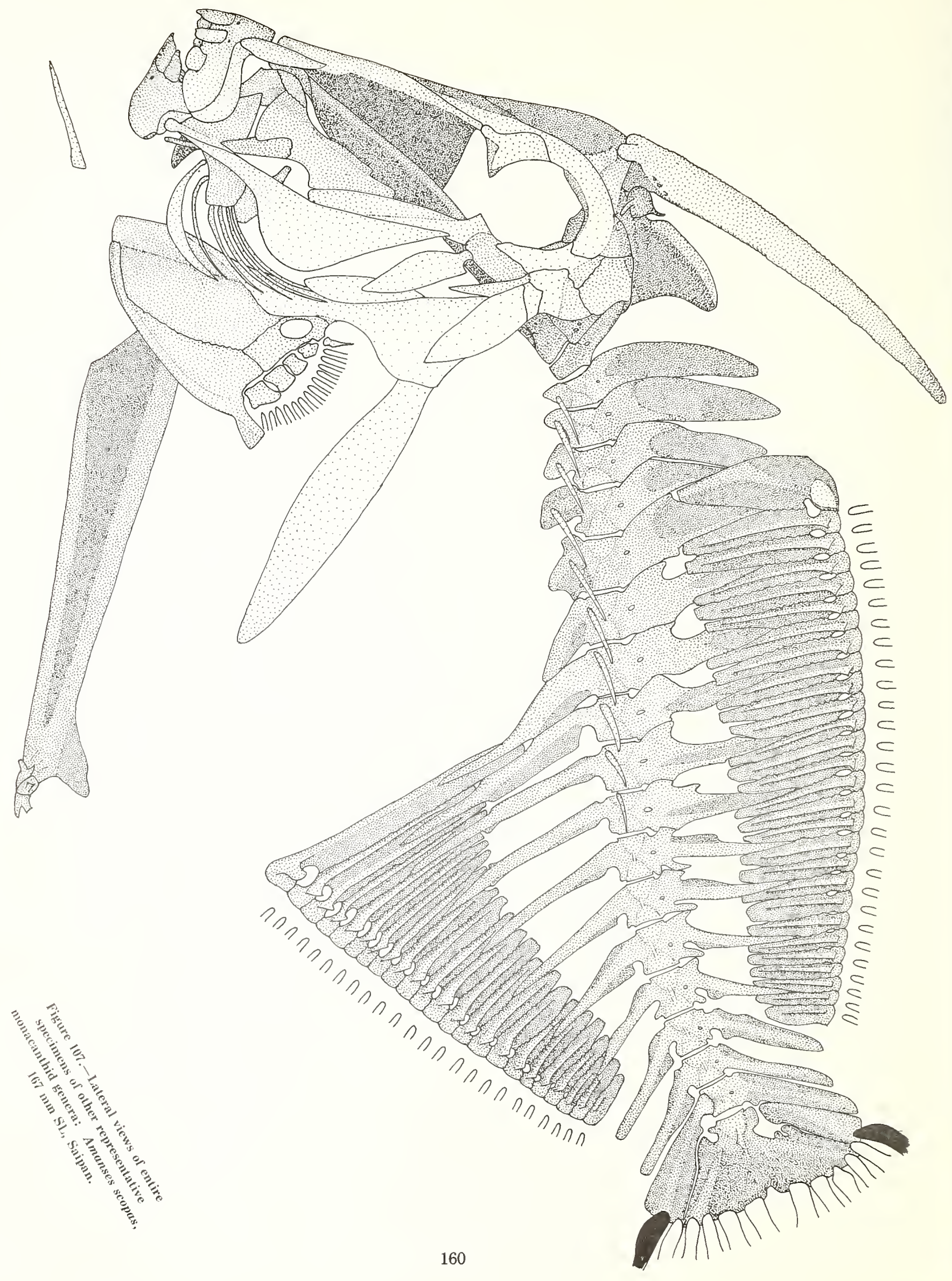



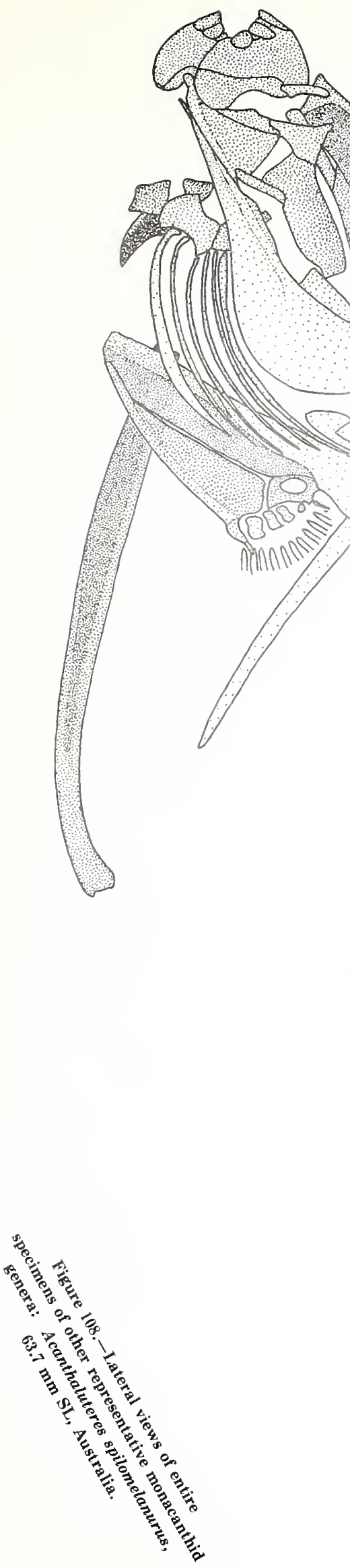


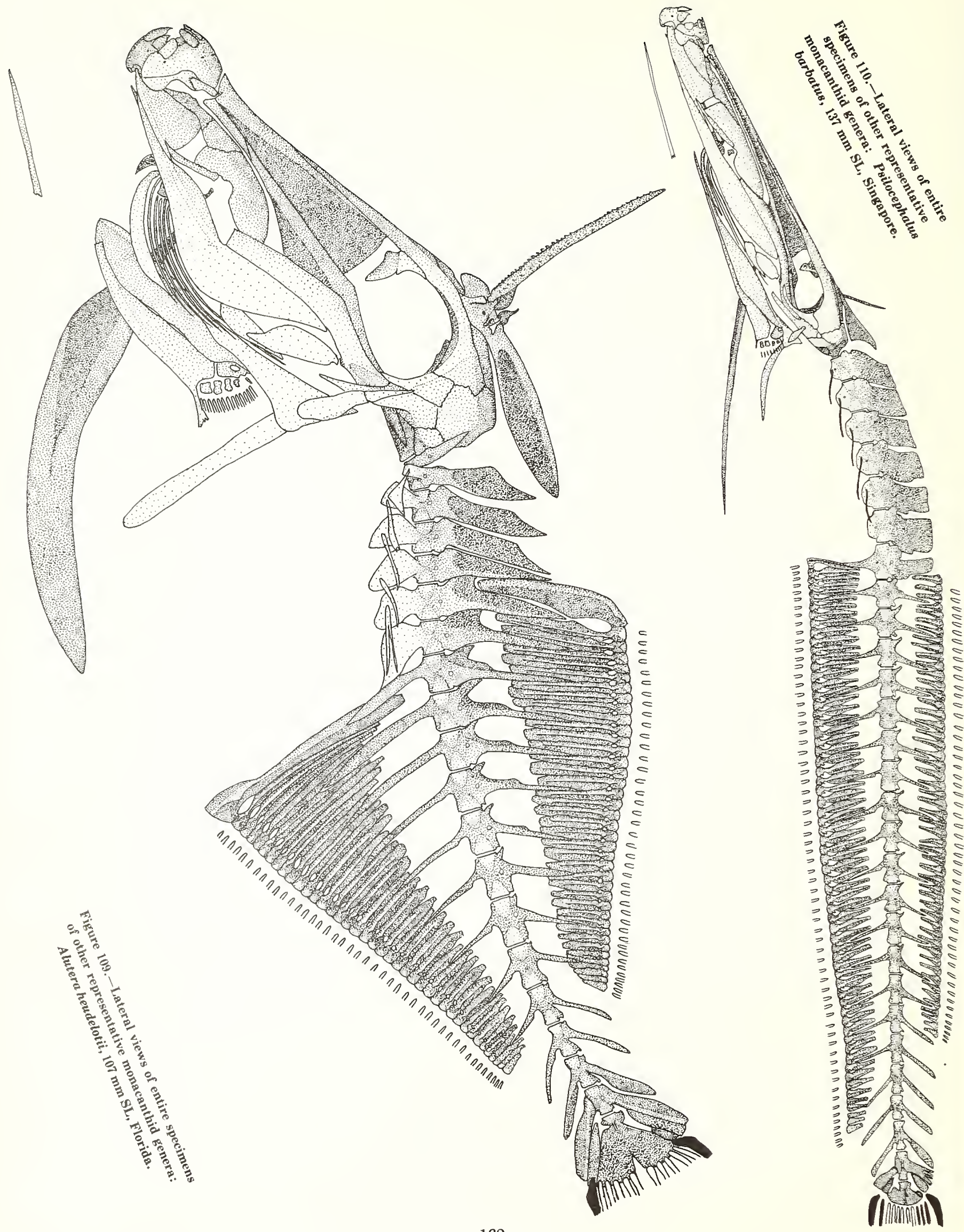




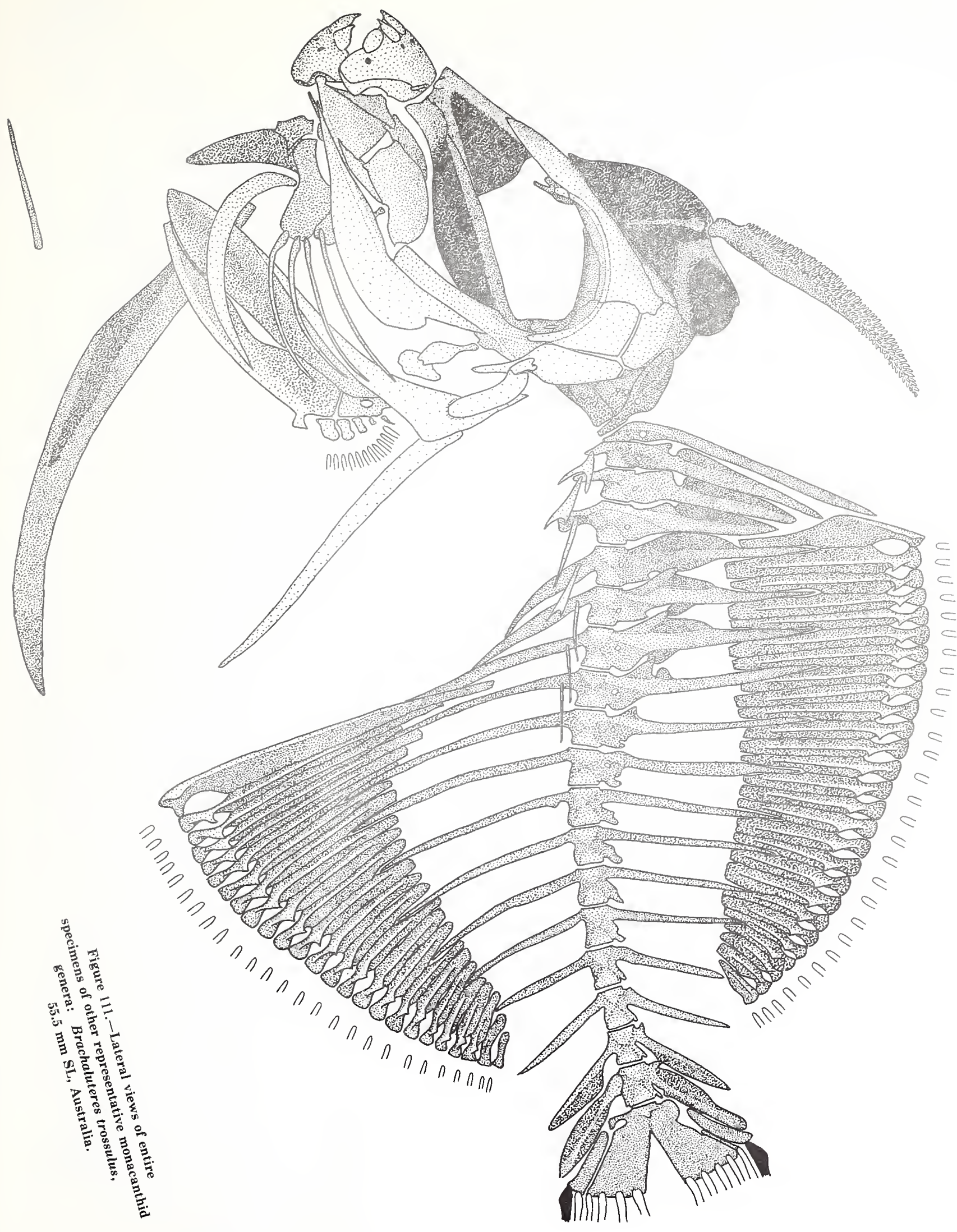




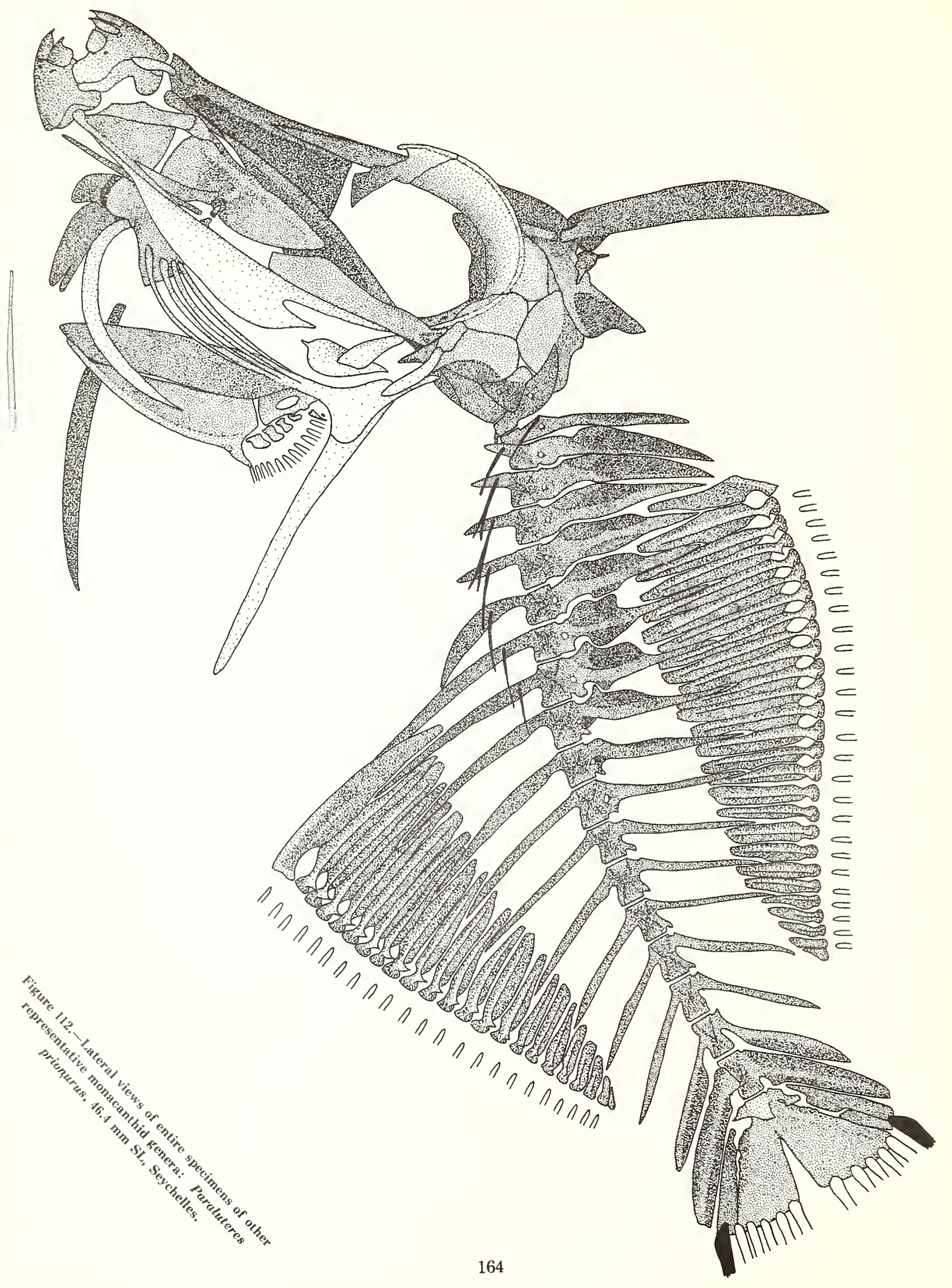




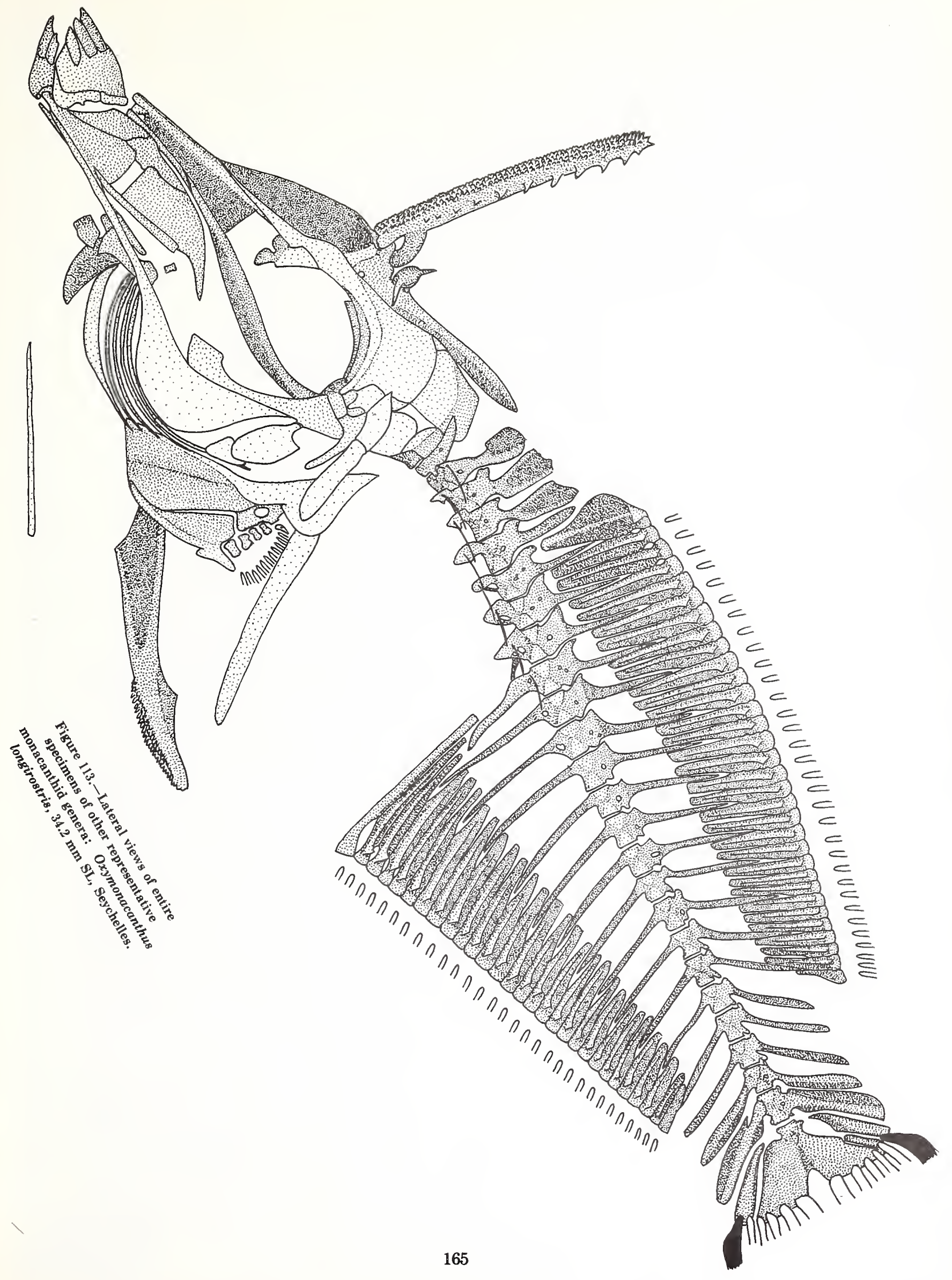




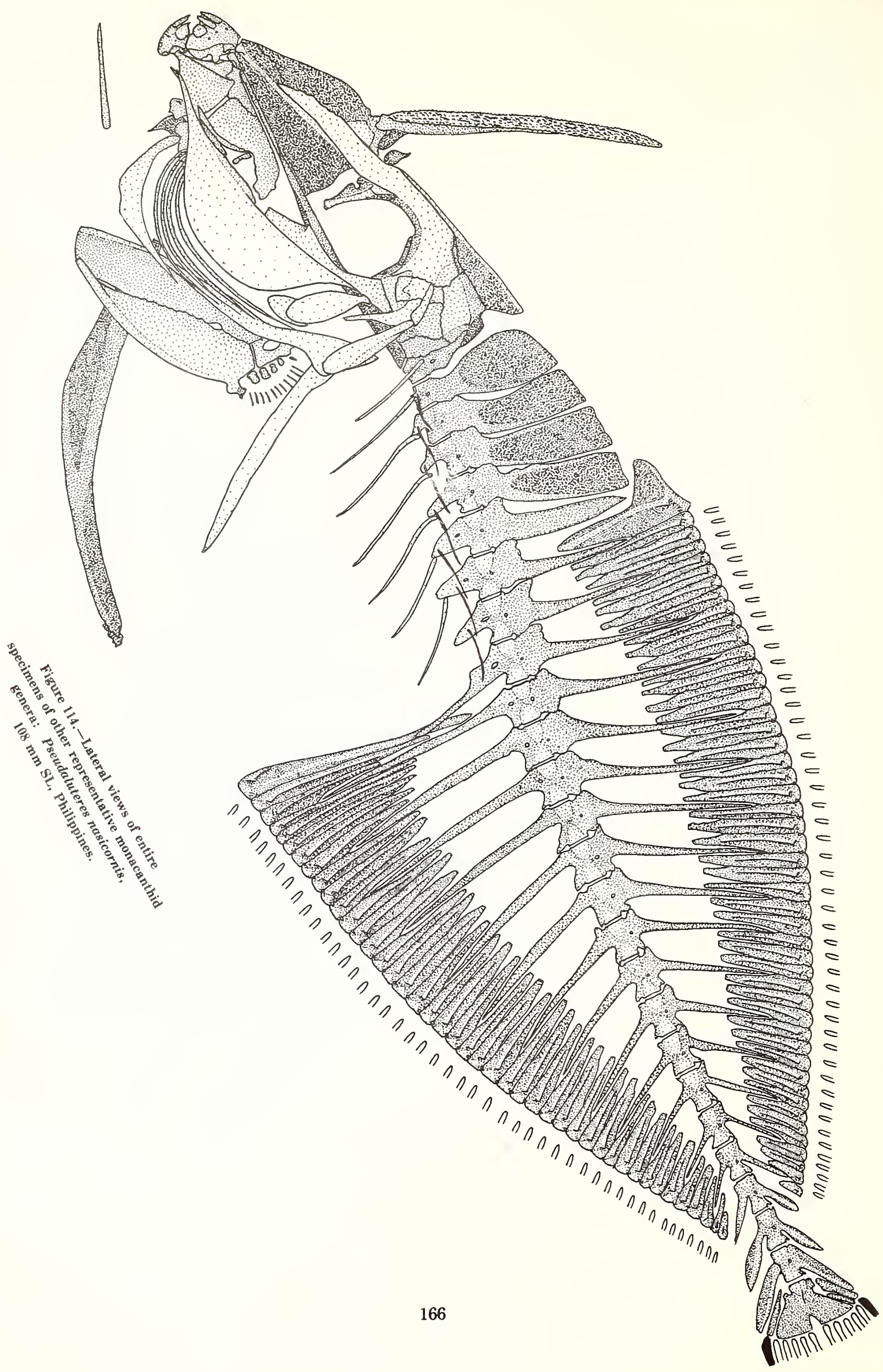


edge of the fan in Psilocephalus are not much enlarged or differentiated from those just anterior to them. The dorsal lobe is poorly developed in Oxymonacanthus, which flares only a small or moderate sized fan and which has no modified scales in the fan.

Of the genera with fixed encasing scales, the pelvis ranges from very strongly (e.g., Amanses) to only moderately (e.g., Oxymonacanthus) developed. Of the genera with no encasing scales, none have a dorsal lobe, and the size of the pelvis ranges from massive (e.g., Alutera), to normal (Brachaluteres), to slightly reduced in size (Pseudaluteres and Acanthaluteres), to short and somewhat slender (Paraluteres), and to long but very weak and slender (Psilocephalus).

In Pervagor alone the lateral surface of the anterior region of the pelvis has a lateral knoblike expansion which articulates with a similar expansion on the posterior edge of the coracoid, forming the point of pivot around which the pelvis is rotated downward and forward to flare the fan.

There is little variation in the branchial apparatus in the monacanthids, except for the number of branchiostegal rays. All species with the exception of Psilocephalus barbatus have three basibranchials, three hypobranchials, five ceratobranchials (the last toothless), four epibranchials, and two pharyngobranchials (both toothed). In Psilocephalus there are only two basibranchials and three epibranchials, and all of the various pieces in the arches are more or less reduced in massiveness, although the ceratobranchials are more elongate.

There are six branchiostegals in a $2+4$ arrangement in the various species examined of Navodon, Acanthaluteres, Alutera, Cantherhines, and Amanses, but only four branchiostegals, in a $1+3$ arrangement, in Psilocephalus. The great majority of species examined, however, have five branchiostegals, in a $1+4$ arrangement, these being of the genera Monacanthus, Stephanolepis, Paramonacanthus, Pervagor, Laputa, Rudarius, Oxymonacanthus, Chaetoderma, Paraluteres, Brachaluteres, and Pseudaluteres. When five rays are present, it is the second of the anterior group of two that has been lost, while in Psilocephalus, with four rays, one has also been lost from the posterior series of four. It is of interest that of 12 specimens of Monacanthus ciliatus examined, 11 had the $1+4$ arrangement on both sides, but one had $1+4$ on one side and $2+4$ on the other, the second ray of the anterior group being present on one side only.

There are great differences in the number, size, and placement of epipleural bones in monacanthids, which has led to confusion. Fraser-Brunner (1941b:176), in his diagnoses of the Balistidae and Monacanthidae, stated that in balistids epipleurals were found on no more than the first two caudal vertebrae, while monacanthids had epipleurals on the first four or five caudal vertebrae. From the materials examined here, it appears that most balistids have epipleurals on the second abdominal to the first caudal vertebra, but in the species of the genus Rhinecanthus they extend back from the second abdominal to the fifth or even sixth caudal vertebra. In most monacanthids the epipleurals begin on the second abdominal vertebra and usually but not always extend onto the caudal vertebrae. However, in a number of species the epipleurals are confined to the abdominal vertebrae. In the species of Alutera, for example, the epipleurals extend from the second abdominal only to the sixth (next to last) or, rarely, seventh (last) abdominal vertebra, while in Pseudaluteres they are present from the second to the eighth (next to last) abdominal vertebra and in Psilocephalus from the second to sixth (next to last) abdominal vertebra. As an examination of the lateral view illustrations of monacanthids presented here will show, the epipleurals of other genera extend posteriorly variously anywhere from the first to fifth caudal vertebrae, while in Rudarius (both ercodes and minutus) and Brachaluteres they are present only from the third abdominal to the second to fourth caudal vertebrae, being absent on the second abdominal vertebra. Thus, here is no absolute familial distinction concerning the epipleurals between the balistids and monacanthids.

The epipleurals in monacanthids are usually slender splints, less sturdy than in most balistids, but they are very sturdy in at least the single large adult of Amanses examined, and relatively well developed with large surface area in Brachaluteres and Alutera. In Alutera the epipleurals become hyperostotic in large adults.

True ribs have previously been found among plectognaths only in the primitive gymnodont Triodon macropterus (see Tyler 1962a:798 for discussion), and in the monacanthid scleroderm Pseudaluteres nasicornis as well (see Tyler 1973b). The latter would be a less amazing occurrence of ribs, in light of the ancestral balistids lacking true ribs, were Pseudaluteres at least a primitive monacanthid rather than being, as discussed under generic relationships, surely one of the most specialized.

The genetic information on constructing ribs would appear to have been retained in the otherwise ribless monacanthids and their ancestral balistids and their ancestral and equally ribless triacanthids and triacanthodids from the doubtless rib bearing basal group of plectognaths from which both the scleroderms and gymnodonts evolved. What peculiarity in the functional life of Pseudaluteres has made it advantageous to have ribs when other monacanthids (and Recent scleroderms) do not is a mystery to me, but it would not appear to be associated with its two other primary specializations; the far forward placement of the dorsal fin spine in front of the eye or of the lack of encasing scales and loss of the rudimentary pelvic fin-ray element.

A posttemporal is present in all monacanthids examined except Psilocephalus barbatus, none of the three adult specimens of which shows any evidence of one. Whether the ossification center for the posttemporal is lost or incorporated indistinguishably with that of the pterotic remains problematical. The dorsal head of the supracleithrum in Psilocephalus articulates directly with the lateral surface of the pterotic. This loss of the posttemporal is undoubtedly correlated with the greatly reduced 
Figure 115.-Stephanolepis hispidus: lateral view of head,

$50.4 \mathrm{~mm}$ SL, Florida.
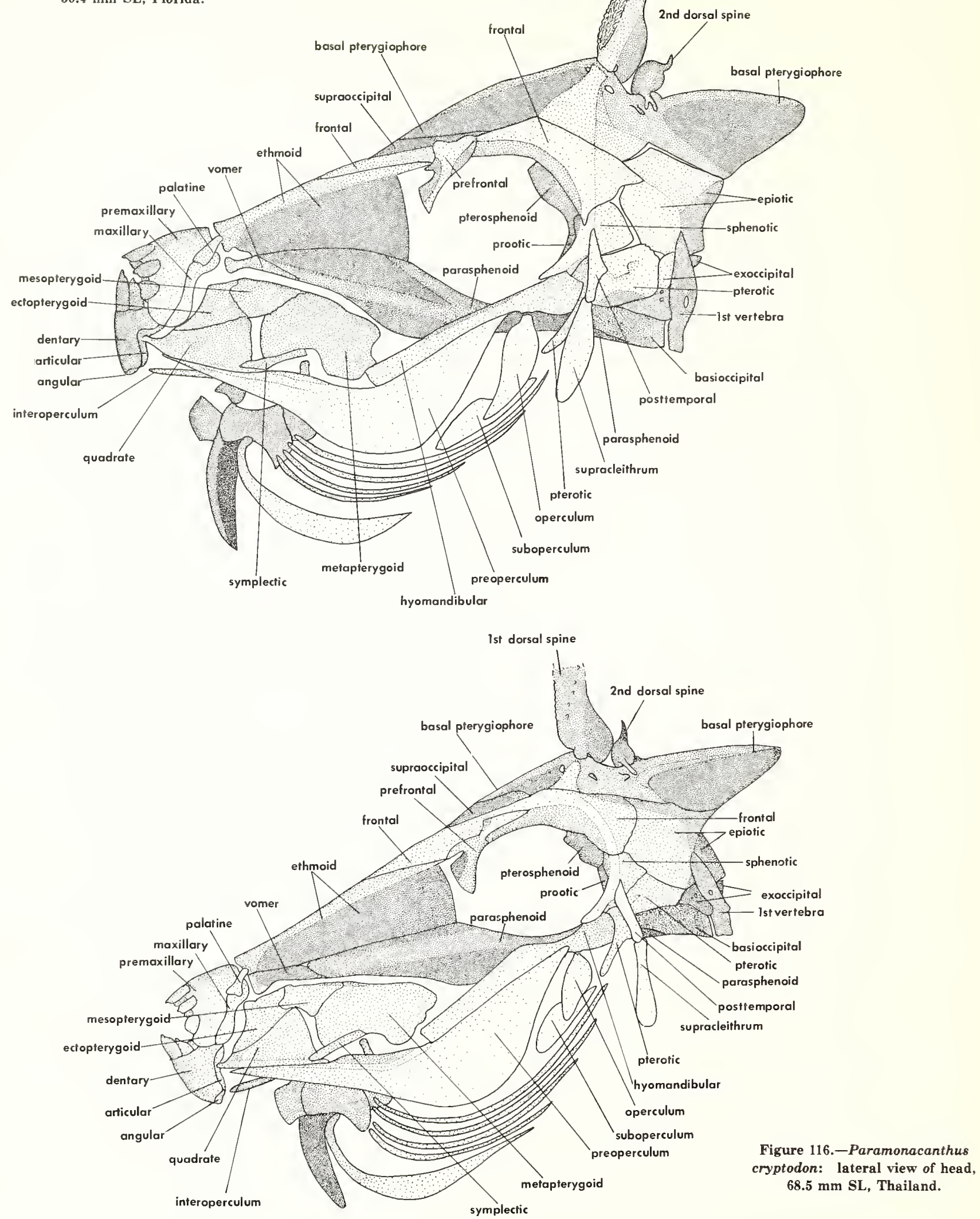
Figure 117.-Pervagor spilosomus: lateral view of head, $80.0 \mathrm{~mm}$ SL, Hawaii.

lst dorsal spine

basal pterygiophore prefrontol frontal basol pterygiophore

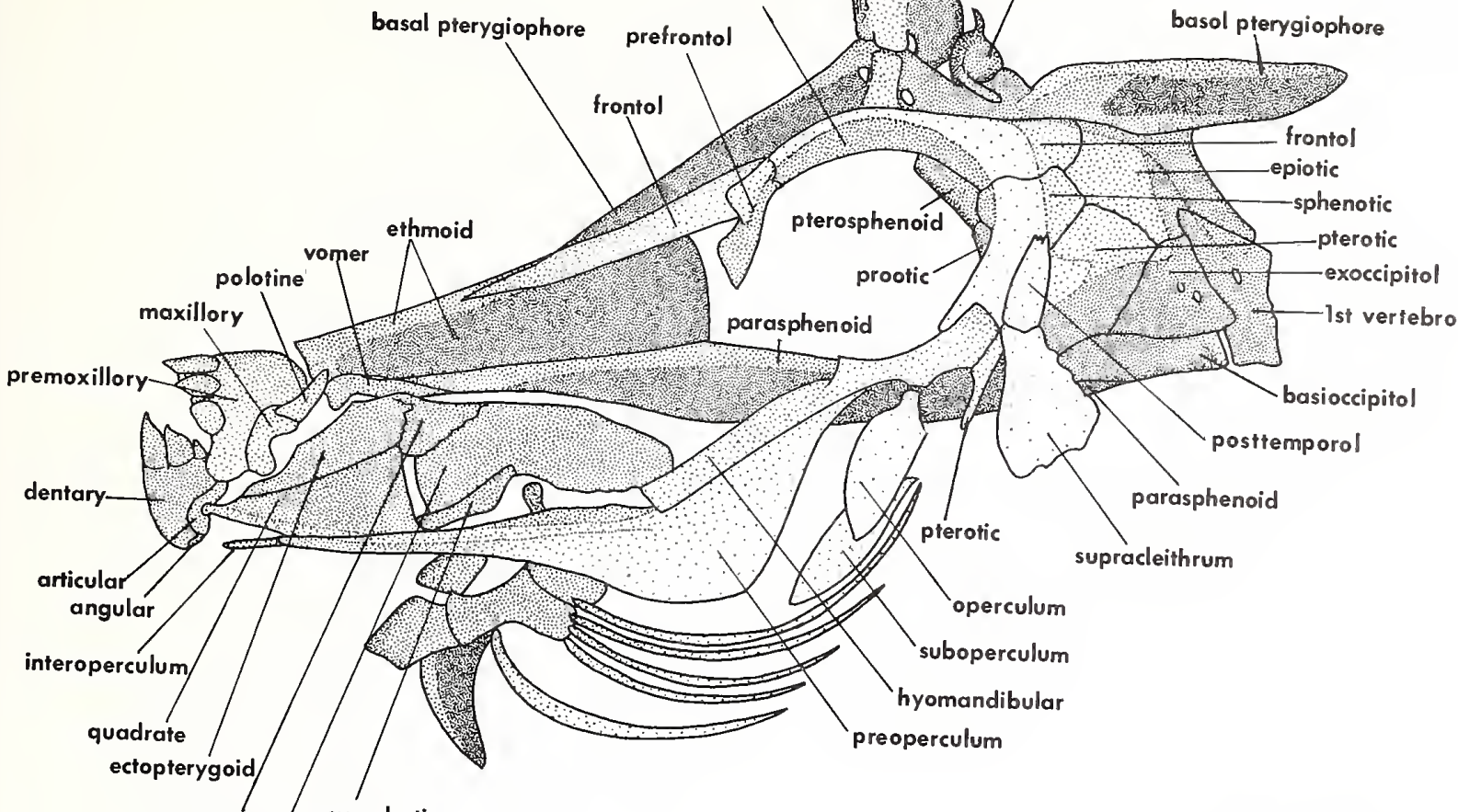

mesopterygoid symplectic

metapterygoid

lateral view of head,

167 mm SL, Saipan.

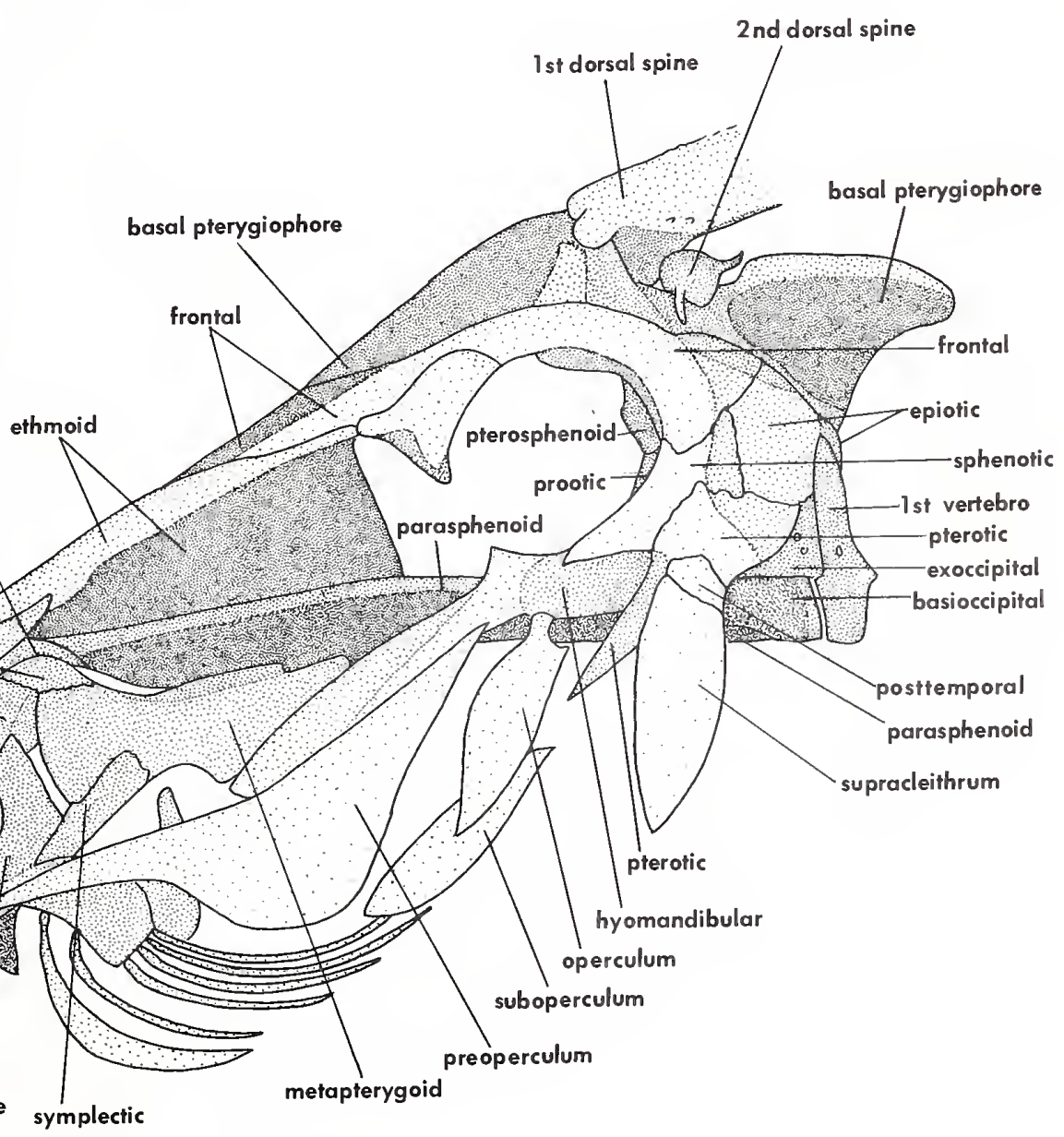


Gure 119.-Alutera heudelotii:

lateral view of head,

$107 \mathrm{~mm}$ SL, Florida.
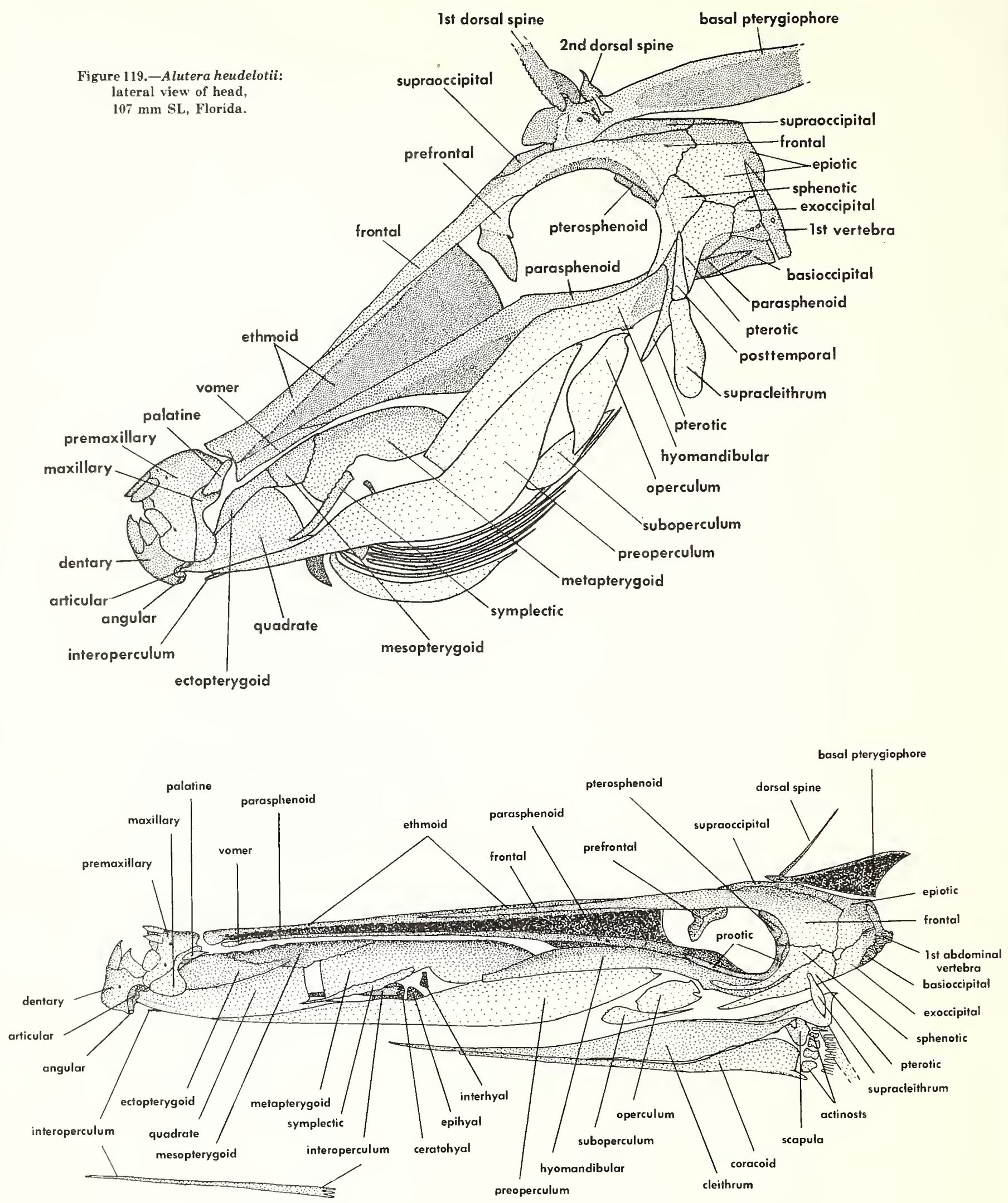

Figure 120.-Psilocephalus barbatus: lateral view of head, $137 \mathrm{~mm}$ SL, Singapore. 
Figure 121.-Brachaluteres trossulus: lateral view of head, $55.5 \mathrm{~mm} \mathrm{SL}$, Australia.

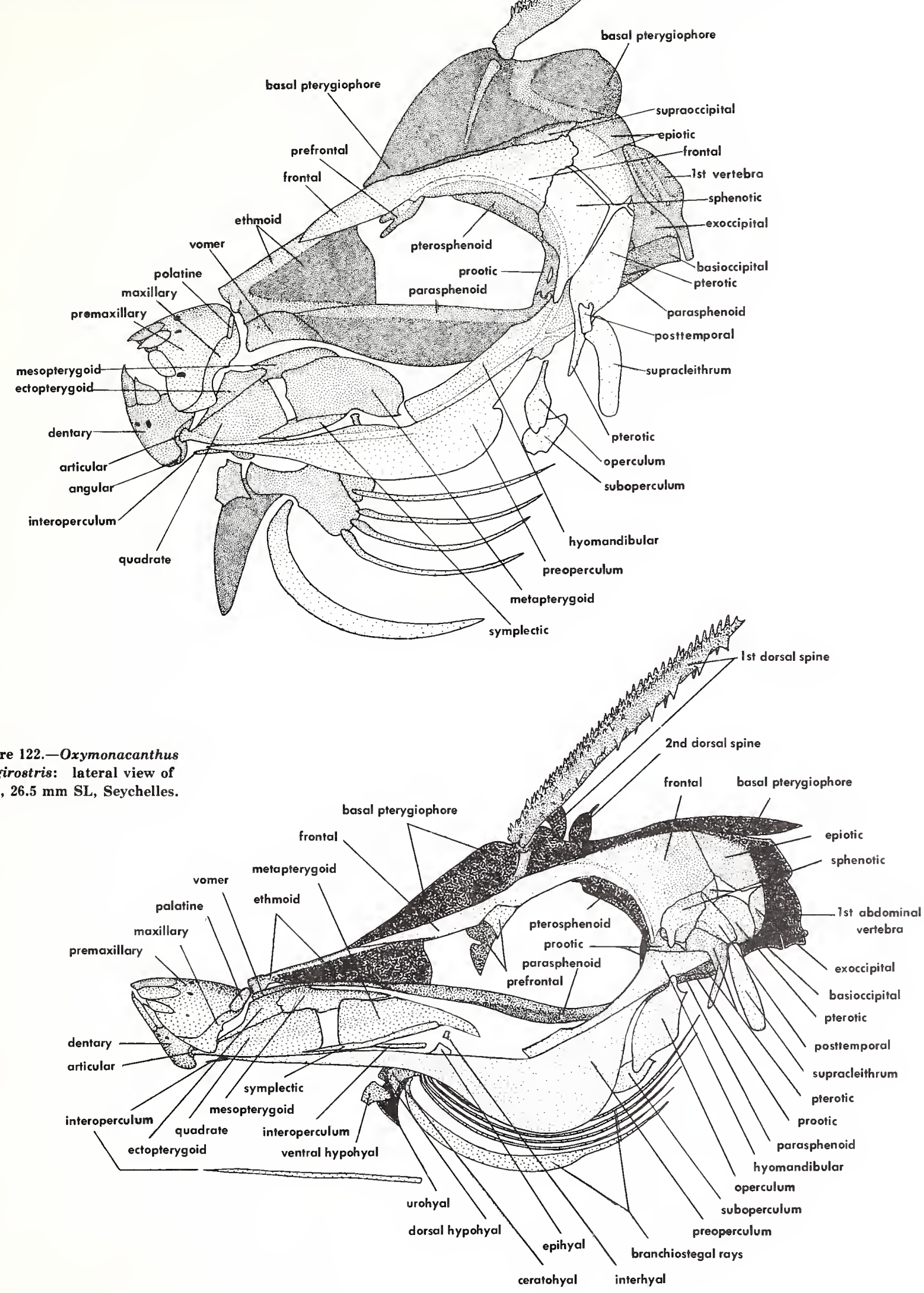


Figure 123.-Pseudaluteres nasicornis: lateral view of head, $108 \mathrm{~mm}$ SL, Philippines, with inset above showing detail of the snout region
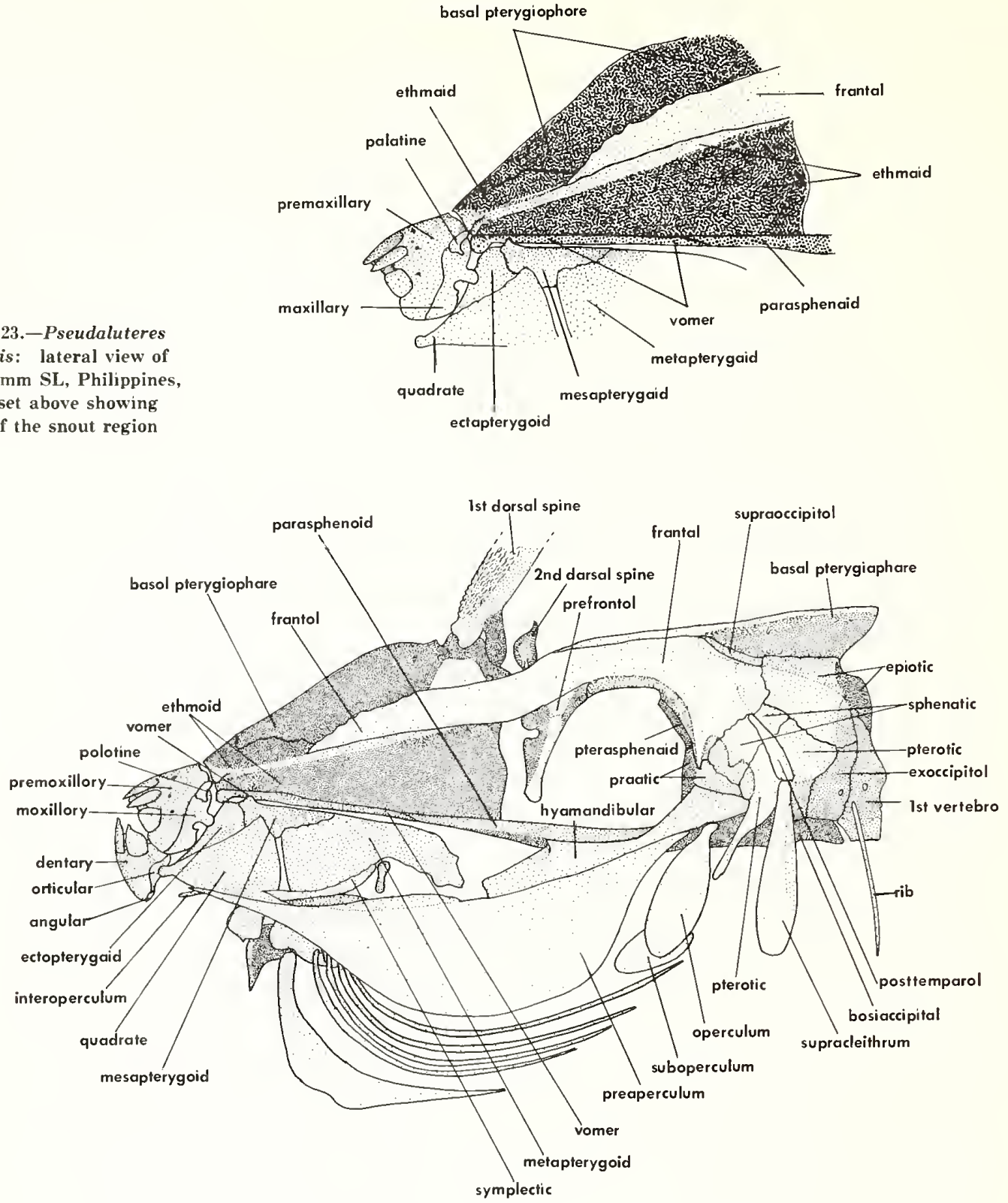

size of the pectoral girdle and of the fin it supports, with the rays reduced in number to eight (usually) or nine, plus the uppermost rudimentary ray. This attests to the far greater reliance in Psilocephalus on the especially long-based and many-rayed soft dorsal (43-52 rays; average of five specimens 49) and anal (53-66 rays, average 58) fins for locomotion. Psilocephalus is the only monacanthid regularly to have far more anal than dorsal fin rays.

As in balistids, the scapula completely encloses its foramen in most monacanthids, but in Pseudaluteres and Psilocephalus the scapular foramen is incomplete anteriorly, being bounded by the cleithrum. In Psilocephalus this is probably correlated with the reduc- ed size of the pectoral girdle and fin, but Pseudaluteres has a well-developed pectoral girdle and a moderate number (11-13) of rays.

Variation in the monacanthid caudal skeleton mainly concerns the presence or absence of an upper free hypural. There is always a single epural and usually a free upper hypural in contrast to the other hypurals which are fused to one another and to the centrum, and a free parhypural. A free upper hypural is absent in the majority of specimens of Monacanthus ciliatus examined and in those of Rudarius ercodes and $R$. minutus and in the single specimen of Amanses scopas examined (Tyler 1970b:15, erroneously implied that $R$. ercodes has an upper free hypural). Of 12 specimens of $M$. ciliatus examin- 
ed, only 2 had a free upper hypural. Other variation in the monacanthid caudal skeleton (discussed in Tyler $1970 \mathrm{~b}$ ) is that the usually horizontal crest for muscle attachment on the last centrum is reduced to a prong in Brachaluteres trossulus, and its neural and haemal canals are better developed than in other monacanthids, being roofed over distally rather than open. In Psilocephalus only the middle 6 to 8 rays of the extremely elongate caudal fin are branched, rather than having 10 branched rays as in all other monacanthids. The posterior edge of the fused hypural plate is much more convex in Psilocephalus than in all other monacanthids, while in Brachaluteres the cleft in the posterior edge of the fused hypural plate, that marks the region of fusion between what in generalized plectognaths like triacanthodids are the second and third hypurals, is much deeper than in all other monacanthids.

In balistids and in all but two genera of monacanthids the side of the rear part of the cranium just above the region of articulation of the upper end of the hyomandibular is formed by the sphenotic anteriorly and by the pterotic posteriorly, the hyomandibular articulating with a groove across the surface of the prootic and pterotic. The sphenotic usually has a well-developed (least developed in Rudarius) ventrally or anteroventrally directed prong from its lower edge and the pterotic a larger ventrally directed flange that overlies the posterodorsal end of the hyomandibular. The anterolateral edge of the sphenotic forms the lower rear margin of the orbit, with the frontal forming the margin more dorsally.

The two exceptions to these conditions are Oxymonacanthus and Pseudaluteres, in both of which the sphenotic is displaced posteriorly by a ventral extension of the frontal, the side of the rear of the cranium above the articulation of the hyomandibular being formed by the frontal anteriorly and the pterotic posteriorly, with the sphenotic squeezed in between. The sphenotic retains a short ventrally directed prong and the pterotic a normally developed large flange overlying the posterodorsal end of the hyomandibular, which articulates in a normal manner with a groove across the surface of the prootic and pterotic. The frontal, which forms all of the posterior margin of the orbit in these two genera to the exclusion of the sphenotic, has a ventrally directed prong from its anteroventral end in this region. This prong on the frontal is comparable to that on the sphenotic of all other monacanthids, where it forms the lower rear margin of the orbit.

Monacanthids always have the prootic shelf much less strongly developed than in balistids. The shelf in monacanthids does not extend as far forward as the level of the middle of the orbit, except in Psilocephalus, in which the shelf is long, thin, and delicate and reaches to the front of the orbit. Within these limits, the prootic shelf of monacanthids is variously developed, from relatively well to only moderately, and in two genera it is completely absent, these being Oxymonacanthus and Pseudaluteres.

All monacanthids have an outer series of three and an inner series of two teeth in each premaxillary, the inner series closely applied to the inner (or under) surface of the outer series and to the bone. In the dentary there is a single series of teeth, corresponding to the outer series of the upper jaw, usually three in number, but reduced to two in Psilocephalus barbatus, Rudarius ercodes and $R$. minutus, Brachaluteres trossulus and (according to Clark and Gohar 1953:46) B. baueri and (according to Scott 1969:40) B. wolfei, Paraluteres prionurus, and $O x y$ monacanthus longirostris (presumedly also only two teeth in the closely related $O$. halli Marshall as well). While three teeth are present in the dentary of Pseudaluteres nasicornis, the outermost tooth is much smaller than in other monacanthids with three dentary teeth. In all monacanthids the medial edges of articulation of the apposed dentaries are well-denticulated.

The teeth are relatively thinner and have more delicate cutting edges than in balistids, but they are usually notched in basically the same way in both families. The least notched condition of the teeth among the monacanthids examined is found in Acanthaluteres spilomelanurus, in which the two most medial teeth in both the upper and lower jaws (the most medial tooth of both premaxillaries and both dentaries) are relatively straight edged, forming a broad relatively sharp straight nipping edge along the front of the mouth. The position of the mouth tends to be terminal or only slightly supraterminal in most monacanthids, but it is distinctly supraterminal in the elongate Psilocephalus barbatus. The mouth of Oxymonacanthus is relatively small and laterally compressed, with the teeth also relatively narrow but elongate, for what is probably a specialized mode of feeding between the branches of coral of this strictly reef-dwelling species. Among the monacanthids examined, the teeth are most massive in Amanses scopas, but this could in large part be a function of the large size of the single specimen examined. It will be of interest to know the size of the teeth in juveniles and young adults of Amanses, which have yet to be collected (Randall 1964:335).

While the number of vertebrae in the ancestral balistids is almost invariably $7+11=18$ (in contrast to their ancestral triacanthoids in which it is $8+12=20$ ), the number of vertebrae in monacanthids is highly variable, although the most frequent formula is $7+12=$ 19 and none of the species examined normally has as few as the 18 vertebrae of balistids. Only a few species of monacanthids have other than seven abdominal vertebrae, most of the variation in total number being in the caudal series. The only monacanthids normally with six abdominal vertebrae are the two Atlantic species of Monacanthus (ciliatus and tuckeri, the subgenus Leprogaster of Fraser-Brunner, with $6+13=19$ in contrast to the $7+12=19$ of the Indo-Pacific species) and Acanthaluteres spilomelanurus $(6+14=20)$. The only monacanthids normally with eight abdominal vertebrae are Oxymonacanthus longirostris $(8+17=25)$ and Pseudaluteres nasicornis $(8+18=26)$.

When the number of vertebrae is increased beyond what is probably the generalized number of 19 , it is usually by the addition of one or more vertebrae in the 


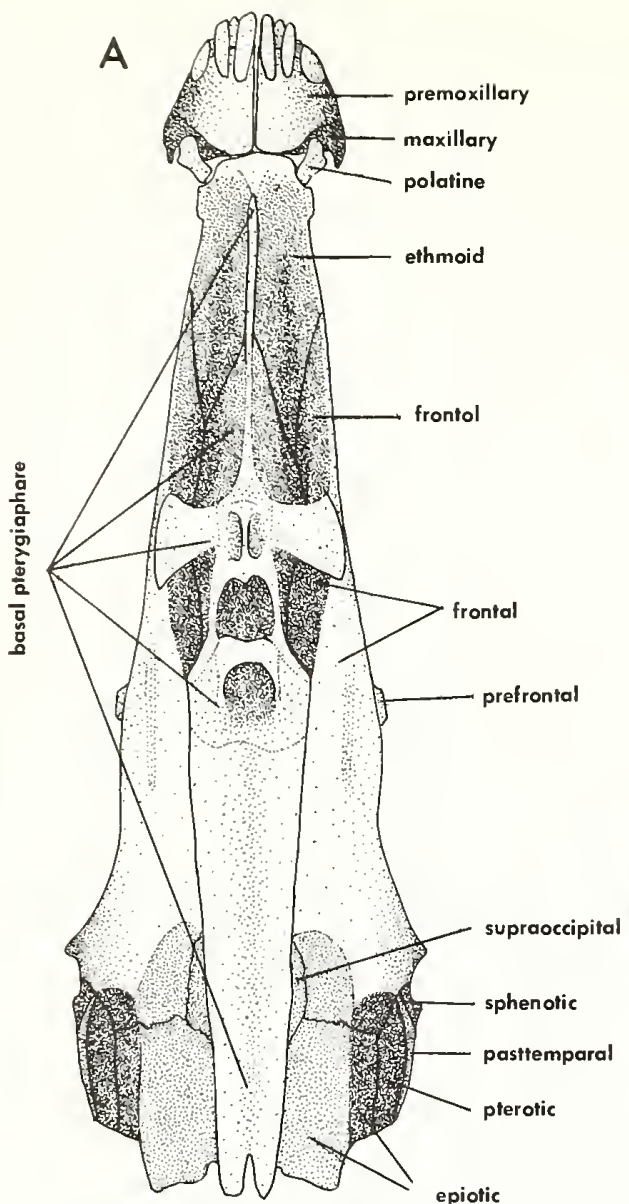

caudal series (as well as, in Oxymonacanthus and Pseudaluteres, by one in the abdominal series), as exemplified by Alutera, whose four species have normal vertebral counts ranging from 20 to 23 but all of which retain 7 abdominal vertebrae. The greatest increase in number of vertebrae is in the extremely elongate body of Psilocephalus barbatus, the increase again being confined to additions in the caudal series. Four of the five specimens of $P$. barbatus cleared and stained or radiographed have 7 abdominal and 22 or 23 caudal vertebrae, while one has 8 abdominal and 22 caudal vertebrae.

The neural spines of the abdominal vertebrae anterior to the first basal pterygiophore of the soft dorsal fin vary from relatively narrow long slender shafts (e.g., Brachaluteres) to short slender shafts (e.g., Chaetoderma) to broadly anteroposteriorly expanded plates (e.g., Pseudaluteres), with intermediate conditions found in other genera. As in balistids, which always have five vertebrae anterior to the first basal pterygiophore of the soft dorsal fin, the great majority of monacanthids also have five so placed. The only exceptions are the two Atlantic species of Monacanthus (ciliatus and tuckeri), the single species of Acanthaluteres examined, nd one of the two species of Rudarius (minutus), all of which have only four vertebrae anterior to the first soft dorsal
Figure 124.-Dorsal views of skulls of: A, Pseudaluteres nasicornis, $108 \mathrm{~mm}$ SL, Philippines, highly specialized;

B, Paraluteres prionurus, $46.4 \mathrm{~mm} \mathrm{SL}$, Seychelles, moderately specialized; C, Chaetoderma spinosissimus, $33.0 \mathrm{~mm} \mathrm{SL}$ Malaya, relatively generalized.

fin basal pterygiophore, and Pseudaluteres nasicornis with six and Psilocephalus barbatus with eight.

As in balistids, the lateral line system in most monacanthids is inconspicuous, and can usually only be followed in cleared and stained specimens examined under a microscope. However, it can be relatively easily seen with the unaided eye even in alcohol preserved specimens of a few species of Monacanthus (especially chinensis), Paramonacanthus, and Paraluteres prionurus, and, to a lesser extent, in Psilocephalus barbatus.

The scales of the lateral line in monacanthids typically have a foramen in the basal plate with an upright spiny process like that of the other scales bordering the foramen above and below. The only species examined in which such lateral line scales could not be found was Pseudaluteres nasicornis.

In all species except Paraluteres prionurus the head and body are more or less fully covered with scales whose upright spinulations usually give a shagreenlike quality 


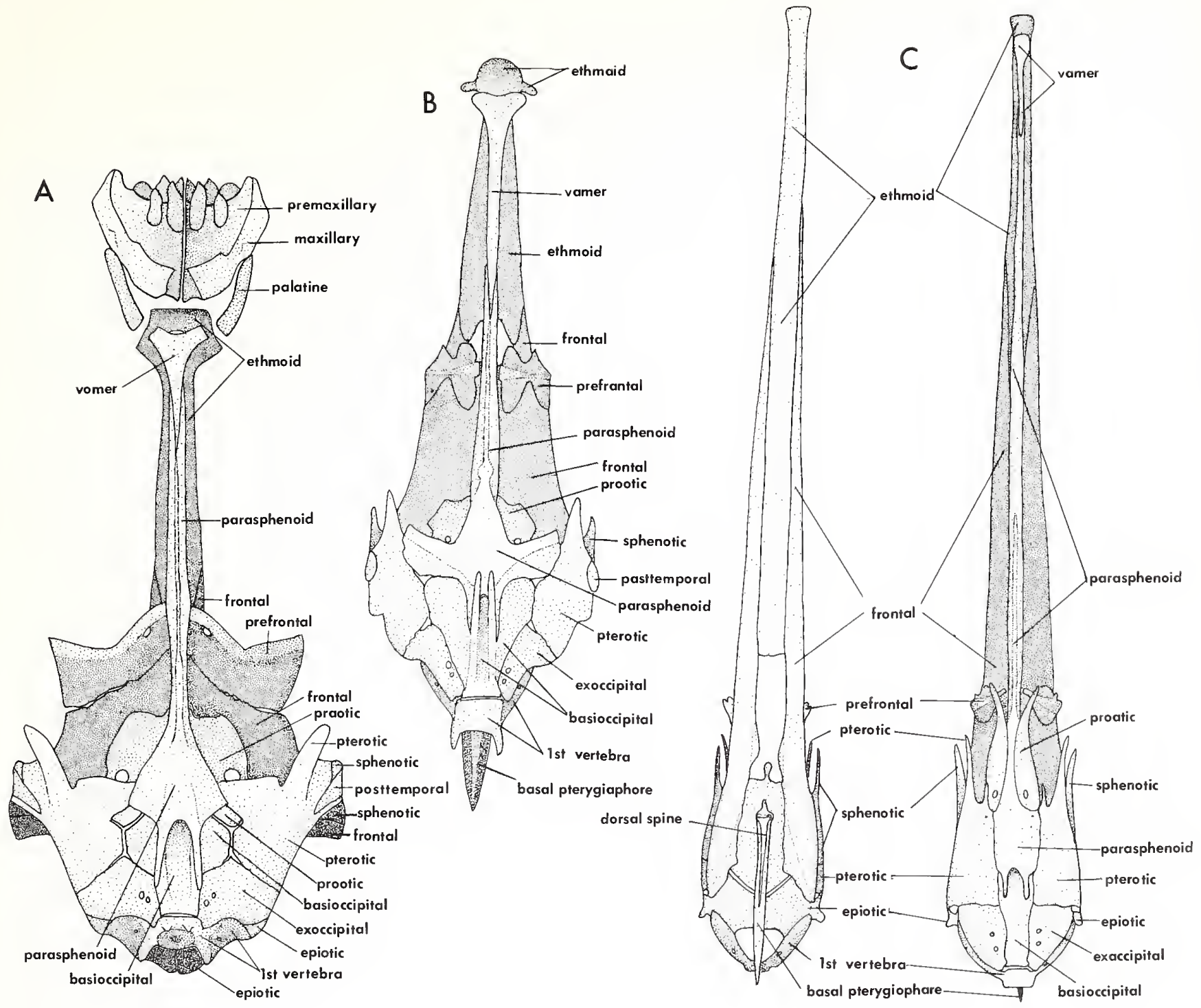

to the skin. In $P$. prionurus the skin is smooth to the touch, except on the caudal peduncle of mature males where there are two pairs of retrorse barbs and a patch of short upright setae extending forward to the level of the anal fin origin. The fact that there are very low weakly developed spinulose scales on the head and ventral surface from the mouth to the anus is only readily apparent in cleared and stained specimens.

The scales of monacanthids vary greatly in the degree and structure of the spinulation and in the size and degree of overlap (if any) of the usually rounded to rectilinear basal plates, but they are always much smaller than in balistids. In most species the basal plates more or less broadly but irregularly overlap, while in others (e.g., Chaetoderma) there is little if any overlapping of the relatively large and more or less triangular plates. The scales of Chaetoderma are more or less regularly arranged in rows, and, according to Fraser-Brunner (1941b:178), they are in distinct longitudinal tracts in
Figure 125.-From left to right:

A, Paraluteres prionurus, ventral view of skull, 46.4 mm SL, Seychelles; B, Pervagor spilosomus, ventral view of skull,

ca. $65 \mathrm{~mm}$ SL, Hawaii; C, Psilocephalus

barbatus, dorsal and ventral views of skull, $137 \mathrm{~mm} \mathrm{SL}$, Singapore.

Arotrolepis, while in the great majority of monacanthids the arrangement is irregular. There is always at least one upright spinule (least developed in Paraluteres, best in Chaetoderma) per scale plate, and often many. The individual scale plates are largest in Chaetoderma, in which many of the upright spinules support large dermal flaps, and smallest in Psilocephalus.

All monacanthids, like balistids, have two nostrils in a scaleless area on both sides, each nostril usually at the end of a short tube, but sometimes more or less flush with the surface (especially Paraluteres and Psilocephalus). 


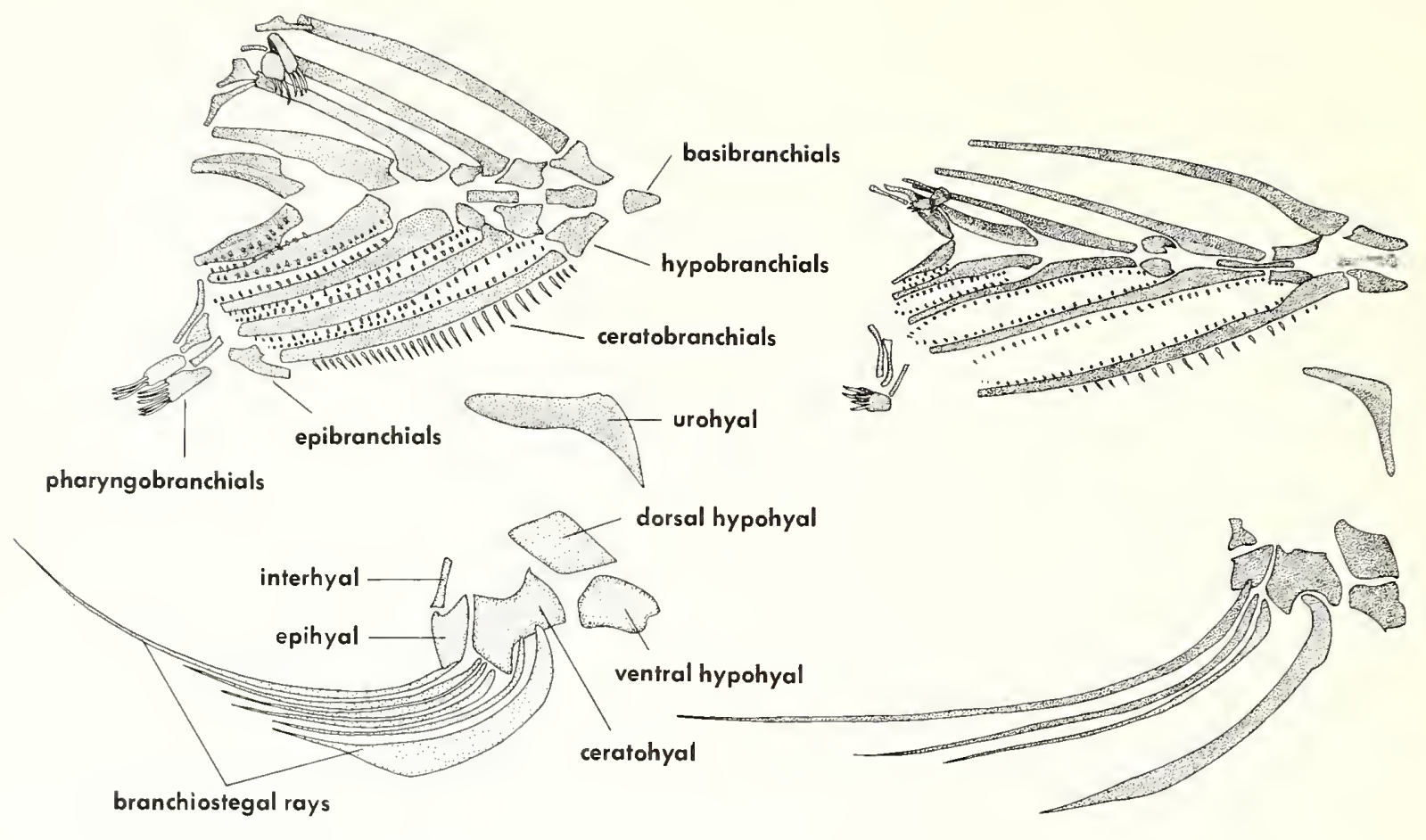

The nasal sac beneath the surface usually has a single longitudinal upraised fold or lamella.

Generic relationships. - Given their evolution from balistids, one would expect generalized monacanthids to have a relatively well-developed pelvis with a dorsal lobe and at least rudiments of the fin-ray element hidden within a flexible series of encasing scales of a maximum number of segments. Likewise, the basal pterygiophore supporting the dorsal fin spines would be expected to be well developed and over the rear part of the skull (i.e., the least distance migrated forward) and with the skull the least flattened for articulation with it (i.e., with some remnant of the medial supraoccipital crest of balistids).

Other generalized features to be expected a priori would be an only slightly elongate body and terminal mouth, six branchiostegals, a groove posterior to the dorsal spines into which they are folded more or less flush with the surface when unerected, the least reduction in the number of teeth, the least increase in the number of vertebrae, and the presence of an upper free hypural.

Of the above features, I tend to place greatest emphasis on the pelvic apparatus and the form of the top of the skull in relation to the basal pterygiophore of the spiny dorsal fin. The supraoccipital is best developed in Stephanolepis, Monacanthus, and Paramonacanthus, reaching to the front of the eye, and only in these three genera does the supraoccipital retain a vertical medial crest anteriorly for articulation with the laterally compressed platelike anterior region of the spiny dorsal fin basal pterygiophore. I take this low anteriorly placed supraoccipital crest as the remnant of the much sturdier

crest that is found more or less throughout the length of the balistid supraoccipital and which ends posteriorly in the thick lateral expansion which helps, along with the epiotics, to support the anterior end of the first basal pterygiophore of the spiny dorsal fin.

Stephanolepis, Monacanthus, and Paramonacanthus also have the pelvic apparatus well developed, with the dorsal lobe of the pelvis of moderate to large size and with the maximum monacanthid number of three segments of flexible encasing scales surrounding a hidden fin-ray element to which muscles attach through tendons running along the dorsal and ventral surface of the pelvis, the dorsal tendon coursing through a canal in the base of the dorsal lobe. In all three of these genera the dorsal spines are placed relatively posteriorly on the skull, at a level behind the middle of the eye.

In most other genera of monacanthids examined (Pervagor, Amanses, Cantherhines, Acanthaluteres, Oxy. monacanthus, Rudarius, Laputa, Navodon, Pseudaluteres, Paraluteres, Psilocephalus) the supraoccipital does not extend as far forward as in Stephanolepis, Monacanthus, and Paramonacanthus and there is no crest at all. With the exception of Laputa (and Chaetoderma as well), the former group of genera are also specialized in having an inflexible series of encasing scales, or none at all, and no fin-ray element, other than sometimes a mere cartilaginous plug at the end of the pelvis.

Laputa is the only genus with flexible encasing scales and a rudimentary fin-ray element (small in the single species examined) in which the supraoccipital does not extend far forward and is without a crest, although the 
Figure 126. (opp. page)-Dorsal view of branchial arches (extended on lower side) and

lateral view of hyoid arch and urohyal of: left, Alutera heudelotii,

$114 \mathrm{~mm}$ SL, Florida (labeled), and right, Psilocephalus barbatus, $139 \mathrm{~mm}$ SL,

Singapore (unlabeled).

Figure 127.-Medial views of upper (left) and lower (right) jaws of: A, Alutera heudelotii, $114 \mathrm{~mm}$ SL, Florida;

B, Monacanthus ciliatus, $51.3 \mathrm{~mm} \mathrm{SL}$, Colombia; C, Psilocephalus barbatus, $137 \mathrm{~mm} \mathrm{SL}$, Singapore;

D, Amanses scopas, $167 \mathrm{~mm}$ SL, Saipan;

E, Acanthaluteres spilomelanurus, $63.7 \mathrm{~mm} \mathrm{SL}$, Australia.
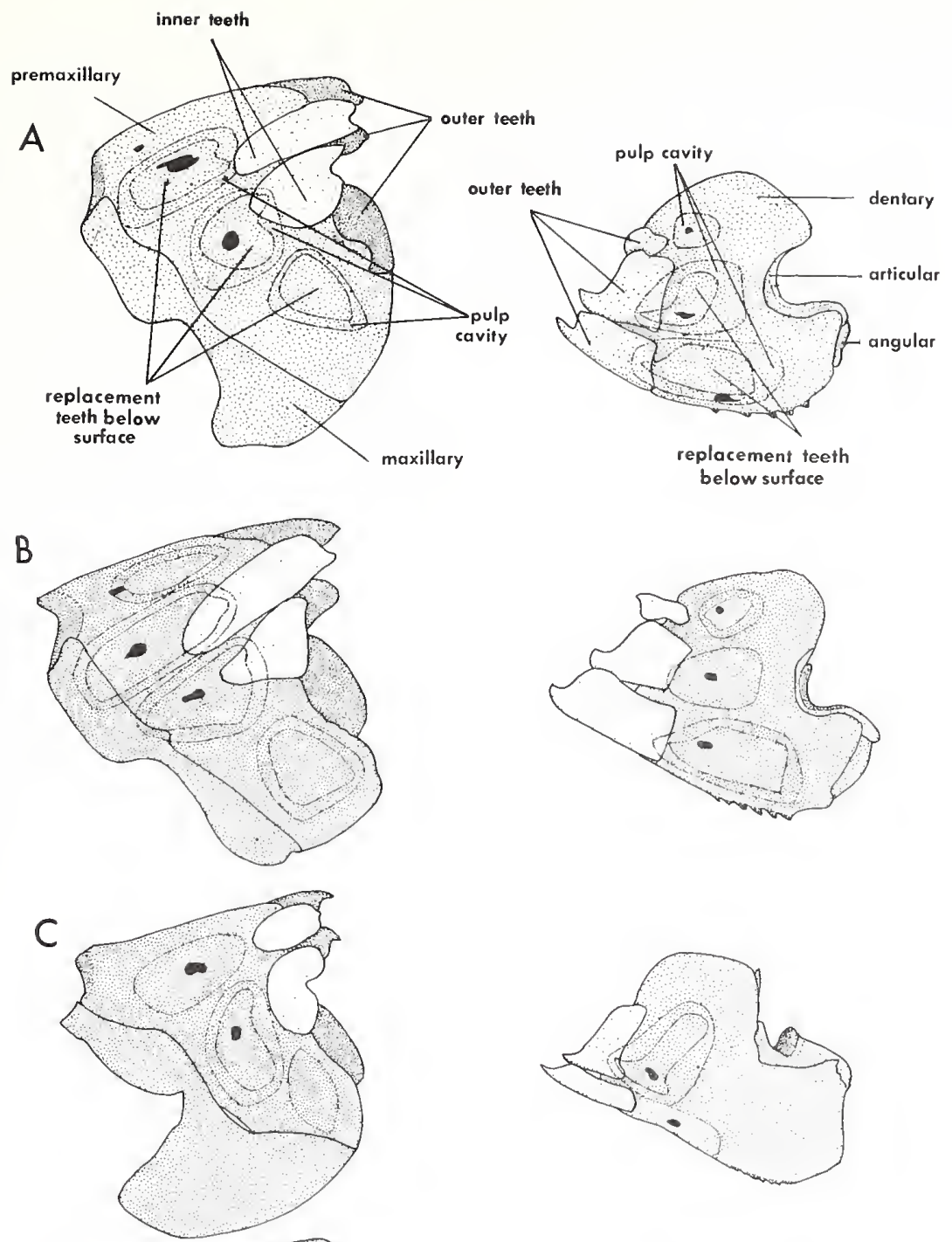

D
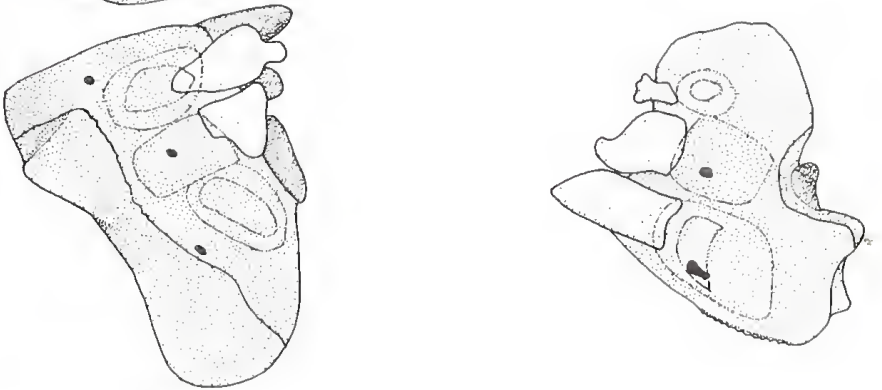

E

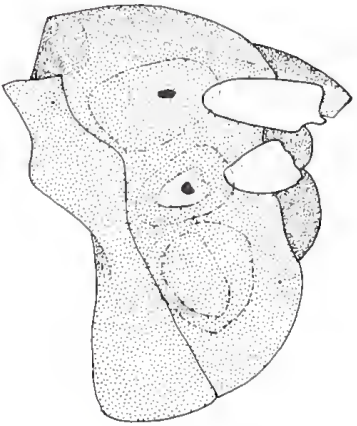

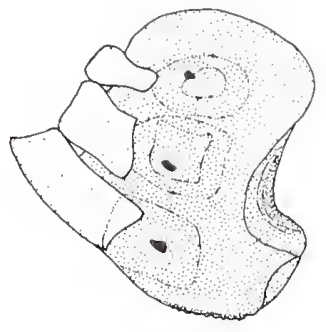




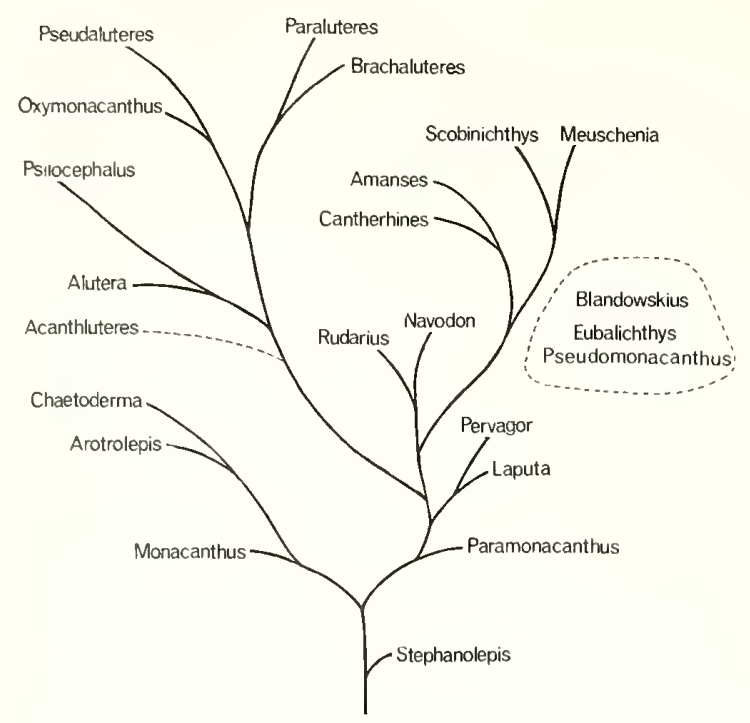

Figure 128.- Hypothesized phylogenetic relationships of the genera of Monacanthidae.

dorsal spines are placed posteriorly on the head. Thus, Laputa is as generalized as Stephanolepis, Monacanthus, and Paramonacanthus except for the shorter and more flattened condition of the supraoccipital.

In Chaetoderma there are only two encasing scale segments, a slight specialization, but minute remnants of the fin-ray element remain and the encasing scale segments are flexible, the minuteness of the fin-ray element also being a slightly specialized condition. Moreover, Chaetoderma has a relatively well developed forward extension of the supraoccipital, almost to the front of the eye and only slightly shorter than in Stephanolepis, Monacanthus, and Paramonacanthus. The forward extension of the supraoccipital in Chaetoderma bears a thin low crest over the middle and posterior regions of the eye which is probably a remnant of that found in the three genera in which the crest is well developed.

In two other genera besides Chaetoderma the supraoccipital extends forward only slightly less than the front of the eye, but both are obviously specialized by the total loss of the pelvic fin-ray element and the dorsal lobe of the pelvis, as well as by either the total loss of the encasing scale series or its reduction to a single scale that is lost in large adults. These two genera are Alutera, in which all four species have a low supraoccipital crest on the forward extension, and the single species of Brachaluteres examined (trossulus), in which there is no crest in the smaller of the two specimens but a very low crest present from the middle of the eye posteriorly in the larger specimen.

One other genus must be mentioned in connection with the shape of the supraoccipital, that being Psilocephalus, in which there is no true long forward and mainly medial extension of the supraoccipital as found in the genera just discussed. In Psilocephalus the supraoccipital is represented only by the relatively larger more laterally expanded posterior portion. But probably because of the relative shortening of the posterior part of the skull and the great elongation of the snout, the anterior end of the supraoccipital in Psilocephalus does extend forward to the level of the dorsal end of the prefrontals, although still short of the front of the eye.

In my opinion, the combination of the most generalized condition of the pelvic apparatus and that of the supraoccipital supporting the basal pterygiophore and its dorsal spines placed over the rear of the eye points to Stephanolepis, Monacanthus, and Paramonacanthus as representing the most generalized group of monacanthids. Of the other features listed in the opening paragraph of this section as being considered generalized a priori on the basis of the structure of the ancestral balistids, these three genera have terminal mouths with the most typical monacanthid number of teeth (the minimum reduction from balistids), 19 vertebrae (the minimum increase in number from balistids), and an upper free hypural, except that only a minority of specimens of one of the species (ciliatus) of Monacanthus have a free upper hypural.

However, Stephanolepis, Monacanthus, and Paramonacanthus are among those majority of monacanthids with $1+4$ branchiostegals, rather than the $2+$ 4 arrangement found in balistids and in Navodon, Acanthaluteres, Alutera, Cantherhines, and Amanses among the monacanthids, and in having no relatively distinct and deep groove medially behind the basal region of the dorsal spines into which the latter are received and held more or less flush with the surface, as found in balistids and in the monacanthids Acanthaluteres, Cantherhines, Amanses, Meuschenia, Oxymonacanthus, Eubalichthys, and most but not all species of Pervagor.

The $2+4$ versus $1+4$ number of branchiostegals and the degree of development of a groove for the reception of the dorsal spines seem in this case to be less important indicators of the overall generalized condition of monacanthids than do the other outstanding features discussed above, this especially in light of the fact that, as described here, Monacanthus ciliatus at least sometimes has the $2+4$ branchiostegal number and that among the apparently closely related species of Pervagor, most have a groove behind the dorsal fin, while at least one species (tomentosus, according to Fraser-Brunner 1941b:183) does not.

The three most generalized genera, Stephanolepis, Monacanthus, and Paramonacanthus, seem very closely related, and only a single genus has often been recognized for the species now placed in Stephanolepis and Monacanthus. The latter two genera have been best differentiated by Berry and Vogele $(1961: 63,68)$, mostly on the basis of the spinulation of the scales. Monacanthus has unbranched and relatively fewer spinules per scale than does Stephanolepis, which has branched spinules, although the number of spinules increases greatly with increasing specimen size in both genera, just as in most other monacanthids. Berry and Vogele also pointed out that the ventral dewlap between the end of the pelvis and 
the anus is much larger in Monacanthus, in which it extends out far beyond the end of the encasing scales, than in Stephanolepis, in which it extends out only to the distal end of the encasing scales.

In Paramonacanthus the ventral dewlap is especially short, extending posteriorly only to the anterior edge of the encasing scale series, so that the end of the pelvis protrudes prominently from the ventral contour. The scales in Paramonacanthus have unbranched spinules, as in Monacanthus and the vast majority of other monacanthids, but the spinules are less coarse than in Monacanthus and the skin of Paramonacanthus thus has much the same velvety shagreen consistency as found in Stephanolepis, rather than the rougher consistency of Monacanthus. In Paramonacanthus the scale spinules are unmodified, while, as described in detail by Berry and Vogele (1961), mature males of Stephanolepis develop a patch of bristles on the caudal peduncle and mature males of Monacanthus have bristles and retrorse barbs, females of Monacanthus developing smaller posteriorly pointed barbs on the caudal peduncle but very little if any bristle patch.

In Monacanthus the dorsal lobe of the pelvis is very large, the longest among monacanthids, being associated with support of the modified scales in the enormous dewlap. In the various species of Stephanolepis and Paramonacanthus the dorsal lobe is only moderately developed, about that normal for the family when a dorsal lobe is present at all.

In Paramonacanthus and Stephanolepis there is always a free uppermost hypural, as is also the case in the Indo-Pacific species of Monacanthus. In the two Atlantic species of Monacanthus, one species (tuckeri) usually has a free upper hypural (present in three out of four cleared and stained specimens) while the other species (ciliatus) usually lacks the free hypural (present in 2 out of 12 cleared and stained specimens).

In Stephanolepis and Paramonacanthus epipleurals usually extend back to the fifth caudal vertebra while in Monacanthus they usually extend back only to the second or third caudal vertebra (one specimen of $M$. chinensis with epipleurals on the fourth caudal vertebra).

In Stephanolepis, Paramonacanthus and the IndoPacific species of Monacanthus there are 7 abdominal and 12 caudal vertebrae, with 5 of the abdominal vertebrae anterior to the first basal pterygiophore of the soft dorsal fin, this being the most common vertebral condition in the family. In the two Atlantic species of Monacanthus the total number of vertebrae remains 19 , but it is the haemal spine of the seventh rather than that of the eighth vertebra that supports the anterodorsal end of the first basal pterygiophore of the anal fin, and the neural spine of the fourth rather than that of the fifth vertebra supports the anteroventral end of the first basal pterygiophore of the soft dorsal fin, $M$. ciliatus and tuckeri thereby having only 6 rather than 7 abdominal vertebrae and only 4 rather than 5 predorsal vertebrae.

With the similarities and differences discussed above between the three genera here considered to be the most generalized monacanthids, the question is whether one of them can be considered closer to the ancestral group than the other two. There is little to go on.

In balistids the ventral fan is only moderately developed, with the expansible skin extending posteriorly across most of the length of the encasing scale series, ending at about the beginning of the most distal of the four segments of scales. This condition is somewhat intermediate between that of Paramonacanthus, with a very short dewlap, and Stephanolepis, with a moderate dewlap, but closer to that of Stephanolepis.

The moderate dorsal lobe of the pelvis of Paramonacanthus and Stephanolepis is closer to that of balistids than is the extremely large one of Monacanthus.

The upright spinules on small basal scale plates in monacanthids is so different from the structure of the scales of balistids that it is impossible to say whether the branched spinules of Stephanolepis are more generalized or specialized than the unbranched spinules in Monacanthus and Paramonacanthus, and in any case many of the scales of the head and extreme upper and lower parts of the body in the Indo-Pacific species of Monacanthus have branched spinules, while those of most of the body are unbranched but sometimes notched along their anterior edge.

The phylogenetic implications of the presence of enlarged caudal peduncular scales forming a patch of bristles or spines in mature males of Stephanolepis and in mature males and, to a lesser extent, in mature females of Monacanthus, but in neither sex of Paramonacanthus, is difficult to interpret. Among balistids only two genera (Balistapus and Rhinecanthus) have well-developed caudal armature, in the form of large spines, but numerous genera (e.g., Sufflamen, Melichthys, Xanthichthys, Abalistes, Balistoides) have horizontal ridges formed by upraised areas on the successive rows of scales on the caudal peduncle and posterior region of the body, and only a few genera are totally lacking these ridges (e.g., Balistes and Odonus). Without knowing from what type of balistids the monacanthids have been derived, it cannot be said at present whether the caudal armature present in a few monacanthids is a generalized holdover from their balistid ancestors or a relatively specialized feature.

I would guess that Stephanolepis is the most generalized of the three genera, basically because of its moderate dorsal lobe of the pelvis and moderate dewlap. Monacanthus would be a slightly specialized close derivative of Stephanolepis whose evolutionary trend is for a great increase in the size of the dewlap and of the dorsal lobe supporting it, while in another direction Paramonacanthus is an equally close relative of a Stephanolepislike stock, specialized by a great reduction in the size of the dewlap but not of the dorsal lobe.

Fraser-Brunner (1941b:181) considered Pervagor the most generalized monacanthid, stating that: "Pervagor, in which dorsal and pelvic spines are better developed than in the succeeding [i.e., all the other] genera, exhibits two features which are not found among the other forms possessing a movable pelvic spine - the forward position of the dorsal spine and the presence of a deep 
groove in which it is received when depressed (the latter character, however, being lacking in the subgenus Acreichthys noted [described as new] below). On the one hand it leads to the rest of the genera retaining the pelvic spine but having the dorsal spine behind the eye and without groove; of these, Stephanolepis seems to be the group round which the specialized forms such as Chaetoderma and Monacanthus are clustered. On the other hand extends the large series of genera in which the pelvic spine has been lost. ..."

I do not find that the dorsal spines and encasing scales in Pervagor are better developed than in most other genera, and certainly they are no better developed than in Stephanolepis, Monacanthus, and Paramonacanthus. Moreover, I do not think that the somewhat forward position of the dorsal spine (over the middle of the eye) can be considered the generalized condition when the ancestral balistids have the dorsal spines behind the eye.

As discussed previously, the least forward migration of the dorsal spines is the most generalized monacanthid condition, with the spines over the rear of the eye. Pervagor does not possess the generalized monacanthid condition of the supraoccipital, for it lacks the forward extension with vertical crest to the front of the eye that is a remnant of the condition of the balistid supraoccipital.

In fact, the only definitely generalized feature of Pervagor to my way of thinking is its pelvic apparatus, with it having a moderate dorsal lobe, three segments in the flexible encasing scale series and moderately welldeveloped rudiments of the fin-ray element. As discussed previously, a groove behind the dorsal spines would seem a priori a generalized condition in monacanthids since the ancestral balistids have such a groove. But of the genera of monacanthids with a groove behind the dorsal spines, only Pervagor has a generalized pelvic apparatus, all the other genera having the segments of encasing scales reduced in number and inflexible or $a b$. sent entirely, and without a fin-ray element.

All of the genera with the groove behind the dorsal spines have the most specialized condition of the supraoccipital, without a long or even moderate forward extension and no crest. It seems as likely that the monacanthid postdorsal groove is a de novo development in moderately specialized forms as it is that it is a hold over from the ancestry of the monacanthids, the most generalized Recent species of which would then have to be presumed to have subsequently lost it.

A similar situation occurs with the interpretation of the $2+4$ branchiostegal number found only in a few genera of monacanthids, these all being genera with a specialized pelvic apparatus in which the fin-ray element is absent and the segments of encasing scales are reduced in number and inflexible or absent entirely, a small dorsal lobe is present on the pelvis, and there is either no forward supraoccipital extension (Navodon, Acanthaluteres, Cantherhines, Amanses) or only a small extension to above the middle of the eye (Alutera). Thus, on all of the most important grounds, the genera with the 2 +4 number of branchiostegals are much more specializ- ed in general than are many of the genera with the $1+4$ number, including Stephanolepis, Monacanthus, and Paramonacanthus.

Pervagor also possesses one unique feature found in neither the other monacanthids nor in balistids. The lateral surface of the anterior region of the pelvis has a protuberance for articulation with a similar protuberance from the posterior edge of the coracoid, the pelvis rotating around this joint when the dewlap is expanded.

In short, Pervagor cannot be considered one of the most generalized monacanthids, but, rather, it is probably a derivative of a Paramonacanthus-like stock. In both Paramonacanthus and Pervagor the dewlap is short, not extending out beyond the beginning of the encasing scale series, which protrude conspicuously from the ventral contour. The specializations of Pervagor beyond the Paramonacanthus level are the loss of the forward extension of the supraoccipital, the more anterior position of the dorsal spines, the greater elongation of the body, and the development of the rotation processes on the coracoid and pelvis.

Two other genera with a flexible encasing scale series and rudiments of the fin-ray element are Laputa and Chaetoderma, both of which also have the dorsal spines placed in the generalized location over the rear of the eye.

Chaetoderma has a relatively well-developed forward extension of the supraoccipital and at least a low weak crest, the forward extension being not much less extensive than in Stephanolepis, Monacanthus, and Paramonacanthus. The most outstanding specializations of Chaetoderma are that the encasing scale segments have been reduced to two, while retaining their flexibility, and that the two rudiments of the fin-ray element are minute. The ventral flap of Chaetoderma is small and similar to that of Paramonacanthus. Chaetoderma could well be a derivative of Paramonacanthus, specialized by the increased depth of the body, the great development of dermal flaps on the skin, the reduction in the number of segments of encasing scales and in the size of the rudiments of the fin-ray element, and the slight reduction in the size of the forward extension of the supraoccipital.

However, the scales of Chaetoderma are strongly reminiscent of those of the rough skinned Monacanthus, especially those of the Indo-Pacific species, in which the strong central upright spinule is backwardly directed and bears a notch along its anterior or outer edge. The scales of Chaetoderma are an elaborate version of this, with a deep cleft in the usually strong single spinule dividing the spinule into a smaller upwardly or anteriorly directed prong and a larger posteriorly directed prong.

I suspect that the Australasian Chaetoderma is derived from the Indo-Pacific stock of Monacanthus, by all the ways of specialization mentioned above in comparison to Paramonacanthus, and additionally by the loss of caudal peduncle armature and the great reduction in the size of the dewlap probably associated in some way with the camouflage value of the extensively developed dermal flaps. Additional evidence for a close Chaetoderma and Indo-Pacific Monacanthus relation- 
ship is that at least some species of the latter have at least poorly developed dermal flaps.

In Laputa there is a full complement of three segments in the flexible encasing scale series and the fin-ray rudiments, while small, are not minute. The dorsal lobe of the pelvis is of moderate size and the dewlap just as short as in Paramonacanthus. The most prominent specializations of Laputa in comparison to the other genera with flexible encasing scales and fin-ray elements are that the forward extension of the supraoccipital has been lost and that the encasing scale series is somewhat reduced in size. I suspect that Laputa is on the same line as that leading from Paramonacanthus to Pervagor, with Laputa being a derivative of the forerunner of Pervagor in which the dorsal spine had not yet migrated forward to above the middle of the eye.

In addition to Stephanolepis, Monacanthus, and Para monacanthus, with fully developed forward extensions of the supraoccipital bearing a relatively well-developed crest, and Chaetoderma, with a somewhat shorter forward extension and very shallow crest, two other genera have a moderately developed forward extension and low crest, a still rather generalized condition, and another genus has the forward extension but no crest. These are Alutera, Brachaluteres, and Psilocephalus, in all of which the forward extension reaches to between the middle and almost the front of the eye, with the crest relatively distinct in Alutera but only very poorly developed in Brachaluteres and absent in Psilocephalus. All three of these genera have highly specialized pelvic apparatuses, with no dorsal lobe to the pelvis, no pelvic fin-ray element, and either no encasing scales or a single enlarged scale representing the remnant of the series (some Alutera), even this being lost in large adults.

The first dorsal spine is placed over about the middle of the eye in Alutera and Brachaluteres, and only slightly more posteriorly in Psilocephalus, while Brachaluteres and Psilocephalus are further specialized by having lost the small second dorsal spine, and Psilocephalus by the great elongation of the body, increased number of vertebrae and development of a long chin barbel. In fact, of the genera studied here, I suspect that at least the majority of those without a dorsal pelvic lobe, with the encasing scale series essentially absent and with no fin-ray element, form a natural group representing two divergent lines of diversification from a more or less Aluteralike ancestral group, which itself evolved from some derivative of the Stephanolepis-Paramonacanthus level of organization, perhaps from an early Rudarius-like group that still retained the forward extension of the supraoccipital, and which had the dorsal spine placed over the middle of the eye and a tendency for the reduction of the fixed encasing scale series, such as is evident in the two Recent species, $R$. ercodes with two segments and $R$. minutus with only one.

The Alutera-like ancestral group referred to above is envisioned as being essentially like Recent Alutera, with the exception of having a better developed spiny dorsal fin basal pterygiophore more closely applied to the skull. This ancestral group is seen as diverging into two lines.
One line leads to Alutera and Psilocephalus by a decrease in the size and closeness of association of the basal pterygiophore with the skull, reduction in the size of the first dorsal spine, and elongation of the body and increased number of vertebrae, as found in some Recent Alutera (vertebrae 20 to 23 ) and carried to an extreme in Psilocephalus (vertebrae 29 or 30). In Psilocephalus the basal pterygiophore is greatly reduced in size and only closely attached to the skull anteriorly, while the first dorsal spine is slender and delicate and the second spine is lost, and the pelvis is reduced to a thin narrow shaft.

The other line of evolution from the Alutera-like ancestral group would seem to lead to those genera with a simplified pelvic apparatus (no dorsal lobe, no encasing scales, no fin-ray element) but with a well-developed spiny dorsal fin basal pterygiophore and a relatively welldeveloped first dorsal spine. On this line is Brachaluteres, which retains the forward extension of the supraoccipital and at least a remnant of the crest, as well as the relatively low number of 20 vertebrae found also in one species of Alutera, while the body depth is increased rather than decreased. Part of the increased size of the deep basal pterygiophore in Brachaluteres may be associated with this increased depth of the body and thus of the muscle bands attaching to the sides of the pterygiophore. The first dorsal spine of Brachaluteres is strong, but the second spine is absent. Brachaluteres has the same kind of elaboration and branching of the epipleurals as found in some Alutera.

Undoubtedly also on this line and closely related to Brachaluteres is Paraluteres, with an equally low number of vertebrae, an even more reduced pelvis and neither a forward extension of the supraoccipital nor a crest. The basal pterygiophore, while strong and closely held to the skull, is placed a little further back on the skull than in Brachaluteres, and the dorsal spine is over the rear rather than the middle of the eye, perhaps in conjunction with the resculpturing of the skull that took place as Paraluteres developed its mimicry of Canthigaster valentini, with it being advantageous for the dorsal spine to be able to be laid back inconspicuously against the body rather than jutting out prominently from the head. In fact, the dorsal spine in Paraluteres is covered with thick scaleless skin and in life is probably not capable of being erected at a full $90^{\circ}$ to the dorsal profile, even though the second dorsal spine and presumedly also the locking mechanism are present.

Paraluteres probably evolved from the same ancestral group as Brachaluteres, but before the second dorsal spine was lost and the body depth so greatly increased. From this same ancestral group from which Brachaluteres and Paraluteres evolved also probably came $O x y$. monacanthus and Pseudaluteres, with much the same tendencies for elongation and increased number of vertebrae as in the Alutera-Psilocephalus line, but with the exact opposite trend with the basal pterygiophore and dorsal spine, the pterygiophore remaining large and closely associated with the skull, as in Brachaluteres and Paraluteres.

In Oxymonacanthus the basal pterygiophore of the 
spiny dorsal fin is prolonged anteriorly over the posterior one-third of the surface of the ethmoid, and the first dorsal spine is placed over the front of the eye. In Pseudaluteres the basal pterygiophore is even further prolonged anteriorly, being of such great length that it covers nearly the entire length of the dorsal surface of the skull, the dorsal spines being placed further anteriorly than in any other monacanthid, distinctly in front of the eye.

As discussed before, there is no counterpart in any other scleroderm plectognath fish of the true or pleural ribs found in Pseudaluteres.

Oxymonacanthus and Pseudaluteres share a specialized condition of the sphenotic found in no other monacanthids. In other monacanthids the lower region of the side of the cranium, just above the region of articulation of the upper end of the hyomandibular, is formed by the sphenotic anteriorly and by the pterotic posteriorly, the former ending ventrally as a ventrally or anteroventrally directed prong and the latter having a larger ventrally directed prong that overlies the posterodorsal region of the hyomandibular. In both Oxymonacanthus and Pseudaluteres, as explained in detail in the section on anatomical diversity, the sphenotic is displaced posteriorly by a ventrally directed portion of the posterior region of the frontal bearing its own ventrally directed prong, the side of the cranium just above the articulation of the hyomandibular thus being formed by the frontal anteriorly and the pterotic posteriorly, with the sphenotic squeezed in between and with a relatively small ventral prong. Moreover, Oxymonacanthus and Pseudaluteres are the only two genera of monacanthids to have completely lost the prootic shelf.

Oxymonacanthus is speculated to be an early offshoot of the line leading to Pseudaluteres, an offshoot of the pre-Alutera group before the dorsal lobe of the pelvis was lost and the encasing scales nearly entirely lost. In $O x y$ monacanthus the dorsal lobe of the pelvis is only slightly developed and the encasing scales are reduced to an indeterminate number of scales gradually and slightly increased in size from those of the surrounding region, while the number of vertebrae is increased to about 25 (only 1 less than in Pseudaluteres), and the forward extension of the supraoccipital is absent.

Except for its specialized small nipping mouth (with reduced number of dentary teeth) and slightly elongate snout, a form such as Oxymonacanthus could easily have given rise to Pseudaluteres by the continued reduction in the dorsal lobe and encasing scales and the further migration forward of the dorsal spine and the anterior elongation of the basal pterygiophore. The shared highly specialized nature of the sphenotic in both genera is assurance of their close relationship.

All of the other genera of monacanthids examined here, but not yet discussed, form the middle group of moderately specialized genera intermediate in many ways between the basal Stephanolepis-MonacanihusParamonacanthus group and their close relatives and the group of genera of several lines thought to be derived from a pre-Alutera-like form. The middle group contains genera without a forward extension of the supraoc- cipital and without a fin-ray element, but with encasing scales usually present in an inflexible series or only minutely developed, with 19 or 20 vertebrae and the body not especially either elongate or deepened. These are Amanses, Cantherhines, Rudarius, Navodon, and Acanthaluteres.

Of these, Amanses and Cantherhines have two and a half segments of encasing scales, Navodon two, Rudarius two or one, and Acanthaluteres only minute series when present. Amanses, Cantherhines, and Acanthaluteres have a deep groove posterior to the dorsal spines which is not present in Navodon and Rudarius, while the first dorsal spine is placed behind the middle of the eye in Navodon, Rudarius, and Acanthaluteres, but over the middle or front of the eye in Amanses and Cantherhines, the latter two genera also having relatively plain dorsal spine ornamentation.

Amanses and Cantherhines have long been considered closely related, rightly so I think, and have been well characterized by Randall (1964), who showed them to differ primarily in spinulation (Amanses with coarser scales and a patch of long quill-like spines on the side of the body between the soft dorsal and anal fins) and a deeper caudal peduncle and lower numbers of soft dorsal and anal fin rays. Amanses is obviously a slightly specialized spinier scaled version of Cantherhines, and Randall (1964:332) has suggested that Scobinichthys and Meuschenia (neither studied here) are also closely related to Cantherhines.

I suspect that Cantherhines and its close relatives are derived from a Pervagor-like stock (prior to the development of the special rotation joint between the pelvis and coracoid), some species of which have a groove behind the dorsal spines located above the middle of the eye, by a decrease in the amount of ornamentation of the first dorsal spine and sometimes of its slight forward migration, and by the reduction of the encasing scale series from a flexible three segments around a fin-ray element to an inflexible two and a half segments without a fin-ray element.

Whether Acanthaluteres, with a deep groove behind the dorsal spines, is related to the Cantherhines-like genera is difficult to say, for it has a more generalized dorsal spine position over the rear of the eye but a more specialized pelvic apparatus, the dorsal lobe being essentially absent and the encasing scales either absent or minute. I suspect that Acanthaluteres is an offshoot of the line leading to the pre-Alutera-like group hypothesized here as containing the Alutera-Psilocephalus line and the Brachaluteres-Paraluteres and the Oxymonacanthus-Pseudaluteres lines.

Rudarius is probably a derivative of the line leading from a Pervagor-like form to those of the Cantherhineslike genera, but with the placement of the dorsal spine remaining a little more posterior, usually just behind the middle of the eye, while the trend of reducing the inflexible encasing scale series continued further to only two segments in one of the species and to one segment in the other, while the dorsal lobe and ventral dewlap remained of moderate to small size. 
The dense patch of setae found on the caudal peduncle of male Rudarius ercodes is similar to that found in males of some species of Cantherhines (others have pairs of retrorse spines; see Randall 1964 and Tyler 1970e), while the much longer posteriorly directed spines on the caudal peduncle of male $R$. minutus are undoubtedly a specialized development from the ancestral $R$. ercodeslike form and are not in any way related to the even longer quills further forward on the body of Amanses. Similarly, the large dermal flaps found in $R$. minutus have a much smaller counterpart in some species of Cantherhines (see Randall 1964).

Navodon shares many characteristics with Rudarius, as pointed out by Fraser-Brunner (1941b:178-179), and the two are probably closely related, both specialized in their own way, Rudarius with a relatively deep small body and only two teeth in each dentary and Navodor with a larger more elongate body and a full complement of three dentary teeth but a more forwardly placed gill slit and reduced size of the ventral dewlap.

Four genera not examined for this work and not discussed above should be briefly mentioned, these being Arotrolepis, Pseudomonacanthus, Blandowskius, and Eubalichthys. According to the data in Fraser-Brunner (1941b), these four genera can be characterized as follows:

Arotrolepis has the dorsal spines originating behind the middle of the eye, a flexible encasing scale series (presumedly of three segments and with a fin-ray element) of small size, the ventral dewlap of no more than moderate size, and the scales usually with a single strong central spinule and arranged in distinct longitudinal tracts. Fraser-Brunner thought Arotrolepis most closely related to Monacanthus, although in his key to the genera (which he cautions does not show the true relationships of some of the genera) it is coupled with Chaetoderma. I suspect that he is right and that Arotrolepis is on the Monacanthus-Chaetoderma line. It obviously would be of great interest to know the form of the supraoccipital in Arotrolepis.

Pseudomonacanthus (most data from Fraser-Brunner 1940c) has the dorsal spines originating over the middle or behind the middle of the eye and an inflexible short series of encasing scales (presumedly of less than three segments and with the fin-ray element absent) and no dorsal pelvic lobe.

Blandowskius, which Fraser-Brunner thought was most closely related to Pseudomonacanthus, has no encasing scales at all and the dorsal spines over the rear of the eye, with both genera being intermediate between the Rudarius and the Alutera levels of organization.

Eubalichthys, with the dorsal spines over or in front of the middle of the eye and followed by a groove for their reception, and with the inflexible encasing scale series much reduced in size until it is minute and inconspicuous, was thought by Fraser-Brunner to be a derivative of the Cantherhines-Amanses line.
In short, many of the generic relationships within the monacanthids remain unclear, and will probably continue to be unclear until many more species, representing all genera, have been examined osteologically than it has been possible to do here. However, it does seem clear that the most generalized forms are those with an anteriorly elongate supraoccipital bearing a vertical crest and with a well-developed series of flexible encasing scales of three segments covering over a rudimentary finray element, and with the dorsal spine placed behind the middle of the eye. The genera sharing these conditions are Stephanolepis, Monacanthus, and Paramonacanthus.

A Stephanolepis-like stock is probably ancestral to both Monacanthus and Paramonacanthus. Chaetoderma (and probably Arotrolepis) seems a derivative of a Monacanthus-like stock, while Laputa is probably derived from Paramonacanthus along with Pervagor. It is suspected that a Pervagor-like stock is ancestral to the various moderately specialized genera with inflexible encasing scale series and no fin-ray element. An Aluteralike stock is suspected to have evolved from some derivitive of a Paramonacanthus-like stock, perhaps from a form like Rudarius or Navodon, and to have diverged in two directions, one leading to Alutera and Psilocephalus and the other to two lines leading to Brachaluteres and Paraluteres and to Oxymonacanthus and Pseudaluteres.

\section{SUPERFAMILY OSTRACIOIDEA}

Comparative diagnosis (contrast with that of the Balistoidea).- - Head and most of body encased in a relatively inflexible (except on cheek in front of gill slit) cuirass of especially thick and mostly hexagonal scale plates whose apposed edges are articulated by minute interdigitations, the portion of the body posterior to the carapace with or without isolated scale plates of various shape but never continuously covered by scales; body outline in cross section less laterally compressed and always with two or more angles or ridges; no spiny dorsal fin; soft dorsal and anal fins short-based, with 9 to 13 rays and a slightly lesser number of basal pterygiophores; caudal fin with 10 or 11 rays; pelvis and pelvic fin absent; teeth relatively small and more or less conical or only slightly compressed basally but often constricted distally, between 6 and 17 in a single series in both jaws; lateral line not associated with grooves or spiny processes on the scale plates; branchiostegals usually $2+4$ but sometimes $1+4$ or $2+3$, at least some of the rays in the posterior division as broad and laterally compressed as those in the anterior division; distal end of last branchiostegal ray always articulated to the inner surface of the suboperculum; elements of the hyoid arch more compacted together anteroposteriorly and most elements less elongate and more deep bodied; urohyal much reduced in size, a more or less flattened plate or a slightly curved rod, a ventral flange either absent or very poorly developed; fifth ceratobranchial (lower pharyngeal) al- 
ways toothless; pharyngobranchials consisting either of a toothless suspensory element followed by three elements bearing small but protruding or minute nonprotruding teeth, or a toothless suspensory element (absent in some Acanthostracion) followed by two elements, one or both of which bear minute nonprotruding teeth; epibranchials always four; gill rakers always present along anterior edge of fifth ceratobranchial (posterior edge of last gill slit); caudal fin supporting structures extremely consolidated, the epural, hypural, parhypural, and centrum elements fully fused into a single plate; haemal spine of penultimate vertebra either autogenous or fused to its centrum; neural arch of the last vertebra complete, the canal accommodated in a tube through the plate exiting on the posterior half of the dorsal edge, while the haemal arch is either complete and the canal accommodated in a tube through the plate or the arch is essentially absent, the haemal region of the plate solid and not pierced by the canal; uroneurals never present; vertebrae normally $9+9=18$ or $10+8=18$, but $9+10$ $=19$ in one species, and always 9 or 10 abdominal vertebrae; the first 2 to 5 vertebrae reduced in size at least anteroposteriorly and at least partially fused to the rear of the skull; 7 , more rarely 8 , abdominal vertebrae with neural spines anterior to the first basal pterygiophore of the soft dorsal fin; 3 to 5 caudal vertebrae posterior to the last basal pterygiophores of both the soft dorsal and anal fins; usually no more than 2 , rarely 3 , soft dorsal fin basal pterygiophores placed between successive neural spines; most neural spines positioned strongly obliquely in relation to the axis of the vertebral column; haemal spines above the anal fin basal pterygiophores relatively shorter, either rudimentary or well developed as anteroposteriorly expanded plates but never long and shaftlike and not penetrating into the proximal region of the series of anal fin basal pterygiophores, and at least some of these haemal spines markedly different in shape and size from the neural spines above them; soft dorsal fin basal pterygiophores 8 to 10 ; anal fin basal pterygiophores 8 to 10 ; prominent thin lateral flanges not present on the soft dorsal and anal fin basal pterygiophores; distal pterygiophores either absent or unossified in both the soft dorsal and anal fins; 4 to 6 , or about half, of the anal fin basal pterygiophores with only their distal ends placed in the midline of the body, their proximal regions increasingly divergent variously to the left and right of the midline in the musculature bordering the rear of the abdominal cavity; no spiny dorsal fin and hence no spiny dorsal fin basal pterygiophores, but a supraneural element present anteriorly from the dorsal end of the first basal pterygiophore of the soft dorsal fin, this supraneural element representing a modified basal pterygiophore, perhaps the supraneural strut of balistids; epipleurals and ribs never present; uppermost pectoral fin ray either of two relatively well-developed halves of about equal length (aracanids) or of a single piece bearing a foramen basally (ostraciids); actinosts inflexible and articulated by suturing to one another and to the scapula and coracoid; coracoid and cleithrum enlarged; coracoid expanded ventrally, as wide as or wider there than dorsally, with prominent broad flanges; coracoid with or without a posterior prong along its posterodorsal edge, the prong when present not so well-developed or closely associated with the lowermost actinost; scapular foramen always complete; cleithrum with an anterior flange from its lower anteromedial edge; postcleithrum usually with two distinct halves, rarely as a single piece, the bone directed posteriorly or only slightly obliquely downward and variously slightly to enormously expanded posteriorly and ventrally into a flat relatively thin plate, but never as a long sturdy rod; nearly the entire length of the supracleithrum overlying the cleithrum, or cleithrum and postcleithrum, and the supracleithrum very firmly held to them and the posttemporal; Baudelot's ligament ossified as a stout heavy rod between the posterior region of the parasphenoid and the region of articulation of the supracleithrum, cleithrum, and posttemporal; posttemporal usually relatively large; palatine an elongate block of bone representing an enlarged foot of the $\mathrm{T}$-shaped balistid palatine and firmly sutured along all but the distal end of its medial surface to the ectopterygoid and mesopterygoid while its distal end is held by ligament primarily to the vomer; vomer much enlarged, having either a strongly laterally expanded anterior end and a relatively short posterior tapering shaft fitting into a shallow concavity in the parasphenoid (aracanids) or a strongly expanded lateral surface throughout its length, so that the bone is more or less square and has a flattened posterior surface that sutures to the similarly flattened anterior end of the parasphenoid (ostraciids); ventral edge of the ventral flange of the parasphenoid laterally expanded slightly to moderately and only partially along its length (aracanids) or well expanded along all of its length anterior to the level of about the prefrontal (ostraciids); ventral flange of the parasphenoid without a deep indentation at about the level of the prefrontal; parasphenoid with a high dorsal flange in the medial septum of the orbit which sutures broadly or only slightly with long anteroventral extensions of the pterosphenoids into the medial septum; the medial edges of the pterosphenoids not in contact in the posterior wall of the orbit, well separated there; myodome small or absent; apposed surfaces of the parasphenoid and basioccipital not excavated and no canal between them leading anteriorly into the myodome cavity; epiotics not in contact medially on the posterior surface of the skull, widely separated there by the more posteriorly placed supraoccipital; supraoccipital either with or without a posterior crest, but never with an anterior crest on the surface of the main body of the bone; prootic shelf usually relatively larger, always with a prominent ventral or ventrolateral flange from its lateral edge; the major foramen in the prootic shelf relatively large and elongate, and not completely enclosed by the prootic, being bounded laterally by the prootic and medially by the parasphenoid; anterior edge of the upper part of the preoperculum articulated below along the rear edge of the hyomandibular but above to a groove on the lateral surface of the hyomandibular; hyomandibular a greatly expanded plate, without much of a shaftlike portion. 
Family Aracanidae

Comparative diagnosis (contrast with that of the Ostraciidae).-Supraorbital region of the skull relatively strong, the frontal relatively thick in this region and not held extraordinarily firmly to the undersurface of the carapace; frontal with a long forward extension broadly overlying the dorsolateral surface of the ethmoid to, or very nearly to, the extreme anterior end of the snout; supraoccipital with a long, thin, vertical crest extending posteriorly well beyond the level of the base of the skull; epiotic much prolonged posterolaterally, well beyond the level of the base of the skull, and beyond the level of the distal end of the supraoccipital crest; prootic shelf with a recurved wing from its lateral edge which makes contact with the anterior edge of the laterally expanded posterior region of the bone; myodome small but distinct; four pharyngobranchials, the first a toothless suspensory element, the second either toothless or with minute teeth, the third and fourth with few but large teeth; branchiostegals usually $2+4$, but sometimes $1+4$ or 2 +3 ; ethmoid relatively deep and platelike and not much laterally expanded anteriorly; pterosphenoid and parasphenoid with a broad region of suturing in the interorbital septum; parasphenoid anterior to its region of suturing with the anteromedial edges of the prootic shelves either not much expanded laterally or expanded laterally only for a portion of its length there, the laterally expanded portion being either anteriorly near the vomer or posteriorly near the prootic shelf, but not forming a complete hard palate over the roof of the oral cavity; posterodorsal region of the coracoid with a moderately to well-developed posterior prong; two small vertebrae, represented mostly by neural arch material, at the front of the vertebral column variously fused and sutured to one another and to the exoccipitals and basioccipital, the fusion region without a ventral process below the level of the centra; vertebrae immediately following the fusion region with long neural spines and anteroposteriorly much compressed centra with welldeveloped transverse processes; the centra of the first several vertebrae anterior to the caudal plate not much compressed anteroposteriorly; haemal arch and spine of the penultimate vertebra relatively well developed and autogenous; caudal fin rays i, 9, i (except the Eocene Proaracana, with i, 8, i); postcleithrum (especially the ventral piece) greatly expanded posteriorly into a deep thin plate reaching the level of the anterodorsal ends of the more anterior anal fin basal pterygiophores; supraneural long and well developed, with a relatively deep ventral flange making contact with most or all of the neural spines of the predorsal vertebrae (exclusive of those of the small first two fused vertebrae), extending anteriorly well beyond the level of the anteroventral end of the first dorsal fin basal pterygiophore; haemal spines on the more posterior abdominal and on most of the caudal vertebrae well developed, especially those above the anal fin basal pterygiophores which they support through a connective tissue sheet rather than by close apposition; first anal fin basal pterygiophore without

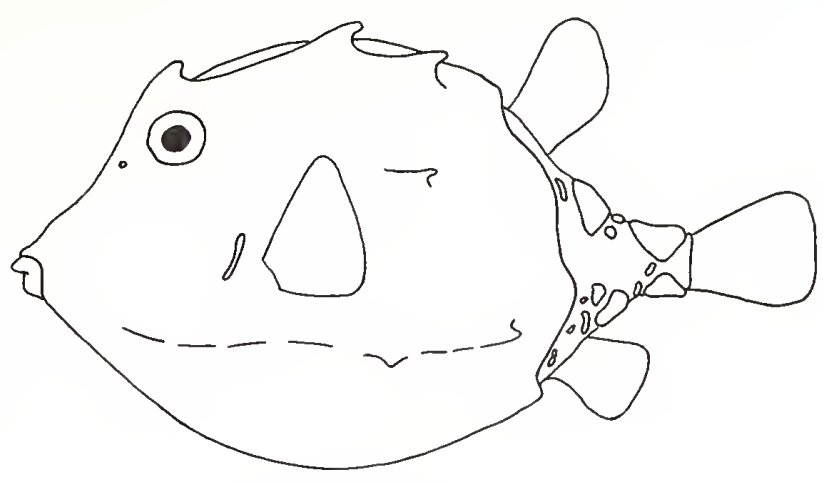

Figure 129.-Typical body form in the Recent Aracanidae: Aracana aurita.

anterolateral wings from its distal end; haemal canal entirely straight, in the midline under the vertebral centra and relatively well enclosed by well-developed haemal arches and spines on all but the more anterior abdominal vertebrae; none of the vertebrae posterior to the anteriormost two fused vertebrae sutured to one another; uppermost pectoral fin ray relatively well developed, consisting of two halves with a few cross-striations distally, the two halves of about the same length or one half, usually the lateral, only slightly shorter than the other; body relatively deep, the distance between the distal ends of the first dorsal and anal fin basal pterygiophores being contained less than 3 times in the SL and the distance between the top of the rear of the cranium and the ventralmost edge of the pectoral girdle being contained about one and three-fourths to slightly more than twice in the SL; carapace open behind the dorsal and anal fins; carapace with a well to only slightly developed ventral keel; caudal peduncle always with scale plates isolated from the carapace proper, often almost completely, if not completely, encircling it.

\section{Detailed Description of Kentrocapros aculeatus.}

Material examined.-Two cleared and stained specimens; $90.0-90.7 \mathrm{~mm}$.

\section{SKULL.}

\section{Occipital Region.}

Basioccipital. - A short column, slightly expanded anterolaterally; cartilage filled anterodorsally; articulates through cartilage and interdigitation dorsally with the exoccipitals and anterolaterally with the prootics, while its ventromedial surface is broadly overlain by and extensively interdigitated with the bifurcate posterior end of the parasphenoid. The upper region of the extreme posterolateral surface of the basioccipital is more or less indistinguishably fused with the basal region of the rudimentary first two abdominal vertebrae, as explained in the section on the vertebral column. 
Figure 130.- Range of diversity in body form and external features of representative aracanid genera:

Strophiurichthys inermis (above) and S. robustus-in front of each, above, nasal region as seen externally (far left) and the olfactory lamellae as seen with the top of the nasal sac removed, and, below,

outline of cross section of middle of body.

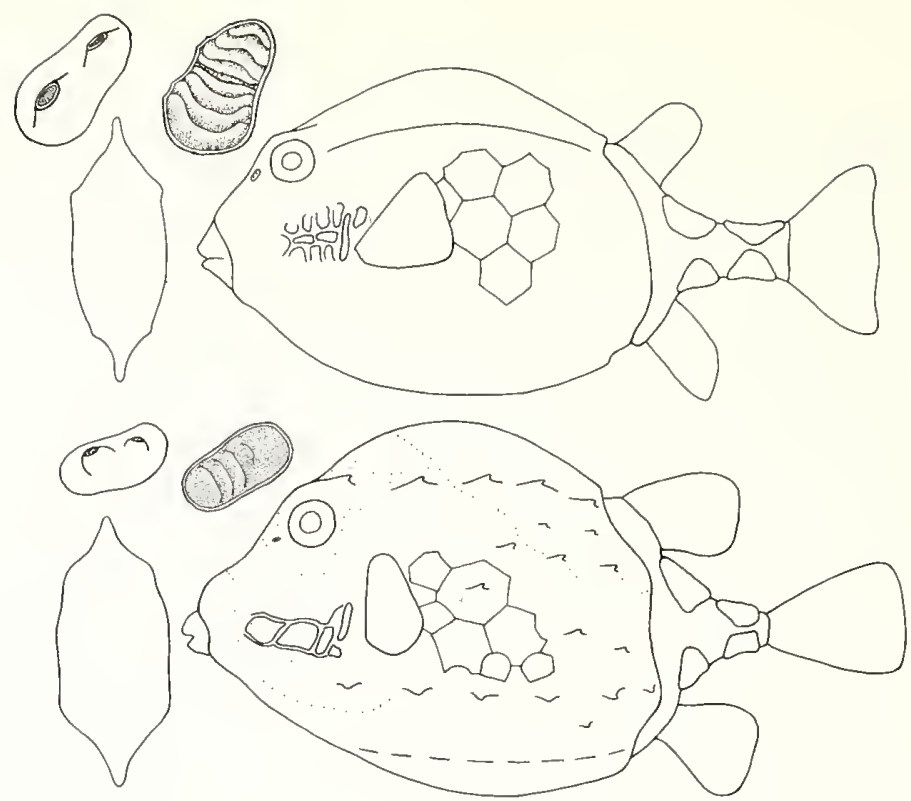

Exoccipital. - Cartilage filled along all of its edges of articulation with the other cranial bones; articulates through cartilage posteromedially with its opposite member and posterodorsally with the supraoccipital; articulates through cartilage and extensive interdigitation posterolaterally with the epiotic, ventromedially with the basioccipital, and anteroventrally with the prootic, while ventrolaterally it articulates mainly through cartilage but with some interdigitation with the pterotic. The lateral surface of the extreme posterior end of the exoccipital is overlain by and interdigitated with the neural spines of the rudimentary first two abdominal vertebrae, as explained in the section on the vertebral column. In this region the exoccipitals form the lateral walls of the foramen magnum, while the dorsal wall is formed by the cartilaginous sheet between the posteromedial edges of the two exoccipitals; the ventral surface of the foramen magnum is bounded by the basioccipital.

Supraoccipital. - Laterally expanded and with a well-developed supraoccipital crest directed posteriorly; cartilage filled along all of its edges of articulation with the other cranial bones; articulates by extensive interdigitation anteriorly and anterolaterally with the frontals, while it articulates through cartilage laterally with the epiotics and ventrally with the exoccipitals.

\section{Otic Region.}

Pterotic. - Cartilage filled along all of its edges of articulation with the other cranial bones; articulates through cartilage and interdigitation anteroventrally with the prootic, posteroventrally with the exoccipital, posterodorsally with the epiotic, and anterodorsally with the sphenotic; the posterodorsal portion of the sphenotic intervening between the pterotic and frontal so that the latter two bones do not articulate directly with one another. For a short distance medially along its anteroventral edge the pterotic supports through cartilage the posterodorsal edge of the hyomandibular. The anterolateral region of the pterotic is prolonged ventrally into a stout shaft whose medial edge articulates through fibrous tissue with the posterodorsal region of the hyomandibular while laterally it is broadly overlain and extensively interdigitated with the posttemporal and medially it helps to support by fibrous tissue the expanded lateral end of the ossified Baudelot's ligament.

Sphenotic. - Cartilage filled along all of its edges of articulation with the other cranial bones; articulates through cartilage and interdigitation posterodorsally with the pterotic and, to a lesser extent, with the epiotic, while anterodorsally it interdigitates with the frontal; medially in the posterior wall of the orbit the sphenotic articulates through cartilage and interdigitation with the pterosphenoid, prootic, and pterotic. The dorsolateral surface of the sphenotic is broadly overlain by the frontal.

Epiotic.-A rounded sturdy cone anteriorly but prolonged posteroventrally into a thin flange; cartilage filled along all of its edges of articulation with the other cranial bones; articulates through cartilage and interdigitation dorsally with the frontal, anteroventrally along its lateral edge with the sphenotic and pterotic and posteroventrally with the exoccipital and medially, through cartilage only, with the supraoccipital.

Prootic. - Cartilage filled along all of its edges of articulation with the other cranial bones, except anteriorly and ventrally where it articulates with the parasphenoid; articulates by interdigitation ventromedially with the laterally compressed keellike dorsal region of 
Figure 131.-Range of diversity in body form and external features of representative aracanid genera: Aracana aurita-upper left, nasal region as seen externally (olfactory lamellae, if present, indistinct in specimen examined); lower left, outline of cross section of middle of body.

Figure 132.-Range of diversity in body form and external features of representative aracanid genera: Anoplocapros amygdaloidesupper left, nasal region as seen externally (far left) and the olfactory lamellae as seen with the top of the nasal sac removed; lower left, outline of cross section of middle of body.

Figure 133.-Range of diversity in body form and external features of representative aracanid genera: Capropygia unistriata-upper left, nasal region as seen externally (olfactory lamellae, if present, indistinct in specimen examined); lower left, outline of cross section of middle of body.

Figure 134.-Range of diversity in body form and external features of representative aracanid genera: Caprichthys gymnura-upper left, nasal region as seen externally (olfactory lamellae, if present, indistinet in specimen examined); lower left, outline of cross section of middle of body.
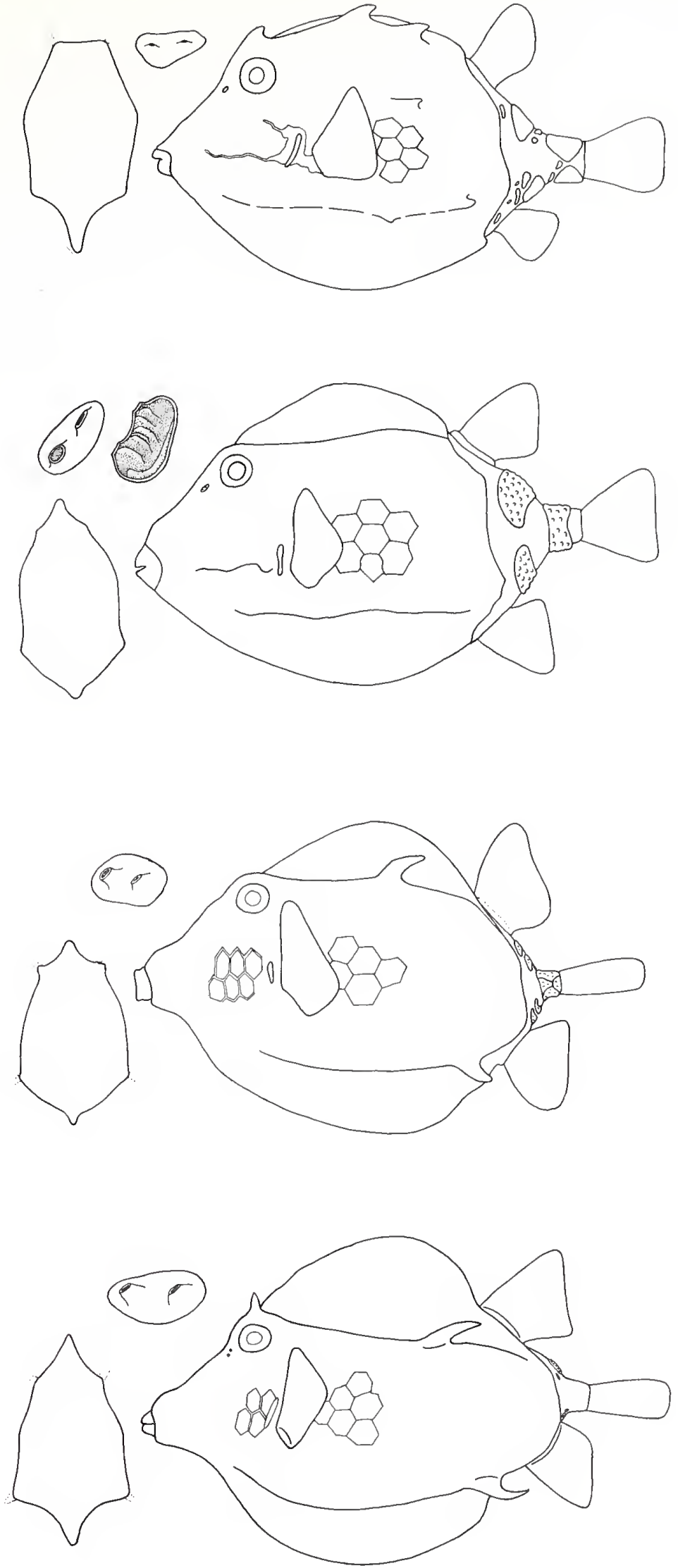
the parasphenoid; articulates through cartilage and interdigitation ventrolaterally with the pterotic, posteroventrally with the basioccipital and exoccipital, dorsomedially with the pterosphenoid, and dorsolaterally with the sphenotic. Along a short distance of the anterior edge of its laterally expanded posterior portion the prootic articulates through cartilage with the posterodorsal end of the hyomandibular. The anteromedial region of the prootic possesses a long forward extension under the orbit which makes contact by interdigitation with the parasphenoid at the level of the prefrontals. A recurved portion of this prootic subocular shelf is directed posterolaterally and makes contact with the anterolateral region of the rear half of the prootic, the two parts of the bone interdigitating in this region just medial to the articulation of the prootic with the dorsal edge of the hyomandibular. Just ventral to this region of contact between the posterolateral wing of the prootic shelf with the rest of the prootic, the wing is thickened and articulates by fibrous tissue with the dorsal surface of the lateral region of the ossified Baudelot's ligament. The medial edges of the prootics form the lateral walls of the myodome, while medially directed shelves from the medial edges of the prootics more or less meet in the midline and articulate through cartilage with one another to form the dorsal roof of the myodome. The anterior edge of the myodome is formed by the prootic, except ventrally where it is formed by the parasphenoid.

\section{Orbital Region.}

Frontal. - Wide in the posterior half of its length, then rapidly tapering to a point anteriorly; extending throughout almost the entire length of the skull and a relatively sturdy bone throughout its length; articulates through cartilage and interdigitation posteromedially with the supraoccipital and posterolaterally with the epiotic and sphenotic, broadly overlying the latter. In the posterior wall of the orbit the frontal articulates through cartilage and interdigitation with the pterosphenoid and sphenotic. The anterior prolongation of the frontal broadly overlies and is held by fibrous tissue to the dorsolateral surface of the ethmoid. Immediately posterior to where it begins to overlie the ethmoid, the ventral surface of the frontal is held by fibrous tissue to the dorsal surface of the prefrontal.

Prefrontal. - Large and wedge-shaped; cartilage filled along its medial edge where it is continuous with the ethmoid cartilage; articulates by fibrous tissue dorsally with the broadly overlying frontal and ventrally with the dorsal edge of the parasphenoid, the latter articulation perhaps strengthened by slight interdigitation. Its major surface of articulation, however, remains with the ethmoid cartilage, that broadly intervenes between the prefrontal and the ethmoid.

Parasphenoid. - An elongate, mostly laterally compressed, slab of bone; expanded in the middle of its length for articulation by interdigitation with the anteromedial edges of the prootic shelves, and, more posteriorly along its ventral edge, where it interdigitates with the prootics and basioccipital. Dorsally in the region of the orbit the parasphenoid has a large dorsal flange which meets and interdigitates with the ventral flanges of the pterosphenoids. Just anterior to this dorsal flange the parasphenoid articulates by fibrous tissue and perhaps slight interdigitation with the ventral end of the prefrontal. Anterodorsally the parasphenoid articulates by fibrous tissue and interdigitation with the ventral edge of the ethmoid, while the extreme anteroventral edge of the parasphenoid becomes concave for reception of the posterior end of the vomer, with which it interdigitates. At its extreme posterior end the parasphenoid bifurcates in the region that overlies the ventral surface of the anterior half of the basioccipital. However, there is no apparent opening into the myodome in this region such as is found in triacanthoids and balistoids. Along its laterally expanded ventral surface in the region of the rear of the orbit the parasphenoid articulates by fibrous tissue and perhaps slight interdigitation with the medial ends of the ossified Baudelot's ligaments from either side.

Pterosphenoid. - Cartilage filled along all of its edges of articulation with the other cranial bones, except for a very short distance anteroventrally; articulates through cartilage and interdigitation posterodorsally with the frontal, which somewhat overlies it, posteriorly with the sphenotic, and posteroventrally with the prootic. The anterior end of the pterosphenoid is prolonged anteroventrally into a process which interdigitates with the dorsal edge of the dorsal flange of the parasphenoid in about the middle of the orbit.

\section{Ethmoid Region.}

Ethmoid.-Elongate; laterally expanded and somewhat rounded dorsally, but ventrally becoming laterally compressed where it articulates by interdigitation and fibrous tissue with the parasphenoid, which in the posterior region of the articulation overlies the ventrolateral edges of the ethmoid; cartilage filled at its posterior edge, where it is continuous with the ethmoid cartilage; articulates by fibrous tissue dorsally with the anterior prolongation of the frontal, which broadly overlies the dorsolateral surface of the ethmoid. Anteroventrally the ethmoid articulates through cartilage and slight interdigitation with the dorsal surface of the vomer. At its anterior edge the ethmoid helps support, through fibrous tissue, the upper jaw.

Vomer. - A short, squarish block of bone with two lateral expansions and a posterior tapering shaft; articulates through cartilage and interdigitation dorsally with the ethmoid and by interdigitation posteriorly where its shaft fits into the concave anteroventral edge of the parasphenoid. The anterior end of the vomer sup- 
ports, through fibrous tissue, the upper jaw. The concave region between the two lateral expansions of the vomer articulates by strong fibrous tissue with the medial surface of the palatine, holding it immovably to it.

\section{Mandibular Region.}

Hyomandibular. - Expanded posteriorly, and slightly narrowed anteriorly where it ends bluntly; cartilage filled at its posterior and anterior edges; articulates by fibrous tissue posteriorly with the extreme lateral edge of the posterior portion of the prootic and with the anteromedial edge of the pterotic, as well as along the medial surface of the ventral shaft of the pterotic. Dorsomedially the hyomandibular is firmly held by fibrous tissue to the lateral edge of the prootic shelf and its posterolateral wing. Anteriorly the hyomandibular articulates along its dorsal edge by fibrous tissue with the posteroventral end of the metapterygoid, while its extreme anteroventral edge articulates through cartilage and fibrous tissue to the fibrous tissue sheet between the metapterygoid, symplectic, and preoperculum. In about the middle of its length the posterior edge of the hyomandibular has a blunt process with a concave head for articulation by fibrous tissue with the head of the operculum. Just anterior to this articular area, the hyomandibular bears an elongate groove along its posterolateral surface into which the slender posterodorsal end of the preoperculum fits and is tightly held by fibrous tissue.

Quadrate. - Wide posteriorly, tapering anteriorly to a knob for articulation with the articular in the lower jaw, while from its posteroventral edge it possesses a well-developed posteriorly directed process; cartilage filled at its posterior edge; articulates by interdigitation dorsally with the ectopterygoid, and, to a lesser extent, with the extreme ventral edge of the mesopterygoid; articulates posteriorly through cartilage with the metapterygoid; at the indented region on its lower posterior edge the quadrate articulates by fibrous tissue and some interdigitation with the anterior end of the symplectic, which broadly overlies its lateral surface. Along most of its ventral edge the quadrate articulates by fibrous tissue with the preoperculum.

Metapterygoid. - A more or less elongate, rectangular plate, somewhat wider anteriorly than posteriorly; cartilage filled at its anterior edge; articulates anterodorsally by interdigitation with the mesopterygoid, which it broadly overlies; articulates anteroventrally through cartilage with the quadrate, while along the anterior half of its ventral edge it articulates by interdigitation with the symplectic. The posterior and posteroventral edges of the metapterygoid are firmly held by fibrous tissue to the anterodorsal edge of the hyomandibular. The dorsal end of the interhyal articulates by fibrous tissue with the ventral edge of the metapterygoid just posterior to the posterodorsal end of the symplectic and just in front of a ventral process of the metapterygoid.

Symplectic. - Slender and somewhat triangular in shape; slightly filled with cartilage at its anterior and, to a lesser extent, posterodorsal end; articulates by fibrous tissue and interdigitation anteriorly with the quadrate, which it broadly overlies, and posterodorsally by fibrous tissue and extensive interdigitation with the anteroventral surface of the metapterygoid, which it also overlies. The posterior edge of the symplectic is in contact with the fibrous tissue sheet between the symplectic, metapterygoid, hyomandibular, and preoperculum, and its posterodorsal end is closely adjacent to the region where the dorsal end of the interhyal articulates with the metapterygoid.

\section{Palato-Pterygoid Region.}

Palatine. - A sturdy dome; articulates by extensive interdigitation ventrally with the ectopterygoid and mesopterygoid. Dorsomedially the palatine articulates by fibrous tissue with the concave region on the lateral surface of the vomer between the two laterally expanded processes of the vomer.

Ectopterygoid. -Elongate, slightly widest in the middle; articulates by extensive interdigitation dorsally with the palatine, posteriorly with the mesopterygoid, and ventrally with the quadrate, which broadly overlies its posteroventral region.

Mesopterygoid. - A large triangular slab whose lateral surface is broadly overlain by the metapterygoid, to which it is extensively interdigitated; anteriorly the mesopterygoid extensively interdigitates with the palatine and ectopterygoid and, to a much lesser extent, with the upper posterior edge of the quadrate.

\section{Opercular Region.}

Operculum. - A relatively flat plate except at its upper end where it is expanded into a facet for articulation by fibrous tissue with the slight concavity on the ventrally directed knob of the posterior edge of the hyomandibular. Ventrally the operculum broadly overlies and articulates by fibrous tissue with the suboperculum.

Suboperculum. - A thin plate, widest anteriorly, its ventral region broadly rounded, tapering to a point posteriorly; articulates by fibrous tissue dorsally with the broadly overlying operculum. At the anterior edge of the region where the operculum overlies the suboperculum, a strong ligament coming from the interoperculum makes contact with the suboperculum and, to a lesser extent, with the operculum. 
Interoperculum. - A short rod of somewhat irregular shape but usually slightly wider in the middle region than at either end; extends from the level of the anterior end of the preoperculum to the level of the posterior end of the epihyal; connects by a strong ligament anteriorly to the angular in the lower jaw, while posteriorly it connects by a short ligament to the epihyal and by a longer more diffuse ligament to the anterior edge of the suboperculum and, to a lesser extent, of the operculum.

Preoperculum. - Relatively short; moderately expanded in the middle region and tapering to narrow ends anteriorly and posteriorly; articulates by fibrous tissue anteriorly along its dorsal edge with the quadrate, while posteriorly the narrow shaft of the preoperculum is held by fibrous tissue along the ventral edge of the hyomandibular and, more dorsally, in the shallow groove on the lateral surface of the hyomandibular. The middle of the dorsal edge of the preoperculum also connects to the fibrous tissue sheet between the symplectic, hyomandibular, and metapterygoid.

\section{Upper Jaw.}

Premaxillary. - A slightly curved plate, wider dorsally than ventrally; its posterodorsal region flattened for articulation by fibrous tissue with the anterior edges of the vomer and ethmoid; the anterior edge of the upper jaw formed by the premaxillary, except for a short distance ventrally where it is formed by the maxillary; the dorsomedial edges of the two premaxillaries held in close apposition by fibrous tissue. Each premaxillary bears four teeth in a single row in the two specimens examined. The teeth are borne in relatively deep and elongate grooves on the outer surface of the premaxillary. The lowermost teeth are shaftlike and taper to sharp points, but more dorsally they are flattened and blunter at the distal ends, except when they first erupt through the gum as replacement teeth, at which time they too are sharp pointed but apparently rapidly become worn down to bluntness through use. At the posterior end of each tooth bearing groove there is a deep socket in which new teeth develop before moving forward to replace the old ones. Most of the interior of the premaxillary contains the dental pulp from which the new teeth develop. This pulp cavity communicates with the exterior not only by the deep sockets in which the new teeth develop but also by a large hole in the posterodorsal surface of the maxillary. The premaxillary articulates by extensive interdigitation with the maxillary along all of its posterior edge, except for a short distance dorsally.

Maxillary. - Widest ventrally, with a deep indentation along its lower posterior edge; articulates by extensive interdigitation anteriorly along all of its length except extremely ventrally with the premaxillary, which it somewhat overlies. The maxillary articulates by fibrous tissue posterodorsally with the anterior edges of the vomer and ethmoid, and ventromedially with the dorsolateral surface of the dentary.

\section{Lower Jaw.}

Dentary. - Wider posteriorly than anteriorly; its posteromedial surface concave dorsally to accommodate the articular, with which it interdigitates. Just below the articular, the dentary interdigitates with the angular. The ventromedial edges of the two dentaries are held closely together by fibrous tissue. Laterally from its posterodorsal region the dentary articulates by fibrous tissue with the medial surface of the maxillary. Each dentary bears four teeth, like those of the upper jaw, in deep grooves on its outer surface, each of the tooth bearing grooves ending posteriorly in a deep socket in which new teeth develop. The sockets are in communication with the large pulp cavity that fills most of the hollow interior of the dentary. The pulp cavity communicates with the exterior not only at the sockets but also at its posterior concave region of articulation with the articular.

Articular.--Small; its posterior edge with a concavity for articulation by fibrous tissue with the anterior knoblike process of the quadrate. Anteriorly the articular interdigitates with the concave upper half of the posteromedial surface of the dentary. On the medial side of its ventral edge the articular interdigitates with the angular, but the lateral surfaces of the two bones are not in contact; rather, they are slightly separated by the dentary. The sesamoid articular is a flattened nubbin of bone mostly held to the medial surface of the anterior end of the articular just behind the region where the upper medial edge of the articular meets the medial surface of the dentary.

Angular. - Small and mainly confined to the medial surface of the lower jaw; articulates by interdigitation dorsomedially with the articular, while dorsolaterally, anteriorly, and ventrally it interdigitates with the dentary. Posteriorly the angular connects by ligament with the anterior end of the interoperculum.

\section{BRANCHIAL APPARATUS.}

\section{Hyoid Arch, Branchiostegal Rays, and Urohyal.}

Hypohyals. - Both elements well developed; ventral element larger than the dorsal element; dorsal element cartilage filled at its ventral and posterior edges, the ventral element cartilage filled at its dorsal and posterior edges. The two elements articulate with one another and with the ceratohyal mainly through cartilage, but on their medial surfaces the two hypohyals have thin extensions which interdigitate with one another. The anteromedial edges of both elements articulate by fibrous tissue with their opposite members. The dorsomedial edge of the dorsal hypohyal articulates 
by fibrous tissue posteriorly with the first basibranchial and anteriorly with the reduced urohyal, while the dorsomedial edge of the ventral hypohyal also articulates by fibrous tissue with the urohyal.

Ceratohyal. - A wide flat plate; shortened anteroposteriorly and expanded dorsoventrally, particularly posteriorly; cartilage filled along all of its edges except for the indented regions dorsally and ventrally; articulates through cartilage anteriorly with the dorsal and ventral hypohyals. and posteriorly with the epihyal. The first two branchiostegal rays articulate by fibrous tissue with slight concavities on the anterior half of the ventral edge of the ceratohyal. The next three branchiostegal rays articulate by fibrous tissue with the posteroventral edge of the ceratohyal, and the last ray with the ventral region of the lateral face of the epihyal and, to a lesser extent, the lateral face of the extreme posterior end of the ceratohyal.

Epihyal. - Large, elongate dorsoventrally; cartilage filled at its anterior, anterodorsal, and ventral edges; articulates through cartilage anteriorly with the ceratohyal, while posterodorsally it supports the interhyal by fibrous tissue. Just anterior to its articulation with the interhyal, the lateral surface of the epihyal articulates by fibrous tissue with the posterior end of the interoperculum.

Interhyal. - A short column; cartilage filled at both ends; articulates by fibrous tissue ventrally with the epihyal and dorsally with the concavity on the ventral edge of the metapterygoid immediately behind the posterodorsal end of the symplectic.

Branchiostegal rays. - Six in number; the last ray slightly longer than the others; articulates by fibrous tissue to the ceratohyal and, to a lesser extent, the epihyal, as explained under those bones.

Urohyal.-Reduced to a somewhat irregularly curved rod without a ventral keel; articulates by fibrous tissue anterodorsally with the anteromedial edge of the dorsal hypohyal and the dorsomedial edge of the ventral hypohyal; articulates by fibrous tissue posterodorsally with the ventral surface of the first basibranchial.

Branchial Arches. - All the elements are cartilage filled at their edges of articulation with the other elements in the series, and the articulations are usually through cartilage and fibrous tissue. The branchial arches are composed of three basibranchials, three pairs of hypobranchials, five pairs of ceratobranchials, four pairs of epibranchials, and four pairs of pharyngobranchials. Four gills are present, with a small slit between the fourth arch and the lower pharyngeal.

First arch.-Basi-, hypo-, cerato-, epi-, and pharyngobranchial elements present. First basi- branchial short, only slightly wider posteriorly than anteriorly; displaced forward so that it articulates posteriorly with the second basibranchial and anteriorly with the hypohyals and urohyal, but with no direct connection with the first hypobranchials. First hypobranchial a square block of about the same size as the second hypobranchial; articulates ventrally with the lateral surface of the second basibranchial and dorsally with the first ceratobranchial. First ceratobranchial a sturdy rod; about equal in length to the other ceratobranchial elements; somewhat greater in depth ventrally than dorsally, this increased depth at the ventral end increasing from the first to the last ceratobranchial, the last being widest in the middle region; no ventrally directed flange present on any of the ceratobranchials; articulates ventrally with the first hypobranchial and dorsally with the first epibranchial. First epibranchial a sturdy column; articulates anterodorsally with the base of the first or suspensory pharyngobranchial. First pharyngobranchial a toothless flattened plate; articulates dorsally by fibrous tissue to the undersurface of the extreme anterior end of the prootic suborbital shelf just lateral to the region where the prootic interdigitates with the laterally expanded portion of the parasphenoid in the anterior region of the orbit.

Second arch. -Basi-, hypo-, cerato-, epi-, and pharyngobranchial elements present. Second basibranchial the largest of the three elements in the series; articulates anteriorly with the first basibranchial, laterally with the first hypobranchial, and posteriorly with the third basibranchial. Second hypobranchial articulated ventrally with area of articulation between the second and third basibranchials and dorsally with the second ceratobranchial. Second ceratobranchial articulated dorsally with the second epibranchial. Second epibranchial a wide heavy column; articulates dorsally with the base of the second pharyngobranchial. Second pharyngobranchial the largest of the four pharyngobranchial elements and the first of the tooth bearing elements. The teeth are very small and difficult to see and in life may largely be buried in the pharyngeal tissues. The 15 to 20 minute teeth on the second pharyngobranchial are much shorter than those on the third and fourth pharyngobranchials, and are grouped together in the central region of the ventral face of the element.

Third arch.-Basi-, hypo-, cerato-, epi-, and pharyngobranchial elements present. Third basibranchial a short column, the shortest of the three basibranchials; articulates anteriorly with the second basibranchial, anterolaterally with the second hypobranchials, posterolaterally with the third hypobranchials and third ceratobranchials, and posteriorly to the region between the fourth certobranchials. Third hypobranchial a long slender rod, directed anteroventrally and with only its extreme posterodorsal end at the level of the other hypobranchial elements; articulates posterolaterally with the third ceratobranchial and 
posteromedially with the third basibranchial, while its ventrally directed anterior end articulates by fibrous tissue with the undersurface of the more anterior branchial elements, although I am unable in the two study specimens to see exactly where the attachments end. Third ceratobranchial articulated ventrally with the posterior end of the third hypobranchial and third basibranchial, and dorsally with the third epibranchial. Third epibranchial slender dorsally and somewhat expanded ventrally; articulates dorsally with the third pharyngobranchial. Third pharyngobranchial smaller than the second pharyngobranchial but larger than the fourth; bearing a single row of four or five long slender teeth with relatively sharp points on the compressed ventral edge of the bone; articulates ventrally with the third epibranchial and is held by fibrous tissue more or less closely to the second and fourth pharyngobranchials.

Fourth arch.-Cerato-, epi-, and pharyngobranchial elements present. Fourth ceratobranchial articulated ventrally with the cartilaginous area between the third ceratobranchials and the third basibranchial, and dorsally with the fourth epibranchial. Fourth epibranchial the longest of the epibranchial elements; rodlike; articulates dorsally with the fourth pharyngobranchial. Fourth pharyngobranchial a very small plate bearing a single row of two or three long slender teeth much like those of the third pharyngobranchial but slightly smaller.

Fifth arch. - Ceratobranchial (lower pharyngeal) element only. Fifth ceratobranchial the widest and shortest of the ceratobranchial elements; much expanded in the middle region of its length; articulates ventrally with the cartilaginous region between the bases of the fourth ceratobranchials; toothless.

\section{PAIRED FIN GIRDLES.}

\section{Pectoral Fin.}

Posttemporal. -A large long shaft broadly overlying the lower half of the lateral surface of the pterotic, to which it is firmly interdigitated; anterodorsally it also interdigitates with the sphenotic, while its ventral head is firmly held by fibrous tissue to the supracleithrum. On its ventromedial surface the posttemporal helps, along with the pterotic and, to a far lesser extent, the cleithrum, to support by fibrous tissue the expanded lateral end of the ossified Baudelot's ligament.

Baudelot's ligament. - This ligament is fully ossified as a large stout laterally expanded shaft giving great support to the pectoral girdle. It interdigitates in the midline with its opposite member and is firmly held by fibrous tissue at its medial end to the ventral surface of the parasphenoid just below the level of the origin of the prootic shelf. Its expanded lateral end is firmly held by fibrous tissue mainly to the ventromedial surface of the ventral flange of the pterotic and to the ventral end of the posttemporal, and, to a much lesser extent, to the extreme dorsal end of the cleithrum. Along its dorsal edge, just lateral to its middle region, Baudelot's ligament connects by fibrous tissue with the recurved portion of the prootic shelf, while its ventral edge helps support by a fibrous tissue sheet the dorsal edge of the medially expanded platelike portion of the cleithrum.

Supracleithrum. - Located slightly obliquely posterodorsally to anteroventrally in relation to the axis of the body; relatively short and overlain for a short distance anterodorsally by the ventral end of the posttemporal, to which it is articulated firmly and relatively immovably by fibrous tissue. The medial surface of the supracleithrum broadly overlies and is firmly held by fibrous tissue to the anterodorsal surface of the cleithrum.

Cleithrum. - Greatly expanded both laterally and medially along all the length of its anterior edge, except for a short distance ventrally, so that a large thin vertical plate is formed at right angles to the axis of the body; also greatly expanded posteriorly in the ventral twothirds of its length; articulates dorsally by fibrous tissue on its lateral surface with the broadly overlying supracleithrum and on its medial surface with the anterior end of the dorsal postcleithrum; along its posterior edge it articulates by fibrous tissue and interdigitation with the anterior edge of the scapula, which it somewhat overlies ventrally, while more ventrally along its posterior edge it articulates through cartilage and slight interdigitation with the coracoid. Ventromedially the cleithrum articulates by fibrous tissue with its opposite member, while the dorsal edge of its medially expanded platelike portion is held by fibrous tissue to the ventral surface of Baudelot's ligament.

Postcleithra. - The postcleithra are greatly expanded into an extremely wide, thin plate whose lateral surface is closely held by fibrous tissue to the cuirass. There are distinct dorsal and ventral segments, the ventral segment much larger than the dorsal. The anterior end of the dorsal segment articulates by fibrous tissue with the medial surface of the dorsal end of the cleithrum, while posteriorly it interdigitates with the ventral postcleithrum. The ventral edges of both postcleithra are thicker than the dorsal region, and the anterior end of the dorsal postcleithrum is thickened and shaftlike in the area of its articulation with the cleithrum.

Coracoid.-Somewhat wider ventrally than dorsally; its posterior edge with a laterally directed flange throughout its length, the flange ending dorsally as a posteriorly directed prong below the lowermost actinost; cartilage filled at its dorsal and anterior edges; an upraised flange present on its lower lateral surface, running, with increasing height of the flange, from postero- 
dorsally to anteroventrally where it contacts the posteroventral end of the cleithrum; articulates dorsally through cartilage with the scapula, while posterodorsally it articulates through cartilage (and interdigitation in one of the two study specimens) with the third actinost and through cartilage and interdigitation with the fourth actinost. It is probable that in large specimens the third actinost would also interdigitate with the coracoid. Anteriorly the coracoid articulates through cartilage and in some places slight interdigitation with the posterior edge of the cleithrum.

Scapula.-Completely encloses the scapular foramen; cartilage filled at its posteroventral and anterior edges; articulates by fibrous tissue and interdigitation anteriorly and anteroventrally with the cleithrum, while posteroventrally it articulates through cartilage with the coracoid. Posterodorsally the scapula articulates through fibrous tissue and interdigitation with the bases of the first two actinosts and, in one of the two study specimens, with the anterior end of the base of the third actinost. Just anterior to its articulation with the first actinost the scapula bears a projection with a concave surface for support of the short uppermost pectoral fin ray, to which it is held by fibrous tissue.

Actinosts. - Four elements; cartilage filled at their ventral edges; first actinost the smallest, the others of slightly increasing size posteriorly in the series; all four elements held to one another by interdigitation; first and second actinosts articulated ventrally by interdigitation with the posterodorsal edge of the scapula; third actinost articulated ventrally either through cartilage or by interdigitation with the dorsal edge of the coracoid; fourth actinost interdigitated with the posterodorsal edge of the coracoid. Distally the actinosts support by fibrous tissue all of the fin rays, except for the first, which is supported by the scapula, and perhaps the second, which may be supported in part by the scapula as well as by the first actinost.

Fin rays. - Twelve to thirteen fin rays in most specimens, with the first ray only about one-fourth or one-fifth the length of the second ray and articulated directly with the scapula instead of with the actinosts, as are all the other rays with the possible exception of the second, which articulates more or less in the region of interdigitation between the scapula and first actinost; first ray with its two halves distinct and of about equal size. The first two rays unbranched, the others branched. The first ray has cross-striations at its extreme distal end and the other rays are more fully cross-striated.

VERTEBRAL COLUMN. - All vertebrae with biconcave centra, except the last, which ends posteriorly in the fused hypural plate, and the highly modified first two vertebrae. However, the third and fourth vertebrae particularly are much compressed anteroposteriorly and the biconcaveness of the centra is only slightly indicated.

\section{Abdominal Vertebrae.}

First two vertebrae. - In the two adult study specimens, the first two abdominal vertebrae are rudimentary and are not only fused to one another and to the skull but are much smaller than any of the subsequent vertebrae. The neural arches of the first two vertebrae are slender and the arches from each side do not meet their opposite members in the midline above the spinal cord. They are distinct from one another in the dorsal halves of their lengths and are fused to one another and to the exoccipitals and basioccipital only basally. The fused centra of the first two vertebrae are so compressed anteroposteriorly and shortened dorsoventrally that they form only a thin plate fused to the dorsal region of the posterior end of the basioccipital. The neural arches of both vertebrae bear small neural foramens. The structure of the first two vertebrae and of the vertebral column in general has been described by Tyler (1963a:164-171).

Other abdominal vertebrae. - As used here the term abdominal vertebrae refers to all of those vertebrae anterior to the vertebra to which is attached the first anal fin basal pterygiophore. In the case of ostracioids, with their highly unusual anal fin basal pterygiophore arrangement, this definition is not applicable. The more anterior of the anal fin basal pterygiophores of ostracioids do not remain in the midvertical plane of the body, but, rather, are laterally divergent from their medially placed bases and thus no longer connected with the ventral surface of the vertebral column. Only the last three or four basal pterygiophores are invariably in the midline of the body, and the proximal ends of even these pterygiophores in ostracioids do not make as close a contact with the vertebrae as in other plectognaths. Under these circumstances (discussed more fully by Tyler 1963a:169) it is necessary to arbitrarily state that the first caudal vertebra is that vertebra to which the proximal end of the first basal pterygiophore that consistently lies entirely in the midline of the body is most closely associated. Although this divides the vertebral column into abdominal and caudal segments that are not comparable to those of other plectognaths, it has consistency within the superfamily, for all specimens of ostracioids examined have, by this definition, 9 abdominal vertebrae, regardless of how many of the anterior elements are fused together, and either 9 (usually) or 10 caudal vertebrae. In Kentrocapros aculeatus the first basal pterygiophore of the anal fin that lies entirely in the midline of the body is supported or most closely associated with the sequentially 10 th vertebra, which arbitrarily is thus defined as the first caudal vertebra. The third to ninth abdominal vertebrae have normal, unfused, centra, and complete neural arches with well-developed neural spines. These abdominal vertebrae differ from the more anterior of the caudal vertebrae only in that the first few vertebrae following the two rudimentary vertebrae (i.e., the third to about the sixth 
vertebrae), have their centra anteroposteriorly compressed, the degree of which decreases posteriorly in the series, and by the fact that the third to eighth abdominal vertebrae have transverse processes laterally from the centra. The posterolaterally directed transverse process of the third abdominal vertebra arises from the upper part of the centrum and the lower part of the neural arch. The processes of the fourth and fifth abdominal vertebrae are placed successively lower on the centra and the processes of the sixth to eighth vertebrae are low on the ventral edge of the centra. None of these abdominal vertebrae, up to and including the eighth, have haemal arches or spines. The ninth and arbitrarily designated last abdominal vertebra has a short haemal arch and spine differing from those in the caudal series only by its smaller size. The neural spines of the third to seventh abdominal vertebrae lie anterior to the first basal pterygiophore of the dorsal fin. The neural spines of the third, fourth, and sometimes fifth abdominal vertebrae are held distally in a narrow concavity along the ventral edge of the ventral keel of the supraneural element or carina, while the neural spines of the fifth to seventh vertebrae simply articulate by fibrous tissue with the ventral edge of the keel. The neural spines of the eighth and ninth abdominal vertebrae articulate by fibrous tissue between the basal pterygiophores of the anterior region of the dorsal fin. The haemal arch and spine of the ninth abdominal vertebra is symmetrically placed in the midline below the centrum and there is no indication here or on any of the more posterior vertebrae that the haemal canal lies other than in the midline, in contrast to the condition in the Ostraciidae. The neural spine and arch of the seventh abdominal vertebra bears a low ridge along its length, while a similar ridge is present on the eighth and ninth abdominal vertebrae, but much more prominently developed, ending ventrally on the anterior end of the centrum as a flange.

Caudal Vertebrae. - The caudal vertebrae numbered nine in two specimens. All of the caudal vertebrae possess complete neural and haemal arches and spines. The haemal spine of the first caudal vertebra is better developed than that of the last abdominal vertebra, but still shorter than that of the second caudal vertebra, which is the largest in the series. Posterior to the second caudal vertebra the haemal spines decrease gradually in size in the series to the seventh caudal vertebra. The haemal spine of the eighth caudal vertebra is larger than that preceding it and it is autogenous to the centrum. The neural spines decrease in length gradually in the series from the first to the seventh caudal vertebrae, while the neural spine of the eighth caudal vertebra is somewhat larger than that preceding it. The haemal spines of the first to fourth caudal vertebrae support the distal ends of the last four basal pterygiophores of the anal fin, these being the only four which consistently lie in the midline of the body, rather than being divergent from it as are the more anterior pterygiophores. The neural and haemal canals lie in the midline of the body and are not divergent from it. Each of the caudal verte- brae, as with the abdominal vertebrae, possesses a neural foramen low on the neural arch region.

Caudal Skeleton. - The caudal complex consists of a large rectangular plate, with a rounded expansion in the middle region of its anterior edge representing the centrum of the last caudal vertebra, and a deep cleft in the middle of its posterior edge representing the division between what in more generalized plectognaths such as triacanthodids would be the second and third hypurals. However, the hypurals are fully fused to the centrum and to themselves and no real distinction can be made between them. The anteroventral region of the rectangular plate represents the parhypural which is fully fused to the centrum and hypurals. That this is the region of the parhypural is indicated by the haemal canal penetrating the anterior region of the rectangular plate just below the centrum and exiting at a foramen a short distance posterior to where it first enters the plate. This foramen represents the region of fusion between the parhypural and the hypurals. The anterodorsal region of the rectangular plate represents the completely fused epural, for the neural canal penetrates the plate, again just above the centrum, and courses through it to exit about midway along the dorsal edge of the plate.

Caudal fin rays. - Eleven fin rays are present in both specimens and generally throughout the Aracanidae; the uppermost ray and the lowermost ray unbranched, the intervening nine rays branched; all rays with cross-striations. The fin is vaguely divided into an upper and lower lobe, the upper lobe containing five rays articulated to the fused hypural plate above the indentation in its posterior edge and the lower six rays articulated to the lower half of the plate. The bifid bases of the rays do not overlap the hypural plate, to which they are articulated through fibrous tissue. The branched fin rays become increasingly branched toward the center of the fin, where the rays are branched in up to incomplete quadruple dichotomies.

\section{DORSAL AND ANAL FINS.}

\section{Dorsal Fin.}

Fin rays and pterygiophores. - Eleven fin rays are present in both study specimens; the first ray unbranched, the other rays branched in single to triple dichotomies. Distal pterygiophores are either absent or unossified. The bifid bases of the fin rays are supported through fibrous tissue by 9 or 10 basal pterygiophores. The specimen with 9 basal pterygiophores (the illustrated specimen) has the last pterygiophore a compound element obviously representing the fusion product of 2 pterygiophores, for in the other study specimen there are 2 separate basal pterygiophores in this region for a total of 10 . With the exception of the first and last pterygiophores the basal pterygiophores are more or less slender rods, cartilage filled at both ends, and of slightly 
decreasing length posteriorly in the series. At their dorsal ends the pterygiophores are slightly expanded into articular knobs. The pterygiophores articulate with one another and with the neural spines supporting them by fibrous tissue with little or no interdigitation between the pterygiophores. Just below their expanded articular faces the pterygiophores are slightly constricted so that there is a definite gap between their apposed surfaces. The first pterygiophore is unlike the others only in that it is much larger and more expanded anteriorly and posteriorly into a thin plate filling the space between the distal regions of the neural spines of the seventh and eighth abdominal vertebrae. Anterodorsally the first basal pterygiophore articulates by fibrous tissue and interdigitation with the posterior end of the supraneural element or carina. The supraneural is a long strut reaching nearly to the posterior end of the skull. Its dorsal surface is laterally expanded and its bears a deep ventral keel. Anteriorly the ventral edge of the keel is concave to enclose the distal tips of the neural spines of the third, fourth, and, in one specimen, fifth abdominal vertebrae, articulating with them by fibrous tissue. The distal tips of the neural spines of the sixth and seventh vertebrae end at the ventral edge of the keel and do not penetrate it. The dorsal surface of the supraneural lies just below the cuirass. The basal pterygiophores of the dorsal fin articulate between the neural spines of the seventh abdominal to third caudal vertebrae.

\section{Anal Fin.}

Fin rays and pterygiophores. - Eleven fin rays are present; the first ray unbranched, the others branched in up to incomplete triple dichotomies. Distal pterygiophores are either absent or unossified. The bifid bases of the fin rays articulate by fibrous tissue to nine basal pterygiophores. These pterygiophores are basically similar to those of the dorsal fin except that they tend to be longer, more anteroposteriorly expanded and much more firmly held to one another, usually by extensive interdigitation. However, while all of the dorsal fin basal pterygiophores lie in the midvertical plane of the body, only the last four anal fin basal pterygiophores consistently lie entirely in this medial plane, the five pterygiophores anterior to them diverging to the right and to the left from their ventral ends, which are in the midvertical plane. The sixth to ninth basal pterygiophores have their dorsal ends held by fibrous tissue at some distance from the ventral ends of the haemal spines of the first to fourth caudal vertebrae. The second to fifth pterygiophores have their slightly expanded ventral articular ends in the midvertical plane, but their long more or less rodlike anterodorsally directed portions lie to the right or to the left of the midline in the anterior portion of the large muscle mass connected to the anal fin. In the two study specimens three of these pterygiophores diverge to the right and two to the left. The first basal pterygiophore is expanded just above its knoblike distal end into a thin plate which lies only slightly to one side of the midline. It has the largest keellike expansion of any of the pterygiophores. It is the second to the fifth pterygiophores that diverge widely from the midline, two to the left and two to the right. The second to fifth pterygiophores remain rodlike throughout their lengths, while the sixth to ninth pterygiophores, that lie in the midline of the body throughout their lengths, are variously expanded into thin plates for parts of their lengths. The knoblike distal ends of these more posterior basal pterygiophores are closely apposed to one another and articulate by fibrous tissue but they are not fused or sutured. The shafts of the first to fifth pterygiophores are tightly held to one another in the midline before they diverge to the right or left, and the surfaces of apposition seem to be at least extensively interdigitated, if not, in some cases, perhaps even fused. The concave region on the posteroventral edge of the last basal pterygiophore rests against the edge of the carapace, just as the similarly indented region on the last dorsal basal pterygiophore supports the carapace in that region.

Anatomical diversity. - Very little anatomical diversity is present in this small family of deepwater box fishes comprising about 10 species from the Indo-Pacific (Hawaii to South Africa), but mainly from Australia. They have been relatively poorly collected and the genera as presently recognized (McCulloch and Waite 1915; Fraser-Brunner 1935b, 1941c) seem extremely finely split, the distinctions based exclusively on carapace characteristics, many of which are rather trivial (number of spiny processes and degree of development of isolated caudal peduncular scale plates). Three of the genera (Kentrocapros, ${ }^{3}$ Capropygia, Caprichthys) are monotypic, while Aracana and Strophiurichthys each have two species, and Anoplocapros two, perhaps three (if grayi is valid).

The carapace in all genera except Kentrocapros and Aracana has six major ridges or angles: single dorsal and ventral crests and two paired ridges along the side of the body, dorsolateral and ventrolateral in position. In Kentrocapros and Aracana there is no dorsal crest, the back being relatively flat or gently convex rather than high crested, so that there is a total of five ridges. In the single fossil species of the family, Proaracana dubia (Blainville 1818) from the Eocene of Monte Bolca, Italy, the dorsal crest is well-developed and terminates at its greatest height in a large spiny process similar to that of the ventral crest, spines in these positions being unique in the family.

In addition to the major ridges, a mediolateral ridge or slightly convex region may be present about midway between the dorsolateral and ventrolateral ridges, but it is usually less distinct than the other ridges.

The carapace extends further posteriorly and the caudal fin is less strongly developed in Caprichthys and Capropygia than in the other genera.

Posterior to the carapace there are always isolated

\footnotetext{
${ }^{3}$ Aracanostracion Smith (1949b) is tentatively considered a synonym of Kentrocapros, until the single known specimen, the type of rosapinto, can be examined.
} 


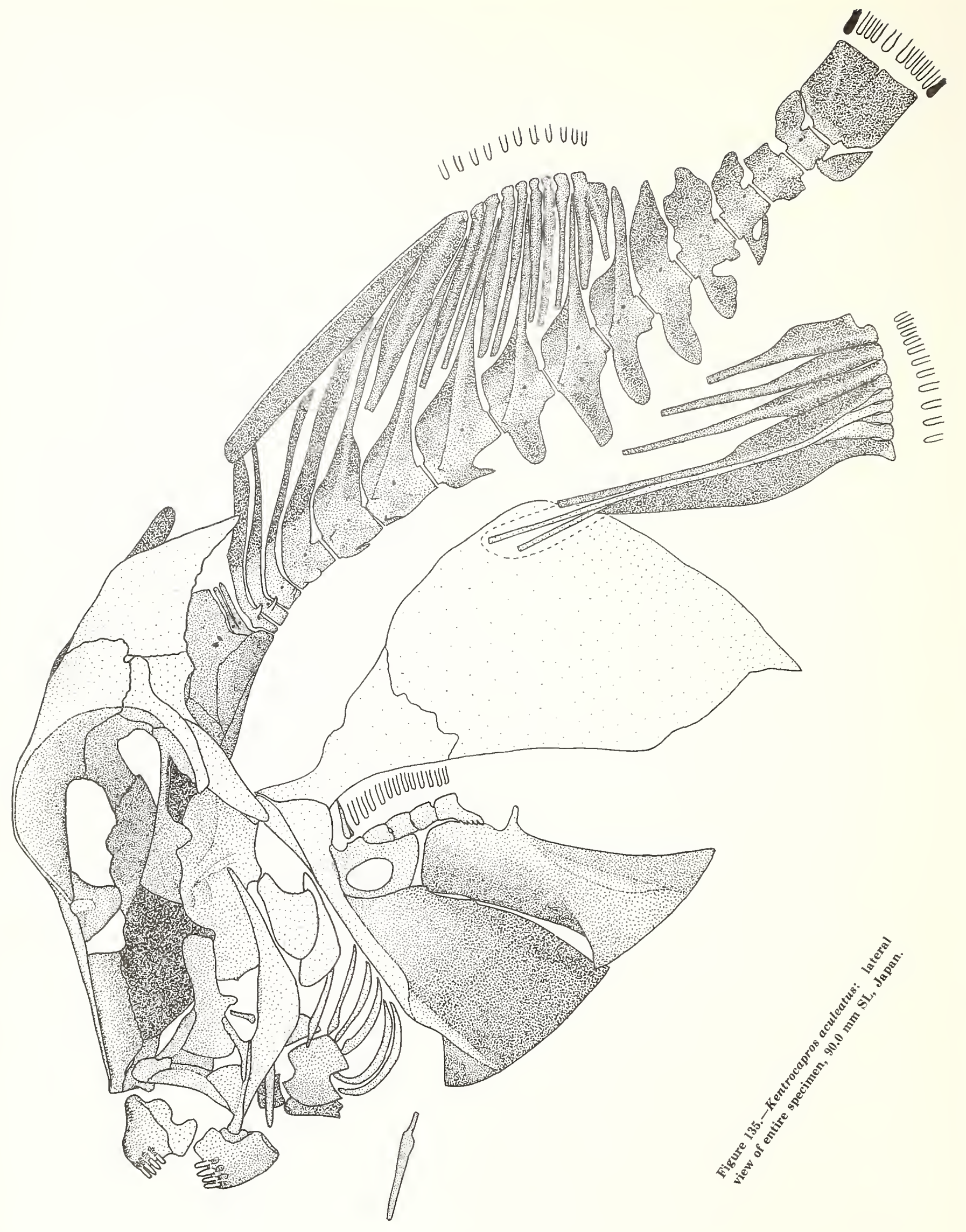


Figure 136.-Kentrocapros aculeatus: lateral view of head, $90.0 \mathrm{~mm} \mathrm{SL}$, Japan.

Figure 137.-Kentrocapros aculeatus: ventral (left) and dorsal (right) views of skull, $90.7 \mathrm{~mm}$ SL, Japan.

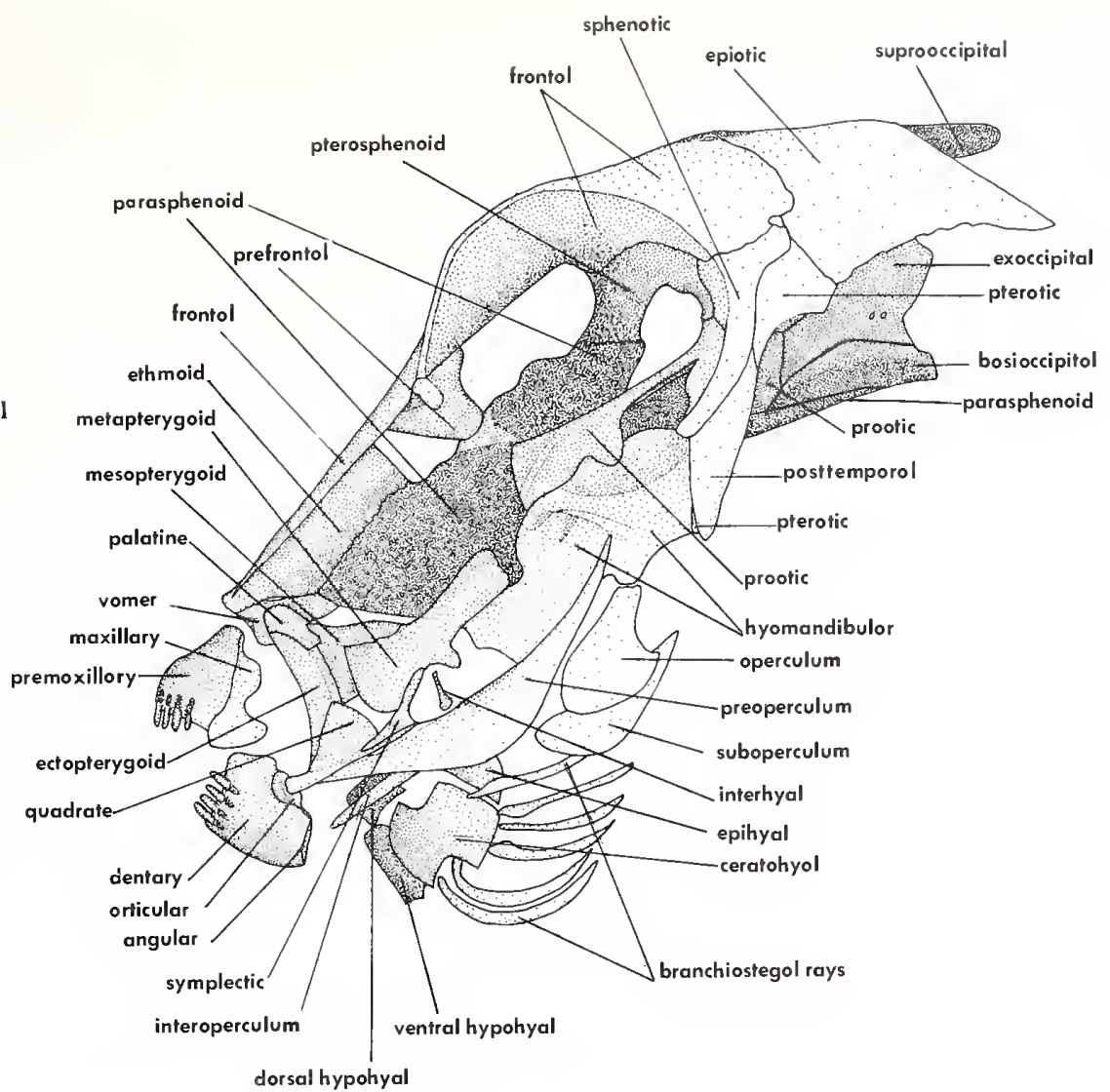

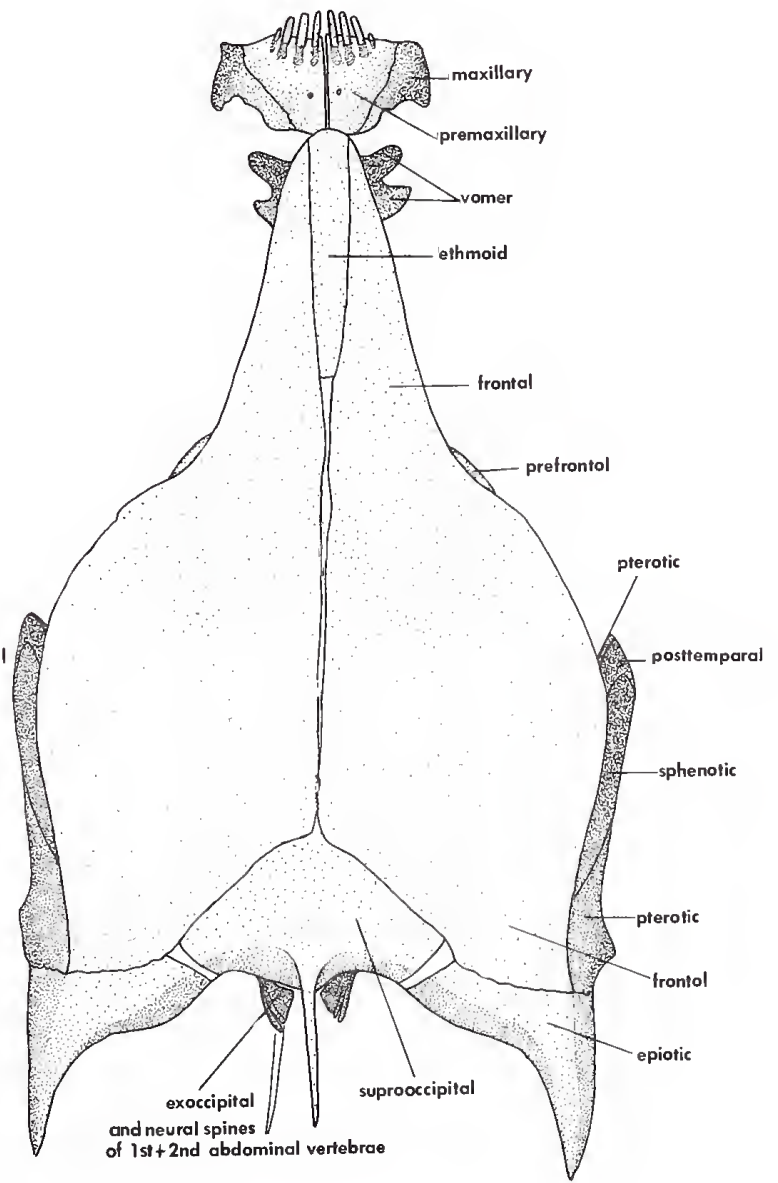

of $1 \mathrm{st}+2 \mathrm{nd}$ abdominal vertebrae 


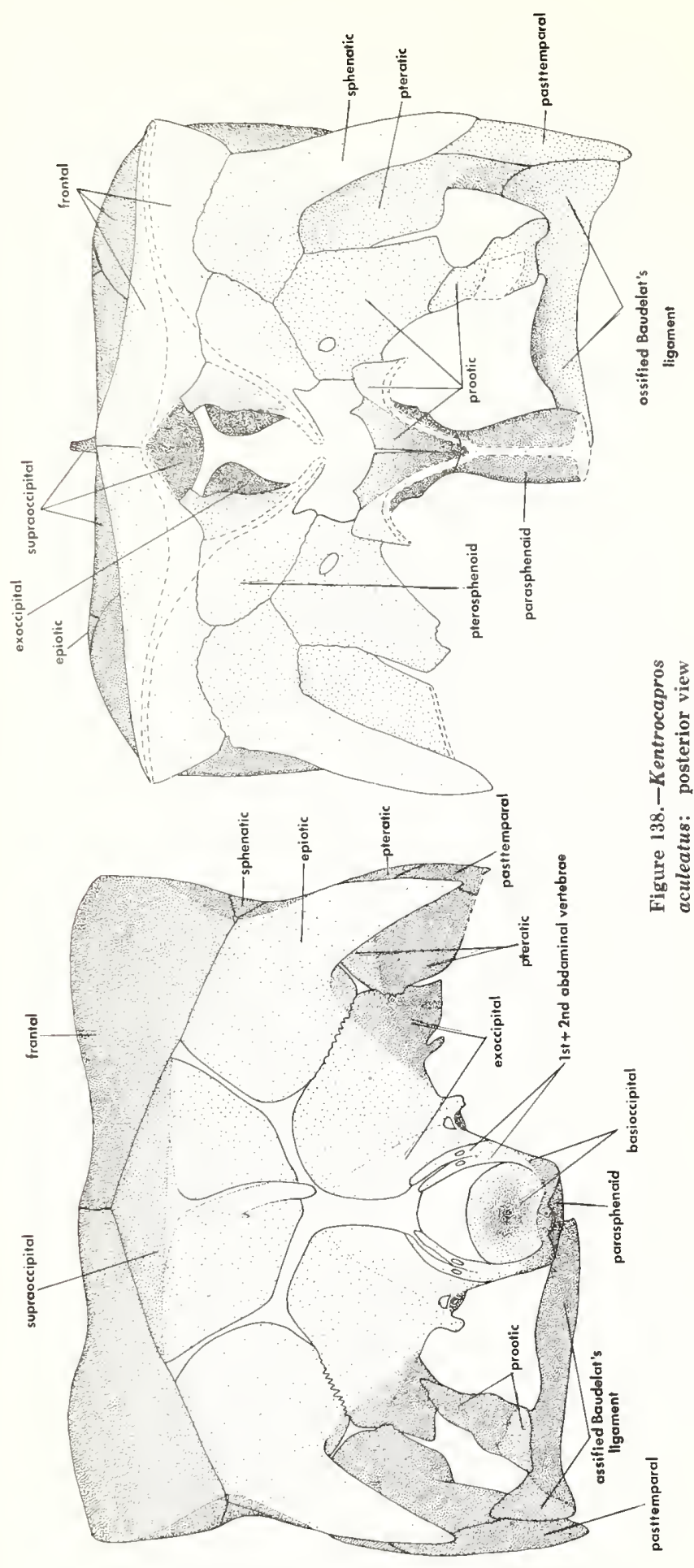

scale plates on the caudal peduncle. These plates are least developed in Caprichthys, in which there are only one to three relatively small scutes dorsally and ventrally on the anterior region of the caudal peduncle just behind the bases of the dorsal and anal fins. The caudal plates are best developed in Capropygia and Anoplocapros, in which a posterior set of plates forms a completely closed ring around the rear of the peduncle, and another set of plates more anteriorly just behind the bases of the dorsal and anal fins form broad saddles above and below the peduncle which do not meet one another mediolaterally. In Kentrocapros, Aracana, and Strophiurichthys the two anterior saddles are similar to those of Capropygia and Anoplocapros, except that the individual scales making up the anterior saddle in Kentrocapros and Aracana are less well-consolidated into a single unit than they are in Strophiurichthys, Capropygia, and Anoplocapros. Posteriorly, instead of a complete ring around the peduncle as in Capropygia and Anoplocapros, there are similar saddles over the dorsal and ventral regions of the peduncle that fail to meet mediolaterally, although in large specimens the edges of these two posterior saddles are almost in contact. In the Eocene Proaracana the dorsal and
Figure 139.-Kentrocapros aculeatus dorsal view of branchial arches (extended on lower side); lateral view of hyoid arch and urohyal; $90.7 \mathrm{~mm}$ SL, Japan

ventral regions of the caudal peduncle are covered with numerous semi-isolated small scale plates that do not form compact saddles, and the mediolateral region is scaleless.

The center of each carapace scale plate in most species usually bears a spinule larger than those of the rest of the plate, while large prominent spiny processes are variously developed. In Kentrocapros there is a small supraorbital spine, a larger one on the dorsolateral ridge and several on the mediolateral and ventrolateral ridges. Aracana is similar to Kentrocapros, but with the supraorbital spine larger and with two or more spines on the dorsolateral ridge. In Capropygia and Caprichthys there is a single large spine on the dorsolateral and ventrolateral ridges, with Caprichthys additionally having a small supraorbital spine in the young which is resorbed in the adult. In Anoplocapros and Strophiurichthys prominent spines of the magnitude found in the other genera are absent, although in large adults of one of the species of the latter genus, $S$. robustus, there is a small supraoccipital spine and the central spinule of many of the individual scale plates of the carapace is relatively much larger than the others, forming spines intermediate in size between those on the ridges of such genera as Kentrocapros, Aracana, Capropygia, and Caprichthys, and those of the center of the plates in all other species. Young specimens of all species probably have the 


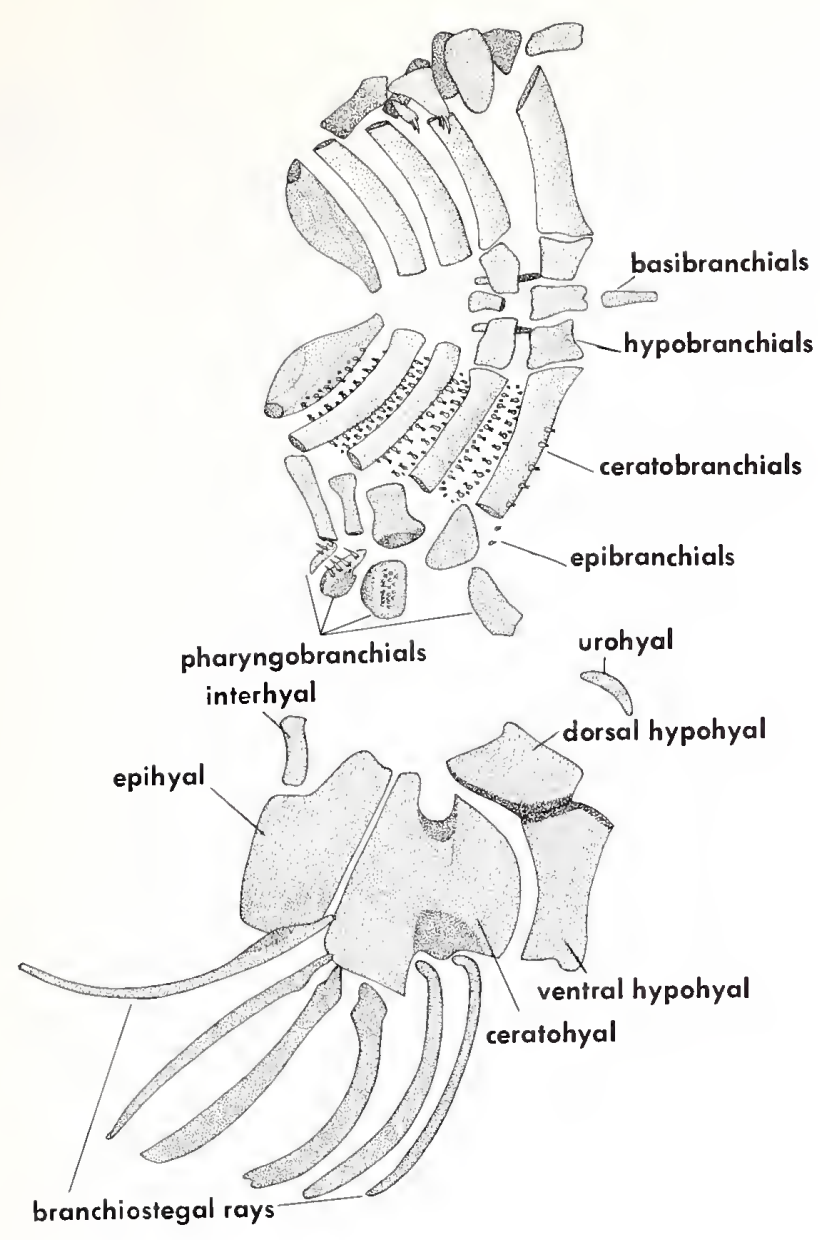

spinules of the individual scale plates, including the variously enlarged central spinule, better developed than in adults, i.e., the plates in the young are more highly sculptured and ornamented than in adults.

Aracanids generally have between 10 and 13 dorsal and anal fin rays, with Capropygia and Caprichthys tending to have closer to 13 dorsal and 12 anal and the other genera tending to have closer to 10 or 11 in these fins, the anal with the same number, or one less, than the dorsal. All of the species tend to have either 10 or 11 pectoral fin rays in addition to the small uppermost ray.

There are usually 8 to 10 teeth in the upper jaw and 8 in the lower. The numbers of teeth found in the jaws of the specimens examined (including alcohol preserved material) are as follows, with the total in the upper jaw followed by that of the lower jaw: Strophiurichthys robustus, 9 and 8 in four specimens, 8 and 8 in one, 10 and 7 in one; $S$. inermis, 10 and 8 in one; Kentrocapros aculeatus, 8 and 8 in one, 7 and 8 in one; Aracana aurita, 8 and 8 in one; A. ornata, 8 and 8 in two; Caprichthys gymnura, 10 and 8 in two; Capropygia unistriata, 10 and 8 in two.

In most osteological characteristics the aracanids are remarkably similar, closely following the same general plan in genus after genus.
In Capropygia and Caprichthys, with relatively high numbers of dorsal and anal fin rays, there are usually 12 dorsal fin basal pterygiophores and 11 anal fin basal pterygiophores, while in the other genera these range in number from 8 to 10. There are always seven predorsal vertebrae, the more numerous rays and basal pterygiophores in Capropygia and Caprichthys being accommodated toward the rear of the fin; e.g., the last pterygiophore of the dorsal fin in these two genera being placed between the neural spines of the 13th and 14th vertebrae, while in the other genera it is placed between the 12 th and 13th.

The branchiostegal rays are usually $2+4$, except that the single specimen of Caprichthys gymnura examined had $2+4$ on one side and $1+4$ on the other, and that of the two species of Aracana examined, the single specimen of $A$. aurita had $1+4$ on both sides, while of the two specimens of $A$. ornata examined one had $1+4$ on both sides and the other had $1+4$ on one side and $2+3$ on the other. It would appear that in Aracana the branchiostegals are usually reduced to five, while the normal situation in Caprichthys awaits the examination of further specimens, as it does also in Anoplocapros, no species of which have been examined internally for this work.

In Kentrocapros, Aracana, and Strophiurichthys the second pharyngobranchial bears minute teeth, while in Caprichthys and Capropygia it is entirely toothless. The number of large teeth respectively on the third and fourth pharyngobranchials are as follows for single specimens of each of the species closely examined for this feature: Strophiurichthys robustus 6 and 6 (plus a few smaller teeth on the third element in addition to the larger ones); Aracana ornata 6 and 3; Aracana aurita 4 and 2; Kentrocapros aculeatus 4 and 3; Caprichthys gymnura 3 and 2; Capropygia unistriata 3 and 2. Thus, Strophiurichthys has the best developed pharyngobranchial dentition and Caprichthys and Capropygia the least, with Aracana and Kentrocapros more or less intermediate.

The ventral flange of the carina or supraneural is deeper for a greater proportion of its length in the high crested Strophiurichthys, Capropygia, and Caprichthys than it is in the relatively flat-backed Kentrocapros and Aracana.

In Kentrocapros the autogenous haemal spine of the penultimate vertebra is smaller than in the other genera. In Kentrocapros, Aracana, and Strophiurichthys the haemal canal enters the fused centrum-epural-hypuralparhypural plate at the end of the vertebral column and exits shortly behind at a prominent foramen low on the plate, the foramen marking the region of fusion between what would be the parhypural and lowermost hypural in more generalized forms. In Capropygia and Caprichthys this foramen is either absent or minute (Tyler 1970b:18) and the haemal canal which pierces the front edge of the plate either stops within the plate or has only a minute foramen that could not be detected in either of the single specimens examined of the two species involved.

In one of the species of Aracana, A. ornata, the snout becomes convex and laterally expanded in adults, this 


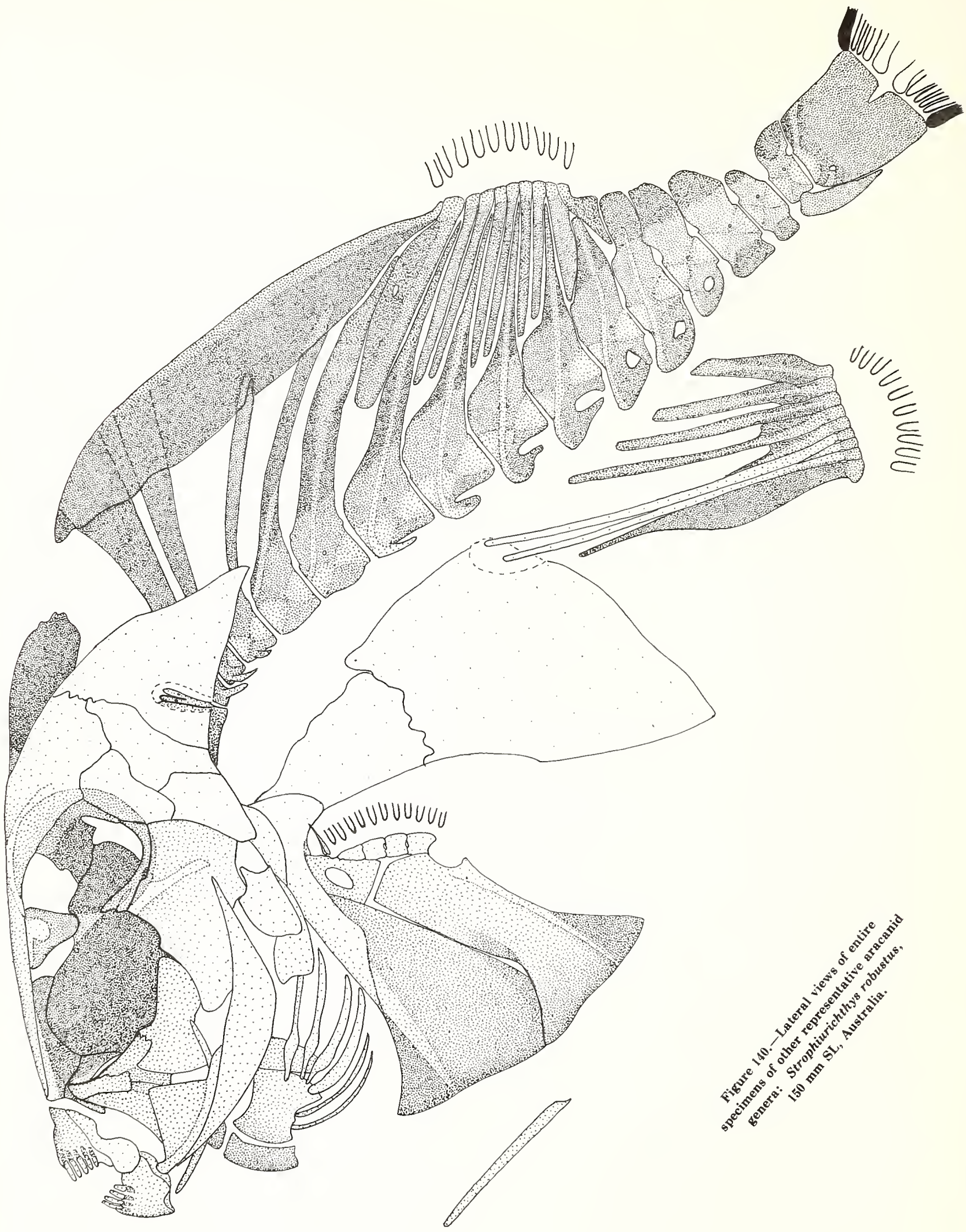




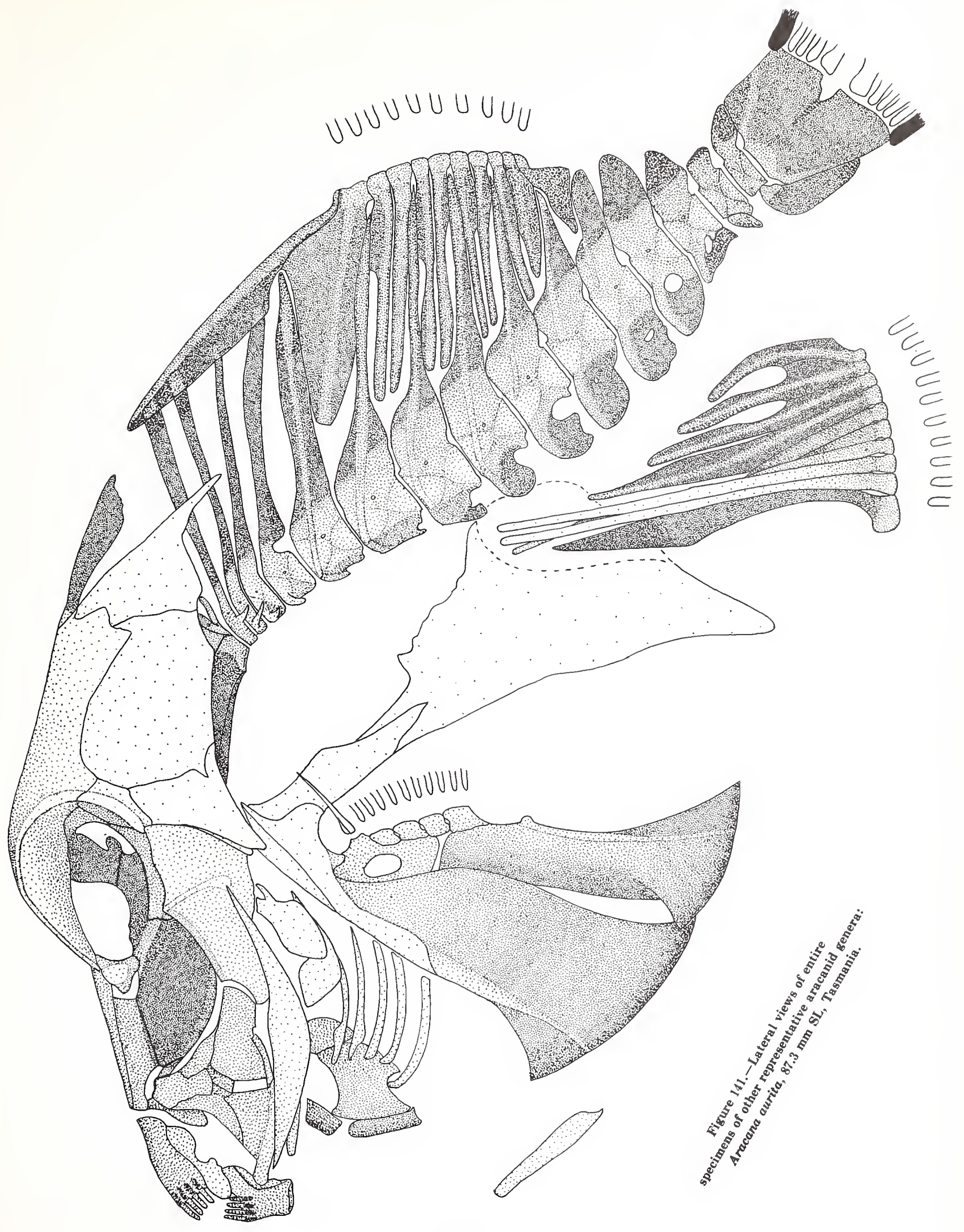




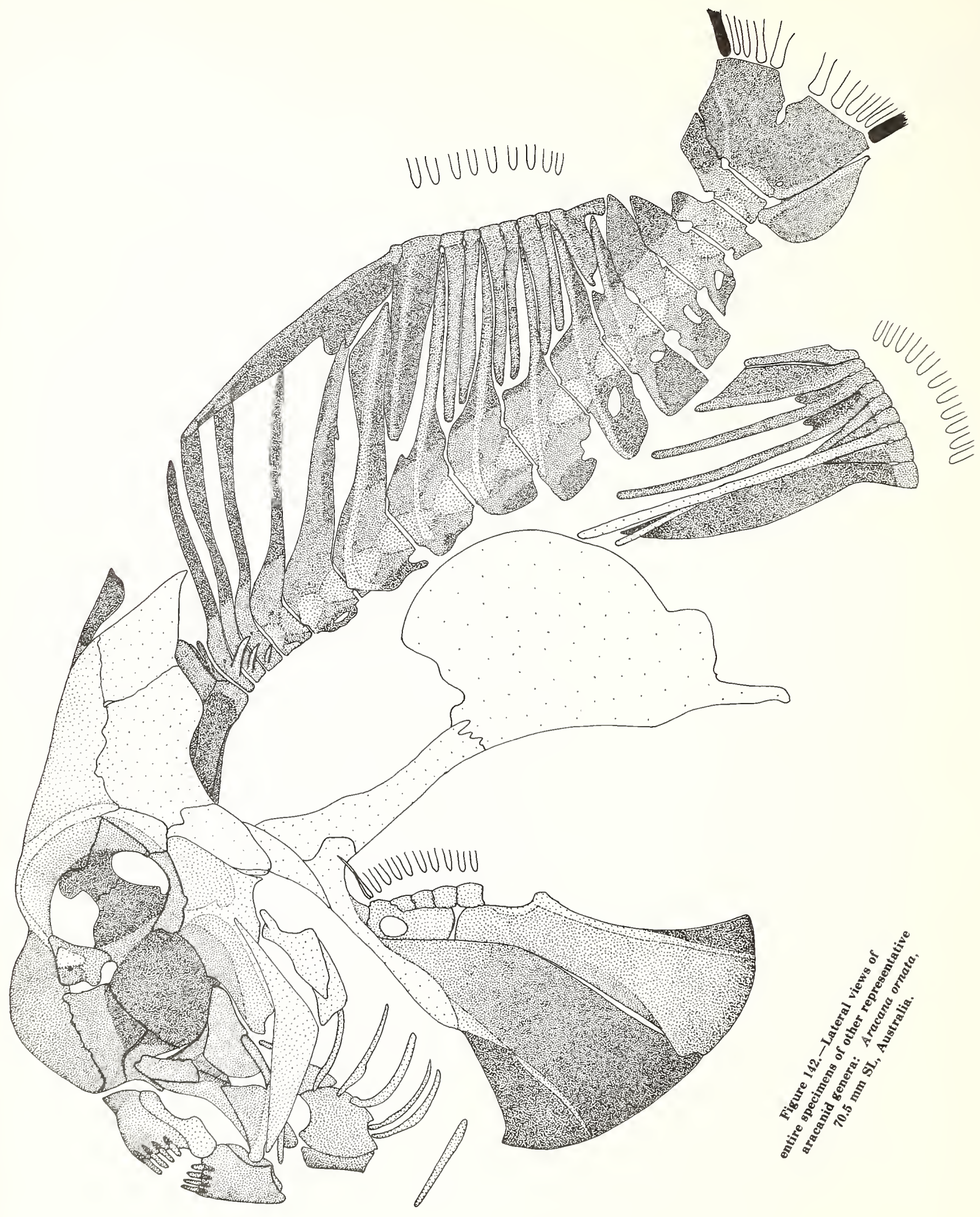




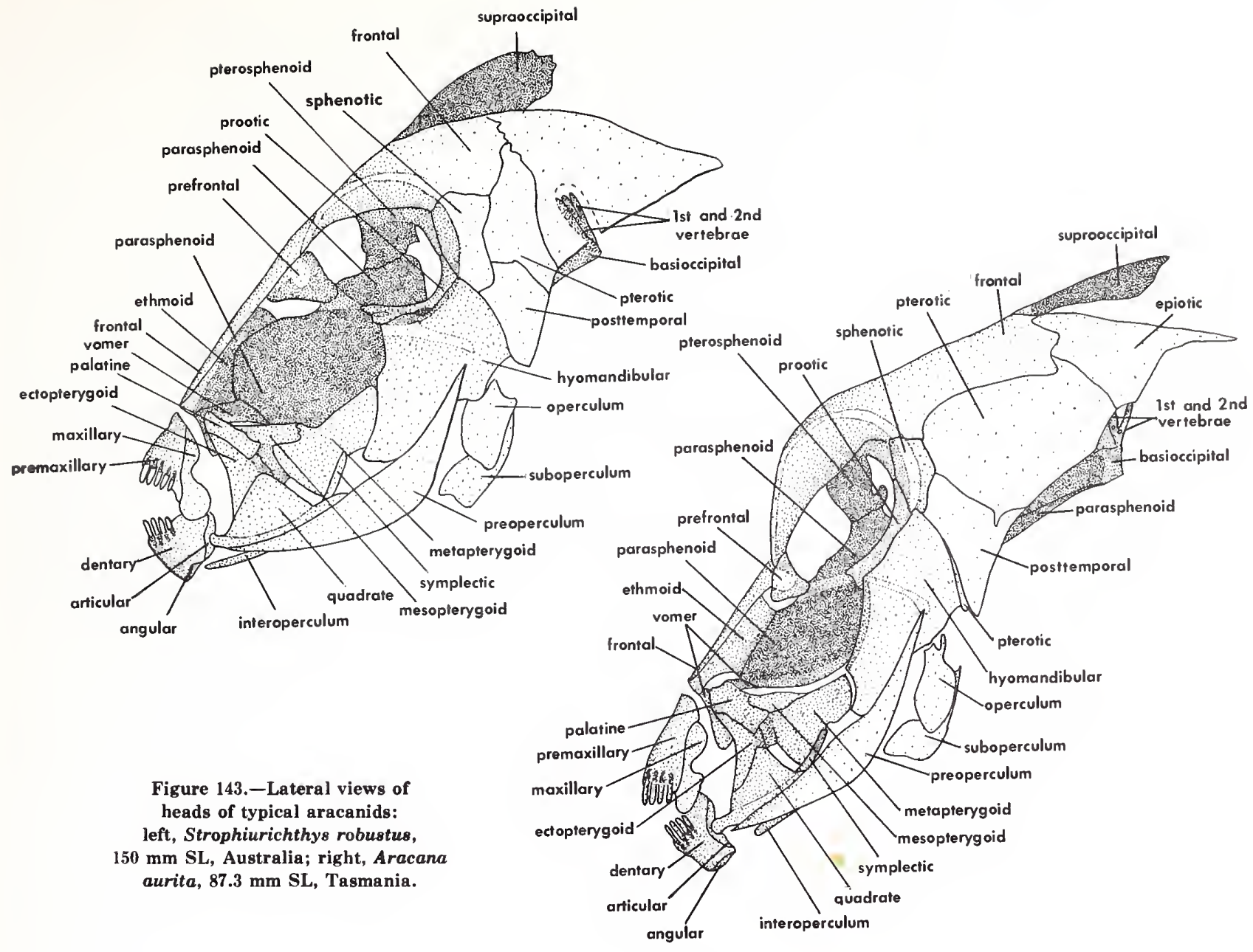

from a great enlargement of the anterior prolongation of the frontals from the level of the eye forward. This swelling of the snout is more prominent in males (ornata) than in females (the synonymous flavigaster) and occurs in the family only in this species, even the closely related $A$. aurita showing no signs in large specimens of any snout or other enlargements.

The structure of the parasphenoid presents variation of special interest. In Kentrocapros and Strophiurichthys the ventral edge of the vertical platelike portion of the parasphenoid anterior to its articulation with the anteromedial edges of the prootic shelves is relatively unexpanded laterally throughout its length, being only slightly wider anteriorly where it sutures with the vomer than more posteriorly. In Aracana the ventral edge of the

Figure 144.-Ventral views of the two types of configuration of the ventral surface of the vertically expanded anterior portion of the parasphenoid: A, Caprichthys gymnura,

$74.1 \mathrm{~mm} \mathrm{SL}$, Australia, representative of the shape in Caprichthys and Capropygia;

B, Aracana aurita, $87.3 \mathrm{~mm} \mathrm{SL}$, Tasmania, representative of the shape in the

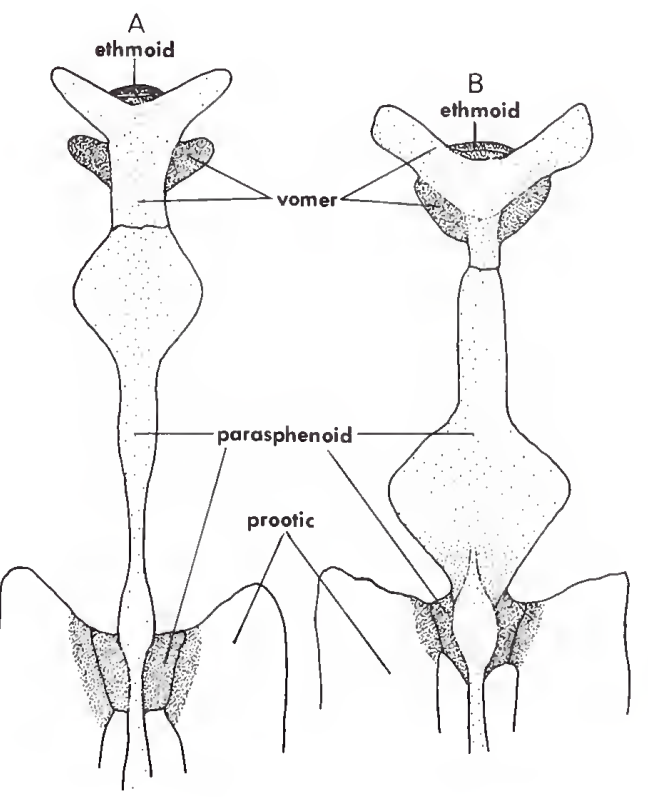
two species of Aracana. 


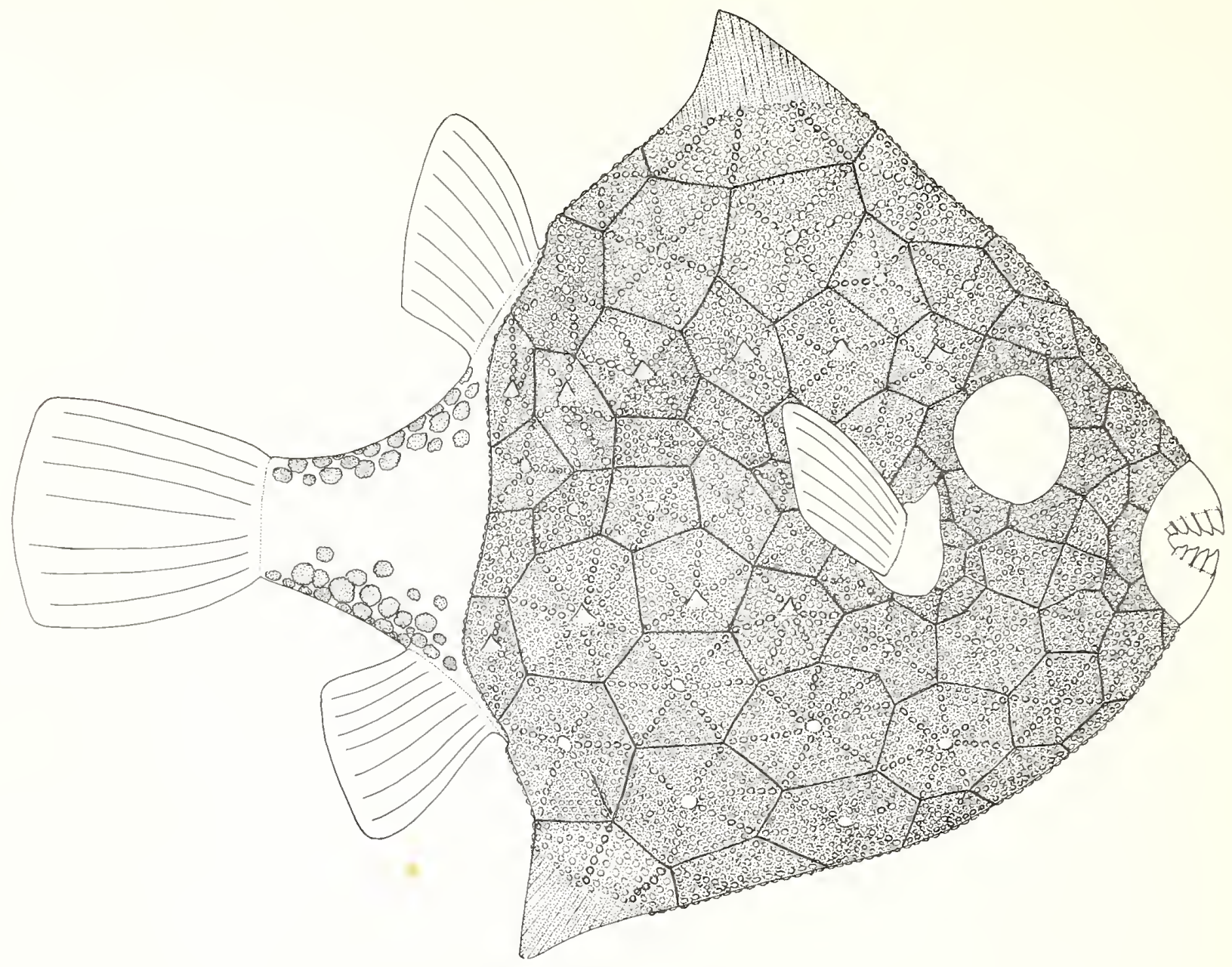

parasphenoid is relatively as narrow as in Kentrocapros and Strophiurichthys in the anterior half of its length anterior to the prootic shelves, but it is much expanded laterally just in front of the shelves, forming a partial hard palate over the rear of the oral cavity. In Caprichthys and Capropygia the ventral edge of the parasphenoid is relatively as narrow as in Kentrocapros and Strophiurichthys throughout most of its length anterior to the prootic shelves, but it becomes laterally expanded anteriorly behind the voiner, forming a partial hard palate over the front of the oral cavity. The possible phylogenetic implications of these differences and of the others mentioned above are discussed in the section on generic relationships that follows.

Generic relationships.-Probably having been derived from the same line of fishes that connects the triacanthids and balistids, the primitive aracanids also probably had a laterally compressed body whose crosssectional outline would be a dorsoventrally elongate oval. The body was probably fully covered with enlarged, perhaps slightly overlapping, scale plates. While the balistids retained a more flexible body and flexible scale covering, the aracanids specialized in a thicker and less
Figure 145.-Proaracana dubia: lateral view of entire specimen, composite based on three specimens, including the holotype, $31.4-54.5 \mathrm{~mm} \mathrm{SL}$, all specimens from the Eocene of Monte Bolca, Italy (Tyler 1973a:fig. 7).

flexible scale covering with a concomitant reduction in swimming ability but greatly increased protection from the exoskeleton. The relatively complete covering of somewhat flexible scales would have become consolidated into a relatively inflexible carapace of hexagonal plates with marginal interdigitations, except that many of the scale plates on the check remained small and free from one another to allow for respiratory movements and that the scales around and behind the dorsal and anal fins remained similarly small and free from one another to allow for lateral flexion of the caudal peduncle when the caudal fin was used in rapid swimming. The tendency would be for the scales that originally entirely covered the caudal peduncle to become reduced in size and in coverage of the peduncle, within the limits of also providing some protection from the bites of predators.

The Eocene Proaracana dubia provides a firm example of an early aracanid, the carapace over most of the body being fully consolidated and the caudal peduncle bearing 
a large number of small, at least semi-isolated, scale plates in a long patch both dorsally and ventrally but not mediolaterally. The carapace is high crested both dorsally and ventrally so that in cross-sectional outline it would be in the form of a laterally compressed oval. The carapace does not extend posteriorly beyond the level of the rear of the bases of the dorsal and anal fins. This can probably be taken as the generalized aracanid carapace condition, and the one on which the Recent species have modified mainly only in a greater specialization of the caudal peduncular scale plates. Unfortunately, the internal anatomy of $P$. dubia is mostly unknown, being largely hidden from view by the carapace in the few specimens presently available. However, the more posterior portion of the vertebral column is relatively easily seen in some of the specimens, and the indications are that the caudal plate is as fully fused together as in Recent species and that the anterior anal fin basal pterygiophores diverged from the midline. The teeth were discrete and low in number, similar to those of Recent species. Proaracana has only one known specialized feature relative to the Recent species of the family, this being that it has only 10 caudal fin rays rather than the 11 found in all Recent species.

In triacanthids and balistids the ventral edge of the parasphenoid anterior to the orbit is narrow, and the pharyngobranchials consist of a toothless suspensory element followed by three (triacanthids) or two (balistids) elements bearing large teeth. One would expect that the more generalized of the aracanids would have been derived from these conditions. Strophiurichthys and Kentrocapros have the ventral edge of the parasphenoid the least expanded in the family, and Strophiurichthys has the best developed dentition on the two pharyngobranchials (third and fourth) bearing large teeth, as well as minute teeth on the second pharyngobranchial. Kentrocapros has minute teeth on the second pharyngobranchial but fewer large teeth on the third and fourth pharyngobranchials than in Strophiurichthys. Strophiurichthys has a high dorsal crest, similar in magnitude to that of Proaracana if the high dorsal spiny process in the latter is ignored.

In short, of the genera examined, Strophiurichthys appears to be the most generalized of the Recent forms. A form like it probably gave rise on the one hand to a line leading to Kentrocapros and hence Aracana and on the other hand to a line leading to Anoplocapros (not studied internally) and Capropygia-Caprichthys, the latter two monotypic genera being so similar that they scarcely merit distinction. In the line leading to Kentrocapros the high crested dorsal ridge was lost, with the back becoming flattened or only very gently convex, while the ventral carapace ridge was also reduced in size. The pharyngeal dentition was slightly decreased and the degree of development of large spiny processes increased. Aracana is obviously closely related to Kentrocapros, sharing with it a flattened back and a more or less comparable pharyngeal dentition, and differing from it externally only by a continuing slight increase in the number of large spiny carapace processes and the probable reten- tion from a slightly more generalized ancestor than the Recent Kentrocapros of a deeper ventral carapace ridge. Internally Aracana is further specialized by the apparently usual loss of one of the two anterior branchiostegal rays, and, more importantly, by the development of a wide lateral expansion of the ventral edge of the parasphenoid just in front of its articulation with the anteromedial edges of the prootic shelves. In one respect Kentrocapros and Aracana have remained slightly more generalized than the ancestral Strophiurichthys-like form in that the individual scale plates of the two anterior caudal peduncular saddles are less fully consolidated into functionally single pieces.

Probably a close derivative of the ancestral Strophiurichthys-like form is Anoplocapros, whose internal structure has not been studied but which is very similar to Strophiurichthys externally in the features of its relatively spineless high crested carapace. Anoplocapros differs from Strophiurichthys mainly in having a complete ring of scales around the posterior region of the caudal peduncle instead of two saddles. However, this is surely a minor distinction, and McCulloch and Waite (1915:479) pointed out that the ring "may be incomplete in the young." In short, the two only narrowly separated posterior peduncular saddles as found in Strophiurich. thys have simply met mediolaterally in adult Anoplocapros. The Strophiurichthys-Anoplocapros line probably also gave rise to Capropygia and Caprichthys, both of which are specialized by the loss of even minute teeth on the second pharyngobranchial and the reduction in number of large teeth on the third and fourth pharyngobranchials, while the carapace extends back further posteriorly than in any of the other genera.

The most distinctive internal feature linking Capropygia and Caprichthys is the development of a moderate lateral expansion of the ventral edge of the parasphenoid just behind its articulation with the vomer, in contrast to the more posteriorly placed lateral expansion

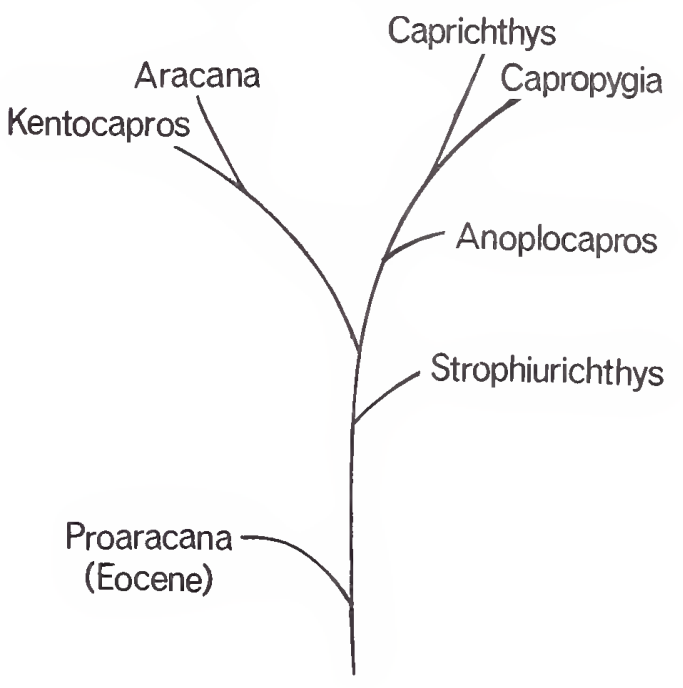

Figure 146.- Hypothesized phylogenetic relationships of the genera of Aracanidae. 
just in front of the prootics found in Aracana. Capropygia and Caprichthys differ almost exclusively on the basis of the caudal peduncular scales, although Caprichthy's sometimes develops a supraorbital spine whereas Capropygia never does. In both Caprichthys and Capropygia the small scale plates that make up what are the anterior peduncular saddles in other genera are less consolidated and do not form distinctive saddles that are functionally single pieces. This can be considered a reduction from the condition seen in Strophiurichthys and Anoplocapros. The posterior series of peduncular plates forms a complete ring around the peduncle in Capropygia, just as in Anoplocapros, while the posterior plates are completely lost in Caprichthys.

It seems evident that Capropygia is a derivative of an Anoplocapros-like ancestral stock specialized by the reduction of the anterior peduncular plates, a posterior elongation of the carapace, a reduction in the size of the caudal fin, the development of prominent spiny processes on the carapace, the reduction in the pharyngeal dentition and the development of a partial hard palate over the front of the oral cavity. Caprichthys is simply a closely related derivitive of Capropygia in which the anterior peduncular plates are further reduced in size and the posterior plates completely lost, and with a tendency for one more carapace spine to develop.

Capropygia and Caprichthys have a slightly higher number of dorsal and anal fin rays than do the other genera, and a relatively large number of fin rays might be expected to be a primitive character in a group derived from a posttriacanthid and prebalistid ancestral stock, both of which families have long-based and many-rayed dorsal and anal fins. However, Proaracana has only 10 or 11 dorsal and anal fin rays, like all of the Recent genera except Capropygia and Caprichthys. I suspect that the number of dorsal and anal fin rays in Capropygia and Caprichthys is a de novo increase associated with the greater dependence on these two fins for locomotion demanded by the longer posterior extension of the carapace and concomitant reduction in lateral flexibility of the caudal peduncle, at the end of which is a caudal fin less well developed than ir all of the other genera.

Relationship to the Ostraciidae.-The deepwater aracanids are so obviously closely related and ancestral to the shallow water, more speciose (about 20 species), ostraciids, that it is needless to belabor the point. The changes from the aracanid to ostraciid levels of organization mostly are associated with the increased length of the carapace and its more complete enclosure posterior to the dorsal and anal fins of the more elongate body concomitant with a reduction in the size and strength of the orbital and postorbital regions of the skull and an extensively sutured, inflexible, generally weaker vertebral column within the carapace, with four or five rather than only two vertebrae involved in the variously fused and sutured complex at the rear of the skull, and a general reduction in the size of most of the neural and haemal arches. The caudal fin supporting apparatus in the more generalized ostraciids is similar to that of aracanids, except that there are only 10 fin rays rather than 11 , while the apparatus becomes highly specialized in most other ostraciids.

Differences in the type of food available in deep versus shallow water that the aracanids and ostraciids are specialized in feeding on may account for the slight differences in dentition between the two families, ostraciids having a much reduced pharyngobranchial dentition but usually a few more teeth in the jaws, especially in the upper jaw, relative to aracanids. The differences in the structure of the ethmoid supporting the upper jaw and of the completeness of the parasphenoid forming a hard palate over the roof of the oral cavity between the two families are also undoubtedly related to differences in diet, the shallow-water ostraciids perhaps making greater use of plant material in their omnivorous diet than do the deepwater aracanids.

Other evolutionary trends from the aracanids to the ostraciids are the reduction in the size of the postcleithral apparatus, perhaps associated with a lesser need for buttressing the side of the carapace in the more completely and solidly enclosed ostraciid body, the reduction of the size of the uppermost pectoral fin ray, the development variously by the basal pterygiophores and neural and haemal spines of a firmer system of support for the carapace around the dorsal and anal fins, the diversion of the haemal canal away from the midline and its close apposition to the ventral surface of the centra, perhaps a space saving device in a crowded abdominal region from which even muscles are largely excluded laterally, the loss of the ventral keel of the carapace and the reduction in the number of isolated scale plates on the caudal peduncle posterior to the carapace.

With the aracanids obviously ancestral to the ostraciids, a critical question is whether the latter can be shown to have evolved from one or the other of the two main evolutionary lines postulated here as diverging from a Strophiurichthys-like ancestral stock, or whether it was from such a generalized form as Strophiurichthys or Proaracana. This is discussed under the section on generic relationships of the Ostraciidae, with the conclusion being that the ostraciids, and more particularly the lactophrysins, the more generalized of the two subfamilies, probably evolved from one of the two lines possessing a laterally expanded parasphenoid shelf over the roof of the oral cavity, but whether from the line with the shelf placed posteriorly (Aracana) or anteriorly (Capropygia and Caprichthys) cannot be determined.

It is of interest that in both the triacanthoids, in which the deepwater Triacanthodidae are clearly ancestral to the derived shallow-water Triacanthidae, and in the ostracioids, in which the deepwater Aracanidae are clearly ancestral to the derived shallow-water Ostraciidae, all of the families occur together in the same strata of the upper portion of the lower Eocene of Monte Bolca, Italy. The Triacanthodidae are represented there by Spinacanthus cuneiformis, Protobalistum imperiale, and Eoplectus bloti, all so different from the Recent species 
of the family that they are placed in different subfamilies than the Recent species, while the Triacanthidae are represented by Protacanthodes ombonii, a somewhat intermediate form between the Triacanthodidae and Triacanthidae and different enough from the Recent triacanthids and those known from the Oligocene and Miocene to be placed in a separate subfamily.

By contrast, of what little is known of them, the single species of Eocene aracanid and ostraciid are relatively modern enough in general countenance to be easily accommodated in the same higher categories as the Recent species. The diversifications of the families apparently was rapid and in both cases with the derived families specialized for a shallow-water existence coextant with the ancestral families successful continuance in deeper waters.

Relationship to the Balistidae.-The derivation of the ostracioids presents a slight enigma. Both families of ostracioids appeared in the Eocene with genera not markedly different from Recent genera, and paleontology offers no clue as to what plectognath group the ostracioids are most closely related. As pointed out in the historical section of the Introduction, the ostracioids have been considered variously as a third major subordinal group of plectognaths, or as members of both the Sclerodermi and Gymnodontes. Regardless of how they have been classified, their relationships to the triacanthoids and balistoids, with which they are usually placed, have never been analyzed much beyond the simple statement that ostracioids have individual discrete teeth protruding from the jaws and hence show an affinity with the scleroderms and that since they lack the spiny dorsal and pelvic fins, they are probably related to the balistoids, which have the spiny dorsal and pelvic fins at least reduced in size or in number of elements in relation to the triacanthoids.

This is not to belittle the clue that the presence of discrete protruding relatively normal teeth and lack of spiny dorsal and pelvic fins in ostracioids affords, for I agree that they are important indications of their relationship with the balistoid scleroderms. Any such clues are important, for ostracioids are so highly modified for life within a shell that many of their features are unique.

The divergence of many of the anal fin basal pterygiophores away from the midline is not found in fishes other than ostracioids, while the fusion of several abdominal vertebrae to the skull and the heavy ossification of Baudelot's ligament are at least highly unusual features among fishes. Other features of the ostracioids that are less distinctive, but at least unique among the plectognaths, are the heavy lateral expansions of the ventral edge of the parasphenoid forming a partial hard palate, the articulation of the preoperculum with a groove on the lateral surface of the hyomandibular, the complete fusion of all epural, hypural, and parhypural elements into a single large plate, the displacement in ostraciids of the haemal canal to one side or the other of the midline, and the great expansion in aracanids of the postcleithrum. Beset with a multitude of such specializations one is fortunate to find even a few structures in ostracioids that give evidence concerning the origin of the group.

The forward extension of the prootics as a shelf under the orbit is unusual among fishes, and in the plectognaths it is found only in the balistoids and ostracioids. The interoperculum is a short and simple rod not extending posteriorly past the level of the epihyal only in balistoids and ostracioids among the plectognaths, and the operculum and suboperculum are about equally reduced in the two groups. Only in balistoids and ostracioids is the hyomandibular supported dorsally by the prootic and pterotic alone, without contacting the sphenotic. The palatine in balistoids and ostracioids is reduced in size in comparison to other plectognaths, although it is articulated differently in these two superfamilies. The shape and size of the inflexibly articulated premaxillary and maxillary are very similar in balistoids and ostracioids, as is the rotation of the upper jaw around a laterally expanded and buttressed ethmoid-vomerine region. The shape of the teeth of Recent ostracioids is somewhat intermediate between that of triacanthodids and that of triacanthids and balistids, but there is an indication that the teeth of the Eocene ostracioids were more balistidlike than at present (see description of Eolactoria).

The ostracioids do not show any such similarities with any of the gymnodonts, and it is obvious from the above that they have their closest anatomical affinity with the balistoids. Since the ostracioids have completely lost the spiny dorsal and pelvic fins, and the pelvis, one must consider the possibility that they are, among the balistoids, more closely related to the derivative monacanthids than to the ancestral balistids, for it is among the monacanthids that the reduction in size and number of dorsal fin spines (to the presence of a single and sometimes weakly developed spine in a few genera) and in the size of the pelvic fin (completely lost in many genera) and pelvis (to a relatively slender shaft in a few genera) has reached its extreme for the superfamily. However, the monacanthids possess a number of specialized features in comparison to balistids that show, as discussed below, that the ostracioids are more closely related to balistids than to monacanthids.

The T-shaped palatine of balistids, with the foot of the $\mathrm{T}$ articulated against the ectopterygoid and the crossbar articulated between the maxillary and ethmoid-vomerine region, becomes a simple rod in monacanthids representing only the crossbar of the balistid palatine, and it is usually well removed from the ectopterygoid, even though connected to it by a strong ligament. The columnar palatine of ostracioids, with its ventral end sutured to the ectopterygoid and its dorsal end firmly held to the ethmoid-vomerine (especially to the latter) region is difficult to derive from the highly specialized and greatly reduced in size monacanthid condition but easy to derive from the balistid condition. The ostracioid palatine represents basically the shaftlike foot of the T-shaped 
balistid palatine, the foot now sutured to the ectopterygoid (and mesopterygoid) rather than simply articulated closely to it through a short ligament, with the top of the ostracioid palatine probably representing a combination of the top part of the shaft and the posterior part of the crossbar held by ligament to the ethmoid-vomerine (especially the former) region in balistids.

The specialized nibbling incisors of monacanthids are far less like the dentition of ostracioids than is that of balistids. Balistids have four teeth in an outer series in each half of the upper and lower jaws, while the derived monacanthids have reduced the number to three in the upper jaw and to three or, in some cases, only two in the lower jaw. In ostracioids there are usually four or five teeth in each half of both the upper and lower jaws. It is unlikely that the reduced in number and relatively broad incisors of monacanthids could be ancestral to the more elongate and basically conical teeth in greater numbers as found in ostracioids.

While the number of teeth in the outer series in balistids is similar to that in the single series in ostracioids, their shapes, at least at present, are not. The teeth in balistids are somewhat wider, thicker, and more notched than in Recent ostracioids. However, the teeth of the two species of Eocene ostracioids probably were wider, thicker, and more notched than in the Recent species, approximating the balistid condition. It is suggested here simply that the Eocene balistids (for which there are as yet no fossils from that period) and ostracioids could easily have had rather similar numbers, sizes, and shapes of teeth, those of balistids somewhat smaller and less notched than at present and those of ostracioids somewhat larger and more notched.

There are marked similarities between the balistid and ostracioid parasphenoid, ethmoid, and prefrontal that do not exist in the monacanthids. In balistids and ostracioids the prefrontal is relatively well developed and extends ventrally to articulate with a thickened region of the parasphenoid, while in monacanthids the prefrontal is greatly reduced in size and is far removed from any contact with the parasphenoid. In balistids and ostracioids the ethmoid has only a relatively shallow ventral keel, if present at all, while in monacanthids the ventral keel is always extremely well developed. In balistids and ostracioids the parasphenoid is expanded dorsally into a thick plate in front of the orbit, but no such expansion is present in monacanthids. The large, thick, usually rhomboidal scale plates of balistids are far closer to the larger, even thicker, usually hexagonal scale plates of ostracioids than are the small, thin, usually more or less rounded to rectilinear scale plates of monacanthids, and in some balistids the scale plates are hexagonal.

In all ostracioids there are 18 vertebrae, with the exception of one specialized genus with a secondary increase to 19 , and all balistids normally have 18 vertebrae also, while monacanthids always have 19 or more vertebrae. Balistids and ostracioids have mostly branched rays in the soft dorsal, anal, and pectoral fins, while these rays are all unbranched in monacanthids. A supraneural is present in both balistids and ostracioids, although it is possible that their origins are different, while a supraneural is absent in monacanthids. The lesser reduction in number of pharyngobranchial elements in balistids versus monacanthids is more similar to the condition in most ostracioids. In balistids and ostracioids the parasphenoid is only slightly, if at all, expanded laterally just behind the orbit, while in monacanthids it is moderately to greatly expanded there, except in one highly specialized genus. In balistids and ostracioids the postcleithrum is sometimes composed of two pieces, while in monacanthids it is always a single piece.

By contrast, there are only a few ways in which monacanthids are more similar to ostracioids than are balistids. In monacanthids and ostracioids the medial edges of the pterotics on the ventral surface of the skull are widely separated, while they are only narrowly separated in balistids. However, balistids and monacanthids are similar in that the separation is by the parasphenoid and basioccipital, while in ostracioids it is by the prootic and exoccipital, a rather different arrangement. The posttemporal of monacanthids and ostracioids is more superficially held to the skull than is that of balistids, which is always placed in a deep groove on the skull. However, the posttemporal in ostracioids is usually much larger and more extensively sutured to the pterotic than is that of monacanthids, and the slight resemblance between the posttemporal of monacanthids and ostracioids is probably coincidental and of no phylogenetic significance.

In monacanthids and ostracioids the supracleithrum is not posteriorly expanded and the postcleithrum does not have a dorsal prong, while in balistids a posterior expansion and dorsal prong are present. However, these structures in balistids probably are involved with support of the specialized tympanal region above the pectoral fin base only found in balistids and not to be expected in groups lacking a tympanum. In monacanthids and ostracioids the fifth ceratobranchial is toothless but has a series of gill rakers along its anterior edge, while in balistids the fifth ceratobranchial bears teeth but no gill rakers. These differences are surely correlated with the usually coarser diet of balistids versus monacanthids and ostracioids, and the loss of teeth from and the gain of gill rakers along the anterior edge of the fifth ceratobranchial probably occurred independently in monacanthids and ostracioids. It is perhaps instructive that in triacanthoids, from which the balistids are derived, the fifth ceratobranchial also is toothed but lacks gill rakers.

Thus, the evidence strongly indicates that it is the balistids among the balistoids to which the ostracioids are most closely related, and not to the monacanthids that are derivatives of the balistids. Moreover, since the ostraciids are clearly derived from the aracanids, and the aracanids have remained far more generalized, the closest relationship of the balistids to the ostracioids is to the aracanids and not to the ostraciids.

There are only a few ways in which balistids are more 
specialized than aracanids, and these are mostly concerned with dentition and correlated with the coarser diet of balistids. In balistids there are only three pharyngobranchials, a toothless suspensory element followed by two elements bearing prominent teeth, while in aracanids the toothless suspensory element is followed by three elements, the first of which is either toothless or with minute teeth but the third and fourth elements with teeth almost as well developed as in balistids but usually of lesser number. The relatively conical teeth of aracanids are more generalized than the heavier notched incisors of balistids in the sense that they are closer in structure to those of the more generalized triacanthodids, the basal plectognaths, while those of balistids are more similar to those of the triacanthids derived from the triacanthodids. However, as indicated previously, there is evidence that the structure of the teeth in balistids and aracanids might not have been much different in the Eocene. By the retention of an inner series of teeth in the upper jaw, balistids are more generalized than aracanids, while the variable presence in aracanids of a fifth tooth in what is the outer series of balistids, which always have only four in each half of both jaws, is slightly more generalized than in balistids.

The uppermost pectoral fin ray of aracanids is relatively well developed and the two halves are of about equal length, while in balistids this ray is greatly reduced in size and the medial half is larger than the splintlike nubbin that represents the lateral half of the ray. Here again the condition in aracanids is similar to that in triacanthodids while that of balistids is similar to that in triacanthids, although the lateral half of the ray in balistids is even more reduced than in triacanthids. It is presumed here that these few more specialized features of balistids were acquired after the divergence of the common triacanthoid phyletic line leading on the one hand to balistids and on the other to aracanids, as discussed subsequently.

The conversion of a balistidlike fish into an aracanid requires mainly the following: 1) the complete loss of the pelvis along with its rudimentary pelvic fin-ray element and encasing scales; 2) the complete loss of the three dorsal fin spines and of their three pterygial and supraneural supports, with the possible exception of one of them; 3 ) a rearrangement of the posterodorsal part of the head that no longer supports the spiny dorsal fin, including the development of a posteriorly projecting supraoccipital crest, subsequently to be lost by the ostraciids; 4) a flattening of the dorsal surface of the supraoccipital; 5) the elimination of the articulation foramen of the first basal pterygiophore of the spiny dorsal fin between the epiotic and supraoccipital, and a reduction in the posteromedial region of the exoccipitals so that they no longer are closely apposed to one another in the midline on the posterior wall of the skull; 6) the development of a dorsal flange on the parasphenoid into the orbital septum to meet an anteroventral prolongation of the pterosphenoids; 7) an enlargement of the vomer with a broader surface of suturing to the ethmoid and parasphenoid; 8) a reduction of the anterior crossbar of the T-shaped palatine and a firm suturing of the foot of the $T$ to the ectopterygoid and mesopterygoid; 9) the loss of the inner series of teeth but the retention of a slightly more generalized form and number in the outer series than in Recent balistids; 10) a foreshortening and deepening of many of the hyoid arch elements along with the reduction in width of the first branchiostegal and the development of a constant articulation between the last branchiostegal and the suboperculum; 11) the retention of a third toothed pharyngobranchial and the reduction in size of the teeth on the first of the toothed elements; 12) loss of teeth on the fifth ceratobranchial and development of gill rakers along its anterior edge; 13) great reduction in the size of the urohyal; 14) great increase in the size of the hyomandibular, posttemporal, postcleithrum, cleithrum, coracoid, epiotic, and pterotic; 15) reduction in the size of the myodome and the elimination of the posterior opening into it; 16) the ossification of Baudelot's ligament; 17) the elaboration of the prootic shelf including a recurved lateral wing; 18) a wider separation of the pterotics on the ventral surface of the skull; 19) the reduction in size and the fusion of the first two vertebrae to the skull; 20) the loss of epipleurals; 21) complete fusion of all the caudal fin supporting elements of the last vertebral centrum; 22) an increase in the size of the neural spines of the predorsal vertebrae and a great reduction in length but a broadening of the haemal spines of most of the caudal vertebrae; 23) a great reduction in the number of dorsal and anal fin rays and of their basal pterygiophores and the development of divergent anal fin basal pterygiophores; 24) concomitant with the reduction in the dorsal and anal fins, an increase in the number of vertebrae with neural or haemal spines anterior to the first basal pterygiophores of both fins (i.e., an increase in predorsal and abdominal vertebrae); 25) development of lateral flanges on many of the more centrally located vertebrae; 26) loss of one branched caudal fin ray; 27) the enlargement and thickening of the scales into heavy, more or less hexagonal, plates over the head and body anterior to about the level of the ends of the dorsal and anal fin bases; 28) the enlargement of a supraneural element into a long strut projecting anteriorly from the dorsal fin base; 29) the suturing of the actinosts to one another and to the scapula and coracoid.

Some of these above changes from the balistid to aracanid type of organization are not shared by the ostraciids. For example, ostraciids do not have: 1) the posteriorly prolonged supraoccipital crest; 2) the especially elongate supraneural in front of the dorsal fin; 3) the immensely enlarged postcleithrum; 4) the posteriorly prolonged epiotic and generally more elongate postorbital region of the head; 5) the elongate neural spines of most of the predorsal vertebrae. This indicates either that the ostraciids diverged from the aracanids at a time before the ancestral line had developed these latter differences with balistids or that the ostraciids at any early stage had similar differences with balistids which they have subsequently modified. I suspect, with- 
out proof, that it is mainly a case of the latter, but it could well be some combination of both possibilities.

As in the evolution of the triacanthoids and balistoids, the major features in the diversification of the aracanids from a prebalistidlike group and of ostraciids from aracanids are largely reductive.

It is not suggested here that the aracanids evolved from a group with a level of organization like that of the Recent or few known fossil balistids, but rather that aracanids and balistids share a common ancestry at a lower level of organization, around that of the triacanthids. However, this joint ancestral line of the aracanids and balistids must have been more generalized than any of the Recent triacanthids, and probably split off from the triacanthids at a level of organization somewhat like that exemplified by Protacanthodes, the Eocene ancestral triacanthid that probably evolved from hollardiinlike triacanthodids. That is, the triacanthid line leading to the balistids and aracanids probably did not yet have such specialized features as found in the Recent triacanthids as: 1) the especially large notched incisors; 2) the forward extension of the prefrontal suturing to the vomer; 3 ) a fully elongate soft dorsal fin with many more rays than the anal fin; 4) the uppermost pectoral fin ray much reduced in size and one half smaller than the other; 5) the second and third basal pterygiophores of the spiny dorsal fin greatly reduced in size; 6) the absence of a free parhypural and autogenous haemal spine of the penultimate vertebra; 7) an elongate tapering caudal peduncle with a deeply forked caudal fin. The triacanthid line leading to the balistids and aracanids would have had to retain from its triacanthodid ancestry more generalized conditions of these features, much as did Protacanthodes, the basal triacanthid. Whether the balistid-aracanid ancestral line diverged from the early triacanthids at a level of organization slightly more generalized than that represented by Protacanthodes or at a level between that of Protacanthodes and the Recent triacanthids is difficult to ascertain, for too many critical features of Protacanthodes remain unknown, but it was probably the former, as discussed under the Balistidae.

This ancestral pretriacanthid line is seen as diverging into two radiations, one line leading with little change to the Eocene Protacanthodes and the other triacanthids on the one hand, and the other line leading through greater changes to the balistids and aracanids, with the balistids (as discussed under that family) remaining more generalized and thus anatomically closer to their pretriacanthid ancestors than did the aracanids, whose specializations are built around the defensive shell that encases their bodies. While the balistid line continued to lengthen the soft dorsal and anal fin bases and to develop a locking mechanism between the first two dorsal spines and an elaborate flexing mechanism of rudimentary rays at the end of the pelvis, the aracanid line lost the spiny dorsal fin and pelvic apparatus completely while shortening the bases and decreasing the number of rays in both the soft dorsal and anal fins.

When the aracanid line split off from that of the prebalistids it rapidly lost, still in the Eocene, the spiny dor-

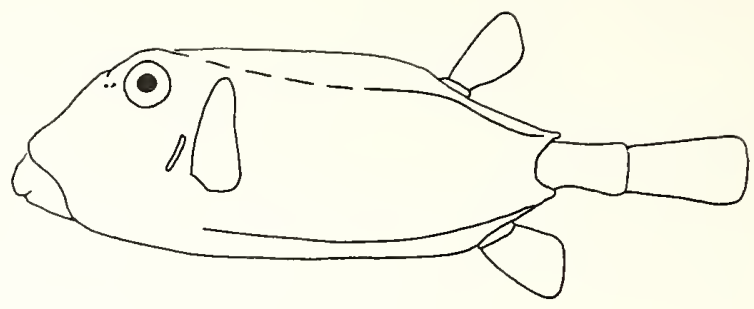

Figure 147.-Typical body form in the Recent Ostraciidae: Ostracion lentiginosum.

sal and pelvic fins as the developing carapace took on the major line of defensive protection. The aracanids became less flexible and less swift in sustained swimming as the soft dorsal and anal fins were reduced in number of rays and basal pterygiophores. While the pelvis was completely lost, there remains some trace of either the now absent spiny dorsal fin supports or of those of the now absent anterior part of the originally longer based soft dorsal fin. The long supraneural element of aracanids that extends out from the anterior end of the dorsal fin is undoubtedly a modified basal pterygiophore, but whether from the spiny dorsal fin or the anterior region of the soft dorsal fin is impossible to say with assurity, because as the spiny dorsal was being lost so was some of the soft dorsal fin, probably from anteriorly to posteriorly judging from the position of that which remains.

In balistoids the tendency has been for the spiny dorsal fin and its pterygiophores to migrate anteriorly as the fin is reduced in size and number of elements from balistids to monacanthids, and the latter retain no remnants of the third spine, second pterygiophore, and supraneural element of balistids. If the spiny dorsal fin of aracanids migrated anteriorly as it became rudimentary, it may have left free one of the more posterior pterygiophores (corresponding in balistids to either the second pterygiophore or to the supraneural strut, the latter itself being a modified third pterygiophore) which then became enlarged to support the carapace. Conversely, in the only group of plectognaths other than aracanids to lose the spiny dorsal fin, the gymnodonts, the loss of the fin, on the evidence of Triodon, has been by the posterior migration of the spines and pterygiophores as they became rudimentary. If the loss in aracanids was by posterior migration, then the supraneural still represents an enlarged pterygiophore, or an enlarged consolidation of two or more of them. Equally possible is that the aracanid spiny dorsal fin, regardless of whether it migrated anteriorly or posteriorly, lost not only the spines but also all the pterygiophores, and that the supraneural is actually an enlarged pterygiophore, or an enlarged consolidation of two or more of them, from the soft dorsal fin that became available for carapace support as the soft dorsal was shortened from anteriorly to posteriorly. 


\section{Family Ostraciidae}

Comparative diagnosis (contrast with that of the Aracanidae). - Supraorbital region of the skull relatively weak, the frontal extremely thin in this region and tightly held to the undersurface of the carapace; frontal without a long forward extension anterior to the orbit, ending anteriorly over or only slightly in front of the prefrontal and not overlying the ethmoid; supraoccipital crest absent; epiotic little, if any, prolonged posterolaterally, scarcely if at all beyond the level of the base of the skull; prootic shelf without a recurved wing; myodome either small and shallow or essentially absent; usually three pharyngobranchials, occasionally only two, the first a toothless suspensory element and sometimes absent, the second with a series of small to minute teeth, and the third either toothless or with minute rudimentary teeth; branchiostegals $2+4$; ethmoid a more or less rounded shaft posteriorly and much expanded laterally in the anterior one-third or more of its length; pterosphenoid and parasphenoid with only a very limited region of suturing in the interorbital septum; parasphenoid much expanded laterally throughout its length anterior to its region of suturing with the anteromedial edges of the prootic shelves, forming a complete hard palate over the roof of the oral cavity; posterodorsal region of coracoid without a posterior prong; four or five vertebrae, represented by both neural arch and centrum material, at the front of the vertebral column variously fused and sutured to one another and to the exoccipitals and basioccipital, the fusion region with a prominent ventral process below the level of the centra; vertebrae immediately following the fusion region with relatively short neural spines and with centra of about normal length without transverse processes; the centra of two or more of the vertebrae immediately preceding the caudal plate much compressed anteroposteriorly; haemal arch and spine of the penultimate vertebra relatively small and either autogenous or fused to the centrum, in which latter case it may be rudimentary; caudal fin rays, i, 8, i; postcleithrum of moderate size, formed of one or two pieces, and not extending posteriorly much beyond the level of the posterior edge of the pectoral girdle; carina (supraneural) relatively short and either without a ventral flange or with only a weak shallow one, not extending anteriorly as far as the level of the anteroventral end of the first dorsal fin basal pterygiophore and not in contact with any of the neural spines of the predorsal vertebrae;

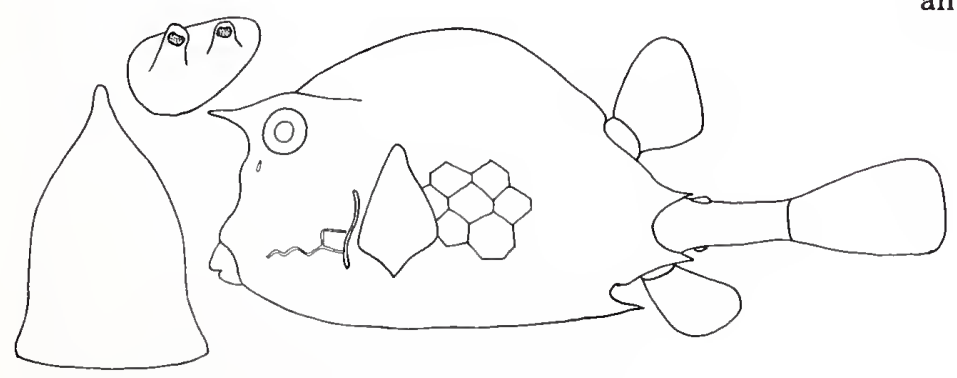

haemal spines poorly developed and absent on many of the abdominal and caudal vertebrae, except for the heavy haemal spine(s) which supports by close apposition and sometimes interdigitation the last anal fin basal pterygiophore, the other anal fin basal pterygiophores that lie in the midline of the body also making relatively close contact along their distal ends with the vertebral column; first anal fin basal pterygiophore expanded anterolaterally at its distal end into wings supporting the carapace; haemal canal not entirely straight, diverted under the centra of the more posterior abdominal vertebrae (usually between the seventh abdominal to first caudal vertebrae) either to the left or to the right of the midline, or alternatively to the left and right, and relatively poorly enclosed under most vertebrae by weakly developed haemal arches and spines; most of the vertebrae posterior to the anteriormost four or five fused vertebrae and anterior to the postanal vertebrae sutured to one another (suturing between at least the fifth and sixth abdominal vertebrae to the third and fourth caudal vertebrae); uppermost pectoral fin ray short, composed of a single piece without cross-striations and bearing a foramen representing the region of otherwise complete fusion between the original halves of the ray; body (exclusive of vertical carapace spines) relatively less deep, the distance between the distal ends of the first dorsal and anal fin basal pterygiophores being contained more than 3 times in SL, and the distance between the top of the rear of the cranium and the ventralmost edge of the pectoral girdle being contained about 2.3 to 2.5 times in SL; carapace closed behind the anal fin and, with the exception of one species, behind the dorsal fin as well; carapace never with a ventral keel; caudal peduncle usually without scale plates isolated from the carapace proper.

Detailed description of Acanthostracion quadricornis.

Material examined: - Thirteen cleared and stained specimens, $8.2-350 \mathrm{~mm}$; three dry skeletons, $130-163 \mathrm{~mm}$.

\section{SKULL.}

Occipital Region.

Basioccipital. - A short column, expanded anterolaterally; cartilage filled along its anterior and dorsal edges; articulates by interdigitation dorsally with the exoccipitals, anterolaterally with the prootics and anteriorly with the overlying posterior end of the para-
Figure 148.-Acanthostracion quadricornis: upper left, nasal region as seen externally (olfactory epithelium relatively smooth in this and all other species of ostraciids); lower left, outline of cross section of middle of body; pattern of scale plates shown only behind pectoral fin. 
sphenoid. The posterior half of the basioccipital is hidden from view by the forward displacement of the highly modified first five abdominal vertebrae, as explained in the section on the vertebral column.

Exoccipital. - Cartilage filled along all of its edges of articulation with the other cranial bones; articulates by interdigitation posterodorsally with the epiotic, ventrolaterally with the pterotic, ventromedially with the basioccipital, and anteroventrally with the prootic. Posteriorly the exoccipitals form the lateral walls and most of the dorsal walls of the foramen magnum, while ventrally the foramen is closed by the dorsal surface of the basioccipital. Posterodorsally the medial edges of the exoccipitals closely approach, but do not meet, one another and are held together by a thin sheet of fibrous tissue. More anteriorly, however, the dorsomedial edges of the exoccipitals are more distantly separated and the space between them is filled by a thin sheet of cartilage. The lateral surface of the extreme posterior end of the exoccipital is overlain by and interdigitated with the more anterior of the highly modified first five abdominal vertebrae, as explained in the section on the vertebral column.

Supraoccipital. - Laterally expanded; no supraoccipital crest; cartilage filled along all of its edges of articulation with the other cranial bones; articulates by interdigitation anteriorly and anterolaterally with the frontals and posterolaterally with the epiotics.

\section{Otic Region.}

Pterotic. - Cartilage filled along all of its edges of articulation with the other cranial bones; articulates by interdigitation posterodorsally with the epiotic, anterodorsally with the sphenotic, anteroventrally with the prootic and posteroventrally with the exoccipital. For a short distance medially along its anteroventral edge the pterotic supports by fibrous tissue the posterodorsal edge of the hyomandibular. The anterolateral region of the pterotic is prolonged ventrally into a stout shaft that is mostly obscured from lateral view by the broadly overlying posttemporal, to which it is interdigitated. At the ventromedial end of this shaft the pterotic helps to support by fibrous tissue the laterally expanded end of the ossified Baudelot's ligament and medially the posterolateral edge of the hyomandibular.

Sphenotic. - Cartilage filled along all of its edges of articulation with the other cranial bones; articulates by interdigitation posterodorsally with the frontal, posteroventrally with the pterotic and for a short distance with the anterodorsal end of the posttemporal, dorsomedially with the pterosphenoid, and ventromedially with the prootic. The dorsolateral surface of the sphenotic is broadly overlain by the frontal.

Epiotic. - More or less rounded, but with a short ventrally directed process from its ventrolateral edge; cartilage filled along all of its edges of articulation with the other cranial bones; articulates by interdigitation dorsally with the frontal, anteroventrally along its lateral edge with the sphenotic and pterotic, posteroventrally with the exoccipital, and medially with the supraoccipital. For a short distance the medial edge of the epiotic is in contact with the cartilaginous piate that separates the medial edges of the exoccipitals.

Prootic. - Cartilage filled along all of its edges of articulation with the other cranial bones, except at its anteriormost region of articulation with the parasphenoid; articulates by interdigitation ventromedially with the laterally compressed keellike dorsal region of the parasphenoid, ventrolaterally with the pterotic, posteroventrally with the basioccipital and exoccipital, dorsomedially with the pterosphenoid and dorsolaterally with the sphenotic. Along most of the anterior edge of its laterally expanded posterior portion the prootic possesses a slight concavity with which the dorsal head of the hyomandibular articulates by fibrous tissue. The anteromedial region of the prootic possesses a long forward extension under the orbit which makes contact by interdigitation with the parasphenoid at the level of the prefrontals. A bony myodome is essentially absent.

\section{Orbital Region.}

Frontal. - Wide posterolaterally; extremely thin and delicate anterolaterally, where it is in close contact with the ventral surface of the cuirass; articulates by interdigitation posteriorly with the supraoccipital and posterolaterally with the epiotic and sphenotic, broadly overlying the latter. Anteroventrally, in the orbital region, the frontal interdigitates with the pterosphenoid. Anteriorly the frontal is prolonged into a very thin projection that overlies the dorsomedial edge of the prefrontal and the dorsal surface of the ethmoid cartilage and reaches almost to the posterior end of the ethmoid. Since the thin anterolateral expansion of the frontal is closely held by fibrous tissue to the ventral surface of the cuirass over the orbital region, a large portion of the frontal is very easily torn away when the cuirass is removed. Thus, the few figures of the skulls of trunkfishes that have been previously published usually show the frontal incompletely and unrealistically with ragged edges.

Prefrontal. - Large and wedge-shaped; cartilage filled along its medial edge where it is continuous with the ethmoid cartilage; articulates by fibrous tissue dorsomedially with the frontal, while ventrally it articulates by fibrous tissue and, in large specimens, by slight interdigitation with the parasphenoid. Its major surface of articulation, however, remains with the ethmoid cartilage that broadly intervenes between the prefrontal and the ethmoid.

Parasphenoid. - Elongate, running almost the entire length of the skull; expanded ventrally along nearly all of its length into a thin keel, which itself is laterally 
expanded along the anterior third of its ventral edge to form a slightly concave horizontal plate over the roof of the oral cavity. The parasphenoid articulates by interdigitation posterolaterally with the prootics, while at its extreme posterior end it broadly overlies and interdigitates with the basioccipital. At its blunt anterior end the parasphenoid is deeply and firmly interdigitated with both the ethmoid and vomer, and in large specimens (over approximately $200 \mathrm{~mm}$ ) these articulations become truly fused. Anterodorsally the parasphenoid interdigitates with the ethmoid, while dorsally in about the middle of its length the parasphenoid becomes slightly expanded laterally and articulates by fibrous tissue and, in large specimens, by interdigitation with the bases of the prefrontals. In the anterior half of the orbital cavity the parasphenoid is present as a thin flat plate, the extreme posterodorsal edge of which makes contact, in large specimens at least, with the extreme anterior end of the pterosphenoid. In large specimens the articulation of the parasphenoid and pterosphenoid is by interdigitation, whereas in smaller specimens the articulation is through the interorbital sheet of fibrous tissue. In about the middle of its length, where it is laterally expanded, the parasphenoid makes contact by interdigitation with the anterior prolongation of the prootics.

Pterosphenoid. - Cartilage filled along all of its edges of articulation with the other cranial bones, except anteriorly; articulates by interdigitation posterodorsally with the somewhat overlying frontal, posteriorly with the sphenotic and posteroventrally with the prootic. The anterior edge of the pterosphenoid is prolonged anteriorly into a flattened process which makes contact with the posterior edge of the platelike orbital expansion of the parasphenoid, as explained above.

\section{Ethmoid Region.}

Ethmoid. -Elongate; a rounded shaft posteriorly, but becoming laterally expanded anteriorly; cartilage filled at its posterior edge, where it is continuous with the ethmoid cartilage; articulates by interdigitation ventrally along the posterior two-thirds of its length with the parasphenoid, while ventrally in the anterior one-third of its length it firmly articulates by extensive interdigitation with the vomer. In large specimens the articulation between the ethmoid and vomer becomes fused. At its anterior edge the ethmoid helps support, through fibrous tissue, the upper jaw.

Vomer.-Short, slightly expanded laterally in about the middle of its length; articulates by interdigitation dorsally with the ethmoid and posteriorly with the parasphenoid, but in large specimens both of these articular surfaces become fused. Anterolaterally, just in front of its laterally expanded region, the vomer supports through fibrous tissue the palatines, while at its extreme anterior end it supports the upper jaw. A slight concavity in the lateral surface of the vomer marks the place of articulation between the vomer and palatine.

\section{Mandibular Region.}

Hyomandibular. - Much expanded posteriorly, tapering gradually to a blunt end anteriorly; cartilage filled at its posterior and anterior edges; articulates by fibrous tissue posteriorly with the slight concavity on the anterior edge of the laterally expanded posterior portion of the prootic and, for a short distance, with the continuation of that concavity on the anteromedial edge of the pterotic, as well as along the medial surface of the ventral shaft of the pterotic. The dorsomedial edge of the hyomandibular is also supported through fibrous tissue by the lateral surface of the ventral flange of the prootic shelf. The hyomandibular possesses a slight concavity on its ventral edge in which the rounded dorsal end of the operculum is held by fibrous tissue. Just anterior to this articular area the hyomandibular bears an elongate groove on its lateral surface into which the slender posterodorsal end of the preoperculum fits and is tightly held by fibrous tissue. Anteriorly the hyomandibular is attached to the fibrous tissue sheet between the metapterygoid, symplectic, and preoperculum.

Quadrate.-Wide posteriorly, tapering anteriorly to a knob for articulation with the articular in the lower jaw, while from its posteroventral edge it possesses a short posteriorly directed process; cartilage filled at its posterior edge; articulates by interdigitation dorsally with the ectopterygoid, posterodorsally with the mesopterygoid and posteroventrally with the symplectic. Along the posterior two-thirds of its ventral edge the quadrate articulates by fibrous tissue with the preoperculum.

Metapterygoid. -Elongate; wide anteriorly but becoming narrower posteriorly; cartilage filled at its anterior edge; articulates by interdigitation anterodorsally with the mesopterygoid and anteroventrally with the symplectic, which it somewhat overlies. Posteriorly the metapterygoid articulates by fibrous tissue with the hyomandibular and interhyal.

Symplectic. - Slender and elongate; no cartilage filled edges evident; articulates by interdigitation anteriorly with the quadrate, posteriorly with the metapterygoid and by fibrous tissue posteroventrally with the preoperculum and hyomandibular.

\section{Palato-Pterygoid Region.}

Palatine. -A small wedge of bone; articulates by interdigitation ventrally with the ectopterygoid and, to a lesser extent, with the mesopterygoid. Even though the palatine has often been said to be absent in ostraciids, it is distinct from the ectopterygoid even in large specimens and the suture between the two can be seen upon close examination. Dorsomedially the palatine articulates by fibrous tissue from a slightly rounded prominence on its upper medial surface with the slight concavity on the lateral surface of the vomer. 
Ectopterygoid. -Elongate; articulates by interdigitation dorsally with the palatine, posteriorly with the mesopterygoid, which it somewhat overlies, and ventrally with the quadrate, which it also overlies.

Mesopterygoid. - Large; articulates by interdigitation posteroventrally with the metapterygoid, while anteriorly it interdigitates with and is somewhat overlain by the palatine, ectopterygoid, and quadrate.

Opercular Region.

Operculum. - Relatively short and thin; more or less rounded in outline, with a protuberance dorsomedially for articulation by fibrous tissue with a slight concavity on the ventral edge of the hyomandibular. Ventrally the operculum broadly overlies and articulates by fibrous tissue with the suboperculum.

Suboperculum. - Very thin; widest in the middle, broadly rounded anteriorly, tapering to a point posteriorly; articulates by fibrous tissue dorsally with the broadly overlying operculum. At the anterior edge of the region where the operculum overlies the suboperculum, a strong ligament coming from the interoperculum makes contact with the suboperculum and, to a lesser extent, with the operculum.

Interoperculum. - A short rod; extends from the level of the anterior end of the preoperculum to the level of the junction of the ceratohyal and epihyal; connects by a strong ligament anteriorly to the angular in the lower jaw, while posteriorly it connects by a short ligament to the epihyal and by a longer more diffuse ligament to the anterior edge of the suboperculum and, to a lesser extent, of the operculum.

Preoperculum. - Relatively short; not much expanded in its middle region, and tapering to narrow ends anteriorly and posteriorly; articulates by fibrous tissue anteriorly along its dorsal edge with the quadrate and, to a slight extent, with the symplectic; posteriorly the narrow shaft of the preoperculum is held by fibrous tissue in an elongate concavity on the lower lateral surface of the hyomandibular.

\section{Upper Jaw.}

Premaxillary. - A slightly curved plate, wider dorsally than ventrally; its posterodorsal region somewhat concave for articulation by fibrous tissue with the anterior edges of the vomer and ethmoid; the anterior edge of the upper jaw formed by the premaxillary, except for a short distance ventrally where it is formed by the maxillary; the dorsomedial edges of the two premaxillaries held in close apposition by fibrous tissue. Each premaxillary in adults usually bears five or six teeth in a single row. The teeth are borne in relatively deep and elongate grooves on the outer surface of the premaxillary. The lowermost teeth are shaftlike and taper to sharp points, but more dorsally and medially they are flattened and blunter at their distal ends. At the posterior end of each tooth-bearing groove there is a deep socket in which new teeth develop before moving forward to replace the old ones. Most of the interior of the premaxillary contains the dental pulp from which the new teeth develop. This pulp cavity communicates with the exterior not only by the deep sockets in which the new teeth develop but also by a large hole in the posterodorsal surface of the premaxillary. The premaxillary articulates by extensive interdigitation with the maxillary along all of its posterior edge, except for a short distance dorsally.

Maxillary.-Widest ventrally, constricted in the middle of its length; articulates by extensive interdigitation anteriorly along all of its length with the premaxillary, which it somewhat overlies. The maxillary articulates by fibrous tissue posterodorsally with the anterior edges of the vomer and ethmoid and ventromedially with the dorsolateral surface of the dentary.

\section{Lower Jaw.}

Dentary. - Wider posteriorly than anteriorly; its posteromedial surface concave dorsally to accommodate the articular, with which it interdigitates. Just below the articular, the dentary interdigitates with the angular. The ventromedial edges of the two dentaries are held closely together by fibrous tissue. Laterally from its posterodorsal region the dentary articulates by fibrous tissue with the medial surface of the maxillary. Each dentary in adults usually bears four or five teeth, like those of the upper jaw, in deep grooves on its outer surface, each of the tooth-bearing grooves ending posteriorly in a deep socket in which new teeth develop. The sockets are in communication with the large pulp cavity that fills most of the hollow interior of the dentary. The pulp cavity communicates with the exterior not only at the tooth sockets but also at its posterior concave region of articulation with the articular.

Articular. - Small; its posterior edge with a concavity for articulation by fibrous tissue with the anterior knoblike process of the quadrate. Anteriorly the articular interdigitates with the concave upper half of the posteromedial surface of the dentary. On the medial side of its ventral edge the articular interdigitates with the angular, but the lateral surfaces of these two bones are not in contact; rather, they are slightly separated by the dentary. The sesamoid articular is a roundish nubbin of bone closely held to the medial surface of the articular just behind the region where the upper medial edge of the articular meets the medial surface of the dentary.

Angular. - Small, slightly elongate; articulates by interdigitation dorsomedially with the articular, while dorsolaterally, anteriorly, and ventrally it interdigitates with the dentary. Posteriorly the angular connects by ligament with the anterior end of the interoperculum. 


\section{BRANCHIAL APPARATUS.}

\section{Hyoid Arch, Branchiostegal Rays, and Urohyal.}

Hypohyals. - Both hypohyal elements well developed; ventral element larger than the dorsal element; dorsal element cartilage filled along its posterior and ventral edges, the ventral element cartilage filled along its posterior and dorsal edges. The two elements articulate with one another and with the ceratohyal through cartilage; the anteromedial edges of both elements articulate by fibrous tissue with their opposite members. The dorsomedial edge of the dorsal hypohyal articulates by fibrous tissue posteriorly with the first basibranchial and anteriorly with the reduced urohyal, while the dorsomedial edge of the ventral hypohyal also articulates by fibrous tissue with the urohyal.

Ceratohyal. - A wide flat plate; shortened anteroposteriorly and expanded dorsoventrally to such an extent that the former dimension is shorter than the latter; cartilage filled along all of its edges except at the indented regions posterodorsally and anteroventrally; articulates through cartilage anteriorly with the ventral hypohyal, anterodorsally with the dorsal hypohyal and posteriorly with the epihyal. The first two branchiostegal rays articulate by fibrous tissue with slight depressions on the ventral edge of the ceratohyal at the anterior edge of its deeply indented anteroventral region. The next three branchiostegal rays articulate by fibrous tissue with the posteroventral edge of the ceratohyal, and the last ray with the ventral edge of the area of articulation between the epihyal and ceratohyal.

Epihyal. - Large, elongate dorsoventrally; cartilage filled at its anterior, anterodorsal and ventral edges; articulates through cartilage anteriorly with the ceratohyal, while posterodorsally it supports the interhyal by fibrous tissue. Just anterior to its articulation with the interhyal, the lateral surface of the epihyal articulates by fibrous tissue with the posterior end of the interoperculum.

Interhyal. - A short, slender rod; cartilage filled at both ends; articulates by fibrous tissue ventrally with the epihyal and dorsally with the slight concavity on the ventral edge of the metapterygoid immediately behind the posterodorsal end of the symplectic.

Branchiostegal rays. - Six in number; the first ray shorter than the second; the third to fifth rays of about the same length as the first ray; the sixth ray by far the longest. The rays articulate by fibrous tissue to the ceratohyal and, to a lesser extent, the epihyal, as explained under those bones.

Urohyal. - Reduced to a short depressed plate without a ventral keel; articulates by fibrous tissue anterodorsally with the anteromedial edge of the dorsal hypohyal and dorsomedial edge of the ventral hypohyal; articulates by fibrous tissue posteriorly with the ventral surfaces of the first two basibranchial elements.

Branchial Arches. - All the elements are cartilage filled at their edges of articulation with the other elements in the series, and the articulations are usually through cartilage and fibrous tissue. The branchial arches are composed of three basibranchials, three pairs of hypobranchials, five pairs of ceratobranchials, four pairs of epibranchials, and two (sometimes three) pairs of pharyngobranchials. Four gills are present, with a small slit between the fourth arch and the lower pharyngeal.

First arch.-Basi-, hypo-, cerato-, epi-, and, sometimes, pharyngobranchial elements present. First basibranchial short, slightly wider posteriorly than anteriorly; displaced forward so that it articulates posteriorly with the second basibranchial and anteriorly with the hypohyals and urohyal, but with no direct connection with the first hypobranchials. First hypobranchial wide dorsally but very narrow ventrally; the largest of the hypobranchial elements, which decrease in size posteriorly in the series; articulates ventrally with the lateral surface of the middle region of the second basibranchial and dorsally with the first ceratobranchial. First ceratobranchial a long sturdy compressed rod; the longest of the ceratobranchial elements, which decrease in length posteriorly in the series; from the first to the fourth ceratobranchial the ventral regions become increasingly enlarged (the degree of compression of the rods, and hence their width, appears to increase somewhat with increasing specimen size); no ventrally directed flange present on any of the ceratobranchials; articulates ventrally with the first hypobranchial and dorsally with the first epibranchial. First epibranchial a short rod, somewhat narrowed in the middle; articulates dorsally with the anterolateral surface of the second pharyngobranchial and with the base of the first or suspensory pharyngobranchial when such is present; the shortest of the epibranchial elements, which increase slightly in size posteriorly in the series. First pharyngobranchial absent, at least as an ossification, in the majority of the specimens examined, but present in 3 out of 13 specimens as a short slender toothless rod whose distal end is held by fibrous tissue to the medial surface of the extreme anterior end of the ventral flange of the prootic shelf just lateral to the region where the prootic interdigitates with the laterally expanded portion of the parasphenoid in the anterior region of the orbit.

Second arch.-Basi-, hypo-, cerato-, epi-, and pharyngobranchial elements present. Second basibranchial the longest of the basibranchials, the first and third being of about the same length, but of different widths; articulates anteriorly with the first basibranchial, laterally with the first hypobranchials, and posteriorly with the third basibranchial. Second hypobranchial somewhat wider dorsally than ventrally; articulates ventrally with the area of articulation between 
the first and second basibranchials, and dorsally with the second ceratobranchial. Second ceratobranchial only slightly shorter than the first ceratobranchial; slightly expanded anteroventrally; articulates dorsally with the second epibranchial. Second epibranchial a short rod; articulates dorsally with the posterolateral surface of the second pharyngobranchial. Second pharyngobranchial the first and larger of the two toothed pharyngobranchial elements; even in the largest specimen studied $(350 \mathrm{~mm})$ it remains partially unossified, because a large cartilaginous region is present anterodorsally in its mass; more or less squarish in outline, except for its concave and vertically oriented posterior surface; articulates along its lateral surface posteriorly with the second epibranchial and anteriorly with the first epibranchial; articulates along its concave posterior surface by fibrous tissue to the rounded anterior surface of the third pharyngobranchial. The posterior surface of the second pharyngobranchial is more deeply concave ventrally than dorsally, so that the ventral surface of the element is U-shaped. It bears an irregular band of up to about 25 minute teeth on its ventral surface along the bend of the $\mathrm{U}$. The teeth are so small that it is doubtful if they are functional or even if they protrude to the surface through the skin of the oral cavity.

Third arch.-Basi-, hypo-, cerato-, epi-, and pharyngobranchial elements present. Third basibranchial the widest of the basibranchial elements; rectangular in shape; articulates anteriorly with the second basibranchial, anterolaterally with the second hypobranchials, posterolaterally with the third hypobranchials and third ceratobranchials, and posteriorly with the fourth ceratobranchials. Third hypobranchial a relatively straight and slender rod; articulates posterolaterally with the third ceratobranchial and posteromedially with the third basibranchial, while its ventrally directed anterior end articulates by fibrous tissue with the under surface of the more anterior basibranchial elements. Third ceratobranchial articulated ventrally with the posterior ends of the third hypobranchial and third basibranchial, and dorsally with the third epibranchial. Third epibranchial rodlike; slightly expanded anteriorly in the middle of its length, at which place it makes fibrous tissue contact with the posterior surface of the second epibranchial; articulates dorsally with the lateral surface of the third pharyngobranchial. Third pharyngobranchial smaller than the second pharyngobranchial; more or less columnar; its ventral surface concave; better ossifed than the second pharyngobranchial, but nevertheless with several cartilaginous areas present; articulates anteriorly with the concave posterior surface of the second pharyngobranchial and laterally with the dorsal ends of the third and fourth epibranchials. It usually bears one to six minute and nonprotruding teeth in a row along the anterior edge of its ventral surface, but no such even rudimentary teeth could be found in some of the specimens examined.

Fourth arch. - Cerato- and epibranchial elements only. Fourth ceratobranchial much expanded ventrally; articulates ventrally with the posterior end of the third basibranchial and dorsally with the fourth epibranchial. Fourth epibranchial the longest of the epibranchial elements; much wider ventrally than dorsally; articulates dorsally with the lateral surface of the third pharyngobranchial.

Fifth arch. - Ceratobranchial (lower pharyngeal) element only. Fifth ceratobranchial the shortest of the ceratobranchial elements; much expanded ventrally throughout the middle region of its length; articulates ventrally with the ventral end of the fourth ceratobranchial; toothless.

\section{PAIRED FIN GIRDLES.}

\section{Pectoral Fin.}

Posttemporal. - A large long shaft broadly overlying the lower half of the lateral surface of the pterotic, to which it is firmly interdigitated; anterodorsally it also interdigitates, to a much lesser extent, with the sphenotic, while its ventral head is firmly held by fibrous tissue to the supracleithrum. On its ventromedial surface the posttemporal helps, along with the pterotic and, to a far lesser extent, the cleithrum, to support by fibrous tissue the expanded lateral end of the ossified Baudelot's ligament.

Baudelot's ligament. - The ligament fully ossified as a large stout shelf giving great support to the pectoral girdle. It articulates firmly by fibrous tissue at its medial end with the extreme posterolateral edge of the parasphenoid immediately anterior to the posteriormost point of contact between the parasphenoid and basioccipital. Its expanded lateral end is firmly held by fibrous tissue mainly to the ventromedial surface of the ventral flange of the pterotic and to the ventral end of the posttemporal, and, to a much lesser extent, to the extreme dorsolateral end of the cleithrum. The dorsal edge of the medially expanded platelike portion of the cleithrum is firmly held by a sheet of fibrous tissue to the ventral surface of Baudelot's ligament.

Supracleithrum. - Located slightly obliquely posterodorsally to anteroventrally in relation to the axis of the body; relatively short and broadly overlain by the posttemporal; articulates firmly by fibrous tissue, and slight interdigitation in large specimens, dorsally with the overlying posttemporal and ventrally with the cleithrum, which it broadly overlies.

Cleithrum. - Greatly expanded both laterally and medially along all the length of its anterior edge, except for a short distance ventrally, so that a large thin vertical plate is formed at right angles to the axis of the body; also greatly expanded posteriorly in the ventral half of its length; articulates dorsally by fibrous tissue 
and slight interdigitation with the broadly overlying supracleithrum and by fibrous tissue with the anterior edge of the dorsal postcleithrum; posteriorly in about the middle of its length it articulates by fibrous tissue and slight interdigitation with the scapula and coracoid. Ventromedially the cleithrum articulates by fibrous tissue with its opposite member, while the dorsal edge of its medially expanded platelike portion is held by fibrous tissue to the ventral surface of Baudelot's ligament.

Postcleithra. - The postcleithra form a thin wide plate, closely held by fibrous tissue to the cuirass, from the upper end of the cleithrum to about the level of the posteriormost point of the pectoral girdle. The dorsal postcleithrum is widest and thickest at its anterior edge where it articulates by fibrous tissue with the cleithrum. Posteriorly the dorsal postcleithrum articulates by fibrous tissue, and in large specimens by slight interdigitation, with the ventral postcleithrum. The ventral postcleithrum is an extremely thin plate of variable shape, but it is always much smaller than the dorsal postcleithrum. The two postcleithra overlie one another in a variable manner at their region of articulation.

Coracoid. - Wider ventrally than dorsally; its posterior edge with a laterally directed flange throughout its length, except at the extreme dorsal and ventral ends; a short dorsal projection present from its posterodorsal edge which makes contact with the posterior edge of the last actinost; cartilage filled at its dorsal edge; an upraised flange present on its lateral surface, running, with increasing height of the flange, from posterodorsally to anteroventrally; articulates dorsally through cartilage with the scapula, while posterodorsally its small dorsally directed flange interdigitates with the posterior edge of the last actinost. Dorsally along its anterior end the coracoid articulates by fibrous tissue and slight interdigitation with the cleithrum, which broadly overlies it.

Scapula. - Completely encloses the scapular foramen; cartilage filled at its ventral and posterior edges; articulates by fibrous tissue and slight interdigitation anteriorly and anteroventrally with the cleithrum, and through cartilage ventrally with the coracoid; posterodorsally the scapula interdigitates with the bases of the first two actinosts, while more anteriorly on its dorsal edge it bears a concavity to which the reduced first pectoral fin ray articulates by fibrous tissue.

Actinosts. - Four elements; all cartilage filled at their dorsal edges; first actinost the smallest, the others of slightly increasing size posteriorly in the series; all four elements held to one another by interdigitation; first and second actinosts articulated ventrally by interdigitation with the posterodorsal edge of the scapula; third actinost articulated ventrally by fibrous tissue with the scapula and coracoid; fourth actinost articulated by fibrous tissue ventrally with the coracoid, as well as by interdigitation posteriorly with the dorsally directed process of the coracoid. Distally the actinosts support by fibrous tissue all of the fin rays, except for the first, which is supported by the scapula, and the second, which is supported by both the scapula and first actinost.

Fin rays. - Twelve fin rays in most specimens, with the first ray about one-sixth the length of the second ray and articulated directly with the scapula instead of with the actinosts, as are all the other rays, except for the second, which articulates with the region of interdigitation between the scapula and first actinost; first ray with its two halves fused together, the division between the two halves being indicated only by an oblong cavity running horizontally through the base of the ray; the medial half of the ray larger than the lateral half. The first two rays unbranched, the others branched. The first ray without cross-striations, the other rays cross-striated.

VERTEBRAL COLUMN. - All vertebrae with biconcave centra, except the last, which ends posteriorly in the fused hypural plate, and the highly modified first five vertebrae.

\section{Abdominal Vertebrae.}

First five vertebrae. -What has usually been called the first vertebra is in fact a compound element resulting from the fusion of the first five abdominal vertebrae to themselves and to the posterior end of the basioccipital (as described in detail by Tyler 1963a). In adult specimens there is slight evidence of this fusion of the first five vertebrae into a single piece, for there are five neural foramina in the upper half of the lateral surface of the fusion product and its neural arch shows, except in extremely large specimens, a division or lobation dorsally into five successive regions separated from one another by clefts which extend downward about onethird to one-half the distance from the top of the neural arch to the region of the centrum. In the $8.2 \mathrm{~mm}$ specimen each of the last three of the first five vertebrae possesses a very thin centrum and neural arch in a single continuous piece separate from that succeeding and preceding it. The first and second vertebrae are even thinner than the others and their centra are in close apposition and may even be fused at this early developmental stage. These two centra, in turn, appear to be in the process of fusing with the basioccipital, but their neural arches are still separate from one another. In the $15.3 \mathrm{~mm}$ specimen the first two vertebrae have their centra and the lower one-fourth of their neural arches indistinguishably fused, while the centra are similarly fused to the basioccipital. The third and fourth vertebrae have their centra and the lower three-fourths of their neural arches indistinguishably fused, but separate from the fused first two vertebrae and the fifth vertebra. In the 
study specimens of $25.0 \mathrm{~mm}$ and larger the centra of the first five vertebrae are all fully fused to one another and to the basioccipital, while their neural arches become progressively more fused together until only the lobation dorsally remains from their original distinctness (see Tyler 1963a:158-160 for details). After the centra have fused with the basioccipital I am unable to distinguish where the one ends and the other begins. In the adult, the posterior end of the fused basioccipital and first five vertebral centra is a concave rounded surface which articulates by fibrous tissue with the sixth abdominal vertebra. One can suppose that this concave articular surface is formed from material contributed by the centrum of the fifth vertebra. At least the first two vertebrae seem to lie principally lateral to the posterior region of the basioccipital, for it appears that they have fused not to the extreme posterior end of the basioccipital but rather to its posterolateral surface. The neural arch of the first vertebra overlies and interdigitates with the posterodorsal surface of the exoccipitals. Ventrolaterally from each side of the fused first five vertebral centra there is a wide, but delicate, ventral process which attaches by fibrous tissue posteriorly with a similar pair of projections from the sixth abdominal vertebra. The small muscles which attach to these ventral projections have a complex relationship with the air bladder. The dorsomedial edges of the neural arches of the first five vertebrae meet in the midline and are held together at first by fibrous tissue, but in large specimens this articulation becomes interdigitated to form a complete bony roof over the neural canal. No neural spines are present. The lower half of the posterior edge of the fused neural arches of the first five vertebrae strongly interdigitates with the anterior edge of the lower portion of the neural arch of the sixth abdominal vertebra.

Other abdominal vertebrae. - As explained in the preceding section on the Aracanidae, the first caudal vertebra is arbitrarily designated as the anteriormost vertebra whose ventral surface is most closely associated with the proximal end of the first anal fin basal pterygiophore which consistently lies in the midvertical plane of the body. In 13 specimens there are nine abdominal vertebrae; which is to say that the first five vertebrae are fused into a single piece, and that this element is followed by four separate and distinct vertebrae. The sixth abdominal vertebra articulates by fibrous tissue at its concave anterior end with the posterior concave surface of the fused first five vertebrae and basioccipital, while laterally the lower half of the anterior edge of the neural arch of the sixth vertebra is extensively interdigitated with the lower posterior edge of the neural arch of the fused first five vertebrae. The sixth abdominal vertebra possesses a short and thin neural spine along most of the length of the dorsal surface of its neural arch. The haemal processes from the ventrolateral edges of the anterior end of the sixth vertebra are anteriorly expanded at their distal ends. The distal ends of these processes do not fuse to one another in the midline of the body; rather, they are held to one another by fibrous tissue. This in- complete haemal arch is held by fibrous tissue anteriorly to the similar structure from the fused first five vertebrae and, like the latter, it is a point of attachment for a complex of muscles associated with the air bladder. The seventh to ninth abdominal vertebrae have large neural spines and complete, although much reduced, haemal arches without haemal spines. The sixth to ninth abdominal vertebrae articulate with one another not only by fibrous tissue between their concave articular faces but also by deep and firm interdigitation of the edges of the neural arches. The neural spine of the seventh abdominal vertebra is long, thin, and delicate; the anteroposterior depth of its basal region is about equal to that of the vertebra, but the spine tapers to a point distally. The posterior edge of the neural spine of the seventh $a b$ dominal vertebra articulates by fibrous tissue with the first dorsal fin basal pterygiophore. The neural spines of the eighth and ninth abdominal vertebrae are narrow rods arising from the posterodorsal surfaces of their neural arches and directed posterodorsally between the dorsal fin basal pterygiophores almost to the distal ends of the latter elements. The neural spine of the eighth abdominal vertebra lies between the first and second pterygiophores, and the neural spine of the ninth between the third and fourth pterygiophores. The neural spines and pterygiophores are held to one another by a sheet of fibrous tissue. The haemal arches of the seventh to ninth abdominal vertebrae are complete, although thin and very delicate and of somewhat variable shape from specimen to specimen. No haemal spines are present. The haemal arches arise from the anterior end of the ventrolateral surfaces of the centra and do not project very far ventrally, thus enclosing only a shallow cavity through which the haemal canal runs. The arches of the eighth and ninth vertebrae are distinctly displaced to one side of the midline of the body, usually to the right. The longitudinal concavity on the ventral surface of the seventh to ninth vertebrae, which marks the course of the haemal canal, is likewise displaced to a greater or lesser degree to one side of the midline of the body. The longitudinal concavity on the ventral surface of the sixth vertebra is in the midline of the body, as it is on the anterior end of the seventh vertebra. As the concavity passes from the anterior to the posterior end of the seventh vertebra, it is displaced usually to the right of the midline, and along the eighth and ninth vertebrae it is similarly usually displaced to the right of the midline. The ventrolateral edges of the seventh to ninth abdominal vertebrae are interdigitated with one another. The eighth and ninth abdominal vertebrae possess slightly upraised ridges diagonally across the lateral surfaces of their centra from the bases of the neural spines to the anterolateral edges of the centra. The neural foramen of each of the abdominal vertebrae from the sixth to ninth emerges relatively low on the lateral surface of the vertebra.

Caudal Vertebrae. - The caudal vertebrae numbered 10 in 13 specimens, although all other species of ostraciids, including the other three species of Acantho- 
stracion, have only 9 caudal vertebrae (see Tyler 1965b:268). The first and second caudal vertebrae are like the eighth and ninth abdominal vertebrae, except that their neural spines are shorter and that their anteroventral surfaces support by fibrous tissue the first two anal fin basal pterygiophores which lie entirely in the midvertical plane of the body. The neural spine of the first caudal vertebra lies between the fifth and sixth dorsal fin basal pterygiophores. The haemal arches of the first, second, and third caudal vertebrae are delicate and complete, like those of the seventh to ninth abdominal vertebrae. The haemal arches of the second and third caudal vertebrae are more or less symmetrically placed in the midline of the body, but that of the first caudal vertebra is displaced somewhat to the right. The longitudinal concavity present on the ventral surfaces of the first to fourth caudal vertebrae, which marks the course of the haemal canal, is more or less in the midline, except in the case of the first caudal vertebra, where the concavity is displaced to the right at the anterior end of the vertebra. The fourth caudal vertebra usually possesses only the longitudinal concavity on its ventral surface, and no haemal arch. The third and fourth anal fin basal pterygiophores that lie in the midvertical plane of the body articulate by fibrous tissue with the anteroventral surfaces of, respectively, the third and fourth caudal vertebrae. The neural spine of the third caudal vertebra is anteroposteriorly expanded into a flattened plate which along the dorsal half of its anterior edge is firmly articulated by fibrous tissue with the posterior edge of the last dorsal fin basal pterygiophore, while along its posterior edge it is deeply interdigitated with the anterior edge of the neural spine of the fourth caudal vertebra. The neural spine of the fourth caudal vertebra is anteroposteriorly expanded into a flat plate which is firmly interdigitated at its anterior and posterior edges with, respectively, the posterior edge of the neural spine of the third caudal vertebra and the anterior edge of the neural spine of the fifth caudal vertebra. Whereas the third caudal vertebra is the last caudal vertebra to make contact with the dorsal fin basal pterygiophores, the fifth caudal vertebra is the last to make contact with the anal fin basal pterygiophores. The fifth caudal vertebra has its neural spine anterodorsally expanded, with its anterior edge interdigitating with the posterior edge of the neural spine of the fourth caudal vertebra, while its posterior edge is well separated from the neural spine of the sixth caudal vertebra and is held to the latter only by fibrous tissue. The fifth caudal vertebra possesses a welldeveloped haemal arch and spine, with the haemal arch running the length of the vertebra. The haemal spine of the fifth caudal vertebra is a thick compressed plate which is concave along the lower half of its anterior edge and articulates by fibrous tissue with the middle region of the posterior surface of the last anal fin basal pterygiophore. The sixth to ninth caudal vertebrae are basically similar to one another. They possess sturdy neural arches and spines and haemal arches and spines, all of which decrease slightly in size posteriorly in the series. The centra of these four vertebrae are much shortened antero- posteriorly and are held to one another by fibrous tissue. These vertebrae, and the last vertebra, are thus the only vertebrae which can be laterally flexed to any appreciable extent, since all the vertebrae anterior to the sixth caudal vertebra are interdigitated with one another over large areas of their surfaces of contact. Thus, the third to sixth caudal vertebrae are interdigitated with one another along the surfaces of contact of their neural arches and spines; the seventh abdominal to the second caudal vertebrae are interdigitated with one another not only along the surfaces of contact of their neural arches but also at their ventrolateral edges of contact; the sixth abdominal vertebra is interdigitated along the anterior and posterior edges of its neural arch with the vertebrae anterior and posterior to it; the first five abdominal vertebrae are completely fused to one another.

Caudal Skeleton. - The caudal complex consists of a large rectangular plate, with a rounded expansion in the middle region of its anterior edge representing the centrum of the last caudal vertebra, and a deep cleft in the middle of its posterior edge representing the division between what in more generalized plectognaths would be the second and third hypurals. However, the hypurals are fully fused to the centrum and to themselves and no real distinction can be made between them. Examination of young specimens shows that the anterior portion of the caudal skeleton develops from a centrum which has a complete neural arch and spine and haemal arch and spine. The neural (epural) and haemal (parhypural) apparatus in the $8.2 \mathrm{~mm}$ specimen already appear to be continuous with the centrum, although a deep indentation in the dorsal edge of the plate partially separates the epural from the fused hypurals. In all of the small specimens a urostylar thickening can be seen projecting a short distance posterodorsally from the posterior end of the last vertebra, just in front of the anterodorsal edge of the hypural region. This complex that represents the last caudal vertebra corresponds to about the anterior oneseventh of the adult caudal skeleton. Posterior to the region of the last caudal vertebra in the $8.2 \mathrm{~mm}$ specimen, and continuous with it, is the hypural plate, representing the hypural elements fully fused already to one another and to the last vertebra, except in the region of the deep cleft in the posterior edge, the cleft being much deeper in young specimens than in adults. In adults all of these elements are simply more extensively and indistinguishably fused into the single rectangular plate already apparent at $8.2 \mathrm{~mm}$. A small foramen is present in the anteroventral region of the plate and this is the last opening into the haemal canal, which forms a short tube in the substance of the plate anterior to the foramen and is continuous with the haemal canal of the more anterior vertebrae. This foramen thus marks the region of fusion of the lower hypural region with the parhypural. The neural canal enters the anterior edge of the plate just above the centrum and courses through the plate to exit at a foramen on its posterodorsal edge. The region of the plate above the neural canal represents the fully fused epural. 
Caudal fin rays. - Ten in number, the uppermost ray and the lowermost ray unbranched, the others becoming increasingly branched toward the middle rays, which are branched in triple dichotomies. The five upper rays articulate by fibrous tissue at their bifid bases with the upper lobe of the fused hypural plate and the lower five rays with the lower lobe.

\section{DORSAL AND ANAL FINS.}

\section{Dorsal Fin.}

Fin rays and pterygiophores. - Ten fin rays are present in most specimens; the first ray unbranched, the other rays branched in single or double dichotomies. Distal pterygiophores are either absent or unossified. The bifid bases of the fin rays are supported through fibrous tissue by nine basal pterygiophores. With the exception of the first pterygiophore, all of them are slender rods, cartilage filled at both ends and of decreasing length posteriorly in the series. At their dorsal ends these rodlike pterygiophores are somewhat compressed and are closely held to one another by fibrous tissue and slight interdigitation, with the degree of interdigitation between them increasing with increased specimen size. From the second to the ninth pterygiophore, slight concavities are present in the surfaces of contact of the pterygiophores with each other, so that gaps are present in the otherwise interdigitated surfaces. The first pterygiophore is unlike the others only in that it is expanded anteriorly throughout most of its length into a thin flange. The anterodorsal edge of the first pterygiophore interdigitates with the posterior edge of the supraneural. The supraneural is a short, laterally expanded, plate whose dorsal surface is convex and whose ventral surface is concave. The dorsal surface of the supraneural is in close fibrous tissue contact with the cuirass. The dorsal fin basal pterygiophores articulate by fibrous tissue between the neural spines of the seventh abdominal to third caudal vertebrae. The articulation of the ninth pterygiophore is somewhat different from the others in that it makes a much more intimate contact with the adjacent neural spine than do the others, for it lies in close apposition with the concave anterior edge of the neural spine of the third caudal vertebra.

\section{Anal Fin.}

Fin rays and pterygiophores. - Ten fin rays are present in most specimens; the first ray unbranched, the others branched in single or double dichotomies. Distal pterygiophores are either absent or unossified. The bifid bases of the fin rays are supported through fibrous tissue by 9 (occasionally 10) basal pterygiophores. These pterygiophores are basically similar to those of the dorsal fin in that they are slender rods, compressed at their ventral ends into flattened narrow plates held to one another by fibrous tissue and slight interdigitation. Concavities are present in their surfaces of contact with each other so that gaps are present in their otherwise inter- digitated surfaces. Whereas all of the dorsal fin pterygiophores lie in the midvertical plane of the body, only the last four anal fin pterygiophores lie entirely in this medial plane, the five pterygiophores anterior to them diverging to the right and to the left from their ventral ends, which are in the midvertical plane. The sixth to ninth pterygiophores have their dorsal ends held by fibrous tissue to the anteroventral surfaces of, respectively, the first to fourth caudal vertebrae. The middle region of the posterior edge of the ninth pterygiophore is also held by fibrous tissue to the concavity on the anterior edge of the haemal spine of the fifth caudal vertebra. The second to fifth pterygiophores have their flattened ventral regions in the midvertical plane, but their long rodlike anterodorsally directed portions lie to the right or to the left of the midline in the anterior portion of the large muscle mass connected to the anal fin (only the two pterygiophores that diverge to the left are shown in the figure of the lateral view of the entire skeleton). The anterodorsal rodlike portion of the first anal fin basal pterygiophore is placed only very slightly to one side of the midvertical plane, either to the right or to the left depending on the individual. The ventral edge of its rodlike portion is expanded into a low and thin keel throughout most of its length. The first pterygiophore has by far the largest distal end of any of the pterygiophores. Its base is expanded anterolaterally to either side to form a U-shaped projection which lies just under the cuirass. In large specimens the usually rodlike dorsal portions of the second to fifth pterygiophores may become laterally expanded into thin flanges in the region where these pterygiophores converge toward the midvertical plane of the body.

Anatomical diversity.-The carapace extends well behind the level of the posterior ends of the dorsal and anal fins and completely encloses the fin bases in all species of the family except Lactophrys trigonus, the latter having the carapace somewhat extended beyond the dorsal and anal fin bases but only completely closed behind the anal fin. Posterior to the dorsal fin in $L$. trigonus the two posterodorsal extensions of the carapace often closely approach one another in the midline, especially in large specimens, and are separated from one another and from the anterior half of the large free plate that lies just behind the dorsal fin only by a very narrow scaleless space. In one especially large specimen of $L$. trigonus examined (ANSP 102757, $366 \mathrm{~mm}$ ) externally, the posterodorsal extensions of the carapace and the usually free plate are in intimate contact and are as fully interdigitated with one another as are the other scale plates of the carapace, the carapace in this specimen forming a complete wide bridge over the caudal peduncle behind the dorsal fin.

In most genera (Acanthostracion, Rhinesomus, Lactophrys, Tetrosomus) the carapace has a basically triangular shape, the horizontal distance between the ventrolateral ridges being greater than between the dorsolateral ridges, with the carapace extended above into a dorsal ridge. A mediolateral ridge is scarcely devel- 
Figure 150.-Acanthostracion quadricornis: lateral view of head, composite based on several specimens, $\mathbf{5 8 . 2 - 3 5 0} \mathrm{mm}$ SL, Gulf of Mexico and Caribbean.

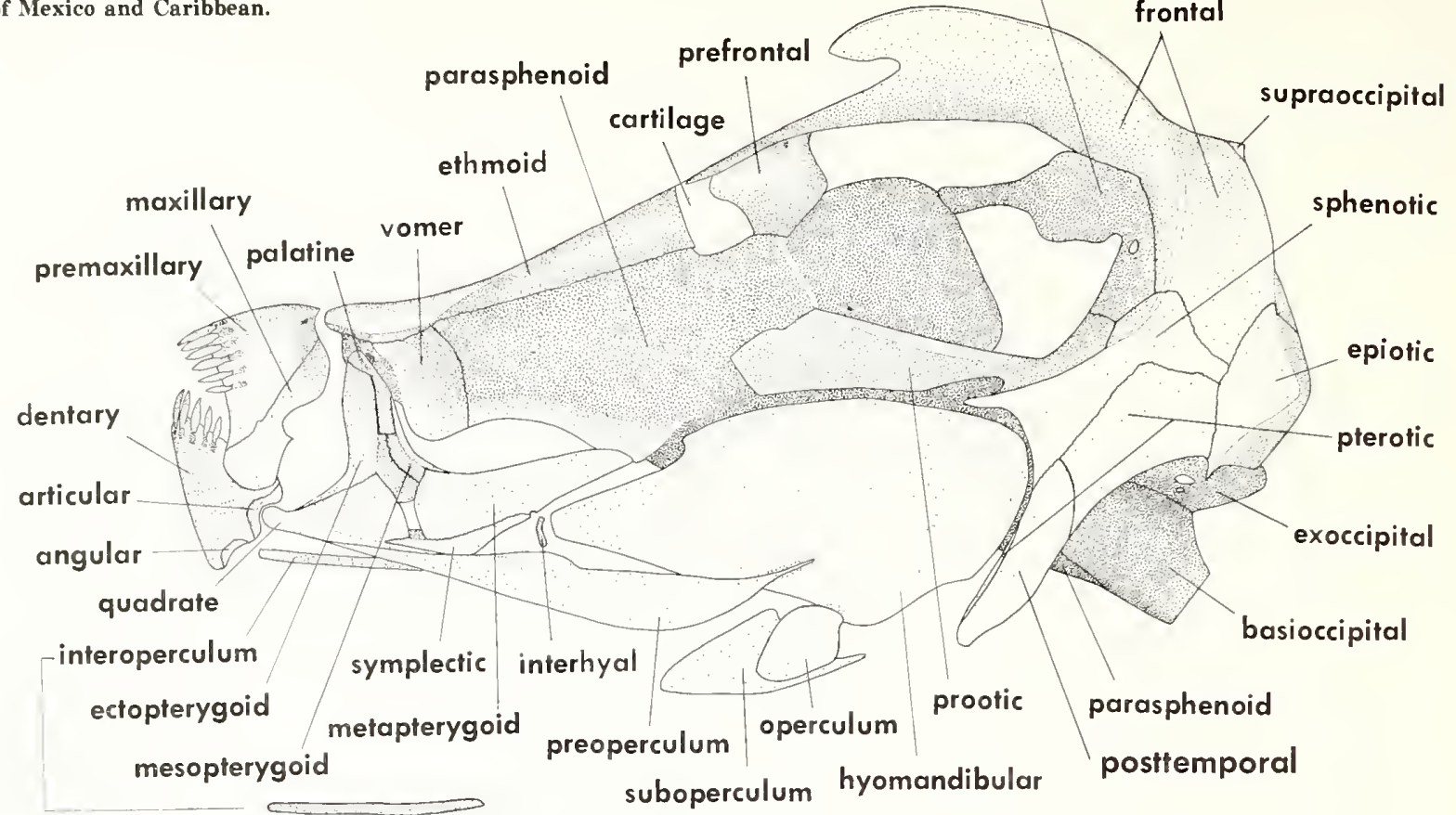

essentially being absent. Two other genera are in various ways intermediate between the two extremes of carapace shape. In Lactoria the carapace is basically pentagonal, with the distance between the ventrolateral ridges much greater than that between the dorsolateral ridges, but with only a low dorsal ridge, extended in two species (fornasinii and diaphana) into a prominent spine. In Rhynchostracion the carapace in one species (rhinorhynchus) is as rectangular as in Ostracion, while in the other species (nasus) there is a prominent and relatively high dorsal ridge so that the carapace is pentagonal. In the pentagonal carapace of $R$. nasus the distance between the ventrolateral ridges is only very slightly greater than that between the dorsolateral ridges and this shape may be most closely related to the rectangular form, while the pentagonal carapace of Lactoria, with the distance between the ventrolateral ridges much greater than that between the dorsolateral ridges, may be most closely related to the triangular form.

Isolated scale plates on the caudal peduncle behind the carapace are found only in Acanthostracion quadricornis (commonly) and in $A$. polygonius (rarely, see Tyler 1965a:8), in addition, of course, to the single large plate found in Lactophrys trigonus, discussed above.

In the only known fossil specimen of ostraciid, Eolactoria sorbinii from the Eocene of Monte Bolca, Italy, it is impossible to say with assurity whether the carapace was triangular, pentangular, or rectangular. However, there is a slight indication (Tyler 1973a:108) that the scale plates along the region that would be the dorsolateral ridge had larger central tubercules or spines than the surrounding plates, suggesting that the dorsolateral ridge was prominent and that there was a dorsal crest, the carapace perhaps being pentangular as in the Recent Lactoria and Rhynchostracion rhinorhynchus.

Spiny processes are present on the carapace except in Ostracion, Rhynchostracion, and Rhinesomus triqueter. In Acanthostracion, Lactoria, and the Eocene Eolactoria there are paired preorbital and postanal spines, with Eolactoria having in addition an unpaired anteriorly directed spine between the eyes and Lactoria having a well-developed spine on the dorsal ridge in some species. In Lactophrys and Rhinesomus bicaudalis there are postanal spines, while in Tetrosomus there are three to five spines along the ventrolateral ridge, a supraorbital spine and one or two spines along the dorsal ridge.

In general, the carapace of ostraciids is slightly more fully consolidated than in aracanids, the only region with much flexibility and unsutured scale plates being the cheek, whereas in aracanids many of the scale plates around the mouth and along the ventral region and around the anus are often unsutured and slightly flexible.

The number of teeth is slightly variable in ostraciids, which tend to have a few more teeth in the jaws, especially the upper, than in aracanids. Most ostraciids have 10 to 12 teeth in the upper jaw and 8 to 10 in the lower jaw. There is only a slight tendency for an increase in the number of teeth with increasing specimen size, except in Lactoria diaphana, a relatively small species which at sizes below about $30 \mathrm{~mm}$ tends to have 10 to 12 teeth in the upper jaw and 6 to 7 in the lower jaw, but at larger sizes to have about 13 to 16 in the upper and 7 to 9 in the lower. The numbers of teeth in the upper and lower 


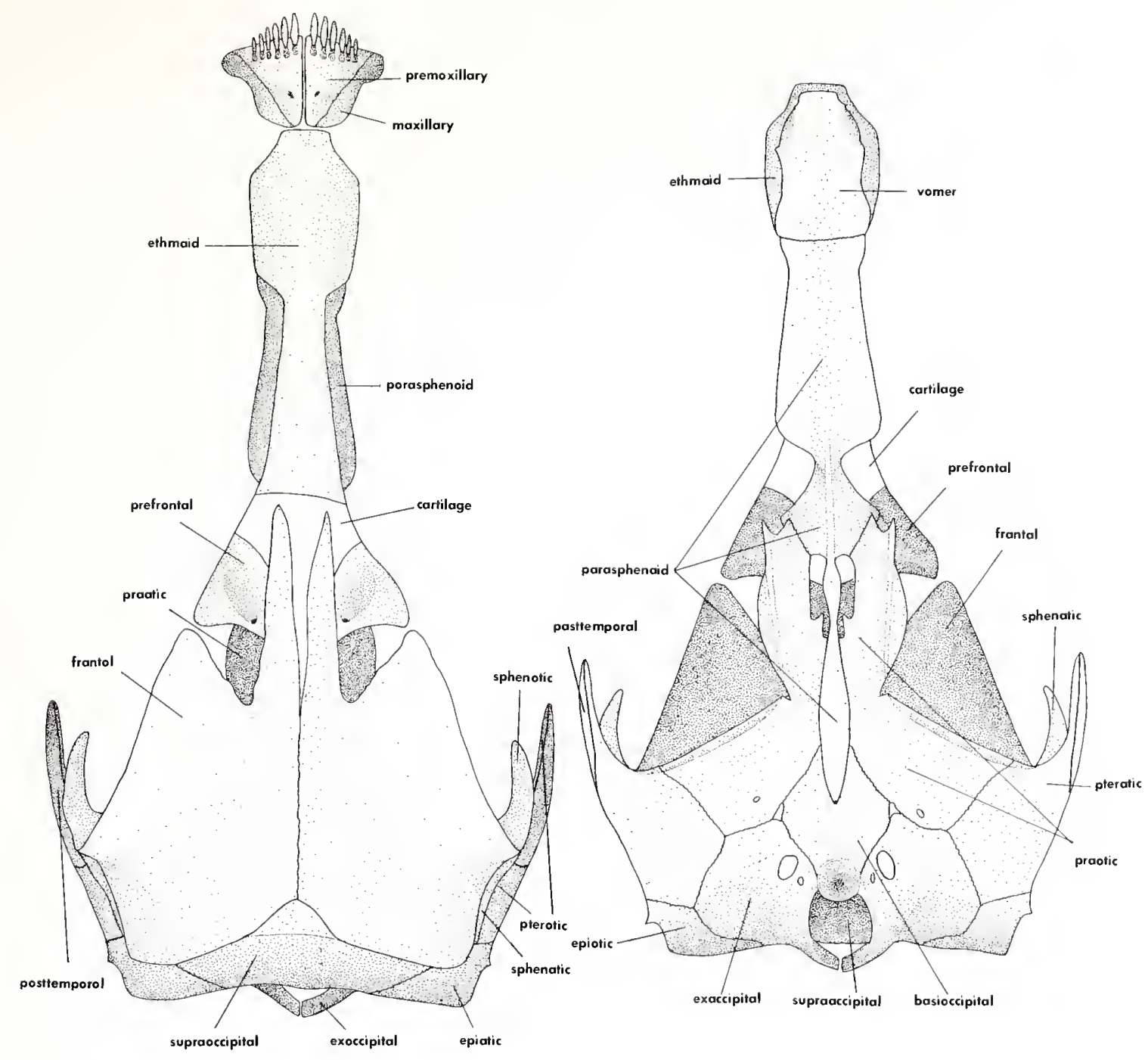

jaws of those species for which the most counts were made are shown in Table 3 and Figures 165-166 (for Lactoria cornuta, $L$. fornasinii, and $L$. diaphana; Ostracion tuberculatus and $O$. lentiginosum; Acanthostracion quadricornis and A. polygonius; Lactophrys trigonus; and Rhinesomus triqueter and $R$. bicaudalis). There is nothing out of the ordinary in the tooth counts recorded for the fewer specimens of the other species of ostraciids examined but not listed above. In the Eocene Eolactoria the total number of teeth in the jaws is not known, but they seem to be slightly wider basally and more decidedly constricted distally or cusped than in the Recent species, somewhat reminiscent of the teeth of balistids (Tyler 1973a).

In all species of the Indo-Pacific genera (Lactoria, Tetrosomus, Ostracion, and Rhynchostracion) the dorsal and anal fin rays are modally 9 and the pectoral fin rays modally 10 , excluding the uppermost rudimentary pectoral ray. In all of the species of the Atlantic genera (Acanthostracion, Rhinesomus, and Lactophrys) the dorsal and anal fin rays are modally 10 and the pectoral fin rays modally 12 in all but Acanthostracion quad-

Figure 151.-Acanthostracion quadricornis: dorsal (left) and ventral views of skull, composite based on several specimens, $58.2-350 \mathrm{~mm}$ SL, Gulf of Mexico and Caribbean.

ricornis, which has only 11 (see Tyler 1965a, b). Correlated with the differences in the number of dorsal and anal fin rays are similar differences in the number of basal pterygiophores. In the Indo-Pacific genera there are modally eight dorsal and anal fin basal pterygiophores and in the Atlantic genera nine. In both cases the anterior divergent anal fin basal pterygiophores number five. When one more than the modal number of rays is present, there is also often one additional basal pterygiophore.

In all ostraciids there are two nostrils on each side, nearly always in the form of two short upright tubes. However, in Rhinesomus bicaudalis the anterior tube is extremely bulbous (see Böhlke and Chaplin 1968:678, fig. 212; and Fig. 159 here) at all specimen sizes, while in Lactophrys trigonus it becomes bulbous, to about half the extent of that in $R$. bicaudalis, in large specimens. 


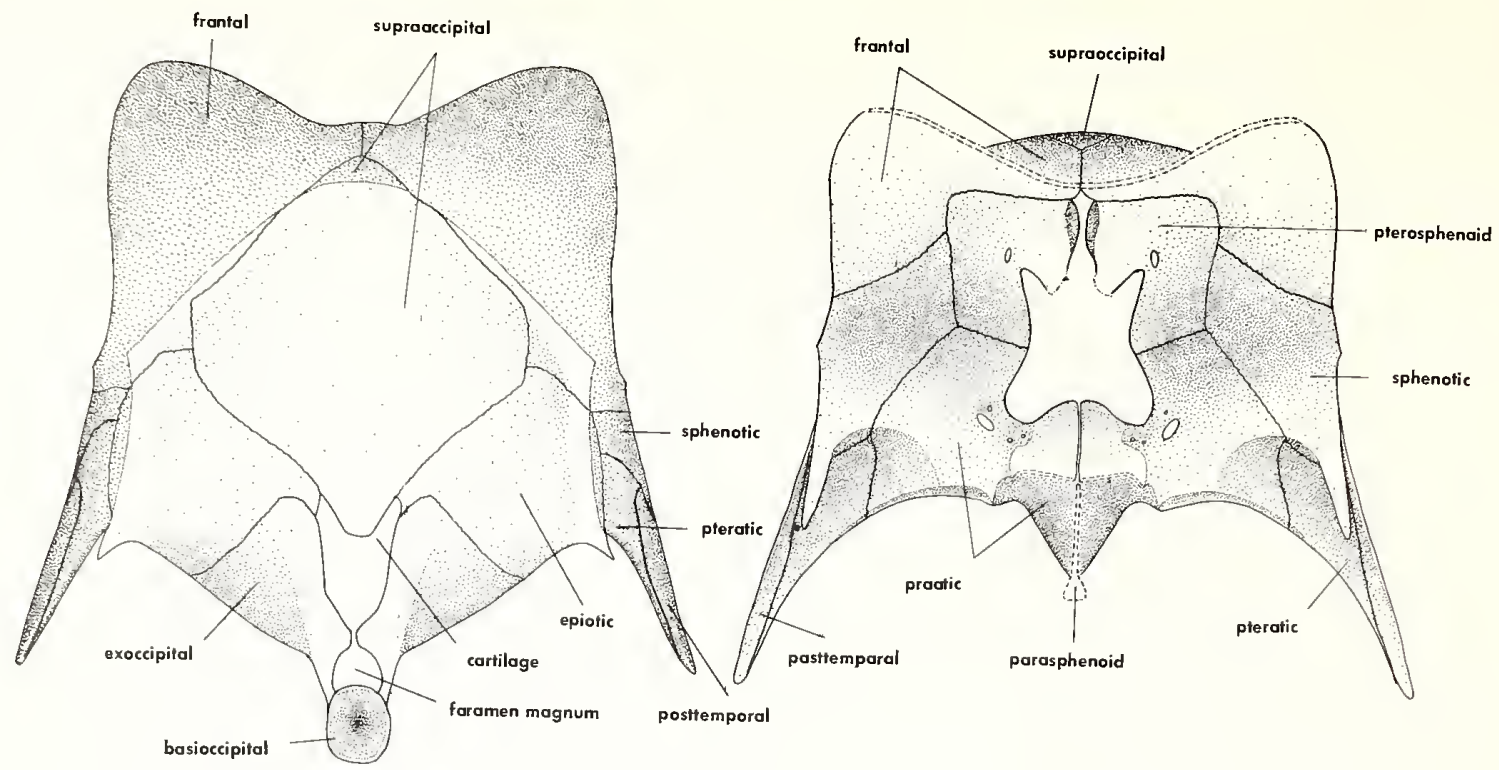

Figure 152.-Acanthostracion quadricornis: posterior views of skull (left) and of orbit (right) (cross section of skull; dashed lines represent cut surfaces of frontals, pterosphenoids, prootics, and parasphenoid), composite based on several specimens, 58.2-350 $\mathrm{mm} \mathrm{SL}$, Gulf of Mexico and Caribbean.
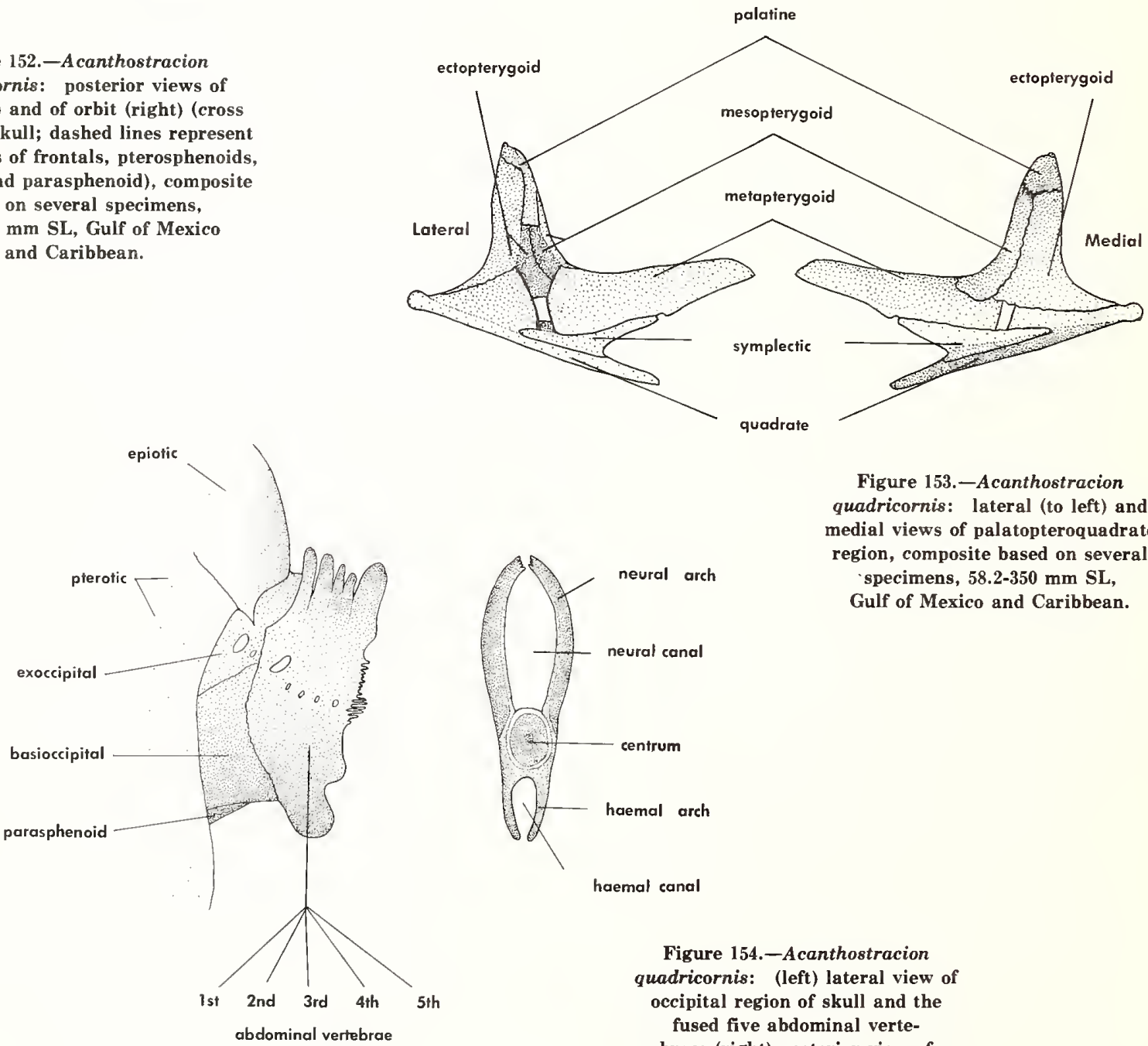

Figure 153.-Acanthostracion quadricornis: lateral (to left) and medial views of palatopteroquadrate region, composite based on several specimens, 58.2-350 mm SL, Gulf of Mexico and Caribbean

haemal canal

Figure 154.-Acanthostracion quadricornis: (left) lateral view of occipital region of skull and the

fused five abdominal verte-

brae; (right) posterior view of fused first five abdominal vertebrae; 77.7 mm SL, Florida. 


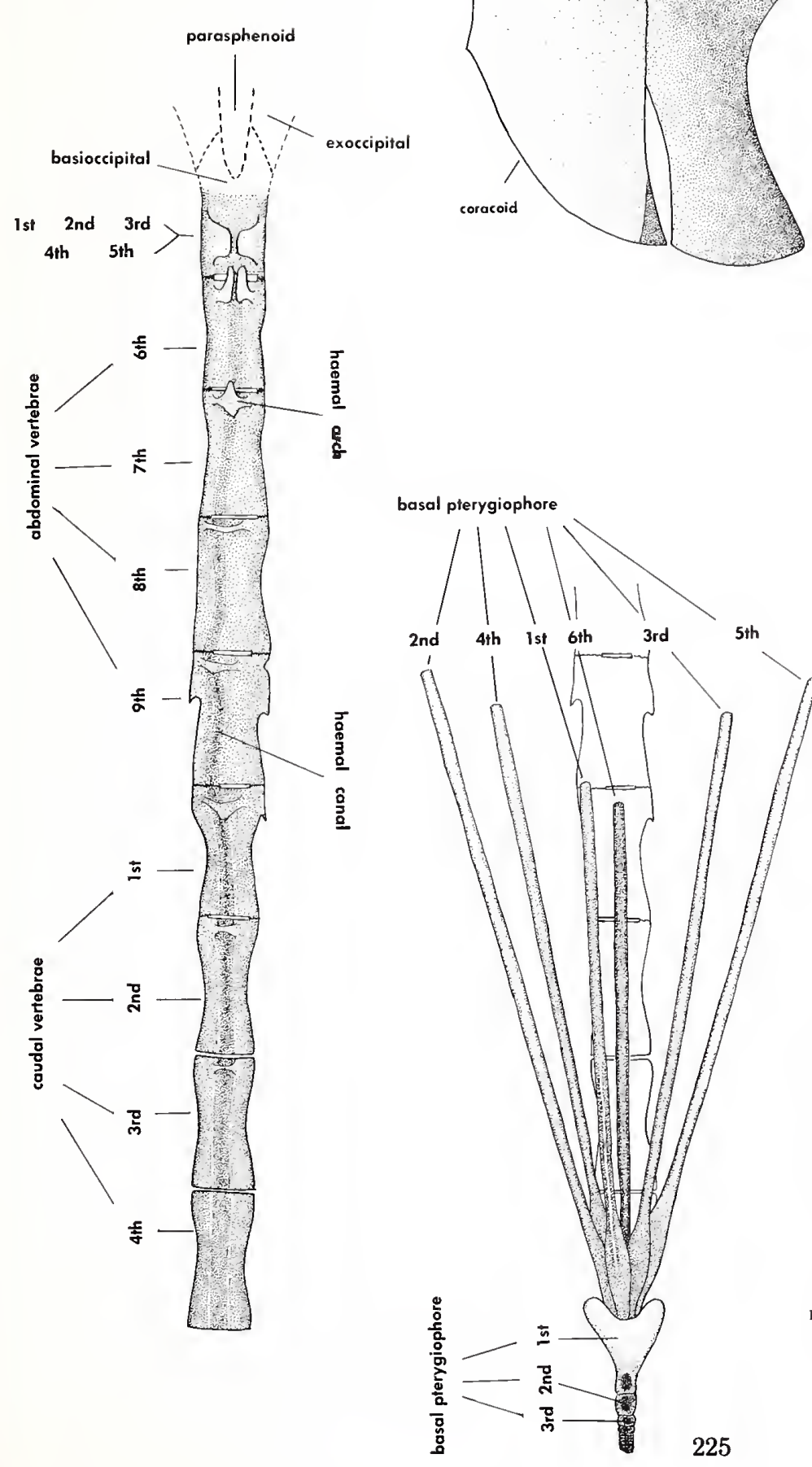

Figure 155.-Acanthostracion quadricornis: medial (left) and lateral (right) views of pectoral girdle, composite based on several specimens, $58.2-350 \mathrm{~mm} \mathrm{SL}$, Gulf of Mexico and Caribbean.

Figure 156.-A canthostracion quadricornis: above, ventral view of vertebral column from the fused first five abdominal vertebrae to the fourth caudal vertebra, showing the haemal spines and the displacement of the haemal canal; below, ventral view of the basal pterygiophores of the anal fin, showing the displacement of the more anterior pterygiophores to the left and to the right of the midline; composite based on several specimens, 58.2-350 mm SL, Gulf of Mexico and Caribbean. 


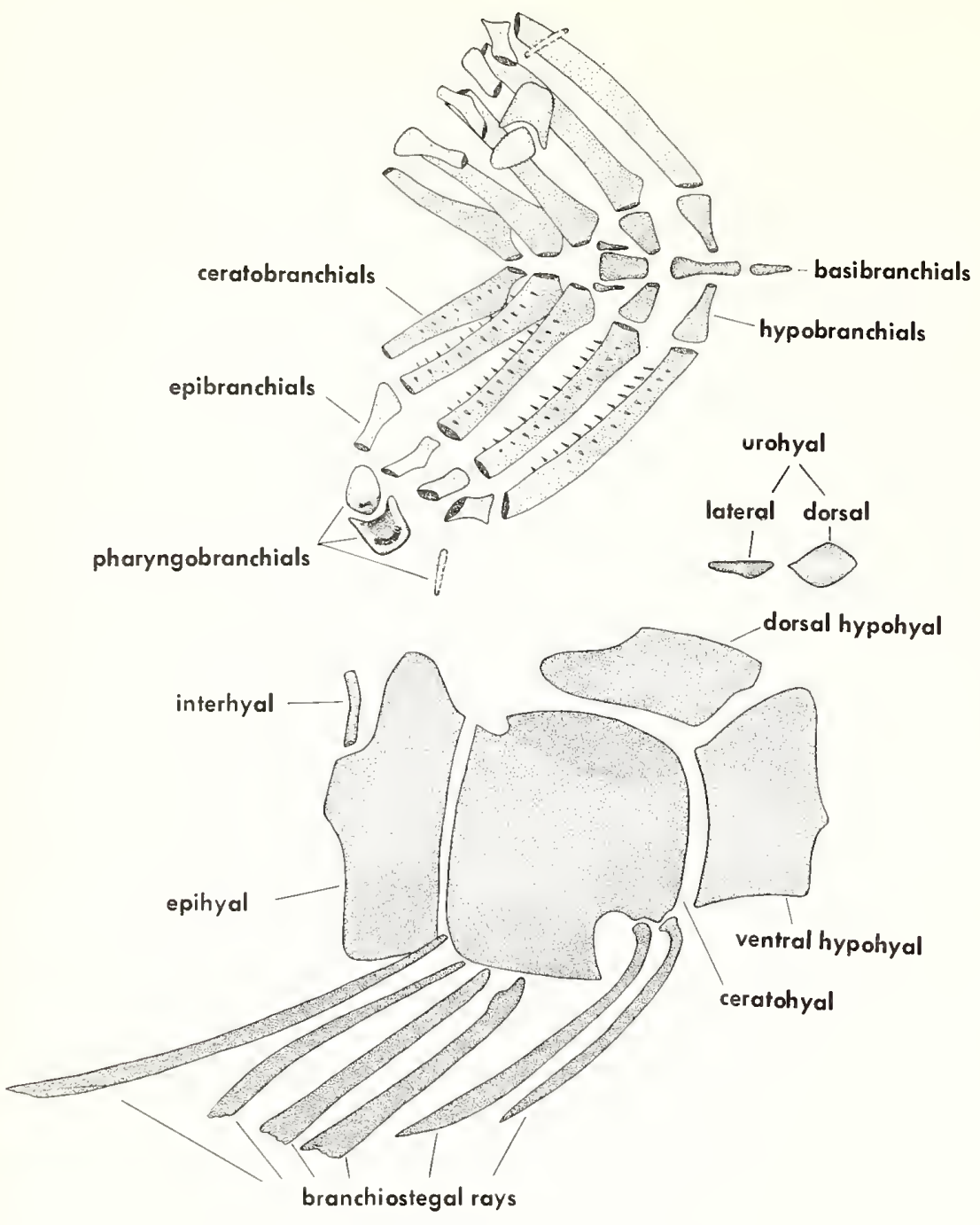

Figure 159. (opp. page)-External features of other representative ostraciid genera: A, Rhinesomus bicaudalisupper left, nasal region as seen externally and, lower left, outline of cross section of middle of body: B, $R$. triqueterto show the course of the inconspicuous lateral line canals and their major pores, as decifered by placing drops of ink on each pore found by microscopic search of a partially drying specimen; C, $R$. triqueterupper left, nasal region as seen externally and, lower left, outline of cross section of middle of body, with pattern of scale plates shown only behind pectoral fin on main body illustration.

Figure 157.-Acanthostracion quadricornis: dorsal view of branchial arches (extended on lower side); lateral view of hyoid arch; lateral and dorsal views of urohyal; composite based on several specimens, $58.2-350 \mathrm{~mm}$ SL, Gulf of

Mexico and Caribbean.

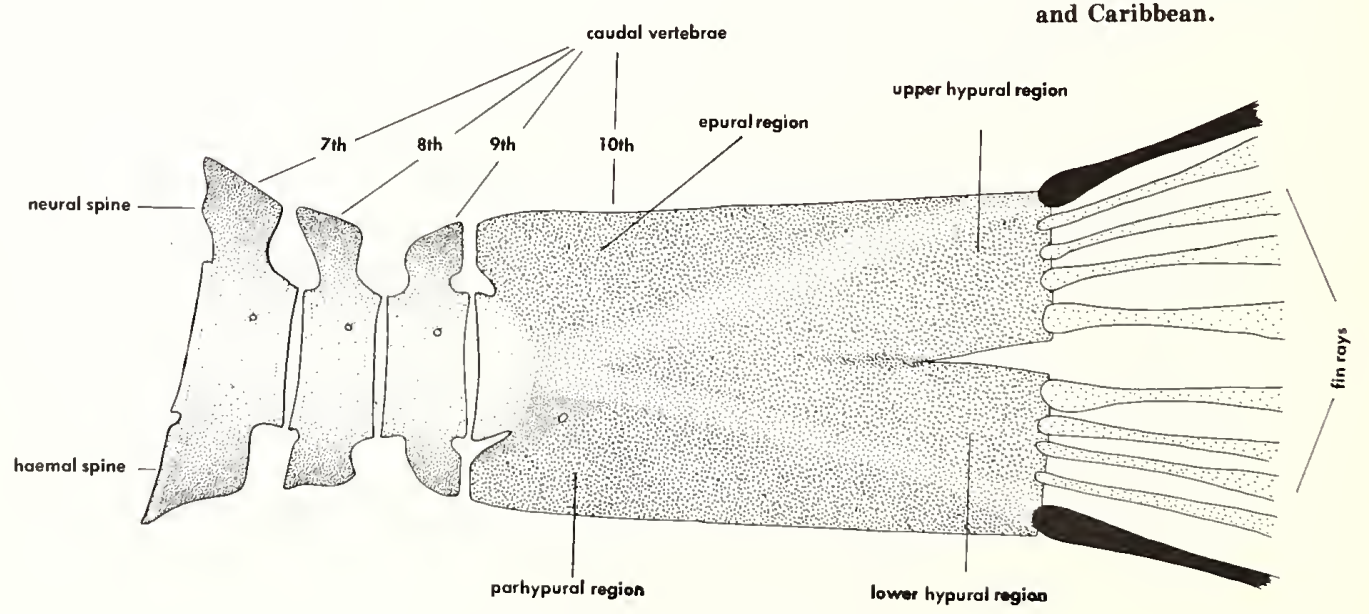

Figure 158.-Acanthostracion quadricornis: lateral view of caudal fin supporting structures, composite based on several specimens,

58.2-350 mm SL, Gulf of Mexico and Caribbean. 

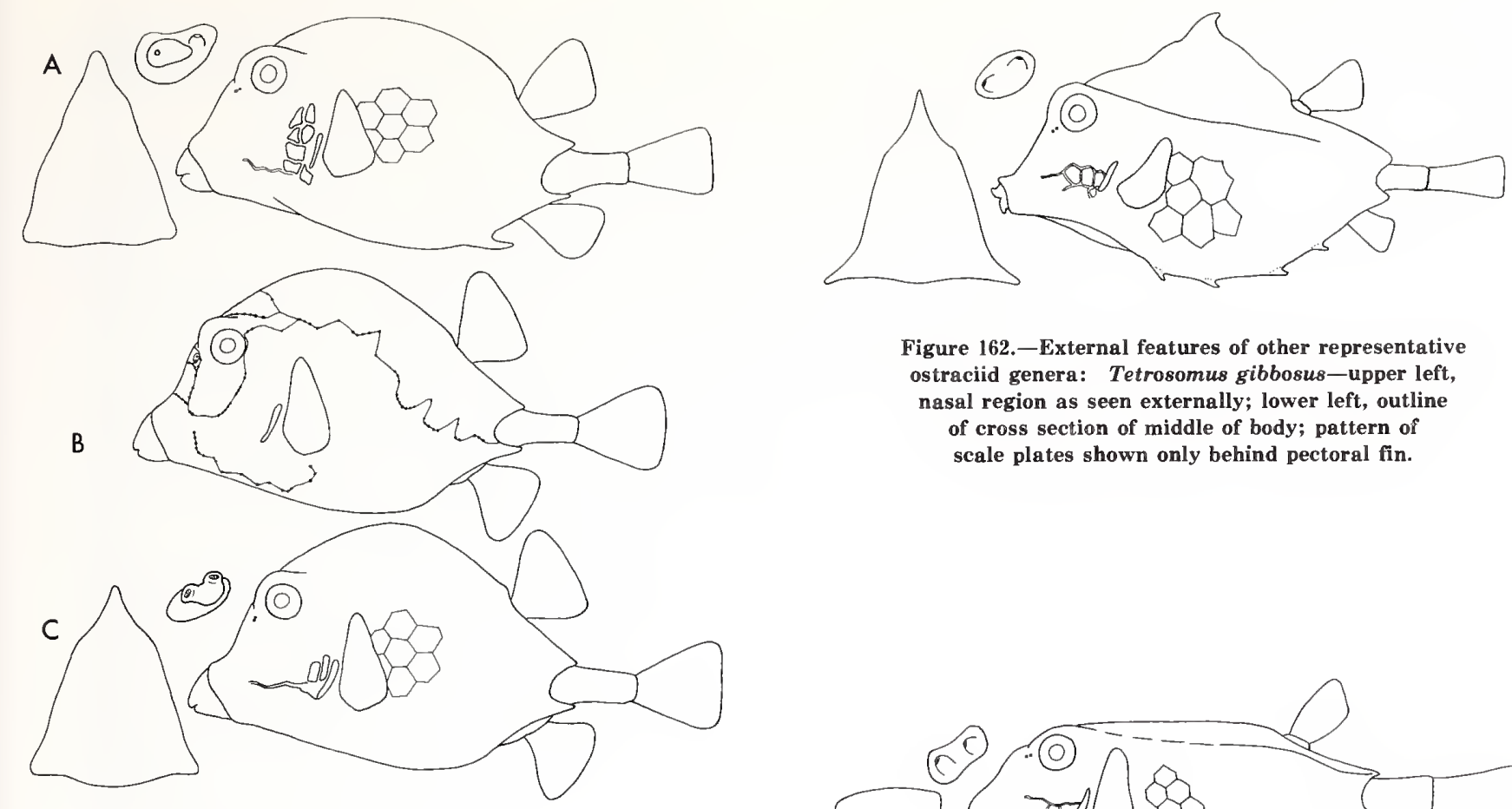

Figure 162.-External features of other representative ostraciid genera: Tetrosomus gibbosus-upper left, nasal region as seen externally; lower left, outline of cross section of middle of body; pattern of scale plates shown only behind pectoral fin.

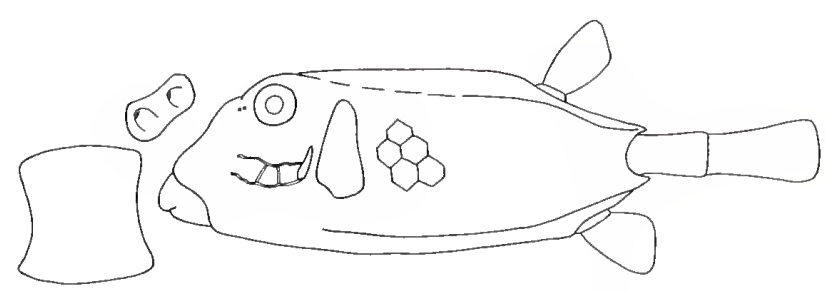

Figure 163.-External features of other representative ostraciid genera: Ostracion lentiginosum-upper left, nasal region as seen externally; lower left, outline of cross section of middle of body; pattern of scale plates shown only behind pectoral fin.

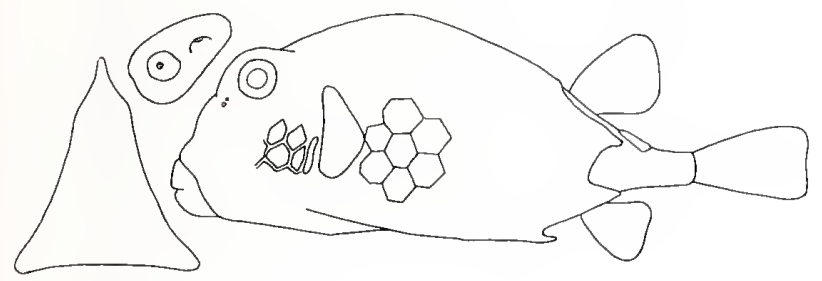

Figure 160.-External features of other representative ostraciid genera: Lactophrys trigonus-upper left, nasal region as seen externally; lower left, outline of cross section of middle of body; pattern of scale plates shown only behind pectoral fin.

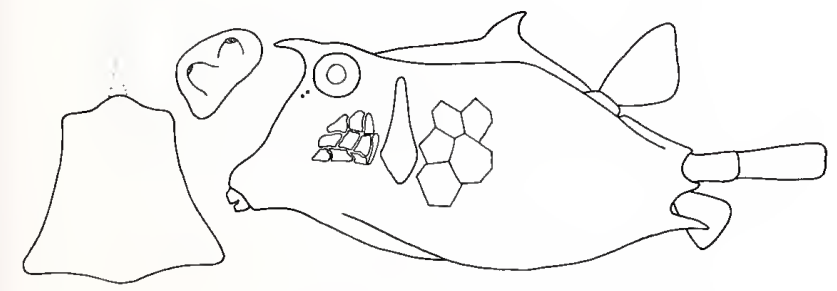

Figure 161.-External features of other representative ostraciid genera: Lactoria fornasini-upper left, nasal region as seen externally; lower left, outline of cross section of middle of body; pattern of scale plates shown only behind pectoral fin.

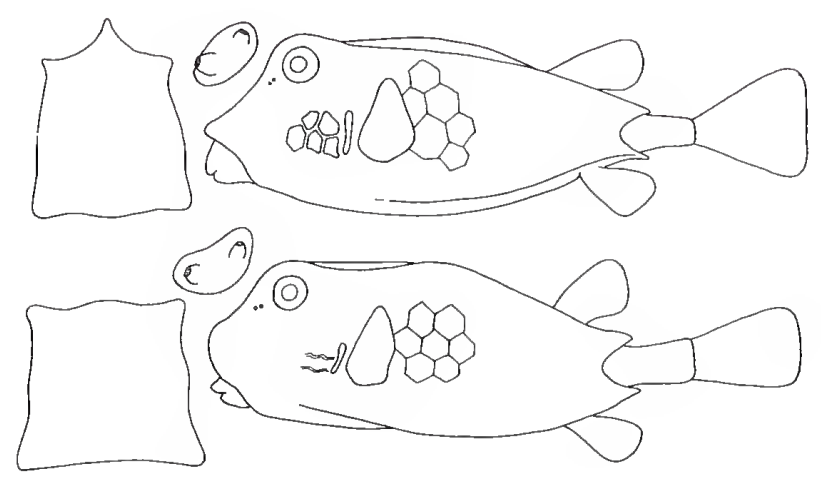

Figure 164.-External features of other representative ostraciid genera: Rhynchostracion nasus (above) and $\boldsymbol{R}$. rhinorhynchus-in both cases, upper left, nasal region as seen externally; lower left, outline of cross section of middle of body; pattern of scale plates shown only behind pectoral fin. 


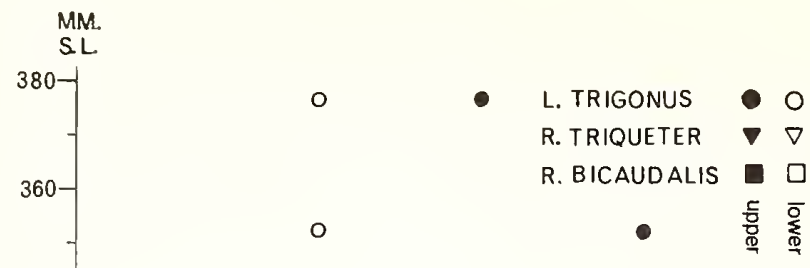

$-340-1$

(320-

300

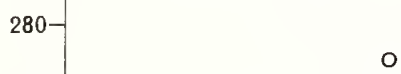

260

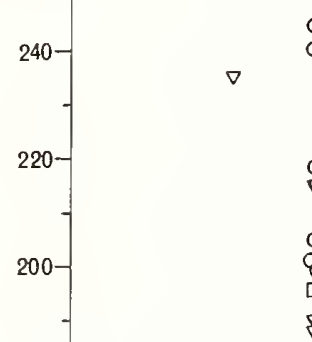

$180-1$

160
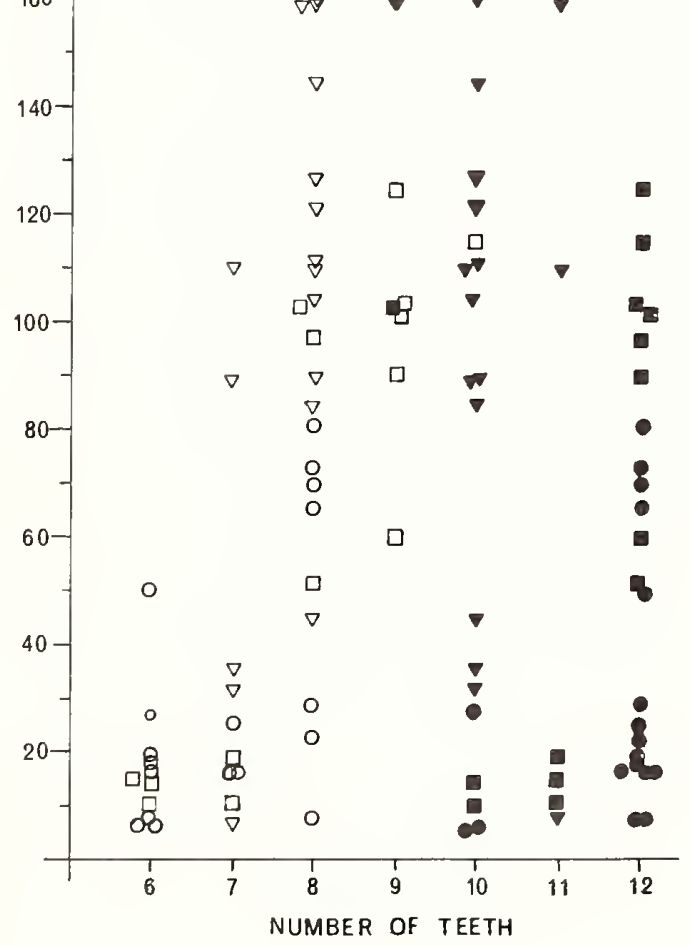

The fundamental plan of the skull is even more conservative in the ostraciids than in the aracanids, and nearly all of the differences between the species to be pointed out involve the vertebral column.

In all of the species of the Indo-Pacific genera ( Lactoria, Tetrosomus, Ostracion, and Rhynchostracion) a small but distinct myodome is present, while in all of the species of the Atlantic genera (Acanthostracion, Rhinesomus, and Lactophrys) the myodome is essentially absent. In the Atlantic species there is no anterodorsal roof to the prootic at the appropriate place over the posterior eye muscles, although in the rear of the orbit where the prootics are in contact medially the two bones are curved upward to form a shallow concavity bounded posteriorly by a low crest, which region can be considered as the posterior and posterodorsal walls of a rudimentary myodome. If these surfaces of the prootics in the Atlantic species were a little more concave and the posterior myodome region more uplifted and anterodorsally oriented, a small myodome could be said to be present, but such is not quite the case. In the Indo-Pacific species a small and shallow myodome is more distinctly present. In all of the species of the more generalized family Aracanidae, a small but distinct myodome is present.

In all of the Indo-Pacific species at least two of the vertebrae posterior to the last which helps support the last dorsal fin basal pterygiophore have trifid neural spines, while none of the neural spines are trifid or even bifid in the Atlantic species. The greatest number of trifid neural spines is found in Lactoria cornuta, in which the 14 th to 17 th vertebrae have them. In $L$. fornasinii there is one less, the trifid spines being present on the 14 th to 16 th vertebrae. In Tetrosomus concatenatus and $T$. gibbosus well-developed trifid neural spines are present on the 15th and 16th vertebrae, and a less strongly developed one may be present or absent on the 17th vertebra. In Ostracion lentiginosum they are trifid on the 15 th to 17 th vertebrae, as they also are in 0 . tuberculatus and Rhynchostracion rhinorhynchus, except that the spine of the 17th vertebrae is sometimes single rather than trifid. The trifid neural spines apparently afford a broader surface of support for the carapace in this region than does the single neural spine.

In all of the Atlantic species and in the Indo-Pacific Lactoria fornasinii the first five vertebrae are involved in the fusion complex with the base of the skull, while all of the Indo-Pacific species except $L$. fornasinii have only the first four vertebrae involved in the fusion complex. Of the two species of Ostracion examined, at least one has slightly less fusion between the first four vertebrae than in the other Indo-Pacific species. In Ostracion tuberculatus the first two vertebrae are fully fused to one

Figure 165.-Number of teeth in upper (solid symbols) and lower (open symbols) jaws in relation to standard length, to show the slightly greater number of teeth in the upper versus the lower jaw, and the relatively negligible increase in number of teeth with increasing standard length at sizes greater than about $40 \mathrm{~mm}$ SL; Lactophrys trigonus, Rhinesomus triqueter, $R$. bicaudalis. 


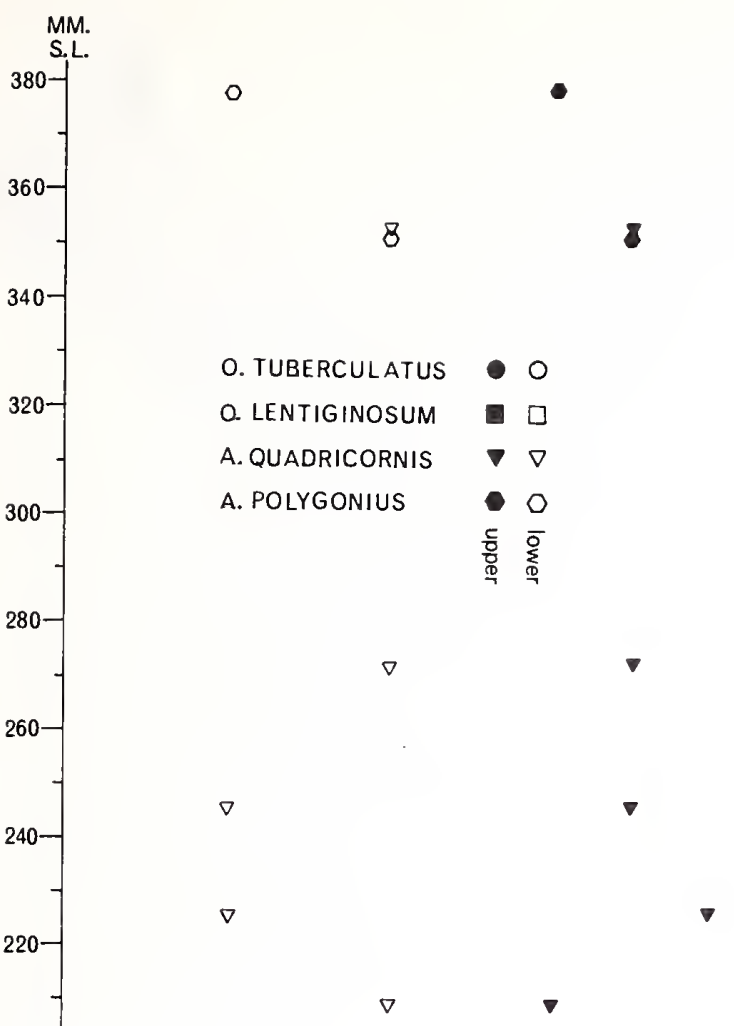

another and to the basioccipital and exoccipital basally, while distally there is only partial fusion of their neural spines. The third and fourth vertebrae are similarly fully fused with one another basally, while their neural spines are only partially fused. The degree of fusion of the neural spines increases with increased specimen size, much as described by Tyler (1963a) for Acanthostracion quadricornis. But even in the two largest specimens of $O$. tuberculatus examined $(96.7-122 \mathrm{~mm}$ ) the fused firstsecond vertebrae and the fused third-fourth vertebrae remain distinct from one another. In $O$. lentiginosum the two smallest specimens examined (24.4-33.2 $\mathrm{mm}$ ) have the first and second vertebrae fully fused to themselves and to the basioccipital and exoccipital basally, with the neural spines only partially fused, and the third and fourth vertebrae are similarly fused to themselves, with the second and third remaining separate. But in all of the larger specimens $(68.2-115 \mathrm{~mm})$ the fused first-second vertebrae and the fused third-fourth vertebrae are at least partially fused together between the second and third, and in the largest specimens almost completely fused. However, this variously partial to almost complete fusion between the two fusion complexes in $O$. lentiginosum is less complete and occurs at a larger specimen size than in the other Indo-Pacific genera.

The divergence of the haemal canal away from the midline under most of the unfused abdominal vertebrae is highly variable. There follows a listing of the course of the divergence in the specimens closely examined for it: Tetrosomus concatenatus, to the right of the midline in 1 specimen; $T$. gibbosus, left in 1 ; Lactoria cornuta, right in 4, left in 1, alternately right and left in 2, almost straight in $1 ; L$. fornasinii, right in 1 , essentially straight in 2; Ostracion lentiginosum, right in 4, left in 1; 0 . tuberculatus, right in 5; Rhynchostracion rhinorhynchus, right in 1; Acanthostracion quadricornis, right in 6 , left in 2; A. polygonius, right in 1, alternately right and left in $1 ; A$. guineensis, alternately right and left in $1 ; A$. notacanthus, right in 1; Lactophrys trigonus, right in 2, left in 1, alternately right and left in 2; Rhinesomus bicaudalis, left in $2 ; R$. triqueter, left in 2 , alternately right and left in 2, almost straight in 1 . Thus, in both the Indo-Pacific species and in the Atlantic species, the canal can be diverted to either the right or left, or alternately to the right and left. If enough specimens were examined it might be possible to show that there was a greater frequency of right deviation in the Indo-Pacific species and of left or alternately right and left deviation in the Atlantic species, but such cannot yet be done.

The structure of the last few vertebrae shows interesting variation, as described by Tyler (1970b) and briefly

Figure 166.-Number of teeth in upper (solid symbols) and lower (open symbols) jaws in relation to standard length, to show the slightly greater number of teeth in the upper versus the lower jaw, and the relatively negligible increase in number of teeth with increasing standard length at sizes greater than about $40 \mathrm{~mm}$ SL: Ostracion tuberculatus, O. lentiginosum, Acanthostracion quadricornis, A. polygonius. 


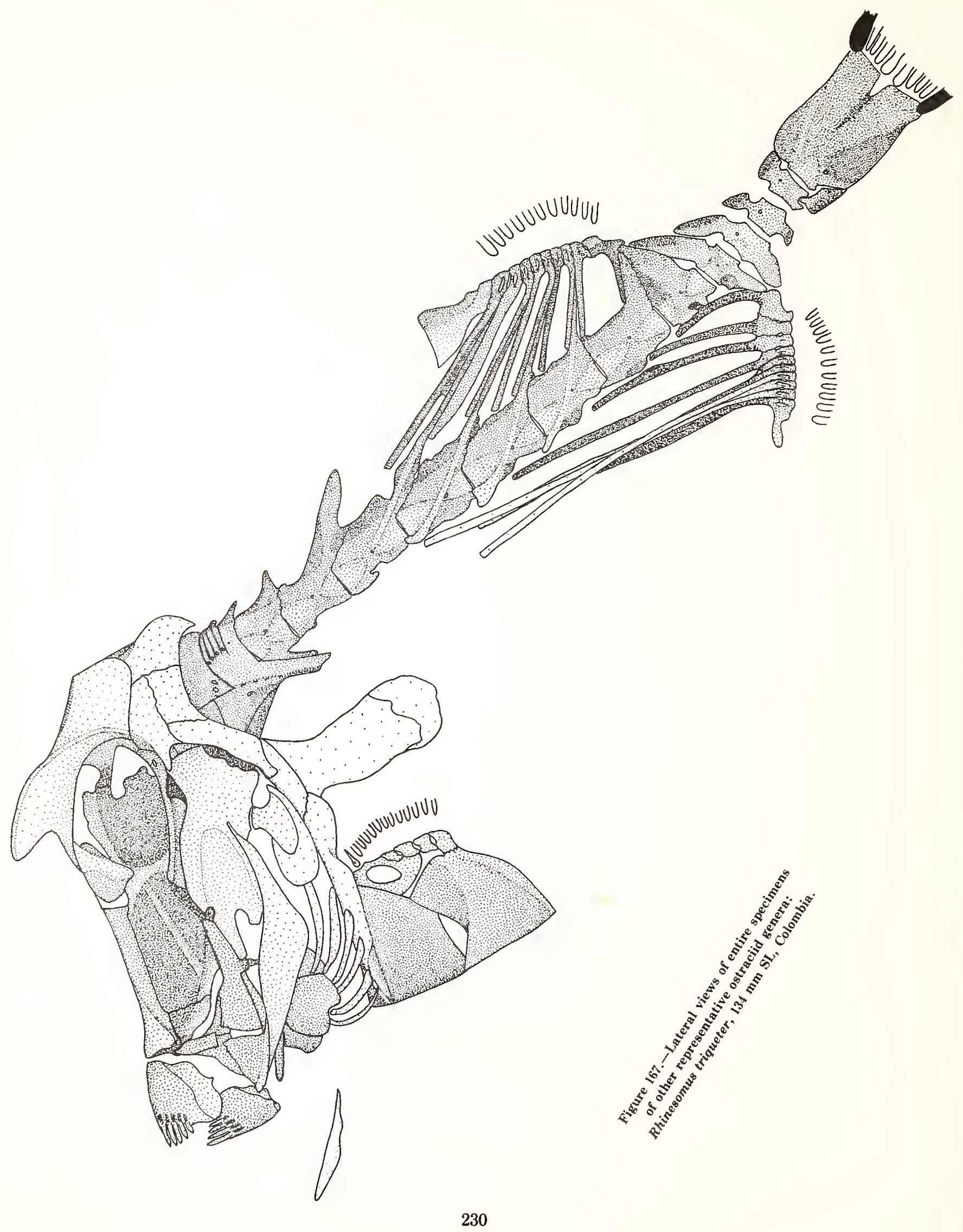




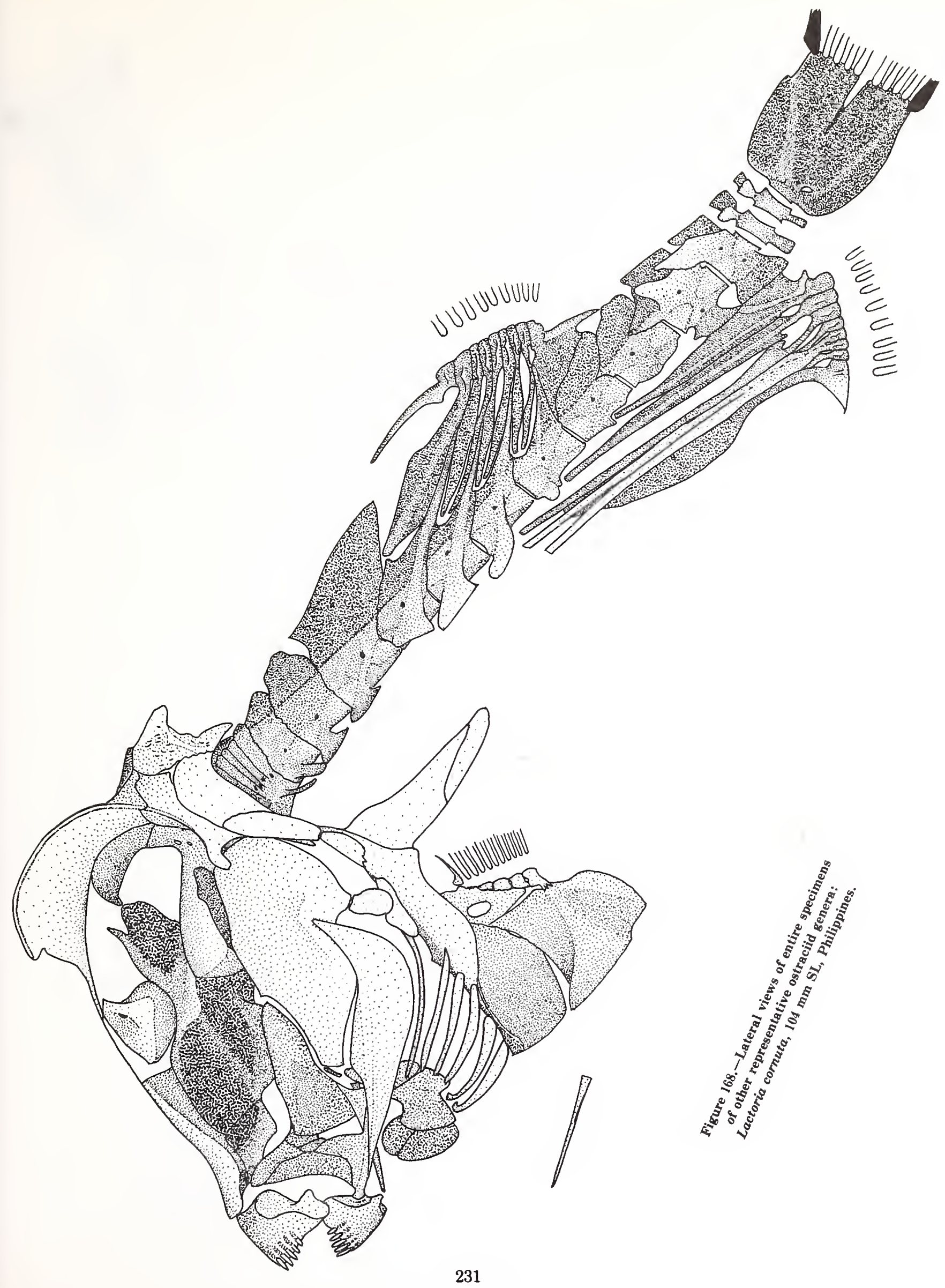




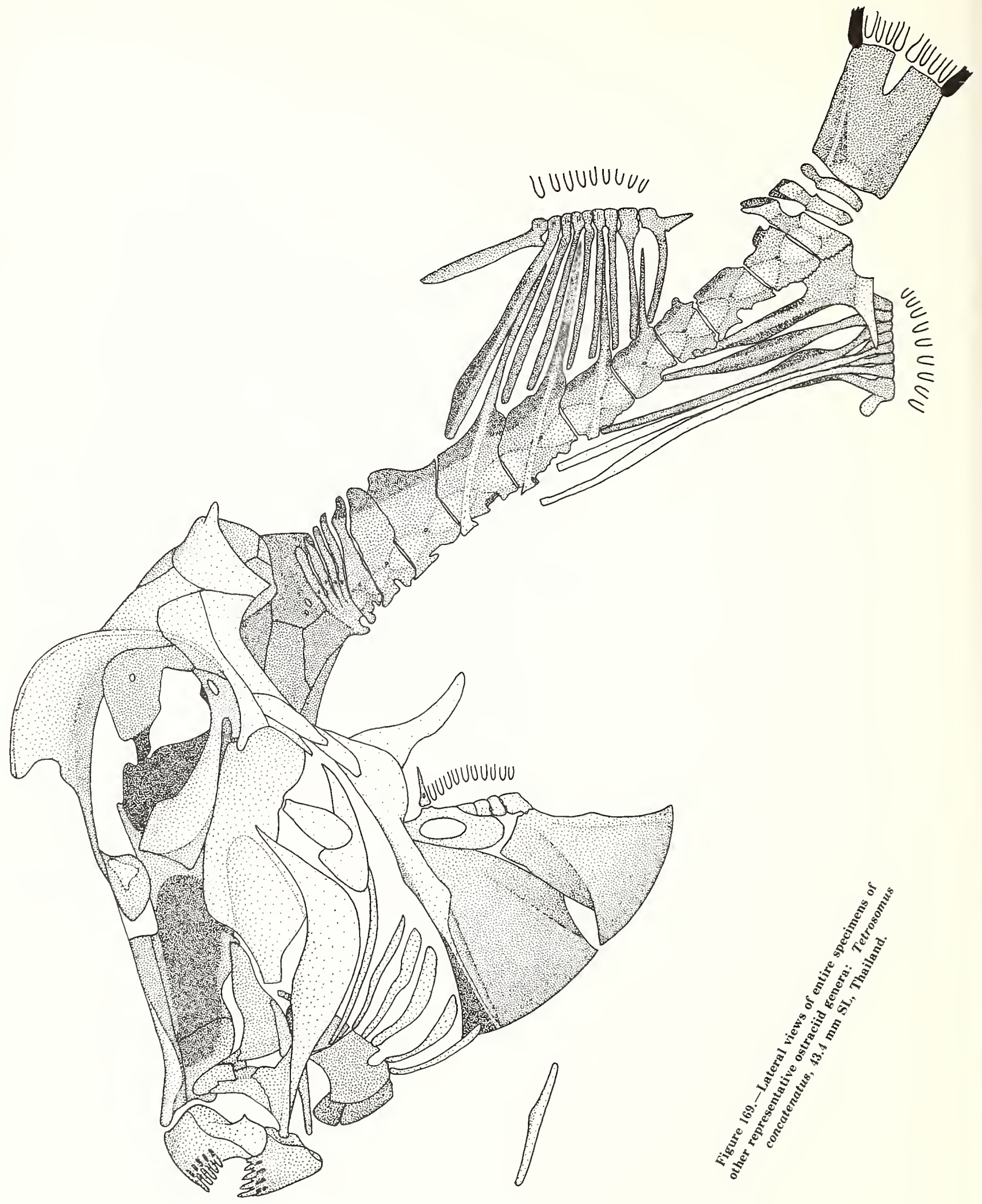




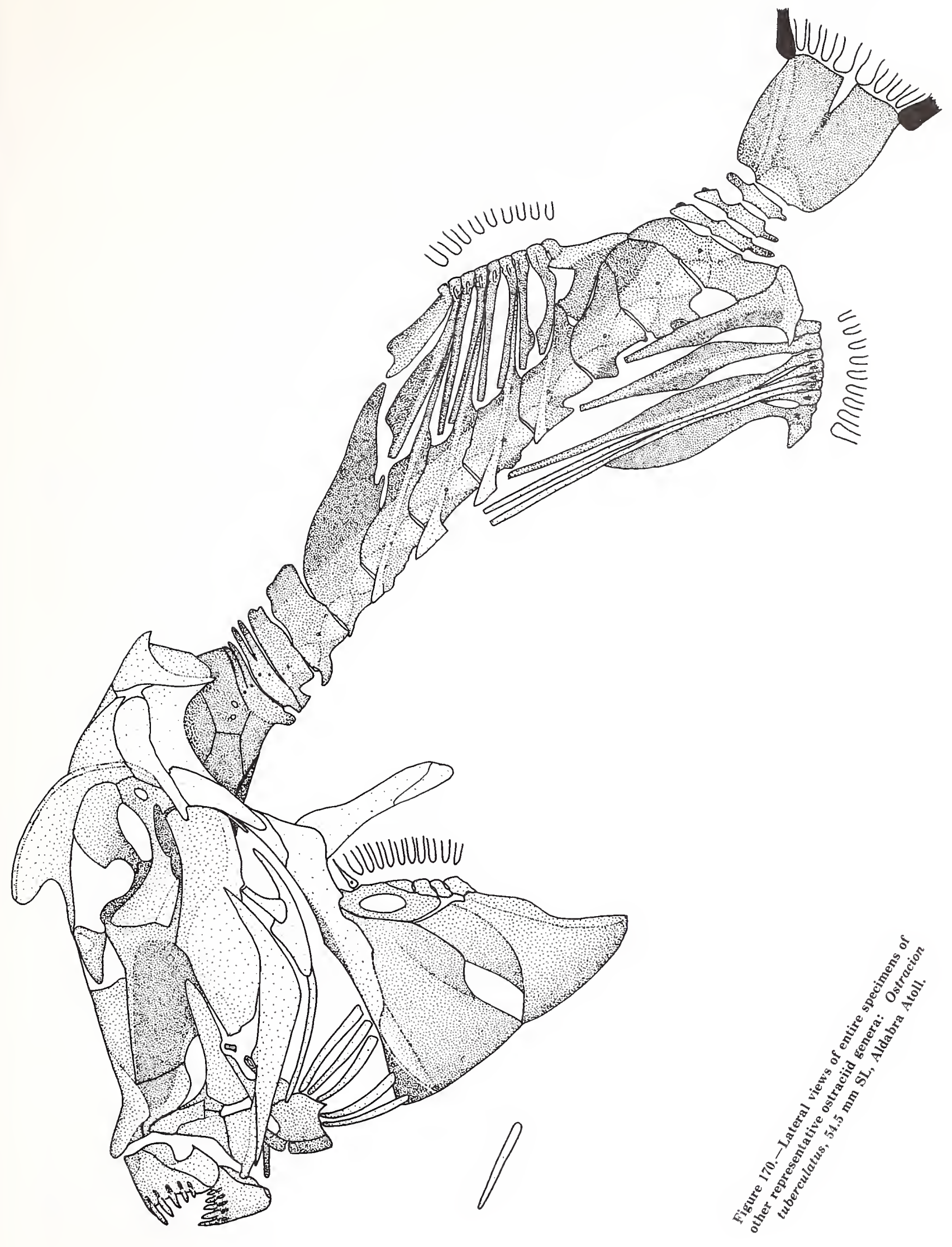




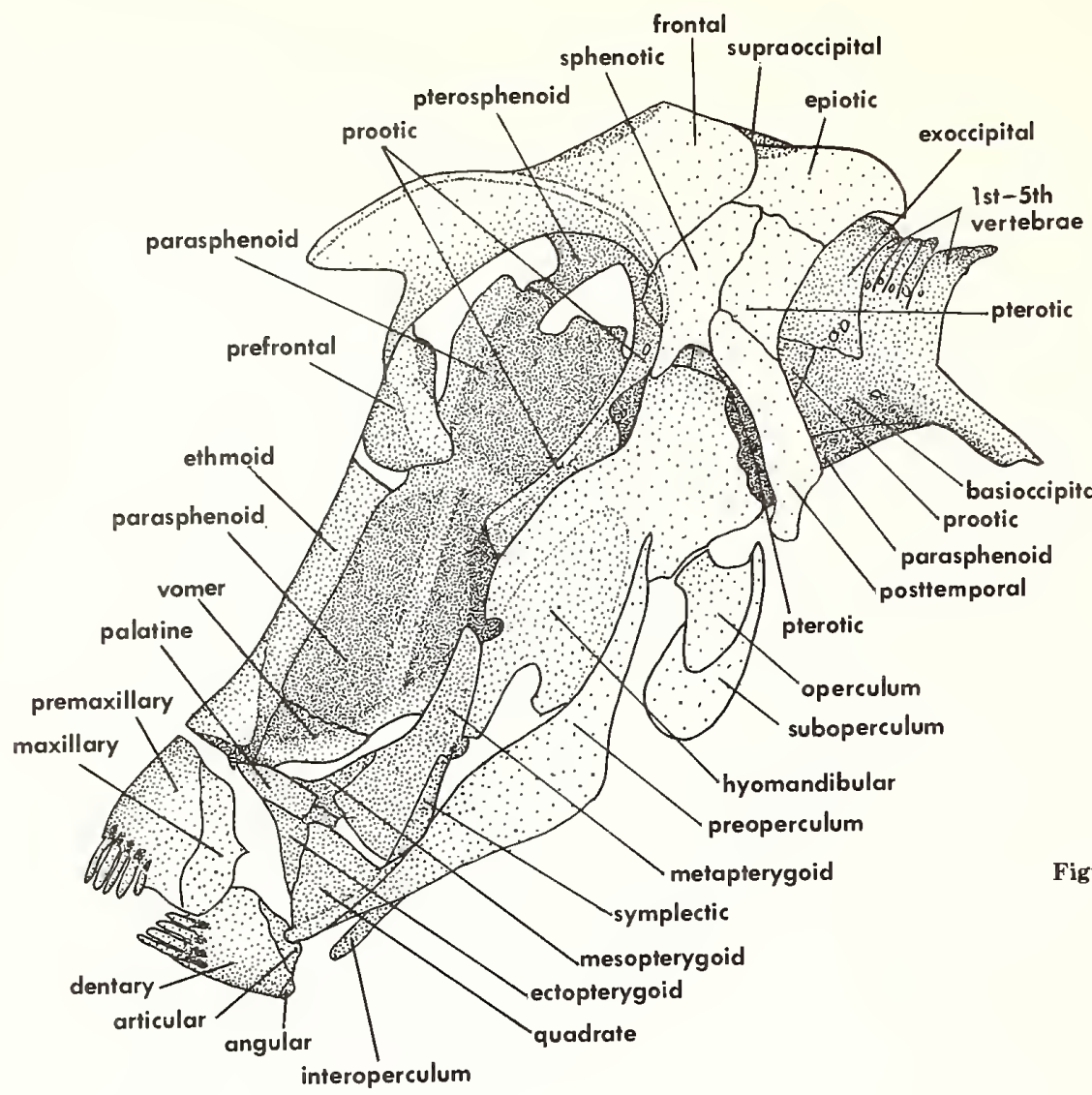

Figure 171.-Rhinesomus triqueter: lateral view of head, $134 \mathrm{~mm} \mathrm{SL}$, Colombia.

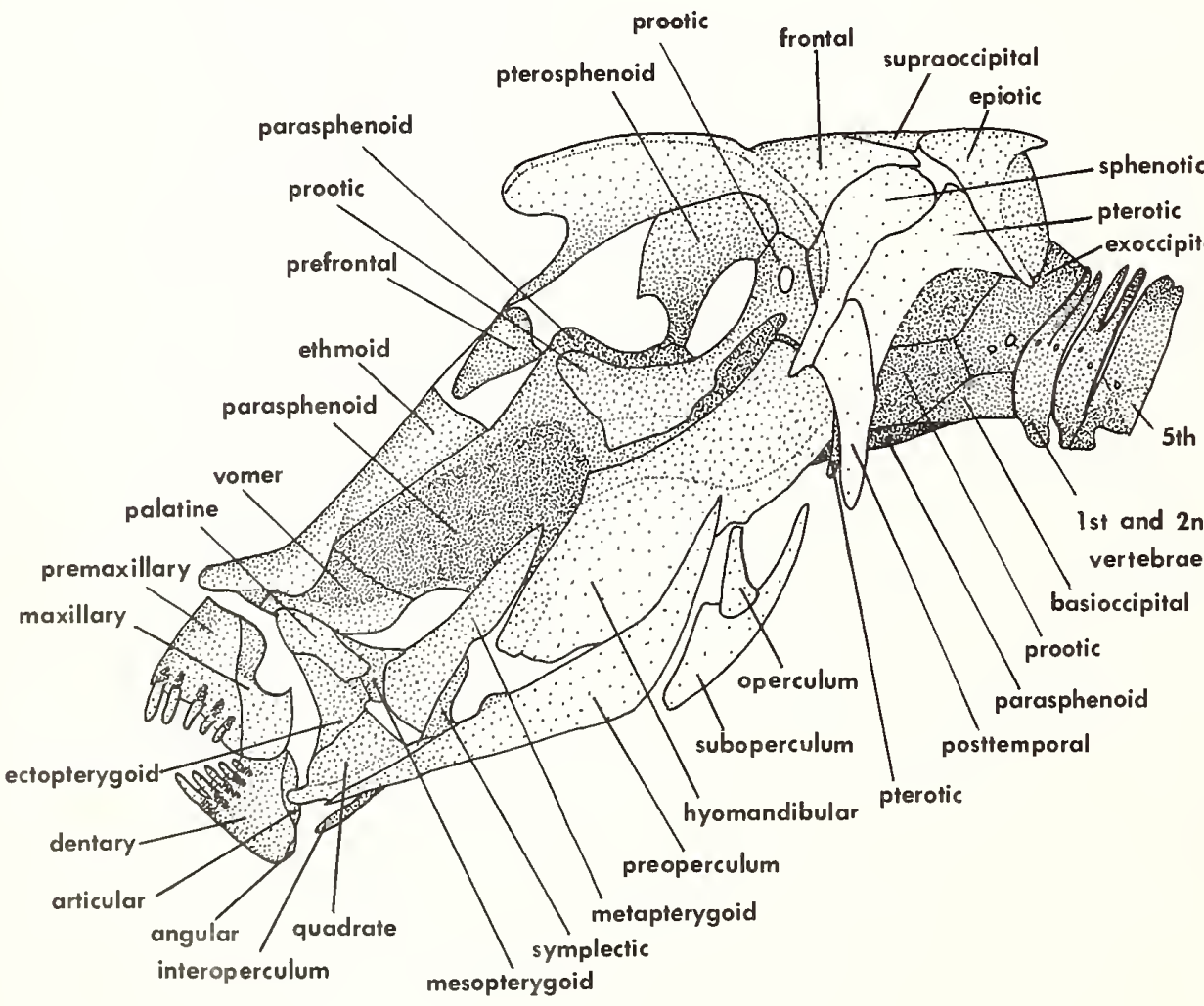

Figure 172.-Ostracion tuberculatus: lateral view of head, $54.5 \mathrm{~mm} \mathrm{SL}$, Aldabra Atoll. 


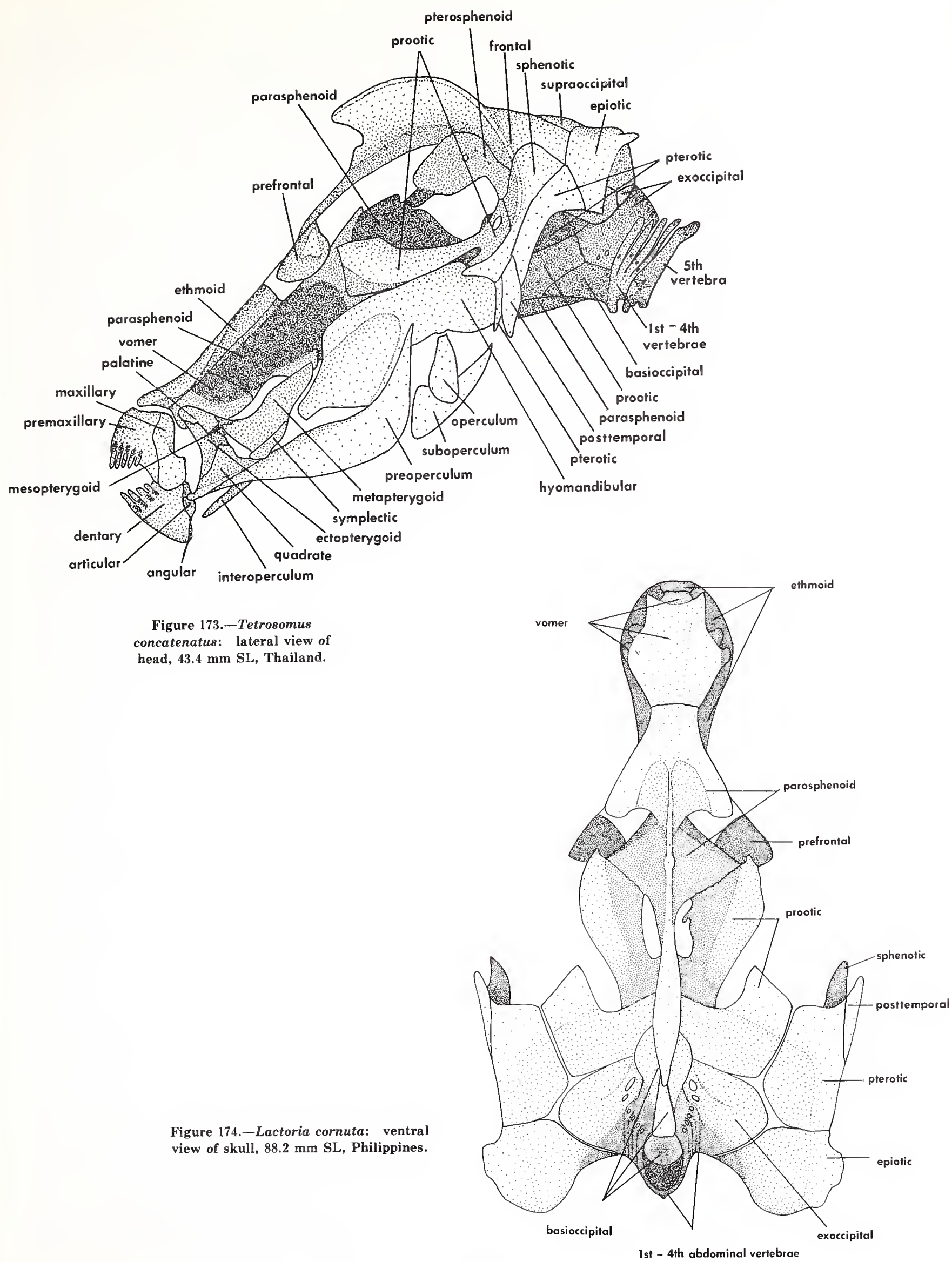




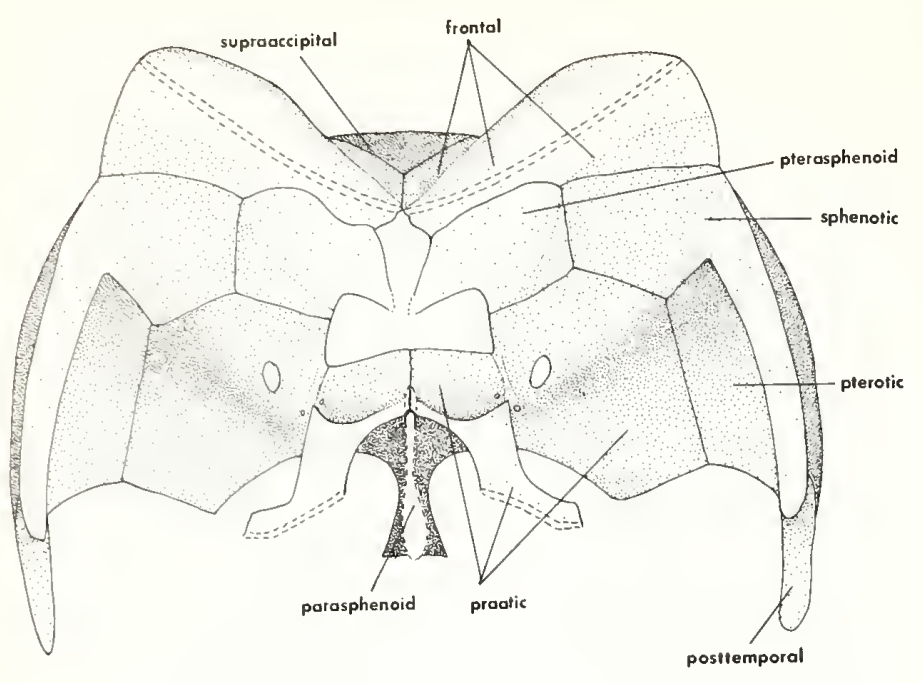

Figure 175.-Lactoria fornasinii: posterior view of orbit (cross section of skull; dashed lines represent cut surfaces of frontals, pterosphenoids, prootics, and parasphenoid), $65.2 \mathrm{~mm}$ SL, Hawaii.

summarized here. The most generalized condition of the caudal skeleton is found in Lactophrys trigonus and the two species of Rhinesomus, the haemal spine of the penultimate vertebra being relatively large and autogenous and the haemal canal passing through it and into the caudal plate to exit at a foramen just below the region of the centrum, the foramen marking the region of fusion between what in more generalized plectognaths are the parhypural and lowermost hypural. All three species have three postanal vertebrae. The moderately specialized condition of the caudal skeleton is found in Lactoria cornuta and the four species of Acanthostracion, the haemal spine of the penultimate vertebra being reduced in size and fused to its centrum, while the haemal canal pierces and exits in the caudal plate just as in Lactophrys and Rhinesomus. There are three postanal vertebrae in Lactoria cornuta, four in A. polygonius, $A$. guineensis, and $A$. notacanthus, and five in $A$. quadricornis. Since all ostracioids with the exception of $A$. quadricornis have 18 vertebrae, and quadricornis 19 , it is assumed that 18 is the generalized number and that the addition of a vertebra in quadricornis has taken place in the postanal series.

The most specialized condition of the caudal skeleton is found in Lactoria fornasinil, the two species of Ostracion, the two species of Tetrosomus, and in Rhynchostracion rhinorhynchus. In these species the haemal arches and spines of all the postanal vertebrae are usually much reduced in size, solid, fused to the centra, and not pierced by the haemal canal, which also does not enter the foramenless caudal plate. Of these species, the solid haemal spines are best developed in Ostracion tuberculatus (illustrated here), the haemal spines being shorter in O. lentiginosum (Tyler 1963a:fig. 13, which incorrectly shows nontrifid neural spines) and just as rudimentary if not more so in Tetrosomus and Rhynchostracion. There are four postanal vertebrae in Ostracion and Rhynchostracion, and three in Lactoria and Tetrosomus.

All species of ostraciids have 9 abdominal and 9 caudal (10 caudal in $A$. quadricornis) vertebrae, and all have 7 predorsal vertebrae, with the postanal, flexibly articulated, vertebrae varying from 5 to 3 .

The postcleithrum is nearly always composed of two pieces, both of which, but especially the ventral piece, are relatively thin and delicate, only the anterior end of the dorsal piece around its region of articulation with the cleithrum being of much strength. Only in the single specimens examined of the two species of Tetrosomus was the division into two pieces not seen, and it may have simply escaped notice in the posterior half of the bone which tends to break away from the front portion during dissection and hold fast to the carapace.

In all ostraciids the distal end of the first anal fin basal pterygiophore is expanded into a pair of anterolateral wings more or less surrounding the rear half of the anus and supporting the carapace in this region. The carapace has additional specialized supporting structures around both the dorsal and anal fins in the Indo-Pacific species, but not in those of the Atlantic. In addition to the trifid neural spines of two or more of the postdorsal vertebrae that broaden the base of support for the carapace in the Indo-Pacific species, the last dorsal and anal fin basal pterygiophores are also variously modified to help support the carapace.

Just above its distal end the last anal fin basal pterygiophore is always laterally expanded into a shelf upon which the carapace rests. In Lactoria cornuta the shelf is mainly a simple lateral expansion, but in $L$. fornasinii and all of the other Indo-Pacific species it is expanded anteriorly as well as laterally into a pair of broad anterolaterally directed prongs supporting the carapace.

The last dorsal fin basal pterygiophore, just below the distal end, is variously expanded laterally and posteriorly into a supporting flange. In Ostracion, Rhynchostracion, and Lactoria cornuta this basal portion of the last dorsal fin basal pterygiophore is much expanded anteroposteriorly and closely held between the stout neural spines of the 11 th and 12 th vertebrae, while the distal portion of the pterygiophore is expanded both laterally and posteriorly into a shelf upon which the carapace rests. The posterior expansion of the distal end of the pterygiophore usually makes contact with the neural spine of the 13 th vertebra. In Lactoria fornasinii the distal end of the last dorsal fin basal pterygiophore is only slightly expanded laterally and posteriorly into a supporting shelf and the basal portion is rodlike, not expanded anteroposteriorly. Moreover, the trifid neural spines of the 14th to 16 th vertebrae are not as massive in $L$. fornasinii as in $L$. cornuta, and the neural spine of the 13 th vertebra in $L$. fornasinii is long and slender and not in contact with the last pterygiophore rather than massive and in contact with it, while that of the 12 th verte- 
bra is also much smaller than in L. cornuta and only contacts the basal half of the rodlike portion of the last pterygiophore.

The last dorsal fin basal pterygiophore in the two species of Tetrosomus is similar to that of $L$. fornasinii, but the neural spines of the vertebrae below it are even more reduced in size. In Tetrosomus the distal end of the pterygiophore is only slightly expanded laterally and posteriorly and the basal portion is rodlike, its extreme basal end being supported variously by the long neural spine of the 11 th vertebra. The rest of the length of the pterygiophore is not in contact with any other vertebrae, mainly because the posterior extension of the distal end is short and the neural spines of the 13 th and 14 th vertebrae are extremely low. As in L. fornasinii, the trifid neural spines of the $15 \mathrm{th}$ and $16 \mathrm{th}$ vertebrae in Tetrosomus are not massive.

The degree of development of lateral flanges extending down from the neural spines across the lateral surfaces of the centra to end in broad transverse processes extending out anterolaterally from the lower surface of the centra is difficult to compare between species other than relatively subjectively. The flanges are best developed in Lactoria and Ostracion, moderately developed in Tetrosomus and Rhynchostracion and only slightly, if at all, less so in Rhinesomus, and poorly developed in Lactophrys and, especially, Acantho- stracion. Thus, there is a tendency for the Indo-Pacific species to have the lateral flanges better developed than in at least most of the Atlantic species.

Probably associated with the more bulbous snout of Rhynchostracion is the fact that the ethmoid in this genus is wider and more massive than in all other genera.

Variation in the branchial arches of ostraciids is main. ly confined to the presence or absence of minute and perhaps nearly functionless teeth on the third pharyngobranchial. The second pharyngobranchial in all species bears equally minute or only slightly larger teeth than those of the third pharyngobranchial. The first pharyngobranchial is a toothless suspensory element that is

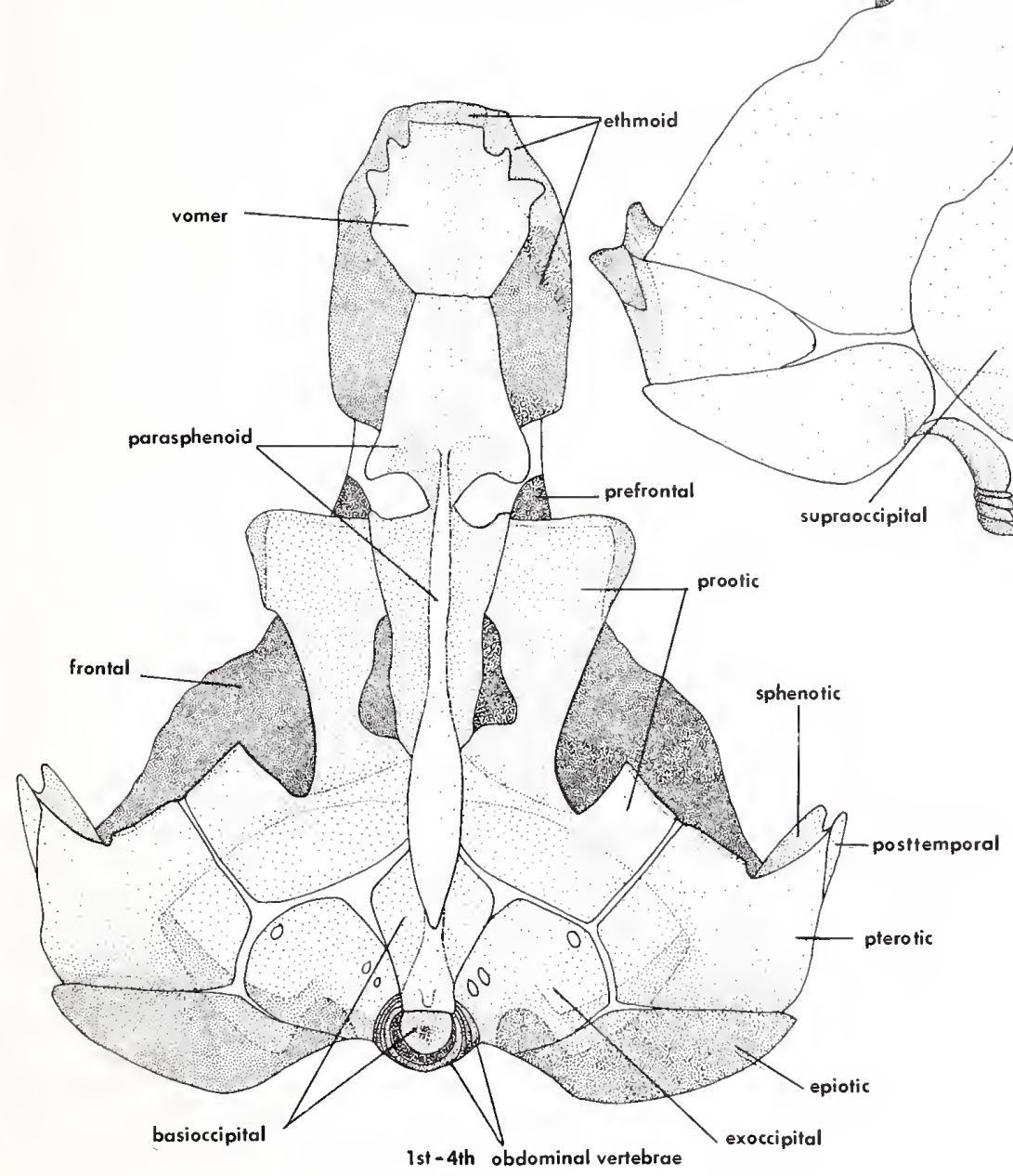

Figure 176.-Rhynchostracion rhinorhynchus: ventral (left) and dorsal (right) views of skull, $88.2 \mathrm{~mm} \mathrm{SL}$, Java. 


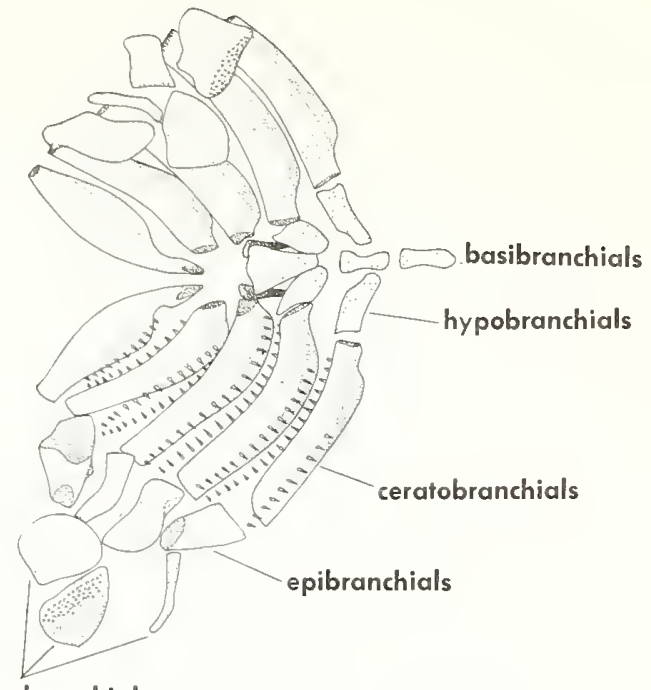

pharyngobranchials

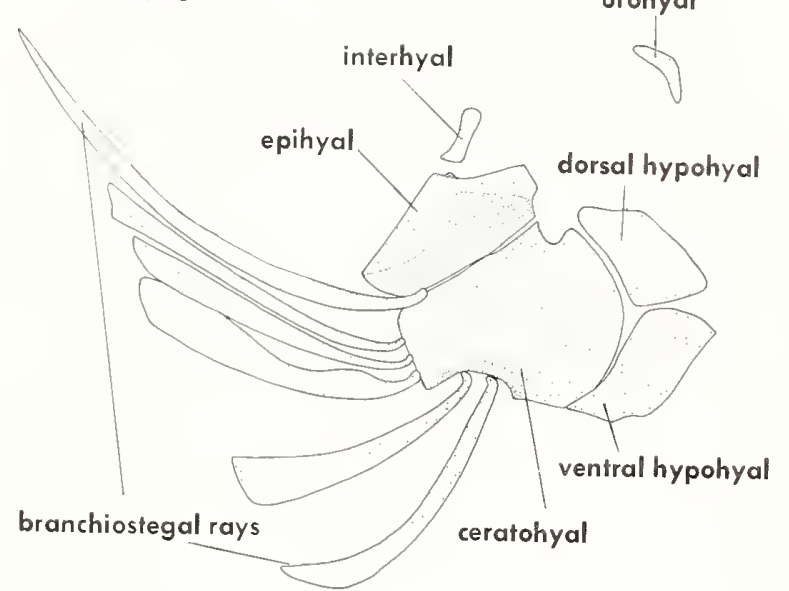

Figure 177.-Lactoria cornuta: dorsal view of branchial arches (extended on lower side); lateral view of hyoid arch and urohyal; $88.2 \mathrm{~mm} \mathrm{SL}$, Philippines.

present in all species, with the exception that only a minority of the specimens of Acanthostracion quadricornis examined had a first pharyngobranchial present, at least as an ossification, and that the first pharyngobranchial may also have been absent in the single specimen of $A$. notacanthus examined, the specimen having been poorly cleared and crudely dissected in this region and the presence or absence of that pharyngobranchial now being impossible to decipher. In most of the species examined the third pharyngobranchial is toothless, but minute teeth are present on it in Lactophrys trigonus, Tetrosomus concatenatus, and in most but not all of the specimens examined of Acanthostracion quadricornis and Lactoria cornuta. Such variation is to be expected in what appear to be highly rudimentary structures, and if more specimens of the species in which no third pharyngobranchial teeth were found had been examined, the suspicion is that at least some of these species could be added to the list above of those known to at least sometimes have teeth on this element.

Generic relationships and comparative diagnoses of subfamilies (Ostraciinae, Lactophrysinae).-Fraser-Brunner (1941c) divided the ostraciids into two subfamilies, the Indo-Pacific Ostraciinae and Atlantic Lactophrysinae, on the basis of the lower number of dorsal, anal, and pectoral fin rays in the former and of supposed vertebral differences between the two groups. Tyler (1963a:185) showed that the vertebral differences mentioned by Fraser-Brunner did not stand close examination of a larger number of species than Fraser-Brunner apparently had examined, but Tyler only hinted at a few other vertebral characters that might eventually be used to separate the two groups. These and additional characters that distinguish the two subfamilies are discussed more fully in the preceding section on anatomical diversity in the family.

The separation of the ostraciids into two phyletic lines of subfamilial rank seems justified to me on the basis of the following differences:

\section{OSTRACIINAE}

dorsal and anal fin rays modally 9 dorsal and anal fin basal pterygiophores modally 8

pectoral fin rays modally 10

four vertebrae involved in the fusion complex at the rear of the skull, except for one species with five

two or more postdorsal vertebrae with trifid neural spines

last anal fin basal pterygiophore laterally or anterolaterally expanded into a prominent flange for carapace support

last dorsal fin basal pterygiophore moderately or greatly expanded laterally and posteriorly for carapace support

haemal spine of penultimate vertebra fused to the centrum, either with a foramen or solid present

Indo-Pacific distribution. myodome small and shallow, but

\section{LACTOPHRYSINAE}

dorsal and anal fin rays modally 10 dorsal and anal fin basal pterygiophores modally 9

pectoral fin rays modally 12 , except one species with 11

five vertebrae involved in the fusion complex at the rear of the skull

all vertebrae with unbranched neural spines

last anal fin basal pterygiophore not expanded for carapace support

last dorsal fin basal pterygiophore not expanded for carapace support

haemal spine of penultimate vertebra autogenous or fused to the centrum, always with a foramen myodome essentially absent

Atlantic distribution (to South Africa).

If, as suggested, the two subfamilies represent separate phyletic lines, it is assumed that the involvement of the fifth vertebra in the anterior fusion complex of the IndoPacific Lactoria fornasinii has taken place independently by convergence from that in the Atlantic species, and that the fusion of the haemal spine of the penultimate vertebra to its centrum in the four species of Atlantic Acanthostracion has been similarly independent from that in the Indo-Pacific species. This, it seems to me, is far easier to believe than that the entirely constant differences: 1) the numbers of dorsal, anal, and pectoral fin rays; 2) the structure of the neural spines of two or more postdorsal vertebrae; 3 ) the structure of the last basal pterygiophore of the dorsal and anal fins; and 4) the different distributions and myodome development, between the two groups have no phylogenetic meaning. 
Generalized conditions in ostraciids can be considered those which deviate the least from the structure of the ancestral aracanids. Only two anterior vertebrae are fused in aracanids, so the involvement of only four vertebrae in the fusion complex of all but one species of ostraciins is less specialized than the involvement of five in the lactophrysins. Aracanids have single unbranched neural spines, as do lactophrysins, and the trifid neural spines of some of the vertebrae in ostraciins can be considered as specialization. Aracanids have no lateral or other expansions toward the distal ends of the last dorsal and anal fin basal pterygiophores for support of the carapace, nor do the lactophrysins, and the expansions of these pterygiophores in ostraciins can be considered a specialization. The higher numbers of dorsal, anal, and pectoral fin rays, and of the dorsal and anal fin basal pterygiophores, in lactophrysins is more similar to that of aracanids than are the lower numbers found in ostraciins, the latter again more specialized. In aracanids the haemal spine of the penultimate vertebra is autogenous, while only among the lactophrysin ostraciids are there species with the penultimate haemal spine autogenous, the ostraciins again having the more specialized condition. Moreover, it is only among the species of ostraciins that the penultimate and the preceding one or two haemal spines are reduced in size, solid and without a foramen for the haemal canal, the ostraciins again at least tending to have a more specialized caudal fin supporting apparatus than in the lactophrysins. The moderate degree of lateral flange development across the surface of the centra in aracanids is about intermediate between that of the moderate to well-developed flanges found in ostraciins and that of the moderate to poorly developed flanges of lactophrysins.

In only two ways can ostraciins be considered more generalized than lactophrysins. In aracanids and ostraciins a small myodome is present, but this has been essentially lost by lactophrysins. Aracanids and ostra.

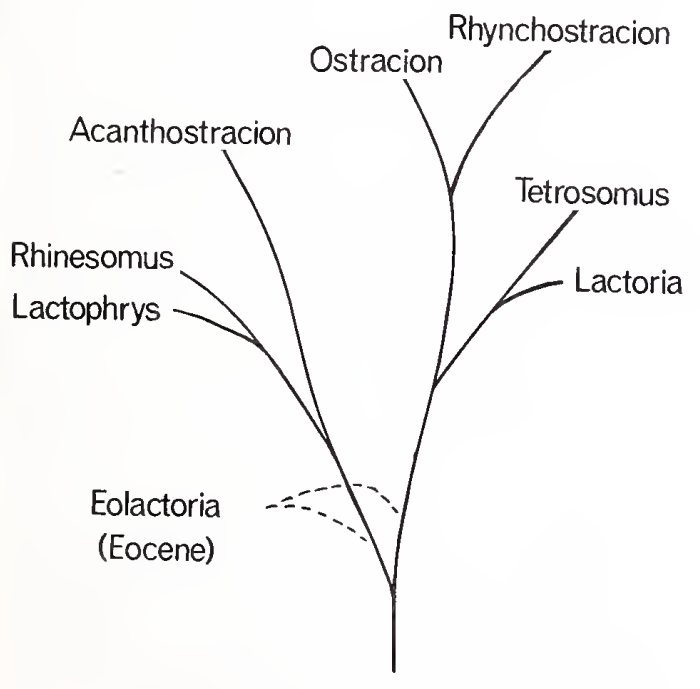

Figure 178.-Hypothesized phylogenetic relationships of the genera of Ostraciidae. ciins both have an Indo-Pacific distribution, while that of lactophrysins is Atlantic.

In short, in most of the anatomical characters discussed above, with the notable exception of the anterior vertebral fusion and mydome development, the lactophrysins are seen as the more generalized of the two subfamilies. It seems best to assume that the lactophrysins have remained more generalized than the ostraciins in nearly all respects, except that the myodome became reduced and the fifth vertebra became involved in the anterior fusion complex in all species, while the generally more specialized ostraciins retained from the same generalized stock that gave rise to both subfamilies a slightly better developed myodome and a less extensive anterior vertebral fusion complex. In this view it is likely that the Ostraciidae diverged into two lines in the IndoPacific, with the more specialized ostraciins eventually becoming dominant there to the exclusion of the lactophrysins, which remained anatomically closer to the ancestral stock, and were only permanently successful in the Atlantic, in what is perhaps at least a partially relict distribution.

Within the Lactophrysinae three genera were recognized by Fraser-Brunner (1935b:317, 1941c:307), exclusively on the basis of carapace characters, Acanthostracion for the species (quadricornis, polygonius, guineensis, and notacanthus) with the carapace closed behind the dorsal fin and with preorbital as well as postanal carapace spines, Rhinesomus for the two species (bicaudalis and triqueter) with the carapace closed behind the dorsal fin, no preorbital carapace spines but with the postanal spines present or absent, and Lactophrys for trigonus, with the carapace open behind the dorsal fin, no preorbital carapace spines but with postanal spines. Since the presence of preorbital spines seems to have no more magical phylogenetic quality than the presence of postanal spines, one could with equal simplicity group together those species with postanal spines (Acanthostracion, Lactophrys, and Rhinesomus bicaudalis) as distinct from $R$. triqueter, and within the former group split off $R$. bicaudalis and $L$. trigonus from Acanthostracion on the basis of the presence or absence of preorbital spines, and further separate $R$. bicaudalis and $L$. trigonus on the basis of whether the carapace is closed behind the dorsal fin. A great many such combinations are as logically valid on the basis of carapace characteristics alone. With this in mind, most workers have not recognized all three genera as valid, variously lumping them all together in one genus (Lactophrys) or recognizing Lactophrys for the three species without preorbital spines and Acanthostracion for the four species with preorbital spines.

Several skeletal characters indicate the advisability of recognizing two genera rather than one or three for the Lactophrysinae. In Lactophrys and Rhinesomus the penultimate haemal spine is autogenous while in Acanthostracion it is fused to the centrum. In Lactophrys and Rhinesomus there are three postanal (posterior to the last vertebra supporting the anal fin) vertebrae while in Acanthostracion there are four in three 
species and five in one (quadricornis), i.e., the 15th vertebra helps to support the last anal fin basal pterygiophore in Lactophrys and Rhinesomus but not in Acanthostracion. In Lactophrys and Rhinesomus suturing between adjacent vertebrae extends from the 5 th and 6 th back to between the 12 th and 13th, while in Acanthostracion it extends back to between the 13th and 14th (erroneously stated by Tyler 1963a:171, to be between the 12th and 13th in A. quadricornis). Lateral flanges across the centra are slightly better developed in Lactophrys and Rhinesomus than in Acanthostracion.

On the basis of the above, only two genera should be recognized in the Lactophrysinae, with Lactophrys = Rhinesomus being more generalized in all of the characteristics listed above than Acanthostracion. Whether the condition of having the carapace slightly open behind the dorsal fin in $L$. trigonus is a hold over from the ancestral aracanids that gave rise to the ostraciids or is a case of the subsequent reduction of the carapace in this region from a more immediate ancestor with a complete bridge across the back behind the dorsal fin is impossible to say with assurance. In the only fossil ostraciid, the Eocene Eolactoria, the carapace is complete behind the dorsal fin. I suspect, especially in light of the fact that the carapace is complete behind the dorsal fin at least occasionally in large specimens of $L$. trigonus just as it is in Eolactoria and all other ostraciids, that the condition in $L$. trigonus is a secondary reduction of the posterior end of the carapace and not the retention of a primitive condition. It seems possible that $L$. trigonus and $R$. bicaudalis are slightly more closely related to one another than to $R$. triqueter, despite the behind the dorsal fin carapace similarity between bicaudalis and triqueter. In addition to bicaudalis and trigonus both having postanal carapace spines, both have the anterior nostril bulbous, more so in bicaudalis and at all sizes, and less so and only in large specimens of trigonus. It would be intriguing to know whether the anterior nostril in triqueter, which is a smaller species than the other two, would become bulbous were it to reach sizes comparable to trigonus.

Acanthostracion is probably derived from a Lactophrys = Rhinesomus-like stock, undoubtedly from a form with the carapace closed behind the dorsal fin and with postanal spines. Acanthostracion is specialized internally in the ways mentioned above, while the presence of preorbital spines could indicate either that they are a new development from the Lactophrys = Rhinesomuslike line which give rise to it or that the immediate ancestry of the Lactophrys = Rhinesomus line had preorbital spines which were lost by the Recent species of that group but retained by the line leading to Acanthostracion. Within Acanthostracion, quadricornis is obviously the most specialized form (the addition of 1 vertebra to the postanal series for a total of 5 in the series and 19 for the entire column, both unique in the family, and the total number of vertebrae unique in the superfamily; the modal reduction by one of the number of pectoral fin rays, unique in the subfamily; the frequent presence of isolated scale plates above and below on the caudal peduncle, unique in the family), and notacanthus, polygonius, and guineensis are more closely related to one another than to quadricornis, with the relationship between notacanthus and polygonius being especially close on the basis of the coloration, carapace, and caudal fin shape characteristics discussed by Tyler (1965b:275).

In the Ostraciinae the generic relationships, and which genera are generalized versus specialized, are less clear than in the lactophrysins. The rectangular carapace of Ostracion and Rhynchostracion rhinorhynchus can be considered a specialization, being further removed from the laterally compressed oval of aracanids and the high crested triangle of lactophrysins and of Tetrosomus, with the high crested but otherwise rectangular form of $R$. nasus being a variant of the Ostracion and $R$. rhinorhynchus form and the pentangular carapace of Lactoria a low crested variant of the triangular form.

In the caudal skeleton the presence of a haemal canal piercing the more posterior haemal spines and entering the caudal plate, as found only in Lactoria cornuta among the ostraciins, is clearly a relatively generalized condition in comparison to the highly specialized solid postanal haemal spines, usually reduced in size and never pierced by the haemal canal, which also does not enter the caudal plate, found in L. fornasinii, Tetrosomus, Ostracion, and Rhynchostracion. The reduction in size of several of the neural spines below the last dorsal fin basal pterygiophore, so that the pterygiophore is supported only basally by a neural spine, as found in $L$. fornasinii, and, especially, Tetrosomus, seems specialized in comparison to the more normal neural spines in this position found in L. cornuta, Ostracion, and Rhynchostracion. However, the relatively small size and poor development of shelves supporting the carapace on this pterygiophore in L. fornasinii and Tetrosomus are much closer to the condition found in the lactophrysins and aracanids, and must be considered either more generalized than or a secondary reduction in size from the far more massive last dorsal fin basal pterygiophore with well-developed specialized shelves found in $L$. cornuta, Ostracion, and Rhynchostracion.

The only moderately developed lateral flanges across the centra in Tetrosomus and Rhynchostracion would seem slightly less specialized than the larger flanges of Lactoria and Ostracion. The relatively small lateral shelf for carapace support on the last anal fin basal pterygiophore in $L$. cornuta seems the least removed from the condition in lactophrysins and aracanids and thus less specialized than the much larger anterolateral shelf found in L. fornasinii, Tetrosomus, Ostracion, and Rhynchostracion.

The number of postanal vertebrae, three in Lactoria and Tetrosomus and four in Ostracion and Rhynchostracion, can be compared only to the condition in lactophrysins. In aracanids there is a far less close association of the last (and other) anal fin basal pterygiophore with the haemal spines of the caudal vertebrae (with only the proximal end of the element at all associated with a particular haemal spine instead of most of its posterodorsal 
edge closely in contact with several vertebrae) which leads to incomparably high postanal counts. In lactophrysins the more generalized group, Lactophrys = Rhinesomus, have three postanal vertebrae and the more specialized group, Acanthostracion, four, while Ostracion and Rhynchostracion would thus be considered to have a more specialized number of postanal vertebrae.

Trifid neural spines on some of the postdorsal vertebrae being a specialization found in all ostraciins, it seems reasonable to assume that the greater the number of vertebrae with trifid neurals, the greater the degree of specialization in this character. The greatest number, four, is found in $L$. cornuta, with $L$. fornasinii having three, and Tetrosomus, Ostracion, and Rhynchostracion either two or three.

While the number of vertebrae involved in the fusion complex with the rear of the skull in all species of the subfamily is four, except five in $L$. fornasinii, the lack of fusion between the fused first-second vertebrae and the fused third-fourth vertebrae in $O$. tuberculatus even in large adults and of the sometimes only partial fusion in this region in $O$. lentiginosum seem more generalized than having at least the basal regions of the four elements fully fused, as in Rhynchostracion, Lactoria, and Tetrosomus.

As seen above, no one genus has a relatively full complement of either the specialized or generalized characteristics discussed, all of the genera having a difficult to interpret mixture of both. What follows is a highly speculative interpretation of the evidence.

The probably triangularly or pentagonally carapaced ancestral group of the Ostraciidae had no more than four vertebrae involved in the anterior fusion complex, the haemal spine of the penultimate vertebra autogenous, the last dorsal and anal fin basal pterygiophores without shelves for carapace support, and the neural spines of the more posterior vertebrae undivided. This ancestral group gave rise on the one hand to the Lactophrysinae, which remained relatively unchanged from the ancestral condition except for subsequently involving the fifth vertebra in the fusion complex and having the penultimate haemal spine become fused to the centrum in the most specialized genus, in which the number of postanal vertebrae was also increased. On the other hand the ancestral group gave rise to the Ostraciinae, which retained the ancestral condition of the anterior vertebral fusion complex but which specialized in a number of ways mostly involving the simplification of the postanal haemal spines and of the development of carapace supporting structures on the last dorsal and anal fin basal pterygiophores and on some of the neural spines of the postdorsal vertebrae.

The line immediately ancestral to the Recent ostraciins is envisioned as having the last dorsal and anal fin basal pterygiophores moderately well developed (i.e., larger than in the lactophrysins), with moderate shelves (probably less well developed than in their greatest development in the Recent species), and with only two or three of the postdorsal vertebrae with trifid neural spines. This hypothetical ancestral line leading from the immediate ancestry of the lactophrysins would probably have had a triangular or pentangular carapace, and it is postulated to have diverged into two lines of Recent species, one line containing basically triangular forms with many carapace spines (Lactoria and Tetrosomus) and the other basically rectangular forms with a relatively spineless carapace (Ostracion and Rhynchostracion).

In the Lactoria-Tetrosomus line of ostraciins, a form close to $L$. cornuta, but with a still only moderately enlarged last dorsal fin basal pterygiophore and only two or three trifid neural spines, was probably ancestral, $L$. cornuta being the only species to have the haemal canal pierce the fused haemal spine of the penultimate vertebra and enter into and exit from the caudal plate and to have a relatively moderate lateral shelf on the last anal fin basal pterygiophore. The $L$. cornuta-like (with the exceptions noted) ancestral line probably gave rise to $L$. cornuta on the one hand by the further enlargement of the last dorsal fin basal pterygiophore and its shelf and by the trifid division and enlargement of additional postdorsal neural spines.

On the other hand the pre- $L$. cornuta ancestor is seen as having given rise to $L$. fornasinii with no increase in the number and size of trifid neural spines, the reduction of the size of the haemal arches of the postanal vertebrae, and the elimination of their foramina so that they are solid and not pierced by the haemal canal which also does not pierce the caudal plate, an enlargement of the moderate shelf on the last anal fin basal pterygiophore into a more substantial anterolateral shelf, a reduction in the size of the neural spine of the vertebra (13th) between that which supports the base of the last dorsal fin basal pterygiophore and the most anterior of the three vertebrae (14th to 16 th) with trifid neural spines, and a slight reduction in the size of the last dorsal fin basal pterygiophore and its posterior carapace shelf so that the basal portion of the pterygiophore is rodlike rather than anteroposteriorly expanded while the posterior end of the distal shelf does not make contact with any neural spines.

Probably a close derivative of the immediate ancestor of $L$. fornasinii is Tetrosomus. Tetrosomus shows the same tendencies, but more strongly, as $L$. fornasinii does in the reduction of the size of the neural spines below the last dorsal fin basal pterygiophore and in the size of the latter. In Tetrosomus the size of the neural spines of the 12 th to 14 th vertebrae is greatly reduced, and that of the 14 th is no longer trifid. The trifid neural spines of the 15 th and 16 th vertebrae are of about the same moderate size as in $L$. fornasinii, the anterolateral shelf on the last anal fin basal pterygiophore just as massive, and the solid haemal spines of the postanal vertebrae just as reduced in size and not pierced by the haemal canal, which likewise does not enter the caudal plate. Thus, $L$. fornasinii shares many peculiarities with Tetrosomus, and a form like it is very likely to have been ancestral to Tetrosomus. The higher crested carapace in Tetrosomus could be either an enlargement of the lower crest in Lactoria or a hold over from the line leading from the pre- 
fornasinii-like ancestor, which may have been higher crested than the Recent Lactoria.

In the Ostracion-Rhynchostracion line of ostraciins derived from a probably pentangular form, there seems to have been a tendency for the distance between the ventrolateral ridges to be decreased to about the same as that between the dorsolateral ridges, while the dorsal carapace crest tended to be reduced in height, leading to a basically rectangular form with overtones of the ancestral pentangular form depending on the degree of development, if any, of the dorsal crest. Ostracion and Rhynchostracion probably evolved from the same preLactoria cornuta-like line that gave rise to Lactoria and Tetrosomus. The Ostracion-Rhynchostracion line is envisioned as diverging from them in the shape of the carapace and in the loss of spines from the probably spiny carapaced ancestor, while developing large last basal pterygiophores with large carapace supporting shelves in both the dorsal and anal fins and reducing the size of the haemal spines of the four postanal vertebrae, with the haemal spines losing the foramen and being solid.

Ostracion shows the extreme in dorsal carapace crest reduction and increased distance between the dorsolateral ridges, the carapace being essentially rectangular, while it retains the most generalized ostraciid condition of the anterior vertebral fusion complex. In Rhynchostracion, however, one species (nasus) retains a relatively well-developed dorsal carapace crest while in the other (rhinorhynchus) it is obsolete, the carapace being almost as rectangular as in Ostracion, with both species of Rhynchostracion having the anterior four vertebrae fully fused to one another. Rhynchostracion has the additional slight specialization of a bulbous or protruding snout. Ostracion and Rhynchostracion can be viewed as closely related sibling genera from a common ancestral group, with Rhynchostracion slightly more specialized in the greater anterior vertebral fusion and expanded ethmoid region while retaining a slightly more generalized carapace shape.

The Eocene Eolactoria is impossible to place with confidence in either one or the other of the two subfamilies recognized here for the Recent species, simply because its dorsal, anal, and pectoral fin rays are not preserved and none of the internal features equally diagnostic between the two subfamilies can be seen (Tyler 1973a). The presence of enormous preorbital and postanal carapace spines in Eolactoria would seem to relate it to either the Atlantic Acanthostracion (Lactophrysinae) or the IndoPacific Lactoria (Ostraciinae), from both of which it differs in the immensity of the elongation of the spines (equal to the standard length of the fish) and in the presence of a much shorter unpaired spine directed anteriorly from between the front of the eyes, the latter unique in the family. Without knowing the appropriate critical diagnostic characteristics, Eolactoria is simply placed here questionably in the Lactophrysinae, the more generalized of the two subfamilies, on the theory that an Eocene ostraciid is more likely to be generalized in most respects than specialized. It is possible that

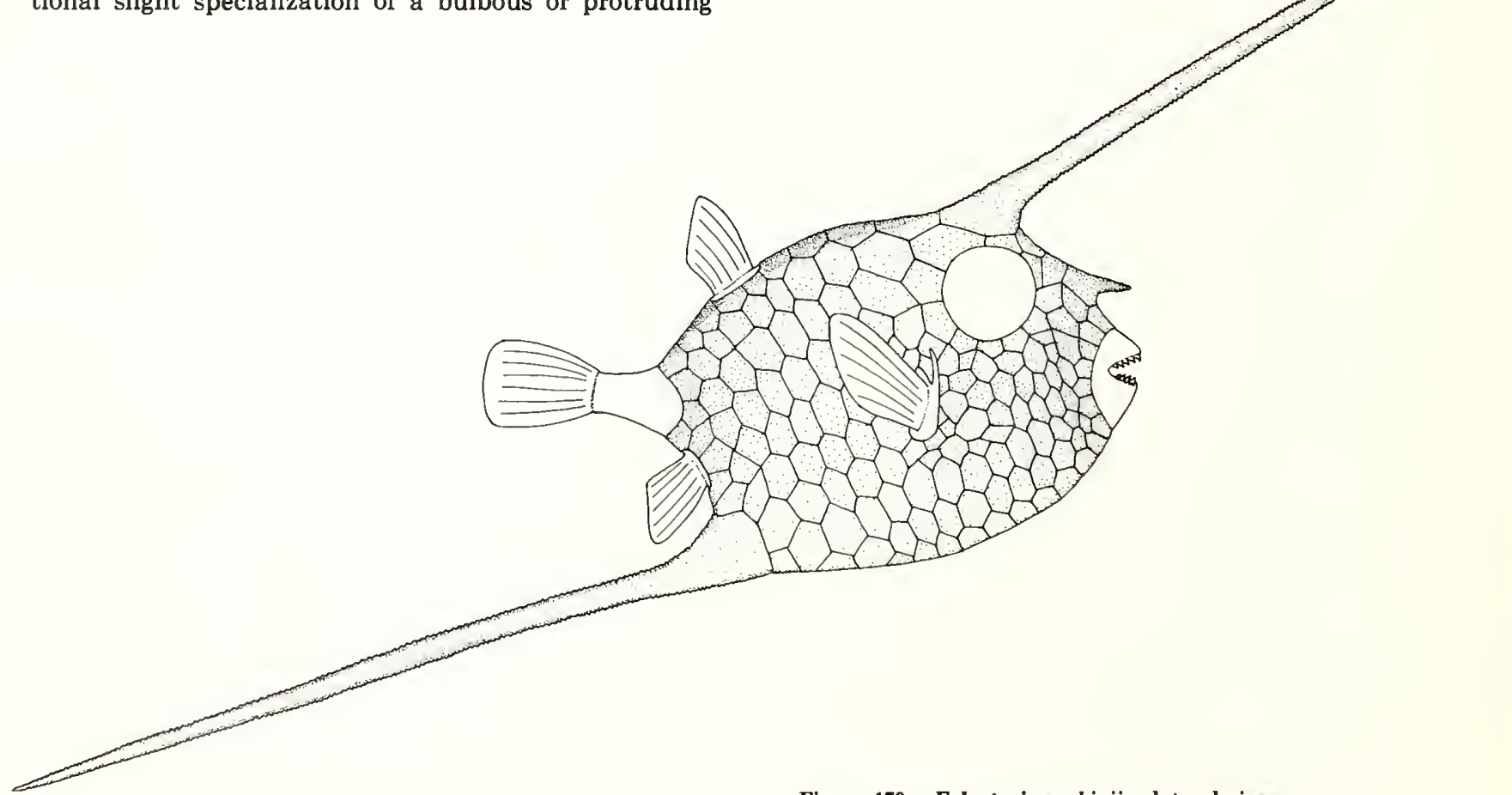

Figure 179.-Eolactoria sorbinii: lateral view of holotype, $15.5 \mathrm{~mm}$ SL, Eocene of Monte Bolca, Italy (Tyler 1973a:fig. 1). 
Eolactoria is a representative of the line which gave rise to Acanthostracion on the one hand and to Lactophrys = Rhinesomus on the other, with the latter variously losing the preorbital and postanal carapace spines, and that another more specialized derivative of the Eolactoria to Acanthostracion line gave rise to that of Lactoria and Tetrosomus on the one hand and to that of Ostracion and Rhynchostracion on the other, with the latter two genera also losing the preorbital and postanal carapace spines.

Since all ostraciids have the ventral edge of the parasphenoid laterally expanded into a roof over the oral cavity anterior to the level of the prefrontals, they can be expected to have evolved from one of the two lines of aracanids with a similar but less extensive expansion of the ventral edge of the parasphenoid, either the Aracana line with the expansion limited to a posterior region or the Capropygia-Caprichthys line with the expansion limited to an anterior region. However, it is impossible to say with any confidence which one of these two lines was more likely ancestral to the ostraciids (see discussion under Aracanidae).

\section{SUBORDER TETRAODONTOIDEI}

\section{(GYMNODONTES)}

Comparative diagnosis (contrast with that of the Balistoidei). - Teeth either small rounded units or long rodlike structures, but always nonprotruding and fully incorporated into the matrix of the jaw bones, in one family indistinguishably so, the otherwise discrete teeth in molids no longer distinguishable from the bony matrix, at least at 30 magnifications; dentaries and/or premaxillaries often fused to their opposite members; the medial articulation of the premaxillaries to one another, if unfused, strengthened by alternating emarginations and indentations, least developed in Triodon, the most generalized member of the suborder; posttemporal absent; urohyal absent, except in Triodon; pelvis absent, except in Triodon; pelvic fin always absent; palatine relatively large and massive, always firmly sutured or otherwise closely and immovably held to both the ethmoid-vomerine region and the pterygoid arch; myodome with a complete dorsal roof absent, except in Triodon; prootic shelf under the orbit never present; supracleithrum always placed distinctly obliquely to the axis of the skull; scapular foramen incomplete, except in Triodon; scapula without any special knob or crest for articulation with the uppermost pectoral fin ray, except in Triodon; distal pterygiophores of the soft dorsal and anal fins always unossified; spiny dorsal fin absent, except present as a rudiment placed far behind the skull in Triodon; first branchiostegal ray modified, with a slightly (Triodon) to enormously enlarged and inturned dorsomedial edge, except unmodified in molids.

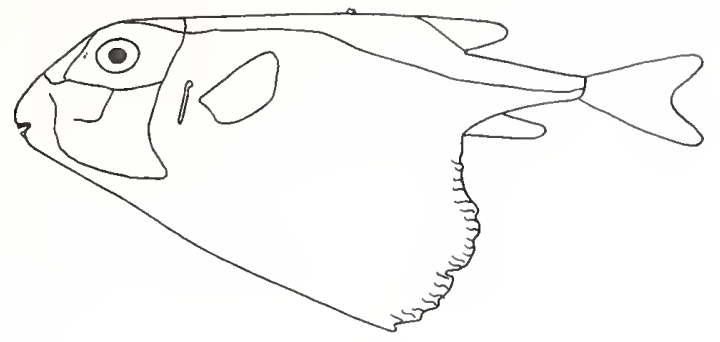

Figure 180.-Body form in the only known Recent species of Triodontidae: Triodon macropterus.

\section{Infraorder Triodontoideo}

Comparative diagnosis (contrast with that of the Tetraodontoideo), which is also that of its only contained Superfamily, the Triodontoidea, and family, the Triodontidae.-A rudimentary spiny dorsal fin of one or, more usually, two small spines borne on two basal pterygiophores present in most specimens of one of the populations (Indonesia to Japan) of the single included Recent species, the second basal pterygiophore succeeded by two supraneural elements; ribs and epipleurals present; caudal fin with 12 principal rays and numerous procurrent rays; caudal fin deeply forked; caudal skeleton with four separate hypurals, two uroneurals, and a hypurapophysis; haemal spine of antipenultimate vertebra autogenous; neural and haemal spines of penultimate vertebra long rounded shafts oriented highly obliquely and directly supporting caudal fin rays; caudal peduncle distinctly tapered to narrow transversely indented regions above and below just in front of the caudal fin, the least depth of the peduncle being about $3 \% \mathrm{SL}$ and the least width at this region always greater than the least depth; many of the caudal vertebrae with large anterolateral processes from the region of the neural arch and base of the neural spine; pelvis present; a huge expansible dewlap of skin between the end of the pelvis and anus, but no inflatability of the abdominal region; cleithrum greatly elongate anteriorly, reaching forward to between the lower jaw; basisphenoid a small rod placed far posteriorly in the interorbital septum and articulated with the anterior edge of the dorsal roof of the myodome; a large myodome present with a complete dorsal roof; a shallow channel present between the apposed surfaces of the parasphenoid and basioccipital leading into the myodome; scapular foramen complete, entirely enclosed by the scapula; scapula with a distinct knob for articulation with uppermost pectoral fin ray; four actinosts, none of which are sutured to one another or to the scapula or coracoid; urohyal present; four pharyngobranchials present; fifth ceratobranchial well-covered with prominent teeth; dentaries and premaxillaries totaling three separate pieces; premaxillaries articulated to one another by interdigitation or by only minute 
more regular interlocking emarginations; sphenotic relatively small and confined to the posterior wall of the orbit, not reaching the lateral or dorsal surface of the skull; first branchiostegal ray with its dorsal edge slightly inturned, articulated with the ventrolateral surface of the ceratohyal; interoperculum with a ventral flange and a short posterior shaft extending only slightly behind the ventral flange and level of the epihyal; pterotic prolonged posteroventrally as a stout laterally compressed shaft broadly articulating with the hyomandibular and supracleithrum; epiotic confined to the lateral region of the top of the skull, separated from the supraoccipital by the exoccipital; exoccipital in contact with the frontal; frontal in contact posteriorly with the pterotic in the rear of the orbit; olfactory epithelium in the form of a rosette, the lamellae radiating out from a horseshoe-shaped base, the olfactory sac below the surface of the body and the two nostrils more or less flush with the surface, the anterior nostril with an upraised flap posteriorly and the posterior nostril with an upraised flap anteriorly.

\section{Detailed description of Triodon macropterus.}

Material examined.-Two cleared and stained specimens, $391-463 \mathrm{~mm}$. It will be advantageous in the future to compare the amount of interdigitation in the skull structure of these two large adult specimens with that in a young specimen, but the species as yet is known only from several dozen relatively large (about 285-480 $\mathrm{mm}$, see Tyler 1967:90) adults. This species has often been called T. bursarius, but Boeseman (1962) has thoroughly reviewed the literature and shown $T$. macropterus to have priority.

\section{SKULL.}

\section{Occipital Region.}

Basioccipital. - A very short column, slightly expanded anterodorsally; cartilage filled at its anterior edge; articulates by extensive interdigitation anteriorly with the overlying parasphenoid, anterolaterally with the prootics, and posterolaterally with the exoccipitals. A slight depression is present medially on the ventral surface of the anterior end of the basioccipital just behind the region where it is overlain by the parasphenoid. This depression continues anteriorly as a narrow canal between the otherwise interdigitated surfaces of the basioccipital and parasphenoid, and opens into the extreme posterior end of the myodome. The extreme posteroventral portion of the wall of the myodome is formed by the anterodorsal end of the basioccipital. The rim of the round concave posterior end of the basioccipital articulates by fibrous tissue with the rim of the concave anterior face of the centrum of the first vertebra.

Exoccipital. -Extremely large; cartilage filled along its dorsal and dorsolateral edges; articulates by extensive interdigitation dorsomedially with the supraoccipital, anterodorsally with the frontal, dorsolaterally

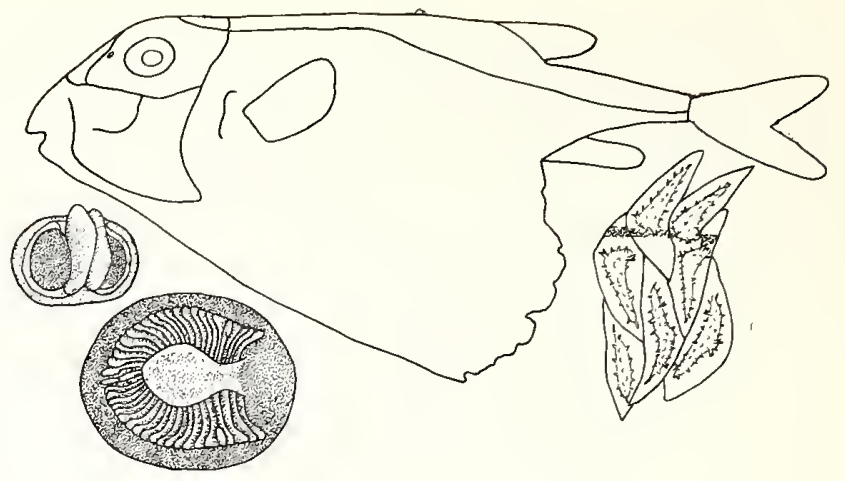

Figure 181.-Triodon macropterus: showing the course of the lateral line; lower left, the nasal region as seen externally (above) and the olfactory lamellae as seen with the top of the nasal sac removed; lower right, scales from upper middle region of body, including three lateral line canal bearing scales.

with the epiotic and pterotic, ventrolaterally with the prootic, and ventromedially with the basioccipital. The posteromedial edges of the two exoccipitals form the ventral and lateral walls of the foramen magnum, while dorsally the wall of the foramen is formed mostly by the exoccipitals, but also for a short distance medially by the ventral edge of the supraoccipital. Strong condyles project from the posteromedial portions of the exoccipitals and make fibrous tissue contact over the anterior half of the lateral surfaces of the centrum of the first vertebra.

Supraoccipital. - Somewhat expanded anteriorly, but drawn out into a short, stout, laterally compressed spine posteriorly; cartilage filled along all of its edges of articulation with the other cranial bones, except posteroventrally; articulates by interdigitation anteriorly and anterolaterally with the frontals and posterolaterally with the exoccipitals.

\section{Otic Region.}

Pterotic. - Very large; cartilage filled along its medial edge; articulates by interdigitation anterodorsally with the epiotic, anteroventrally with the sphenotic, ventromedially with the prootic, and posteromedially with the exoccipital. Posteroventrally the pterotic is prolonged into a stout, laterally compressed shaft which articulates by fibrous tissue along its anterior edge with the hyomandibular and along its posterior edge with the supracleithrum. The articulation with the supracleithrum appears to also involve some interdigitation in the smaller specimen, but not in the larger; in neither case is the articulation very flexible. The more normal articulation of the pterotic with the supracleithrum is through fibrous tissue along the slightly concave ventral surface of the extreme posterodorsal region of the pterotic. Just anterior to the base of its stout shaft the pterotic is deeply concave to receive and articulate by fibrous tissue with most of the length of the dorsal end of the hyomandibular. 
Sphenotic. - Relatively small and confined to the posterior wall of the orbit; cartilage filled along all of its edges of articulation with the other cranial bones; articulates by interdigitation anterodorsally with the frontal, posterodorsally with the pterotic, anteroventrally with the pterosphenoid, and ventrally with the prootic. The ventral edge of the sphenotic is deeply concave for articulation by fibrous tissue with the anterolateral region of the dorsal head of the hyomandibular. This concavity of the sphenotic is continuous with that along the lateral edge of the prootic, which supports the anteromedial region of the head of the hyomandibular, and with that of the pterotic forming the main support for that head.

Epiotic. - Relatively large, but thin; cartilage filled along its medial edge; articulates by interdigitation anteriorly with the frontal, medially with the exoccipital and posteriorly with the pterotic.

Prootic. - Cartilage filled along all of its edges of articulation with the other cranial bones, except anteriorly; forms all of the walls of the myodome, except for the medial portion of the ventral wall and the short section of the anterior wall formed by the parasphenoid and for the extreme posterior portion of the wall formed by the basioccipital; articulates by interdigitation anteriorly with the dorsolateral wing of the parasphenoid, dorsomedially with the pterosphenoid, dorsolaterally with the sphenotic, ventrolaterally with the pterotic, ventromedially with the parasphenoid and basioccipital, and posteriorly with the exoccipital. From its oblique medial surface the prootic gives rise to the horizontal plate of bone which meets its opposite member in the midline to form the dorsal roof of the myodome. These two projections interdigitate with one another in the midline and each possesses a small foramen laterally near its dorsal edge. Another pair of foramina are present in the ventral wall of the myodome to either side of the midline, where there is a slight gap in the interdigitated surfaces of the prootics and the parasphenoid. Anteromedially from the dorsal roof of the myodome the prootics support by fibrous tissue the posterior end of the basisphenoid. At the concavity along its lateral edge the prootic articulates by fibrous tissue with the anteromedial region of the dorsal head of the hyomandibular.

\section{Orbital Region.}

Frontal. - Large and massive; laterally expanded posteriorly but tapering to a bluntly rounded end anteriorly. Throughout its entire length the medial edge of the frontal is broadly, but not deeply, concave and covers a core of cartilage that is continuous anteriorly with the cartilage of the ethmoid region and posteriorly with that of the occipital region. The frontal articulates by interdigitation dorsomedially in the posterior half of its length with its opposite member, while directly posteromedially it interdigitates with the supraoccipital. Posterolaterally on its dorsal surface it interdigitates with the exoccipital and epiotic. Posteroventrally it interdigitates with, from anterior to posterior, the pterosphenoid, sphenotic, and pterotic. The ventromedial edges of the two frontals are in close fibrous tissue contact for most of their lengths, diverging from one another only posteroventrally just in front of the pterosphenoids and anteriorly just behind the prefrontals. Anteriorly the frontal broadly overlies and slightly interdigitates with the ethmoid, while anterolaterally it interdigitates with the dorsomedial edge of the prefrontal.

Prefrontal. - Relatively large, both dorsally and ventrally; cartilage filled along all of its ventromedial edges where it is continuous with the ethmoid cartilage; articulates dorsally by interdigitation with the frontal and the posterolateral edges of the ethmoid, while posteroventrally it articulates through cartilage and fibrous tissue with the anterodorsal surface of the parasphenoid. Along most of its ventral edge the prefrontal articulates through cartilage and interdigitation with the long posterior portion of the palatine. In about the middle of its medial surface the prefrontal is deeply concave, so that a horizontal canal is formed between the prefrontal and the ethmoid cartilage, with which the prefrontal is otherwise continuous. The nerves and blood vessels that course through this canal run not only to the olfactory organ but also to the anteriormost regions of the head by way of a similar canal between the palatine and ethmoid.

Parasphenoid. - Elongate, with a thin ventral keel throughout most of its length. The anterior end of the parasphenoid is deeply concave to accommodate the posterior end of the vomer, with which it is interdigitated. The parasphenoid also interdigitates anterolaterally with the posterior portion of the palatine, while anterodorsally it articulates through cartilage and fibrous tissue with the prefrontal. Posteriorly the parasphenoid somewhat overlies and strongly interdigitates with the basioccipital, while at the same time leaving open the small canal in the midline between their otherwise interdigitated surfaces. About five-sixths of the way back in its length, the parasphenoid gives rise to its paired dorsolateral wings which interdigitate with the anteromedial edges of the prootics and form a section of the anterior wall of the myodome. On its ventral surface between the level of its dorsolateral wings and its meeting with the basioccipital, the lateral edges of the parasphenoid interdigitate with the ventromedial edges of the prootics, and in so doing the parasphenoid forms the medial portion of the ventral wall of the myodome. At the posterior end of its ventral keel the parasphenoid becomes thickened and posterolaterally expanded into a bony knob to which the distal end of the first (suspensory) pharyngobranchial and associated muscles are attached.

Pterosphenoid. -A thick plate; broadly cartilage filled along its dorsal and lateral edges; articulates by interdigitation dorsally with the frontal, posterolaterally with the sphenotic, and posteroventrally with the prootic. 
Basisphenoid. - Laterally compressed throughout its length, except posteriorly where it is laterally expanded into a rounded process which articulates by fibrous tissue with the anterior edge of the dorsal roof of the myodome in the smaller specimen, while in the larger specimen the posterior end is attached more dorsally to the membranous wall between the two pterosphenoids. From its posterior place of attachment to the prootics, the basisphenoid is directed anteroventrally and ends in the fibrous tissue sheet of the interorbital septum. This anterior edge, which is slightly cartilage filled, is some distance removed from the dorsal surface of the parasphenoid below it.

\section{Ethmoid Region.}

Ethmoid. - Large and wide; relatively thin in the posterior half of its length, but becoming much deeper anteriorly; the posterior half of its ventral surface irregularly concave and continuous with the ethmoid cartilage; articulates posterodorsally by interdigitation with the overlying frontals and posterolaterally through cartilage and interdigitation with the prefrontals. Anterolaterally the ethmoid is extensively interdigitated with the medial edges of the palatines. The medial region of the anteroventral surface of the ethmoid is extensively interdigitated with the dorsal surface of the vomer in the smaller specimen, but only lightly interdigitated to it in the larger. The more or less vertical anterior face of the ethmoid supports the posteromedial ends of the premaxillaries and maxillaries. The lateral surface of the anterior one-third of the ethmoid is concave, so that when it articulates laterally with the equally concave medial surface of the palatine a spacious canal is left between the two bones. Through this canal run the nerves and blood vessels from the similar canal between the medial surface of the prefrontal and lateral surface of the ethmoid cartilage.

Vomer. -A narrow shaft throughout its length, except anteriorly where it becomes somewhat expanded dorsally to articulate by fibrous tissue with the posteromedial arms of the premaxillary and maxillary; articulates by interdigitation posteriorly with the concave anterior end of the parasphenoid, laterally with the palatines, and anterodorsally with the ethmoid. Posterodorsally the ethmoid cartilage intervenes between the dorsal surface of the vomer and the ventral surface of the ethmoid.

\section{Mandibular Region.}

Hyomandibular. - Very wide for most of its length, only tapering to a stout shaft for a short distance anteroventrally; cartilage filled at its dorsal and anteroventral edges; articulates by fibrous tissue dorsally with the elongate concavity formed anterolaterally by the sphenotic, anteromedially by the prootic, and posteriorly by the pterotic. The hyomandibular articulates by fibrous tissue along its posterior edge with the preoper- culum and anteriorly with the symplectic and interhyal, as well as with the slightly overlying posterior edge of the metapterygoid.

Quadrate. - Widest posteriorly, tapering to a knob anteriorly for articulation by fibrous tissue with the articular in the lower jaw; cartilage filled at its posterior edge; prolonged from its posteroventral edge into a thin process which articulates by fibrous tissue with the symplectic; articulates by fibrous tissue anterodorsally with the ectopterygoid, ventrally with the preoperculum, posteriorly with the metapterygoid, and posterodorsally with the mesopterygoid.

Metapterygoid. - Large, thick, more or less square; cartilage filled at its anterior edge; articulates by fibrous tissue anterodorsally with the mesopterygoid, anteriorly with the quadrate, and posteriorly with the hyomandibular. Ventrally the metapterygoid slightly overlies and interdigitates with the symplectic and also articulates by fibrous tissue with the interhyal.

Symplectic. - Large and elongate; cartilage filled at its posterior edge; articulates dorsally by slight interdigitation with the overlying metapterygoid, while it articulates by fibrous tissue posteroventrally with the preoperculum and interhyal, and anteroventrally with the overlying quadrate.

\section{Palato-Pterygoid Region.}

Palatine.-Expanded into a thick plate posteroventrally, but becoming laterally expanded anterodorsally; articulates by firm interdigitation along the anterior half of its dorsomedial edge with the ethmoid and along the anterior half of its ventromedial edge with the vomer. The palatine is equally firmly interdigitated posterodorsally with the prefrontal and posteroventrally with the parasphenoid. The medial surface of the upper region of the anterior half of the palatine is concave, so that a canal is formed between it and the ethmoid, as described previously. The medial and anterior surface of the anterodorsal end of the palatine forms the articular facet for support through fibrous tissue of the lateral surface of the posteromedial wing of the maxillary.

Ectopterygoid. -Expanded posteriorly; only slightly curved along its anterior edge; articulates by fibrous tissue dorsally with the palatine and ventrally with the quadrate, while posteriorly it articulates by fibrous tissue and slight interdigitation with the mesopterygoid. The palatine and quadrate slightly overlie the ectopterygoid, while the ectopterygoid slightly overlies the mesopterygoid.

Mesopterygoid. - Thin; irregular in its posterior and ventral outline; articulates by slight interdigitation anteroventrally with the ectopterygoid and by fibrous tissue anteriorly with the palatine, ventrally with the quadrate and posteroventrally with the metapterygoid. 


\section{Opercular Region.}

Operculum. - Thin and expanded ventrally; a dorsally directed process for muscle attachment present above its articular region with the preoperculum; articulates ventrally by fibrous tissue with the suboperculum, which it broadly overlies, while along its upper anterior edge the operculum is slightly expanded laterally into the articular facet whose concave face attaches by fibrous tissue to the preoperculum.

Suboperculum. - Thin and delicate in its regions that lie behind and below the operculum, but slightly thicker at its anterodorsal end; articulates by fibrous tissue dorsally with the overlying operculum, while at the end of its anterodorsal process it connects by a ligament with the upper prong at the posterior end of the interoperculum.

Interoperculum. - A long sturdy rod for all of its length, except posteriorly where it bifurcates into two thin prongs. The more ventral of these two prongs lies in the fibrous tissue sheet between the branchiostegal rays and the region of the operculum and suboperculum. The dorsal prong connects by ligament with the anterodorsal process of the suboperculum. Anteriorly the interoperculum connects by ligament with the angular in the lower jaw. Just in front of its ventral prong the medial surface of the interoperculum is held by fibrous tissue to the area of articulation between the epihyal and interhyal.

Preoperculum. - Relatively thin and narrow throughout its length, being only slightly expanded ventrally in its middle region in the smaller specimen, but about one-third wider in the larger specimen; articulates by fibrous tissue along the posterior half of its dorsal edge with the hyomandibular and along the anterior half of its dorsal edge with the quadrate and the region of the symplectic, metapterygoid, and interhyal. Along the upper portion of its posterior edge the preoperculum possesses a slight convexity for articulation through fibrous tissue with the operculum.

\section{Upper Jaw.}

Premaxillary. - Posteromedial arm thick and sturdy; together with the fused teeth forms a massive crushing plate; its anterior edge forming the anterior border of the upper jaw, except for a short distance ventrally where the maxillary forms the border. The dorsomedial surfaces of the two premaxillaries are firmly held to one another by fibrous tissue and extensive interdigitation, which, especially in the larger specimen, takes the form of numerous small projections from the otherwise flattened medial surfaces of apposition of each premaxillary alternating with one another. The posterolateral surface of the premaxillary is strongly interdigitated with the overlying maxillary. The premaxillary contains an elongate internal cavity which houses the dental pulp and which communicates with the exterior by two openings on the posterior edge of the interdigitated surfaces of the premaxillary and maxillary, as well as at numerous smaller openings along the lateral surface of the tooth bearing region, especially dorsally. The posteromedial arm of the premaxillary articulates by fibrous tissue posteriorly with the vertical anterior face of the ethmoid. The fused teeth of the jaws retain much of their individual identity and are particularly clearly seen at the edge of the jaw. About 25 to 30 of these small dental units, with the rounded faces oriented toward the biting edge of the jaw and the apparently slightly concave edges oriented toward the pulp cavity, can be seen packed closely together at the edge of the jaw, being held immovably in place by an extremely dense bony matrix. How much fusion actually takes place between the tooth elements themselves and between the tooth elements and the bony matrix of the premaxillary could only be told by a histological examination not attempted here. The tooth elements become less and less distinctly seen at the surface further away from the edge of the jaw, except at the extreme dorsal edge of the tooth bearing lateral surface, where the primordia of the individual teeth can be seen forming in the small pockets in the matrix that open by pores to the exterior on the lateral surface. The primordia obviously move gradually toward the distal crushing edge of the jaw and become more fully impacted with the matrix of the premaxillary as new primordia form behind it. There are about 10 to 15 such small teeth in various stages of incorporation with the matrix between the generative region at the inner edge of the tooth bearing surface and the crushing outer edge of the jaw. In the medial region of its ventral surface the premaxillary bears a massive trituration plate formed of fused teeth. The process by which this plate is formed on the undersurface of the premaxillary can be seen at the posterior edge of the plate. Four or five anteroposteriorly compressed teeth are formed in deep sockets at the posterior edge of the plate and are clearly evident as entirely individual and separate units held relatively loosely in their sockets. Immediately in front of this row of newly formed teeth in their individual sockets, the surface of the trituration plate no longer shows individual tooth elements, and only the ridges and grooves on the surface give evidence of what are evidently the now fused teeth that had moved up from the formation area. The medial edges of the trituration plates of either premaxillary do not meet in the midline but, rather, are separated by a slight gap.

Maxillary. - Somewhat curved forward at both ends; forms the anterior border of the upper jaw at its ventral end. Posteromedially the maxillary possesses a relatively long, but thin, process which overlies the lateral and most of the ventral edges of the posteromedial arm of the premaxillary. The lateral surface of this posteromedial arm of the maxillary is slightly concave, forming the articular surface which makes fibrous tissue contact with the medial surface of the anterodor- 
sal region of the palatine. The posterior edge of the posteromedial arm of the maxillary is supported against the anterior vertical face of the ethmoid. The maxillary is firmly interdigitated along most of its medial surface with the premaxillary, except at the extreme ventral end where it no longer overlies the premaxillary and articulates by fibrous tissue with the lateral surface of the posterodorsal end of the dentary. In the larger of the two specimens the posteromedial arm of the premaxillary is narrower and that of the maxillary wider than that illustrated for the smaller specimen, and the maxillary, rather than the premaxillary, forms the major articulation with the ethmoid and vomer.

Lower Jaw.

Dentary.-Dentaries indistinguishably fused together at what would normally be their medial edges of contact, so that the combined dentaries form a massive U-shaped bone. No medial line of fusion between the two halves can be observed externally or internally, but the two canals leading into the pulp cavity occur side by side to either side of the midline. The pulp cavity of the combined dentaries is smaller than that of the premaxillaries. The teeth of the crushing jaw are exactly like those described for the premaxillary, as are those of the trituration plate, and are formed from primordia in the same way. The trituration plate of the dentaries, however, is a single, almost squarish, massive block which shows no evidence of the fusion line between what may be assumed to have been at one time the separate right and left halves. The posterior end of the dentary is extremely concave to accommodate the articular, to which it attaches by interdigitation. Posteroventrally the dentary articulates by fibrous tissue with the angular. The dorsolateral surface of the dentary articulates by fibrous tissue with the ventromedial surface of the maxillary.

Articular. - More or less triangular in shape; its posterior edge somewhat laterally expanded; cartilage filled at its anterior edge where it is continuous with the remains of Meckel's cartilage; articulates by interdigitation over most of its lateral surface and over the anterior portions of its medial surface with the dentary. Posteroventrally it interdigitates with the angular. At the concave surface of the lateral expansion on its lower posterior edge the articular is supported through fibrous tissue by the anterior knob of the quadrate. The sesamoid articular is a slightly elongate nubbin of bone held alongside the anteromedial edge of the articular just above the remains of Meckel's cartilage and just below the posteromedial edge of the dentary, and is relatively much larger in the larger specimen than in the smaller.

Angular. - Small; articulates dorsally by interdigitation with the articular and anteriorly by fibrous tissue with the dentary. Posteriorly it connects by ligament with the anterior end of the interoperculum.

\section{BRANCHIAL APPARATUS.}

Hyoid Arch, Branchiostegal Rays, and Urohyal.

Hypohyals. - Both hypohyal elements present, the dorsal the larger of the two; dorsal hypohyal cartilage filled at its posterior and ventral edges, ventral hypohyal cartilage filled at its posterior and dorsal edges; both hypohyals articulate through cartilage and, in the larger of the two specimens, by slight interdigitation of their medial edges with one another and with the ceratohyal; dorsomedially the dorsal hypohyal articulates by fibrous tissue with its opposite member.

Ceratohyal. -Elongate; dorsoventrally expanded at both its anterior and posterior ends; cartilage filled at its anterior and posterior edges; articulates through cartilage anteriorly with the dorsal and ventral hypohyals and posteriorly with the epihyal, strengthened in the case of the larger of the two specimens by slight interdigitation. Of the six branchiostegal rays, the first three are held directly to the ceratohyal and the fourth is held near the posterior edge of the ceratohyal on the cartilage separating the latter from the epihyal. The somewhat enlarged first branchiostegal ray is held to the lower lateral surface of the ceratohyal about one-third the way back its length. The second branchiostegal ray is held to a very slight concavity in about the middle of the ventral edge of the ceratohyal or slightly dorsomedial to it, while the third branchiostegal attaches to the lower posterolateral surface of the ceratohyal.

Epihyal. - Rounded posteroventrally but slightly prolonged anterodorsally; cartilage filled at its ventral and anterior edges; articulates through cartilage and, in the larger specimen, by interdigitation anteriorly with the ceratohyal, while at a slight prominence on its posterodorsal edge it articulates by fibrous tissue with the interhyal. Just below its articulation with the interhyal, the epihyal articulates by fibrous tissue laterally with the interoperculum.

Interhyal. - An elongate column; cartilage filled at its dorsal and ventral edges; articulates by fibrous tissue ventrally with the epihyal and dorsally with the fibrous tissue sheet between the hyomandibular, metapterygoid, symplectic, and preoperculum.

Branchiostegal rays. - Six in number; the first branchiostegal ray shorter but, in the anterior two-thirds of its length, wider than the other rays; its dorsal edge distinctly curved medially while its ventral platelike expansion lies in the vertical plane; articulates by fibrous tissue with the lower lateral surface of the ceratohyal about one-third the way back its length. The second branchiostegal ray is a long thin shaft held to about the middle of the length of the ventral edge of the ceratohyal in the smaller specimen (illustrated), but distinctly on the medial surface just above the middle of the ventral edge in the larger specimen. The third and fourth branchiostegal rays are slightly shorter, and much stouter anteriorly, than the second ray. The third ray is 
held to the lower posterolateral surface of the ceratohyal, while the fourth is held to the posterior edge of the ceratohyal and to the cartilage between the epihyal and ceratohyal. The fifth and sixth branchiostegal rays are held to the lateral surface of the epihyal; the sixth branchiostegal is the longest of the branchiostegal rays. All of the branchiostegal rays articulate with the ceratohyal or epihyal by fibrous tissue.

Urohyal. - Thin and shallow; laterally expanded and wider than long; articulates by fibrous tissue posterodorsally with the anterior edge of the first basibranchial and anterodorsally with the dorsomedial surface of the dorsal hypohyal; in the larger specimen the urohyal is even more laterally expanded than as illustrated for the smaller specimen.

Branchial Arches. - All the elements are cartilage filled at their edges of articulation with the other elements of the series, and the articulations are usually through cartilage and fibrous tissue. The branchial arches are composed of three basibranchials, three pairs of hypobranchials, five pairs of ceratobranchials, four pairs of epibranchials, and four pairs of pharyngobranchials. Four gills are present, with a slit between the fourth arch and the lower pharyngeal.

First arch.-Basi-, hypo-, cerato-, epi-, and pharyngobranchial elements present. First basibranchial elongate, slightly compressed in the middle; displaced forward so that it articulates posteriorly with the second basibranchial and only posterolaterally with the first hypobranchials. First hypobranchial an elongate rod; articulates with the anterior end of the second basibranchial and the posterior end of the first basibranchial. First ceratobranchial a narrow rod; slightly shorter than the second ceratobranchial but of about the same length as the third and fourth ceratobranchials; articulates ventrally with the first hypobranchial and dorsally with the first epibranchial. First epibranchial rodlike ventrally but becoming wider and flatter dorsally; the largest of the epibranchials; its dorsal end with two articular prominences, the anterior of which connects with the first pharyngobranchial, while the posterior process connects with the base of the second pharyngobranchial. First pharyngobranchial (suspensory pharyngeal) a curved rod; toothless; articulates ventrally with the first epibranchial and dorsally with the lateral surface of the base of the large ventral process of the posteroventral surface of the parasphenoid.

Second arch. -Basi-, hypo-, cerato-, epi-, and pharyngobranchial elements present. Second basibranchial only slightly longer than the first basibranchial, but much wider; articulates anteriorly with the first basibranchial, anterolaterally with the first hypobranchials, posterolaterally with the second hypobranchials, and posteriorly with the third basibranchial. Second hypobranchial the largest of the hypobranchials; much expanded anterolaterally; articulates posteromedially with the second basibranchial and dorsally with the second ceratobranchial. Second ceratobranchial the longest of the ceratobranchial elements; articulates dorsally with the second epibranchial. Second epibranchial columnar, with a slight expansion posteroventrally; articulates dorsally with the second pharyngobranchial. Second pharyngobranchial roughly L-shaped, with an irregular series of about 25 well-developed and sharp-pointed teeth borne on the slightly longer of its two arms. The toothless arm of the pharyngobranchial articulates ventrally with the posterodorsal process of the first epibranchial and with the dorsal end of the second epibranchial. The teeth are borne in individual sockets and are replaced by new teeth developing in sockets irregularly scattered between the sockets of the old teeth. The second pharyngobranchial is closely held to the other two toothed pharyngobranchials by fibrous tissue.

Third arch.-Basi-, hypo-, cerato-, epi-, and pharyngobranchial elements present. Third basibranchial the longest of the basibranchials; laterally expanded in the anterior two-thirds of its length; articulates anteriorly with the second basibranchial, posterolaterally with the third hypobranchials, and posteriorly with the fourth ceratobranchials. Third hypobranchial produced anteroventrally, at which end it articulates by fibrous tissue with the ventral surface of the first basibranchial; articulates posteromedially with the third basibranchial and posterolaterally with the third ceratobranchial. Third ceratobranchial like the others; articulates dorsally with the third epibranchial. Third epibranchial triangular in shape; articulates anterodorsally with the third pharyngobranchial and posterodorsally with the middle of the anterior edge of the fourth epibranchial. Third pharyngobranchial rounded ventrally, only slightly expanded dorsally; toothed in the same manner as the second pharyngobranchial, but with somewhat fewer teeth on its slightly shorter and thicker tooth-bearing edge.

Fourth arch. -Cerato-, epi-, and pharyngobranchial elements present. Fourth ceratobranchial like the others; articulates ventrally with the third basibranchial and dorsally with the fourth epibranchial. Fourth epibranchial a column expanded posteriorly in the middle of its length; articulates dorsally with the fourth pharyngobranchial. Fourth pharyngobranchial the smallest of the toothed pharyngobranchials, but with the widest tooth-bearing surface; teeth like those of the other pharyngobranchials, except slightly smaller.

Fifth arch. - Ceratobranchial (lower pharyngeal) element only. Fifth ceratobranchial a stout shaft; rounded anteroventrally but tapering to a narrow blunt end posterodorsally; articulates anteroventrally with the base of the fourth ceratobranchial. The rounded anterior region of the fifth ceratobranchial bears teeth like those of the pharyngobranchials, except slightly smaller, but more posteriorly on the dorsal surface of the shaftlike portion the teeth are extremely small. 


\section{PAIRED FIN GIRDLES.}

\section{Pectoral Fin.}

Supracleithrum. - In position at about a $45^{\circ}$ angle to the axis of the body; a massive straight shaft, very thick dorsally but thinner ventrally. At its wide dorsal edge the supracleithrum articulates by fibrous tissue with the ventral surface of the posterolateral portion of the pterotic, while anterodorsally the supracleithrum abuts against the posterior edge of the posteroventral flange of the pterotic and articulates with it by fibrous tissue and, in the smaller specimen, by interdigitation, the supracleithrum being immovably held to the pterotic. Ventrally the supracleithrum broadly overlies the cleithrum and anterior end of the dorsal postcleithrum, to both of which bones it is firmly held by fibrous tissue. There is no evidence in either of the two study specimens of a posttemporal bone intervening between the supracleithrum and pterotic, even as a small bone extensively interdigitated or partially fused to one of them. It would be of interest to know whether young specimens of this species, the most generalized of the Recent gymnodonts, give evidence to the fate of the posttemporal in gymnodonts.

Cleithrum. - Extremely long, reaching anteriorly to between the dentaries in the lower jaw; laterally expanded along most of its length but expanded posteriorly only to a very slight extent in the area of the scapula; articulates by fibrous tissue dorsolaterally with the overlying supracleithrum and posterodorsally with the anterior edge of the dorsal postcleithrum. Along its upper medial edge the cleithrum articulates by fibrous tissue with the anterior edge of the dorsal postcleithrum. Along its upper medial edge the cleithrum articulates by fibrous tissue with the anterior edge of the scapula and the anterodorsal edge of the coracoid. The ventral end of the coracoid also articulates by fibrous tissue with the medial edge of the cleithrum about one-third the way back the length of the cleithrum. At their extreme anterior ends the medial surfaces of the two cleithra are firmly bound to one another by fibrous tissue, while just posterior to this region the medial surfaces of the two cleithra support the anterior end of the pelvis.

Postcleithra. - The postcleithra form a long strut from the ventral end of the supracleithrum along the abdominal wall musculature to about one-third the way back the length of the abdominal cavity. The dorsal postcleithrum articulates by fibrous tissue anteriorly with the posterodorsal edge of the cleithrum and anterolaterally with the posteromedial surface of the overlying supracleithrum. Along nearly all of its ventral edge the dorsal postcleithrum articulates by fibrous tissue with the dorsal edge of the anterior half of the ventral postcleithrum, which is a somewhat slimmer shaft than the dorsal postcleithrum.

Coracoid. - Rounded anterodorsally, but tapering to a slender shaft in the ventral half of its length, a large posterodorsally directed process present from the posterior edge of the rounded portion of the coracoid; cartilage filled along the anterior edge of its rounded portion; articulates by fibrous tissue anteriorly with the cleithrum and posterodorsally with the third and fourth actinosts; anterodorsally it articulates through cartilage with the scapula.

Scapula. - Scapular foramen entirely enclosed by the scapula; cartilage filled at its anterior and ventral edges; articulates by fibrous tissue anteriorly with the cleithrum and ventrally through cartilage with the coracoid. Along the upper half of its posterior edge the scapula possesses two slightly protruding articular facets, the more dorsal for articulation with the first fin ray and the other for articulation with the ventral edge of the first actinost. At the bottom of its posterior edge the scapula supports the second actinost.

Actinosts. - Four elements; all cartilage filled at both ends; first actinost by far the smallest of the elements and articulated by fibrous tissue with the upraised area on the posterodorsal edge of the scapula; second, third, and fourth actinosts much larger than the first and articulated by fibrous tissue with the posteroventral edge of the scapula in the case of the second actinost and to the dorsal edge of the coracoid in the case of the third and fourth actinosts. Distally the actinosts support through fibrous tissue all of the pectoral fin rays, except for the small first fin ray, which articulates with the scapula.

Fin rays. - Fifteen fin rays present on both sides of the smaller specimen and 16 on both sides of the larger; the first ray short, composed of two distinct halves throughout its length, the medial half being by far the stouter of the two; first ray articulated with the scapula, but the other rays articulated with the actinosts. The first two rays and the last ray unbranched, the other rays branched; first ray without cross-striations, the other rays cross-striated.

\section{Pelvic Fin.}

Pelvis. - An extremely long and stout shaft; its posterior half tapering to a thin rod, while its anterior half becomes ventrolaterally expanded and then tapers to a bluntly rounded anterior end; the two halves of the pelvis firmly interdigitated with one another, except at the narrow posterior end where the interdigitation becomes so extensive that distinct halves can no longer be recognized and where fusion of the medial surfaces of each half may have taken place. The ventral surface of the anterior half of the pelvis is deeply concave and houses the muscle mass whose contraction causes the downward and forward rotation of the pelvis around its anterior articulation with the cleithra in the process of expansion of the huge ventral flap or dewlap. A small gap is present in the otherwise interdigitated medial surfaces of the two halves at a point just behind the middle of the 
length of the pelvis. Anteriorly the pelvis articulates by tough fibrous tissue with the medial edges of the two cleithra in the region below the quadrate. There is no trace of pelvic fins or of any of the rudimentary fin ray elements such as are found in balistoids.

VERTEBRAL COLUMN. -All vertebrae with biconcave centra, except for the last, which ends posteriorly in the urostyle.

\section{Abdominal Vertebae.}

First vertebra. - Lateral wall of neural arch from each side of the centrum meeting its opposite member dorsally above the neural canal but not continuous or interdigitated with it; rather, the medial edges are held to one another by fibrous tissue; the dorsal surface of this articular area is slightly upraised medially to give the suggestion of a neural spine. The upper anterior portion of the centrum and lower portion of the neural arch are deeply concave and form a facet for articulation by fibrous tissue with the exoccipital condyle.

Other abdominal vertebrae. - Nine abdominal vertebrae in two specimens, all of which, except for the first and ninth in the smaller specimen, bear true ribs; from the first to the ninth vertebrae the neural spines become increasingly well developed; the two halves of the neural spine of the second vertebra, like that of the first, are not fused together above the neural canal, but are held to one another by fibrous tissue, while the neural spines of the more posterior vertebrae are single pieces. The first to the sixth abdominal vertebrae do not possess haemal arches, but the seventh to ninth have complete haemal arches and progressively better developed haemal spines which project slightly posterior to the haemal arch, that of the seventh with only a short posterior tapering to the haemal arch. Haemal prezygapophyses are not developed and haemal postzygapophyses only begin to develop from about the seventh vertebra and never extend posteriorly even to the level of the end of the centrum above them. Neural postzygapophyses are present on the abdominal vertebrae, but the greatest development of the zygapophyses involves the neural prezygapophyses. The neural prezygapophyses, and particularly the portions of the neural arches and spines above them, become enlarged from the second to about the seventh and eighth abdominal vertebrae. At its full development the region anterior to the thickened shaftlike part of the neural spine becomes enlarged into a relatively flat plate which projects anteriorly slightly past the anterior edge of its vertebral centrum to fit below the posteriorly projecting neural spine of the preceding vertebra. These anterior expansions are held by fibrous tissue to the posterior edge of the neural spine region of the preceding vertebra and increase the rigidity of the vertebral column. The tip of the neural spine of the fourth vertebra supports the anteroventral edge of the first supraneural (= first basal pterygiophore of the spiny dorsal fin when the latter is present), while the neural spines of the fifth and sixth abdominal vertebrae articulate with the ventral edge of this element further back along the length of the latter. The neural spine of the seventh abdominal vertebra articulates dorsally with the ventral edges of the second and third supraneurals (terminology when no spiny dorsal fin is present) and posteriorly with the anterior edge of the first soft dorsal fin basal pterygiophore. The neural spines of the eighth and ninth abdominal vertebrae articulate between the more anterior dorsal fin basal pterygiophores.

Ribs and epipleurals. - True ribs are present on all of the abdominal vertebrae in the large specimen, but are absent on the first and last abdominal vertebrae in the smaller (illustrated) specimen. The point of articulation of the rib with the vertebra is at first with the lower anterolateral surface of the centrum, but it becomes progressively lower on the centrum until finally the ribs on the last few abdominal vertebrae articulate with the lateral surfaces of the haemal arches. The ribs become progressively longer from the first to the fourth or fifth, and then become slightly shorter again. The ribs border the internal surface of the abdominal cavity and there can be no doubt that they are pleural ribs. The first two ribs (attached to the first and second vertebrae) of the larger specimen and the first rib (attached to the second vertebra) of the smaller specimen do not bear epipleurals (intermuscular bones), but all of the other ribs have well-developed epipleurals attached to their dorsal surfaces. In the smaller of the two study specimens the epipleurals attached to the second to fifth abdominal vertebrae are composed of two pieces which are variously branched. The two pieces of these intermuscular bones are held together by fibrous tissue. The epipleurals attached to the sixth and seventh ribs are composed of a single unbranched piece, and while that of the sixth vertebra is held by fibrous tissue to the pleural rib, that of the seventh vertebra is fused to the rib. The ninth abdominal vertebra has an unbranched epipleural attached by fibrous tissue to the lateral surface of its haemal arch. Short, unbranched epipleurals are attached by fibrous tissue to the lateral surf $c$ e of the haemal arches of the first five caudal vertebrae. In the larger study specimen the epipleurals are more extensively branched, and only one, that attached to the fifth abdominal vertehra, is composed of two pieces. The epipleurals of the second abdominal vertebra are both unbranched, while those of the third are branched on one side and unbranched on the other. The epipleurals of the fourth to seventh abdominal vertebrae are extensively branched, while those on the eighth and more posterior vertebrae are unbranched. Whereas in the smaller specimen the epipleurals extend to the fifth caudal vertebra, in the larger there are epipleurals on both sides of the sixth caudal vertebra as well.

Caudal Vertebrae. - Eleven caudal vertebrae in two specimens; all, except the last, with well-developed haemal arches and spines; neural spines well developed 
on all but the last of the caudal vertebrae; neural spines decreasing in length from the first to the eighth, but increasing in length from the 9 th to 10th. As the neural spines of the first to sixth caudal vertebrae decrease in height, they become laterally compressed into anteroposteriorly extended plates. The neural spines of the first to third caudal vertebrae are placed between, and articulate by fibrous tissue with, the dorsal fin basal pterygiophores. The anterior edge of the neural spine of the fourth caudal vertebra articulates by fibrous tissue with the posterior edge of the 11th, or last, basal pterygiophores. The neural spine of the 9th caudal vertebra elongates almost directly posteriorly to form a roof over the 10th caudal vertebra for almost the entire length of the centrum of the latter. The neural spine of the 10th caudal vertebra is an elongate shaft which distally supports the first 4 or 5 procurrent caudal fin rays. The anterior ends of the neural arches and bases of the neural spines of all of the caudal vertebrae, except for the last two or three, are prolonged anterolaterally into thick spinelike processes to which are attached large muscle masses. Just above the centrum on the lower anterior edge of the neural arch there is a shorter anterior process which articulates by fibrous tissue with the posterolateral surface of the neural arch and base of the neural spine of the preceding vertebra. This anterior process, representing the neural prezygapophysis, is increasingly well developed from the first to about the fifth and sixth caudal vertebrae, posterior to which it becomes progressively smaller again. The haemal arches and spines of the first to fifth or sixth caudal vertebrae bear epipleurals laterally and the first to fifth support through fibrous tissue ventrally the basal pterygiophores of the anal fin. Along most of its posterior edge the haemal spine of the first caudal vertebra supports the upper anterior edge of the enlarged first basal pterygiophore of the anal fin. The haemal spines of the second to fourth caudal vertebrae support most of the anal fin basal pterygiophores. The posterolaterally expanded and slightly concave anterior surface of the large haemal spine of the fifth caudal vertebra supports the small ninth, or last, pterygiophore. The ventrolateral surface of the posterior half of each centrum from the first to fifth caudal vertebrae becomes increasingly expanded ventrally to form the side walls of the trough through which the haemal canal courses. At the sixth caudal vertebra these ventral expansions articulate by fibrous tissue with the dorsal edge of the posteriorly prolonged flange of the haemal spine. There are thus, in effect, two arches over the haemal canal-the haemal arch proper and the arch formed by the meeting of the haemal spine with the ventral flange from either side of the posteroventral surface of the centrum. The seventh and eighth caudal vertebrae have the same arrangement, except that the surface of contact between the haemal spine and the ventral flanges is fused, leaving only a foramen to indicate what was formerly the wide space between the dorsal edge of the posteriorly directed haemal spine and the ventrolateral surface of the centrum. The haemal spine of the 9th caudal vertebra, like its neural spine, is prolonged posteriorly to form a roof over the haemal arch and base of the haemal spine of the 10th caudal vertebra. The haemal spine of the 10th caudal vertebra, like its neural spine, forms a long shaft that distally supports most of the procurrent rays of the lower lobe of the caudal fin. The haemal arches and spines of the 9th and 10th caudal vertebrae are autogenous.

Caudal Skeleton. - The caudal fin supporting structures are composed of the 11th caudal vertebra and its urostylar projection, an epural, two pairs of uroneurals, four hypurals, and a parhypural, as well as the shaftlike neural spine and haemal spine of the 10th caudal vertebra. The centrum of the 11 th caudal vertebra is prolonged posterodorsally into a urostylar process whose posterior edge is concave and supports the upper three hypurals, while its anterodorsal edge is similarly concave and helps support the uroneurals. Because of its concave anterodorsal and posterior surfaces, the upper half of the urostyle is forked into right and left halves, since there is no bony material in the midline of the urostyle in this region. From the anterolateral region of its dorsal surface the centrum possesses an anteriorly directed prong or neural prezygapophysis which articulates by fibrous tissue with the posterolateral surface of the neural spine of the 10th caudal vertebra. The dorsomedial edges of the two sides of the neural arch of the last centrum are not in close contact in the midline over the neural canal, only partially roofing over the latter. The epural is a large column of bone which is concave along the upper half of its posterior edge. It articulates by fibrous tissue anteriorly with the posterior edge of the neural spine of the 10th caudal vertebra, posteriorly with the first uroneural and ventrally with the dorsal edges of the incomplete neural arch of the 11th caudal vertebra. The second uroneural is a long rounded shaft, with a medial groove along its length representing the region of complete fusion of its two halves, whose anteroventral edge rests against the concave dorsal surface of the urostyle mainly in the region of its posterior bifurcation. The posterodorsal end of the second uroneural supports the deeply forked base of the first principal ray of the upper lobe of the caudal fin. Along the ventral two-thirds of its round anterior surface the second uroneural has closely applied to it a large, but very thin, pair of bones, the first uroneurals, which articulate with it, and with each other medially, by fibrous tissue. Along their anteroventral edges the first uroneurals articulate by fibrous tissue with the dorsal surface of the neural arch and urostyle of the last centrum. The fourth hypural, or uppermost, is more or less triangular in shape, with the lower two-thirds of its anterior edge resting against the concave posterior surface of the urostyle. Along its ventral edge the fourth hypural is closely held by fibrous tissue to the dorsal edge of the third hypural. The third hypural is widest posteriorly, narrow anteriorly to a slightly convex and laterally expanded articular facet which fits against a concavity on the anterior one-third of the dorsal edge of the second hypural. The extreme anterior end of the second hypural 
akes only slight contact with the posterior edge of the ostyle. The anterior end of the second hypural rests ainst the lower posterior edge of the urostyle, while its rsal edge is slightly expanded laterally along the anrior one-third of its length into a concave articular facet contact with the anterior end of the third hypural, as plained above. The ventral edge of the second hypural ticulates with the dorsal edge of the first hypural by fious tissue posteriorly but more anteriorly by slight inrdigitation. The first hypural articulates dorsally with e second hypural as just described, while anteriorly it sts against, and possibly slightly interdigitates with, e posteroventral edge of the last centrum. The first pural articulates ventrally with the dorsal edge of the rhypural by fibrous tissue posteriorly but more anriorly by slight interdigitation. The parhypural is obously the haemal arch and spine of the last, or 11th, udal vertebra, but, like the haemal arches and spines the 9 th and 10 th caudal vertebrae, it is autogenous. rsally the parhypural articulates with the first hypural rough fibrous tissue and interdigitation, as described ove. The portion of the dorsolateral surface of the rhypural that lies below the anterior one-third of the st hypural is laterally expanded into a flange to which udal fin-ray muscles are attached. A similar, but much aller, lateral flange is present from the anterior edge of e first hypural. The anterior end of the flange from the st hypural overlies the anterodorsal surface of the inge from the parhypural. The combined flanges from e parhypural and first hypural compose the hypuraphysis. The anterior half of the dorsal articular surce of the parhypural is concave, so that where it intergitates with the last centrum and with the anterovenlend of the first hypural, a canal is formed in the mide of the otherwise interdigitated surfaces between the ree bones. The canal opens to the exterior posteriorly a slight gap in the articulated surfaces of the parhyral and first hypural just behind the lateral flange of e parhypural. The canal is continuous anteriorly with e haemal canal of the preceding vertebrae.

Caudal fin rays. - Twelve principal (branched rays us the unbranched ray directly above and directly low the series of branched rays) fin rays preceded by ght (smaller specimen) or nine procurrent rays above d six (smaller specimen) or seven procurrent rays low. The 10 branched rays become increasingly anched toward the middle 2 rays, which are branched triple dichotomies. The uppermost branched ray and e lowermost branched ray are the longest of the caudal ays, while the two middle rays are the shortest, being out one-half the length of the longest branched rays. ne two unbranched principal caudal rays are some2at shorter than the longest branched rays, and the ocurrent caudal rays rapidly decrease in length anriorly in the series. The first two or three procurrent ys are without cross-striations, while all the other ocurrent rays and principal rays are cross-striated. The per unbranched principal caudal ray articulates with e second uroneural; the lower unbranched principal caudal ray with the parhypural. The upper three and lower two branched rays of the dorsal lobe articulate, respectively, with the fourth hypural and with the third hypural. The upper two and lower three branched rays of the ventral lobe articulate, respectively, with the second hypural and with the first hypural. All the rays articulate by fibrous tissue with the supporting elements.

\section{DORSAL AND ANAL FINS.}

\section{Dorsal Fin.}

Spines and pterygiophores. - The presence or absence of a spiny dorsal fin in T. macropterus has been discussed by Tyler (1962a:794-796; 1967:92-93), it being shown that most specimens from Japan to Indonesia have a minute spiny dorsal fin, usually of two spines, while the specimens now known from the Indian Ocean lack the spiny dorsal fin. The smaller of the two specimens studied for the present work, SU 13747, from the Philippines, had been skinned, then cleared and stained, and then dissected by the author prior to his discovery of a spiny dorsal fin in other whole specimens, and it is impossible to say, upon reexamination of the cleared and stained SU 13747 specimen, whether spines had been present or not. Being from the Philippines, it probably did have spines which were lost during its processing as an osteological preparation. The larger study specimen, ANSP 98917, from the Volcano Islands south of Japan, was processed with the knowledge of its possession of a spiny dorsal fin. The lateral view illustration of the entire skeleton presented here is based on SU 13747, except that the dorsal spines are based on ANSP 98917, as are the detailed lateral and dorsal views of the spiny dorsal fin.

When dorsal spines are present, the first is longer than the second, and both can be laid back in a shallow groove in the skin in the midline of the body. The bases of the two spines are relatively close together, the first articulating with the posterodorsal surface of the long first basal pterygiophore (= first supraneural when no spiny dorsal fin is present), and the second spine articulating in the middle of the much shorter second basal pterygiophore. From the anterolateral surface on either side of the base of the first spine a tendon runs anteroventrally along a groove in the dorsal and lateral surfaces of the first basal pterygiophore to connect to a small muscle whose contraction causes the erection of the spine. The second spine does not have such muscles and tendons associated with it, but a low membrane connects the first and second spines so that the erection of the first spine causes the erection of the second as well. The ventral ends of both spines articulate by fibrous tissue to the relatively flat surfaces of their basal pterygiophores.

There are rudiments of what is probably another dorsal spine in the form of two nubbins of bone, one to either side of the midline, lying beneath the skin on the dorsal surface of the first basal pterygiophore immediately in front of the base of the first relatively well-developed dor- 
sal spine. How constant this pair of nubbins are in their occurrence cannot be determined until more specimens of this species are available for clearing and staining, but I suspect that the nubbins represent the right and left basal regions of a rudimentary spine. In all other plectognaths with two or more dorsal spines, the first two spines are always borne on the first basal pterygiophore, while the spines posterior to them are each borne on individual basal pterygiophores, which additionally leads me to believe that the paired nubbins in $T$. macropterus are homologous to the first dorsal spine in other plectognaths and that the two relatively well-developed spines in $T$. macropterus are homologous to the second and third spines of other plectognaths. If that is true, Triodon exhibits a feature not seen in other plectognaths with a spiny dorsal fin, for when the size and number of the dorsal spines decreases in the triacanthoids and balistoids it is always by reduction and loss of elements from posteriorly to anteriorly in the series, and the first spine is always much larger than the others.

Two other bony elements without interneural processes are placed above the dorsal ends of the neural spines between, and in series with, the two basal pterygiophores supporting the dorsal spines and the first basal pterygiophore of the soft dorsal fin. When a spiny dorsal fin is not present, these four elements anterior to the anterodorsal end of the first basal pterygiophore of the soft dorsal fin would be called supraneurals. But where the two more anterior elements in the series support dorsal spines, they must be referred to as basal pterygiophores, even while the two more posterior elements technically remain supraneurals. Thus, the distinction between supraneurals and basal pterygiophores in Triodon is arbitrary, and indicates that the supraneural element that occurs in ostracioids and gymnodonts is probably a simplified basal pterygiophore that no longer supports dorsal fin spines.

Of the four elements that are supraneural in position in Triodon, the first (the first basal pterygiophore when a spiny dorsal fin is present) is by far the largest and articulates by fibrous tissue anteriorly with the distal end of the neural spine of the fourth abdominal vertebra, ventrally with the distal ends of the neural spines of the fifth and sixth abdominal vertebrae, and posteriorly with the anterior edge of the second element. The second element is much shorter than the first and articulates by fibrous tissue anteriorly with the first, ventrally with the neural spine of the seventh abdominal vertebra and posteriorly with the anterior edge of the third element. The third element is slightly shorter than the second and articulates anteriorly by fibrous tissue with the second and with the neural spine of the seventh abdominal vertebra. Posteriorly the third element slightly interdigitates with the anterior edge of the fourth, while posteroventrally it articulates by fibrous tissue with the first basal pterygiophore of the soft dorsal fin. The small fourth element articulates by interdigitation ventrally with the first basal pterygiophore of the soft dorsal fin and anteriorly with the third element.
Fin rays and pterygiophores. - Eleven fin rays present; the first ray unbranched, the others branched in single, double, or triple dichotomies; third and fourth rays longest; first ray about equal in length to the next to last ray. Each fin ray has a well-developed pair of distal pterygiophores as two distinct halves between the bifurcate base of the ray. In the smaller specimen the two halves are not in close contact with one another, while in the larger specimen the two halves have their medial edges in close apposition and are held firmly together by fibrous tissue and in some cases apparently by slight interdigitation. The fin rays are supported basally through fibrous tissue by 11 basal pterygiophores, which articulate with one another and with the neural spines of the vertebrae by fibrous tissue. The dorsal ends of the basal pterygiophores are slightly enlarged and are in close contact with one another. The upper lateral surfaces of the first three or four basal pterygiophores possess shallow lateral flanges, but these flanges decrease in size posteriorly in the series and are effectively absent on the last few pterygiophores. The pterygiophores are cartilage filled at both ends. The interneural portions of the pterygiophores articulate between the neural spines of the seventh abdominal to the fourth caudal vertebrae.

\section{Anal Fin.}

Fin rays and pterygiophores. - Ten fin rays present; the first ray unbranched, the others branched in single, double, or triple dichotomies; third and fourth rays longest; first ray about as long as the last ray. Each fin ray has a well-developed pair of distal pterygiophores as two distinct halves between the bifurcate base of the ray, with the two halves in close apposition medially only in the larger specimen, just as with the soft dorsal fin. The fin rays are supported basally through fibrous tissue by nine basal pterygiophores, which are cartilage filled at both ends. At their distal ends the pterygiophores are slightly expanded anteroposteriorly, but they do not make as close a fibrous tissue contact with one another as do the soft dorsal fin basal pterygiophores. Other than at their distal ends, the anal fin pterygiophores, with the exception of the first, are slender shafts without any lateral projections or flanges from their surfaces. The first pterygiophore is a much stouter shaft and ventrally it possesses a large lateral flange to either side of its anterior edge. The second pterygiophore is extremely thin, and is held between the first and third pterygiophores without reaching dorsally to make contact with a haemal spine. The other pterygiophores articulate by fibrous tissue dorsally with the haemal spines of the first to fifth caudal vertebrae.

Anatomical diversity.-The single Recent species of this family apparently consists of two at least partially reproductively isolated populations (Tyler 1967) differing grossly only in that the population from Japan to Indonesia usually retains a rudimentary spiny dorsal fin 
while the Indian Ocean population usually completely lacks even rudimentary dorsal fin spines.

Fragments of premaxillaries and fused dentaries with small rounded teeth incorporated into the matrix of the biting edge, found as early as the Eocene of Europe (see Material Examined), have been assigned to the Triodontidae as Triodon antiquus Leriche $(1905,1906,1919$, 1920 ), entirely on the rationale that the jaws are in three major pieces rather than the two of diodontids or four of tetraodontids.

Tetraodontids would be eliminated from consideration for the antiquus jaw fragments because in antiquus the individual dental units are small and rounded as in triodontids and diodontids rather than long rods as in tetraodontids. Diodontids can be eliminated from consideration only because the premaxillaries in antiquus remain separate from their opposite members, while they
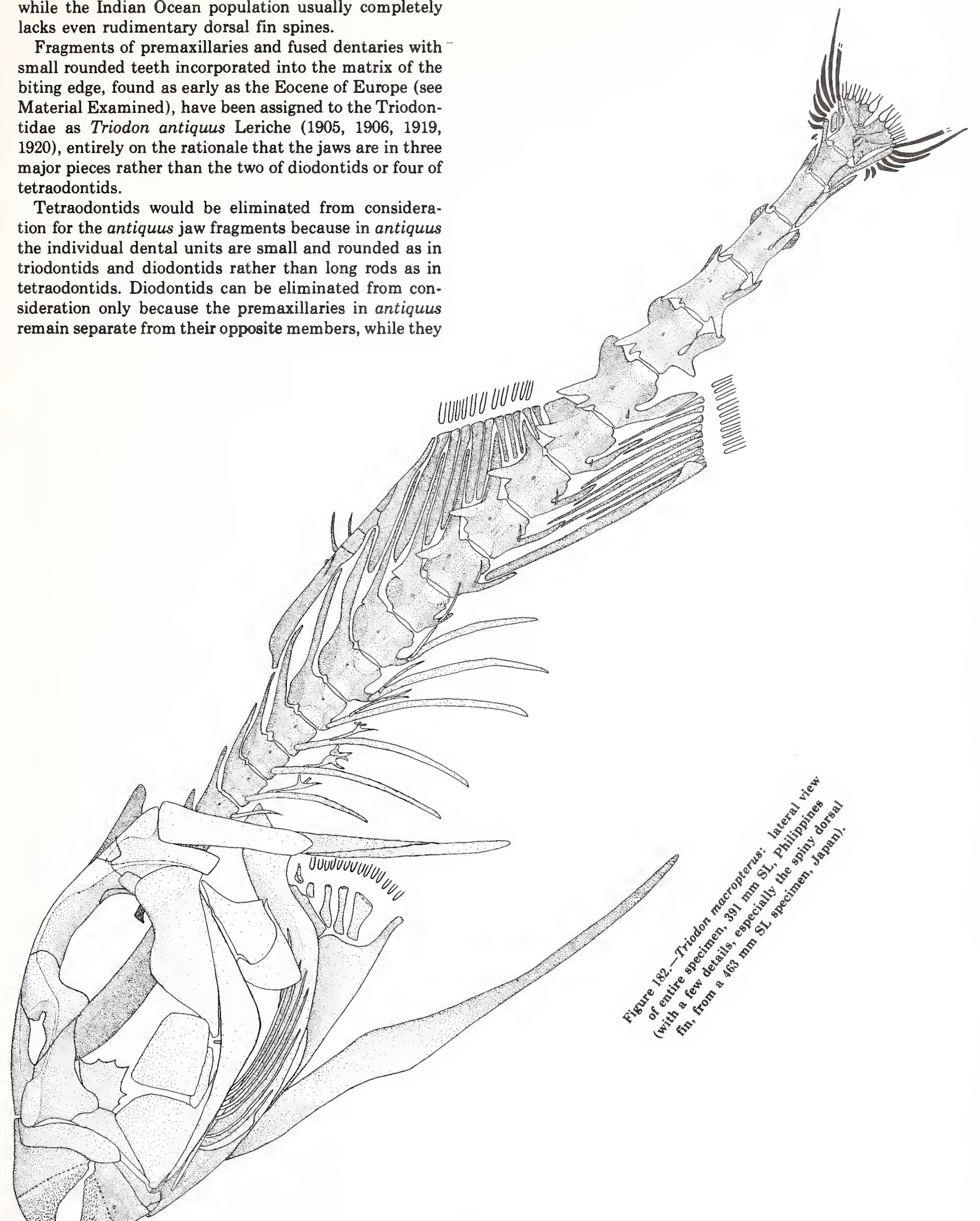
Figure 183.-Triodon macropterus: lateral view of head, $391 \mathrm{~mm}$ SL, Philippines.
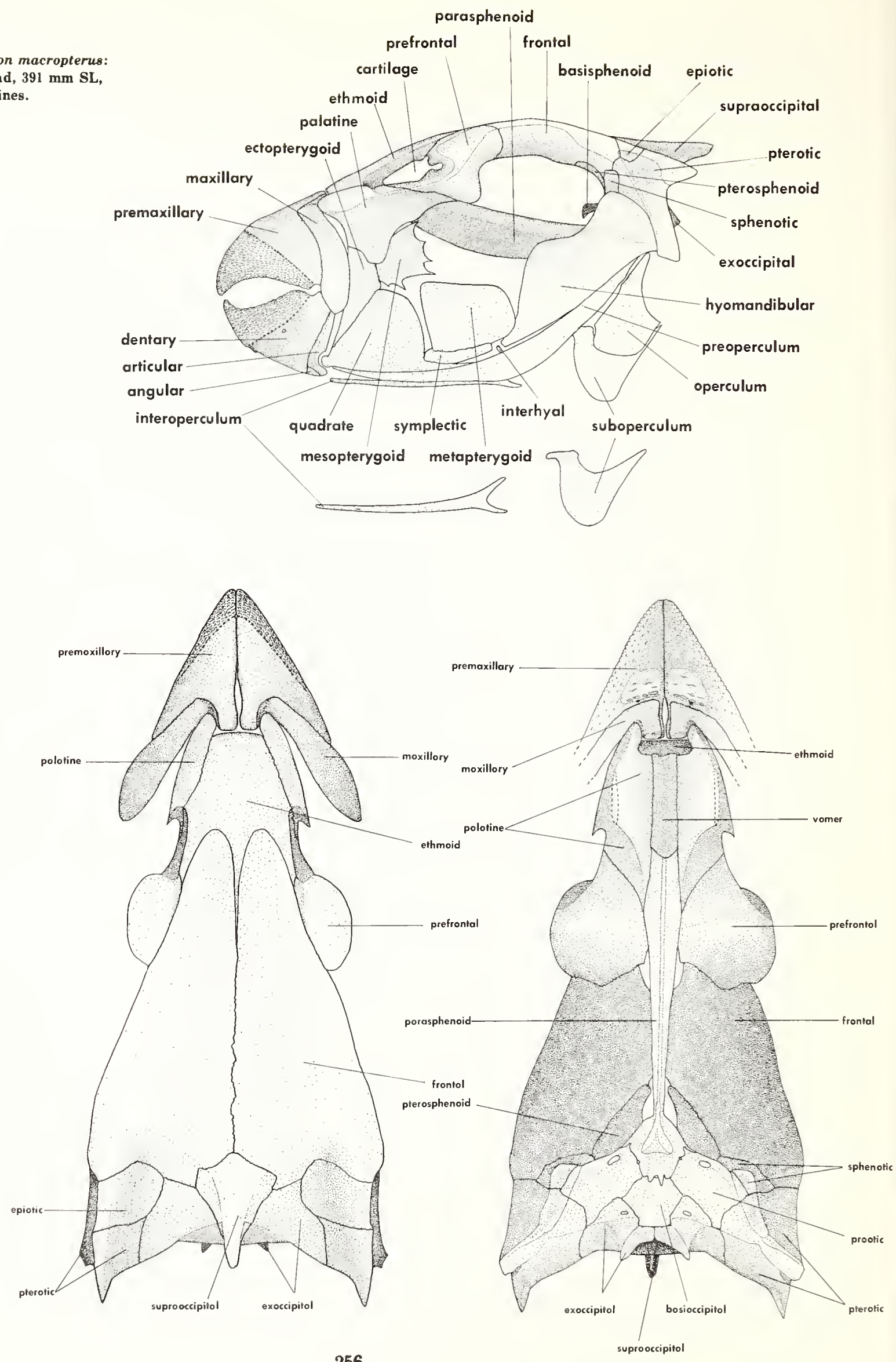


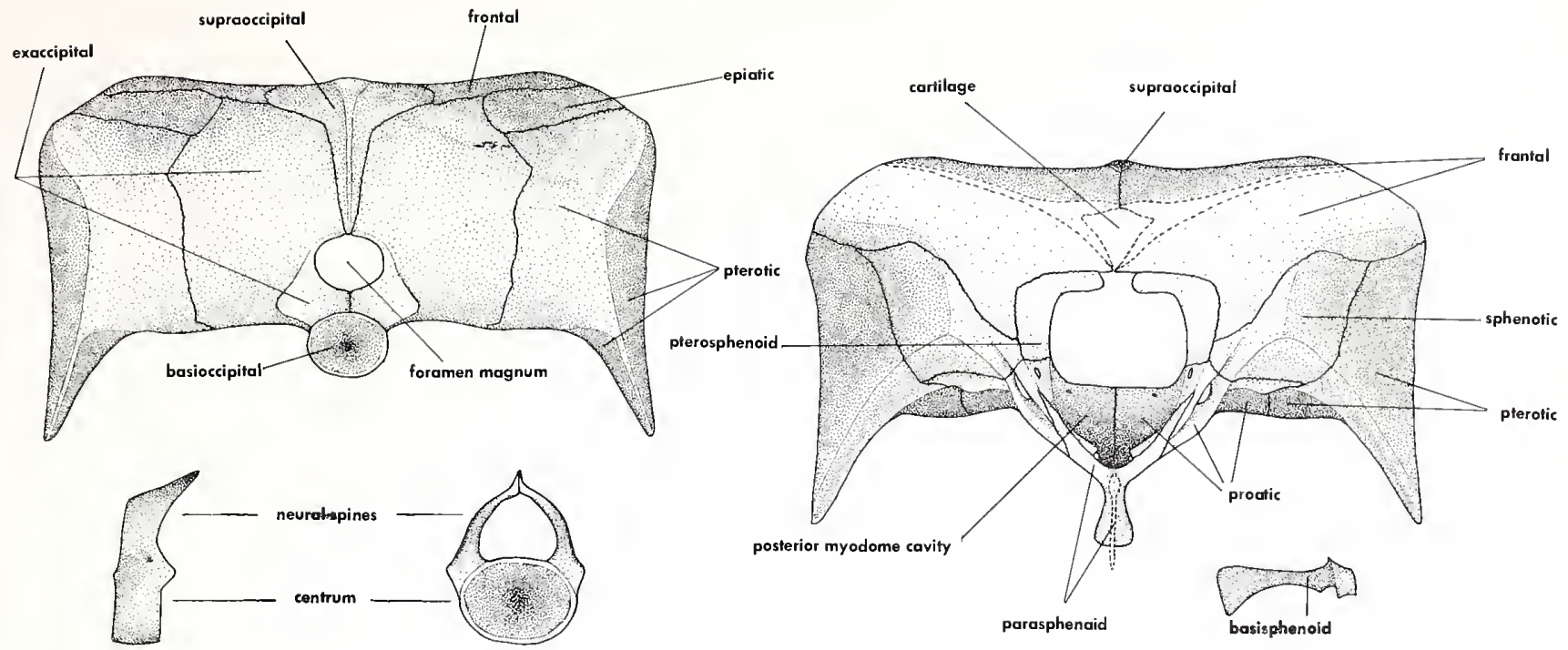

Ficure 185.-Triodon macropterus: posterior view of skull (left), with, below, lateral and posterior views of first abdominal vertebra; posterior view of orbit (right) (cross section of

skull; dashed lines represent cut surfaces of frontals and parasphenoid), with, below, lateral view of basisphenoid (anterior to left); $391 \mathrm{~mm}$ SL, Philippines.

Figure 184. (opp. page)-Triodon macropterus: dorsal (left) and lateral (right) views of skull, 391 mm SL, Philippines.

Figure 186. (right)-Triodon macropterus: dorsal view of branchial arches (extended on lower side); lateral view of hyoid arch; dorsal and lateral views of urohyal; $391 \mathrm{~mm}$ SL, Philippines. .

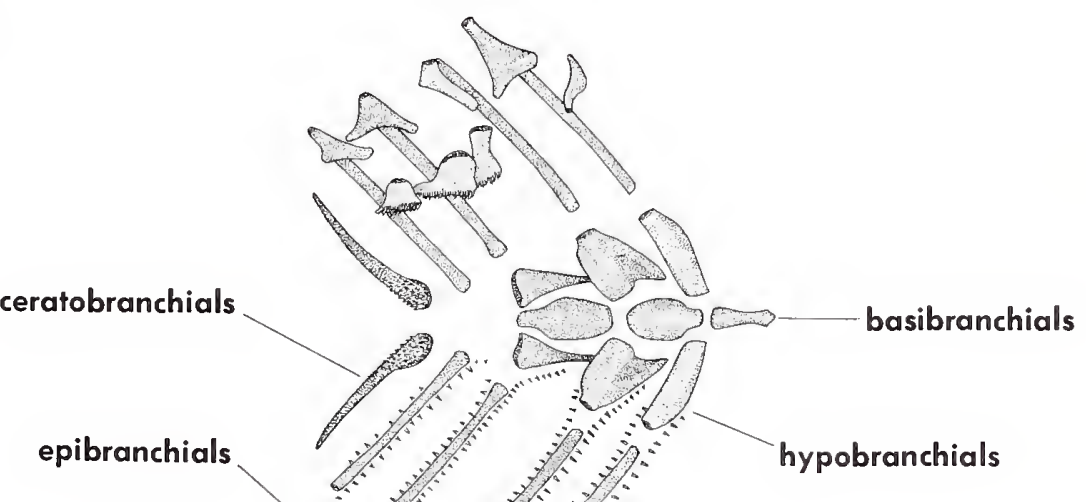

pharyngobranchials
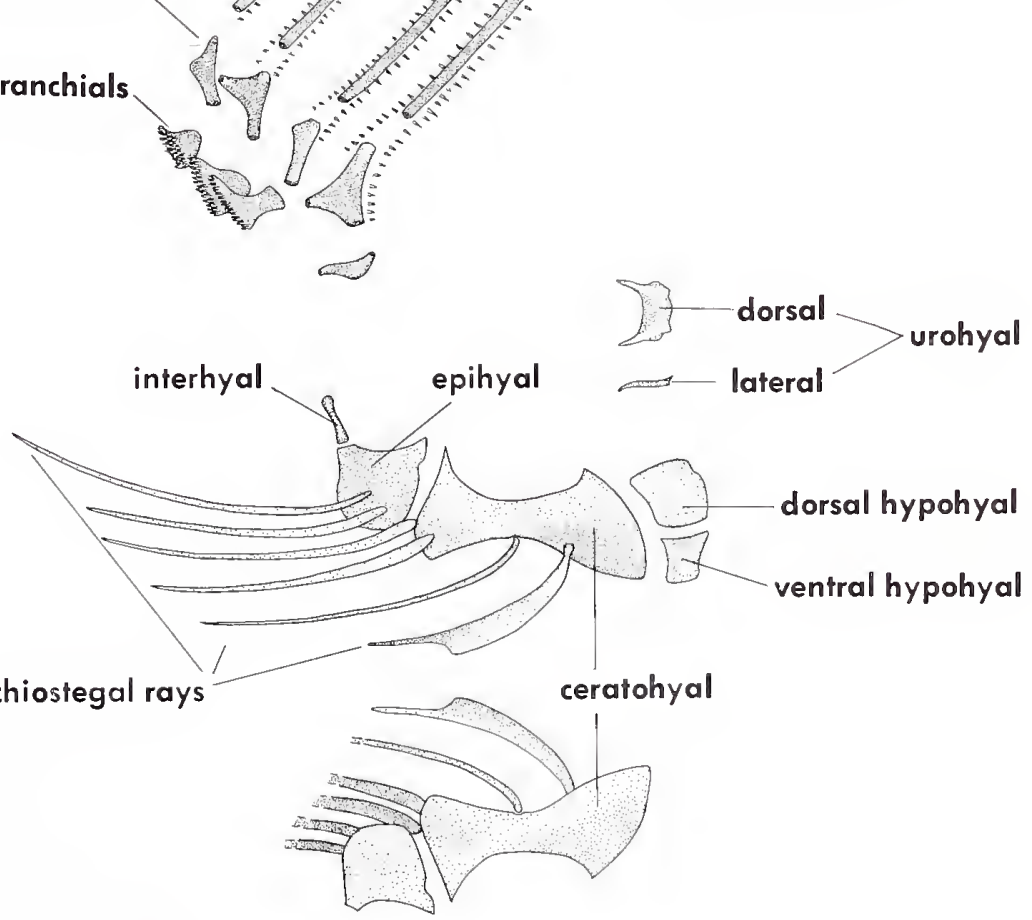


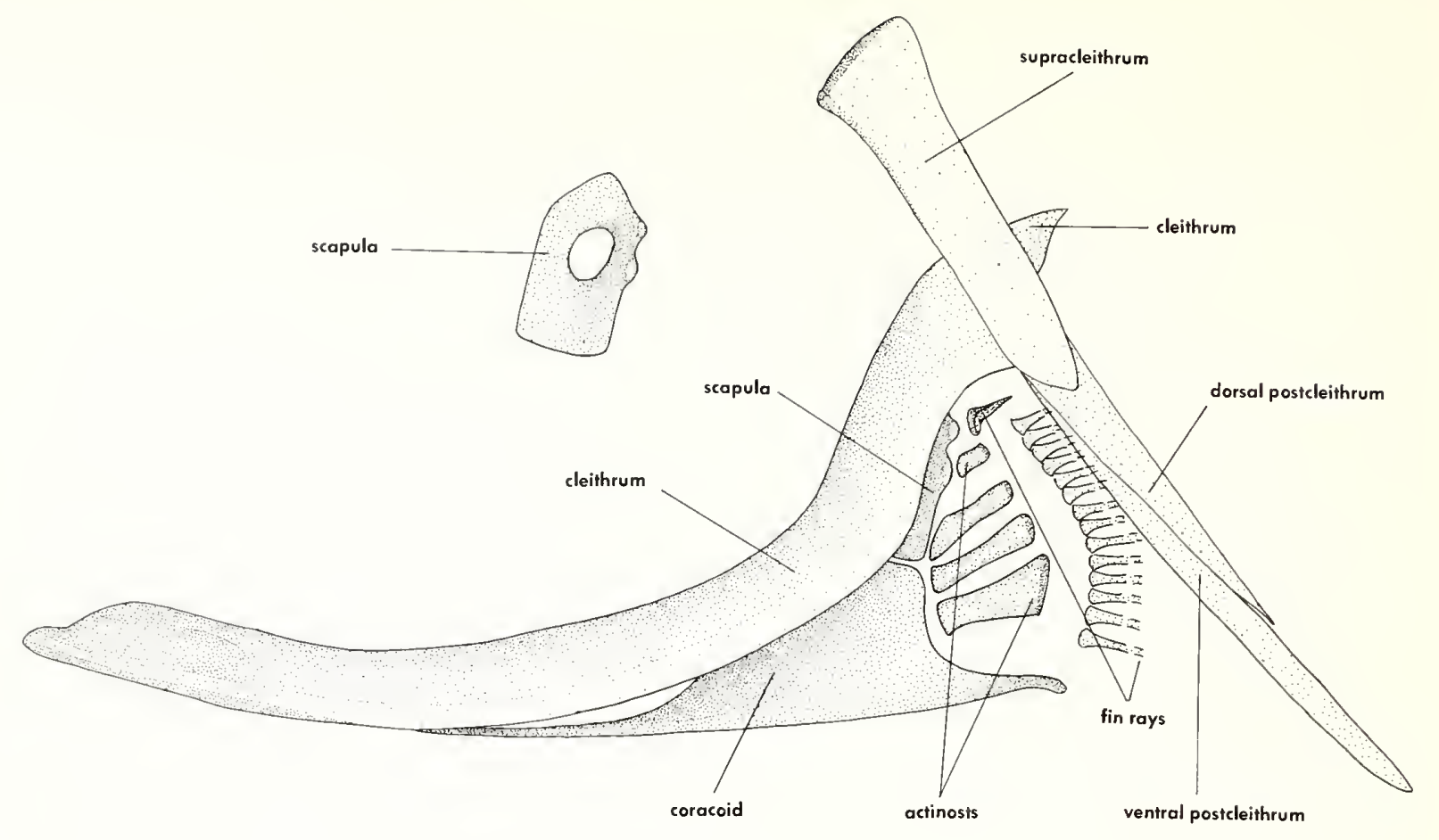

Figure 187.-Triodon macropterus: lateral view of pectoral girdle, with inset showing full extent of scapula in lateral view, $391 \mathrm{~mm}$ SL, Philippines.
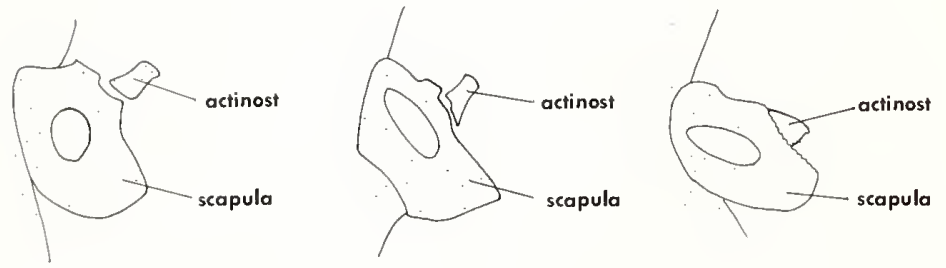

Parahollardia lıneata

Balistapus undulatus

Acanthostracion quadricornis

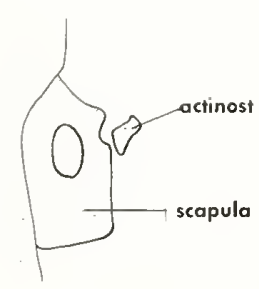

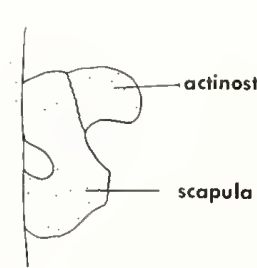

Lagocephalus laevigatus

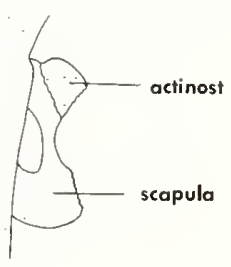

Canthigaster rostrata

Triodon macropterus

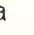

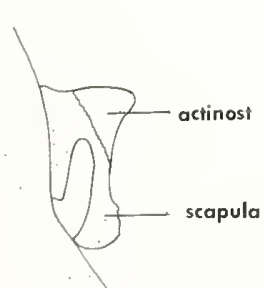

Diodon holocanthus

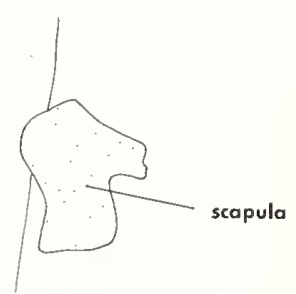

Mola mola
Figure 188.-Lateral views of scapula and first (uppermost) actinost in representatives of all superfamilies, showing the completely enclosed scapular foramen of Triodon macropterus, unique among the gymnodonts and similar to the scleroderms. 


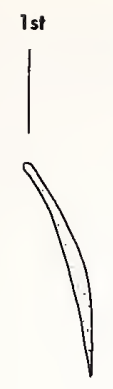<smiles>C[123I]</smiles><smiles>C[18OH]</smiles>

th

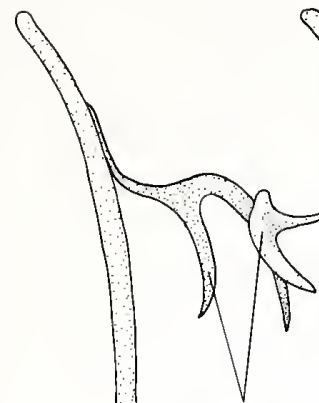

9

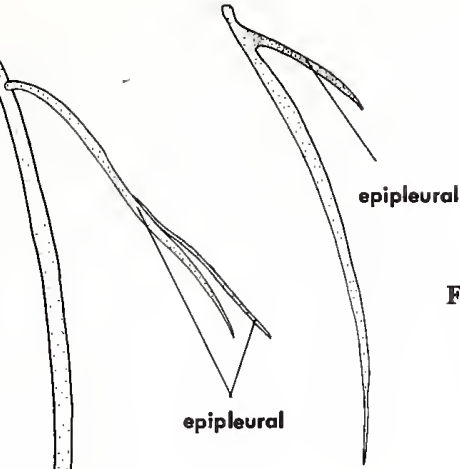

articular

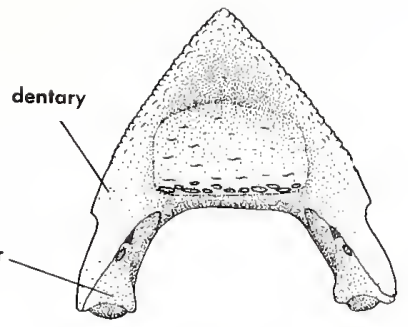

Figure 189.-Triodon macropterus: lateral views of alternate pleural ribs and their epipleurals (left); dorsal view of lower jaw (right) to show the trituration plate; $391 \mathrm{~mm}$ SL, Philippines.

Figure 190.-Triodon macropterus: lateral (above) and dorsal views of rudimentary spiny dorsal fin and its basal pterygiophores, 463 mm SL, Japan.

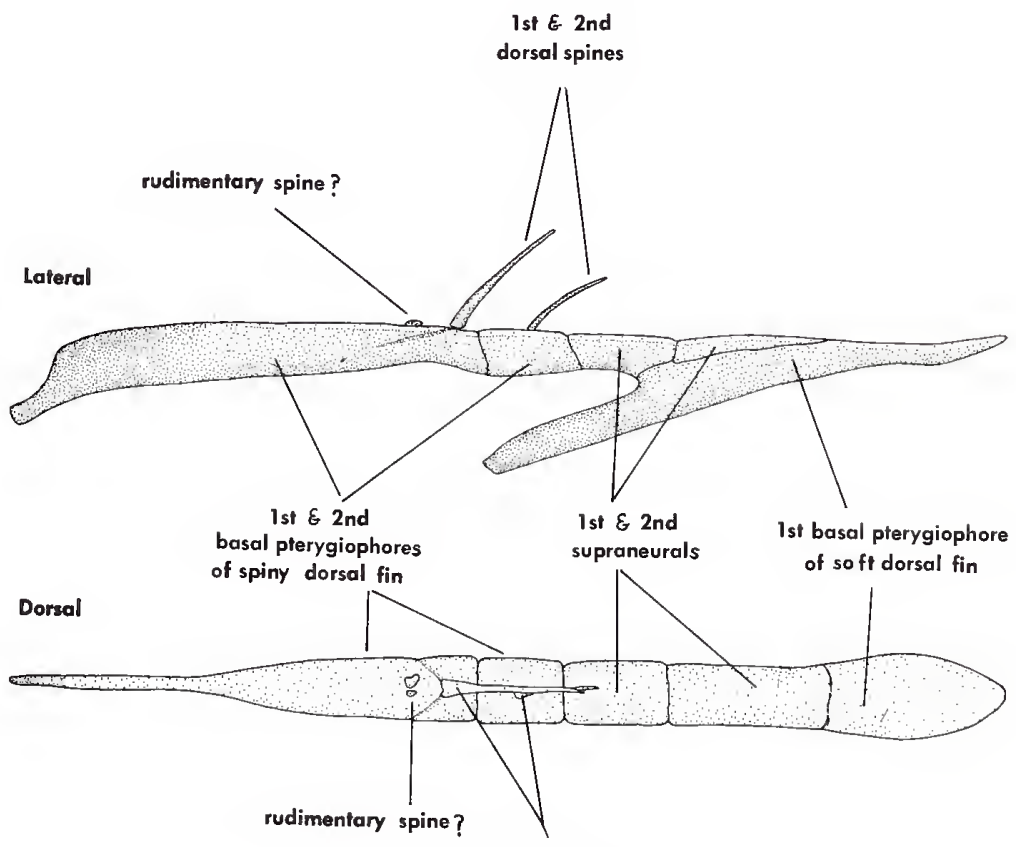

1st \& 2nd

dorsal spines

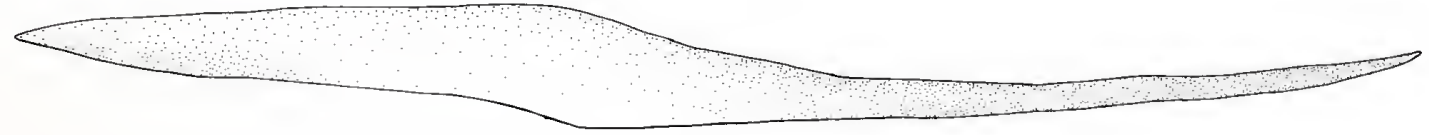

Figure 191.-Triodon macropterus: ventral, dorsal, and lateral views of pelvis, $391 \mathrm{~mm}$ SL, Philippines. 


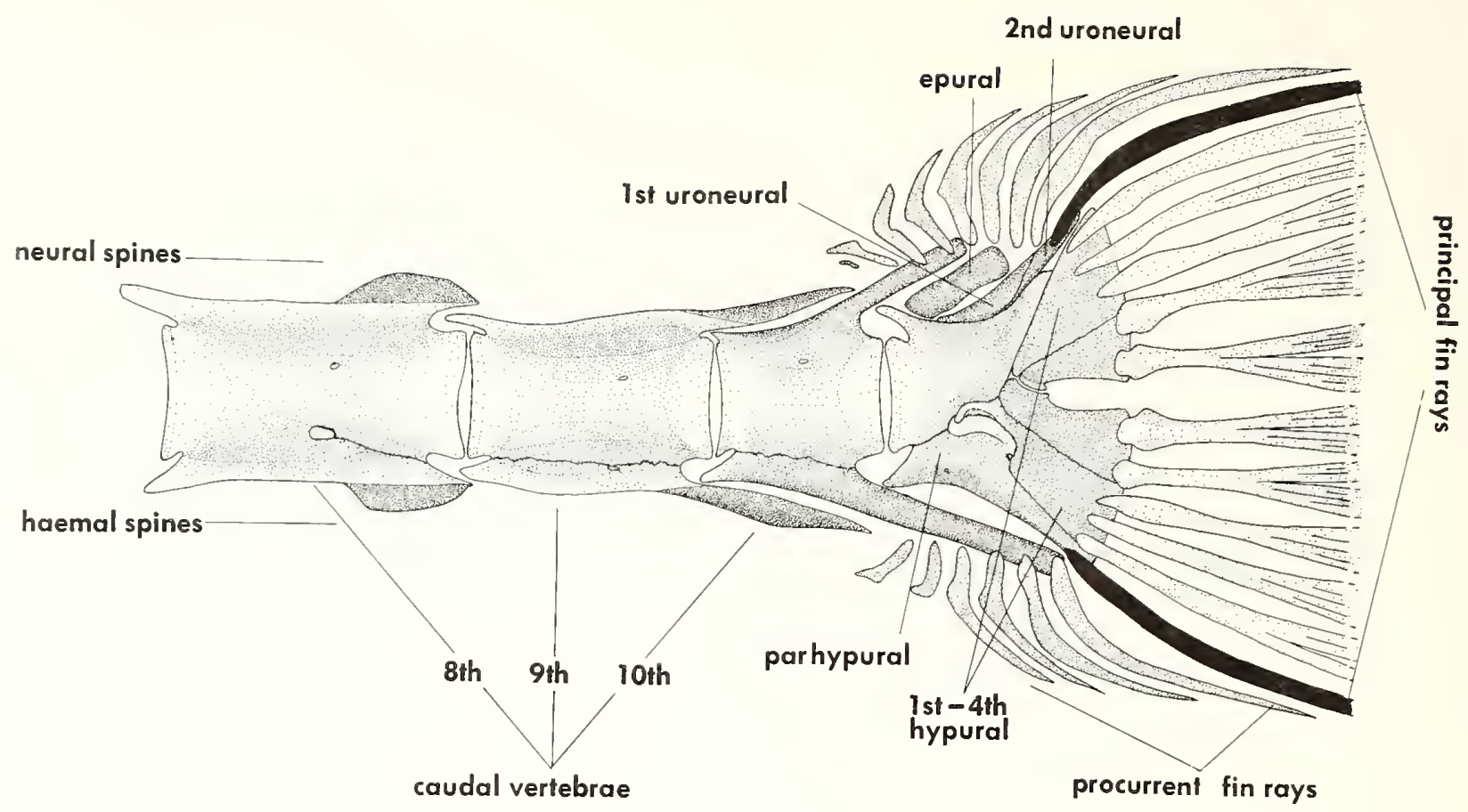

are fully fused together in diodontids. Even accepting this reasoning, the presence of Triodon-like jaw fragments tells us nothing about what the fish behind the jaws was like, there being no guarantee that the general form of antiquus was at all like that of the Recent Triodon macropterus. Moreover, ilpper jaws without fused premaxillaries but with small rounded dental units in the matrix are what one would expect to find in the Eocene ancestors of the early to late Eocene diodontids such as Prodiodon and Progymnodon.

Relationships to the Balistoidei and to the other Tetraodontoidei.-The relationship of the Triodontidae as an intermediary between the eoplectin Triacanthodidae and the other more specialized Tetraodontoidei is discussed under the subfamilial relationships of the Triacanthodidae, it being shown, in essence, that Triodon, which is by far the most generalized of the gymnodonts, clearly is derived from the eoplectins, which retain many generalized triacanthodid features while having highly specialized gymnodontlike jaws with small rounded dental units incorporated into the matrix of the premaxillaries and dentaries. Since it is highly improbable that such complex dentitional changes as found in the gymnodonts have arisen independently in various lines, the eoplectins are obviously ancestral to the gymnodonts, with their closest relatives among the gymnodonts being the triodontids.

While the evolution of small rounded dental units incorporated into the matrix of the jaw bones is a highly complex matter that has arisen only once among plectognaths (although similar dentition has been independently developed in some of the Scaridae among the perciform fishes), the same is not true of the fusion of the dentaries and premaxillaries to their opposite mem-
Figure 192.-Triodon macropterus: lateral view of caudal fin supporting structures (see Tyler 1970b:figs. 42a and $42 \mathrm{~b}$, for details), $391 \mathrm{~mm}$ SL, Philippines.

bers, which, relative to the dentitional and general structural changes involved in developing a crushing or biting beak, is a simple matter. The relative superficiality of the jaw bone fusion is attested to by the fact that the dentary and premaxillary of very large specimens of tetraodontids occasionally fuse to their opposite members and that Reuvens (1894:130) described a young molid in which the dentaries were fused but the premaxillaries were separate. Thus, the form of the dental units in the biting edge of the jaws is a far more anatomically complex and phylogenetically important indicator than is the fusion or lack of fusion of the dentaries and premaxillaries.

The fusion of these bones to their opposite members undoubtedly at least slightly increases the rigidity and strength of the beak beyond that which it would possess if the premaxillaries and dentaries remained separate, but I doubt that the difference is functionally of great magnitude, for the two halves of the upper and lower jaws of tetraodontids are firmly and relatively inflexibly held together medially by a combination of interlocking emarginations and thick bands of tough fibrous tissue. The two halves of the upper jaw in Triodon, for example, are so extensively interdigitated that they are exceedingly difficult to force apart, and I doubt that much more pressure would be needed to break apart the fused dentaries than to separate the interdigitated premaxillaries.

The most generalized dentitional condition in gymnodonts is small rounded units incorporated into the 
matrix of the biting edge of the premaxillaries and dentaries, as found in the triodontids, the most generalized gymnodonts, and in their ancestral eoplectin triacanthodids (as well as in the moderately specialized diodontids). Of the two known eoplectins, the biting edges of the jaws are exposed only in Eoplectus, which has small rounded dental units, but this can also be expected to be the condition in the related Zignoichthys. The eoplectins undoubtedly evolved from a group of early triacanthodids with a generalized dentition of numerous conical teeth in an outer series, internal to which there were a smaller number of conical inner series teeth.

Conversion of this generalized dentition into that as found in eoplectins and triodontids probably involved a great increase in the number of outer series teeth and their placement in more than one row concomitant with a great reduction in size of the individual teeth, which eventually protruded less and less to the exterior beyond their basal sockets in the premaxillaries and dentaries and finally became entirely nonprotrudant, being fully surrounded by the matrix of the bone. It is not known whether eoplectins had trituration plates internal to the biting edges of the jaws, but it is probable that they did, for trituration plates are found in all triodontids, diodontids, molids, and in many tetraodontids, and the jaws of eoplectins are just as massive as in most gymnodonts and the eoplectin diet probably consisted of hard shelled invertebrates for which trituration plates would be useful in crushing and grinding. These trituration plates are obviously formed from modified internal series teeth as found in the more generalized triacanthodids, the teeth becoming greatly increased in number, and sometimes in size, to form a series of rows which variously retained much of their individual identity or became incorporated into a plate in which some of the teeth lost their individual identity, especially anteriorly in the plate away from the posterior region of tooth replacement. However, the development of trituration teeth, whether as plates or not, is probably a highly labile feature in various lines of gymnodonts closely correlated with dietary changes as species evolved in differing habitats.

The generalized gymnodont dentition of small rounded units in the biting edge has been retained by triodontids and diodontids, but tetraodontids and molids have greatly modified the dentition of the biting edge. In molids discrete dental units are no longer present, at least as observed at 30 magnifications, the ancestral small rounded units apparently indistinguishably fused to the bony matrix. In tetraodontids the ancestral small rounded units have been modified into less numerous long rods lying in series approximately parallel to the biting edge. The tetraodontid dental units of the biting edge obviously did not become specialized long rods until after the division of the joint tetraodontid-diodontid ancestral line, for diodontids retained small rounded units from this line.

It seems reasonable to assume that the tetraodont jaw type (but not tooth type), with both the premaxillaries and dentaries closely articulated but not fused to their opposite members, was the primitive condition of early gymnodonts, and that both the triodont jaw type, with only the dentaries fused to their opposite members, and the diodont jaw type, with both the dentaries and premaxillaries fused to their opposite members, are derived from a tetraodont jaw type ancestry, either independently or with the diodont type perhaps having been preceded by a triodont type ancestral group.

It is not known whether the premaxillaries and dentaries were fused or articulated to their opposite members in the Eocene triacanthodid Eoplectus, but in the apparently closely related Zignoichthys from the same strata, at least one of the jaws, probably the lower, had the two halves (presumedly dentaries) fully fused together.

If these two Eocene triacanthodids, representing the subfamily Eoplectinae, are indeed representatives of the ancestral line leading to Triodon and the other gymnodonts, then at least Zignoichthys is already too specialized in its jaw structure (which must be either triodont or diodont type) to be considered as ancestral to the tetraodontids. It seems to me extremely unlikely that once the full fusion of the dentaries and/or premaxillaries was established in a line of gymnodont evolution that consistent reversal to an unfused condition could take place, especially in light of the intricate interlocking interdigitations that are almost always present when the premaxillaries or dentaries are articulated to one another rather than fused.

It is assumed here that the immediate ancestry of the few known eoplectins and thus of the triodontids had the premaxillaries and dentaries separate from their opposite members, and that the tetraodontids diverged from this ancestral line at a time in the Eocene when at least some members of that line retained separate premaxillaries and dentaries. This line was probably Triodon-like except in the retention of separate dentaries and also probably before the elongate tapered caudal peduncle as seen in the Recent Triodon had been fully established. Since it is here considered that the diodontids are more closely related to tetraodontids than to molids, an additional implication of the above reasoning is that the fusion of the premaxillaries and dentaries in molids and diodontids has taken place independently, that in diodontids from a tetraodontid ancestral group, and that in molids from the same eoplectin-triodontid line retaining separate premaxillaries and dentaries from which tetraodontids are evolved.

The features in the conversion of an eoplectinlike fish into a triodontidlike one are discussed under Eoplectus in the account of the Triacanthodidae. The conversion of a triodontidlike fish into a fish like that of any of the other derived families of gymnodonts involves primarily the loss of most of its more generalized or triacanthodidlike features.

The features of Triodon that are lost by all other gymnodonts are: 1) the rudimentary spiny dorsal fin and all but one of the basal pterygiophores and supraneural elements supporting it; 2) the ribs and epipleurals; 3) the pelvis; 4) uroneurals and hypurapophysis, and the consolidation of the hypurals so that only one free element is present and the conversion from an autogenous to fused 
haemal spine on the antipenultimate vertebra; 5) the procurrent caudal fin rays and at least one of the principal rays (from the upper lobe of the fin); 6) a complete dorsal roof to the myodome and the channel leading into it posteriorly; 7) the knob on the scapula for articulation with the uppermost pectoral fin ray, and the complete scapular foramen; 8) urohyal; 9) one of the pharyngobranchials and well-developed teeth on the fifth ceratobranchial; 10) the deep olfactory sac and normal olfactory rosette; 11 ) four actinosts, none of which are sutured to one another or to the scapula or coracoid.

Triodon, as represented by the single Recent species upon which our entire knowledge of the family is based except for the fossil jaw fragments possibly related to it, has certain features found in neither the triacanthodids nor in other gymnodonts. These undoubtedly are specializations which were acquired by Triodon after its ancestral stock had given rise to the lines leading to the molids on the one hand and to the tetraodontids and diodontids on the other hand. These specialized features of Triodon are: 1) the long caudal peduncle tapering to a transversely indented region just in front of the base of the deeply forked caudal fin; 2) the prominent anterolateral processes from the neural arch region of many of the caudal vertebrae and the long rodlike neural and haemal spines of the penultimate vertebrae, all associated with the musculature and support of the caudal peduncle and caudal fin used for apparently sustained rapid swimming; 3 ) the rotatability of the pelvis and the expansible dewlap of skin between the end of the pelvis and the anus; 4) the great anterior elongation of the cleithrum; 5) the small sphenotic entirely confined to the rear of the orbit; 6) the articulation of the first branchiostegal ray on the ventrolateral surface of the ceratohyal; 7) the short posterior shaft of the interoperculum behind the level of the epihyal; 8) the posteroventrally prolonged shaft of the pterotic articulating broadly with the hyomandibular; and 9) the exoccipital in contact with the frontal and excluding the epiotics from contact with the supraoccipital.

Since neither the triacanthodids nor any of the other gymnodonts possess anything similar to these specializations of Triodon, the ancestral line leading to the Recent Triodon can be expected to have had more triacanthodidlike conditions in these features and that they remained relatively generalized in them until after the other gymnodont linages split off from the early Triodonlike fishes.

The ancestral line connecting the eoplectin triacanthodids and the triodontids is hypothesized as having given rise to the line leading to the great diversification of the gymnodonts, this line diversifying in two basic directions, one leading to the molids and one to the tetraodontids and diodontids, at a pre-Recent Triodon level of organization, i.e., at a level of organization that retained all of the generalized features of Triodon but that did not yet have the specialized features of the Recent Triodon noted above, as well as with both the premaxillaries and dentaries unfused and the first branchiostegal ray entirely unmodified.
The molid line of radiation from the pre-Recent Triodon level of organization is represented by only a few species, at least surviving today, which became vastly modified for a slow swimming oceanic and mostly pelagic existence and relatively huge size within a protective wall of thickened skin, while retaining from its triodontid ancestry several generalized features lost in the tetraodontid-diodontid line of radiation. Molids have retained: 1) the basisphenoid; 2) fourth gill and gill slit between the fourth and fifth arches; 3 ) unmodified first branchiostegal ray; 4) uninflatable gut; and 5) unsutured ceratohyal and epihyal.

Moreover, the configuration of the bones of the snout in molids is in many ways remarkably similar to that in Triodon, far more so than is the case in the tetraodontiddiodontid line. In Triodon and molids the ethmoid tends to be a large squarish block of bone bordered on either side by the large palatines and prefrontals, with the palatine broadly held medially to the ethmoid, vomer (unossified in Ranzania), parasphenoid and prefrontal. The shape and size of the frontals in Triodon and molids is also remarkably similar. An anteriorly directed prong in the suboperculum, as found in Triodon and diodontids, is retained in molids, even though the molid operculum and suboperculum are greatly reduced in size.

While these similarities between Triodon and molids indicate the relationship between the two groups, molids possess an array of specializations beyond the generalized Triodon level of organization, many of which are centered around the aborted rear end of the body and the support of the continuous dorsal, anal, and pseudocaudal fins. The major ways in which molids differ from Triodon, other than those already mentioned above that distinguish Triodon from all other gymnodonts, whether they be the generalized triacanthodidlike features of Triodon that are lost or the specialized features of Triodon developed after the radiation of the other gymnodonts from a triodontid ancestral group, are: 1) the apparently indistinguishable incorporation of the dental material into the matrix of the jaws, along with the fusion of the premaxillaries, even though well-developed individual trituration teeth are retained in both the upper and lower jaws; 2) the loss of an ossified sesamoid articular; 3) the great enlargement of the basisphenoid and the complete loss of the dorsal roof of the myodome and of the posterior opening into it; 4) the loss of teeth on the fifth ceratobranchial and the development of gill rakers along the front of the fifth ceratobranchial and along the anterior edge of the first gill slit, even though only Triodon and molids among the gymnodonts retain the fourth gill, well-developed teeth on all three of the toothed pharyngobranchials, unsutured ceratohyal and epihyal, the consistent presence of both dorsal and ventral hypohyals and the interhyal, and a relatively unmodified first branchiostegal ray; 5) the loss of the pharyngobranchial of the first arch; 6) the loss of the first or uppermost actinost; 7) the consolidation of the postcleithra into a single piece and the development of an anterior spur from it to the region of the actinosts; 8) the development of a dome or posterior prolongation on the 
epiotics; 9) the development of a posterior prolongation of the pterotics broadly articulating with the supracleithrum; 10) the dorsal prolongation of the basioccipital excluding the exoccipitals from contact with the first vertebra; 11) the loss of haemal arches and spines on at least some of the abdominal vertebrae and the reduction in size of their neural spines; 12) the loss of all of the supraneural elements and the vast rearrangements of the vertebral column and basal pterygiophores of the dorsal and anal fins in the formation of the continuous fin around the posterior end of the body with the abortion of the true caudal fin and its supporting structures and the development of a pseudocaudal fin of posteriorly migrated dorsal and anal fin rays and their basal pterygiophores; 13 ) reduction in the number of vertebrae from 20 to between 16 and 18 ; 14) reduction in the size of the olfactory apparatus; 15) development of thickened or hardened skin; 16) reduction in the size of the gill opening; and 17) the loss of the air bladder.

The tetraodontid-diodontid line of radiation from the pre-Recent Triodon level of organization diversified greatly, with well over a hundred species alive today, and have become in many ways just as morphologically different if not more so from triodontids as have molids, while retaining none of the few generalized characters shared by triodontids and molids, even though in general body form the tetraodontid-diodontid line is more similar to that of Triodon (exclusive of the expansible dewlap) than is that of molids.

The major ways in which tetraodontids and diodontids differ from Triodon, other than those previously mentioned that distinguish Triodon from all other gymnodonts, whether they be the generalized triacanthodidlike features of Triodon that are lost or the specialized features of Triodon developed after the radiation of the other gymnodonts from a triodontid ancestral group, are: 1) the loss of the basisphenoid; 2) the loss of the fourth gill and of the gill slit between the fourth and fifth arches; 3 ) the loss of at least well-developed teeth on the fifth ceratobranchial and on one of the three pharyngobranchials; 4) the loss of the pharyngobranchial of the fourth arch; 5) the loss of gill rakers behind the anterior edge of the fourth arch; 6) the great expansion of the first branchiostegal ray into a horizontal pumping plate articulated to the medial surface of the ceratohyal; 7) the development of an inflatable diverticulum of the gut; 8) the suturing of the ceratohyal with the epihyal; 9) the frequent loss of the interhyal and dorsal hypohyal; 10) the loss of at least most of the dorsal roof of the myodome and of the posterior opening into it; 11) the loss of all, or all but one, of the supraneural elements; 12) the development in one of the two families of long rodlike dental units and of the frequent reduction in size or loss of the trituration plates or teeth; 13) the development of a more limited area of articulation of the palatine with the cranium either at a notch and flange between the palatine and ethmoid-vomerine region or by extensive suturing between the palatine and frontal; 14) a reduction in the massiveness of the prefrontal and supracleithrum; 15) the usual better development of the mesopterygoid (except absent in one species) and its firm suturing to the metapterygoid as well as to the palatine; and 16) the development in three or more of the abdominal vertebrae of bifid neural spines, always including the first three abdominal vertebrae.

Thus, even though Triodon is by far the most generalized gymnodont and retains many primitive features of its triacanthodid ancestry, the structure of the only species of which we have knowledge other than jaw fragments, the Recent Triodon macropterus, is too specialized for an Eocene fish closely similar to it to have been the ancestral line from which the molid and tetraodontid-diodontid lines radiated. This ancestral triodontid line had a more generalized organization than that of $T$. macropterus, not yet possessing such specializations as the small size and entirely orbital placement of the sphenotics allowing the frontals and exoccipitals to meet, and the elongation and tapering of the caudal peduncle and associated vertebral modifications. Nevertheless, an early Eocene Triodon-like fish minus the specializations as seen in the single Recent species is undoubtedly ancestral to the other two major subgroups of gymnodonts and itself evolved from the eoplectin triacanthodids in the early Eocene.

\section{Infraorder Tetraodontoideo}

Comparative diagnosis (contrast with that of the Triodontoideo).--Spiny dorsal fin completely absent and no more than one supraneural element present; ribs and epipleurals absent; caudal fin with 11 or fewer principal rays and no procurrent rays; caudal fin varying from moderately forked to rounded; caudal skeleton with no more than one separate hypural, and no uroneurals and hypurapophysis; haemal spine of antipenultimate vertebra fused to its centrum; neural and haemal spines of penultimate vertebra various but not long rounded shafts directly supporting caudal fin rays; caudal peduncle not distinctly tapered to narrow transversely indented regions above and below just in front of the caudal fin, the least depth of the peduncle being about $6 \% \mathrm{SL}$ or greater, and the least width at this region always less than the least depth; none of the caudal vertebrae with anterolateral processes above the centra; no pelvis; no expansible dewlap of skin in front of the anus, but inflatability of the abdominal region present in all families except molids; cleithrum not elongate anteriorly, reaching forward no further than about the level of the middle of the ceratohyal; basisphenoid either absent or present as a large plate in the interorbital septum; myodome either absent or present only as a rudiment of the dorsal roof represented by medial wings of the prootics, the roof always highly incomplete; no channel present between the apposed surfaces of the parasphenoid and basioccipital; scapular foramen incomplete, closed anteriorly by the cleithrum; scapula without a distinct knob for articulation with the uppermost pectoral fin ray; three or four actinosts, if four present at least some sutured either to one another or to the 
scapula or coracoid, the uppermost always sutured to the scapula; urohyal absent; no more than three pharyngobranchials present; fifth ceratobranchial usually toothless, rarely with even a small patch of minute teeth; dentaries and premaxillaries totaling either two or four separate pieces; premaxillaries, if separate, articulated to one another by prominent regular interlocking emarginations; sphenotic relatively large and not confined to the posterior wall of the orbit, but present on both the lateral and dorsal surfaces of the skull as well; first branchiostegal ray with its dorsal edge either not inturned at all and articulated to the ventral edge of the ceratohyal or greatly inturned into a huge plate and articulated to the medial surface of the ceratohyal; interoperculum with a ventral flange and a long posterior shaft extending well behind the ventral flange and level of the epihyal, except in molids in which the interoperculum is a short to long simple slender rod without a ventral flange; pterotic not prominently prolonged posteroventrally as a stout shaft; epiotic placed more medially on the top of the skull, always in contact with the supraoccipital; exoccipital never in contact with the frontal; frontal never in contact posteriorly with the pterotic in the rear of the orbit, separated from it by the sphenotic, while in some tetraodontins posterolateral wings from the dorsal surface of the frontal make contact with the pterotic on the top of the rear of the skull; olfactory epithelium smooth, pitted or in parallel folds, never in a rosette, the olfactory sac either above the surface in a tube or tentacle with one or two nostrils, or at or below the surface and rudimentary.

\section{SUPERFAMILY TETRAODONTOIDEA}

Comparative diagnosis (contrast with that of the Moloidea).--Inflatable diverticulum of the gut present; first branchiostegal ray with the dorsal edge inturned and enormously enlarged into a more or less horizontal pumping plate articulated to the medial surface of the ceratohyal; air bladder well developed; three gills, not greatly expanded dorsally; no gill slit between the gillless fourth and fifth arches and no gill rakers along the posterior edge of the fourth arch and the anterior edge of the fifth arch; no gill rakers along the anterior edge of the first gill slit; pharyngobranchials with moderate to minute teeth, and one sometimes toothless, the three elements being those of the first to third arches (that of the third sometimes absent); ceratobranchial and epibranchial sutured to one another; interhyal and dorsal hypohyal often absent; teeth in biting edge of jaws retaining much of their individual identity; basisphenoid absent; caudal fin relatively normal, with 9 to 11 rays supported by variously consolidated and fused but normal vertebral elements; most dorsal, anal, caudal, and pectoral fin rays less extensively branched but with a normal amount of cross-striations, these not confined to only the distal ends of the rays; sesamoid articular usually present; postcleithrum without an anteriorly directed process; four actinosts; supracleithrum less elongate, only its extreme proximal end articulated directly to the pterotic; coracoid less long and slender, with a posterodorsal prong below the lower actinost always developed to some degree; operculum and suboperculum of much greater complexity of structure and lateral surface area; interoperculum with a ventral flange and posterior shaftlike portion extending posteriorly well beyond the level of the epihyal; basioccipital not prolonged dorsally behind the exoccipitals, the exoccipitals bordering all but the bottom edge of the foramen magnum; exoccipitals with condyles and in contact with the first vertebra, which articulates anteriorly with both the basioccipital and exoccipitals; epiotic without any kind of posterodorsal prolongation; pterotic not prolonged posteriorly, not reaching posteriorly to the level of the end of the basioccipital; bony canal, when present, for the nerves and blood vessels running from the orbit to the nasal region nearly always incomplete, surrounded by the prefrontal laterally, above and below, but not medially; palatine receiving its main support dorsally either by a complex interlocking with the vomer and ethmoid or by extensive suturing to the frontal; at least the first three abdominal vertebrae with bifid neural spines projecting dorsally or dorsolaterally on each side of the neural arch; centra of at least some of the abdominal vertebrae always with ventral or ventrolateral processes of some sort, whether or not forming complete haemal arches or zygapophyses; dorsal and anal fin rays not widely separated from their basal pterygial supports by a large block of cartilage; scales, when present, small to large, the basal plates not forming a completely continuous covering over the entire body, and some of the scales always forming prominent prickles or spines; one or two nostrils in a prominent upraised sac or tentacle, or a single minute nostril in a low tube; lateral line present, whether conspicuous or inconspicuous, but nearly always clearly seen within 30 magnifications.

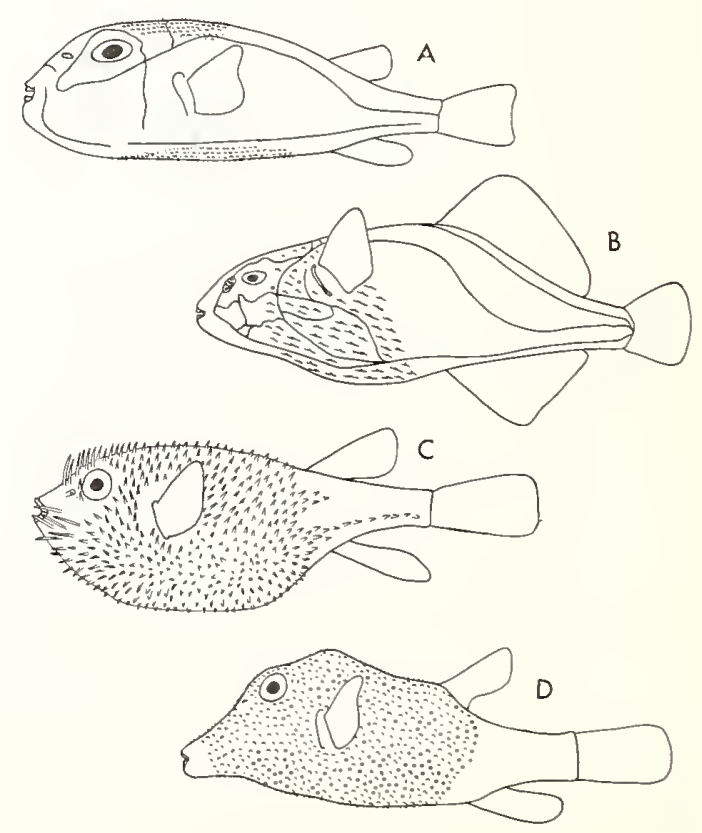


Comparative diagnosis (contrast with that of the Diodontidae).- Teeth incorporated into the matrix of the biting edge of the jaws as long slender rods; premaxillaries and dentaries not fused to their opposite members in the midline, the articulation strengthened by interlocking emarginations; lateral surface of maxillary neither deeply indented nor laterally flanged, the surface relatively even; the jaws usually less massive; small trituration teeth often present in the upper and, less frequently, lower jaw as well, but seldom with a large trituration plate in both jaws; first pharyngobranchial with small or, usually, minute teeth, or sometimes toothless, but second and third pharyngobranchials with small teeth; dorsal hypohyal often absent; interhyal sometimes present; anterior edge of ectopterygoid distinctly concave; ethmoid and vomer relatively well developed and sturdy, although sometimes at least partially fused together; palatine with a notched region posterodorsally for firm articulation with a crested region of the vomer and/or ethmoid, and never making contact with the frontal; prefrontal usually well developed, absent only in two closely related specialized genera, Xenopterus and Chonerhinos; frontals less wide and massive, except in Xenopterus; anterior end of parasphenoid less wide and less deeply concave, the concavity filled by the posterior articulating shaft of the vomer; rear margin of the orbit formed by the frontal and sphenotic; sphenotic often laterally expanded anteriorly, but never as a long, slender lateral prong; frontal not in contact posteroventrally in the rear of the orbit with the prootic, separated from it by the sphenotic and pterosphenoid; suboperculum without an anteriorly directed prong, and the interoperculum articulated posteriorly by a short ligament to the anterior edge of the operculum; supracleithrum usually positioned at about a $45^{\circ}$ angle to the axis of the body, but with great variation between species on the degree of obliqueness to the body; postcleithrum in two pieces, and much longer than the distance along the scapula to the lowest actinost; supraoccipital spine laterally compressed and mainly in a vertical plane, although its dorsal edge may be thicker than the ventral plate; exoccipital condyles well developed; at least the first two vertebrae anterior to the first basal pterygiophore of the dorsal fin without bifid neural spines, only the first three to five abdominal vertebrae with bifid divergent neural spines; none of the vertebrae with prominent lateral flanges from the centra; neural spines of the vertebrae supporting the basal pterygiophores of the dorsal fin relatively normal long slender shafts penetrating relatively deeply the interspaces between the

Figure 193.-Range of diversity in body form in the Recent Tetraodontidae:
A, Lagocephalus spadiceus,
B, Xenopterus naritus,
C, Amblyrhynchotes piosae,

D, Canthigaster rostrata. pterygiophores; a supraneural element often present; at least some of the basal pterygiophores of the dorsal and anal fins usually, but not always, interdigitated with one another; one or more of the more posterior abdominal vertebrae usually, but not always, with a complete haemal arch; none of the vertebrae posterior to the bases of the last basal pterygiophores of the dorsal and anal fins anteroposteriorly compressed, of about the same centrum length as those more anteriorly; abdominal vertebrae usually fewer in number than the caudal vertebrae, sometimes of equal number but never of greater number; dorsal and anal fins more anterior in position; at least four vertebrae fully posterior to that whose haemal spine is the last support of the last anal fin basal pterygiophore; caudal fin supporting skeleton with a free epural, one free uppermost hypural that in a few species may be partially fused to the centrum, a free parhypural and an autogenous haemal spine of the penultimate vertebra; no prominent lateral flange present on the fused hypural-centrum plate; haemal canal penetrating the last vertebral complex to exit between the parhypural and fused hypural-centrum plate; caudal fin rays 11 , the two lowermost rays unbranched; scales always relatively smaller, even when best developed, as in the moderate quills of Torquigener piosae or the enlarged basal plates of adult Ephippion guttifer.

Comparative diagnoses of Subfamilies (Tetraodontinae and Canthigasterine).-Subfamily Tetraodontinae: ethmoid varying from long to short, and of a variety of shapes, but never distinctly T-shaped in cross section; supraoccipital with an only moderate to low crest, usually arising from a flattened anterior region of the bone from which it is prolonged posteriorly, the posterior end of the crest not visible externally through the skin; posterolateral region of frontal variously laterally expanded or not, but never as two flanges whose distal ends closely approach or are in contact with one another to form a bony well around the muscle mass leading to the operculum; sphenotic a prominent component of the dorsal surface of the skull, and usually extended anterodorsally at least a short distance forward of the rear edge of the orbit; base of prefrontal always either in contact with or in very close proximity to the vomer; trituration teeth often present; one or two nostrils in a moderately low to high sac or tube, or a single or bifid tentacle or flap, but always conspicuous; lateral line conspicuous (with the possible exception of the long-spined Torquigener piosae); gill opening usually extending ventrally below the level of the middle of the pectoral fin base; vertebrae modally 17 to 29 ; vertebral column usually not highly arched anteriorly, the axis of the anterior portion of the column usually not especially oblique to that of the skull; haemal arches and spines usually not especially well developed on most of the abdominal vertebrae.

Subfamily Canthigasterinae: ethmoid long and $\mathrm{T}$. shaped in cross section, its upper surface a laterally ex- 
panded more or less flat plate of decreasing width anteriorly and its lower surface a similarly flat vertical plate of decreasing depth anteriorly; supraoccipital with a high well-developed crest throughout most of its length, the dorsal edge of the posterior end of the crest often indicated externally by a break in the contour of the dorsal profile; posterolateral region of frontal prolonged laterally as two flanges whose distal ends closely approach or are in contact with one another to form a partial to complete bony well around the muscle mass leading to the operculum; sphenotic mostly excluded from the dorsal surface of the skull, mostly confined to the ventrolateral surface of the skull behind the orbit; base of prefrontal well removed from the vomer, broadly separated from it by the ethmoid and parasphenoid; trituration teeth never present; a single nostril on each side, set in a very low inconspicuous tube; lateral line inconspicuous, apparent only with magnification; gill opening restricted, extending ventrally no further than about the level of the middle of the pectoral fin base; vertebrae always modally 17 ; vertebral column highly arched anteriorly, the axis of the arched portion highly oblique to that of the skull; haemal arches and spines especially well developed on most of the abdominal vertebrae.

\section{Detailed description of Lagocephalus laevigatus.}

Material examined-Three cleared and stained specimens, $61.4-166 \mathrm{~mm}$; one wet completely disar- ticulated specimen, approximately $290 \mathrm{~mm}$, prepared by maceration; one dry skeleton, approximately $290 \mathrm{~mm}$.

\section{SKULL.}

\section{Occipital Region.}

Basioccipital. - A short column, slightly expanded anteriorly; cartilage filled at its anterior and anterolateral edges; articulates by interdigitation anteriorly with the slightly overlying parasphenoid, anterolaterally with the prootic and laterally with the exoccipitals. The anterodorsal end of the basioccipital reaches to and forms the lower posterior wall of the vestigial myodome (see description of the prootic). The rim of the round concave posterior end of the basioccipital articulates by fibrous tissue with the rim of the concave anterior face of the centrum of the first vertebra. The posterodorsal surface of the basioccipital forms the ventral wall of the foramen magnum.

Exoccipital. - Cartilage filled at its anterior and ventromedial edges; articulates by interdigitation ventromedially with the basioccipital, posterolaterally with the pterotic, anterodorsally with the epiotic, and anteroventrally with the prootic. Dorsomedially the exoccipital forms the lateral wall of the foramen magnum, while the dorsal wall of the foramen is formed by the close fibrous tissue articulation of the extreme dorsomedial edges of the two exoccipitals. Ventrally the foramen magnum is closed not by medial projections of
Figure 194.-Lagocephalus laevigatus (above), with $L$. lunaris (center) and

L. Bcleratus (below) for comparison: in all three examples, upper left, nasal region as seen externally (far left) and the olfactory lamellae as seen with the top of the nasal sac removed (center), and the outline of an anteroposterior cross section of the sac and lamellae; center left, scales from upper middle region of body, including, in $L$. lunaris and $L$. scleratus, the small scales associated with the lateral line.
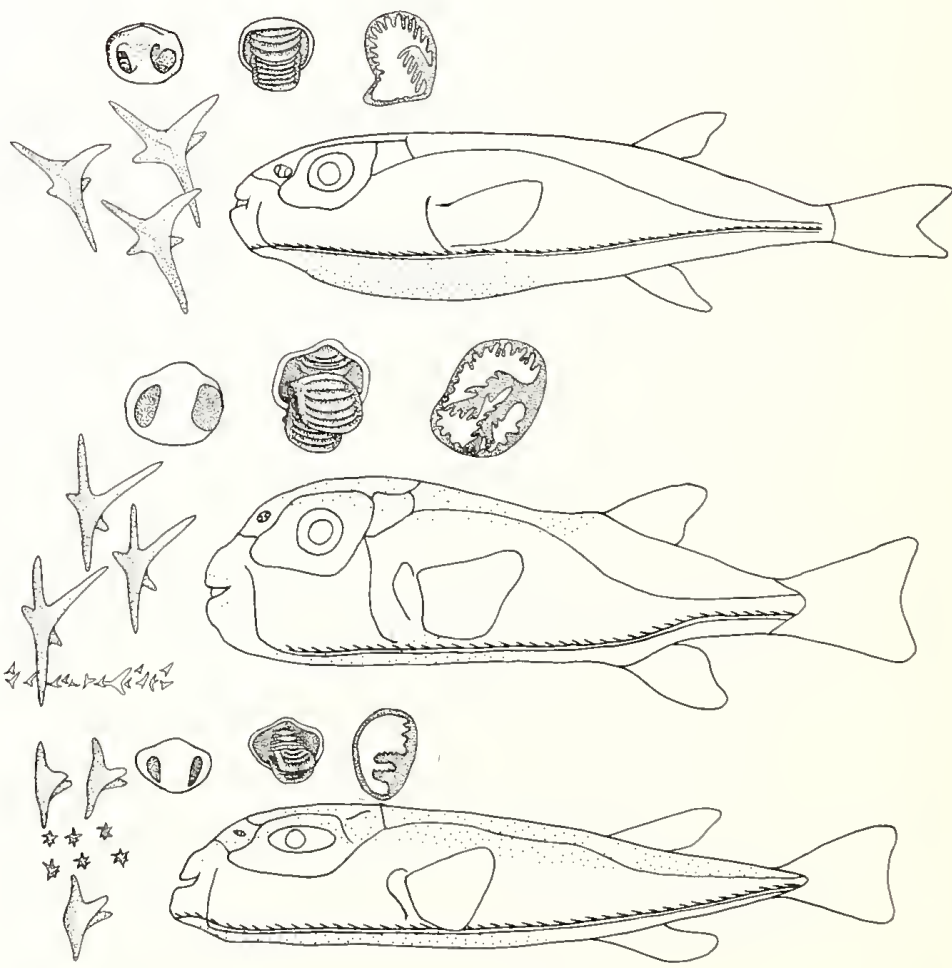
the exoccipitals, but, rather, by the posterodorsal surface of the basioccipital. From the posterior end of its ventromedial edge the exoccipital possesses a modified condyle in the form of a posteroventral process that articulates by fibrous tissue with the lateral surface of the neural arch and centrum of the first vertebra.

Supraoccipital. - A rounded plate anteriorly, but drawn out posteriorly into a long, laterally compressed spine; cartilage filled along all of the edges of its rounded anterior portion; articulates by interdigitation posterolaterally with the epiotics and anteriorly and anterolaterally with the frontals. Along the middle of its anterior end, as seen dorsally, the supraoccipital is broadly overlain by the posteromedial edges of the frontals. The supraoccipital spine is drawn out posteriorly between the bifid neural spine of the first vertebra and sometimes reaches posteriorly to above the second vertebra. The anterior half of the ventral edge of the supraoccipital spine articulates by tough fibrous tissue with the dorsomedial edges of the epiotics and exoccipitals.

\section{Otic Region.}

Pterotic. - Cartilage filled along its anteromedial edge; articulates by interdigitation posteromedially with the exoccipital, dorsomedially with the epiotic, anterodorsally and along the lateral part of its anteroventral edge with the sphenotic, and anteroventrally with the prootic. At the anterodorsal edge of its most laterally expanded portion the pterotic articulates by fibrous tissue with the posterolaterally projecting arm of the frontal. Along the middle of its posterior surface the pterotic has a concavity for articulation by fibrous tissue with the supracleithrum. In the middle of its ventral surface the pterotic articulates by fibrous tissue with the hyomandibular.

Sphenotic. - Broadly cartilage filled at its medial edge; articulates by interdigitation anterodorsally and dorsomedially with the frontal, posteromedially on its dorsal surface with the epiotic, posterodorsally with the pterotic, posteromedially on its ventral surface with the pterosphenoid, and anteroventrally with the frontal. Posteromedially on its ventral surface the sphenotic articulates with the hyomandibular by fibrous tissue.

Epiotic.-Flat, more or less rounded; broadly cartilage filled along all of its edges of articulation with the other cranial bones; articulates by interdigitation anteriorly with the frontals, anteromedially with the rounded anterior portion of the supraoccipital, anterolaterally with the sphenotic, posterolaterally with the pterotic, and posteromedially with the exoccipital. The medial edges of the two epiotics articulate with one another and with the ventral edge of the supraoccipital spine by fibrous tissue.

Prootic. - Cartilage filled along all of its edges of articulation with the other cranial bones, except an- teriorly; articulates by interdigitation anteroventrally with the dorsolateral wing of the parasphenoid, anterodorsally mostly with the sphenotic but also with the pterosphenoid, laterally with the sphenotic, posterolaterally with the pterotic, and anteromedially with the parasphenoid. From about the middle of its vertical anteromedial edge the prootic possesses a thin splint of bone projecting medially almost to the midline of the skull, where it articulates by fibrous tissue with the splintlike projection from the other prootic. These delicate spines are evidently all that remains of the dorsal roofing of the myodome. The small myodome is now roofed over only by a sheet of dense fibrous tissue which begins anteriorly where it binds together the two medial projections of the prootics and continues on posteroventrally to the floor of the cranial cavity, attaching posteriorly to the region where the parasphenoid and basioccipital interdigitate with the prootics. The myodome is thus enclosed dorsally mainly by a fibrous tissue sheet, and only at its upper anterior edge is the roof enclosed by the medial projections of the prootics. Laterally the myodome is bordered by the medial surfaces of the prootics, ventrally by the dorsal surface of the parasphenoid, and posteriorly by the anterior end of the basioccipital.

\section{Orbital Region.}

Frontal. - Laterally expanded in the middle of its length; with a long posterolaterally directed arm. The bone is generally dense and hard, but along the approximately anterior two-thirds of its medial portion a layer of spongy connective tissue is present between the medial surfaces of the two frontals. This spongy connective tissue layer extends laterally into the frontal for about onefourth or one-fifth the width of the bone and anteriorly it becomes cartilaginous and continuous with the ethmoid cartilage. The frontal articulates by interdigitation dorsomedially in the midline of the skull with its opposite member, anteriorly with the ethmoid, which it broadly overlies, anterolaterally with the prefrontal, posterolaterally with the sphenotic, posteriorly on its dorsal surface with the epiotic, and posteromedially on its dorsal surface with the supraoccipital. From above the region where it articulates with the sphenotic, the frontal possesses a long posterolaterally directed process that articulates by fibrous tissue with the anterodorsal edge of the most laterally expanded portion of the pterotic. The lateral fossa thus enclosed is bordered above by the frontal and below by the sphenotic and pterotic. On its ventral surface the frontal sends a ventromedially directed process into the deeply concave dorsal surface of the vertical interorbital projection of the parasphenoid, with extensive interdigitation occurring between the two bones. Just lateral to its ventromedial projection, the frontal is broadly overlain by the pterosphenoid, with slight interdigitation occurring between the two surfaces.

Prefrontal. - In the form of a dorsolaterally expanded column; cartilage filled at its rounded ventral 
edge; articulates by fibrous tissue ventrally with the region of articulation between the vomer and parasphenoid; articulates at its dorsal surface by interdigitation anteromedially with the ethmoid and posteromedially and posteriorly with the frontal. Along most of its medial surface it is attached to the ethmoid cartilage, with which it is continuous.

Parasphenoid.-Elongate, with a well-developed ventral keel in the suborbital region. The anterior end of the parasphenoid is deeply concave and into this concavity the shaftlike posterior end of the vomer interdigitates. The parasphenoid articulates lateraliy by fibrous tissue with the base of the prefrontal in this region. Posteriorly the parasphenoid slightly overlies the anterior end of the basioccipital and strongly interdigitates with it. About three-fourths the way back its length the parasphenoid gives rise to its paired dorsolateral wings that interdigitate with the anteromedial edges of the prootics. Posterior to this area of interdigitation with the anteromedial edges of the prootics, the lateral edges of the parasphenoid interdigitate with the ventromedial edges of the prootics. In about the middle of its length the parasphenoid gives rise to an interorbital projection into whose deeply concave dorsal surface the ventromedial projections of the frontals interdigitate.

Pterosphenoid. - A thin plate; cartilage filled along its dorsal edge; articulates by interdigitation posteroventrally with the prootic and posterolaterally with the sphenotic. For most of its length the pterosphenoid overlies the posteromedial portion of the ventral surface of the frontal, and slightly interdigitates with it.

\section{Ethmoid Region.}

Ethmoid. - Large, more or less rectangular; articulates by interdigitation posterodorsally with the overlying frontals and posterolaterally with the prefrontals. Along the anterior half of its ventral surface the ethmoid articulates with the vomer, the posterior part of this articular surface showing interdigitation, while more anteriorly the two bones are completely fused. In small specimens (under approximately $100 \mathrm{~mm}$ ) it can be seen that the anterior edge of the ethmoid region is actually formed by the upturned anterior edge of the vomer, even though in large specimens no such distinction can be made. Anterolaterally the ethmoid articulates by fibrous tissue with the palatine, although the main articulation of the latter is with the vomer. In large specimens the ethmoid tends to become swollen and porous, or hyperostotic. Just behind its articulation with the vomer, the posteroventral surface of the ethmoid is continuous with the remains of the ethmoid cartilage.

Vomer. - Broad anteriorly, but tapering to a stout shaft posteriorly; articulates with the ethmoid by fusion anterodorsally but by interdigitation posterodorsally. The posterior shaft of the vomer interdigitates with the ncave anterior end of the parasphenoid. Along the $d$ solateral surface of the vomer there is a laterally proj ting bony shelf above and below which fits the dee notched posterodorsal region of the palatine, the arti lation being by fibrous tissue.

\section{Mandibular Region.}

Hyomandibular. - Expanded dorsally, tapering stout shaft anteroventrally; cartilage filled at its ante ventral and dorsal edges; articulates by fibrous tis dorsolaterally with the sphenotic and pterotic and dor medially with the prootic and pterotic. Along the ven three-fourths of its posterior edge it articulates by fibr tissue with the preoperculum, while just above the dor end of the latter the hyomandibular supports the arti lar face of the operculum. Anteriorly the hyomandibu articulates by fibrous tissue principally with the $p$ terior region of the metapterygoid and symplectic.

Quadrate.-Wide posteriorly, but tapering $t$ knob anteriorly for articulation with the articular in lower jaw; a short, posteriorly directed process pres from its posteroventral edge; cartilage filled at its $p$ terior edge; articulates by fibrous tissue anteriorly w the articular, anterodorsally by interdigitation with slightly overlying ectopterygoid, dorsally by interd tation with the broadly overlying mesopterygoid, ventrally by fibrous tissue with the preoperculu Posteriorly the quadrate articulates through cartil with the metapterygoid and symplectic, the anterior $p$ of the latter being overlain by the short posterior proc of the quadrate.

Metapterygoid. -Broad anteriorly; cartilage fi at its anterior edge; articulates through cartil anteriorly with the quadrate and ventrally with symplectic, the latter also slightly overlying and in digitating with the metapterygoid. The metapteryg articulates by fibrous tissue posteroventrally with hyomandibular, preoperculum, and interhyal, wl anterodorsally it broadly overlies and slightly interd tates with the mesopterygoid.

Symplectic. - Small, somewhat irregular in sh from specimen to specimen; cartilage filled at its $p$ terior edge; articulates through cartilage and slight in digitation anteriorly with the overlying process of quadrate and dorsally with the metapterygoid; arti lates by fibrous tissue posteroventrally with the preop culum and interhyal.

\section{Palato-Pterygoid Region.}

Palatine. -Expanded posteriorly; a deep, an riorly directed cleft present in its upper posterior ec which fits tightly above and below the thin late shelf of the vomer, articulating with it by fibrous tiss Anteroventrally the palatine interdigitates with the topterygoid, while posteriorly it overlies and interd 
tates with the mesopterygoid. Anterodorsally the palatine is expanded laterally to form the articular facet for support of the maxillary through fibrous tissue.

Ectopterygoid. -Somewhat V-shaped, with the apex directed posteriorly; articulates by interdigitation dorsally with the palatine, posteriorly with the mesopterygoid, which it broadly overlies, and ventrally with the quadrate, which slightly overlies it.

Mesopterygoid. - Variable in shape, but usually thin anteriorly and thickened at its posterior edge. It appears to be relatively small as seen laterally, because it is overlain by each of the four bones with which it articulates by interdigitation; anterodorsally with the palatine, anteriorly with the ectopterygoid, anteroventrally with the quadrate, and posteroventrally with the metapterygoid.

\section{Opercular Region.}

Operculum. - Thin and expanded posteroventrally; a dorsally directed process from its dorsal surface present for muscle attachment; articulates by fibrous tissue dorsally at its flattened articular surface with the upper posterior edge of the hyomandibular, while ventrally it articulates with the deeply cleft region of the suboperculum, which it slightly overlies. In about the middle of its anterior edge the operculum articulates by a tough ligament with the rodlike interoperculum.

Suboperculum. - Thin; deeply and broadly cleft in its upper region; the portion of the bone anterior to the cleft somewhat prolonged dorsally; articulates by fibrous tissue along the edges of its cleft region with the slightly overlying operculum.

Interoperculum. - A long rod, with a small ventral flange from about the middle of its ventral edge; articulates by strong ligaments posteriorly with the operculum and anteriorly with the angular in the lower jaw. The ventral flange articulates by fibrous tissue with the lateral surface of the epihyal.

Preoperculum. - Large; expanded posteroventrally; slightly convex laterally; the anterior half of its dorsal edge somewhat laterally expanded to present a broad surface for fibrous tissue articulation with the ventral edge of the quadrate; articulates by fibrous tissue along the posterior half of its dorsal edge with the quadrate, symplectic, interhyal, and metapterygoid.

\section{Upper Jaw.}

Premaxillary. - Posteromedial arm short; together with the fused teeth forms a massive crushing plate; its anterior edge forming the anterior border of the upper jaw, except for a short distance ventrally where the maxillary forms the border. The premaxillaries articulate dorsomedially with one another by fibrous tissue, with the articulation strengthened by a single row of a dozen or more well-developed medial projections from the dorsomedial surface of each premaxillary. These projections alternate with one another and decrease in size anteriorly. The short posteromedial arm of the premaxillary articulates by fibrous tissue with the anteroventral surface of the vomer. Posteriorly and laterally the premaxillary is firmly articulated by extensive interdigitation with the broadly overlying maxillary. The premaxillary contains an internal cavity which communicates with the exterior through a small opening placed just lateral to the posteromedial arm that articulates with the vomer. This cavity in the premaxillary contains the dental pulp, which continually gives rise to the long, thin, rodlike, highly modified teeth. These teeth lie parallel to the anterior edge of the premaxillary and are constantly being moved forward to replace those dental lamellae worn down through use. There are usually 5 to 10 of these dental lamellae present in each premaxillary, of which only the most anterior one or two are actually exposed at the edge of the jaw. However, the lamellae posterior to them can be seen easily through the very thin portion of the premaxillary covering them, giving the impression that many more of the dental lamellae are exposed than is actually the case. On its ventral surface the premaxillary bears a variable number (two to six) of more or less anteroposteriorly compressed blunt teeth, set in shallow sockets, in a longitudinal row just lateral to its medial edge. These teeth, like the dental lamellae, are replaced from the posterior end of the series by the activity of the pulp tissue.

Maxillary. - Curved forward and slightly expanded dorsally and ventrally; broadly overlies and firmly interdigitates with the premaxillary along all of its length, except for a short distance ventrally where it is free of the premaxillary and forms the anterior border of the upper jaw. Posterodorsally at a slight groove on its surface the maxillary is supported through fibrous tissue by the anterodorsal edge of the palatine. The ventromedial surface of the maxillary articulates by fibrous tissue with the dorsolateral surface of the dentary.

\section{Lower Jaw.}

Dentary. - Somewhat squarish; articulates posteriorly by fibrous tissue and interdigitation with the articular, which it broadly overlies laterally but only slightly overlies medially. Posteroventrally the dentary articulates by fibrous tissue, or in large specimens by interdigitation, with the angular. The dorsolateral surface of the dentary articulates by fibrous tissue with the ventromedial surface of the maxillary. The dentary is hollow internally, although not as extensively so as the premaxillary. The cavity contains the dental lamellae producing pulp material, which functions in the same way as described for the premaxillary. The pulp cavity opens to the exterior at the region of articulation of the anterior end of the articular with the dentary. Only long, thin, rodlike, dental lamellae are produced, there being no 
stubby trituration teeth as there are on the ventral surface of the premaxillary. Ventromedially the dentary articulates by fibrous tissue with its opposite member, with about 15 stubby projections strengthening the articulation, as in the case of the premaxillary.

Articular. - More or less triangular in shape, with the apex pointing anteriorly into the hollowed out posterior part of the dentary; cartilage filled at its anterior edge where it is continuous with the remains of Meckel's cartilage; articulates by fibrous tissue and interdigitation anteriorly with the dentary, posteriorly by fibrous tissue at a groove on its surface with the knoblike anterior end of the quadrate, posteroventrally by fibrous tissue, and interdigitation in large specimens, with the angular. The sesamoid articular is a rod of bone lying alongside the anteromedial surface of the articular just posterior to the region where the latter interdigitates with the dentary.

Angular. - Small; articulates by fibrous tissue with the dentary and articular, or in large specimens by interdigitation with both of these bones. Posteriorly the angular makes ligamentous connection with the anterior end of the interoperculum.

\section{BRANCHIAL APPARATUS.}

\section{Hyoid Arch and Branchiostegal Rays.}

Hypohyals. - Both hypohyal elements present but not large, the dorsal hypohyal being particularly small; dorsal hypohyal cartilage filled at its ventral edge and ventral hypohyal cartilage filed at its posterior edge. The hypohyals articulate through cartilage with one another and with the ceratohyal, while they articulate by fibrous tissue anteromedially with their opposite members.

Ceratohyal. - Elongate, somewhat expanded posteriorly; cartilage filled at its anterior and posterior edges; articulates through cartilage anteriorly with the hypohyals and through cartilage and interdigitation posterodorsally with the epihyal. Of the six branchiostegal rays, only five usually articulate by direct contact through fibrous tissue with the ceratohyal.

Epihyal. - Rounded posteriorly; cartilage filled at its anterior edge; articulates anteriorly through cartilage and interdigitation with the ceratohyal and by fibrous tissue posterodorsally with the interhyal and laterally with the ventral flange of the interoperculum.

Interhyal. - Short and columnar; cartilage filled at its dorsal and ventral edges; articulates by fibrous tissue ventrally with the epihyal and dorsally with the fibrous tissue sheet between the symplectic, metapterygoid, and preoperculum.

Branchiostegal rays. - Six in number; the first branchiostegal ray a large, relatively flat horizontal plate with a down-turned lateral edge which anteriorly becomes a thick vertical flange for articulation by fibrous tissue with a vertical groove in the middle of the medial surface of the ceratohyal. The second branchiostegal ray is the longest of the six elements and it is a normal unexpanded shaft articulating by fibrous tissue with the ventral edge of the ceratohyal just posterior to the region of articulation of the first branchiostegal ray. The third, fourth, and fifth branchiostegal rays are also normal in shape, increasing slightly in length from the third to fifth and articulating by fibrous tissue with the lateral surface of the posteroventral region of the ceratohyal. The sixth branchiostegal ray is sometimes broad posteriorly, but always tapers to a narrow shaft anteriorly where it articulates by fibrous tissue with the dorsal edge of the fifth branchiostegal ray, rather than with the ceratohyal.

Branchial Arches. - All the elements are cartilage filled at their edges of articulation with the other elements of the series, and the articulations are usually mediated through cartilage and fibrous tissue. The branchial arches are composed of three basibranchials, three pairs of hypobranchials, five pairs of ceratobranchials, four pairs of epibranchials, and three pairs of pharyngobranchials. Three gills are present; the fourth arch possesses no gill and there is no slit between it and the lower pharyngeal.

First arch.-Basi-, hypo-, cerato-, epi-, and pharyngobranchial elements present. First basibranchial elongate and rodlike; displaced forward so that it articulates posteriorly with the second basibranchial and posterolaterally with the first hypobranchials. First hypobranchial slightly expanded dorsally; the largest of the hypobranchial elements, which decrease in size posteriorly in the series; articulates ventrally with the region of articulation of the first basibranchial with the second basibranchial and dorsally with the first ceratobranchial. First ceratobranchial the shortest of the ceratobranchial elements, which, except for the fifth ceratobranchial, increase in size posteriorly in the series; possesses a ventrally directed flange along most of its ventral surface, this flange on the succeeding ceratobranchials decreases in size posteriorly until it is almost absent on the last ceratobranchial; articulates dorsally with the first epibranchial. First epibranchial a narrow rod; the shortest of the epibranchial elements, which increase in length posteriorly in the series; articulates dorsally with the first pharyngobranchial. First pharyngobranchial (suspensory pharyngeal) a rounded plate with a short ventral process for articulation with the first epibranchial; toothless; placed in line with the two tooth bearing pharyngobranchials rather than being oriented toward, and having its distal end attached by fibrous tissue to, the ventral surface of the skull. The dorsal regions of the branchial arches are held to the ventral surfaces of the parasphenoid and prootics by fibrous tissue attaching to the dorsolateral surfaces of the epibranchials and pharyngobranchials. 
Second arch.-Basi-, hypo-, cerato-, epi-, and pharyngobranchial elements present. Second basibranchial short, but much expanded laterally both anteriorly and posteriorly; articulates anteriorly with the first basibranchial, posteriorly with the third basibranchial, anterolaterally with the first hypobranchials, and posterolaterally with the second hypobranchials. Second hypobranchial a short rod; articulates ventrally with the posterolateral surface of the second basibranchial and dorsally with the second ceratobranchial, which in turn articulates dorsally with the second epibranchial. Second epibranchial a slender rod; articulates dorsally with the ventral arm of the second pharyngobranchial. Second pharyngobranchial roughly L-shaped; bearing a single row of 12 to 17 well-developed teeth, which are relatively sharp pointed and curved slightly posteriorly, along the larger of the two wings of the $\mathrm{L}$. The toothless ventral wing articulates principally with the second epibranchial, but also, to a lesser extent, with the third epibranchial. The teeth are set in shallow sockets and are replaced by new teeth developing in sockets just anterior to and below the bases of the old teeth. The second pharyngobranchial is held to the other two pharyngobranchial elements by fibrous tissue.

Third arch.-Basi-, hypo-, cerato-, epi-, and pharyngobranchial elements present. Third basibranchial like second basibranchial, but larger; articulates anteriorly with the second basibranchial, posteriorly with the fourth ceratobranchials and posterolaterally with the third hypobranchials. Third hypobranchial with an anteroventral process that articulates by fibrous tissue with the ventral surface of the first basibranchial; posteriorly it articulates with the posterolateral surface of the third basibranchial and with the ventral edge of the third ceratobranchial. Third ceratobranchial articulated ventrally with the third hypobranchial and dorsally with the third epibranchial. Third epibranchial a stout rod, with a stubby projection from its posterolateral surface articulating by fibrous tissue with a similar process from the fourth epibranchial; articulates dorsally with the second and third pharyngobranchials. Third pharyngobranchial roughly L-shaped, with the larger of the two arms bearing about 10 to 12 teeth in a single row; teeth similar to those of the second pharyngobranchial and replaced in a similar manner; articulates by the smaller of its two arms ventrally with the third and fourth epibranchials.

Fourth arch. - Cerato- and epibranchial elements only. Fourth ceratobranchial the longest of the ceratobranchial elements; articulates ventrally with the third basibranchial and dorsally with the fourth epibranchial. Fourth epibranchial an elongate rod, the longest of the epibranchial elements; possesses a stubby projection from its anterolateral edge which articulates through fibrous tissue with the similar process on the third epibranchial; articulates dorsally with the third pharyngobranchial.
Fifth arch. - Ceratobranchial (lower pharyngeal) element only. Fifth ceratobranchial a stout rod, slightly expanded medially in about the first one-third of its length; toothless; articulates ventrally with the base of the fourth ceratobranchial.

\section{PAIRED FIN GIRDLES.}

\section{Pectoral Fin.}

Supracleithrum. - In position at about a $45^{\circ}$ angle to the axis of the body; a stout shaft with a lateral flange along most of its length; articulates by fibrous tissue dorsally with a slight concavity on the posterior surface of the pterotic and ventrally with the cleithrum, which it overlies.

Cleithrum. - Laterally expanded along most of its length; articulates by fibrous tissue dorsally with the overlying supracleithrum and with the dorsal postcleithrum, which it overlies. Along its posterior surface it articulates by fibrous tissue with the scapula and coracoid. Ventromedially the cleithrum articulates by tough fibrous tissue with its opposite member in the midline of the body between the medial edges of the horizontal platelike portions of the first branchiostegal rays.

Postcleithra. - The postcleithra form a long strut, widened posteriorly, along the abdominal wall musculature from the supracleithrum to about halfway back the length of the abdominal cavity. The dorsal postcleithrum articulates by fibrous tissue anterolaterally with the overlying cleithrum and posterolaterally with the ventral postcleithrum, which is much deeper and more laterally compressed than the dorsal postcleithrum.

Coracoid. - Rounded dorsally, but tapering to a point anteroventrally; a posterodorsally directed spinelike process present from its posteroventral edge; cartilage filled at its dorsal edge; articulates anteriorly by fibrous tissue with the cleithrum and dorsally through cartilage with the scapula and the second to fourth actinosts.

Scapula. - Scapular foramen not entirely enclosed by the scapula, but, rather, with its anterior edge closed by the cleithrum; cartilage filled at its dorsal, ventral, and anterior edges; articulates by fibrous tissue anteriorly with the cleithrum, posteriorly by slight interdigitation dorsally with the small first actinost and ventrally with the base of the second actinost, and through cartilage ventrally with the coracoid.

Actinosts. - Four elements; all cartilage filled at both ends, except for the first, which is only cartilage filled at its dorsal edge. The first actinost is reduced to a small wedge between the upper regions of the scapula and the second actinost, articulating with the former by interdigitation and with the latter through cartilage. The second and third actinosts are constricted in the middle, 
with the third being slightly larger than the second. The fourth actinost is only concave on the side toward the third actinost. The actinosts articulate with one another dorsally through cartilage and ventrally, except for the small first actinost, with one another by slight interdigitation. The second actinost interdigitates anteroventrally with the base of the scapula, while the second to fourth actinosts articulate ventrally through cartilage with the coracoid. Distally the actinosts support all of the fin rays, except for the small first fin ray, which articulates with the scapula.

Fin rays. - Usually 17 to 19 fin rays present; the first ray small, its medial half thicker than its lateral half; first ray articulated with the scapula, but the other rays articulated to the actinosts. The first two rays and last ray unbranched, the other rays branched. First ray without cross-striations, the other rays cross-striated.

VERTEBRAL COLUMN. -All vertebrae with biconcave centra, except the last, which ends posteriorly in the modified urostyle and fusion with some of the hypurals.

\section{Abdominal Vertebrae.}

First vertebra. - Neural spine befid and relatively short; neural arch with a complete bony roof over the neural canal, as do all the other vertebrae; articulates by fibrous tissue laterally at a shallow but broad concavity over the upper anterior half of its centrum with the posteroventrally projecting spinelike exoccipital condyles. Along the rim of its concave anterior end the centrum articulates by fibrous tissue with the rim of the round posterior end of the basioccipital. The first vertebra articulates by fibrous tissue posterodorsally at a shallow concavity on its lateral surface with the neural prezygapophysis of the second vertebra, while posteroventrally from its lateral edge it sends a large process posteriorly to fit under a shallow groove on the anterior half of the ventrolateral surface of the centrum of the second vertebra.

Other abdominal vertebrae. - In 12 specimens, the abdominal vertebrae numbered eight. The second and third abdominal vertebrae have bifid neural spines very similar to that of the first vertebra. The fourth abdominal vertebra, however, has the neural spine bifid anteriorly but single posteriorly. All the vertebrae, both abdominal and caudal, posterior to the fourth abdominal vertebra have undivided neural spines. The neural spines of the fifth to eighth abdominal vertebrae become increasingly thinner and longer. From the second to eighth abdominal vertebrae the neural and haemal prezygapophyses gradually become larger, but the haemal postzygapophyses remain about the same size so that each of the last few abdominal vertebrae articulates ventrally by the apposition of its posteroventrally projecting haemal postzygapophyses with the anteroventrally projecting haemal prezygapophyses of the vertebra pos- terior to it. No haemal arches or spines are present. T neural spine of the seventh abdominal vertebra arti lates by fibrous tissue along its posterior edge with first basal pterygiophore of the dorsal fin, while neural spine of the eighth abdominal vertebra arti lates between the first and second basal pterygiopho of the dorsal fin.

Caudal Vertebrae. - In 12 specimens, the cauc vertebrae numbered 11 in 10 specimens and 10 in 2 spe mens. All the caudal vertebrae, and only the caur vertebrae, possess haemal arches, while only those ver brae just below and posterior to the last basal pteryg phore of the anal fin possess large haemal spines. $T$ haemal arches of the first four caudal vertebrae (the without conspicuous haemal spines) are modified for ticulation by fibrous tissue with the dorsal ends of basal pterygiophores of the anal fin. From the haen prezygapophyses of each of these vertebrae there is 0 projection directed anteriorly and another directed p teromedially. The anterior projections from the haen prezygapophyses on each side of the vertebra do not m in the midline under the centrum, while the poste medial projections from each side do meet and fuse in 1 midline under the centrum at the open area between 1 anterior projections from the haemal prezygapophyses the vertebra behind it. Thus, the posteromedial proj tions from the haemal prezygapophyses form the haen arch, which is here displaced posterodorsally from position it would more normally assume. The anter projections from the haemal prezygapophyses are mu shorter than the posteromedial projections, except in 1 case of the first caudal vertebra, in which the anter projection is much enlarged and somewhat ventrally rected for support along its ventral surface of the dor end of the enlarged first basal pterygiophore of the at fin. The anterior projections from the haemal prezy pophyses of the second and third caudal vertebrae st port through fibrous tissue, respectively, the second a third anal fin basal pterygiophores. The fourth cau vertebra supports the fourth and fifth anal fin ba pterygiophores from, respectively, its anterior haen prezygapophyseal projections and from its haemal ar The fifth caudal vertebra supports the sixth anal basal pterygiophore from its haemal arch. The fifth $c$ dal vertebra, in all but one of the study and rad graphed specimens, possesses a haemal spine. The p teromedial projections of the haemal prezygapophyses the fifth caudal vertebra not only fuse to each other the midline, but also fuse to the ventrolateral edges the centrum, leaving open a medial canal beneath centrum and enclosing a large foramen laterally. Fr the area of fusion with the centrum, a long haemal sp: is given off ventrally from the fifth caudal vertebra support by fibrous tissue the last anal fin basal pteryg phore. The haemal apparatus of the sixth to ninth ver brae is similar to that of the fifth vertebra in that haemal arch fuses posterolaterally to the centrum a completely encloses the haemal canal, except laterally the foramen. The haemal spines of the sixth and sever 
caudal vertebrae are the largest of those of the caudal vertebrae. In large specimens (over $200 \mathrm{~mm}$ ) these two haemal spines become enlarged and swollen, taking on the hyperostotic consistency that is also characteristic of the ethmoid in large specimens. The haemal structures of the last two vertebrae are autogenous.

The neural spines of the first five caudal vertebrae are slender rods which support most of the basal pterygiophores of the dorsal fin. They arise from the posterodorsal surface of the neural arches at the region of the neural postzygapophyses. The neural spine of the first caudal vertebra is placed between the third and fourth basal pterygiophores and that of the fourth caudal vertebra behind the ninth and last basal pterygiophore. The neural spine of the fifth caudal vertebra is larger than those of the caudal series anterior to it, but it is relatively small in comparison to the neural spine of the sixth caudal vertebra. Posterior to the sixth caudal vertebra the neural spines become progressively smaller. It is of interest to note that whereas the haemal spines of the sixth and seventh caudal vertebrae are swollen and spongy in the two largest study specimens, the neural spines of these same vertebrae are normal thin hard plates.

Caudal Skeleton. - The supporting structure of the caudal fin appears to be a single large block of bone, square in its lateral outline, but it is a compound structure formed of four separate bony elements firmly interdigitated with one another. The ventral portion of the caudal skeleton is formed by the parhypural. A slight concavity is present in about the middle of its dorsal surface just below a similar concavity on the ventral surface of the bony element that lies above it, which is the fused centrum-lower hypurals. The parhypural and the fused centrum-lower hypurals are extensively interdigitated with each other, except in the region where the concavities occur in their apposed surfaces so that a foramen is enclosed between them. This foramen is the last opening into the haemal canal, the latter being connected to the canal in the preceding vertebrae by a small longitudinal groove along the articular surface between the parhypural and the centrum-lower hypural element anterior to the foramen. Anteriorly the parhypural is laterally expanded to form haemal prezygapophyses. The epural is much like the parhypural in shape, but it is shorter and only forms the dorsal margin of the anterior two-thirds of the caudal skeleton. Along most of its ventral surface it firmly interdigitates with the centrum but posteriorly it interdigitates with the autogenous upper hypural plate. Concavities exist on the ventral and dorsal surfaces, respectively, of the epural and centrum so that a foramen is enclosed by the otherwise apposed surfaces of the two bones. A deep longitudinal groove is present along the ventral surface of the epural and the dorsal surface of the centrum which permits the neural canal to be present in the midline of the otherwise interdigitated surfaces of these two elements. The neural canal opens anteriorly into the neural canal of the preceding vertebrae, while posteriorly it opens to the exterior between the posterior end of the epural and the dorsal surface of the autogenous upper hypural plate. The anterior end of the epural is expanded laterally to form the neural prezygapophyses. The fused centrum-lower hypurals form the largest bone of the caudal skeleton, its anterior portion corresponding to the last vertebral centrum and abbreviated urostyle, and its posterior portion corresponding to what in generalized plectognaths would be the first and second hypurals. The anterior portion interdigitates dorsally with the epural, posterodorsally with the upper hypural plate and ventrally with the parhypural. The posterodorsal region of the anterior portion, which represents the urostyle, is extensively interdigitated with the anteroventral edge of the upper hypural plate. The posteroventrally expanded portion representing the lower hypurals articulates by interdigitation dorsally with the upper hypural plate and ventrally with the parhypural. There is a short concavity, or blindly ending tube, proceeding posteriorly and slightly dorsally into the lower hypural region from the area of the haemal foramen between the centrum and parhypural. This tube probably encloses the end of the haemal canal. The lower hypural region supports the lower six caudal fin rays, with the support of the lowermost ray shared with the parhypural. The autogenous upper hypural plate forms the posterodorsal region of the caudal skeleton and represents what in generalized plectognaths would be the third to fifth (or, in Triodon, third and fourth) hypurals. It interdigitates strongly with the centrum-lower hypural plate and with the posterior end of the epural. The upper hypural plate supports the upper five caudal fin rays.

Caudal fin rays. - Eleven in number, the uppermost ray and lowermost two rays unbranched, the intervening rays becoming increasingly branched toward the middle rays, which are branched in at least triple dichotomies. The upper five rays articulate by fibrous tissue at their bifid bases to the upper hypural plate and the lower six rays mainly to the lower hypural region, as described above.

\section{DORSAL AND ANAL FINS.}

\section{Dorsal Fin.}

Fin rays and pterygiophores. - Fifteen fin rays present in most specimens, the first two rays and the last one or two rays unbranched, the others branched in single or double dichotomies. The first ray is small and rudimentary, barely protruding to the surface, formed of two separate halves and without cross-striations, while all the other rays are cross-striated. Distal pterygiophores are either absent or unossified. The fin rays are supported below by nine basal pterygiophores which are strongly interdigitated with one another dorsally. The interneural processes of these pterygiophores are large anteriorly in the series but decrease in size posteriorly. The first and second basal pterygiophores are placed well 
in advance of the base of the dorsal fin. The interneural process of the first basal pterygiophore lies between the neural spines of the seventh and eighth abdominal vertebrae and those of the last two basal pterygiophores between those of the third and fourth caudal vertebrae. On the upper end of each of the basal pterygiophores there is a short columnar projection whose deeply concave surface is cartilage filled, except for the last pterygiophore, which has two of these facets with which the fin rays articulate by fibrous tissue. The pterygiophores are also cartilage filled at their ventral edges. From its anterodorsal edge the first basal pterygiophore has an anteriorly directed process, lying in the midline of the body just beneath the skin, which reaches to about the level of the tip of the neural spine of the sixth abdominal vertebra. At its anterior end it is attached by fibrous tissue to a rodlike supraneural. The supraneural lies just below the skin in the midline of the body from the level of the tip of the neural spine of the sixth abdominal vertebra to about the region above the fourth abdominal vertebra. The supraneural is surrounded by a longtitudinal band of muscles which lies between the dorsomedial edges of the general epaxial muscle masses. This longtitudinal band of muscles continues anteriorly and partially fills the space between the bifid neural spines of the first three abdominal vertebrae and ends by connecting firmly with the supraoccipital spine. The ninth, or last, basal pterygiophore has a posteriorly directed spine from its posterodorsal edge that ends over the neural spine of the fifth caudal vertebra. The fact that the ninth basal pterygiophore bears two columnar articular facets may indicate that it is a fusion product of two originally separate basal pterygial elements. None of the basal pterygiophores possess lateral projections along its length for muscle attachment.

\section{Anal Fin.}

Fin rays and pterygiophores. - Fourteen fin rays present in most specimens, the first two rays and the last one or two rays unbranched, the others branched in single or double dichotomies. The first ray is small and rudimentary, like that of the dorsal fin. Distal pterygiophores are either absent or unossified. The fin rays are supported below by six basal pterygiophores which are strongly interdigitated with one another ventrally. The "interhaemal" processes of these pterygiophores are large anteriorly in the series but decrease in size posteriorly, with the first basal pterygiophore being by far the largest of the series. The first, second, third, and fourth basal pterygiophores articulate by fibrous tissue dorsally with the haemal prezygapophyses of, respectively, the first, second, third, and fourth caudal vertebrae. The fifth and sixth basal pterygiophores articulate similarly with about the middle of the haemal arches of, respectively, the fourth and fifth caudal vertebrae. On the ventral surface of each pterygiophore there is a short columnar projection whose ventral edge is deeply concave and cartilage filled, except for the first basal pterygiophore, which has two of these projections, and the sixth basal pterygiophore, which usually has thr them. From these columnar facets the fin rays artic by fibrous tissue. The pterygiophores are also cart filled at their dorsal ends. As is the case with the basal pterygiophore of the dorsal fin, the presen more than one columnar articular process may ind that the first and the last anal fin basal pterygioph are the fusion products of two or more originally arate elements. The sixth basal pterygiophore bears its posteroventral edge a posterior projection tha tends back under the haemal spine of the sixth ca vertebra. None of the pterygiophores possess lateral jections along their lengths for muscle attachment

\section{Detailed description of Canthigaster rostrata.}

Material examined. - Five cleared and stained s mens, $10.0-59.6 \mathrm{~mm}$, and one dry, partially disar lated skeleton, approximately $96.5 \mathrm{~mm}$.

\section{SKULL.}

\section{Occipital Region.}

Basioccipital. - A long column, laterally expar anteriorly; cartilage filled at its anterior and pos lateral edges; articulates anteriorly by interdigits with the slightly overlying parasphenoid, anterolate with the prootics, and laterally with the exoccipitals. posterior concave end of the basioccipital is some depressed, its rim articulating by fibrous tissue with rim of the anterior concave face of the first vertebra. dorsal edge of the basioccipital forms the ventral we the foramen magnum.

Exoccipital. - Cartilage filled at its anterior ventromedial edges; articulates by interdigitation tromedially with the basioccipital, ventrolaterally the pterotic, anterodorsally with the epiotic, and $\mathrm{d}$ medially with the supraoccipital. At the extreme terior end of its dorsomedial edge the exoccipital i digitates with its opposite member to form the $d$ wall of the foramen magnum, while the posterom edges of the exoccipitals form the lateral walls of foramen. From its posteroventral edge the exocci condyle projects posteriorly well past the posterior er the basioccipital and articulates by fibrous tissue the lateral surface of the anterior half of the centru the first vertebra.

Supraoccipital. - Flattened anteriorly, but $\mathrm{dr}$ out into a deep laterally compressed spine posteri cartilage filled along its anterior edge; articulates b: terdigitation anteriorly with the frontals, w? somewhat overlie it, laterally with the epiotics and terolaterally with the exoccipitals. The posterior ed the supraoccipital spine is slightly expanded later particularly in the dorsal region. The spine does not ject posteriorly far beyond the end of the skull. 


\section{Otic Region.}

Pterotic. - Cartilage filled along all of its edges of articulation with the other cranial bones; articulates by interdigitation anterodorsally with the sphenotic, dorsomedially with the epiotic, ventromedially with the exoccipital, and anteroventrally with the prootic and sphenotic. Placed transversely along the middle of its ventral surface, the pterotic possesses a low ventrally directed flange for muscle attachment. Anterior to this ventral flange the pterotic has a slight concavity on its surface for articulation by fibrous tissue with the posterior half of the dorsal edge of the hyomandibular.

Sphenotic. - Cartilage filled at its medial edge; articulates by interdigitation anterodorsally with the frontal, anteromedially with the pterosphenoid, ventromedially with the prootic, posteroventrally and posterodorsally with the pterotic, and posteromedially on its dorsal surface with the epiotic. On its ventral surface the medial edge of the sphenotic articulates with the anterior end of the dorsal edge of the hyomandibular by fibrous tissue.

Epiotic. - Somewhat expanded laterally; cartilage filled along all of its edges of articulation with the other cranial bones; articulates by interdigitation anteriorly with the frontal, anterolaterally with the sphenotic, laterally with the pterotic, posteriorly with the exoccipital, and medially with the supraoccipital. 
Figure 196.-Lagocephalus laevigatus: lateral view of head, composite based on several specimens, 61.4-166 mm SL, Gulf of Mexico.
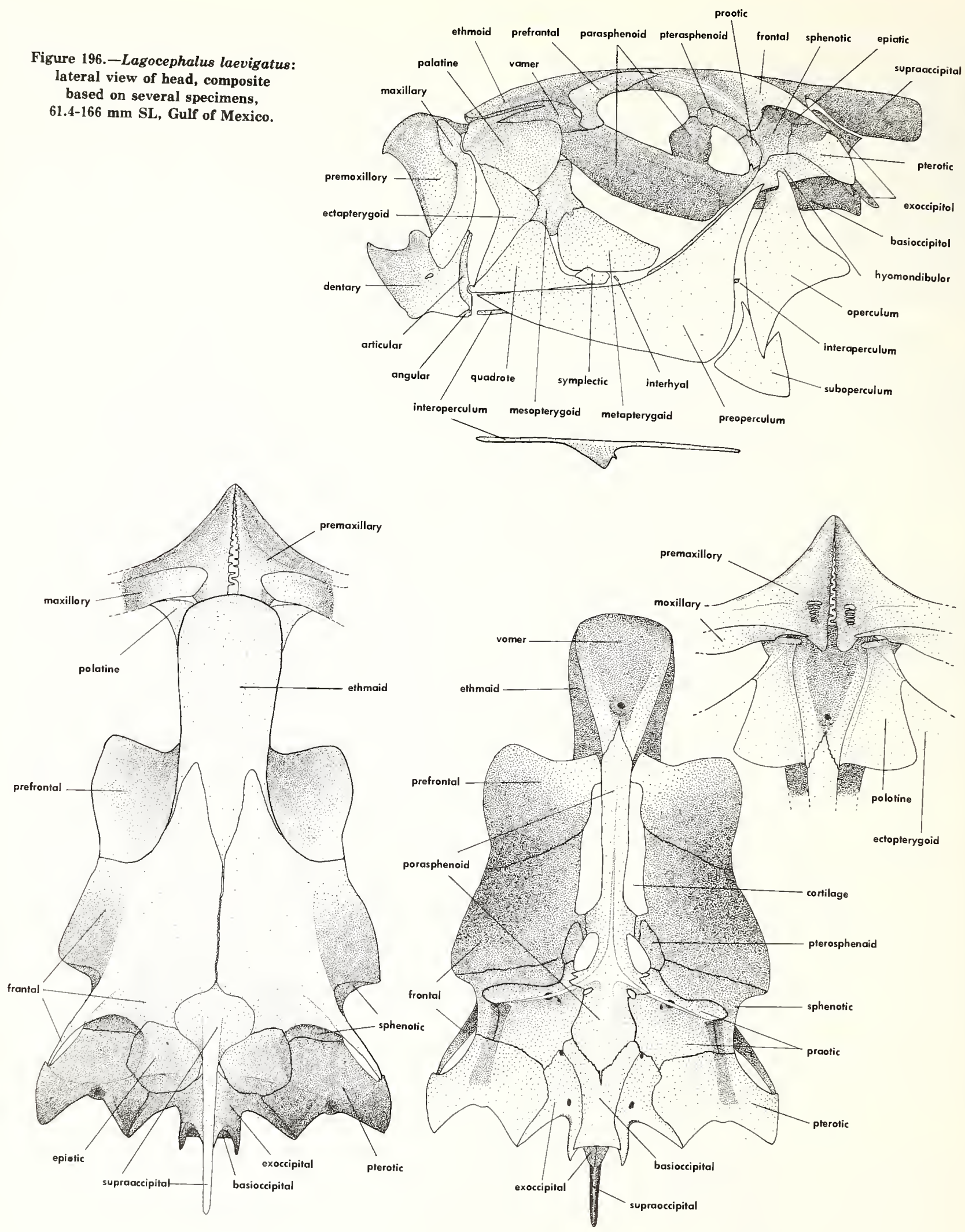

Figure 197.-Lagocephalus laevigatus: dorsaI (left) and ventral (right) views of skull, with inset at top right showing a ventral view detail of the articulation of the upper jaw with the palatines and vomer, composite based on several specimens, 61.4-166 mm SL, Gulf of Mexico. 


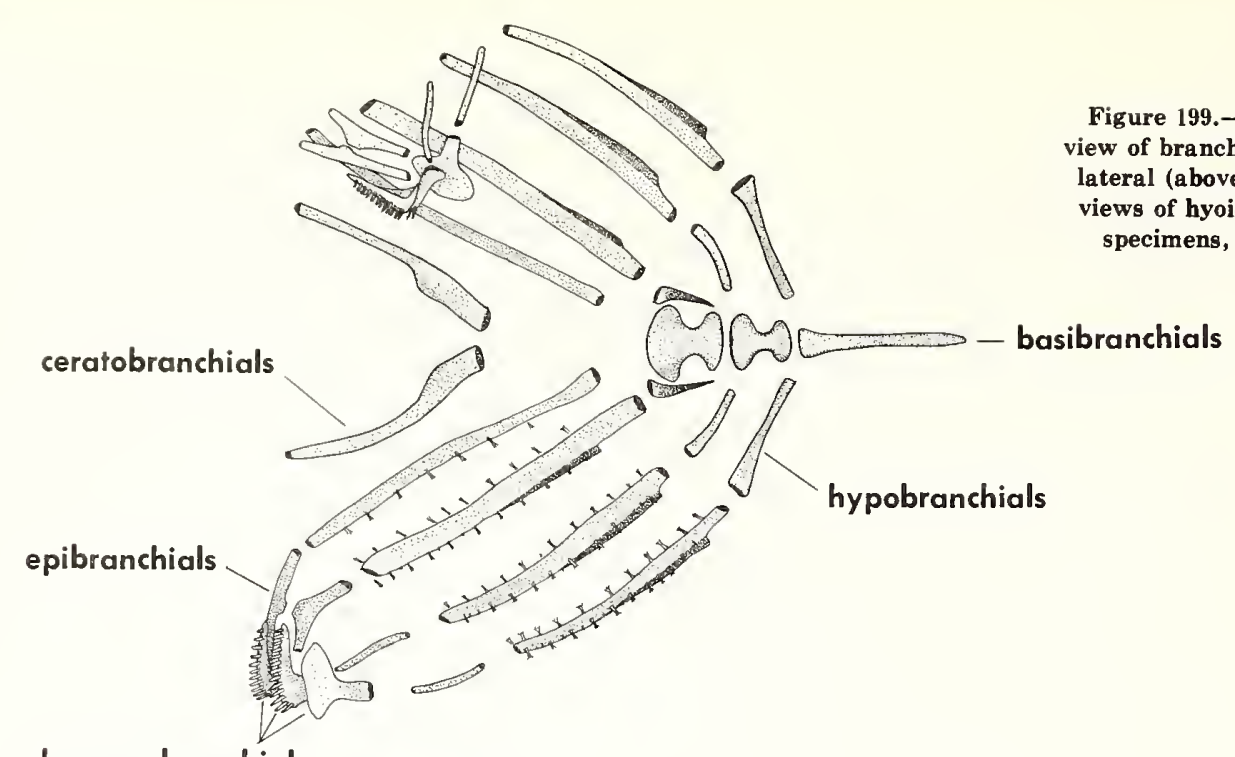

pharyngobranchials

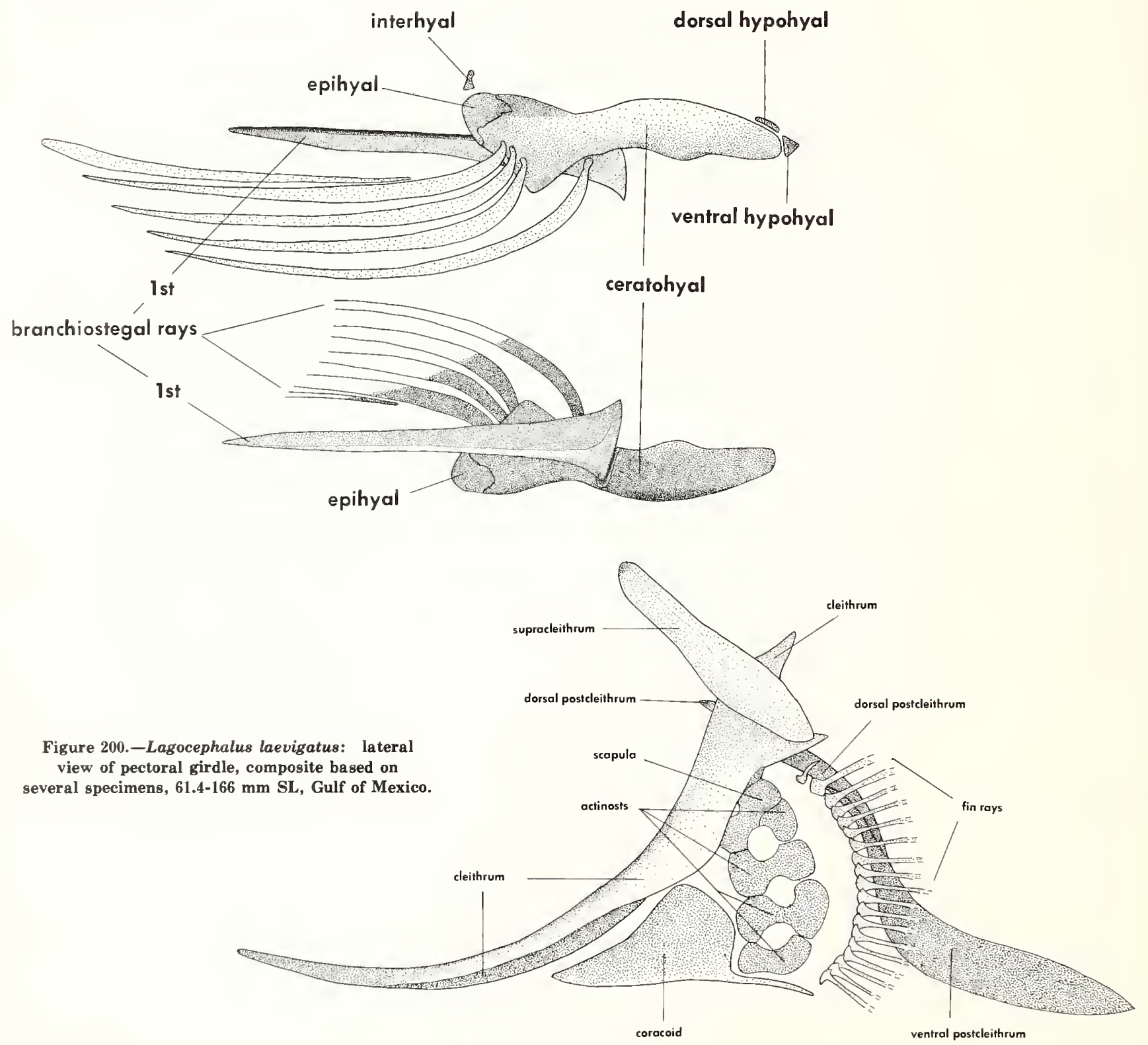




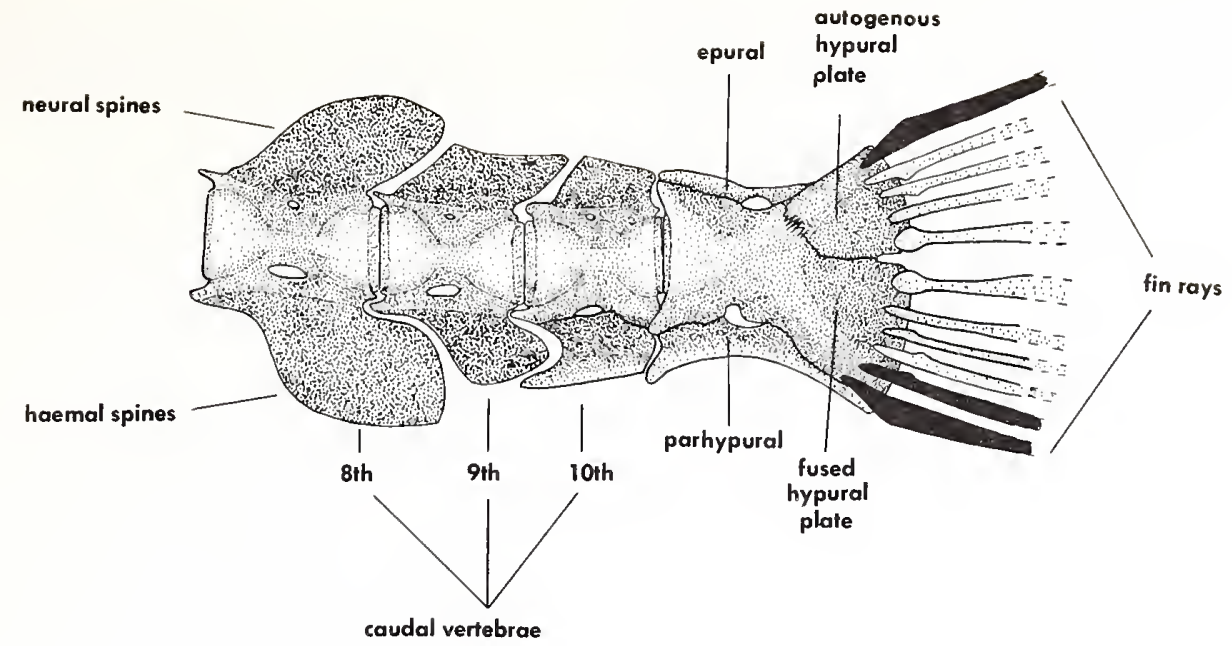

Figure 201.-Lagocephalus laevigatus: lateral view of caudal fin supporting structures, composite based on several specimens, $61.4-166 \mathrm{~mm}$ SL, Gulf of Mexico.

Figure 202.-Canthigaster rostrata (A, above), with $C$. valentini $(B)$ and two renditions

of $C$. amboinensis (C): the lower showing the course of the lateral line canals and their major pores as decifered by placing drops of ink on each pore found by microscopic search of a partially drying specimen; in front of the top three figures, nasal region as seen externally (above) and scales from upper middle region of body.
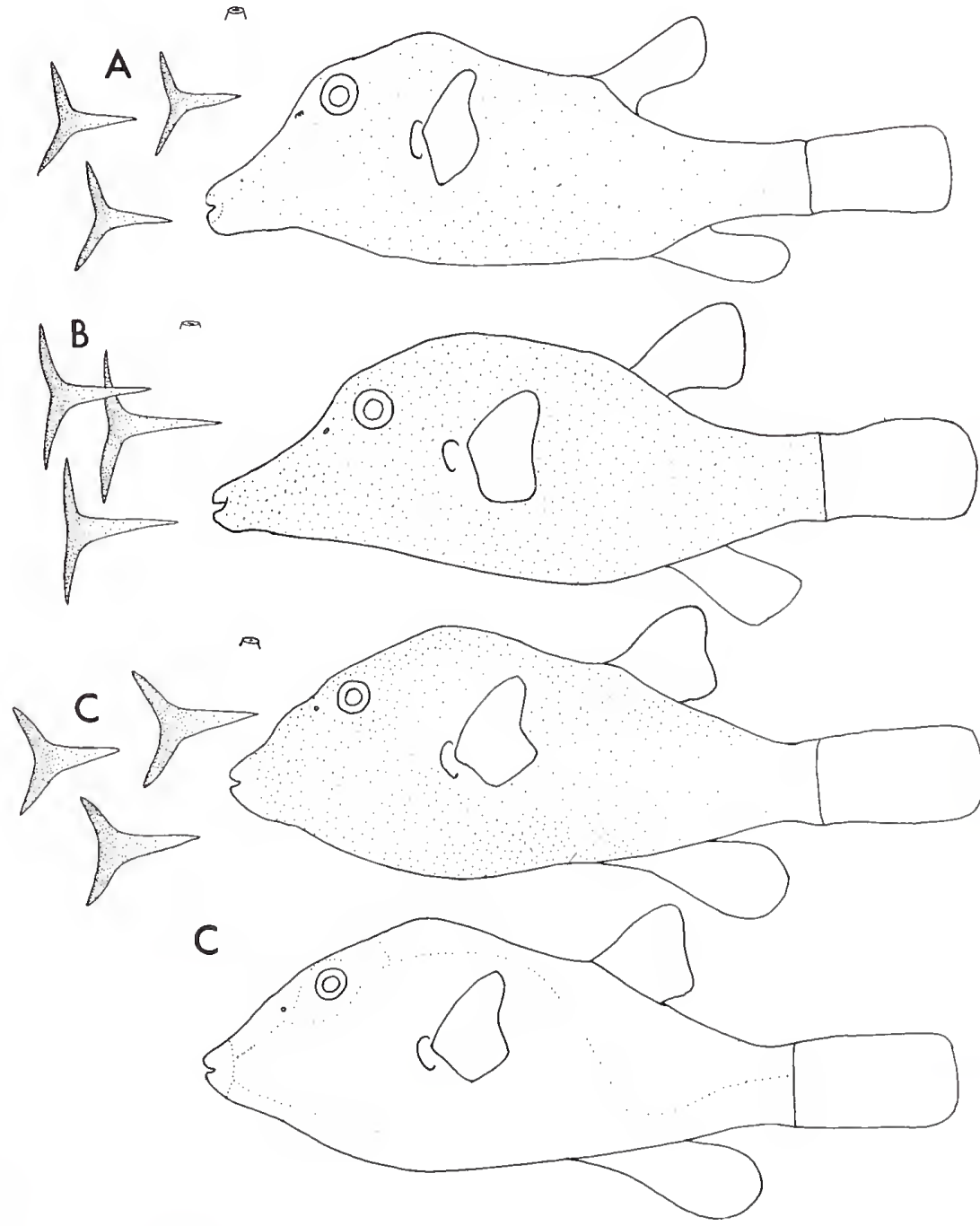
tates with the anterior end of the basioccipital, while just anterior to this region the parasphenoid interdigitates with the ventromedial edges of the prootics. About threefourths the way back its length the parasphenoid gives rise to its dorsolateral wings which interdigitate with the anteromedial edges of the prootics.

Pterosphenoid. -A small, thin plate; cartilage filled at its dorsal and lateral edges; articulates by slight interdigitation dorsally with the frontal, laterally with the sphenotic and ventrally with the prootic.

\section{Ethmoid Region.}

Ethmoid. - More or less T-shaped in cross section; its dorsal surface laterally expanded, increasingly so posteriorly, while its ventral surface is drawn out into a thin medial flange in the posterior two-thirds of its length; articulates by slight interdigitation posteriorly with the frontals and prefrontals, posteroventrally with the somewhat overlying parasphenoid and anteroventrally with the vomer.

Vomer.-Thin and laterally compressed posteriorly, but dorsoventrally depressed anteriorly; anterior end concave; anterolateral edge with a deep indentation around which the anterodorsal forked region of the palatine fits and is held by fibrous tissue; articulates by slight interdigitation dorsally with the ethmoid and posteriorly with the concave anterior end of the parasphenoid.

\section{Mandibular Region.}

Hyomandibular. - Expanded dorsally, tapering gradually to a stout shaft anteroventrally; cartilage filled at its dorsal and anteroventral edges; articulates by fibrous tissue dorsolaterally with the sphenotic and pterotic and dorsomedially with the prootic and pterotic. The ventral three-fourths of the posterior edge of the hyomandibular articulates by fibrous tissue with the preoperculum, while just above the dorsal end of the latter the hyomandibular supports the articular face of the operculum. At its anteroventral end the hyomandibular makes fibrous tissue contact mainly with the preoperculum, and only secondarily with the symplectic and metapterygoid.

Quadrate.-Somewhat wider posteriorly than anteriorly; prolonged posteroventrally into a thin tapering piece below the metapterygoid; cartilage filled only for a short distance along its posterodorsal edge; articulates by fibrous tissue anteriorly with the articular in the lower jaw and ventrally with the preoperculum. It articulates by interdigitation dorsally with the overlying ectopterygoid, while posterodorsally it overlies and interdigitates with the metapterygoid.

Metapterygoid. - A more or less rounded plate; cartilage filled only for a short distance along its antero- ventral edge; articulates by interdigitation anteriorly with the ectopterygoid and palatine, dorsally with the mesopterygoid, anteroventrally with the quadrate, and posteroventrally with the symplectic.

Symplectic. - A thin delicate rod; cartilage filled at its posterior edge; articulates by interdigitation dorsally with the metapterygoid and by fibrous tissue ventrally with the preoperculum.

\section{Palato-Pterygoid Region.}

Palatine.-Expanded posteriorly; a short anteriorly directed cleft present in the anterior part of its dorsal edge; articulates anterodorsally by firm fibrous tissue attachment of its cleft surface in the anterolateral indentation of the vomer; articulates by interdigitation ventrally with the ectopterygoid, posteroventrally with the metapterygoid, and posterodorsally with the mesopterygoid.

Ectopterygoid. - Roughly triangular, its posterior end tapering to a blunt point; articulates by interdigitation dorsally with the palatine, posteriorly with the metapterygoid, and ventrally with the quadrate, which it broadly overlies.

Mesopterygoid. - Broad anteriorly, but becoming narrower posteriorly; articulates by interdigitation anteriorly with the palatine and ventrally with the metapterygoid, both of which bones overlie the mesopterygoid to a variable extent.

\section{Opercular Region.}

Operculum. - Elongate; wide in the middle of its length, but tapering gradually to points anteriorly and posteriorly; its dorsolateral surface produced into a strong keel which extends dorsally as a stout shaft above the articular facet for connection with the hyomandibular. This dorsal process serves as a place of attachment for the muscles originating on the posterolateral surface of the frontal. The operculum articulates by fibrous tissue anterodorsally with the upper posterior edge of the hyomandibular and ventrally with the suboperculum, which it overlies. In about the middle of its anterior edge the operculum makes ligamentous contact with the rodlike posterior end of the interoperculum.

Suboperculum. - Thin and delicate; rounded ventrally but produced dorsally into two processes, the more anterior of which is by far the longer. The posterior edge of the more anterior of these two dorsal processes articulates by fibrous tissue with the anterior edge of the operculum. The lateral surface of the rounded ventral portion of the suboperculum is broadly overlain by the ventral end of the operculum.

Interoperculum. - A long rod, with a ventral flange along the middle region of its ventral edge; articulates by 
ligaments posteriorly with the operculum and anteriorly with the angular in the lower jaw. The ventral flange articulates by fibrous tissue with the lateral surface of the epihyal.

Preoperculum. - Large, expanded posteroventrally; slightly expanded laterally along the anterior half of its dorsal edge for articulation by fibrous tissue with the ventral surface of the quadrate; articulates by fibrous tissue posterodorsally with the hyomandibular and anterodorsally with the symplectic, metapterygoid, and quadrate.

\section{Upper Jaw.}

Premaxillary. - Posteromedial arm short; together with the fused teeth forms a relatively sharp-edged cutting plate; its anterior edge forming the anterior border of the upper jaw, except for a short distance ventrally where the maxillary forms the border. The dorsomedial edges of the two premaxillaries articulate with one another by fibrous tissue, with the articulation strengthened by 15 to 20 short but firm projections, which decrease in size anteriorly in the series, from the dorsomedial edge of each premaxillary. The posteromedial arms of the premaxillaries articulate by fibrous tissue with the posteroventral surface of the vomer. Posterolaterally the premaxillary articulates by interdigitation with the overlying maxillary. The premaxillary is relatively hollow interiorly to accommodate the dental pulp. The long, thin, rodlike teeth produced by the dental pulp lie parallel to the edge of the premaxillary and are continuously moved forward to replace those being worn away by use at the biting edge. About 15 to 20 such rodlike dental lamellae are present in each premaxillary. Only the most anterior one or two lamellae are exposed at the cutting edge of the jaw, but the other lamellae are easily seen posterior to them because of the thinness of the overlying anterior region of the premaxillary. The pulp-filled internal cavity of the premaxillary is open to the exterior through a small canal just lateral to the base of its posteromedial arm.

Maxillary. - Not especially curved forward; widest ventrally where it forms the border of the upper jaw; broadly overlies and firmly interdigitates with the premaxillary along all of its length except at its expanded ventral edge, where its medial surface articulates by fibrous tissue with the dorsolateral surface of the dentary. The maxillary articulates posterodorsally by fibrous tissue at a groove on its surface with the palatine.

\section{Lower Jaw.}

Dentary. - Somewhat squarish; its posterior end concave to accommodate and interdigitate with the anterior portion of the articular; the dentary overlies the articular more extensively laterally than medially. Posteroventrally the dentary articulates by fibrous tissue or slight interdigitation with the angular, while anteromedially it articulates by fibrous tissue with its opposite member. The connection with its opposite member is strengthened by about 15 stubby medial projections from each dentary which alternate with one another and decrease in size anteriorly, as is the case with the premaxillary. The dorsolateral surface of the dentary attaches by fibrous tissue to the ventromedial surface of the maxillary. About 15 dental lamellae are present in the dentary, in the same manner as described for those of the premaxillary. The dentary is filled with the pulp cavity that produces these rodlike teeth, and the cavity opens to the exterior at the concave posterior end of the dentary just in front of the anterior end of the articular.

Articular. - Somewhat triangular in shape; cartilage filled at its anterior edge; the anterior portion of the articular fits into and interdigitates with the concave posterior end of the dentary. The posterior edge of the articular is thickened around the concavity at which it ar. ticulates by fibrous tissue with the quadrate. Posteroventrally the articular articulates by fibrous tissue with the angular, but in larger specimens this articulation is by interdigitation. The sesamoid articular is a thin nubbin of bone lying alongside the medial surface of the articular just behind the articulation of the latter with the dentary.

Angular. - Small; articulates by fibrous tissue, or slight interdigitation in larger specimens, with the dentary and articular. Posteriorly it articulates by a ligament to the anterior end of the interoperculum.

\section{BRANCHIAL APPARATUS.}

Hyoid Arch and Branchiostegal Rays.

Urohyal, basihyal, and interhyal-Absent.

Hypohyal. - Dorsal hypohyal absent; ventral hypohyal wide posteriorly but tapering to a blunt point anteriorly; cartilage filled at its posterior edge; articulates through cartilage posteriorly with the ceratohyal and by fibrous tissue medially with its opposite member.

Ceratohyal. - Elongate and slightly expanded posteriorly; cartilage filled at its anterior and posterior edges; articulates anteriorly through cartilage with the hypohyal and posterodorsally by interdigitation with the epihyal. The ceratohyal supports by fibrous tissue all of the six branchiostegal rays.

Epihyal. - Cartilage filled at its anterior and ventral edges; articulates anteriorly by interdigitation with the ceratohyal. Along its lateral surface the epihyal articulates by fibrous tissue with the ventral flange of the interoperculum, while dorsally it connects, without the intervention of an interhyal, with the symplectic-metapterygoid region. 
Branchiostegal rays. - Six in number; first branchiostegal ray a large flat oblique plate with a downturned lateral edge which becomes thickened anteriorly to form the articular facet for contact with the vertical groove on the ventromedial surface in about the middle of the length of the ceratohyal; like that described for Lagocephalus laevigatus, except that it is held in a much more oblique position. Second branchiostegal slightly laterally compressed; articulates at its knoblike anterior end with a slight depression on the ventral surface of the ceratohyal just behind the articular area of the first branchiostegal; second branchiostegal ray about the same length as, or slightly longer than, the third to sixth rays. Third to sixth branchiostegal rays of about the same length, but the sixth ray much narrower than the others; all four rays held by fibrous tissue to the lateral surface of the posteroventral region of the ceratohyal.

Branchial Arches. - All the elements are cartilage filled at their edges of articulation with the other elements in the series, and the articulations are usually through cartilage and fibrous tissue. The branchial arches are composed of three basibranchials, three pairs of hypobranchials, five pairs of ceratobranchials, four pairs of epibranchials, and three pairs of pharyngobranchials. Three gills are present; the fourth arch has no gill and there is no slit between it and the lower pharyngeal.

First arch.-Basi-, hypo-, cerato-, epi-, and pharyngobranchial elements present. First basibranchial wider posteriorly than anteriorly; displaced forward so that it articulates posteriorly with the second basibranchial and posterolaterally with the first hypobranchials. First hypobranchial a slender rod, slightly wider dorsally than ventrally; the longest of the hypobranchial elements, which decrease in size posteriorly in the series; articulates ventrally with the region of articulation between the first and second basibranchials and dorsally with the first ceratobranchial. First ceratobranchial the shortest of the first four ceratobranchial elements, which increase in length posteriorly in the series, except for the fifth ceratobranchial which is slightly shorter than the first ceratobranchial; first ceratobranchial with a ventrally directed flange along most of its ventral surface, while a similar flange is present on the second and third ceratobranchials, as well as on the fourth ceratobranchial in a much reduced state; a large posterodorsally directed flange is present from the dorsal edge of the ventral region of the first ceratobranchial, and a similar, although slightly smaller, flange is present on the second and third ceratobranchials; articulates ventrally with the first hypobranchial and dorsally with the first epibranchial. First epibranchial a slender rod, the shortest of the epibranchial elements; articulates dorsally with the first pharyngobranchial. First pharyngobranchial a rounded plate with a ventral shaftlike process for articulation with the first epibranchial; bears about 15 to 25 small sharply pointed teeth in a single but somewhat irregular row along the edge of the rounded platelike region; the teeth smaller than those of the second and third pharyngobranchials. The dorsal regions of the branchial arches are held to the ventral surfaces of the parasphenoid and prootics by fibrous tissue attaching to the dorsolateral surface of the epibranchials and pharyngobranchials.

Second arch.-Basi-, hypo-, cerato-, epi-, and pharyngobranchial elements present. Second basibranchial somewhat constricted in the middle of its length; articulates anteriorly with the first basibranchial, anterolaterally with the first hypobranchials, posterolaterally with the second hypobranchials and posteriorly with the third basibranchial. Second hypobranchial a short slender rod; articulates ventrally with the posterolateral edge of the second basibranchial and dorsally with the second ceratobranchial, which in turn articulates dorsally with the second epibranchial. Second epibranchial slender, rodlike; articulates dorsally with a stubby projection on the ventral arm of the second pharyngobranchial. Second pharyngobranchial the largest of the pharyngobranchial elements; more or less Lshaped, bearing a single row of about 10 to 15 sharply pointed teeth along the edge of the wider of the two arms of the L. The teeth are set in shallow sockets and are curved slightly posteriorly. They are replaced by new teeth developing in new sockets alongside the sockets of the old teeth. The teeth of the second pharyngobranchial are of about the same size as those of the third. The second pharyngobranchial is held by fibrous tissue to the other two pharyngobranchials.

Third arch.-Basi-, hypo-, cerato-, epi-, and pharyngobranchial elements present. Third basibranchial large, rather squarish, articulates anteriorly with the second basibranchial, posterolaterally with the third hypobranchials and posteriorly with the fourth ceratobranchials. Third hypobranchial a slender Lshaped bone whose ventral arm articulates by fibrous tissue with the ventral surface of the first basibranchial; articulates posterodorsally with the posterolateral edge of the third basibranchial and with the ventral edge of the third ceratobranchial. Third ceratobranchial articulated dorsally with the third epibranchial. Third epibranchial a slender rod, with a stubby projection from about the middle of its posterior edge which articulates by fibrous tissue with a similar process from the fourth epibranchial; articulates dorsally with the third pharyngobranchial. Third pharyngobranchial like the second pharyngobranchial, but much smaller and bearing only about 7 to 10 small sharply pointed teeth in a single row; articulates ventrally with the third and fourth epibranchials.

Fourth arch. - Cerato- and epibranchial elements only. Fourth ceratobranchial a slender rod with only a very low ventral flange along a short portion of its length; articulates ventrally with the third basibranchial and dorsally with the fourth epibranchial. Fourth epibranchial a slender rod with a low flange along its posterior edge, and a stubby emargination from about the middle 
of its anterior edge which articulates by fibrous tissue with the third epibranchial; the dorsal end of the fourth epibranchial articulates with the third pharyngobranchial.

Fifth arch. - Ceratobranchial (lower pharyngeal) element only. Fifth ceratobranchial a stout shaft with a small medial expansion in about the middle third of its length; articulates ventrally with the base of the fourth ceratobranchial; toothless.

\section{PAIRED FIN GIRDLES.}

\section{Pectoral Fin.}

Supracleithrum. - In position at about a $45^{\circ}$ angle to the axis of the body; a stout shaft with a lateral flange along most of its length; articulates by fibrous tissue anterodorsally with the slight concavity on the lateral expansion of the pterotic and ventrally with the cleithrum, which it broadly overlies.

Cleithrum. - Laterally expanded along most of its length; articulates by fibrous tissue dorsally with the overlying supracleithrum and with the anterior end of the dorsal postcleithrum, which it overlies; along its posterior edge it articulates by fibrous tissue with the scapula and coracoid. Ventromedially the cleithrum articulates by fibrous tissue with its opposite member in the midline of the body between the medial edges of the platelike portions of the first branchiostegal rays.

Postcleithra. - The postcleithra form a stout strut along the abdominal wall musculature from the supracleithrum to halfway back the length of the abdominal cavity. The dorsal postcleithrum articulates by fibrous tissue anterolaterally with the overlying cleithrum and posteroventrally with the ventral postcleithrum, which tapers to a point posteriorly. The dorsal and ventral postcleithra are only slightly laterally compressed.

Coracoid.-Rounded dorsally but gradually tapering to a stout shaft ventrally; along the dorsal third of its length the posterior edge of the coracoid is inturned to form a medial flange whose dorsal edge is prolonged into a spinelike process below the fourth actinost; cartilage filled at the edge of its rounded dorsal portion and at its extreme ventral edge; articulates by fibrous tissue anteriorly with the cleithrum and through cartilage dorsally with the scapula and last two actinosts.

Scapula. - Scapular foramen not entirely enclosed by the scapula, but, rather, with its anterior edge closed by the cleithrum; cartilage filled at its anterior and ventral edges; articulates anteriorly by fibrous tissue with the cleithrum, ventrally through cartilage with the coracoid, posterodorsally by slight interdigitation with the anterior edge of the first actinost, and posteroventrally by slight interdigitation with the ventral edge of the second actinost.
Actinosts. - Four elements; all cartilage filled at both ends, except for the first actinost, which is filled with cartilage only at its dorsal edge. First actinost reduced to a triangular wedge between the upper parts of the scapula and second actinost, to both of which elements it interdigitates. Second actinost rounded dorsally, constricted in the middle and reduced ventrally to a narrow splint that interdigitates ventrally with the scapula and posteriorly with the base of the third actinost; articulates by interdigitation anterodorsally with the first actinost and posterodorsally with the third actinost. Third and fourth actinosts slightly constricted in the middle; the third actinost articulating dorsally and ventrally by interdigitation with the second and third actinosts, while it articulates through cartilage just below its base with the coracoid; the fourth actinost articulating by interdigitation anterodorsally and anteroventrally with the third actinost and ventrally through cartilage with the coracoid. Distally the actinosts support all of the fin rays.

Fin rays. - Usually 17 fin rays present; the first fin ray short, about one-third or one-fourth the length of the second ray, but normal in shape and symmetry, its two halves of equal size; all rays articulated by fibrous tissue with the dorsal ends of the actinosts. The first two or three rays unbranched, the other rays branched. The first ray without cross-striations, the others cross-striated.

VERTEBRAL COLUMN. - All vertebrae with biconcave centra, except the last, which ends posteriorly in the urostylar process and fusion with some of the hypurals.

\section{Abdominal Vertebrae.}

First vertebra. - Neural spine bifid and relatively short; neural arch with a complete bony roof over the neural canal, as do all the other vertebrae; articulates by fibrous tissue over the anterior half of the lateral surface of its centrum with the posteriorly projecting exoccipital condyles, while the rim of the concave anterior face of its centrum articulates with the rim of the concave posterior end of the basioccipital. Posteroventrally on its lateral surface the centrum of the first vertebra possesses a flattened posterior process which fits under the anterior half of the ventrolateral surface of the centrum of the second vertebra.

Other abdominal vertebrae. - In 17 specimens the abdominal vertebrae numbered eight. The second and third abdominal vertebrae have their neural spines bifid, but somewhat longer than that of the first vertebra. The fourth vertebra has its neural spine enlarged anteroposteriorly, and while it is bifid anteriorly, it becomes single posteriorly. All of the vertebrae, both abdominal and caudal, posterior to the fourth abdominal vertebra have undivided neural spines. The neural spines of the fifth and sixth abdominal vertebrae are of about the same height as that of the fourth vertebra, but they are 
less anteroposteriorly expanded than the latter. The seventh and eighth abdominal vertebrae have their neural spines in the form of long stout shafts between which the first basal pterygiophore of the dorsal fin articulates. Small neural prezygapophyses are present from about the fourth to the last abdominal vertebra, and increase in size posteriorly in the series. From the posterolateral surface of the second vertebral centrum a stout ventrally directed process is present which makes fibrous tissue contact with a similar ventrally directed process from the anterolateral surface of the centrum of the third vertebra. These ventral processes from either side of these two centra do not meet their opposite members in the midline to completely enclose the haemal canal. However, the abdominal vertebrae posterior to the third vertebra have stout ventrally directed processes from the anterolateral surfaces on either side of their centra which do meet and fuse in the midline to enclose completely the haemal canal. The haemal spines possess posteriorly directed flanges along their posterior edges just below the haemal canal. The haemal spines increase in size posteriorly in the series and form broad surfaces for muscle attachment.

Caudal Vertebrae. - In 17 specimens the caudal vertebrae numbered nine. All of the caudal vertebrae possess neural arches and spines and haemal arches and spines. Neural prezygapophyses are present on all of the caudal vertebrae, although they decrease in size posteriorly so that the last caudal vertebra has them only weakly developed. The neural spines of the first two caudal vertebrae are slender but strong shafts which distally support the more posterior of the dorsal fin basal pterygiophores. These two neural spines are shorter than the last two neural spines of the abdominal vertebrae, which support the more anterior of the dorsal fin basal pterygiophores. The neural spines of the third to sixth caudal vertebrae are slender but strong shafts which are slightly longer than those of the two preceding caudal vertebrae. The neural spine of the seventh caudal vertebra is enlarged anteroposteriorly, and that of the eighth caudal vertebra is even more enlarged. The neural spines of these two vertebrae make close fibrous tissue contact with one another and form a large thin plate above their centra. Each neural arch possesses a small neural foramen. The haemal arches and spines of the first three caudal vertebrae are like those of the abdominal vertebrae just anterior to them, except that the haemal spine of the first caudal vertebra is even more enlarged posteriorly than are the others and ventrally supports by fibrous tissue the much expanded first basal pterygiophore of the anal fin. The posteriorly expanded platelike portions of the haemal spines of the second and third caudal vertebrae ventrally support through fibrous tissue the second to the fifth (last) anal fin basal pterygiophores. The haemal spine of the fourth caudal vertebra is less anteroposteriorly expanded than are those anterior to it, but it is somewhat longer. The haemal spines of the fifth to seventh caudal vertebrae become increasingly expanded anteroposteriorly so that the haemal spine of the seventh is a rounded flat plate whose posterior edge makes fibrous tissue contact with the anterior edge of the much modified haemal spine of the eighth caudal vertebra. Whereas the centrum and the neural arch and spine of the eighth caudal vertebra are fused together, the haemal arch and its spine are autogenous and held to the centrum by fibrous tissue and interdigitation. The haemal spine of the eighth caudal vertebra is much enlarged, and possesses a posterior extension which reaches almost to the base of the lowermost caudal fin ray. The edge of the haemal apparatus of the eighth caudal vertebra that makes contact with the centrum is somewhat concave so that a haemal canal is present throughout the length of the region of articulation of the two elements. The haemal canal is continuous anteriorly with the haemal canal of the preceding vertebrae, while posteriorly it is continuous with the canal between the surfaces of contact of the parhypural and the centrum of the last vertebra.

Caudal Skeleton. - The caudal complex is composed of four separate bony elements closely held to one another variously by fibrous tissue and interdigitation. The ventral portion of the caudal skeleton is formed by the parhypural, which is broad anteriorly but tapers to a stout shaft posteriorly where it supports the lowermost caudal fin ray. Anteriorly it is extensively interdigitated with the posterodorsal edge of the haemal spine of the penultimate vertebra. A distinct notch is present in its dorsal edge a little forward of its middle region. Anterior to this notch the dorsal edge of the parhypural is extensively interdigitated with the region of the centrum of the large bony plate above it, which is the fused centrumlower hypurals. The notch in the parhypural is the last opening into the haemal canal, the latter being connected to the canal in the preceding vertebrae by a longitudinal groove medially along the otherwise interdigitated articular surface between the parhypural and the centrum anterior to the foramen. The dorsal surface of the parhypural posterior to the foramen is held by fibrous tissue to the ventral edge of the hypural region of the fused centrum-lower hypural plate. The epural is a flattened plate closely held by.fibrous tissue between the posterior edge of the neural spine of the penultimate vertebra and the anterior edge of the urostylar region of the fused centrum-lower hypural plate and of the anteroventral region of the upper edge of the autogenous upper hypural plate. Ventrally the epural slightly interdigitates with the incomplete neural arch region of the last vertebra, forming the dorsal roof of the neural arch. The neural canal thus enclosed is continuous anteriorly with the canal in the preceding vertebrae, while posteriorly the canal opens to the exterior just behind the end of the area of articulation between the epural and the neural arch of the last vertebra. In large specimens (over 100 $\mathrm{mm}$ ) the articulation between the epural and the lateral walls of the neural arch of the last vertebra tends to become more intimately interdigitated and perhaps even fused. Similarly, the articulation of the epural with the neural spine of the penultimate vertebra and the urostylar region of the last vertebra tends to become slightly 
interdigitated in large specimens. The largest element of the caudal skeleton is that formed from the fusion of the centrum of the last vertebra posteroventrally with the lower hypurals, which in generalized plectognaths would correspond to the first and second hypurals but which are here indistinguishably fused with one another and with the centrum. The concave anterior face of the centrum portion of this fusion element articulates in a normal manner with the concave posterior face of the centrum of the penultimate vertebra, but immediately below this fibrous tissue articulation the ventral expansions of these two vertebrae interdigitate with one another, while ventrally that of the last centrum interdigitates with the anterodorsal end of the parhypural, except at the medial longitudinal groove between their apposed surfaces enclosing the haemal canal. The urostyle of the last centrum is represented by a tapering thickened shaft extending posterodorsally from the centrum portion of the composite plate and is extensively interdigitated along its posterior edge with the anterior edge of the autogenous upper hypural plate. The anterior edge of the urostylar region articulates by fibrous tissue, and by interdigitation in larger specimens, with the epural. The ventral edge of the hypural region of the fused centrumlower hypurals articulates by fibrous tissue with the posterodorsal edge of the parhypural, while its dorsal edge is extensively interdigitated with the anteroventral end of the autogenous upper hypural plate. The upper hypural plate is composed of indistinguishably fused hypurals corresponding to what in generalized plectognaths would be the third to fifth elements, the plate being extensively interdigitated with the urostylar and hypural regions of the fused centrum-lower hypural plate, and held for a short distance anterodorsally by fibrous tissue to the epural. In the smallest specimen examined, $10.0 \mathrm{~mm}$, the lower hypurals are as fully and indistinguishably fused to one another and to the centrum as in adults, while the autogenous upper hypural plate, the epural and parhypural are, as expected, scarcely if at all interdigitated with the fused centrum-lower hypurals, but the upper hypural plate more so than the epural and parhypural.

Caudal fin rays. - Eleven in number, the uppermost ray and the lowermost ray unbranched, the others becoming increasingly branched toward the middle rays, which are branched in triple dichotomies. The uppermost five rays are held by fibrous tissue to the autogenous upper hypural plate, the lowermost ray to the parhypural and the upper five rays of the lower lobe to the hypural region of the fused centrum-lower hypural plate.

\section{DORSAL AND ANAL FINS.}

\section{Dorsal Fin.}

Fin rays and pterygiophores. - Ten fin rays are present in most specimens, the first one or two rays unbranched, the others branched in single or double dicho- tomies; the first ray almost as long as the longest ray. Distal pterygiophores either absent or unossified. The fin rays are supported basally by eight basal pterygiophores which are broadly interdigitated with one another and which decrease slightly in length posteriorly in the series. The first basal pterygiophore is by far the largest and fills much of the space between the neural spines of the seventh and eighth abdominal vertebrae. The second to fourth basal pterygiophores have their ventral or interneural portions between the neural spines of the eighth abdominal and first caudal vertebrae, while those of the fifth to seventh basal pterygiophores are between the neural spines of the first and second caudal vertebrae. The eighth basal pterygiophore has its ventral region placed just behind the upper end of the neural spine of the second caudal vertebra. The pterygiophores articulate with the neural spines by fibrous tissue. Each pterygiophore ends dorsally in a short columnar projection whose deeply concave dorsal edge is cartilage filled. It is to these columnar projections that the fin rays are held by fibrous tissue. The ventral ends of the pterygiophores are all deeply cartilage filled. The anterodorsal edge of the first pterygiophore is slightly prolonged anteriorly and articulates by fibrous tissue with the rounded shaftlike supraneural. The supraneural extends from above the posterior region of the neural spine of the fourth abdominal vertebra to just in front of the dorsal end of the neural spine of the seventh abdominal vertebra. The supraneural is connected with a band of longitudinal muscles in the midline of the body which anteriorly connects with the supraoccipital spine. None of the pterygiophores possess lateral flangelike projections along their lengths for muscle attachment, although they are slightly thicker in the middle regions throughout their lengths than they are anteriorly or posteriorly.

\section{Anal Fin.}

Fin rays and pterygiophores. - Nine fin rays are present in most specimens, the first one or two rays unbranched, the others branched in single or double dichotomies; the first ray only slightly shorter than the longest ray. Distal pterygiophores either absent or unossified. The anal fin rays are supported through fibrous tissue by five basal pterygiophores which are interdigitated with one another only for a short distance ventrally. Posterior to the enlarged first pterygiophore, the remaining pterygiophores decrease only very slightly in length posteriorly in the series. The dorsal ends of the pterygiophores articulate by fibrous tissue with the ventral edges of the haemal spines of the caudal vertebrae, with the first pterygiophore attached to the first caudal vertebra and the remaining pterygiophores attached to the second and third caudal vertebrae. Like the pterygiophores of the dorsal fin, those of the anal fin are cartilage filled proximally, while distally they possess short columnar projections whose deeply concave edges are cartilage filled. Whereas the second to fourth pterygiophores possess a single columnar projection distally, the 

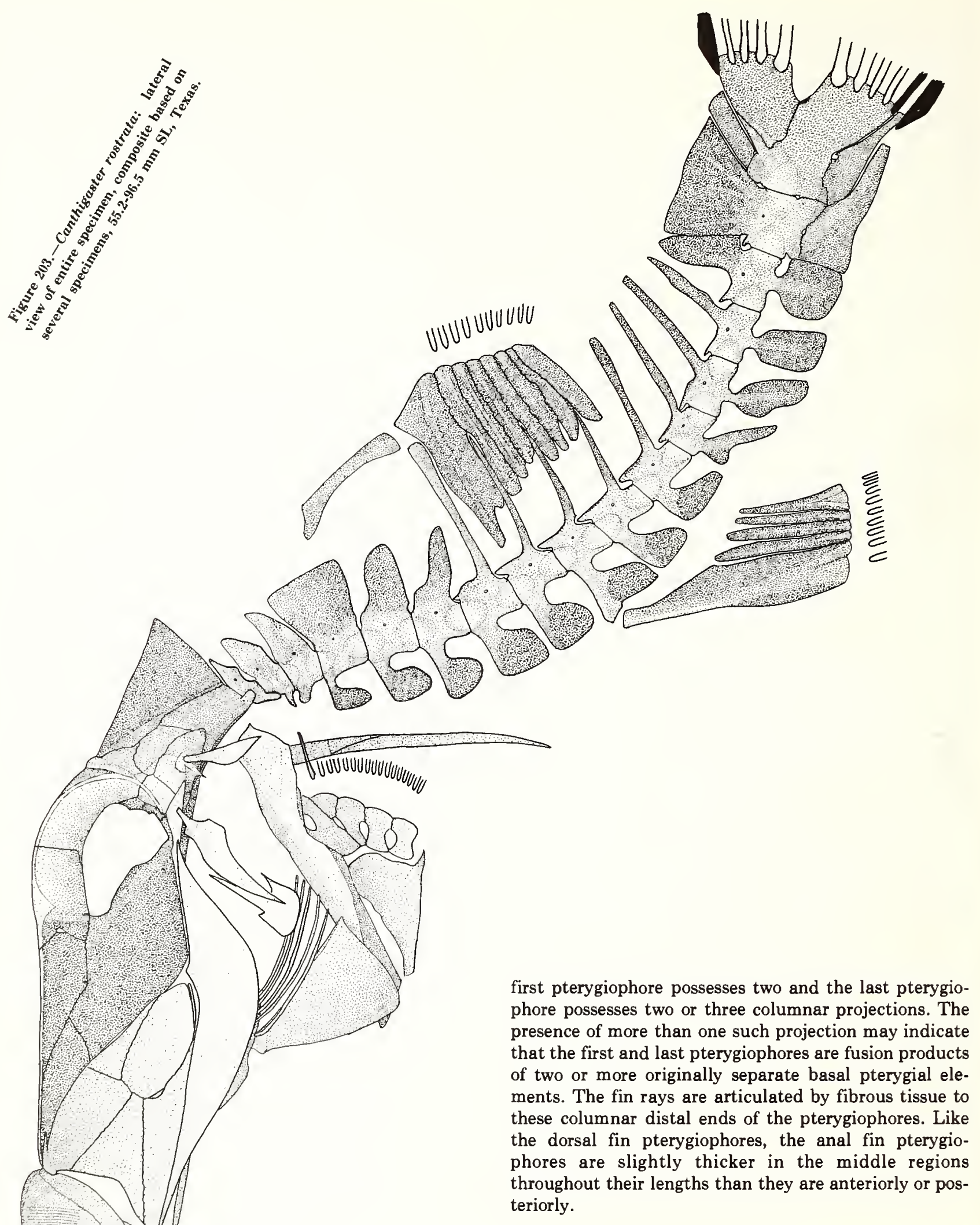

Anatomical diversity and generic relationships. - The fossil record of tetraodontids is meager. The only relatively complete specimen of a tetraodontid is Tetraodon pygmaeus Zigno (1887b) from the Eocene of 


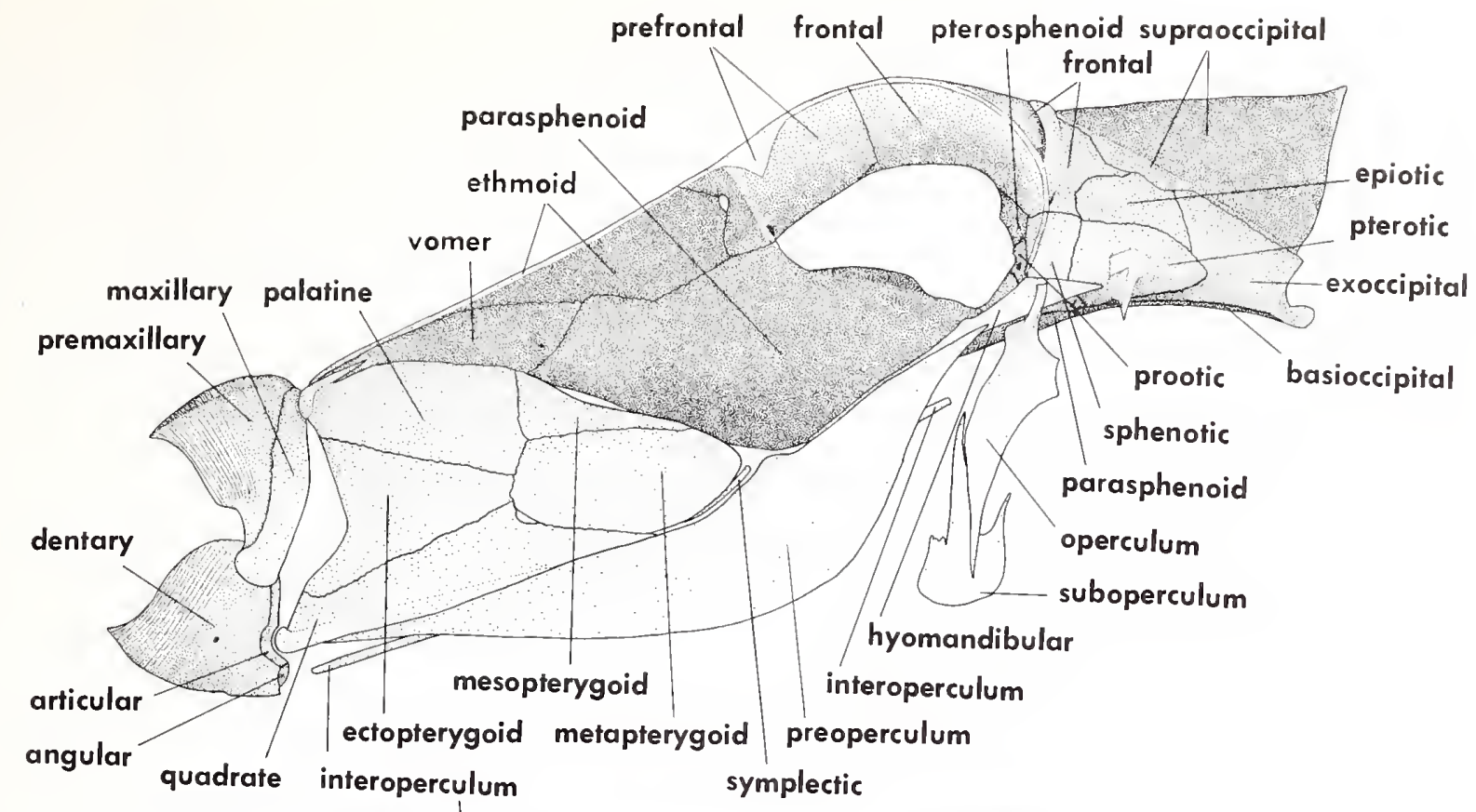

Monte Bolca, Italy. The holotype and only known specimen, IGUP 6890-91, $18.2 \mathrm{~mm} \mathrm{SL}$, in counterpart, is small and only moderately well preserved. It is a lateral impression and the medial region of the upper and lower jaws is not exposed. Thus, it cannot be told at present how the dentaries and premaxillaries articulate to their opposite members. However, the body is covered by very fine small prickles and the abdominal vertebrae (either 9 or 10) are fewer than the caudal vertebrae (12), while the rodlike postcleithrum is in two pieces, all these features being more characteristic of tetraodontids than diodontids. There are about 10 or 11 dorsal and anal fin rays, and the caudal fin seems to have 12 rays, one more than in any Recent species of tetraodontid, but the same number of principal rays as in the ancestral gymnodont triodontids and scleroderm eoplectins. Moreover, there is a strong indication that there are slender ribs present on many of the abdominal vertebrae, while ribs are absent in all Recent gymnodonts except the basal triodontids (and one of the two species of scleroderm eoplectins also seems to have ribs). The above are the only features of interest that I can distinguish in the specimen, which is sufficiently distinct from all Recent species to merit separate generic recognition, and Eotetraodon is proposed herein for pygmaeus Zigno (type-species by monotypy and original designation).

The only other tetraodontid fossil materials are jaw fragments found from the Miocene onward, and usually referred to as Tetraodon lecointrae Leriche and $T$. lawleyi Carraroli. They indicate only that the individual dental units incorporated into the biting edge of the jaws were elongate rods such as in the Recent species.
Figure 204.-Canthigaster rostrata: lateral view of head, composite based on several specimens, 55.2-96.5 mm SL, Texas.

The three external characters that have been prominently used in conjunction with internal features in subdividing the Recent tetraodontids (the number of dorsal and anal fin rays, the form and number of the lateral lines, and the form of the nasal apparatus) will be discussed here first, followed by an analysis of the osteological diversity of the family. In the two most recent revisions of the group (Fraser-Brunner 1943 and Le Danois 1959, 1961a) five families have been recognized in what is here considered a single family with two subfamilies, and the term Tetraodontidae as used here is senso lato, although closely corresponding to that in general use in the contemporary ichthyological literature.

Chonerhinos and Xenopterus have the dorsal and anal fins longer based and with more rays than in other tetraodontids. In Chonerhinos there are about 23 to 29 dorsal rays and in Xenopterus about 32 to 38 , with the anal fin in both cases having several less rays than the dorsal fin. In other tetraodontids the number of dorsal fin rays ranges modally from about 7 to 18 , with the anal fin having either the same number or one to several rays less than the dorsal fin.

Sanzo (1930) was the first to describe in detail the lateral line of tetraodontids, and Fraser-Brunner (1943) the first to call attention to its systematic importance. 

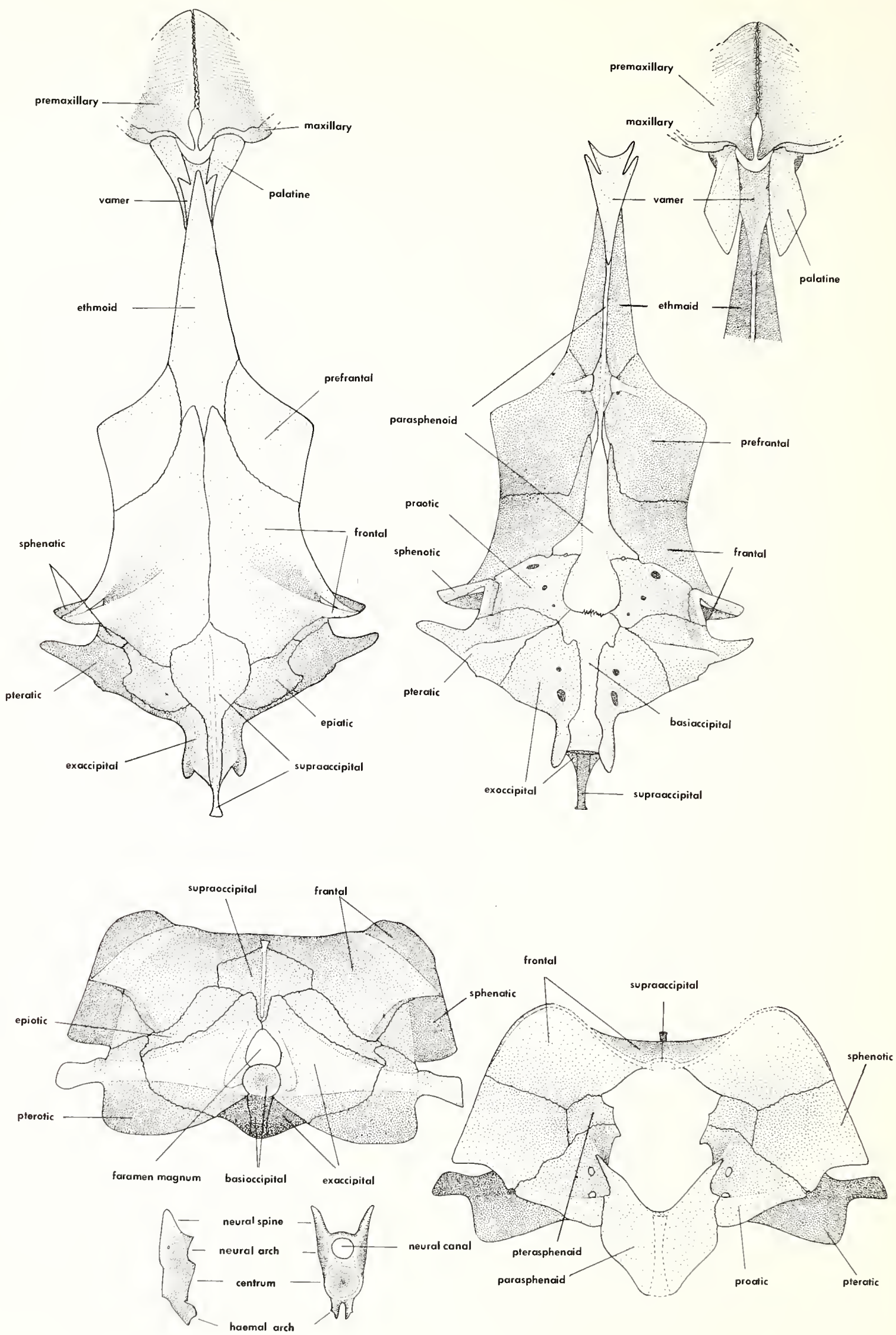
Figure 205. (opp. page)-Canthigaster rostrata: dorsal (left) and ventral (right) views of skull, with inset at top right showing a ventral view detail of the articulation of the upper jaw with the palatines and vomer, composite based on several specimens, 55.2-96.5 mm SL, Texas.
Figure 206. (opp. page)-Canthigaster rostrata: posterior view of skull (left); below, lateral and posterior views of first abdominal vertebra; posterior view of orbit (right) (cross section of skull; dashed lines represent cut surfaces of frontals and parasphenoid); composite based on several specimens, 55.2-96.5 mm SL, Texas.

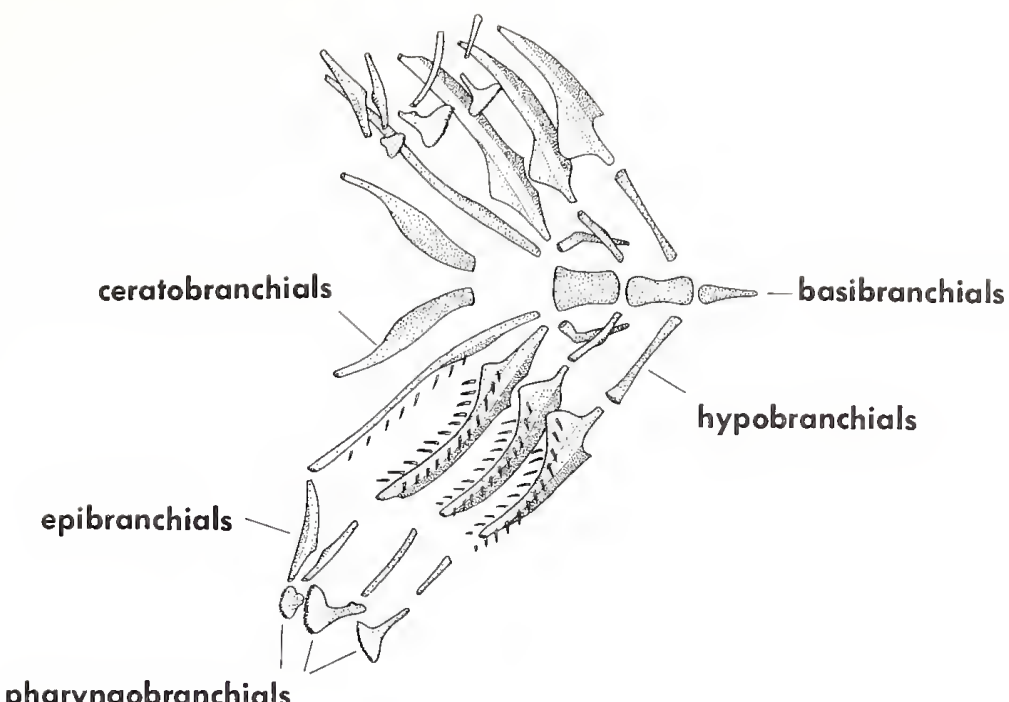

pharyngobranchials

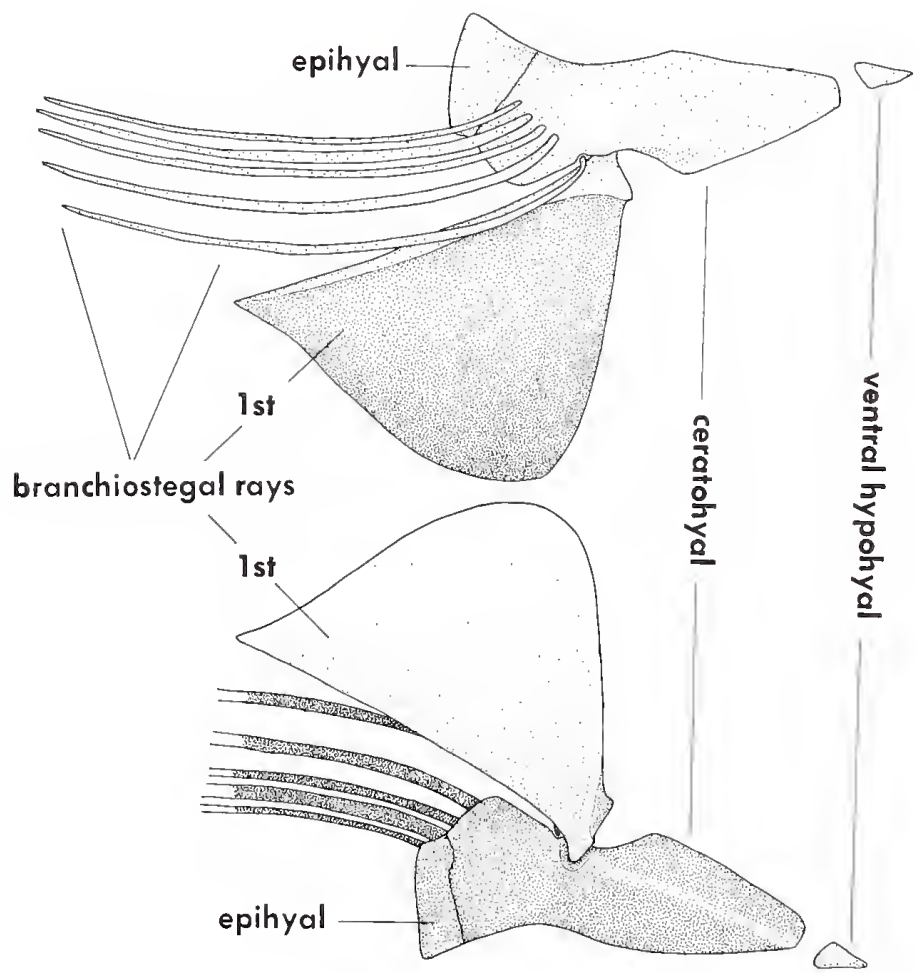

Figure 207.-Canthigaster rostrata: dorsal view of branchial arches (extended on lower side); lateral (above) and medial (below, upside down) views of hyoid arch; composite based on several specimens, $55.2-96.5 \mathrm{~mm}$ SL, Texas. 


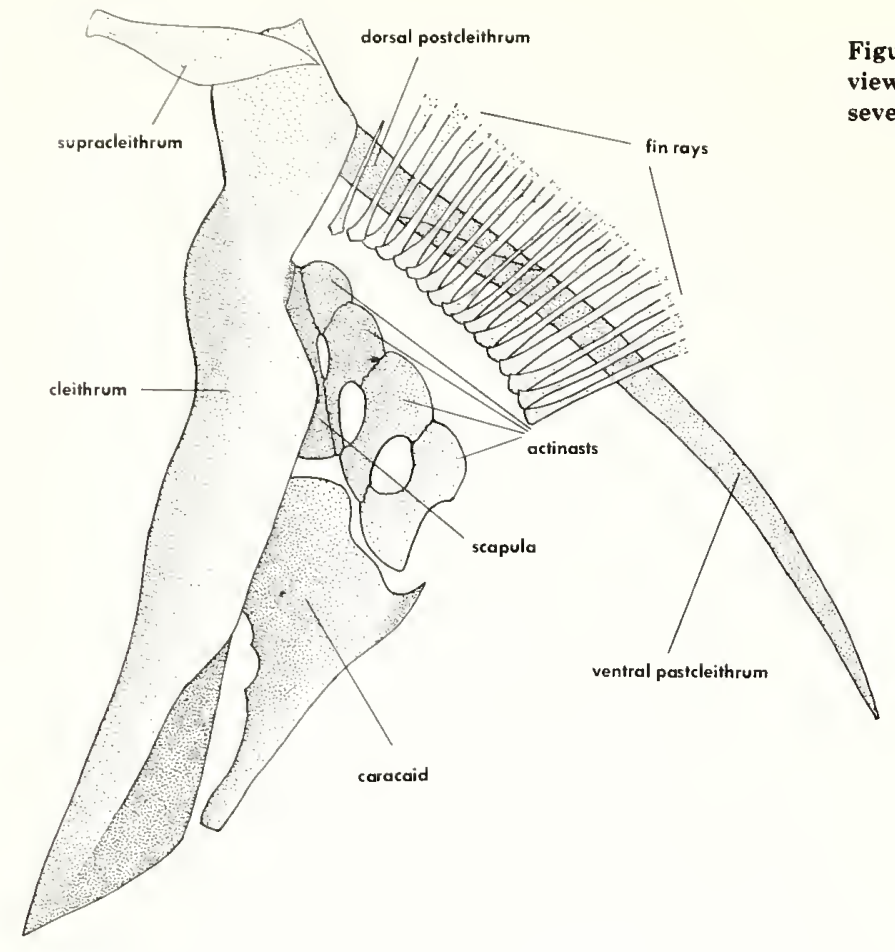

Wiedersheim (1887a, b; 1888) was the first to describe in detail the nasal apparatus of tetraodontids, while its systematic importance was first stressed by Bibron (see Duméril 1855), although an overemphasis on the nasal apparatus has led to confusion. Dunker and Mohr (1931) described the changes in the nasal tube in Chelonodon with increasing body size, and Barnard (1927) showed the variety of nasal organs in South African puffers, while Le Danois (1959) illustrated it for an even larger selection of tetraodontids. Inger (1953) illustrated the differences in the olfactory epithelium between Tetraodon kretamensis and Chelonodon fluviatilis.

Chonerhinos and Xenopterus have the lateral line more elaborately developed than in other tetraodontids, with three lines on the body rather than only one or two,
Figure 208.-Canthigaster rostrata: lateral iew of pectoral girdle, composite based on veral specimens, 55.2-96.5 mm SL, Texas.

while in Canthigaster the lateral line system is so inconspicuous that it can only be seen with the aid of magnification. Nasal specializations also distinguish these genera from other tetraodontids. In Chonerhinos and Xenopterus (the Chonerhinidae of Fraser-Brunner) the nasal apparatus is larger than in other tetraodontids, in the form of a large, low open cup with numerous lamellae or folds, while in Canthigaster (the Canthigasteridae of Fraser-Brunner) the nasal apparatus is much smaller than in other tetraodontids, in the form of a small, low simple tube with a single opening.

In other tetraodontids the nasal apparatus ranges from an upright sac with two nostrils (in Lagocephalus, Sphoeroides, Guentheridia, Amblyrhynchotes, Fugu, and Torquigener, these being the Lagocephalidae of Fraser-Brunner, except that for purposes of the present discussion the genera are more finely split than as recognized by Fraser-Brunner, and in Colomesus, the Colomesidae of Fraser-Brunner) to a tube with a single nostril or a bifid tentacle or a simple single flap (Ephippion, Arothron, Monotreta, Chelonodon, Carinotetraodon, and Tetraodon, the Tetraodontidae of FraserBrunner, except, as above, for purposes of the present discussion, more finely split). While the lateral line systems in Chonerhinos-Xenopterus and in Canthigaster are each in their own way just as distinctive as their nasal apparatuses, the situation is not so neatly simple in the other tetraodontids.

Among those genera with the relatively normal nasal apparatus as an upright sac with two nostrils, Sphoeroides and Guentheridia have a single lateral line on the body, although short segments of an additional lower line are sometimes present (see illustrations of $S$. lobatus, $S$. dorsalis, and $G$. formosa), while in Lagocephalus, Amblyrhynchotes, Fugu, Torquigener, and Colomesus two lateral lines usually are present, the

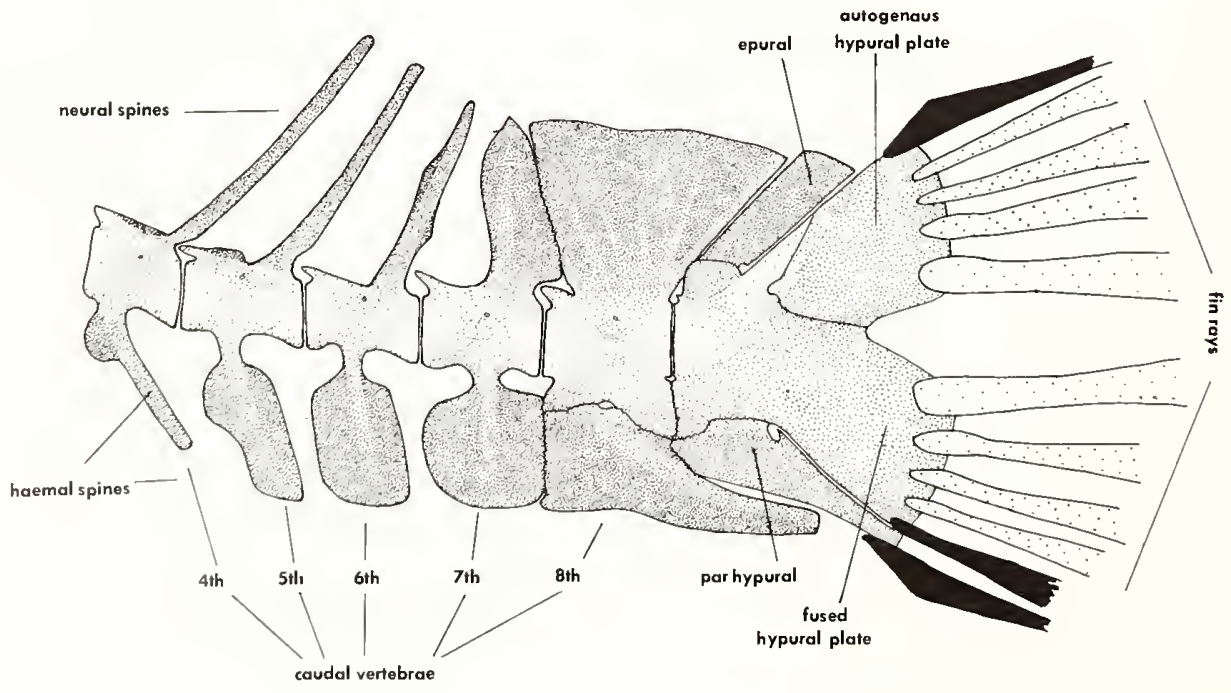

Figure 209.-Canthigaster rostrata: lateral view of caudal fin supporting structures, composite based on several specimens, 55.2-96.5 mm SL, Texas. 
lower one always better developed than in the traces of it sometimes found in Sphoeroides and Guentheridia, even though the lower line may not run the full length of the caudal peduncle (see illustration of Torquigener pleurostictus). Possible exceptions are Amblyrhynchotes piosae, in which the exceptionally long spines mostly obscure the lateral line, so that in the single alcoholpreserved specimen examined I am unable to find any lateral line at all on the caudal peduncle, and $A$. richei, in which I cannot find a lower lateral line in any of the 10 alcohol preserved specimens examined, although Le Danois (1959:172) showed it as present. A distinctly upraised horizontal ridge of skin is present ventrolaterally along the caudal peduncle in all species of Lagocephalus, in most species of Torquigener (absent in pleurostictus) and Fugu (absent or only weakly developed in chrysops), in at least some species of Amblyrhynchotes (honckenii and hyselogenion) and Sphoeroides (e.g., see illustrations of lobatus, testudi- neus, and dorsalis), but it is absent in Guentheridia and Colomesus. The presence or absence of this ridge is of very limited systematic interest at the generic level, while the presence or absence of a second, lower, lateral line is more variable within certain genera than previously thought.

In those genera with a single nostril or a nasal tentacle, there is a single lateral line in Arothron, while in Chelonodon and Monotreta the upper lateral line normally curves ventrally to join the lower lateral line in the region above the anal fin, the lower line continuing posteriorly to the tail as well as anteriorly to the abdominal region from the point of juncture with the upper lateral line. Tetraodon has some species with basically the same arrangement as in Chelonodon and Monotreta (see illustrations of $T$. lineatus and $T . \mathrm{mbu}$ ), but in at least one species (see illustration of $T$. miurus) there seems to be no lower lateral line, the upper line continuing directly onto the tail, while in another (see illustration of $T$.
Figure 210.-External features of other representative tetraodontid genera:

A, Sphoeroides nephelus, upper left, nasal region as seen externally (far left) and olfactory lamella as seen with front of nasal sac removed, and, lower left, scales from upper middle region of body;

B, $S$. testudineus, upper left, nasal region as seen externally (olfactory lamella, if present, indistinct in specimen examined), and, lower left, scales from upper middle region of body; $\mathrm{C}, \boldsymbol{S}$. dorsalis, upper left, nasal region as seen externally (far left) and olfactory lamella as seen with front of nasal sac removed, and, lower left, scales from upper middle region of body; $\mathrm{D}, S$. lobatus, upper left, nasal region as seen externally (olfactory lamella, if present, indistinct in specimen examined), and, lower left, scales from upper middle region of body (larger markings on rear of body, and one on dorsum, represent flaps rather than

scales); E, S. pachygaster, lower left, nasal region as seen externally and, upper left, olfactory lamellae as seen with front of nasal sac removed, showing more numerous lamellae than in other species of Sphoeroides (scales absent).
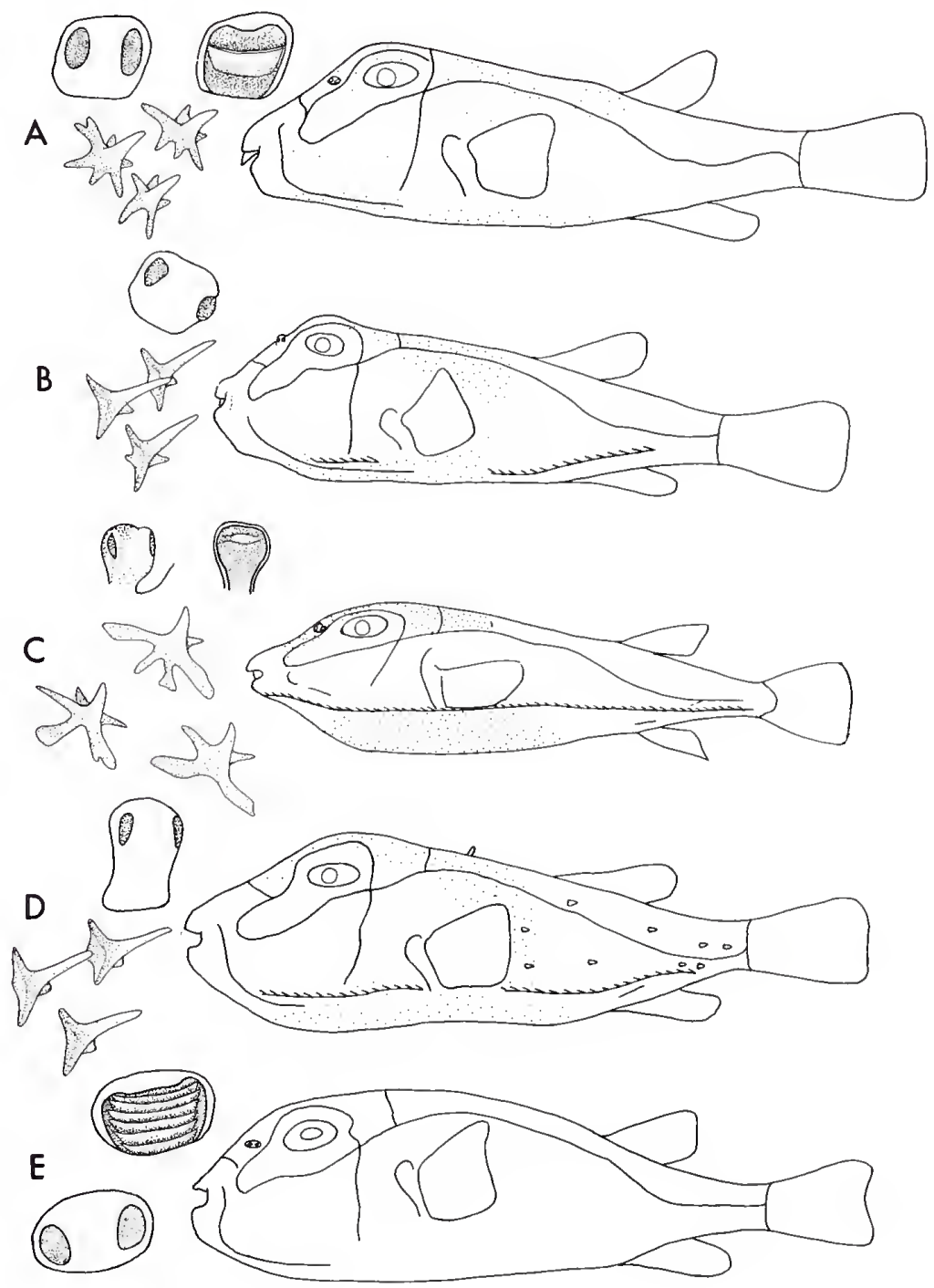


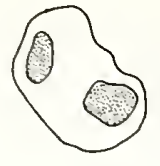

A

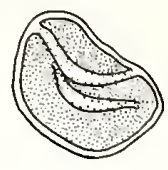

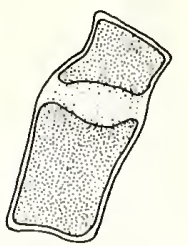

B

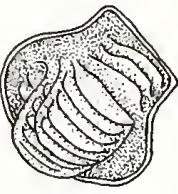

D
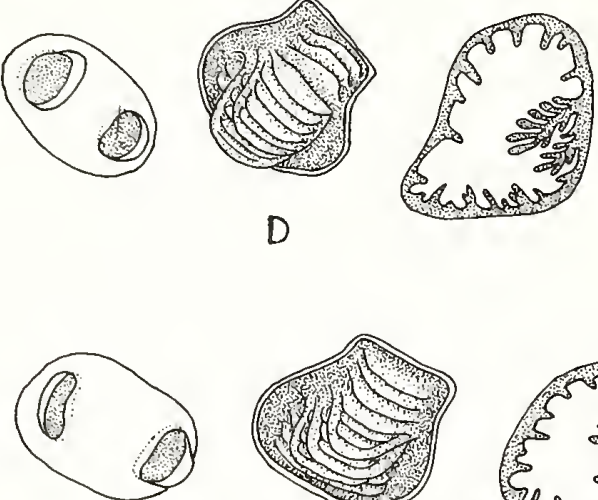

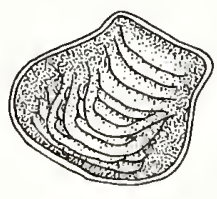

$\mathrm{F}$

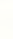

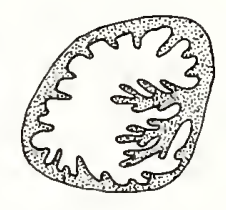

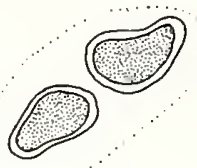
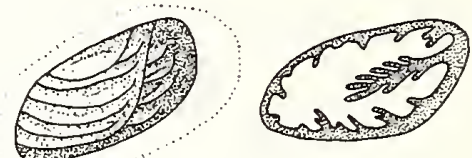

Figure 211.--Nasal organs and olfactory lamellae of representative species of Sphoeroides (top row, A-C) and Lagocephalus (D-F): to left in each set, the nasal region as seen externally, and to its right the olfactory lamellae as seen with top or front of nasal

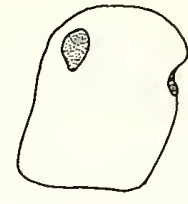

C

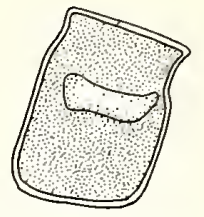

$E$
Figure 212.-External features of other representative tetraodontid genera: Guentheridia formosa-upper left, nasal region as seen externally (far left) and the pitted olfactory epithelium as seen with the top of the nasal sac removed; lower left, scales from upper middle region of body.

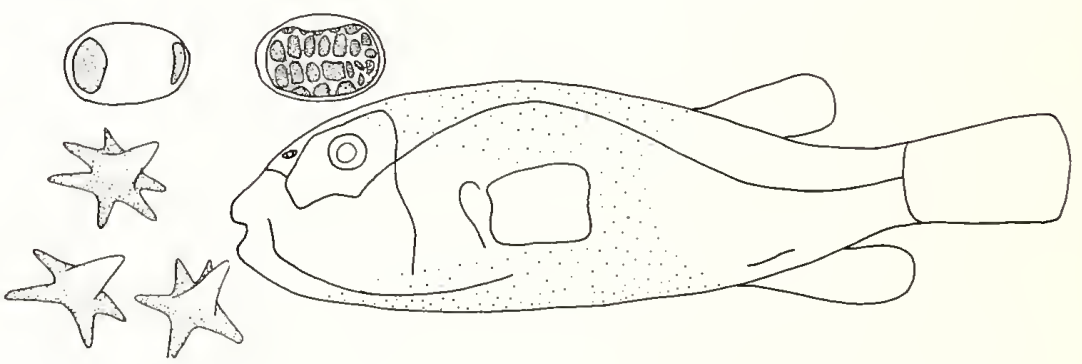

Figure 213.-External features of other representative tetraodontid genera: Colomesus psittacus-upper left, nasal region as seen externally (far left) and the olfactory lamella as seen with the front of the nasal sac removed; lower left, scales from upper middle region of body.

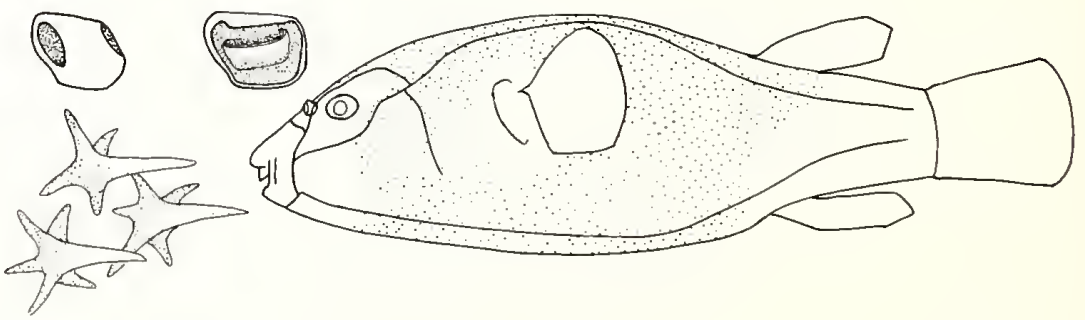

sac removed, and to its right, in Lagocephalus, the outline of an anteroposterior cross section of the sac and lamellae.

A, Sphoeroides trichocephalus;

B, S. spengleri; C, S. maculatus;

D, Lagocephalus spadiceus;

E, L. lagocephalus; F, L. inermis. 
Figure 214.-External features of other representative tetraodontid genera: A, Amblyrhynchotes piosaeupper left, nasal region as seen externally (far left) and the olfactory lamellae as seen with the front of the nasal sac removed, and, lower left, scales from upper middle region of body (spines on caudal peduncle surrounded by fleshy flaps which are better developed there than more anteriorly); B, $A$. honckenii-upper left, nasal region as seen externally (far left) and the olfactory lamellae as seen with the top of the nasal sac removed, and, lower left, scales from upper middle region of body; $\mathrm{C}, \mathrm{A}$. richeiupper left, nasal region as seen externally (two lower figures), indicating that 1 out of 10 specimens has the nostrils confluent and the nasal tube with a single large opening, with the upper figure showing the olfactory lamellae with the top of the nasal sac removed, and, lower left, scales from upper middle region of body.
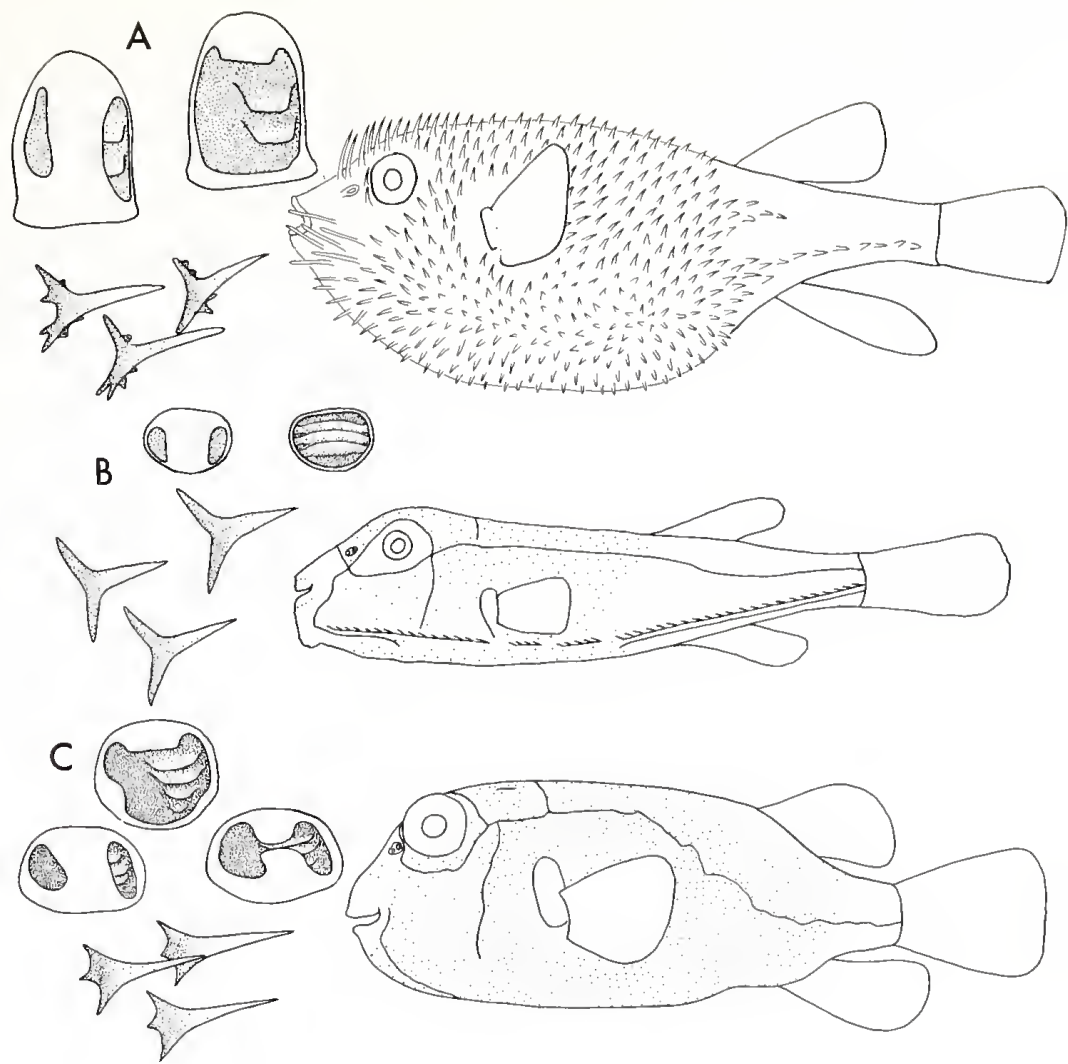

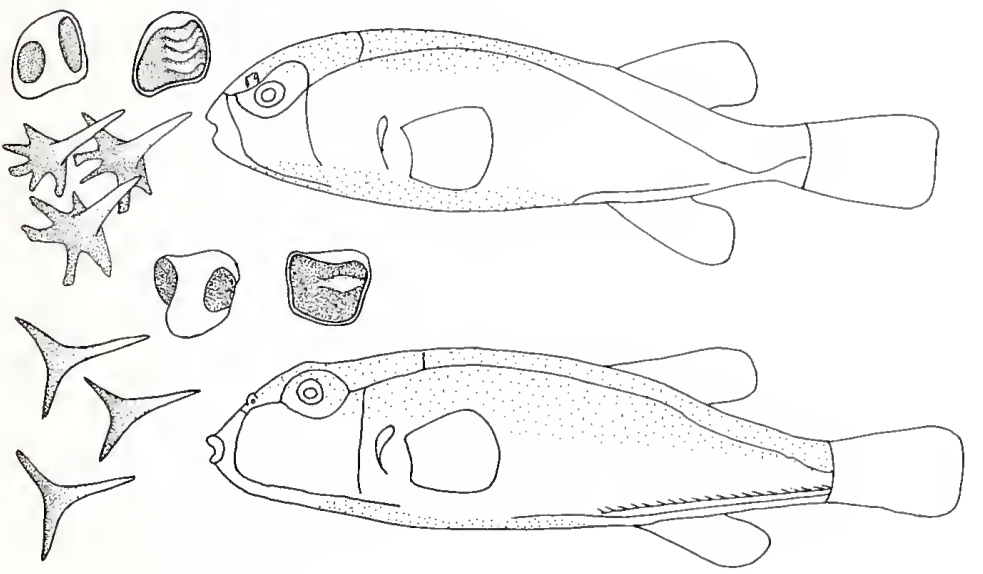

Figure 215.-External features of other representative tetraodontid genera: Torquigener pleurostictus (above) and T. hamiltoni-in both cases, upper left, nasal region as seen externally (far left) and the olfactory lamella(e) as seen with the front of the nasal sac removed, and, lower left, scales from upper middle region of body.

Figure 216.-External features of other representative tetraodontid genera: Fugu vermicularis-left, bottom to top, nasal region as seen externally, the olfactory lamellae as seen with the front of the nasal sac removed, and the outline of an anteroposterior cross section of the sac and lamellae.

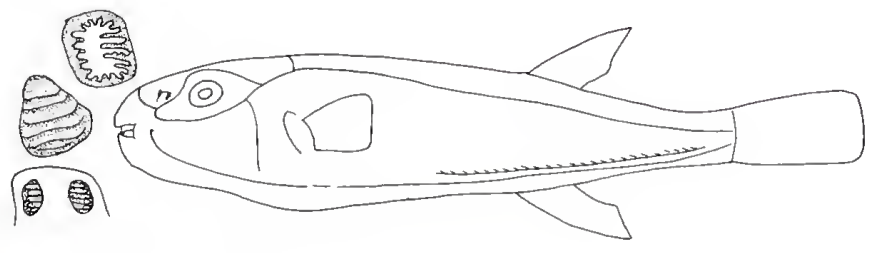



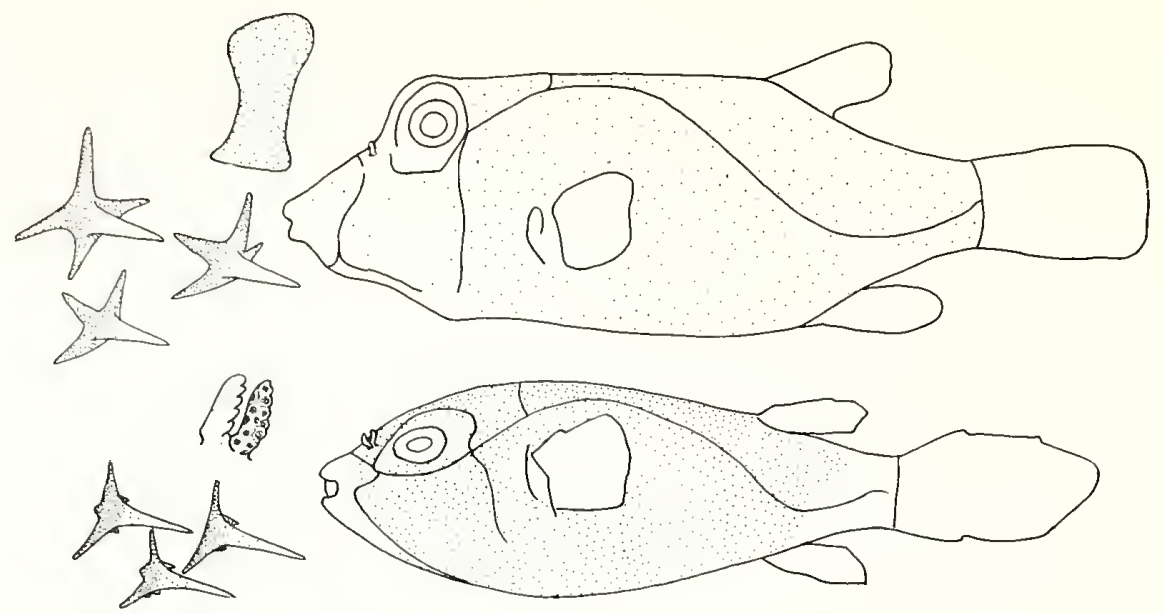

Figure 217.-External features of other representative tetraodontid genera: Arothron armilla (above) and

A. immaculatus-in both cases, upper left, nasal region as seen externally and, lower left, scales from upper
Figure 218.-External features of other representative tetraodontid genera: A, Tetraodon miurus,

B, T. lineatus, C, T. kretamensis, and D, T. schoutedeni-in all cases, upper left, nasal region as seen externally (with inset below for $T$. schoutedeni showing the pitted nasal epithelium) and, lower left, scales from upper middle region of body. middle region of body (nasal epithelium

of A. immaculatus pitted as shown;

that of $A$. armilla, not exposed in

the illustration, is only a slightly

irregular medial surface of the

single simple nasal flap).
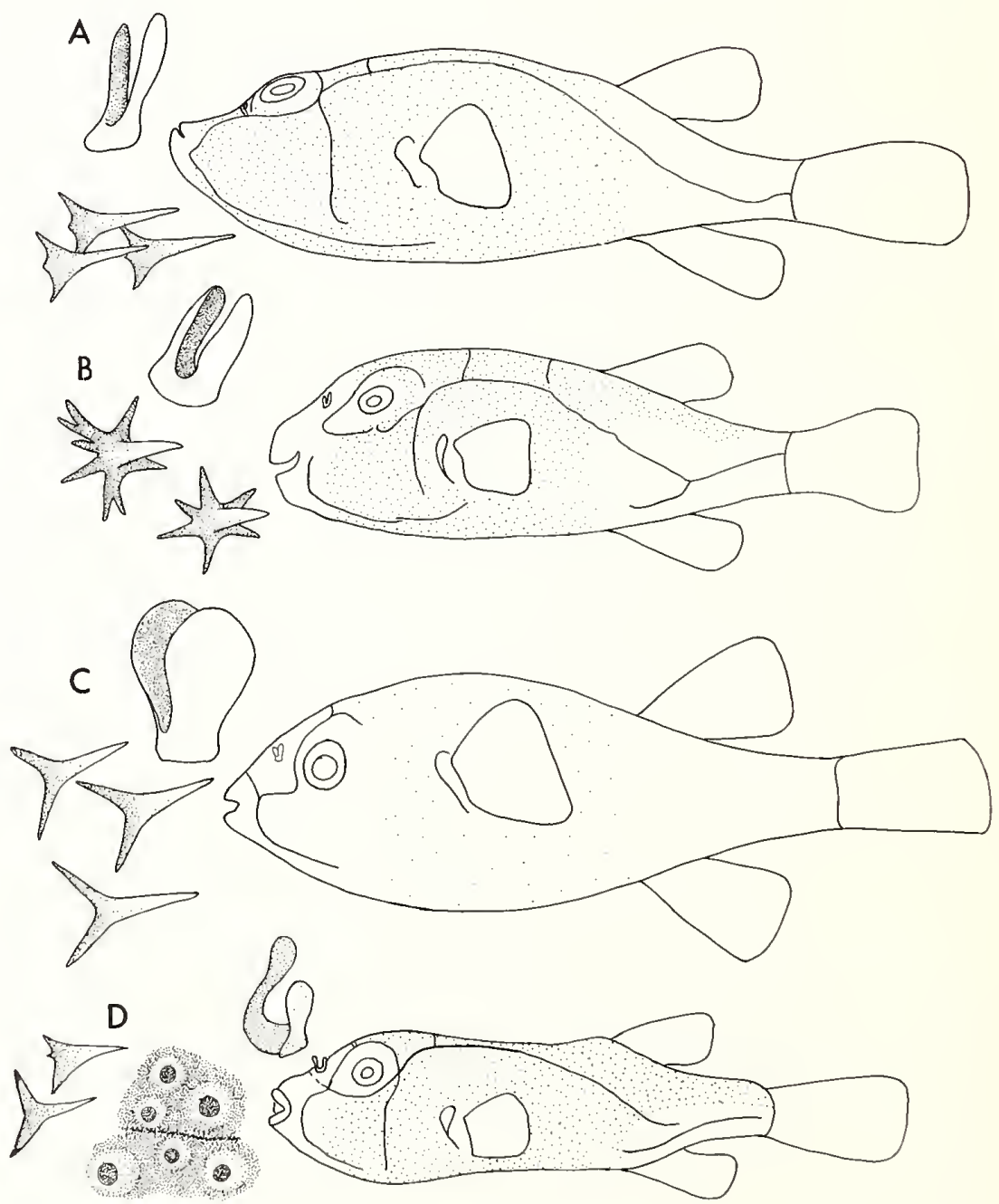

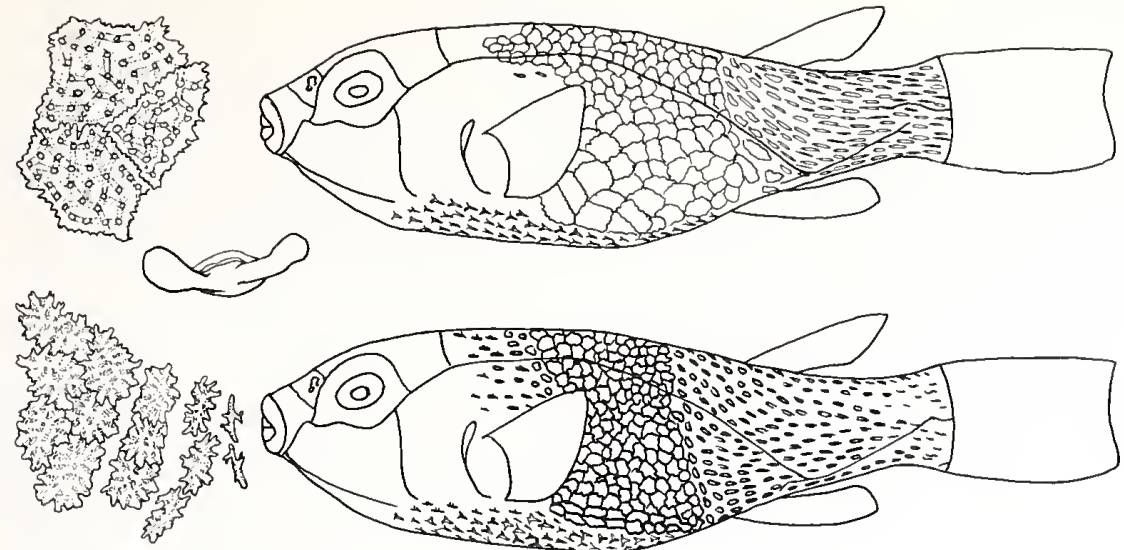

Figure 219.-External features of other representative tetraodontid genera: Ephippion guttifer of decreasing sizes, from top to bottom $(325,232$, and $101 \mathrm{~mm} \mathrm{SL})$ to show the enlargement of the scale plates with increasing standard length until, in large adults, a firm saddle is formed over the back and sides (but not belly); other two insets show nasal region as seen externally; scales of $101 \mathrm{~mm} \mathrm{SL}$ specimen shown for both belly (below) and sides.

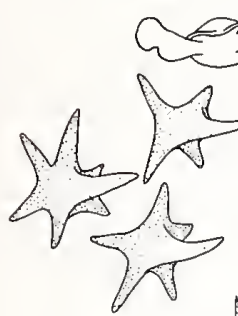

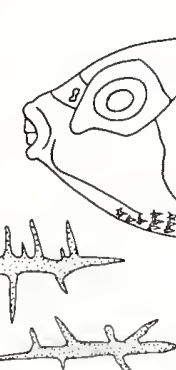

Figure 220.-Photographic detail of interdigitated scale plates from lower side of body of Ephippion guttifer,

$325 \mathrm{~mm}$ SL, also shown in

Figure 219 (greatest length of largest scale plate $23.0 \mathrm{~mm}$ ).

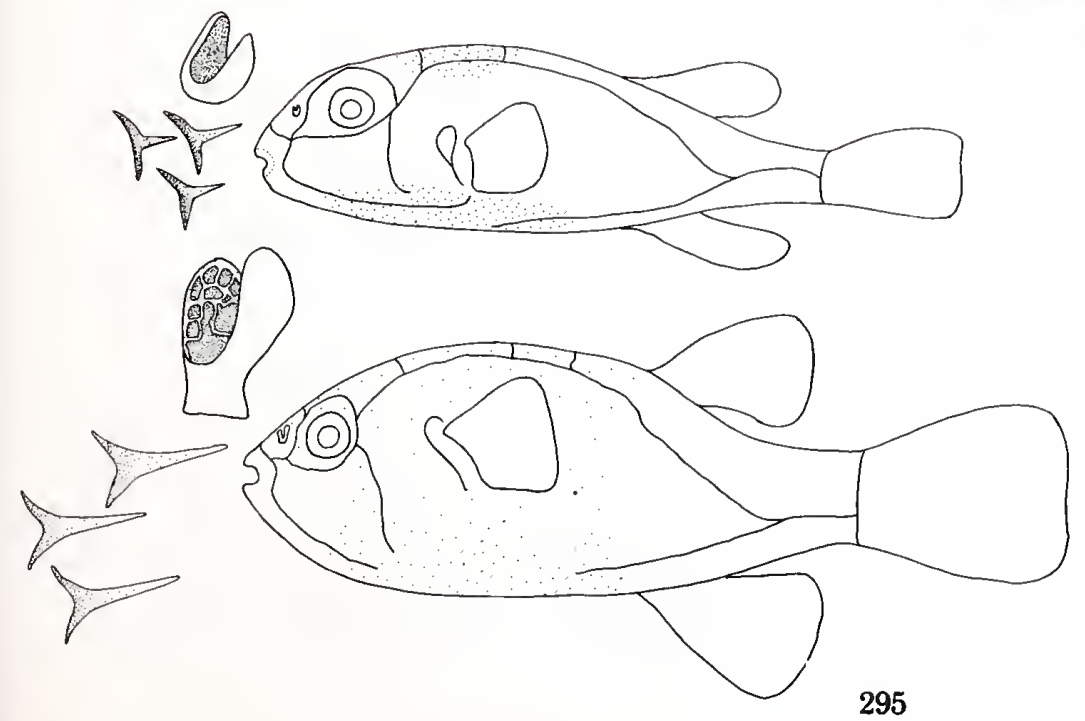

Figure 221.-External features of other representative tetraodontid genera: Chelonodon patoca (above) and C. fluviatilis-in both cases, upper left, nasal region as seen externally, and, lower left, scales from upper middle region of body. 
Figure 222.-External features of other representative tetraodontid genera:

Monotreta palembangensis (above) and

$M$. leiurus -in both cases, upper

left, nasal region as seen externally,

and, lower left, scales from upper middle region of body.
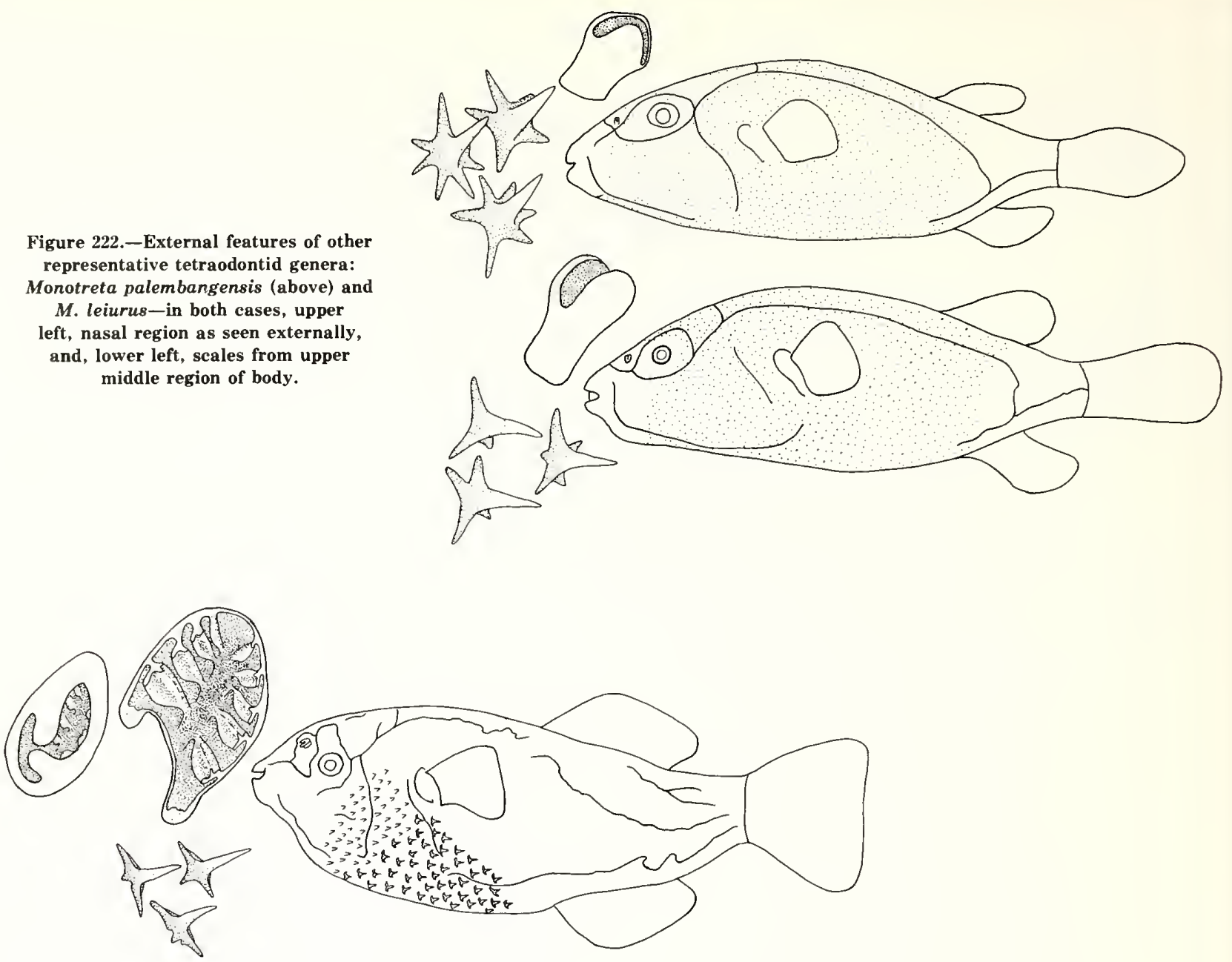

Figure 223.-External features of other representative tetraodontid genera: Chonerhinos modestus - upper left, nasal region as seen externally (far left) and the olfactory lamellae as seen with the

top of the nasal sac removed; lower left, scales from upper middle region of body.

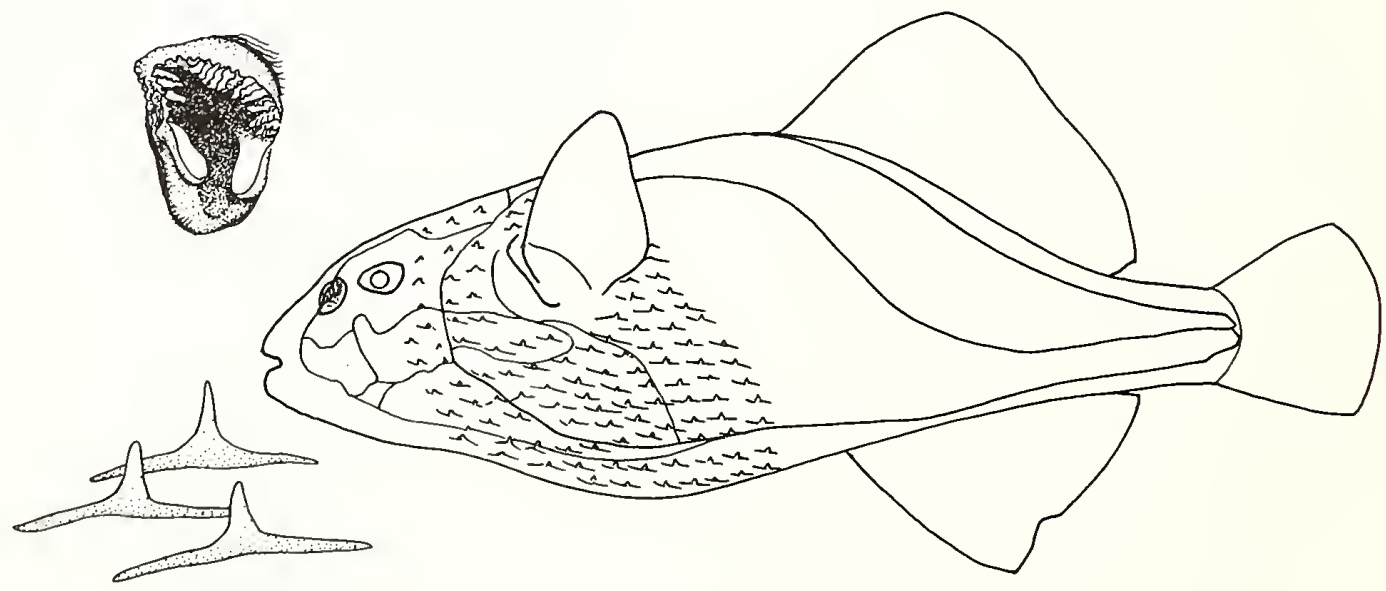

Figure 224.-External features of other representative tetraodontid genera: Xenopterus naritus-upper left, nasal region as seen externally; lower left, scales from upper middle region of body. 


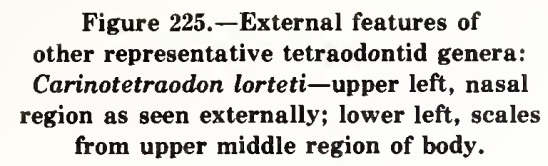

Figure 225. - External features of other representative tetraodontid genera: Carinotetraodon lorteti-upper left, nasal from upper middle region of body.
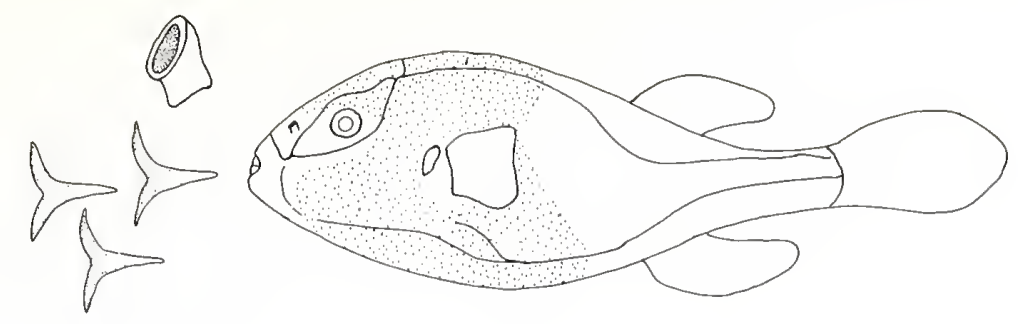

kretamensis) the course of the lateral line was found to be impossible to trace posteriorly in the single alcoholpreserved specimen examined. In Carinotetraodon a well-developed lower lateral line is present, but, at least in the few specimens examined, it does not join with the upper lateral line, continuing on directly to the tail (see illustration). In Ephippion a lower lateral line is present, but its juncture with the upper line is highly variable within the single species, as is the length of its extension anterior to the point of juncture (see illustrations). None of the genera with a single nostril or nasal tentacle have an upraised ridge of skin ventrolaterally along the caudal peduncle.

In short, it can be said that, of those genera with two nostrils, Sphoeroides and Guentheridia have only a single well-developed lateral line on the body, while in Lagocephalus, Amblyrhynchotes, Fugu, Torquigener, and Colomesus two lateral lines usually are present, and that of those genera with a single nostril or nasal tentacle, Arothron has a single lateral line, while Chelonodon, Monotreta, and Ephippion have two which usually merge on the caudal peduncle, Carinotetraodon usually has two which do not merge, and Tetraodon has either two which merge or, in at least a few species, a single lateral line.

There is also intraspecific variation in the form of the nasal apparatus, although probably less than that described here subsequently for the Diodontidae. In one species with two nostrils (Amblyrhynchotes richei), 9 (18.9-47.3 mm, ANSP 109916) out of 10 specimens examined had the normal arrangement of two nostrils separated by a broad band of tissue, but one specimen (49.1 mm, ANSP 109916) had apparently resorbed the middle region of the band in both the right and left nasal apparatuses to leave the nostrils confluent, and only incompletely separated by two flaps of skin (see illustration).

In the genera with a single nostril or nasal tentacle, the olfactory epithelium is usually relatively smooth, but in at least a few species (see illustrations of Arothron immaculatus and Chelonodon fluviatilis) the inner surfaces of the bifid tentacles are deeply pitted.

In the genera with two nostrils, the olfactory epithelium ranges from smooth to highly folded into numerous successive lamellae, but in the monotypic Guentheridia formosa the olfactory epithelium is deeply pitted just as in some of the species with bifid tentacles (all of the relatively normal species of Arothron and one of the species of Chelonodon). The degree of lamellar development is variable within some genera. For example, in Lagocephalus lamellae are exceptionally well developed in all species as folds that cover the entire inner surface of the nasal sac, with one or two of the folds on the rear wall enlarged as protruding flaps which themselves bear lamellae, except in $L$. scleratus, in which folds are present only on the rear wall of the sac and the two prominent protruding flaps are not themselves extensively folded. Similarly, in Sphoeroides, most species have the olfactory epithelium either smooth or with only one or two prominent folds or horizontal ridges on the rear wall, but one species, $S$. pachygaster, has the folds on the rear wall much better developed and more numerous, between five and eight in number. While the habitat of $L$. scleratus is similar to that of some (e.g., the equally streamlined and open water $L$. lagocephalus) of the other species of Lagocephalus with extensive olfactory flap development, $S$. pachygaster, in contrast to all other species of Sphoeroides, is a deepwater species, which may rely more heavily on olfaction than do the shallower water species. In Fugu the folds are only slightly less well developed than in most Lagocephalus and occur on the entire inner surface of the nasal sac, although the larger folds on the rear wall never become so extensively folded themselves as they do in most species of Lagocephalus. The numbers and size of the lamellae are especially great in $F$. oblongus. In the species of Colomesus, Torquigener, and Amblyrhynchotes examined, one to about four folds or ridges are developed on the rear wall of the sac.

There is variation in the size of the prickly spines and in their coverage of the body. Among the materials examined there are four genera in which most of the species have prickles but in which one or two species are completely spineless. In the speciose Sphoeroides most species have spines on both the back and belly but two species are spineless, $S$. angusticeps in the eastern Pacific and S. pachygaster (of which Liosaccus cutaneus is one on many synonyms, according to Shipp 1974:4447 ) in the Atlantic and Indo-Pacific to Japan. These two species are not closely related within the genus, as discussed subsequently, and the loss of prickles undoubtedly has occurred independently in the two species. Moreover, Shipp and Yerger (1969a) and Shipp (1974:98) reported that a minority of specimens of $S$. nephelus are completely spineless, and nephelus does not seem closely related to either pachygaster or angusticeps.

In the equally speciose Fugu, most species have spines on both the back and belly but two species are spineless, $F$. chrysops and $F$. vermicularis, which on the basis of the osteological data presented by Kuronuma (1943) do not seem closely related within the genus and are placed in different subgenera by Abe (1952). Here again, the loss of 
spines in these two species has occurred independently. T. Abe (pers. commun.) has informed me that, additionally, $F$. pardalis is at least superficially spineless. Lagocephalus and Tetraodon each contain a spineless species, L. inermis and T. mbu. In T. mbu, and, to a far lesser extent, in the two scaleless species of Fugu, there are pits in the skin that appear to be filled with a secreted matter, which is presently under histological investigation by the author. In $L$. inermis, and, to a lesser extent, in S. pachygaster, the skin of the belly is irregular in comparison to the smooth skin of the rest of the body, but no spines are present.

With the exception of these spineless species (and there are probably others among the species of tetraodontids not examined for this work), spines are always present on the belly of tetraodontids, but there is great variation both between and within genera in the degree of covering by prickles dorsally and laterally on the body. In Lagocephalus, for example, several species (lagocephalus and laevigatus) have spines only on the belly, while others (lunaris, scleratus, and spadiceus) have prickles variously developed on the dorsum in front of the dorsal fin. In Sphoeroides prickles are present (except in the two naked species) on the belly and dorsum, but are about as frequently absent as present on the side of the body (see Shipp 1974). In Torquigener prickles usually are absent from the sides of the body, but in Ambly. rhynchotes they are present there. In Ephippion the prickles on the sides of the body become enormously enlarged into plates forming a partial carapace (see illustration for form of spines at three specimen sizes), while one species of Amblyrhynchotes (piosae) has the projecting portion of the prickle much longer than in any other tetraodontid. In Chonerhinos and Xenopterus the prickles of the belly and sides of the body tend to be larger than in other tetraodontids.

In a few tetraodontids the scales along the course of the lateral line are modified, being much smaller, more numerous, and with less development of the protruding spinule. For example, in Lagocephalus, the three species (lunaris, scleratus, spadiceus) which have prickles along the back and upper sides in the region of the lateral line show great differentiation of the small scales immediately along the line from those adjacent to them. In the other tetraodontids examined, there is no differentiation of the prickles immediately along the line from those adjacent to them, although the course of the lateral line is sometimes clearly indicated in cleared and stained specimens by a wider spacing of the prickles leading to a spineless stripe along the course of the line (especially clearly marked in the two species of Colomesus, and, to a lesser extent, in a few species of Monotreta).

The internal anatomical diversity of the tetraodontids is much greater than the external. The long-based, many-rayed dorsal fin in Chonerhinos and Xenopterus is reflected in a greater number of vertebrae than in other tetraodontids, Chonerhinos has 26 vertebrae modally (25-27), of which 10 are usually abdominal, while Xenopterus has 29 or 30 vertebrae, of which 10 or 11 are abdominal. All other tetraodontids have modal values ranging from 17 to 23 , the only species with modal values above 20 being numerous species of Fugu and some of Monotreta and Torquigener. At the opposite extreme, 17 vertebrae modally, are all of the species of Canthigaster, that of Carinotetraodon and of Guentheridia, and several species of Lagocephalus, Sphoeroides, and Tetraodon, the formula always being eight abdominal and nine caudal when the total is modally 17 . Since both the Eoplectinae and Triodontidae, ancestral to the tetraodontids, have 20 vertebrae $(9+11)$, as do the other basal Triacanthodidae $(8+12)$, the presence of somewhere around 20 vertebrae can be considered generalized in tetraodontids, and the great increase in number in Chonerhinos and Xenopterus as well as the decrease in number to as low as 17 can both be considered specializations. Moreover, since the Eoplectinae have only a moderately long soft dorsal fin base and a moderate number of rays (14 to 17), with an indication that the number of rays is in the process of being reduced posteriorly in the series, and the Triodontidae a short-based dorsal fin with a low number of rays (modally 11), the generalized tetraodontid condition can be considered to be a relatively short-based dorsal fin and lowered number of rays (approximately 10 to 12 ).

Thus, the great increase in the length of the base and in the number of rays in the dorsal fin of Chonerhinos and Xenopterus must be considered specializations for stronger more sustained swimming, perhaps associated with their invasion of fluviatile fresh waters, although they are also found in coastal marine waters, with the possible exception that the problematical $C$. africanus may be confined to the Congo. Similarly, the elaborate open cup nasal apparatus and increased number of lateral lines in these two genera are specializations. Chonerhinos and Xenopterus also have specialized skulls (lacking prefrontals in both genera, and with enormously enlarged frontals in Xenopterus).

Chonerhinos and Xenopterus are highly specialized genera. Chonerhinos, which has lengthened the base of the dorsal and anal fins and increased the number of rays to a lesser extent than Xenopterus, and which has a less specialized skull than Xenopterus, obviously is the more generalized of the two. Fraser-Brunner (1943:4) also considered these two closely related genera as highly specialized, with the increased numbers of vertebrae and fin rays "a secondary development." The contention of Le Danois (1959:248) that these two genera are the most primitive of the tetraodontids and ancestral to the diodontids cannot be taken seriously.

While Chonerhinos and Xenopterus are highly specialized, in my opinion they are not sufficiently differentiated anatomically from the other tetraodontids to be recognized as even subfamilially distinct (much less as a separate family). However, one genus of tetraodontids, Canthigaster, is usually recognized as a distinct family both in the general ichthyological literature and in that more specifically devoted to plectognaths, a practice that I have previously followed. Since about two dozen species of Canthigaster are usually recognized as a separate family, and it is being suggested here that this 
be changed, a detailed osteological description of $C$. rostrata is given here for the sake of comparison with that of another, less specialized, tetraodontid, Lagocephalus laevigatus.

Following below is first a discussion of the differences between Canthigaster and the other tetraodontids, and then of the anatomical diversity of the Tetraodontinae.

The species of Canthigaster are distinguished from one another externally primarily by coloration, with slight aid from the number of dorsal fin rays, one species ( $a m$ boinensis) usually having 11 or 12 rather than 9 or 10 , and perhaps from the caudal peduncle length versus depth (differences between species not yet well worked out). The species are as similar internally as externally, there being an unrelieved sameness in the osteological configuration: 1) the vertebral column is always highly arched; 2) the haemal arches of the first three vertebrae are relatively well developed although they do not usually completely enclose the haemal canal (first arch sometimes complete); 3) the haemal spines of the other abdominal vertebrae are well developed and have a characteristic rounded and flattened posterior lobe; 4) the haemal spines of the caudal vertebrae are also well developed and of similar shape in all the species; 5) the neural spines of the first three vertebrae are bifid and that of the fourth is bifurcate anteriorly; 6 ) the neural spine of the seventh abdominal vertebra is always a long shaft lying along the anterior edge of the first basal pterygiophore of the dorsal fin, while the neural spines of the successive vertebrae until the antipenultimate are also elongate shafts; 7) the neural spine of the antipenultimate vertebra is slightly expanded anteroposteriorly and that of the penultimate even more so; 8 ) the caudal fin supporting skeleton is essentially similar in all species; 9) the basal pterygiophores of the dorsal fin are all placed between the neural spines of the seventh abdominal to the third caudal vertebrae; 10 ) the basal pterygiophores of the anal fin are supported mostly by the haemal spines of the first to third caudal vertebrae but sometimes with assistance of the fourth; 11) the first basal pterygiophores of the dorsal and anal fins are always much larger than the others; 12) the supraneural is similarly well developed and usually arched; 13) the snout is relatively long and narrow; 14) there is always only one hypohyal; 15) there is never an interhyal; 16) there is only a slight trace of the dorsal roof of the myodome; 17) there are never trituration teeth; 18) the parasphenoid never has a dorsal flange in the orbit to the frontals; 19) the pharyngobranchial of the first arch always bears small teeth; 20 ) the supraoccipital is always high crested; 21) the ethmoid is extremely long and Tshaped; 22) the frontal has a pair of posterolateral wings meeting or closely approaching one another distally; 23) the prefrontal is flattened dorsally and gently downcurved anterolaterally and is always placed in about the middle of the skull; 24) the sphenotics are not much exposed on the dorsal surface of the skull; 25) the vomer is always well developed and relatively well compressed laterally and well removed from the prefrontals; and 26) the parasphenoid always has a deep keel.

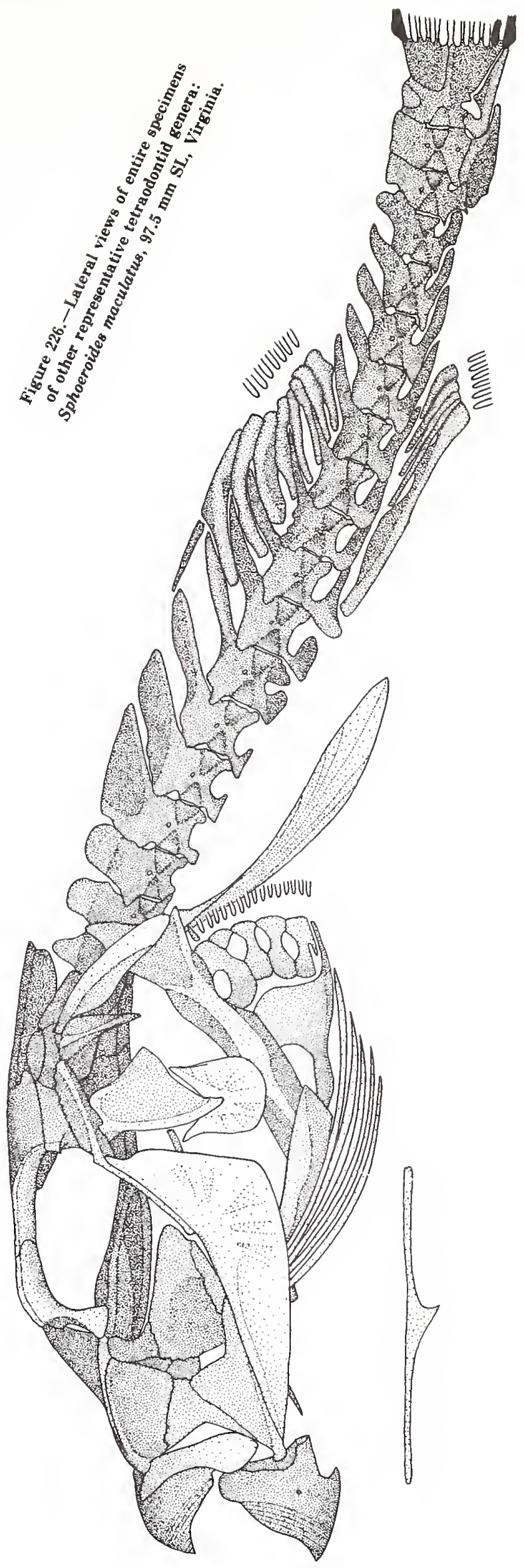




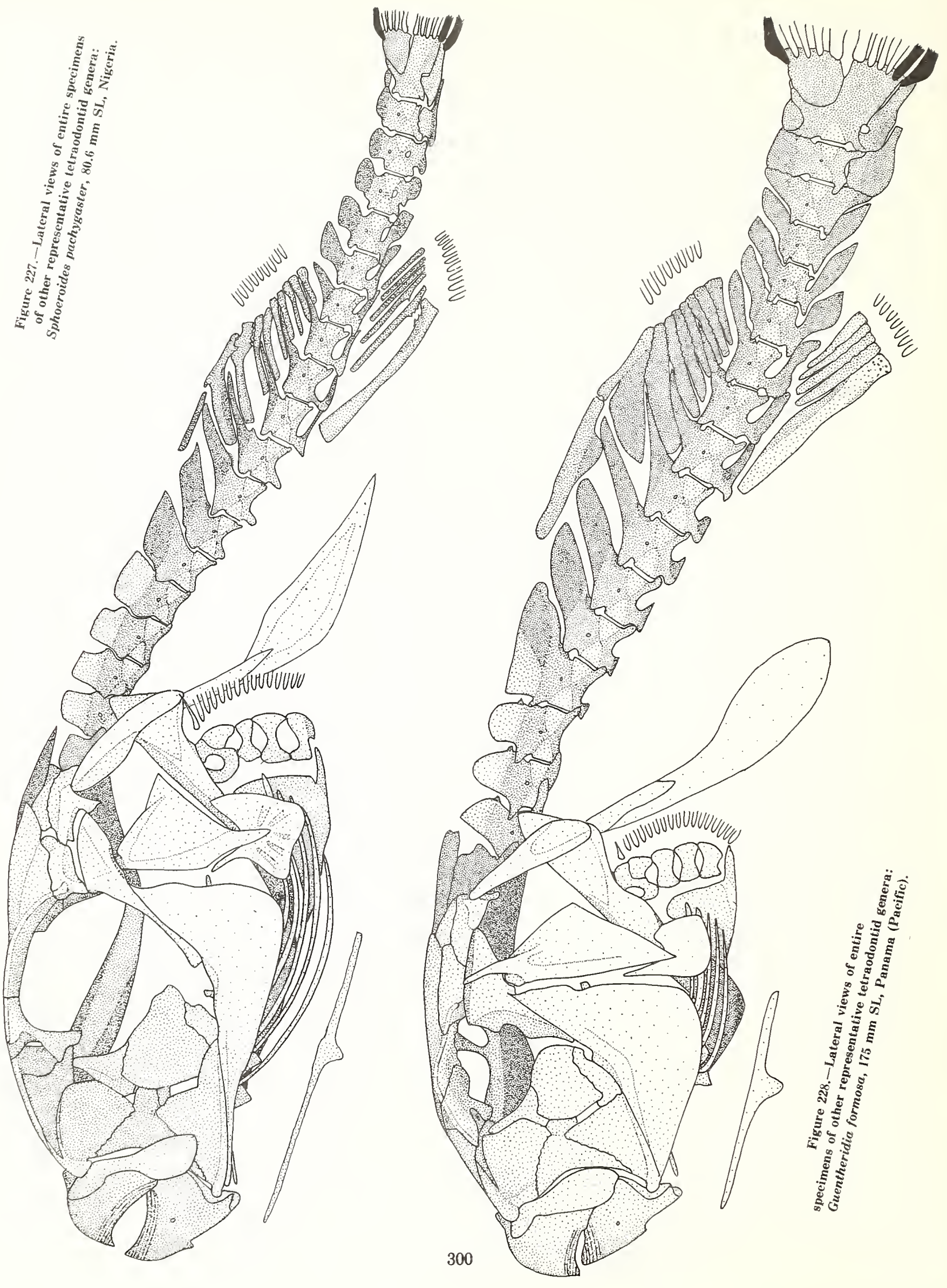




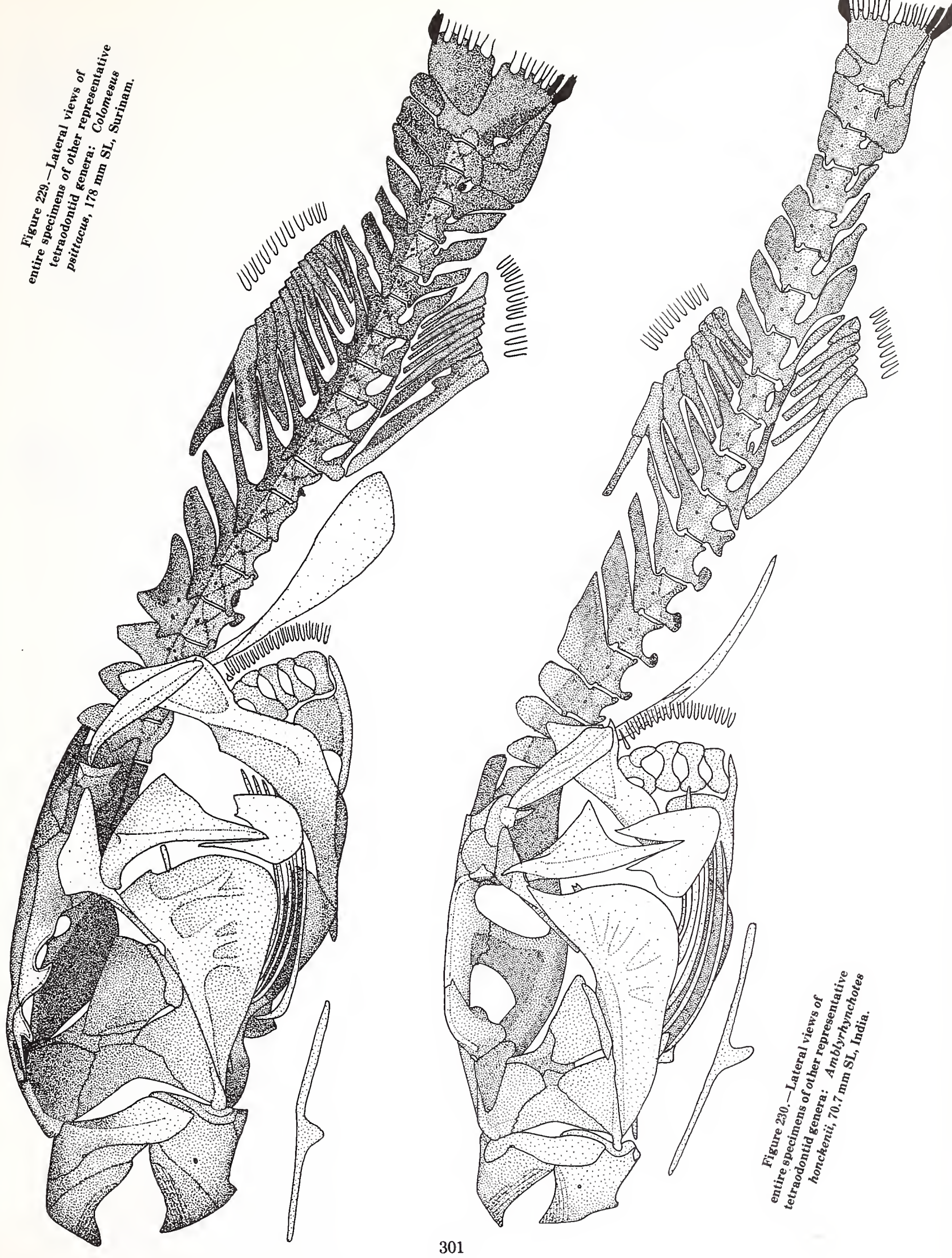



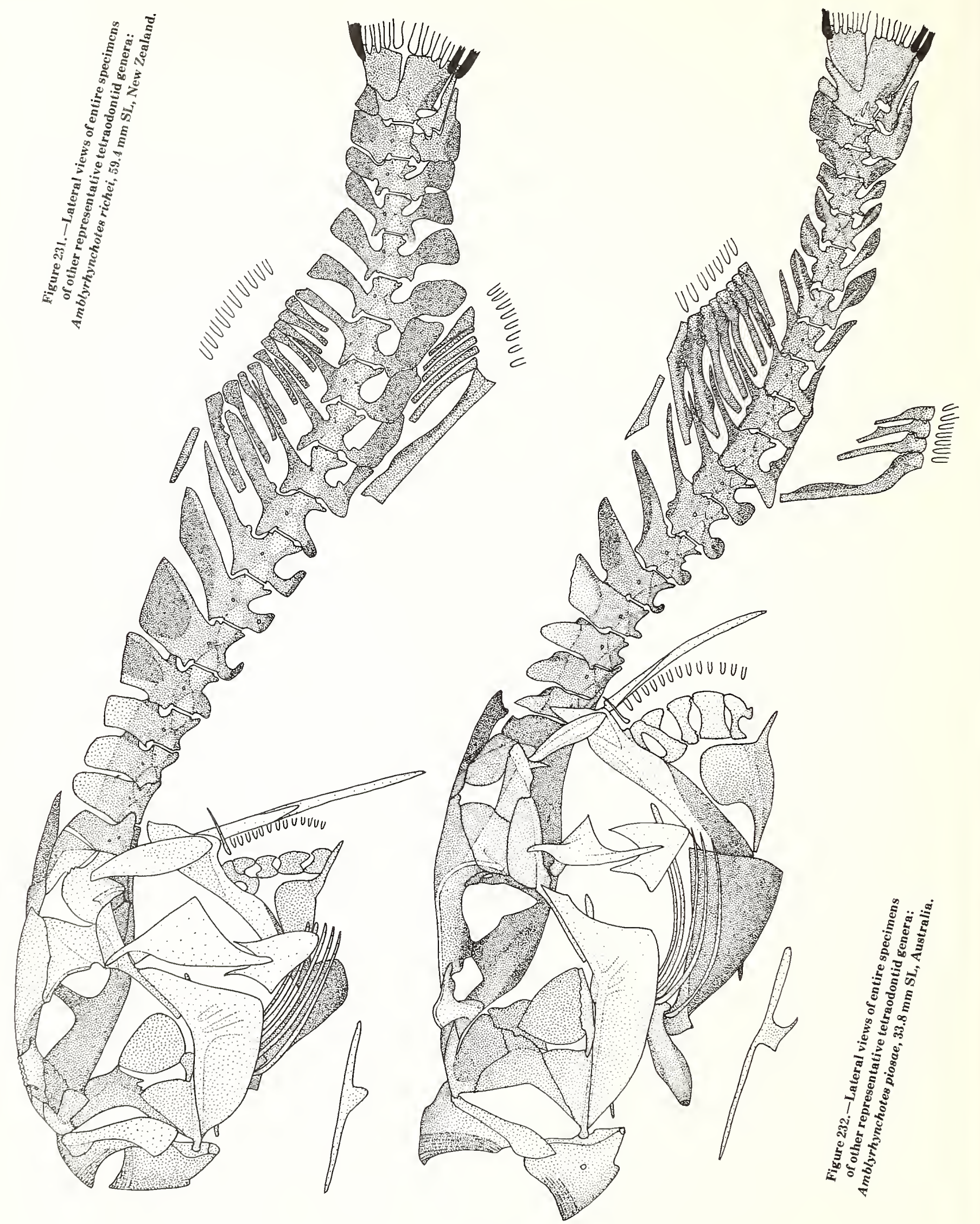


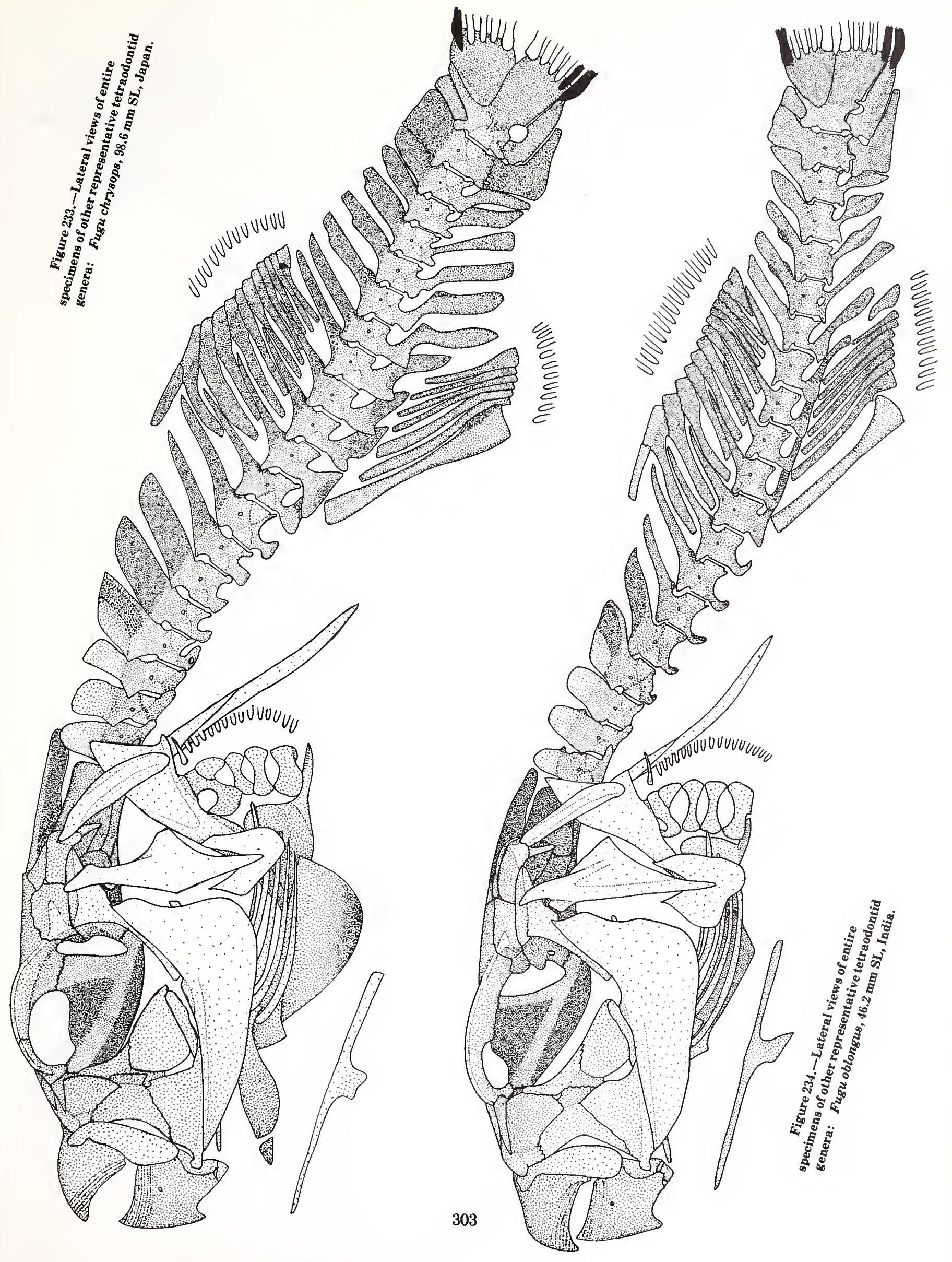




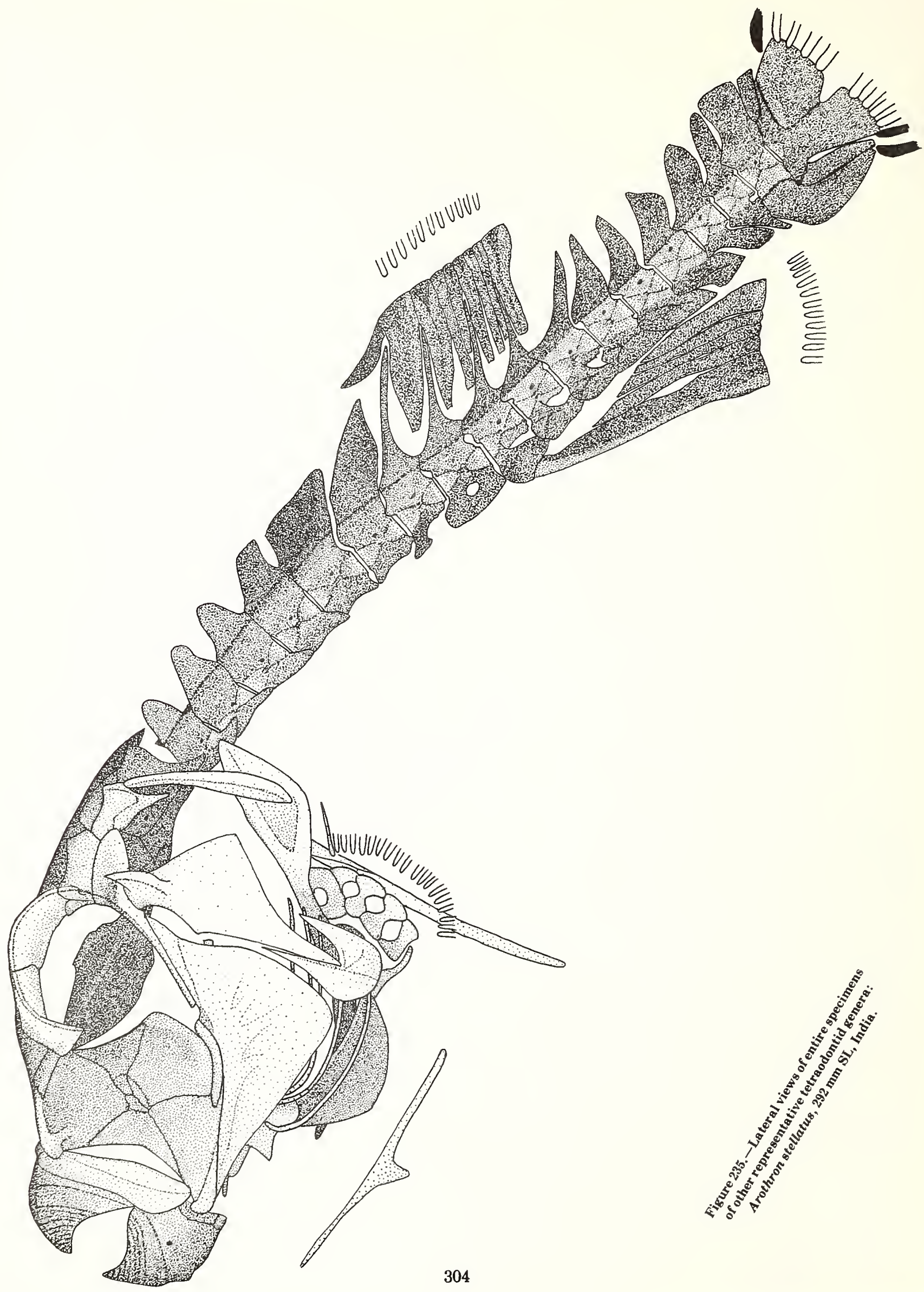




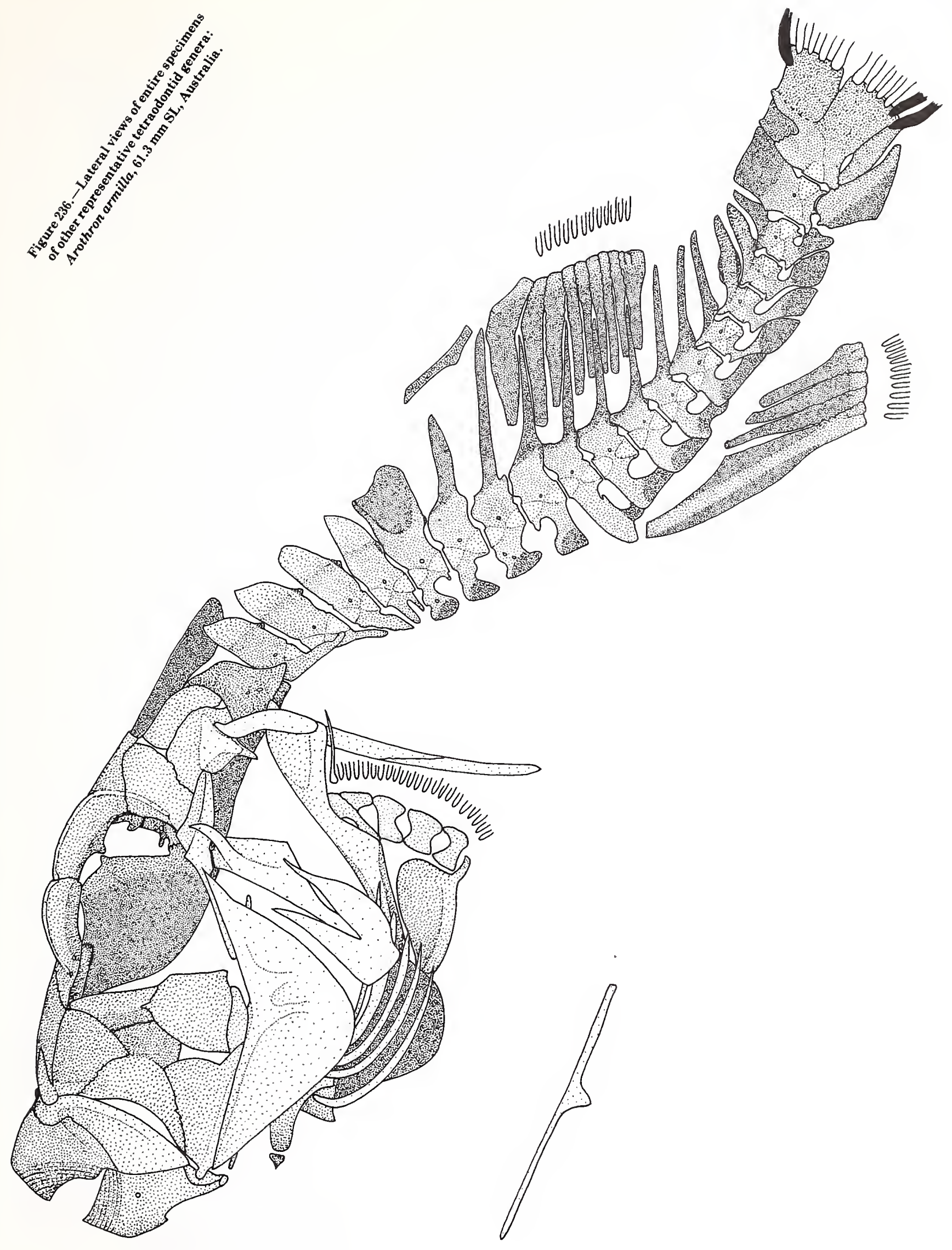



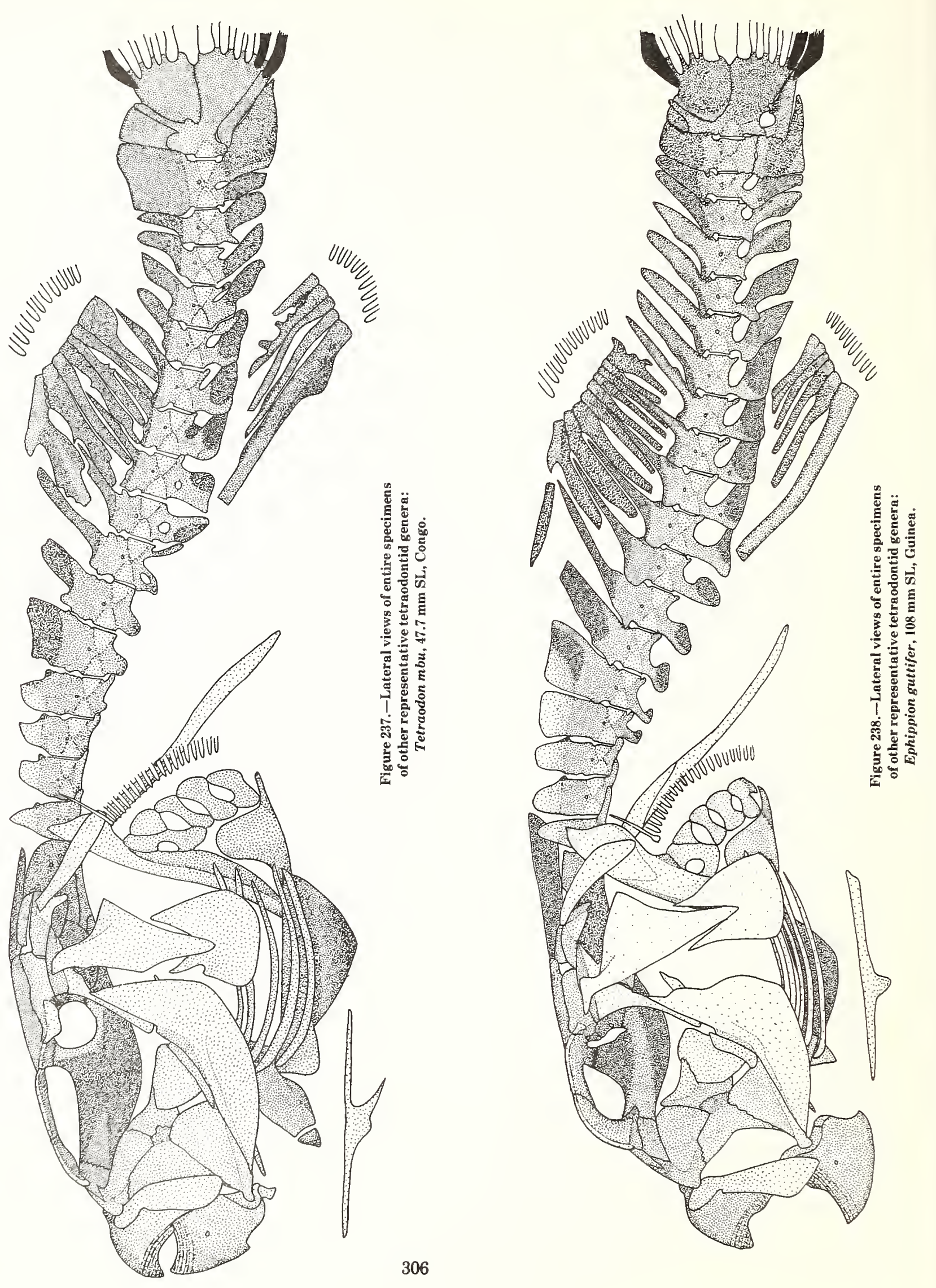


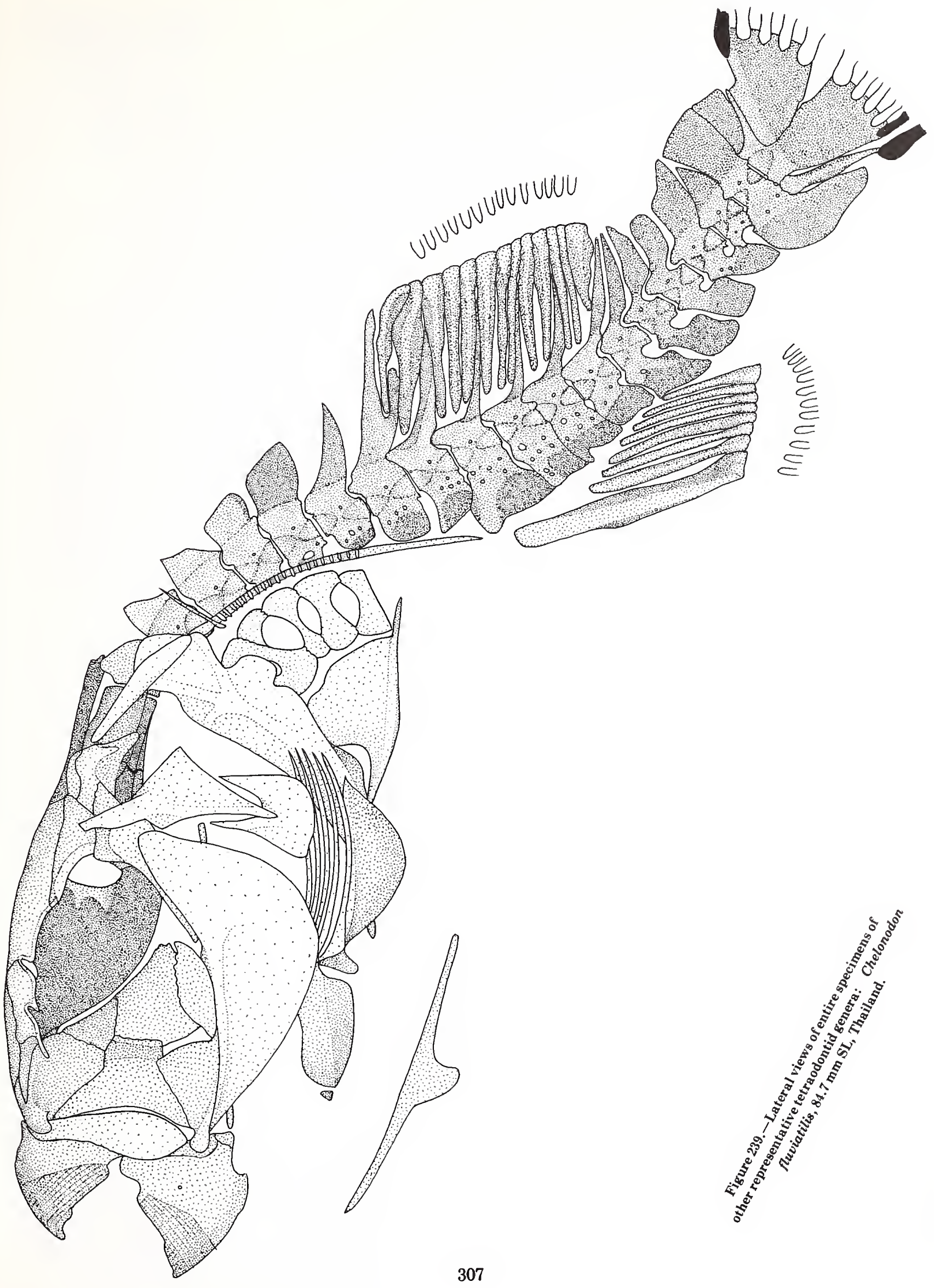




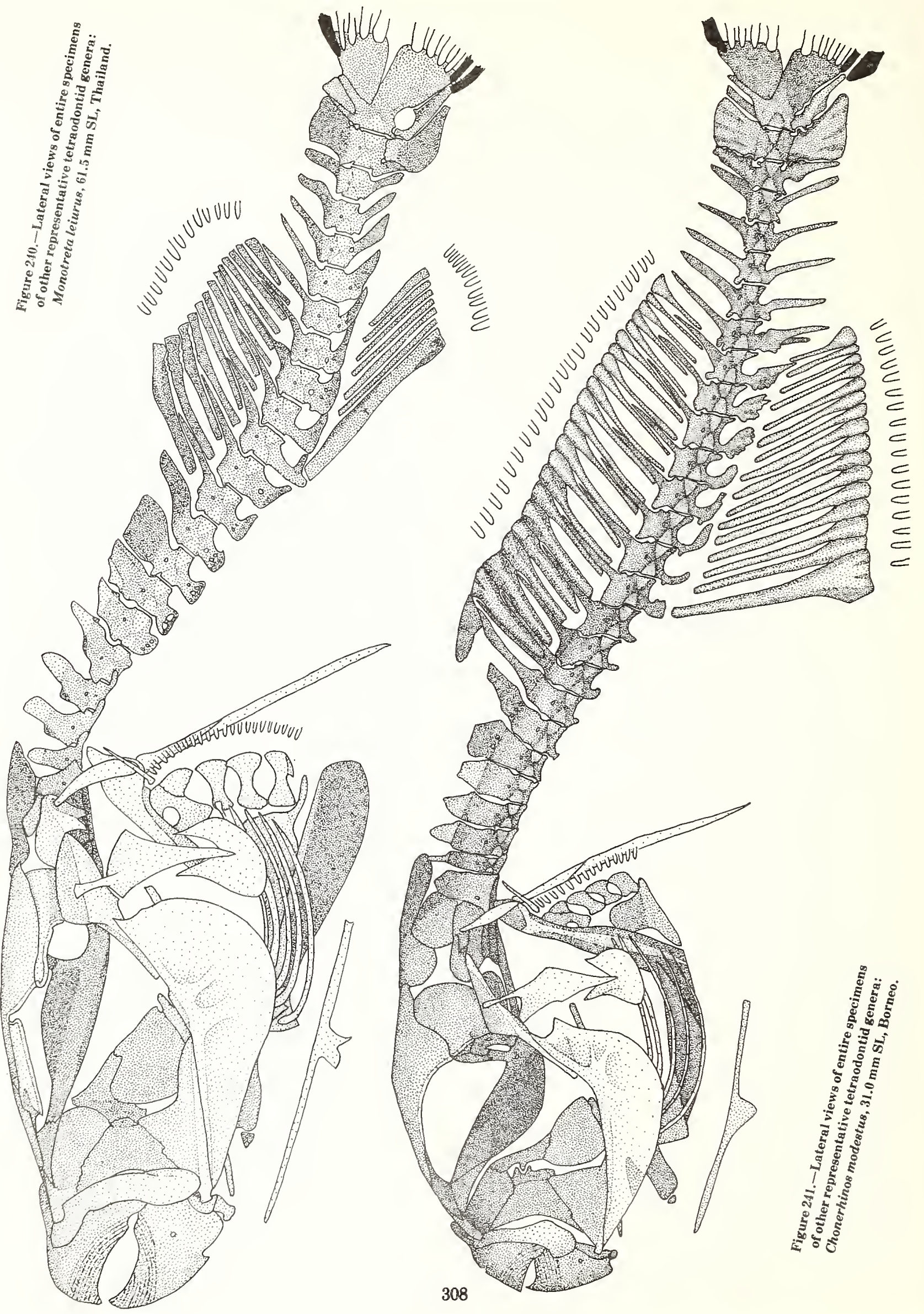




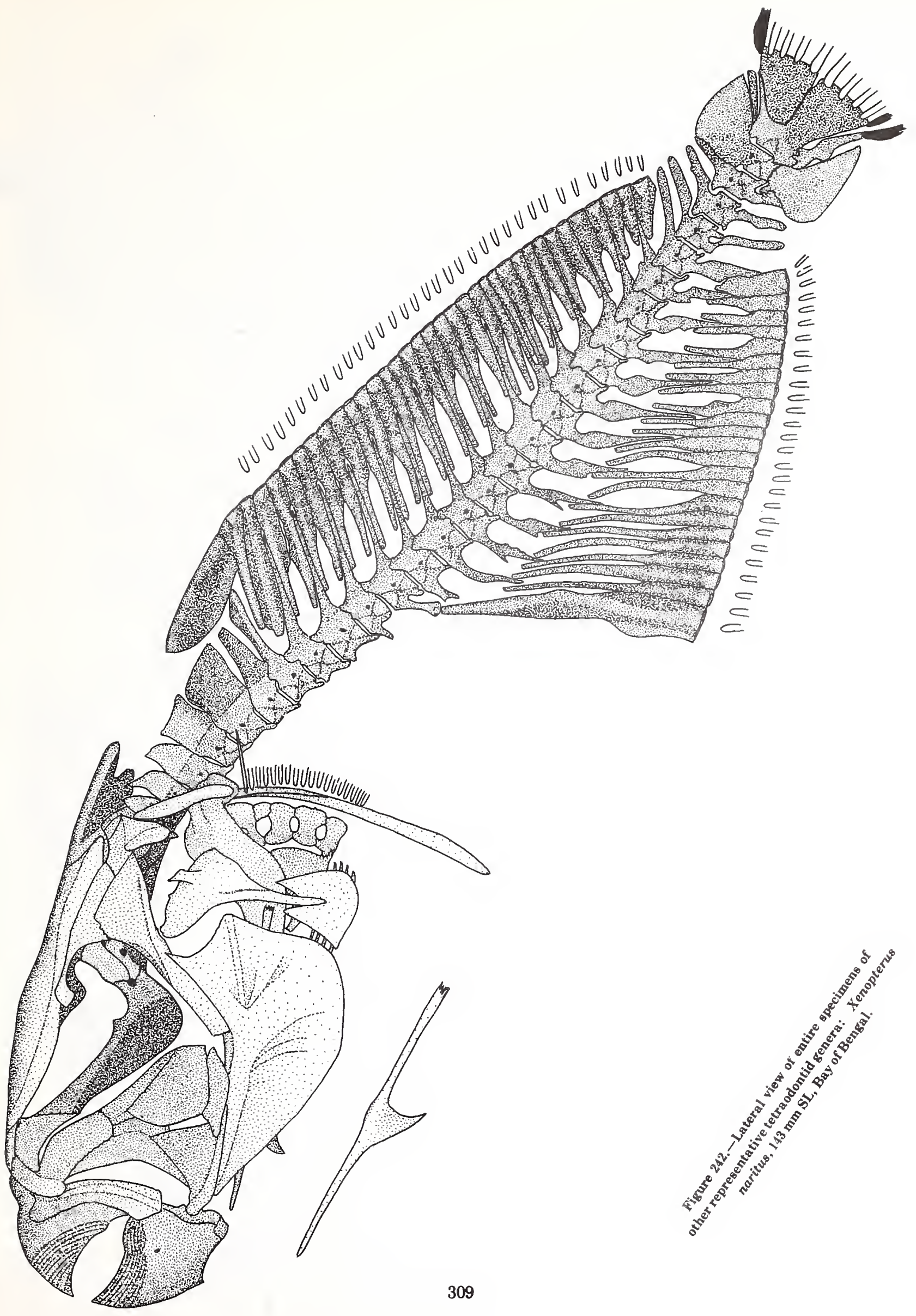




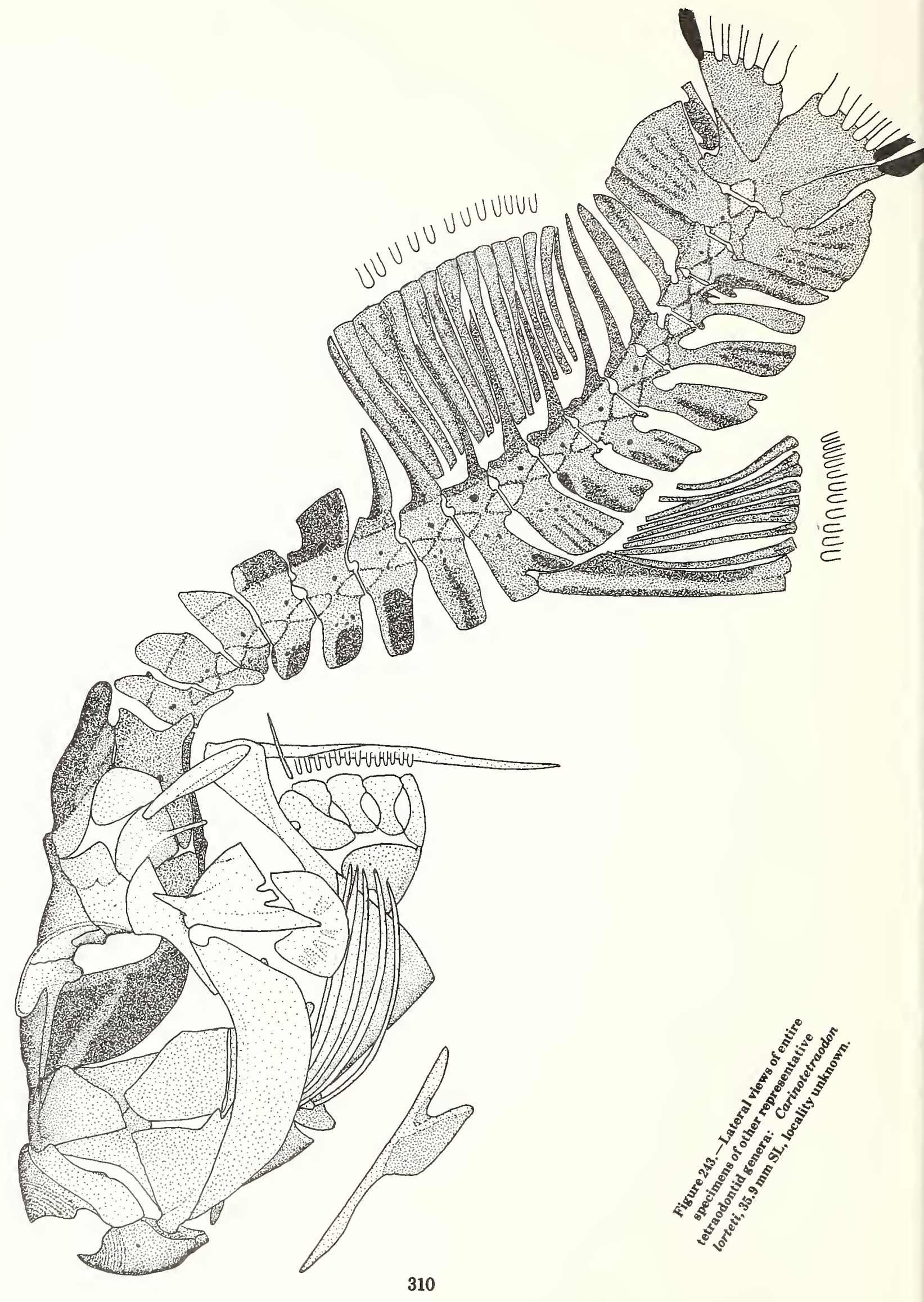




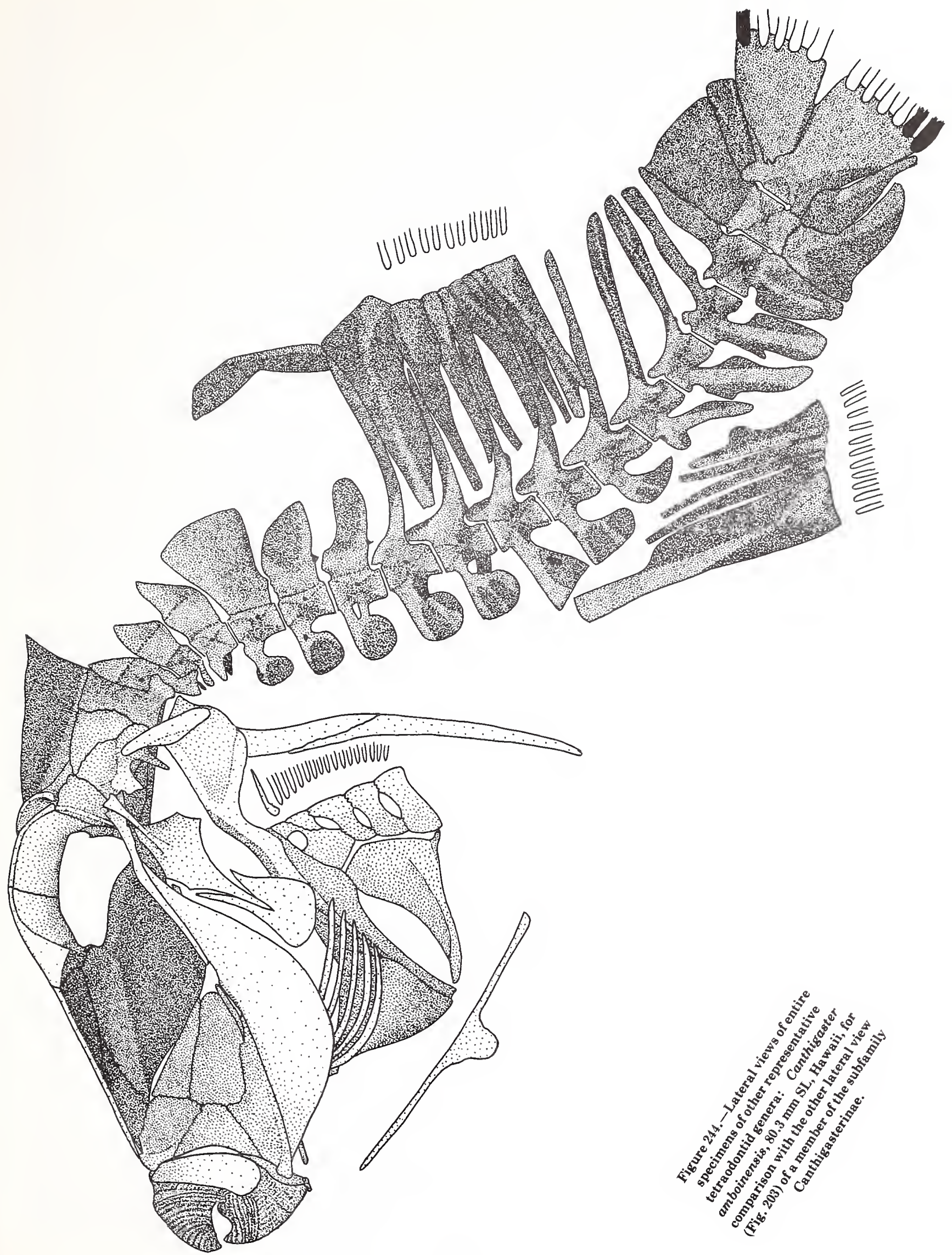


In general, there is such skeletal similarity between the species that for most practical purposes it can be truly said that to see the skeleton of one species of Canthigaster is to have seen them all, which is decidedly not the case with other genera of tetraodontids with similar numbers of species.

Until recently I had thought that a goodly number of these monotonously similar features of the species of Canthigaster were not shared by any tetraodontids and that Canthigaster could with good justification be recognized as familially distinct from the Tetraodontidae. But the skeletal structure of one relatively specialized tetraodontid examined recently, and, to a lesser extent, that of a few other species related to it, shows so many similarities to Canthigaster that I am forced to the conclusion that they share a close common ancestry. From this point of view, Canthigaster seems to me to merit only subfamilial recognition on the basis of the anatomical differences between it and the other tetraodontids which remain after consideration of the structure of Carinotetraodon lorteti, and its relatives.

Recently described as Tetraodon somphongsi (Klausewitz, April 1957a and 1957b) and immediately thereafter as Carinotetraodon chlupatyi (Benl, July 1957; Benl and Chlupaty 1957), based on specimens from fresh water in Thailand, Dekkers (1975) has shown that the proper specific name is lorteti Tirant 1885. Benl (1959) suggested that the species be retained in the genus Carinotetraodon since it differed from all other tetraodontids (Canthigaster being considered familially distinct) in being able to raise up a large fold of skin in the midline both dorsally and ventrally, just as in Canthigaster. It was believed that such behavioral and anatomical skin changes would probably indicate other, more internal, differences between somphongsi and the other tetraodontids. Tyler (1978) has reviewed the growing aquarium literature on lorteti and the history of its name.

Because of its moderate tubelike nasal apparatus with a single rounded nostril, Carinotetraodon lorteti otherwise would have to be accommodated in Monotreta. In fact, on the basis of its coloration and external morphometrics, lorteti seems to be most closely related to $M$. caria (Hamilton-Buchanan), but lorteti is sufficiently distinct from the four species of Monotreta examined (cutcutia, which is the type-species, palembangensis, leiurus, and gularis) to warrant its retention in Carinotetraodon.

Regardless of its nomenclature, $C$. lorteti shares with Canthigaster not only the ability to lift up a ridge of skin dorsally and ventrally along the midline, but a number of internal features as well. The vertebral column in Carinotetraodon is highly arched and almost exactly similar in configuration to that of Canthigaster. The first three vertebrae have bifid neural spines and welldeveloped haemal spines which do not completely enclose the haemal canal, while the fourth vertebra has the neural spine bifurcate anteriorly, and a large haemal spine, although the flattened region of the spine does not form a distinctive posterior lobe as in Canthigaster. The haemal spines of the fifth and subsequent vertebrae are as well developed as in Canthigaster, but again they do not have distinctive posterior lobes. The neural spine of the fourth vertebra is shorter than in Canthigaster, that of the fifth similar to Canthigaster and that of the sixth longer. The long neural spine of the seventh vertebra, supporting the anterior edge of the first basal pterygiophore, and the succeeding neural spines until the antipenultimate, are also long shafts, just as in Canthigaster, and the basal pterygiophores of the dorsal fin are accommodated between the neural spines of the 7 th to 11 th vertebrae in both genera. However, even though both genera possess a specialized reduced number of 17 vertebrae, there are eight abdominal in Canthigaster and only seven in Carinotetraodon. In both genera there are seven vertebrae with neural spines anterior to the first basal pterygiophore of the dorsal fin and seven with neural spines posterior to the last basal pterygiophore. The caudal fin supporting skeleton, and, in general, the last three vertebrae, are highly similar in both genera. The anal fin basal pterygiophores are closely supported basally primarily by the haemal spines of the first three caudal vertebrae, with secondary assistance from that of the fourth, in both genera. Although the number of basal pterygiophores in the dorsal (12) and anal (9) fins of Carinotetraodon is greater than in Canthigaster (usually 8 or 9 dorsal and 5 anal), the first basal pterygiophores of both fins in Canthigaster are enormously larger than the others and could represent fusion products of what are the first few pterygiophores in these fins in Carinotetraodon.

The similarities between Carinotetraodon and Canthigaster in the skull are less extensive than in the vertebral column, but are of phylogenetic interest. In Carinotetraodon the frontal does not have a pair of posterolateral processes whose distal ends meet or closely approach one another to partially enclose the muscle to the operculum, one of the most characteristic features of Canthigaster, but a perhaps functionally somewhat similar arrangement is formed by the sphenotic of Carinotetraodon. The sphenotic in Carinotetraodon is broadly present on the dorsal surface of the skull, with an anterolateral wing excluding the posterolateral edge of the frontal from the upper rear margin of the orbit, and, more importantly to the present discussion, a posterolateral wing prominently projecting out from the lateral surface of the skull, a feature found in none of the other tetraodontids examined. The space between the anterolateral and posterolateral wings of the sphenotic of Carinotetraodon would seem to correspond to that enclosed by the posterolateral wings of the frontal of Canthigaster. It is suggested here that the condition such as found in Carinotetraodon could have given rise to than in Canthigaster by the gradual posterolateral expansion of the frontals overlying first the anterolateral wing of the sphenotic, which would become reduced in size and eliminated eventually, and then overlying the posterolateral wing of the sphenotic, which likewise would be eliminated eventually as the frontal took over its supportive function, leaving only a small portion of the 
sphenotic visible on the dorsal surface of the skull. Completion of the process would require only the coming together in close proximity of the distal ends of the two posterolateral wings of the frontal (those that had replaced the two wings of the sphenotic) to form a more complete well around the muscle to the operculum.

In Carinotetraodon the supraoccipital crest is not as high and laterally compressed as in Canthigaster, but it is higher than in most other tetraodontids, and such a condition could easily give rise to that of Canthigaster. The parasphenoid of Carinotetraodon has a welldeveloped ventral flange and is arched dorsally in front of the orbit much as in Canthigaster. In Carinotetraodon the prefrontal is relatively posterior in position, being only slightly forward of about the middle of the skull, and while it does not have the characteristic smooth flat dorsal surface gently curved downward anterolaterally as found in Canthigaster, it is in contact anteriorly with the vomer only by a thin but wide anterior prolongation. If this anterior prolongation was reduced in size and then lost, the prefrontal of Carinotetraodon would have the Canthigaster condition of being far removed from the vomer. The ethmoid of Carinotetraodon is not especially long in comparison to many other tetraodontids, but it is long enough for one to envision its elongation in the process of lengthening the snout in Canthigaster and the conversion into a $\mathrm{T}$-shaped cross section. A few other features that would be necessary to the conversion of a Carinotetraodon-like fish into a Canthigaster-like one are the development of a high anterodorsal wing on the suboperculum and a straightening of the dorsal edge of the operculum.

One of the important distinguishing features of Canthigaster is the single nostril at the end of a very small short tube, and it is reasonable to suppose that Canthigaster was derived from a tetraodontid line with a single nostril at the end of a better developed nasal tube. Among tetraodontids a nasal tube with a single nostril is found only in a few species of Monotreta (a few other species of the genus have the opening bilobed) and in the closely related Carinotetraodon.

Only Carinotetraodon and Canthigaster are known to have the ability to lift up a ridge of skin along the midline, and the osteology of Carinotetraodon shows striking similarities to that of Canthigaster, more so than does that of any other tetraodontid. It seems highly likely that Carinotetraodon and Canthigaster share a close common ancestry, from which Carinotetraodon has diverged little but from which Canthigaster has become highly enough modified to warrant subfamilial recognition. It would be of interest to know if the common ancestral group was marine, fresh water, or euryhaline.

Monotreta and Chelonodon, closely related to Carinotetraodon, contain species which show a few of the same features (arched vertebral column, well-developed haemal spines on the abdominal vertebrae) of similarity between Carinotetraodon and Canthigaster, but, to a much lesser degree, than in Carinotetraodon. Neverthe-

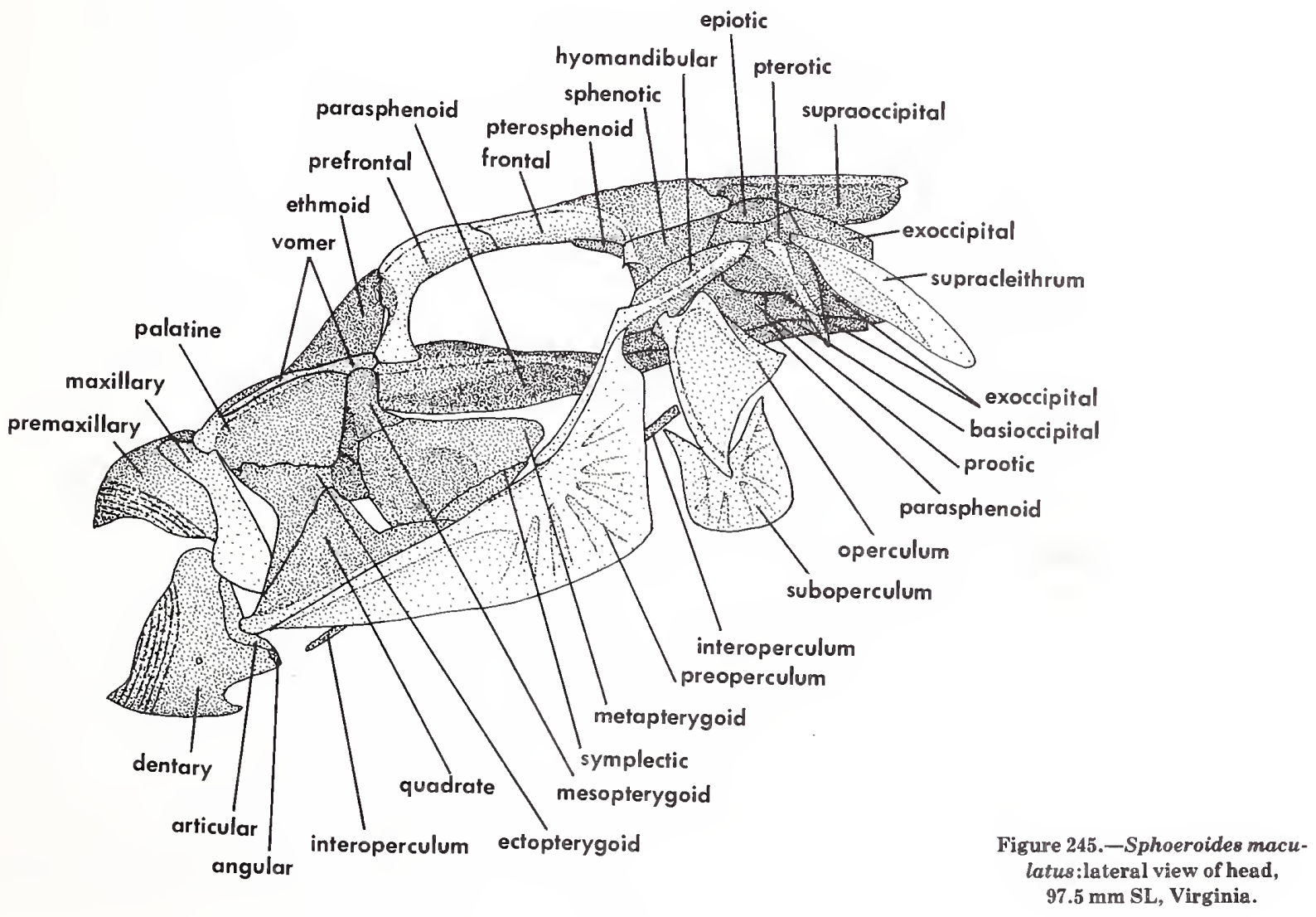




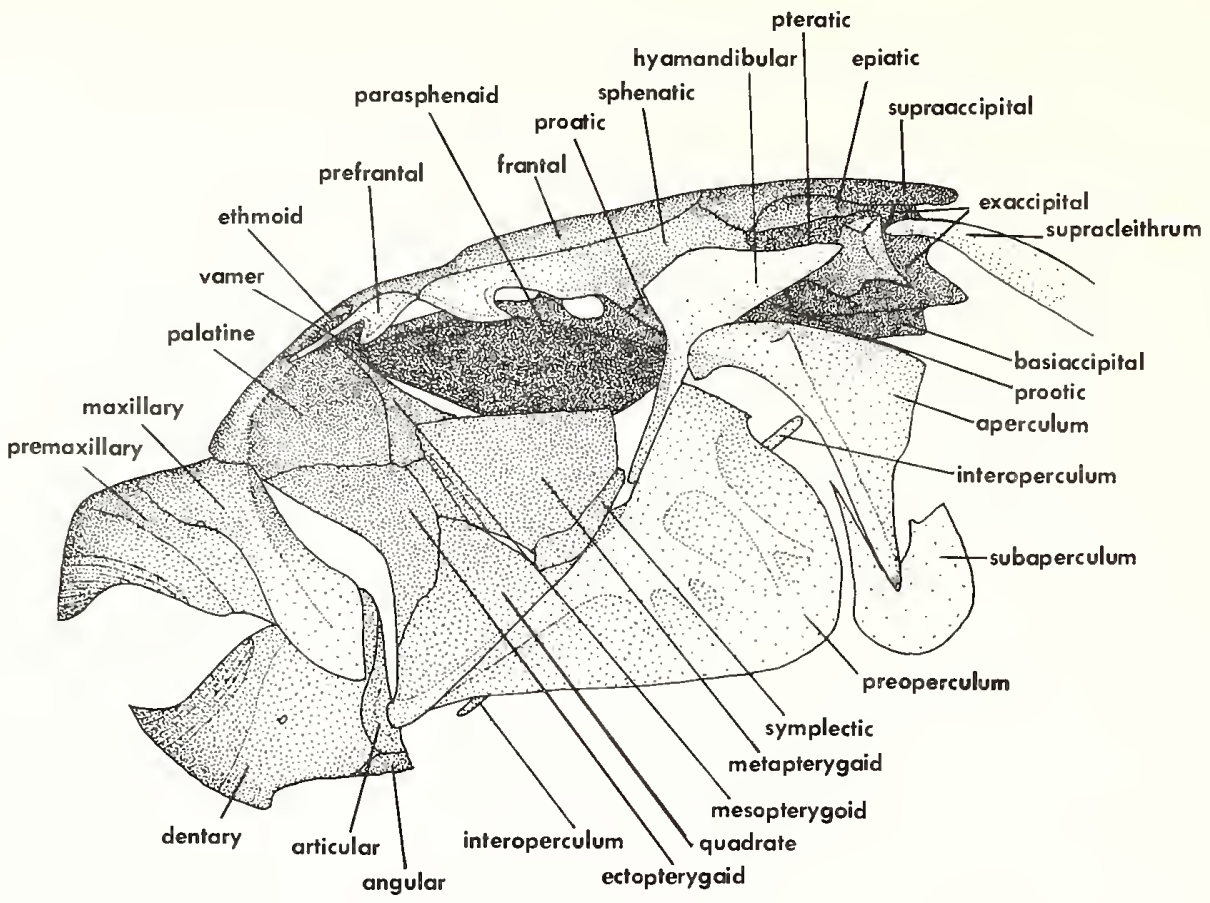

Figure 246. - Colomesus psittacus: lateral view of head, $178 \mathrm{~mm}$ SL, Surinam.

Figure 247.-Amblyrhynchotes richei: lateral view of head, $59.4 \mathrm{~mm}$ SL, New Zealand.

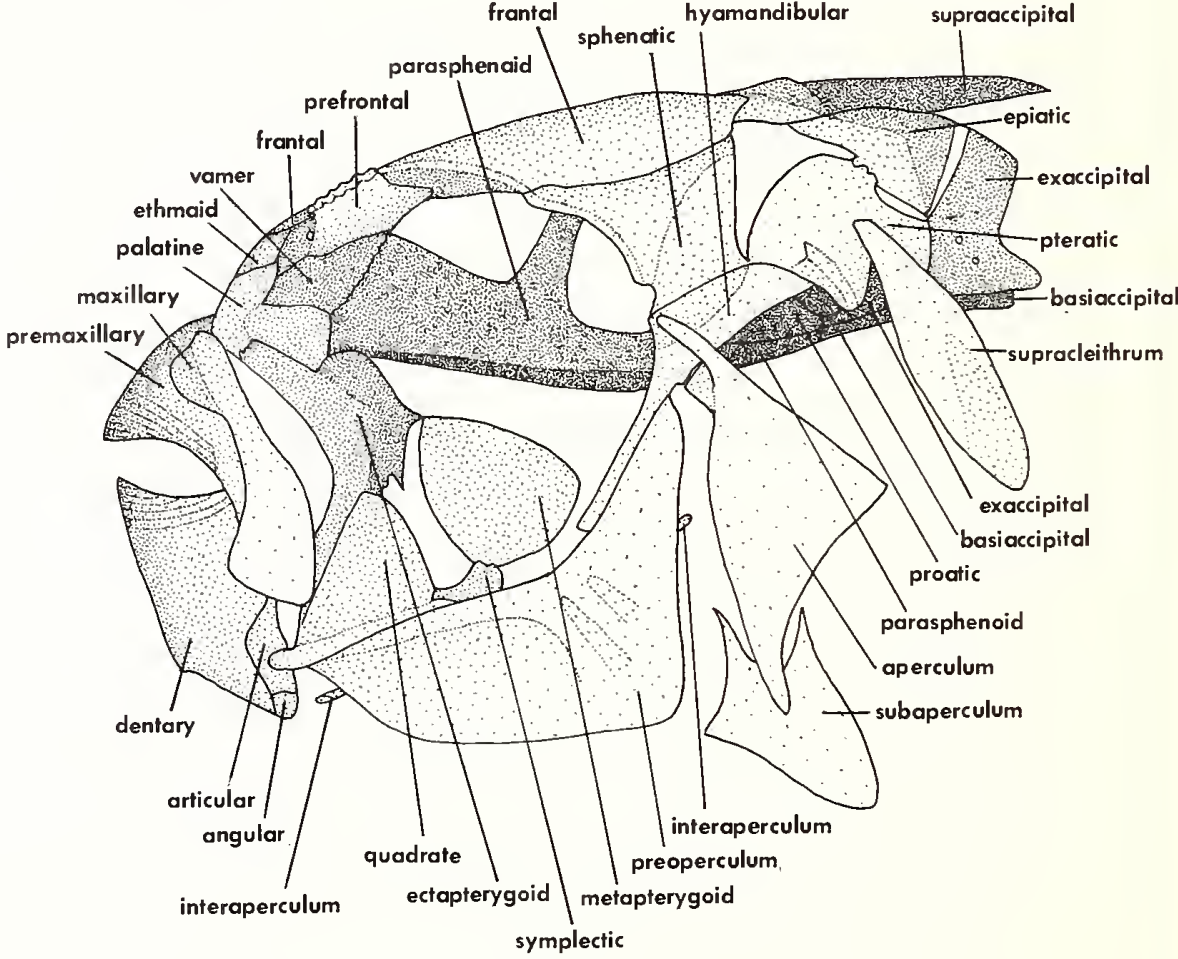

less, this adds a confirmatory note to the hypothesized ancestry of Canthigaster as being from among a group of Carinotetraodon-like fishes.

In contrast to the origin and anatomical specializations of the Canthigasterinae discussed above, the diversity of the Tetraodontinae is far greater and more complex. Before a consideration of the anatomical diversity between genera can be undertaken, it is first necessary to determine the diversity to be expected within genera, especially those with relatively large numbers of species. With this in mind, as many species of the systematically relatively well known and speciose genera Sphoeroides and Lagocephalus have been examined as possible (11 of Sphoeroides and 6 of Lagocephalus, the recognition of the Atlantic species of the former being greatly aided by the recent works of Shipp, see literature cited). Sphoeroides occurs in the eastern Pacific and Atlantic (mostly in the western Atlantic), 


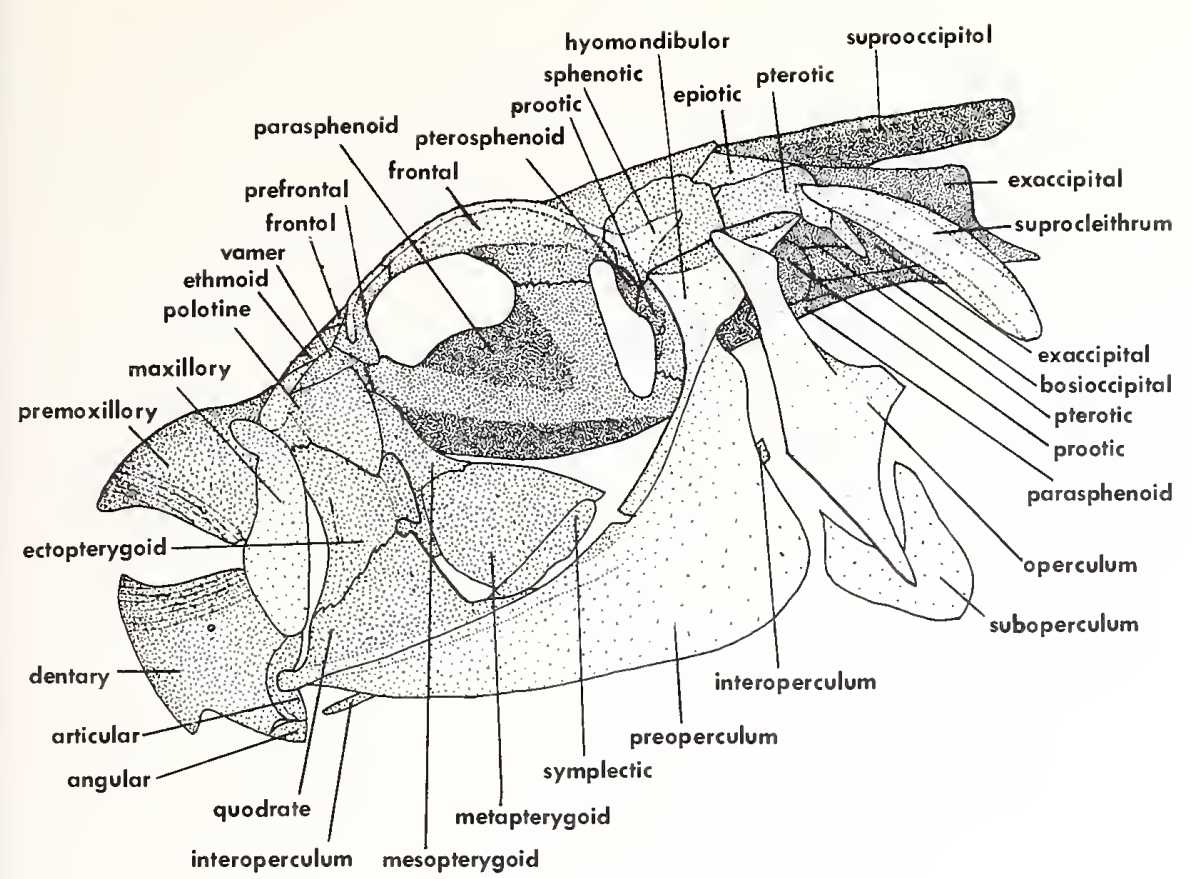

Figure 248.-Fugu chrysops: lateral view of head, $98.6 \mathrm{~mm} \mathrm{SL}$, India.

Figure 249.-Fugu oblongus: lateral view of head, $46.2 \mathrm{~mm} \mathrm{SL}$, India.

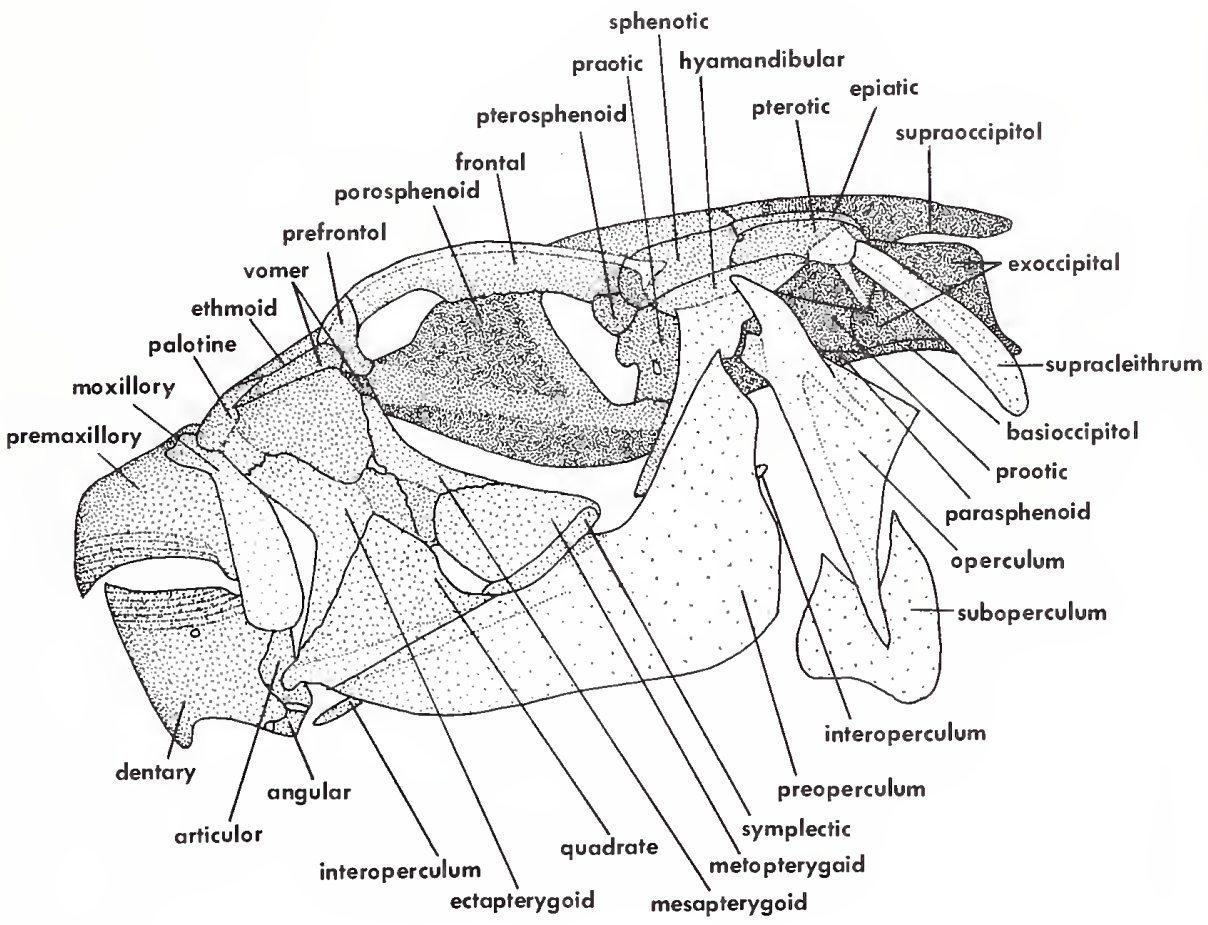

and while they are primarily shallow-water coastal forms, one deepwater species (pachygaster) occurs on both sides of the Atlantic as well as in the Indo-Pacific. Lagocephalus is world wide in distribution and tends to be found further offshore than Sphoeroides, with at least one of its species (lagocephalus) relatively oceanic and circumtropical in distribution.

The basic structure of the vertebral column does not vary greatly among the species of Sphoeroides, there always being eight abdominal vertebrae modally, with most species (angusticeps, dorsalis, greeleyi, trichocephalus, lobatus, sechurae, spengleri) having a total of 17 vertebrae, with others (annulatus, nephelus, pachy- gaster, testudineus) a total of 18 , one (maculatus) a total of 19, and another (marmoratus) a total of 20 (all figures modal). Lowered numbers of vertebrae can be considered a specialization.

In contrast to the vertebral column, the range in skull structure in Sphoeroides is so diverse that if only the two species at the extremes of the osteological range were studied one would receive the definite impression that they were not at all closely related and could not be contained in the same genus.

To contrast the two extremes, $S$. dorsalis has: 1) a narrow skull and long slender snout region; 2) the palatines are not widely divergent and the jaws are rela- 


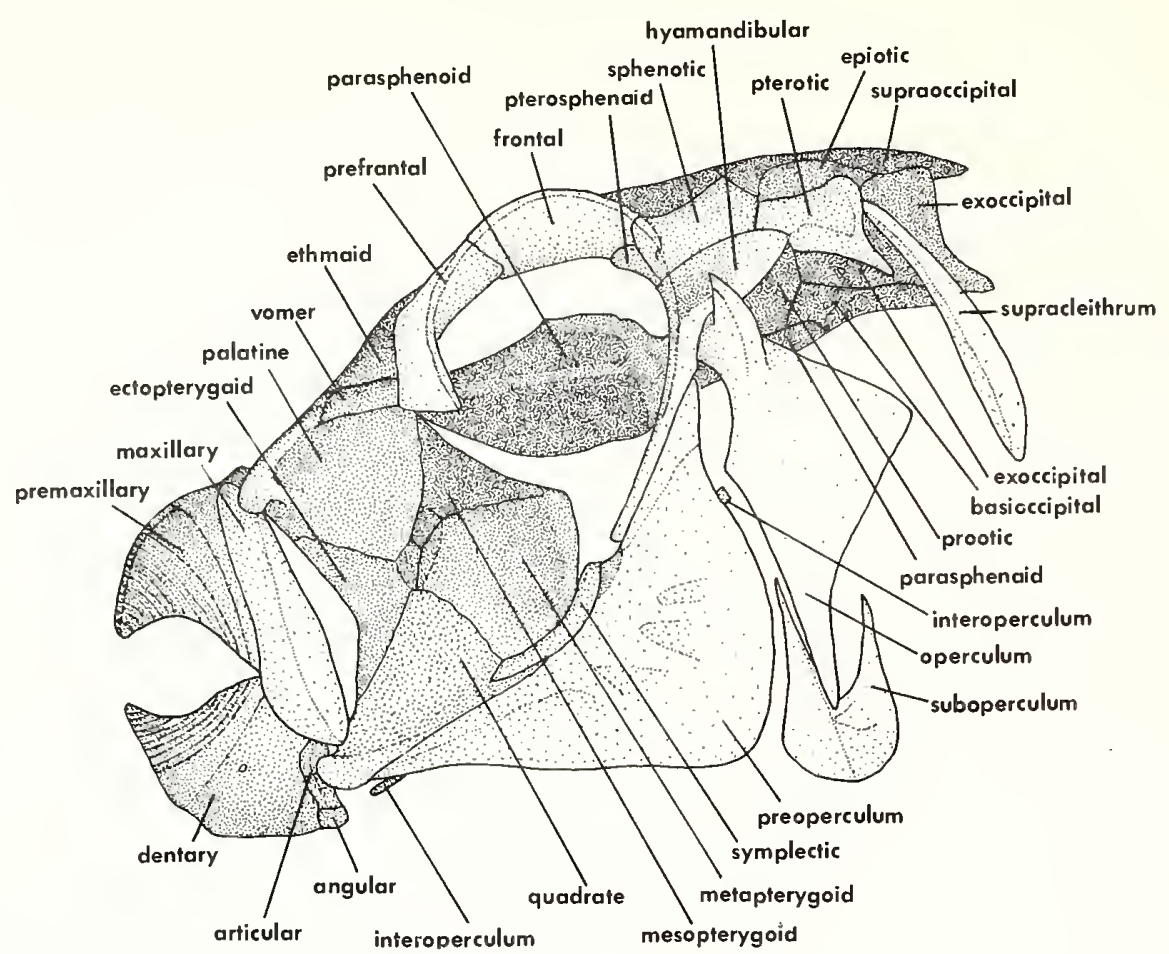

Figure 250.-Arothron stellatus: lateral view of head, $292 \mathrm{~mm} \mathrm{SL}$, India.

Figure 251.-Tetraodon mbu: lateral view of head, $47.7 \mathrm{~mm} \mathrm{SL}$, Congo.

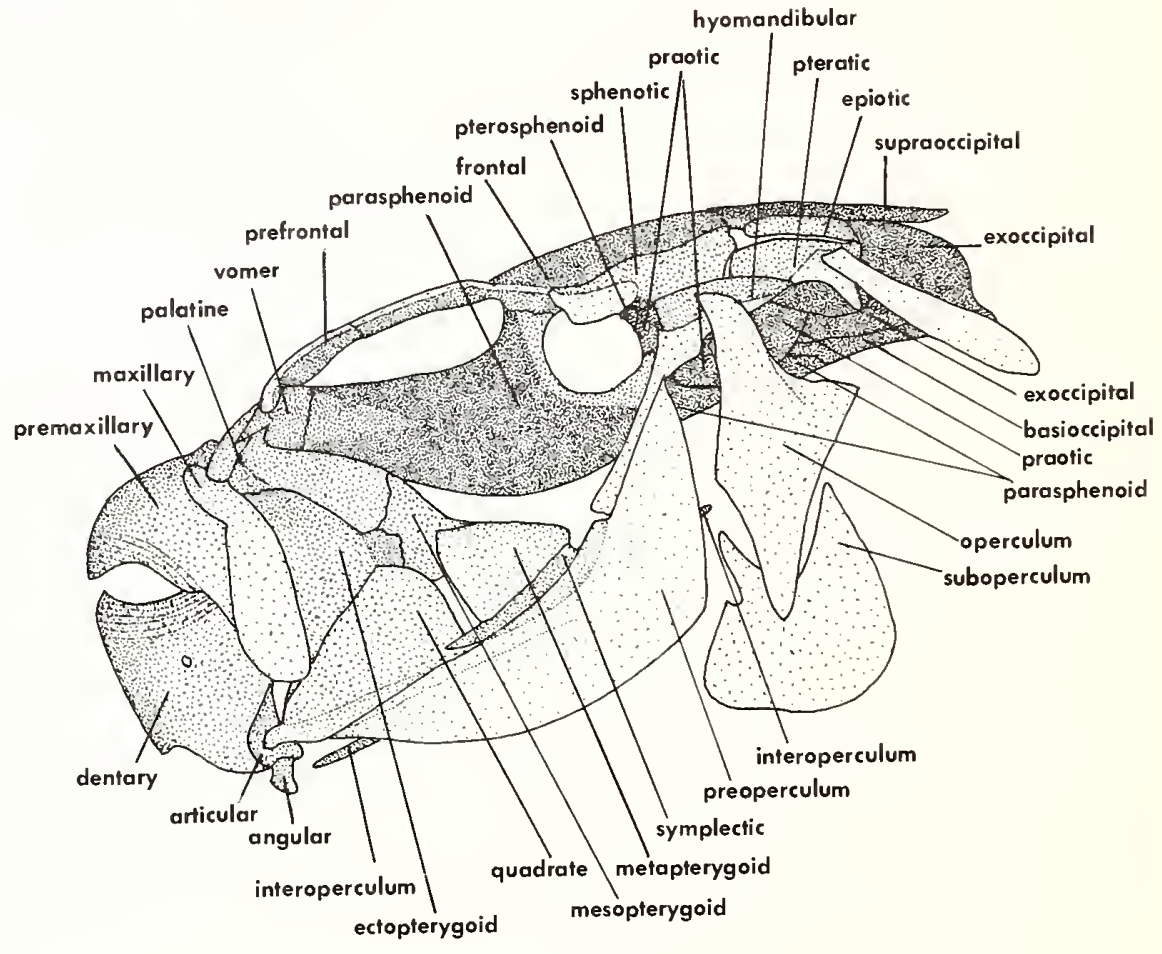

tively narrow; 3) the ethmoid and vomer are extremely elongate; 4) the prefrontals are placed in about the middle of the skull; 5) the sphenotics form only the rear margin of the orbit; and 6) the frontals are wide posteriorly over the skull but very narrow interorbitally and of constantly decreasing width anteriorly. By comparison, S. annulatus has: 1) a broad skull and short wide snout region; 2) the palatines are widely divergent and the jaws are relatively wide; 3 ) the ethmoid is of moderate length and the dorsal surface of the vomer is exceptionally short; 4) the prefrontals are placed anteriorly well in front of the middle of the skull; 5) the sphenotics are prolonged anterodorsally to form not only the rear but also part of the dorsal margin of the orbit; 6 ) the frontals are laterally expanded anteriorly to the extent that they are wider anteriorly than posteriorly. 


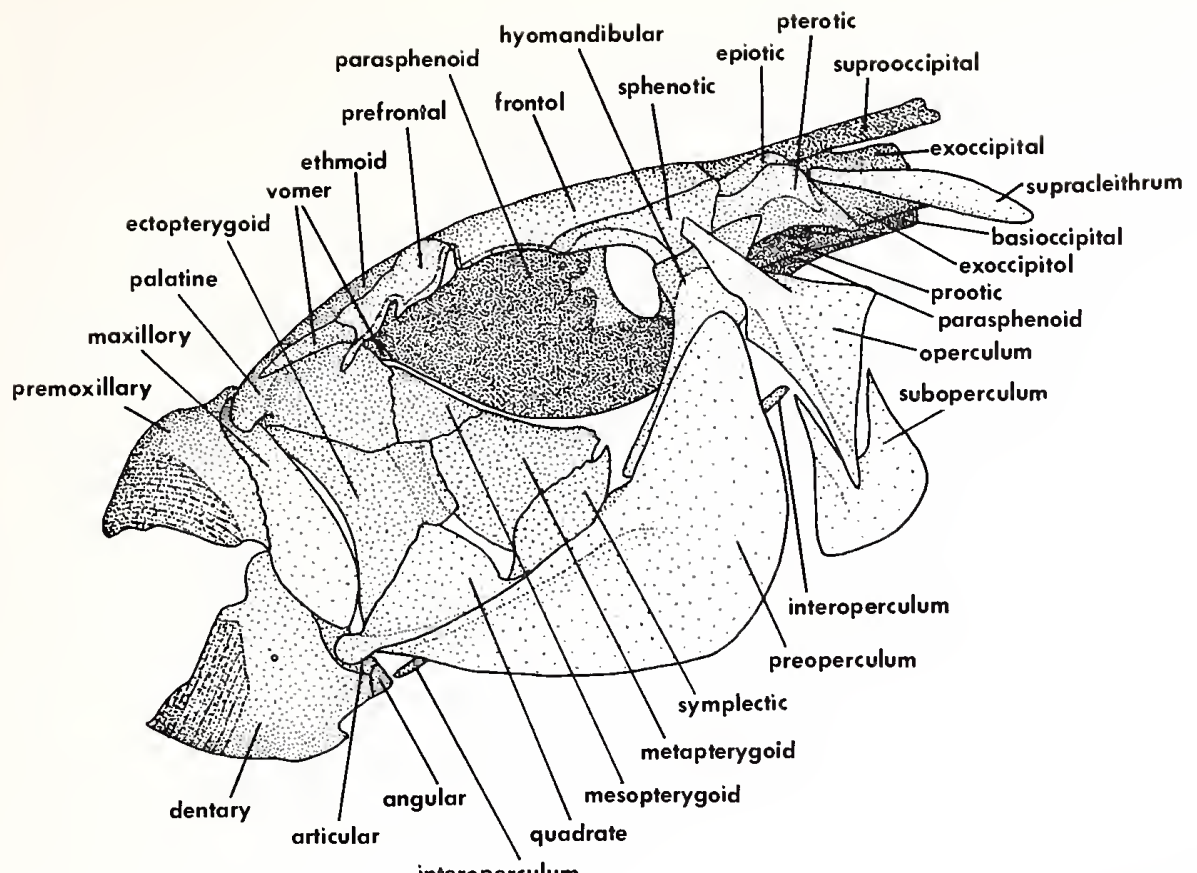

Figure 252.-Chelonodon

fluviatilis: lateral view of head, $84.7 \mathrm{~mm}$ SL, Thailand.

Figure 253.- Monotreta

leiurus: lateral view of head, $61.5 \mathrm{~mm}$ SL, Thailand.

interoperculum

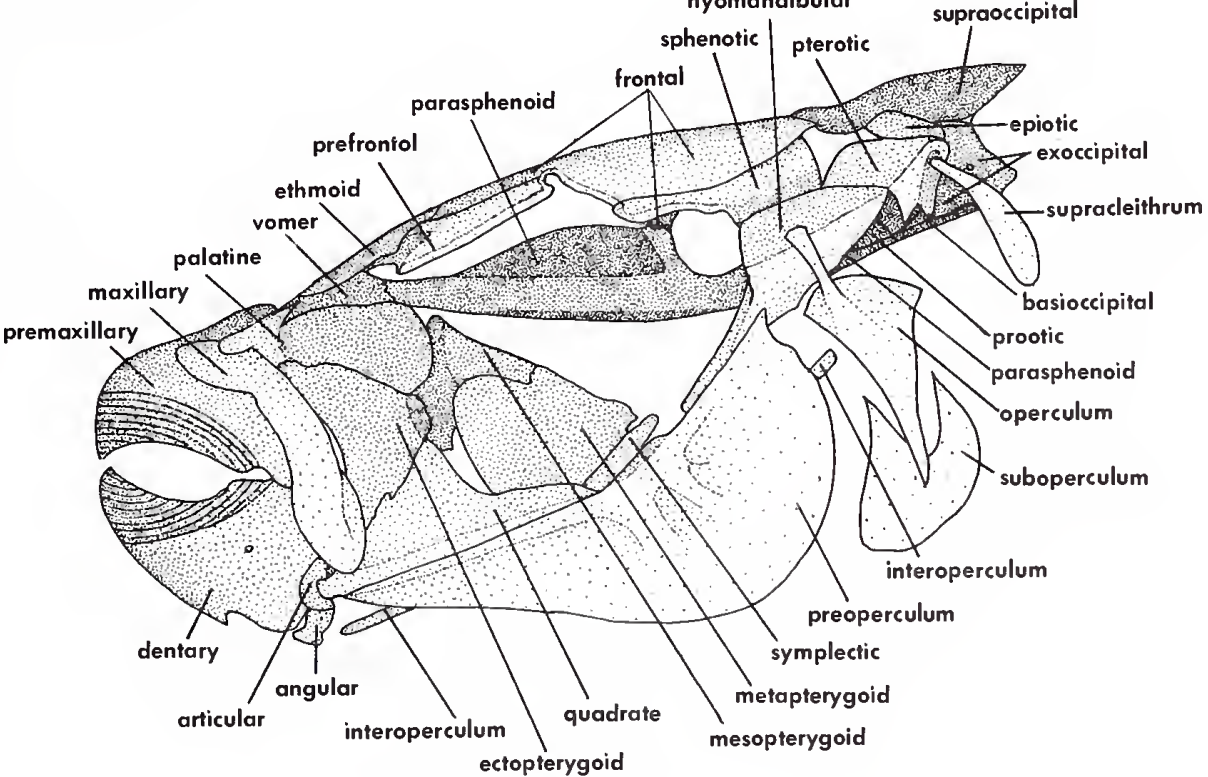

Between these two extremes of dorsalis and annulatus, however, are other species of Sphoeroides which form an almost continuous series of intermediate conditions. Thus, S. lobatus, angusticeps, and nephelus have only slightly wider skulls and slightly less elongate snout regions than $S$. dorsalis and otherwise are similar to it, while a number of other species (S. spengleri, maculatus, and greeleyi) have progressively wider skulls and less elongate snout regions, leading to species such as $S$. trichocephalus and pachygaster with wider frontals, progressively less slender or tapering anteriorly, and eventually to $S$. testudineus in which the frontals are only slightly tapered anteriorly above the orbit, not being greatly narrower there than posteriorly, and only tapering to a point far anteriorly and abruptly at the rear edge of the prefrontals. The above series of progressively wider skulls does not necessarily indicate precisely similar specific relationships.

Among the species of Sphoeroides the condition of the skull in testudineus is that which most closely approaches that of annulatus. In fact, these two species are usually considered to be closely related geminates to each side of the Central American isthmus (annulatus in the eastern Pacific and testudineus in the Gulf of Mexico and the Caribbean) which have retained relatively similar color patterns of pale circles and reticulations unique in the genus.

One would suspect that the extremes of dorsalis and annulatus both represent specializations, and that a generalized skull structure in tetraodontids would 


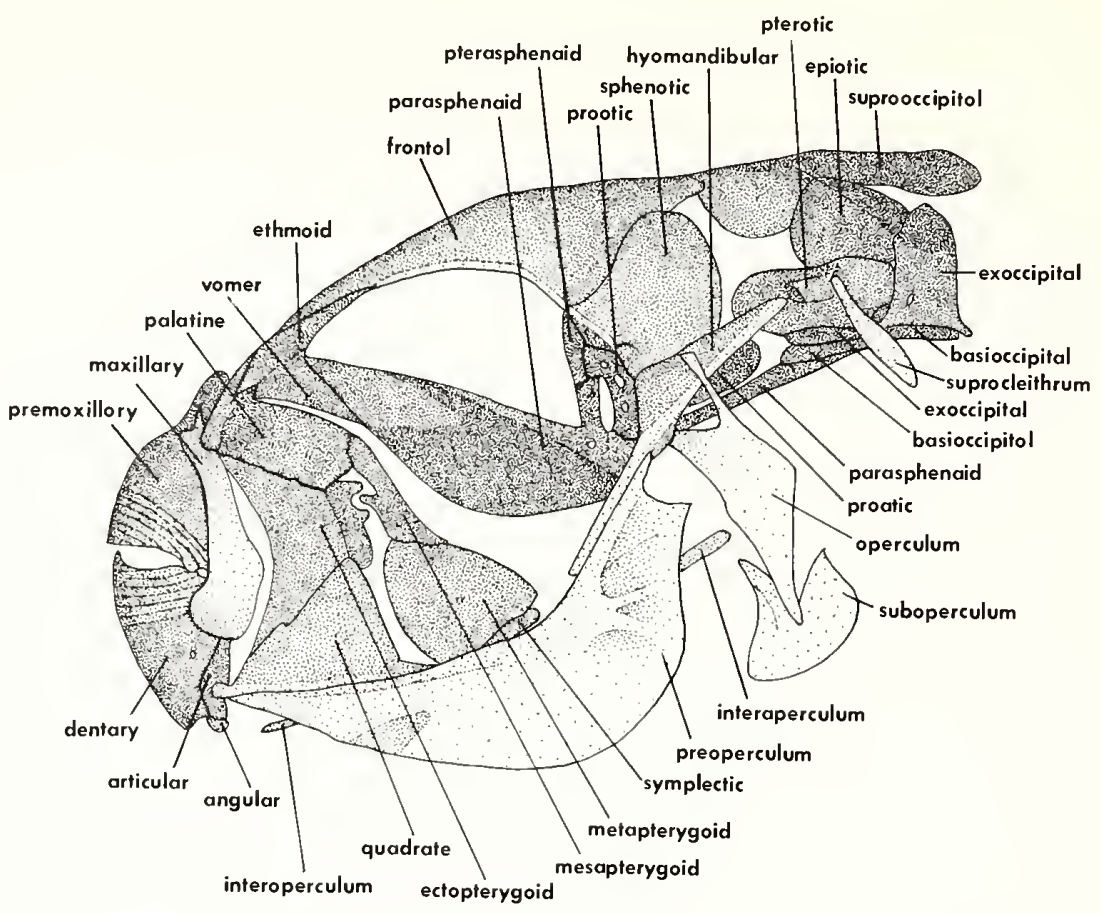

Figure 254.-Chonerhinos modestus: lateral view of head, $31.0 \mathrm{~mm}$ SL, Borneo.

Figure 255.-Xenopterus naritus: lateral view of head, $143 \mathrm{~mm}$ SL, Bay of Bengal.

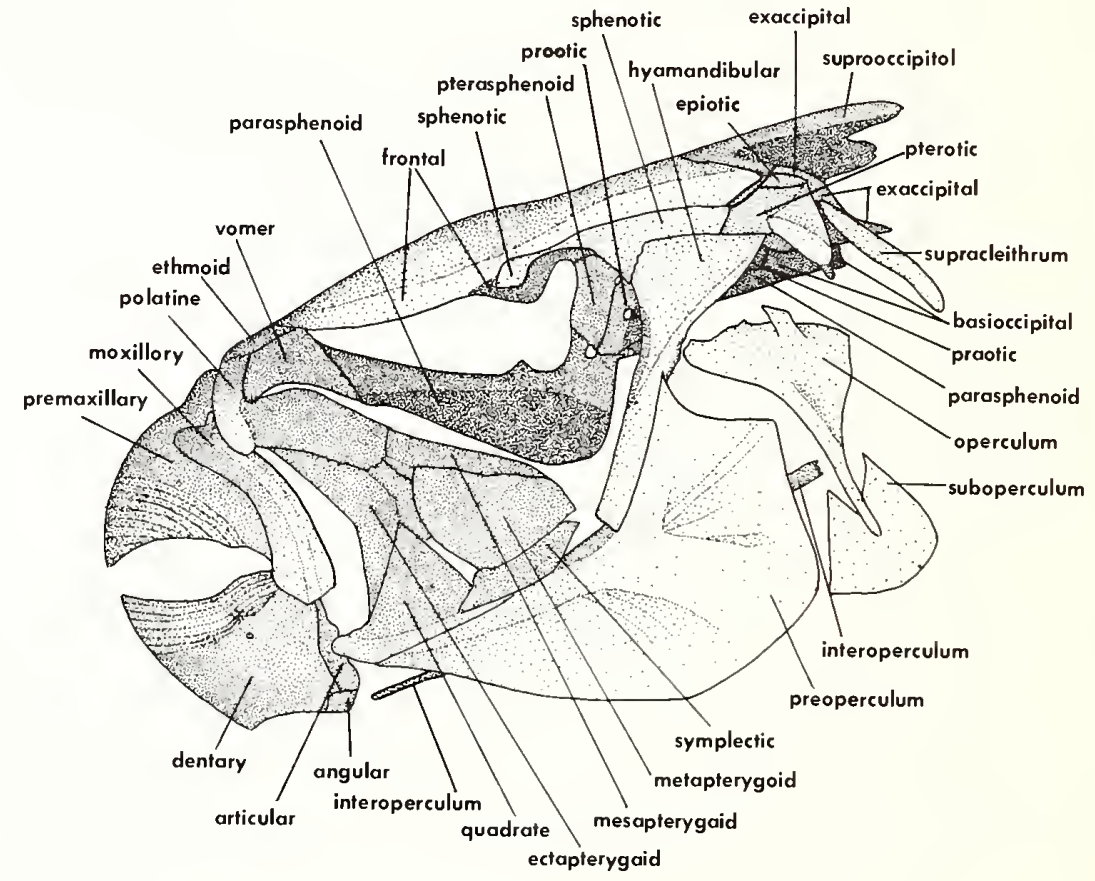

feature a moderate skull width and snout region length, with the frontals wide posteriorly but gradually and evenly narrowed anteriorly, and the sphenotics not prolonged anterodorsally to form more than the rear margin of the orbit, these being conditions as found in the ancestral triodontids. In this view, species such as $S$. maculatus, trichocephalus, and pachygaster have relatively generalized skulls in which the frontals are of moderate width and taper gradually anteriorly, while, going in one direction, greeleyi is perhaps very slightly specialized in at least this one respect by the slightly abrupt narrowing of the frontals at the level of the prefrontals, while testudineus is more specialized by the lesser anterior tapering of the frontals and the more abrupt narrowing at the level of the prefrontals. The testudineus-like condition could be ancestral to that of annulatus through an increased expansion of the anterior region of the frontals and an anterodorsal expansion of the sphenotics.

The monotypic Guentheridia in the eastern Pacific 


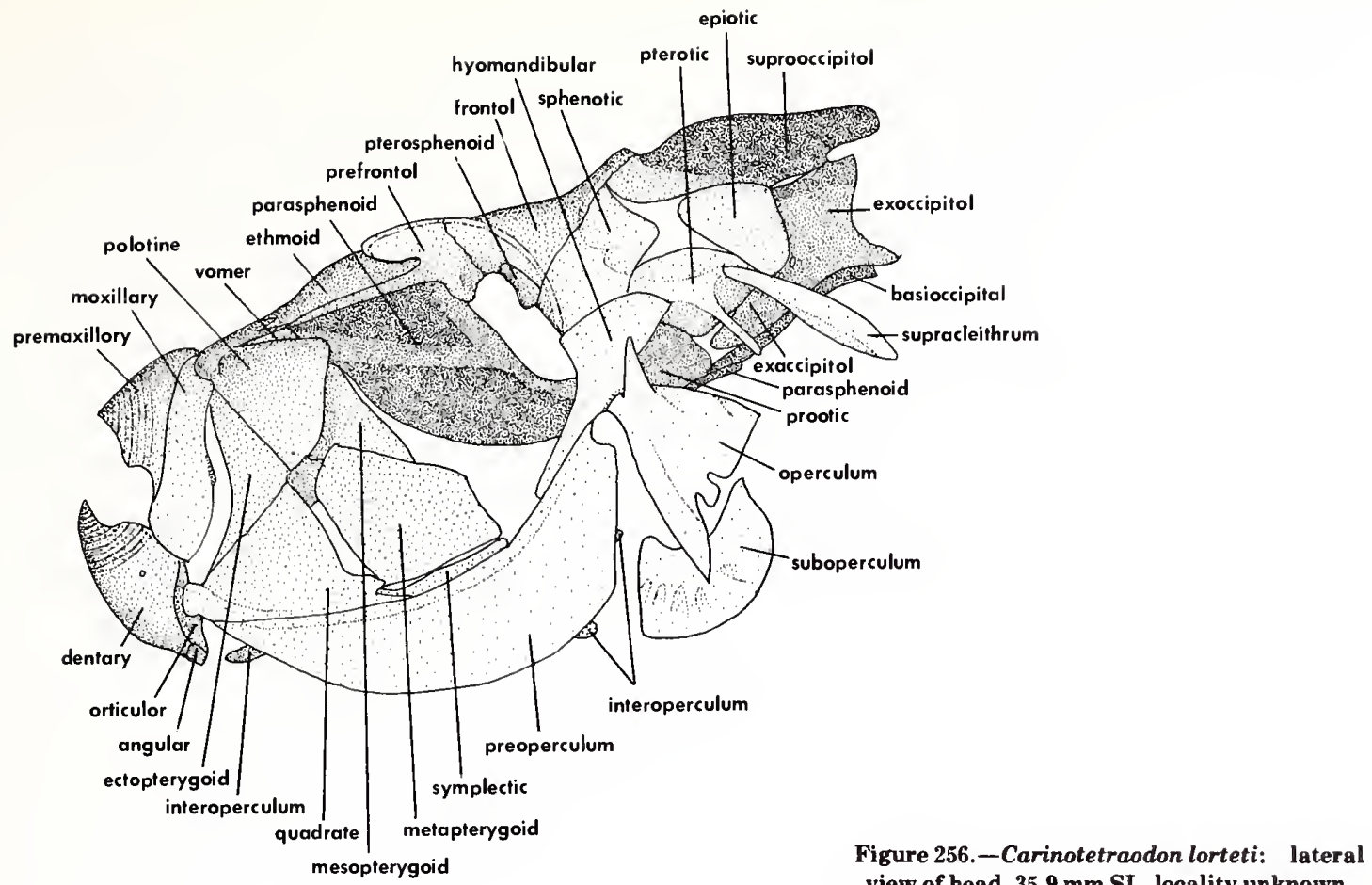

Figure 256.-Carinotetraodon lorteti: lateral view of head, $35.9 \mathrm{~mm} \mathrm{SL}$, locality unknown.

differs externally from Sphoeroides only in having the internal epithelium of the nasal sac deeply pitted rather than smooth or with ridges, and the gill rakers anteriorly on the fourth arch less well developed. The single species, formosa, is often placed in Sphoeroides (as by Fraser-Brunner 1943). The skull structure of formosa is remarkably similar to that of annulatus, being an even more specialized version of it, with the frontals more laterally expanded anteriorly and the sphenotics even more anterodorsally expanded to form at least half of the dorsal margin of the orbit. Only in annulatus among the species of Sphoeroides does the parasphenoid have a dorsal flange in the interorbital septum which meets the frontal, and formosa also has a similar flange. The color pattern of formosa can be considered a variation on that of annulatus, with more numerous light reticulations and circles and larger dark spots. It is obvious that annulatus is a specialized derivative of a testudineus-like stock, and that formosa is a specialized derivative of an annulatus. like stock. Thus, formosa should be included in Sphoeroides as the most extreme example of frontal widening and sphenotic anterior prolongation, for the pitted epithelium of its nasal sac and smaller gill rakers on the fourth arch certainly are not sufficiently distinctive features to warrant even subgeneric recognition of formosa within Sphoeroides.

Two of the examined species of Sphoeroides in which the skull is only slightly less wide and the snout region only slightly less elongate than in the extreme condition of dorsalis share with dorsalis one external peculiarity not otherwise found among the tetraodontids. In the western Atlantic $S$. dorsalis and in the eastern Pacific $S$. lobatus and angusticeps there are a pair of dark dermal flaps which are relatively constant in position on the dor- sum (sometimes absent as an intraspecific variation), while Shipp (1974:59) reported that this pair of flaps is also present in the eastern Atlantic $S$. marmoratus, not studied here. These three species (four including marmoratus) undoubtedly share a close common ancestry, with the ancestral species becoming divided into two isolated populations with the emergence of the Central American isthmus. The Atlantic population evolved into the highly specialized (in narrowness of skull) dorsalis (and probably marmoratus), while the eastern Pacific population diverged into lobatus and angusticeps with a slightly lesser narrowing of the skull, differing from one another mainly in angusticeps having a plainer coloration and having lost all the spines.

Sphoeroides nephelus, which also has a relatively narrow skull, is probably also related to the line which gave rise to dorsalis, lobatus, and angusticeps, while its closest relative is maculatus (see Shipp and Yerger 1969a, b, who show that parvus, not studied here, nephelus, and maculatus constitute a closely related species complex). On the basis of its skull structure, spengleri, with a moderate skull width, is not far removed from that complex, while pachygaster, with a somewhat wider skull, may be derived from a spenglerilike form.

The deepwater S. pachygaster, with its thick, flabby spineless skin, seems externally to be one of the most distinctive and specialized species of Sphoeroides. However, internally pachygaster is only moderately specialized by a slightly more than moderate width of the skull, a slight anterodorsal prolongation of the sphenotics, a less firm ossification of the skull, and an unusually great amount of sculpturing on the dorsal surface of the skull, especially on the frontals, and by the loss of teeth on the first 
pharyngobranchial, pachygaster being the only species of Sphoeroides examined lacking at least minute teeth on this pharyngobranchial. The characteristics of the skull of pachygaster were first well described and illustrated by Kuronuma (1943). The possible relationships of $S$. pachygaster to Lagocephalus is discussed subsequently.

In addition to the anatomical diversity of Sphoeroides discussed above (number of vertebrae, skull shape, rare presence of a dorsal flange of the parasphenoid, rare loss of teeth on the first pharyngobranchial), a few other items can be mentioned. A dorsal and ventral hypohyal are present in most species, but only a single hypohyal is present in $S$. greeleyi and trichocephalus (and Guentheridia formosa). An interhyal is absent in most species, but it is present in greeleyi, maculatus, and pachygaster. All species have two or more (most numerous in annulatus, in a disorganized plate) trituration teeth to either side of the midline in the upper jaw, but most species do not have trituration teeth in the lower jaw, these being present only in $S$. angusticeps, annulatus, dorsalis, and greeleyi (and Guentheridia formosa) as three or more units, often tending to form a platelike structure (especially with increasing specimen size?) to either side of the midline. Remnants of the dorsal roof of the myodome are present in a few species. In $S$. dorsalis medial prongs of the prootics are well developed, almost as well as described and illustrated here for Lagocephalus laevigatus, while smaller prongs are present in $S$. angusticeps and greeleyi. In $S$. maculatus most specimens have only a very weak indication of a medial projection from the prootics, but some have moderately developed prongs about as large is in angusticeps and greeleyi.

The amount of variation in the structure of the dorsal surface of the skull that is correlated with specimen size can be judged from the illustration of four specimens of $S$. maculatus ranging from 12.4 to $201 \mathrm{~mm}$.

While the above gives an idea of the anatomical diversity to be expected within a speciose genus and at least a broad view of the species relationships with one another, a far more detailed analysis based on numerous external features of all of the Atlantic species is given by Shipp (1974), including several newly described species not studied here.

All of the six species of Lagocephalus have been examined to provide an additional survey of the anatomical diversity to be expected within a genus. The variation in skull structure in Lagocephalus is only slightly less than that found in the far more numerous species of Sphoeroides examined.

Three of the six species of Lagocephalus have relatively deep chunky bodies and drab coloration and seem to be closely related on the basis of external features alone, differing mainly in scale pattern on the dorsum: lunaris having scales from the snout to the dorsal fin, spadiceus from the rear of the snout to no more than half way back the distance between the head and dorsal fin, and iner$m$ is with spines totally absent. These three species have the olfactory epithelium folded over the entire inner surface of the sac, usually with two of the folds on the rear wall much larger than the others and themselves bearing additional smaller folds. Two other species are somewhat more elongate and conspicuously patterned and seem closely related, laevigatus with a pattern of crossbars on the dorsum and lagocephalus, slightly more elongate than laevigatus, with a dark dorsum, often with black spotting, and gradually paler ventrum. Both of these species lack spines on the back but have them well developed on the abdomen, and both tend to have only one of the folds on the rear wall of the nasal sac much larger than the others and itself bearing smaller folds.

The most distinctive species of Lagocephalus is scleratus, with an elongate and depressed body and distinctly depressed caudal peduncle, and a color pattern of a dark dorsum with pale and dark spots and reticulations
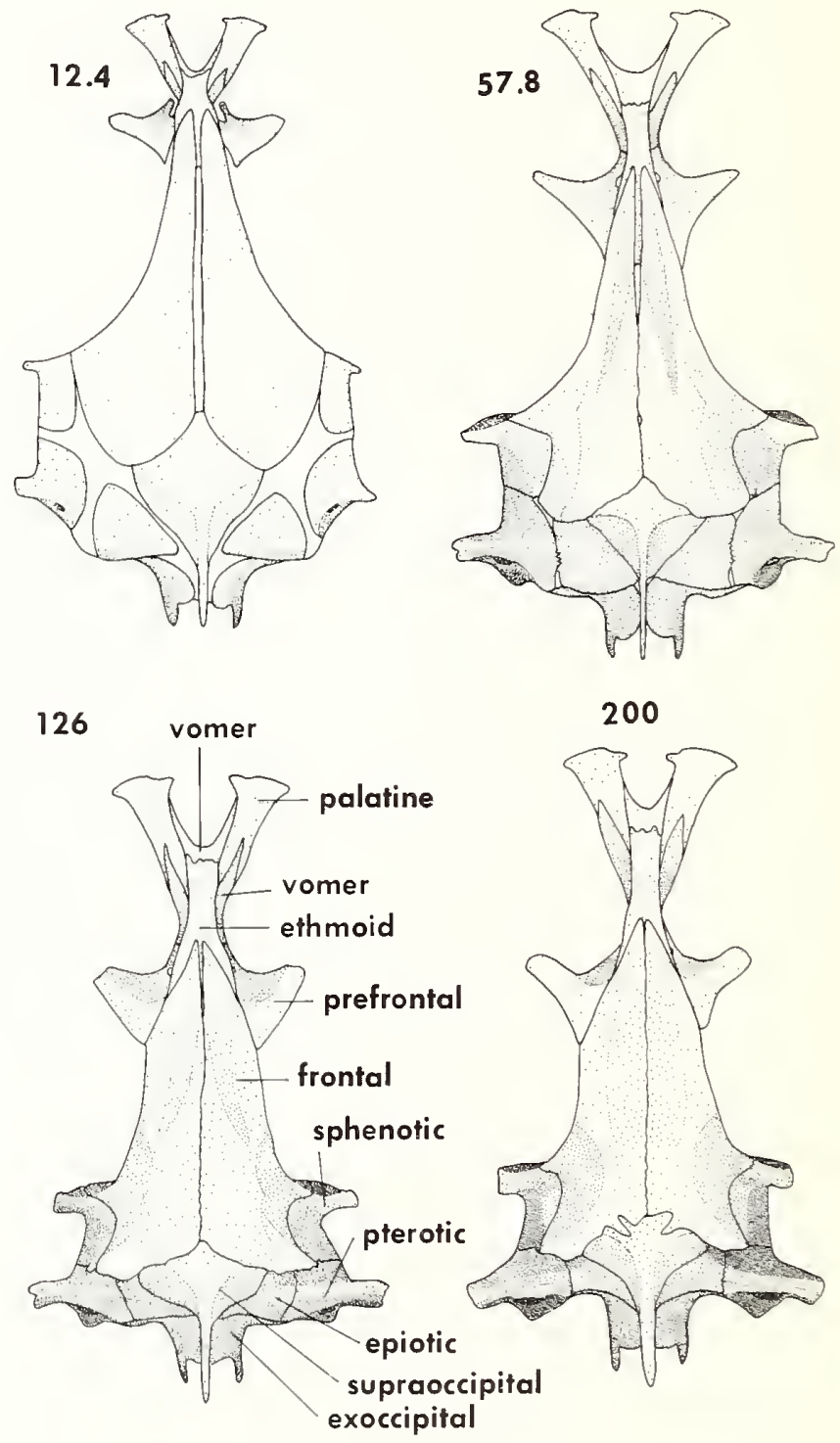

Figure 257.-Sphoeroides maculatus: dorsal views of skulls to show changes in shape, amounts of cartilage visible, and degree of suturing with increasing specimen sizes, as indicated, 12.4-201 mm SL, New Jersey and Virginia. 


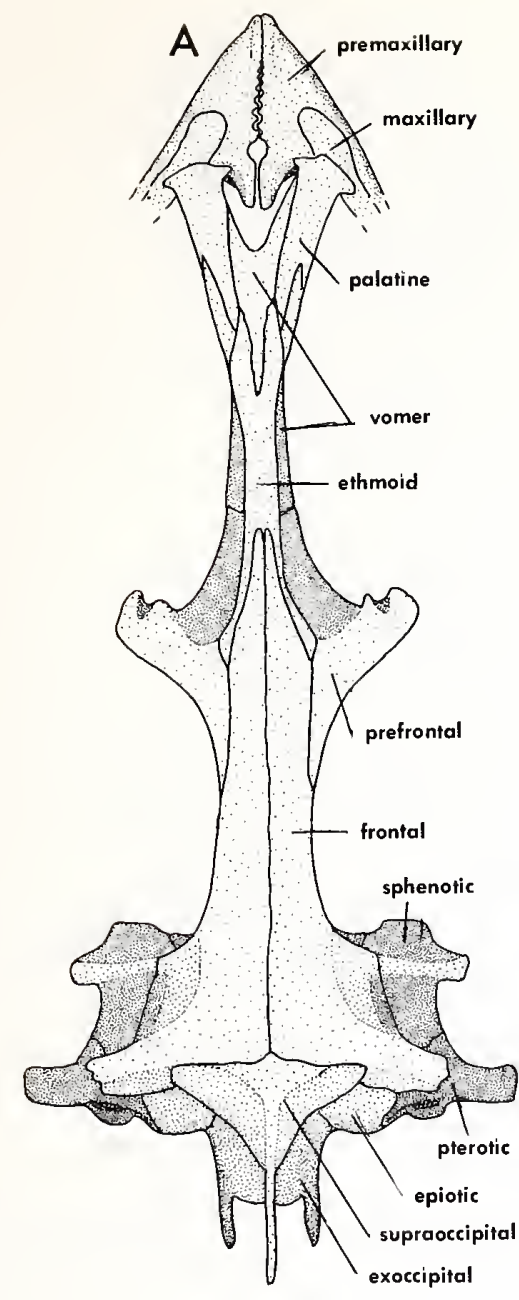

abruptly changing on the middle of the side of the body to plain pale below. It also has the olfactory epithelium less folded than in the other species, the folds confined to the rear wall of the sac and the enlarged folds not themselves bearing elaborate folds, and fewer dorsal and anal fin rays. In scleratus the dorsal rays are usually 10 to 12 and in the other species 13 to 15 , while the anal fin usually has one less ray than the dorsal in all of the species. While the depressed body and caudal peduncle are specializations in some way associated with its probably rapid swimming, and its color pattern unique in the genus, the less elaborate folding of the olfactory epithelium is probably a more generalized condition than in the other species. Since the majority of tetraodontids have relatively short-based fins with relatively few rays, as does Triodon, I would think that the moderate number of rays in scleratus is more generalized than the larger number in the other species.

There are more numerous internal differences between the species of Lagocephalus. A specialized dorsal flange of the parasphenoid in the interorbital septum that meets and sutures with the ventral surface of the frontals is present in laevigatus, lagocephalus, lunaris, and spadiceus but is absent in inermis and scleratus. In laevigatus and lagocephalus the pterosphenoid is in con-
Figure 258.-Dorsal views of skulls of:

A, Sphoeroides dorsalis, $155 \mathrm{~mm} \mathrm{SL}$, Florida;

B, S. nephelus, $128 \mathrm{~mm}$ SL, Bahamas;

C, S. lobatus, $67.5 \mathrm{~mm} \mathrm{SL}$, Panama (Pacific).

tact with the dorsal flange of the parasphenoid, but not in the other two species with a dorsal flange. A single hypohyal is present in all species except laevigatus, which retains the more generalized condition of both a dorsal and ventral hypohyal. The first pharyngobranchial is toothless in laevigatus, lagocephaliss, and spadiceus, but in lunaris it bears a few minute teeth (much smaller than those on the second and third pharyngobranchials) and in inermis and scleratus numerous minute teeth, the retention of numerous teeth being the most generalized condition.

A feature of the skull unique to Lagocephalus among the tetraodontids is the development of a posterolateral wing of the frontal which meets or closely approaches the posterodorsal surface of the pterotic to completely or partially roof over a temporal fossa. These specialized wings are best developed in lunaris, laevigatus, spadiceus, and lagocephalus (in respective increasing order of greatest size and length of the wing), in which their wings usually make direct contact with the pterotic to completely roof 


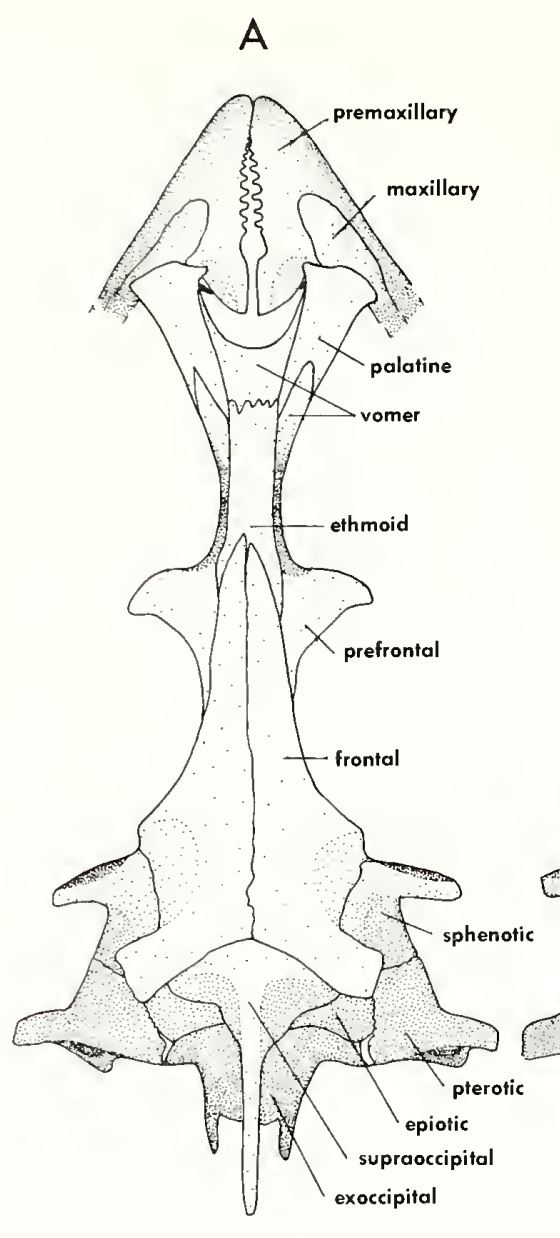

over the fossa, but the wings are relatively shorter in inermis and scleratus and do not meet the posterodorsal surface of the pterotic and thus only incompletely roof over the fossa. The lesser development of the wings in inermis and scleratus would seem to be the most generalized condition. The posterolateral region of the pterotic is directed more or less laterally in laevigatus, lunaris, scleratus, and spadiceus, but it is prolonged posterolaterally in inermis and, especially greatly so, in lagocephalus. The ventral flange along the middle of each side of the rear of the skull formed by the pterotic and exoccipital is much longer in lagocephalus than in the other species. A larger portion of this flange in Lagocephalus is formed by the exoccipital than in most, but not all, other tetraodontids (see, for example, illustration of Tetraodon lineatus).

The shape of the anterior portion of the frontals in Lagocephalus is probably of as much phylogenetic interest as is that of the posterolateral wing development. In scleratus the frontal tapers gradually and evenly toward the front and is of moderate width, this being similar to the condition in the more generalized species of Sphoeroides. In inermis the frontal is somewhat broader over the orbit than in scleratus and abruptly begins to taper to a point at the rear of the prefrontals. In lunaris the configuration is much the same as in inermis, except
Figure 259.-Dorsal views of skulls of:

A, Sphoeroides angusticeps, $172 \mathrm{~mm}$ SL, Galapagos;

B, S. spengleri, $92.8 \mathrm{~mm}$ SL, Nicaragua;

C, S. maculatus, $179 \mathrm{~mm}$ SL, Virginia.

that there is greater abruptness in the tapering, the length of the broad region of the frontal above the orbit is shorter, and the lateral edge of the prefrontal forms a proportionally greater amount of the edge of the orbit. In laevigatus, lagocephalus, and spadiceus the frontal is even wider over the orbit than in lunaris, and is similarly abruptly tapered, with the prefrontal forming a large part of the relatively straight edge of the orbit. Since a gradually tapered frontal of moderate width, as found in the ancestral triodontids, can be considered the generalized condition, the above series is one of increasing specialization. The most generalized species in this respect, scleratus, is also one of the two species with the most generalized condition of the posterolateral wing of the frontal, while the other species (inermis) with a generalized posterolateral wing has the next most generalized condition of anterior tapering.

The extreme posterolateral region of the dorsal surface of the pterotic in most species of Lagocephalus is upraised into a flange, with which the posterolateral wing of the frontal articulates in lunaris, spadiceus, and laevigatus, 

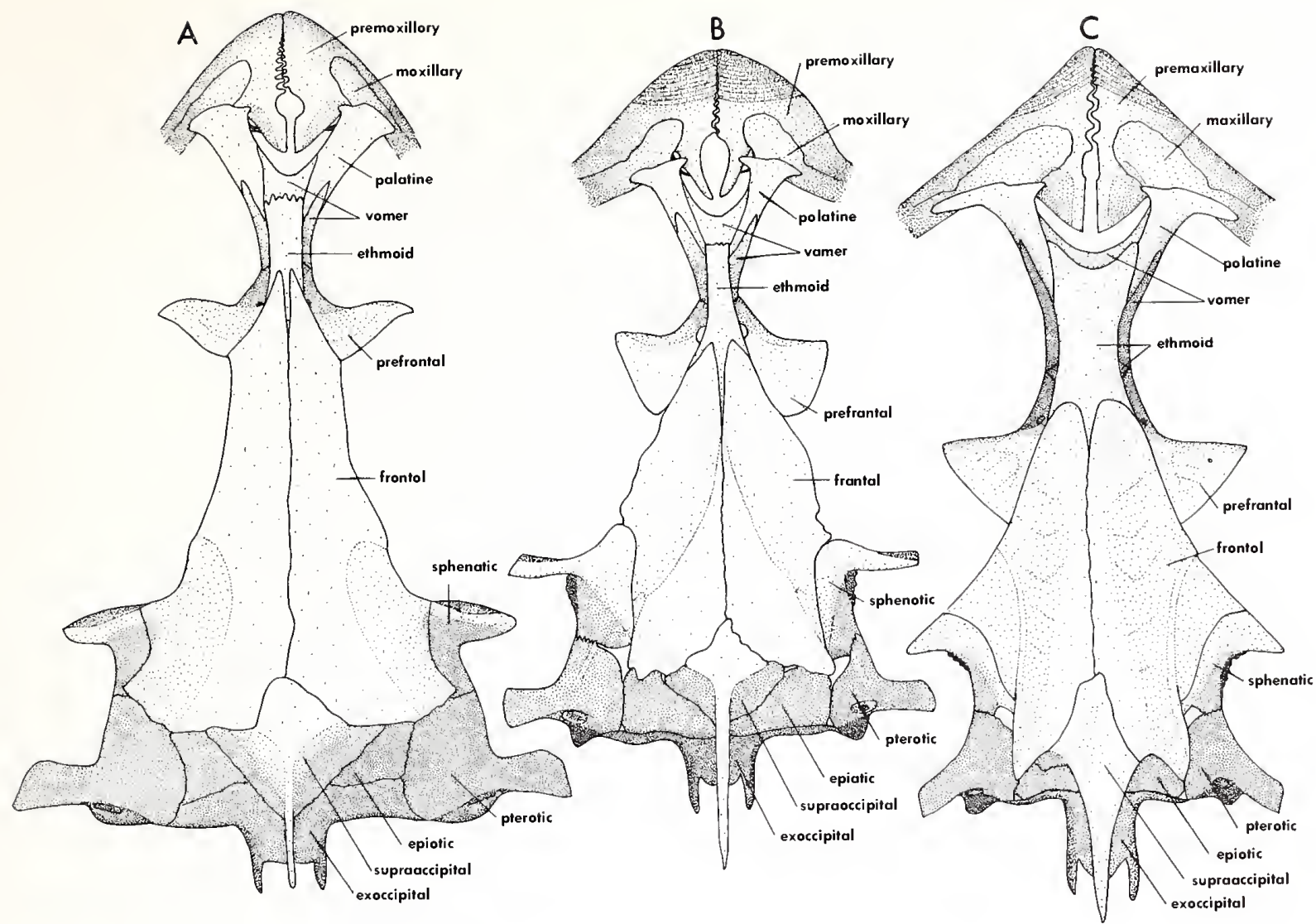

or is directed toward in scleratus and inermis. No such flange is present in lagocephalus, but the area of contact between the especially long posterolateral prolongations of both the frontal and pterotic is much greater than in the other species.

The ethmoid in Lagocephalus is relatively long in all six species, but its width varies from moderate in scleratus and lunaris to wide (the other four species). Anteriorly the ethmoid always broadly sutures with the dorsal surface of the vomer, and, as explained for laevigatus in the detailed osteological description, this articulation sometimes becomes fully fused in large specimens. In laevigatus the ethmoid and the haemal spines of the sixth and seventh, and, to a lesser extent, of the eighth, caudal vertebrae become swollen or hyperostotic in large adults. The only other species studied here as a large adult specimen, a $214 \mathrm{~mm}$ lagocephalus, does not show any hyperostosis, but the specimens of inermis, lunaris, scleratus, and spadiceus studied are all too small to have hyperostotic parts even if that should be the norm for large adults.

The supraneural element is relatively long in most species of Lagocephalus, while it is extremely long in lagocephalus and only moderately iong in inermis. Medial prongs from the prootic in the rear of the orbit, representing the remains of the dorsal roof of the myodome, are well developed in scleratus and laevigatus, reaching aimost to the midline, and are moderately developed in lunaris and spadiceus, while

Figure 260.-Dorsal views of skulls of:

A, Sphoeroides greeleyi, $60.8 \mathrm{~mm} \mathrm{SL}$, locality unknown; B, S. trichocephalus, 57.1 mm SL, Panama (Pacific); C, S. pachygaster, $117 \mathrm{~mm}$ SL, Mozambique.

they are absent in inermis and lagocephalus. The amount of surface sculpturing (not fully shown in the illustrations) of the top of the skull varies from slight in scleratus to moderate or well developed in the other species. This, however, may be subject to intraspecific variation or change with increasing specimen size, for Kuronuma (1943) reported that lunaris and spadiceus, in contrast to inermis, had little surface sculpturing, mostly confined to the ethmoid.

The modal number of vertebrae in Lagocephalus is 17 (lunaris, scleratus, spadiceus), 18 (inermis, lagocephalus), and 19 (laevigatus), with the lower numbers more specialized. Neural prezygapophyses, especially on the caudal and more posterior abdominal vertebrae, are extremely well developed as anterolaterally directed prongs in lagocephalus and scleratus, the two most streamlined and probably rapid swimming species, but are only moderately developed in the other four species. Likewise associated with muscle attachment are keels or ridges along the dorsolateral region of the neural arches (and, to a lesser extent, along the ventrolateral region of the haemal arches of the caudal vertebrae). These keels are well developed in lagocephalus and scleratus, moderately developed in laevigatus and spadiceus, and 


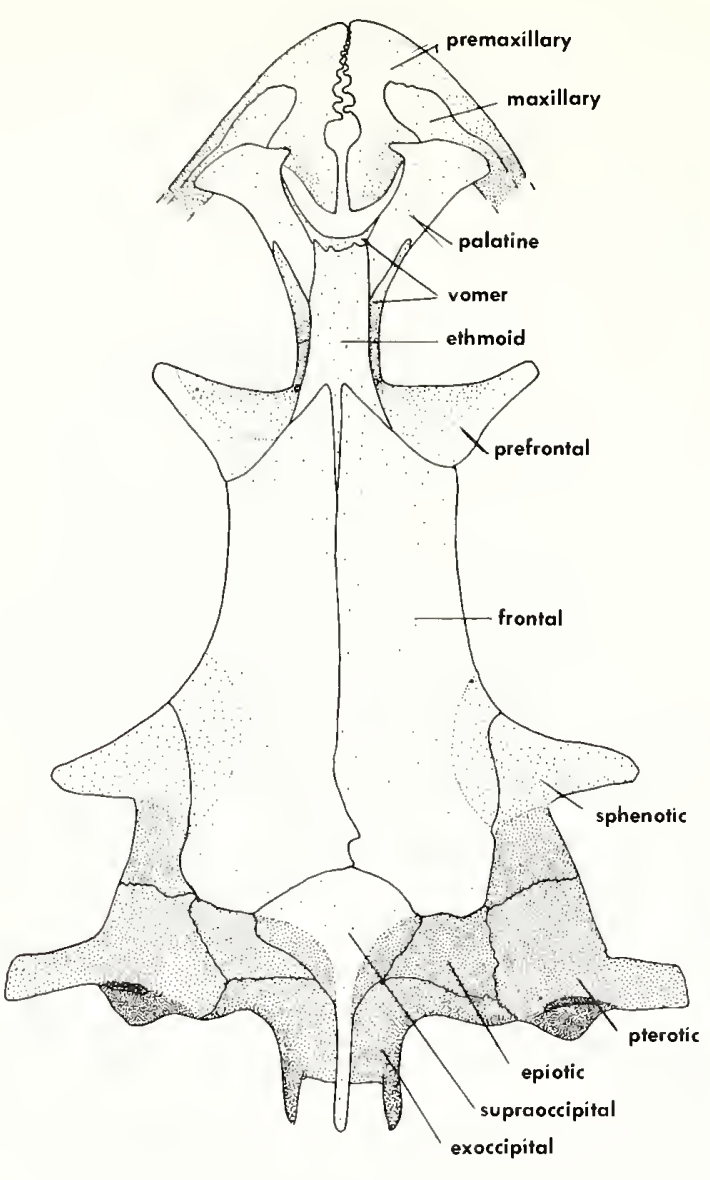

scarcely developed at all in inermis and lunaris. The neural and haemal spines of the last few caudal vertebrae are shorter in scleratus than in the other species, associated with the depressed caudal peduncle.

A feature unique to Lagocephalus among the tetraodontids is the posterior prolongation of the distal ends of the last basal pterygiophores of the dorsal and anal fins as prongs above and below the neural and haemal spines of the vertebrae just behind the bases of these fins. The prongs are moderately developed in inermis and lagocephalus, slightly longer in laevigatus and lunaris, and of greatest length in spadiceus (dorsal basal pterygiophore only, the anal basal pterygiophore having a prong of only moderate length) and in scleratus.

All of the species of Lagocephalus have two or three rounded trituration teeth in a single series to each side of the midline of the upper jaw but none in the lower jaw, and all possess an interhyal, while none of the abdominal vertebrae possess complete haemal arches. The first ray in both the dorsal and anal fins of Lagocephalus is exceptionally short (slightly longer in young than adults) and sometimes lacks cross-striations, and it is shorter than the first ray of any of the other tetraodontids examined. In all of the species of Lagocephalus the form of the epural is characteristic. In other tetraodontids the epural varies from a more or less square block of bone to an elongate rod, but the orientation of the bone is more or less vertical or obliquely anteroventral to posterodorsal,

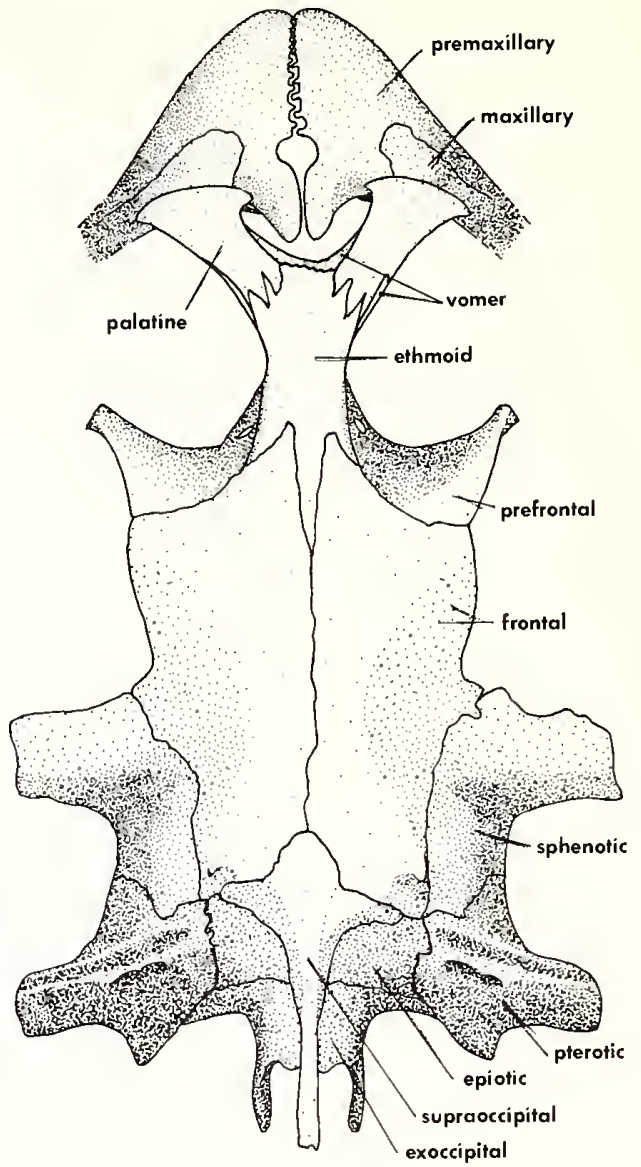

Figure 261.-Dorsal views of skulls of: left, Sphoeroides testudineus, $68.5 \mathrm{~mm} \mathrm{SL}$, Venezuela; right, $S$. annulatus, $174 \mathrm{~mm}$ SL, locality unknown.

while in Lagocephalus the epural is dorsoventrally flattened and prolonged anteroposteriorly, in which direction it is oriented, an apparently specialized condition unlike that of any other gymnodont. The presence of two lateral lines on the body in Lagocephalus can also be considered a specialization, since only a single lateral line is present in triodontids and the basal triacanthodids.

Fraser-Brunner (1943) believed that Lagocephalus is the most primitive tetraodontid and that Canthigaster was derived from it, but he gave no reasons for so thinking. As discussed earlier, Canthigaster probably evolved from a Carinotetraodon-like line. I find no particular similarities between Canthigaster and Lagocephalus. Fraser-Brunner thought that the skull of molids was "almost exactly similar to that of Lagocephalus, even possessing the postero-lateral limbs of the frontals characteristic of that genus." In fact, the frontals of molids do not have prominent posterolateral wings and to my eyes the skulls of molids show no particular similarities to those of Lagocephalus, but, rather, as discussed under the Molidae, they do show similarities to that of Triodon. One of the few similarities that at least a few species of Lagocephalus have to Triodon not found in 


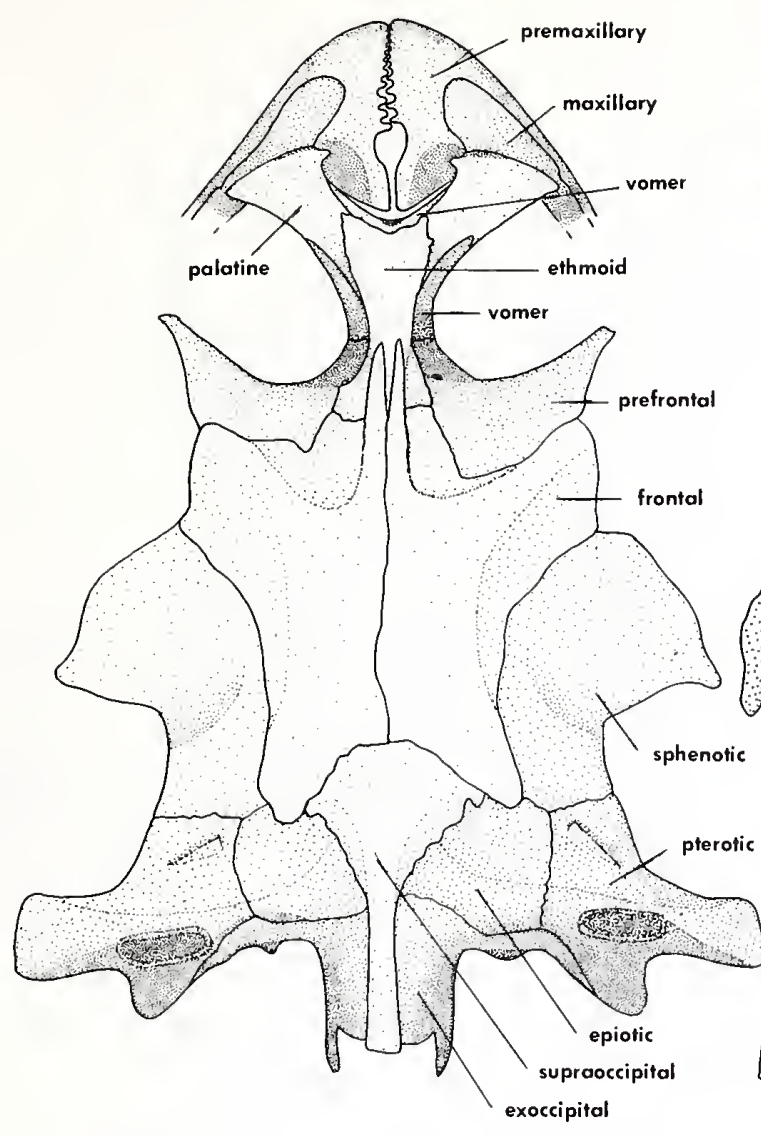

ther tetraodontids are the exceptionally well-developed neural prezygapophyses as anterolaterally projecting prongs found in lagocephalus and scleratus, which, while not as large as in Triodon, at least approach those of Triodon in size. However, these prongs and the keels on the neural arches seem to be specialized structures associated with the musculature of a strongly powered caudal peduncle for rapid swimming and are probably independently evolved in Triodon and in a few of the species of Lagocephalus.

Lagocephalus cannot be reasonably considered as an especially generalized tetraodontid. It possesses many unique features not found elsewhere among the tetraodontids or the ancestral triodontids and triacanthodids (most importantly the posterolateral wings of the frontals partially or completely enclosing a temporal fossa, the horizontal epural, especially short first dorsal and anal fin rays, posterior prolongation of the distal ends of the last dorsal and anal fin basal pterygiophores) and other features that, while not unique to it, can still be considered specialized (highly folded olfactory epithelium, two lateral lines).

It seems more reasonable to me to consider Lago-

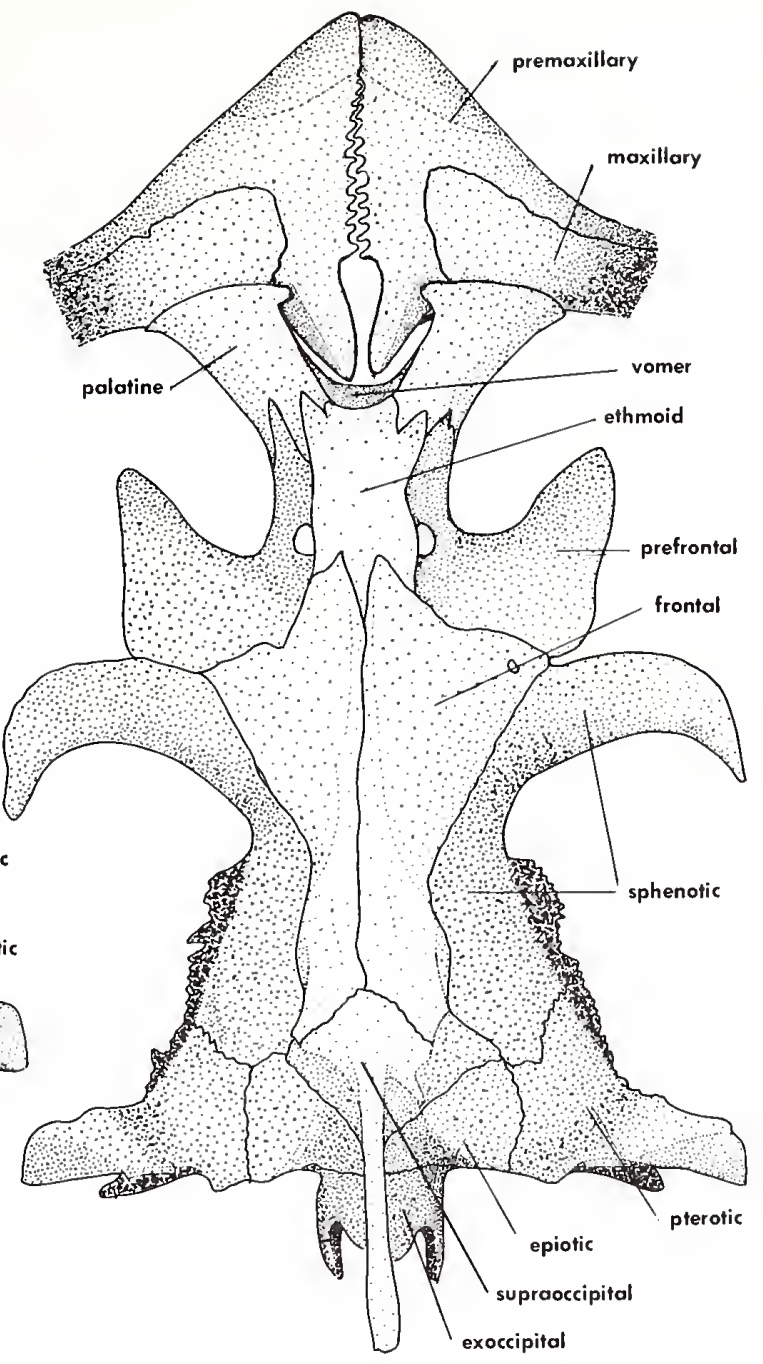

Figure 262.-Dorsal views of skulls of:

left, Guentheridia formosa, $175 \mathrm{~mm}$ SL, Panama (Pacific); right, Colomesus psittacus, $179 \mathrm{~mm} \mathrm{SL}$, Surinam.

cephalus a specialized derivative of a Sphoeroides-like group, for the following reasons. Lagocephalus scleratus must be considered, overall, the most generalized species of the genus, because, in spite of a few specializations probably mostly associated with its mode of swimming (depressed body and caudal peduncle, 17 vertebrae, single hypohyal, exceptionally well-developed neural prezygapophyses and last basal pterygiophore prongs) it has a lesser degree of development of the specialized features that characterize the genus (especially the even. ly tapered frontals of moderate width and the relatively poorly developed posterolateral wings which do not meet the pterotic and thus only partially enclose the temporal fossa) as well as many other generalized features (first pharyngobranchials with numerous teeth, no dorsal flange on the parasphenoid contacting the frontals in the orbit, well-developed prootic prongs representing the remains of the dorsal roof of the myodome, moderate 


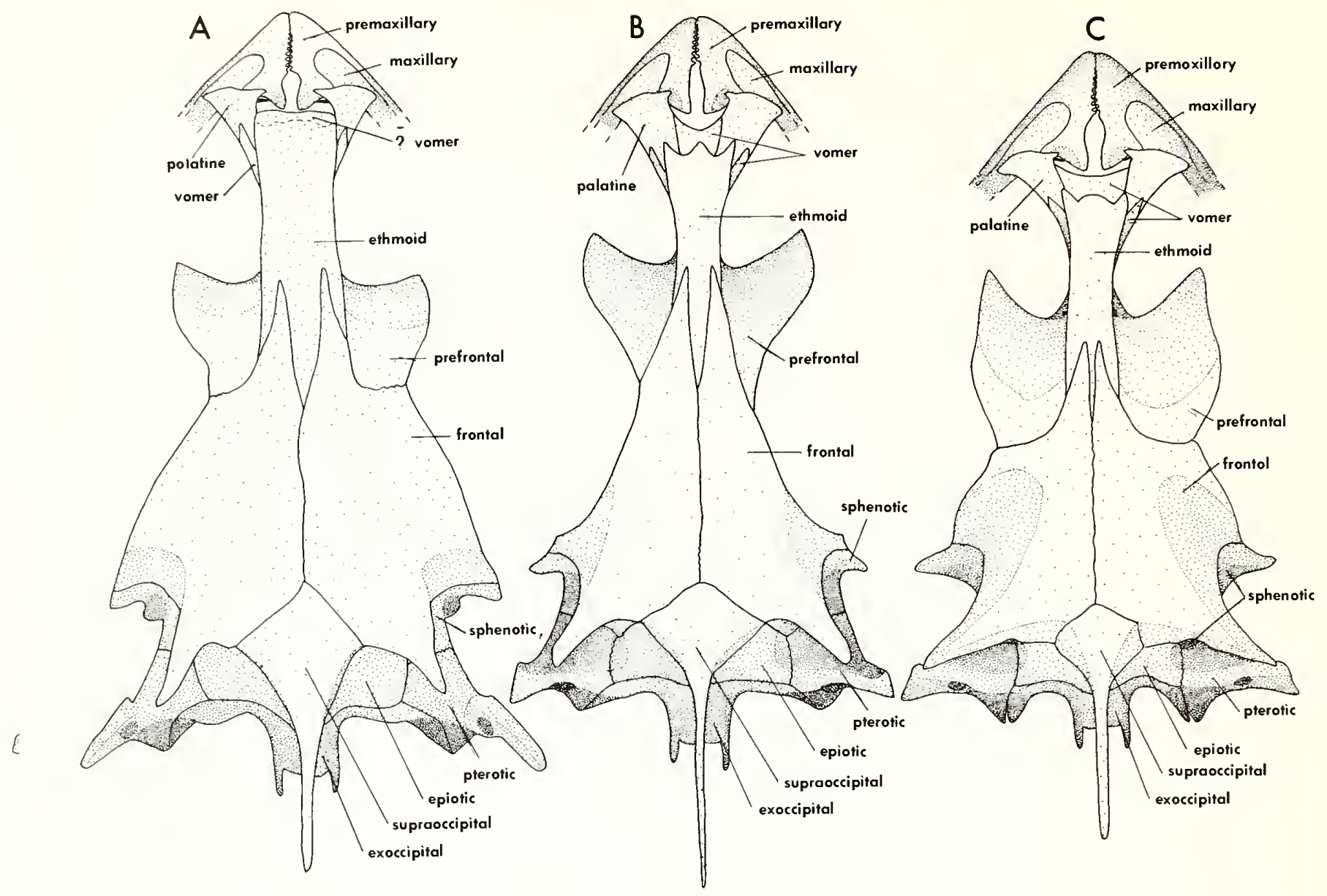

number of dorsal and anal fin rays, least highly folded olfactory epithelium, minimal surface sculpturing on top of the skull, spines on the back as well as the belly), a greater combination of generalized features than any of the other species.

A scleratus-like stock, minus its specializations, probably gave rise to inermis, which alone among Lagocephalus shares a few of the generalized features of scleratus (first pharyngobranchial with numerous teeth, no dorsal flange on parasphenoid) and has the second most generalized configuration of the cranium, with the posterolateral wing of the frontal similar to scleratus and the anterior region of the frontal only slightly more specialized than in scleratus by its greater width and more abrupt tapering. It is probable that this line leading to inermis also gave rise, by further specializations and before the scales were totally lost, to lunaris, and that a lunaris-like stock is ancestral to spadiceus, laevigatus, and lagocephalus. I would guess that in general spadiceus has remained closer to this ancestral line than have laevigatus and lagocephalus, with lagocephalus a specialized more open water derivative of a laevigatuslike stock.

If scleratus can be accepted as the most generalized species of Lagocephalus, then it is probable that Lagocephalus is an originally deepwater derivative of a Sphoeroides-like ancestral group, for the cranium of
Figure 263.-Dorsal views of skulls of:

A, Lagocephalus inermis, $52.2 \mathrm{~mm}$ SL, Bay of Bengal;

B, L. scleratus, $80.9 \mathrm{~mm}$ SL, Philippines;

C, L. lunaris, $62.3 \mathrm{~mm} \mathrm{SL,} \mathrm{Bay} \mathrm{of} \mathrm{Bengal.}$

scleratus is not markedly different from that of several species of Sphoeroides, including that of pachygaster, which alone among Sphoeroides has a deepwater habitat, a highly folded olfactory epithelium, and a general countenance similar to that of the deep, chunky bodied species of Lagocephalus, such as inermis, the closest relative of scleratus and a species which may have retained the general appearance of the ancestral line leading to it and scleratus, which scleratus lost as it became specialized for more rapid swimming. In $S$. pachygaster the frontals are about as wide as in $L$. scleratus, and they are similarly evenly tapered anteriorly, and the ethmoid-vomerine regions are remarkably similar. Moreover, while not prolonged posterolaterally, the broad posterior end of the frontal projects out over the underlying epiotic and pterotic as a short roof over this region. In many other species of Sphoeroides, both specialized (e.g., dorsalis and testudineus) and generalized (e.g., spengleri and maculatus) the posterior end of the frontal is slightly prolonged posterolaterally over the underlying epiotic and pterotic as a short roof. An only slightly increased posterolateral prolongation of 


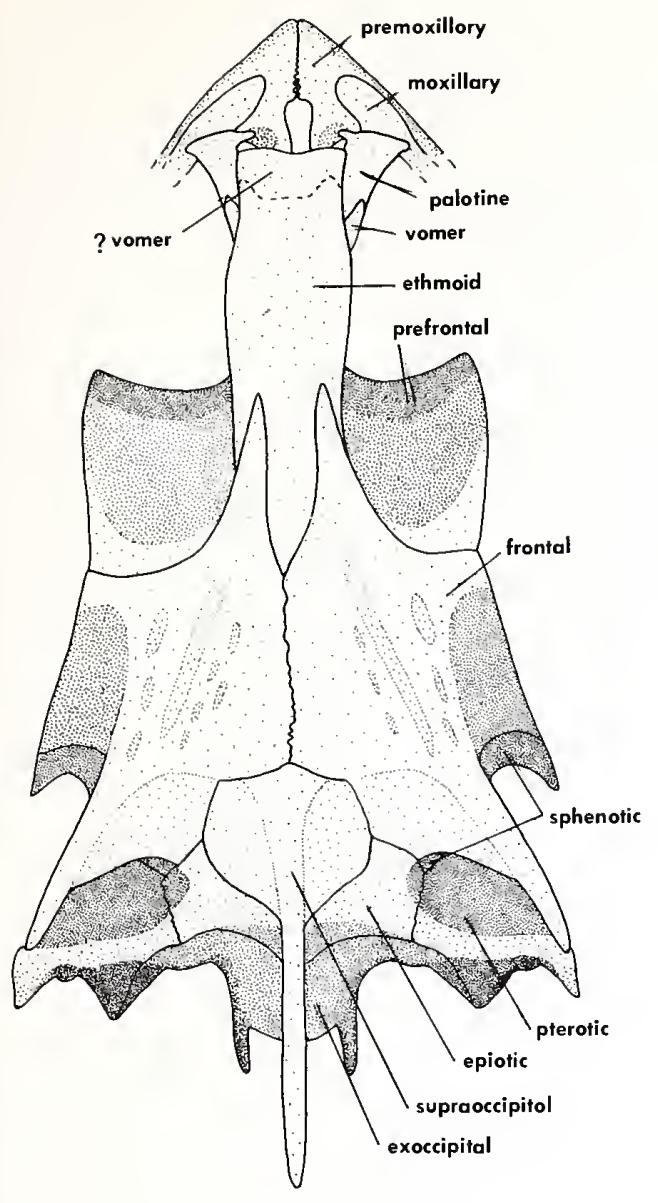

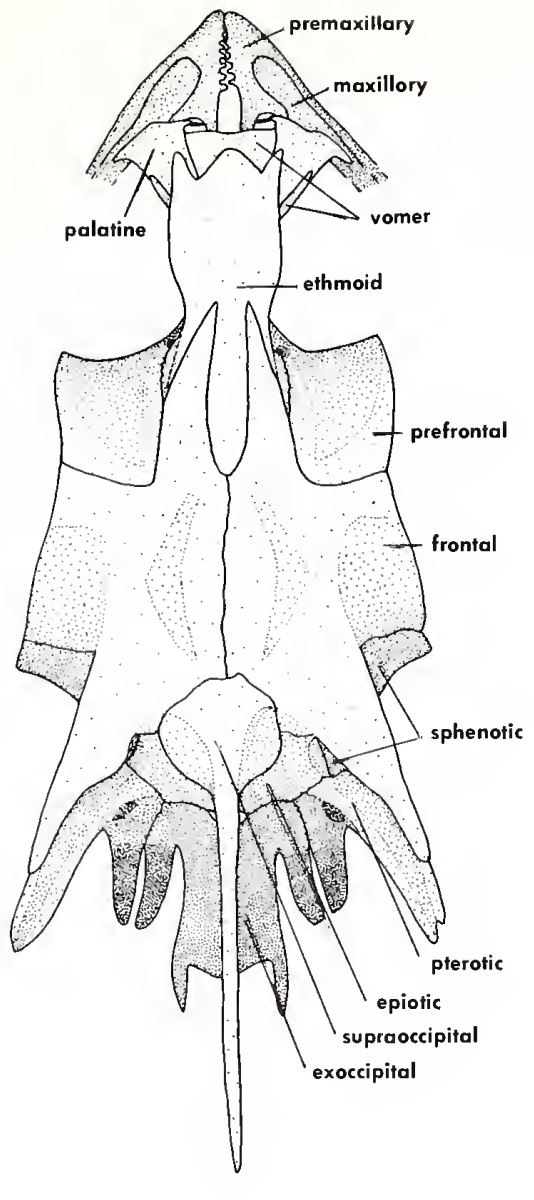

\author{
Figure 264.-Dorsal \\ views of skulls of: \\ left, Lagocephalus spadiceus, \\ $98.2 \mathrm{~mm}$ SL, Mozambique; \\ right, L. lagocephalus, \\ 214 mm SL, Malpelo Islands.
}

the frontal in pachygaster or any of the other species of Sphoeroides with a moderately wide, evenly tapered frontal would lead to exactly the condition of the frontal found in $L$. scleratus.

These species of Sphoeroides also share with $L$. scleratus the generalized features of the absence of a dorsal flange of the parasphenoid in the orbit, while most of them have numerous small to minute teeth on the first pharyngobranchial, except for $S$. pachygaster in which it is a toothless plate similar to that of most Lagocephalus. Most of these species of Sphoeroides have several small rounded trituration teeth in a single row to either side of the midline and none in the lower jaw, just as in Lagocephalus, and most also have both a dorsal and ventral hypohyal, a probable condition of the ancestral stock of Lagocephalus since $L$. laevigatus retains two hypohyals. A few of these species of Sphoeroides have moderately to well-developed prootic prongs in the rear of the orbit representing the remains of the dorsal roof of the myodome, and a few have interhyals, all conditions to be expected in the ancestral stock of Lagocephalus.

In short, Lagocephalus seems relatively clearly to have been derived from a Sphoeroides-like ancestral group, the connection between the two being most clearly seen in $L$. scleratus and in any number of relatively generalized species of Sphoeroides, as well as particularly in $S$. pachygaster. I would suspect that it was the same line of
Sphoeroides radiation leading to the deepwater pachygaster that gave rise to Lagocephalus, at a time before the few specializations of pachygaster (loss of teeth on first pharyngobranchial, loss of spines, complete loss of remnants of the dorsal roof of the myodome) had become established, this line leading to a form with two lateral lines, moderately folded olfactory epithelium, and the skeletal structure of scleratus and external characteristics of inermis (except with spines on the belly and dorsum), with the scleratus-like line diverging in external and a few internal features associated with its more rapid swimming and the inermis-like line developing a more specialized skull structure, this latter line being ancestral to most of the other species of Lagocephalus.

Perhaps Sphoeroides was more widespread in the IndoPacific than at present, and has subsequently become confined to the Atlantic and eastern Pacific as it met superior competition in shallow Indo-Pacific waters from the plethora of genera of tetraodontids evolving there, and was able to remain in the Indo-Pacific only in the form of a single deepwater species.

Fraser-Brunner (1943) associated Amblyrhynchotes and Torquigener (including Fugu) with Sphoeroides (as the Sphoeroidinae) and Lagocephalus (the Lagocephalinae, together with the Sphoeroidinae comprising the Lagocephalidae), on the basis of their having the sphenotics small and separated from the prefrontals by 


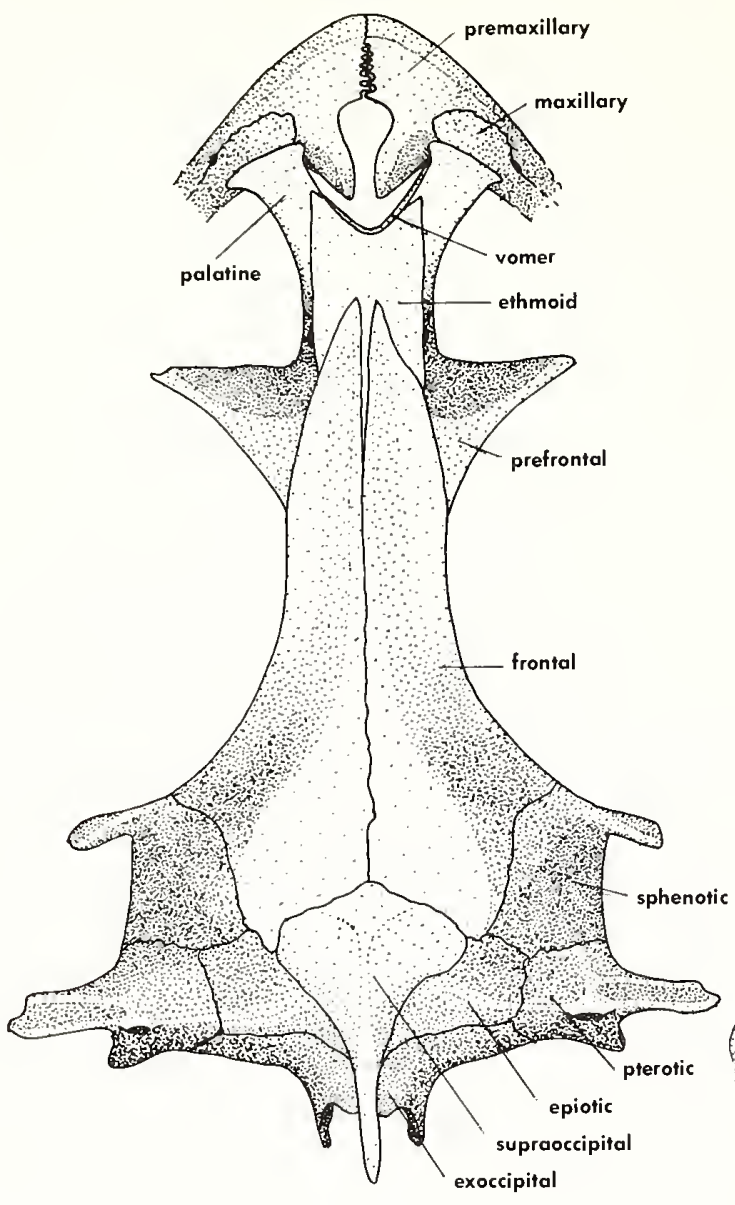

over

mis

face

over

erm,

ed $c$

direı

scler

latel

ceph

side

occi

spec

form

tetra

linea

$\mathrm{Tr}$

Lago

teres

In $s$

towa

simil

Spho

over

tapel

the $\mathrm{c}$ the frontals, in contrast to Colomesus (family Colomesidae), another genus with two nostrils, in which the sphenotics are large and prolonged anteriorly to meet the prefrontals, excluding the frontals from the orbital margin.

I agree that the generalized condition of the nasal sac with two nostrils probably does link the "Lagocephalidae" and "Colomesidae" in a natural group as apposed to the "Tetraodontidae," and that Sphoeroides is distinctive among them in retaining the generalized condition of the lateral line. However, when numerous species are examined the osteological differences between the groups are not as clear cut as previously thought, and they scarcely merit familial recognition.

For example, Colomesus does have the sphenotics prolonged anteriorly further than in any other tetraodontid, and the posterior recurving of its anterolateral region is also distinctive. However, the sphenotics become fully prolonged anteriorly to meet or very nearly meet the prefrontals and exclude the frontals from the margin of the orbit only in specimens of about $100 \mathrm{~mm}$ and larger (see Tyler 1964 for illustrations of the skull at various sizes). At sizes of about $50 \mathrm{~mm}$ the skulls of the two species of Colomesus bear a strong resemblance to those of Sphoeroides annulatus and formosa, both of which, like Colomesus, have the frontal narrower poste-

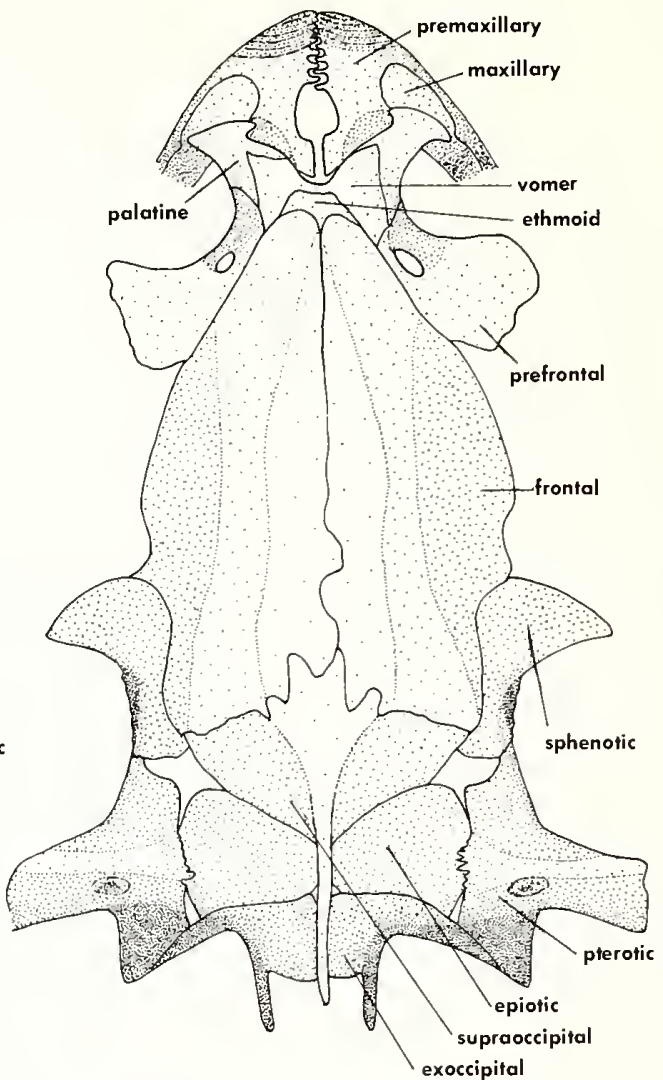

Figure 265.-Dorsal views of skulls of: left, Amblyrhynchotes honckenii, $97.4 \mathrm{~mm}$ SL, Mozambique; right, $A$. richei, $59.4 \mathrm{~mm}$ SL, New Zealand.

riorly than anteriorly and the sphenotics prolonged anteriorly, although not as far forward in adults of $S$. annulatus and formosa as in adults of Colomesus. In both $S$. annulatus and formosa the anterior region of the sphenotics is laterally expanded, although the expansion is not recurved as in Colomesus. Among Sphoeroides (including Guentheridia) only annulatus and formosa have a dorsal flange of the parasphenoid meeting the frontals in the interorbital septum, and one (psittacus, along the coast of northern South America) of the two species of Colomesus also has a dorsal flange of the parasphenoid while the other (asellus, fresh water of northern South America) does not.

Both species of Colomesus have two hypohyals, as does S. annulatus, while formosa has only one. In Colomesus there are numerous trituration teeth in both jaws, sometimes consolidated into paired plates, and both $S$. annulatus and formosa have the same arrangement, somewhat unusual among Sphoeroides. Colomesus has minute teeth on the first pharyngobranchial and lacks an interhyal, as do $S$. annulatus and formosa, along with 


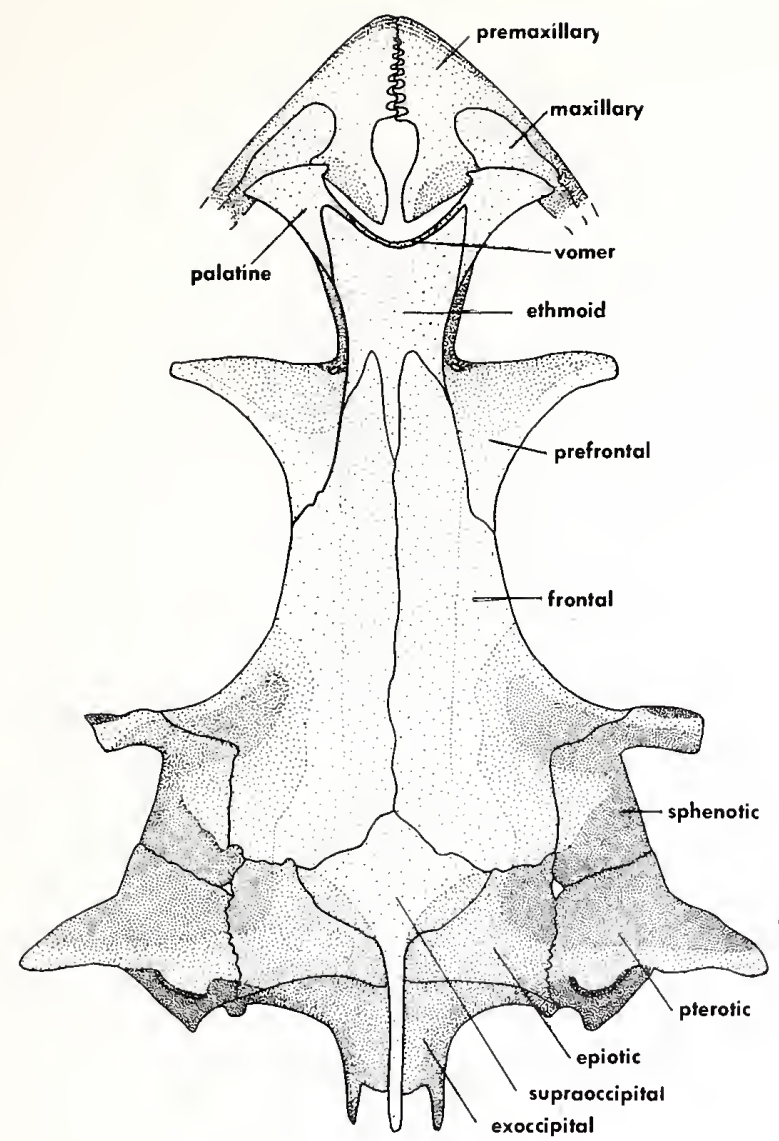

most other Sphoeroides. Colomesus has 19 vertebrae, as does $S$. annulatus, while formosa has a more specialized reduced number of 17 . In Colomesus medial prongs of the prootic are present representing the remains of the dorsal roof of the myodome, although these are less welldeveloped in psittacus than asellus, while neither $S$. annulatus nor formosa retain these remnants, a slightly more specialized condition. In both $S$. annulatus and formosa there are eight dorsal rays and seven anal rays, while Colomesus has a perhaps slightly more generalized number of 10 or 11 rays in these fins.

In short, there are striking similarities between the osteological makeup of Colomesus, $S$. annulatus and formosa, and the conversion of an annulatus-formosa-like fish into one like a Colomesus would require only the retention of remnants of the myodome and a few more dorsal and anal fin rays along with the further anterior prolongation and recurving of the sphenotics and the development of a second lateral line, short segments of which are present in some specimens of many species of Sphoeroides, including $S$. annulatus and formosa. It seems likely to me that Colomesus arose from the same line of Sphoeroides radiation as that which gave rise to annulatus and formosa from a testudineus-like ancestry. Perhaps this happened somewhere between the annulatus and formosa levels of organization, with Colomesus becoming far more specialized than either annulatus or formosa. Fraser-Brunner (1943) also con-

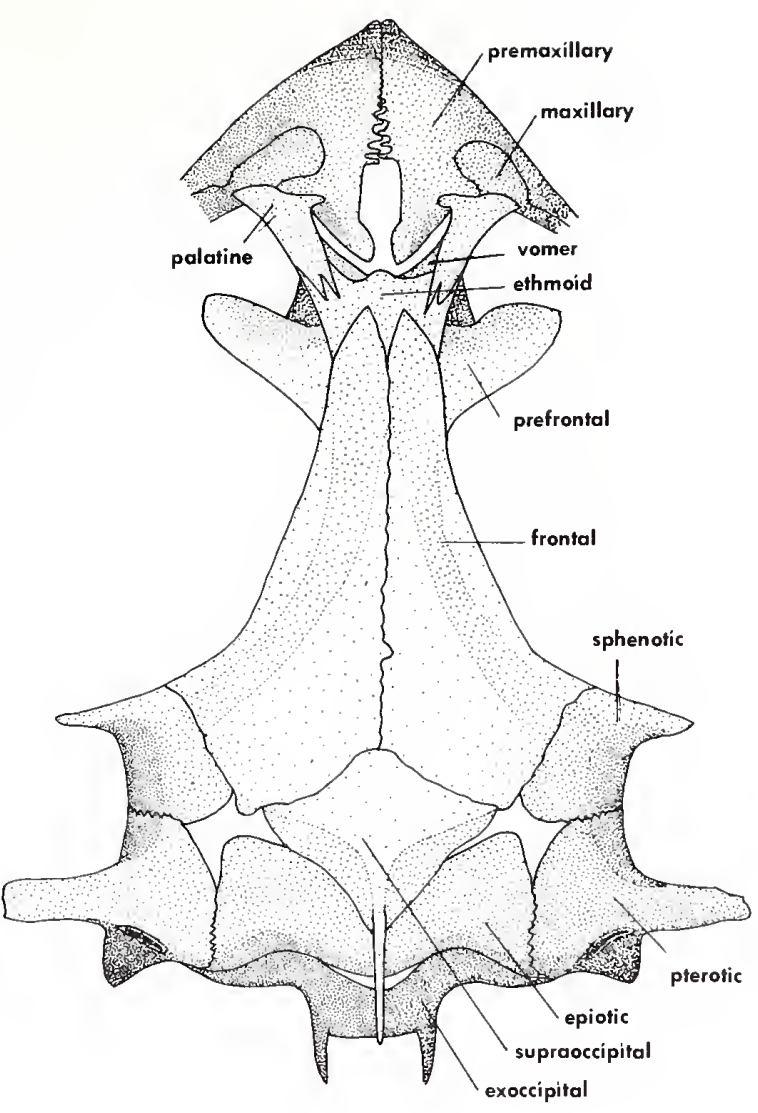

Figure 266.-Dorsal views of skulls of: left, Torquigener pleurogramma, $113 \mathrm{~mm} \mathrm{SL}$, Australia; right, Amblyrhynchotes piosae, $33.8 \mathrm{~mm}$ SL, Australía.

sidered Colomesus to be a derivative of a Sphoeroideslike stock, but for unstated reasons, which I would guess were zoogeographic.

While Lagocephalus and Colomesus are relatively easily distinguished from the ancestral Sphoeroides(including Guentheridia here and following)-like stock, the relationships of the Indo-Pacific Amblyrhynchotes, Torquigener, and Fugu are less clear. Fraser-Brunner (1943) said that Sphoeroides has a long ethmoid, with the frontals well removed from the premaxillary pedicels, 17 vertebrae, and no lower lateral line, while Ambly. rhynchotes, Torquigener, and Fugu have the ethmoid shorter, the frontals reaching far forward, close to the premaxillary pedicels, 20 to 21 vertebrae, and a lower lateral line.

Sphoeroides does tend to have a longer ethmoid, a longer ethmoid-vomerine region, and the frontal further removed from the anterior end of the ethmoid-vomerine region than in Amblyrhynchotes, Torquigener, and Fugu, in most species of which the portion of the ethmoid-vomerine region that is exposed dorsally is relatively short so that the frontals do closely approach the anterior end of the ethmoid-vomerine region. However, 


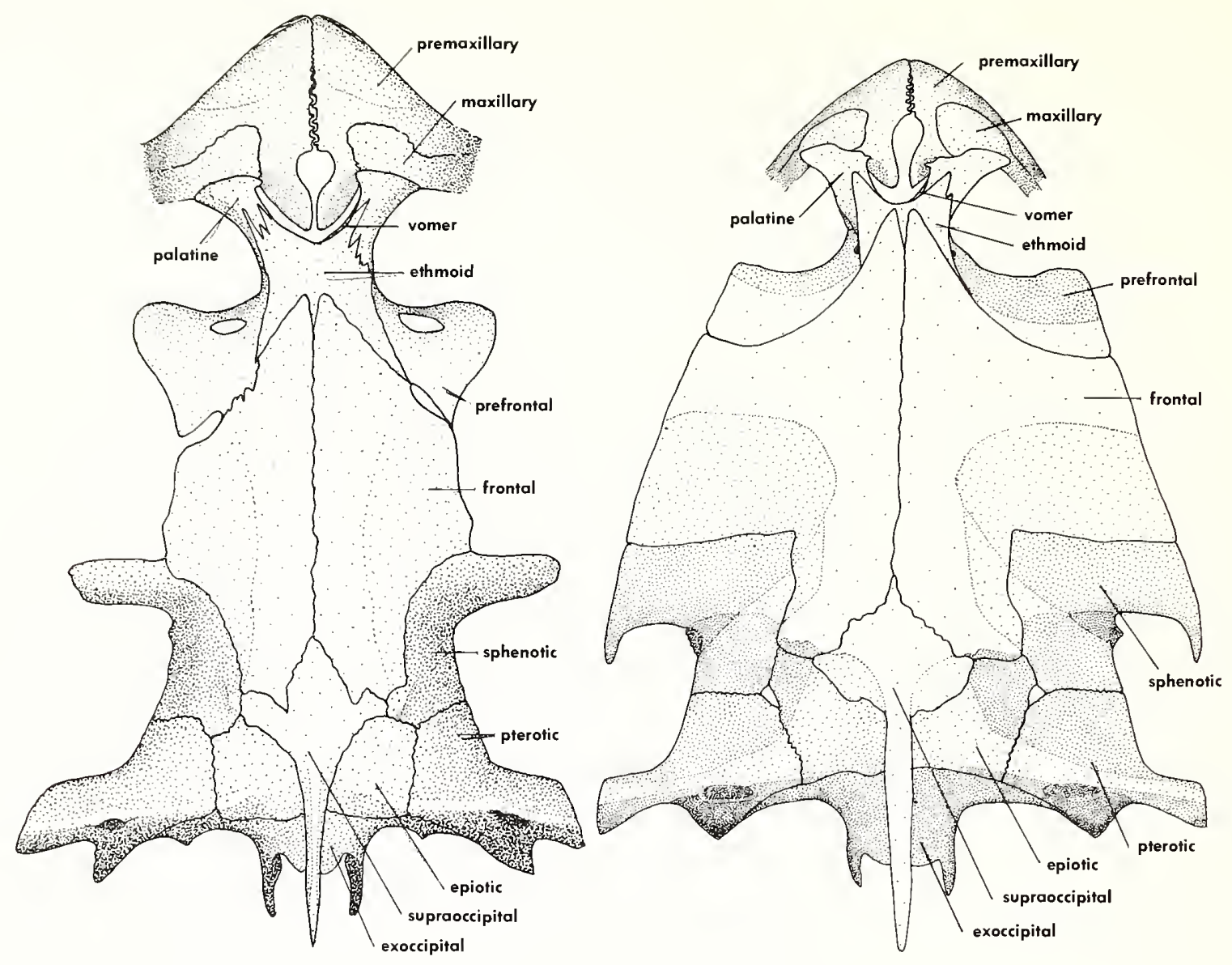

in Torquigener pleurogramma, for example, the ethmoid is no longer than in, for example, Sphoeroides greeleyi, nor is the entire ethmoid-vomerine region of $T$. pleurogramma shorter than in $S$. greeleyi, and the frontals are about equally far removed from the anterior end of the ethmoid-vomerine region. Fugu rubripes and Amblyrhynchotes honckenii likewise have relatively long ethmoid-vomerine regions in contrast to the other species of those genera examined, while these regions are still shorter than in any species of Sphoeroides. The usually greater length of the ethmoid-vomerine region in Sphoeroides helps to distinguish that genus from the other three, and this moderate length in Sphoeroides can be considered more generalized, for it more closely corresponds to that of triodontids and triacanthodids than does the usually foreshortened ethmoid-vomerine region of Amblyrhynchotes, Torquigener, and Fugu.

While the modal number of vertebrae in Sphoeroides ranges from 17 to 20 , only two species have 19 or 20 . In Amblyrhynchotes the modal number in the three species studied is 19, and using Fraser-Brunner's (1943) figure of 20 , the range is 19 to 20 . In Torquigener the modal number in the three species studied ranges from 19 to 21 . In Fugu the modal number ranges from 20 to 23. Thus, the number of vertebrae tend to be one to several units higher in most species of Amblyrhynchotes, Torquigener, and Fugu than in most species of Sphoeroides.
Figure 267.-Dorsal views of skulls of: left, Torquigener pleurostictus, $87.1 \mathrm{~mm}$ SL, Australia; right, Fugu chrysops, $98.6 \mathrm{~mm}$ SL, Japan.

Fraser-Brunner (1943) said that Amblyrhynchotes had the frontal evenly narrowed anteriorly, 20 vertebrae, prickles on the side of the body at least behind the pectoral fin and no ridge along the lower lateral line, while Torquigener (including the species assigned to Fugu) had the frontals much wider behind the prefrontals than between them, 21 vertebrae, no prickles on the side of the body and a ridge along the lower lateral line. As previously discussed, the ridge along the lower lateral line is present in some species of Amblyrhynchotes as well as in Torquigener and Fugu, although perhaps more commonly in Torquigener and Fugu. The modal vertebral numbers do not significantly differ, except that $F u g u$ has proportionally more species with more than 20 vertebrae than does Torquigener. At least the species of Amblyrhynchotes studied here have prickles on the side of the body which are absent in all of the species of Torquigener and Fugu studied.

In the three species of Amblyrhynchotes studied the frontals are of moderate width and gradually taper anteriorly in honckenii and piosae, very much as in the species of Sphoeroides with moderately wide frontals, except 


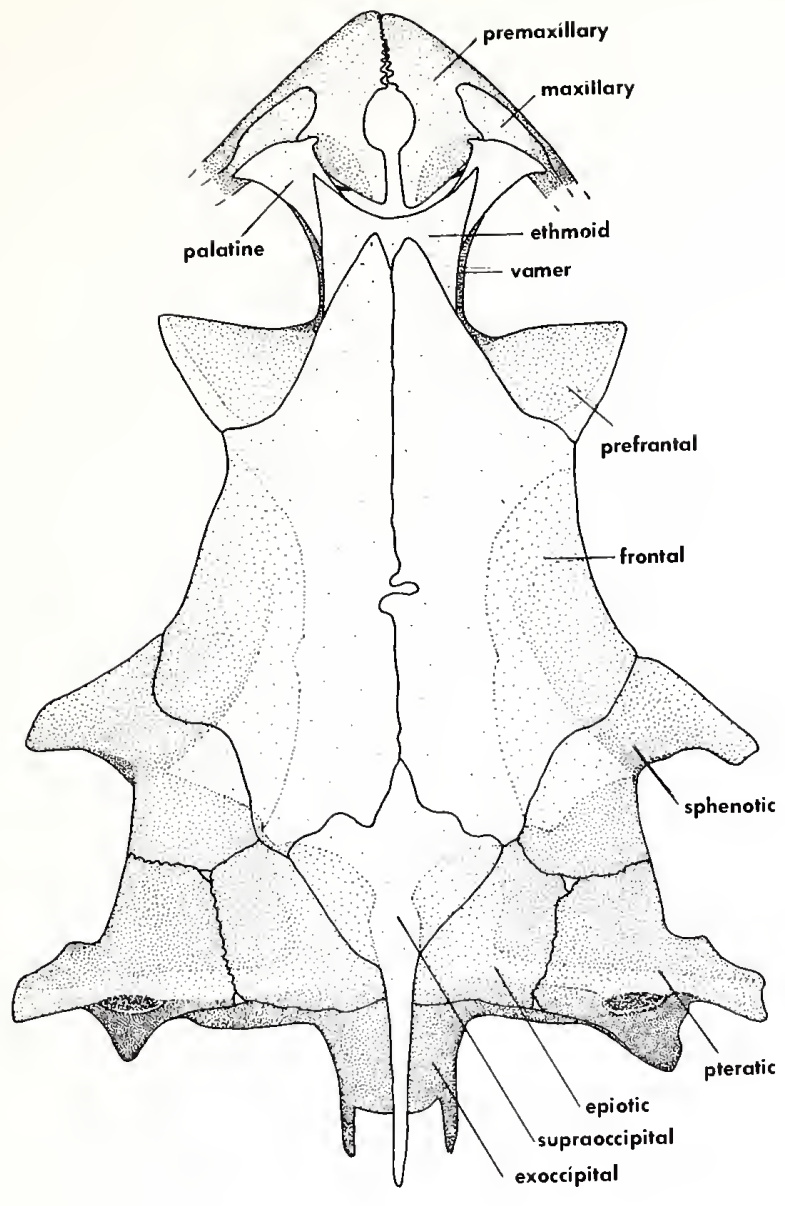

that the ethmoid-vomerine region is at least somewhat shorter, while in richei the frontals over the rear of the orbit are very wide, at least as wide as more posteriorly, and evenly taper anteriorly to bluntly rounded ends, in front of which is an extremely short ethmoid-vomerine region. The two species of Torquigener studied are about as different in cranial configuration as $A$. richei is in comparison to $A$. honckenii and piosae. In T. pleurogramma the frontal over the orbit evenly tapers to the posterior edge of the prefrontal, and then more abruptly tapers medial to the prefrontal, with a general configuration not much different than that of, for example, Sphoeroides testudineus, except for having a wider ethmoid. In $T$. pleurostictus the frontal is laterally expanded over the orbit, much wider there than more posteriorly, and only begins to taper abruptly to a point at the posterior edge of the prefrontal. The sphenotic in pleurostictus is more anterodorsally expanded than in pleurogramma. The major features of the skull in 10 species of $F u g u$ has been described and illustrated by Kuronuma (1943), who compared their configuration to that of three species of Lagocephalus and one of Sphoeroides (pachygaster). The structure of three of the species of Fugu studied here (rubripes, oblongus, and chrysops) more or less encompasses the diversity found by Kuronuma. In rubripes and oblongus the sphenotic is somewhat anterolaterally expanded; the frontal is laterally expanded over the orbit,

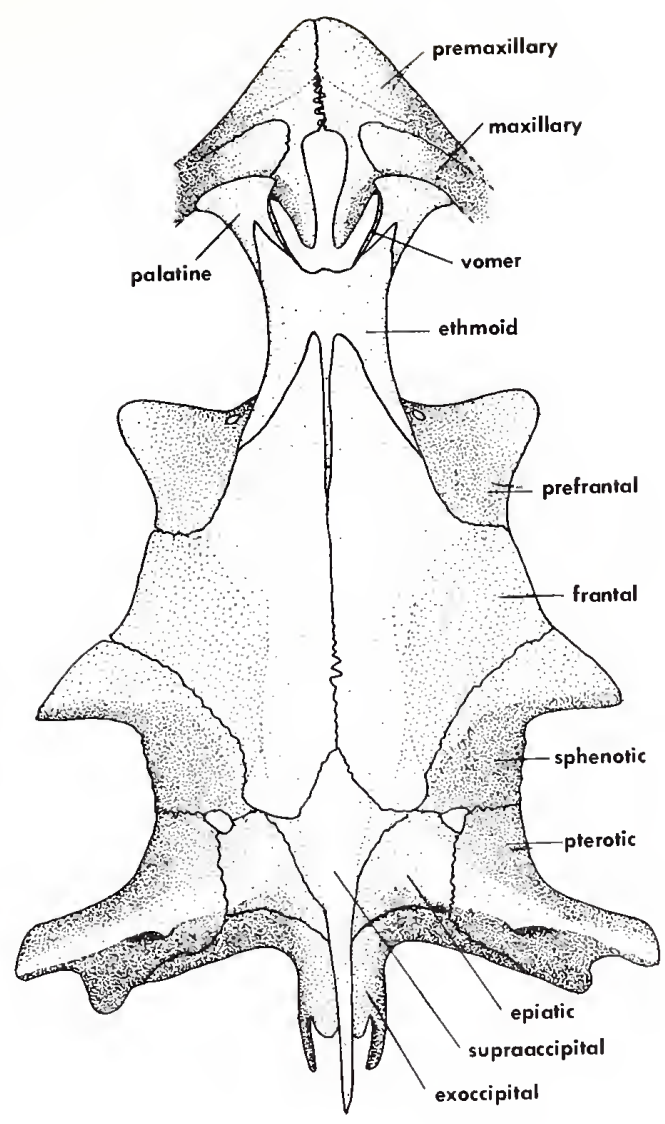

Figure 268. -Dorsal views of skulls of: left, Fugu oblongus, $46.2 \mathrm{~mm}$ SL, India; right, F. rubripes, $151 \mathrm{~mm} \mathrm{SL,} \mathrm{Japan.}$

usually gently tapers to the posterior edge of the prefrontal, and then abruptly tapers medial to the prefrontal. The skull of chrysops differs from the others by being exceptionally wide and having relatively straight lateral margins, the frontal being especially wide.

In all of the species of Amblyrhynchotes, Torquigener, and Fugu studied the parasphenoid has a dorsal flange in the orbit meeting the frontals, there are small to minute teeth on the first pharyngobranchial, a supraneural is present but the interhyal is absent and there are essentially no prootic medial prongs representing the remains of the dorsal roof of the myodome. In all of the species of these three genera studied there are one to three small rounded trituration teeth in a single row to either side of the midline of the upper jaw but none in the lower jaw, except for $A$. richei, which had no trituration teeth in either jaw. Amblyrhynchotes piosae has both dorsal and ventral hypohyals, while the other two species (honckenii and richei) of that genus have only the ventral hypohyal. Torquigener pleurogramma has both hypohyals but pleurostictus has only one. In Fugu all three species studied (chrysops, oblongus, rubripes) had a single hypohyal. Amblyrhynchotes richei is unique among the 


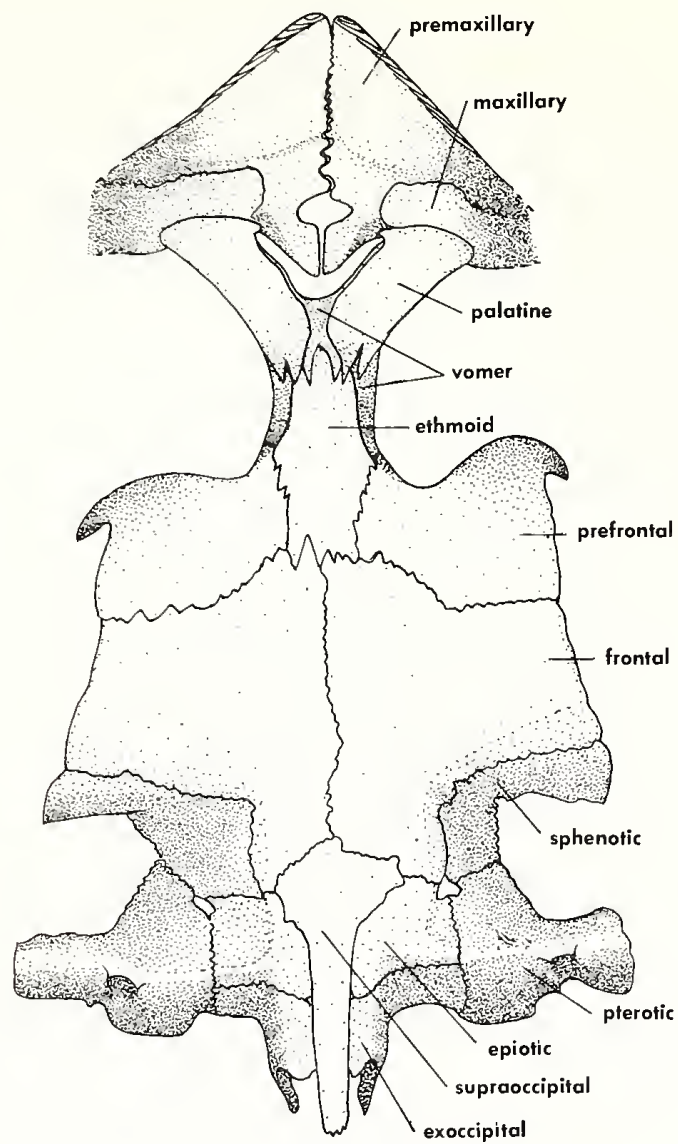

tetraodontids studied in lacking even a trace of a mesopterygoid.

On the basis of the material examined, I am unable to distinguish Fugu from Torquigener, and I suspect that when more species of Torquigener are examined the distinction would be even more difficult to make. Amblyrhynchotes is obviously closely related to Torquigener and Fugu, differing from them by the tendency to have the frontal evenly narrowed anteriorly and to have prickles on the side of the body. Much more remains to be done on the external and internal morphology of these Indo-Pacific genera with two nostrils and, most usually, two lateral lines.

It is pure surmise, but I would guess that an early Sphoeroides-like stock with a generalized moderately wide skull and evenly tapered frontals in the Indo-Pacific gave rise to Amblyrhynchotes, Torquigener, and Fugu, with the major changes from the ancestral type being the usual development of a lower lateral line, the usual shortening of the ethmoid-vomerine region, the constant development of the dorsal flange of the parasphenoid, and the frequent anterodorsal prolongation of the sphenotics. If this hypothesis is correct, the ancestral Sphoeroides-like group has subsequently become extinct in the shallow waters of the Indo-Pacific, and is represented there only by a single deepwater species.

All of the genera discussed above with two nostrils (the "Lagocephalidae" and "Colomesidae") were said by

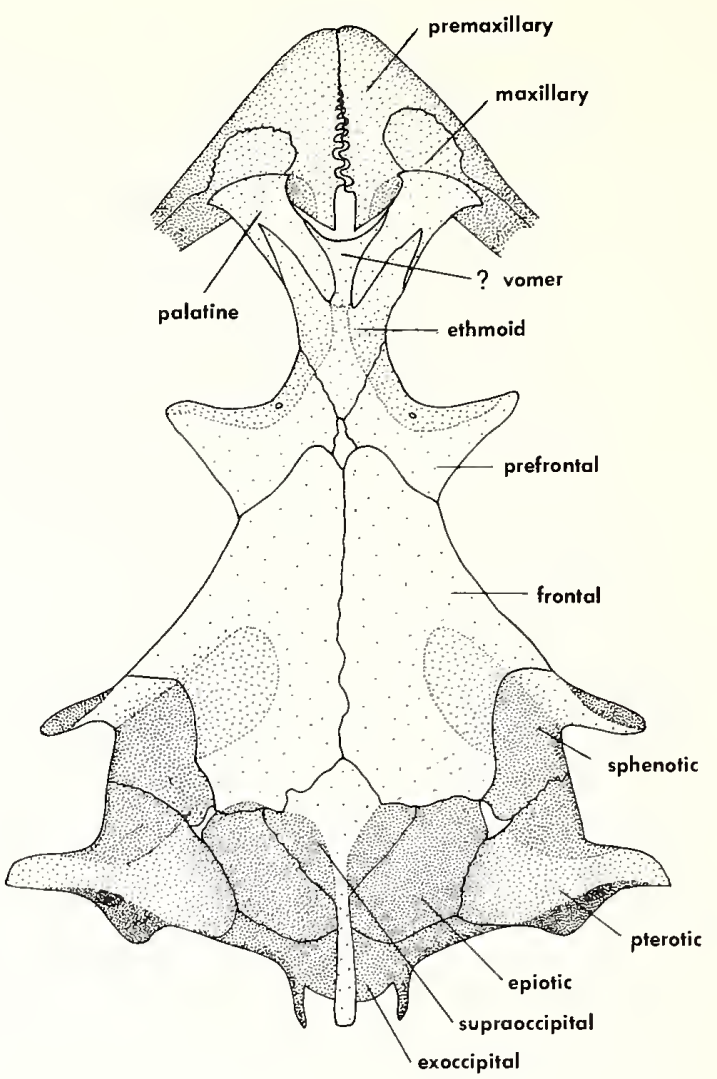

Figure 269.--Dorsal views of skulls of: left, Arothron stellatus, ca. $420 \mathrm{~mm} \mathrm{SL}$, Seychelles; right, A. armilla, $61.3 \mathrm{~mm}$ SL, Australia.

Fraser-Brunner (1943) to have the prefrontals separated on the dorsal surface of the skull mainly by the frontals, while in Ephippion, Arothron, Monotreta, Chelonodon, Carinotetraodon, and Tetraodon (the "Tetraodontidae"), all with a single nostril, the prefrontals were said to be separated mainly by the ethmoid (and the sphen. otics separated from the prefrontals by the frontals, as in the "Lagocephalidae").

Whether one considers the ethmoid or the frontal to be the main element separating the prefrontals is often a highly subjective decision. In only a minority of species of both groups can it be said clearly that the prefrontals on the dorsal surface of the skull are nearly exclusively separated by either the frontals or the ethmoid. In the great majority of species of both groups the ethmoid extends posteriorly approximately to the level of the posterior end of at least the main body of the prefrontals, although much of this posterior region of the ethmoid is often overlaid by the frontals and thus cannot be seen in dorsal view. In Sphoeroides, Lagocephalus, and Colomesus, for example, the prefrontals are separated about half by the ethmoid and half by the frontals, and there is much variation between species. In Amblyrhynchotes 


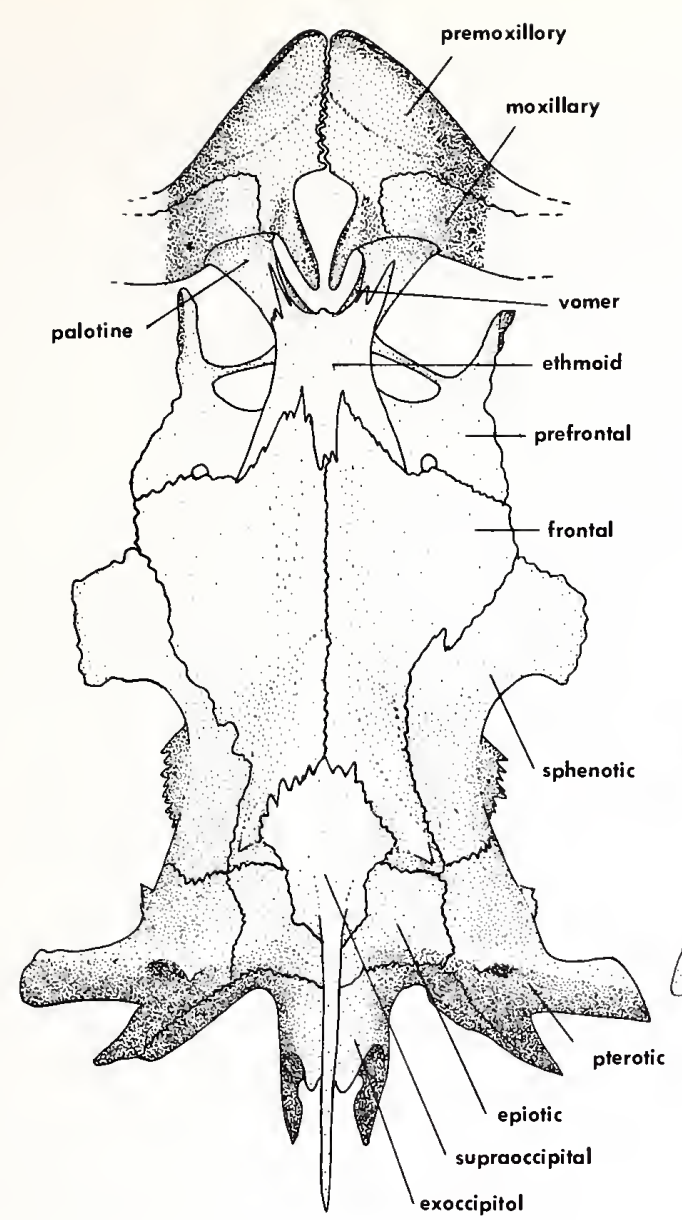

the prefrontals tend to be separated mainly by the frontals, while in Fugu it is variously mostly by the frontals or about half by the ethmoid and half by the frontals. In Torquigener the two species examined have the prefrontals separated about half by the ethmoid and half by the frontals. Again, however, this is more a simple matter of how broadly the frontals cover the dorsal surface of the ethmoid rather than a characteristic of fundamental im. portance.

In Ephippion, Arothron, Monotreta, Chelonodon, Carinotetraodon, and Tetraodon the ethmoid tends to form a greater proportion of the prefrontal separation than does the frontal, and a greater proportion than in most (but not all) species of the genera with two nostrils. In Arothron, for example, most species have the prefrontals separated almost entirely by the ethmoid, but in one species (armilla) the prefrontals are separated almost exactly half and half by the ethmoid and frontals. In Tetraodon, Carinotetraodon, and Chelonodon the separation is mostly if not entirely by the ethmoid, while in Monotreta the separation in most species is about half and half by the ethmoid and frontals, but almost exclusively by the frontals in one species (gularis).

Fraser-Brunner said that Arothron (as the Arothroninae) had the sphenotics not laterally expanded beyond the rest of the orbital roof formed by the frontals, the orbital roof strongly arched, the prefrontal curved down

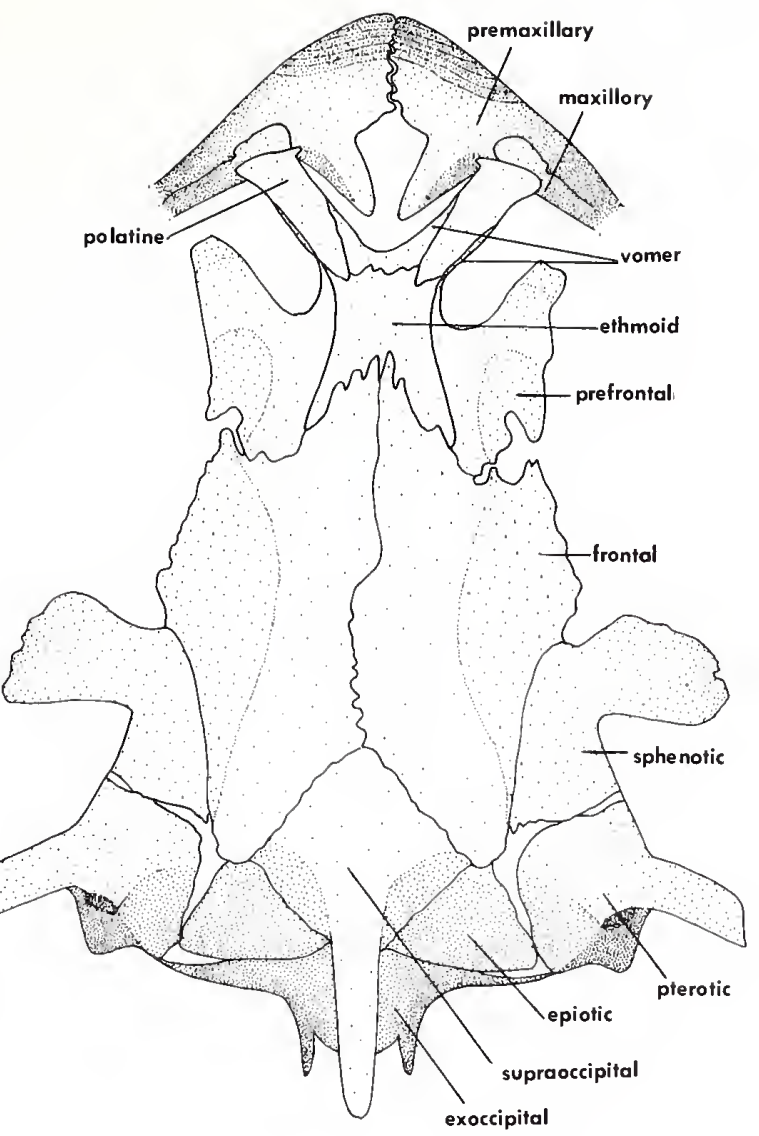

Figure 270.-Dorsal views of skulls of: left, Tetraodon lineatus, 222 mm SL, French Equitorial Africa; right, T. $m b u, 47.7 \mathrm{~mm} \mathrm{SL}$, Congo.

before the eye and enclosing the olfactory foramen, the ethmoid relatively narrow and compressed, and a single lateral line, while in Ephippion, Monotreta, Chelonodon, Carinotetraodon, and Tetraodon (the Tetraodontinae) the sphenotics are laterally expanded beyond the frontal as a prominent lobe, the orbital roof is not much arched, the prefrontal not curved down before the eye and not enclosing the olfactory foramen, the ethmoid broad and a lower lateral line present which joins the upper.

It is true that the approximately six species of Arothron form a distinctive subgroup of Indo-Pacific puffers that is recognizable by external features alone: by a certain difficult to describe sameness in configuration (short, heavy bodies), as well as by the normally bifid tentacle with pitted inner surfaces and the single lateral line. In the relatively normal members of Arothron (represented in species studied here by hispidus, nigropunctatus, stellatus) the sphenotics are only slightly if at all expanded beyond the edge of the frontal, primarily because the frontal is exceptionally wide at the posterior region of the orbit (about 3 times as wide as more posteriorly in front of the supraoccipital), and the orbital roof 


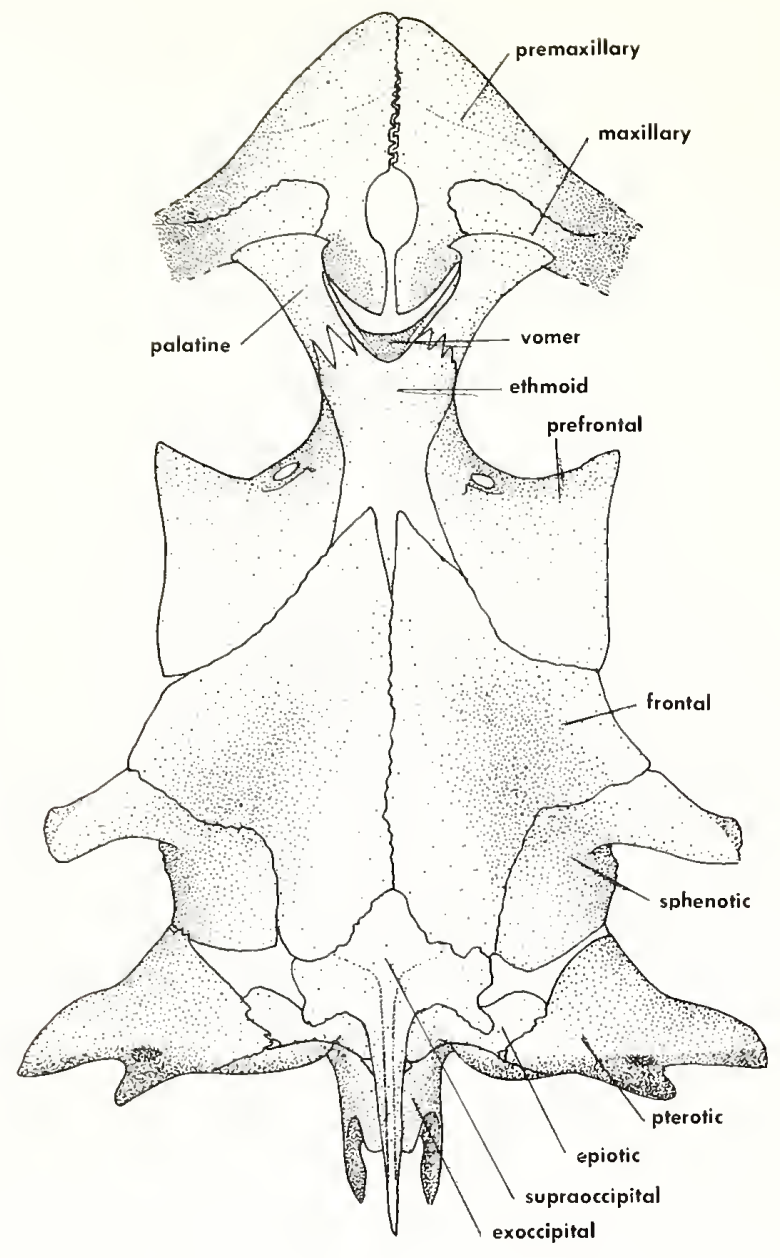

Figure 271.-Dorsal view of skull of Ephippion guttifer, $101 \mathrm{~mm}$ SL, Guinea.

is at least moderately arched, with the anterolateral end of the prefrontals curved down in front of the eye, more so in adults than in the young, and enclosing the olfactory foramen, and the ethmoid of moderate to narrow width (less wide than in Tetraodon and Ephippion but no less wide than in Chelonodon, Carinotetraodon, and most species of Monotreta).

Not all of these typical features are confined to Arothron, for the prefrontal entirely encloses the olfactory foramen in the related Ephippion and in Chelonodon patoca (but not C. fluviatilis), while in the related Tetraodon lineatus (but not T. $m b u$ ) the prefrontal encloses all but the medial edge of a large olfactory foramen. The foramen completely encloses the prefrontal in several species of the more distantly related genera Amblyrhynchotes, Torquigener, and Fugu, although in none of these do the prefrontals have such large downcurved anterolateral regions as found in most adult Arothron. The sphenotics are not laterally expanded beyond the frontals in Monotreta gularis, and are only slightly to moderately expanded beyond them in the other species of Monotreta.
Moreover, one species, originally described as Tetraodon armilla McCulloch, that has the general external configuration and look of an Arothron, including a single lateral line, differs greatly from the typical Arothron skull plan. Externally, armilla differs from Arothron in having the nasal apparatus represented by a single flap of skin on each side of the head, the outer surface smooth and the inner only very slightly irregular, while in Arothron there is always a bifid tentacle whose inner surfaces are pitted by circular olfactory organs.

In the three typical species of Arothron studied (hispidus, nigropunctatus, stellatus), the parasphenoid either does not have a dorsal flange in the orbit, or does not have it well enough developed to reach dorsally far enough to contact the frontals, while in armilla the dorsal flange is well developed and contacts the prefrontals as well as the frontals. While the typical species of Arothron have minute teeth on the first pharyngobranchial, in armilla they are relatively well developed, being only slightly smaller than those of the second and third pharyngobranchials. In typical Arothron there is little or no evidence of prootic prongs in the rear of the orbit representing the remains of the dorsal roof of the myodome, while the prootic prongs are well developed in armilla, reaching almost to the midline. In typical Arothron several trituration teeth are present in a single series to either side of the midline of the upper jaw, but none are present in the lower jaw, while in armilla, even at the small size of the examined individual, the numerous trituration teeth in both the upper and lower jaws are consolidated into large composite plates to either side of the midline. Like the typical species of Arothron, armilla has only a ventral hypohyal and no interhyal.

The most dramatic and perhaps phylogenetically interesting way, however, in which armilla differs from typical Arothron is in the shape of the frontals and prefrontals. Instead of having the frontals greatly laterally expanded above the orbit, as in typical Arothron, the frontals of armilla are only slightly wider over the rear of the orbit than more posteriorly, and gradually and evenly taper to bluntly rounded ends anteriorly, much as in most of the more generalized species of genera with two nostrils. The prefrontals of armilla are not enlarged and laterally expanded to the same degree as the frontals at the rear of the orbit, and, although they do completely enclose the olfactory foramen, they are only slightly downcurved anterolaterally. The prefrontals in armilla are separated from one another about half and half by the ethmoid and frontals, a probably more generalized condition than having them separated mostly by the ethmoid as in typical Arothron.

Although in two features (a single nasal flap and a dorsal flange of the parasphenoid meeting the frontals) armilla is more specialized than the typical species of Arothron, it has a far more generalized condition of skull configuration, especially of the frontals and prefrontals. In fact, if the several species of Arothron not examined for this work have skull structures similar to that of the three typical species examined here and not intermediate between them and armilla, then armilla may be con- 


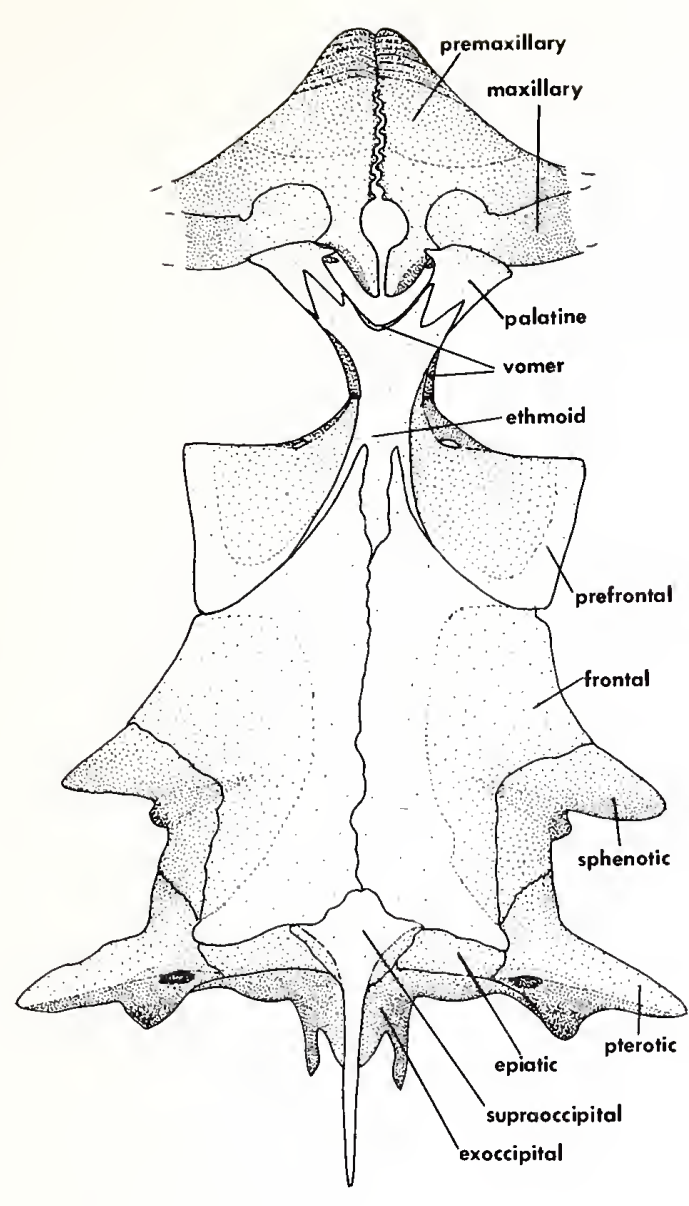

sidered sufficiently distinct from Arothron to merit generic recognition, the name Omegophora Whitley being available for it (by monotypy and original designation, even though not sufficiently diagnosed).

More importantly, it seems likely to me that a form like armilla which still retained a bifid nasal tentacle and the dorsal flange of the parasphenoid not yet fully developed, could represent the ancestral group from which the typical Arothron arose, for armilla has the most generalized condition of the frontals (moderate width, evenly and gradually tapering anteriorly), sphenotics (not especially laterally expanded and not expanded anterodorsally) and prefrontals (moderate size, not greatly downcurved before eye) found among the Arothron-like species.

It is possible that the pitted cup inner olfactory epithelium, as found in typical Arothron, indicates a relationship with Chelonodon, one of whose species (fluviatilis) is the only other one among these related genera (Fraser-Brunner's "Tetraodontidae") to have a pitted cup epithelium. However, the skull structure in typical Arothron and Chelonodon is not especially similar and the partial similarly in olfactory epithelium may be fortuitous, as is, I would guess, the slight similarity in skull structure between $C$. patoca and $A$. armilla.

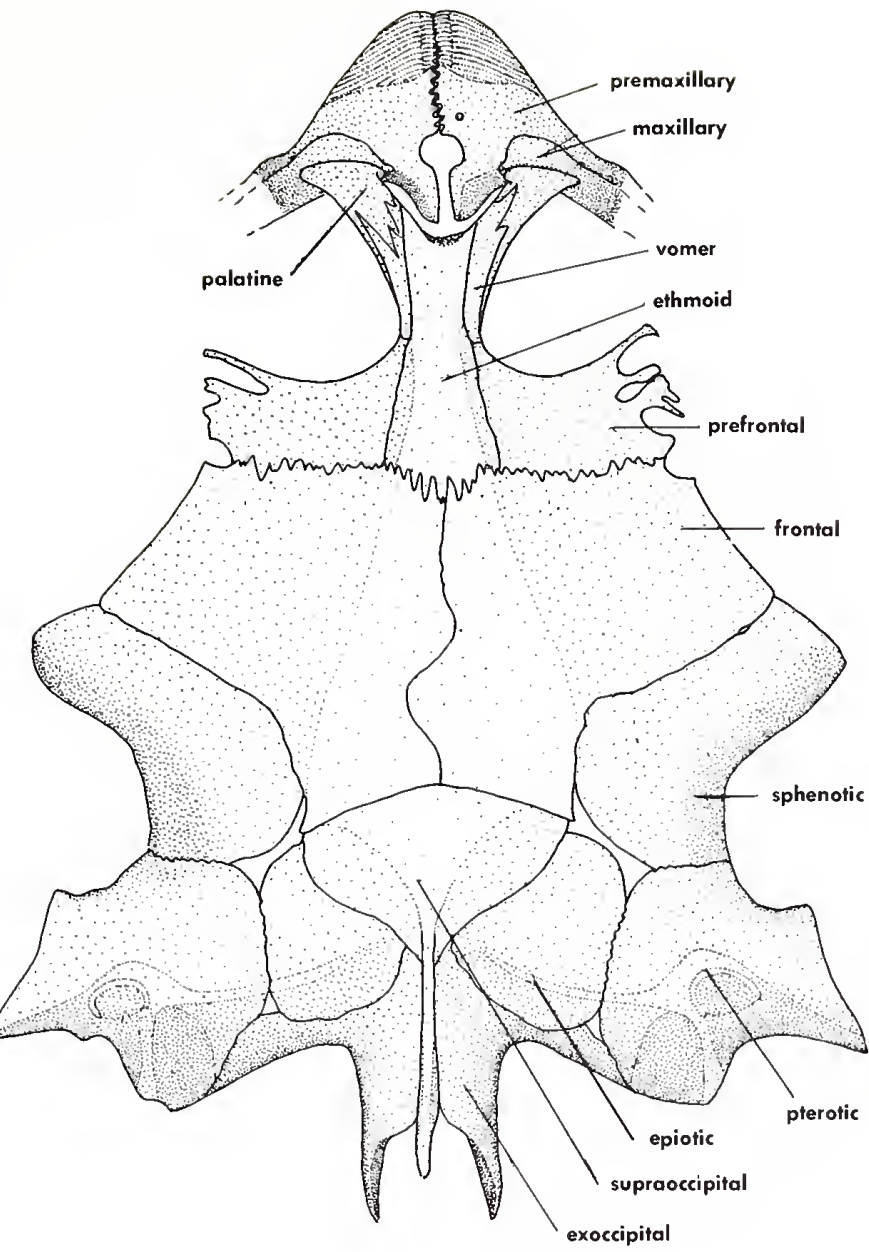

Figure 272.-Dorsal views of skulls of: left, Chelonodon patoca, $70.6 \mathrm{~mm}$ SL, New Guinea; right, $C$. fluviatilis, $84.7 \mathrm{~mm} \mathrm{SL}$, Thailand.

The monotypic Ephippion of the west coast of Africa is tolerant to fresh and brackish water when young, but adults seem to be found primarily in marine coastal habitats. Since Ephippion has a decidedly bifid nasal tentacle, as do many species of Tetraodon, several of which live in African fresh waters, and both genera have an upper lateral line which, usually, is joined by a lower lateral line, it has usually been thought that Ephippion is a close relative of Tetraodon with specialized scales. As previously described, the scales of Ephippion even in juvenile stages are larger than those of any other tetraodontids except Xenopterus and Chonerhinos, while with increasing specimen size the scales of Ephippion become enlarged into a partial carapace over the body (except ventrally and to some extent dorsally) between the head and the dorsal and anal fins, the scales of adults being far larger there than in any other plectognaths except ostracioids.

The skull of Ephippion differs from that in the two species of Tetraodon studied mostly by having the anterolateral wings of the sphenotics heavier and thicker, and 

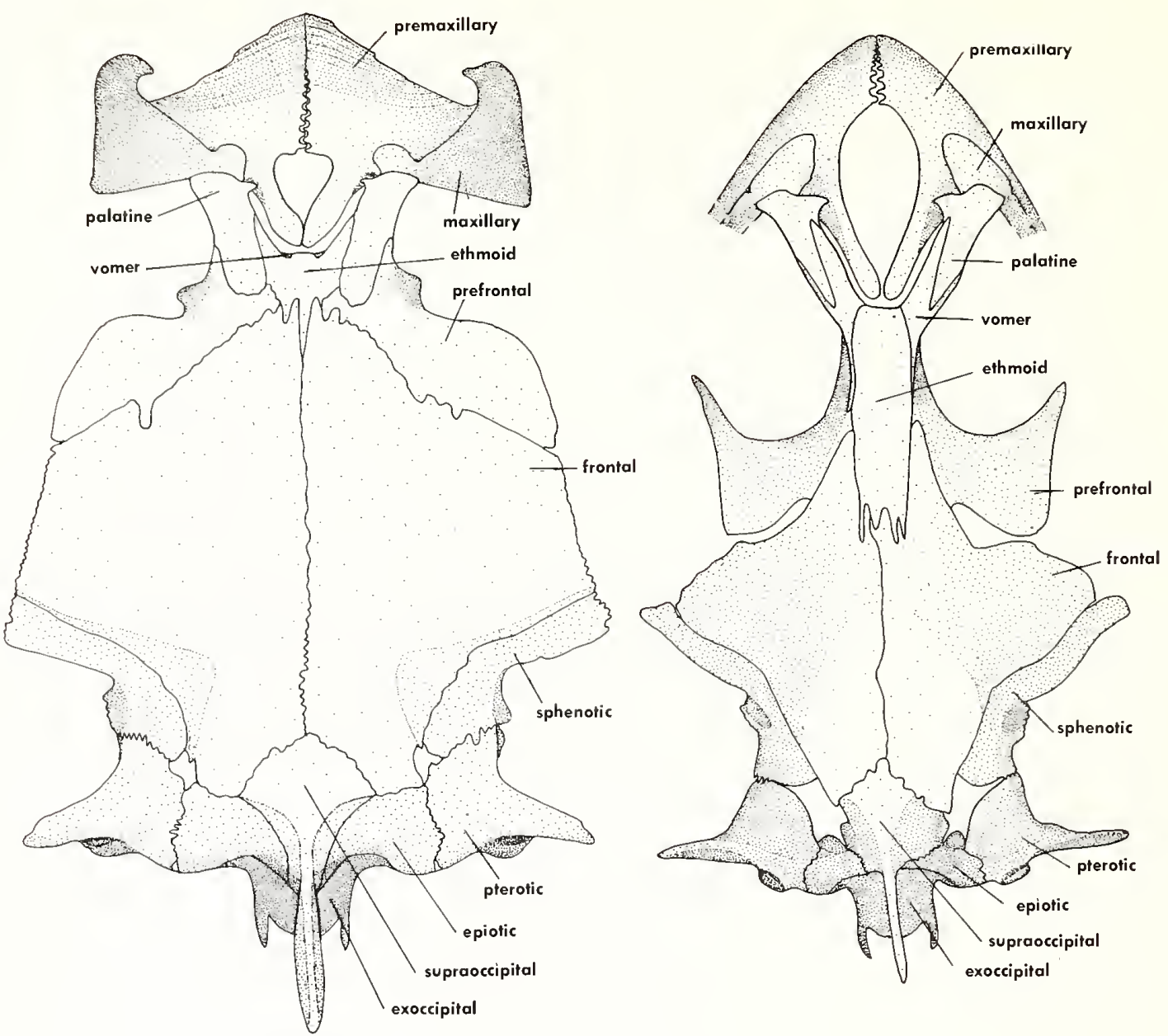

less dorsoventrally compressed into a plate. The frontal in Ephippion is about as laterally expanded over the middle of the orbit as in Tetraodon, but it tapers somewhat more evenly and gradually to a point anteriorly than in Tetraodon. In Ephippion the prefrontals are separated about half and half by the ethmoid and frontals, while in Tetraodon they are mostly separated by the ethmoid. The ethmoid of Ephippion is slightly less wide than in Tetraodon. The vertebrae in Ephippion are $8+$ $12=20$, while in the three species of Tetraodon for which vertebral counts are presented the range is $8+9=17$ to $8+11=19$. In Ephippion there are several trituration teeth in a single row to either side of the midline in the upper jaw, but none in the lower; while in the two species of Tetraodon cleared and stained, there are no trituration teeth in either jaw. In both Ephippion and Tetraodon there are minute teeth on the first pharyngobranchial and the dorsal flange of the parasphenoid in the orbit meets the frontals, but there are no remnants of the dorsal roof of the myodome, no interhyal, and only a single hypohyal.

Until recently, the categories Monotreta, Chelonodon, and Tetraodon were badly in need of revision. They are defined, as subgenera of Tetraodon, by Fraser-Brunner (1943) entirely on nasal and scale pattern characteristics

Figure 273.-Dorsal views of skulls of: left, Monotreta gularis, $46.8 \mathrm{~mm}$ SL, Burma; right, $M$. leiurus, $61.5 \mathrm{~mm} \mathrm{SL}$, Thailand.

that are less than adequate. These categories have nearly always been used at the generic level, for failure to do so leaves Tetraodon an unmanageable assemblage of numerous species, some obviously far more closely related than others. The use of these three categories also presents problems, which will probably only be solved when each of the species not discussed here has had its external and internal features compared with those described here. Dekkers (1975) has provided an excellent revision of these Asiatic and mainly freshwater puffers based on external characters, placing them all in one genus, with five unnamed subcategories for 15 species, two of which (erythrotaenia and waandersii) contain single species not studied here. For purposes of comparative discussion in this monograph, Tetraodon, Chelonodon, and Monotreta are recognized at the generic level.

In Monotreta (nasal apparatus a tube with a single nostril, the aperture of the tube with or without lips or flaps) three of the four species studied are rather similar to one another, and possess one feature unique to the 


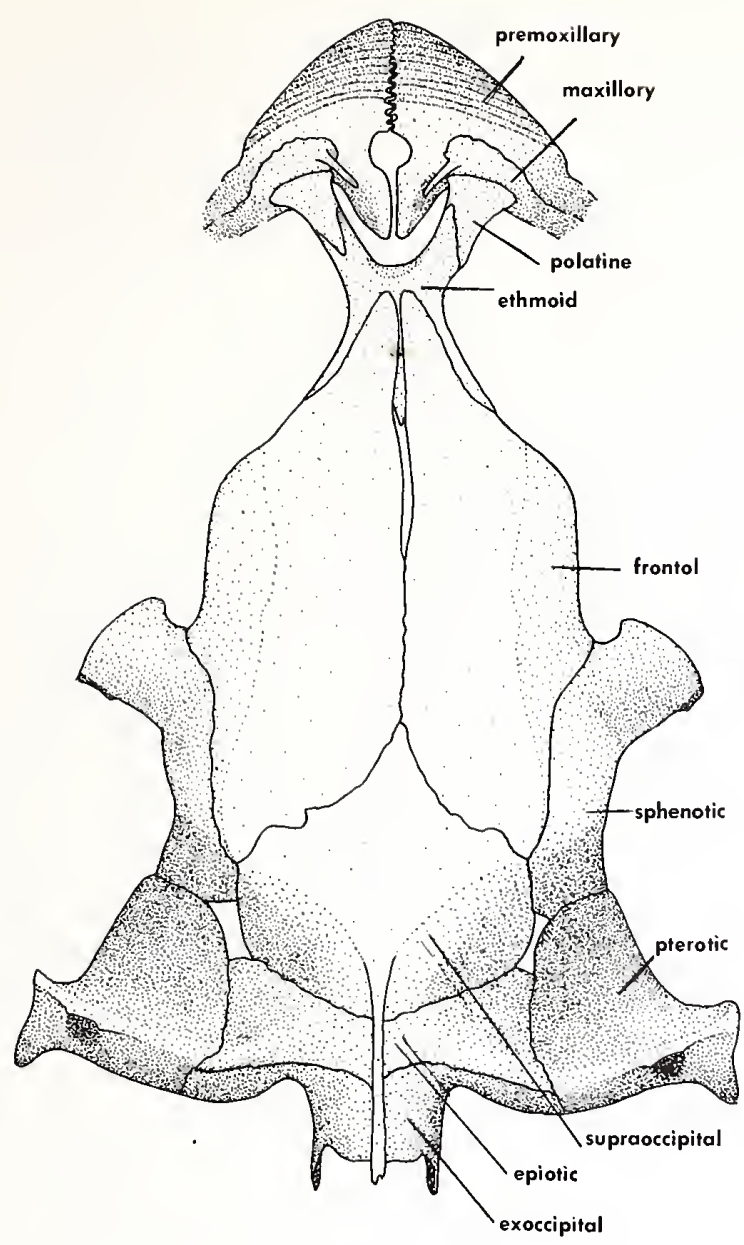

tetraodontids, while the other species does not share these similarities. All four species studied are rather similar externally, with the nasal apparatus about the same in all and varying only in the length of the tube, the upper lateral line joining the lower, at least a few prickles on the side of the body, and a color pattern featuring at least one large black spot on the side of the body.

In M. gularis (Dekkers 1975:95, considered gularis a synonym of cutcutia, but the single specimen I have identified and studied as gularis is not conspecific with cutcutia), the sphenotic does not extend laterally beyond the edge of the frontal, the frontal is much expanded laterally over the middle of the orbit, the posterolateral region of the prefrontal is not much less wide than the average width of the interorbital region, the lateral edge of the prefrontal is gently curved, the ethmoid is very short and relatively wide, the palatine-vomerine strut supporting the upper jaw is relatively short, and the premaxillary pedicel is of moderate length (as in most other tetraodontids).

However, in the other three (leiurus, cutcutia, palembangensis) species of Monotreta studied the sphenotics extend laterally beyond the edge of the frontal (at least as much as illustrated for leiurus; in palembangensis the sphenotic is even wider and further extended laterally), the frontal is only moderately laterally expanded over

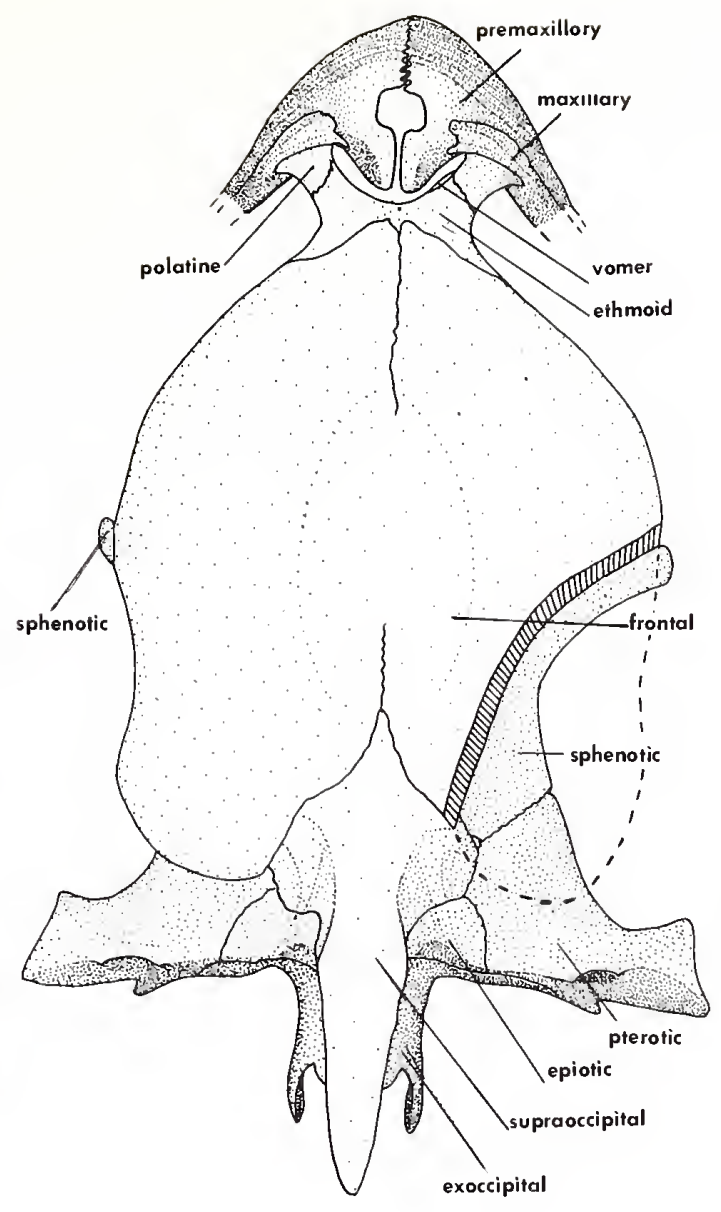

Figure 274.-Dorsal views of skulls of: left, Chonerhinos modestus, $54.5 \mathrm{~mm} \mathrm{SL}$, Borneo; right, Xenopterus naritus, $143 \mathrm{~mm} \mathrm{SL}$, Bay of Bengal, with the barred band representing the cut surface of the thickened frontal, removed to expose the portions of the sphenotic and pterotic which it overlies (dashed line marks lateral edge of removed portion of frontal).

the middle of the orbit and is strongly tapered anteriorly to the posterolateral region of the prefrontal, which is much less wide than the average width of the interorbital region, the lateral edge of the prefrontal is relatively straight and produced anterolaterally to a point, the ethmoid is very long and of moderate width, the palatine-vomerine strut supporting the upper jaw is long relative to gularis (but not relative to a large number of other tetraodontids), and the premaxillary pedicel is of relatively great length.

The open space enclosed between the dorsomedial edges of the two premaxillaries in $M$. leiurus, cutcutia, and palembangensis is much greater than in gularis or any other tetraodontid, partially because of the relatively great length of the premaxillary pedicels, but equally important because the open space extends far further forward beyond the level of the anterior ends of 


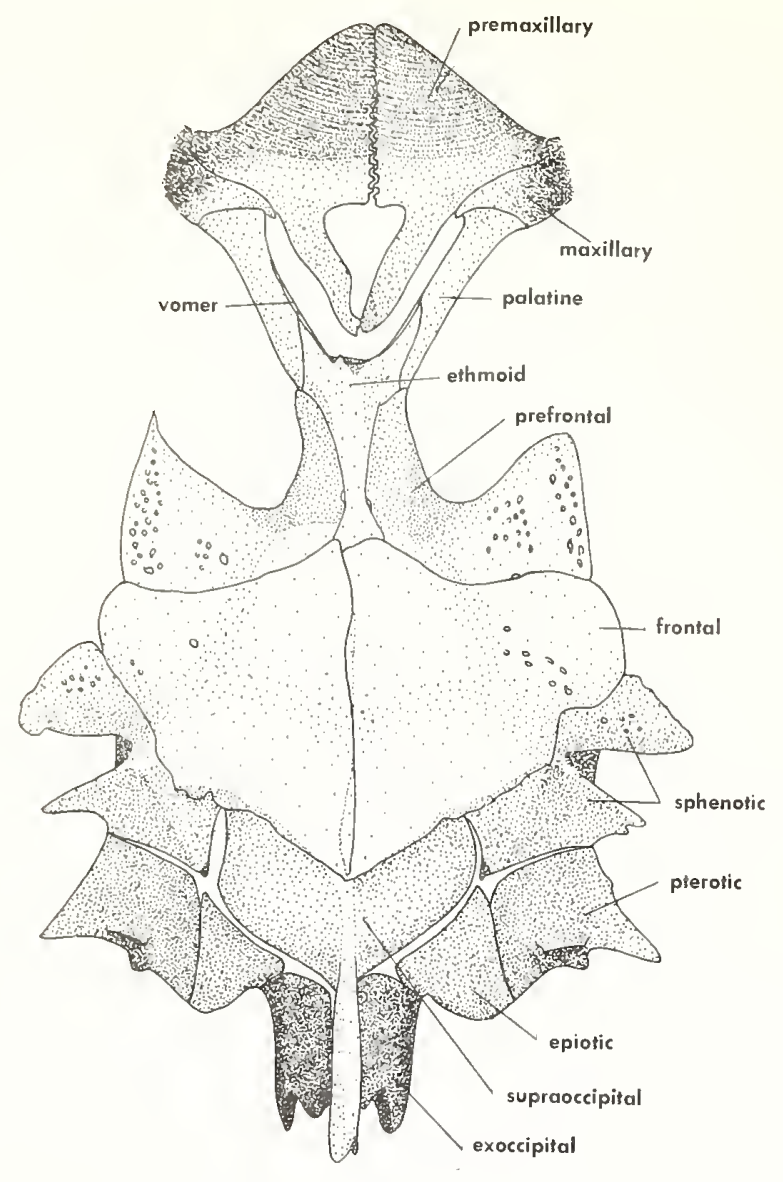

Figure 275.-Dorsal view of skull of Carinotetra odon lorteti, $33.1 \mathrm{~mm} \mathrm{SL}$, locality unknown.

the palatines than in any other tetraodontids, i.e., the medial edges of the premaxillaries in leiurus, cutcutia, and palembangensis have a much longer concave region than in any other tetraodontids.

The four species of Monotreta studied are alike in that there are small to minute teeth on the first pharyngobranchial, no trituration teeth in either jaw, no evidence of prootic prongs representing remnants of the dorsal roof of the myodome, no interhyal, a single hypohyal (one specimen of leiurus with two on one side and one on the other), and no supraneural element. The only other tetraodontids in which the supraneural is absent are members of the closely related genera Tetraodon (in which it is absent in $m b u$ but present in lineatus), Chelonodon (absent in fluviatilis but present in patoca), and Carinotetraodon (absent in the single species studied). In one of the species of Monotreta (leiurus) the first five abdominal vertebrae have bifid neural spines, and the neural spine of the sixth abdominal vertebra is bifid anteriorly but single posteriorly, while in the other three species the neural spines of only the first four vertebrae are bifid. In most other tetraodontids the first three abdominal vertebrae have bifid neural spines, and the neural spine of the fourth vertebra is bifid anteriorly but single posteriorly. In Arothron, however, the neural spines of the first four abdominal vertebrae are bifid, and at least a short portion of the anterior end of the neural spine of the fifth vertebra is bifid. Thus, Arothron and Monotreta tend to have a slightly greater development of bifid neural spines than do the other genera of tetraodontids, a specialization.

In Monotreta the vertebrae are 18 in cutcutia and gularis, but 20 or 21 in leiurus and palembangensis.

Even though the ensemble of subsidiary characters, internal and external, does not serve to separate gularis from the other three species of Monotreta studied, the differential shapes and sizes of the frontal, prefrontal, ethmoid, vomer, palatine, and, especially, premaxillary clearly indicate that there are two lines of diversification within the species of Monotreta studied. If additional species of Monotreta not studied here are eventually shown not to bridge the gap between the two groups, they should be recognized as at least subgenerically distinct (the identification of the specimen here studied as gularis needs verification). One suspects that the examination of additional species will bridge the gap. For example, Carinotetraodon lorteti, otherwise assignable to Monotreta because of the nasal tube with a single nostril (but with the upper and lower lateral lines not joining and both reaching the tail), has the length of the ethmoid about intermediate between gularis and the other three species of Monotreta, the palatine-vomerine shaft about as long as in the three specialized species, the length of the premaxillary pedicel intermediate between gularis and the other three species, and the size of the space between the concave posteromedial regions of the two premaxillaries very similar to that of gularis. The anterolateral wing of the sphenotic in Carinotetraodon is about like that of one of the three specialized species (palembangensis) of Monotreta, but there is no structure in any of the four species of Monotreta similar to the posterolateral wing of Carinotetraodon.

It seems obvious that Carinotetraodon and thus Canthigaster, as discussed earlier in this section, have their closest relationships among the Monotreta-like tetraodontids, but that a clearer understanding of the relationships of these fishes awaits the time when the critical internal and external features can be compared for a larger number of species than it has been possible to do here. Such a further study must also obviously include Chelonodon and Tetraodon, the generic limits of neither of which are presently clear.

For example, in Tetraodon the lateral line system is highly variable, but it is probably basically represented by a lower line which joins the upper and continues to the tail, this being modified in some species by the loss of the connection between the upper and lower lines, or even the loss of the lower line, and perhaps of much of the upper line as well. The bifid nasal tentacle tends to be deeply split, almost to the base, and the inner epithelium smooth. The skulls of the two species studied are relatively similar, differing mainly that in lineatus the sphenotics are more anteriorly expanded than in $\mathrm{mbu}$ (probably partially attributable to the much greater size of the study individual of lineatus) and that the postero- 
A

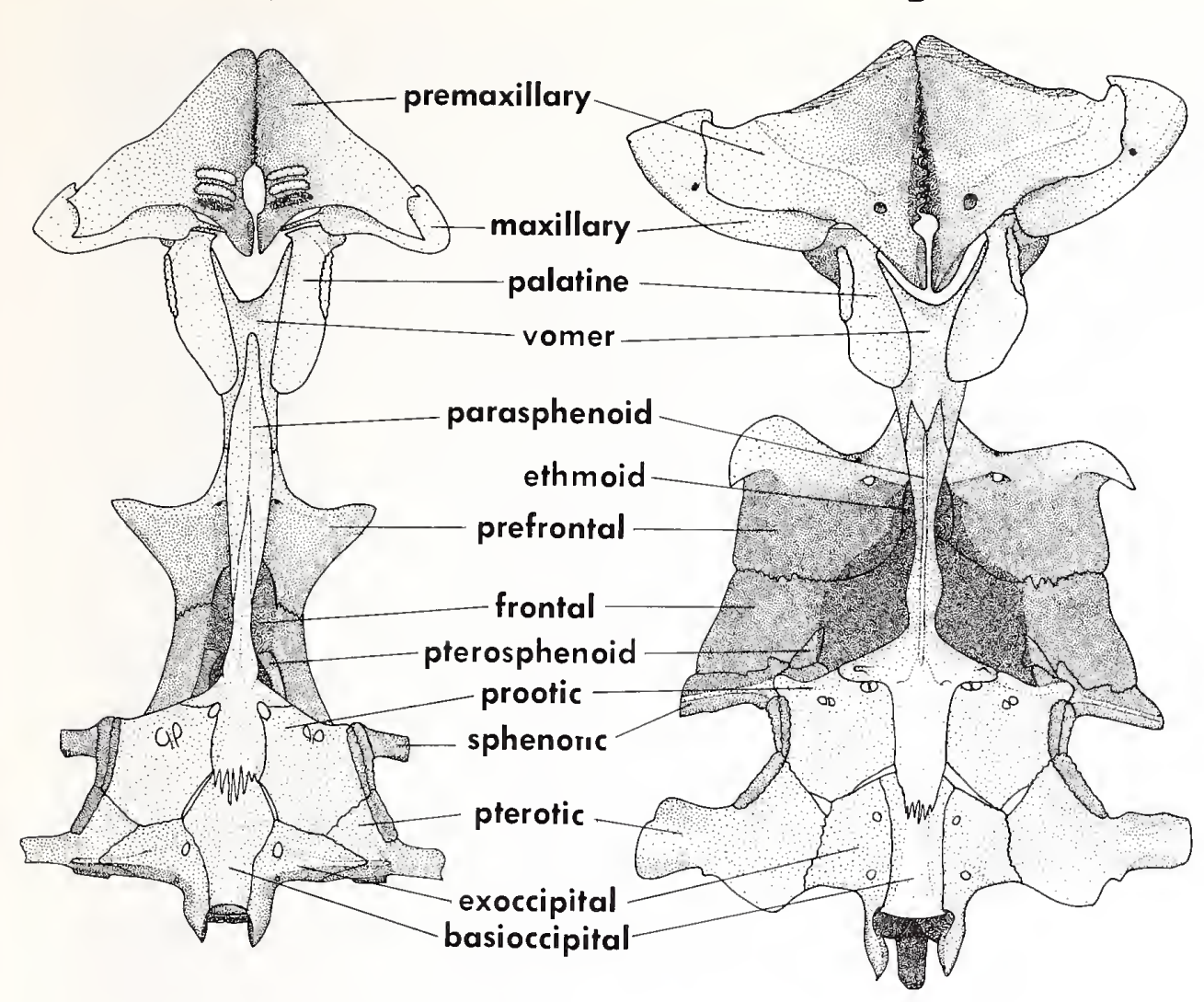

Figure 276. - Ventral views of skulls of: left, Sphoeroides maculatus, $179 \mathrm{~mm}$ SL, Virginia right, Arothron stellatus, ca. $420 \mathrm{~mm}$ SL, Seychelles.

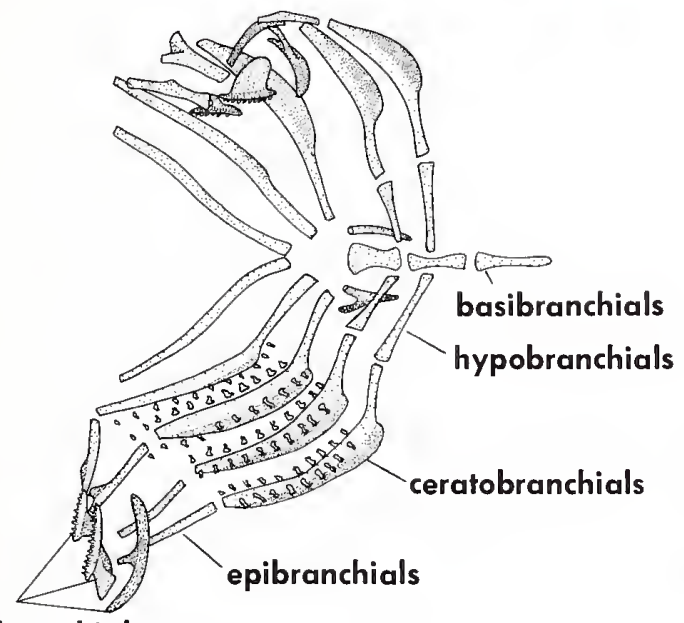

pharyngobranchials
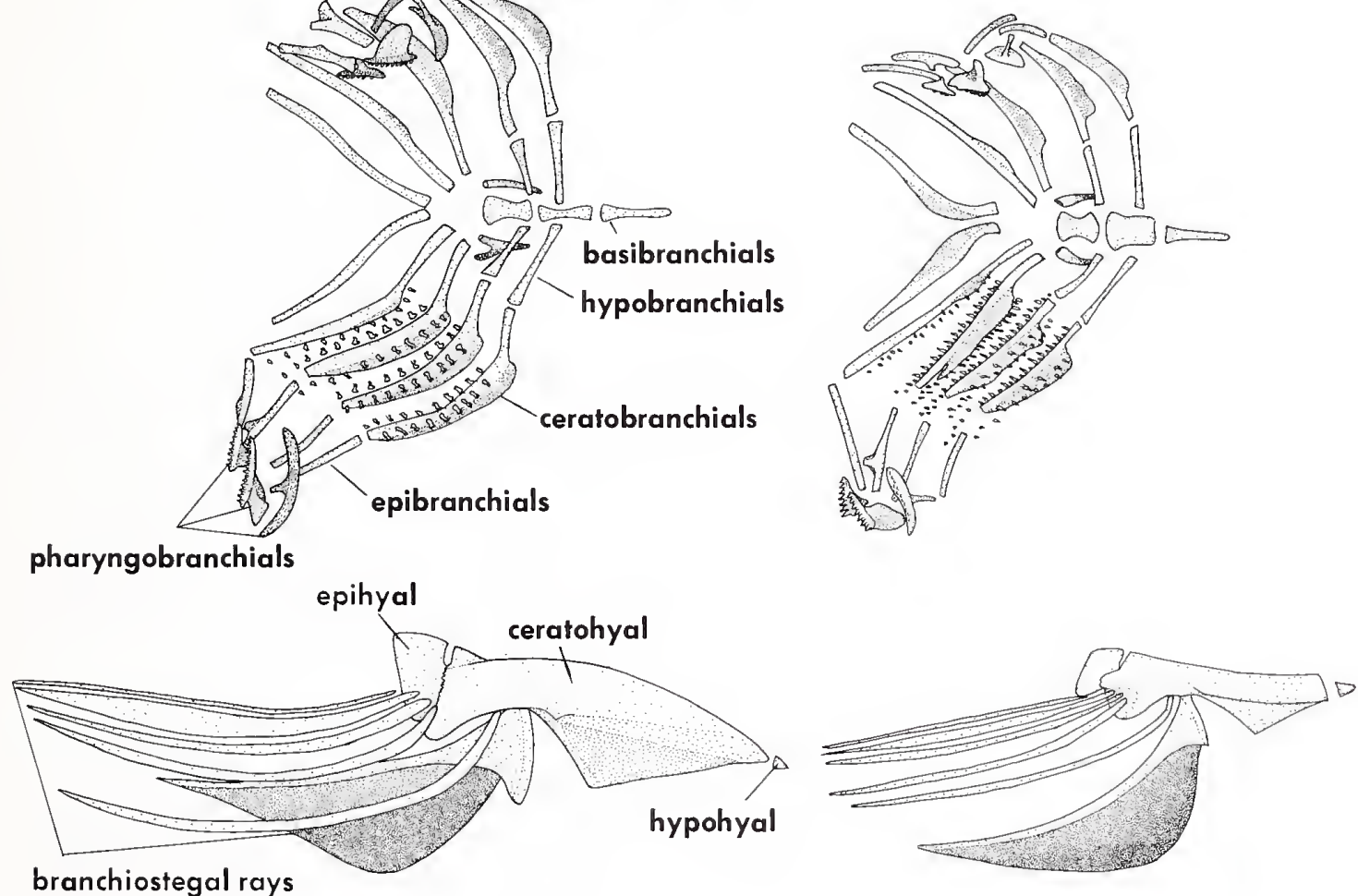

Figure 277.-Dorsal views of branchial arches (extended on lower side) and lateral views of hyoid arch of: (left) Xenop- terus naritus, $108 \mathrm{~mm} \mathrm{SL}$, Bay of Bengal; (right)

A rothron nigropunctatus,

$56.8 \mathrm{~mm} \mathrm{SL}$, Solomon Islands. 
ventral flange of the pterotic in lineatus has a goodly contribution from the exoccipital but in $m b u$ next to none. Tetraodon $\mathrm{mbu}$ is unique among the tetraodontids studied in completely lacking a pterosphenoid. The ethmoid-vomer-palatine region is essentially similar in both lineatus and $\mathrm{mbu}$, and the prefrontals differ mainly in that of lineatus having an anteromedial arm helping to enclose the olfactory foramen. The skull shape of Ephippion is not far removed from that of Tetraodon and both probably have a close common ancestral group, perhaps as close as that which unites Tetraodon with Monotreta and Chelonodon.

The only two species usually assigned to Chelonodon differ slightly more than do the two of Tetraodon examined. In $C$. fluviatilis, which has a deeply pitted olfactory epithelium, the frontals abruptly end anteriorly in a more or less straight transverse line at the rear edge of the prefrontals, the latter being relatively thin and entirely separated by the ethmoid. In C. patoca the frontals become narrower anteriorly over the orbit, but they do not stop abruptly at the level of the posterior edge of the prefrontals, continuing anteriorly as rapidly tapering points between the prefrontals, the latter being relatively thick and separated by both the ethmoid and frontals. The sphenotics in patoca are less anterodorsally extended than in fluviatilis. The skull condition in patoca is slightly more generalized than that of fluviatilis, and patoca retains a supraneural which is lost by fluviatilis. Both species lack any remnants of the dorsal roof of the myodome, and there is no interhyal and only one hypohyal. The parasphenoid has a dorsal flange in the orbit meeting the frontals and there are minute teeth on the first pharyngobranchial, while fluviatilis has numerous trituration teeth to either side of the midline in both the upper and lower jaws, and patoca has only two or three teeth in each series in the upper jaw and none in the lower jaw. The vertebrae are modally 18 in fluviatilis and 19 in patoca.

On the basis of the differences in the olfactory epithelium, and of fluviatilis having the lobes of the olfactory apparatus oriented parallel to the body versus at a right angle to it in patoca, Le Danois (1959) generically separated fluviatilis (as Dichotomycterus) from patoca (Chelonodon). The validity of such minor nasal differences alone in distinguishing genera is highly questionable, but should other species assignable to Chelonodon other than the commonly collected fluviatilis and patoca come to light (a few valid species probably lurk among the numerous synonyms usually listed for each of these names) and fall into one or the other of the fluviatilis or patoca skull plans and not into intermediate types, there may be justification for establishing two genera for what is now Chelonodon.

The precise relationship of Chelonodon to Tetraodon and Monotreta is not clear on the basis of the present data.

As previously discussed, Chonerhinos and Xenopterus are highly specialized tetraodontids which have secondarily increased the number of vertebrae and of dorsal and anal fin rays, elaborated the lateral line system until there are approximately three lines on the body, increased the size and amount of folding of the olfactory epithelium in the open cup nasal apparatus, and increased the size of at least some of the spines, mostly those of the belly. The greater increase in numbers of vertebrae and dorsal and anal fin rays in Xenopterus indicates that it is the more specialized of the two, and this is also borne out in the structure of the skull. While both species are unique among the tetraodontids in the loss of the prefrontals (Fraser-Brunner 1943 said that the prefrontals are very small, but I find no trace of them at all), the skull of Chonerhinos otherwise is not markedly different from that of many of the species of the Monotreta-Chelonodon-Tetraodon group. The frontals of Chonerhinos are slightly wider over the middle of the orbit than more posteriorly and are tapered gradually and evenly to gently rounded points anteriorly that broadly overlie the relatively broad ethmoid, which is of moderate length, while the sphenotics are well extended anteroventrally, projecting out beyond the edges of the frontals and forming about the rear half of the upper edge of the orbit.

In Xenopterus the frontals are much more laterally expanded and thickened than in Chonerhinos, forming a large plate over most of the dorsal surface of the skull. In the two smaller specimens studied the frontals are normally articulated by interdigitation in the midline, but in the largest specimen the two frontals are indistinguishably fused to one another in about the middle third of their lengths. While the sphenotic of Xenopterus is about as anterolaterally extended as in Chonerhinos, it is nearly entirely overlain by the frontal and only its extreme distal end appears in dorsal view, projecting slightly beyond the edge of the frontal in about the middle of the upper edge of the orbit. The main body of the supraoccipital in Xenopterus is less wide than in Chonerhinos, but the supraoccipital crest is wider and heavier in the former than in the latter. In Xenopterus the neural and haemal spines of the penultimate vertebra become hyperostotic, but this does not occur in Chonerhinos.

The ethmoid in Xenopterus is shorter but broader than in Chonerhinos and in both genera the anterodorsal end of the vomer tends to fully fuse with the anteroventral end of the ethmoid. Both genera are also similar in having the pterosphenoids in contact with the parasphenoid in the rear of the orbit, the pterosphenoid, parasphenoid, and prootic forming a more elaborate and massive structure there than in any other tetraodontids. This is perhaps functionally similar to the bracing strut of a dorsal flange from the parasphenoid in the middle of the orbit to the under surface of the frontals as found in many other tetraodontids, but not in Chonerhinos and Xenopterus. The only other tetraodontids in which the pterosphenoid meets the parasphenoid are several species of Lagocephalus, but this is associated with the dorsal flange of the parasphenoid in the middle of the orbit and thus is not analogous to that in Chonerhinos and Xenopterus. In Xenopterus the supraneural is larger and deeper bodied than in Chonerhinos. Both genera lack any remnants of the dorsal roof of the myodome, there is no 
interhyal and only one hypohyal, the first pharyngobranchial has small to minute teeth and there are no trituration teeth in either jaw. A sesamoid articular was not found in the lower jaw of any of the specimens of Chonerhinos and Xenopterus examined, and these genera may be at least unusual, if not unique, among the tetraodontids in the loss of this element.

In short, the skull in the more generalized of these two specialized genera bears its greatest similarity to that of some of the species of Monotreta, Chelonodon, and Tetraodon, perhaps especially to the latter, but the precise relationship of Chonerhinos to any of them is unclear. One would expect Chonerhinos to have arisen from a line having a nasal sac with a single nostril, a welldeveloped lateral line system with at least one and a half or two lines on the body, a tendency to increase the number of dorsal and anal fin rays above the perhaps generalized number of about 10 to 12 and a tendency to increase the number of vertebrae above the generalized number of 20 , all of which features are found in varying degrees among one or the other of Monotreta, Chelonodon, and Tetraodon, and the ancestry of Chonerhinos is probably shared at one point with that of one or more of those three closely related genera.

Summary of generic relationships and intrafamilial classification.-Because of the complexity of the external and osteological diversity of the tetraodontids, most of the analyses of the generic relationships within the family are given in the preceding section on anatomical diversity, which need be only summarized here.

The genera having a nasal sac with two nostrils seem to form a natural group whose more generalized representatives are more generalized than most of those genera in which a single nostril is present at the end of a tube or in which there is a tentacle or an open cup nasal apparatus. Among the genera with two nostrils, Sphoeroides is the only one with a single lateral line, and its osteology seems to be overall the most generalized, with Lagocephalus and Colomesus derived from a Sphoeroides-like ancestral group, but from rather different lines of radiation within that group. Amblyrhynchotes, Fugu, and Torquigener may also have been derived from an early Sphoeroides-like group, and are probably more closely related to one another than to any of the other genera with two nostrils, but their more precise relationships are not clear on the basis of the present work.

The genera in which the nasal sac has opened up by the loss of the separation between the two nostrils are probably derived from an ancestral group with two nostrils and a single lateral line. A Carinotetraodon-like form is probably ancestral to Canthigaster, and Carinotetraodon itself is probably most closely related to Monotreta. Ephippion is probably a close derivative of a Tetraodon-like form, and the relationship between Monotreta, Chelonodon, and Tetraodon undoubtedly is close but the details of those relationships are not clear on the basis of the present work. The highly specialized
Chonerhinos and, progressively more so, Xenopterus are probably derived from the ancestry of the MonotretaChelonodon-Tetraodon group, but their more precise relationships remain unknown.

Canthigaster is deemed to be sufficiently anatomically distinct from the other tetraodontids to be recognized as subfamilially distinct (Canthigasterinae) from them (Tetraodontinae), although the author is biased toward the conservative approach of only subfamilial recognition for Canthigaster, since recently it usually is given full familial rank. Almost as much anatomical distinctiveness is present between Chonerhinos-Xenopterus and the other tetraodontins as there is between the canthigasterins and tetraodontins. Moreover, there is no genus known as closely intermediate between Chonerhinos-Xenopterus and the other tetraodontins as Carinotetraodon is between the canthigasterins and the other tetraodontins. Thus, there is no compelling reason to recognize Canthigaster as even subfamilially distinct, and it is done here more as a matter of personal preference than on the basis of persuasive anatomical evidence.

The argument against subfamilial recognition of Canthigaster could also take into account the situation

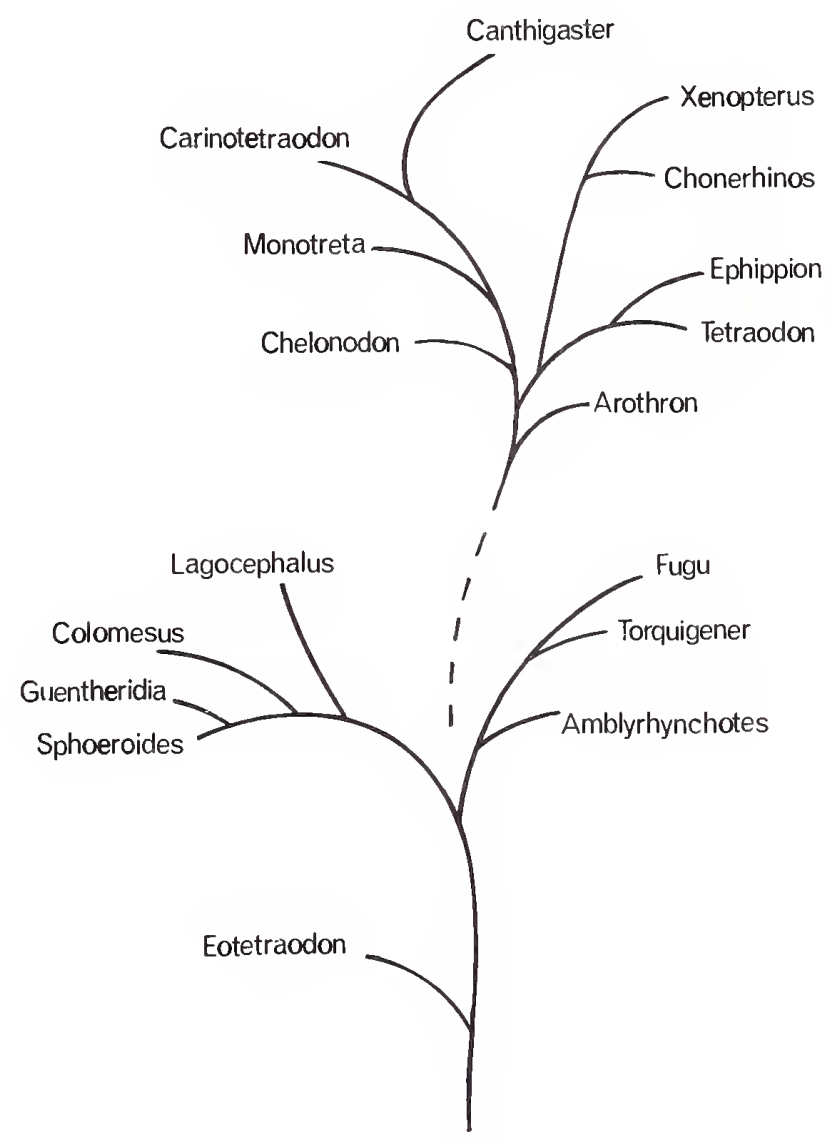

Figure 278.-Hypothesized phylogenetic relationships of the genera of Tetraodontidae. 
in the Monacanthidae and in the triacanthodid subfamily Triacanthodinae. In the monacanthids the highly specialized genus Psilocephalus could be considered as subfamilially distinct (as it sometimes has been in the past) from the monacanthids, and is not so recognized here mainly because some of the intermediates between its structure and that of more generalized monacanthids are found in some of the Alutera-like fishes. Similarly, the highly specialized monacanthid Pseudaluteres could be considered subfamilially distinct, and is not so recognized here mainly because it is clear that Oxymonacanthus is intermediate between it and the more generalized monacanthids, and an Oxymonacanthus-like form gave rise to it. In the triacanthodids, the two longsnouted highly specialized genera of the Recent subfamily Triacanthodinae could each be recognized as a distinct subgroup (tribe) and are not so recognized here mainly because a different genus is intermediate between each of the two long-snouted genera and the more generalized triacanthodins, i.e., a Bathyphylax-like line is ancestral to Halimochirurgus and one like Tydemania to Macrorhamphosodes.

Relationships to the Diodontidae and to the Other Tetraodontoidei.- The ways by which a triodontidlike ancestral group probably gave rise to two major lines of radiation, one leading to the tetraodontids and diodontids and the other to the molids, are discussed under the Triodontidae. The molids undoubtedly branched off the common ancestral line at a more generalized level of triodontidlike organization than did the tetraodontoids, for molids retain a significant number of important generalized features found in triodontids but not in tetraodontoids, even though molids superficially seem far removed from triodontids and almost totally specialized. In fact, the tetraodontoids are at least as highly specialized and as anatomically far removed from the ancestral triodontidlike fishes as are the molids, as further discussed under the Triodontidae.

In the vast majority of ways that tetraodontids differ from diodontids, tetraodontids retain more generalized, triodontidlike, conditions than do diodontids. But there are important exceptions in which diodontids have the more generalized conditions, indicating that the division of the ancestral line into tetraodontids and diodontids took place early in the evolution of the superfamily (Eocene, on the basis of the fossil record), with diodontids retaining a few generalized features while overall becoming far more specialized than the tetraodontids.

As previously discussed, it seems reasonable to assume that the ancestral eoplectins that gave rise to the triodontids and other gymnodont lines did so at a time when the premaxillaries and dentaries were not yet fused to their opposite members, but only interdigitated to them, and with the teeth in the biting edge of the jaws small rounded units incorporated into the matrix of the bone but retaining much of their individual identity. It is here assumed that the line of triodontidlike fishes which gave rise to the tetraodontoids had the premaxillaries and dentaries unfused and that the fusion of these bones to their opposite members in diodontids and molids has been independent. It is possible that the triodontidlike fishes which gave rise to the molids already had the dentaries fused, as in Triodon and at least Zignoichthys of the eoplectins, and that molids became further specialized by having the premaxillaries fused as well (along with numerous other specializations, including the loss of distinct teeth in the biting edge of the jaws).

While diodontids have the more specialized condition of fused premaxillaries and dentaries in relation to tetraodontids having both of these bones articulated to their opposite members by interlocking emarginations, the fusion of these two jaw bones is a relatively uncomplex event in comparison to the changes in the dental units incorporated into the matrix of the bone. Diodontids retain the generalized condition of small rounded dental units in the biting edge, just as in triodontids and eoplectins, while tetraodontids have extremely specialized teeth, perhaps the most specialized among teleosts, these being long, slender rods lying obliquely transverse to the body axis, parallel to the biting edge and incorporated into the matrix. The large trituration plates present in the upper and lower jaws of diodontids are of about the same size as those of Triodon, even though there are usually fewer series of teeth involved in the formation of the composite plates (see discussion under the diodontid Chilomycterus orbicularis). However, the form of the trituration teeth and plates has probably been highly variable in most groups of gymnodonts, correlated with changes of diet in newly occupied habitats, and not too much importance can be attached to the at least superficial similarity of the trituration plates in Triodon and diodontids, i.e., the trituration plates of diodontids are not necessarily to be considered generalized.

Other than the form of the teeth of the biting edge of the jaws, diodontids are more generalized and Triodonlike than tetraodontids only by: 1) the more frequent presence of both a dorsal and ventral hypohyal; 2) the presence of a prominent anteriorly directed prong on the suboperculum attached by ligament to the interoperculum; 3) having none of the basal pterygiophores of the dorsal and anal fin interdigitated to one another distally; and 4) the presence of a prominent lateral flange on the fused hypural plate, if this is homologous with the hypurapophysis of Triodon, which is debatable.

In all of the other far more numerous characters listed here in the comparative diagnoses of the tetraodontids and diodontids, the conditions found in the tetraodontids are the more generalized and the least far removed from those in the ancestral triodontids (preRecent Triodon level of organization).

The diodontids must thus be considered an early Eocene offshoot of the basal tetraodontids, with most of the diodontid specializations centering around a more highly defensively armoured exoskeleton variously of long erectile quills or short nonerectile spines with massive bases forming an open quilted carapace around a relatively slow swimming body with a reduced caudal region and usually relatively more massive jaws with a greater crushing and grinding function. 
Family Diodontidae

Comparative diagnosis (contrast with that of the Tetraodontidae). - Teeth incorporated into the matrix of the biting edge of the jaws as small and more or less rounded units; premaxillaries and dentaries fully fused to their opposite members in the midline; lateral surface of the maxillary with a deeply indented or laterally flanged surface, the thickened ridges increasing its strength; the jaws massive; a large trituration plate always present in the upper and lower jaws; first and second pharyngobranchials with minute teeth, third pharyngobranchial with minute teeth or toothless, and sometimes absent; dorsal and ventral hypohyal usually both present; interhyal never present; anterior edge of ectopterygoid relatively straight and only slightly concave; ethmoid and vomer greatly reduced in size and fused together into a relatively thin and functionless plate; palatine not notched posteriorly, but broadly sutured thereto, and taking its main support from, the frontal; prefrontal small or absent; frontals exceptionally wide and massive; anterior end of parasphenoid exceptionally wide and deeply concave, the concavity not being a place of articulation for other bones; rear margin of the orbit formed by the frontal alone; sphenotic with a long, slender, laterally directed sturdy prong from its anterolateral edge; frontal broadly in contact posteroventrally in the rear of the orbit with the prootic, and, to a lesser extent, with the pterosphenoid, but not in contact with the sphenotic; suboperculum with a prominent anteriorly directed prong attached by a short ligament to the posterior end of the interoperculum, the latter not articulating with the operculum; supracleithrum positioned horizontally almost in the same line as the axis of the body; postcleithrum a single short piece, no longer than about the distance along the scapula to the lowest actinost; supraoccipital crest dorsoventrally compressed and entirely in a horizontal plane, wider than deep throughout its length; exoccipital condyles poorly developed; all of the vertebrae anterior to the first basal pterygiophore of the dorsal fin and a few of those posterior to the last basal pterygiophore of the dorsal fin with bifid divergent neural spines; many of the more posterior abdominal vertebrae and several of the more anterior caudal vertebrae with prominent lateral flanges from the ventrolateral surfaces of the centra; neural spines of the vertebrae supporting the basal pterygiophores of the dorsal fin short and broad, not slender shafts and not penetrating deeply the interspaces between the pterygiophores; a supraneural element never present; none of the basal pterygiophores of the dorsal and anal fins interdigitated with one another; none of the abdominal vertebrae with haemal arches, complete or incomplete; several of the vertebrae posterior to the bases of the last basal pterygiophores of the dorsal and anal fins anteroposteriorly compressed, much shorter in centrum length than those more anteriorly; abdominal vertebrae always greater in number than the caudal vertebrae; dorsal and anal fins more posterior in position; only two vertebrae fully posterior to that whose haemal spine is the last support of the last anal fin basal pterygiophore; caudal fin supporting skeleton with no free epural, no free hypurals, and no free parhypural, and with the haemal spine of the penultimate vertebra fused to its centrum; a prominent lateral flange present on the fused hypural-centrum plate; haemal canal not penetrating the last verteb;al complex; caudal fin rays modally either 9 or 10 , in the ventral region of the fin only the single lowermost ray unbranched, perhaps 11 caudal rays in the Eocene Prodiodon; scales always relative massive, whether long erectile quills or shorter spines borne on a large triradiate plate, or some combination of erectile and fixed spines.

\section{Detailed description of Diodon holocanthus.}

Material examined:-Five cleared and stained specimens, $12.3-113 \mathrm{~mm}$; one dry partially disarticulated skeleton, $124 \mathrm{~mm}$.

\section{SKULL.}

\section{Occipital Region.}

Basioccipital. - A short column, expanded anterolaterally; cartilage filled at its anterior and anterolateral edges; articulates by interdigitation posterolaterally with the exoccipitals, anterolaterally with the prootics, and anteriorly with the overlying parasphenoid. In all of the specimens examined a certain amount of externally visible cartilage persists at the region of junction of the basioccipital, exoccipitals, and prootics, as it also does at the junction of the exoccipital, prootic, and pterotic and at the junction of the posterior portions of the parasphenoid and prootics. Extremely large specimens can be expected to have more extensive interdigitation and less cartilage visible in these areas than shown in the illustrations. The rim of the round concave posterior end of the basioccipital articulates by fibrous tissue with the rim of the concave anterior face of the first vertebra. The posterodorsal surface of the basioccipital forms the lower wall of the foramen magnum.

Exoccipital. - Cartilage filled at all of its edges of articulation with the other cranial bones; articulates by interdigitation anterodorsally with the epiotic, laterally with the pterotic, anteroventrally with the prootic, and
Figure 279.-Range of diversity in body form in the Diodontidae: Diodon holocanthus (left) and Chilomycterus schoepfi (right).

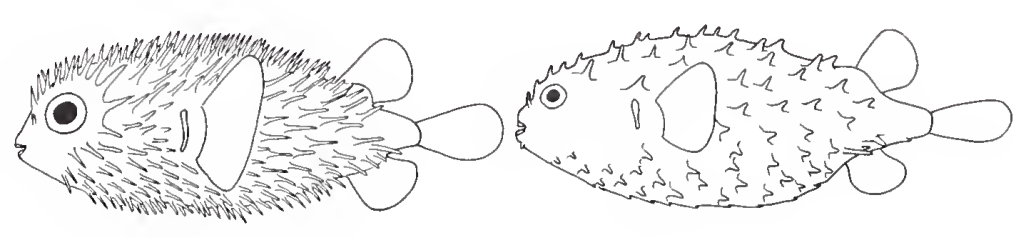



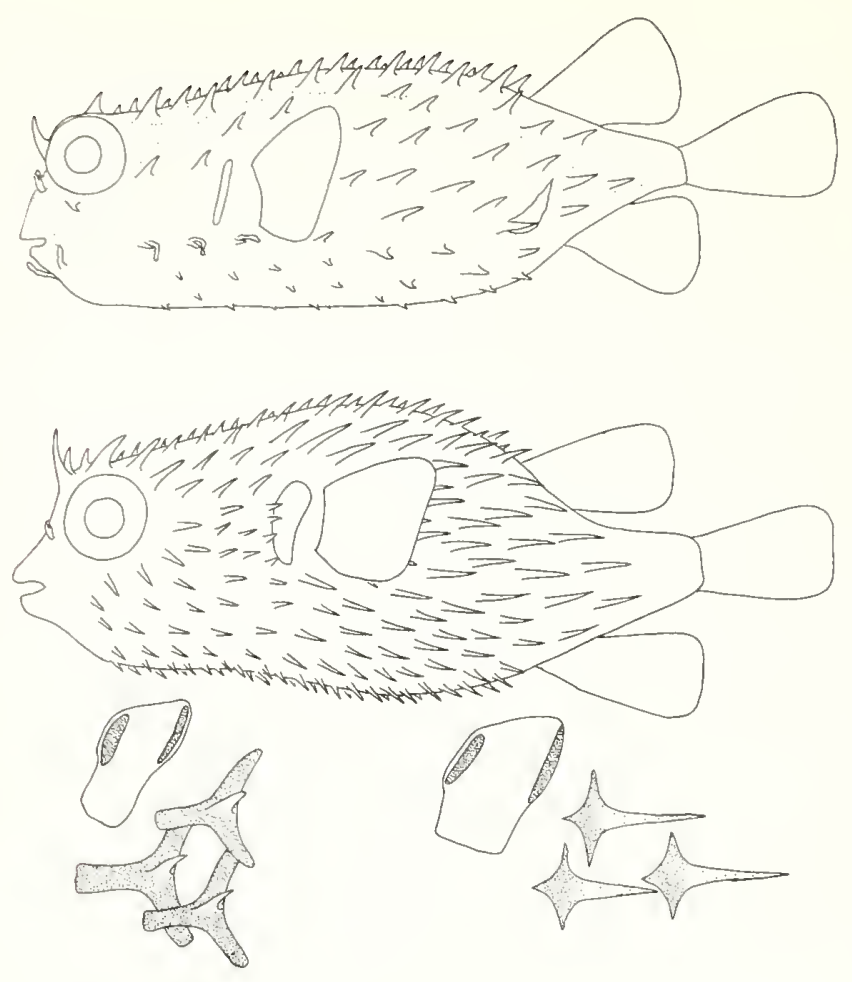

Figure 280.-Diodon holocanthus (center), with Chilomycterus schoepfi (above) for comparison: lower left, nasal region as seen externally and scales from upper middle region of body of C. schoepfi, and, lower right, nasal region as seen externally and scales from upper middle region of body of D. holocanthus; dotted line on figure of $C$. schoepfi shows the course of the lateral line canals and their major pores, as deciphered by placing drops of ink on each pore found by microscopic search of a partially drying specimen.

ventromedially with the basioccipital. Posteromedially the dorsal edges of the exoccipitals interdigitate with one another so that the dorsal as well as the lateral walls of the foramen magnum are formed by the exoccipitals. From the posterior end of its ventrolateral edge the exoccipital possesses a pair of short but sturdy processes which overlie and articulate by fibrous tissue with the anterolateral region of the first vertebra, these processes being the modified exoccipital condyle.

Supraoccipital. - A flat plate anteriorly, but drawn out posteriorly into a much depressed spine which reaches to about the level of the end of the first vertebral centrum; articulates by interdigitation anteriorly with the frontals, anterolaterally with the sphenotics, and posterolaterally with the epiotics and exoccipitals. The ventral surface of the anterior half of the supraoccipital spine interdigitates with the dorsomedial surfaces of the exoccipitals.

\section{Otic Region.}

Pterotic.-Expanded posterolaterally into a flattened, almost vertical, supporting strut for the pectoral girdle; broadly cartilage filled along its medial edges; articulates by interdigitation anterodorsally with the sphenotic, anteroventrally with the prootic, posteroventrally with the exoccipital, and dorsomedially with the epiotic. At a concavity on the posterior surface of its posterolaterally expanded portion, the pterotic articulates by fibrous tissue with the anterior end of the supracleithrum. Along the anterolateral edge of its ventral surface the pterotic supports the hyomandibular. This articulation between the pterotic and hyomandibular is by fibrous tissue anteriorly, but posteriorly the two bones become extensively interdigitated with one another

Sphenotic.-Confined to the dorsal and lateral portions of the skull and not entering into the formation of the wall of the orbit; cartilage filled along all. of its edges of articulation with the other cranial bones; articulates by interdigitation anteriorly with the frontal, medially with the supraoccipital, posteromedially with the epiotic, posterolaterally with the pterotic, and ventrolaterally with the prootic. The region of articulation between the sphenotic and prootic forms a concave surface to which the anterior half of the dorsal edge of the hyomandibular is held by fibrous tissue. The dorsolateral edge of the sphenotic possesses a stout, pronglike, lateral process which serves as the place of origin for muscles which insert on the operculum.

Epiotic. - A thin, more or less squarish plate; cartilage filled along all of its edges of articulation with the other cranial bones; articulates by interdigitation anteriorly with the sphenotic, medially with the supraoccipital, posteriorly with the exoccipital, and laterally with the pterotic.

Prootic. - Cartilage filled along all of its edges of articulation with the other cranial bones, except anteriorly; articulates by interdigitation anterodorsally with the frontal, anteromedially with the pterosphenoid, anteroventrally with the parasphenoid, posteromedially with the basioccipital, posteriorly with the exoccipital, posterolaterally with the pterotic, and laterally with the sphenotic. Medially on its ventral surface the prootic articulates with the lateral edge of the posterior end of the parasphenoid. This articulation is usually through cartilage, and only in large specimens do the two bones become interdigitated to any appreciable extent. Cartilage persists in this region long after it has at least mostly disappeared from external view between the region of junction of the basioccipital, exoccipital, and prootic and the region of junction of the prootic, exoccipital, and pterotic. There is no evidence of a myodome. Along the concave area at the region of articulation between the prootic and sphenotic, the hyomandibular is supported through fibrous tissue. This support is strengthened, however, by the extensive inter- 
digitation of the anterolateral edge of the prootic with the anterodorsal edge of the hyomandibular.

\section{Orbital Region.}

Frontal. - Extremely large and laterally expanded; articulates by interdigitation posteromedially with the supraoccipital, which it slightly overlies, and posterolaterally with the sphenotic. Medially along its ventral surface in the region of the orbital cavity the frontal interdigitates with the pterosphenoid. At its anterior end the frontal is extensively interdigitated medially with the palatine and laterally with the prefrontal, the latter bone being broadly overlain by the frontal. Along the posterior half of its medial edge the frontal interdigitates with its opposite member, but more anteriorly the medial edges of the two frontals articulate with one another only by fibrous tissue. Between the regions where the medial edge of the frontal is in close contact with its opposite member and where it interdigitates with the palatine, the frontal overlies the ethmoid cartilage.

Prefrontal. - A thin plate of extremely variable size, but always broadly overlain by the frontal and hence apparently very small as seen dorsally. The prefrontal articulates by extensive interdigitation medially with the palatine and posteriorly and laterally with the frontal.

Parasphenoid. - More or less in the form of a cross, with the longer shaft becoming increasingly deeper and wider toward its anterior end. The anterior end of the parasphenoid is so deeply concave that the cavity extends back posteriorly almost to the level of the shorter transverse arms of the parasphenoid. The parasphenoid articulates by interdigitation posterolaterally along the dorsal surface of its transverse arms with the prootics, while at its extreme posterior end the parasphenoid overlies and interdigitates with the basioccipital. Between its regions of interdigitation with the basioccipital and with the prootic, the parasphenoid has its lateral edges in contact with the cartilage that is present along the medial edges of the prootics. Anterolaterally the parasphenoid interdigitates with the medial edge of the palatine. The highly concave anterior end of the parasphenoid has its dorsal surface held to the ventral surface of the ethmoid cartilage. The posterior end of the platelike ossification that occurs between the ethmoid cartilage and the dorsal surface of the parasphenoid, to be described below as the ethmoid-vomer, is slightly overlain by and interdigitated with the anterior concave end of the parasphenoid. A very shallow ventral flange or keel is present along the medial portion of the ventral surface of the parasphenoid in the region under the orbital cavity.

Pterosphenoid. - Relatively elongate dorsoventrally; much wider dorsally than ventrally; cartilage filled along all of its edges, except medially; articulates by interdigitation dorsally with the frontal and ventrally with the prootic.

\section{Ethmoid Region.}

Ethmoid-vomer. - All that remains of the ossifications of the ethmoid region is a plate of bone which is very thin throughout its length, except at its anterior edge where it becomes substantially thicker. The plate of bone lies between the ventral surface of the ethmoid cartilage and the anterodorsal portion of the parasphenoid. The posterior end of the plate fits under and interdigitates with the inner surface of the dorsal half of the deeply concave anterior end of the parasphenoid, while the anterior edge of the plate lies anterior to the ethmoid cartilage. There is no evidence in any of the specimens examined that any of the edges of the plate are cartilage filled, but even if the plate were entirely an endochondral ossification the bone is so thin that one would not expect to find cartilage filled edges. Only by histological examination of the developing bone would it be possible to state whether the bone is of dermal or endochondral origin or of a combination of the two. From the position of the anterior portion of the plate (between the frontals and in at least close apposition with the ethmoid cartilage) one would suspect that the bone is the ethmoid. However, the posterior end of the bone fits into the concavity of the parasphenoid, a characteristic of the vomer in most plectognaths. Until histological examination of the development of the bone sheds light on its nature, I presume that it probably represents the fused rudiments of both the ethmoid and vomer.

\section{Mandibular Region.}

Hyomandibular. - Expanded dorsally, tapering to a stout shaft anteroventrally; cartilage filled at its anteroventral edge and along the middle of its dorsal edge; articulates dorsally by fibrous tissue with the concavity along the ventrolateral edges of the prootic and sphenotic and along the anterior half of the anteroventral edge of the pterotic. The support of the hyomandibular is further strengthened by the extensive interdigitation of its anterodorsal end with the anterolateral edge of the prootic and of its posterodorsal end with the ventrolateral edge of the pterotic. Anteriorly the hyomandibular articulates by fibrous tissue with the posterior ends of the metapterygoid and symplectic. In large specimens the articulation between the hyomandibular and the metapterygoid becomes slightly interdigitated. Along the ventral half of its posterior edge the hyomandibular articulates by fibrous tissue with the preoperculum. Immediately behind its uppermost point of contact with the preoperculum, the hyomandibular possesses an upraised region whose posterior surface is hollowed out to receive and hold by fibrous tissue the anterior rounded articular facet of the operculum.

Quadrate. -Wide posteriorly, tapering to a knob anteriorly for articulation with the articular in the lower jaw; only a very short posterior process present from its ventral edge between the symplectic and preoperculum; cartilage filled at its posterior edge; articulates by inter- 
digitation anterodorsally with the ectopterygoid and posteroventrally with the symplectic, which it broadly overlies; articulates by fibrous tissue ventrally with the preoperculum and through cartilage posteriorly with the metapterygoid. The anterior knoblike end of the quadrate articulates against the groove on the posterior edge of the articular in the lower jaw, with the fibrous tissue articulation strengthened by a short anteromedially directed process from the anterior edge of the quadrate just above its knoblike anteroventral end.

Metapterygoid. - A large plate of bone; cartilage filled along its anteroventral edge; articulates by interdigitation anterodorsally with the ectopterygoid and mesopterygoid and anteroventrally with the symplectic, all three of which bones the metapterygoid broadly overlies; articulates posteroventrally by fibrous tissue and slight interdigitation with the hyomandibular, while anteriorly it articulates through cartilage with the quadrate.

Symplectic. - Large; broadly overlain by both the metapterygoid and quadrate; cartilage filled at its posterior end; articulates through cartilage with the anterior end of the hyomandibular, and by interdigitation dorsally with the metapterygoid and anteriorly with the quadrate. Ventrally the symplectic articulates by fibrous tissue with the preoperculum.

\section{Palato-Pterygoid Region.}

Palatine.-Expanded dorsally into a horizontal plate; articulates by interdigitation dorsally with the frontal, ventrally with the ectopterygoid, and posterodorsally with the parasphenoid. Posteroventrally the palatine broadly overlies and articulates by slight interdigitation with the mesopterygoid. The anterior edge of the portion of the palatine which overlies the mesopterygoid is cartilage filled in all but the larger study specimens. Anterodorsally the rounded edge of the palatine articulates by fibrous tissue with the concave articular facet of the maxillary, while a medially directed prong from the anterior edge of the palatine articulates by fibrous tissue with the posteromedial edge of the premaxillary.

Ectopterygoid. - An almost straight shaft of bone, except for a thin posterodorsally expanded portion that interdigitates with the palatine, mesopterygoid, and metapterygoid; articulates by extensive interdigitation dorsally with the palatine and ventrally with the quadrate.

Mesopterygoid. - Somewhat variable in shape, but always broadly overlain by the palatine and metapterygoid; articulates anterodorsally by slight interdigitation with the palatine, while anteroventrally and posteroventrally it articulates by more extensive interdigitation with, respectively, the ectopterygoid and metapterygoid.

\section{Opercular Region.}

Operculum. - A large flat plate with a high, welldeveloped, lateral flange which ends dorsally by projecting over the hyomandibular to serve as a place of attachment for muscles originating on the lateral wing of the sphenotic; articulates by fibrous tissue ventrally with the suboperculum. The upper anterior edge of the operculum is laterally expanded into a stout facet for fibrous tissue articulation with the concave surface of the upraised area on the posterior edge of the hyomandibular.

Suboperculum. - A relatively flat plate, except for a lateral thickening along its edge of fibrous tissue articulation with the anterior edge of the operculum. From its anterodorsal region the suboperculum is prolonged anteriorly as a narrow shaft to a level slightly forward of the posterior edge of the preoperculum. The anterior end of this shaftlike process connects by a short ligament with the posterior end of the interoperculum.

Interoperculum. - A stout rod, with a large ventral flange in about the middle of its length; articulates by ligaments anteriorly with the angular in the lower jaw and posteriorly with the anterior end of the suboperculum. The medial surface of the ventral flange of the interoperculum articulates by fibrous tissue with the lateral surface of the epihyal and the posterolateral surface of the ceratohyal.

Preoperculum. --Large; expanded posteroventrally; its dorsal edge somewhat laterally expanded to form a broad surface of fibrous tissue articulation with the ventral edges of the quadrate, symplectic, and hyomandibular.

\section{Upper Jaw.}

Premaxillary. --The two premaxillaries are indistinguishable fused in the midline and together with the fused teeth form a massive crushing plate; anterior edge of premaxillary forming the border of the upper jaw for about the dorsal two-thirds of that border, ventral to which the maxillary forms the anterior edge of the upper jaw. In the middorsal line the fused premaxillaries form a short posteromedial process which articulates by fibrous tissue with the palatines and the ethmoid-vomer. Posterolaterally the premaxillaries are broadly overlain by and extensively interdigitated with the maxillaries. The fused teeth of the premaxillary are closely similar to those described for Triodon. They are small, discrete, individual pieces formed in the relatively small pulp cavity of the premaxillaries. They move forward toward the edge of the jaw and become closely packed against one another in the bony matrix that surrounds them. By the time they reach the leading edge of the jaw they are so densely packed together that they have lost much of their individuality, at least in large specimens. Whether the teeth at the edge of the jaw ever truly fuse indistinguishably with themselves and the premaxillary is again a 
matter for histological study. The remains of approximately 20 of the formerly separate dental units can be seen along the edge of the premaxillary to either side of the midline and to a depth of 5 to 10 units posteriorly from the edge. At the posterior end of the tooth bearing region, the sockets surrounding the individual primordia open to the exterior on the outer surface of the premaxillaries by small pores, similar to those described for Triodon. A large trituration plate is present in the dorsomedial region of the inner surface of the fused premaxillaries. The trituration plate is divided into right and left halves whose medial edges are in close contact. Each plate has its relatively flat surface marked by approximately five parallel grooves which show the limits of the originally separate dental plates that are now fused together in a solid mass. These dental plates are formed in a large pulp cavity, above the trituration plate, which is separated from the pulp cavity in which the teeth of the jaws are formed by a thin bony partition and which is broadly open to the exterior posteriorly to either side of the midline. The newly developed platelike trituration teeth are obliquely placed in an anterodorsal to posteroventral plane at about a $45^{\circ}$ angle to the surface of the trituration plate. At first, only the posteroventral edge of the new tooth plate is exposed at the surface of the trituration plate, but as the tooth is moved forward and downward, its whole substance is gradually worn away. As the tooth plates are moved forward they become more and more closely packed together, until they lose most of their individual identity, at least in larger specimens.

Maxillary. - Expanded ventrally where it forms the lower one-third of the anterior margin of the upper jaw; broadly overlies and extensively interdigitates with the premaxillary. The medial surface of its free ventral end articulates by fibrous tissue with the dorsolateral surface of the dentary. Posterodorsally the maxillary possesses a medially directed process which runs under the anterior end of the palatine to make fibrous tissue contact with the lateral edge of the posteromedial projection of the fused premaxillaries. The concavity on the posterodorsal edge of the maxillary articulates by fibrous tissue with the anterior end of the palatine. In about the middle of its length the maxillary is laterally expanded into a heavy flange which serves as a place for muscle attachment.

\section{Lower Jaw.}

Dentary. - The two dentaries are indistinguishably fused in the midline, and, like the premaxillaries, form a huge crushing beak in conjunction with the fused teeth. The concave posteromedial surface of the dentary interdigitates with the lateral surface of the articular. Posteroventrally the dentary interdigitates with the angular. A large trituration plate, divided into right and left halves in close contact with one another, is present in the medial region of the inner surface of the fused dentaries. The structure and development of the dental units of the trituration plate and biting edge of the lower jaw are exactly like that described for the premaxillary, except that the internal cavity for the dental pulp is somewhat smaller. The dorsolateral surface of the dentary articulates by fibrous tissue with the ventromedial surface of the maxillary.

Articular. -More or less triangular in shape; its posterior edge laterally expanded basally and bearing a groove for fibrous tissue articulation with the quadrate; cartilage filled for only a short distance anteriorly where it is continuous with the remains of Meckel's cartilage; articulates by extensive interdigitation anteriorly with the dentary and posteroventrally with the angular. The sesamoid articular is a nubbin of bone, of variable size, which is usually interdigitated with the articular just above and posterior to the remains of Meckel's cartilage.

Angular. - A small bone interdigitated anteriorly with the dentary and dorsally with the articular. Posteriorly the angular attaches by ligament to the interoperculum.

\section{BRANCHIAL APPARATUS.}

\section{Hyoid Arch and Branchiostegal Rays.}

Hypohyals. - Dorsal and ventral hypohyals present; the ventral hypohyal about twice as large as the dorsal hypohyal; dorsal hypohyal cartilage filled at its ventral edge, ventral hypohyal cartilage filled at its posterior edge; articulate through cartilage with one another and with the anterior end of the ceratohyal; articulate by fibrous tissue medially with their opposite members.

Ceratohyal. - Somewhat expanded posteriorly; cartilage filled at its anterior and posterior edges; articulates through cartilage anteriorly with the hypohyals, and through cartilage and slight interdigitation posteriorly with the epihyal, which it overlies. All six branchiostegal rays articulate by fibrous tissue with the ceratohyal, the platelike first ray with a vertical groove on the medial surface in about the middle of its length, as explained below.

Epihyal. - Round and broadly overlain by the posterior end of the ceratohyal, with which it articulates through cartilage and slight interdigitation. The lateral surface of the epihyal articulates by fibrous tissue with the medial surface of the ventral flange of the interoperculum.

Branchiostegal rays. - Six in number; the first branchiostegal ray a large plate, of increasing width posteriorly, whose lateral edge is sharply downturned and whose medial edge is more gradually upturned. Anteriorly the downturned lateral edge of the first branchiostegal becomes thickened into a vertical articular face which fits against the vertical groove on the medial surface of the ceratohyal. The second branchiostegal ray is a 
normally tapering shaft, articulating with a slight indentation on the ventromedial surface of the ceratohyal just posterior to the articulation of the first branchiostegal. The third to sixth branchiostegal rays articulate one just behind the other with the lower half of the posterolateral surface of the ceratohyal. The third branchiostegal is more laterally expanded in the anterior third of its length than are the other rays.

Branchial Arches. - All the elements are cartilage filled at their edges of articulation with the other elements of the series, and the articulations are usually through cartilage and fibrous tissue. The branchial arches are composed of three basibranchials, three pairs of hypobranchials, five pairs of ceratobranchials, four pairs of epibranchials, and three pairs of pharyngobranchials. Three gills are present; the fourth arch has no gill and there is no slit between the fourth arch and the lower pharyngeal.

First arch.-Basi-, hypo-, cerato-, epi-, and pharyngobranchial elements present. First basibranchial the largest of the basibranchial elements; displaced forward so that it articulates posteriorly with the second basibranchial and posterolaterally with the first hypobranchials. First hypobranchial the longest of the hypobranchial elements; articulates ventrally with the region of articulation between the first and second basibranchials and dorsally with the first ceratobranchial. First ceratobranchial the shortest of the ceratobranchial elements, which, except for the first ceratobranchial, increase in length posteriorly in the series; possesses weakly developed flanges from its anteroventral and posteroventral edges, similar flanges being increasingly well developed on the second and third ceratobranchials but not present on the fourth or fifth ceratobranchials; articulates ventrally with the first hypobranchial and dorsally with the first epibranchial. First epibranchial a slender rod; articulates dorsally with an upraised area on the anterodorsal surface of the first pharyngobranchial. First pharyngobranchial a relatively flat plate; wider laterally than medially; bearing over all of its ventral surface innumerable, small, villiform teeth, slightly larger in the posterior region than anteriorly; articulates at an upraised area on its anterodorsal surface with the first epibranchial and at an upraised area on its posterodorsal surface with the second epibranchial.

Second arch.-Basi-, hypo-, cerato-, epi-, and pharyngobranchial elements present. Second basibranchial the smallest of the basibranchial elements; articulates anteriorly with the first basibranchial, anterolaterally with the first hypobranchials, posteriorly with the third basibranchial, and posterolaterally with the second hypobranchials. Second hypobranchial the shortest of the hypobranchial elements; articulates ventrally at the region of articulation between the second and third basibranchials and dorsally with the second ceratobranchial. Second ceratobranchial articulated dorsally with the second epibranchial. Second epibranchial a long slender rod; like the first epibranchial, but with a slight expansion on its posterior edge for fibrous tissue articulation with the third epibranchial; articulates dorsally principally to the upraised area on the second pharyngobranchial, only secondarily with the upraised area on the posterodorsal surface of the first pharyngobranchial. Second pharyngobranchial the longest of the pharyngobranchial elements; its toothed surface narrower but longer than that of the first pharyngobranchial; innumerable villiform teeth present, like those on the first pharyngobranchial, but with those along the posterior edge distinctly larger than more anteriorly; articulates at an upraised area on its dorsal surface principally with the second epibranchial but also with the anterodorsal end of the third epibranchial.

Third arch.-Basi-, hypo-, cerato-, epi-, and pharyngobranchial elements present. Third basibranchial somewhat wider posteriorly than anteriorly; articulates anteriorly with the second basibranchial, anterolaterally with the second hypobranchials, posterolaterally with the third hypobranchials, and posteriorly with the fourth ceratobranchials. Third hypobranchial almost as long as the first hypobranchial; directed anteroventrally under the second hypobranchial, with its narrow anterior end articulated by fibrous tissue with the region of the first basibranchial and dorsal hypohyals. Third ceratobranchial articulated ventrally with the third hypobranchial and dorsally with the third epibranchial. Third epibranchial thicker than those anterior to it; expanded dorsally into two short flanges, the more anterior of which articulates with the upraised area on the second pharyngobranchial, while the more posterior flange articulates with the anterior edge of the fourth epibranchial. Third pharyngobranchial an elongate, thin, flat plate; toothless; held in place primarily by fibrous tissue to the posterior edge of the second pharyngobranchial, without any special connection with any of the other branchial elements.

Fourth arch. - Cerato- and epibranchial elements only. Fourth ceratobranchial a stout shaft; without ventral flanges; the longest of the ceratobranchial elements; articulates ventrally with the third basibranchial and dorsally with the fourth epibranchial. Fourth epibranchial by far the longest and stoutest of the epibranchial elements; somewhat produced into a thin flange posteriorly along the lower two-thirds of its length; articulates ventrally with the fourth ceratobranchial, while dorsally it ends in the general fibrous tissue that binds the dorsal surfaces of the pharyngobranchial elements to the ventral surfaces of the parasphenoid and prootics.

Fifth arch. - Ceratobranchial (lower pharyngeal) element only. Fifth ceratobranchial large; slightly expanded laterally along most of its length; toothless; articulates ventrally with the base of the fourth ceratobranchial. 


\section{PAIRED FIN GIRDLES.}

\section{Pectoral Fin.}

Supracleithrum. - In position almost parallel to the axis of the body; a round shaft anteriorly, but becoming wider and dorsoventrally depressed posteriorly; articulates at its rounded anterior end by fibrous tissue with the concavity on the posterior surface of the laterally directed wings of the pterotic. The posterior portion of the supracleithrum overlies and articulates by fibrous tissue with the dorsolateral surface of the cleithrum and postcleithrum.

Cleithrum. - Wide dorsally, but tapering to a narrow shaft in the lower third of its length; much expanded posterolaterally throughout the middle of its length. The cleithrum articulates by fibrous tissue dorsally with the overlying supracleithrum and with the anterior half of the ventral edge of the postcleithrum, which it overlies. Posterodorsally the cleithrum articulates by fibrous tissue and slight interdigitation with the anterior edge of the scapula. Along its posterior edge, in about the middle of its length, the cleithrum articulates by fibrous tissue with the anterodorsal and anteroventral edges of the coracoid. The anterior ends of the two cleithra articulate with each other by fibrous tissue in the midventral line of the body between the medial edges of the platelike portions of the first branchiostegal rays at the level of the end of the ceratohyal.

Postcleithrum. - A rounded shaft anteriorly, but becoming compressed posteriorly into a thin sheet whose outline is highly irregular from specimen to specimen. In none of the specimens is there any evidence of two separate elements making up the postcleithrum, for the dorsal and ventral postcleithra apparently have fused into one piece. The postcleithrum articulates by fibrous tissue anteriorly with the cleithrum and supracleithrum.

Coracoid.-Constricted in the middle, but expanded dorsally and even more expanded ventrally; cartilage filled along its dorsal and anteroventral edges; articulates by fibrous tissue anterodorsally and anteroventrally with the cleithrum, while dorsally it articulates through cartilage with the base of the scapula and bases of the second to fourth actinosts.

Scapula. - Scapular foramen not entirely enclosed by the scapula, but, rather, with the lower half of its anterior edge closed by the cleithrum; cartilage filled at its dorsal and ventral edges; articulates by interdigitation anteriorly with the cleithrum, posterodorsally with the anterior edge of the first actinost and posteroventrally with the anteroventral edge of the second actinost. Ventrally the scapula is supported through cartilage by the coracoid.
Actinosts. - Four elements; all cartilage filled at both ends, except for the reduced first actinost, which is cartilage filled only dorsally; first actinost a triangular wedge interdigitating with the dorsal half of the posterior edge of the scapula and the anterodorsal edge of the second actinost; second, third, and fourth actinosts more or less constricted in the middle, but with decreasing amounts of constriction from the second to the fourth. The second, third, and fourth actinosts interdigitate with one another at their ventral edges of contact, and the anteroventral edge of the second actin sst interdigitates with the posteroventral edge of the scapula. Dorsally the first, second, and third actinosts interdigitate with one another. The fourth actinost articulates anterodorsally with the third actinost by fibrous tissue in some specimens but by interdigitation in others. The second to fourth actinosts are supported basally through cartilage by the coracoid. Distally the actinosts and scapula support by fibrous tissue most of the fin rays.

Fin rays. - Twenty-two to twenty-four fin rays present in most specimens; the first ray very small and divided into two halves throughout its length, the medial half much larger than the lateral half. The first ray articulates by fibrous tissue with the scapula, whereas the other rays articulate with the actinosts. The first two rays and the last ray are unbranched; all the others are branched. First ray without cross-striations, the others cross-striated.

VERTEBRAL COLUMN. - All vertebrae with biconcave centra, except for the last, which ends posteriorly in fusion with the parhypural and hypurals.

Abdominal Vertebrae.

First vertebra. - Neural spine bifid; neural arch with a bony roof over the neural canal, the shelflike medial processes from each side of the neural arch meeting and interdigitating in the midline; articulates by fibrous tissue over the upper half of the anterolateral surface of its centrum with the short exoccipital condyles, while the rim of the concave anterior end of the centrum rests against the rim of the concave posterior end of the basioccipital. The deeply concave posterolateral edge of the neural arch articulates by fibrous tissue with the anteriorly projecting neural prezygapophysis of the second vertebra.

Other abdominal vertebrae. - Twelve abdominal vertebrae in 10 specimens. The 1 st to the 11 th abdominal vertebrae have bifid and divergent neural spines. The bifid neural spines are of about the same height on all the vertebrae, but the anteroposterior length of the spines increases from the 1st to about the 4th abdominal vertebra and then decreases from the 5 th to the 11 th abdominal vertebra. Shelflike medial projections from each side of the neural arch meet and interdigitate (or even fuse) in the midline to form the bony 
roof over the neural canal on the first to ninth abdominal vertebrae. The 10 th and 11 th abdominal vertebrae have no such bony roof over the neural canal, the canal being roofed over between the divergent neural spines of these two vertebrae only by fibrous tissue. The dorsomedial region of the bony roof over the neural canal becomes upraised into what is, in effect, a third neural spine on some of the abdominal vertebrae. There is only a trace of such a dorsomedial flange on the third ab. dominal vertebra but on the fourth abdominal vertebra it is distinctly present, and by the fifth and sixth abdominal vertebrae it reaches its maximum development, then becomes progressively less well developed on the seventh and eighth abdominal vertebrae until by the ninth abdominal vertebra it is no longer present. At its greatest development, on the fifth and sixth abdominal vertebrae, this dorsomedial flange is prolonged anteriorly to such an extent that it protrudes over the posterior region of the neural arch of the preceding vertebra, with fibrous tissue attaching it to the bony roof over the neural canal. Neural prezygapophyses are well developed on all of the abdominal vertebrae and articulate by fibrous tissue with the posterodorsal regions of the lateral surfaces of the centrum just anterior to them. Haemal arches are not present on any of the ab. dominal vertebrae, but from the 9 th to 12 th abdominal vertebrae progressively larger ventrolateral flanges are present from the ventrolateral edges of the centra. These flanges are the place of attachment of large muscle masses. The 12 th abdominal vertebra differs from the other abdominal vertebrae in that its neural arch does not possess a bifid and divergent neural spine. From the base of its neural arch area two broad plates project dorsally and slightly medially to meet the bases of the first two dorsal fin basal pterygiophores. There is no distinct bony roof over the neural canal of the 12th abdominal vertebra, the functional roof being formed by the fibrous tissue articulation of the ventral ends of the basal pterygiophores with the dorsal ends of the lateral walls of the neural arches.

Caudal Vertebrae. - Nine caudal vertebrae in 10 specimens; the first six caudal vertebrae variously supporting the dorsal and anal fin basal pterygiophores. The first three caudal vertebrae are structurally similar to the last abdominal vertebra, but their ventrolateral flanges become progressively shorter, and delicate posteroventrally directed processes from the ventrolateral surfaces of their centra are present which articulate by fibrous tissue with the dorsal ends of the anal fin basal pterygiophores. As is the case with the last abdominal vertebra, the lateral walls of the neural arches of the first three caudal vertebrae articulate by fibrous tissue dorsally with the ventral ends of the dorsal fin basal pterygiophores. The fourth caudal vertebra differs from the preceding caudal vertebrae by the only slight development of its ventrolateral flange, and by the presence along the posterior half of the dorsal surface of its neural arch of a bifid and divergent neural spine. The anterior half of the dorsal surface of this neural arch possesses the dorsomedially directed bony plates which articulate by fibrous tissue with the bases of the last two dorsal fin basal pterygiophores, in the same way as described for the preceding caudal vertebrae. From its posteroventral edge the fourth caudal vertebra possesses a short posterior process which articulates by fibrous tissue with an anteriorly directed prong from the haemal process of the fifth caudal vertebra. The fifth caudal vertebra possesses a bifid and divergent neural spine between which is supported by fibrous tissue the last dorsal fin basal pterygiophore, with no bony roof present over the neural canal between the medial edges of its divergent neural spine. Delicate ventral processes are present from the ventrolateral edges of the fifth caudal vertebra which support the dorsal end of the last anal fin basal pterygiophore, while a bifid and divergent haemal process is present ventrally to either side of the upper end of the last anal fin basal pterygiophore. There is no special bony roof over the haemal canal, except the functional one formed by the ventral processes of the fifth caudal vertebra meeting with the dorsal end of the last anal fin basal pterygiophore. The anterior edge of the bifid haemal process is produced into a short prong which articulates by fibrous tissue with the posterior process from the fourth caudal vertebra. The sixth and seventh caudal vertebrae are similar to one another, their centra being relatively short anteroposteriorly and both possessing bifid neural and haemal spines. No bony roofs are present between these bifid neural and haemal spines, so that the neural and haemal canals are roofed over only by fibrous tissue. The anterior edges of the neural and haemal spines of the sixth caudal vertebra support by fibrous tissue, respectively, the last dorsal fin basal pterygiophore and the last anal fin basal pterygiophore. The eighth caudal vertebra has its neural and haemal spines bifid and divergent anteriorly, but as single medial plates posteriorly. The undivided posterior portions of the neural and haemal spines of this vertebra are posteriorly expanded, and they interdigitate with the anterior edge of the plate formed by the last vertebra and associated caudal fin supporting elements. From the lateral surface of the haemal spine of the eighth abdominal vertebra, a posteriorly directed process is present which articulates by fibrous tissue with the anteriorly directed process from the last vertebral segment.

Caudal Skeleton. - The caudal fin supporting structures are consolidated into a single plate which in adults shows only meager traces of areas of suturing or fusion of the originally separate elements. In specimens smaller than about $100 \mathrm{~mm}$, however, at least one of the elements retains its individuality, this being the epural. The elongate epural is interdigitated with the posterior edge of the neural spine of the eighth caudal vertebra and with the anterodorsal edge of the main portion of the plate supporting the caudal fin. In larger specimens the suturing between these two elements becomes obscure and true fusion may take place. Anteroventrally on the caudal plate in the smaller study specimens there is some indication of an originally separate parhypural having 
fused with the main body of the plate, but even in the $12.3 \mathrm{~mm}$ specimen this thinner parhypural region is continuous with the main body of the plate. The rest of the plate is composed of the last vertebral centrum fused with all of the hypural elements. In about the anterior two-thirds of its length the caudal plate possesses a lateral flange whose depth increases anteriorly. The anterior end of the lateral flange articulates by fibrous tissue with the posterolateral process from the haemal spine of the penultimate vertebra. The posterior edge of the caudal plate supports the caudal fin rays.

Caudal fin rays. - Nine in number; the uppermost ray and the lowermost ray unbranched, the other rays becoming increasingly branched toward the middle rays, which are branched in triple dichotomies. The bifid bases of the rays articulate by fibrous tissue with the posterior edge of the caudal plate.

\section{DORSAL AND ANAL FINS.}

\section{Dorsal Fin.}

Fin rays and pterygiophores. - Fifteen fin rays usually present, the first two rays and the last ray unbranched, the others branched in single or double dichotomies. Distal pterygiophores either absent or unossified. The fin rays are supported through fibrous tissue at their bifid bases by 12 basal pterygiophores. The pterygiophores are cartilage filled at both ends, and all of them, with the exception of the last, are stout rods which decrease in width posteriorly in the series. The last pterygiophore is rodlike anteriorly, but posteriorly it is expanded into a flat plate. The ventral edge of the last pterygiophore articulates by fibrous tissue with the bony roofs over the neural canal of the fourth and fifth caudal vertebrae. The other pterygiophores articulate ventrally by fibrous tissue with the irregular dorsal edges of the neural arch plates of the 12 th abdominal to 4 th caudal vertebrae. The pterygiophores articulate by fibrous tissue dorsally with one another and with the dorsal fin rays.

\section{Anal Fin.}

Fin rays and pterygiophores. - Thirteen or fourteen fin rays usually present; the first two rays and the last ray unbranched, the others branched in single or double dichotomies. Distal pterygiophores either absent or unossified. The fin rays are supported through fibrous tissue at their bifid bases by nine basal pterygiophores. The basal pterygiophores decrease slightly in length posteriorly in the series and are all, with the exception of the last pterygiophore, stout rods. The last pterygiophore is rodlike anteriorly, but slightly expanded posteriorly into a flat plate. The amount of expansion of the last anal fin pterygiophore is not equal to that of the last dorsal fin pterygiophore, but in large specimens the difference is not great. The pterygiophores are cartilage filled at both ends. The dorsal ends of the pterygiophores articulate by fibrous tissue with the irregular ventral edges of the haemal processes of the first to fifth caudal vertebrae. At their distal ends the pterygiophores articulate with one another by fibrous tissue.

Anatomical diversity.-.-The few genera of Recent diodontids form an anatomically compact family of gymnodonts that has probably changed little in overall configuration since the Eocene, with the exception of an increase in the size of the scales and in certain rearrangements of the dentition and jaw supporting structures.

The few relatively complete fossil diodontids are from the Eocene of Monte Bolca, Italy, and are referable to Diodon tenuispinus Agassiz and D. erinaceus Agassiz. Agassiz (1844b) simply said that $D$. erinaceus was larger and rounder, and had shorter and heavier spines, than in the more fully described $D$. tenuispinus. The types of $D$. tenuispinus are in Paris, and Le Danois $(1955,1959)$ proposed the new generic name Prodiodon for tenuispinus on the basis of the supposedly anteriorly elongate sphenotics broadly entering the edge of the orbit above and of the supposedly sutured (rather than fully fused) premaxillaries which would distinguish tenuispinus from all Recent species.

The three type-specimens of $P$. tenuispinus (see Material Examined) have been examined for this work. None of the three show much detail of the jaws, skull structure, vertebral column, and armament. A dorsal view illustration of the only one of these three specimens that is in counterpart, and considered at the Paris museum to be the holotype, is presented by Le Danois (1959:215, fig. 184). The illustration, in my opinion, is wildly inaccurate and impressionistic, being rendered with heights of artistic license. I find it difficult to decipher any pertinent details in the dorsoventrally compressed and probably fractured cranium, but Le Danois showed the shapes and sizes of most of the bones there, with the sphenotic being quite unlike that of any Recent species, lacking a lateral prong and being prolonged anteriorly to form much of the lateral edge of the upper orbit, much as in the tetraodontid Colomesus. I seriously doubt that the degree of detail shown in the illustration by Le Danois is actually present.

Le Danois described and showed the upper jaws with the premaxillaries sutured as in tetraodontids, with interlocking emarginations, while saying that the dentaries are either fused to one another or at least closely attached. To my eyes the jaws that are exposed in the three specimens seem to be fully fused medially without any evidence of sutured right and left halves. Several transversely elongate trituration teeth are present to either side of the midline on what is apparently the inner surface of the lower jaw in the specimen in counterpart. Le Danois showed the pectoral and dorsal fins far more clearly than they exist on the specimen. What vague indication remains of the dorsal fin in the fossil is far shorter based than illustrated by Le Danois, with the true fin corresponding only to the posterior half of the illustrated fin. The illustration clearly shows 23 vertebrae, but I would estimate that the much vaguer outlines represent about 18 to 20 vertebrae. 
The extremely long spine shown in the illustration by Le Danois of $P$. tenuispinus behind the pectoral fin base is hinted at in the specimen in counterpart, but it is not as definite as shown, and could represent either a large spine or the postcleithrum. Most of the spines that are apparent seem to have been relatively short and without massive three-rooted bases, perhaps having been mostly erectile and like those of the Recent Diodon except shorter. The spines just behind the pectoral fin base seem to have been somewhat longer than the others. The placement of the branchiostegals is clear, but the first, presumedly platelike, branchiostegal is not evident.

In the specimen in counterpart there seems to have been 11 caudal fin rays, one more than in any Recent species, although some of the rays are displaced and the count is not certain. In two of the three specimens there

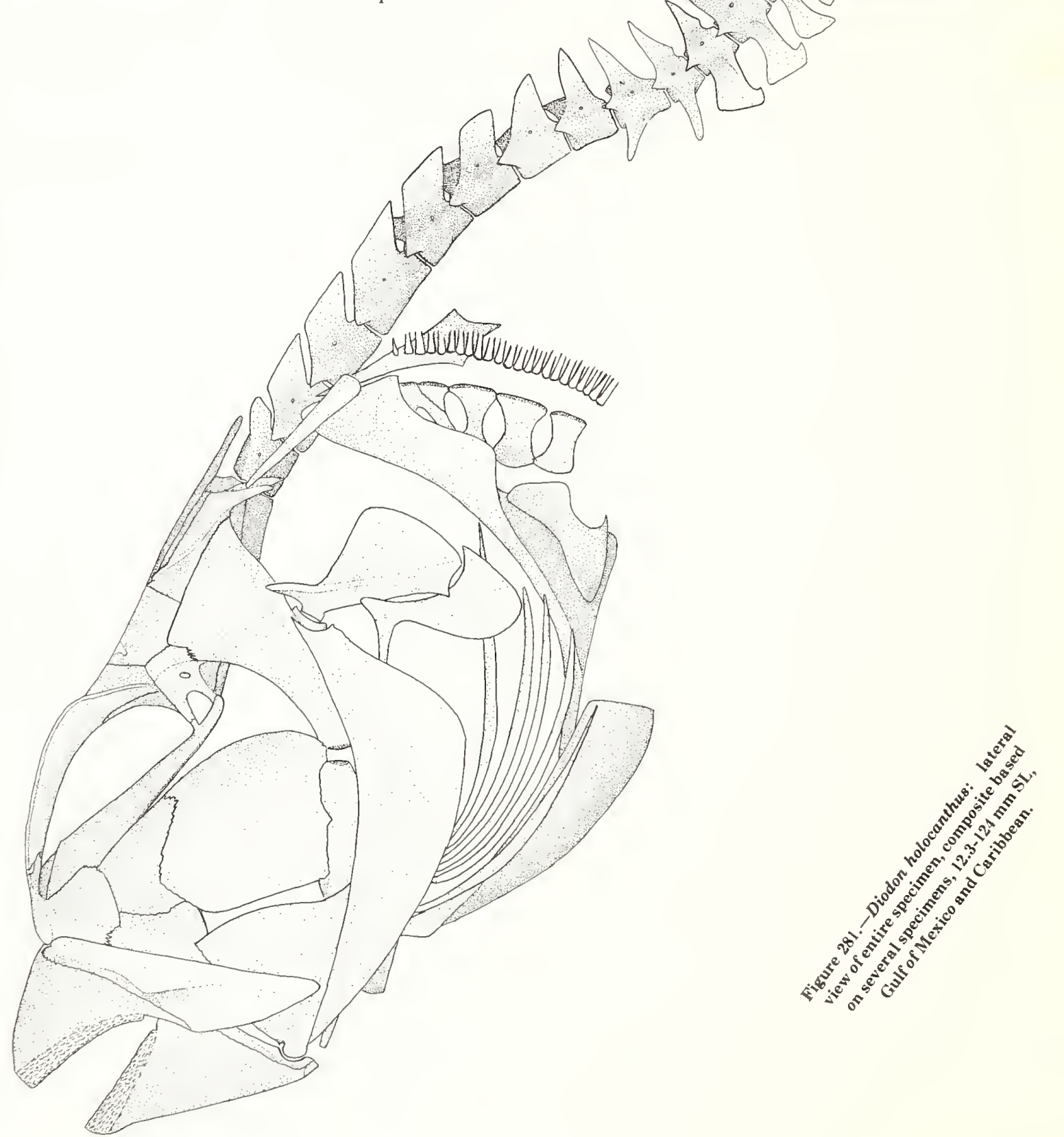




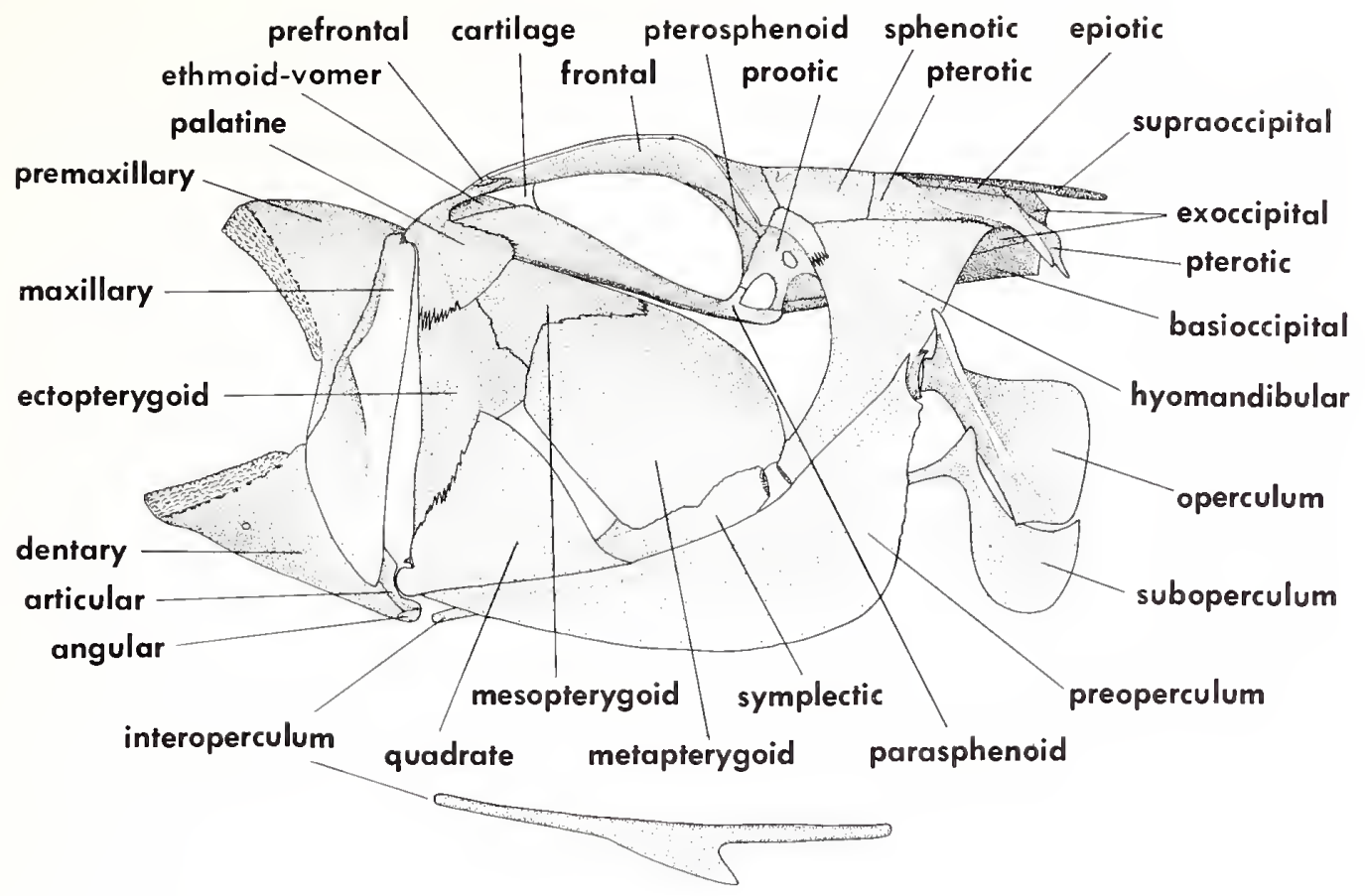

is some indication that the hypurals were not as fully fused together as in Recent species, with it being possible that there were two more or less separate plates of about equal size, one above and one below, but, again, it is only clear in this regard that there was some sort of groove or less ossified narrow horizontal region in the middle of the caudal plate posterior to the region of the last vertebral centrum.

Four additional specimens (see Material Examined) that are identified as P. tenuispinus in European collections add little to what is known on the basis of the typespecimens. In MCSNV B.18, $31.5 \mathrm{~mm}$ SL, the only items of interest to the present discussion are that, as in the type-specimens, there seem to be 11 caudal fin rays and the trituration teeth are paired, at least one transversely elongate tooth being placed to each side of the midline, and that the spines just behind the pectoral fin base (up to $1.1 \mathrm{~mm}$ long) are a little more than twice the length of the spines elsewhere (0.3-0.4 $\mathrm{mm}$ long), while the basal plate of the spine has up to six radiations, these being relatively small, about one-half the length of the projecting spine. The scales are similar to this in MCSNV B.19, $40.5 \mathrm{~mm}$ SL.

In the type-specimen of $D$. erinaceus some of the scales, especially posteriorly on the body, do seem to be three rooted and thus unerectile, although the roots are relatively short and do not approach the massiveness of those found in Chilomycterus. It is possible, however, that the larger size of the roots in the type of $P$. erinaceus $(77.5 \mathrm{~mm} \mathrm{SL})$ in comparison to those of the types of P. tenuispinus (12.6-46.5 mm SL) is at least partially accounted for by the differential specimen sizes. The spines just behind the region of the pectoral fin (which is not clear) base are longer $(3.3 \mathrm{~mm}$ ) than those elsewhere (up
Figure 282.-Diodon holocanthus: lateral view of head, composite based on several specimens, 12.3-124 mm SL, Gulf of Mexico and Caribbean.

to $1.6 \mathrm{~mm}$ ) on the body of the type of $P$. erinaceus and may have been two rooted and erectile, although their impressions are so poor that this is difficult to tell for sure.

Other specimens labeled $P$. erinaceus in European collections (see Material Examined) variously show the transversely elongate trituration teeth in a single series of one or two units to each side of the midline, just as in $P$. tenuispinus, and spines slightly longer behind the pectoral fin base than elsewhere and of a small size similar to that of $P$. tenuispinus, some seeming to have short multiradiate bases and others only biradiate bases, and thus probably some combination of small erectile and nonerectile spines. The number of caudal fin rays and the structure of the last few caudal vertebrae are not clear in any of the specimens assigned to $P$. erinaceus, but in one of them (IGUP 8670-71) there is a strong indication that the first branchiostegal ray is an enlarged horizontal plate just as in Recent species.

Since there is the possibility that the Eocene diodontids assigned to $P$. tenuispinus, and by implication to the at least closely related $P$. erinaceus, differ from the Recent species by having 11 caudal fin rays and the hypurals not fully fused to one another, the generic term Prodiodon is retained for them, especially in light of the fact that the numerous diodontid jaws known from the Eocene onward have been given generic nomenclatural status separate from that of the Recent species, as explained below. 

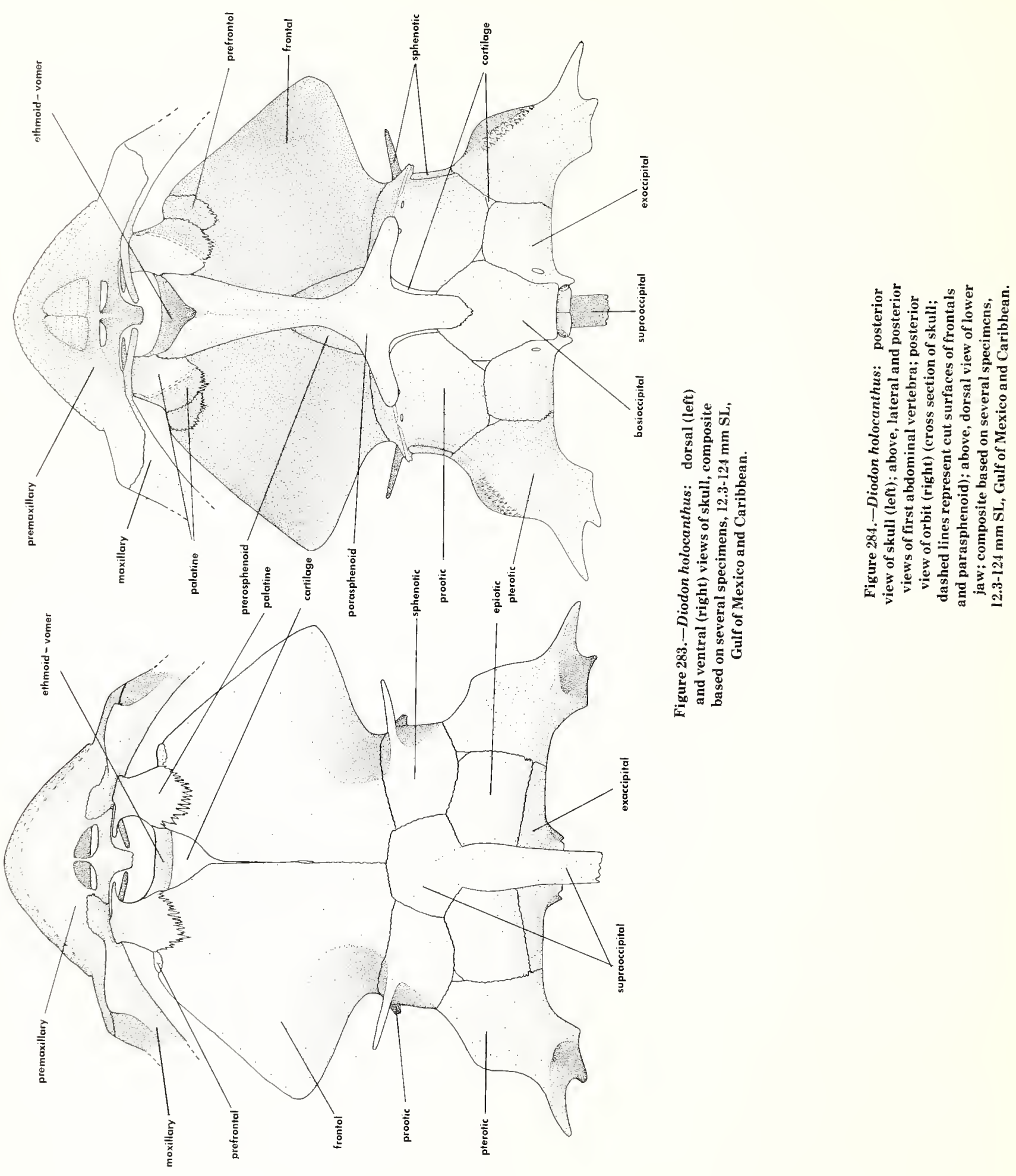


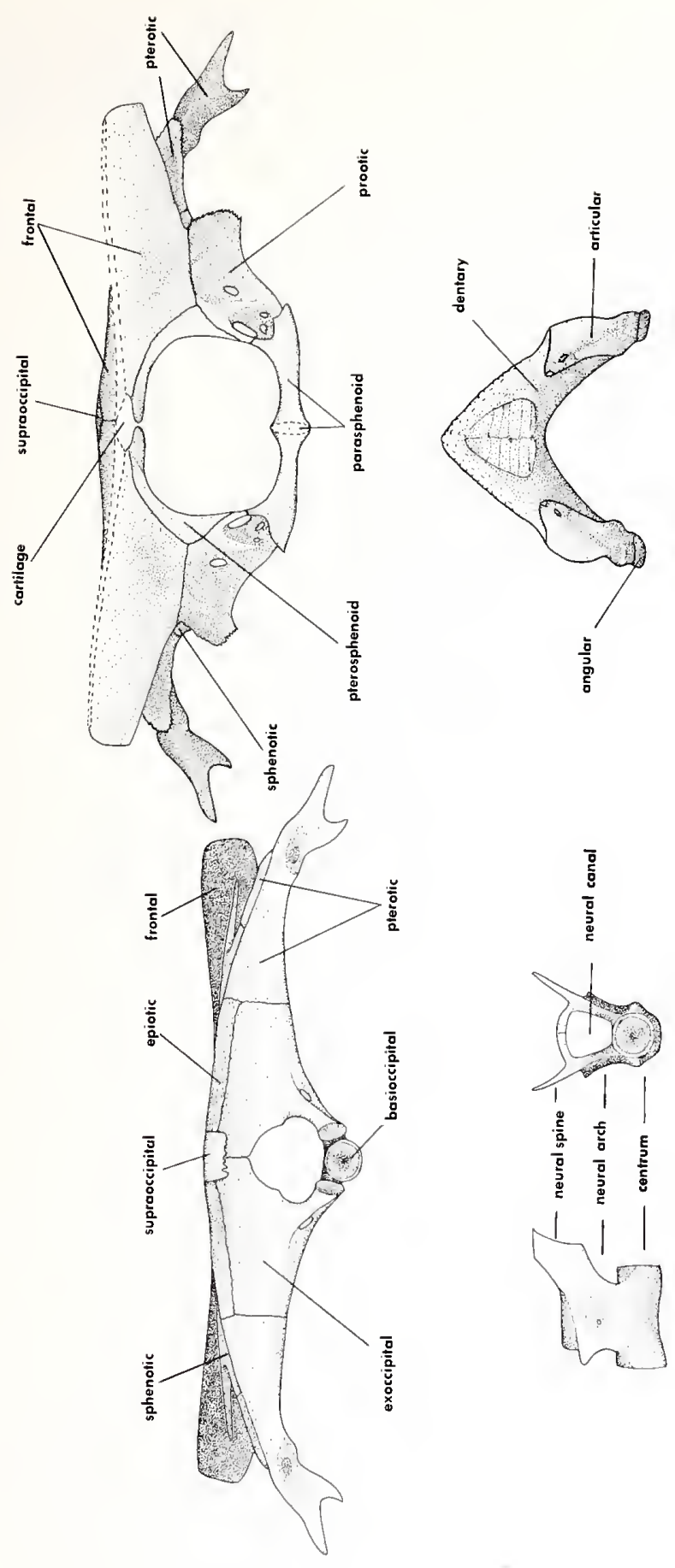

Being especially strong and massive, isolated diodontid jaws and fragments have been widely found in every period from the Eocene onward, and the confused nomenclature given to these parts has been extensively and astutely reviewed by Tavani (1955), who recognized several new genera on the basis of dental structure, as only briefly summarized here. Tavani found that Eodiodon, from the middle and upper Eocene of Europe, differed from all other diodontid jaws by having a uniform bony mass not differentiated into small teeth at the biting edge and larger elements in an internal trituration plate, as well as a difference in the place of articulation with the palatine.

Tavani (1955) recognized Eodiodon as the family Eodiodontidae, in contrast to four genera with distinct and differentially formed teeth in the biting and trituration regions. Of the latter four genera, Tavani differentiated Progymnodon (see Dames 1883), from the middle and upper Eocene of Europe, and Kyrtogymnodon, from the Pliocene of Europe, from the remaining two genera, Oligodiodon from the Oligocene and Miocene of Europe and North America, and Diodon, from the Miocene of Europe to Recent, on the basis of the depth of the osseous jaw tissue separating the small teeth in the biting edge from the large teeth in the trituration plate. Progymnodon and Kyrtogymnodon, as the subfamily Progymnodontinae, have only a thin band of bony tissue separating the two, and Oligodiodon and Diodon, as the Diodontinae, have a broad band.

The difference between the Progymnodon and Oligodiodon type spatial arrangement as so carefully described by Tavani (1955) undoubtedly represents the evolutionary change that took place leading to the arrangement as found in the Recent species, in which the biting edge and trituration teeth are well separated by a deep layer of bone, although less so in young specimens than adults. However, I am skeptical about the reported dental condition in Eodiodon, of it not having any teeth differentiated from the osseous tissue of the jaws. My skepticism is primarily because in the two groups most basal in the ancestry of the gymnodonts, the eoplectin triacanthodids and triodontids, the teeth are clearly differentiated from the bone, as they are in all diodontids from the Eocene to Recent, with the possible exception of Eodiodon.

I suspect that the apparent lack of discrete teeth in Eodiodon alone is some artifact of preservation of the few known jaw fragments assigned to Eodiodon, or that the biting edge teeth and those of the trituration plate were lost sometime between the process of preservation and the eventual recovery of the abraded fragments. With the true nature of the dental units of Eodiodon perhaps still unknown, and with no knowledge of what the structure of the fish behind the jaws was like in Eodiodon, Progymnodon, Kyrtogymnodon, and Oligodiodon, and only the slightest knowledge of the body of Prodiodon, I feel no compulsion for recognizing Eodiodon as familially distinct from the other diodontids, and none for recognizing subfamilies on the basis alone of the width of the osseous tissue separating the biting and trituration teeth, while still being keenly aware of the great value of Tavani's work.

With the exception of Tavani's (1955) careful analysis of the dental structure in fossil diodontid jaws, and of the few hints about the general configuration of the body in Prodiodon, our knowledge of the anatomical diversity of the family rests essentially on that of the Recent species.

The diodontids differ externally mainly in the form of the nasal apparatus (two nostrils or one) and spines (erectile or nonerectile). In times past, only two genera of diodontids were usually recognized, Chilomycterus for 


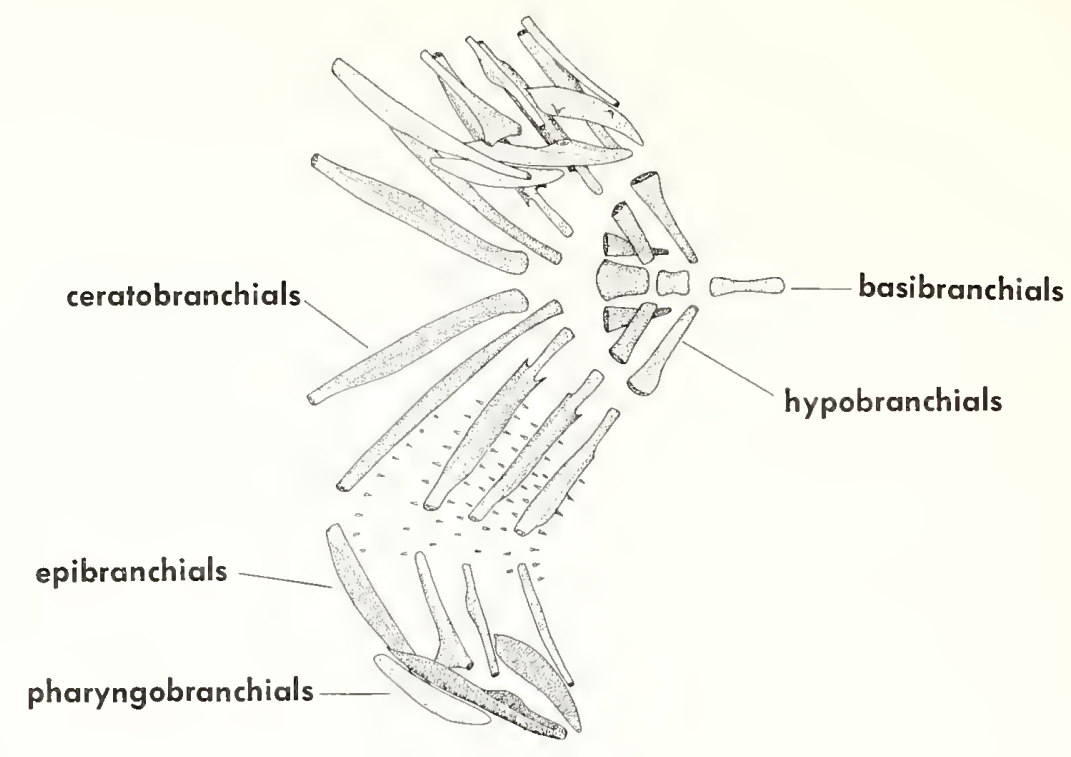

Figure 285.-Diodon holocanthus:

dorsal view of branchial arches

(extended on lower side); lateral

(above) and medial (below, upside down)

views of hyoid arch; composite based

on several specimens 12.3-124 mm SL,

Gulf of Mexico and Caribbean.

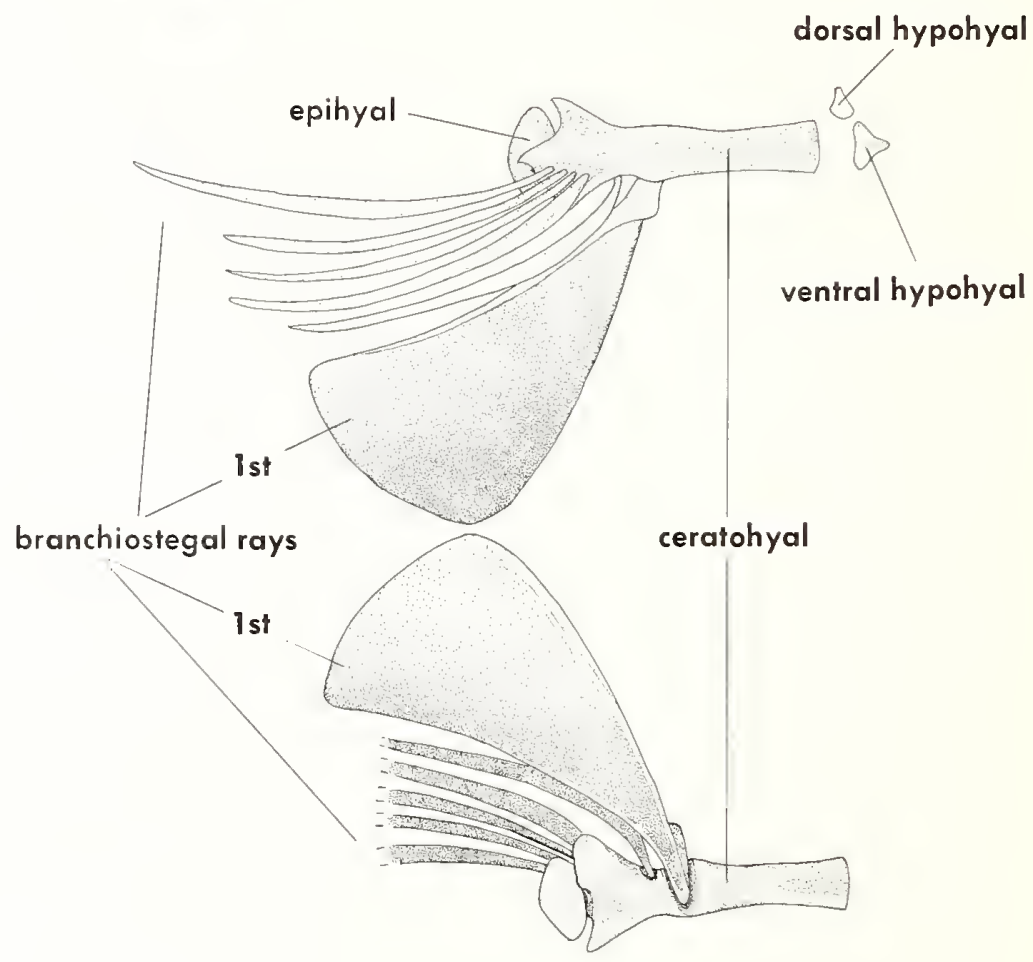

those species in which all of the spines have massive trior quadriradiate bases and are nonerectile and Diodon for those species in which at least some of the spines have less massive and only biradiate bases and are erectile. However, in the two most recent revisions of diodontid systematics, three genera have been recognized by Fraser-Brunner (1943) and Le Danois (1959), entirely on the basis of the nasal apparatus and spines, and none of the three genera are entirely comparable between the two works.

Fraser-Bruner (1943) recognized Diodon for those species with two nostrils and with at least some of the spines erectile (principally hystrix, holocanthus, jaculiferus,

calori), Dicotylichthys for those with a bifid nasal tentacle and with at least some of the spines erectile (principally nicthemerus, pilatus, punctulatus, and diversispinis), and Chilomycterus for those with two nostrils (the division between which might be fragile and easily broken) and with all of the spines three rooted and nonerectile (numerous species).

Two or three subgenera were recognized by FraserBrunner (1943) in each of the three genera but these have not been used by subsequent workers. The three subgenera of Diodon and Dicotylichthys have exactly the same characters, one subgenus in each for those species all of whose spines are two rooted and erectile and two sub- 
Figure 286.-Diodon holocanthus: lateral view of pectoral girdle, composite based on several specimens, 12.3-124 mm SL, Gulf of Mexico and Caribbean.

Figure 287.-Diodon holocanthus: lateral view of caudal fin supporting structures, composite based on several specimens, 12.3-124 mm SL, Gulf of Mexico and Caribbean.

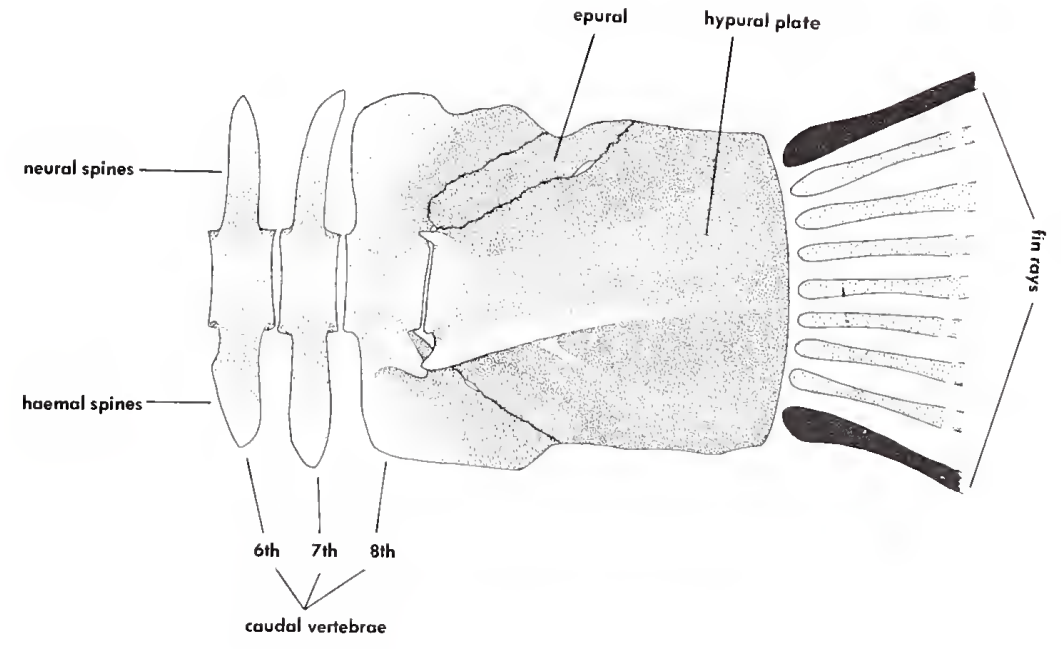

division between nostrils feeble, easily broken" (Chilomycterus for affinis, atinga, tigrinus = reticulatus, and californiensis, a synonym of affinis).

As discussed subsequently, the nasal differences between the subgenera Cyclichthys and Chilomycterus are valid, as modified, and those species with an open pitted cup do lack a spine in the middle of the forehead while those with two nostrils always have a spine there. The number of spines above the eye is not consistently different between the two groups, and much depends on how one interprets the position of the third spine in the 
series over the upper edge of the orbit. In most species of the subgenus Cyclichthys the third spine has its external process placed distinctly behind the eye, but in orbicularis it is placed just above the rear margin of the eye, while in the subgenus Chilomycterus, only affinis has the external process just above the rear margin of the eye, while in atinga and tigrinus it is placed just behind the rear margin of the eye and in reticulatus distinctly behind the rear margin of the eye.

Some of the difficulties in this arrangement of genera are that: 1) Diodon contains species such as jaculiferus in which most of the spines have massive triradiate bases and only a few just behind the pectoral fin base are especially elongate and erectile, the bases of these spines being only biradiate, or with a triradiate base in which one of the radiations (that normally directed anteriorly when there is a triradiate base and nonerectile spine) is shortened and directed strongly dorsally or ventrally toward one of the two well-developed radiations; 2) Diodon contains species such as calori in which only the spines on the forehead are two rooted and erectile; 3) those species of Diodon such as hystrix and holocanthus that have all or most of the spines essentially two rooted and erectile in young stages have most of the spines nonerectile in large adults, the base of the spine tending to become massive and triradiate with the development of an anteriorly directed root; 4) in Diodon at least two species, jaculiferus and calori, sometimes do not have two nostrils, the septum between the nostrils in a minority of specimens (about $10 \%$ in jaculiferus) apparently being resorbed (and not damaged by tearing); 5) in Dicotylichthys, just as in Diodon, there are species such as pilatus and punctulatus in which most of the spines are triradiate and nonerectile, those that are essentially biradiate and erectile being, respectively, just behind the pectoral fin base and on the head and belly; 6) in Dicotylichthys at least one species, nicthemerus, usually has a nasal tube with two nostrils in young specimens, the partition between the two nostrils apparently usually being resorbed in adults to produce a bilobed tube or tentacle, and Le Danois (1959:227) reported a specimen with both conditions, one on either side; 7) in Chilomycterus there are two types of nasal apparatuses, most species having two nostrils and a relatively smooth or only slightly folded epithelium on the inner surface of the tube, but three species, reticulatus, tigrinus, and affinis having the nasal apparatus as an open low cup (i.e., one large nostril) with a pitted epithelium, perhaps at all sizes, and another species, atinga, in which the nasal apparatus is tubular with two nostrils and a relatively smooth inner epithelium in young specimens, but with the great majority of large specimens having converted this into an open cup with a pitted surface by the resorption of the partition originally separating the two nostrils, the remains of the partition apparent even in large adults as an unpitted ridge across the middle of the pitted cup.

Le Danois (1959) recognized Diodon for those species with either two nostrils or a bifid tentacle and with at least some of the spines two rooted and erectile, this be- ing the combination of Fraser-Brunner's (1943) Diodon and Dicotylichthys, while Fraser-Brunner's Chilomycterus, containing all the species in which all the spines are three rooted and nonerectile, in Le Danois' system is split into Chilomycterus for reticulatus (and tigrinus), with the nasal apparatus an open cup with a pitted surface, and Atinga for all the other species, supposedly all with two nostrils and an unpitted inner epithelium. Le Danois' system has all of the drawbacks of FraserBrunner's in that Diodon contains species with a covering of almost as fully nonerectile, triradiate spines as in Fraser-Brunner's Chilomycterus, and of two different types of nasal tentacles, while Le Danois' Chilomycterus contains a single species (she considered tigrinus and reticulatus synonymous) with a pitted cup nasal apparatus (as well as one poorly preserved Miocene species, acanthodes, which seems to have had some two-rooted erectile spines and an unknown nasal apparatus, and would thus be assignable by her own system to Diodon) and her Atinga contains species having a nasal tube with two nostrils except for two species, affinis, which has a pitted cup at all stages as far as known, and atinga, in which adults develop a pitted cup nasal apparatus exactly as found in Chilomycterus reticulatus, tigrinus, and affinus.

Neither of the above two systems are tenable, but internal characters do little to clarify the situation, even though a large number of species were examined for this work. For purposes of discussion, the generic categories of Fraser-Brunner are used below. The nomenclature and diagnostic characters of many of the species of Chilomycterus are confused, and one or two of the names used here may be synonymous. For example, $C$. reticulatus, the type-species of Chilomycterus, is known only from very large adults (300 to over $600 \mathrm{~mm}$ ), and C. tigrinus may be the younger adult of it, since both are extremely similar osteologically. They differ mainly in tigrinus having fewer but larger dark spots and few if any larger dark blotches.

Before passing on to the osteological diversity of the diodontids, one additional external feature is of systematic significance. As outlined by Tyler (1970b:25), the great majority of diodontids have 9 caudal fin rays, while a few species of Chilomycterus (sensu Fraser-Brunner) have 10 . The four species presently known with 10 rays are affinis, atinga, reticulatus, and tigrinus, all four of which have the nasal apparatus as a pitted cup, at least in adults. Since the ancestral tetraodontids and at least some of the Eocene diodontids have 11 caudal rays, the four species of Chilomycterus with 10 caudal rays are more generalized in this respect than are the other species of diodontids, all of which have the caudal rays further reduced to 9, at least modally. Conversely, these four species are more specialized than other diodontids in their nasal apparatus, for at least the more generalized of the ancestral tetraodontids, as well as the triodontids and triacanthodids, have two nostrils to each side.

One unusual internal feature is shared by the four species of Chilomycterus with the combination of 10 caudal rays, no spines on the forehead, and a pitted cup nasal 


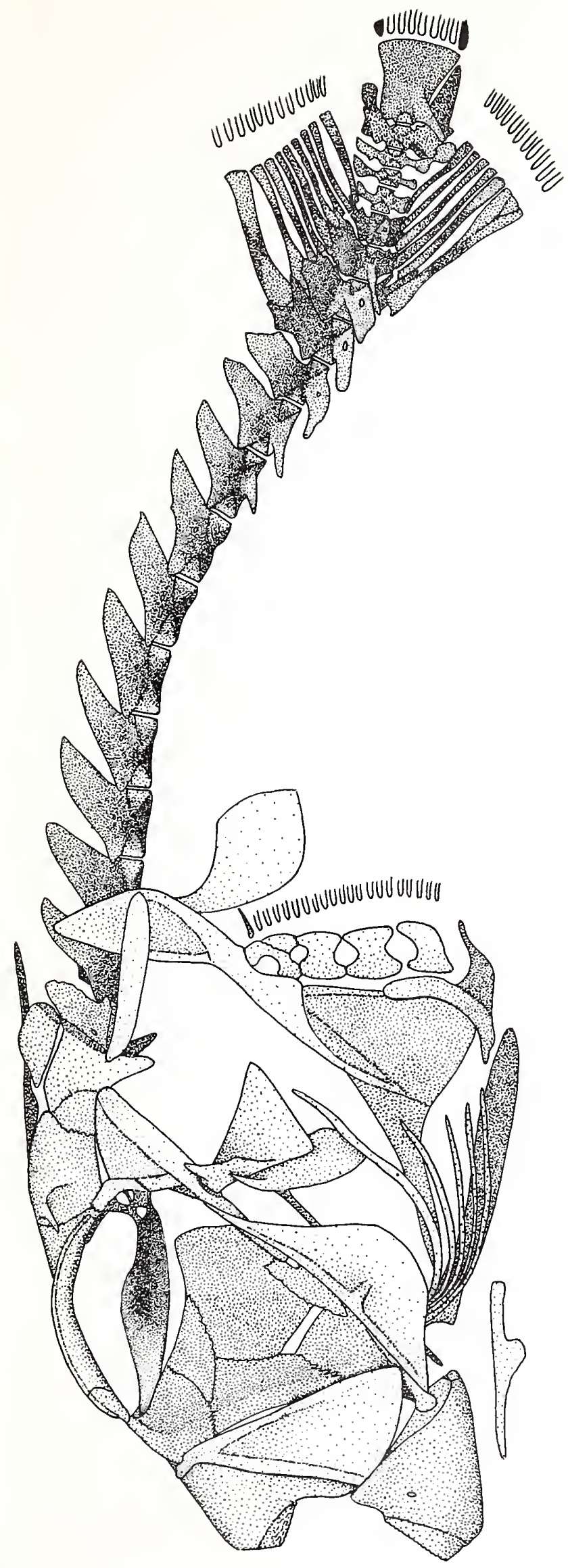

apparatus. All four have the specialized condition of the absence of the prefrontal. However, the absence of a prefrontal is not entirely confined to these four species, for C. orbicularis lacks the prefrontal but has nine caudal rays, a spine on the forehead, and a nasal tube with two nostrils. In $C$. orbicularis the palatines are more elongate and less widely spaced than in the other species of Chilomycterus, and the frontals are deeply indented in the region where prefrontals ordinarily occur.

The minor variation in the caudal fin supporting structures in diodontids is discussed by Tyler $(1970 \mathrm{~b})$, this involving the degree of fusion between the epural and the neural spine of the penultimate vertebra and between the parhypural variously to the fused hypural-centrum plate or to the haemal spine of the penultimate vertebra. These regions are so difficult to interpret in the specimens examined that no information of diagnostic or phylogenetic usefulness was found.

In many diodontids, as in all other gymnodonts except Triodon, the fifth ceratobranchial is toothless. However, in C. affinis, orbicularis, and tigrinus the fifth ceratobranchial bears a small patch of minute teeth. In the single large specimen of $C$. reticulatus examined a small patch of minute teeth is present on the fifth ceratobranchial on one side but not on the other. The two species of Dicotylichthys examined (nicthemerus and punctulatus) both have a well-developed elongate patch of minute teeth on the fifth ceratobranchials. These small teeth could either be remnants of those that probably occurred on the fifth ceratobranchial of the ancestral tetraodontid line, retained from its triodontid ancestry before the fourth gill was lost, or a de novo acquisition in a few diodontids from an immediate ancestry lacking teeth on the fifth ceratobranchial. The latter seems more reasonable, for the loss of teeth on the fifth ceratobranchial is undoubtedly associated with the loss of the fourth gill and of the gill slit between the fourth and fifth arches, which event occurred in the ancestral line common to both the tetraodontids and diodontids, and both families probably have a long history of lacking teeth on the fifth ceratobranchial while still retaining the ability to occasionally develop teeth there as dietary changes took place in various evolutionary lines making use of slightly differing foods.

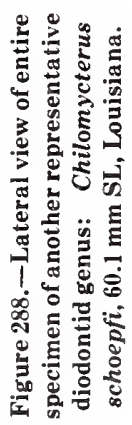




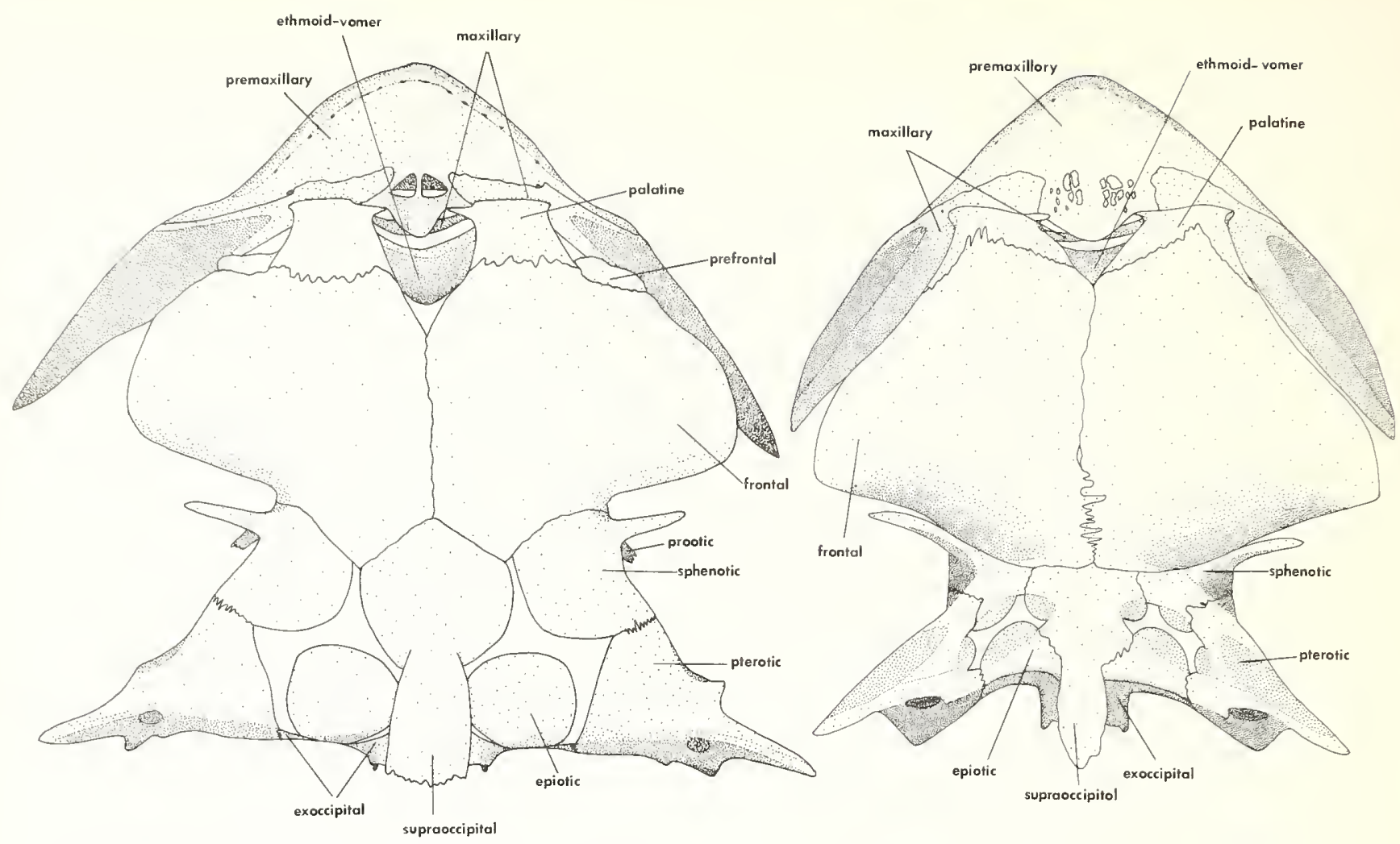

Figure 289.-Dorsal views of skulls of: left, Chilomycterus schoepfi, $60.1 \mathrm{~mm}$ SL, Louisiana; right, C. affinis, $310 \mathrm{~mm} \mathrm{SL}$, Galapagos.
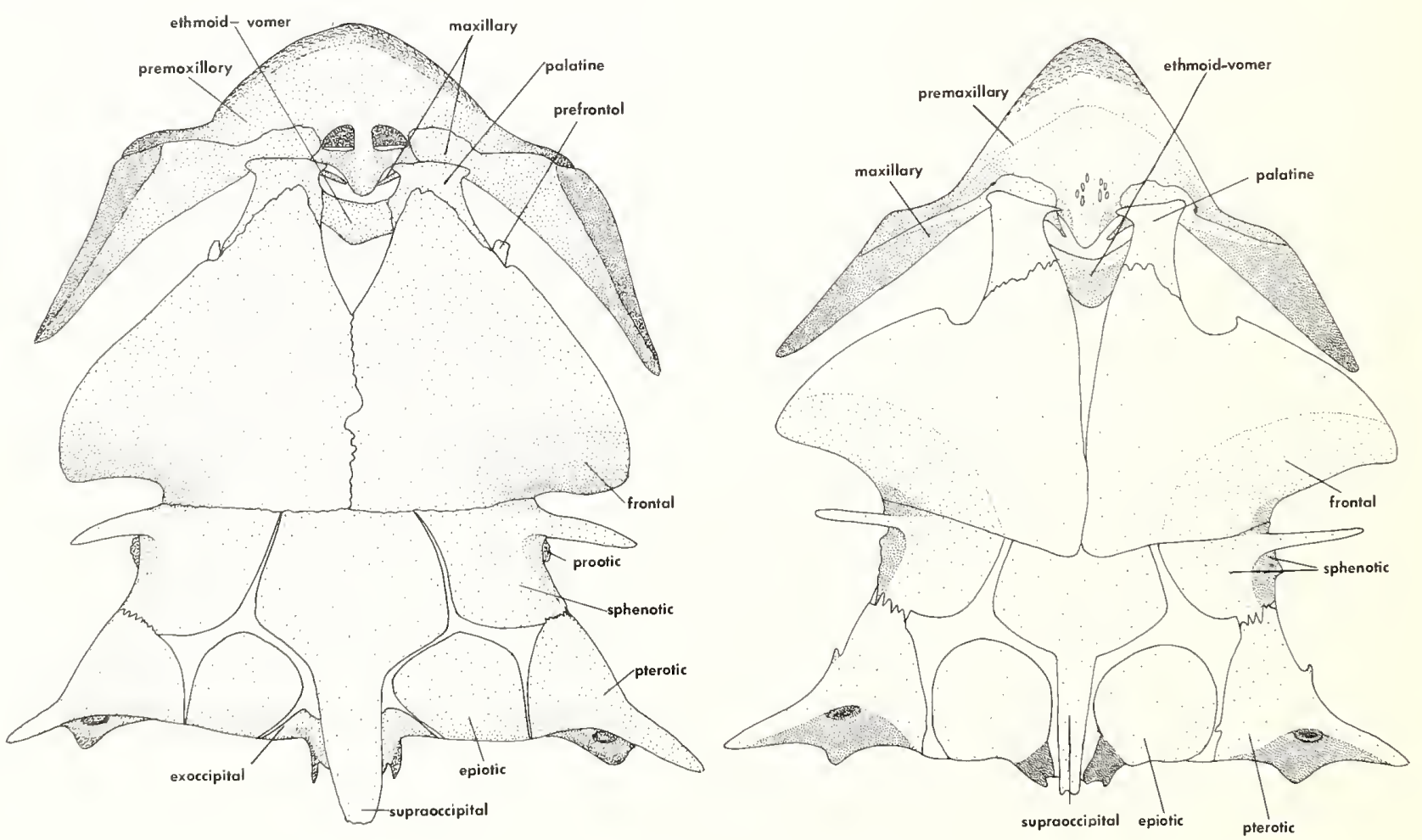

Figure 290.-Dorsal views of skulls of: left, Diodon jaculiferus, $53.4 \mathrm{~mm}$ SL, Australia; right, Chilomycterus orbicularis, $72.9 \mathrm{~mm} \mathrm{SL}$, Somalia. 


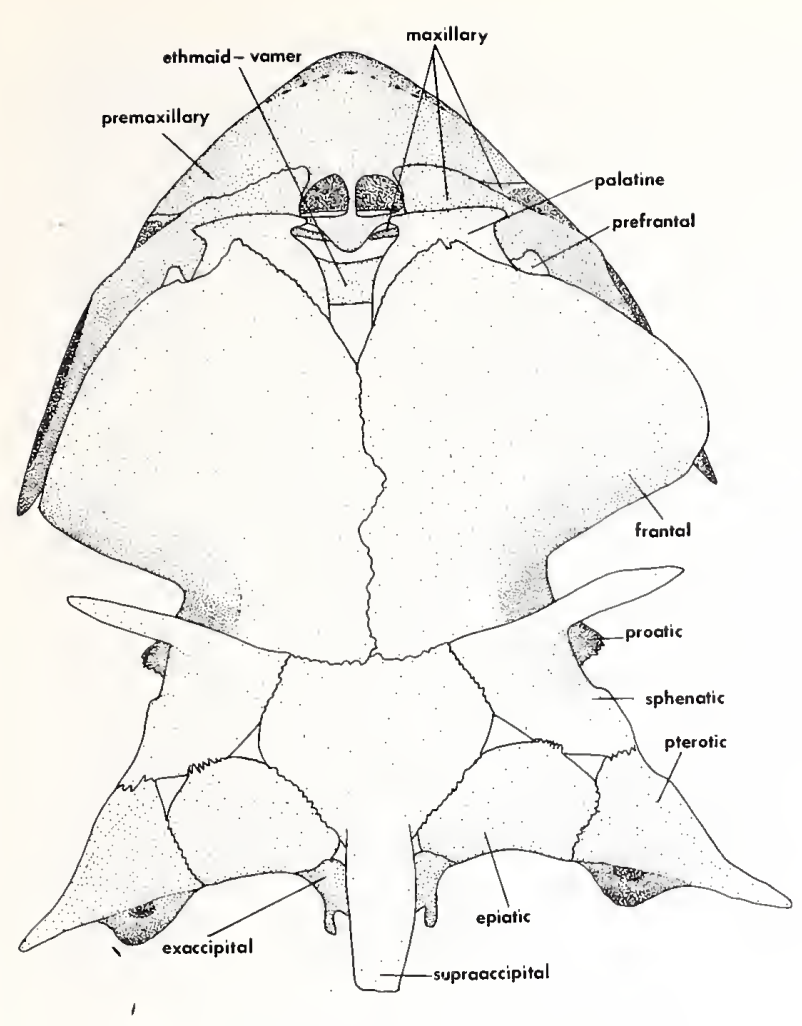

Figure 291.-Dorsal view of skull of Dicotylichthys punctulatus, $226 \mathrm{~mm} \mathrm{SL}$, Australia.

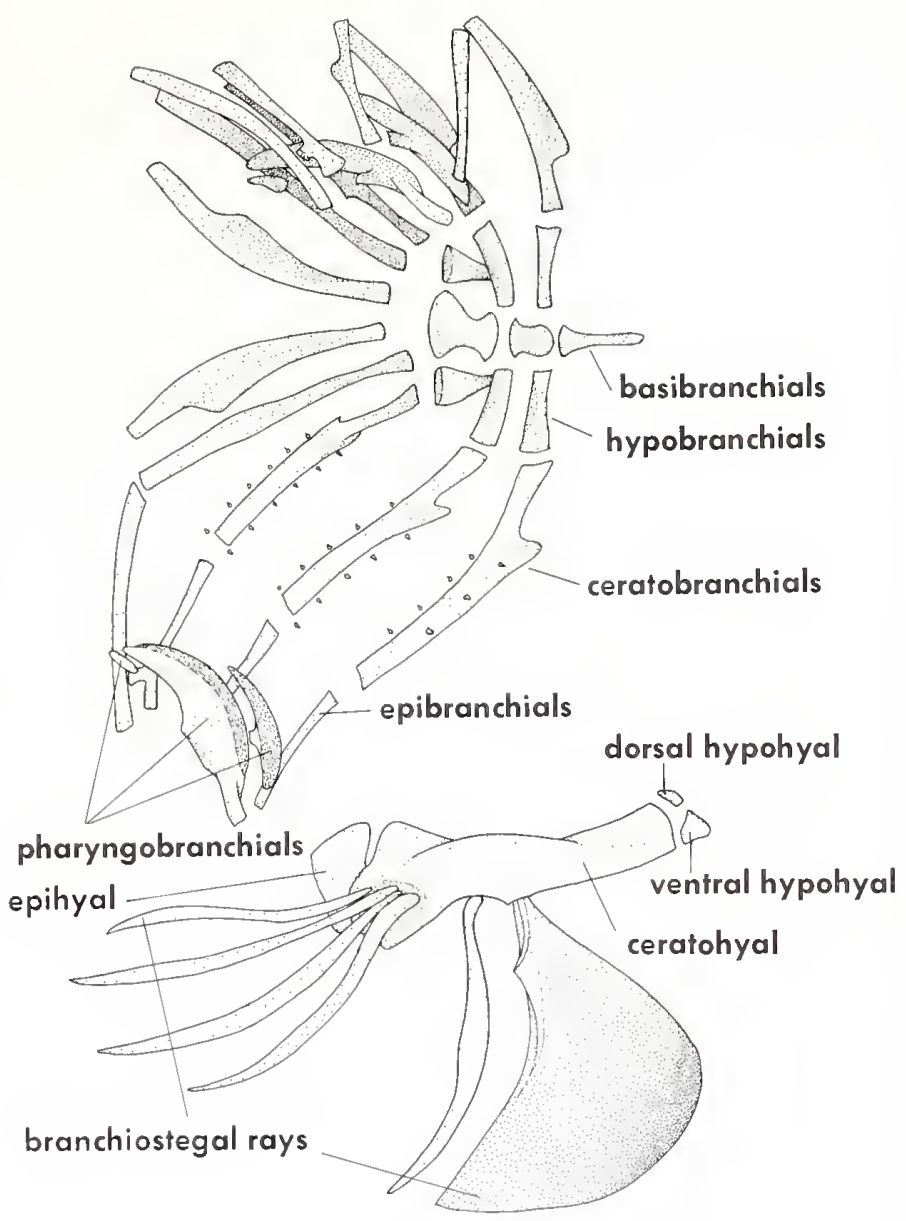

Figure 292.-Chilomycterus schoepfi: dorsal view of branchial arches (extended on lower side) and lateral view of hyoid arch, $168 \mathrm{~mm}$ SL, Florida.
Figure 293. - Nasal a pparatuses of representative diodontids: A, Chilomycterus mauretanicus;

B, C. orbicularis; C, C. schoepfi; D, C. antennatus, 1 being the normal condition of two nostrils in each tube and a ridge along the inner surface, while 2 and 3 are variations of abnormal conditions, 2 having a single nostril on one side but the normal two nostrils on the other side (USNM 249592, 75.2 $\mathrm{mm}$ ), and 3 having a single nostril on both sides (USNM 249592, $85.7 \mathrm{~mm})$; E, C. reticulatus; F, C. atinga, 1 being the normal condition of an open nasal sac (one nostril) on each side and 2 being an abnormal condition of a closed sac with two nostrils on one side but an open sac on the other (ANSP 103900, $278 \mathrm{~mm}$ ); G, Diodon hystrix; H. D. holocanthus, 1 being the normal condition of two nostrils in each nasal sac and 2 being an abnormal condition of a single nostril on one side but two nostrils on the other (ANSP 105586, $186 \mathrm{~mm}$ ); I, $D$. jaculiferus, 1 being the normal condition of two nostrils in each nasal sac and 2 being an abnormal condition of a single nostril on one side but two nostrils on the other (USNM 176952, $42.2 \mathrm{~mm}$ ); J, Dicotylichthys punctulatus; $\mathrm{K}, D$. nicthemerus, a bifid tentacle in adults but two nostrils in a tube in young specimens.
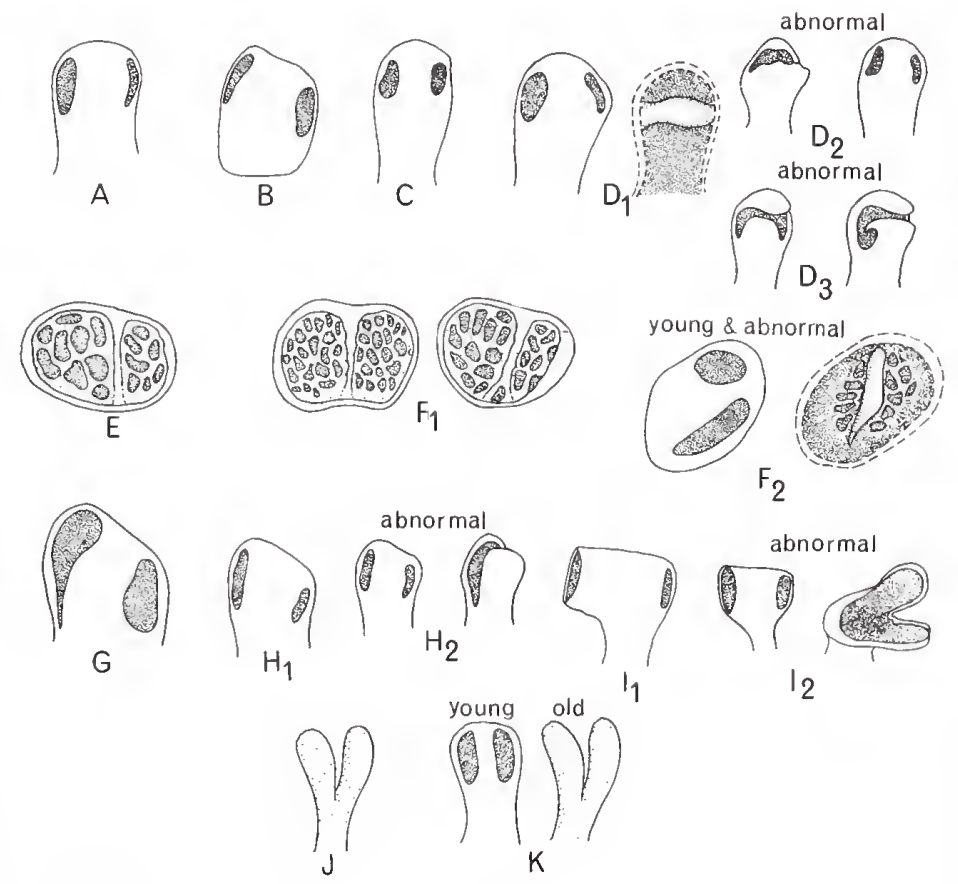

$\mathrm{I}_{2}$ 


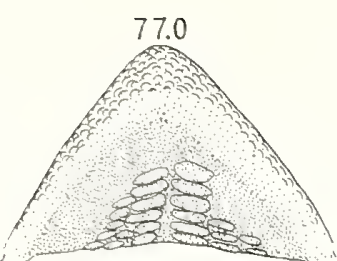

A
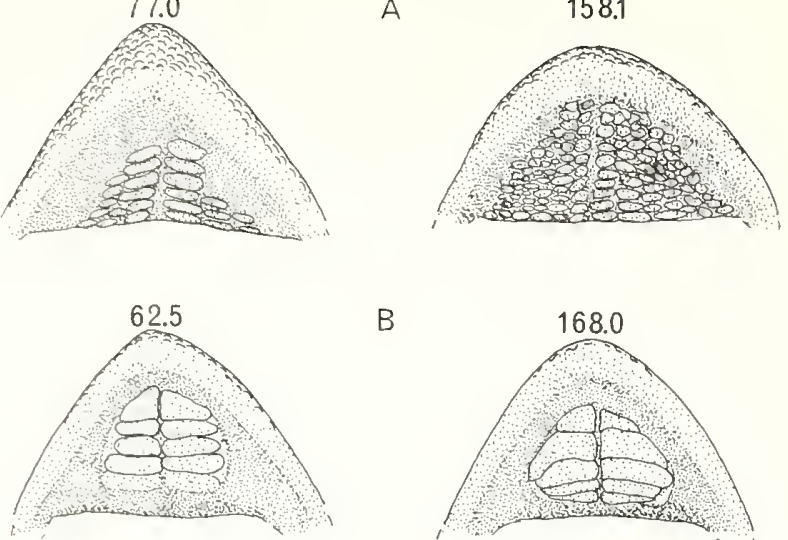

B

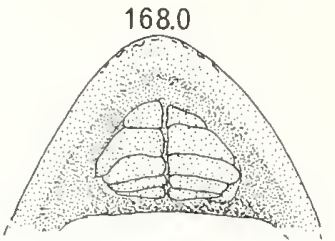

Figure 294.- Ventral views of upper jaws to show trituration tooth plates: A, Chilomycterus orbicularis, $77.0 \mathrm{~mm} \mathrm{SL}$, Somalia, and $158 \mathrm{~mm} \mathrm{SL}$, Philippines; B, C. schoepfi, $62.5 \mathrm{~mm} \mathrm{SL}$, Texas, and $168 \mathrm{~mm} \mathrm{SL}$, Florida, the latter species with trituration plates more or less typical of all diodontids except $C$, orbicularis.

Figure 295.-Chilomycterus schoepfi: upper left, lateral view of upper jaw, with inset showing detail of lateral edge of crushing beak with its individual dental units incorporated into but distinct from the bony matrix of the premaxillary; lower left, cross section through middle of one of the individual flattened disklike trituration teeth; right, outline of about one-half of a trituration tooth, with the detail showing the irregular surface; $168 \mathrm{~mm}$ SL, Florida.
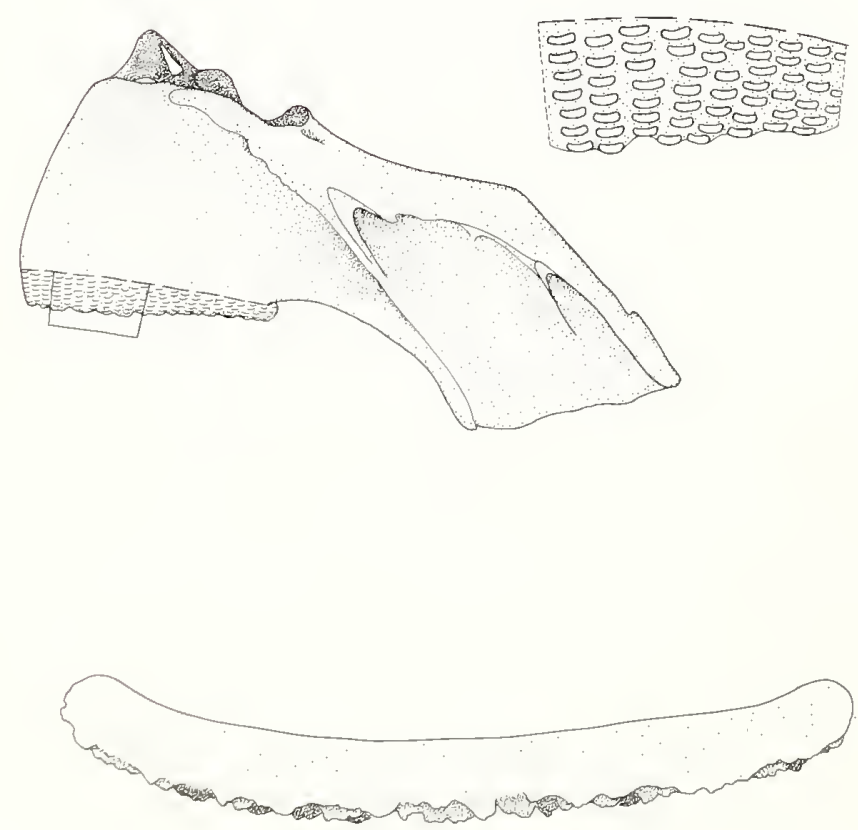

The dentition of the pharyngobranchials is also slightly variable in diodontids. The pharyngobranchials of the first and second arches always bear small to minute teeth, while the pharyngobranchial of the third arch, when present, is always smaller than those preceding it and is nearly always toothiess. The pharyngobranchial of the third arch is absent in Chilomycterus affinis, atinga, reticulatus, and tigrinus, and it is especially small and toothless in C. antillarum, mauretanicus, orbicularis, spinosus, and Dicotylichthys nicthemerus. In C. schoepfi this pharyngobranchial is as small as in the preceding species, but it sometimes bears minute teeth even though usually it is toothless. In $D$. punctulatus this pharyngobranchial is toothless but of moderate size. In Diodon this pharyngobranchial is toothless and of moderate (hystrix, jaculiferus) to relatively large (holocanthus) size.

Gill rakers along the anterior edge of the fourth ceratobranchial are present in Chilomycteris affinis, atinga, reticulatus, tigrinus, orbicularis, Diodon holocanthus, hystrix, jaculiferus, and in Dicotylichthys nicthemerus and punctulatus, while they are absent in $C$. antennatus, antillarum, mauretanicus, schoepfi, and spinosus. The loss of gill rakers along the anterior edge of the fourth arch must be considered a specialization, since in the only other family without a fourth gill, the tetraodontids, rakers are always present here.

Both the dorsal and ventral hypohyals are present in all of the diodontids examined except for Chilomycterus atinga, reticulatus, and tigrinus, which lack (in the single specimen examined of each species) the dorsal element.

The trituration teeth internal to the biting edge of the upper and lower jaws always form a large plate divided into right and left halves, each half formed by a single series of large wide flattened tooth plates whose medial

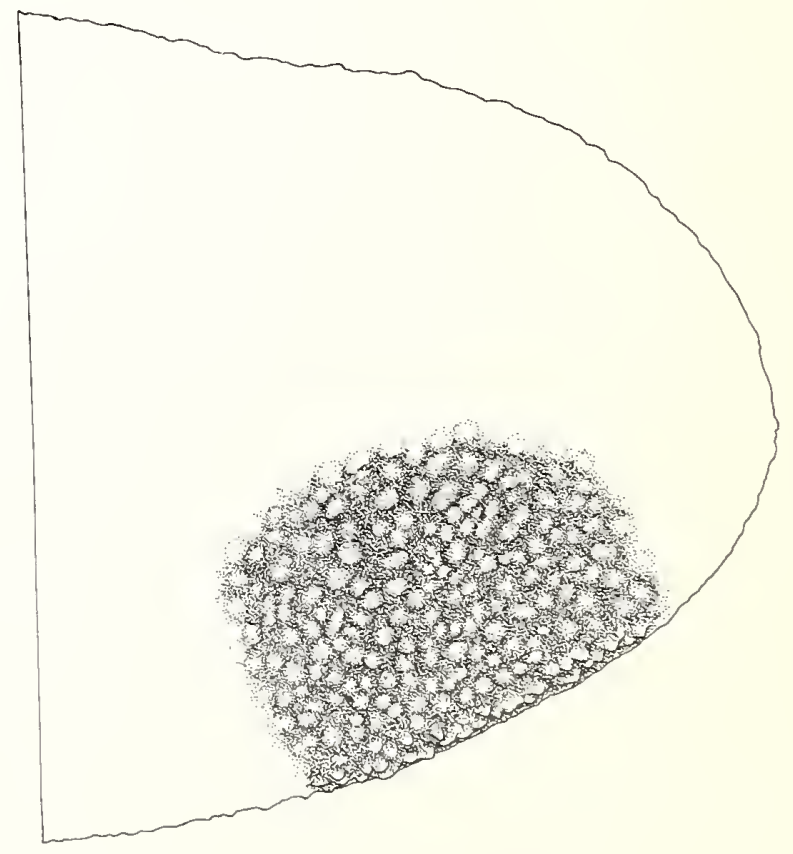


edges are straight and the other edges rounded, in all species examined except for $C$. orbicularis. In $C$. orbicularis the trituration plate is smaller than in the other species, the division into right and left halves is less distinct, and there are two or more series of far smaller and less wide teeth in each half of the plate. In fact, the individual teeth in the trituration plate of $C$. orbicularis are not much larger than those of the biting edge, at least in adults, in which the number of series of teeth increases greatly over the two or three to each side found in young specimens, while at the same time the width of the rows, especially of the innermost row, is greatly decreased.

Having numerous series of trituration teeth to each side of the midline and not greatly different in size from those in the biting edge would seem to be a more generalized condition than that of a single series of large wide plates to each side of the midline and greatly different from the teeth of the biting edge. Such numerous series of small trituration teeth are also found in the triodontids, the most generalized gymnodonts. However, C. orbicularis is highly specialized in certain other features of the skull, and tetraodontids, the closest relatives of the diodontids, are more generalized than diodontids and usually have only a single series of small trituration teeth to each side of the midline, when they occur at all. Moreover, the trituration teeth in the earliest known diodontids, in the Eocene, are large transversely elongate units that occur in a single series to each side of the midline, just as in all Recent species except $C$. orbicularis. I suspect that the numerous trituration teeth of $C$. orbicularis are a de novo acquisition of this single specialized diodontid and thus not the retention of an ancestral condition such as found in triodontids. The numerous small trituration teeth of $C$. orbicularis can be considered just as specialized in their own way as the far larger trituration teeth in a single series to either side of the midline found in all other diodontids.

The jaws of $C$. orbicularis tend to be less massive and to have a sharper biting edge than in other diodontids, and this, in conjunction with the differences in the trituration plates, probably indicates that $C$. orbicularis has a diet of less hard bodied food than do the other diodontids.

In the large trituration plates as found in the great majority of diodontids, the wide individual tooth plates are formed at the base of the pulp cavity and have a slightly concave smooth upper surface and a slightly convex papillate lower surface. The individual plates migrate toward the exposed surface of the trituration plate to replace those worn away through use as new plates are continuously being formed at the edge of the pulp cavity. As they move toward the exposed trituration surface the individual plates become increasingly flattened and more closely cemented together. The number of individual plates in the single series to each side of the midline usually increases greatly with increasing specimen size,
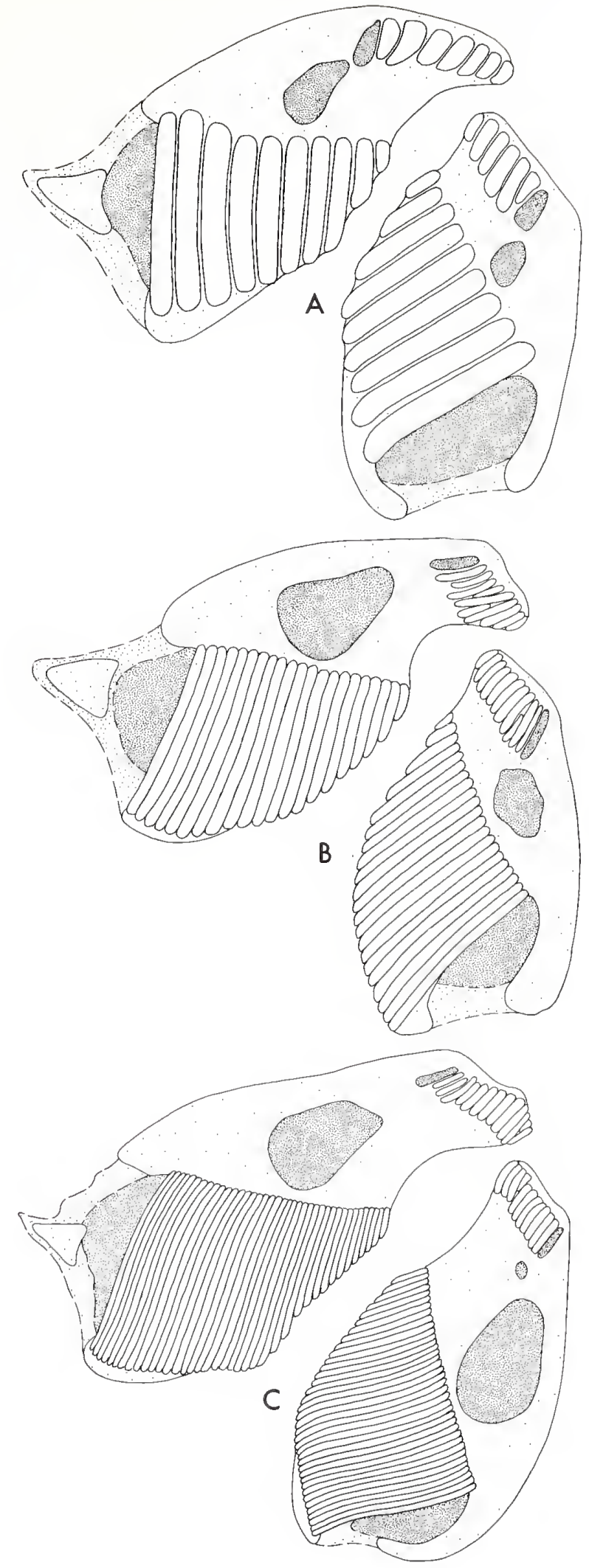

Figure 296.-Diodon hystrix: cross section of upper (above in each set) and lower jaws just to one side of the midline, showing the numbers of dental units in the biting edges of the jaws and in the trituration plates, increasing greatly in number with increasing specimen size: A, $88.3 \mathrm{~mm} \mathrm{SL}, \mathrm{B}, 228 \mathrm{~mm} \mathrm{SL}$, and C, $505 \mathrm{~mm} \mathrm{SL}$. 


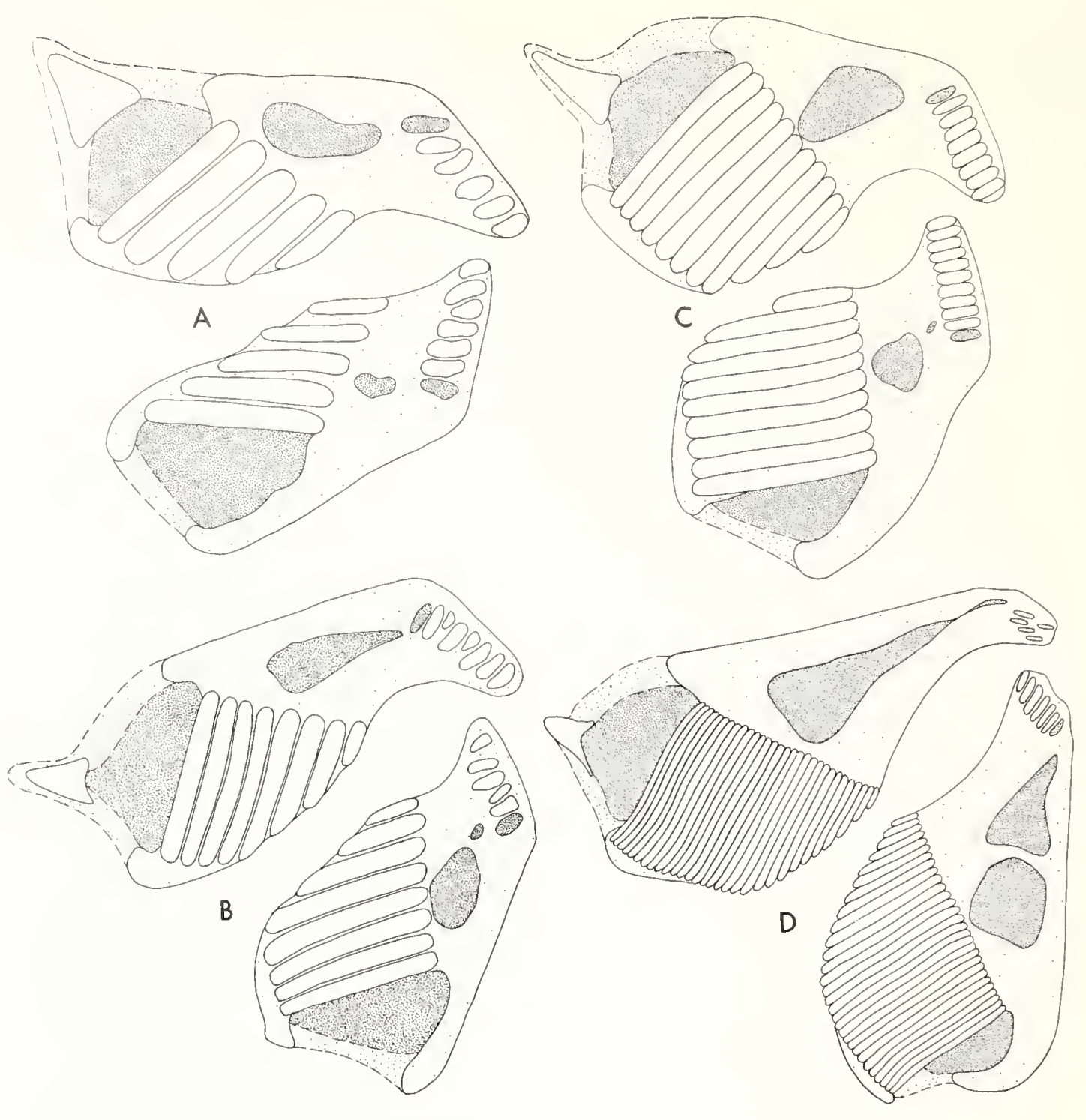

Figure 297.-Diodon holocanthus: cross section of upper (above in each set) and lower jaws just to one side of the midline, showing the numbers of dental units in the biting edges of the jaws and in the trituration plates, increasing greatly in number with increasing specimen size: A, $63.4 \mathrm{~mm} \mathrm{SL}$; B, $122 \mathrm{~mm} \mathrm{SL;} \mathrm{C,} 183 \mathrm{~mm}$ SL; D, $375 \mathrm{~mm} \mathrm{SL}$.

but there is little difference between species in the number of plates at any given size, based on the limited survey made (Fig. 302).

However, the largest specimen of a diodontid examined for internal trituration teeth, a single $545 \mathrm{~mm}$ specimen of $C$. reticulatus, had only about 18 plates, approximately the number to be expected from the other species examined at sizes between about 200 and $220 \mathrm{~mm}$. The total number of plates in the series cannot be counted externally because only about a third to a half or fewer have any of their surfaces exposed, and the total number can only be seen by carefully sawing through the jaw just

to one side of the midline, a laborious procedure. The trituration surface is somewhat oblique to the broad plane of the individual plates, and the exposed surface is covered by several overlapping plates.

In most diodontids there are a large pair of apertures posteromedially on the dorsal surface of the premaxillaries just to either side of the midline which open into the large posterior edge of the pulp cavity, but in Chilomycterus affinis and orbicularis the apertures on the dorsal surface of the premaxillaries are smaller, more numerous, and less precisely arranged than in the other diodontids. This character may be particularly prone to change with increasing specimen size.

The numbers of vertebrae in the diodontids examined show no differences useful in recognizing natural groups. In Chilomycterus the total number varies modally from 18 to 23 , with 10 to 13 abdominal and 8 to 10 caudal, while in Diodon there are 19 to 21 total, with 10 to 12 abdominal and usually 9 caudal. In the single specimens of 


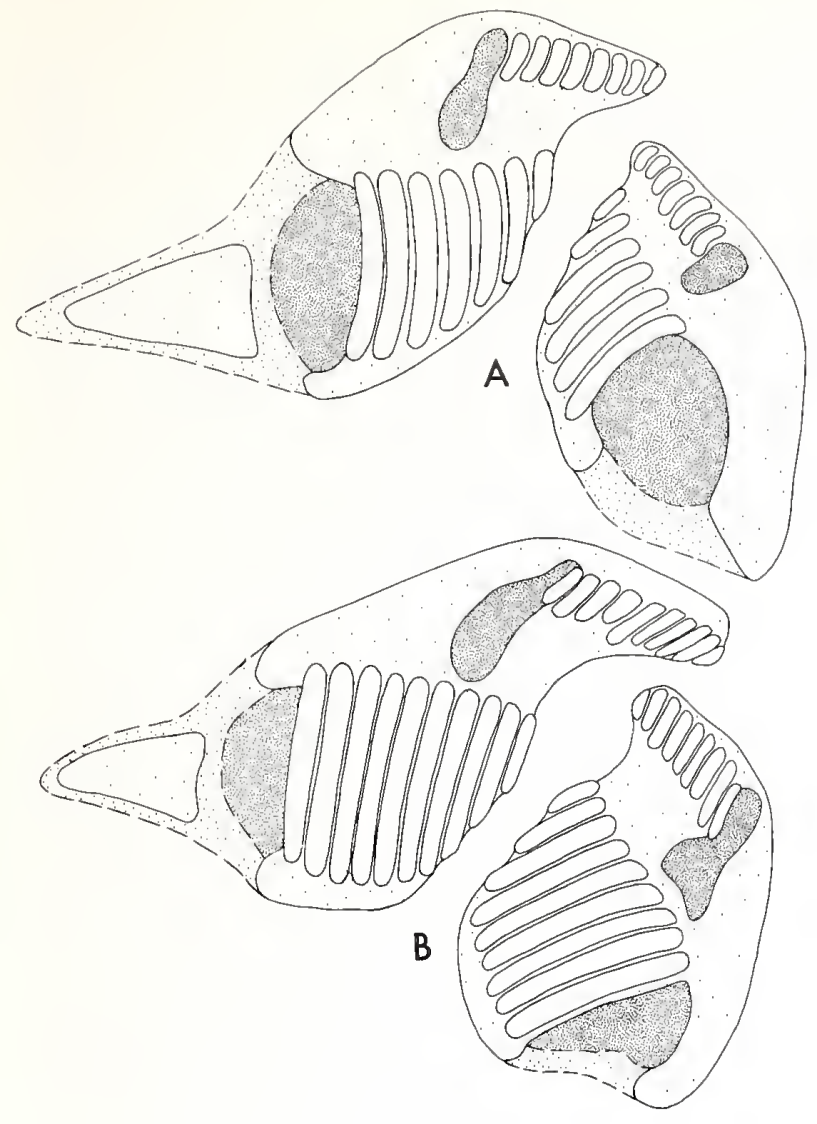

Figure 298.-Chilomycterus schoepfi: cross section of upper (above in each set) and lower jaws just to one side of the midline, showing the numbers of dental units in the biting edges of the jaws and in the trituration plates, increasing greatly in number with increasing specimen size: A, $97.6 \mathrm{~mm} \mathrm{SL}$ and B, $166 \mathrm{~mm}$ SL.

the two species of Dicotylichthys examined, both had 9 caudal vertebrae, one with 11 abdominal and the other with 12 .

The uppermost pectoral fin ray in diodontids is usually relatively short and formed of two approximately equal unsegmented halves, but in the single specimen of Chilomycterus affinis examined, a large adult of $310 \mathrm{~mm}$, this ray is a single piece of bone, the two halves that can be expected to be found in smaller specimens apparently having completely fused, or one of the halves having been resorbed.

Generic relationships.-It is difficult to discuss generic relationships without first establishing a natural division of the family into genera, and as pointed out in the preceding section, the two most recent revisions recognized three noncomparable genera on the basis of nostril and spine characteristics, with each of the revisions having serious limitations. The osteology of the species examined here helps to some extent, but leaves much left to be done.

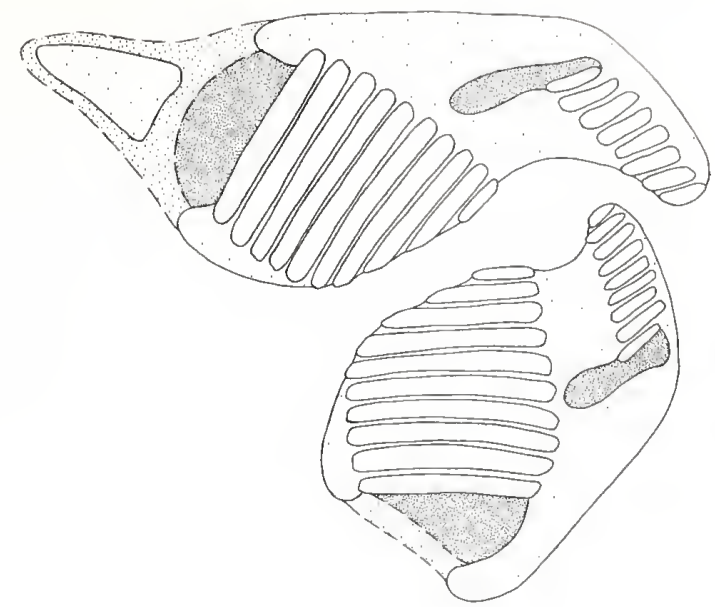

Figure 299.-Chilomycterus antillarum: cross section of upper (above) and lower jaws just to one side of the midline, showing the numbers of dental units in the biting edges of the jaws and in the trituration plates, $116 \mathrm{~mm} \mathrm{SL}$.

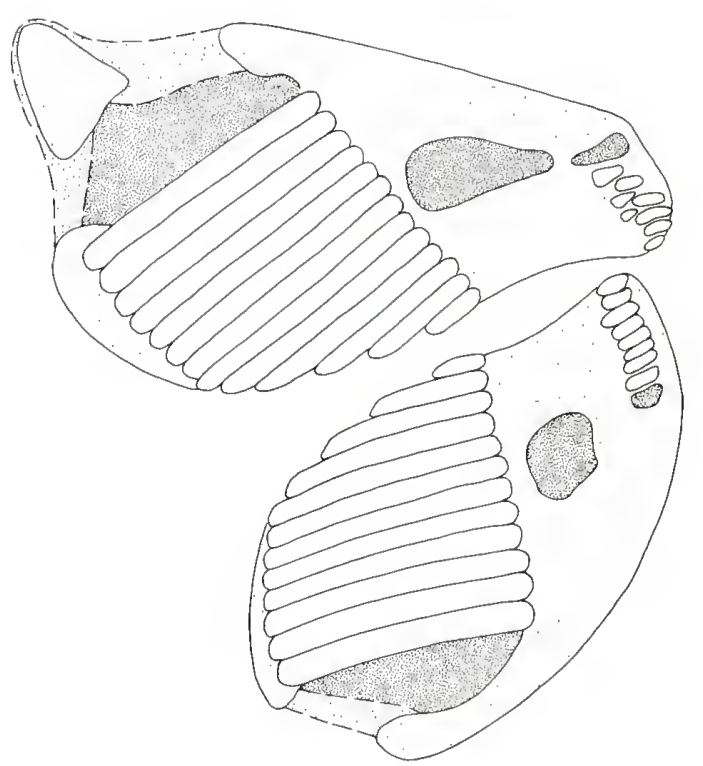

Figure 300.-Chilomycterus atinga: cross section of upper (above) and lower jaws just to one side of the midline, showing the numbers of dental units in the biting edges of the jaws and in the trituration plates, $173 \mathrm{~mm}$ SL.

Within Chilomycterus, by far the most speciose genus of diodontids, three groups are recognizable. Chilomycterus affinis, atinga, reticulatus, and tigrinus are unique among the diodontids by having the third pharyngobranchial absent, a pitted open cup nasal apparatus (at least as adults), no spines on the forehead and 10 caudal fin rays. Three of these four species are also unique by the presence of only a single hypohyal. All four species have the prefrontal absent and similar skull shapes, the prefrontal otherwise being absent in diodontids only in 


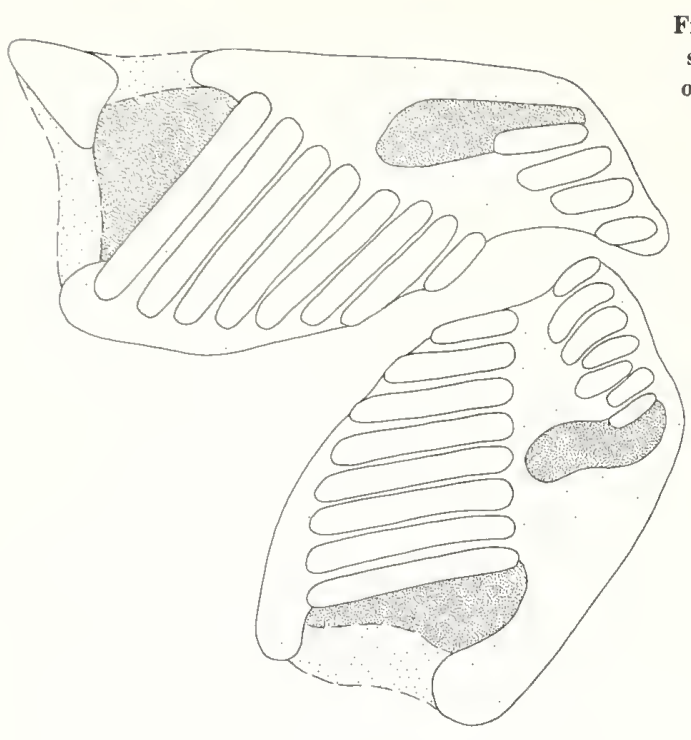

$\bigcirc$

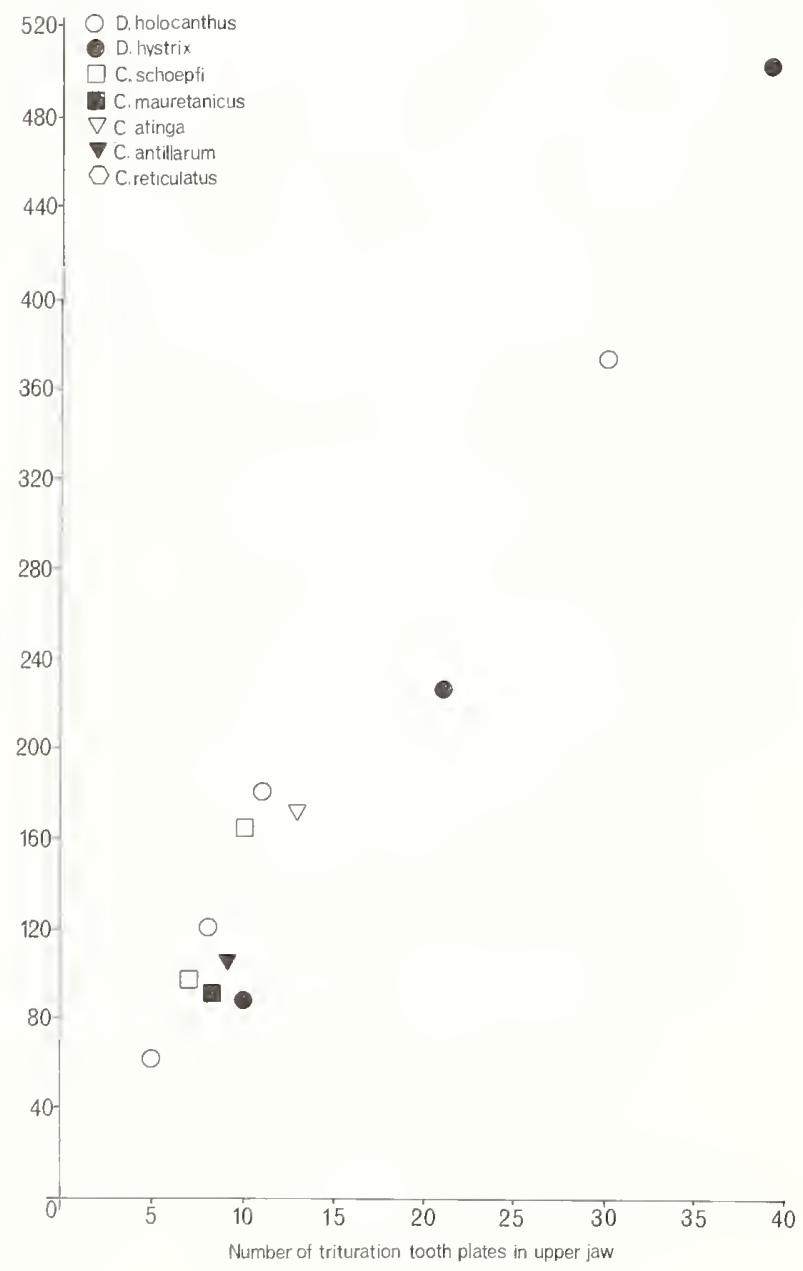

Figure 301.-Chilomycterus mauretanicus: cross section of upper (above) and lower jaws just to one side of the midline, showing the numbers of dental units in the biting edges of the jaws and in the trituration plates, $92.2 \mathrm{~mm}$ SL.

C. orbicularis, which has a much different skull shape and arrangement of the trituration teeth. All four species have gill rakers along the anterior edge of the fourth arch, as does C. orbicularis (as well as Diodon and Dicotylichthys), all of these species being from the IndoPacific with the exception of $C$. affinis, from the Atlantic, while the other species of Chilomycterus (antennatus, antillarum, mauretanicus, schoepfi, and spinosus), all from the Atlantic, do not have gill rakers along the anterior edge of the fourth arch. The only species of Chilomycterus with teeth on the fifth ceratobranchial are orbicularis and three (affinis, reticulatus, tigrinus) of the four species with a pitted cup nasal apparatus, no spines on the forehead and 10 caudal rays.

The evidence indicates that $C$. affinis, atinga, reticulatus, and tigrinus are all closely related, and that $C$. antennatus, antillarum, mauretanicus, schoepfi, and spinosus are a distinct subgroup of equally closely related species.

The Indo-Pacific $C$. orbicularis would seem to have its closest relatives among the primarily Indo-Pacific former group than to the latter Atlantic group, for it shares a few differential characters (prefrontal absent, gill rakers present on anterior edge of fourth arch, teeth on fifth ceratobranchial) with them and none with the Atlantic group. Most of the differential features of C. affinis, atinga, reticulatus, and tigrinus are specializations (pitted open cup nostril, loss of prefrontal and pharyngobranchial of third arch, usual presence of teeth on the fifth ceratobranchial, and usual loss of the dorsal hypohyal), and their retention of 10 caudal fin rays is the only way in which they are more generalized than $C$. orbicularis and the other speciose subgroup of Chilomycterus (and other diodontids). The presence in C. orbicularis of a toothless small pharyngobranchial of the third arch, two hypohyals, and a nasal apparatus of a tube with two nostrils is less specialized than in C. affinis, atinga, reticulatus, and tigrinus, but its other features that distinguish it from them are specialized (narrowness of the region around the palatine and anterior end of the frontal, numerous rows of trituration teeth, nine caudal fin rays), while it shares with them the specialized features of the loss of the prefrontal and the presence of teeth on the fifth ceratobranchial.

The exclusively Atlantic subgroup of Chilomycterus is specialized only in the loss of gill rakers on the anterior

Figure 302.-Chart showing the increased number of trituration plates in the upper jaw with increasing specimen size, with the same relationship holding for the lower jaw also, in Diodon holocanthus, D. hystrix,

Chilomycterus schoepfi, C. mauretanicus,

C. atinga, C. antillarum, and C. reticulatus. 
edge of the fourth arch and in having nine caudal fin rays, while being more generalized than either of the other two subgroups by always retaining a prefrontal, and more generalized than the $C$. affinis, atinga, reticulatus, and tigrinus subgroup by the constant presence of two hypohyals and a pharyngobranchial on the third arch, the constant absence of teeth on the fifth ceratobranchial, and the normal presence of a nasal tube with two nostrils. The only specialized feature that the exclusively Atlantic subgroup shares with $C$. orbicularis is the presence of nine caudal fin rays, but otherwise the Atlantic subgroup is far more generalized than $C$. orbicularis.

Whether the three subgroups within Chilomycterus should be recognized subgenerically is a matter of opinion, but on a practical level I doubt that such categories would be generally used and none are here proposed.

In summary, $C$. orbicularis is most closely related to the $C$. affinis, atinga, reticulatus, and tigrinus subgroup and in its own way is about as specialized as them, probably having diverged from a common ancestral line at a time when the nasal apparatus was still a tube with two nostrils. The $C$. antennatus, antillarum, mauretanicus, schoepfi, and spinosus subgroup is more distantly related to the other two and in most ways is more generalized than them, probably having diverged from the line leading to the other two subgroups at a time when there were still 10 caudal fin rays and gill rakers on the anterior edge of the fourth arch, with the subsequent loss of one of the caudal rays and of those gill rakers while in general becoming less differentiated from the basal stock than did the other two subgroups.

The three species of Diodon studied, two of which (holocanthus and hystrix) have all of the spines erectile and the other (jaculiferus) with only a few behind the pectoral fin erectile, scarcely differ osteologically, the prefrontal in jaculiferus being slightly smaller than in the other two. The two species of Dicotylichthys studied, one (nicthemerus) with all the spines erectile and the other (punctulatus) with only those on the head erectile, are equally similar osteologically and can be distinguished from Diodon internally only by the presence of a specialized well-developed band of teeth on the fifth ceratobranchial, this being entirely toothless in Diodon, while externally they differ only by Diodon having a nasal tube with two nostrils versus the specialized bilobed tentacle of Dicotylichthys. I do not think that this combination of two characters is of sufficient magnitude to warrant generic recognition, it being no greater, and in actuality less, than that between the three unnamed subgroups of Chilomycterus. It is suggested that Dicotylichthys be placed in the synonymy of Diodon.

Moreover, the skeletal structure of Diodon and Dicotylichthys is nearly indistinguishable from that of the entirely Atlantic subgroup of Chilomycterus. Both Diodon and Dicotylichthys differ from it only by the presence of at least a few erectile spines and of gill rakers on the anterior edge of the fourth arch, and Dicotylichthys additionally by the presence of teeth on the fifth ceratobranchial, a rather unimpressive array of differences.

Diodon, Dicotylichthys, and the entirely Atlantic subgroup of Chilomycterus have apparently diverged little from the generalized ancestral stock. The presence of a full covering of erectile spines without massive radiating bases would seem to be the most generalized condition in diodontids, as it is the closest to the normal condition in tetraodontids. In this view the development of a huge triradiate base to the scale, which makes it nonerectile, is a specialization, and the species of Diodon and Dicotylichthys with all of the spines erectile are more generalized than those with only a minority of them erectile, while by the same token Chilomycterus, all of whose species have all of the spines with huge triradiate bases, is the most specialized of all.

In short, Diodon and Dicotylichthys do not seem anatomically different enough to warrant separate generic recognition, and while they are more generalized and easily distinguishable osteologically from the two

Figure 303.-Hypothesized phylogenetic relationships of the genera of Diodontidae.

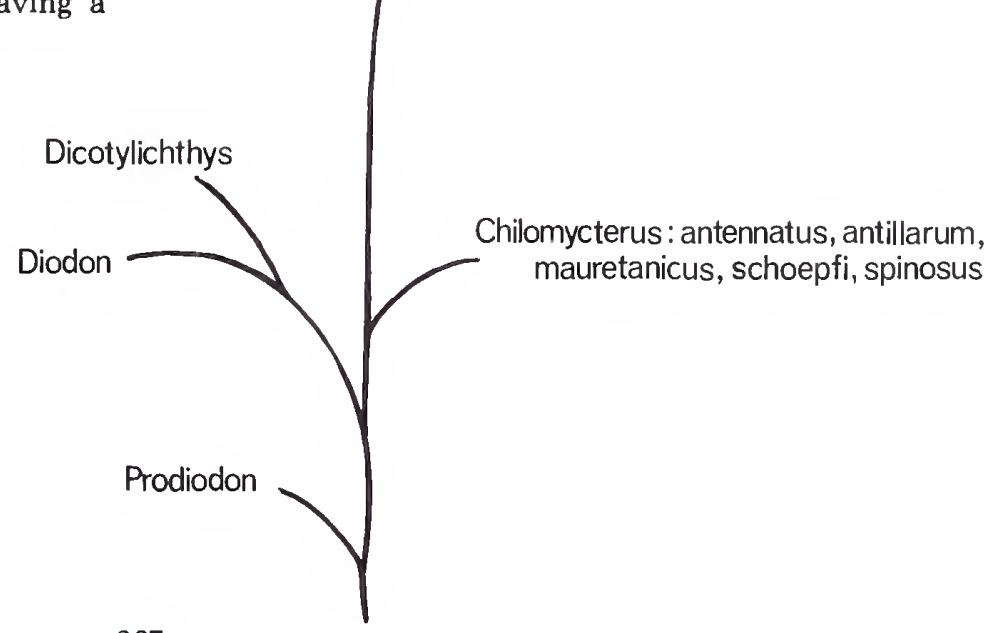


more specialized subgroups of Chilomycterus (the affinis, atinga, reticulatus, tigrinus subgroup, and the orbicularis subgroup) they differ from the more generalized subgroup of Chilomycterus (antennatus, antillarum, mauretanicus, schoepfi, spinosus) only slightly, primarily by retaining at least some erectile spines without huge triradiate bases.

Relationship to the other Tetraodontoidei.-The relationship of the Diodontidae as a specialized offshoot of the line of gymnodonts leading to the Tetraodontidae is discussed under the latter and under the Triodontidae, with additional remarks under the Molidae.

\section{SUPERFAMILY MOLOIDEA}

Comparative diagnosis (contrast with that of the Tetraodontoidea), which is also that of its only contained family, the Molidae.-No inflatable diverticulum of the gut; first branchiostegal ray without an inturned and enlarged dorsal edge, articulated to the ventral edge of the ceratohyal and not forming a pumping plate; air bladder absent, at least in adults; four gills, greatly expanded dorsally above and beyond the supporting arches; a gill slit present between the gill bearing fourth arch and the gill-less fifth arch, with gill rakers present along both the posterior edge of the fourth arch and the anterior edge of the fifth arch; gill rakers present along the anterior edge of the first gill slit; pharyngobranchials with extremely large teeth, the three elements being those of the second to fourth arches; ceratohyal and epihyal not sutured to one another; interhyal and dorsal hypohyal always present; teeth in biting edge of jaws apparently indistinguishably incorporated into the bony matrix of the premaxillary and dentary; basisphenoid present; caudal fin aborted, either absent altogether or represented by only a few rays in the central region of the pseudocaudal fin formed by posteriorly migrated soft dorsal and anal fin rays and supported mostly by equally posteriorly migrated basal pterygiophores from the soft dorsal and anal fins; dorsal, anal, caudal, and pectoral fin rays often extensively branched but with extremely few cross-striations, those present only at the extreme distal ends of the rays; sesamoid articular absent; postcleithrum with an anteriorly directed process toward or over the actinosts; three actinosts; supracleithrum extremely elongate, broadly articulated over the anterior one-third to one-half of its length with the pterotic; coracoid long and slender, without a posterodorsal prong below the lower actinost; operculum and suboperculum of greatly simplified structure and reduced lateral surface area; interoperculum absent as an ossification or present as a simple slender rod of bone not extending posteriorly beyond the level of the epihyal; basioccipital greatly prolonged dorsally behind the exoccipitals to border the foramen magnum to the exclusion of the exoccipitals; exoccipitals without
Figure 304.- Range of diversity in body form in the Molidae: Mola mola (left) and Ranzania laevis (right).

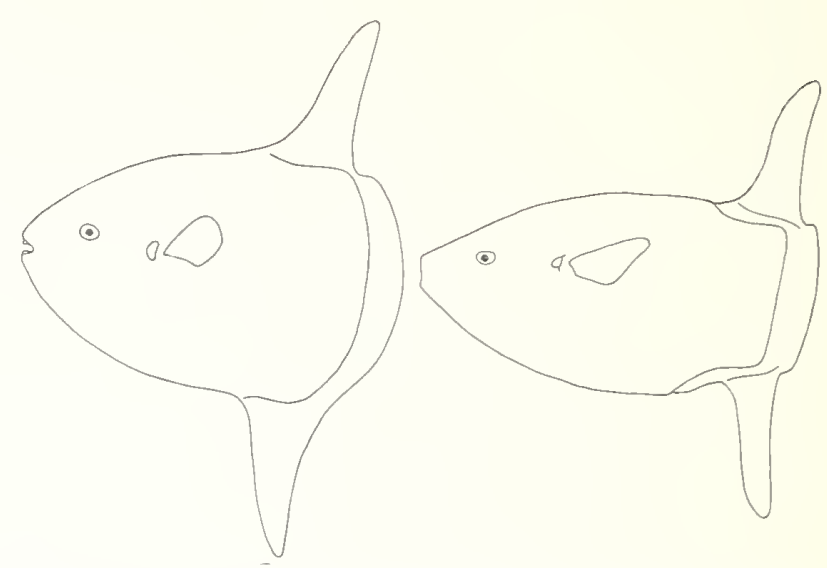

condyles and not in contact with the first vertebra, which articulates anteriorly only with the basioccipital; epiotic with a high dome or ribbonlike posterodorsal prolongation; pterotic greatly prolonged posteriorly, well past the level of the end of the basioccipital; bony canal for the nerves and blood vessels running from the orbit to the nasal region complete, entirely surrounded by the prefrontal; palatine receiving its main support dorsally by a broad articulation with the ethmoid, vomer (if present), prefrontal, and parasphenoid; no vertebrae with bifid neural spines projecting dorsally or dorsolaterally on each side of the neural arch; centra of the abdominal vertebrae without any ventral or ventrolateral processes, the ventral and ventrolateral surfaces of the centra perfectly smooth; dorsal and anal fin rays widely separated from their basal pterygial supports by a large block of cartilage; scales small but the basal plates in more or less close contact and forming a continuous covering over the entire body, with none of the scales in the form of prominent prickles or spines; two minute nostrils flush with the surface of the skin; lateral line either absent or extremely inconspicuous (not discernible to me on either cleared and stained or intact alcohol preserved specimens at 30 magnifications).

\section{Detailed description of Mola mola.}

Material examined.-Two cleared and stained specimens, $306 \mathrm{~mm}$ and $310 \mathrm{~mm}$; two sets of jaws from large specimens of unknown length, one dry and one alcohol preserved.

\section{SKULL.}

\section{Occipital Region.}

Basioccipital. - A short column, expanded at the anterior end and prolonged anterodorsally into a pair of sturdy prongs much like those of the first vertebra; broadly cartilage filled along the expanded anterior edge 


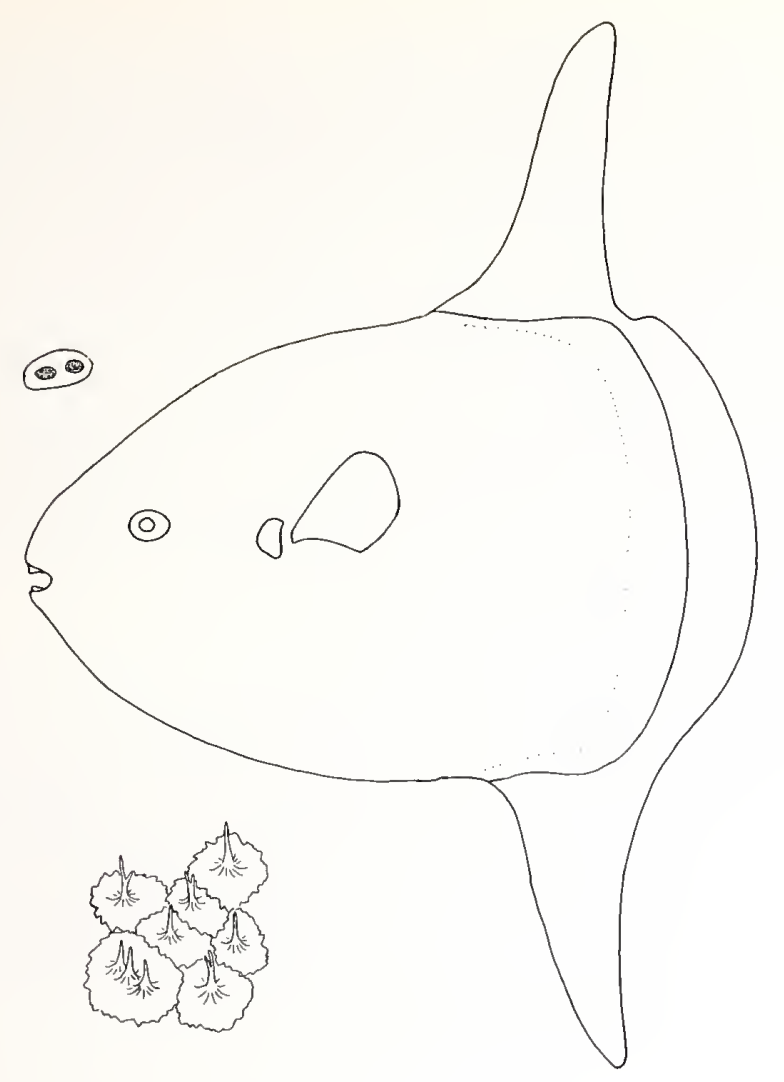

Figure 305.-Mola mola: upper left, nasal region as seen externally; lower left, scales from upper middle region of body.

of the columnar portion; articulates through cartilage anteroventrally with the prootics and anterodorsally with the exoccipitals. The posterior end of the parasphenoid overlies the anterior half of the midventral surface of the basioccipital and is held to it by fibrous tissue, the basioccipital remaining largely cartilaginous in the region overlain by the parasphenoid. The anterodorsally directed prongs of the basioccipital articulate by fibrous tissue anteriorly with the exoccipitals and posteriorly with the bifid neural spine of the first vertebra. The medial edges of the anterodorsally directed prongs form the lateral walls of the foramen magnum, while the dorsal wall is formed by cartilage and the ventral wall by the dorsal surface of the columnar portion of the basioccipital. The rim of the round concave posterior end of the basioccipital articulates by fibrous tissue with the rim of the concave anterior end of the first vertebra.

Exoccipital. -A large, nearly flat plate; cartilage filled along all of its edges of articulation with the other cranial bones; articulates through cartilage dorsomedial with the supraoccipital, dorsolaterally with the epiotic, laterally with the sphenotic and pterotic, ventrally with the prootic, and medially with the basioccipital. Along the middle region of its medial edge the exoccipital articulates by fibrous tissue with the anterodorsal prong of the basioccipital. The exoccipital does not articulate with the first vertebra, nor does it enter into the formation of the walls of the foramen magnum.

Supraoccipital. - A rounded plate ventrally, but produced dorsally into a high and stout supraoccipital crest; cartilage filled along all of its ventral edges; articulates through cartilage laterally with the epiotics and posteriorly with the exoccipitals. Anteriorly the base of the supraoccipital is overlain by the frontals, with which it articulates by fibrous tissue.

\section{Otic Region.}

Pterotic. - Broadly cartilage filled along its anterior edge; articulates through cartilage anterolaterally with the sphenotic, anteromedially on its dorsal surface with the epiotic and exoccipital and anteromedially on its ventral surface with the prootic. Along most of the length of its dorsal surface the pterotic possesses an upraised flange just lateral to which the supracleithrum articulates by fibrous tissue. Along most of the length of its lateral surface a similar flange is present just lateral to which the hyomandibular articulates by fibrous tissue.

Sphenotic. - Cartilage filled along its medial and anterior edges; articulates through cartilage posteriorly with the pterotic, dorsomedially with the epiotic and exoccipital, and ventromedially with the prootic and pterosphenoid. Anteriorly the sphenotic articulates by fibrous tissue with the overlying frontal. At its posterodorsal edge the sphenotic possesses a posterior process which articulates closely by fibrous tissue with the dorsal surface of the pterotic and which supports the anteromedial edge of the supracleithrum. Posteriorly along its ventral surface the sphenotic articulates by fibrous tissue with the anterior edge of the hyomandibular.

Epiotic. - A more or less rounded plate ventrally, but prolonged posterodorsally into a spine which connects by a tendon to the muscle mass of the dorsal fin; cartilage filled along all of its ventral edges; articulates through cartilage medially with the supraoccipital, posteriorly with the exoccipital and laterally with the sphenotic. Anteriorly the epiotic articulates by fibrous tissue with the overlying frontal.

Prootic. - Cartilage filled along all of its edges of articulation with the other cranial bones; articulates through cartilage anterodorsally with the pterosphenoid, anterolaterally with the sphenotic, posterolaterally with the pterotic, and posteriorly with the exoccipital and basioccipital. The anteroventral edge of the prootic articulates by fibrous tissue with the posterodorsal wing of the parasphenoid, while more posteriorly the medial edge of the prootic similarly articulates with the lateral edge of the parasphenoid. Along its anteroventral edge the prootic is produced into a laterally expanded wing which articulates by fibrous tissue with the anteromedial edge of the dorsal end of the hyomandibular. 
Orbita! Region.

Frontal. - A relatively flat plate; expanded posterolaterally to overlie and articulate by fibrous tissue with the supraoccipital, epiotic, and sphenotic. The medial edges of the two frontals are broadly concave and enclose between themselves the anterior portion of the cartilaginous tissue of the otic and occipital regions. The dorsomedial edges of the two frontals articulate with one another by fibrous tissue. Along its posteroventral edge the frontal overlies and articulates by fibrous tissue with the pterosphenoid and sphenotic. Anteriorly the rounded end of the frontal broadly overlies and articulates by fibrous tissue with the ethmoid and prefrontal.

Prefrontal. - A more or less vertical column posterolaterally, but expanded into a thin vertical sheet anteriorly; cartilage filled along the middle region of its medial surface; articulates by fibrous tissue posterodorsally with the overlying frontal, anteromedially with the ethmoid, and anterolaterally with the palatine. A canal for the olfactory nerve and vessels is present through the substance of the prefrontal, rather than being present at the interface of the prefrontal, frontal, and ethmoid cartilage.

Parasphenoid.-Elongate; expanded ventrally along most of its length into a stout, but not particularly deep, flange. About two-thirds the way back its length the parasphenoid gives rise to a pair of short posterodorsally directed wings which articulate by fibrous tissue with the anteroventral edges of the prootics. Posterior to these dorsal wings, the parasphenoid articulates by fibrous tissue laterally with the posteromedial edges of the prootics and posteriorly with the anteromedial surface of the basioccipital. Just anterior to its dorsal wings, the dorsal surface of the parasphenoid becomes concave for a short distance to receive and hold by fibrous tissue the ventral edge of the basisphenoid. Along the lateral surface of about the anterior one-fourth of its length the parasphenoid articulates by fibrous tissue with the thin posterior portion of the palatine. The anterior end of the parasphenoid is deeply concave and filled with gelatinous tissue. The posterior end of the vomer does not fit into this concavity; rather, the ventral edge of the concave anterior end of the parasphenoid supports by fibrous tissue the posterior edge of the vomer. The dorsal portion of the concave anterior edge of the parasphenoid articulates by fibrous tissue with the ventral surface of the ethmoid.

Pterosphenoid. - A relatively flat plate; cartilage filled along all of its edges, except medially; articulates through cartilage posteroventrally with the prootic and posterodorsally with the sphenotic. Dorsally the pterosphenoid is overlain by the frontal, with which it articulates by fibrous tissue. The ventral edge of the pterosphenoid articulates by fibrous tissue with the dorsal edge of the basisphenoid.
Basisphenoid. - A large rounded plate anteriorly, but laterally expanded posteriorly into a process whose concave posterior surface articulates by fibrous tissue with the medial edge of the anteroventral region of the prootic. The ventral edge of the basisphenoid articulates by fibrous tissue with the longitudinal concavity on the dorsal surface of the parasphenoid. The anterior and dorsal edges of the upper half of the basisphenoid are cartilage filled. Dorsally the basisphenoid articulates by fibrous tissue with the ventral edge of the pterosphenoid. A small gap is present between the otherwise closely apposed edges of the pterosphenoid and basisphenoid which serves as a foramen for the exit of vessels from the cranial cavity.

\section{Ethmoid Region.}

Ethmoid.-Thick and squarish; continuous posteroventrally with the remains of the ethmoid cartilage; articulates by fibrous tissue along the anterior half of its ventral surface with the vomer and along the posterior half of its ventral surface with the dorsal surface of the concave anterior end of the parasphenoid. The lateral surfaces of the ethmoid articulate by fibrous tissue anteriorly with the palatines and posteriorly with the prefrontals.

Vomer. - A small squarish bone articulated by fibrous tissue dorsally with the anterior half of the ventral surface of the ethmoid, laterally with the medial edges of the palatines and posteriorly with the ventral edge of the concave anterior end of the parasphenoid. The anterior edges of both the vomer and ethmoid articulate by fibrous tissue with the posteromedial edge of the upper jaw.

\section{Mandibular Region.}

Hyomandibular. - Expanded posterodorsally, but tapering anteroventrally to a thick rounded shaft; cartilage filled at its anteroventral edge and along the anterior one-third of its dorsal edge. The hyomandibular articulates by fibrous tissue along most of the length of its dorsal edge with the ventrolateral surface of the pterotic, but anterodorsally it is also supported by the medial portion of the posteroventral edge of the sphenotic and by the ventrolateral flange of the prootic. Along the ventral half of its posterior edge the hyomandibular articulates by fibrous tissue with the posterior half of the dorsal edge of the preoperculum. Dorsally along its anteroventral end the hyomandibular articulates by fibrous tissue with the posteroventral edge of the metapterygoid. Just above the posterodorsal end of the preoperculum, the hyomandibular possesses a thickened area whose concave posterior face articulates by fibrous tissue with the concave anterior end of the operculum.

Quadrate.-Wide posteriorly, but tapering to a knob anteriorly for articulation with the articular in the lower jaw; a short posteriorly directed process present 
from its posteroventral region; slightly cartilage filled along its posterior edge; articulates by fibrous tissue anterodorsally with the ectopterygoid and ventrally with the preoperculum. Posteriorly the quadrate articulates through cartilage with the metapterygoid. The inner surface of the posteroventral portion of the quadrate that overlies the symplectic forms a concave groove in which the symplectic is held by fibrous tissue. The articulation of the knoblike anterior end of the quadrate with the articular in the lower jaw is strengthened by the fibrous tissue attachment of an anteromedial projection from the anterior edge of the quadrate with the posteromedial edge of the articular.

Metapterygoid. - Broad anteriorly, but tapering to a point posteriorly; cartilage filled along its anterior and anteroventral edges; articulates through cartilage anteriorly with the quadrate and by fibrous tissue anteroventrally with the symplectic and posteroventrally with the hyomandibular. The cartilaginous region between the hyomandibular, metapterygoid, and symplectic is the place of fibrous tissue articulation of the dorsal end of the interhyal. The anterodorsal edge of the metapterygoid articulates by fibrous tissue with the posterior end of the mesopterygoid.

Symplectic. - A long rod, slightly wider posteriorly than anteriorly; cartilage filled at its posterior and anterior edges; articulates by fibrous tissue dorsally with the metapterygoid and anteroventrally with the concavity on the inner surface of the quadrate.

\section{Palato-Pterygoid Region.}

Palatine. - Wide anteriorly, but becoming a flat vertical plate posteriorly; articulates by fibrous tissue anteromedially with the ethmoid and vomer, posteromedially with the parasphenoid, ventrally with the ectopterygoid and mesopterygoid, and posterodorsally with the prefrontal. The anterodorsal edge of the palatine, which is produced medially as a slender prong, articulates by fibrous tissue with the posterodorsal edge of the maxillary.

Ectopterygoid. - Only slightly V-shaped, with the apex directed posteriorly; articulates by fibrous tissue dorsally with the slightly overlying palatine, ventrally with the quadrate, and posteriorly with the mesoptery. goid, which it slightly overlies.

Mesopterygoid.-More or less squarish; articulates by fibrous tissue anteriorly with the slightly overlying palatine and ventrally with the cartilaginous region between the metapterygoid and quadrate.

\section{Opercular Region.}

Operculum. - A straight shaft of bone, becoming laterally compressed posteriorly; articulates at its concave anterior edge by fibrous tissue with the concave facet on the posterior edge of the hyomandibular, while ventrally it overlies and articulates by fibrous tissue with the suboperculum.

Suboperculum. - Long and flat; widest in about the middle of its length and becoming much thinner both anteriorly and posteriorly; articulates by fibrous tissue posteriorly with the overlying operculum and anteriorly with the long ligament in which the interoperculum is embedded.

Interoperculum. - A long delicate needle of bone entirely embedded within the ligament which runs between the angular in the lower jaw and the anterior end of the suboperculum. At the level of the posterior end of the interoperculum, the ligament is particularly firmly held to the general connective tissue around the lateral surface of the epihyal.

Preoperculum.-More or less flat throughout its length, except along its dorsal edge where it is slightly expanded to form a broadened surface for fibrous tissue articulation posteriorly with the hyomandibular and anteriorly with the quadrate. In about the middle of its length the dorsal edge of the preoperculum articulates by fibrous tissue with the cartilaginous region between the hyomandibular, metapterygoid, and symplectic.

\section{Upper Jaw.}

Premaxillary. - The two premaxillaries are indistinguishably fused in the midline and together with the fused teeth form a large nibbling plate; anterior edge of premaxillary forming about the dorsal two-thirds of the border of the upper jaw, the lower third of the border being formed by the anterior edge of the maxillary. The premaxillaries articulate laterally by fibrous tissue with the broadly overlying maxillaries. Dorsally, however, the expanded upper ends of the maxillaries fit into deep concavities in the surface of the premaxillaries and are held there by fibrous tissue. The premaxillaries thus broadly overlie the dorsal ends of the maxillaries. The posterior edge of the fused premaxillaries is overlain by the maxillaries along all of its length, except for a very short distance medially. The pulp cavity of the fused premaxillaries is small, shallow, and confined to the dorsal region of the bone. The dorsal roof over the pulp cavity is thin and smooth internally, but the ventral floor of the cavity is thick and highly irregular. The pulp material extends into and between the innumerable bony lamellae and spikes rising from the floor of the cavity. No discrete teeth or dental units of any kind are visible there in either of the two cleared and stained study specimens, or in the two additional sets of much larger jaws, nor can any such structures be distinguished in the hard sub. stance of the biting edge of the fused premaxillaries. A large trituration plate is present on the medial third of the under surface of the fused premaxillaries. In the two relatively small cleared and stained specimens, the trituration plate is distinctly divided into closely apposed 
right and left halves, each of which contains four or five elongate teeth. The teeth are set in deep sockets and remain distinct and separate from one another but become increasingly intimately held to the bony matrix anteriorly. As an old tooth at the anterior end of the trituration plate is worn away or resorbed, a new tooth develops in a new socket at the posterior end of the plate. In the two sets of jaws from specimens apparently at least several times as large as the two cleared and stained specimens, the teeth of the trituration plate are far more numerous, less regularly arranged, relatively smaller and placed more anteriorly on the undersurface of the premaxillaries. The trituration teeth apparently undergo extensive change with increasing size.

Maxillary. - Straight and rather flattened, except dorsally where it becomes expanded into a large rounded head which fits into the deep concavity on the dorsal surface of the premaxillary. Below the latter region the maxillary broadly overlies and articulates by fibrous tissue with the dorsal surface of the premaxillary. Posterodorsally the medial ends of the two maxillaries and the medial edge of the fused premaxillaries articulate by a fibrous tissue sheet with the anterior edges of the ethmoid and vomer. The ventromedial surface of the maxillary articulates by fibrous tissue with the dorsolateral surface of the dentary.

\section{Lower Jaw.}

Dentary. - The two dentaries are indistinguishably fused in the midline and, with the fused teeth, form a large nibbling plate like that of the upper jaw. The posteromedial surfaces of the fused dentaries are deeply concave to receive and articulate by fibrous tissue with the anterior ends of the articulars. Posteroventrally the dentary articulates by fibrous tissue with the anterior end of the angular. Posterodorsally along its lateral surface the dentary articulates by fibrous tissue with the medial surface of the maxillary. The biting edge of the dentary is a hard and apparently completely homogenous substance, like that of the upper jaw. A trituration plate composed of separate, but closely apposed, right and left halves is present on the medial third of the inner surface of the fused dentaries in the two relatively small cleared and stained specimens. Each side contains two series of separate and distinct teeth set in deep sockets. The inner series contains four elongate teeth, while the other series contains three somewhat rounded teeth. The pulp cavity and replacement of the teeth of the trituration plate are the same as described for the fused premaxillaries, and the two sets of jaws from much larger specimens similarly have far more numerous and smaller teeth placed more anteriorly on the bone.

Articular. - More or less triangular in shape; cartilage filled for a short distance anteriorly on its medial surface where it is continuous with the remains of Meckel's cartilage. The tapering anterior portion of the articular articulates by fibrous tissue with the concave medial surface of the dentary. Posteroventrally the medial surface of the articular is concave and forms a groove in which the dorsal end of the angular is held by fibrous tissue. In about the middle of its posterior edge the articular possesses a transverse groove which articulates by fibrous tissue with the quadrate. A sesamoid articular is absent.

Angular. - A short rod; cartilage filled at its dorsal edge; articulates by fibrous tissue anteriorly with the dentary and dorsally with the groove on the medial surface of the articular. Posteriorly the angular connects with the ligament that encloses the interoperculum.

\section{BRANCHIAL APPARATUS.}

\section{Hyoid Arch and Branchiostegal Rays.}

Hypohyals. - Dorsal and ventral hypohyals present, the ventral slightly larger than the dorsal; the ventral and posterior edges of the dorsal hypohyal and the dorsal and posterior edges of the ventral hypohyal cartilage filled; articulate through cartilage with one another and with the anterior edge of the ceratohyal. The anterodorsal end of the dorsal hypohyal articulates by fibrous tissue with the middle of the lateral surface of the basibranchial. The anteromedial edges of the hypohyals articulate by fibrous tissue with their opposite members.

Ceratohyal. - Short, but wide; more expanded anteriorly than posteriorly; cartilage filled at its anterior and posterior edges; articulates through cartilage anteriorly with the hypohyals and posterodorsally with the epihyal. The posterior half of the ventral edge of the ceratohyal possesses two successive indentations separated by a ventrally directed prong. The ceratohyal supports the first three branchiostegal rays.

Epihyal. -Small; cartilage filled along its anterior and ventral edges; articulates anteriorly and ventrally through cartilage with the ceratohyal, while posterodorsally it articulates by fibrous tissue with the base of the interhyal, and laterally supports the last few branchiostegal rays. The lateral surface of the epihyal articulates by fibrous tissue with the ligament enclosing the interoperculum at the level of the posterior end of the latter.

Interhyal. - A short, thick column; deeply cartilage filled at both ends; articulates by fibrous tissue ventrally with the epihyal and dorsally with the cartilaginous area between the hyomandibular, ectopterygoid, sympletic, and preoperculum.

Branchiostegal rays. - Six in number; the first five rays long, flat, and relatively straight; the sixth branchiostegal wide for a short distance anteriorly, but rapidly tapering posteriorly to a long, thin, slender shaft. The branchiostegal rays articulate by fibrous tissue with the hyoid arch elements as follows: first and second branchiostegals with the successive concavities on the ventral 
edge of the ceratohyal; third branchiostegal with a slight concavity on the posterior edge of the ceratohyal; fourth branchiostegal with the cartilage between the epihyal and ceratohyal; fifth and sixth branchiostegals with the lateral surface of the epihyal.

Branchial Arches. - The elements are cartilage filled at their edges of articulation with the other elements of the series, and the articulations are usually through cartilage and fibrous tissue. The branchial arches are composed of three basibranchials, three pairs of hypobranchials, five pairs of ceratobranchials, four pairs of epibranchials, and three pairs of pharyngobranchials. Four gills are present, with a large slit between the fourth arch and the lower pharyngeal. The gills are enormously enlarged and only about the lower third of their lengths are supported by the branchial arches; these were described long ago by Alessandrini (1839) and most recently, in great detail, by Adeney and Hughes (1977). The anterior edges of the upper two-thirds of their lengths are held by fibrous tissue to the ventral surfaces of the posterior end of the cranium and the first several vertebrae.

First arch. - Basi-, hypo-, cerato-, and epibranchial elements present. First basibranchial laterally compressed anteriorly; about the same length as the third basibranchial and somewhat shorter than the second basibranchial; with a ventral keel medially on its ventral surface; displaced forward so that it articulates posteriorly with the second basibranchial and posterolaterally with the first hypobranchials. First hypobranchial the longest of the hypobranchial elements, which decrease in length posteriorly in the series; articulates dorsally with the first ceratobranchial, ventrally with the second basibranchials and anteroventrally with the first basibranchial. First ceratobranchial slightly longer and deeper than the other ceratobranchials, which are about equal in length but which decrease in depth posteriorly in the series; articulates ventrally with the first hypobranchial and dorsally with the first epibranchial. First epibranchial a slender rod articulating dorsally with the fibrous tissue sheet between the dorsal edges of the metapterygoid and hyomandibular and the ventral edge of the parasphenoid.

Second arch. -Basi-, hypo-, cerato-, epi-, and pharyngobranchial elements present. Second basibranchial the longest and widest of the basibranchial elements; with a ventral keel medially on its ventral surface; articulates anteriorly with the first basibranchial, anterolaterally with the first hypobranchials, posterolaterally with the second hypobranchials, and posteriorly with the third basibranchial. Second hypobranchial only slightly shorter and narrower than the first hypobranchial; articulates ventrally with the anterolateral edge of the third basibranchial and posterolateral edge of the second basibranchial, while dorsally it articulates with the second ceratobranchial. Second ceratobranchial articulated dorsally with the second epibranchial. Second epibranchial a very narrow rod articulating dorsally with the middle of the toothless edge of the second pharyngobranchial. Second pharyngobranchial a rounded plate bearing about four long teeth set in sockets along its ventral edge. The bases of the teeth are expanded and articulate with their sockets by fibrous tissue.

Third arch. - Basi-, hypo-, cerato-, epi-, and pharyngobranchial elements present. Third basibranchial rectangular in shape; its ventral surface without a keel; articulates anteriorly with the second basibranchial, anterolaterally with the second hypobranchials, and posterolaterally with the dorsal ends of the third hypobranchials and the ventral ends of the third ceratobranchials, while posteriorly it supports the cartilaginous area to which are attached the fourth and fifth ceratobranchials. Third hypobranchial a short column of bone, almost vertical in position and sunken below the general connective tissue that lies between the rest of the basibranchials and hypobranchials; articulates dorsally with the ventral surface of the cartilage between the posterolateral end of the third basibranchial and the ventral end of the third ceratobranchial, while its ventral end connects by a band of fibrous tissue with the ventral keel of the second basibranchial and, continuing anteriorly, with the ventral keel of the first basibranchial. Third ceratobranchial articulated dorsally with the third epibranchial. Third epibranchial a stout rod; articulates dorsally with the third pharyngobranchial. Third pharyngobranchial the largest of the pharyngobranchial elements; bears about six long, sharp-pointed teeth whose expanded bases articulate by fibrous tissue with their sockets on the ventral edge of the pharyngobranchial; articulates ventrally with the third epibranchial and anteriorly and posteriorly with, respectively, the second and fourth pharyngobranchials.

Fourth arch. - Cerato-, epi-, and pharyngobranchial elements present. Fourth ceratobranchial articulated ventrally with the third basibranchial and dorsally with the fourth epibranchial. Fourth epibranchial a large flattened plate, wider ventrally than dorsally; articulates ventrally with the dorsal ends of the fourth and fifth ceratobranchials and dorsally with the fourth pharyngobranchial. Fourth pharyngobranchial similar to the second pharyngobranchial; bearing four teeth in a single row.

Fifth arch. - Ceratobranchial (lower pharyngeal) element only. Fifth ceratobranchial like the others in the series, but not as deep; toothless; articulates ventrally with the base of the fourth ceratobranchial.

\section{PAIRED FIN GIRDLES.}

\section{Pectoral Fin.}

Supracleithrum. - Long and flat, somewhat expanded ventrally where it overlies the cleithrum; in position more or less parallel to the posterior end of the skull; articulates by fibrous tissue posteromedially with 
the cleithrum and posterodorsally with the postcleithrum. Anteriorly the medial edge of the supracleithrum articulates by fibrous tissue with the entire length of the dorsolateral surface of the pterotic and with the posterolateral edge of the sphenotic.

Cleithrum. -Widest dorsally, constricted at the level of the scapula and becoming a thin flat plate ventrally. Above the level of the scapula, the posterior region of the medial surface of the cleithrum articulates by fibrous tissue dorsolaterally with the broadly overlying supracleithrum, while the dorsal edge of the portion of the cleithrum overlain by the supracleithrum articulates with the anteroventral edge of the postcleithrum. Along its posterior edge the cleithrum possesses a broad but shallow concavity in which the anterodorsal edge of the scapula is held by fibrous tissue. The posterior edge of the cleithrum below the scapula articulates by fibrous tissue with the anterior edge of the coracoid. The ventromedial surfaces of the two cleithra articulate with one another by fibrous tissue.

Postcleithrum. -Approximately Y-shaped; with the bifurcate portion at the level of the actinosts and the long arm articulated by fibrous tissue anterolaterally with the supracleithrum and anteroventrally with the cleithrum. In neither of the two cleared and stained specimens is there any evidence of the postcleithrum being composed of two elements, the dorsal and ventral postcleithra apparently having fused into a single piece. The lateral surface of the portion of the postcleithrum that lies posterior to the cleithrum is embedded in the thick, firmly collagenous subdermal tissue of the skin. The medial surface of the anterior fork of the inverted Y overlies and articulates by fibrous tissue with the bases of the three actinosts.

Coracoid. - A flattened plate throughout its length, except ventrally where it becomes more rounded and shaftlike; slightly expanded anteriorly in the middle region of its length and more expanded anteriorly at its dorsal end; cartilage filled at its anterodorsal edge; articulates anterodorsally through cartilage with the base of the scapula, while its dorsal edge articulates through cartilage and fibrous tissue with the bases of the three actinosts. The anterior edge of the coracoid articulates by fibrous tissue with the posterior edge of the cleithrum.

Scapula. - Widest dorsally, constricted in the middle and only becoming slightly expanded ventrally; scapular foramen not entirely enclosed by bone, for the anteroventral edge of the scapula is well separated from the posterior edge of the cleithrum. A sheet of fibrous tissue, bearing a small pore representing the scapular foramen, connects these edges of the scapula and cleithrum. The scapula is deeply cartilage filled at its dorsal and ventral edges. The posterodorsal edge of the scapula is somewhat expanded posteriorly and overlies the anterodorsal edge of the anteriormost actinost, with which it articulates by fibrous tissue. The posteroventral edge of the scapula articulates by fibrous tissue with the anteroventral edge of the anteriormost actinost, while ventrally the scapula articulates through cartilage with the coracoid.

Actinosts. - Three actinosts present; decreasing in size and degree of central constriction posteriorly in the series. The reduced first actinost of other plectognaths is not present as a separate piece, although it is possible that the posterodorsal portion of the scapula represents the remains of this actinost indistinguishably fused to the scapula. The three actinosts articulate with one another dorsally and ventrally by fibrous tissue and with the coracoid through cartilage and fibrous tissue. The actinosts are cartilage filled at their dorsal and ventral edges.

Fin rays. - Twelve fin rays present, the first three rays and the last ray unbranched, the others so extensively branched distally that up to 20 terminal segments (incomplete quintuple dichotomies) are present on some fin rays. The medial and lateral halves of each fin ray are not closely apposed to one another except distally, a large amount of connective tissue otherwise separating the two halves for most of their lengths. For the vast majority of their lengths the rays lack cross-striations, which are only present extremely distally on some of the branches as poorly defined articulations. The first ray differs from the others by possessing a slender anteroventral process from the anterior edge of the medial half of the fin ray. The deeply bifurcate bases of the rays surround plugs of cartilage whose ventral regions are calcified either as a single piece or as a pair (lateral and medial) of calcifications (not shown in the figures).

VERTEBRAL COLUMN. - All vertebrae with biconcave centra, except for the last, which ends posteriorly with a relatively flat surface.

\section{Abdominai Vertebrae.}

First vertebra. - Neural spine bifid; no bony roof over the neural canal. The rim of the concave anterior face of the centrum articulates by fibrous tissue with the rim of the concave posterior end of the basioccipital. The anterolateral edges of the bifid neural spine articulate by fibrous tissue with the medial surfaces of the anterodorsal wings of the basioccipital. The dorsal edges of the bifid neural spine are overlain by the anterior edge of the neural spine of the second vertebra, while its posterolateral edges are indented to accommodate the short prongs from the anterolateral edges of the neural spine of the second vertebra.

Other abdominal vertebrae. - Eight abdominal vertebrae in two specimens; neural spines increasing in length from the second to the fifth abdominal vertebrae; neural spines of the fifth to eighth abdominal vertebrae about equal in length; second to eighth abdominal vertebrae with bony roofs over the neural canal. The neural arches from either side of the second abdominal verte- 
bra do not fuse with one another above the neural canal, but, rather, have their medial surfaces closely apposed and articulated with one another by fibrous tissue. This dorsomedial region of apposition is thickened and prolonged anteriorly and posteriorly into a neural spine whose right and left halves are likewise closely apposed medially and held together by fibrous tissue. The ventral surface of the anterior prolongation of the neural spine of the second vertebra overlies the dorsal edge of the bifid neural spine of the first vertebra and effectively roofs over the neural canal in this area. The posterior prolongation of the neural spine of the second vertebra overlies the anterior edge of the neural arch and base of the neural spine of the third vertebra. The neural arches and spines of the third and fourth abdominal vertebrae are likewise only closely apposed, with fibrous tissue holding the right and left halves closely together. The neural spines of the third and fourth abdominal vertebrae are prolonged only posteriorly, and overlie the neural arch and spine of the vertebra just posterior to them. The posterodorsal end of the neural spine of the fourth abdominal vertebra articulates by fibrous tissue with the ventral edge of the first dorsal fin basal pterygiophore. The right and left sides of the neural arches of the fifth to eighth abdominal vertebrae fuse to one another in the midline above the neural canal and are prolonged posterodorsally into long, stout, undivided neural spines. The lower posterior edges of these neural spines overlie the anterior edges of the neural arches of the vertebra just posterior to them. More distally the neural spines of the fifth to eighth abdominal vertebrae articulate by fibrous tissue between the more anterior of the dorsal fin basal pterygiophores.

Caudal Vertebrae. - Nine caudal vertebrae in two specimens. With the exception of the last two vertebrae, all of the caudal vertebrae have well-developed and undivided neural and haemal spines. The neural and haemal spines decrease slightly in stoutness, but not particularly in length, posteriorly in the series. The degree of anteroposterior expansion of the neural arch and base of the neural spine decreases from the first to the sixth caudal vertebrae so that the neural spines of the sixth and seventh caudal vertebrae are slender shafts throughout their entire lengths. The neural spines of the first to seventh caudal vertebrae support by fibrous tissue the more posterior of the dorsal fin basal pterygiophores. The distal three-fourths of the haemal spines of the first and second caudal vertebrae articulate with one another by fibrous tissue and the thick shaft thus formed is overlain laterally and anteriorly by the deeply concave posterior surface of the enlarged first anal fin basal pterygiophore. The posterior edge of the haemal spine of the second caudal vertebra articulates with the anterior edge of the second anal fin basal pterygiophore. The haemal spines of the third to seventh caudal vertebrae support the other anal fin basal pterygiophores. The size of the neural and haemal canals through the neural and haemal arches of the caudal vertebrae decreases posteriorly in the series until these canals are very narrow in the seventh caudal vertebra. The short neural spine of the eighth caudal vertebra arises directly from the centrum and contains no canal whatsoever. The haemal process, however, of the eighth caudal vertebra contains an extremely narrow canal through its substance in one of the specimens but not in the other. The neural and haemal spines of the eighth caudal vertebra curve anteriorly and their distal ends articulate with, respectively, the posterior edges of the neural spine and of the haemal spine of the seventh caudal vertebra. The ninth caudal vertebra is a simple shaft which ends posteriorly with a flat surface abutting against a calcified cartilage, explained below.

DORSAL, ANAL, AND PSEUDOCAUDAL FINS. While a larval caudal fin fold without rays is present in at least the molids Masturus and Ranzania, this is lost in development and the adult pseudocaudal fin in molids is apparently a secondary formation from dorsal and anal fin rays (Gudger 1937a, b; Raven 1939a; Tyler 1970b). The fin rays of the pseudocaudal fin are continuous with those of the dorsal and anal fin series and are supported basally by modified basal pterygiophores of the dorsal and anal fins. Only an arbitrary distinction can be made between the dorsal, pseudocaudal, and anal fins, but such a distinction is perhaps advisable for the sake of discussion. The pseudocaudal fin, composed of posteromedially migrated dorsal and anal fin rays, is here considered to include all those fin rays supported by the modified basal pterygiophores posterior to the neural and haemal spines of the seventh caudal vertebra.

The 15 dorsal fin basal pterygiophores and the 9 anal fin basal pterygiophores anterior to the seventh caudal vertebra have a normal relationship with the neural and haemal spines of the vertebrae to which they articulate. The ventral ends of these dorsal fin basal pterygiophores are cartilage filled while the distal ends of all but the first dorsal fin basal pterygiophore are irregularly cartilage filled and closely apposed to the ventral surface of the large cartilaginous plate that intervenes between them and the dorsal fin rays. The first dorsal fin basal pterygiophore tapers to a point distally and articulates by fibrous tissue posteriorly with the neural spine of the fifth abdominal vertebra and with the anterior edge of the second basal pterygiophore. Along the dorsal third of its anterior edge the first basal pterygiophore articulates by fibrous tissue, and possibly slight interdigitation, with the posteroventral edge of the supraneural. The supraneural tapers to a blunt point anteriorly and is embedded between the right and left muscle masses of the dorsal fin. The large cartilaginous plate that intervenes between the basal pterygiophores and the dorsal fin rays is calcified irregularly in the two cleared and stained specimens. The posterior one-third of the plate is the best calcified portion, but calcareous areas are also present at the anterior end and along much of the ventral portion of the plate. The plate is homogenous posteriorly, but shows some evidence anteriorly of being composed of successive cartilaginous blocks closely applied to one another. The lateral surface of the plate possesses upraised areas between which run the ligaments from the fin rays to the 
dorsal fin muscle mass. There are 18 dorsal fin rays present anterior to the first dorsal fin ray supported by a modified dorsal fin basal pterygiophore posterior to the neural spine of the seventh caudal vertebra. The first five dorsal fin rays are unbranched, and the sixth ray is only slightly branched at its extreme distal end. The 7th to 16 th fin rays are extensively branched distally, so much so that some of the rays have over 50 terminal segments (incomplete sextuple dichotomies). The right and left halves of each of the rays are well-separated by fibrous tissue from one another medially throughout their lengths, except distally where they begin to branch. As with the pectoral fin rays, cross-striations are only present extremely distally on some of the branches as poorly defined articulations. The bifurcate bases of the dorsal fin rays enclose plugs of calcified cartilage which articulate by fibrous tissue with the cartilaginous plate below them. There are thus three series of pterygial elements supporting the dorsal fin rays: 1) the ossified basal pterygiophores; 2) the partially calcified cartilaginous plate representing the closely apposed or confluent medial pterygiophores; and 3) the calcified cartilaginous plugs or distal pterygiophores at the bifurcate bases of the fin rays.

Except for the anteriormost pterygiophore, the nine anal fin basal pterygiophores are like those of the dorsal fin, except longer. They have concave proximal ends which are cartilage filled and they articulate by fibrous tissue with the haemal spines of the caudal vertebrae and with one another. Their distal ends are irregularly cartilage filled and closely apposed or continuous with the partially calcified cartilaginous plate that intervenes between them and the anal fin rays. The first anal fin basal pterygiophore is deeply concave along the posterior surface of the upper two-thirds of its length where it overlies and articulates by fibrous tissue with the haemal spines of the first two caudal vertebrae. Distally the first basal pterygiophore is bifurcate into two parts which fit against the medial pterygial plate. The medial pterygial plate is, like the dorsal fin medial pterygial plate, irregularly calcified. Sixteen anal fin rays are present anterior to the first anal fin ray supported by a modified basal pterygiophore posterior to the haemal spine of the seventh caudal vertebra. The first five anal fin rays are unbranched, and the sixth is only slightly branched distally. The 7 th to 15 th anal fin rays are branched in the same extensive manner as the corresponding rays of the dorsal fin. The 16th anal fin ray is much less branched than those anterior to it. The anal fin rays have the same structure as those of the dorsal fin and likewise have plugs of calcified cartilage, or distal pterygiophores, embedded between their bifurcate bases.

Posterior to the neural spine of the seventh caudal vertebra there are seven modified dorsal fin basal pterygiophores which distally support the seven dorsal fin rays of the upper half of the pseudocaudal fin. The uppermost, or first, modified basal pterygiophore is placed at about a right angle to the vertebral column, but the second to seventh modified basal pterygiophores are progressively more obliquely placed, until the seventh is almost parallel to the vertebral column. Except for the first, these modified basal pterygiophores are cartilage filled at both ends and articulate by fibrous tissue proximally with the neural spines of the seventh or eighth caudal vertebrae and distally with the blocks of calcified cartilage that form the medial pterygiophores of the pseudocaudal fin. The proximal ends of the second to fifth modified basal pterygiophores articulate with the posterior edge of the neural spine of the seventh caudal vertebra, while the proximal ends of the sixth and seventh modified basal pterygiophores articulate with the posterior edge of the neural spine of the eighth caudal vertebra. The proximal end of the first modified basal pterygiophore tapers to a narrow shaft articulated by fibrous tissue with the posterior edge of the last unmodified dorsal fin basal pterygiophore. The distal end of the first modified basal pterygiophore articulates with the posteroventral edge of the large, partially calcified, cartilaginous mass that makes up the medial pterygiophore of the dorsal fin. The medial pterygiophore above the second modified basal pterygiophore is also continuous with the medial pterygiophore of the dorsal fin, being delimited from it only by a constricted region of cartilage. The calcified cartilages of the medial pterygiophores at the distal ends of the third to sixth modified basal pterygiophores remain separate from one another in the two cleared and stained specimens. The medial pterygiophore of the modified seventh basal pterygiophore is connected with the cartilage at the end of the ninth caudal vertebra and with the medial pterygiophore of the eighth modified anal fin basal pterygiophore. It is to be expected that in larger specimens more of the medial pterygiophores of the pseudocaudal fin become continuous with one another, because even in the two relatively small study specimens, the short, thin processes of the fifth and sixth medial pterygiophores almost make contact with the medial pterygiophores below them. The distal pterygiophores of the pseudocaudal fin, whose posterolateral surfaces are overlain by the bifurcate bases of the fin rays, are blocks of calcified cartilage which increase in size in the series from that distal to the first to that distal to the seventh modified basal pterygiophore. The distal pterygiophores are thickest at their ends which articulate by fibrous tissue with the medial pterygiophores. The seven fin rays supported by the distal pterygiophores increase slightly in length in the series from that attached to the first to that attached to the seventh pterygiophore. The fin ray above the first modified basal pterygiophore is branched in a double dichotomy, but the other rays of the pseudocaudal fin are simply divided into two terminal segments. None of the fin rays are cross-striated. In the two study specimens, bony ossicles are just beginning to be evident around the bifurcate distal ends of a few of the more medial rays of the pseudocaudal fin, these ossicles being well developed in adults.

The anal fin portion of the pseudocaudal fin has basically the same structure as the dorsal fin portion. However, since eight modified anal fin basal pterygiophores are present, rather than seven modified basal pterygiophores as in the dorsal portion, there are eight anal fin 
rays that can be assigned to the anal portion of the pseudocaudal fin. The lowermost, or first, modified anal fin basal pterygiophore is placed at about a right angle to the vertebral column, but the second to eighth modified basal pterygiophores are progressively more obliquely placed so that the eighth is placed about parallel to the vertebral column. The first modified basal pterygiophore articulates distally with the inner edge of the cartilaginous plate that forms the medial pterygiophore of the anal fin, while proximally it articulates by fibrous tissue with the posterior edge of the last unmodified anal fin basal pterygiophore. The second modified basal pterygiophore ends distally at its medial pterygiophore, which is continuous with the medial pterygiophore of the anal fin and is delimited from it only by a slightly constricted region of cartilage. The anterior edge of the second modified basal pterygiophore articulates proximally by fibrous tissue with the posterior edge of the first modified basal pterygiophore. The third to fifth modified basal pterygiophores articulate proximally by fibrous tissue with the posterior edge of the haemal spine of the seventh caudal vertebra, while the sixth to ninth modified basal pterygiophores articulate with the posterior edge of the haemal spine of the eighth caudal vertebra. Distally the modified basal pterygiophores connect with the calcified cartilage of their medial pterygiophores. The medial pterygiophores distal to the third to the seventh modified basal pterygiophores are separate from one another, but that distal to the eighth modified basal pterygiophore is continuous with the calcified cartilage at the end of the ninth caudal vertebra and with the medial pterygiophore distal to the seventh modified basal pterygiophore of the dorsal portion of the pseudocaudal fin. The distal pterygiophores of calcified cartilage in the anal portion of the pseudocaudal fin have the same structure as those of the dorsal portion. The lowermost fin ray of the anal portion of the pseudocaudal fin is branched in a double dichotomy, but the other seven fin rays of the anal portion are simply divided distally into two terminal segments. None of the rays are crossstriated, and bony ossicles have just begun to form, just as in the dorsal portion, in the two study specimens.

The pseudocaudal fin, as here defined, thus consists of 15 fin rays, the uppermost ray and lowermost ray of which are branched in double dichotomies, while the other 13 rays are simply bifurcate distally. The upper seven rays belong to the dorsal fin and are supported by seven bony modified dorsal fin basal pterygiophores, as well as by calcified cartilages which form a medial and a distal series. The lower eight rays belong to the anal fin and are supported by eight bony modified anal fin basal pterygiophores, as well as by calcified cartilages which form a medial and a distal series. The dorsal and anal fin rays form a continuous series around the posterior end of the body, with those dorsal to the ninth caudal vertebra being considered as dorsal fin rays and those ventral to that vertebra being considered as anal fin rays. The division of the dorsal and anal fin rays into those of the dorsal and anal fins proper and those of the pseudocaudal fin is arbitrary, but convenient.
Anatomical diversity. - While three genera of molids are presently recognized, there is some doubt regarding the number of species in two of them, as most recently revised (Fraser-Brunner 1951). Ranzania is monotypic (laevis = truncatus). Masturus is probably monotypic, Fraser-Brunner stating that the two forms he tentatively recognized as specifically distinct were probably only the sexes of a single species (lanceolatus $=o x y u$ ropterus). Fraser-Brunner believed that Mola was represented by two species, the worldwide $M$. mola being largely replaced in the south Pacific by $M$. ramsayi, the latter differing from $M$. mola mainly in having several more fin rays in the pseudocaudal fin, larger bony ossicles at the distal ends of these rays, and no band of smaller scales along the base of the pseudocaudal fin.

Subsequent to Fraser-Brunner's (1951) revision, a new genus and species of molid has been described, Pseudomola lassarati Cadenat (1959), based on a single specimen from west Africa. The specimen was thought to be unusual by the presence of a large white abdominal region and additional white spots and reticulations. It otherwise was said to differ from Mola only in lacking, at its large size (1,090 $\mathrm{mm}$ total length), bony ossicles at the distal ends of at least some of the rays of the pseudocaudal fin and to differ from Masturus only by lacking the posteriorly prolonged lobe of the pseudocaudal fin. This lobe is often lost (bitten off?) in Masturus and evenly healed over, while little is known about variation in the time of development of the ossicles in Mola. Pseudomola lassarati could easily be a Mola mola that has not yet developed the bony ossicles along the edge of the pseudocaudal fin or a Masturus lanceolatus that has lost the posterior lobe of the pseudocaudal fin. However, some specimens of $M$. lanceolatus are known to have a white abdominal region and additional white spots or blotches (see photographs in Gudger $1937 \mathrm{a}$, b) very similar to those of $P$. lassarati, and it is probably with $M$. lanceolatus that $P$. lassarati is synonymous.

A fossil species of molid, Mola pileatus (Beneden), is known from the Miocene on the basis of the bony ossicles that are present in the skin above and below the mouth, just as in the Recent species of Mola (these being the remains of the postlarval skin spines, according to Fraser-Brunner 1951:110) and of a few fused premaxillaries and dentaries that are more molidlike than diodontidlike (see Leriche 1907 and 1926, and contained references, and Deinse 1953).

Fraser-Brunner (1951) distinguished Ranzania (as the Ranzaniinae) from Mola and Masturus (Molinae) as follows: Ranzania more elongate; vertebrae $8+10$ or 11 (vs. $9+8$ ); carapace of hexagonal plates (vs. a collagenous carapace); lips produced and funnellike (vs. lips normal); gill rakers free (vs. concealed in thick skin); 5 branchiostegal rays (vs. 6); no secondary postlarval metamorphosis (vs. the development of prominent spiny processes from the body during a Molacanthus stage). Masturus was distinguished from Mola by having the middle fin rays of the pseudocaudal fin not supported basally by basal pterygiophores and none of the pseudocaudal fin rays developing bony ossicles at their distal ends. 


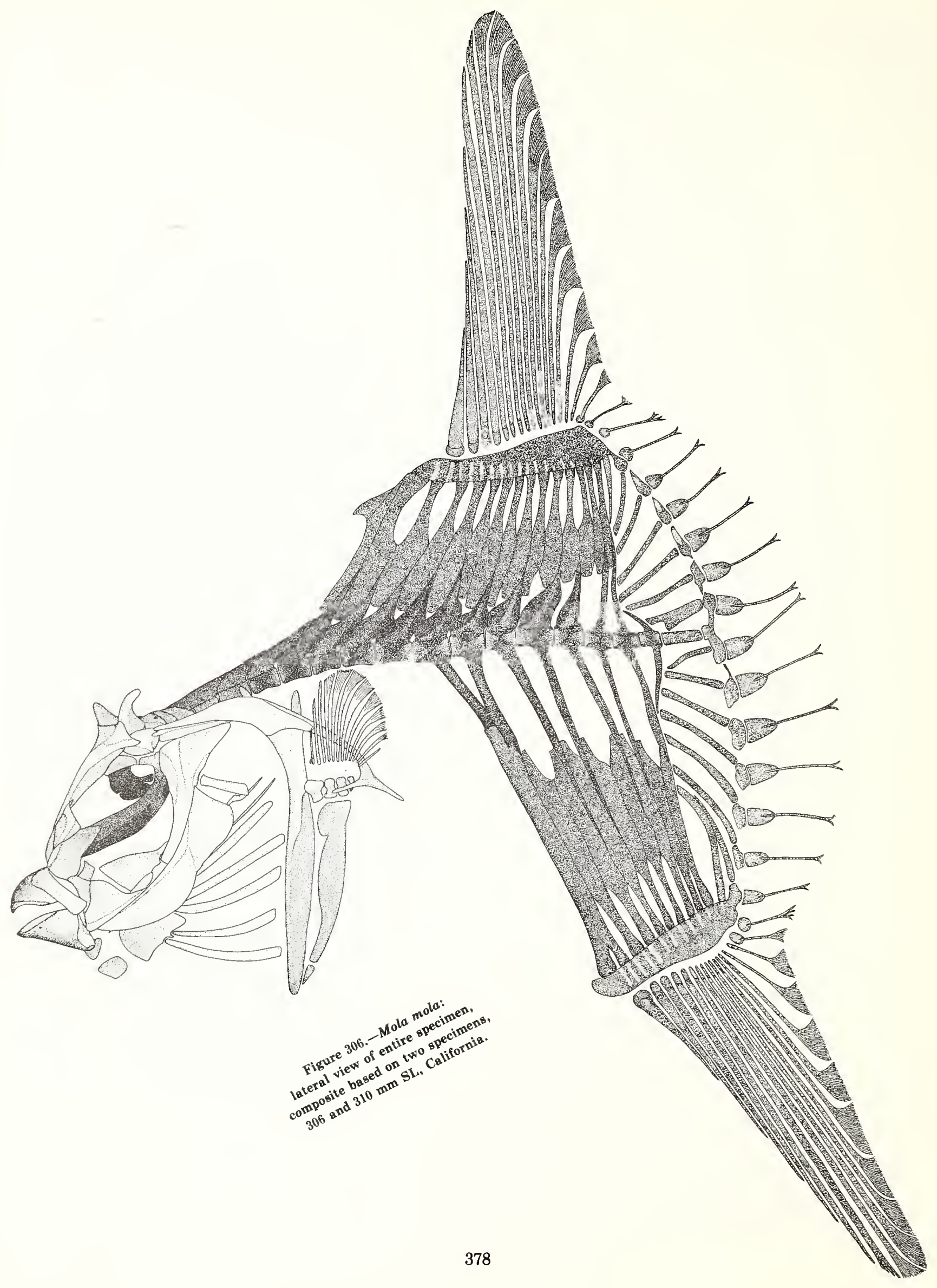




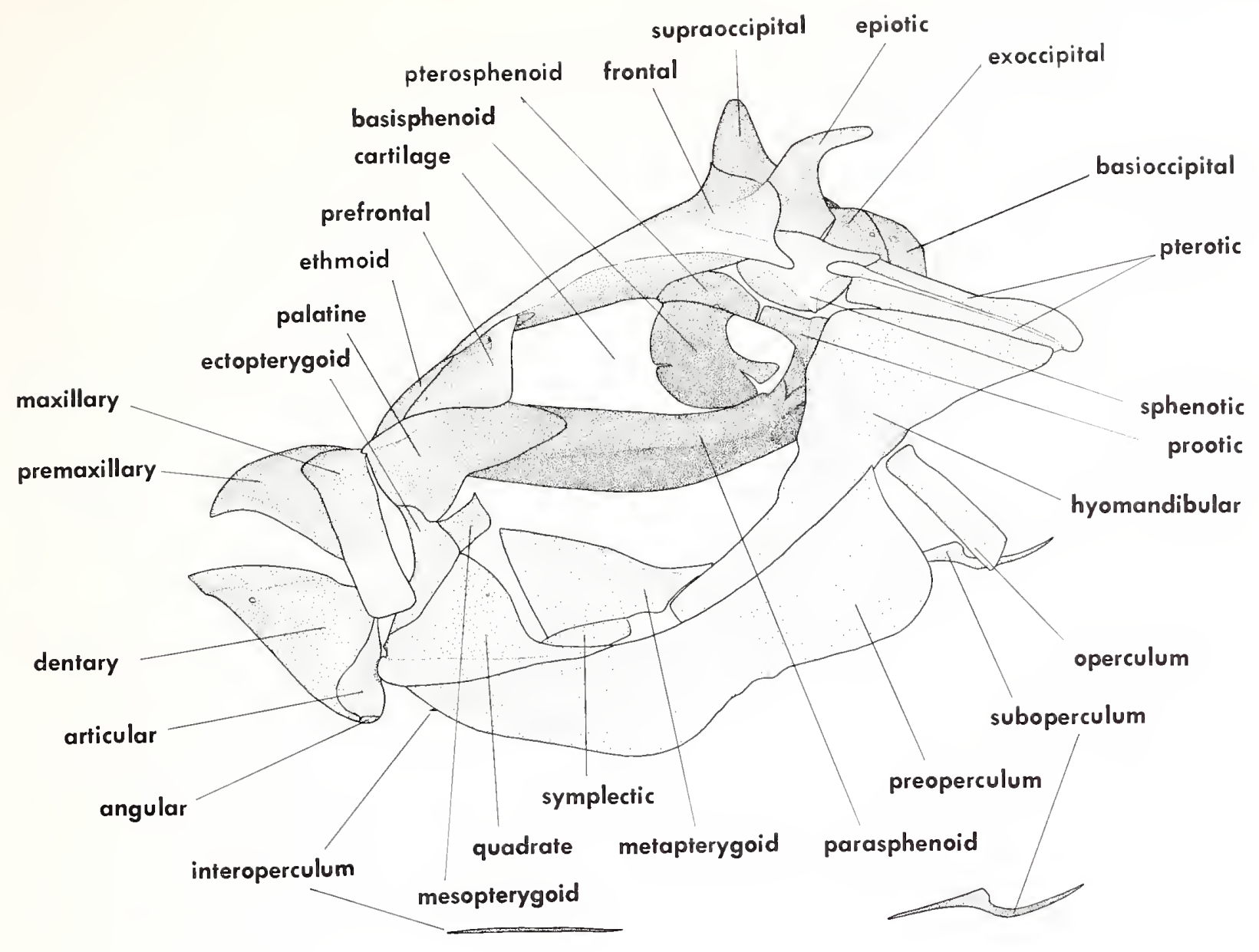

I would slightly modify some of the above statements. The body depth in Ranzania is about 3 times in the standard length in the young, but large adults are deeper bodied, the depth being only twice, or slightly less than twice, in the standard length. In Mola and Masturus the depth is usually between one and one and a half in the standard length, with the young slightly less deep bodied than large adults. The individual scale plates in Ranzania are thicker and more angular (often being hexagonal) than in Mola and Masturus, whose scale plates are more or less circular. However, the carapace of Ranzania is relatively thin, for in Mola and Masturus the thinner scale plates rest upon a thick layer of collagenous connective tissue. The funnellike mouth in Ranzania, which when closed forms a vertical slit, is unique among the plectognaths. The gill rakers in the specimens of Mola and Masturus examined here, none of which are large adults, do not have the gill rakers concealed in thick skin, although a flap of skin from the leading edge of the raker to the gill arch strengthens their articulation to the arch, more so than in Ranzania. It is apparently only in large adults of Mola and Masturus that the gill rakers become more concealed. In the four specimens of Ranzania either cleared and stained or radiographed, the vertebrae were $8+10=18$, while in two specimens of Mola they were $8+9=17$ and in two of Masturus $8+8$ $=16$, and it would appear that eight is the normal

Figure 307.-Mola mola: lateral view of head, composite based on two specimens, 306 and $310 \mathrm{~mm}$ SL, California.

number of abdominal vertebrae in molids and that there is a modal difference of one caudal vertebra between the three genera. It is possible that Fraser-Brunner's counts of nine abdominal vertebrae in Mola and Masturus were made from radiographs and that the anterodorsal prongs of the basioccipital were mistaken for the first vertebra.

A few additional external characters distinguish Ranzania from Mola and Masturus. In Ranzania the pectoral fin is relatively longer and more falcate, and fits into a shallow concavity on the carapace when folded back, while in Mola and Masturus the pectoral fin is shorter and more rounded, and there is no concavity for it on the carapace. In Ranzania the rays of the pseudocaudal fin are highly branched distally, while in Mola and Masturus they are usually not branched in more than single to triple dichotomies. In young Ranzania the distal edge of the pseudocaudal fin is relatively rounded and not set off distinctly from the dorsal and anal fins, much as in both young and adult Mola and Masturus. In adult Ranzania, however, the distal edge of the pseudocaudal fin becomes relatively straight and slightly oblique, and is distinctly set off from the dorsal and anal fins. 


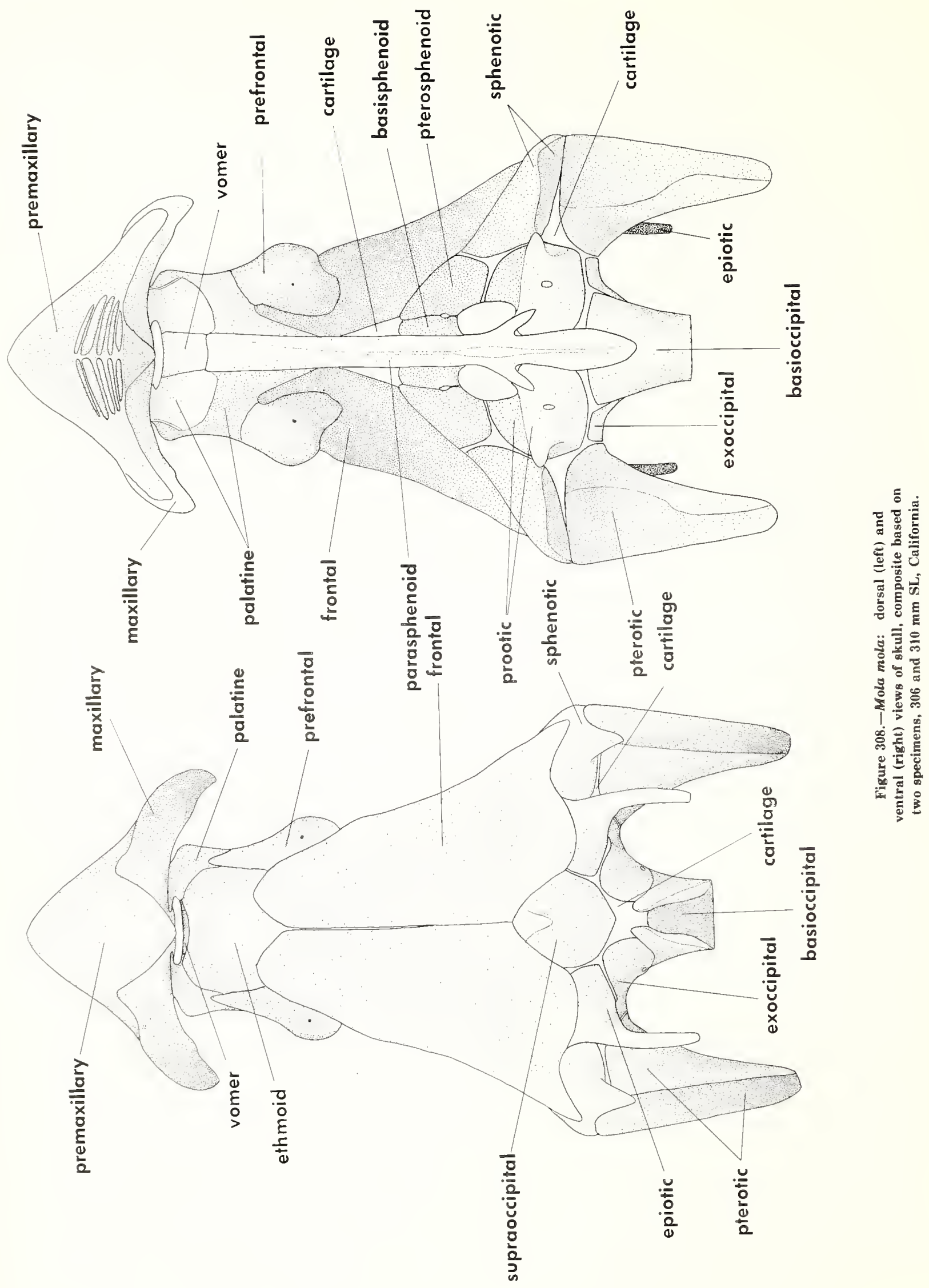




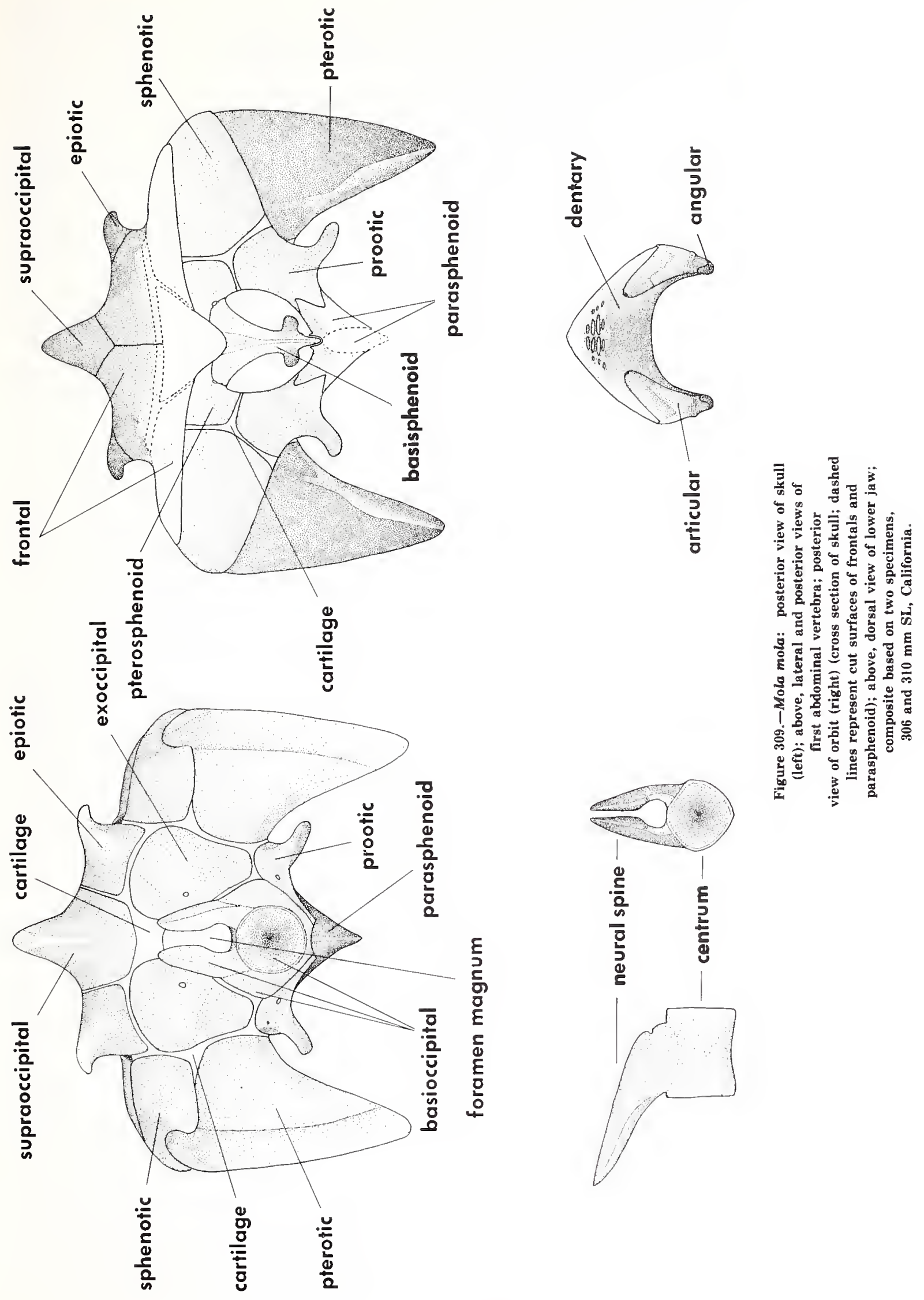



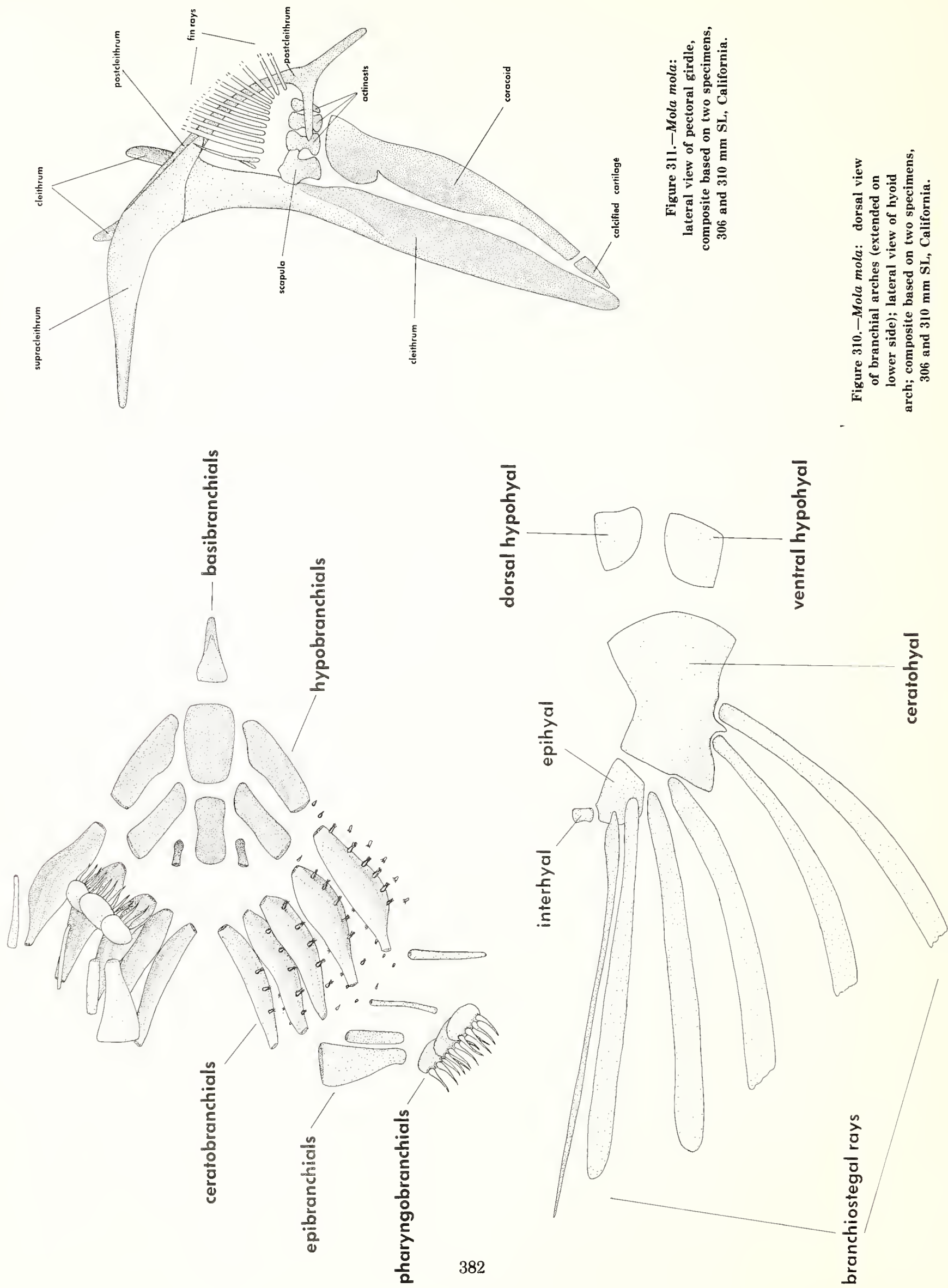


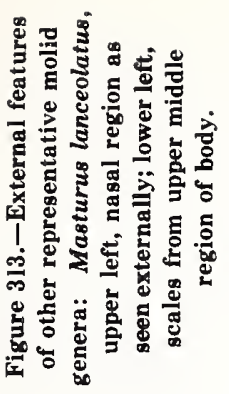

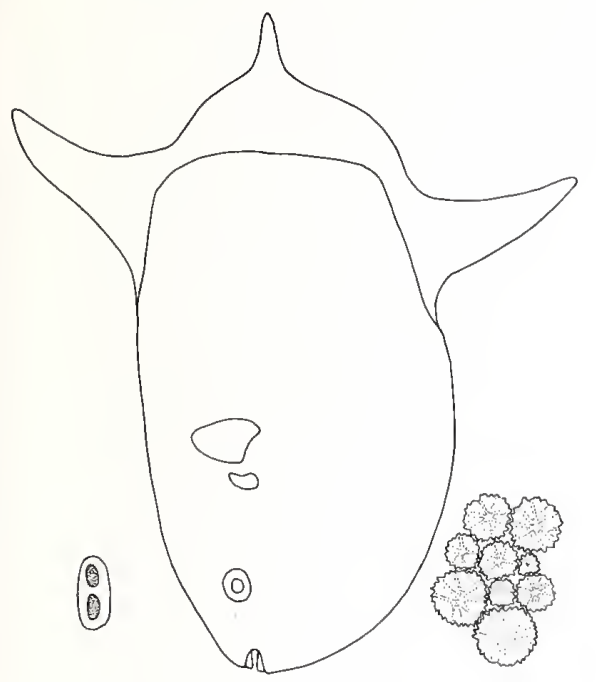

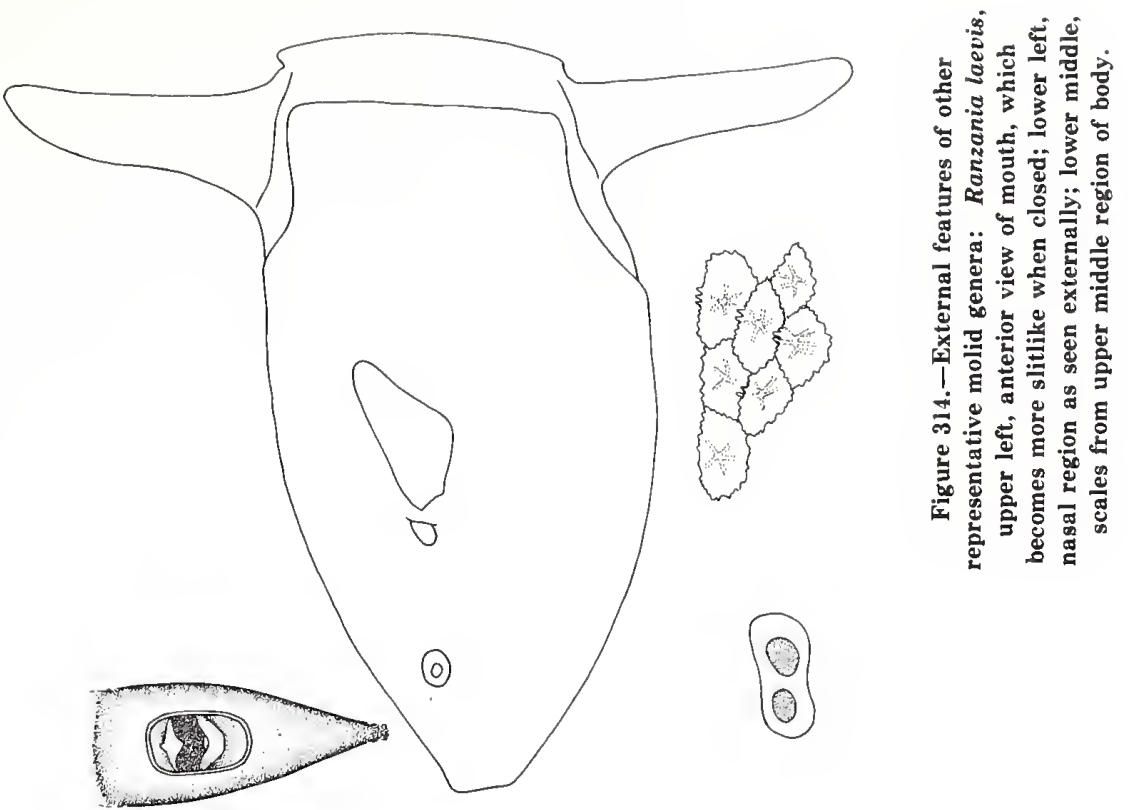

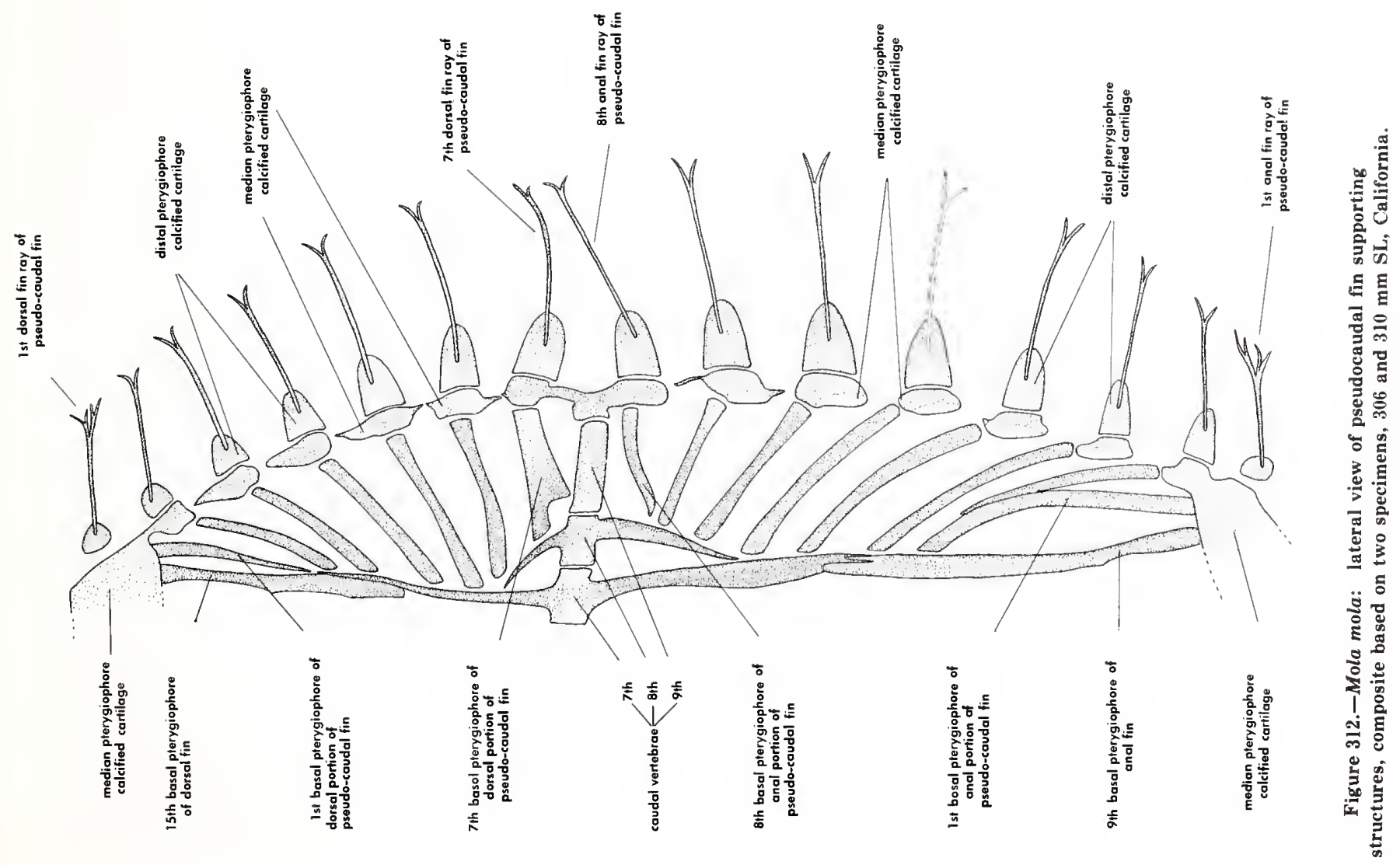


Most of the internal differences between the three genera of molids clearly indicate that Mola and Masturus are much more closely related to one another than either is to Ranzania, as widely supposed in the past, mostly on the basis of external appearances.

In Mola and Masturus the mesopterygoid is a small squarish bone which does not make contact posteriorly with the metapterygoid, while in Ranzania it is larger and more elongate, and contacts the metapterygoid. In Mola and Masturus the epiotics are dome-shaped and only moderately prolonged posterodorsally, while in Ranzania they are greatly elongate posterodorsally as thin but wide bands of bone. In Mola and Masturus the supraoccipital crest is short and broad, while in Ranzania it is long and narrow, extending back as far beyond the head to contact the anterior prolongation of the first basal pterygiophore of the dorsal fin. In Mola and Masturus the sphenotic only slightly overlies the anterolateral surface of the pterotic, while in Ranzania it broadly overlies it. In Mola and Masturus the vomer is ossified, while it is unossified in Ranzania. In Mola and Masturus the basisphenoid is placed in the posterior half of the orbit and articulates with the prootic and pterosphenoid as well as with the parasphenoid, while in Ranzania the basisphenoid is placed in the middle of the orbit and articulates with the frontals above and the palatines and parasphenoid below. In Mola and Masturus the anterodorsal prolongations from either side of the basioccipital do not meet one another in the midline above the neural canal, being separated there by the long anterior extension of the neural spine of the first vertebra, while in Ranzania the anterodorsal prolongations of the basioccipital meet and fuse or suture in the midline above the neural canal, being only slightly separated from one another posteriorly by the short anterior extension of the neural spine of the first vertebra. In Mola and Masturus there are six branchiostegal rays, the fifth about the same size as the fourth and the sixth much more slender than any of the others, while in Ranzania there are only five branchiostegals, the sixth either being lost or fused with the fifth, which is much larger than any of the other branchiostegals. In Mola and Masturus the ceratobranchials are exceptionally deep bodied, but in Ranzania they are not. In Mola and Masturus the operculum is shorter and wider than in Ranzania. In Mola and Masturus the suboperculum retains a posterior prolongation behind or below the operculum as well as an anterior portion directed internal to the rear of the preoperculum, while the suboperculum of Ranzania is represented only by the anterior portion, which is longer than in Mola and Masturus. In Masturus the interoperculum is unossified and in Mola it is a short rod well separated from the suboperculum, while in Ranzania it is a long rod which contacts the suboperculum. In Mola and Masturus none of the actinosts are sutured to one another, while in Ranzania all of them are sutured or interdigitated to one another to some extent. In Mola and Masturus the postcleithrum is not greatly expanded posteriorly as a flattened plate, while it is in Ranzania. In Mola and Masturus the parasphenoid is about as wide anteriorly as it is toward the rear of the orbit, while in Ranzania it is narrower anteriorly than more posteriorly. In Mola and Masturus the posterior portion of the palatine articulates broadly to the lateral surface of the parasphenoid, while in Ranzania it articulates more to the dorsal surface of the parasphenoid. In Mola and Masturus the symplectic is of moderate length, extending back posteriorly only about half the length of the ventral edge of the metapterygoid, while in Ranzania it is elongate and extends back nearly the whole length of the ventral edge of the metapterygoid. In Mola and Masturus the neural arch and spine of the second vertebra is prolonged anteriorly and posteriorly well beyond the levels of the anterior and posterior edges of the centrum, while in Ranzania they are not prolonged. In Mola and Masturus the neural arches of the abdominal vertebrae are not interdigitated with one another, while in Ranzania they are broadly and deeply interdigitated. In association with their deeper bodies, the basal pterygiophores of the dorsal and anal fins in Mola and Masturus are less elongate, and the neural and haemal spines and the pterygiophores they support are less obliquely placed than in Ranzania. In Mola and Masturus only the first two haemal spines of the caudal vertebrae are decidedly oriented toward one another, while in Ranzania most of the successive sets of two haemal spines from the caudal vertebrae are decidedly oriented toward one another. The first basal pterygiophore of the dorsal fin is a relatively simple shaft in Mola and Masturus, and it is broadly in contact with the second basal pterygiophore, while in Ranzania the first basal pterygiophore is a complex element obviously representing the fusion of two basal pterygiophores, and it is not in contact with the second basal pterygiophore. A short but deep supraneural is present in Mola, but the similarly shaped region anterodorsally on the first basal pterygiophore of the dorsal fin in the single specimen of Masturus studied is fully fused to the pterygiophore. In Ranzania the long anterior extension from the complex first basal pterygiophore may represent a supraneural fully fused to the pterygiophore. In Mola and Masturus the posterior surface of the proximal end of the first basal pterygiophore of the anal fin is deeply concave and encloses the distal end of the haemal spines of the first two caudal vertebrae, while in Ranzania this pterygiophore is not concave proximally and articulates along the anterior edge of the haemal spine of the first caudal vertebra. In Mola and Masturus most of the basal pterygiophores of the dorsal and anal fins are anteroposteriorly expanded and platelike, while in Ranzania they are mostly long slender rods. In Mola and Masturus the bases of the first dorsal and anal fin rays are only slightly, if at all, larger than those just behind them, wh:le in Ranzania these bases are greatly enlarged anteriorly. In Mola and Masturus the ossification of the skeleton is less complete than in Ranzania.

In only a few ways are either Mola or Masturus more like Ranzania than one another. The trituration teeth in the upper jaw of all three genera occur as a single series of elongate teeth to either side of the midline. In the lower 


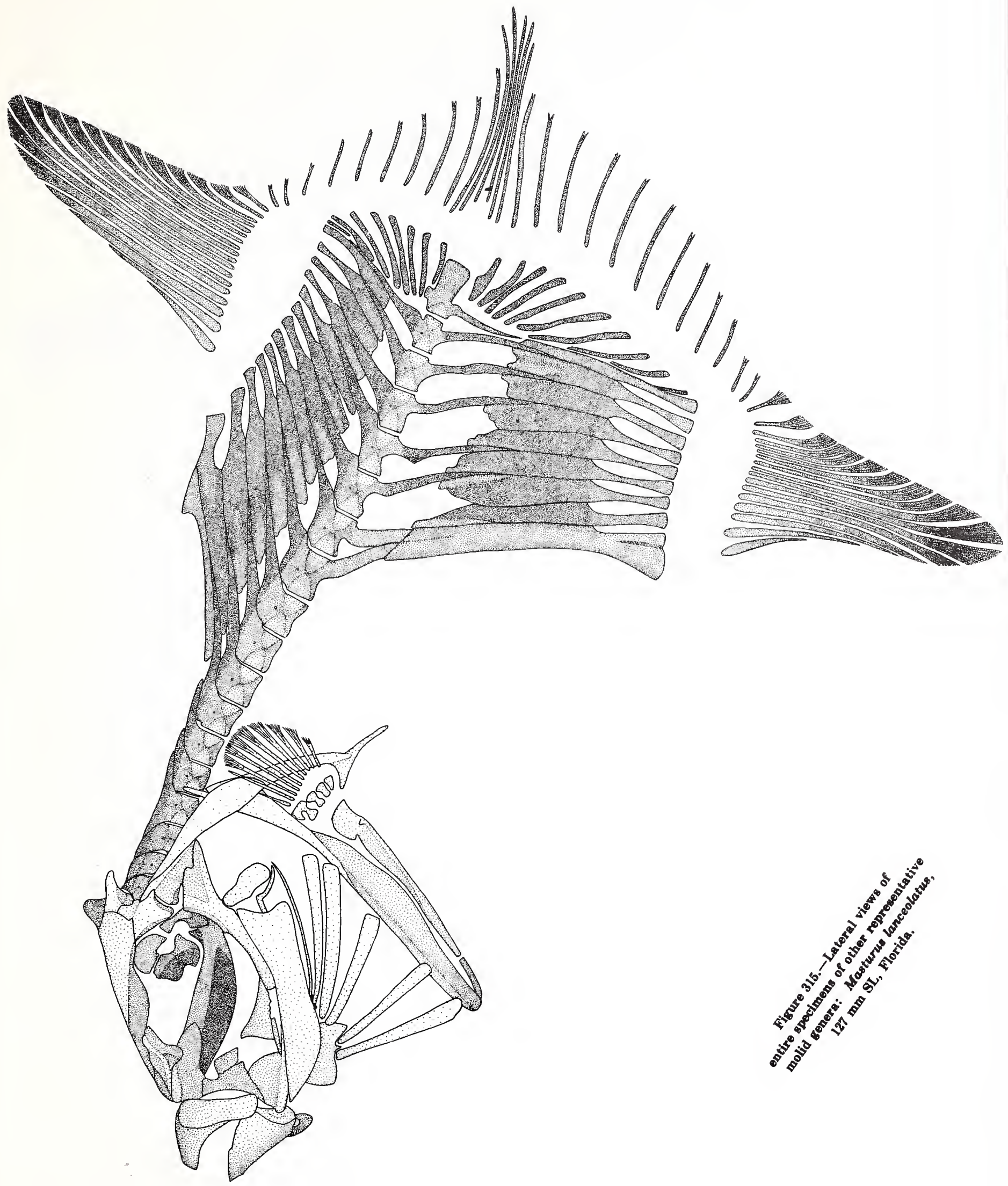




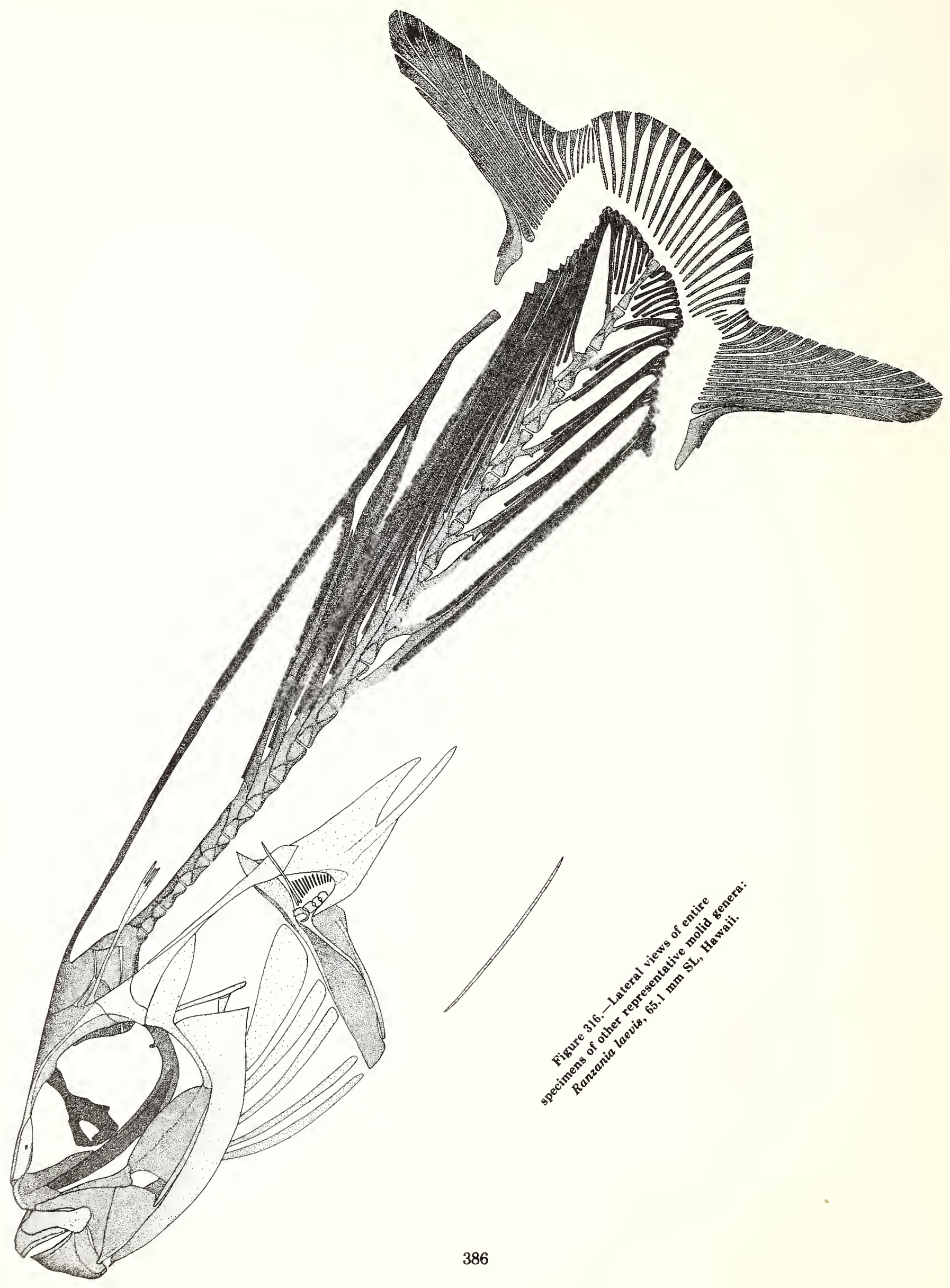




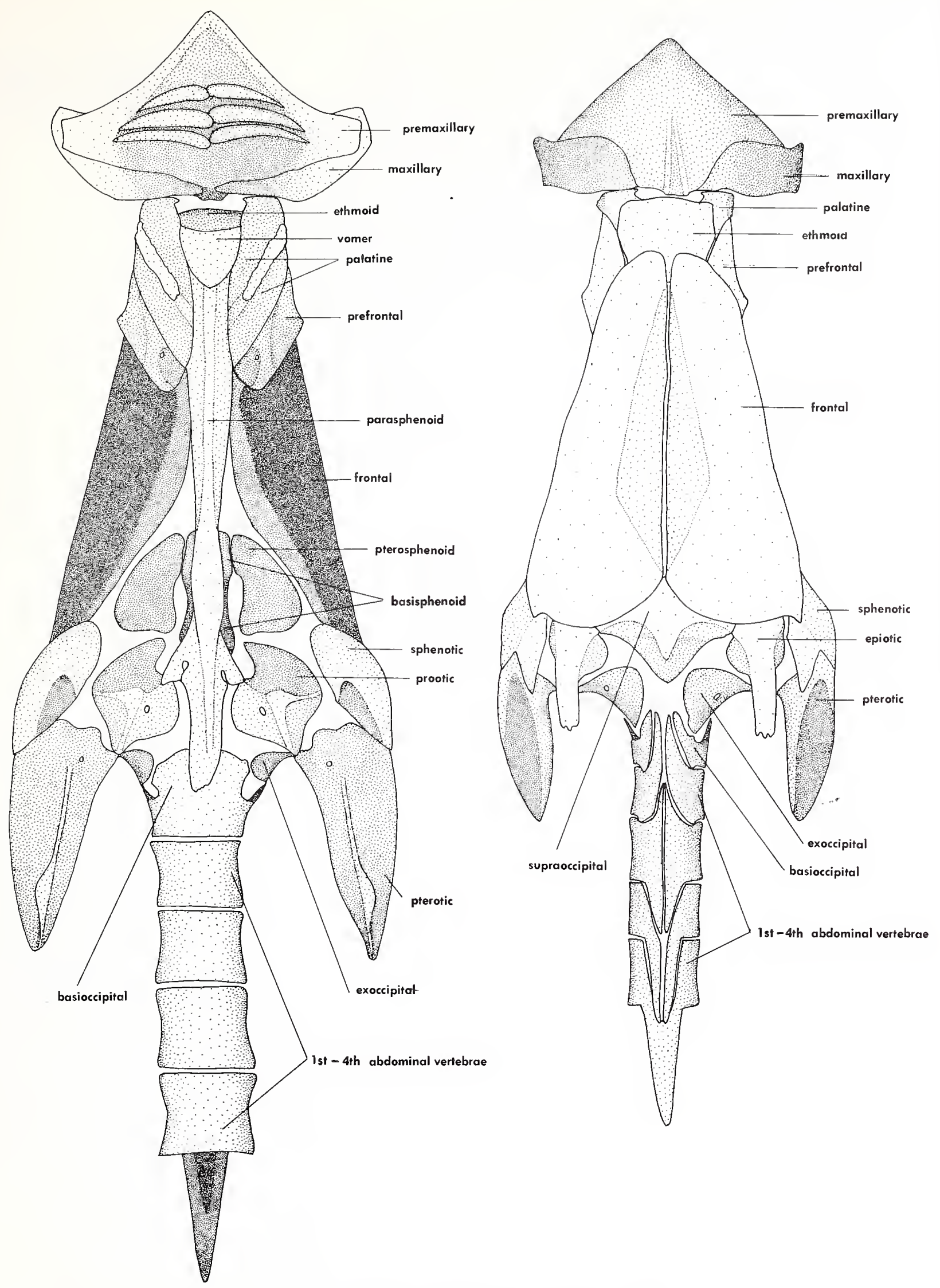

Figure 317.-Masturus lanceolatus: ventral

(left) and dorsal (right) views of skull,

$127 \mathrm{~mm}$ SL, Florida. 

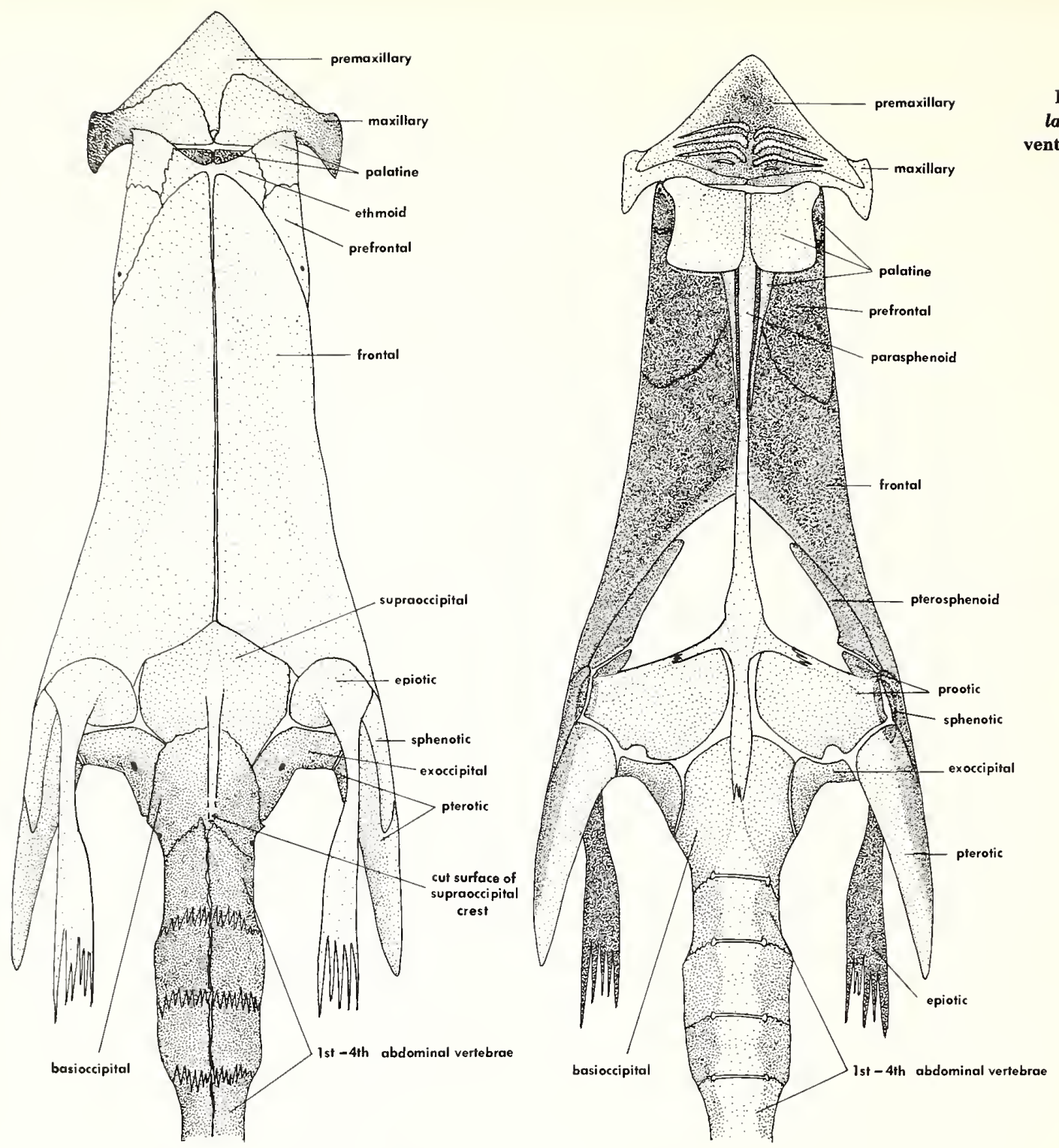

Figure 318.-Ranzanio

laevis: dorsal (left) and entral (right) views of skull, $65.1 \mathrm{~mm}$ SL, Hawaii.
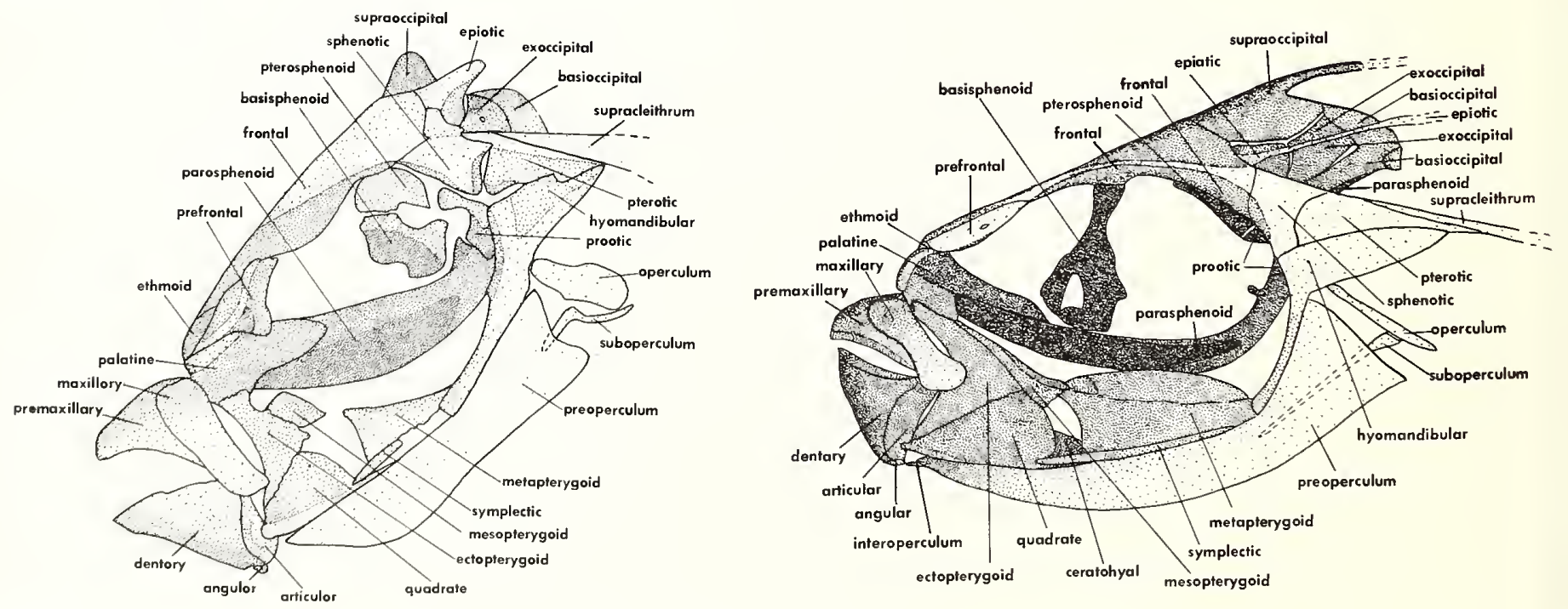

Figure 319.-Masturus lanceolatus: lateral view of head, $127 \mathrm{~mm} \mathrm{SL}$, Florida. 


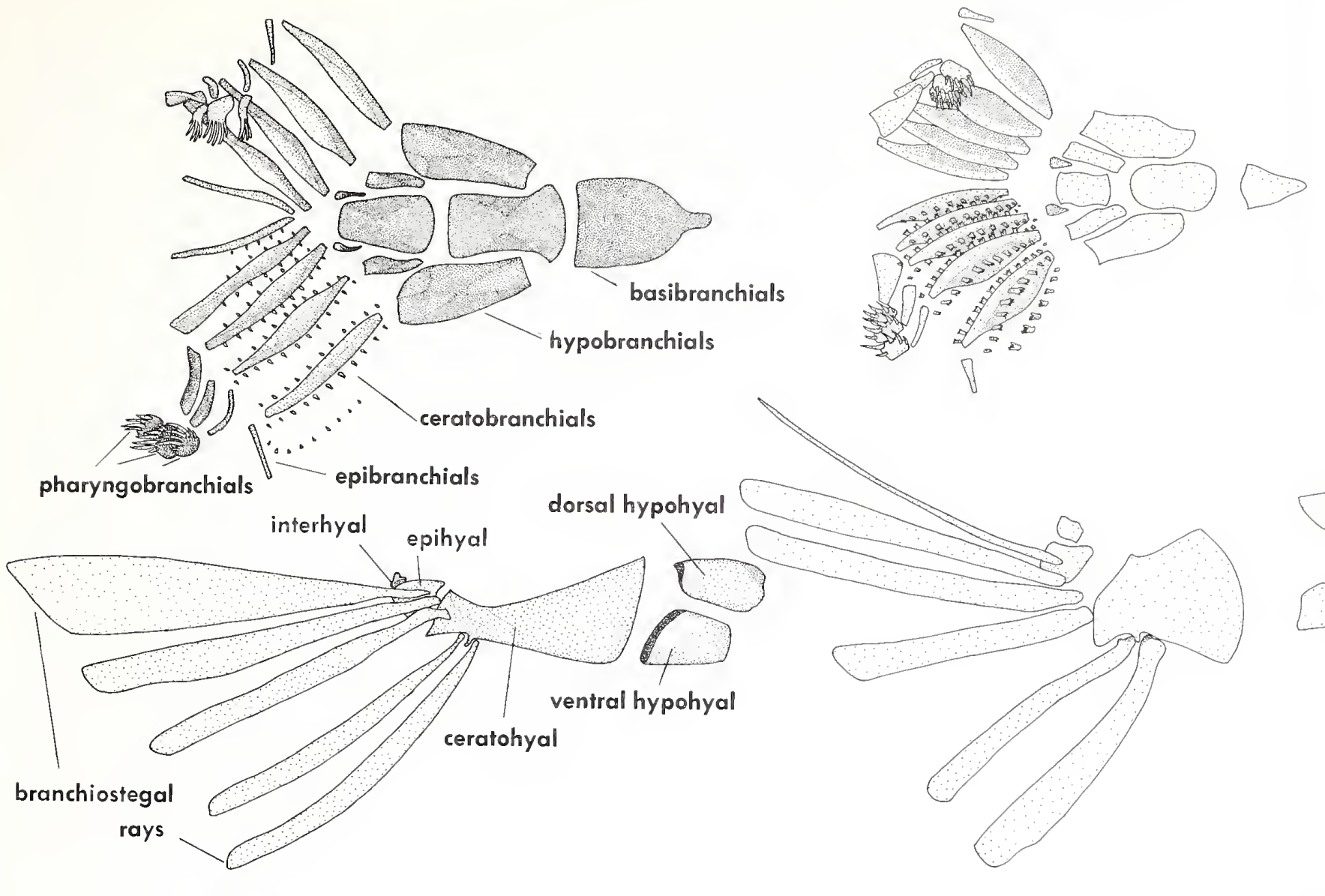

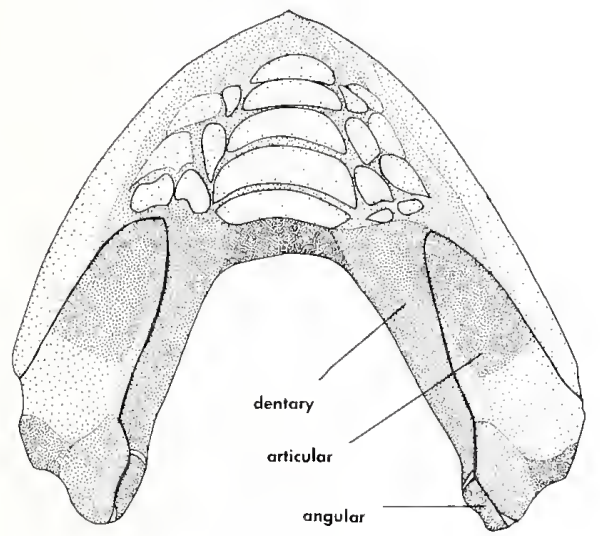

Figure 322.-Masturus lanceolatus: dorsal view of lower jaw, $127 \mathrm{~mm}$ SL, Florida.
Figure 321.-Dorsal views of branchial arches (extended on lower side) and lateral views of hyoid arch of: left, Ranzania laevis, $66.9 \mathrm{~mm} \mathrm{SL}$, Hawaii right, Masturus lanceolatus, $127 \mathrm{~mm} \mathrm{SL}$, Florida.
Figure 323.-Ranzania laevis: A, dorsal view (left) of lower jaw and ventral view (right) of upper jaw, $493 \mathrm{~mm}$ SL, Hawaii, to show the more numerous trituration teeth in a larger specimen, in comparison to; $\mathrm{B}$, dorsal view of lower jaw, $65.1 \mathrm{~mm} \mathrm{SL}$, Hawaii.

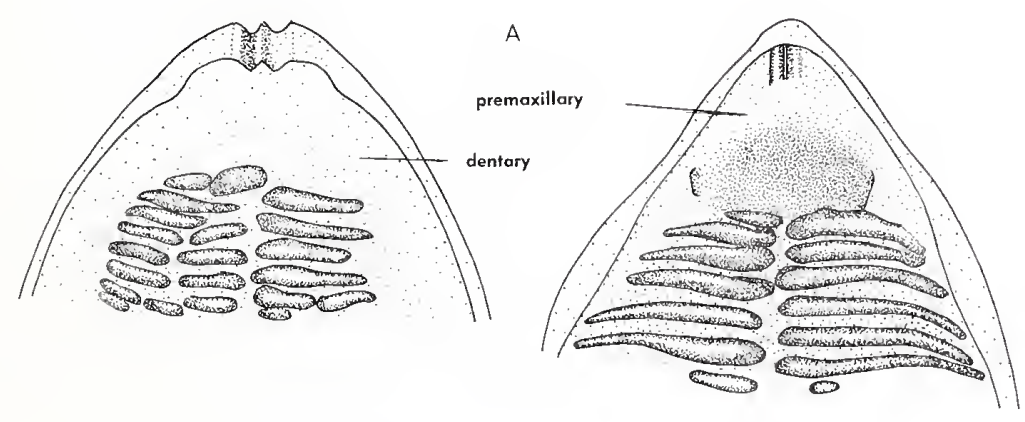

389

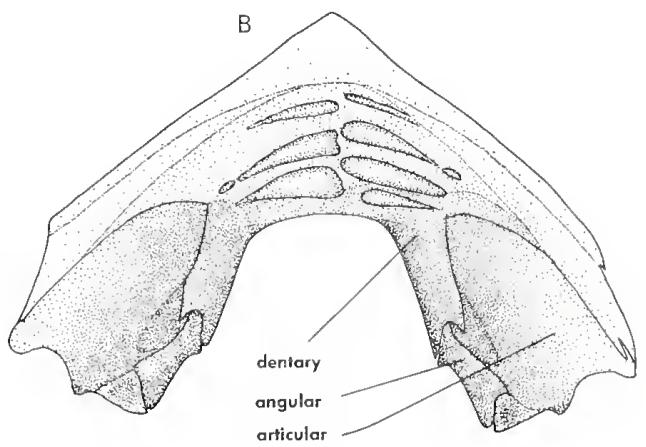




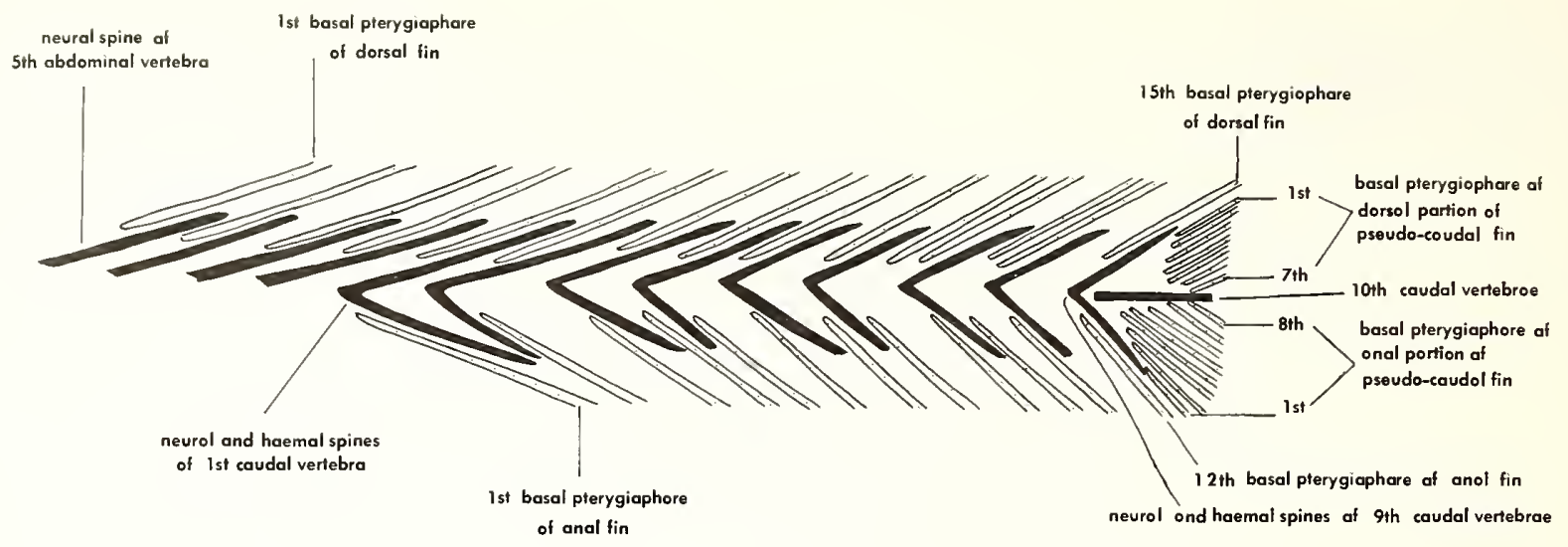

Figure 324.-Ranzania laevis: diagrammatic representation of the relationships between the basal pterygiophores of the dorsal, anal,

and pseudocaudal fins and the neural and haemal spines of the supporting vertebrae, $65.1 \mathrm{~mm}$ SL, Hawaii.

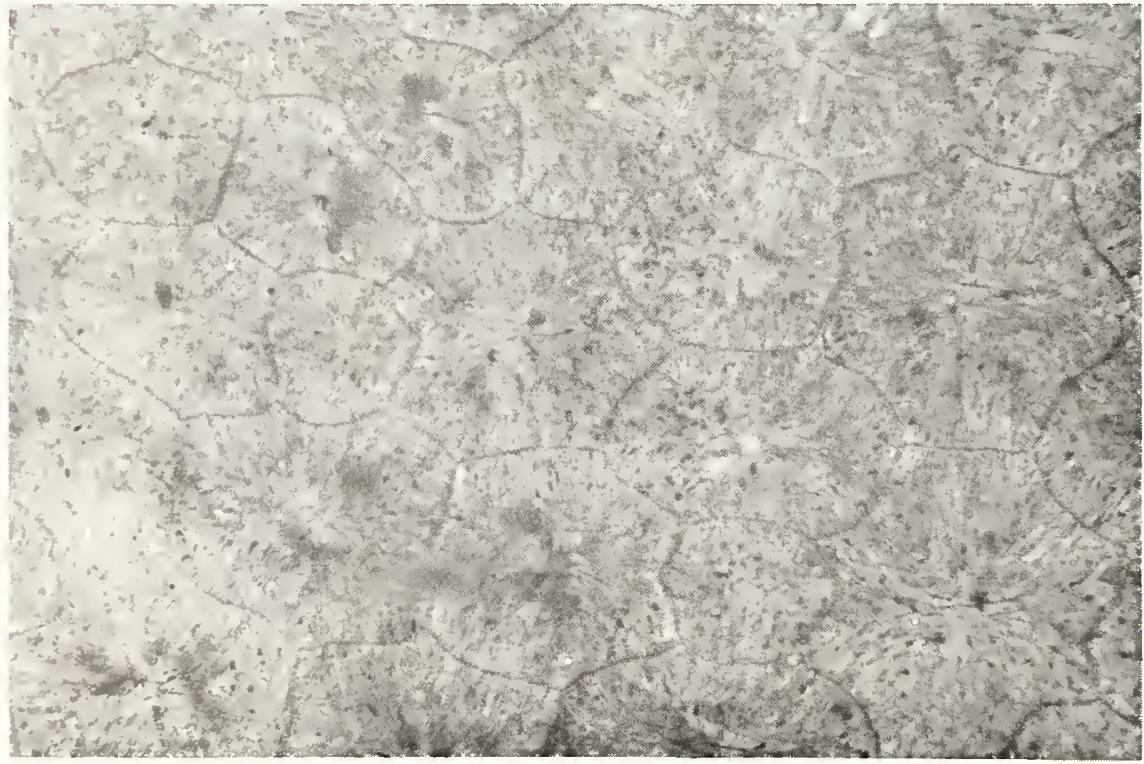

Figure 325.-Ranzania laevis: scales from upper middle region of body, to show the approximately hexagonal scale plates, articulated to one another by extensive minute interdigitations along all of their edges of contact (greatest length of largest scale plate $6.0 \mathrm{~mm}$ ), $493 \mathrm{~mm}$ SL, Hawaii.

jaw of Mola and Ranzania the trituration teeth are less elongate than in the upper jaw and occur in a major series to either side of the midline as well as in a series of smaller teeth to either side lateral to the major series. In Masturus the trituration teeth in the lower jaw are not divided into right and left sets, but rather has a single major series placed medially, lateral to which are two series of smaller teeth on each side.

In general configuration the pseudocaudal fin and its supporting elements are much more similar in Mola and Masturus than in Ranzania. While a normally shaped and placed larval caudal fin fold without rays is known to be present in at least Masturus and Ranzania, this is lost in development and the adult pseudocaudal fin in molids is a secondary formation from posteromedially migrated dorsal and anal fin rays and their basal pterygial supports, although it is possible that the rays in the central nipple of the pseudocaudal fin of Masturus are remnants of true caudal fin rays (as believed by Fraser-Brunner 1951; see Tyler 1970b for discussion).

In Ranzania the pseudocaudal fin is supported by the last two caudal vertebrae. The last vertebra is a simple rod seemingly representing a single centrum, which Leis (1977) has shown to be a fusion product of two anlagen in larval stages. The penultimate vertebra has relatively well-developed neural and haemal spines which anteriorly support the last basal pterygiophores of the dorsal and anal fins and which posteriorly support the radial elements of the pseudocaudal fin. Most of the radials probably are posteromedially migrated basal pterygiophores (Tyler 1970b:27). There are seven radials above and eight below in two of the three specimens of Ranzania examined, but only six above and seven below in the other (as also illustrated by Leis 1977:fig. 11), and a total of 19 or 20 fin rays in the pseudocaudal lobe, while Fraser-Brunner (1951) recorded 22 rays as the norm. 
Contrary to Tyler (1970b:29), at least the more extensively branched dorsal, anal, and pectoral fin rays of all molids, and in Ranzania the pseudocaudal rays as well, often bear cross-striations distally, the number of crossstriations probably increasing with increasing specimen size. The molid cross-striations, however, are fewer in number and more distally placed than in the fins of other plectognaths.

In Mola the pseudocaudal fin is supported by the last three caudal vertebrae, of which the last is a simple rod representing only a centrum. The penultimate vertebra has short neural and haemal spines which curve anteriorly to be supported at their distal ends by the fully developed neural and haemal spines of the antipenultimate vertebra, while their posterior edges support the more medially placed radial elements. But it is the neural and haemal spines of the antipenultimate vertebra which support most of the radial elements. There are seven radial elements above and eight below, and 15 pseudocaudal fin rays, in both specimens examined. Fraser-Brunner (1951) gave 16 rays as the norm for the south Pacific $M$. ramsayi and 12 for the worldwide $M$. mola, with which distinction the two California specimens of $M$. mola examined here are not in agreement.

Masturus has one less caudal vertebra than Mola, and it is obvious that Masturus has lost what is the last vertebra of Mola, the simple rod representing a centrum. With the exception of Masturus lacking this rodlike centrum the pseudocaudal supports of Mola and Masturus are rather similar, the ultimate vertebra of Masturus being homologous and functionally corresponding to the penultimate of Mola, and the penultimate of Masturus to the antipenultimate of Mola.

The most diagnostically important difference between Masturus and Mola in this region is that Masturus has more ( 20 or more) rays in the pseudocaudal fin than does Mola, the additional rays mostly being accounted for by those in the medial lobe that is present in Masturus but absent in Mola, and that bony ossicles do not develop distally on any of the pseudocaudal rays in Masturus but do in Mola. Whereas at least most of the rays in the upper and lower halves of the pseudocaudal fin of both Masturus (exclusive of the medial lobe) and Mola are individually supported by radial elements, at least most of the rays of the medial lobe of Masturus are not supported by radial elements but rather take support from the last vertebral centrum. In the single specimen of Masturus examined there are about (it being difficult to decide where the pseudocaudal rays begin) 7 rays in the upper half of the pseudocaudal, 10 below, and 6 in the medial lobe, with the dorsal fin having 20 rays and the anal fin 19 , a total dorsal, pseudocaudal, and anal count of 62 . Fraser-Brunner (1951) gave a total count of 60 to 62 , with eight (rarely seven or nine) rays in the medial lobe for $M$. lanceolatus, and a total of 55 to 57 , with four (rarely three or five) in the medial lobe for $M$. oxyuropterus. Obviously, more extensive data is needed for these various fin counts in both Mola and Masturus, and such can be easily ascertained only from cleared and stained specimens, or from very finely radiographed specimens.
In short, Mola and Masturus differ primarily mainly in the details of the pseudocaudal fin and its supports: 1) Mola has a ninth caudal vertebral centrum that is lost by Masturus; 2) Masturus has a group of rays in a medial lobe of the pseudocaudal fin that are supported by the last vertebral centrum rather than by radials, this medial lobe not being present in Mola and perhaps being the remnants of true caudal fin rays; 3) Mola develops bony ossicles at the distal end of many of the pseudocaudal rays while Masturus never does; and 4) Mola has a better developed neural spine on the eighth caudal vertebra than does Masturus. Other differences are: 1) Mola has a supraneural that appears in Masturus to be fully fused to the first basal pterygiophore of the dorsal fin; 2) Mola has the interoperculum ossified, while it is unossified in the single small specimen of Masturus examined; 3) the trituration teeth in the lower jaw of Mola are divided into right and left series, while Masturus has a major medial series.

The above differences between Mola and Masturus seem to justify the retention of them as distinct genera, even if they should be found to be represented by a single species each. The far more numerous differences listed between Ranzania and Mola-Masturus reflect in part the ease of distinguishing between subgroups composed of only a few species. In the present case each of the three genera either has only a single species or only a single species was examined for this work, so there is, in essence, no intrageneric variation and the comparisons made are only between three units. Thus, it seems to me that the extensive differences listed between Ranzania and Mola-Masturus do not necessarily justify the recognition of two subfamilies within the family Molidae, and, as a personal opinion, I do not think the differences between the two groups are of sufficient magnitude for subfamilial recognition.

Generic relationships.-With it being clear that Mola and Masturus are far more closely related to one another than to Ranzania, the most pertinent remaining question is whether one or the other of these two lines of molid evolution is more generalized than the other and anatomically closer to the triodontidlike ancestral group. The only other question of consequence is whether Mola or Masturus is the more generalized within its line of radiation.

To address the last question first. Mola is more generalized than Masturus by: 1) the retention of the ninth caudal vertebra, separate supraneural, and ossified interoperculum; 2) by the better development of the neural spine of the eighth caudal vertebra; 3 ) by the retention of the trituration teeth in right and left series to either side of the midline in the lower jaw. Conversely, Masturus is more generalized than Mola by: 1) the possible retention of true caudal fin rays in the medial lobe of the pseudocaudal fin; and 2) the lack of ossicles at the ends of any of the pseudocaudal fin rays. Overall, it would seem that Mola has remained slightly more generalized than Masturus.

Many of the differences between Ranzania and MolaMasturus indicate that Ranzania is more specialized 


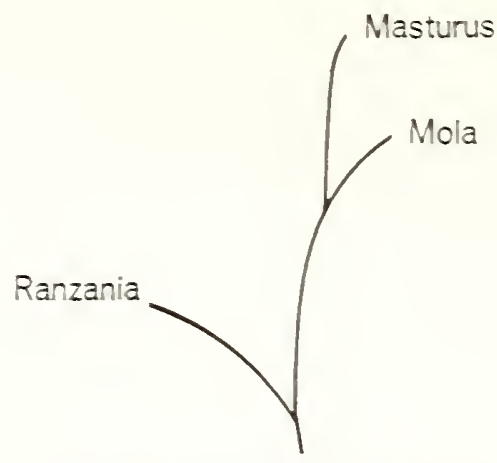

Figure 3\$5.-Hџpothesized phylogenetic relationships of the generg of Molidae.

than the other two genera. these specializations often associated with the streamlining of the body for what is probably more rapid and sustained swimming.

The specialized features of Ranzania (i.e., the features furher removed in comparison to Molo-Masturus from those of the hypothetical pre-Triodon ancestral group, discussec under Triocion) are: 1) the funnellike lips, closing to a vertical groove; 2) the falcate pectoral fins, resting in an indented region on the carapace; 3) the thickenec. angular scale plates of the carapace; the pseudocaudal fin distinctly set off from the dorsal and anal ins in adults; j) the great posterior prolongation of the epiotics and of the supraoccipital crest; 6) the unossinted vomer; i) the anterior displacement of the basisphenoid: $\delta$ ) the seater anterodorsal prolongations of the basioccipital, meeting in the midline over the neural canal; 9) the strong interdigitation of the neural arches and spines of the abdominal and more anterior caudal vertebrae leading to greater rigidity of the vertebral column within a slightly less flexible carapace; 10) the loss of the sixth branchiostegal and great enlargement of the fittin; 11) the loss of the posterio: portion of the suboperculum: 12, the elongate. rodlike operculum; 13) the interdigitation of the actinosts to one another; 14) the Eeat platelike expansion of the postcleithrum beneath the carapace in the region of the pectoral fin; 15) the decreased width of the anterior end of the parasphenoid; 16) the articulation of the posterior region of the palatine with the dorsal suriace of the parasphenoid; 1i) the elongation of the basal ptergiophores, and the greater obliqueness of them and their neural and haemal spine support; is) the grouping in pairs of most of the successive sets of two haemal spines of the caudal vertebae; 19: the complexity of the first basal pterygiophore of the corsal fin; and 20) the anterior expansion of the bases of the first dorsal and anal fin rays.

Conversely, a lesser number of features of Ranzanic can be considered more generalized than in MoloMasturas, these being: 1) the lesser reduction in the number of caudal vertebrae, the centrum of the 10 th being retained; 2) the branching of the rays of the pseudocaudal in not much less than that of the dorsal and anal Ens; 3) the better development of the interoperculum and mesopterygoid; 4) the lack of a secondary larval stage; j) the lack of a deep collagenous layer under the scales, probably associated with the better ossification of the skeleton; 6) the gill rakers perhaps less concealed in adults; 7) ceratobranchials not as deep bodied; and 8) the second abdominal vertebra without prominent anterior and posterior extensions of its neural arch and spine.

On the whole, Ranzania has far more specializations than do Mola and Masturus, and Ranzania must be considered to be the more specialized of the two lines of molid diversification. The fewer specializations of Molo and Masturus (the opposite of the generalized conditions of Ranzania discussed above) can be assumed to have arisen after the divergence of the early molids into the two lines leading on the one hand to Mola and the slightly more specialized Masturus and, on the other hand, through even greater specialization, to Ranzania.

Raven (1939b), on the basis of the musculature and skeleton, also concluded that Ranzania was more specialized than Molo and Masturus, while FraserBrunner (1951), on more superficial and fewer characters, believed Ranzania, in spite of certain specializations. to be the most generalized of the molids, and Masturus to be slightly more generalized than Mola, primarily because of the reputed retention of true caudal fin rays in the medial lobe of the pseudocaudal fin.

Relationships to the other Tetraodontoidei.-As discussed under the Triodontidae, molids have their closest anatomical affinity among the gymnodonts with the triodontids, retaining a number of generalized features (e.g., fourth gill and gill slit; basisphenoid; unmodified first branchiostegal ray; uninflatable gut; general configuration of the bones of the snout) from their triodontid ancestr. while at the same time becoming remarkably specialized with the abortion of the rear end of the body and the encasement of the relatively slow swimming body in a firm or thickened skin. While molids are most closely related to triodontids, they undoubtedly evolved from them at a level of organization somexhat less specialized than that of the Recent Triodon, as discussed more fully under the latter.

Molids have sometimes been thought to be closely related to diodontids, since both the premaxillaries and dentaries are fully fused to their opposite members only in these two families of gymnodonts. However, as discussed under Triodon, the fusion of the premaxillaries and dentaries is not that complex an event and the phylogenetic usefulness of it is meager within the gymnodonts. While it is true that the generalized biting edge dentition of diodontids (with numerous small units) could have given rise to that of molids (discrete units essentially absent), the structure of the rest of the head and body of diodontids is extremely unlike that of molids, there being no similarities such as are found between molids and triodontids. In one other superficial respect there is a minor similarity between molids and diodontids. Diodontids have a short caudal peduncle and a reduced number of caudal vertebrae, especially of those posterior to the dorsal and anal fin bases, while in molids 
this latter region is even more reduced. In light of the fact that molids have their closest anatomical affinity with triodontids and that diodontids and molids are anatomically extremely different, there is every reason to believe that the reduction in the bony structure in the caudal region of diodontids has taken place independently of that in molids, and that it in no way indicates that the diodontid caudal peduncle was a precursor to the abortion of the rear end of the body in molids. The diodontid caudal peduncle has probably become reduced from that found in most of the ancestral tetraodontoids concomitant with the development of the huge spines that guard the body in diodontids as a slow swimming highly defensive mode of life was evolved.

\section{Material Examined}

Length in millimeters is always standard length, and, unless otherwise stated, the Recent specimens listed below are cleared and alizarin stained preparations. Institutional abbreviations are as follows: ANSP, Academy of Natural Sciences of Philadelphia; BMNH, British Museum (Natural History), London; GVF, George Vanderbilt Foundation, fishes now at the California Academy of Sciences, San Francisco; JLBSI, J.L.B. Smith Institute of Ichthyology, Grahamstown, South Africa; SU, Stanford University, Calif. (now at the California Academy of Sciences, San Francisco); TABL, Tropical Atlantic Biological Laboratory, U.S. Bureau of Commerical Fisheries (now National Marine Fisheries Service), Miami, Fla.; USNM, United States National Museum (National Museum of Natural History), Washington, D.C.; WAM, Western Australian Museum, Perth.

\section{Recent Species}

\section{PLECTOGNATHI}

\section{Triacanthodidae}

Atrophacanthus japonicus (Kamohara): ANSP 102138, 2, 9.1-10.4 mm, Celebes; ANSP 102139, 5, 35.6-43.1 mm, Celebes; BMNH 1960. 5.4.1, 1, $34.7 \mathrm{~mm}$, Celebes.

Halimochirurgus alcocki Weber: USNM 93474, 1, 124 mm, Philippines.

Halimochirurgus centriscoides Alcock: ANSP 100828, 2, 99.2-113 mm, Bay of Bengal.

Hollardia hollardi Poey: ANSP 103303, 1, $84.7 \mathrm{~mm}$, Puerto Rico; ANSP 100867, 2, 62.7-95.5 mm, Honduras; ANSP 103299, 3, 72.0-129 mm, Nicaragua; ANSP 97654, 1, $174 \mathrm{~mm}$, Venezuela.

Hollardia meadi Tyler: ANSP 97396, 1, $64.5 \mathrm{~mm}$, Bahamas.

Johnsonina eriomma Myers: ANSP 97750, 2, 75.5-85.5 $\mathrm{mm}$, Panama; ANSP 103149, 2, 60.1-66.3 mm, Panama; ANSP 103300, 2, 67.0-68.0 mm, Puerto Rico.

Macrorhamphosodes platycheilus Fowler: ANSP 100862, 1, ca. $85 \mathrm{~mm}$ (posterior part of body absent), Bay of Bengal; ANSP 100865, 2, 80.3-85.3 mm, Bay of Bengal; USNM 93482, 1, too disintegrated to measure, Philippines.

Macrorhamphosodes uradoi (Kamohara): ANSP 101254, 2, 69.9-114 mm, Japan.
Parahollardia lineata (Longley): ANSP 100473, 1, 45.7 mm, Florida; ANSP 93375, 1, $62.2 \mathrm{~mm}$, Florida; ANSP 102144, 1, $82.0 \mathrm{~mm}$, Florida; ANSP 102145, 1, 86.1 $\mathrm{mm}$, South Carolina; ANSP 97637, 3, 79.4-84.4 mm, Louisiana.

Parahollardia schmidti Woods: ANSP 100866, 5, 48.7$62.5 \mathrm{~mm}$, Honduras; ANSP 103302, 2, 62.0-74.0 mm, Nicaragua; ANSP 100128, 4, 56.8-77.8 mm, Nicaragua.

Paratriacanthodes retrospinis Fowler: ANSP 103285, 1, $85.3 \mathrm{~mm}$, Mozambique.

Triacanthodes anomalus (Schlegel): ANSP 101257,4, 50.6-59.7 mm, Japan; ANSP 101256, 1, $71.5 \mathrm{~mm}$, Japan; SU 49435, 1, 91.0 mm, Formosa.

Triacanthodes ethiops Alcock: USNM 93486, 2, 55.3$63.7 \mathrm{~mm}$, Philippines; ANSP 103286, 1, $76.1 \mathrm{~mm}$, Kenya.

Tydemania navigatoris Weber: ANSP 100861, 6, 58.8$67.0 \mathrm{~mm}$, Bay of Bengal; ANSP 100863, 2, 60.1-62.2 $\mathrm{mm}$, Bay of Bengal; ANSP 102137, 1, $63.3 \mathrm{~mm}$, Bay of Bengal; USNM 93471, 1, ca. $95 \mathrm{~mm}$, dry skeleton, Philippines.

\section{Triacanthidae}

Pseudotriacanthus strigilifer (Cantor): SU 41732, 1, $79.0 \mathrm{~mm}$, India; ANSP 89387, 4, $119.145 \mathrm{~mm}$, Thailand.

Triacanthus biaculeatus (Bloch): SU 27746, 2, 113-118 $\mathrm{mm}$, Borneo; ANSP 76585, 1, $124 \mathrm{~mm}$, China; SU 41730, 1, $25.6 \mathrm{~mm}$, India; GVF reg. no. $2655,3,10.9$ $19.1 \mathrm{~mm}$, Thailand.

Triacanthus nieuhofi Bleeker: ANSP 102982, 1, 108 $\mathrm{mm}$, possibly Australia.

Tripodichthys angustifrons (Hollard): ANSP 98719, 1, $137 \mathrm{~mm}$, Australia.

Tripodichthys blochi (Bleeker): ANSP 103298, 3, 55.1$88.9 \mathrm{~mm}$, locality unknown; ANSP 103301, 3, 69.4-97.3 mm, locality unknown; ANSP 63429-54, 11, 18.4-50.9 $\mathrm{mm}$, Philippines; ANSP 63476, 1, $81.0 \mathrm{~mm}$, Philippines; ANSP 63421-25, 5, 24.3-105 mm, Philippines; SU 26930, 2, 92.0-107 mm, Philippines.

Tripodichthys oxycephalus (Bleeker): ANSP 102325, 1, $125 \mathrm{~mm}$, Bay of Bengal.

Trixiphichthys weberi (Chaudhuri): ANSP 102136, 1, $29.6 \mathrm{~mm}$, Bay of Bengal; ANSP 101389, 3, 101-119 $\mathrm{mm}$, Bay of Bengal. 


\section{Balistidae}

Abalistes stellatus (Lacepède): ANSP 111538, 1, 87.6 mm, India.

Balistapus undulatus Mungo Park: ANSP 102146, 1, $124 \mathrm{~mm}$, unknown western Pacific locality; ANSP 102147, 1, 122 mm, unknown western Pacific locality; ANSP 102152, 3, ca. 120 mm, unknown western Pacific locality, wet partially disarticulated skeletons.

Balistes capriscus Gmelin: ANSP 109437, 2, 38.4-46.1 mm, Texas; ANSP 109438, 1, $44.7 \mathrm{~mm}$, Texas; ANSP 109534, 1, $127 \mathrm{~mm}$, Mexico, dry partially disarticulated skeleton; ANSP 109535, 1, $93.7 \mathrm{~mm}$, Louisiana, dry partially disarticulated skeleton; USNM 12983, 1, ca. $360 \mathrm{~mm}$, Gulf of Mexico.

Balistes forcipatus Gmelin: ANSP 103217, 1, $164 \mathrm{~mm}$, Guinea.

Balistes polylepis Steindachner: ANSP 88972, 1, 56.1 mm, Galapagos; ANSP 109530, 1, ca. 390 mm, Mexico.

Balistes vetula Linnaeus: ANSP 109439, 1, $59.8 \mathrm{~mm}$, Colombia.

Balistoides conspicillum (Bloch and Schneider): ANSP 105836, 1, $214 \mathrm{~mm}$, locality unknown.

Balistoides viridescens (Bloch and Schneider): ANSP 106793, 1, $87.8 \mathrm{~mm}$, Borneo.

Canthidermis maculatus (Bloch): ANSP 100085, 1, $80.1 \mathrm{~mm}$, Alabama; ANSP 101364, 1, $217 \mathrm{~mm}$, Mexico.

Hemibalistes bursa (Bloch and Schneider): ANSP 109441, 2, 141-160 mm, locality unknown.

Hemibalistes chrysopterus (Bloch and Schneider): ANSP 68600, 1, $90.1 \mathrm{~mm}$, New Hebrides.

Melichthys niger (Bloch): ANSP 109440, 2, 147-168 mm, locality unknown.

Melichthys vidua (Solander): ANSP 109442, 1, 202 mm, locality unknown.

Odonus niger (Rüppell): ANSP 100991, 1, $173 \mathrm{~mm}$, New Guinea.

Rhinecanthus aculeatus (Linnaeus): ANSP 97373, 1, $72.8 \mathrm{~mm}$, Samoa; ANSP 109443, 2, 172-207 mm, locality unknown.

Rhinecanthus rectangulus (Bloch and Schneider): ANSP 101777, 1, $37.4 \mathrm{~mm}$, Phoenix Islands; ANSP 113259, 1, $70.4 \mathrm{~mm}$, Chagos Archipelago.

Rhinecanthus verrucosus (Linnaeus): ANSP 72220, 1, $98.2 \mathrm{~mm}$, Borneo.

Sufflamen frenatus (Latreille): ANSP 106816, 1, 74.3 $\mathrm{mm}$, Somalia; ANSP 109436, 1, $180 \mathrm{~mm}$, locality unknown.

Sufflamen verres (Gilbert and Starks): ANSP 100279, 2, 30.9-39.5 mm, Panama.

Xanthichthys lineopunctatus (Hollard): ANSP 91806, 1, $181 \mathrm{~mm}$, Hawaii.

Xanthichthys ringens (Linnaeus): ANSP 74895, 1, 40.7 mm, Lesser Antilles; ANSP 113814, 2, 57.6-62.2 mm, Bahamas.

\section{Monacanthidae}

Acanthaluteres spilomelanurus (Quoy and Gaimard): ANSP 109810, 1, $63.7 \mathrm{~mm}$, Australia.
Alutera heudelotii Hollard: ANSP 109455, 2, 107-114 mm, Florida; ANSP 109536, 2, ca. 190 mm, Florida, wet completely disarticulated skeletons.

Alutera monoceros (Linnaeus): ANSP 111505, 2, 111$136 \mathrm{~mm}$, India.

Alutera schoepfi (Walbaum): ANSP 105131, 1, 82.8 mm, Colombia; ANSP 109454, 1, ca. 200 mm, Florida, wet partially disarticulated skeleton.

Alutera scripta (Osbeck): ANSP 100109, 2, 46.2-73.3 $\mathrm{mm}$, Florida.

Amanses scopas (Cuvier): ANSP 109739, 1, $167 \mathrm{~mm}$, Saipan.

Brachaluteres trossulus (Richardson): SU 20566, 2, 43.2-55.5 mm, Australia.

Cantherhines pardalis (Rüppell): ANSP 104784, 1, 79.4 mm, Madagascar.

Cantherhines pullus (Ranzani): ANSP 109444, 1, 56.2 $\mathrm{mm}$, Bahamas; ANSP 101613, 3, 35.1-42.6 mm, Bahamas; ANSP 97383, 1, 45.9 mm, Lesser Antilles; ANSP 109445, 2, 68.7-83.2 mm; Louisiana.

Cantherhines sandwichiensis (Quoy and Gaimard): ANSP 10032, 1, $92.5 \mathrm{~mm}$, Hawaii.

Chaetoderma spinosissimus (Quoy and Gaimard): ANSP 109812, 1, $33.0 \mathrm{~mm}$, Malaya.

Laputa cingalensis Fraser-Brunner: ANSP 100831, 1, $51.9 \mathrm{~mm}$, Bay of Bengal.

Monacanthus chinensis (Bloch): ANSP 90145, 1, 79.4 $\mathrm{mm}$, Moluccas; ANSP 89557, 2, 84.4-101 mm, Thailand.

Monacanthus ciliatus (Mitchill): ANSP 109446, 2, 51.3-58.2 mm, Colombia; ANSP 109447, 2, 75.7-81.3 mm, Florida; ANSP 109448, 2, 52.5-78.4 mm, Florida; ANSP 109449, 3, 57.2-88.1 mm, Florida; TABL uncatalogued (Silver Bay station 1268), 1, $74.5 \mathrm{~mm}$, North Carolina; TABL uncatalogued (Oregon station 5402), 1, $38.3 \mathrm{~mm}$, Jamaica; TABL uncatalogued (Oregon station 3589), 1, $119 \mathrm{~mm}$, Panama.

Monacanthus mylii (B. de Saint-Vincent): ANSP $117147,1,60.8 \mathrm{~mm}$, New Guinea.

Monacanthus tuckeri Bean: ANSP 84488, 3, 28.4-31.9 mm, Bahamas; ANSP 110521, 1, $70.4 \mathrm{~mm}$, Bahamas.

Navodon setosus (Waite): ANSP 97904, 1, $31.0 \mathrm{~mm}$, New Zealand; ANSP 96426, 1, $69.2 \mathrm{~mm}$, New Zealand.

Oxymonacanthus longirostris (Bloch and Schneider): ANSP 109434, 1, $26.5 \mathrm{~mm}$, Seychelles; ANSP 104808, 5, 18.0-56.7 mm, Seychelles; SU 8884, 2, 63.5-73.2 $\mathrm{mm}$, Samoa.

Paraluteres prionurus (Bleeker): ANSP 102875, 1, 46.4 $\mathrm{mm}$, Seychelles.

Paramonacanthus barnardi Fraser-Brunner: ANSP 109808, 1, $42.5 \mathrm{~mm}$, South Africa.

Paramonacanthus cryptodon (Bleeker): ANSP 96729, 1, $40.3 \mathrm{~mm}$, Philippines; ANSP 63130, 1, $68.5 \mathrm{~mm}$, Siam; USNM 169045, 2, 64.1-68.9 mm, Philippines.

Paramonacanthus curtorhynchus (Bleeker): ANSP 100821, 3, 44.7-47.4 mm, Bay of Bengal.

Pervagor melanocephalus (Bleeker): ANSP 104788, 2, 57.4-74.4 mm, Mauritius.

Pervagor spilosomus (Lay and Bennett): ANSP 109451, 1, $103 \mathrm{~mm}$, locality unknown; ANSP 109450, 3, 67.7- 
$83.2 \mathrm{~mm}$, Hawaii; ANSP 112743, 1, $54.4 \mathrm{~mm}$, Hawaii; ANSP 84774, 4, all ca. $65 \mathrm{~mm}$, Hawaii, dry partially disarticulated skeletons.

Pseudaluteres nasicornis (Schlegel): SU 26926, 2, 50.8$108 \mathrm{~mm}$, Philippines.

Psilocephalus barbatus (Gray): ANSP 109648, 1, 142 mm, Australia; SU 35714, 2, 137-139 mm, Singapore.

Rudarius ercodes Jordan and Fowler: ANSP 29477-85, 3, 37.7-44.9 mm, Japan.

Rudarius minutus Tyler: ANSP 109788, 1, $17.9 \mathrm{~mm}$, Borneo.

Stephanolepis auratus (Castelnau): ANSP 106265, 1, $112 \mathrm{~mm}$, Ghana.

Stephanolepis cirrhifer (Schlegel): ANSP 76598, 1, 50.2 mm, Hong Kong.

Stephanolepis hispidus (Linnaeus): ANSP 109452, 2, 42.8-50.4 mm, Florida; ANSP 109543, 1, $80.2 \mathrm{~mm}$, Florida.

Stephanolepis setifer (Bennett): ANSP 94610, 1, 113 $\mathrm{mm}$, Bahamas.

\section{Aracanidae}

Aracana aurita (Shaw): ANSP 109572, 1, $87.3 \mathrm{~mm}$, Tasmania; ANSP 98627, 1, ca. 110 mm, Australia, dry partially disarticulated skeleton.

Aracana flavigaster Gray: ANSP 33169, 2, 45.0-70.0 $\mathrm{mm}$, Australia, dry partially disarticulated skeletons; perhaps the female of $A$. ornata.

Aracana ornata Gray: ANSP 109570, 1, $70.5 \mathrm{~mm}$, Australia; ANSP 33173, 1, $67.5 \mathrm{~mm}$, Australia.

Caprichthys gymnura McCulloch and Waite: WAM P7711, 1, $74.1 \mathrm{~mm}$, Australia.

Capropygia unistriata Kaup: ANSP 109575, 1, 87.9 $\mathrm{mm}$, Australia.

Kentrocapros aculeatus (Houttuyn): SU 53434, 2, 90.0$90.7 \mathrm{~mm}$, Japan.

Strophiurichthys robustus Fraser-Brunner: ANSP 109569, 1, $150 \mathrm{~mm}$, Australia.

\section{Ostraciidae}

Acanthostracion guineensis Bleeker: ANSP 102874, 1, $178 \mathrm{~mm}$, Ivory Coast.

Acanthostracion notacanthus (Bleeker): ANSP 102909, 1, $148 \mathrm{~mm}$, St. Helena.

Acanthostracion polygonius Poey: ANSP 83840, 1, 117 mm, Bahamas; ANSP 80008, 1, 92.5 mm, Lesser Antilles.

Acanthostracion quadricornis (Linnaeus): ANSP 98614, 1, $67.1 \mathrm{~mm}$, Florida; ANSP 98616, 1, $58.2 \mathrm{~mm}$, Mexico; ANSP 98615, 1, $77.7 \mathrm{~mm}$, Florida; ANSP 98617, 2, 8.2-15.3 mm, Louisiana; ANSP 98618, 1, 73.0 mm, Texas; SU 51172, 3, 17.5-25.0 mm, Guiana; ANSP 98843, 2, 121.152 mm, Surinam; ANSP 102749, 1, $254 \mathrm{~mm}$, Colombia; ANSP 103506, 1, $350 \mathrm{~mm}$, Venezuela; ANSP 98619, 3, 130-163 mm, locality unknown, dry partially disarticulated skeletons.

Lactophrys trigonus (Linnaeus): ANSP 49179-80, 2,
89.9-107 mm, Panama; ANSP 98626, 4, 105-193 mm, locality unknown, dry partially disarticulated skeletons.

Lactoria cornuta (Linnaeus): ANSP 91662, 1, $43.0 \mathrm{~mm}$, Guam; ANSP 98621, 1, $114 \mathrm{~mm}$, Philippines; ANSP 98622, 1, $88.2 \mathrm{~mm}$, Philippines; ANSP 98623, 1, 104 mm, Philippines; ANSP 98620, 1, $119 \mathrm{~mm}$, China Sea.

Lactoria fornasinii (Bianconi): ANSP 89016, 2, 12.5$18.0 \mathrm{~mm}$, Hawaii; ANSP 83863, 1, $65.2 \mathrm{~mm}$, Hawaii; ANSP 104837, 1, $15.4 \mathrm{~mm}$, Madagascar; ANSP 104866, 2, 50.3-66.2 mm, Seychelles.

Ostracion lentiginosum Bloch and Schneider: ANSP 112738, 2, 24.4-33.2 mm, Hawaii; ANSP 98624, 1, 88.8 mm, Hawaii; ANSP 106667, 1, $68.2 \mathrm{~mm}$, southwest Pacific; ANSP 104875, 2, 95.9-115 mm, Mauritius.

Ostracion tuberculatus Linnaeus: ANSP 104830, 1, $29.8 \mathrm{~mm}$, Seychelles; ANSP 112942, 1, $54.5 \mathrm{~mm}$, Aldabra Atoll; ANSP 112881, 1, $38.7 \mathrm{~mm}$, Australia; ANSP 112904, 2, 96.7-122 mm, Australia.

Rhinesomus bicaudalis (Linnaeus): ANSP 85199, 1, $83.7 \mathrm{~mm}$, Haiti; ANSP 70147, 1, $77.4 \mathrm{~mm}$, Honduras. Rhinesomus triqueter (Linnaeus): ANSP 74890, 3, 15.5-36.9 mm, Florida; ANSP 98625, 2, 88.7-136 mm, Puerto Rico; ANSP 91385, 1, 134 mm, Colombia.

Rhynchostracion rhinorhynchus (Bleeker): ANSP 90158, 1, $88.2 \mathrm{~mm}$, Java; ANSP 95825, 1, $133 \mathrm{~mm}$, Java.

Tetrosomus concatenatus (Bloch): ANSP 104755, 1, $43.4 \mathrm{~mm}$, Thailand.

Tetrosomus gibbosus (Linnaeus): ANSP 10081, 1, 96.3 mm, Burma.

\section{Triodontidae}

Triodon macropterus Lesson: SU 13747, 1, $391 \mathrm{~mm}$, Philippines; ANSP 98917, 1, 463 mm, Japan.

\section{Tetraodontidae}

Amblyrhynchotes honckenii (Bloch): ANSP 11507, 1, $70.7 \mathrm{~mm}$, India; ANSP 104778, 1, $97.4 \mathrm{~mm}$, Mozambique.

Amblyrhynchotes piosae (Whitley): ANSP 113990, 1, $33.8 \mathrm{~mm}$, Australia.

Amblyrhynchotes richei (Fréminville): USNM acc. no. 244693, 1, $59.4 \mathrm{~mm}$, New Zealand; ANSP 109916, 1, $50.8 \mathrm{~mm}$, Australia.

Arothron armilla (Waite and McCulloch): ANSP 109790, 1, $61.3 \mathrm{~mm}$, Australia.

Arothron hispidus (Linnaeus): ANSP 104798, 1, 40.8 $\mathrm{mm}$, Seychelles.

Arothron nigropunctatus (Bloch and Schneider): ANSP 106817, 1, $56.8 \mathrm{~mm}$, Solomon Islands; ANSP 104737, 1, $182 \mathrm{~mm}$, Thailand.

Arothron stellatus (Bloch and Schneider): ANSP 109529 , 1, ca. $420 \mathrm{~mm}$, Seychelles, dry partially disarticulated skull; ANSP 78242, 1, $292 \mathrm{~mm}$, India.

Canthigaster amboinensis (Bleeker): ANSP 82355, 1, $80.3 \mathrm{~mm}$, Hawaii. 
Canthigaster bennetti (Bleeker): ANSP 104825, 1, 58.3 $\mathrm{mm}$, Seychelles.

Canthigaster jactator Jenkins: ANSP 89255, 1, 54.2 mm, Hawaii.

Canthigaster janthinoptera (Bleeker): ANSP 104806, 2, 42.6-45.5 mm, Seychelles.

Canthigaster margaritata (Rüppell): ANSP 104829, 1, $46.0 \mathrm{~mm}$, Seychelles; ANSP 109471, 1, $76.6 \mathrm{~mm}$, locality unknown.

Canthigaster punctatissima (Günther): ANSP 109472, 2, 13.1-20.2 mm, Costa Rica; ANSP 109473, 2, 19.6$46.1 \mathrm{~mm}$, Costa Rica; ANSP 81467, 3, 42.5-49.5 mm, Mexico.

Canthigaster rivulata (Schlegel): ANSP 84675, 1, 101 $\mathrm{mm}$, Hawaii.

Canthigaster rostrata (Bloch): ANSP 113827, 3, 10.0$18.2 \mathrm{~mm}$, Virgin Islands; ANSP 102141, 1, $59.6 \mathrm{~mm}$, Texas; ANSP 102142, 1, $55.2 \mathrm{~mm}$, Texas; ANSP 102143, 1, $96.5 \mathrm{~mm}$, Texas, dry partially disarticulated skeleton.

Canthigaster valentini (Bleeker): ANSP 99975, 4, 33.9$72.9 \mathrm{~mm}$, Seychelles; ANSP 99948, 9, 30.5-72.8 mm, Seychelles; ANSP 99962, 10, 18.1-70.7 mm, Seychelles; ANSP 104790, 1, $80.3 \mathrm{~mm}$, Mauritius.

Carinotetraodon lorteti (Tirant): ANSP 109469, 1, 25.1 mm, locality unknown; ANSP 109470, 2, 33.1-35.9 $\mathrm{mm}$, locality unknown.

Chelonodon fluviatilis (Hamilton-Buchanan): ANSP 109456, 4, 21.1-30.2 mm, locality unknown; ANSP 109457, 3, 70.1-84.7 mm, Thailand.

Chelonodon patoca (Hamilton-Buchanan): ANSP 117140, 1, $70.6 \mathrm{~mm}$, New Guinea.

Chonerhinos modestus (Bleeker): SU 33563, 3, 31.0$54.5 \mathrm{~mm}$, Borneo.

Colomesus asellus (Müller and Troschel): ANSP 98840, 3, 27.3-33.6 mm, Peru; ANSP 98908, 2, 50.6-50.8 mm, Brazil; ANSP 76254, 1, $113 \mathrm{~mm}$, Venezuela; ANSP 37899, 1, $128 \mathrm{~mm}$, Venezuela.

Colomesus psittacus (Bloch and Schneider): ANSP 75845, 2, 49.7-52.3 mm, Trinidad; ANSP 98869, 2, 76.9-112 mm, Surinam; ANSP 98907, 1, $179 \mathrm{~mm}$, Surinam; ANSP 97658, 2, 178-180 mm, Surinam, dry skeletons.

Ephippion guttifer (Bennett): ANSP 103236, 1, 101 mm, Guinea; ANSP 103245, 1, 108 mm, Guinea.

Fugu chrysops (Hilgendorf): ANSP 97548, 1, $98.6 \mathrm{~mm}$, Japan.

Fugu oblongus (Bloch): ANSP 77245, 1, $46.2 \mathrm{~mm}$, India.

Fugu rubripes (Temminck and Schlegel): ANSP 95480, 1, 83.2 mm, Japan; USNM 26455, 1, 151 mm, Japan.

Guentheridia formosa (Günther): ANSP 95552, 1, 175 $\mathrm{mm}$, Panama.

Lagocephalus inermis (Temminck and Schlegel): ANSP 100832, 1, 52.2 mm, Bay of Bengal.

Lagocephalus laevigatus (Linnaeus): ANSP 103120, 1, $61.4 \mathrm{~mm}$, Alabama; ANSP 102155, 2, 143-166 mm, Florida; ANSP 102153, ca. $290 \mathrm{~mm}$, Uruguay, wet disarticulated skeleton; ANSP 102154, 1, ca. $290 \mathrm{~mm}$, Uruguay, dry skeleton.
Lagocephalus lagocephalus (Linnaeus): ANSP 70299, 1, $214 \mathrm{~mm}$, Malpelo Islands, eastern Pacific.

Lagocephalus lunaris (Bloch and Schneider): ANSP 111509, 1, $62.3 \mathrm{~mm}$, Bay of Bengal.

Lagocephalus scleratus (Gmelin): ANSP 96685, 1, 80.9 $\mathrm{mm}$, Philippines.

Lagocephalus spadiceus (Richardson): ANSP 104787, 1, $98.2 \mathrm{~mm}$, Mozambique.

Monotreta cutcutia (Hamilton-Buchanan): ANSP 63132, 1, $45.4 \mathrm{~mm}$, Thailand; ANSP 59928-37, 1, 73.9 $\mathrm{mm}$, Thailand.

Monotreta gularis (Hamilton-Buchanan): USNM 44811, 2, 46.8-47.1 mm, Burma.

Monotreta leiurus (Bleeker): ANSP 59928-37, 2, 61.5$66.3 \mathrm{~mm}$, Thailand.

Monotreta palembangensis (Bleeker): ANSP 27770, 1, $103 \mathrm{~mm}$, Sumatra.

Sphoeroides angusticeps (Jenyns): ANSP 95841, 1, 172 $\mathrm{mm}$, Galapagos.

Sphoeroides annulatus (Jenyns): ANSP 109459, 3, 15.0-21.4 mm, California; ANSP 109461, 3, 10.9-15.8 mm, California; ANSP 109460, 1, 13.5 mm, California; ANSP 109458, 1, $174 \mathrm{~mm}$, locality unknown.

Sphoeroides dorsalis Longley: ANSP 109462, 1, 131 mm, Florida; ANSP 109519, 1, 139 mm, Georgia, dry skeleton; ANSP 109520, 1, 155 mm, Florida, dry skeleton.

Sphoeroides greeleyi Gilbert: ANSP 109463, 3, 24.2$60.8 \mathrm{~mm}$, locality unknown.

Sphoeroides lobatus (Steindachner): ANSP 97332, 1, $67.5 \mathrm{~mm}$, Panama.

Sphoeroides maculatus (Bloch and Schneider): ANSP 109466, 1, $126 \mathrm{~mm}$, Virginia; ANSP 109465, 3, 31.0$57.8 \mathrm{~mm}$, Virginia; ANSP 109464, 2, 97.5-106 mm, Virginia; ANSP 84307, 3, 9.2-10.2 mm, New Jersey; ANSP 102043, 1, 12.4 mm, New Jersey; ANSP 109467, 1, $201 \mathrm{~mm}$, Florida; all the following 11 specimens are dry and partially to completely disarticulated skeletons from Virginia of between ca. 50 and $200 \mathrm{~mm}$, ANSP 109516-18, 109521-28.

Sphoeroides nephelus (Goode and Bean): ANSP 105222, 1, $48.5 \mathrm{~mm}$, Mississippi; ANSP 110533, 1, 128 $\mathrm{mm}$, Bahamas.

Sphoeroides pachygaster (Ranzani): ANSP 109468, 2, 134-137 mm, Florida; ANSP 101322, 1, $80.6 \mathrm{~mm}$, Nigeria; ANSP 104781, 1, 117 mm, Mozambique.

Sphoeroides spengleri (Bloch): ANSP 10531, 1, ca. 90 mm, Florida, dry skeleton; ANSP 10532, 1, $92.8 \mathrm{~mm}$, Nicaragua, dry skeleton.

Sphoeroides testudineus (Linnaeus): ANSP 107328, 1, $68.5 \mathrm{~mm}$, Venezuela.

Sphoeroides trichocephalus (Cope): ANSP 109742, 1, $57.1 \mathrm{~mm}$, Panama.

Tetraodon lineatus Linnaeus: ANSP 77913, 1, $222 \mathrm{~mm}$, French Equitorial Africa.

Tetraodon mbu Boulenger: ANSP 112236, 1, $47.7 \mathrm{~mm}$, Belgian Congo.

Torquigener pleurogramma (Regan): ANSP 98690, 1, 113 mm, Australia. 
Torquigener pleurostictus (Günther): ANSP 89848, 1, $87.1 \mathrm{~mm}$, Australia.

Xenopterus naritus (Richardson): ANSP 100814, 3, 108-143 mm, Bay of Bengal.

\section{Diodontidae}

Chilomycterus affinis Günther: ANSP 103806, 1, 310 $\mathrm{mm}$, Galapagos.

Chilomycterus antennatus (Cuvier): ANSP 76412, 1, $70.5 \mathrm{~mm}$, Trinidad.

Chilomycterus antillarum Jordan and Rutter: ANSP $97512,1,66.4 \mathrm{~mm}$, Surinam.

Chilomycterus atinga (Linnaeus): ANSP 103900, 1, 278 $\mathrm{mm}$, Florida.

Chilomycterus mauritanicus Le Danois: ANSP 103209, 1, $82.1 \mathrm{~mm}$, Guinea.

Chilomycterus orbicularis (Bloch): ANSP 108827, 2, 72.9-77.0 mm, Somalia; ANSP 98008, 1, $158 \mathrm{~mm}$, Philippines.

Chilomycterus reticulatus (Linnaeus): ANSP 102574, 1, $545 \mathrm{~mm}$, Sierra Leone.

Chilomycterus schoepfi (Walbaum): ANSP 109476, 2, 20.3-22.6 mm, Louisiana; ANSP 109477, 1, $60.1 \mathrm{~mm}$, Louisiana; ANSP 109478, 1, $62.5 \mathrm{~mm}$, Texas; ANSP 109474, 1, $159 \mathrm{~mm}$, Louisiana; ANSP 109479, 1, 35.2 mm, Louisiana; ANSP 109475, 1, $168 \mathrm{~mm}$, Florida; ANSP 109513, 1, ca. $80 \mathrm{~mm}$, Texas, dry partially disarticulated skeleton; ANSP 109514, 1, ca. $125 \mathrm{~mm}$, Florida, dry partially disarticulated skeleton.

Chilomycterus spinosus (Linnaeus): ANSP 109669, 1, $51.0 \mathrm{~mm}$, Brazil.

Chilomycterus tigrinus (Cuvier): ANSP 101341, 1, 165 $\mathrm{mm}$, Somalia.

Dicotylichthys nicthemerus (Cuvier): USNM 201630, 1, $51.8 \mathrm{~mm}$, Australia.

Dicotylichthys punctulatus Kaup: USNM 47923, 1, 226 $\mathrm{mm}$, Australia.

Diodon holocanthus Linnaeus: ANSP 102151, 1, 12.3 mm, Louisiana; ANSP 109480, 1, 53.5 mm, Texas; ANSP 102149, 1, 108 mm, Florida; ANSP 102148, 1, $81.8 \mathrm{~mm}$, Florida; ANSP 102150, 1, $113 \mathrm{~mm}$, Florida; ANSP 102162, 1, $124 \mathrm{~mm}$, Virgin Islands, dry partially disarticulated skeleton.

Diodon hystrix Linnaeus: ANSP 104740, 2, 80.6-84.4 mm, Somalia; ANSP 106756, 2, 45.1-42.2 mm, Florida; ANSP 109515, 1, ca. $200 \mathrm{~mm}$, Florida, dry partially disarticulated skull.

Diodon jaculiferus Cuvier: ANSP 98272, 1, $53.4 \mathrm{~mm}$, Australia.

\section{Molidae}

Masturus lanceolatus (Liénard): USNM 117330, 1, 127 mm, Florida.

Mola mola (Linnaeus): SU 16438, 1, $306 \mathrm{~mm}$, California; SU 16441, 1, 310 mm, California; USNM 27238, dry jaws only from a large specimen of unknown length from Massachusetts; USNM 102086, alcohol preserved jaws only, from a large specimen of unknown length from Massachusetts.

Ranzania laevis (Pennant): ANSP 109435, 2, 65.1-66.9 mm, Hawaii; ANSP 109561, 1, 493 mm, Hawaii.

\section{NONPLECTOGNATHS}

\section{Acanthuridae}

Acanthurus sp. (acronurus stage): ANSP 86416, 1, 53.6 $\mathrm{mm}$, Society Islands,

A canthurus gahhm (Forskål): ANSP 109483, 2, 155-158 $\mathrm{mm}$, unknown western Pacific locality.

Acanthurus leucosternon Bennett: ANSP 108204, 1, $114 \mathrm{~mm}$, Seychelles.

Acanthurus lineatus (Linnaeus): ANSP 109484, 2, 103$118 \mathrm{~mm}$, unknown western Pacific locality; ANSP 109482, 1, ca. $150 \mathrm{~mm}$, unknown western Pacific locality, dry partially disarticulated skeleton; ANSP 109481, 1, ca. $160 \mathrm{~mm}$, unknown western Pacific locality, dry partially disarticulated skeleton.

Acanthurus nigoris Cuvier: ANSP 109487, 1, $127 \mathrm{~mm}$, locality unknown.

Acanthurus nigrofuscus (Forskål): ANSP 109485, 4, 62.3-73.3 $\mathrm{mm}$, unknown western Pacific locality; ANSP 109486, 3, 77.3-131 mm, locality unknown.

Acanthurus olivaceus Bloch and Schneider: ANSP 109488, 1, 109 mm, locality unknown; ANSP 109480, 1, $152 \mathrm{~mm}$, locality unknown.

Acanthurus sandvicensis Streets: ANSP 109490, 1, 69.0 mm, Hawaii.

Acanthurus triostegus (Linnaeus): ANSP 83246, 2, 29.1-29.8 mm, Marquesas Islands; ANSP 87546, 3, 27.9-35.1 mm, Marquesas Islands; ANSP 109491, 6, 40.6-68.9 mm, locality unknown.

Ctenochaetus striatus (Quoy and Gaimard): ANSP 109492, 4, 74.8-123 mm, locality unknown.

Ctenochaetus strigosus (Bennett): ANSP 108208, 1, $93.0 \mathrm{~mm}$, Seychelles.

Naso sp.: ANSP 108416, 1, 107 mm, Seychclles; ANSP 108419, 1, $72.0 \mathrm{~mm}$, Seychelles.

Naso sp., probably $N$. annulatus (Quoy and Gaimard): $\mathrm{MCZ}$ uncatalogued, 1, ca. $370 \mathrm{~mm}$, locality unknown, dry skull.

Naso brevirostris (Cuvier and Valenciennes): ANSP 109493, 1, 209 mm, locality unknown; ANSP 88537, 1, $228 \mathrm{~mm}$, Tuamotus.

Naso fageni Morrow: ANSP 103532, 1, $515 \mathrm{~mm}$, Seychelles.

Naso hexacanthus (Bleeker): ANSP 109495, 1, $158 \mathrm{~mm}$, locality unknown; ANSP 109494, 1, $188 \mathrm{~mm}$, locality unknown.

Naso literatus (Bloch and Schneider): ANSP 109497, 2, 111-209 mm, unknown western Pacific locality; ANSP 109496, 1, $191 \mathrm{~mm}$, locality unknown.

Naso thynnoides (Cuvier and Valenciennes): JLBSII 616d, 1, $191 \mathrm{~mm}$, Tanganyika.

Naso unicornis (Forskăl): ANSP 89114, 1, $267 \mathrm{~mm}$, Hawaii. 
Paracanthurus hepatus (Linnaeus): ANSP 108441, 1, $21.2 \mathrm{~mm}$, Seychelles; ANSP 108444, 1, $31.6 \mathrm{~mm}$, Seychelles; ANSP 90446, 1, $179 \mathrm{~mm}$, Java.

Prionurus punctatus Gill: ANSP 81238, 3, 35.0-47.9 mm, Galapagos.

Prionurus scalprum Cuvier and Valenciennes: ANSP 109779, 1, 44.3 mm, Japan; ANSP 109553, 1, 111 mm, Japan.

Zebrasoma flavescens (Bennett): ANSP 109498, 1, 60.0 mm, unknown western Pacific locality; ANSP 109499, 2, both $101 \mathrm{~mm}$, locality unknown.

Zebrasoma rostratus (Günther): ANSP 108278, 1, 94.7 $\mathrm{mm}$, Seychelles.

Zebrasoma veliferum (Bloch): ANSP 109500, 1, 156 $\mathrm{mm}$, locality unknown.

\section{Zanclidae}

Zanclus cornutus (Linnaeus): ANSP 109504, 1, ca. 70 $\mathrm{mm}$, locality unknown; ANSP 109501, 1, $58.0 \mathrm{~mm}$, locality unknown; ANSP 109502, 1, $66.4 \mathrm{~mm}$, locality unknown; ANSP 109503, 1, $70.4 \mathrm{~mm}$, locality unknown.

\section{Chaetodontidae}

Chaetodon citrinellus Broussonet: ANSP 109506, 1, $81.6 \mathrm{~mm}$, unknown western Pacific locality.

Chaetodon octofasciatus Bloch: ANSP 109508, 1, 67.1 mm, unknown western Pacific locality.

Chaetodon striatus Linnaeus: ANSP 91118, 1, 44.6 mm, Bahamas; ANSP 91611, 1, $57.4 \mathrm{~mm}$, Virgin Islands.

Chaetodon triangulum Cuvier and Valenciennes: ANSP 73227, 1, $87.2 \mathrm{~mm}$, Philippines.

Chelmon rostratus (Linnaeus): ANSP 109511, 3, 48.7$93.4 \mathrm{~mm}$, unknown western Pacific locality.

Chaetodontoplus mesoleucus (Bloch): ANSP 109510, 3, 59.2-76.3 mm, unknown western Pacific locality.

Centropyge multispinis (Playfair): ANSP 108469, 3, 19.0-69.0 mm, Seychelles.

Centropyge urolicki (Bleeker): ANSP 109505, 1, 90.4 $\mathrm{mm}$, unknown western Pacific locality.

Forcipiger longirostris (Broussonet): ANSP 109512, 1, $114 \mathrm{~mm}$, locality unknown; ANSP 108393, 2, 139-140.0 $\mathrm{mm}$, Seychelles.

Holacanthus ciliaris (Linnaeus): ANSP 91094, 2, 35.7$54.4 \mathrm{~mm}$, Bahamas; ANSP 104989, 1, $26.0 \mathrm{~mm}$, Cayman Islands.

Holacanthus tricolor (Bloch): ANSP 104970, 2, 40.2$68.4 \mathrm{~mm}$, Cayman Islands.

Pomacanthodes imperator (Bloch): ANSP 108461, 1, $27.2 \mathrm{~mm}$, Seychelles.

Pomacanthus aureus (Bloch): ANSP 91609, 1, 56.6 $\mathrm{mm}$, Florida.

\section{Fossil Species}

Institutional abbreviations for the repositories of the fossils examined are as follows: AMNH, American Museum of Natural History, New York; BMNH, British Museum (Natural History), London; IGPUB, Istituto di Geologia e Paleontologia della Università di Bologna; IGPUP, Istituto di Geologia e Paleontologia della Università di Pisa; IGPUR, Istituto di Geologia e Paleontologia della Università di Roma; IGUN, Institute de Geologie, Université de Neuchâtel; IGUP, Istituto di Geologia della Università di Padova; MCSNV, Museo Civico di Storia Naturale, Verona; MNHN (IP), Muséum National d'Histoire Naturelle, Institute de Paléontologie, Paris; NSKG, Naturwissenschaftliche Sammlungen des Kantons Glarus, Switzerland.

\section{PLECTOGNATHI}

\section{Triacanthodidae}

Eoplectus bloti Tyler: MCSNV NS 52-53, in counterpart, $65.2 \mathrm{~mm}$, Eocene of Monte Bolca, Italy, holotype.

Protobalistum imperiale (Massalongo): MCSNV T910, in counterpart, $522 \mathrm{~mm}$, Eocene of Monte Bolca, Italy, holotype of Ostracion imperialis.

Spinacanthus cuneiformis (de Blainville): MNHN (IP) 10918, single plate, $104 \mathrm{~mm}$, Eocene of Monte Bolca, Italy, holotype of Blennius cuneiformis.

Zignoichthys oblongus (Zigno): IGUP 6789, single plate, ca. $161 \mathrm{~mm}$, Eocene of Monte Bolca, Italy, holotype of Ostracion oblongus.

\section{Triacanthidae}

Acanthopleurus collettei Tyler, new species: all specimens from the Oligocene of Canton Glaris, Switzerland; NSKG 2689, single plate, $110 \mathrm{~mm}$, holotype; NSKG 146, single plate, $96.2 \mathrm{~mm}$, paratype; NSKG 56, single plate, ca. $120 \mathrm{~mm}$, paratype; NSKG 6b, single plate, $82.7 \mathrm{~mm}$, paratype; NSKG uncatalogued, single plate, last few vertebrae missing and length unmeasurable, paratype; BMNH P 524, single plate, ca. $82 \mathrm{~mm}$, paratype; IGUN uncatalogued, single plate, $108 \mathrm{~mm}$, paratype.

Acanthopleurus serratus (Agassiz): all specimens from the Oligocene of Canton Glaris, Switzerland; BMNH P 454, single plate, ca. $91 \mathrm{~mm}$, cotype of Pleuracanthus serratus; BMNH P 3974, single plate, front of head missing and length unmeasurable, cotype of Pleuracanthus serratus; BMNH P 1892, single plate, ca. 78 mm; NSKG 222 a-b, in counterpart, $114 \mathrm{~mm}$; NSKG 7 , single plate, $93.3 \mathrm{~mm}$; NSKG $158 \mathrm{~b}$, single plate, 153 mm; NSKG 8, single plate, $109 \mathrm{~mm}$; NSKG uncatalogued, single plate, $120 \mathrm{~mm}$; NSKG uncatalogued, single plate, $117 \mathrm{~mm}$; NSKG uncatalogued, single plate, $127 \mathrm{~mm}$; IGUN uncatalogued, single plate, last few vertebrae missing and length unmeasurable.

Acanthopleurus sp.: three plates representing poor impressions or distorted and incomplete specimens unidentifiable to species, all from the Oligocene of 
Canton Glarus, Switzerland; BMNH uncatalogued, ca. $135 \mathrm{~mm}$; BMNH P 4522, ca. $120 \mathrm{~mm}$; BMNH P 1893, unmeasurable.

Protacanthodes ombonii (Zigno): IGUP 10.901-902, in counterpart, $112 \mathrm{~mm}$, Eocene of Monte Bolca, Italy, holotype of Protobalistum ombonii.

\section{Balistidae}

Balistomorphus orbiculatus (Heer): NSKG 2688, single plate, $65.6 \mathrm{~mm}$, Oligocene of Canton Glarus, Switzerland, holotype of Acanthoderma orbiculatum.

Balistomorphus ovalis (Agassiz): both specimens from the Oligocene of Canton Glarus, Switzerland; IGUN 228, single plate, $121 \mathrm{~mm}$, holotype of Acanthoderma ovale; NSKG 178b, single plate, $119 \mathrm{~mm}$.

Balistomorphus spinosus (Agassiz): both specimens from the Oligocene of Canton Glarus, Switzerland; BMNH P. 3973, single plate, ca. $90 \mathrm{~mm}$, holotype of Acanthoderma spinosum; NSKG $189 \mathrm{a}-\mathrm{b}$, in counterpart, too indistinct to measure.

\section{Aracanidae}

Proaracana dubia (de Blainville): all three specimens from the Eocene of Monte Bolca, Italy; MNHN (IP) 10974-75, in counterpart, $54.5 \mathrm{~mm}$, holotype of Balistes dubius; MCSNV T8 and T63, in counterpart, 31.4 $\mathrm{mm}$; IGPUP uncatalogued, single plate, ca. $52 \mathrm{~mm}$.

\section{Ostraciidae}

Eolactoria sorbinii Tyler: MCSNV T6-7, in counterpart, $15.5 \mathrm{~mm}$, Eocene of Monte Bolca, Italy, holotype.

\section{Triodontidae}

Triodon antiquus Leriche: BMNH P 12629, large fragment of right premaxillary, Eocene of Barton, Hants., England; BMNH P 15193, large fragment of right premaxillary, Eocene of Barton, Hants., England; BMNH P 15726, large fragment of fused dentaries, Eocene of Schaerbeek, Belgium; BMNH P 46696, fragment of middle of fused dentaries, Eocene of the London Clay, England; BMNH P 28899, small fragment of teeth from edge of jaw, Eocene of the London Clay, England; BMNH P 25776-81, five fragments of fused dentaries and one right premaxillary, Eocene of Barton Hants., England.

\section{Tetraodontidae}

"Tetraodon" lecointrae Leriche: IGPUP Miocene of Piromafo, Italy, no. 13, three fragments of the elongate dental lamellae at edge of jaw.

Eotetraodon pygmaeus Zigno: IGUP 6890-91, in counterpart, $18.2 \mathrm{~mm}$, Eocene of Monte Bolca, Italy.

\section{Diodontidae}

Diodon scillae Agassiz: IGPUP Miocene of Terra Rossa, Italy, no. 1, one complete trituration plate with right and left halves; IGPUP Miocene of Livello ad Aturia, Italy, no. 3 , one half of a trituration plate; IGPUP Miocene of Terreno Agrario, Italy, no. 27, one half of a trituration plate.

Diodon tenuispinus Agassiz: seven specimens from the Eocene of Monte Bolca, Italy; MNHN (IP) 10976-77, in counterpart (dorsoventral), $19.7 \mathrm{~mm}$, holotype; MNHN (IP) 10978, single plate (dorsoventral), 12.6 $\mathrm{mm}$; MNHN (IP) 10979, single plate (dorsoventral), $46.5 \mathrm{~mm}$; MCSNV B. 18, single plate (dorsoventral), $31.5 \mathrm{~mm}$; MCSNV B. 19, single plate (dorsoventral), $40.5 \mathrm{~mm}$; BMNH $\mathrm{P} 11168$, in counterpart (dorsoventral), $22.9 \mathrm{~mm}$; $B M N H ~ P ~ 12360$, single plate (dorsoventral), $13.5 \mathrm{~mm}$.

"Diodon" sp.: eight specimens from the Eocene of Monte Bolca, Italy; MCSNV T 10, single plate (dorsoventral), $11.8 \mathrm{~mm}$, Italy; MCSNV T 11 , single plate (dorsoventral), $35.1 \mathrm{~mm}$; IGUP 12810-11, in counterpart (dorsoventral), $27.3 \mathrm{~mm}$; IGUP 6894, single plate (dorsoventral), $17.4 \mathrm{~mm}$; IGUP 6861, single plate (dorsoventral), $11.8 \mathrm{~mm}$; MCSNV MS 50-51, in counterpart (dorsoventral), $68.9 \mathrm{~mm}$; MCSNV T2, single plate (dorsoventral), $18.4 \mathrm{~mm}$; BMNH P 10735, in counterpart (dorsoventral), $25.8 \mathrm{~mm}$.

Eodiodon erinaceus (Agassiz): five specimens from the Eocene of Monte Bolca, Italy; BMNH P 3873, single plate (dorsoventral), $77.5 \mathrm{~mm}$, holotype of Diodon erinaceus; BMNH P 10426, single plate (dorsoventral), $96.5 \mathrm{~mm}$; IGUP 8855-56, in counterpart (dorsoventral), $50.3 \mathrm{~mm}$; IGUP 8853-54, in counterpart (dorsoventral), $68.8 \mathrm{~mm}$; IGUP 8670-71, in counterpart (dorsoventral), ca. $64 \mathrm{~mm}$.

Kyrtogymnodon capellinii (de Stefano): IGPUP Miocene of Livello ad Aturia, Italy, no. 4, right and left halves of a trituration plate; IGPUP Miocene of Terreno Agrario, Italy, no. 28, fragment of a large trituration plate.

Oligodiodon acanthodes (Sauvage): IGPUP uncatalogued, most of left premaxillary and top of maxillary, Oligocene of Monti Livornesi, Italy.

Oligodiodon platyodus (Portis): IGPUR uncatalogued, one half of a trituration plate, $15.4 \mathrm{~mm}$ greatest length, Oligocene of Montecchio Maggiore, Italy, type specimen of Diodon platyodus.

Progymnodon hilgendorfi Dames: BMNH P 11089, large fragment of jaw with teeth and trituration plate, Eocene of Fayum, Egypt.

Progymnodon gigantodus (Portis): IGPUR uncatalogued, right and left halves of a trituration plate, 41.8 $\mathrm{mm}$ greatest length of entire plate, Eocene of Castel Madama, Italy, type specimen of Diodon gigantodus; IGPUP Miocene of Terra Rossa, Italy, no. 1, two separate halves of the same trituration plate; IGPUP Miocene of Livello ad Aturia, Italy, no. 3, half of a large trituration plate; IGPUP Miocene of Terreno Agrario, Italy, no. 27, two halves of a trituration plate. 


\section{NONPLECTOGNATHS}

\section{Acanthuridae}

(Identifications under revision)

Acanthurus sp.: three specimens from the Eocene of Monte Bolca, Italy; BMNH P 16130 and P 17020, in counterpart, the two halves separately catalogued, 120 mm; MCSNV T 3, single plate, $25.6 \mathrm{~mm}$; MCSNV T 1, single plate, $18.8 \mathrm{~mm}$, possibly a young Naseus nuchalis.

Acanthurus ovalis Agassiz: both specimens from the Eocene of Monte Bolca, Italy; MCSNV $\mathrm{T}$ 4-5, in counterpart, $127 \mathrm{~mm}$; IGUP 6874, single plate, 76.1 $\mathrm{mm}$.

Acanthurus tenuis Agassiz: BMNH P 11176, single plate, $86.6 \mathrm{~mm}$, Eocene of Monte Bolca, Italy.

Naseus intermedius Zigno: IGUP 6917-18, in counterpart, $105 \mathrm{~mm}$, Eocene of Monte Bolca, Italy, holotype.

Naseus nuchalis Agassiz: eight specimens from the Eocene of Monte Bolca, Italy; MNHN (IP) 10910-11, in counterpart, $155 \mathrm{~mm}$, holotype; BMNH P 19059, single plate, $212 \mathrm{~mm}$; BMNH P 11174, in counterpart, $151 \mathrm{~mm}$; BMNH P 11098, in counterpart, $177 \mathrm{~mm}$; IGUP 12062-63, in counterpart, $190 \mathrm{~mm}$; IGUP 1160910 , in counterpart, $152 \mathrm{~mm}$; MCSNV $\mathrm{T} 12$, single plate, $109 \mathrm{~mm}$; MCSNV B 1965.13, single plate, 106 $\mathrm{mm}$.

Naseus rectifrons Agassiz: 18 specimens from the Eocene of Monte Bolca, Italy; MNHN (IP) 10908-09, in counterpart, $189 \mathrm{~mm}$, holotype; BMNH P 10427, single plate, $205 \mathrm{~mm}$; BMNH P 11173, in counterpart, $112 \mathrm{~mm} ; \mathrm{BMNH} \mathrm{P} 41890$, single plate, $171 \mathrm{~mm}$; BMNH P 9831, single plate, 67.5 mm; BMNH P 21393, single plate, ca. $200 \mathrm{~mm}$, incomplete; BMNH P 43490, in counterpart, $38.4 \mathrm{~mm}$; IGUP 11895 , single plate, $83.0 \mathrm{~mm}$; IGUP 25103, single plate, $160 \mathrm{~mm}$; IGUP 25101, single plate, $189 \mathrm{~mm}$; IGUP 8701-02, in counter- part, $185 \mathrm{~mm}$; IGUP 8698-99, in counterpart, $97.0 \mathrm{~mm}$; MCSNV VIII C 58-59, two specimens with the same catalogue number, both in counterpart, 92.4 and 195 $\mathrm{mm}$; MCSNV VIII C 56-57, in counterpart, $88.8 \mathrm{~mm}$; MCSNV VIII C 50, single plate, $144 \mathrm{~mm}$; MCSNV VIII C 70, single plate, $108 \mathrm{~mm}$; MCSNV VIII C 68, single plate, $187 \mathrm{~mm}$; AMNH $9531 \mathrm{~A}-\mathrm{B}$, in counterpart, 212 $\mathrm{mm}$.

Naso deani (Hussakof): AMNH 7483, single plate, 231 $\mathrm{mm}$, Antigua, West Indies, uncertain age, holotype of Zebrasoma deani.

\section{Acanthonemidae}

Acanthonemus subaureus (de Blainville): 10 specimens from the Eocene of Monte Bolca, Italy; MNHN (IP) 10904-05, in counterpart, $192 \mathrm{~mm}$, holotype of Chaetodon subaureus; MNHN (IP) 1090607, in counterpart, $99.5 \mathrm{~mm}$; BMNH P 16201, single plate, $126 \mathrm{~mm}$; BMNH P 9940, single plate, $165 \mathrm{~mm}$; BMNH P 16200-01, in counterpart, $126 \mathrm{~mm}$; IGUP 25100 , single plate, ca. $123 \mathrm{~mm}$; IGUP 25102, single plate, $167 \mathrm{~mm}$; IGUP 11606-07, in counterpart, 126 $\mathrm{mm}$; IGUP 6884, single plate, $62.8 \mathrm{~mm}$; MCSNV VD 108-109, ca. $72 \mathrm{~mm}$.

\section{Zanclidae}

Eozanclus brevirostris (Agassiz): MNHN (IP) 1074041, in counterpart, $101 \mathrm{~mm}$, Eocene of Monte Bolca, Italy, holotype of Zanclus brevirostris.

\section{Teleostei Incertae Sedis}

Protriacanthus gortanii d'Erasmo: IGPUB uncatalogued, single plate, $20.5 \mathrm{~mm}$, Lower Cenomanian of Comen, near Trieste, Italy, holotype.

\section{EPILOGUE}

\section{Remaining Problems}

The more outstanding remaining problems on the anatomy, classification, and phylogeny of the plectognaths of which I am aware are the need for: 1) systematic surveys of other anatomical systems to complement that on the myology by Winterbottom (1974) and on the osteology and external features presented here; 2) systematic worldwide familial revisions of the balistoids, ostracioids, tetraodontoids, and molids, to expand the coverage of groups begun by Tyler (1968) for triacanthoids; 3) future diggings to increase the number of pertinent fossils available and tell us more about the phylogeny and anatomical diversity of the order and its relatives; 4) rigorous comparisons between the fossil and Recent acanthurids and their chaetodontoidlike relatives with the fossil and Recent plectognaths to definitively determine if these groups share a late Cretaceous or early Eocene ancestral stock; 5) a reconciliation of any conflicting classificatory schemes for plectognaths based on similar hypothesized phylogenies; and 6) clarification of specific identifications and nomenclature of many Indo-Pacific tetraodontids, diodontids, and monacanthids. 


\section{ACKNOWLEDGMENTS}

This monograph is a much revised and expanded outgrowth of a work begun at Stanford University in 1958 as a doctoral dissertation under the guidance of George S. Myers; his instructive and encouraging influences prevailed over so many aspects of the germinal stages of this monograph that it would be impossible to list them, and I will simply express my lasting appreciation for his help and innumerable kindnesses devoted to my education.

Stanley H. Weitzman, then also of Stanford University, was equally helpful to the early formative aspects of this work, and he has continued to the present to freely make available on many occasions his osteological, systematic, and phylogenetic expertise.

The late Margaret H. Storey of Stanford's Natural History Museum was of constant curatorial and bibliographic assistance, while the interchange of ideas, techniques, and data with my fellow students was most invaluable and is here gratefully acknowledged, these then student friends being Warren C. Freihofer, Hugh $\mathrm{H}$. DeWitt, and Tyson R. Roberts.

The majority of this work was done while a member of the curatorial staff of the Academy of Natural Sciences of Philadelphia, and I am especially grateful to $\mathrm{H}$. Radclyffe Roberts, until 1973 its Director, for encouraging this research during my time there. His understanding of the vagaries of research is much appreciated. My associates there in the Department of Ichthyology and Iferpetology constantly assisted in the preparation of this monograph, these coworkers being Jane H. Baker, Ann L. Berkes, Warren N. Berkes, Eugenia B. Böhlke, James E. Böhlke, Charles C. G. Chaplin, Kathy Depolito, Lynn Keane, Mark D. Lange, and Judith Silver; I would like to especially single out Judith Silver and Lynn Keane, successive secretarymajor domos of the department, for unstinting cooperation in every aspect of this work, from typing to proofreading, and from bibliographic searching to the considerate care of the researcher. I have been blessed by a succession of equally cooperative and artistic scientific illustrators whose skillful techniques form a major portion of any merit to this monograph and who were exceptionally pleasant to work closely with: Gail Costanzo, Mary H. Fuges, Olivia B. Hall, Helga O. Kumpera, and Joanne R. Schatz. Additionally, Stephen P. Gigliotti generously gave his advice on illustrative matters and James E. Böhlke did so on systematic questions.

Other members of the Academy of Natural Sciences of Philadelphia were immeasurably helpful in a variety of ways. C. Willard Hart, then editor of Academy publications, provided many helpful suggestions in coordinating the manuscript and illustrations, as did the Academy's engraver, Hal Talman, president of Phototype of Philadelphia. Larry Herbert, the late Oliver Bradley, and Joseph Green of the Academy engineering department were always on call to build or repair, often on short notice, the mechanical and electrical contriv- ances essential to this project. Beverly Mowbray and Nancy Steele of the publications staff at the Academy could always see a lighter side to a heavy scientific tale. Jesse J. Freese and Mary E. Sink kept the convolutions of budgetary and administrative rules and reports to the efficient minimum. Charles Sibre, and his sons John and Michael Sibre, of the photographic department, gracefully as well as proficiently provided the $35 \mathrm{~mm}$ negatives of the cleared and stained specimens that formed the basis for the initial traced outlines for most of the osteological illustrations presented here. Their good humor in the face of messy containers of glycerine scattered about their studio was remarkable.

The introductory and concluding portions of this monograph, and of the updating and revisions of the entire manuscript, were written while serving as the Director of the Lerner Marine Laboratory, Bimini, Bahamas, of the American Museum of Natural History, and while on the staff of the Office of Resource Research of the National Marine Fisheries Service, Washington, D.C., where Lamarr B. Trott, Chief of the then Division of Research Management, provided many kindnesses, and then as a member of the Southeast Fisheries Center of that service, Miami, Fla., where the support of Harvey R. Bullis, Jr., the then Center Director, and William J. Richards, Miami Laboratory Director, and Laurie Smith, secretary to the Atlantic Bluefin Tuna Program, were especially helpful.

Most of the 10 years of research at the Academy of Natural Sciences of Philadelphia leading to the major portion of this monograph were supported in large part by the National Science Foundation through grants GB-1248, GB-5102, GB-6859X, and GB-16190. J. Frances Allen, Richard F. Johnston, William Sievers, and J. T. Spencer, the officers of the National Science Foundation then administering these grants, are sincerely thanked for their support, and for doing so with a minimal amount of bureaucratic paper work. The thoughtfulness and trust of the National Science Foundation and of their advisory boards and ad hoc committees of colleagues mostly unknown to me is a true pleasure to acknowledge.

The success of any osteological survey of a speciose worldwide group of fishes such as the plectognaths is dependent on obtaining for dissection specimens representing as many species as possible. The great majority of specimens studied here were either loaned or donated to Stanford University and the Academy of Natural Sciences of Philadelphia by the following cooperative colleagues: Tokiharu Abe, Frederick H. Berry, Harvey R. Bullis, Jr., Daniel M. Cohen, H. Adair Fehlmann, Leslie W. Knapp, Giles W. Mead, George S. Myers, and Robert R. Rofen. Without the specimens from them, my coverage of the plectognaths would be so meager as not to warrant publication.

Photographic prints of many of the illustrations, used in preference to constant handling for over a decade of the final ink drawings, generously were provided by Vic- 
tor Kumpera and Vlastimil Wagner, of São Paulo, Brazil.

The cross sections of the jaws of diodontids, showing the trituration plates and teeth of the biting edge, all were skillfully cut and polished by Edgar R. Lawrence, dental surgeon of West Chester, $\mathrm{Pa}$.

More generally, Helga O. Kumpera was a mainspring in the laborious mechanism leading to the completion of this monograph, as the culmination of a 20 -year study. Her help ran the gamut from the typing of hundreds of pages of manuscript to translating into English numerous articles in several foreign languages, and from thousands of hours spent in stippling illustrations to equally numerous hours spent in proofreading.

The following colleagues have generously provided specimens for examination or made available data about or assistance with specimens in their care, and their vital help is greatly appreciated (affiliations listed as of the time the help was rendered, and therefore sometimes outdated at this time): Tokiharu Abe, Tokaiku Fisheries Research Laboratory, Tokyo; B. Accordi, Istituto di Geologia e Paleontologia dell'Università di Roma; Gerald R. Allen and John E. Randall, Bernice P. Bishop Museum, Honolulu; Roberto D. Andreucci, Escola Paulista de Medicina, São Paulo; James E. and Ethyl H. Atz, Gareth J. Nelson, Donn E. Rosen, Bobb Schaeffer, and C. Lavett Smith, American Museum of Natural History, New York; Reeve M. Bailey and Teruyo Uyeno, University of Michigan, Ann Arbor; Keith E. Banister, P. Humphrey Greenwood, Alison Longbottom, Rosemary McConnell, G. Palmer, Colin Patterson, Ethelwynn Trewavas, Charlotte Welch, and Peter J. Whitehead, British Museum (Natural History), London; M. L. Bauchot, M. Blanc, Jacques Blot, and J. Guibé, Muséum National d'Histoire Naturelle, Paris; Frederick H. Berry, National Marine Fisheries Service, Miami; E. Bertelsen, Marinebiologisk Laboratorium, Charlottenlund Slot; M. Boeseman and G.F. Mees, Rijksmuseum van Natuurlijke Historie, Leiden; James E. Böhlke, Charles C. G. Chaplin, and Neal R. Foster, Academy of Natural Sciences of Philadelphia; Niels Bonde, Mineralogisk-Geologisk Institut, København; Margaret G. Bradbury, San Francisco State College; Heraldo A. Britski, Museu de Zoologia da Universidade de São Paulo; Harvey R. Bullis, Jr., and Richard A. Waller, National Marine Fisheries Service, Miami and Washington, D.C.; Vernon E. Brock, Warren E. Burgess, and William A. Gosline, University of Hawaii, Honolulu; Jean Cadenat, Institute Français d'Afrique Noire, Goŕee, Sénégal; David K. Caldwell, University of Florida, St. Augustine; Edgar Casier, Institut Royal des Sciences Naturelles de Belgiques, Brusselles; William Chan, Fisheries Research Station, Aberdeen, Hong Kong; Edward Chin, Richard L. Haedrich, and Andrew Konnerth, Woods Hole Oceanographic Institution, Woods Hole, Mass.; Eugenie Clark, University of Maryland, College Park; Glenn H. Clemmer and Royal D. Suttkus, Tulane University, New Orleans; Daniel M. Cohen and Bruce B. Collette, National Systematics Laboratory, National Marine Fisheries Service, Washington, D.C.; Walter R.
Courtenay, Florida Atlantic University, Boca Raton; Giambattista Dal Piaz, Istituto di Geologia, Paleontologia e Geologia Applicata dell'Università di Padova; William P. Davis, Aquatic Sciences, Inc., Boca Raton; L. F. de Beaufort, H. Nijssen, and P. J. H. van Bree, Zoölogisches Museum, Amsterdam; Kurt Deckert, Humboldt Universität, Berlin; Thomas Devany, C. Richard Robins, and David G. Smith, University of Miami; Hugh H. DeWitt, University of Maine, Walpole; Myvanwy M. Dick, Alfred S. Romer, and Tyson R. Roberts, Museum of Comparative Zoology, Cambridge; Pedro Duarte Bello, Universidad de La Habana; Alfred W. Ebeling, University of California, Santa Barbara; Paul R. Ehrlich and Donald Kennedy, Stanford University; Donald S. Erdman, Department of Agriculture, San Juan, Puerto Rico; William N. Eschmeyer, W. I. Follett, Warren C. Freihofer, George S. Myers, and Pearl M. Sonoda, California Academy of Sciences, San Francisco; H. Adair Fehlmann and Leslie W. Knapp, Smithsonian Oceanographic Sorting Center, Washington, D.C.; P. Fourmanoir, Centre Office de la Recherche Scientifique et Technique Outre-Mer, Paris; A. J. Fraser and R. J. McKay, Western Australian Museum, Perth; A. FraserBrunner and John C. Marr, Food and Agriculture Organization of the United Nations, Rome; K. C. George, Central Marine Fisheries Research Substation, Kerala; Robert R. Gibbs, Edgar N. Gramblin, Robert H. Kanazawa, Ernest A. Lachner, Leonard P. Schultz, Victor G. Springer, William R. Taylor, and Stanley H. Weitzman, National Museum of Natural History, Washington, D.C.; Carter R. Gilbert, University of Florida, Gainesville; J. R. Grindley, South African Museum, Cape Town; Bruce W. Halstead, World Life Research Institute, Colton, Calif.; Carl L. Hubbs, John E. McCosker, and Richard H. Rosenblatt, Scripps Institution of Oceanography; J. Jenny, Naturwissenschaftliche Sammlungen des Kantons Glarus; Robert S. Jones, College of Guam, Agana; S. Jones, Central Marine Fisheries Research Institute, Mandapam Camp, India; Paul Kähsbauer, Naturhistorisches Museum, Wien; Toshiji Kamohara, Kochi University; Wolfgang Klausewitz, Natur-Museum und Forschungs-Institute, Frankfurt; Adolf Kotthaus, Biologische Anstalt Helgoland, Hamburg; Richard J. Kresja, California State Polytechnic College, San Louis Obispo; Louis A. Krumholz, University of Louisville; V. M. Makushok and T. S. Rass, Institute of Oceanology, Academy of Sciences of the U.S.S.R., Moscow; E. Marchal, Centre de Recherches Oceanographiques, Abidjan; G. E. Maul, Museu Municipal do Funchal; Giles W. Mead, Los Angeles County Museum of Natural History; A. G. K. Menon, Zoological Survey of India, Calcutta; Robert V. Miller, National Marine Fisheries Service, Washington, D.C.; Martin A. Moe, Oceanographic Mariculture Industries, Riviera Beach, Fla.; Donald Moore, National Marine Fisheries Service, Galveston; Basil Nafpaktitis, University of California, Los Angeles; Jorgen Nielsen, Universitetets Zoologiske Museum, Kobenhavn; Ross F. Nigrelli, New York Zoological Society, Brooklyn; John R. Paxton, Frank H. Talbot, and Gilbert P. Whitley, 
Australian Museum, Sydney; Michael J. Penrith, State Museum, Windhoek; Craig Phillips, U.S. National Aquarium, Washington, D.C.; E. Postel, Faculté des Sciences, Rennes; Jürgen Remane and J.P. Schaer, Université de Neuchâtel; Robert R. Rofen, Aquatic Research Institute, Hayward, Calif.; Robert L. Shipp, University of South Alabama, Mobile; J. L. B. and Margaret M. Smith, Rhodes University, Grahamstown; Lorenzo Sorbini, Museo Civico di Storia Naturale, Verona; Walter A. Starck, Chino, Calif.; F. Strauch, Universität Köln; Guido Tavani, Licio Giannelli, and Andrea Cerrina Feroni, Museo di Paleontologia dell 'Università di Pisa; Donald A. Thompson, University of Arizona, Tucson; Luiz R. Tommasi, Instituto Oceanografico da Universidade de São Paulo; E. Tortonese, Museo Civico di Storia Naturale, Genoa; Vittorio Vialli, Istituto di Geologia e Paleontologia dell'Università di Bologna; Vlastimil Wagner, São Paulo, Brazil; Frank Williams, Guinean Trawling Survey, Lagos; Richard Winterbottom, Queen's University, Kingston, Ontario; Donald Wohlschlag, University of Texas, Port Aransas; Loren P. Woods, Field Museum of Natural History, Chicago; Ralph W. Yerger, Florida State University, Tallahassee.

Preliminary arrangements toward the publication of this monograph were facilitated by a special grant from the Lerner Fund for Marine Research of the American Museum of Natural History.

The manuscript for this work has benefited greatly from the helpful criticism of several colleagues who volunteered their valuable time to peruse it: first, Richard Winterbottom and Bruce B. Collette, and then
C. Lavett Smith and Stanley H. Weitzman. Their generosity is much appreciated and their suggestions mostly accepted and used.

Richard Winterbottom, while at Queens University, Kingston, Ontario, and at both the Academy of Natural Sciences of Philadelphia and the U.S. National Museum of Natural History, Washington, D.C., provided many highly valuable hours of discussion on the anatomy, classification, and phylogeny of plectognath fishes and freely shared his research data with me. His interest in, and information given toward furthering, the work leading to this monograph has been invaluable, even though he is not necessarily in agreement with all of the phylogenetic conclusions set forth here and probably does not approve of the style of classification adopted here. He is an esteemed colleague of impeccable credentials and more than proven worth in the study of myology and of plectognaths, as well as being a dear friend with whom I happen to disagree on some points of how to divide and group the supra- and subfamilial (but not familial, on which we are mostly in agreement) categories of Tetraodontiformes.

The errors of omission and commission that remain in this monograph, after eluding my strenuous efforts to eliminate them, are entirely my own and are not at all attributable even in part to any of my so freely cooperating colleagues acknowledged above.

This monograph is dedicated to the four friends most intimately associated at the personal level with its preparation: Helga Olga Schrader, Milan Kumpera Tyler, Marisa Alenna Tyler, and Antoinette Carmela De Fazio.

\section{LITERATURE CITED}

ABE, $T$.

1942. Taxonomic studies on the puffers (Tetraodontidae, Teleostei) from Japan and adjacent regions-I. Vertebral variation. Palao Trop. Biol. Stn. Stud. 2:477-496.

1944. Taxonomic studies on the puffers (Tetraodontidae, Teleostei) from Japan and adjacent regions-II. Variation of dorsal fin. Annot. Zool. Jpn. (Zool. Soc., Tokyo) 22:200-234.

1949a. Taxonomic studies on the puffers (Tetraodontidae, Teleostei) from Japan and adjacent regions-III. Variation of anal fin. Bull. Jpn. Soc. Sci. Fish. 14:123-144.

1949b. Taxonomic studies on the puffers (Tetraodontidae, Teleostei) from Japan and adjacent regions-IV. Variation of caudal fin. Bull. Jpn. Soc. Sci. Fish. 15:19-27.

1949c. Taxonomic studies on the puffers (Tetraodontidae, Teleostei) from Japan and adjacent regions $-V$. Synopsis of the puffers from Japan and adjacent regions. Bull. Biog. Soc. Jpn. 14: $1-15 ; 14: 89-140$

1950-51. Taxonomic studies on the puffers (Tetraodontidae, Teleostei) from Japan and adjacent regions-VI. Variation of pectoral fin. Jpn. J. Ichthyol. 1:198-206 (1950); 1:272-283 (1951).

1952. 'Taxonomic studies on the puffers (Tetraodontidae, Teleostei) from Japan and adjacent regions-VII. Concluding remarks, with the introduction of two new genera, Fugu and Boesemanichthys. Jpn. J. Ichthyol. 2:35-44; 2:93-97; 2:117-127.

1954. Taxonomic studies on the puffers from Japan and adjacent
regions-Corrigenda and addenda. Part I. Jpn. J. Ichthyol. 3: 121-128.

1960. Taxonomic studies on the puffers from Japan and adjacent regions-Corrigenda and addenda. Part II. Jpn. J. Ichthyol. 8:3-6.

ADENEY, R. J., and G. M. HUGHES.

1977. Some observations on the gills of the oceanic sunfish, Mola mola. J. Mar. Biol. Assoc. U.K. 57:825-837.

AGASSIZ, L.

1833. Recherches sur les poissons fossiles. Vol. 2, Part 1, p. 1-48. Neuchâtel.

1839. Recherches sur les poissons fossiles. Plate 38 of Vol. 5. Neuchâtel.

1842. Recherches sur les poissons fossiles. Plate 75 of Vol. 2 Neuchâtel.

1844a. Recherches sur les poissons fossiles. Vol. 1, p. 1-188. Neuchâtel.

1844b. Recherches sur les poissons fossiles. Vol. 2, Part 2, p. 73. 336. Neuchâtel.

1844c. Recherches sur les poissons fossiles. Vol. 5, Part 1, p. 33122. Neuchâtel.

1857. [Orthagoriscus mola, on grounds of internal anatomy, does not belong in the same family with Diodon and Tetraodon, but is the type of a distinct family]. Untitled paper, Proc. Am. Acad. Arts Sci. (Boston) 3:319. 
1860. On the various existing systems of classification of fishes. Proc. Am. Acad. Arts Sci. (Boston) 4:8-9.

ALESSANDRINI, A.

1839. De piscium apparatu respirationis tum speciatim Orthragorisci $=$ Orthragoriscus alexandrini Ranzani. Nuovi Comm. Acad. Sci. Inst. Bonon. (Accad. Sci. Istit. Bologna) 3:359-382.

AL-HUSSAINI, A. H.

1947. The feeding habits and the morphology of the alimentary tract of some teleosts living in the neighbourhood of the Marine Biological Station, Ghardaqa, Red Sea. Mar. Biol. Stn., Ghardaqa, Publ. 5:1-61.

ALLEN, G. R., and J. E. RANDALL.

1977. Review of the sharpnose pufferfishes (Subfamily Canthigasterinae) of the Indo-Pacific. Rec. Aust. Mus. 30:475517.

ANDREUCCI, R. D.

1966a. Aspectos morfologicos, macro e microscopicos, dos dentes de Spheroides testudineus (L., 1735) (baiacu). Thesis ("Tese de Doutoramento"), Univ. Sāo José dos Campos, 47 p.

1966b. Aspectos estruturais dos dentes de Spheroides testudineus. Rev. Assoc. Paulista Cirurg. Dent. (Sāo Paulo) 20:1-7.

1967a. Aspectos anatomicos dos dentes de Spheroides testudineus. Prog. V Cong. Brasil. Anat. (Sảo Paulo), p. 9.

1967b. Aspectos da odontogềnese de Spheroides testudineus. Ciênc. Cult. (Sāo Paulo) 19:360.

1968a. Macroscopic and microscopic morphology of Spheroides testudineus teeth (checkered puffer). Acta Anat. (Basel) 71:448471.

1968b. Aspectos anatomicos dos dentes de Spheroides testudineus. Rev. Assoc. Med. Brasil. (São Paulo) 14:245-246.

1969. Dos dentes de Spheroides testudineus (L., 1735) (baiacumirim). Estudo autoradiografico e à luz polarizada. Thesis ("Tese de Livre Docência"), Univ. São José dos Campos, 51 p.

1970. Sóbre a estrutura das lojas denticulares de Spheroides testudineus (baiacu-mirim). Rev. Brasil. Pesq. Med. Biol. (São Paulo) 3:63-67.

ANDREUCCI, R. D., and G. BLUMEN.

1971. Radioautographic study of Spheroides testudineus denticles (checkered puffer). Acta Anat. (Basel) 79:76-83.

ANDREUCCI, R. D., and H. A. BRITSKI.

1968a. Aspectos anatomicos dos dentes de baiacu-de-espinho, Chilomycterus spinosus. Prog. VI Cong. Brasil. Anat. (Campinas), p. 13

1968b. Aspectos da odontogenese de Mola mola. Ciênc. Cult. (São Paulo) 20:346-347.

1969a. Macroscopic and microscopic morphology of the Mola mola teeth (sun fish). Rev. Brasil. Pesq. Med. Biol. (São Paulo) 2: 159-162.

1969b. Aspectos macro e microscopic dos dentes de Lagocephalus laevigatus (L., 1758) e de Colomesus asellus (Mueller \& Troschell, 1848). Ciênc. Cult. (São Paulo) 21:483-484.

1970. Sobre os dentes de Liosaccus intermedius, Ribeiro, 1904 e Masturus lanceolatus (Lienard, 1840). Prog. XXII Reun. Anu. Soc. Brasil. Pesq. Ciênc. (Salvador), p. 305.

1971. Dos dentes de "Tetraodontidae". Prog. VW Cong. Brasil. Anat. (Pelotas), p. 36.

ARBOCCO, G.

1957. Intorno all'apparato digerente dei Monacantidi (Pesci Plettognati). Boll. Zool. (Unione Zool. Ital., Torino) 23:779-783.

ARSUFFI, E.

1939. Beiträge zur vergleichenden Histologie und Histogenese der Zähne (Untersuchungen am Gebiss von Labridae, Sparidae und Gymnodontes). Z. Zellforsch. Mikrosk. Anat. (Berl.), Ser. A, 29:670-693.

ARTEDI, P.

1738. Petri Artedi sueci genera piscium. Ichthyologiae, pars III. Lugduni, 88 p.

AWATI, P. R., and D. W. BAL.

1933. Studies in Indian puffers or globe fishes: I. The endo-skeleton of Tetrodon oblongus-Bloch. J. Bombay Univ. 1(pt. V):74-95.

1934. Studies in Indian puffers or globe fishes. II. The blood vascular system of Tetrodon oblongus (Bloch). J. Bombay Univ. 2(pt. V): $58-74$
BAL, D. W.

1937. Studies in Indian puffers or globe fishes. WI. The nervous system of Tetrodon oblongus, Bloch. J. Bombay Univ. 5(pt. V):4457.

BARNARD, K. H.

1927. A monograph of the marine fishes of South Africa. Ann. S. Afr. Mus. 21:419-1065.

1935. Notes on South African marine fishes. Ann. S. Afr. Mus. 30:645-658

BARTOLINI, M

1941. Ricerche sulla dentatura di alcuni plettognati. Thalassia (Rovigno, Italy) 5:1-11.

BEAUREGARD, $\mathrm{M}$.

1893. Contribution à l'étude de Orthagoriscus truncatus (Flem.). Bull. Soc. Sci. Nat. Ouest. Fr. (Nantes) 3:229-246.

BENL, G. VON.

1957. Carinotetraodon chlupatyi nov. gen., nov. spec., ein Kugelfisch mit Kamm und Kiel. Opusc. Zool. (Munich) 5:1-4.

1959. Zur Nomenklatur siamesischer Kugelfischformen. Aquar.-u. Terrar.-z. (Stuttgart) 12:42-44.

BENL, G. VON, and P. CHLUPATY.

1957. Carinotetraodon, eine neue Kugelfischgattung. Aquar.-u. Terrar.-z. (Stuttgart) 10:227-229.

BERG, L. S

1940. Classification of fishes both Recent and fossil. Trav. Inst. Zool. Acad. Sci. URSS (Leningrad) 5:87-517.

BERRY, F. H., and W. J. BALDWIN.

1966. Triggerfishes (Balistidae) of the eastern Pacific. Proc. Calif. Acad. Sci., Ser. 4, 34:429-474.

BERRY, F. H., and L. E. VOGELE.

1961. Filefishes (Monacanthidae) of the western North Atlantic. U.S. Fish Wildl. Serv., Fish. Bull. 61:61-109.

BLAINVILLE, H. M

1818. Nouveau dictionnaire d'historie naturelle. Pla-por (Vol. 27), 586 p. Paris.

BLEEKER, P.

1852a. Bijdrage tot de kennis der Blootkakige [Gymnognathen] visschen van den Soenda-Moljkschen Archipel, met beschrijving van eenige nieuwe soorton. Verh. Batavia Genoot. Kunsten Wet. (Batavia) 24(10):1-26.

1852b. Bijdrage tot de kennis der Balistini en Ostraciones van den Indischen Archipel. Verh. Batavia Genoot. Kunsten Wet. (Batavia) $24(11): 1-38$.

1865. Atlas ichthyologique des Indes Orientales Nèêrlandaises. Vol. 5 - Baudroies, Ostracions, Gymnodontes, Balistes, p. 1-152. Amsterdam.

1866. Systema Balistidorum, Ostracionidorum, Gymnodontidorumque revisum. Ned. Tijdschr. Dierkd. (Amsterdam) 3:8-19.

BLISS, R., JR.

1872. On the osteology of the anterior vertebrae in Doras niger, with a comparison of the structure of the dorsal fin in Doras and $B a$ listes. Proc. Boston Soc. Nat. Hist. 14:3-12.

BLOCH, M. E

1786. Naturgeschichte der ausländischen Fische. Vol. 2, p. 1-160. Berlin.

BLOCH, M. E., and J. G. SCHNEIDER.

1801. Systema ichthyologiae iconibus cx illustratum. Berolini, 584 p.

BLOT, J.

1969. Studie e richerche sui giacimenti Terziari di Bolca. I. Les poissons fossiles du Monte Bolca. Mem. Mus. Civ. Stor. Nat. Verona, Mem. fuori, Ser. 2, 525 p.

BOESEMAN, $M$.

1962. Triodon macropterus versus Triodon bursarius; an attempt to establish the correct name and authorship. Zool. Meded. R. Nat. Hist. Leiden 38:77-85.

BÖHLKE, J. E., and C. C. G. CHAPLIN.

1968. Fishes of the Bahamas and adjacent tropical waters. Acad. Nat. Sci. Phila., 771 p.

BONAPARTE, C. L.

1832. Saggio d'una distribuzione metodica degli animali vertebrati a sangue freddo. $86 \mathrm{p}$. Rome.

1841a. Iconografia della fauna Italica per le quattro classi degli 
animali vertebrati. Vol. 3. Pesci. Unpaginaged text with 78 plates. Rome.

1841b. A new systematic arrangement of vertebrated animals. Trans. Linn. Soc. Lond. 18:247-304.

BONNATERRE, J.

1788. Tableau encyclopédique et methodique des trois règnes de la nature. Ichthyologie. Panckoucke, Paris, $215 \mathrm{p}$.

BORCEA, J.

1907. Observations sur la musculature branchiostégale des téléostéens. Ann. Sci. Univ. Jassy 4:202-225.

BORN, G.

1827. Bemerkungen über den Zahnbau der Fische. Z. Organ. Phys. (Eisenach) 1:182-206.

BOULENGER, G. A.

1904a. A synopsis of the suborders and families of teleostean fishes. Ann. Mag. Nat. Hist., Ser. 7., 13:161-190.

1904b. Teleostei. In Harmer, S. F., and A. E. Shipley (editors), Fishes. Vol. VII, p. 539-727. MacMillan and Co., Ltd., London.

1907. Zoology of Egypt: the fishes of the Nile. 578 p. London.

BREDER, C. M., JR., and E. CLARK.

1947. A contribution to the visceral anatomy, development, and relationships of the Plectognathi. Bull. Am. Mus. Nat. Hist. 88: 287-319.

BRIDGE, T. W

1896. The mesial fins of ganoids and teleosts. J. Linn. Soc. Lond., Zool. 25:530-602.

BRITSKI, H. A., and R. D. ANDREUCCI.

1971. Sôbre os dentes dos peixes Molidae. Prog. XXIII Reun. Anu. Soc. Brasil. Pesq. Ciênc. (Curitiba), p. 287.

BROUSSONET, P. M.

1780. Mémoire sur les différentes espèces de chiens de mer. Mem. Acad. R. Sci. (Paris), 1780:641-680.

BRÜHL, C. B.

1856. Osteologisches aus dem Pariser Pflanzengarten. Wien:A-G $+1-76+$ i-xliii.

1880. Zootomie aller Thierklassen, nach Autopsien skizzirt. Lief. 24. Wien (160 plates in toto published between 1877-1888).

1891. Balistes-Skelet. Wien (separate plate).

BURKENROAD, M. D.

1931. Notes on the sound-producing fishes of Louisiana. Copeia 1931:20-28.

CADENAT, J.

1959. Notes d'ichthyologie ouest-africaine. XXIV.-Molidae ouestafricains avec description d'une espèce nouvelle: Pseudomola lassarati de Côte d'Ivoire. Bull. Inst. Fr. Afr. Noire (Dakar), Ser. A., 21:1112-1118.

CLARK, E., and H. A. F. GOHAR.

1953. The fishes of the Red Sea: Order Plectognathi. Mar. Biol. Stn., Ghardaqa, Red Sea, Publ. 8:1-80.

CLELAND, J.

1862. On the anatomy of the short sun-fish (Orthagoriscus mola). Nat. Hist. Rev. (Lond.), New Ser., 2:170-185.

CLOTHIER, C. R.

1939. The trigger mechanism of a trigger fish (Capriscus polylepis). Calif. Fish Game 25:233-236.

COPE, E. D.

1871a. Observations on the systematic relations of the fishes. Am. Nat., 5:579-593.

1871b. [On Plectognathi and Lophobranchii]. Untitled paper. Proc. Acad. Nat. Sci. Phila., 1871:157-158.

CUNNINGHAM, J. T.

1910. On the marine fishes and invertebrates of St. Helena. Proc. Zool. Soc. Lond., 1910:86-130.

CUVIER, G.

1805. Leçons d'anatomie comparée. 5 vol. Paris. [Vol I, 518 p.;

Vol. II, 697 p.; Vol. III, 558 p.; Vol. IV, 539 p.; Vol. V, 368 p.]

1817. Le règne animal. Vol. II, $532 \mathrm{p}$. Paris.

1818. Sur les Diodons, vulgairement orbes-épineux. Mem. Mus. Natl. Hist. Nat. 4:121-138.

1829. Le règne animal. Ed. 2., Vol. II, $4 \mathrm{C6}$ p. Paris.

DAMES, $W$.

1883. Über eine tertiäre Wirbelthierfauna von der westlichen Insel

des Birket-el-Qurūn im Fajum (Aegypten). Sitzungsber. K.
Preus. Akad. Wiss. Berl., Phys.-Math. Cl., 1883, Erst. Halb., p. 129-153.

DANIL'CHENKO, P. G.

1960. Bony fishes of the Maikop deposits of the Caucasus. Izdatel'stro Akad. Nauk. SSSR, Moskva. [Jerusalem, Israel Prog. Sci. Transl., 1967, 247 p.]

DARESTE, C.

1849. Observations sur l'ostéologie du poisson appelé Triodon macroptère. Ann. Sci. Nat. (Paris), Zool., Ser. 3, 12:68-83.

1850. Recherches sur la classification des poissons de l'ordre des Plectognathes. Ann. Sci. Nat. (Paris), Zool., Ser. 3, 14:105133.

1872a. Sur les affinités naturelles des poissons de la famille des Balistes. C. R. Acad. Sci. (Paris) 74:1527-1530.

$1872 \mathrm{~b}$. On the natural affinities of the Balistidae. Ann. Mag. Nat. Hist., Ser. 4, 10:68-70.

1872c. Etudes sur les types ostéologiques des poissons osseux. C. R. Acad. Sci. (Paris) 75:942-946, 1018-1021, 1086-1089, 1172$1175,1253-1256$.

DE BEAUFORT, L. F

1926. On a collection of marine fishes from the Miocene of South Celebes. Jaarb. Mijwezen Ned.-Indie (Batavia), Verh., 1925: 115-166.

1962. The fishes of the Indo-Australian Archipelago. Vol. XI, 481 p. Leiden.

DEINSE, A. B. VAN.

1953. Fishes in upper Miocene and lower Pleistocene deposits in the Netherlands. Med. Geol. Sticht. (Geol. Dienst Haarlem), New Ser., 7:5-11.

DEKKERS, W. J.

1975. Review of the Asiatic freshwater puffers of the genus Tetraodon Linnaeus, 1758 (Pisces, Tetraodontiformes, Tetraodontidae). Bijdr. Dierkd. 45:87-142.

D'ERASMO, G.

1946. L'ittiofauna Cretacea dei dintorni di Comeno nel Carso triestino. Atti R. Accad. Sci. Fis. Math. (Soc. R. Napoli), Ser. 3, 2:1136.

DUMERIL, A. H.

1855. Note sur un travail inédit de Bibron relatif aux poissons Plectognathes Gymnodontes (Diodons et Tetrodons). Rev. Mag. Zool. Pure Appl., Ser. 2, 7:274-282

DUMERIL, A. M.

1806. Zoologie analytique, ou méthode naturelle de classification des animaux. 344 p. Paris.

1856. Ichthyologie analytique au essai d'une classification naturelle des poissons, á l'aide de tableaux synoptiques. 511 p. Paris.

DUNKER, G., and E. MOHR.

1931. Die Fische der Südsee - Expedition der hamburgischen wissenschaftlichen Stiftung 1908-1909. 3 Teil. Mitt. Zool. Staat. Zool. Mus. (Hamburg) 44:57-84.

EBINA, $\mathrm{K}$

1932. Sexual dimorphism in a file-fish, Cantherinus modestus (Günther). J. Imp. Fish. Inst. 27:15-18.

EIGENMANN, C. H.

1885. A review of the genera and species of Diodontidae found in American waters. Ann. New York Acad. Sci. 3:297-31i.

FISH, M. P.

1954. The character and significance of sound production among fishes of the western North Atlantic. Bull. Bingham Oceanogr. Coll. 14(3):1-109.

FISH, M. P., A. S. KELSEY, JR., and W. H. MOWBRAY.

1952. Studies on the production of underwater sound by North Atlantic coastal fishes. J. Mar. Res. 11:180-193.

FITZINGER, L. J.

1873. Versuch einer natürlichen Classification der Fische. Sitzungsber. Akad. Wiss. (Wien), Math.-Naturwiss. Kl. 67:5-58.

FORD, E.

1937. Vertebral variation in teleostean fishes. J. Mar. Biol. Assoc. U.K. 22:1-60.

FRASER-BRUNNER, A.

1935a. Notes on the plectognath fishes. I. A synopsis of the genera of the family Balistidae. Ann. Mag. Nat. Hist., Ser. 10, 15:658663. 
1935b. Notes on the plectognath fishes. II. A synopsis of the genera of the family Ostraciontidae. Ann. Mag. Nat. Hist., Ser. 10, 16: 313-320.

1940a. Notes on the plectognath fishes. III. On Monacanthus setifer Bennett and related species, with a key to the genus Stephanolepis and descriptions of four new species. Ann. Mag. Nat. Hist., Ser. 11, 5:518-535.

1940b. Notes on the plectognath fishes. IV. Sexual dimorphism in the family Ostraciontidae. Ann. Mag. Nat. Hist., Ser. 11, 6:390392.

1940c. The fishes of the genus Pseudomonacanthus, with descriptions of two new species. Bull. Raffles Mus. 16:62-67.

1941a. Notes on the plectognath fishes. V. The families of triacanthiform fishes, with a synopsis of the genera and a description of a new species. Ann. Mag. Nat. Hist., Ser. 11, 7:420-430.

$1941 \mathrm{~b}$. Notes on the plectognath fishes. VI. A synopsis of the genera of the family Aluteridae, and descriptions of seven new species. Ann. Mag. Nat. Hist., Ser. 11, 8:176-199.

1941c. Notes on the plectognath fishes. VII. The Aracanidae, a distinct family of ostraciontid fishes, with descriptions of two new species. Ann. Mag. Nat. Hist., Ser. 11, 8:306-313.

1943. Notes on the plectognath fishes. VIII. The classification of the suborder Tetraodontoidea, with a synopsis of the genera. Ann. Mag. Nat. Hist., Ser. 11, 10:1-18.

1950. Studies in plectognath fishes from the "Dana"-Expeditions. 1. An interesting new genus of triacanthodid fishes from the Celebes Sea. Dana-Rep. Carlsberg. Found. 35:1-8.

1951. The ocean sunfishes (family Molidae). Bull. Br. Mus. (Nat. Hist.) Zool. 1:89-121.

FROST, C. A.

1930. A comparative study of the otoliths of neopterygian fishes (concluded). Ann. Mag. Nat. Hist., Ser. 10, 5:621-627.

GARMAN, S.

1891. On Balistes vetula Linné. Bull. Essex Inst. 22:53-55.

GARNAUD, J.

1956. Note sur le squelette céphalique de Balistes capriscus L. Bull. Inst. Océanogr. 1081:1-12.

GEOFFROY SAINT-HILAIRE, 1.

1827. Histoire naturelle des poissons du Nil. In Description de l'Egypte, ... Histoire Naturelle (Paris), 1:141-579.

GHIGl, A.

1905a. Ricerche sulla dentatura dei teleostei. Arch. Zool. (Unione Zool. Ital., Napoli) 2:439-462.

1905b. Dimostrazione de preparati sullo sviluppo dei denti del Balistes capriscus. C. R. VI Cong. Int. Zool. (Berne), p. 327.

1921. Sulla dentatura di alcumi plettognati (Ostracion e Tetrodon). Rend. Sess. Accad. Sci. lst. Bologna, Cl. Sci. Fish., New Ser., 15: 138-140.

GILL, T.

1872. Arrangement of the families of fishes, or classes Pisces, Marsipobranchii, and Leptocardii. Smithson. Misc. Collect. 11(247): $1-49$.

1885. Synopsis of the plectognath fishes. Proc. U.S. Natl. Mus. 7:411-427.

1888a. Some extinct scleroderms. Am. Nat. 22:446-448.

1888b. The extinct scleroderms. Am. Nat. 22:828-830.

1889. Note on the genus Spheroides. Proc. U.S. Natl. Mus. 11: 607-608.

1892a. Notes on the Tetraodontoidea. Proc. U.S. Natl. Mus. 14: $705-720$.

1892b. Note on the genus Chonerhinus or Xenopterus. Proc. U.S. Natl. Mus. 14:697-699.

1897. The distinctive characters of the Molinae and Ranzaniinae. Science, New Ser., 6:966-967.

GMELIN, J. F.

1788. Caroli a Linné ... Systema Naturae. Tomus l, pars III, p. 1033-1516. Leipzig.

GOELDI, E. A

1884. Kopfskelett und Schultergürtel von Loricaria cataphracta, Balistes capriscus und Accipenser ruthenus. Vergleichend-anatomische und entwicklungs-geschichtliche Studien zur Deckknockenfrage. Jenaische Z. Naturwiss., New Ser. 10, 17:401. 447.
GOEPPERT, E.

1895. Untersuchungen zur Morphologie der Fischrippen. Morphol. Jahrb. (Leipzig) 23:145-217.

GOETTE, A

1879. Beiträge zur vergleichenden Morphologie des Skeletsystems der Wirbelthiere. II. Die Wirbelsäule und ihre Anhänge. 5. Die Teleostier. Arch. Mikrosk. Anat. (Bonn) 16:117-142.

GOODE, G. B.

1880. A study of the trunk-fishes (Ostraciontidae), with notes upon the American species of the family. Proc. U.S. Natl. Mus. 2:261 283.

GOODRICH, E. S.

1909. Part IX. Vertebrata Craniata. (First fascicle: Cyclostomes and fishes). In Lankester, R. (editor), A treatise on zoology, p. 1-518. Adam and Charles Black, London.

1930. Studies on the structure and development of vertebrates. 837 p. London.

GOODSIR, J.

1841. On certain peculiarities in the structure of the short sun-fish (Orthagoriscus mola). Edinburgh New Philos. J. 30:188-194.

GOSLINE, W. A

1961. The perciform caudal skeleton. Copeia 1961:265-270.

1968. The suborders of perciform fishes. Proc. U.S. Natl. Mus. 124(3647): 1-77.

1971. Functional morphology and classification of teleostean fishes Univ. Press. Hawaii, Honolulu, 208 p.

GOUAN, A

1770. Historia piscium (Histoire des poissons). Amand König, Strasbourg, $252 \mathrm{p}$.

GREEN, E. H.

1901. The chemical composition of the sub-dermal connective tissue of the ocean sunfish. Bull. U.S. Fish Comm. 19(for 1899):321324

GREEN, E. H., and R. W. TOWER.

1902. The organic constituents of the scales of fish. Bull. U.S. Fish Comm. 21(for 1901):97-102.

GREENWOOD, P. H., D. E. ROSEN, S. H. WEITZMAN, and G. S. MYERS.

1966. Phyletic studies of teleostean fishes, with a provisional classification of living forms. Bull. Am. Mus. Nat. Hist. 131:339-454.

GREGORY, W. K.

1907. The orders of teleostomous fishes. A preliminary review of the broader features of their evolution and taxonomy. Ann. New York Acad. Sci. 17:437-508.

1933. Fish skulls: A study of the evolution of natural mechanisms Trans. Am. Philos. Soc. 23:75-481.

GREGORY, W. K., and H. C. RAVEN.

1934. Notes on the anatomy and relationships of the ocean sunfish (Mola mola). Copeia 1934:145-151.

GRENHOLM, $\AA$

1923. Studien über die Flossenmuskulatur der Teleostier. Ph.D. thesis, Univ. Uppsala, 296 p.

GRIEB, A. W.

1935. Besonderheiten im Bau des Pharyngealapparates bei Fischen aus Ordnung Plectognathi. [In Russ., with Ger. summ.] Tr. Biol. Inst. Peterhof (Trav. Inst. Geol. Peterhof) 13-14:88-95.

GRONOVIUS, L. T.

1754. Museum ichthyologicum, .... Vol. I, 70 p. Lugduni.

1763. Zoophylacii Gronoviani .... 136 p. Lugduni.

GUDGER, E. W.

1935. Some undescribed young of the pointed-tailed ocean sunfish, Masturus lanceolatus. Copeia 1935:35-38.

1936. From atom to colossus. Growth of the pointed-tailed ocean sunfish from one-tenth inch to ten feet - an increase of $60,000,000$ times its original weight. Nat. Hist. 38:26-30.

1937a. The natural history and geographical distribution of the pointed-tailed ocean sunfish (Masturus lanceolatus), with notes on the shape of the tail. Proc. Zool. Soc. London, Ser. A, p. 353 396.

1937b. The structure and development of the pointed tail of the ocean sunfish, Masturus lanceolatus. Ann. Mag. Nat. Hist., Ser. $10,19: 1-46$

1939. Three six-inch pointed-tailed ocean sunfish, Masturus lance- 
olatus, the largest post-larva on record. J. Elisha Mitchell Sci. Soc. 55:305-313.

GUDGER, E. W., and S. M. MacDONALD.

1935. The rarest of the ocean sunfishes. Sci. Mon. (New York) 41:396-408.

GUNTHER, A.

1870. Catalogue of the fishes in the British Museum. Vol. 8, 549 p. London.

1880. An introduction to the study of fishes. 720 p. Edinburgh.

HAINES, R. W.

1937. The posterior end of Meckel's cartilage and related ossifications in bony fishes. Q. J. Microsc. Sci. (Lond.), New Ser., 80:138.

HARTING, P.

1865. Notices zoologiques, anatomiques et histiologiques, sur l'. Orthagoriscus ozodura; suivies de considérations sur l'ostegénèse des téléostiens en général. Verh. K. Akad. Wet. (Amsterdam) $11(2): 1-48$

HEER, 0 .

1865. Die Urwelt der Schweiz. 622 p. Zurich.

1876. The primaeval world of Switzerland. Vol. 1,393 p. London

HERTWIG, $\mathrm{O}$.

1881. Uber das Hautskelet der Fische. Dritte Abtheilung. Morphol. Jahrb. (Leipzig) 7:1-42.

HILGENDORF, F. M.

1886. Ueber Schliffen sogenannter Zusammengesetzter Fischzähne. Sitzungsber. Gesamten Naturforscher. Freunde Berl., 1886:8794.

1893. Ueber die Bezahnung der Gattung Mola (Orthagoriscus). Sitzungsber. Gesamten Naturforscher. Freunde Berl., 1893:3-4.

HOLLARD, $\mathrm{H}$

1853. Monographie de la famille des Balistides. Suite 1. Introduction et première partie. Ann. Sci. Nat. (Paris), Zool., Ser. 3, 20 71-114.

1854a. Monographie de la famille des Balistides. Suite 2. Deuxième partie. Ann. Sci. Nat. (Paris), Zool., Ser. 4, 1:39-72, 303-339.

1854b. Monographie de la famille des Balistides. Suite 3. Ann. Sci. Nat. (Paris), Zool., Ser. 4, 2:321-366.

1855. Monographie de la famille des Balistides. Suite 4. Ann. Sci. Nat. (Paris), Zool., Ser. 4, 4:5-27.

1857a. Monographie de la famille des Ostracionides. Ann. Sci. Nat. (Paris), Zool., Ser. 4, 7:121-170.

1857b. Etudes sur les Gymnodontes et en particulier sur leur ostéologie et sur les indications qu'elle peut fournir pour leur classification. Ann. Sci. Nat. (Paris), Zool., Ser. 4, 8:275-328.

1860. Mémoire sur le squelette des poissons Plectognathes, étudié au point de vue des caractères qu'il peut fournir pour la classification. Ann. Sci. Nat. (Paris), Zool., Ser. 4, 13:4-46.

HOLMGREN, N., and E. STENSIÖ.

1936. Kranium and Visceralskelett der Akranier, Cyclostomen und Fische. In Bolk, L., E. Göppert, E. Kallius, and W. Lubosch (editors), Handbuch der vergleichenden Anatomie der Wirbeltiere. Vol. 4, p. 233-500. Berlin.

HORA, S. L.

1924. Notes on fishes in the Indian Museum. VII. On a new genus of "globe-fishes" (Fam. Tetraodontidae). Rec. Indian Mus. 26: 579-582.

1925. Notes on fishes in the Indian Museum. XIV. On a new species of the genus Kanduka Hora. Rec. Indian Mus. 27:468-469.

HORSHELMANN, C.

1866. Ein Beitrag zur Anatomie der Zunge der Fische. Ph.D. thesis, Univ. Dorpat, 41 p.

HUBBS, C. L.

1919. A comparative study of the bones forming the opercular series of fishes. J. Morphol. 33:61-71.

INGER, R. F.

1953. A new fish from north Borneo, genus Tetraodon. Fieldiana, Zool. 34:149-152.

ISOKAWA, S.

1955. Morphological studies of teeth of fishes. IV. Teeth of filefishes. Zool. Mag. (Tokyo) 64:194-197.

IWAI, $\mathrm{T}$.

1964. A comparative study of the taste buds in gill rakers and gill arches of teleostean fishes. Bull. Misaki Mar. Biol. Inst., Kyoto Univ. 7:19-34.

JACOBS, W.

1935. Ueber laut-erzeugung bei Fischen. Natur Volk 65:155-166.

JENYNS, L.

1842. The zoology of the voyage of H.M.S. Beagle. Part IV. Fish. 172 p. London.

JORDAN, D. S.

1905. A guide to the study of fishes. 2 vols. Henry Holt and Co., New York. [Vol. 1, 624 p.; Vol. 2, 599 p.]

1923. A classification of fishes, including families and genera as far as known. Stanford Univ. Publ., Univ. Ser., Biol. Sci. 3:77243.

JORDAN, D. S., and C. L. EDWARDS.

1887. A review of the American species of Tetraodontidae. Proc. U.S. Natl. Mus. 9:230-247.

JORDAN, D. S., and B. W. EVERMANN

1898. The fishes of North and Middle America. Part II. Bull. U.S. Natl. Mus. 47:1241-2183.

JORDAN, D. S., and H. W. FOWLER.

1903. A review of the trigger-fishes, file-fishes, and trunk-fishes of Japan. Proc. U.S. Natl. Mus. 25:251-286.

JORDAN, D. S., and J. O. SNYDER.

1901. A review of the gymnodont fishes of Japan. Proc. U.S. Natl. Mus. 24:229-264.

KASCHKAROFF, D. N.

1914a. Materialien zur vergleichenden Morphologie der Fische. Vergleichendes Studium der Organisation von Plectognathi. Bull. Soc. Imp. Nat. (Moscow), New Ser., 27:263-370.

1914b. Zur Kenntnis des feineren Baues und der Entwickelung des Knochens bei Teleostiern. I. Die Knochenentwickelung bei Orthagoriscus mola. Anat. Anz. 47:113-138.

1916. La structure et le développement de l'os d'Orthagoriscus mola. Zool. Zh. (Rev. Zool. Russe, Moscow) 1:136-138.

1925. Materials to the knowledge of bone structure in fishes. [In Russ.] Bull. Soc. Nat. (Moscow), New Ser., 34:207-251.

KAUP, J. J

1855. Uebersicht über die Species einiger Familien der Sclerodermen. Arch. Naturgesch. (Berl.) 21:215-233.

KLAUSEWITZ, W

1957a. Tetraodon somphongsi n. sp., ein weiterer neuer Kugelfisch aus Thailand (Pisces, Tetraodontidae). Senckenb. Biol. 38:205208

1957b. Eine neue Kugelfisch-Art aus Siam: Tetraodon somphongsi. Aquar.-u. Terrar.-z. (Stuttgart) 10:115-116.

1964. Uber den Maskenkugelfisch, Arothron diadematus. Aquar.u. Terrar.-z. (Stuttgart) 17:333-334.

KLEIN, E. E

1872. Beiträge zur Osteologie des Genus Balistes Cuv. (Sclerodermi). Jahresh. Ver. Vaterl. Naturkd. Württemberg 28:262-300.

1881. Beiträge zur Osteologie der Fische. Jahresh. Ver. Vaterl. Naturkd. Württemberg 37:325-360.

1884. Beiträge zur Bildung des Schädels der Knochenfishe. I. Jahresh. Ver. Vaterl. Naturkd. Württemberg 40:129-257.

1885. Beiträge zur Bildung des Schädels der Knochenfishe. II. Jahresh. Ver. Vaterl. Naturkd. Württemberg 41:107-261.

1886. Beiträge zur Bildung des Schädels der Knochenfishe. III. Jahresh. Ver. Vaterl. Naturkd. Württemberg 42:205-300.

KLEIN, J. T

1742. Historiae piscium naturalis. Missus tertius. 48 p. Gedani. KOLLIKER, R. A

1859. On the different types in the microscopic structure of the skeleton of osseous fishes. Ann. Mag. Nat. Hist., Ser. 3, 4:6777.

1860. Ueber die Knochen von Orthagoriscus. Sitzungber. Phys.Med. Ges. (Würtzburg), 1859:38.

KURONUMA, K.

1943. Osteological study on Japanese fish. I. Comparative osteology, especially of cranial characters, in tetraodontid genera Liosaccus, Lagocephalus and Sphoeroides. J. Sigen Kagaku Kenkyusyo (Res. Inst. Nat. Resour., Tokyo) 1:119-130

LACEPEDE, B. G. E.

1798-1803. Histoire naturelle des poissons. 5 vols. Paris. [Vol. 
I (1798), 532 p.; Vol. II (1800), 632 p.; Vol. III (1802), 558 p.; Vol. IV (1802), 728 p.; Vol. V (1803), 803 p.]

LATREILLE, P. A.

1825. Familles naturelles du règne animal, exposées succinctement et dans un ordre analytique, avec l'indication de leurs genres. 570 p. Paris.

LE DANOIS, Y.

1954. Sur le dimorphisme sexuel des poissons de la famille des Diodontides. C. R. Acad. Sci. (Paris) 238:2354-2356.

1955. Sur le remaniement du sous-ordre des poissons Plectognaths et la définition d'un nouveau sous-ordre: les Orbiculates. C. R. Acad. Sci. (Paris) 240:1933-1934.

1956. A propos du système muco-sensoriel des poissons Orbiculates. C. R. Acad. Sci. (Paris) 242:684-686.

1959. Etude osteoologique, myologique et systématique des poissons du sous-ordre des Orbiculates. Ann. Inst. Océanog. 36:1-273.

1961a. Remarques sur les poissons Orbiculates du sous-ordre des Ostracioniformes. Mẻm. Mus. Natl. Hist. Nat. (Paris), New Ser. (A, zool.), 19:207-338.

1961b. Transitions morphologiques et ostéologiques entre les espèces du genre Dichotomycterus (Tetraodontidae). Bull. Soc. Zool. Fr. 86:694-700.

LEIS, J. M.

1977. Development of the eggs and larvae of the slender mola, Ranzania laevis (Pisces, Molidae). Bull. Mar. Sci. 27:448-466.

1978. Systematics and zoogeography of the porcupinefishes (Diodon, Diodontidae, Tetraodontiformes), with comments on egg and larval development. Fish. Bull., U.S. 76:535-567.

LERICHE, $M$.

1905. Les poissons Éocènes de la Belgique. Mém. Mus. R. Hist. Nat. Belg. 3:49-228.

1906. Contribution a l'étude des poissons fossiles du nord de la France et des regions voisines. Mém. Soc. Géol. Nord (Lille) 5:1-430.

1907. Revision de la faune ichthyologique des terrains néogènes du

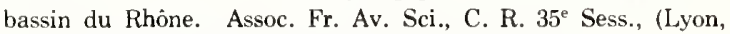
Atti Quarta Riun. Sci. Ital., Padova, 1842:244-245.

1919. Sur des poissons fossiles de la région côtière du Congo et sur la présence de l'Eocène dans cette région. C. R. Hebd. Séanc. Acad. Sci. (Paris) 169:479-481.

1920. Note préliminaire sur des poissons nouveaux du Paléocène et de l'Eocène de la région côtière du Congo. Rev. Zool. Afr. Suppl. Bot. (Brussels) 8:80-86.

1926. Les poissons nèogènes de la Belgique. Mém. Mus. R. Hist. Nat. Belg. 32:365-472.

LEYDIG, F.

1857. Lehrbuch der Histologie des Menschen und der Thiere. 551 p. Frankfurt.

LINNAEUS, C.

1758. Systema naturae .... Editio Decima, Tomus I, 823 p. Holmiae.

1766. Systema naturae ... . Editio Duodecima, Tomus I, 1327 p. Holmiae.

MASSALONGO, A. B.

1857. Vorlaüfige Nachricht über die neueren paläontologischen Entdeckungen am Monte Bolca. Neues Jahrb. Miner., Geogr., Geol. Petrefakten-Kunde (Stuttgart), 1857:775-778.

MAYER, F. J. C.

1864. Ueber den Bau des Gehirns der Fische in Beziehung aug eine daraug Gegründete eintheilung dieser Thierklasse. Nov. Act. Acad. Caes. Leopold.-Carol. German. Nat. Curiosorum (Verh. K. Leopold.-Carol. Dtsch. Akad. Naturforsch., Dresden) 30:1-40.

McALLISTER, D. E

1968. Evolution of branchiostegals and the classification of teleostome fishes, living and fossil. Nat. Mus. Canada, Bull. 221, $239 \mathrm{p}$.

McCULLOCH, A. R., and E. R. WAITE.

1915. A revision of the genus Aracana and its allies. Trans. R. Soc. S. Aust. 39:477-493.

MEEK, A.

1904. Notes on the auditory organ and the orbit of Orthagoriscus mola. Anat. Anz. 25:217-219.
MÖBIUS, K. A.

1889. Balistes aculeatus, ein trommelnder Fisch. Sitzungsber.

[K. Preuss.] Akad. Wiss. Berl., Phys.-Math. Kl., 1889, Erst. Halb., p. 999-10006.

MOHR, E.

1928. Zur Mechanik der vorderen Rückenstacheln bei Balistes und Zeus. Zool. Anz. 75:49-53.

MONOD, T.

1950. Sur trois dispositifs de "verrouillage" osseux chez des poissons. C. R. Prem. Conf. Int. Afr. Ouest, Inst. Fr. Aft. Noire (Dakar) 1:211-215.

1959a. Les nageoires ventrales du Balistes forcipatus Gmelin 1789. Bull. Inst. Fr. Afr. Noire (Dakar), Ser. A, 21:695-709.

1959b. Notes sur l'épine latéro-caudale et la queue de l'Acanthurus monroviae. Bull. Inst. Fr. Afr. Noire (Dakar), Ser. A, 21:710734.

1959c. Verrouillage osseux a trois positions chez Triacanthus brevirostris Temminck et Schlegel (Poissons, Balistiformes). Bull. Mus. Natl. Hist. Nat. (Paris), Ser. 2, 30:498-501.

1960. Sur le systeme de "verrouillage" de la première épine dorsale des Balistidae. Proc. XV Int. Cong. Zool., 1958:409-412.

1968. Le complexe urophore des poissons téléostéens. Mem. Inst. Fond. Afr. Noire 81:1-705.

MOULTON, J. M

1958. The acoustical behavior of some fishes in the Bimini area. Biol. Bull. (Woods Hole) 114:357-374.

MUULLER, $\mathrm{H}$

1844. Ueber den Bau und die Grenzen der Ganoiden und über das natürliche System der Fische. Abh. Akad. Wiss. (Berl.), 1844: 117-216.

MYERS, G. S.

1934. Reports on the collections obtained by the first JohnsonSmithsonian deep-sea expedition to the Puerto Rican Deep. Three new deep-water fishes from the West Indies. Smithson. Misc. Coll. 91(9):1-12.

1958. Trends in the evolution of teleostean fishes. Stanford Ichthyol. Bull. 7:27-30.

1970. A monograph on plectognath fishes of the Superfamily Triacanthoidea. Copeia 1970:204-205.

NARDO, G.

1842. Considerazione sopra alcune nuove famiglie de'Syngnathi e dei Plectognathi, e sui caratteri anatomici che le distinguono. Atti Quarta Riun. Sci. Ital., Padova, 1842:244-245.

NELSON, G. J.

1969. Gill arches and the phylogeny of fishes, with notes on the classification of vertebrates. Bull. Am. Mus. Nat. Hist. 141:475552.

NIEUHOF, J.

1682. Gedenkwaerdige zee en lantreize door de voornaemste lanschappen van West en Oostindien. 2 parts in $1,240 \mathrm{p}$. and $308 \mathrm{p}$. Amsterdam.

NOWIKOFF, $M$.

1910. Ueber den Bau des Knochens von Orthagoriscus mola. Anat. Anz. 37:97-106.

OKADA, Y. K.

1950. A coffer-fish with double caudal fins. Zool. Mag. (Dobutsu Zassi, Tokyo) 59:8.

OKEN, L.

1816. Lehrbuch der Naturgeschichte. 6 vols. in 3 parts: part 3, Zool., Abth. 2, Fleischthiere, 1270 p. Jena.

OWEN, R.

1839. Sur la structure microscopique et le developpement des dents des poissons Gymnodontes. Ann. Sci. Nat., Zool., Ser. 2, $12: 347-352$

1840 \& 1845 . Odontography; or, a treatise on the comparative anato. my of the teeth. 2 vols. London. [Vol 1 (1840), 655 p.; Vol 2 (1845), 37 p. +150 plates.]

1846. Lectures on the comparative anatomy and physiology of the vertebrate animals. Part I. Fishes. 308 p. London.

1853. Descriptive catalogue of the osteological series contained in the Museum of the Royal College of Surgeons of England. Vol. I: Pisces, Reptilia, Aves, Marsupialia. 350 p. London. 
1866. On the anatomy of vertebrates. Vol. I. Fishes and reptiles. Longmans, Green and Co., Lond., 650 p.

PARR, A. E.

1927. On the functions and morphology of the postclavicular apparatus in Spheroides and Chilomycterus. Zoologica 9:245-269.

PATERSON, W.

1786. An account of a new electrical fish. Philos. Trans. R. Soc. Lond. 76:382-383.

PATTERSON, C.

1964. A review of Mesozoic acanthopterygian fishes, with special reference to those of the English Chalk. Philos. Trans. R. Soc. Lond., Ser. B, Biol. Sci. 247:213-482.

PELLEGRIN, J.

1912. Sur la presence d'un banc de Ranzania truncata Retzius à la Martinique. Bull. Soc. Zool. Fr. 37:228-231.

PFLUGFELDER, 0 .

1930. Das Gebiss der Gymnodonten. Ein Beitrag zur Histogenese des Dentins. Z. Anat. Entwicklungsgesch. (Berl.) 93:543-566.

PINTO, S. Y.

1959. Estudos morphólogicos. I-Sôbre as maxilas de Colomesus psittacus (Bloch \& Schneider, 1801) Gill, 1884 (Actinopterygii, Tetrodontifôrmes, Tetrodontidae). Bol. Mus. Nac. Rio de J. Zool., New Ser., No. 203, 11 p.

POPE, E. C.

1945. A fishy monstrosity. Aust. Mus. Mag. 8:383-384.

PUTNAM, F. W.

1871. On the young of Orthagoriscus mola. Am. Nat. 4:629-633

QUEKETT, J. J.

1850-1855. Descriptive and illustrated catalogue of the histological series contained in the Museum of the Royal College of Surgeons of England. 2 vols. London. [Not seen.]

RAFINESQUE, C. S.

1810. Indice d'ittiologica Siciliana. 70 p. Messina.

RANDALL, J. E.

1964. A revision of the filefish genera Amanses and Cantherhines. Copeia 1964:331-361

RATH, J. J. G. VOM.

1859. Beitrag zur Kenntniss der fossilen Fische des Plattenberges im Canton Glarus. Z . Dtsch. Geol. Ges. (Berl.) 11:108-132.

RAUTHER, M.

1919. Notiz über das Integument von Balistes. Anat. Anz. (Jena) 52:214-218.

1927a. Integument. In Bronn's Klassen und Ordnungen des TierReichs. Vol. 6, p. 2-184. Leipzig.

1927b. Skelett. In Bronn's Klassen und Ordnungen des TierReichs. Vol. 6, p. 185-493. Leipzig.

RAVEN, H. C.

1939a. On the anatomy and evolution of the locomotor apparatus of the nipple-tailed ocean sunfish (Masturus lanceolatus). Bull. Am. Mus. Nat. Hist. 76:143-150.

1939b. Notes on the anatomy of Ranzania truncata, a plectognath fish. Am. Mus. Novit. 1038:1-7.

REGAN, C. T.

1903a. On the classification of the fishes of the suborder Plectognathi; with notes and descriptions of new species from specimens in the British Museum collection. Proc. Zool. Soc. Lond. 1902(2): 284-303.

1903b. A revision of the fishes of the genus Triacanthus. Proc. Zool. Soc. Lond. 1903(1):180-185.

1910. The caudal fin of the Elopidae and of some other teleostean fishes. Ann. Mag. Nat. Hist., Ser. 8, 5:354-358.

1929. Fishes. 14th ed. Encycl. Br. 9:305-329. London, New York.

REUVENS, C. L.

1894. Remarks on the genus Orthagoriscus. Notes Leyden Mus. 16:128-130.

RICHARDSON, J.

1844-1848. Ichthyology of the voyage of H.M.S. Erebus and Terror, under the command of Capt. Sir James Clark Ross, R. N., F.R.S Ichthyology. Edward Newman, Lond., 139 p., 60 pls. [Cited page 52, published in 1845 .]

1856. Ichthyology. 8th ed. Encycl. Br. 12:204-331. London.
RISHI, K. K.

1969. The head skeleton of Tetrodon patoca Ham. J. Asiat. Soc. (Calcutta) 9:193-197.

RISSO, A

1826. Histoire naturelle .... Vol 3, 480 p. Paris.

ROON, J. M. VAN.

1942. Some additional notes on external features and on the jaw muscles of Orthagoriscus mola (L.). Zool. Meded. (Leiden) 23: 313-317.

ROON, J. M. VAN, and J. J. TER PELKWIJK.

1939. Mechanism of the jaw and body muscles of Orthagoriscus mola L. Zool. Meded. (Leiden) 22:65-75.

ROSEN, N.

1912. Studies on the plectognaths. 1. The blood-vascular system. Ark. Zool. 7(25):1-24.

1913a. Studies on the plectognaths. 2. The air-sac, with notes on other parts of the intestines. Ark. Zool. 7(30):1-23.

1913b. Studies on the plectognaths. 3. The integument. Ark. Zool. 8(10):1-29.

1913c. Studies on the plectognaths. 4. The body-muscles. Ark. Zool. 8(18):1-14.

1916a. Studies on the plectognaths. 5. The skeleton. Ark. Zool. 10(8):1-28.

1916b. Ueber die Homologie der Fischschuppen. Ark. Zool. 10(7): 1-36.

ROSENTHAL, F.

1839. Ichthyotomische Tafeln. 2d ed. Unnumbered explanatory pages for 27 plates. Berlin. [Exact copy of 1st ed., 1812-25.]

RYDER, J. A

1886. On the origin of heterocercy and the evolution of the fins and fin-rays of fishes. Rep. U.S. Comm. Fish Fish., 1884:981-1107.

SALMON, M., H. E. WINN, and N. SORGENTE.

1968. Sound production and associated behavior in triggerfishes. Pac. Sci. 22:11-20.

SANZO, L.

1930. Ricerche biologische su materiali raccolti dal Prof. L. Sanzo nella Campagna Idrografica nel Mar Rosso della R.N. Ammiraglio Magnaghi 1923-1924. VII. Plectognathi. R. Com. Talassogr. Ital. (Venezia), Mem. 167:1-111.

SARKAR, S. P.

1960. A study of functional morphology of the head of an Incian puffer fish, Sphaeroides oblongus (Bloch). Ph.D. thesis, Univ. Leiden, $119 \mathrm{p}$.

SCHLEGEL, $\mathrm{H}$.

1850. Pisces (last part). In Siebold, P. (editor), Fauna Japonica, p. 270-324. Leiden.

SCHNEIDER, $\mathrm{H}$

1961. Berichte neuere Ergebnisse der Lautforschung bei Fischen. Naturwissenschaften $48: 513-518$.

SCOTT, E. O. G.

1969. Description of Brachaluteres wolfei, sp. nov. (Aluteridae) and first Tasmanian record of Urolophus paucimaculatus Dixon, 1969 (Urolophidae). Pap. Proc. R. Soc. Tasmania 103:35-45.

SHAW, G.

1798. The naturalists' miscellany, or colored figures of natural objects.... Vol. 9, plate 338 . London.

1804. General zoology, or systematic natural history .... Vol. 5, 463 p. London.

SHEN, S.-C, and P.-C. LIM.

1973. Ecological and morphological study on fish-fauna from the waters round Taiwan and its adjacent islands. 6. Study on the plectognath fishes. $-a$. The family of ostraciontoid fishes, Ostraciontidae. Acta Oceanogr. Taiwan, Sci. Rep. Natl. Taiwan Univ. 3:245-268.

1974a. Study on the plectognath fishes-B. The family Canthigasteridae. Bull. Inst. Zool., Acad. Sin. (Taipei) 13:15-34

1974b. Ecological and morphological study on fish-fauna from the waters around Taiwan and its adjacent islands. 9. Study on the plectognath fishes-d. The family Balistidae. Acta Oceanogr. Taiwan, Sci. Rep. Natl. Taiwan Univ. 4:191-224.

SHEN, S.-C., P.-C. LIM, and W.-H. TING.

1975. Ecological and morphological study on fish-fauna from the 
waters around Taiwan and its adjacent islands. 8 . Study on the plectognath fishes-C. The family Tetraodontidae. Acta Oceanogr. Taiwan., Sci. Rep. Natl. Taiwan Univ. 5, p. 152-178.

SHIPP, R. L.

1970. The pufferfishes (Osteichthyes: Tetraodontidae) of the Atlantic Ocean and adjacent waters. Ph.D. thesis, Florida State Univ., Tallahassee, 381 p.

1972a. Three new pufferfishes (Tetraodontidae: Sphoeroides) from the southern Caribbean. Proc. Acad. Nat. Sci. Phila. 124:129. 134 .

1972b. Competition between Atlantic and Pacific pufferfishes with possible extirpation of species along some Atlantic shorelines. Bull. Assoc. Southeastern Biol. (Phila.) 19:99.

1974. The pufferfishes (Tetraodontidae) of the Atlantic Ocean. Publ. Gulf Coast Res. Lab. Mus. (Ocean Springs, Miss.) 4:1162.

SHIPP, R. L., and R. W. YERGER.

1969a. Status, characters, and distribution of the northern and southern puffers of the genus Sphoeroides. Copeia 1969:425433.

1969b. A new puffer fish, Sphoeroides parvus, from the western Gulf of Mexico, with a key to species of Sphoeroides from the Atlantic and Gulf coasts of the United States. Proc. Biol. Soc. Wash. 82:477-488

SHUFELDT, R. W.

1917. Observations on the osteology of the porcupine fish (Diodon hystrix). Anat. Rec. 11:405-407.

1926. Observaçōes sobre certos peixes e mammiferos do Brasil e mais particularmente sobre sua osteologia. Rev. Mus. Paulista (Sāo Paulo) 14:503-561. [Followed by an English translation, p. 563-614.]

SIEBENROCK, F.

1901. Ueber die Verbindungsweise des Schultergürtels mit dem Schädel bei den Teleosteern. Ann. K. Naturhist. Hofmus. (Wiener Mus., Wein) 16:104-141.

SMITH, J. L. B.

1935. The South African species of the family Aluteridae. Rec. Albany Mus. (Grahamstown) 4:358-364.

1949a. The sea fishes of southern Africa. 550 p. Cape Town.

1949b. A new aracanid fish from South Africa. Ann. Mag. Nat. Hist., Ser. 12, 2:354-359.

SORBINI, L

1968. Contributo alla sedimentologia della "Pesciara" di Bolca. Mem. Mus. Civ. Stor. Nat. Verona 15:213-221.

SØRENSEN, W.

1883. Om oppustningssaekken hos Tetrodon og aandedraettet hos Clarias. Naturhist. Tidsskr. (Copenhagen) 13(tred. raek., trett. bind):379-414

1884. Om lydorganer hos fiske. En physiologisk og comparativ-anatomisk unders $\phi$ gelse. Ph.D. thesis, Univ. Copenhagen, 245 p.

1897. Some remarks on Dr. Thilo's memoir on "Die Umbildungen an den Gliedmassen der Fische." Morphol. Jahrb. (Leipzig) 25:170-189.

SOULE, J. D.

1969a. Tooth attachment by means of a periodontium in the trigger-fish (Balistidae). J. Morphol. (Boston) 127:1-3.

1969b. Amelogenesis in the trigger-fish Balistidae. Bull. S. Calif. Acad. Sci. 68:64-71

1970. The organic matrix in developing dental enamel and dentin studied by scanning electron microscopy. Bull. S. Calif. Acad. Sci. 69:104-111.

STANNIUS, F. H

1854. Handbuch der Anatomie der Wirbelthiere. Erstes Buch. Die Fische, 279 p. Berlin.

STARKS, E. C.

1901. Synonomy of the fish skeleton. Proc. Wash. (D.C.) Acad. Sci. 3:507-539.

1905. Some notes on the myodome of the fish cranium. Science, New Ser., 21:754-755.

1907. On the relationship of the fishes of the family Siganidae. Biol. Bull. (Woods Hole) 13:211-218.

1916. The sesamoid articular, a bone in the mandible of fishes Stanford Univ. Publ., Univ. Ser., 40 p.
1926. Bones of the ethmoid region of the fish skull. Stanford Univ. Publ., Univ. Ser., Biol. Sci. 4:139-338.

1930. The primary shoulder girdle of the bony fishes. Stanford Univ. Publ., Univ. Ser., Biol. Sci. 6:149-239.

STEENSTRUP, J., and C. LUTKEN.

1898. Spolia Atlantica. Bidrag til kundskab om klump - eller maanefiskene (Molidae). Dan. Vidensk. Selsk. Skr., 6te Raek., Naturvidensk. Math. Afd. (Copenhagen) 9:1-102.

STEPHAN, P

1900. Recherches histologiques sur la structure du tissus osseux des poissons. Bull. Biol. Sci. Fr. Belg. (Paris), Ser. 5, 2 (=33 of com. plete series):281-429.

STUDNICKKA, F. K.

1916. Ueber den knochen von Orthagoriscus. Anat. Anz. 49:151. $169,177-194$.

SUPINO, F.

1904. Contributo allo studio del tessuto osseo dell'Orthagoriscus. Atti R. Accad. Lincei, Rend., Cl. Sci. Fis., Mat. Nat., Ser. 5 13:118-121.

1905. Morfologio del cranio dei Teleostei. Parte seconda. Plectog nathi. 16 p. Rome.

1907. II crano dei pesci. 100 p. Rome.

SWAINSON, W.

1838-1839. The natural history of fishes, amphibians, and reptiles, or monocardian animals. 2 vols. London. [Vol. 1 (1838) 368 p.; Vol. 2 (1839), 448 p.]

SWINNERTON, H. H.

1902. A contribution to the morphology of the teleostean head skeleton, based upon a study of the developing skull of the threespined stickleback (Gasterosteus aculeatus). Q. J. Microsc. Sci. (Lond.), New Ser., 45:503-593.

TAVANI, G.

1955. Osservagioni su alcuni Plectognathi (Gymnodonti). Atti Soc. Toscana Sci. Nat. (Pisa), Mem., (A) 62:176-200.

THILO, O.

1879. Die Sperrgelenke an den Stacheln einiger Welse, des Stich linges und des Einhornes. Ph.D. thesis, Univ. Dorpat, 21 p.

1896a. Die Gliedmassen der Fische. Korresp. Naturforsch. Ver. Riga 39:96-106.

1896b. Die Umbildungen an den Gliedmassen der Fische. Mor phol. Jahrb. (Leipzig) 24:287-355.

1898. Ergänzungen zu meiner Abhandlung "Die Umbildungen an den Gliedmassen der Fische." Morphol. Jahrb. (Leipzig) 26:81 90.

1899a. Sperrvorrichtungen im Tierreiche. Biol. Zentralbl. 19: 504-517.

1899b. Die Entstehung der Lufts̈acke bei den Kugelfischen. Anat. Anz. 16:73-87.

1900. Ergänzungen zu meiner Abhandlung "Sperrvorrichtungen im Tierreiche." Biol. Zentralbl. 20:452-461.

1902. Maschine und Tierkörper. Verh. V Int. Zool.-Congr. (Berl.), Sekt. 2 (Experimentalzool.):501-503.

1914. Die Vorfahren der Kugelfische. Biol. Zentralbl. 34:523-545.

1920. Das Maulspitzen der Fische. Das Entstehen und Vergehen seiner Mechanik. Biol. Zentralbl. 40:216-238.

THOMPSON, D'A. W.

1888. On the auditory labyrinth of Orthagoriscus mola L. Anat. Anz. 3:93-96.

TRETJAKOFF, D. K

1924a. Die Haut der Plectognathen. I. Die Schuppenhaut von $B a$ listes. Nauchno-Issled. Kafedry (Ber. Wiss. Fors. Inst., Odessa) 1:163-171.

1924b. Die Haut der Plectognathen. II. Der Panzer des Kofferfisches. Nauchno-Issled. Kafedry (Ber. Wiss. Fors. Inst., Odes. sa) $1: 172-181$

1925. Die Mikrostruktur der Flossenstrahlen bei den Pleuronectiden und den Plectognathen. Anat. Anz. 60:182-191.

1926a. Die Haut der Plectognathen. III. Die Schuppen von Orthagoriscus. Nauchno-Issled. Kafedry (Ber. Wiss. Fors. Inst., Odessa) $2: 85-87$.

1926b. Die Haut der Plectognathen. IV. Die Dorne von Diodon und von Tetrodon. Nauchno-Issled. Kafedry (Ber. Wiss. Fors. Inst., Odessa) 2:88-99. 
1926c. Die Zähne der Plectognathen. Z. Wiss. Zool. (Leipzig) 127: 619-644.

TROIS, E. F.

1883-1884. Ricerche sulla struttura della Ranzania truncata. Atti R. Ist. Veneto Sci. Lett. Arti (Venice), Ser. 6, 2[1883]:1269-1306; Ser. 6, 2[1884]:1543-1560.

TURNER, W.

1862. On the structure and composition of the integument of the Orthagoriscus mola. Nat. Hist. Rev. (Lond.), New Ser., 2:185188.

TYLER, J. C.

1962a. Triodon bursarius, a plectognath fish connecting the Sclerodermi and Gymnodontes. Copeia 1962:793-801.

1962b. The pelvis and pelvic fin of plectognath fishes; a study in reduction. Proc. Acad. Nat. Sci. Phila. 114:207-250.

1963a. The apparent reduction in number of precaudal vertebrae in trunkfishes (Ostraciontoidea, Plectognathi). Proc. Acad. Nat. Sci. Phila. 115:153-190.

1963b. A critique of Y. Le Danois' work on the classification of the fishes of the Order Plectognathi. Copeia 1963:203-206.

1964. A diagnosis of the two species of South American puffer fishes (Tetraodontidae, Plectognathi) of the genus Colomesus. Proc. Acad. Nat. Sci. Phila. 116:119-148.

1965a. The trunkfish genus A canthostracion (Ostraciontidae, Plectognathi) in the western Atlantic: two species rather than one. Proc. Acad. Nat. Sci. Phila. 117:1-18.

1965b. A synopsis of the four species of cowfishes (A canthostracion, Plectognathi) in the Atlantic Ocean. Proc. Acad. Nat. Sci. Phila. 117:261-287.

1965c. Poisonous and worthless fishes? Frontiers (Acad. Nat. Sci. Phila.) 30:36-45.

1966. Mimicry between the plectognath fishes Canthigaster valentini (Canthigasteridae) and Paraluteres prionurus (Aluteridae). Not. Nat. (Phila.) 386:1-13.

1967. A redescription of Triodon macropterus Lesson, a phyletically important plectognath fish. Proc. K. Ned. Akad. Wet. (Amsterdam), Ser. C, 70:84-96.

1968. A monograph on plectognath fishes of the Superfamily Triacanthoidea. Monogr. Acad. Nat. Sci. Phila., Vol. 16, 364 p.

1970a. The dorsal and anal spine-locking apparatus of surgeon fishes (Acanthuridae). Proc. Calif. Acad. Sci. 38:391-409.

$1970 \mathrm{~b}$. The progressive reduction in number of elements supporting the caudal fin of fishes of the order Plectognathi. Proc. Acad. Nat. Sci. Phila. 122:1-85.

1970c. Osteological aspects of interrelationships of surgeon fish genera (Acanthuridae). Proc. Acad. Nat. Sci. Phila. 122:87124.

1970d. Abnormal fin and vertebral growth structures in plectognath fishes. Proc. Acad. Nat. Sci. Phila. 122:249-271.

1970e. An especially small, sexually dimorphic new species of filefish (Monacanthidae) from Australasian reefs. Proc. Acad. Nat. Sci. Phila. 122:273-290.

1970f. New records of triacanthoid plectognath fishes. Not. Nat. (Phila.) 435:1-7.

1973a. A new species of boxfish from the Eocene of Monte Bolca, Italy, the first unquestionable fossil record of the Ostraciontidae. Mem. Mus. Civ. Stor. Nat. Verona 2:103-127.

1973b. A new species of triacanthodid fish (Plectognathi) from the Eocene of Monte Bolca, Italy, representing a new subfamily ancestral to the Triodontidae and the other gymnodonts. Mem. Mus. Civ. Stor. Nat. Verona 2:128-156.

1974. Tetraodontiformes. 15th ed. Encycl. Br. T:162-164.

1978. Der Rotaugen-Kammkugelfisch, Carinotetraodon lorteti, aus Südostasien. Aquar.-u. Terrar.-z. (Stuttgart) 31:118-120.

VAN DOBBEN, W. H.

1935. Uber den Kiefermechanismus der Knochenfische. Arch. Neerl. Zool. 2:1-72.

VINCENT, F.

1963. Note preliminaire sur des emissions acoustiques chez Balistes capriscus L. Cent. Etud. Rech. Sci. (Biarritz) 4:307-316.

VOGT, C.

1845. Quelques observations sur les caractères qui servent à la clas- sification des poissons ganoïdes. Ann. Sci. Nat. (Paris), Zool. Ser. 3, 4:53-68.

VOLTA, G. S.

1796. Ittiolitologia veronese del Museo Bozziano. 2 parts. Verona. [Part 1:I-LII; Part 2:I-CCCXXIII.]

WAGNER, $\mathrm{R}$.

1841. Icones zootomicae. Handatlas zur vergleichenden Anatomie. 45 p. Leipzig.

1845. Elements of the comparative anatomy of the vertebrate animals; designed especially for the use of students. J. S. Redfield, Clinton Hall, New York, 264 p.

WAHLGREN, F.

1867. Nagra anteckningar om en stor klumpfish, Mola nasus (Raf.). Acta Univ. Lundensis (Lund; Lunds Univ. Árs-skr.) 4:1-18.

WELLENBERGH, P. H.

1840. Observationes anatomicae de Orthagoriscus mola. Ph.D. thesis, Univ. Lugduni Batavorum (Leiden), $32 \mathrm{p}$.

WEITZMAN, S. H.

1967. The origin of the stomiatoid fishes with comments on the classification of salmoniform fishes. Copeia 1967:507-540.

WETTSTEIN, A.

1886. Ueber die Fischfauna des Tertiaeren Glarnerschiefers. Abh. Schweiz. Paläontol. Ges. (Mem. Soc. Paléontol. Suisse, Basel) 13: 1-103.

WHITEHOUSE, R. H.

1910. The caudal fin of the Teleostomi. Proc. Zool. Soc. Lond. 1910(2):90-627.

WIEDERSHEIM, R.

1887a. Das Geruchsorgan der Tetrodonten nebst bemerkungen über die Hautmuskulatur derselben. In Fest-schrift Albert von Kölliker zur feier seines siebenzigsten Geburtstages gewidmet von seinen Schülern, p. 73-84. Leipzig.

1887b. Ueber rudimentare Fischnasen. Anat. Anz. 2:652-657.

1888. On the degeneration of the olfactory organ of certain fishes. Rep. 57th Meet. Br. Assoc. Adv. Sci., Manchester, 1887, Sect. D Biol., p. 736-738.

WILLEM, V.

1941. Le mode respiratoire de Balistes et d'Ostracion. Acad. R. Belg., Bull. Cl. Sci. (Brussels), Ser. 5, 27:288-294.

1942. Contribution a l'étude des organes respiratories chez les téléostéens Plectognathes. I ${ }^{\text {re }}$ Partie: Les Balistés. Bull. Mus. R. Hist. Nat. Belg. (Brussels) 18(35):1-24.

1944. Contribution a l'étude des organes respiratories chez les téléostéens Plectognathes. $2 e$ Partie: Les Chaetodontiformes. Bull. Mus. R. Hist. Nat. Belg. (Brussels) 20(6):1-21.

1945. Contribution a l'étude des organes respiratories chez les télèostéens Plectognathes. $3^{e}$ Partie: Les Ostracionidés. $4 e$ Partie: Le role de l'interoperculaire dans la manoeuvre respiratoire chez les teleosteens. Bull. Mus. R. Hist. Nat. Belg. (Brussels) 21(23): $1-16$.

1947. Contribution a l'ètude des organes respiratories ches les télèostėens Plectognathes. 5e Partie: Tétrodontes et Diodon. Bull. Mus. R. Hist. Nat. Belg. (Brussels) 23(17):1-17.

1949. Contribution a l'étude des organes respiratories chez les téléostéens Plectognathes. $6^{e}$ Partie: Mola. Bull. Mus. R. Hist. Nat. Belg. (Brussels) 25(24):1-4.

WILLIAMSON, W. C.

1851. Investigations into the structure and development of the scales and bones of fishes. Philos. Trans. R. Soc. Lond., 1851 (pt. Ш):643-702.

WILLUGHBY, F.

1686. Historia piscium libri quatuor, Oxford. $343 \mathrm{p}$.

WINTERBOTTOM, R.

1970. Evolution of the pelvic fin ray musculature of some triacanthoid fishes (Plectognathi). Copeia 1970:453-456.

1971. A reinterpretation of the mechanism of extension of the tetraodontid pufferfish postcleithral apparatus, with notes on the oblique eye muscles of the diodontids (Plectognathi). Not. Nat. (Phila.) 440:1-7.

1974. The familial phylogeny of the Tetraodontiformes (Acanthopterygii: Pisces) as evidenced by their comparative myology. Smithson. Contrib. Zool. 155:1-201. 
WINTHEK $i$.

1877. Fiskene- ansigt: en comparativ-anatomisk unders $\emptyset$ gelse. Tredie afsnit. Naturh. Tids. (Copenhagen), Ser. 3, 11:267-478. IIOODWARD, A. S.

1901. Catalogue of the fossil fishes in the British Museum (Natural History). Part IV. Br. Mus. Nat. Hist., 636 p.

WORTMAN, J. L.

1886. The comparative anatomy of the teeth of the Vertebrata. In Litch, W. F. (editor), The American system of dentistry, p. 351-504. Lea Brothers \& Co., Philadelphia.

ZIGNO, A. DE.

1874a. Annotazioni paleontologiche. Pesci fossili nuovi del calcare
Eoceno dei Monti Bolca e Postale. Mem. R. Ist. Veneto Sci., Lett. Arti (Venice) 18:287-301.

1874b. Catalogo ragionato dei pesci fossili del calcare Eoceno di M. Bolca et M. Postale disposti secondo il metodo dell' Agassiz modificato dal Pictet (continua). Atti R. Ist. Veneto Sci., Lett. Arti (Venice), Ser. 4, 3(Nov. 1873-Oct. 1874):1897-1929.

1887a. Due nuovi pesci fossili della famiglia dei Balistini scoperti nel terreno Eoceno del Veronese. Soc. Ital. Sci. [Soc. XL (dei quaranta)], Mem. Mat. Fis. (Venice), Ser. 3, 6:1-8.

1887b. Nuove aggiunte alla ittiofauna dell'epoca Eocena. Mem. R. Ist. Veneto Sci., Lett. Arti (Venice) 23:9-33. 


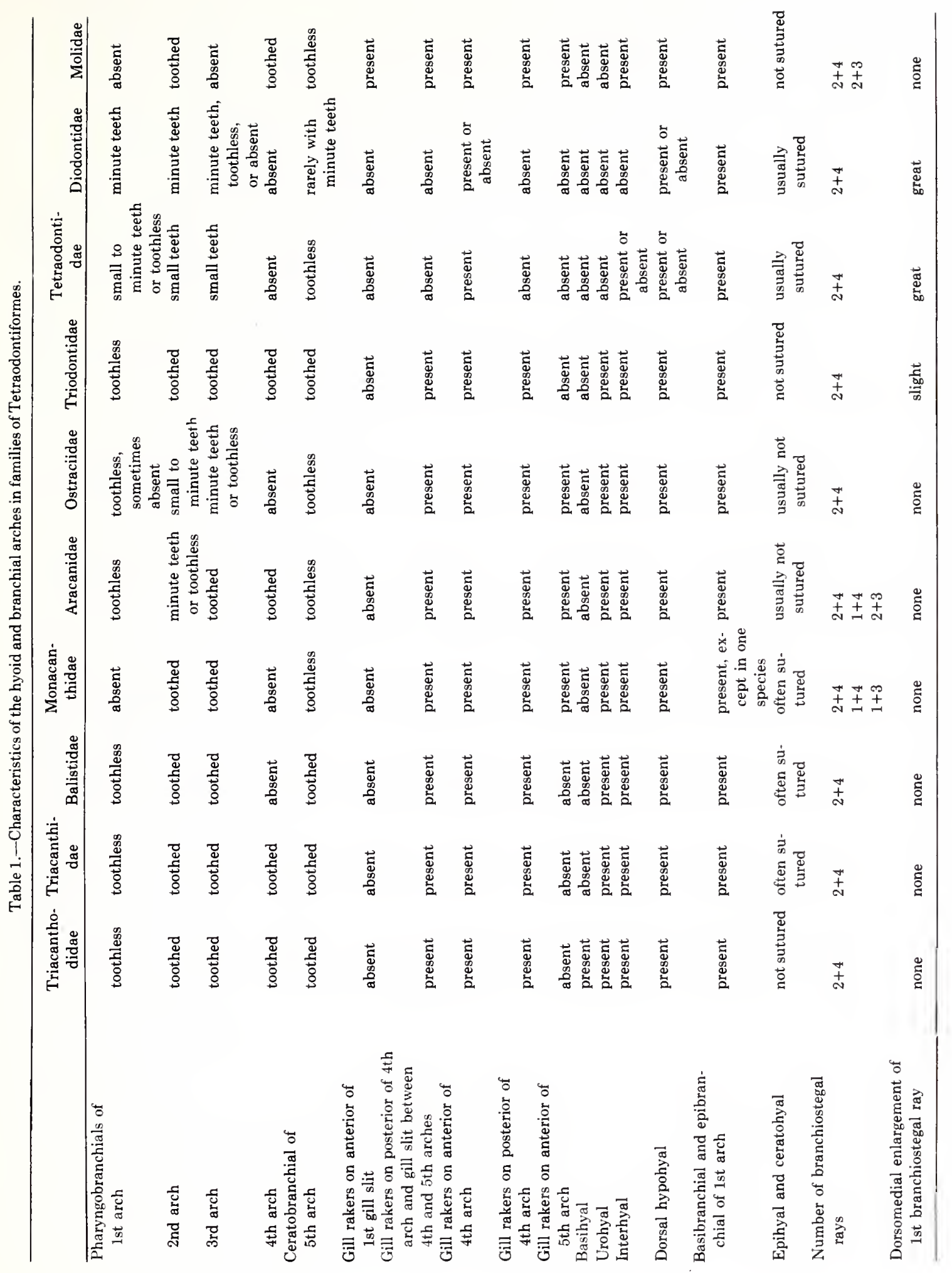


Table 2.-Total number of vertebrae and vertebral formulas of Recent plectognath fishes examined as radiographed and as cleared and stained specimens.

$\begin{array}{lllllllllllllll}16 & 17 & 18 & 19 & 20 & 21 & 22 & 23 & 24 & 25 & 26 & 27 & 28 & 29 & 30\end{array}$

Triacanthodidae

Hollardiinae

Hollardia goslinei $8+12$

Hollardia hollardi $8+12$

Hollardia meadi $8+12$

Parahollardia lineata $8+12$

Parahollardia schmidti 8+12

Triacanthodinae

Atrophacanthus japonicus $8+12$

Bathyphylax bombifrons $8+12$

Bathyphylax omen $8+12$

Halimochirurgus alcocki $8+12$

Halimochirurgus centriscoides $8+12$

Johnsonina eriomma $8+12$

Macrorhamphosodes platycheilus $8+12$

Macrorhamphosodes uradoi $8+12$

Mephisto fraserbrunneri $8+12$

Paratriacanthodes herrei $8+12$

Paratriacanthodes retrospinis $8+12$

Triacanthodes anomalus $8+12$

Triacanthodes ethiops $8+12$

Tydemania navigatoris $8+12$

\section{Triacanthidae}

Pseudotriacanthus strigilifer $8+12$

Triacanthus biaculeatus $8+12$

Triacanthus nieuhofi $8+12$

Tripodichthys angustifrons $8+12$

Tripodichthys blochi $8+12$

Tripodichthys oxycephalus $8+12$

Trixiphichthys weberi $8+12$

\section{Balistidae}

Abalistes stellatus $7+11$

Balistapus undulatus $7+11$

Balistes capriscus $7+11$

Balistes forcipatus $7+11$

Balistes polylepis $7+11$

Balistes vetula $7+11$

Balistoides conspicillum $7+11$

Balistoides viridescens $7+11$

Canthidermis maculatus $7+11$

Hemibalistes bursa $7+11$

Hemibalistes chrysopterus $7+11$

Melichthys niger $7+11$ in 3

$7+10$ in 1

Melichthys vidua $7+11$

Odonus niger $7+11$

Pseudobalistes flavimarginata $7+11$

Rhinecanthus aculeatus $7+11$

Rhinecanthus rectangulus $7+11$ in 5

$$
7+12 \text { in } 1
$$

Rhinecanthus verrucosus $7+11$

Sufflamen frenatus $7+11$

Sufflamen verres $7+11$

Xanthichthys lineopunctatus $7+11$

Xanthichthys ringens $7+11$

Monacanthidae

Acanthaluteres spilomelanurus $6+14$

Alutera heudelotii $7+13$

Alutera monoceros $7+16$

Alutera schoepfi $7+16$ in 11

$7+15$ in 1 
Table 2.-Total number of vertebrae and vertebral formulas of Recent plectognath fishes examined as radiographed and as cleared and stained specimens.-Continued.

Alutera scripta $7+14$ in 3
$7+16$ in 1

Amanses scopas $7+12$

Brachaluteres trossulus $7+13$

Brachaluteres ulvarum $7+13$

Cantherhines pardalis $7+12$

Cantherhines pullus $7+12$

Cantherhines sandwichiensis $7+12$

Cantherhines trachylepis $7+13$

Chaetoderma spinosissimus $7+13$

Laputa cingalensis $7+12$

Monacanthus chinensis $7+12$

Monacanthus ciliatus $6+13$ in 49

$$
6+14 \text { in } 1
$$

Monacanthus mylii $7+12$

Monacanthus tuckeri $6+13$

Navodon setosus $7+13$

Oxymonacanthus longirostris $8+17$ in 6

$$
8+16 \text { in } 1
$$

Paraluteres prionurus $7+13$ in 1

$$
7+14 \text { in } 1
$$

Paramonacanthus barnardi $7+12$

Paramonacanthus cryptodon $7+12$ in 3

$$
7+13 \text { in } 1
$$

Paramonacanthus curtorhynchus $7+12$

Paramonacanthus oblongus $7+12$

Pervagor melanocephalus $7+12$ in 1

$$
6+13 \text { in } 1
$$

Pervagor spilosomus $7+12$

Pervagor tomentosus $7+13$ in 4

$$
7+12 \text { in } 2
$$

Pseudaluteres nasicornis $8+18$

Psilocephalus barbatus $7+22$ in 3

$$
7+23 \text { in } 1
$$$$
8+22 \text { in } 1
$$

Rudarius ercodes $7+13$ in 17

$$
7+14 \text { in } 2
$$

Rudarius minutus $7+12$

Stephanolepis auratus $7+12$

Stephanolepis cirrhifer $7+13$ in 1

$$
7+12 \text { in } 1
$$

Stephanolepis hispidus $7+12$ in 33

$$
\begin{aligned}
& 7+13 \text { in } 1 \\
& 7+11 \text { in } 1
\end{aligned}
$$

Stephanolepis setifer $7+12$

Aracanidae

A racana aurita ( 2 fused) $9+9$

Aracana ornata (2 fused) $10+8$

Caprichthys gymnura (2 fused) $10+8$

Capropygia unistriata ( 2 fused) $10+8$

Kentrocapros aculeatus ( 2 fused) $9+9$

Strophiurichthys robustus (2 fused) $9+9$

Ostraciidae

Ostraciinae

Lactoria cornuta ( 4 fused) $9+9$

Lactoria fornasinii ( 5 fused?) $9+9$

Ostracion lentiginosum ( $2+2$ or 4 fused) $9+9$

Ostracion tuberculatus $(2+2$ fused) $9+9$

Rhynchostracion rhinorhynchus (4 fused) $9+9$

Tetrosomus concatenatus (4 fused) $9+9$

Tetrosomus gibbosus ( 4 fused) $9+9$
11

11

8

1

3

$49 \quad 1$

1

6

1

16

11

1

31

3

2

2
172

4

1

11

$\begin{array}{lll}1 & 33 & 1\end{array}$

14

2

2

1

5

4

4

1

1 
Table 2.-Total number of vertebrae and vertebral formulas of Recent plectognath fishes examined as radiographed and as cleared and stained specimens.-Continued.

$\begin{array}{lllllllllllllll}16 & 17 & 18 & 19 & 20 & 21 & 22 & 23 & 24 & 25 & 26 & 27 & 28 & 29 & 30\end{array}$

Lactophrysinae

Acanthostracion guineensis (5 fused) $9+9$

Acanthostracion notacanthus ( 5 fused) $9+9$

Acanthostracion polygonius (5 fused) $9+9$

Acanthostracion quadricornis ( 5 fused) $9+10$

Lactophrys trigonus (5 fused) $9+9$

Rhinesomus bicaudalis (5 fused) $9+9$

Rhinesomus triqueter ( 5 fused) $9+9$

Triodontidae

Triodon macropterus $9+11$

Tetraodontidae: figures followed by (A) are simplified from Abe's (1942) extensive analysis of vertebral variation in Japanese puffers

Tetraodontinae

Amblyrhynchotes honckenii $8+11$ in 5

$$
8+12 \text { in } 3
$$

Amblyrhynchotes hypselogenion $8+11$ in 5

$$
8+12 \text { in } 2
$$

$7+12$ in 1

Amblyrhynchotes piosae $8+11$

Arothron armilla $8+11$

Arothron hispidus $8+10$ in 12

$$
8+9 \text { in } 2
$$

$$
9+10 \text { in } 1
$$

Arothron immaculatus $8+10$ in 59

$8+9$ in 1

$8+11$ in 1

Arothron meleagris $8+10$ in 2

$9+10$ in 5

$9+11$ in 1

Arothron nigropunctatus $9+9$ in 6

$8+9$ in 1

$8+10$ in 1

Arothron reticulatus $8+10$ (A)

Arothron setosus $9+10$ in 6

$$
9+9 \text { in } 1
$$

$8+9$ in 1

Arothron stellatus $8+10$

Carinotetraodon lorteti $7+10$ in 2

$$
7+9 \text { in } 1
$$

Chelonodon fluviatilis $8+10$ in 38

$$
8+11 \text { in } 9
$$

$8+9$ in 4

Chelonodon patoca $8+11$ in 25

$8+10$ in 1

Chonerhinos modestus $10+16$ in 6

$10+15$ in 3

$10+17$ in 1

$9+16$ in 1

$9+17$ in 1

Colomesus asellus $8+11$ in 8

$$
\begin{aligned}
& 8+12 \text { in } 1 \\
& 8+10 \text { in } 1
\end{aligned}
$$

Colomesus psittacus $8+11$ in 5

$$
8+10 \text { in } 1
$$

Ephippion guttifer $8+12$

Fugu chrysops $9+13$ in 11

$$
9+12 \text { in } 6
$$

Fugu niphobles $8+13$ in 77

$8+12$ in 28

$8+11$ in 1$\}$

$8+14$ in 1 ) 
Table 2. - Total number of vertebrae and vertebral formulas of Recent plectognath fishes examined as radiographed and as cleared and stained specimens.-Continued.

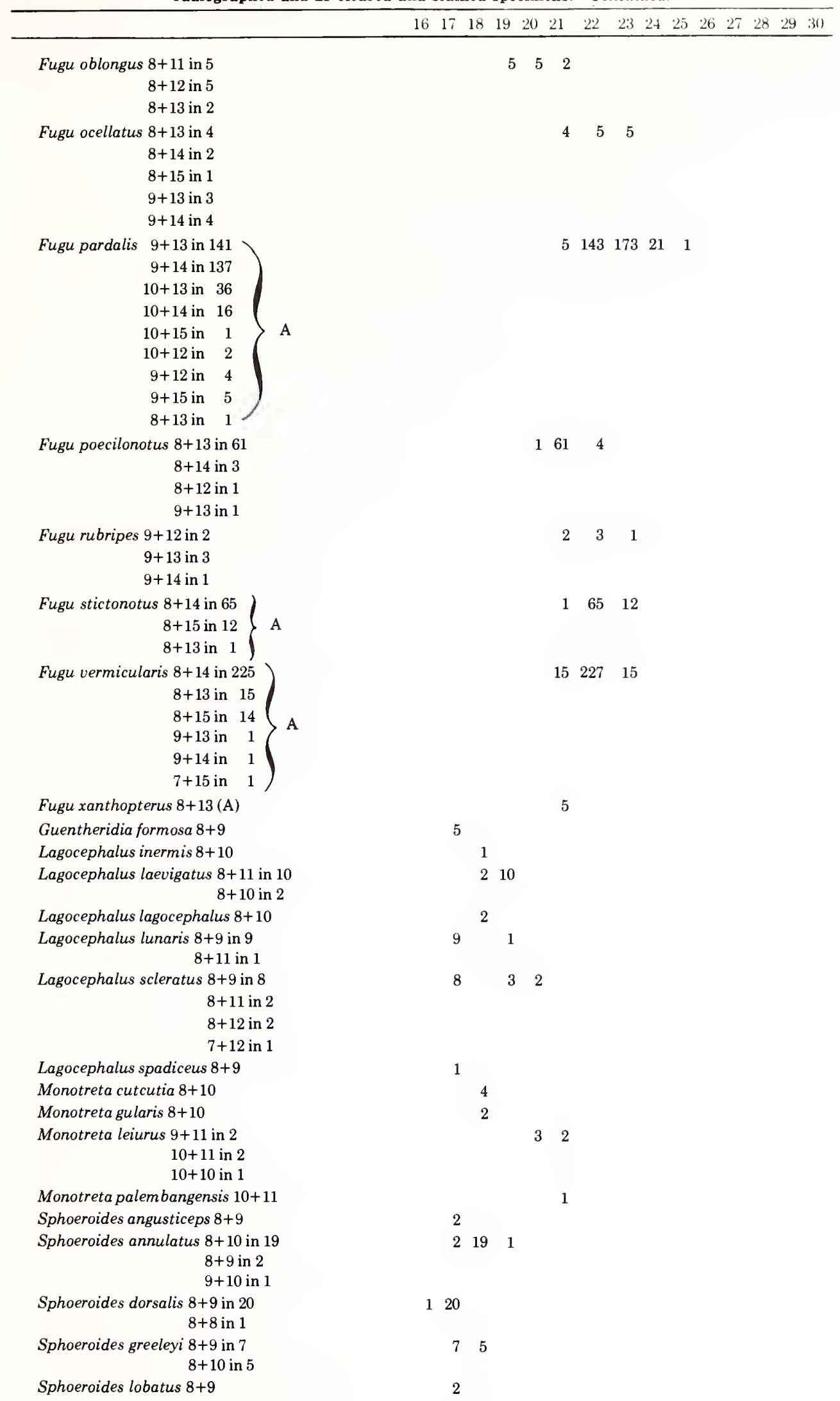


Table 2.-Total number of vertebrae and vertebral formulas of Recent plectognath fishes examined as radiographed and as cleared and stained specimens.-Continued.

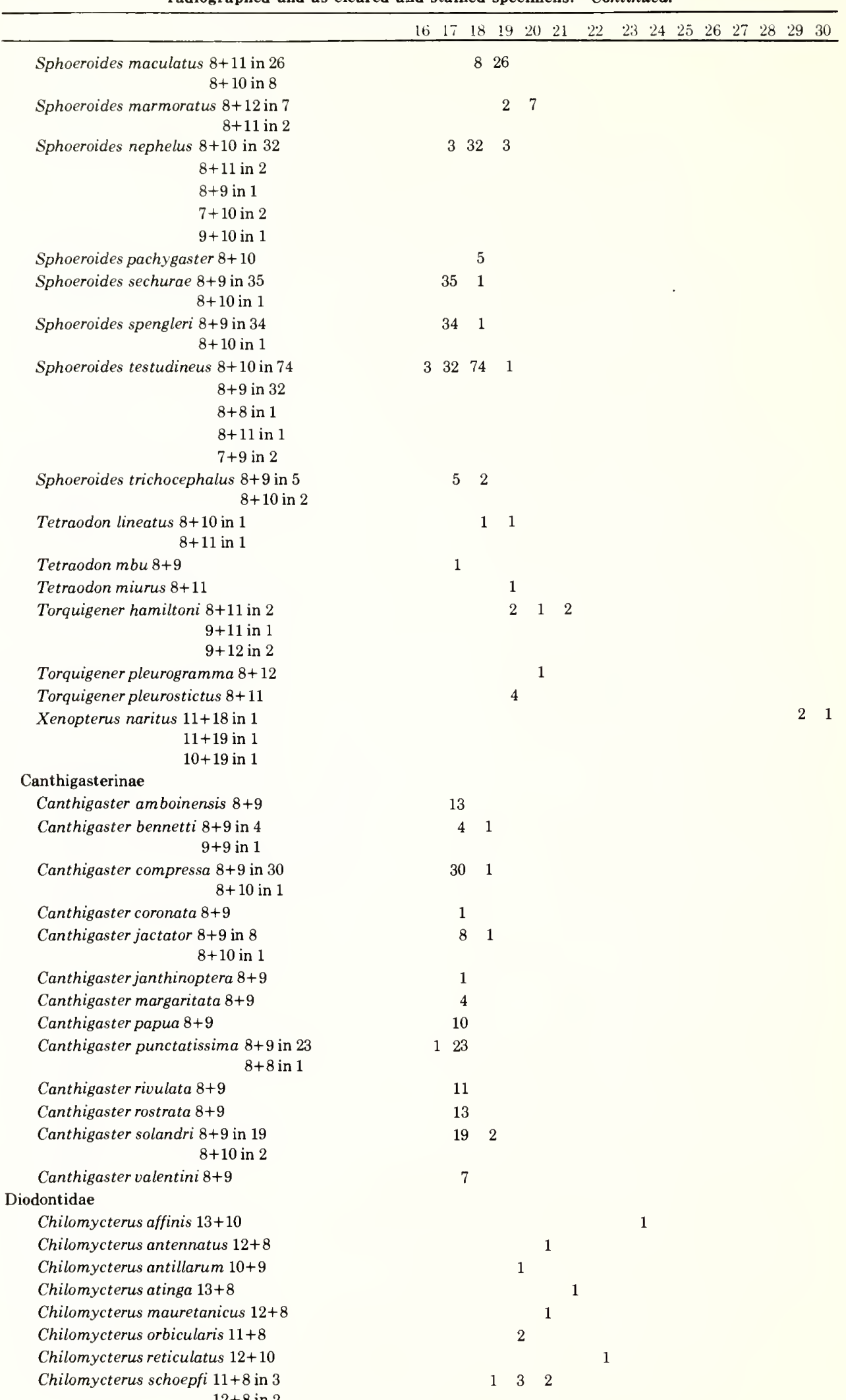


Table 2.-Total number of vertebrae and vertebral formulas of Recent plectognath fishes examined as radiographed and as cleared and stained specimens.-Continued.

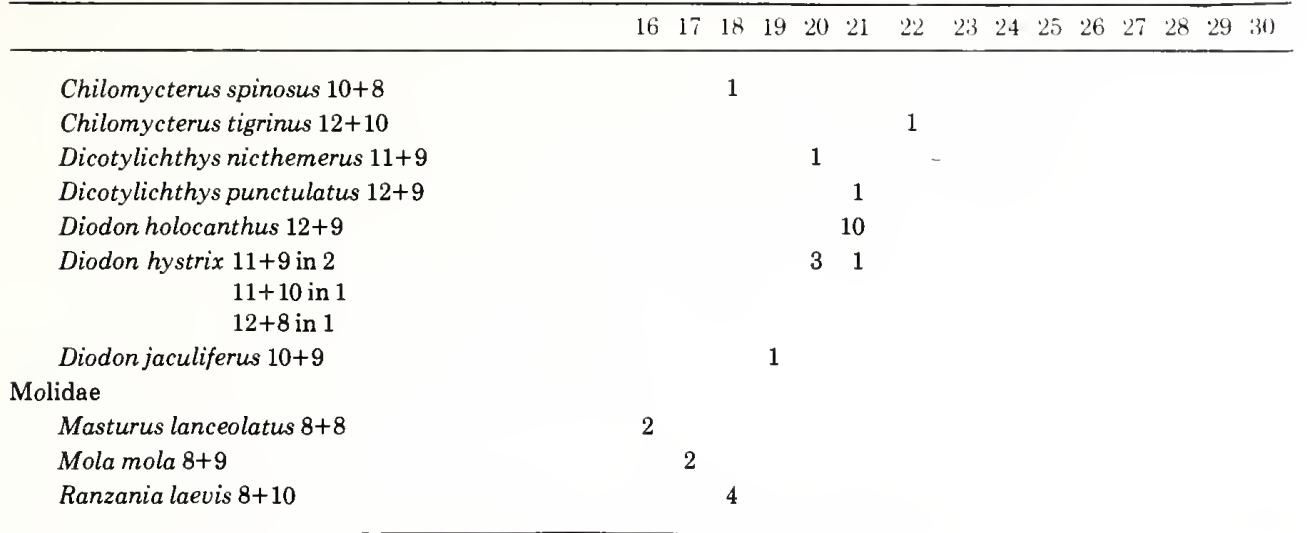

'A vertebra with bifid neural and haemal spines but centrum of normal size. 
Table 3.-Numbers of teeth in the upper and lower jaws of ostracioids.

\begin{tabular}{|c|c|c|c|c|c|c|c|c|c|c|c|c|c|}
\hline & & 6 & 7 & 8 & 9 & 10 & 11 & 12 & 13 & 14 & 15 & 16 & 17 \\
\hline \multicolumn{14}{|l|}{ ARACANIDAE } \\
\hline \multirow[t]{2}{*}{ Aracana aurita } & upper & & & 2 & & 1 & & & & & & & \\
\hline & lower & & 2 & 1 & & & & & & & & & \\
\hline \multirow[t]{2}{*}{ Aracana flavigaster } & upper & & & 2 & 1 & & & & & & & & \\
\hline & lower & & 1 & 1 & 1 & & & & & & & & \\
\hline \multirow[t]{2}{*}{ Aracana ornata } & upper & & & & 3 & 1 & & & & & & & \\
\hline & lower & & & 3 & & & & & & & & & \\
\hline Caprichthys & upper & & & & & 1 & & & & & & & \\
\hline gymnura & lower & & & & 1 & & & & & & & & \\
\hline Capropygia & upper & & & & & 2 & & & & & & & \\
\hline unistriata & lower & & 1 & 1 & & 2 & & & & & & & \\
\hline Kentrocapros & upper & & & 2 & & & & & & & & & \\
\hline aculeatus & lower & & & 2 & & & & & & & & & \\
\hline Strophiurichthys & upper & & & & & 1 & & & & & & & \\
\hline inermis & lower & & & 1 & & & & & & & & & \\
\hline Strophiurichthys & upper & & & 1 & 1 & & & & & & & & \\
\hline robustus & lower & & & 1 & 1 & & & & & & & & \\
\hline \multicolumn{14}{|l|}{ OSTRACIDAE } \\
\hline Acanthostracion & upper & & & 1 & & 1 & 3 & 3 & & & & & \\
\hline guineensis & lower & & 3 & 4 & 1 & & & & & & & & \\
\hline Acanthostracion & upper & & & & 2 & 1 & 1 & & & & & & \\
\hline notacanthus & lower & & 2 & 1 & & & & & & & & & \\
\hline Acanthostracion & upper & & & & & 4 & 10 & 16 & & & & & \\
\hline polygonius & lower & 4 & 5 & 20 & 1 & & & & & & & & \\
\hline Acanthostracion & upper & & & & & 5 & 7 & 15 & 1 & & & & \\
\hline quadricornis & lower & & 4 & 8 & 9 & 7 & & & & & & & \\
\hline Lactophrys & upper & & & & & 4 & 1 & 25 & & & & & \\
\hline trigonus & lower & 8 & 3 & 18 & 1 & & & & & & & & \\
\hline Lactoria & upper & & & 1 & 5 & 15 & 2 & 1 & & & & & \\
\hline cornuta & lower & 1 & 4 & 10 & 2 & 6 & & & & & & & \\
\hline Lactoria & upper & & & 1 & 1 & 2 & & & & & & & \\
\hline diaphana & lower & 1 & 1 & 2 & & & & & & & & & \\
\hline Lactoria & upper & & & & & 5 & 1 & 3 & 4 & 10 & 6 & 2 & 1 \\
\hline fornasinii & lower & 8 & 7 & 17 & 1 & & & & & & & & \\
\hline Ostracion & upper & & & & & 1 & 1 & 2 & & & & & \\
\hline cubicus & lower & 1 & & 1 & 1 & 1 & & & & & & & \\
\hline Ostracion & upper & & & & 3 & 5 & 4 & 10 & & & & & \\
\hline lentiginosum & lower & & 3 & 4 & 6 & 9 & & & & & & & \\
\hline Ostracion & upper & & & & 1 & 13 & 9 & 1 & & & & & \\
\hline tuberculatus & lower & & 2 & 9 & 11 & 2 & & & & & & & \\
\hline Rhinesomus & upper & & & & 1 & 2 & 3 & 10 & & & & & \\
\hline bicaudalis & lower & 3 & 2 & 5 & 4 & 1 & & & & & & & \\
\hline Rhinesomus & upper & & & & 1 & 17 & 3 & & & & & & \\
\hline triqueter & lower & & 5 & 17 & & & & & & & & & \\
\hline Rhynchostracion & upper & & & & & & 2 & 3 & & & & & \\
\hline nasus & lower & & & 1 & 2 & 2 & & & & & & & \\
\hline Rhynchostracion & upper & & & & 3 & 1 & 2 & & & & & & \\
\hline rhinorhynchus & lower & & & 2 & 3 & 1 & & & & & & & \\
\hline Tetrosomus & upper & & & & & 1 & 3 & 1 & & & & & \\
\hline concatenatus & lower & & 1 & 3 & 1 & & & & & & & & \\
\hline Tetrosomus & upper & & & & & 4 & 10 & 6 & 1 & & & & \\
\hline gibbosus & lower & 1 & 6 & 13 & 1 & & & & & & & & \\
\hline
\end{tabular}




\section{Index of Discussions of Genera}

Abalistes ...................123, 128, 179 Acanthaluteres ..... 146, 154, 167, 173-174, 176, 178, 180,182

Acanthopleurus ........4, 79, 88, 96-98, 118, 134 Acanthostacion . . 184, 218, 220-223, 228-229, 236-238, $239-240,241,242$

Acreichthys ....................... 180 Aluterta ......123, 136, 146, 153, 154, 167, 174, 178, $180-183,344$ Amanses ........143, 146, 154, 167, 172, 173, 176, $178,180,182,183$ Amblyrhynchotes .... 290-291, 297-298, 329, 331-334, 336,343 Anoplocapros .............195, 198, 199, 205-206 Aracana ............195-199, 203, 205, 206, 243 Arothron ..........290, 291, 297, 334-337, 340 Arotrolepis ..............146, 154, 175, 183

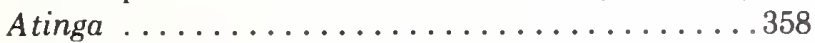
Atrophacanthus .............56, 66, 68, 70 Balistapus ........109, 110, 120, 122-123, 128, 179 Balistoides ...............110, 123, 128, 179 Balistes ...............120, 123, 128, 130, 179 Balistomorphus ...........98, 110, 118, 120-121 Bathyphylax ..........56, 66-68, 70, 73, 344 Blandowskius .................154, 183 Brachaluteres ........136, 144, 146, 153, 154, 167, $173,174,178,181,182,183$ Cantherhines $\ldots .136,146,154,167,176,178,180$, $182-183$

Canthidermis ......77, 99, 101, 110, 120, 122-123, $128,129,130,133$

Canthigaster .........144, 153, 181, 290, 298-299, $314-316,326,340,343$ Caprichthys ........ 195, 198-199, 204, 205-206, 243 Capropygia ........ 195, 198-199, 204, 205-206, 243 Carinotetraodon ..... 4, 144, 290, 297, 298, 314-316, $326,334-336,340,342,343$

Chaetoderma ... 136, 144, 146, 153, 154, 167, 174-175, $176,178,180-181,183$ Chelonodon ........290, 291, 297, 315, 334-338, $340,342,343$

Chilomycterus ... . 344, 355, 357-359, 360-361, 364-370 Chonerhinos ......265, 287, 290, 298, 337, 342-343 Colomesus .. 290-291, 297, 298, 330-331, 334, 343, 353 Cryptobalistes ..........78, 79, 98, 132, 133, 134 Dicotylichthys . . . . 358, 360, 361, 364, 367, 368, 369 Diodon .......353, 354, 357, 358-360, 364, 368, 369 Eodiodon ........................... 357 Eolactoria ........5, 207, 222, 223, 240, 242-243 Eoplectus .4, 7, 56, 64-65, 74-76, 77, 131, 134, 206, 261 Eotetraodon....................287 Ephippion ...... 77, 265, 290, 297, 298, 334, 335, $337-338,342,343$

Eubalichthys ..............154, 178, 183 Fugu .......... 290-291, 297-298, 329, 331-334, $335,336,343$ Guentheridia ...290-291, 297, 298, 320, 322, 330, 331
Halimochirurgus ............ 56, 66-68, 70, 344 Hemibalistes ....................... 128 Hollardia ...............56, 57, 66, 69 Johnsonina .............. 56, 66-69, 70 Kentrocapros ....... 193, 195, 198-199, 203-204, 205

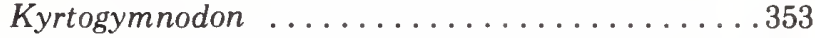
Lactophry:s . ........220, 222, 223, 228, 229, 236, $237,238,239-240,241,242$ Lactoria . . . . . . 222-223, 228, 229, 236-238, 240-243 Lagocephalus ..... 277, 282, 290-291, 297, 298, 299, $316-317,322-329,331,332,334,342,343$ Laputa . . ......146, 154, 167, 176-178, 180, 181, 183 Leprogaster . . . . . . . . . . . . . . . . 173 Liosaccus ..........................297 Macrorhamphosodes ......... 56, 66-68, 70, 342 Marosichthys ............79, 88, 98, 123, 134 Masturus .......77, 377, 379, 381, 386, 392, 393-394 Melichthys .... 101, 110, 120-121, 123, 128-129, 179 Mephisto ............... 56, 66-68, 70 Meuschenia ................154, 178, 182 Mola ........77, 123, 379, 381, 386, 392, 393-395 Molacanthus ........................... Monacanthus .......143, 153, 154, 167, 172, 173, $174,176,178-181,182,183$ Monotreta ......290, 291, 297, 298, 314, 315, 334, $335-336,338-340,342,343$ Navodon ......136, 154, 167, 176, 178, 180, 182, 183

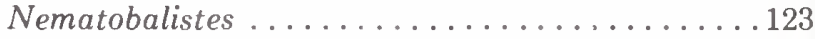
Odonus ........110,120,122, 123, 128, 133, 179 Oligobalistes ....................120, 121

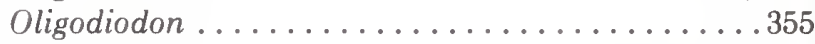

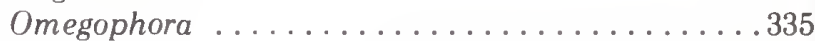
Ostracion ..........221, 222, 223, 228-229, 236, $237,240-241,242,243$

Oxymonacanthus ......154, 167, 173-174, 176, 178, $181-182,183,342$

Parahollardia ...............56, 66, 69 Paraluteres ........99, 146, 153, 154, 167, 173, $174-175,176,181,182,183$ Paramonacanthus .........153, 154, 167, 174, 176, $178-179,180-181,182,183$ Paratriacanthodes ............. 56, 66-68, 70 Pervagor ...154, 167, 176, 178, 179-180, 181, 182, 183 Proaracana ........5, 185, 195, 198, 204-205, 206 Prodiodon .............260, 343, 352-355, 357 Progymnodon .................260, 357 Protacanthodes ...4, 75, 76, 77, 78, 79, 88, 93, 95, 98, $131-132,134,207,210$ Protobalistum ........56, 57, 59, 63-64, 76, 206 Protriacanthus ......................98 Pseudaluteres ........100, 144, 146, 154, 167, 172, $173-174,176,181,182,183,344$

Pseudobalistes....................110, 123

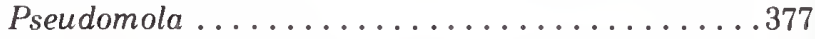

Pseudomonacanthus ......... 88, 92-93, 97, 98 Psilocephalus ..... 100, 135, 144, 146-147, 153, 154, $167,172-173,174,175,176,178,181,182183,344$ 
Rhinecanthus $101,110,120,121,122,123,128$,

167,179

Rhinesomus .........220, 222-223, 228, 229, 236, $237,239-240,241,242$

Rhynchostracion $222,223,228,229,236$, $237,240-241,242,243$

Rudarius ........136, 143, 154, 167, 172, 173, 174, $176,181,182-183$

Scobinichthys ................. 154, 182

Sphoeroides ......... 290, 291, 297, 298, 316-322,

$324,327,328-333,335,343$

Spinacanthus .......... 56, 63-64, 76, 206

Stephanolepis ........ 153, 154, 167, 176, 178-179, $180,181,182,183$

Strophiurichthys . . . 195, 198, 199, 203, 204, 205, 206 Sufflamen ...............123, 128, 130, 179

Tetraodon ........286-287, 290, 291, 297, 298, 314, $324,335,336,337-338,340,342,343$

Tetrosomus .........220, 222, 223, 228, 229, 236, $237,238,240-242,243$

Torquigener ........ 265, 290-291, 297, 298, 329, $331-334,336,343$

Triacanthodes ............... 56, 66-70 Triacanthus .......... 57, 88, 92, 93, 95, 98 Triodon .......6.6, 65, 74-75, 167, 210, 243, 244, $253,254,255,260,261-263,273,323$, $326,344,348,349,361,394$

Tripodichthys ..............88, 92, 93, 98 Trixiphichthys .....78, 79, 82, 88, 92-93, 98, 134 Tydemania ............56, 66, 68, 70, 344 Verrunculus ......................... 123 Xanthichthys 101, 110, 120-121, 122, 123, 128, 133, 179 Xenopterus .......265, 287, 290, 298, 337, 342-343 Zignoichthys .........56, 65, 74, 77, 261, 344 


\section{NOAA TECHNICAL REPORTS \\ NMFS CIRCULAR AND SPECIAL SCIENTIFIC REPOR'T-FISHERIES GUIDELINES FOR CON'TRIBUTORS}

\section{CONTENTS OF MANUSCRIPT}

First page. Give the title (as concise as possible) of the paper and the author's name, and footnote the author's affiliation, mailing address, and ZIP code.

Contents. Contains the text headings and abbreviated figure legends and table headings. Dots should follow each entry and page numbers should be omitted.

Abstract. Not to exceed one double-spaced page. Footnotes and literature citations do not belong in the abstract.

Text. See also Form of the Manuscript below. Follow the U.S. (iovernment Printing Office Style Manual, 1973 edition. Fish names, follow the American Fisheries Society Special Publication No. 6, A List of Common and Scientific Names of Fishes from the United States and Canada, third edition, 1970. Use short, brief, informative headings in place of "Materials and Methods."

Text footnotes. Type on a separate sheet from the text. For unpublished or some processed material, give author, year, title of manuscript, number of pages, and where it is filed-agency and its location.

Personal communications. Cite name in text and footnote. Cite in footnote: John J. Jones, Fishery Biologist, Scripps Institution of Oceanography, La Jolla, CA 92037, pers, commun. 21 May 1977.

Figures. Should be self-explanatory, not requiring reference to the text. All figures should be cited consecutively in the text and their placement indicated in the left-hand margin of the manuscript. Photographs and line drawings should be of "professional" quality-clear and balanced, and can be reduced to $6 \frac{1}{2}$ inches (40 picas) for page width or to $31 / x$ inches (19 picas) for single-column width, but no more than 9 inches (54 picas) high. Photos should be printed on glossy paper-sharply focussed, good contrast. Label each figure. List, and typed double spaced, each figure legend. DO NOT SEND original figures to the Scientific Editor; NMFS Scientific Publications Office will request these if they are needed.

Tables. Each table should start on a separate page and should be self-explanatory, not requiring reference to the text. Headings should be short but amply descriptive. Use only horizontal rules. Number table footnotes consecutively across the page from left to right in Arabic numerals; and to avoid confusion with powers, place them to the left of the numerals. If the original tables are typed in our format and are clean and legible, these tables will be reproduced as they are. In the text all tables should be cited consecutively and their placement indicated in the left-hand margin of the manuscript.

Acknowledgments. Place at the end of text. Give credit only to those who gave exceptional contributions and not to those whose contributions are part of their normal duties.
Literature cited. In text as: Smith and Jones (1977) or (Smith and Jones 1977); if more than one author, list according to years (e.g., Smith 1936; Jones et al. 1975; Doe 1977). All papers referred to in the text should be listed alphabetically by the senior author's surname under the heading "Literature Cited"; only the author's surname and initials are required in the author line. The author is responsible for the accuracy of the literature citations. Abbreviations of names of periodicals and serials should conform to Biological Abstracts List of Serials with Title Abbreviations. Format, see recent SSRF or Circular.

Abbreviations and symbols. Common ones, such as $\mathrm{mm}, \mathrm{m}$, $\mathrm{g}, \mathrm{ml}, \mathrm{mg},{ }^{\circ} \mathrm{C}$ (for Celsius), 'c, \% , etc., should be used. Abbreviate units of measures only when used with numerals; periods are rarely used in these abbreviations. But periods are used in et al. vs., e.g., i.e., Wash. (WA is used only with ZIP code), etc. Abbreviations are acceptable in tables and figures where there is lack of space.

Measurements. Should be given in metric units. Other equivalent units may be given in parentheses.

\section{FORM OF THE MANUSCRIPT}

Original of the manuscript should be typed double-spaced on white bond paper. Triple space above headings. Send good duplicated copies of manuscript rather than carbon copies. The sequence of the material should be:

\section{FIRST PAGE \\ CONTENTS \\ ABSTRACT \\ TEXT \\ LITERATURE CITED \\ TEXT FOOTNOTES \\ APPENDIX}

TABLES (each table should be numbered with an Arabic numeral and heading provided)

LIST OF FIGURE LEGENDS (Entire figure legends, including "Figure" before each number)

\section{FIGURES}

\section{ADDITIONAL INFORMATION}

Send ribbon copy and two duplicated copies of the manuscript to:

Dr. Jay C. Quast, Scientific Editor

Northwest and Alaska Fisheries Center

Auke Bay Laboratory

National Marine Fisheries Service, NOAA

P.O. Box 155

Auke Bay, AK 99821

Copies. Fifty copies will be supplied to the senior author and 100 to his organization free of charge. 


\section{UNITED STATES}

DEPARTMENT OF COMMERCE

NATIONAL OCEANIC AND ATMOSPHERIC ADMINISTRATION

NATIONAL MARINE FISHERIES SERVICE

SCIENTIFIC PUBLICATIONS STAFF

1700 WESTLAKE AVE. N., ROOM 336

SEATTLE, WA 98109

OFFICIAL BUSINESS

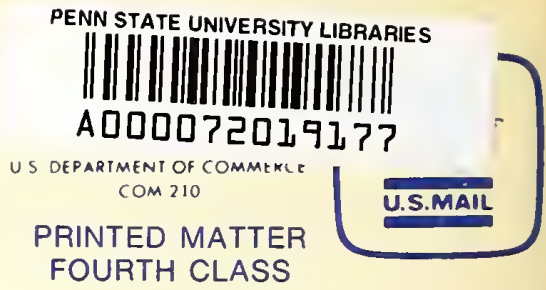

NOAA SCIENTIFIC AND TECHNICAL PUBLICATIONS

The National Oceanic and Almospheric Administration was established as part of the Department of Commerce on October 3, 1970 . The mission responsibilities of NOAA are to assess the sociocconomic impact of natural and technological changes in the environment and to monitor and predict the state of the solid Earth, the oceans and their living resourecs, the atmosphere. and the spuce environment of the Earth.

The major components of NOAA regularly produce various types of scientific and technical information in the following kinds of publications:

PROFESSIONAL PAPERS - Important definitive research results, major techniques, and special investigations.

CONTRACT AND GRANT REPORTS - Rcports prepared by contractors or grantees under NOAA sponsorship.

ATLAS - Presentation of analyzed data generally in the form of maps showing distribution of rainfall, chemical and physical conditions of oceans and atmosphere, distribution of fishes and marine mammals, ionospheric conditions, etc.
TECHNICAL SERVICE PUBLICATIONS - Reports containing dita, observations, instructions, etc. A partial listing includes data serials; prediction and outlook periodicals; technical manuals, training papers, planning reports, and information serials; and miscellaneous technical publications.

TECHNICAL REPORTS - Journal quality with extensive details, mathematical developments, or data listings.

TECHNICAL MEMORANDUMS - Reports of preliminary, partial, or negative research or technology results, interim instructions, and the like.

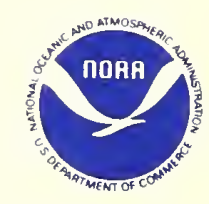

Information on availability of NOAA publications can be obtained from:

ENVIRONMENTAL SCIENCE INFORMATION CENTER (D822)

ENVIRONMENTAL DATA AND INFORMATION SERVICE

NATIONAL OCEANIC AND ATMOSPHERIC ADMINISTRATION

U.S. DEPARTMENT OF COMMERCE

6009 Executive Boulevard

Rockville, MD 20852 